\title{
DOMESTICACIÓN VEGETAL Y GRADOS DE DEPENDENCIA SER HUMANO-PLANTA EN EL DESARROLLO CULTURAL PREHISPÁNICO DEL NOROESTE ARGENTINO
}

Lic. Verónica Lema

Directora: Dra. M.L. Pochettino Co directora: Dra. A. Capparelli

Tesis para optar al grado académico de Doctora en Ciencias Naturales

(FCNYM UNLP) 


\title{
DOMESTICACIÓN VEGETAL Y GRADOS DE DEPENDENCIA SER HUMANO- PLANTA EN EL DESARROLLO CULTURAL PREHISPÁNICO DEL NOROESTE ARGENTINO.
}

\author{
Lic. Verónica S. Lema
}

Directora: Dra. M.L.Pochettino

Co-directora: Dra. A. Capparelli

Tesis para optar al grado académico de

Doctor en Ciencias Naturales

FCNYM - UNLP 

Esta tesis esta dedicada a mis padres, Silvia y Alfredo por su amor y apoyo incondicional.

A la memoria de mis abuelos y de mis tíos Jorge y Daniel. 



\section{AGRADECIMIENTOS}

En primer lugar deseo agradecer a mis directoras por sus pacientes y sabias enseñanzas y por haberme introducido en el maravilloso mundo de los Hombres y las plantas, no sólo desde su aspecto científico, sino también humano.

A las personas que me apoyaron en la realización de esta tesis.

A los siguientes investigadores que contestaron mis frecuentes consultas y tuvieron la gentileza de remitirme material para su estudio:

-Dr. Alberto Abramovich, División Entomología, Museo de Ciencias Naturales de La Plata, Universidad Nacional de La Plata, Argentina.

-Dr. Tomas Andres, Cornell University, Estados Unidos de Norteamérica.

-Lic. Maria Delia Arena, Departamento Científico de Arqueología, Museo de Ciencias Naturales de La Plata, Universidad Nacional de La Plata, Argentina.

-Dra. Lorena Ashworth, Universidad de Córdoba, Argentina.

-Lic. Gabriela Bertone, Universidad de San Marcos, Lima, Perú.

-Sr. Sergio Bogan

-Dr. Claudio Bravi, Facultad de Ciencias Naturales y Museo, Universidad Nacional de La Plata, Argentina.

-Dra. Adriana Callegari, Facultad de Filosofía y Letras, Universidad de Buenos Aires, Argentina.

-Dr. Aníbal Camperi, Sección Ornitología-Zoología vertebrados, Museo de Ciencias Naturales de La Plata, Universidad Nacional de La Plata, Argentina.

-Lic. Jorge Carbonari, LATyR, Museo de Ciencias Naturales de La Plata, Universidad Nacional de La Plata, Argentina.

-Lic. Flavia Carrión.

-Dr. Héctor D’Antoni, NASA, Estados Unidos de Norteamérica.

-Dr. Carlos Darrieu, Sección Ornitología-Zoología vertebrados, Museo de Ciencias Naturales de La Plata, Universidad Nacional de La Plata, Argentina.

-Lic. Mónica De Lorenzi, Museo de Arqueología de Cachi, Argentina.

-Dra. Nilda Dottori, Museo Botánico IMBIV, Córdoba, Argentina.

-Lic. José María Escobar, Facultad de Ciencias Naturales y Museo, Universidad Nacional de La Plata, Argentina.

-Dra. Geraldina Fermoselle INFIVE, Facultad de Ciencias Agrarias y Forestales, Universidad Nacional de La Plata, Argentina.

-Lic. Ana Fernández, Departamento Científico de Arqueología, Museo de Ciencias Naturales de La Plata, Universidad Nacional de La Plata, Argentina. 
-Ing. Aníbal Figini, LATyR, Museo de Ciencias Naturales de La Plata, Universidad Nacional de La Plata, Argentina.

-Dra. Marta Galván, INFIVE, Facultad de Ciencias Agrarias y Forestales, Universidad Nacional de La Plata, Argentina.

-Dra. Lidia García, Facultad de Filosofía y Letras, Universidad de Buenos Aires, Argentina.

-Lic. Diego Gobbo, Facultad de Ciencias Naturales y Museo, Universidad Nacional de La Plata, Argentina.

-Dr. Alberto Rex González.

-Dra. Paula González, Facultad de Ciencias Naturales y Museo, Universidad Nacional de La Plata, Argentina.

-Ing. Roberto Huarte, LATyR, Museo de Ciencias Naturales de La Plata, Universidad Nacional de La Plata, Argentina.

-Dra Alejandra Korstanje, Universidad Nacional de Tucumán, Argentina.

-Lic. Laura López, Universidad Nacional de Córdoba, Argentina.

-Dra. Virginia Mc Rostie, Universidad de Chile, Chile.

-Sr. Antonio Mercado, Museo Arqueológico de Cachi, Salta, Argentina.

-Dr. Michael Nee, New York Botanical Garden, Estados Unidos de Norteamérica.

-Ing. Roberto Newman, INTA (Estación Cerrillos, Salta), Argentina.

-Ing. Andres Nico, Cátedra de Horticultura, Facultad de Ciencias Agrarias y Forestales, Universidad Nacional de La. Plata, Argentina.

-Ing. Lázaro Novara, Museo de Ciencias Naturales de Salta, Argentina.

-Dra. Nurit Oliszewski, Universidad Nacional de Tucumán, Argentina.

-Personal Museo Instituto Interdiscipinario Tilcara, Jujuy, Argentina.

-Personal Museo Adán Quiroga, Catamarca, Argentina.

-Personal Museo Condorhuasi, Catamarca, Argentina.

-Personal Museo Arqueológico de Cachi, Salta, Argentina.

-Dra. Maria Teresa Planella, Universidad de Chile, Chile.

-Pobladores de Rachaite (Jujuy), Coranzulí (Jujuy), Santa Victoria Oeste (Salta) y El Shincal (Catamarca), Argentina.

-Dr. Raúl Pozner, Instituto de Botánica Darwinion, Argentina.

-Lic. Mirta Santoni, Museo de Antropología de Salta, Argentina.

-Dra. Verónica Seldes, Facultad de Filosofía y Letras, Universidad de Buenos Aires, Argentina.

-Prof. Graciela Suarez, Museo de Ciencias Naturales de La Plata.

-Dr. Herwig Teppner, Universidad de Graz, Austria.

-Dr. Rafael Vega Centeno, Universidad de San Marcos, Lima, Perú.

-Dra. Beatriz Ventura, Facultad de Filosofía y Letras, Universidad de Buenos Aires, Argentina. 

ENTONCES apareció el zorro:

- ¿Buenos dias! - dijo el zorro.

_Buenos dias! —respondió cortésmente el principito, que se volvió pero no vio nada.

-Estoy aquí, bajo el manzano — dijo la voz.

¿QQuién eres tú? — preguntó el principito- ¿Qué bonito eres!

- Soy un zorro - dijo el zorro.

—Ven a jugar conmigo — le propuso el principito_, iestoy tan triste!

—No puedo jugar contigo — dijo el zorro-, no estoy domesticado.

—Ah, perdón! — dijo el principito...

Pero después de una breve reflexión, añadió:

_Qué significa "domesticar"?

—Tú no eres de aquí —dijo el zorro- ¿qué buscas?

- Busco a los hombres —le respondió el principito - ¿Qué significa "domesticar"?

-Los hombres —dijo el zorro-tienen escopetas y cazan. ¡Es muy molesto! Pero también crían gallinas. Es lo único que les interesa. ¿Tú buscas gallinas?

—No — dijo el principito - Busco amigos. ¿Qué significa "domesticar"? volvió a preguntar el principito.

—Es una cosa ya olvidada — dijo el zorro-, significa "crear lazos... "

- ¿Crear lazos?

-Efectivamente, verás - dijo el zorro-. Tú no eres para mí todavía más que un muchachito igual a otros cien mil muchachitos. Y no te necesito. Tampoco tú tienes necesidad de mí. No soy para ti más que un zorro entre otros cien mil zorros semejantes. Pero si me domesticas, entonces tendremos necesidad el uno del otro. Tú serás para mí único en el mundo, yo seré para ti único en el mundo...

- Comienzo a comprender - dijo el principito - Hay una flor... creo que ella me ha domesticado...

-Es posible —concedió el zorro-, en la Tierra se ven todo tipo de cosas. 
— Oh, no es en la Tierra! - exclamó el principito.

El zorro pareció intrigado:

¿En otro planeta?

- Sí.

_ ¿Hay cazadores en ese planeta?

- No.

—Qué interesante! ¿Y gallinas?

$-\mathrm{No}$.

- Nada es perfecto suspiró el zorro.

Y después volviendo a su idea:

- Mi vida es muy monótona. Cazo gallinas y los hombres me cazan a mí. Todas las gallinas se parecen y todos los hombres son iguales; por consiguiente me aburro un poco. Si tú me domesticas, mi vida estará llena de sol. Conoceré el rumor de unos pasos diferentes a todos los demás. Los otros pasos me hacen esconder bajo la tierra; los tuyos me llamarán fuera de la madriguera como una música. Y además, imira! ¿Ves allá abajo los campos de trigo? Yo no como pan y por lo tanto el trigo es para mí algo inútil. Los campos de trigo no me recuerdan nada y eso me pone triste. iPero tú tienes los cabellos dorados y será algo maravilloso cuando me domestiques! El trigo, que es dorado también, será un recuerdo de ti. Y amaré el ruido del viento en el trigo.

El zorro se calló y miró un buen rato al principito:

-Por favor... domestícame re dijo.

-Bien quisiera le respondió el principito , pero no tengo mucho tiempo. He de buscar amigos y conocer muchas cosas.

- Sólo se conocen bien las cosas que se domestican dijo el zorro . Los hombres ya no tienen tiempo de conocer nada. Lo compran todo hecho en las tiendas. $Y$ como no hay tiendas donde vendan amigos, Ios hombres no tienen ya amigos. ¡Si quieres un amigo, domestícame!

¿Qué debo hacer? - preguntó el principito.

-Debes tener mucha paciencia — respondió el zorro - Te sentarás al principio un poco lejos de mí, así, en el suelo; yo te miraré con el rabillo del ojo y tú no me dirás nada. El lenguaje es fuente de malos entendidos. Pero cada día podrás sentarte un poco más cerca... 
El principito volvió al día siguiente.

- Hubiera sido mejor — dijo el zorro- que vinieras a la misma hora. Si vienes, por ejemplo, a las cuatro de la tarde; desde las tres yo empezaría a ser dichoso. Cuanto más avance la hora, más feliz me sentiré. A las cuatro me sentiré agitado e inquieto, descubriré así lo que vale la feliçidad. Pero si tú vienes a cualquier hora, nunca sabré cuándo preparar mi corazón... Los ritos son necesarios.

—¿Qué es un rito? -inquirió el principito.

-Es también algo demasiado olvidado - dijo el zorro-. Es lo que hace que un día no se parezca a otro día y que una hora sea diferente a otra. Entre los cazadores, por ejemplo, hay un rito. Los jueves bailan con las muchachas del pueblo. Los jueves, entonces, son días maravillosos en los que puedo ir de paseo hasta la viña. Si los cazadores no bailaran en día fijo, todos los días se parecerían y yo no tendría vacaciones.

De esta manera el principito domesticó al zorro. Y cuando se fue acercando eI día de la partida:

-iAhI — dijo el zorro-, lloraré.

-Tuya es la culpa — le dijo el principito-, yo no quería hacerte daño, pero tú has querido que te domestique...

- Ciertamente - dijo el zorro.

- Y vas a llorar!, — dijo el principito.

- iSeguro!

- No ganas nada.

—Gano - dijo el zorro-, he ganado a causa del color del trigo.

Yluego añadió:

- Vete a ver las rosas; comprenderás que la tuya es única en el mundo.

Volverás a decirme adiós y yo te regalaré un secreto.

El principito se fue a ver las rosas a las que dijo:

- No son nada, ni en nada se parecen a mi rosa. Nadie las ha domesticado ni ustedes han domesticado a nadie. Son como el zorro era antes, que en nada se diferenciaba de otros cien mil zorros. Pero yo le hice mi amigo y ahora es único en el mundo.

Las rosas se sentían molestas oyendo al principito, que continuó diciéndoles:

—Son muy bellas, pero están vacías y nadie daría la vida por ustedes. 
Cualquiera que las vea podrá creer indudablemente que mi rosa es igual que cualquiera de ustedes. Pero ella se sabe más importante que todas, porque yo la he regado, porque ha sido a ella a la que abrigué con el fanal, porque yo le maté los gusanos (salvo dos o tres que se hicieron mariposas) y es a ella a la que yo he oído quejarse, alabarse y algunas veces hasta callarse. Porque es mi rosa, en fin.

$Y$ volvió con el zorro.

-Adiós -le dijo.

-Adiós - dijo el zorro - He aquí mi secreto, que no puede ser más simple: sólo con el corazón se puede ver bien. Lo esencial es invisible para los ojos.

- Lo esencial es invisible para los ojos —repitió el principito para acordarse.

- Lo que hace más importante a tu rosa es el tiempo que tú has perdido con ella.

- Es el tiempo que yo he perdido con ella... - repitió el principito para recordarlo.

- Los hombres han olvidado esta verdad - dijo el zorro-, pero tú no debes olvidarla. Eres responsable para siempre de lo que has domesticado. Tú eres responsable de tu rosa...

-Yo soy responsable de mi rosa... —repitió el principito a fin de recordarlo.

"E1 principito"

Antoine de Saint Exupéry

(1943) 



\section{INDICE GENERAL}

1- INTRODUCCIÓN

1.1- Fundamentación de la tesis. Objetivos.

1.2- Posicionamiento teórico

1.2.1- Delimitación de conceptos básicos.

1.2.2- El abordaje de los inicios de la domesticación de especies vegetales dentro de la perspectiva de la relación ser humano-planta----------13

1.2.3- El por qué de un abordaje paleoetnobotánico y la necesidad de una aproximación etnobotánica a la problemática del manejo de especies vegetales----------------------------------------------------------19

1.2.4- Supuestos teóricos asumidos en esta tesis----------24 1.3- Estrategia metodologica y modo de abordaje de la problemática bajo estudio-

2. ESTADO ACTUAL DE LA PROBLEMÁTICA DE LA DOMESTICACION VEGETAL Y LOS INICIOS DE LA

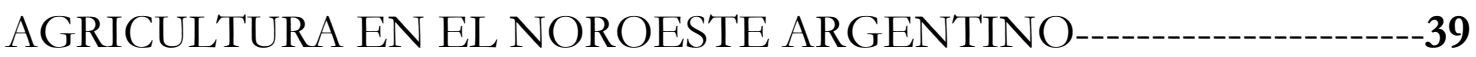

3-SITIOS ARQUEOLOGICOS ANALIZADOS EN ESTA TESIS--------65

4-EL ABORDAJE PALEOETNOBOTÁNICO: EVOLUCIÓN BAJO DOMESTICACIÓN.

4.1- La búsqueda del cambio en los restos vegetales: estudio de caracteres morfo-anatómicos en macrorrestos. $-135$

4.1.1- Género Cucurbita.

4.1.1a- Características que avalan o rechazan la concepción de $C$. maxima Duch. ex Lam. ssp. andreana (Naudin) Filov como posible antecesor de C. maxima ssp. maxima Duch. ex Lam.

155

4.1.1b- Identificación y delimitación del área de origen de C. maxima ssp. maxima y C. maxima ssp andreana-

4.1.1c- Estudio morfo-anatómico en macrorrestos de Cucurbita sp.: semilla.

4.1.1d- Estudio morfo-anatomico en macrorrestos de cucurbitáceas: fruto. 
4.1.1e- Estudio morfo-anatomico en macrorrestos de cucurbitáceas: pedúnculo.

5- LAS LECCIONES DE LA ETNOBOTÁNICA: OPCIONES SOCIALES Y TOMA DE DECISIONES EN LOS HUERTOS DEL NOA. 611

6- ETNOBOTÁNICA ETNOARQUEOLÓGICA: LOS APORTES DE LOS ESTUDIOS ACTUALES A LA INTERPRETACIÓN DEL PASADO-

8- ADENDA: CAMBIO Y CONTINUIDAD: DOMESTICACIÓN VEGETAL, BIOTECNOLOGÍA, CAMPESINADO Y LOS APORTES DE ESTA INVESTIGACIÓN A LA PROBLEMÁTICA ACTUAL.

ANEXO I. Reconstrucción de los contextos del sitio Puente del Diablo (SSalLap20)_a partir de los datos registrados en libretas de campo originales----

ANEXO II. Restos vegetales que conforman la colección de la localidad arqueológica de Pampa Grande (Museo de Ciencias Naturales de La Plata)----- 



\section{Resumen}

El objetivo general de la presente tesis consiste en identificar, desde un abordaje paleoetnobotánico, grados de dependencia en la relación ser humano-planta a lo lago del desarrollo cultural prehispánico en el área del noroeste argentino (NOA) y zonas adyacentes pertenecientes al Área Andina Central y Meridional. En este trabajo de investigación se pretenden establecer, más que las pautas causales de un hecho puntual como el origen de la agricultura, los pasos que se fueron produciendo a lo largo de un proceso continuo de transformaciones en la relación entre comunidades humanas y poblaciones vegetales, fundamentalmente a través de su expresión morfológica en macrorrestos vegetales del género Cucurbita sp. y de la especie Phaseolus vulgaris L.. Se parte del supuesto de que existen distintos grados de

dependencia entre seres humanos y plantas, lo cual redunda en una gran diversidad de forma de manejo (recolección, cultivo sin domesticación, cultivo de plantas domesticadas, tolerancia y erradicación) que se reflejan en distintas formas vegetales (plantas silvestres, plantas cultivadas no domesticadas, plantas cultivadas domesticadas y malezas). Esta visión se planteó como una vía para sortear las divisiones propuestas entre modos de vida cazadorrecolector y agricultor por medio de la superación de la dicotomía silvestre/domesticado.

Mediante el análisis cualitativo y cuantitativo de caracteres macroscópicos y microscópicos de macrorrestos vegetales se procuró reconstruir prácticas de manejo del entorno vegetal de los grupos humanos que produjeron el registro arqueológico de los sitios estudiados y las características de las plantas que se relacionaron con los mismos. Se analizaron colecciones arqueológicas de sitios emplazados en el NOA (Pampa Grande en Guachipas, Salta y Puente del Diablo en el sector norte del Valle Calchaquí, Salta) y restos arqueobotánicos de sitios ubicadas en esta misma región (Los Viscos en el Valle del Bolsón, 
Catamarca; Puente Río La Viña I en el Valle de Lerma, Salta; Campo del Pucara en Andalgalá, Catamarca; Huachichocana III en la Quebrada de Purmamarca, Jujuy y El Shincal en el Valle de Hualfín, Catamarca) y en el Área Andina Central y Meridional (sitios peruanos de Bandurria, Curayacu, Jahuay, Cerro Lampay, Chavín y el sitio chileno Tulan 85).

Se realizaron también investigaciones etnobotánicas en cuatro comunidades campesinas emplazadas en tres ambientes disímiles del NOA (El Shincal, en la provincia fitogeográfica de Monte, Catamarca; Rachaite y Coranzulí en la provincia fitogeográfica de Puna, Jujuy y Santa Victoria Oeste en la provincia fitogeográfica de Yungas, Salta). Estas investigaciones tuvieron un doble objetivo. Por una parte, relevar prácticas de manejo y criterios de selección aplicados por los cultivadores actuales en las mismas especies identificadas en el registro arqueológico. Por otra parte estos estudios etnobotánicos tuvieron una aplicación etnoarquelógica al generar modelos que exploran el paso de lo comportamental (en este caso: practicas de manejo y selección de formas vegetales) a lo material (en este caso: macrorrestos).

El abordaje propuesto permitió la identificación en los restos arqueobotánicos analizados de formas silvestres, domesticadas y cultivos transicionales. La contemporaneidad y asociación contextual de los mismos permitió caracterizarlos como complejos maleza-cultivo-domesticados. Esto indicaría prácticas hortícolas tendientes a la generación y mantenimiento de la diversidad de formas de relación ser humano-plantas en el formativo temprano del NOA y posiblemente también en los sitios del Arcaico Tardío y Formativo temprano del Área Andina Central y Meridional. 



\section{INTRODUCCIÓN.}

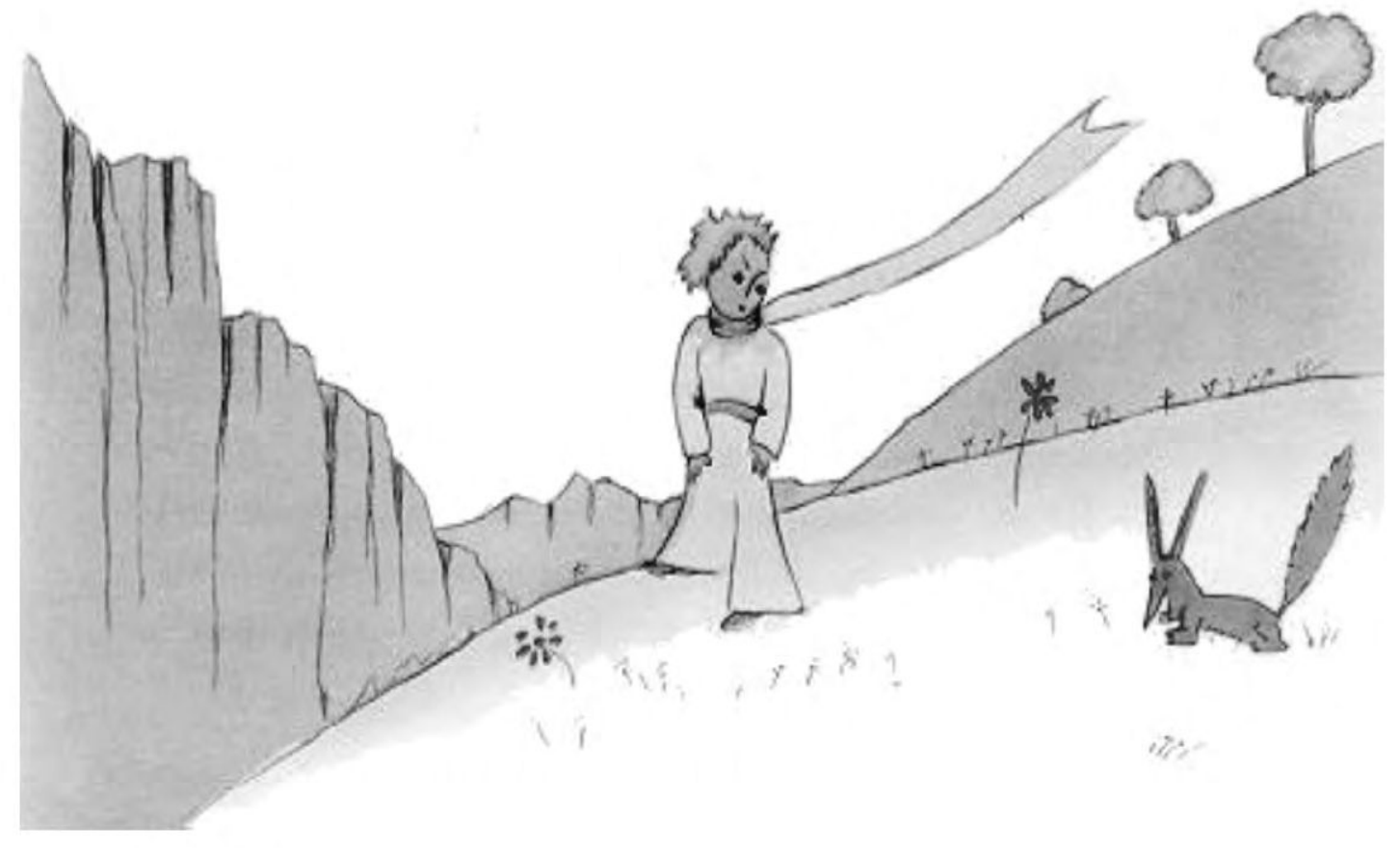




\section{INTRODUCCIÓN}

\subsection{Fundamentación de la tesis. Objetivos.}

El objetivo general de la presente tesis es identificar, desde un abordaje paleoetnobotánico, grados de dependencia en la relación ser humano-planta a lo lago del desarrollo cultural prehispánico en el área del noroeste argentino (NOA) y zonas adyacentes pertenecientes al Área Andina Central y Meridional. En este trabajo de investigación se pretenden establecer, más que las pautas causales de un hecho puntual como el origen de la agricultura, los pasos que se fueron produciendo a lo largo de un proceso continuo de transformaciones en la relación entre comunidades humanas y poblaciones vegetales (Harris 1989), fundamentalmente a través de su expresión morfológica en macrorrestos vegetales. Se parte del supuesto de que dentro de este continum existen distintos grados de dependencia (Harlan 1992), los cuales traen aparejada una división menos rígida entre un modo de subsistencia cazador recolector de otro productor. Por lo tanto, más que caracterizar estados o estadíos estáticos (silvestre/domesticado; cazador recolector/agricultor), se intentarán esclarecer los modos de relación entre poblaciones humanas y plantas en el pasado identificando procesos de selección cultural, toma de decisiones y criterios de manejo con las concomitantes modificaciones en las comunidades vegetales involucradas. Esto supone pensar que en distintos momentos y en distintos puntos geográficos del NOA tuvieron lugar procesos de domesticación locales, lo cual no implica rechazar el posible ingreso de formas vegetales domesticadas provenientes de otras áreas geográficas, sino investigar formas locales de manejo de comunidades vegetales que hayan llevado a la transformación de las mismas. Por lo tanto esta tesis no abarca solamente el lapso en que hipotéticamente se dio el paso de un modo de vida cazador-recolector a uno agricultor en el NOA (entre los 4.500 AP y 3.000 AP, Olivera 2001), sino un 
lapso más amplio donde se incluye el análisis de sitios que se considera representan formas de instalación agrícolo-ganaderas plenas. Esto surge de considerar que los procesos de selección y manipulación humanas no se detienen una vez logradas las primeras formas domesticadas, sino que se continúan en el tiempo en tanto existan caracteres deseables que obtener o modificar.

Considerando lo antes dicho se buscará diferenciar y caracterizar, principalmente a través del análisis de macrorrestos vegetales arqueológicos, modos de relación entre comunidades humanas y poblaciones vegetales pasadas, procurando reconstruir las prácticas sociales de los grupos humanos que produjeron el registro arqueológico de los sitios estudiados y las características de las plantas que se relacionaron con los mismos. Se asume que para reconocer y caracterizar estos modos de relación se deben considerar otros rasgos culturales que acompañaron al establecimiento de formas novedosas de interacción, ya que los mismos están íntimamente relacionados entre sí y pueden estar determinando, condicionando, facilitando o dificultando su mutuo desarrollo. Es por ello que en la presente investigación se considerarán también otros aspectos socioculturales como la tecnología, las unidades de producción, la diferenciación y jerarquización dentro del grupo social, el modo de asentamiento, las redes de interacción y la domesticación de camélidos, entre otros.

\section{2- Posicionamiento teórico.}

\subsubsection{Delimitación de conceptos básicos}

Desde hace tiempo los estudios etnobotánicos han demostrado que existen múltiples formas en que las comunidades humanas se relacionan con su entorno vegetal (Jones 1941, Fosberg 1948, Balick 1996, Alcorn 1995). La perspectiva relacional en etnobotánica se caracteriza por no colocar el énfasis ni en las sociedades humanas ni en las plantas asociadas (Jones 1941, Alcorn 1995), sino en 
la manera en que ambas interaccionan y se influyen mutuamente. En esta sección analizaremos la multiplicidad de formas de relación vinculadas con el modo en que las plantas son procuradas por los grupos humanos, las cuales han sido identificadas en estudios etnobotánicos. Estos modos de obtención y manejo constituyen la base sobre la cual abordaremos luego el objetivo de esta tesis.

Ciertos autores (Harlan y De Wet 1965, Ford 1979, Rindos 1984 en Harris 1989) entienden que la recolección es el empleo de plantas silvestres sin intención de propiciar un cambio morfológico, fisiológico o de otro tipo en las mismas, pudiendo haber por lo tanto sólo modificaciones incidentales a distinta escala. En este sentido, existen técnicas de recolección que favorecen un aumento en la disponibilidad de recursos como, por ejemplo, la aireación y remoción del suelo al excavar la tierra para obtener rizomas y tubérculos silvestres (Hallam 1989). Sin embargo, Hynes y Chase (1982 en Harris 1989, Chase 1989) se oponen a esta perspectiva dado que la misma asume que los cazadores recolectores realizan modificaciones no conscientes, asimilando por lo tanto su comportamiento al de otros mamíferos. A raíz de ello estos autores acuñan el término "domicultura", para referir a modificaciones en el ambiente resultado de la acción humana deliberada que crea un paisaje apropiado socialmente, lo cual diferencia a los grupos humanos -incluidos los cazadores recolectores- de otros organismos domesticadores (Hynes y Chase 1982 en Harris 1989). A su vez Yen (1989) asume una domesticación del paisaje producto de manipulaciones inadvertidas llevadas a cabo por los aborígenes australianos, sin que haya domesticación de una sola planta. Esto mismo detecta Politis (1996) entre grupos Nukak cazadores recolectores de la Amazonia colombiana, quienes incidentalmente modifican las concentraciones naturales de ciertas especies de palmas con frutos comestibles como "Seje" (Oenocarpus batana), "Tarriago" (Phenakospermun guianensis), "guano" o "guada" (Rollinea sp. o posiblemente Topino guianensis según Cabrera et al 1994) y "popere" (Oenocarpus mapora) debido a sus patrones de movilidad, clareado de la selva con tala selectiva 
de ciertos árboles y palmas y alta tasa de residuos vegetales (principalmente semillas) producidos en los campamentos. Este manejo no implica cambios genotípicos ni fenotípicos, afectando solamente la distribución y concentración de plantas, formando "parches" antrópicos en medio de la selva caracterizados por altas concentraciones de plantas comestibles morfológicamente silvestres (Politis 1996, Politis et al 1997). La eliminación de competidores y la concentración de semillas genera un mejor posicionamiento de estas especies útiles en lo que refiere a la adquisición de nutrientes y luz, escasos en la selva amazónica, otorgándole claras ventajas adaptativas (Politis et al. 1997, Cárdenas y Politis 2000). Politis y colaboradores (1997) caracterizan a los Nukak como cazadores-recolectores que manipulan el medio. A partir de propuestas como la de Casas (2001) -quien propone que la selección artificial no se efectúa entre la siembra y la cosecha, sino que opera dejando en pie las plantas ya establecidas que presentan atributos ventajosos- los Nukak pueden ser considerados como productores en tanto cultivadores in situ, incluso como domesticadores. Sin embargo Casas (2001) habla de un control deliberado del ambiente para favorecer la propagación de plantas, cosa que no ocurre en el caso de éste grupo amazónico, cuya manipulación es inconsciente, por lo cual sus actividades serían de recolección y tolerancia. En opinión de de Wet y Harlan (1975) se pueden cultivar especies silvestres por medio del manejo del medio donde crecen, siempre y cuando el mismo no sea perturbado de manera prolongada. Para Ford (1979) en el continum de interacciones humanoplanta, entre la recolección y el cultivo, existe el cuidado ("tend"), en donde el Hombre interviene en el ciclo de crecimiento de la planta aunque sin que ocurran cambios genéticos ni morfológicos detectables, aumentando solamente las ventajas competitivas y las oportunidades de éxito reproductivo de las mismas. Por lo que si seguimos esta propuesta, los Nukak "cuidan" las palmas, pero no las cultivan. Estos comportamientos de cuidado entre grupos cazadores recolectores que modifican la abundancia y las frecuencias genéticas de poblaciones de recursos silvestres fueron señalados para gran cantidad de grupos cazadores recolectores 
actuales asentados en distintos ambientes, difiriendo el grado de intencionalidad de dichas modificaciones en los diversos casos (Casas 2001, Hather y Mason 2002). Mas allá de la presencia o no de modificaciones en las plantas objeto de la recolección, puede caracterizarse a las plantas silvestres como aquellas que crecen naturalmente fuera del hábitat perturbado por el Hombre y no pueden invadir permanentemente y de forma exitosa este tipo de hábitat (Parodi 1938, De Wet y Harlan 1975).

Siguiendo la propuesta original de grados de dependencia de Harlan (1992), quien señala la presencia de plantas toleradas, protegidas y alentadas, Casas (2001) acuña el concepto de silvicultura ${ }^{1}$ entendida como el conjunto de técnicas de manipulación de poblaciones y comunidades de plantas silvestres y arvenses, entre las que se cuentan:

-Recolección: implica cosechar productos útiles de plantas silvestres y arvenses, por lo general no hay manejo de la población y el impacto es bajo, pero puede incluir formas incipientes de manejo como obtención selectiva de algunos fenotipos, rotación de áreas de recolección, restricciones a la extracción de algunos recursos, etc.

-Tolerancia: prácticas dirigidas a mantener dentro de ambientes antropogénicos plantas útiles que existían antes de que el ambiente fuera transformado por el Hombre, por ejemplo: "selvas artificiales".

-Fomento o inducción: estrategias dirigidas a aumentar la densidad de poblaciones de especies útiles en una comunidad vegetal, como quemas, tala, plantación de semillas y/o propágulos.

-Protección: cuidados que implican la eliminación de competidores y depredadores, fertilización, poda, protección contra heladas y plagas para salvaguardar plantas silvestres deseadas.

\footnotetext{
${ }^{1}$ Casas emplea este término en alusión a plantas silvestres, en Argentina se denomina silvicultura a la manipulación de especies forestales, por lo tanto no se empleara este término en las investigaciones desarrolladas en esta tesis a fin de no generar malos entendidos.
} 
Casas (2001) entiende que existen distintas formas de producción no-agrícolas como las quemas intencionales, la tala de bosques para propiciar el aumento de otras especies cuya abundancia se ve favorecida en sitios perturbados, el manejo del agua (inundaciones, canalización, represas, reservorios) o la erradicación de competidores no deseables.

Pasemos ahora a la acción de cultivar, la cual reviste matices distintos según el autor considerado:

1) Es el acto intencional de cuidar u ocuparse de una planta (Farrington y Urry 1985; Harlan 1992; Gremillion 1997).

2) Implica una disrupción en el ciclo de vida de la planta (Ford 1985; Farrington y Urry 1985).

3) Es un método de producción de alimentos vegetales (Harris 1989, Casas 2001).

4) Es el acto de plantar una semilla o propágulo en una situación distinta. (Ford 1979, Yernell 1983 en Smith 1985, Asch y Asch 1985, Hather J. y Mason S. 2002, Buxó y Piqué 2008).

5) Es el acto intencional de aumentar la tasa de reproducción de cierta especie, pudiendo propagarse la misma fuera de su área natural de distribución (Asch y Asch 1985).

6) Implica la preparación de parcelas específicas para la propagación de plantas junto con siembra y cosecha repetida en estas parcelas (Piperno y Pearsall 1998).

7) Es la manipulación del ambiente e inducción o propagación deliberada de plantas en él (cultivo ex situ o in situ ${ }^{2}$ ), implica un control deliberado del ambiente sobre todo en el cultivo in situ (Casas 2001).

8) Es la imposición de presiones selectivas sobre mutantes de las poblaciones silvestres, principalmente el control sobre la reproducción. Los rasgos afectados en las plantas son principalmente morfológicos y fisiológicos (Geps 2005). 
Cultivar implica gran cantidad de actividades diferentes, siendo su principal característica distintiva respecto de la recolección, el hecho de ser actividades conscientes. Cultivar implica las siguientes prácticas:

-cuidado, carpido, transplante y siembra (Ford 1985a). -limpieza de terrenos y cardado sistemático (Harris 1989).

-labrar el suelo, hacer almácigos, desmalezar, podar, proteger, regar y abonar (Harlan 1992).

-preparación del campo, cuidado ("husbandry") de las plantas y selección de conjuntos de semillas y raíces (Farrington y Urry 1985).

A pesar de sus diferencias, todas las definiciones implican actos de cuidado intencionales, concientes, por ello algunos autores consideran que el cultivo es la primer forma de producción. Por lo tanto, ateniéndonos a estas definiciones, se puede considerar que acciones como la protección y el fomento o inducción (Harlan 1992, Casas 2001) serían también formas de cultivo. Sin embargo para varios investigadores el acto crucial que identifica a la acción de cultivar es el plantar una semilla o propágulo en una situación distinta respecto de la propia de una forma silvestre (Ford 1979, Yernell 1983 en Smith 1985, Asch y Asch 1985, Hather y Mason 2002, Buxó y Piqué 2008), por lo que otras formas de cuidado o "husbandry" (termino acunado por Higgs [1972 en Harris 1989] para referir a todo el espectro de intervención y control humano sobre la biología y comportamiento de animales y plantas) no son cultivar. En esta tesis se seguirá un criterio amplio, entendiendo al cultivo como todo acto consciente de cuidado de una población vegetal. Se asume este criterio dado que la voluntad implicada en estas acciones reviste una diferencia crucial con los comportamientos de los cazadores recolectores, quienes no procuran deliberadamente generar cambios en las comunidades vegetales con las que se relacionan. Las plantas cultivadas pueden o

\footnotetext{
${ }^{2}$ Estos términos refieren a fuera (ex situ) o dentro (in situ) del área que ocupan las poblaciones
} 
no estar domesticadas, diferencia que radica en si dependen o no de las comunidades humanas para reproducirse.

De todos los autores citados Ford (1979), Asch y Asch (1985), Hillman y Davies (1990) y Gepts (2005) consideran que las plantas bajo cultivo exhibirán cambios morfológicos y/o fisiológicos bajo presiones de selección. Gremillion (1997) define al cultivo como especies o poblaciones que son plantadas, cosechadas o manipuladas de la manera que sea, más allá de la existencia de un indicador morfológico de dicha relación. Buxó y Piqué (2008) consideran que el cultivo previo a la domesticación no generó cambios, siendo las plantas cultivadas morfológicamente silvestres, aunque su multiplicación se deba a la acción humana. De acuerdo con de Wet y Harlan (1975) y Harlan (1992) es posible cultivar plantas silvestres, como vimos previamente para el caso de los Nukak.

Al igual que en el caso del cultivo, el concepto de domesticación implica aspectos diferentes para distintos autores:

1) Modificación de rasgos genéticos y/o fenotípicos en las plantas por intervención humana (Higgs 1972; Farrington y Urry 1985; Ford 1979, 1985b; Hillman y Davies 1990; Harlan 1992; Gremillion 1997; Casas 2001; Hather y Mason 2002; Geps 2005).

2) Las plantas domesticadas han perdido la capacidad de dispersar sus semillas o propágulos vegetativos por medios naturales (de Wet y Harlan 1975).

3) Las plantas domesticadas no pueden sobrevivir sin la intervención humana (De Wet y Harlan 1975, Ford 1979 y 1985; Hillman y Davies 1990; Harlan 1992; Geps 2005).

4) El tipo de intervención humana es la cría selectiva (Higgs 1972) o selección cultural (Ford 1985).

5) La intervención humana implica aislamiento y protección de las plantas (Farrington y Urry 1985). 
6) Es una relación simbiótica resultado de la coevolución entre la planta y el Hombre (Rindos 1984).

Resumiendo estas propuestas puede decirse que una planta domesticada va a poseer cambios morfológicos, genéticos, fisiológicos y ecológicos respecto de su antecesor que llevan a que la misma no pueda dispersarse y/o reproducirse sin la intervención humana, por lo que se ha generado una relación simbiótica resultado de la coevolución. Obviamente las plantas domesticadas son plantas cultivadas (Ford 1979), pero si bien domesticar implica para Higgs (1972) la cría selectiva, para Ford (1985) la selección cultural y para Farrington y Urry (1985) la protección de las plantas y su aislamiento, sólo este último comportamiento no lo hallamos entre las prácticas vinculadas al cultivo previo a la domesticación. A pesar de que para estos autores la domesticación es un acto consciente, para otros (Rindos 1980, Asch y Asch 1985, Smith 2006) es el resultado de la adaptación de las plantas al ambiente antrópico. Para Hillman y Davies (1990) habría existido una primera etapa de manipulación inconsciente durante el cultivo que habría dado ventajas selectivas a plantas mutantes que carecen de algunas características -especialmente reproductivas- necesarias para sobrevivir en estado silvestre, luego, al alcanzar este tipo de plantas una frecuencia tal que fueran percibidas por los cultivadores, éstos habrían aplicado una selección consciente que fijaría dichos caracteres a nivel poblacional, por lo que el proceso de domesticación incluye cambios genotípicos de poblaciones enteras, más que cambios reversibles del fenotipo de plantas individuales.

Para Casas (2001) la diferencia radica en que "el concepto de cultivo incluye a un conjunto de formas de manejo de poblaciones o comunidades vegetales, mientras que la domesticación es un proceso evolutivo que resulta de manipular los genotipos de las plantas, lo cual no necesariamente se logra con sólo manejar el ambiente" (Casas 2001:129). Este investigador propone otra visión de la domesticación, distinta a la de los modelos clásicos de seminicultura y vegecultura; 
en su propuesta, el manejo silvícola induce a la propagación y mantenimiento de las plantas deseadas en poblaciones vegetales silvestres in situ y se caracteriza porque la selección artificial no se efectúa entre la siembra y la cosecha, sino que opera dejando en pie las plantas ya establecidas que presentan atributos ventajosos, favoreciendo así su futura reproducción, y eliminando las plantas no favorables. Este modelo se aplica fundamentalmente -aunque no exclusivamente- a plantas de polinización abierta y ciclos de vida largos (Casas 2001). Si bien el autor habla de manejo de plantas silvestres, al adoptar en esta tesis un concepto amplio de cultivo estaríamos ante plantas cultivadas, puesto que la manipulación es consciente y genera cambios sustanciales (principalmente morfológicos y de abundancia relativa) en las poblaciones vegetales involucradas (Casas et al 1991, Casas et al 1997, Casas 2001, Arellano \& Casas 2003).

En muchos trabajos se emplea el concepto de "síndrome adaptativo de la domesticación", entendido como el conjunto de cambios fisiológicos y morfológicos que distinguen a una forma vegetal domesticada de su antecesor silvestre y que ocurren bajo cultivo en un ambiente antropomorfizado (Epimaki et al 1996). En opinión de Smith (2006) estos conjuntos de cambios ocurren por una adaptación de la planta al ambiente antrópico y no por selección humana deliberada.

En este punto resulta crucial entender dos instancias presentes en todo proceso evolutivo: la generación de variabilidad y la selección posterior que opera sobre la misma. Obviamente la primera de estas instancias es totalmente motivada por causas naturales (principalmente mutación, recombinación, hibridación, deriva y flujo génico y efecto fundador, León 1968 y Gould 1980). La segunda puede ser natural o cultural. Se considera en esta investigación que ambas, selección natural y selección cultural, operan a lo largo de todo el continuum de relaciones entre seres humanos y plantas, durante el proceso de domesticación, sin que se pueda considerar solamente a una de ellas. Sin embargo, en un punto del proceso ambas fuerzas selectivas se unirán de manera estrecha e indisoluble: cuando la planta 
requiera de la presencia humana para poder reproducirse, momento en el que se alcanza el máximo grado de dependencia. En consecuencia, la selección humana deliberada es imprescindible para que esté presente la domesticación, por lo que el "síndrome adaptativo de la domesticación" no es un mero hecho natural, sino también un producto de la selección cultural. Este último tipo de selección puede ser de diverso tipo, ya sea que opere directamente sobre los caracteres de las plantas manejadas o bien indirectamente sobre el ambiente en el cual prosperan las mismas.

En agronomía y ciencias naturales se utilizan una gama variada de términos para clasificar aquellas plantas que crecen en ambientes antrópicos, empleados muchas veces de manera imprecisa. Si tomamos el diccionario de términos botánicos de Font Quer (1979) encontramos el vocablo "adventicio", el cual se aplica a "plantas advenedizas que no son propias de la localidad considerada, sino que han sido traídas accidentalmente por los seres humanos o por cualquier circunstancia fortuita, como una planta del piso alpino en tierra baja, arrastradas sus semillas por las aguas, u otra, en los trigales, sembrada por el Hombre sin darse cuenta, por venir mezclada su semilla con los granos del cereal. Las plantas adventicias no medran; si, por el contrario, se aclimatan y resisten la competencia de las demás, se dice que se han naturalizado" (Font Quer 1979:22). Siguiendo a este mismo autor, se encuentra el término "ruderal" que se aplica a aquellas plantas que crecen en zonas donde habita el ser humano, en suelos ricos en nitrógeno y específicamente entre construcciones, ruinas o escombros. Este término incluye el de "arvense" o "maleza" para plantas no-deseadas que crecen entre los cultivos, y el de "viario" o "viaria" específicamente para plantas que prosperan a la vera de caminos. En su trabajo de 1965 Harlan y de Wet intentan aproximar una definición de maleza que escape a estas popularmente empleadas donde el carácter no-deseado de esta clase de plantas se vuelve distintivo, puesto que el mismo se halla culturalmente condicionado. Es por ello que se vuelcan a una definición basada en el comportamiento ecológico de las especies vegetales y no en la valoración dada por 
el Hombre a tal tipo de especies. Así, definen maleza como todo conjunto de plantas que son pioneras de sucesiones secundarias, capaces de establecerse de manera exitosa en hábitats disturbados por comunidades humanas, pudiendo reproducirse sin intervención humana directa (de Wet y Harlan 1975). Este último aspecto resulta crucial para diferenciarlas de las plantas domesticadas, las cuales requieren del cultivo y la continua ayuda del Hombre porque han perdido la habilidad para dispersar sus semillas o propágulos vegetativos, lo que significa que las plantas domesticadas y las malezas difieren en el grado de dependencia respecto de las comunidades humanas para prosperar en hábitats permanentemente perturbados por éste (de Wet y Harlan 1975). Los rasgos que son propios de las malezas incluyen: la producción de gran número de semillas pequeñas que no germinan a la vez ya que poseen dormancia prolongada, la capacidad de mimetizarse con los cultivos, una gran plasticidad fenotípica y la presencia de principios tóxicos o estructuras como espinas o raíces engrosadas que permiten que la planta permanezca mayor tiempo en los ambientes antrópicos (Harlan y de Wet 1965). Las comunidades humanas no seleccionan rasgos específicos de las malezas, las cuales pueden permanecer en los ambientes antrópicos porque no son detectadas debido a su capacidad de mimetizarse con los cultivos, o bien porque, siendo reconocidas, son toleradas tal como menciona Harlan (1992). Otra alternativa es que sean erradicas una vez detectada su presencia. Pero si las malezas comienzan a ser protegidas o alentadas pasarán a ser cultivos y si luego estas pierden su capacidad de reproducirse por sus propios medios, se convertirán en plantas domesticadas. En esta tesis emplearemos el término "espontáneo/a" para referir a todo taxa vegetal que no se encuentra bajo cultivo.

Otra distinción es la de cultígeno, término que refiere a una especie vegetal conocida sólo bajo su forma domesticada, que no posee una contraparte o antecesor silvestre, presumiéndose que se originó bajo domesticación y no por un proceso de especiación natural (Plotnicov y Scaglion 1999). 
Un cultivar es "una variedad vegetal que se originó y persistió bajo cultivo (...) se define también como una planta cultivada para la cual existe una variedad silvestre relacionada" (Plotnicov y Scaglion 1999:vii). Este término se aplica por lo general a poblaciones modernas de plantas domesticadas altamente modificadas sujetas a una fuerte presión selectiva, adaptadas a monocultivos y de una muy reducida variabilidad genética y fenotípica (Clement 1999). El termino "landrace" se usa para aludir a cultivares tradicionales y alude a una población domesticada o semidomesticada seleccionada bajo cultivo dentro de un área geográfica restringida, estas poblaciones poseen una alta diversidad fenotípica y una relativamente alta variabilidad genotípica (Clement 1999).

La aclaración de estos conceptos es de importancia ya que el primero de ellos (cultígeno) ha sido -y es- empleado extensamente en la bibliografía arqueológica del NOA para referir a restos arqueológicos vegetales aunque, atendiendo a la definición dada aquí, el mismo se aplicaría solo a aquellas especies domesticadas cuyo antecesor silvestre se desconoce. Por lo tanto, se asume que el empleo que se ha dado al término "cultígeno" en la bibliografía arqueológica del NOA es erróneo y sólo lleva a confusiones y posibles malas interpretaciones, por lo que se lo empleará en esta tesis de acuerdo con los parámetros ya citados.

Finalmente, a modo de resumen de las propuestas presentadas en esta sección, se presenta la tabla 1 donde se expresan las distintas formas de relación entre comunidades humanas y poblaciones vegetales que serán analizadas en esta tesis.

\subsection{2- El abordaje de los inicios de la domesticación de especies vegetales dentro de la perspectiva de la relación ser humano-planta.}

Como dijimos en la primera sección, esta tesis está orientada a la búsqueda de los pasos que se fueron produciendo a lo largo de un proceso continuo de transformaciones en la relación entre comunidades humanas y poblaciones vegetales (Harris 1989). Esta idea de continuidad surge entre autores involucrados 
en el paradigma ecológico-evolutivo gradualista que surge en la década de 1960 en rechazo a la idea de "revolución neolítica" de Gordon Childe (Harris 1989), algunas de las propuestas del momento pueden verse en la tabla 2.

Este cambio de perspectiva se afianza con los planteos de autores como Richard Ford, David Harris, Gordon Hillman y Jack Harlan y se plasma en la edición de "Foraging and farming" (1989) donde se vierten conceptos como el ya mencionado "continuum evolutivo de la interacción gente-planta" propuesto por D. Harris y el de "cultivo pre-domesticación" desarrollado por G. Hillman a partir de la propuesta original de Helbaeck (Hather y Mason 2002). Veamos a continuación tres de los modelos principales generados bajo esta nueva perspectiva:

1. En su planteo Ford (1985a) propone dos estadios sucesivos: forrajeo ("foraging") y "producción vegetal" ("plant production"), dividiendo a este último en cultivo y domesticación. Según este autor habría tres métodos de producción que se suceden: agricultura incipiente, horticultura y agricultura extensiva. Ford (1985a) es el primero en proponer las distintas clases de comportamientos humanos hacia las plantas como un continuum de tipos de interacción: cuidado, labranza, transplante, siembra y crianza de plantas. Esta secuencia de comportamientos lleva desde lo menos disruptivo desde el punto de vista biológico a la domesticación, donde las plantas dependen totalmente del Hombre para existir (Ford 1985a).

2. El modelo de Harris (1989) es un modelo descriptivo y no explicativo donde el gradiente de actividades indica una unión más estrecha entre humanos y plantas, una inversión de energía humana creciente (supone una relación positiva entre la energía invertida por unidad de tierra explotada en el procuramiento/producción de alimento y la energía obtenida medida en términos de calorías) y una mayor modificación de los ecosistemas naturales y su reemplazo por sistemas agrícolas (Figura 1). En este modelo los umbrales señalan el incremento en la inversión de energía humana. En el primero se pasa del procuramiento o forrajeo a la producción, en el segundo se pasa de la producción al cultivo, entendido como la 
combinación de limpieza del terreno y cardado sistemáticos junto a la siembra y cosecha de cultivos no domesticados, sin que esto conduzca necesariamente a la domesticación. Este constituye un segundo umbral ya que el cardado sistemático y la limpieza de terrenos implican una inversión muy grande de energía. El tercer umbral indica el paso a la agricultura, lo que involucra el cultivo de formas domesticadas que requieren preparación del suelo y mantenimiento de su fertilidad, desmalezado, selección y almacenaje de semillas, control de predadores potenciales, todo lo cual implica mayor inversión energética (Harris 1989). Este es un modelo que parte de concepciones ecológicas y evolutivas, no es unidireccional ya que a pesar de que las actividades se presentan de forma secuencial, no implica que se sucedieron y reemplazaron unas a otras; en este sentido las actividades previas a la agricultura se suman luego a los sistemas de cultivo que evolucionan (Harris 1989). Este cambio de enfoque donde las distintas actividades (como recolección o cultivo) implican solamente prácticas de subsistencia y no sistemas más abarcativos (la recolección se refiere al uso de plantas silvestres ya sea que esta relación se dé en una sociedad cazadora recolectora o en una agricultora, por ejemplo) llevó a superar la dicotomía artificiosa entre cazadores-recolectores/agricultores y a visualizar mejor la transición histórica entre ambos (Hather y Mason 2002).

En estos modelos la otrora correlación directa entre domesticación y agricultura ya no existe dado que los cambios genéticos inducidos por el Hombre pueden presentarse en cualquier punto del continum, desde el procuramiento de plantas silvestres hasta la agricultura, a medida que se apliquen nuevas presiones selectivas (Hather y Mason 2002). Más que definir el uso cazador-recolector de las plantas como el de aquellas no-domesticadas, los autores sugieren que es la práctica del cultivo la que se puede ver como agrícola o productora más que de cazadoresrecolectores, es dicha práctica la que resulta clave en la distinción que hace Ford (1985) entre "foraging" y "producción de alimentos" y que hace Harris (1996 en Hather y Mason 2002) entre "procuramiento de alimento de plantas silvestres" y "producción de alimentos vegetales". 
3. El tercer modelo es el planteado por Hillman y Davies (1990) el cual, si bien se centra en la domesticación del trigo (Triticum spp.), constituye uno de los planteos mejor elaborados dada la amplia base de estudios morfológicos, arqueológicos, ecológicos y experimentales que posee. En principio estos autores plantean que el inicio de la domesticación se dio bajo cultivo en parcelas destinadas a tal fin, y no por las actividades de recolección, distinguiendo entre el cultivo que no lleva a la domesticación ("non domestication cultivation") del que sí lo hace ("pre domestication cultivation"). La diferencia entre ambos radica, obviamente, en las consecuencias evolutivas de las prácticas involucradas, consecuencias que se deben a la aparición o no de mutantes en las poblaciones vegetales, al instrumental y tipo de técnica empleada para el cultivo, al momento de desarrollo de la planta en la cual se aplican y al manejo de las parcelas sembradas. Durante el cultivo previo a la domesticación se llevaría a cabo una manipulación inconciente que habría dado ventajas selectivas a plantas mutantes que carecen de algunas características especialmente reproductivas- necesarias para sobrevivir en estado silvestre. Al alcanzar este tipo de plantas una frecuencia tal que fueran percibidas por los cultivadores, éstos habrían aplicado una selección consciente que fijaría dichos caracteres a nivel poblacional, por medio del cultivo extensivo en grandes parcelas (Hillman y Davies 1990). Los autores consideran además otros factores que pudieron, en teoría, retardar la domesticación como tasas elevadas de fecundación cruzada, alta introgresión con formas silvestres, y la persistencia de técnicas no conducentes a la domesticación.

Por lo tanto puede verse que nuevamente el concepto clave a considerar es el de cultivo, el cual habría constituido un cambio crucial en las relaciones entre seres humanos y plantas. El modelo de Hillman y Davies (1990) (y en parte el de Harris 1989) nos advierten que el cultivo puede no resultar en formas domésticas. Si deseamos identificar un cultivo que sí lleva a la domesticación nos encontramos ante la difícil tarea de identificar formas cultivadas transicionales, las cuales son imposibles de identificar en el registro arqueológico de acuerdo con Hillman y 
Davies (1990) dado el escaso tiempo (no más de 200 o 300 años) en el que se dio el paso de plantas silvestres a domesticadas. Las poblaciones vegetales que representan este momento clave en la transición hacia la domesticación han recibido diferentes denominaciones ademas de la de "cultivos transicionales" mencionada por Hillman y Davies (1990) y que se adoptará en esta tesis por hallarse respaldada en un modelo con altas bases de sustentación. Weiss y colaboradores (2006) emplean el término "predomesticado" para referirse a las malezas que crecen en ambientes modificados por el Hombre. En un sentido similar Gremillion (1993) menciona que el morfotipo malezoide ("weed morph") se identifica en el registro arqueológico porque posee caracteres intermedios entre la forma silvestre y domesticada. Esto planteos se asociarían con el reconocimiento de que los antecesores silvestres de las plantas domesticadas deben exhibir como precondición una tendencia malezoide (Hawkes 1969). Como vimos previamente una maleza no es necesariamente una planta en vías de ser domesticada, pero, si ha de serlo, debe ser previamente cultivada, por lo que sigue siendo más apropiado hablar de "cultivo transicional". Probablemente a lo que estos autores están queriendo aludir con la mención de tendencias o rasgos "malezoides" es al concepto ecológico del término, que refiere a la capacidad de estas plantas de prosperar en hábitats antrópicos, pero sin haber perdido la capacidad de reproducción sin asistencia humana, caracteres que, como ya fue mencionado, poseen también los cultivos no domesticados.

Clement (1999) diferencia plantas "incipientemente domesticadas", a las cuales les siguen evolutivamente plantas "semi-domesticadas". Este autor considera que las primeras son poblaciones que han sido modificadas por intervención y selección humanas, pero cuyo fenotipo promedio esta aún dentro de los rangos de variación hallados en las poblaciones silvestres para los rasgos sujetos a selección. Las variaciones de este promedio son, además, probablemente menores que las de la población silvestre original. El segundo tipo de plantas representan poblaciones con mayor grado de intervención humana de manera que el fenotipo promedio 
diverge totalmente del rango de variación hallado en las poblaciones silvestres para los rasgos sujetos a selección, la varianza de este fenotipo promedio puede ser mayor que en la población silvestre, dado que el fenotipo promedio incluye ahora ambos tipos: los comúnmente hallados en la población silvestre y los nuevos; las plantas son aun capaces de sobrevivir sin la intervención humana. Con la domesticación la variabilidad genética decrece respecto de las plantas "semidomesticadas" por el aumento en las presiones selectivas y la pérdida de adaptaciones ecológicas que le permitían reproducirse sin la intervención humana (Clement 1999). La propuesta de este autor resulta interesante ya que evalúa cómo los mayores grados de dependencia implican cambios en la variabilidad de las plantas a nivel poblacional. Sin embargo, términos como "semi-domesticado" o "predomesticado" incluyen en su concepción la idea de aquello en lo que se van a convertir dichas poblaciones vegetales (en formas domesticadas), por lo cual resultan teleológicos. Asumiendo al proceso de domesticación como un continuum de transformaciones no lineales y reversibles, se considera más apropiado el concepto de "cultivo transicional" dado que el mismo no asume un estado futuro al cual arribarán las plantas manipuladas, dando sólo la idea de transformación en el contexto de nuevas formas de relación.

Sin aplicar ninguno de los modelos señalados en esta sección se asume, a partir de los mismos, que existe una sucesión en el tiempo entre los distintos grados de dependencia entre seres humanos y plantas (figura 2), siendo las acciones de cultivo cruciales en el proceso que llevó a la aparición de plantas domesticadas. La figura 2 esquematiza las transformaciones en el tiempo en la relación entre comunidades humanas y poblaciones vegetales. En el mismo se han representado todas las categorías analizadas en este capítulo, constituyéndose en un esquema general que puede representar el proceso de domesticación de algunas especies, pero no de todas. En este sentido resulta de gran importancia el lugar ocupado por las malezas en este esquema, ya que es la única categoría que puede o no estar presente en la secuencia. Además, de haber estado presentes, las malezas pudieron haber derivado 
directamente de las plantas silvestres (maleza I), o haberse generado por cruzas entre plantas domesticadas o cultivadas y silvestres (maleza II), o por escapes de cultivo de las poblaciones domesticadas (maleza III)(de Wet y Harlan 1975, ver capítulo 4.1.1 a). De estos tres tipos, solo el tipo I de maleza se encuentra en el proceso que llevo desde una especie silvestre a una domesticada, los otros dos tipos se generan una vez producida la domesticación. Estos tres tipos representan por lo tanto vías para el surgimiento de las malezas que son excluyentes entre sí.

En la figura 2 puede verse que, además de la sucesión temporal, existe también una contemporaneidad entre las plantas sujetas a distinto tipo de manipulación, las cuales suelen coexistir en los huertos de gran número de horticultores campesinos escasamente tecnificados de distintas partes del mundo. A la coexistencia en ambientes antrópicos de plantas con distinto grado de dependencia se le ha llamado complejos "weed-weedy-crop" (Beebe et al 1997), el cual traduciremos aquí como complejos "maleza-cultivo-domesticado" atendiendo a las definiciones dadas previamente a dichos términos.

\subsection{3- El por qué de un abordaje paleoetnobotánico y la necesidad de una aproximación etnobotánica a la problemática del manejo de especies vegetales.}

Una revisión general de la bibliografía existente en torno a la domesticación vegetal permite ver que la misma se ha estudiado por dos vías separadas debido a recortes disciplinares académicos. Por lo general en arqueología se ha estudiado como sinónimo de agricultura, y en biología se ha abordado como cambio sin considerar la acción humana. En esta tesis se pretende superar esta divergencia poniendo en relación ambas perspectivas para entender un fenómeno que, de hecho, aconteció como una unidad. Es en este punto que un abordaje paleoetnobotánico contribuiría 
tanto desde lo conceptual como desde lo metodológico, entendiendo que ambos aspectos están inextricablemente unidos.

Se considera la paleoetnobotánica como un abordaje cuyo objetivo es caracterizar la relación de las sociedades humanas con las comunidades vegetales en el pasado, compartiendo en este sentido su objeto de estudio relacional con la etnobotánica, diferenciándose de esta última tan sólo desde lo cronológico (Helbaek 1960, Ford 1979). Para distinguirla de la arqueobotánica se siguen los lineamientos adoptados en la mesa de discusión en arqueobotánica realizada durante la Cuarta Reunión Internacional de Teoría Arqueológica en América del Sur - Intercongreso del World Archaeological Congress (WAC) durante el mes de julio de 2007 en Catamarca, Argentina. En dicha oportunidad se acordó denominar arqueobotánica al estudio de restos vegetales recuperados en el registro arqueológico con el objeto de indagar problemáticas arqueológicas que no se centran en las interrelaciones entre comunidades humanas y vegetales, sino en la reconstrucción de comunidades humanas pasadas y sus interrelaciones con otros grupos sociales (Archila et al 2008, Giovannetti et al 2008). Desde lo metodológico, a las técnicas clásicas de la arqueología se suman técnicas tendientes a la identificación de especímenes vegetales arqueológicos. Siguiendo con estos lineamientos $-\mathrm{y}$ difiriendo en este punto con Ford (1979)- se entiende que la paleoetnobotánica no solo intentará reconstruir la interrelación entre humanos y plantas en el pasado por medio del estudio de restos arqueológicos, sino también por medio de registros históricos, artísticos y lingüísticos, entre otros. Estas distinciones entre arqueobotánica y paleoetnobotánica resultan operativas y por lo tanto serán consideradas en la clasificación de investigaciones realizadas por diversos autores en torno a los procesos de manipulación vegetal, independientemente del nombre que ellos mismos den a sus investigaciones, a fin de ordenar los diversos abordajes que existen actualmente.

La paleoetnobotánica no es tan solo la suma de ciencias naturales (ecología, botánica) y ciencias sociales (antropología, arqueología, historia), de allí que en lo 
que respecta al comienzo de la domesticación de plantas y al surgimiento de la agricultura los métodos de la biología y de la arqueología han podido responder al dónde y al cuándo, sin que se conteste de manera acabada el cómo y el por qué (Farrington y Urry 1985), preguntas que sólo pueden ser debidamente respondidas desde una perspectiva relacional.

$\mathrm{Si}$ bien fueron estudios etnoarqueológicos como los realizados por Lee entre los bosquimanos kung! los que lograron romper con el estereotipo del cazador recolector atado a su medio y modo de vida (Lee y De Vore 1968), fueron los estudios etnobotánicos los que lograron complejizar la visión que se tenía del manejo humano del entorno vegetal, tal como vimos en la sección anterior. La comprensión de la gran diversidad de comportamientos humanos que están implicados en la relación con el medio, sumado al estudio de las respuestas de las comunidades vegetales y las especies particulares ante dicho accionar (de Wet y Harlan 1975, Hillman 1984, Ford 1985 a y b, Harris 1989, Hillman y Davies 1990, Harlan 1992), es un paso ineludible en la reconstrucción del proceso de domesticación, concebido de manera independiente al surgimiento de los sistemas agrícolas. La distinción conceptual clave que han hecho los etnobotánicos y paleoetnobotánicos entendiendo que puede haber cultivo sin domesticación, aunque no ocurra lo inverso, llevó a que las sociedades ya no fueran entendidas como cazadoras recolectoras o productoras en un sentido taxativo.

La domesticación es además una problemática que está fuertemente unida al estudio del cambio, definido como la relación entre sociedades humanas y comunidades vegetales en perspectiva histórica. Hasta el momento los estudios de domesticación vegetal en perspectiva diacrónica se han nutrido de conceptos de cambio y marcos teóricos para su estudio desarrollados principalmente en antropología o arqueología. Se puede pensar que, en definitiva, estamos ante procesos de selección dirigidos por sociedades humanas, pero sabemos también que cada especie y cada comunidad vegetal son parte de este devenir e imprimen peculiaridades en el mismo. En la arqueología del NOA son los estudios que 
emplean un marco teórico ecológico- cultural los que se han ocupado del advenimiento de sociedades productoras en la región (Muscio 1998/1999, 1999; Olivera 1992; Yacobaccio 1992). Quienes han estudiado el proceso de domesticación como preámbulo a la agricultura desde una perspectiva paleoetnobotánica lo han hecho mayormente desde dicho marco teórico (Harris 1989, Pearsall 1989b, Piperno 1989, Winterhalder y Goland 1997, Gremillion 1997). Esto es consistente con que la paleoetnobotánica, en tanto abordaje, no ha desarrollado marcos teóricos propios (Ford 1979). La consecuencia de este posicionamiento es que el por qué y el cómo son, en todos los casos, respondidos desde un modelo de toma de decisiones donde seres humanos considerados altamente sensibles al riesgo buscan minimizar el mismo o bien maximizar la eficiencia energética de sus actividades, en el marco de procesos gobernados por la selección natural y la teoría microeconómica (Gremillion 1996).

En este sentido, entender a la paleoetnobotánica como una proyección al pasado de la etnobotánica aporta el interés por la visión emic que ha tenido esta última. Si bien esta alternativa ha sido escasamente explorada en el estudio arqueológico de la domesticación vegetal (Farrington y Urry 1985), ésta sería una instancia enriquecedora al dar la posibilidad de una aproximación más diversa y ontológicamente rica de las sociedades del pasado, siendo por lo tanto la que se desarrollará en esta tesis.

El empleo de estudios etnobotánicos se torna, por lo tanto, fundamental en la comprensión de los comportamientos de manejo y selección que las comunidades humanas ejercen sobre las poblaciones vegetales con las cuales se relacionan a partir de patrones cognitivos, socialmente construidos y transformados, que guían la acción (Ford 1979, Toledo 2002). Tomando esto en consideración se ha procurado en esta tesis identificar criterios de selección y formas de manejo ejercidas por comunidades actuales sobre los taxa vegetales que encontramos en el registro arqueológico del NOA (capítulo 3). Por otra parte, siguiendo a Alcorn (1995), se ha asumido la proyección etnoarqueológica de los estudios etnobotánicos 
en el reconocimiento de poblaciones vegetales modificadas por el Hombre (capítulo 6).

En cuanto al estudio de restos vegetales arqueológicos, destacan los estudios sobre macrorrestos, principalmente en micromorfología cuali y cuantitativa (Gremillion 1993; Butler 1989, 2002; Bruno y Whitehead 2003). Estas han sido técnicas empleadas por la paleoetnobotánica a fin de buscar modificaciones en los órganos vegetales producto de la acción humana. En este sentido, se acuerda con la propuesta de Ford (1985 a) de entender las plantas domesticadas como artefactos culturales, haciéndola extensiva a toda planta intencionalmente manipulada por el Hombre, lo cual incluiría a los cultivos. Por lo tanto al analizar a nivel morfológico restos arqueobotánicos se busca dilucidar en ellos las prácticas humanas pasadas que los transformaron (Hillman 1984). Este acercamiento es el que se ha realizado en esta tesis en el estudio de restos arqueológicos del género Cucurbita, Lagenaria y Phaseolus (capítulos del apartado 4 de esta tesis).

Los restos arqueobotánicos han de estudiarse vinculados con su contexto arqueológico general a fin de dilucidar su cronología, en qué ámbitos se emplearon y con qué otra clase de restos se asocian. Por lo tanto el análisis integral del contexto arqueológico permitirá caracterizar al grupo social que manipuló las poblaciones vegetales cuyos restos recuperamos en el presente, siendo fundamental determinar la forma de organización social del grupo (presencia de jerarquías o heterarquías, por ejemplo), su desarrollo tecnológico, su organización espacial y los rangos de movilidad-interacción (capítulo 3). Como se mencionó previamente, si bien las investigaciones llevadas a cabo en esta tesis se realizan desde una perspectiva paleoetnobotánica, el análisis del contexto arqueológico en su totalidad resulta fundamental a fin de reconstruir formas de interacción ser humano - planta social y ambientalmente contextualizadas (Alcorn 1995).

Por lo tanto, para el análisis de la problemática planteada en esta tesis se empleará un abordaje paleoetnobotánico, incluyendo estudios etnobotánicos (y su aplicación etnoarqueológica) y arqueológicos. 


\subsection{4- Supuestos teóricos asumidos en esta tesis}

Además de los conceptos básicos ya mencionados que serán empleados en el desarrollo de esta tesis, se asumieron una serie de supuestos teóricos que guiaron la investigación, pero que, lejos de tomarse como fundamentos inmutables, fueron constantemente puestos a prueba, reformulados, reflexionados, cuestionados y reescritos a medida que se construyeron los datos que fueron cimentando esta tesis. A continuación se desarrollan los mismos:

1) Postura materialista-constructivista: Empleamos el término "materialista" siguiendo a Núñez Regueiro (1979), Bate (1998) y Gándara (1983) entendiendo que las acciones humanas operan sobre una realidad que es externa al observador. Las realidades culturales son por tanto construcciones efectuadas sobre una materialidad que impone ciertos límites y restricciones a las acciones e interpretaciones que sobre ella se pueden hacer. Por ende, si bien el medio impone ciertas restricciones por su propia materialidad, la misma es incorporada al sistema de conocimiento e interpretación cultural (sistema de cognición) a través de una serie de mediaciones culturales que interpretan sus características contextualizándolas en relación al resto de la cultura y de las coyunturas históricas del momento. La realidad, por lo tanto, es una construcción y de allí que la postura adoptada en esta tesis sea "constructivista".

En cuanto al tema específico bajo investigación, se asume que el mundo vegetal impone ciertos condicionantes (Alcorn 1995) que, una vez aprehendidos e interpretados desde el "cosmos cultural" (Toledo 2002), forman parte de las variables que operan en la toma de decisiones y acciones consecuentes. Las acciones culturalmente mediadas poseen, a su vez, consecuencias en la materialidad sobre la cual operaron originalmente, la cual se modifica no sólo como consecuencia de la acción ejercida, sino también de acuerdo con los propios condicionantes materiales que, en este caso, son los caracteres propios de las plantas que intervienen en dicha interacción. Por ende, las plantas son agentes 
activos que imponen su materialidad en la interacción con las sociedades humanas. De acuerdo con Ford (1979) la biología de las plantas impone ciertas condiciones que impactarán en la elección cultural de las mismas para ciertos usos, de acuerdo con las clasificaciones y lógicas culturales. Luego, las sociedades operan a través de acciones concretas sobre esta materia prima vegetal y la transforman de acuerdo con sus patrones cognitivos, haciendo de las plantas domesticadas artefactos culturales donde se han seleccionado y fijado caracteres que serían desfavorables en condiciones naturales (Ford 1979, 1985a).

2) Las plantas son artefactos con un rol activo en el entramado social: Se asume que la propuesta de que los artefactos son mediadores en las relaciones sociales, reproduciéndolas a la vez que transformándolas, que son símbolos activos y comunicadores culturales (Hodder 1991, Scattolin y Lazzari 1997, Haber 2006) es aplicable también a las plantas cultivadas. Como dice Alcorn (1995) las plantas poseen un rol, el cual implica ciertas características y acciones específicas, dentro del medio social. Estas plantas $-\mathrm{y}$ el ambiente socialmente apropiado y transformado del que forman parte- representan el modo en que los Hombres se relacionan entre sí para relacionarse con su medio y las relaciones que los componentes del medio natural establecen entre sí y con dichos Hombres. Es por ello que el abordaje de este proceso debe ser necesariamente relacional a fin de abarcar los múltiples componentes involucrados. Desde el "perspectivismo" postura asumida por investigadores como Eduardo Viveiros de Castro, Philippe Descola y Carlos Fausto para caracterizar la visión de los indígenas sudamericanos acerca de la naturaleza- se asume que la ontología nativa ve a los animales y plantas como personas con intención y voluntad, por lo cual la diferencia entre éstos y el ser humano es sólo de grado, siendo las interacciones con los mismo de igual tipo que las de parentesco, reciprocidad o alianza (Garnelo 2007). En consecuencia, las interacciones entre comunidades humanas y vegetales no ocuparían una esfera distinta dentro de las interacciones que los humanos mantienen entre sí y con otros 
grupos sociales. En tanto entidades con agencia, las plantas, tanto como cualquier ser humano, se hallan incluidas en el entramado social teniendo la capacidad de transformarlo o de reproducirlo.

Por lo tanto cuando en esta tesis hablamos de la relación seres humanos-plantas, no lo hacemos asumiendo la bipartición naturaleza-cultura, entendiendo a la primera como un escenario estático sobre el cual se desarrolla la trama social, sino como un espacio culturalmente incorporado cargado de entidades (animales, plantas, cerros, ríos, etc.) con agencia social. Dicha agencia será el producto del status ontológico que les fue atribuido por las sociedades pasadas y determinará, en gran parte, la forma en que se dio la relación (y por ende, la interacción) entre humanos y plantas, así como también la transformación de la misma a lo largo del tiempo.

3) En el proceso de domesticación las plantas se encuentran bajo un proceso de evolución, las sociedades humanas, en cambio, bajo un proceso de cambio cultural. Erróneamente puede interpretarse que esta tesis posee un marco teórico evolucionista cultural, por el contrario consideramos al mismo como inadecuado por su carácter economisista y racionalista, con lógicas de razonamiento modernas como la relación costo/beneficio y la noción de optimización energética en estrategias de subsistencia- que limitan la comprensión de sociedades del pasado, en las cuales pudieron haber operado lógicas de interacción totalmente distintas. Si bien el abordaje aquí presentado es relacional, se mantiene la distinción entre comunidades vegetales y sociedades humanas, entendiendo que en cada una de ellas operan principios muy distintos. Las comunidades vegetales, aisladas o no del Hombre, están sujetas a principios ecológicos y a procesos evolutivos signados por mecanismos tales como la selección natural, deriva génica, flujo génico, mutaciones, hibridación, recombinación y efecto fundador (León 1968, Gould 1980). Las sociedades humanas, en cambio, no responden a principios o mecanismos únicos, siendo altamente variables en sus comportamientos sociales tal como lo ha demostrado la antropología en sus casi tres siglos de desarrollo. El cambio en estas 
sociedades opera a nivel social y mediante toma de decisiones de agentes sociales colectivos o individuales que tienen tanto la capacidad de reproducir como de transformar las estructuras culturales en que se enmarca su existencia.

La domesticación - generadora de comunidades vegetales antrópicas- es la bisagra que se encuentra entre estas dos entidades y su abordaje relacional lleva necesariamente a vincularlas, aunque sin extrapolar procesos que se dan en una a la otra.

\subsection{ESTRATEGIA METODOLOGICA Y MODO DE ABORDAJE DE LA PROBLEMÁTICA BAJO ESTUDIO}

El abordaje paleoetnobotánico implica un fuerte vínculo con la etnobotánica. Entender modos de relación entre comunidades humanas y comunidades vegetales, como se pretende en esta tesis, requiere necesariamente hacer trabajo de campo entre comunidades humanas actuales que manipulen las mismas especies (o las plantas domesticadas derivadas de ellas) que se estudian a nivel arqueológico. Esto no sólo permite entender los modos de relación ser humano-planta, sino también la posibilidad de que los mismos se reflejen o no materialmente en las poblaciones vegetales afectadas. Los estudios etnobotánicos resultan cruciales, además, porque permiten entender en toda su complejidad los factores culturales -incluso los que carecen de proyección material- que operan en la conformación de comportamientos sociales relacionales tanto en el actualidad como en el pasado. Con esto se pretende ir mas allá de la mera apreciación de las ventajas de los estudios etnoarqueológicos como generadores de modelos a contrastar, asumiéndose que así como la paleoetnobotánica está estrechamente ligada a la etnobotánica, la arqueología está fuertemente ligada a la antropología. Es el vínculo con ésta última lo que permite posicionarse para entender -aunque sea parcialmente- cómo es el comportamiento social humano y qué factores pueden estar operando en la conformación del mismo. A continuación se describe la 
metodología etnobotánica aplicada en el desarrollo de esta tesis, si bien un desarrollo pormenorizado de la misma puede verse en los capítulos 5 y 6 .

\section{Metodología etnobotánica.}

Se efectuaron tareas de campo en tres comunidades campesinas asentadas en condiciones ambientales diferenciales: Rachaite y Coranzulí en la puna jujeña, Santa Victoria Oeste en el pedemonte del centro-norte salteño, provincia fitogeográfica de Yungas, distrito de los Bosques Montanos (Hurrell1989, Hilgert 2007a) y El Shincal en el valle de Hualfín, Catamarca, provincia fitogeográfica de Monte (Capparelli 2007). Se realizaron entrevistas abiertas y semiestructuradas (Cotton 1995, Martin 1995, Granai 1962) con los pobladores adultos de ambos sexos tendientes a identificar formas de manipulación y criterios de selección que intervienen en su relación con las comunidades vegetales locales silvestres y cultivadas. Las entrevistas fueron registradas en libreta y en soporte digital de audio. Se llevó a cabo observación directa libre y metódica (Granai 1962) en las distintas unidades domésticas (Crivos y Martínez 1996) y en las zonas cultivadas, con registro gráfico y fotográfico de las áreas de cultivo (huertos, viveros, quintas) y artefactos vinculados a la obtención y procesamiento de recursos vegetales (morteros, arneros, palas). En la comunidad de El Shincal se efectuaron también registros de historia de vida (Nazarea 1998) con individuos adultos mayores. Asimismo se colectó -con el previo consentimiento de los pobladores localesmaterial etnobotánico (tanto plantas enteras como órganos útiles tales como frutos y semillas) de referencia (Martin 1995, Barrau 1981) a fin de llevar a cabo identificaciones taxonómicas y análisis morfo-anatómicos en laboratorio. Las muestras colectadas fueron depositadas en el Herbario de Plantas Útiles del Laboratorio de Etnobotánica y Botánica Aplicada (FCNYM, UNLP) asignándoles sigla y número de registro personal. Las entrevistas fueron desgrabadas y la información procesada en una base de datos considerando: área de estudio, fecha 
en que se realizó el trabajo de campo, características de los informantes (nombre, sexo y edad), especies mencionadas, nombres vulgares asignados a las mismas, sigla y número correspondiente de las muestras colectadas con el que se ingresaron al mencionado herbario, usos reconocidos localmente, modos de empleo y prácticas de manipulación (recolección, protección, cultivo, entre otras posibilidades).

En lo que respecta a los restos vegetales arqueológicos en esta tesis se estudiaran sólo macrorrestos y no microrrestos de plantas productoras de semillas (géneros Cucurbita, Lagenaria y Phaseolus). Los primeros se visualizan a ojo desnudo, los segundos, en cambio, requieren del empleo de microscopía de altos aumentos para ser detectados (Pochettino et al. 1998, Pochettino y Capparelli en prensa). El reciente auge en el estudio de microrrestos como almidón y fitolitos ha ofrecido nuevas perspectivas, principalmente en el estudio de sitios tempranos donde no se han recuperado macrorrestos y en el análisis de sitios ubicados en zonas no adecuadas para la preservación de material perecedero (Piperno y Holst 1998, Piperno et al. 2000, Piperno et al. 2002, Stothert et al. 2003, Horrocks et al 2004, Perry et al 2007, Piperno 2008, entre otros), teniendo esta clase de análisis un desarrollo escaso, aunque creciente, en nuestro país (Wurschmidt y Korstanje 1998/1999, Capparelli et al 2005, Babot 2005, 2006; Korstanje y Babot 2007, Babot et al. 2007, entre otros). Sin embargo en esta tesis no se aborda su análisis, o se lo hace sólo de manera complementaria al estudio de macrorrestos, debido a que el tipo de información que ofrecen es esencialmente distinto al que se obtiene al estudiar macrorrestos. Si bien en ciertos estudios han empleado fitolitos y almidones para trazar la domesticación de géneros como Cucurbita y Capsicum (Piperno y Pearsall 1998, Piperno et al. 2000, Piperno et al. 2002, Stothert et al. 2003, Perry et al 2007, Piperno 2008, Piperno y Stothert 2008) el estudio de ambos tipos de microrrestos permite elaborar propuestas en torno solamente a los tejidos vegetales que los producen. En el caso del análisis presentado en esta tesis, no sabemos qué tejidos ni órganos fueron afectados por los distintos modos de 
manipulación humana. Trabajar con almidones o fitolitos es dirigir de manera anticipada la atención a ciertos tejidos en detrimento de otros. Tomando entonces en consideración esta menor capacidad resolutiva de los microrrestos respecto de los macrorrestos (Pochettino y Capparelli en prensa) es que se ha optado por el análisis de los segundos.

A pesar de que autores como Ford (1979) consideran que la metodología aplicada en paleoetnobotánica deriva de la botánica, se asume aquí que, si bien las técnicas sí son en general tomadas de dicha disciplina, la metodología -en tanto conjunto de técnicas cuya aplicación obedece al objetivo de investigación- difiere entre paleoetnobotánica y botánica, cuya diferencia en objetivos ya hemos explicitado.

A continuación se detalla la metodología paleoetnobotánica seguida en esta tesis, un desarrollo pormenorizado de la misma puede verse en los capítulos correspondientes a la sección 4 .

\section{Metodología paleoetnobotánica}

Se realizó la confirmación y/o identificación taxonómica de macrorrestos arqueobotánicos de Cucurbita sp y Phaseolus sp. presentes en las colecciones arqueológicas analizadas, a través de la identificación de caracteres macro y microscópicos de diagnóstico. Estos dos géneros fueron seleccionados puesto que en el caso de Cucurbita sp. varios autores han sugerido su temprana domesticación en territorio argentino (Millán 1945, Whitaker y Bemis 1965, Brücher 1989, Nee 1990, Decker Walters y Walters 2000, Albeck 2001) y porque en el caso de Phaseolus vulgaris $\mathrm{L}$. se han recuperado gran cantidad de restos de la variedad silvestre y domesticada de dicha especie en sitios tempranos del noroeste argentino (Pochettino y Scattolin 1991, Carrizo et al 1999, Oliszewski 2004)

Se procuró identificar caracteres morfológicos-anatómicos y biométricos sujetos a modificación en el proceso de evolución bajo domesticación a fin de determinar el 
grado de dependencia de los especímenes estudiados (Butler 1989, Ladizinski 1989, Renfrew 1969, Pearsall 1989, Körber-Grohne 1991).

Estos análisis se realizan por medio del empleo de microscopios estereoscópico, fotónico y electrónico de barrido, aplicando técnicas estándar de microscopía (Pochettino et al 1998). Para el análisis de caracteres métricos externos se empleó calibre digital. . Para análisis biométricos de caracteres microscópicos se empleó una cámara clara adosada al microscopio fotónico y dos softwares: Image Tool 3.0 y Motic Image Plus 2.0.

Tanto para la identificación taxonómica de los restos arqueobotánicos como para delimitar caracteres morfo-anatómicos y biométricos sujetos a modificación en el proceso de evolución bajo domesticación, resulto imprescindible la construcción de una colección de referencia (Pochettino y Capparelli en prensa). La misma se entiende como el conjunto de ejemplares actuales de un taxón vegetal que son analizados con la finalidad de obtener, a partir de los mismos, rasgos morfológicos, anatómicos, biométricos, fisiológicos o genéticos que sean distintivos -en tanto exclusivos- de dicho taxón. Como puede inferirse a partir de lo antes dicho, la colección de referencia debe estar compuesta por la mayor cantidad posible de taxones a fin de constatar la exclusividad de los rasgos en cada uno de ellos. Dicha colección debe ser rica en cantidad de ejemplares por cada taxón dada la alta variabilidad interpoblacional que existe en las especies vegetales (Hillman et al. 1993), así como también las altas tasas de hibridación que poseen, todo lo cual hace que las plantas sean mucho más plásticas que los animales (Parodi 1938). Debe contar también con representantes procedentes de diversas ubicaciones geográficas, ya que las poblaciones vegetales de una misma especie resultan altamente sensibles a factores como suelo, humedad y fotoperíodo. Otro aspecto a considerar es la posibilidad de preservación de los rasgos diagnósticos de un taxón, puesto que el objetivo último es procurar su detección en restos arqueobotánicos. Por lo tanto muchas veces el problema no radica en la ausencia de este tipo de rasgos, sino en que los mismos se encuentran en tejidos que no resisten la degradación propia del 
material arqueológico (véase por ejemplo Lepofsky et al. 1998) o los procesamientos a los cuales son sometidos los vegetales para su consumo o empleo (vg. hervido, molido, tostado, macerado, entre otros). En este último caso resulta fundamental la inclusión en la colección de referencia de ejemplares de un mismo taxa sujetos experimentalmente a distintos tipos de procesamiento a fin de evaluar en cada uno de ellos la supervivencia, o no, de los caracteres diagnósticos ${ }^{3}$.

En nuestro caso particular de estudio, los materiales botánicos obtenidos tras los trabajos de campo etnobotánicos constituyeron también una colección de referencia, reuniéndose ejemplares representativos de distintos grados de manejo y control por parte de comunidades humanas. Un análisis exhaustivo de diversos rasgos presentes en taxones actuales representados por una colección de referencia formada por gran número de ejemplares es la única vía para encontrar criterios de identificación válidos para el reconocimiento de restos arqueobotánicos (Hillman et al 1993, Cowan y Smith 1993, Pochettino y Capparelli en prensa).

En el caso particular de macrorrestos carbonizados se realizaron ensayos experimentales a fin de replicar, a partir de órganos vegetales actuales de referencia, las transformaciones sufridas bajo distintas temperaturas y tiempo de exposición; evaluándose también la persistencia y transformación de los caracteres de diagnóstico identificados en material fresco (Mangafa y Kotsakis 1996, Wright 2003, Braadbaart 2008, Braadbaart et al 2004).

\section{$\underline{\text { Restos arqueológicos estudiados }}$}

Los macrorrestos analizados corresponden en su totalidad a los resultados de las excavaciones efectuados por distintos investigadores, siendo algunos parte de colecciones arqueológicas depositadas en museos, en tanto otros fueron gentilmente cedidos por los responsables de su extracción (ver capítulo 3). En el

\footnotetext{
${ }^{3}$ Otra utilidad de este tipo de ejemplares es determinar en los restos vegetales rasgos que se produzcan como consecuencia de cada tipo de procesamiento a fin de detectar los mismos en el registro arqueológico (ver por ejemplo Hillman 1984, Capparelli 2008)
} 
caso de colecciones arqueológicas se seleccionaran las correspondientes a sitios mencionados en la literatura como "claves" en el estudio de la problemática de la domesticación temprana de especies vegetales en el NOA y Área Andina Central y Meridional. Se realizó también el análisis de artefactos asociados a los especímenes arqueobotánicos que contribuyeran a la interpretación integral de la ocupación correspondiente. Todo esto se complementó con el estudio de libretas de campo, informes de campaña, planillas de registro y material publicado de los sitios bajo estudio a fin de reconstruir los contextos arqueológicos originales. Cuando fue posible se realizaron entrevistas con las personas que intervinieron en las excavaciones. La colaboración con los investigadores responsables permitió un análisis enriquecido de los restos arqueobotánicos al permitir el acceso a la totalidad de los aspectos del sitio estudiado. 
Tabla 1: tabla que representa los distintos tipos de relación ser humano- planta y sus implicancias.

De arriba hacia abajo aumenta el grado de dependencia.

\begin{tabular}{|c|c|c|c|c|}
\hline Clase de planta & Hábitat & Modo de relación & $\begin{array}{c}\text { Tipo de } \\
\text { modificación }\end{array}$ & $\begin{array}{l}\text { Bibliografía de } \\
\text { referencia }\end{array}$ \\
\hline Silvestre & Natural & Recolección & $\begin{array}{c}\text { Incidental, } \\
\text { inconsciente. Se } \\
\text { modifican } \\
\text { principalmente la } \\
\text { abundancia y } \\
\text { frecuencias génicas } \\
\text { de las poblaciones } \\
\text { naturales. }\end{array}$ & $\begin{array}{c}\text { Harlan y De Wet } \\
\text { 1965, Ford 1979, } \\
\text { Rindos 1984 en } \\
\text { Harris 1989, Hallam } \\
\text { 1989, Yen 1989, } \\
\text { Politis 1996, Casas } \\
2001\end{array}$ \\
\hline $\begin{array}{l}\text { Maleza (ruderal, } \\
\text { arvense) }\end{array}$ & Antrópico & $\begin{array}{l}\text { Tolerancia o } \\
\text { erradicación }\end{array}$ & $\begin{array}{c}\text { Por adaptación } \\
\text { natural a hábitat } \\
\text { disturbado. Puede } \\
\text { reproducirse } \\
\text { exitosamente sin la } \\
\text { asistencia humana. }\end{array}$ & $\begin{array}{c}\text { Harlan y de Wet } \\
\text { 1965, de Wet y } \\
\text { Harlan } 1975\end{array}$ \\
\hline $\begin{array}{l}\text { Cultivada no } \\
\text { domesticada }\end{array}$ & Antrópico & $\begin{array}{l}\text { Acción de Cultivar, } \\
\text { que incluye una o } \\
\text { más de las } \\
\text { siguientes prácticas: } \\
\text {-Fomento o } \\
\text { inducción } \\
\text {-Protección } \\
\text {-Siembra y/o } \\
\text { transplante } \\
\text {-Cosecha } \\
\text {-Preparación del } \\
\text { suelo }\end{array}$ & $\begin{array}{c}\text { Consciente o } \\
\text { dirigida a aumentar } \\
\text { el número de } \\
\text { individuos y el área } \\
\text { de distribución de la } \\
\text { especie. Puede } \\
\text { reproducirse } \\
\text { exitosamente sin la } \\
\text { asistencia humana. } \\
\text { Puede haber } \\
\text { modificaciones } \\
\text { morfológicas, pero } \\
\text { las mismas no se } \\
\text { fijan genéticamente } \\
\text { a nivel poblacional }\end{array}$ & $\begin{array}{c}\text { Ford 1979, 1985a, } \\
\text { Yernell 1983 en } \\
\text { Smith 1985, Asch y } \\
\text { Asch 1985, } \\
\text { Farrington y Urry } \\
\text { 1985; Harris 1989, } \\
\text { Hillman y Davies } \\
\text { 1990, Harlan 1992; } \\
\text { Gremillion 1997, } \\
\text { Piperno y Pearsall } \\
\text { 1998, Casas 2001, } \\
\text { Hather J. y Mason } \\
\text { S. } 2002\end{array}$ \\
\hline \multirow{3}{*}{$\begin{array}{c}\text { Cultivada } \\
\text { domesticada }\end{array}$} & \multirow{3}{*}{ Antrópico } & \multirow{3}{*}{$\begin{array}{l}\text { Acción de Cultivar + } \\
\text { Aislamiento } \\
\text { reproductivo }\end{array}$} & $\begin{array}{l}\text { Modificaciones en el } \\
\text { sistema de } \\
\text { dispersión natural } \\
\text { impide la } \\
\text { reproducción sin } \\
\text { asistencia humana. }\end{array}$ & $\begin{array}{l}\text { De Wet y Harlan } \\
\text { 1975, Ford } 1979 \text { y } \\
\text { 1985; Hillman y } \\
\text { Davies 1990; Harlan } \\
\text { 1992; Geps } 2005\end{array}$ \\
\hline & & & $\begin{array}{c}\text { Inconsciente: por } \\
\text { adaptación natural a } \\
\text { ambiente antrópico }\end{array}$ & $\begin{array}{l}\text { Rindos } 1980, \text { Asch } \\
\text { y Asch 1985, Smith } \\
2006 \\
\end{array}$ \\
\hline & & & $\begin{array}{c}\text { Consciente: } \\
\text { selección cultural de } \\
\text { tipos con sistema de } \\
\text { dispersión } \\
\text { modificado. }\end{array}$ & $\begin{array}{c}\text { Higgs } 1972 \text {, Ford } \\
\text { 1985b, Farrington y } \\
\text { Urry 1985, Hillman y } \\
\text { Davies } 1990\end{array}$ \\
\hline Cultivar & Antrópico & $\begin{array}{c}\text { Separación de } \\
\text { grupos de plantas } \\
\text { domesticadas junto } \\
\text { a su cría selectiva y } \\
\text { aislamiento }\end{array}$ & $\begin{array}{c}\text { Generación } \\
\text { consciente de } \\
\text { grupos morfológicos } \\
\text { con ciertos } \\
\text { caracteres } \\
\text { deseados }\end{array}$ & $\begin{array}{l}\text { Plotnicov y Scaglion } \\
\text { 1999, Clement } 1999\end{array}$ \\
\hline
\end{tabular}


Tabla 2: tabla que muestra las propuestas conceptuales de diversos autores para denominar comportamientos humanos vinculados con la manipulación de especies vegetales que pueden, o no, desembocar en la domesticación de las mismas. Modificada de Harris 1989.

\begin{tabular}{|c|c|c|}
\hline Autor & Denominación & Características \\
\hline $\begin{array}{l}\text { Binford } 1968 \text { y } \\
\text { Flannery } \\
1968\end{array}$ & "procuramiento de alimentos" & $\begin{array}{l}\text { actividades de recolección (gathering) y de colecta } \\
\text { (collecting) de los cazadores-recolectores }\end{array}$ \\
\hline $\begin{array}{l}\text { Harris } 1969, \\
1972 \text { y } 1973\end{array}$ & "manipulación" & $\begin{array}{l}\text { de recursos bióticos que puede llevar a una } \\
\text { intervención en el sistema de crianza (breeding) de } \\
\text { plantas silvestres tal que resulte en la domesticación }\end{array}$ \\
\hline $\begin{array}{l}\text { Harris } 1969, \\
1972 \text { y } 1973\end{array}$ & "transformación" & de ecosistemas naturales a artificiales \\
\hline Higgs 1972 & "husbandry" (cuidar) & $\begin{array}{c}\text { Toda intervención y control humano sobre la biología y } \\
\text { comportamiento de animales y plantas }\end{array}$ \\
\hline Jarman 1982 & $\begin{array}{l}\text { recolección casual, recolección } \\
\text { sistemática, cultivo limitado, cultivo } \\
\text { desarrollado y cultivo intensivo }\end{array}$ & no son estadios unilineales progresivos e irreversibles. \\
\hline Rindos 1984 & domesticación incidental & $\begin{array}{l}\text { resultado de la protección y dispersión humana de } \\
\text { plantas silvestres en el ambiente a nivel general }\end{array}$ \\
\hline Rindos 1984 & domesticación especializada & $\begin{array}{c}\text { mediada por el impacto medioambiental de los } \\
\text { humanos, especialmente en áreas locales donde } \\
\text { residen }\end{array}$ \\
\hline Rindos 1984 & domesticación agrícola & $\begin{array}{l}\text { culminación de los otros dos procesos, es lo que } \\
\text { comúnmente se entiende por domesticación. }\end{array}$ \\
\hline
\end{tabular}


Figura 1: modelo propuesto por David Harris (1989) para explicar el paso de la explotación de plantas silvestres a la domesticación plena de especies vegetales.
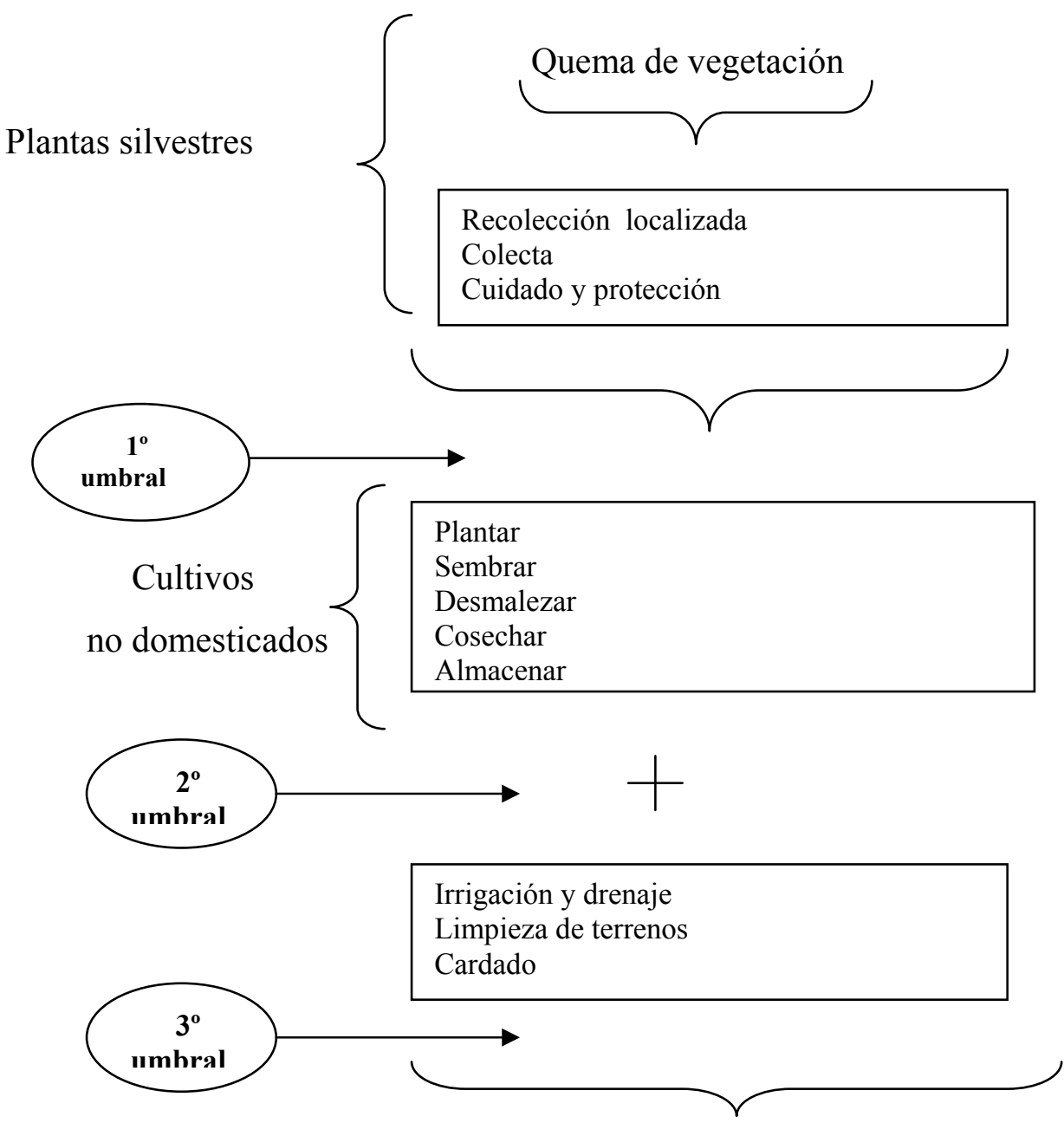

Domesticación de los cultivos entendida en sentido ortodoxo: los sistemas reproductivos de las poblaciones de plantas se han alterado tanto por la intervención sostenida del hombre que las formas domesticadas (genética o fenotípicamente seleccionadas) se volvieron dependientes de la asistencia humana para su supervivencia. 
Figura 2: modelo general de transformaciones en el tiempo en la relación entre comunidades humanas y poblaciones vegetales hasta la obtención de plantas domesticadas y complejos "maleza-cultivo-domesticado". Las flechas enteras indican el proceso de evolución bajo domesticación desde una forma silvestre hasta una domesticada. La presencia de diversos tipos de maleza (I, II o III) es excluyente entre sí y constituyen la única categoría que puede estar ausenten el proceso de domesticación.

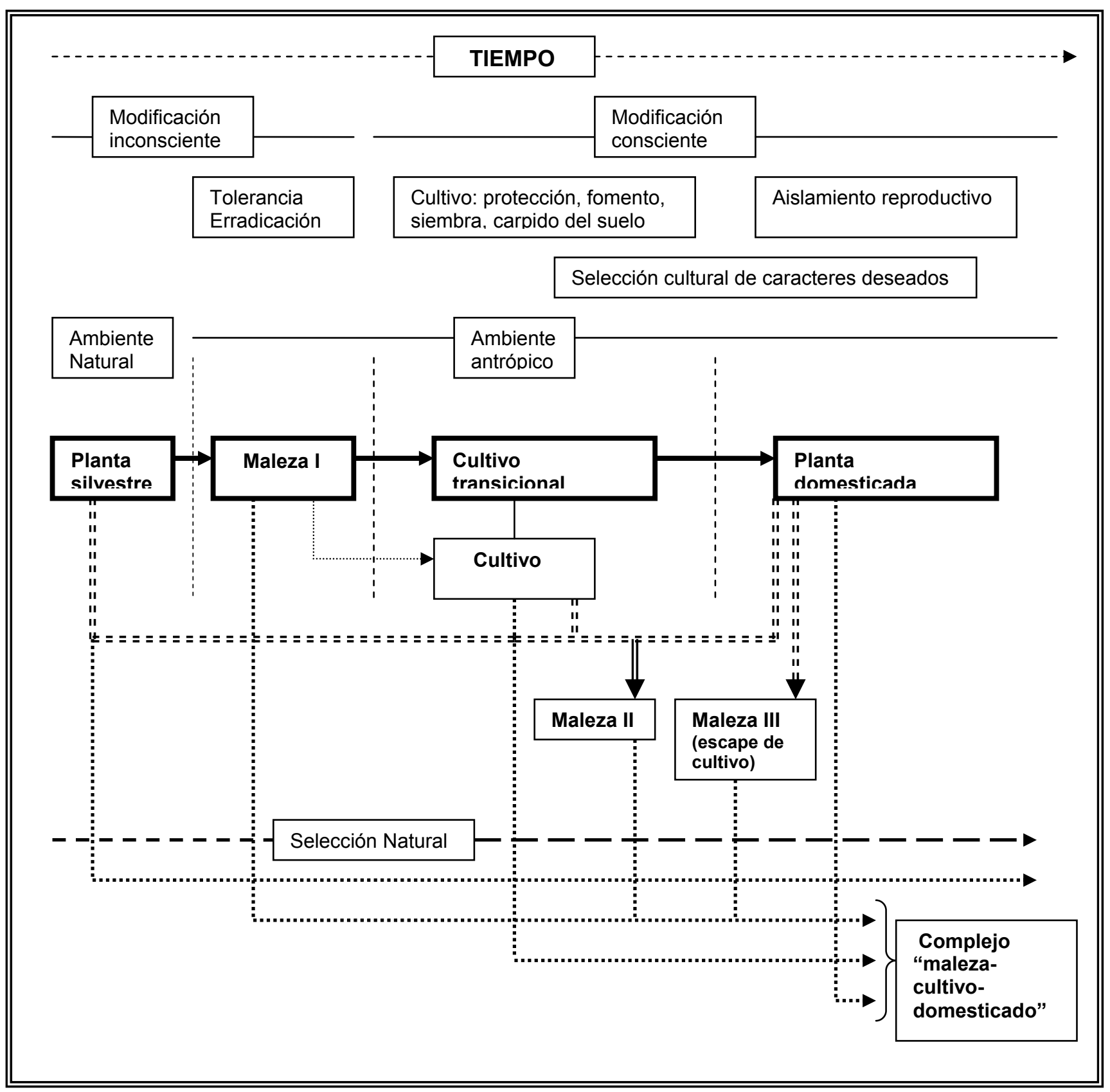




\section{ESTADO ACTUAL DE LA PROBLEMÁTICA DE LA DOMESTICACIÓN VEGETAL Y LOS INICIOS DE LA AGRICULTURA EN EL NOROESTE ARGENTINO.}




\section{ESTADO ACTUAL DE LA PROBLEMÁTICA DE LA DOMESTICACION VEGETAL Y LOS INICIOS DE LA AGRICULTURA EN EL NOROESTE ARGENTINO}

En este capítulo se caracterizarán, a partir del análisis de la bibliografía publicada hasta el momento, las investigaciones y propuestas desarrolladas en torno al advenimiento de formas de vida agrícolas en el desarrollo cultural temprano del NOA. En primer lugar se analizarán los antecedentes del tema y la manera en que se han entendido los procesos de domesticación en el área desde los primeros estudios hasta la actualidad. En segundo lugar se presentará el estado actual de la problemática de la domesticación vegetal e inicios de la agricultura en las sociedades cazadoras recolectoras y formativas del NOA.

I) El Noroeste argentino y la domesticación vegetal. Historia de las investigaciones.

a_Primeros estudios hasta la década de 1970

Si bien ya De Candolle (1959) había señalado que la arqueología podía brindar información esencial respecto del área donde surgen las especies cultivadas, el aporte de la arqueología sudamericana al debate era escaso. El modelo que primaba era el de "centros de origen" propuesto por Vavilov en 1923, el cual se basaba fundamentalmente en el método fitogeográfico diferencial. Dicho método consistía primeramente en determinar las especies linneanas y los grupos genéticos relacionados de varias plantas domesticadas. Luego, se establecían las áreas de distribución de las anteriores haciéndose lo mismo a niveles infraespecíficos. Sobre la base de esta información se construía el patrón de distribución de la diversidad hereditaria, estableciéndose el centro 
de origen geográfico de una especie donde se concentraba la mayor diversidad genética de la misma (Vavilov 1951). A partir de este modelo general irían surgiendo estudios particulares tendientes a identificar el área de origen de ciertos taxones vegetales que se consideraban sudamericanos. Esta vertiente queda plasmada en los trabajos presentados en el XXVII Congreso Internacional de Americanistas que se realizó en Argentina en 1966. En el marco del mismo se llevó a cabo un simposio sobre Etnobotánica, coordinado por J. Cámara Hernández y A. Krapovicas, con amplio predominio de publicaciones referidas a la domesticación de diversos taxones, incluyendo datos surgidos de investigaciones arqueológicas (Capparelli et al. en prensa). En todos estos trabajos los restos son identificados siempre por botánicos o ingenieros agrónomos, habiendo entre los mismos especialistas en ciertas plantas de importancia económica. Entre los argentinos podemos citar a A. Krapovicas para el género Arachis, a J. Cámara Hernández para la problemática del maíz, a A. Hunziker para pseudocereales de los géneros Chenopodium y Amaranthus y A. Burkart para el género Phaseolus. Entre los extranjeros están T. Whitaker y H. Cutler para las cucurbitáceas, quienes identificaron restos de varios sitios argentinos y peruanos. Estas identificaciones se realizaban a partir de macrorrestos, siempre que éstos no se encontraran notoriamente alterados, tal como lo señalan los mismos autores. El aporte de las investigaciones arqueológicas consistía en describir las condiciones de hallazgo de los restos vegetales a fin, principalmente, de asociarlos a una "cultura" y a un lapso de tiempo. En lo que respecta a la problemática tratada en este trabajo resultaba fundamental la antigüedad, ya que era la vía para afianzar esa relación tan buscada entre taxón y área geográfica de origen -no olvidemos que De Candolle y Vavilov eran fitogeógrafos- y que muchas veces se sustentaba tan sólo a partir de la presencia del taxón en el área, de su diversidad en la misma o de relatos de los primeros naturalistas o cronistas que visitaron la región. Como ejemplo 
podemos señalar que los trabajos arqueológicos de A. R. González confirmarán definitivamente el carácter prehispánico del cultivo de zapallo en Argentina (Sarli 1968).

Los botánicos o ingenieros agrónomos que llevaban a cabo las identificaciones del material arqueológico empleaban los criterios de identificación taxonómica vigentes en sus disciplinas de origen. Por lo general recurrían a comparaciones morfológicas de las partes útiles entre ejemplares de diversa procedencia a fin de distinguir "razas" o "variedades indígenas". Había un fuerte énfasis geográfico, superponiéndose la distribución de estas variedades locales en la actualidad, la dispersión de grupos indígenas "portadores" de cultivos con caracteres peculiares, los hallazgos arqueológicos y la antigüedad de los restos. Esta conjunción no es casual, ya que la antropología en ese momento también trabajaba con modelos de fuerte componente geográfico, usando el concepto de "área cultural" tanto en etnografía como en arqueología, lo cual se complementaba con relaciones de difusión entre áreas núcleo generadoras y zonas marginales receptoras. Un ejemplo de esta clase de abordaje puede verse en Krapovickas (1968) y Brieger (1968).

Una mención aparte merecen los trabajos de L. Parodi quien desarrolló una línea propia de investigación en el país. Si bien la gama de trabajos de este autor es muy amplia, en muchas oportunidades se ocupó de las denominadas "plantas útiles", enfocándose en varios de sus trabajos en las prácticas y variedades desarrolladas por las poblaciones indígenas rurales del país. Parodi hace lo que muchos de los científicos naturales al ocuparse de este tipo de plantas: les traza una "historia", la cual transitan de la mano del hombre, y en cuya reconstrucción intervienen datos arqueológicos. Esta es, sin embargo, una historia de paralelas que nunca se cruzan, ya que no se analiza puntualmente qué comportamientos pudieron ocasionar cambios específicos en las plantas, los que serían a su vez la base del accionar humano posterior. No se analizaba en sí la interrelación ser humano-plantas, sino cada elemento 
por separado. En los trabajos donde el autor se ha ocupado del tema de la domesticación de especies vegetales y la agricultura (Parodi 1935, 1938, 1966) se alude a la selección que el hombre hace de las plantas con el fin principal de obtener "control" o "dominio" sobre las mismas. Para Parodi la asociación entre cultivo y Hombre es inseparable una vez establecida, ya que el cultivo no puede reproducirse por sí mismo y el ser humano no podría sostener la civilización que las plantas cultivadas le ayudaron a crear. La visión que este autor tiene de la domesticación vegetal es la de un proceso unilineal, universal, asociado al progreso humano y que posibilita el advenimiento $y$ mantenimiento de la civilización. Entre los supuestos presentes podemos señalar la consideración de que en el proceso de selección cultural habrá caracteres que por ser intrínsecamente nocivos serán desestimados y otros que por ser intrínsecamente útiles serán seleccionados. Si bien Parodi es uno de los que contribuirá a una visión más completa de la llamada "agricultura aborigen", afirma que "es poco probable que el agricultor primitivo haya empleado la hibridación artificial para mejorar sus cultivos" (Parodi 1938:15), aunque no descarta por completo esta posibilidad. Discute la herencia de los caracteres adquiridos, negando que los cambios morfológicos que se producen por cultivo pasen a la descendencia ya que no es el cultivo -entendido a niveles bajos de tecnificación, lo que excluye la manipulación genética- el que determinara la supervivencia de las generaciones sucesivas.

En cuanto al empleo de información aportada por la arqueología, Parodi emplea evidencias de cultivos del Viejo y Nuevo Mundo para discutir teorías hiper difusionistas planteadas desde la arqueología de ese momento, como las que vinculaban a los pueblos de Santiago del Estero con Troya (Parodi 1938). Retoma a Vavilov y a De Candolle con sus perspectivas fitogeográficas y alude a la utilidad que en la reconstrucción de los centros de origen poseen los datos arqueológicos (Parodi 1935), si bien sólo en su trabajo de 1966 logra integrar los aportes de la arqueología argentina gracias a las investigaciones de A. R. 
González. La confluencia de aportes disciplinares diversos es clara en las investigaciones de Parodi, aunque la integración no es del todo lograda, lo cual él mismo señala como una dificultad (Parodi 1935). Quizá esta riqueza de miradas, junto a la necesidad de esa integración aún no lograda, se resuma en lo que el autor expresa en el prólogo de su obra de 1966: "En la Argentina se conservan aún los restos de la agricultura que practicaron los indios antes de la llegada de los europeos que colonizaron estas tierras. Tales reliquias, en parte vivas y en parte sepultadas junto con los cuerpos de sus cultores, nos revelan la riqueza de aquella actividad. Los arqueólogos han investigado su antigüedad; los etnólogos, el estilo de vida de sus actores, y los botánicos, la composición específica de su flora agrícola" (Parodi 1966:5)

Hacia fines de la década del '60 y principios de la del '70 tienen lugar una serie de investigaciones y hallazgos que afianzan al área andina como una zona de gran antigüedad en cuanto a la presencia de vegetales cultivados, corroborando esta área como posible centro de origen, dando apoyo o reformulando posturas que hasta el momento surgían desde estudios botánicos o históricos. Es así que durante esta época se producen los hallazgos de Huaca Prieta por J. Bird y los de Engel y Lanning en territorio peruano. Durante los años 1968 y 1970 Richard Mac Neish lleva adelante el "Proyecto arqueológico-botánico Ayacucho" financiado por la Peabody Foundation for Archeology a raíz del cual se excavan las cuevas de Pikimachay y Jaywamachay (Schobinger 1988). Se estima una antigüedad de 7000 años AC en la zona de Paracas para los primeros cultivos (Caggiano y Sempé 1994). También tienen lugar durante el comienzo de la década de los setenta hallazgos de restos de formas domesticadas de antigüedad notable en el norte chileno como en el sitio San Pedro Viejo de Pichasca excavado por Ampuero y Rivera (Núñez 1989).

González y Pérez (1968) son los primeros arqueólogos argentinos que sintetizan los estudios de restos vegetales hasta ese momento presentando un 
trabajo al respecto también en el congreso de americanistas celebrado en Mar del Plata, aunque en diferente simposio al previamente mencionado. Debido a la ausencia de restos botánicos en momentos previos al Formativo, los autores recurren a las propuestas que se hacen desde las Ciencias Naturales como las de Brücher y Cárdenas y a los hallazgos arqueológicos de países vecinos para trazar un panorama hipotético de ingreso de cultivos al NOA desde centros de domesticación externos. A los modelos surgidos en biología, donde tomando como base el tipo de adaptación se asocia la domesticación de ciertas plantas a ciertos ambientes (pseudocereales y tubérculos microtérmicos al altiplano; maíz, zapallo, maní, ají y poroto a las tierras bajas cálidas del este) se suman rasgos identificados a nivel arqueológico (principalmente cerámica, arquitectura y modalidades de entierro) para identificar las áreas generadoras de los rasgos que se hallan en el Formativo del NOA. De esta forma se hablará de "lo andino" y "lo amazónico" comenzando a notarse a través de esto la influencia de la ecología en la arqueología argentina, proponiéndose incluso que estos rasgos representan diferencias culturales cuya razón fue la adaptación prolongada a diferentes ecosistemas (González y Pérez 1968).

En este momento se asienta, por lo tanto, un modelo de centro-periferia con áreas activas generadoras de bienes y comportamientos -entre los que se hallan las plantas domesticadas y las prácticas sociales asociadas- y áreas pasivas receptoras de los mismos. Este modelo debe en parte su auge a que esta perspectiva estaba presente tanto en las ciencias naturales como en antropología y arqueología.

b_Década de 1970.

Durante esta década aumenta el empleo de fechados radiocarbónicos, lo que propicia las discusiones difusionistas -como por ejemplo el arribo del maíz desde Mesoamérica a los Andes, ya que en la primera de estas áreas habría 
restos más antiguos- produciéndose una puja por identificar contextos con cultivos cada vez más tempranos. La contracara de este avance técnico es que el aumento en los fechados absolutos hace ver la contradicción del "paquete formativo", al evidenciar que los rasgos que se suponía surgían juntos en dicha etapa de desarrollo cultural (sedentarismo+cerámica+cultivo/pastoreo) poseían cronologías disímiles un una misma área. Este cambio de perspectiva surge sobre todo en Perú a partir de los hallazgos realizados por el "Proyecto arqueológico-botánico Ayacucho". Sin embargo, se sigue abusando de la idea de difusión lo cual, como ya vimos, está en relación a la noción de centro de origen (compatible con centro de domesticación) y a los planteos histórico culturales de la arqueología del NOA, si bien las críticas comienzan a hacerse presentes (Núñez Regueiro 1974). Esta fuerte asociación entre domesticación y antigüedad radica en que la primera se concibe exclusivamente como preámbulo a la agricultura y no como un proceso que es independiente de ésta. Si bien la domesticación debe preceder necesariamente a la agricultura entendida como un sistema de subsistencia basado en la siembra y cosecha de plantas domesticadas a gran escala- los procesos de domesticación vegetal no cesan o desaparecen una vez instaurados los sistemas agrícolas.

$\mathrm{Al}$ principio de esta década tienen lugar en el NOA dos hallazgos de gran importancia: Inca Cueva 7 (Aguerre et al. 1973) y Huachichocana III (Fernández Distel 1974), ambos en quebradas laterales a la de Humahuaca, en la provincia de Jujuy. Estas cuevas arrojaron por vez primera contextos de actividad humana de gran antigüedad en estratigrafía, dando una nueva perspectiva al "período precerámico" caracterizado hasta ese momento por industrias líticas definidas a partir de conjuntos superficiales (Ampajanguense, Saladillense, Tres Morros, Mal Paso, Aguilarense, por ejemplo) cuya antigüedad de entre 12.000 y 10.000 AC se suponía por ciertos rasgos morfológicos de los restos recuperados (Cigliano 1964, 1968; Fernández 1968a, 1968b y 1968c). Lo más impactante de estos hallazgos fue la presencia 
de "cultígenos" en capas muy antiguas. Así, en Inca Cueva 7 se recuperaron restos de Lagenaria siceraria en un contexto fechado para el 4080+-80 AP y en Huachichocana III maíz (Zea mays), poroto (Phaseolus sp.) y ají (Capsicum sp.) en contextos sorprendentemente tempranos tal como lo evidenciaron tres fechados radiocarbónicos de 9620+-130 AP, 8670 +-550 AP y 8930+-300 AP (Aguerre et al. 1973, Fernández Distel 1974, Aguerre et al. 1975). Estos resultados generaron un debate en torno al precerámico final en el NOA y al surgimiento de las primeras aldeas agroalfareras. Se ubicaron estos hallazgos junto con los de Morillos (San Juan) y Gruta del Indio (Mendoza)- en el marco general del "desarrollo cultural" sudamericano, buscando el "origen y difusión" de este tipo de contexto en Chile y Perú (Aguerre et al. 1973), hasta finalmente considerarlos representantes de la "Etapa de Agricultura Incipiente, Protoformativa o Arcaica del Área Andina Meridional" (Fernández Distel 1974, 1975; Aguerre et al. 1975)

A partir de este momento el interés en identificar especies vegetales domesticadas por parte de los arqueólogos del NOA se sustenta principalmente en caracterizar ese período transicional entre grupos nómades acerámicos cazadores-recolectores y grupos sedentarios alfarareros agricultores y/o pastores del Formativo. Este interés surge además no sólo a partir de una intención de afinar la cronología local (tomando como base la propuesta original de A.R. González), sino también porque este estadio estaba presente en los esquemas cronológico-culturales de Sudamérica en general (Willey y Phillips 1958, Lanning 1963, Lynch 1967) y de Perú (Lumbreras 1974 (1984)) y Chile (Núñez 1974) en particular, siendo su presencia en territorio argentino motivo de debate. Por lo tanto la presencia o ausencia de formas domesticadas pasa a ser, junto a otros elementos como los artefactos líticos y piezas de alfarería, un rasgo indicativo de un estadio cultural. Incluso

\footnotetext{
${ }^{1}$ El término "cultígeno" es citado literalmente en este trabajo de los arqueólogos que lo emplean para referirse, por lo general, a plantas domesticadas. No obstante, como se dijo en el capitulo 1, entre los especialistas en procesos de domesticación este término se reserva sólo para aquellas especies domesticadas cuyo ancestro silvestre se desconoce.
} 
ciertos vegetales se asociaban a ciertos momentos del desarrollo cultural de un área, así "el ají marca en el Perú el tránsito al período arcaico tardío" y el poroto "caracteriza casi al momento proto-agrícola del continente" (Lumbreras 1970 en Fernández Distel 1975:15).

Las identificaciones botánicas siguen recayendo en manos de "especialistas" tanto argentinos como extranjeros (Fernández Distel 1975, Aguerre et al. 1975, Fernández Distel 1986). En lo que refiere a los hallazgos de Huachichocana III, los mismos causaron gran impacto, siendo notorio el caso del maíz ya que los restos hallados se ubicaban entre los más tempranos de Sudamérica. De los hallazgos de restos vegetales en las capas precerámicas E2 y E3, el ají y el poroto, de acuerdo con A. Hunziker y A. Burkart respectivamente, podrían ser formas silvestres ya que ambas prosperan en el área del hallazgo con idéntico género y especie (Fernández Distel 1975, Aguerre et al. 1975). En cuanto al maíz recuperado en la capa E3, de acuerdo con Cámara Hernández, el mismo poseería "caracteres primitivos", no pudiendo avanzarse más debido a lo escaso y fragmentario de los restos (Fernández Distel 1975, Aguerre et al. 1975, Cámara Hernández ms). Si bien las identificaciones taxonómicas no escapan de la dicotomía silvestredomesticado, en el caso del maíz se intenta aportar algo más a su caracterización, aludiéndose como vimos a su carácter "primitivo" (utilizando este término en un sentido evolutivo) en base a rasgos presentes en las variedades que cultivan actualmente las comunidades rurales del NOA (Cámara Hernández ms.). Varios de los trabajos del Ing. Cámara Hernández (Cámara Hernández y Rossi 1968, Cámara Hernández 1973, Abiusso y Cámara Hernández 1974) se relacionaron con el registro de variedades locales de maíz procedentes de diversas provincias del NOA, habiendo hecho A. Krapovickas un trabajo similar con el maní en el noreste argentino, analizando luego la correspondencia de caracteres entre estas variedades o razas autóctonas y los restos arqueológicos. 
En el debate arqueológico, el momento el paso del período precerámico al cerámico era visto como un cambio muy abrupto, y por lo tanto explicado por difusión de rasgos desde áreas nucleares generadoras como el altiplano boliviano, las florestas tropicales amazónicas, o la costa pacífica. La evidencia más fuerte para el origen por difusión del Formativo eran la cerámica, el patrón de asentamiento, los tubérculos microtérmicos y los camélidos domesticados (Núñez Regueiro 1974, Raffino 1976). Los "cultígenos" tempranos en Huachichocana e Inca Cueva eran en cambio la evidencia más fuerte para el origen autóctono, a lo cual se sumaban propuestas de botánicos e ingenieros agrónomos como Parodi, Krapovickas, Whitaker, Burkart y Brücher que proponen al NOA como área de domesticación de ciertas especies (Raffino 1976, Tarragó 1980). En este momento podemos ver además una suerte de "tensión" entre aquellos que colocan el énfasis en los restos materiales para afirmar la presencia de un período arcaico en el NOA (González y Pérez 1968, Raffino 1976) y aquellos que, basados en periodificaciones elaboradas para otras áreas o para Sudamérica en general, asumen que dicho período debió haber estado presente también en el NOA (Núñez Regueiro 1974, Tarragó 1980).

Un hito clave en el desarrollo de las ideas acerca de la domesticación de vegetales en el NOA vino dado por el V Congreso Nacional de Arqueología Argentina realizado en San Juan en 1978 donde se realizó una mesa redonda denominada "El proceso de agriculturización en los Andes Meridionales". En dicha mesa se presentaron seis trabajos, dos referidos a la región centro-oeste (Gambier 1980 y Lagiglia 1980), dos al NOA (Tarragó 1980, Krapovickas 1980) y uno a Chile (Rivera 1980), teniendo este tipo de temática su antecedente en el trabajo sobre el proceso de agriculturización en Chile presentado por L. Núñez (1970) en el I Congreso Nacional de Arqueología Argentina, entre otros. Todos los autores son arqueólogos, sin que se registre la presencia de investigadores pertenecientes a otras disciplinas, por lo que es 
notorio el contraste de esta mesa con la de Etnobotánica organizada en el marco del XXVII Congreso Internacional de Americanistas ya mencionado.

El trabajo de M. Tarragó (1980) es una muy buena síntesis de lo hecho hasta ese momento en el tema del origen de los modos de vida agrícolas en el área Valliserrana del NOA, siendo el primero de su clase. En la bibliografía consultada puede verse que se citan trabajos etnobotánicos y paleoetnobotánicos publicados en revistas de arqueología como los de Pickersgill (1969) o Harlan y de Wet (1973), así como una clara mención de la autora a los avances y complejización en el estudio de ciertos taxa y procesos de domesticación regionales. Es por ello que la autora es cautelosa y más que un modelo propone una síntesis. Aunque no lo define, Tarragó deja entrever en su trabajo que el proceso de agriculturización es una "larga etapa de preparación y experimentación vegetal que lleva a la paulatina incorporación de cultígenos por parte de grupos cazadores-recolectores" (Tarragó 1980). La caracterización de este proceso como no revolucionario posee antecedentes en los trabajos de González y Pérez (1968) y Núñez Reguiro (1974). A pesar de que la autora considera que son los hallazgos de Inca Cueva, Huachichocana y Puente del Diablo los que avalan la presencia de un estadio Arcaico en el NOA, considera que el proceso de agriculturización debió darse no en la Puna sino en el área Valliserrana. Esta afirmación se basa en que el área de origen y desarrollo de la agricultura temprana debe poseer en sí misma ciertas características, tanto culturales como naturales (ser una zona con vías de acceso rápidas entre zonas ecológicamente contrastables, poseer buenas condiciones de humedad y suelo y especies silvestres potencialmente aprovechables), las cuales se hallan en la segunda área mencionada y no en la primera.

El esquema planteado por Tarragó para describir el proceso de agriculturización consta de cinco etapas. La primera se denomina "Etapa de "cosecha salvaje" con inicios de una agricultura incipiente", se extiende desde 
una fecha indefinida al 500 AC, y se correspondería al Arcaico. Lo que caracteriza a ésta etapa es la "incorporación paulatina de cultígenos y la domesticación de animales" (Tarragó 1980). Esta etapa es planteada sin integrar en su formulación la información procedente de sitios arcaicos, lo cual es notable ya que de acuerdo con la autora los mismos, aunque son escasos en número, permiten caracterizar muy bien a este estadio. De esta manera Tarragó genera un esquema cronológico original separado de las periodificaciones que describen el desarrollo cultural tanto del NOA como de los Andes Meridionales.

Durante esta década se hacen cada vez más numerosas las referencias a la importancia de los aspectos ecológicos en el análisis de las poblaciones prehispánicas. Si bien el ambiente es considerado, lo es como un escenario donde se dan las interacciones sociales. El mismo es concebido como constituido por ámbitos definidos que sólo interesan en tanto fuente de recursos y como condicionantes de ciertos rasgos culturales, fundamentalmente modos de explotación agrícola (Murra 1972, Raffino 1975). No hay un auténtico análisis de la interacción de los grupos humanos con el entorno natural, lo cual se ve reflejado en el caso que nos interesa en que no se discuten comportamientos que sugieran manipulación de especies o poblaciones vegetales, ni la respuesta de éstas ante tales acciones.

c_Décadas de 1980 y 1990

No podemos dejar de mencionar las nefastas consecuencias que los gobiernos militares de facto tuvieron sobre la arqueología argentina. Gran número de investigadores fueron perseguidos debiendo exiliarse, lo que ocasionó que muchos proyectos de investigación y desarrollos teóricos propios del momento quedaran truncos (Tarragó 2003). Creemos que en el caso del 
estudio de la domesticación de especies vegetales esta circunstancia también se hizo notar, con escasa conexión entre los desarrollos que se dieron antes y después del período de gobiernos militares. En este sentido quienes comienzan a desarrollar sus líneas de investigación en las décadas de 1980 y 1990 se nutren principalmente de propuestas planteadas por autores norteamericanos, a diferencia de las décadas anteriores donde la conexión estaba dada mayormente con investigadores sudamericanos, fundamentalmente de Chile y Perú

En este momento se afianzan los modelos ecológicos culturales, tanto de tipo adaptacionista como evolucionista, inspirados en las obras de Binford, Flannery, Dunnel y Kirch, entre otros. Su aplicación viene dada en el NOA, para la temática que nos interesa, fundamentalmente a través de los trabajos de Yacobaccio (1994) y Olivera $(1988,1992)$ en la región puneña, interesado el primero en las sociedades cazadores recolectoras y el segundo en las sociedades formativas. Este tipo de modelos toma como base los desarrollos teóricos en Ciencias Naturales, fundamentalmente la teoría de la evolución en su nueva síntesis, así como también los modelos sistémicos desarrollados en ecología. Partiendo de la noción de que los sistemas sociales deben muchas de sus características y formas de desarrollo a los ecosistemas donde se asientan, se llevan a cabo relevamientos ecológicos por parte de los mismos arqueólogos a fin de evaluar la capacidad de sustentación del ambiente y su potencial para la explotación agrícola. Se identifican las especies de plantas o animales potencialmente utilizables, empleando en algunos casos para ello estudios etnoarqueológicos (Olivera 1992). A su vez, las especies son clasificadas como recursos óptimos o subóptimos (Muscio 1999), al igual que los comportamientos humanos (Yacobaccio 1994). Estos son modelos de optimización que aplican una racionalidad económica moderna a las sociedades del pasado, concibiendo a los actores sociales como sujetos sensibles al riesgo y a los costos energéticos de sus actividades de subsistencia. 
Olivera romperá con el concepto tradicional de Formativo como estadio o período reconstruido a partir de contextos culturales, para entenderlo como un sistema de adaptación (Olivera 1988). Las poblaciones del formativo son productoras y como tales se distinguen de los cazadores recolectores por poseer tecnologías que les permiten un "control total sobre el ciclo de generación del recurso a lo largo de todas sus etapas de desarrollo" (Olivera 1988:85). El autor considera que la mera presencia de especies domesticadas no es suficientes para dar por sentado la existencia de una estrategia productiva, lo cual marca una diferencia con estudios arqueológicos previos donde la identificación de vegetales considerados "cultígenos" era suficiente para plantear la presencia de producción de alimentos o una economía agrícola. Entre sus referentes están Rindos, Cohen y Flannery, todos vinculados a corrientes procesuales o posturas ecológico-culturales (Olivera 1992). Si bien el trabajo de Olivera adopta un criterio sistémico-adaptativo sincrónico, entiende al cambio como un ajuste adaptativo dirigido por la selección natural (Olivera 1992). Sin embargo, en lo que respecta al advenimiento de un modo de vida agrícola en el área de Antofagasta de la Sierra, entiende que “... es muy posible que en algún momento entre el 3000 y 2500 AP llegaran a la región la agricultura y la tecnología cerámica a través de contactos o, más probablemente, de grupos portadores de esos elementos" (Olivera 1992: 310-311), el aumento de la actividad agrícola en épocas posteriores evidenciada a través del registro arqueológico, es vista como una “inscripción cultural de las influencias dominantes" (Olivera 1992: 311) que provino de los valles donde la agricultura es la principal actividad productiva dentro de las estrategias de tipo formativas.

Yacobaccio (1994) y Muscio (1999) llevan a cabo un reestudio de Inca Cueva 4 y Huachichocana III aplicando modelos ecológico- culturales, en su vertiente sistémica y evolutiva respectivamente. En los mismos la puna es vista como una zona de alta incertidumbre en el marco de ecuaciones de 
costo-beneficio y estrategias del manejo del riesgo, resultantes de la aplicación de un modelo de optimización de recursos (Yacobaccio 1994, Aschero 1994, Yacobaccio et al 1997-1998). Esto puede verse sobre todo en la perspectiva de Muscio $(1998 / 1999 ; 1999)$ para quien ésta es una región marginal con escasez e irregularidad en la oferta de nutrientes, en la cual los recursos óptimos son aquellos que aportan gran cantidad de proteínas, proviniendo el principal aporte cárnico de los camélidos. Así, los recursos vegetales entran en la categoría de subóptimos, siendo su función amortiguar las fluctuaciones del recurso óptimo durante momentos de stress.

En 1993 se lleva a cabo la reexcavación de IC7 centrándose su estudio en la complejización de los cazadores recolectores puneños del arcaico manifestada principalmente en el manejo de camélidos (Aschero y Yacobaccio 1998/1999). Esta perspectiva de análisis se enmarca en la propuesta de los Andes centro-sur como un centro independiente de domesticación de la llama (Núñez y Santoro 1990, Aschero 1994, Yacobaccio 1994, Dransart 1999), con opiniones diversas sobre el lugar de la puna argentina en este proceso (Olivera y Elkin 1994). Los proyectos de investigación comienzan a centrarse en la domesticación de los camélidos, discutiendo el concepto mismo y los medios para identificarlo. Yacobaccio (1994, Yacobaccio et al. 1997-1998) será el primero en indagar sobre las formas de interacción y manejo entre comunidades humanas y poblaciones de camélidos, perspectiva que permitió un avance sustancial en el entendimiento del proceso de domesticación de la llama en el NOA. Durante esta década se produce además un avance notable en la cantidad de sitios arcaicos identificados en la región puneña del NOA, principalmente en el sector de Antofagasta de la Sierra (sitios: Quebrada Seca, Punta de la Peña, Peñas Chicas, entre otros) (Aschero 1980).

Haber (2006) entiende que existe una relación estrecha entre la concepción de la puna como marginal e inhóspita y el énfasis durante estas décadas en el estudio de la domesticación y pastoreo de la llama como estrategia de 
adaptación ante limitaciones ambientales. La contracara de esto es que al no ser los recursos vegetales conceptualmente operativos en el manejo del riesgo en el ámbito puneño, los investigadores no se interesan por los mismos a escala local, dando por sentado que el cultivo es un componente alóctono. Esta noción encontraría a su vez apoyo en la escasez de restos vegetales de especies comestibles en los sitios excavados y en que las especies domesticadas poseen sus ancestros silvestres en las tierras bajas orientales. En este momento se realizan además fechados radiocarbónicos AMS sobre los restos de maíz de Huachichocana, los cuales arrojan una datación mucho más reciente $(1560+-190$ AP) a la originalmente reportada (Fernandez Distel 1986).

Para ese entonces el énfasis no está puesto ya en el Arcaico como preámbulo al Formativo, sino como una modalidad socioeconómica producto de cambios en las estrategias económicas postpleistocénicas (Aschero 1980). Por ende ya no interesa tanto ubicar a los sitios arcaicos en esquemas de periodificación tendientes a caracterizar el desarrollo cultural del NOA, sino en redes de interacción a escala regional (Dillehay et al. 1992, Núñez 1989, 1994). Los sitios de Inca Cueva 4 y 7 y Huachichocana III son de interés ya que arrojan vestigios sobre vegetales económicos, evidenciando posiblemente prácticas hortícolas, en contraste con sitios chilenos donde no aparece tal clase de registro; la puna salada tuvo mayor apropiación de recursos vegetales que la puna ariqueña y este posicionamiento la ubica de manera diferencial en los circuitos de interacción (Núñez y Santoro 1990, Aschero 1994, Rodríguez 1999). En esta línea de análisis se encuentra el trabajo de Castro y Tarragó (1992). Este trabajo ya no recae en la oposición aloctono vs. autóctono debido a que no concibe a los distintos ámbitos ecológicos como espacios separados, monolíticos, asociados a cierto número de rasgos naturales y culturales, sino que reconoce una alta correspondencia entre los contextos a ambos lados de los Andes Meridionales. Esta correspondencia se hace evidente en el Arcaico 
Tardío en un nivel de desarrollo social similar gracias al intercambio transversal entre costa, valles andinos occidentales y orientales y precordillera de San Juan y Mendoza. En este panorama quedan fuera las tierras bajas orientales ya que no existe registro temprano de restos vegetales. Para caracterizar esta área se sigue apelando a la presencia actual de ancestros silvestres de plantas domesticadas cuyos restos son hallados en sitios andinos, suponiendo que fue en las zonas bajas orientales donde se desarrolló la tecnología para el manejo de cultivos mesotérmicos (Castro y Tarragó 1992).

Este nuevo posicionamiento en el estudio del Arcaico está también en línea con la tendencia de la arqueología procesual de explicar el cambio principalmente por factores sistémicos internos, rechazando a la difusión como argumento explicativo (Fiedel 1996). A pesar de ello, se sigue empleando la evidencia de "cultígenos andinos" o "de tierras bajas" para reconstruir el origen y derrotero de tradiciones culturales que se integrarían luego por complementación económica en momentos agroalfareros tempranos (Núñez Regueiro y Tartusi 1987).

Finalmente podemos señalar que en estas décadas comienzan los estudios arqueobotánicos y paleoetnobotánicos, lo cual se refleja en la organización de la primer mesa sobre el tema en el XI Congreso Nacional de Arqueología Argentina en 1994 (Pochettino y Capparelli 1998). Los mismos no se abocaron al proceso de domesticación u "origen de la agricultura", sino al registro arqueológico de sitios particulares, a reconstrucciones paleoambientales y a planteos metodológicos tanto de campo (vg. técnicas de recuperación de restos) como de laboratorio (vg. identificación taxonómica)

\section{d_Cambio de milenio}


En los inicios del nuevo milenio no ocurren grandes cambios en lo que respecta a la problemática de la domesticación vegetal en el NOA. En este sentido Olivera afirma que: "Respecto de la cerámica y la agricultura, la arqueología no nos ofrece todavía registros adecuados para discutir las distintas posiciones" (Olivera 2001:93) agregando que "No estamos en condiciones de precisar aún el origen de la agricultura en el NOA, pero todo parece indicar que tuvo un importante componente alóctono como se ha postulado sugiriéndose vías alternativas de ingreso" (Olivera 2001:97) Luego de este párrafo, el autor cita trabajos de la década del '60 y '70, lo cual evidencia lo poco que se ha avanzado en este campo de estudio. Pero unas líneas más adelante, Olivera (2001) reconoce un inicio del proceso de domesticación no sólo de animales sino también de plantas en épocas precerámicas, asociado posiblemente según él, a una restricción en la movilidad. Sin embargo a partir del 3000 AP, aparecería un conjunto de elementos tecnológicos posiblemente por el ingreso de grupos agropastoriles bien consolidados, lo cual habría llevado al dominio y establecimiento definitivo de un modo de vida agropastoril en la puna y quebradas de acceso a la misma.

Con las mismas evidencias disponibles, Lagiglia (2001) logra un planteo distinto de la problemática de la domesticación vegetal y los inicios de la agricultura a partir de una atención a las diferentes aristas que pueden tener ambos procesos. Si bien sigue cuestionando el rol del NOA como área de domesticación de cultivos -salvo evidencias de estudios botánicos como los de A. Krapovickas para el maní- advierte sobre su posible rol como área generadora de variedades o razas locales a través de gran número de procesos diferentes, posibilidad que hasta el momento no había sido planteada. Aunque toma como base los trabajos de Núñez (1970) y Tarragó (1980), el autor plantea una nueva etapa ("Etapa de protoproductores" en lugar de período Arcaico tardío) y una nueva hipótesis ("Exploradores y colonizadores 
agrícolas iniciales") para el NOA y centro-oeste argentino. Esta última plantea el arribo entre el 4000 AP y el comienzo de la era cristiana de "domesticadores" desde los genocentros andinos peruanos. Estos horticultores manejarían la "tétrada americana" (maíz, zapallo, poroto y quínoa) a partir de una vasta experiencia que les permitiría manipular genéticamente a las plantas, controlar las diferentes variedades y conocer otras variables como el suelo. Su presencia no generó competencia, sino una "protocooperación" de subsistencia con los grupos cazadores recolectores. Si bien el carácter alóctono del grupo está sustentado por ciertos rasgos presentes en el registro arqueológico, el autor no cuenta aún con evidencias que den sustento a los comportamientos de manipulación de cultivos que sugiere.

En esta etapa se produce la consolidación de dos aproximaciones metodológicas de gran importancia: el análisis de isótopos estables y el estudio de microrrestos vegetales.

El primer método es desarrollado principalmente por el grupo de investigaciones arqueológicas de Mendoza. Así, desde una perspectiva netamente arqueológica, Gil (1997-1998) propone una evaluación del rol de los restos arqueológicos de cultivos en contextos del sur mendocino. Una mirada atenta a las relaciones contextuales de los restos arqueobotánicos permite al autor evaluar mejor el rol de esta clase de vestigios como indicadores de un sistema cazador recolector o agricultor. Esto se complementa con el empleo de isótopos estables para la reconstrucción de paleodietas, evaluando el aporte de los recursos domesticados (vg. maíz) a las mismas (Gil 2000, Gil et al. 2006).

Si bien el análisis de isótopos estables se ha constituido en un avance metodológico importante para discutir el consumo de plantas domésticas versus silvestres, su aporte para entender el proceso de domesticación vegetal no ha sido igual de trascendente. A esto se suma el hecho de que muy 
probablemente antecesores silvestres, formas transicionales y formas domesticadas respondan a un mismo patrón fotosintético y caracteres fisiológicos generales, por lo cual serán agrupados en una misma categoría isotópica. Incluso a niveles más generales de la técnica existen problemas metodológicos que requieren de sumos recaudos cuando se la emplea en la identificación de vegetales. Por ejemplo, existe superposición de valores de ${ }^{15} \mathrm{~N}$ entre plantas y herbívoros, por lo que un mismo registro puede estar dado tanto por incorporar la planta como a un herbívoro que se haya alimentado de ella. Existe también una gran variabilidad de valores de ${ }^{15} \mathrm{~N}$ tanto a nivel de individuo como entre poblaciones alimentadas en base a plantas altamente proteicas, incluso valores que aparentan producirse por incorporación de carnívoros, podrían originarse por incorporación de nueces, por ejemplo. (Hather y Mason 2002). Finalmente este método no nos permite aproximarnos a los modos de manipulación de las plantas y, por ende, a la presencia, entre las sociedades bajo estudio, de comportamientos de cuidado o cultivo de las mismas, excepto en el caso de los trabajos de Araus, quien utiliza la tasa de isótopos del C en las plantas C3 para calcular la cantidad de agua que éstas recibieron durante la maduración de la semilla, e identificar así prácticas antiguas de irrigación (Araus et al 1997, 2003, Ferrio et al 2005, entre otros).

En lo que respecta al análisis de micorrestos, aumenta el número de investigadores -mayormente con formación en antropología o arqueologíainteresados en su estudio. El campo se diversifica incrementándose por ejemplo el estudio de fitolitos (Korstanje y Babot 2005) y granos de almidón (Babot 2005, 2006). La aplicación de estos análisis al estudio de artefactos arqueológicos arrojó resultados sorprendentes como el hallazgo de almidones de maíz en un artefacto de molienda datado hacia el 4500 AP en Antofagasta de la Sierra (Babot 2005). Este tipo de hallazgos vuelve a abrir el debate en torno a la antigüedad de los vegetales domesticados en el NOA y los medios 
para identificarlos a nivel arqueológico. Sin embargo es aún difícil distinguir formas silvestres de domesticadas mediante microrrestos y los trabajos tendientes a ello están todavía en una etapa de prueba (Perry et al 2007, Babot et al. 2007) sin que sea del todo claro la posibilidad de identificar formas transicionales o cultivares locales mediante su empleo. Quien logrará abrir un panorama totalmente novedoso en lo que a estudios sobre domesticación se refiere es Alejandro Haber. Este autor parte de un enfoque dialéctico donde la domesticación, en tanto representaciones y prácticas de dominación de la naturaleza externa, reproducen a y son reproducidas por las representaciones y prácticas de dominación entre humanos, por lo tanto en la práctica domesticación y dominación serían inseparables (Haber 2006). Partiendo de la domesticación de camélidos el autor propone que ya no debe buscarse la domesticación en la modificación de los esqueletos de los animales -donde puede no estar reflejada- sino en cambios al interior de la estructura social, sobre todo en las reglas de acceso a los recursos tras modificarse los grupos

sociales que actúan como unidades de producción o consumo; la domesticación es entendida como metapatrón en tanto es una nueva relación entre relaciones (Haber 2006). Si bien interesante y completamente distinto a lo propuesto en arqueología del NOA hasta el momento, la propuesta de este autor no incluye el estudio del proceso de domesticación vegetal.

\section{II) Síntesis actual: las sociedades tempranas del NOA y el manejo de recursos vegetales}

El estado actual de las investigaciones en el NOA arroja una serie de consideraciones de interés al estudiar las formas de manejo de comunidades vegetales en los primeros momentos del desarrollo cultural del área.

En lo que respecta a las ocupaciones cazadoras recolectoras (todas detectadas en el área puneña-prepuneña del NOA) las evidencias de recolección 
corresponden mayormente a macrorrestos de frutos de especies arbóreas (Prosopis spp. y Geoffroea decorticans (Gillies ex Hook y Arm.) Burkart principalmente) y de tubérculos silvestres (Hypsocharis tridentata Griseb., Coursetia heterantha (Griseb.) Lavin., Oxalis compacta Gill., Juellia subterránea Hoffmansegia gracilis (R. et P.) Hook. et Arn. e Ipomoea minuta R.E. Fries) (Fernández 1969/1970, Aguerre et al. 1973, Fernández Distel 1974, Aschero 1980, Fernández Distel 1986). Un caso notable lo constituye el área de Antofagasta de la Sierra donde se han identificado microrrestos de Cucurbita sp., Chenopodium sp., Amaranthus sp., Phaseolus sp. y Zea mays L. en artefactos provenientes de diversos contextos cazadores recolectores con fechados entre el 6000 y 3500AP (Hocsman 2006, Rodríguez et al 2006). En cuanto a los macrorrestos recuperados en esta área se cuenta con el registro de un resto seco de fruto de Arachis sp. en el sitio Quebrada Seca III en un contexto fechado en el 5380 +- 70 AP (Hocsman 2006). En el sitio Peñas Chicas 1.3 se recuperaron tallos de Chenopodium quinoa con un fechado de 3400 AP (Aguirre 2005 en Rodríguez et al 2006). Para momentos posteriores en esta misma región se recuperaron 110 semillas de Chenopodium quinoa Willd., seis cariopses de Zea mays variedades amylacea o capia, amarillo y pisingallo y una semilla de Phaseolus vulgaris del sitio Punta de la Peña 4, también en la región de Antofagasta de la Sierra, el fechado por AMS de los restos vegetales evidenció un rango del 560 al 760 AP (Rodríguez et al 2006). Fuera de estos sitios en cueva y en momentos cronológicos posteriores se encuentran los sitios agropastoriles plenos Casa Chávez Montículos 1 y Real Grande 1 (Olivera 1992, 1998, Hocsman 2006). En la puna sur se encuentran también los sitios formativos de Tebenquiche (Haber 2006) y los del área de Laguna Blanca (Delfino 2005). En Humahuaca, los sitios agroalfareros más tempranos son Antumpa, El Alfarcito y Estancia Grande (Olivera 2001).

En cuanto a los sitios del Formativo Temprano (período correspondiente al desarrollo cultural previo a la integración regional Aguada) del área 
Valliserrana, a pesar de la diversidad presente en los mismos, éstos se han caracterizado a nivel general como sitios de tipo "aldeano" de pequeña a mediana escala, con corrales y estructuras agrícolas como terrazas y canchones junto a sistemas de regadío simples (Cagiano y Sempé 1994, Sempé 1975, Raffino 1975, 1976; Tarrago 1980, Olivera 1989, 1992, 2001). En estos sitios se recuperaron restos de especies domesticadas comestibles, principalmente diversas variedades de Zea mays y, en menor medida, Phaseolus vulgaris, Arachis bypogea. L., Cucurbita spp. y Chenopodium quinoa (esta última identificada sólo a partir de microrrestos), así como también restos de recolección como frutos de Prosopis sp. Geoffroea decorticans, Trichocereus sp. y Zisyphus mistol Gr. (Tarrago 1980, Pochettino 1985, Carrizo et al 1999, Korstanje y Würschmidt 1999, Oliszewski 2004ay b, 2008, Korstanje y Babot 2007).

Dentro del período formativo se producirá un cambio sustancial a nivel regional a partir de la integración socio-económica que ocurre con Aguada (400-950 DC), entidad que surge en el valle de Ambato y Hualfín, Catamarca, como resultado del desarrollo de entidades formativas valliserranas previas (Vaquerías, Ciénaga y Condorhuasi) (Pérez Gollán y Heredia 1987, González y Baldini 1992, Laguens 2004). El principal cambio a nivel económico consiste en que las modalidades de producción vegetal dejan de ser familiares y pasan a ser comunales, con grandes extensiones de sistemas de riego de fondo de valle que superan a las de menor escala previas (Perez Gollan y Heredia 1987, González y Baldini 1992, Laguens 2004). Esta intensificación de la producción a nivel comunitario permite generar un mayor volumen de excedentes, lo cual se evidencia a través de la presencia de grandes urnas destinadas al almacenamiento de semillas (Pérez Gollán y Heredia 1987, Laguens 2004). Se interpreta también que existió un cambio desde una ritualidad doméstica (como la de Alamito) a una comunitaria (Laguens 2004). Esta nueva ritualidad pudo haber sido un elemento que cohesionara las fuerzas de trabajo, siendo también crucial en la expansión de Aguada desde el 
valle de Ambato y Hualfín hacia nuevas regiones como el norte de San Juan y La Rioja y el oriente de Tucumán y Salta (González 1972, González 1998, González y Baldini 1992, Baldini et al 1998, 2003, Tartusi y Núñez Regueiro 2005). Las influencias de Aguada no son notorias en los valles de Santa María, Calchaquí y Lerma, ni en el área al norte de los mismos, la cual parece haber formado parte de una esfera de interacción con el sur de Perú y Bolivia (Tarragó 1983, Scattolin 2007).

Las manifestaciones culturales Aguada del valle de Ambato poseen además vínculos trasandinos con San Pedro de Atacama y orientales con el este catamarqueño y la cultura Las Mercedes de la región de los ríos Dulce y Salado de Santiago del Estero (Pérez Gollán y Heredia 1987).

Respecto a los cultivos se considera que a partir de Aguada se produjo un aumento en la diversidad de razas de maíz (Tarragó 1983, Pérez Gollán y Heredia 1987, González y Baldini 1992, Laguens 2004), aunque estudios recientes mostrarían que dicha diversidad pudo haber estado presente en momentos cronológicos previos dentro del formativo (Oliszewski 2008).

Los restos de plantas domesticadas de los sitios formativos siguen sin tener un origen claro. Desde momentos cazadores recolectores la interacción entre los territorios chilenos, la puna, los valles y las tierras bajas del NOA está claramente establecida, habiendo participado los restos vegetales silvestres y domesticados en estas esferas y/o circuitos de interacción (Aschero 1980, Tarrago 1983, Rodríguez y Martínez 2001). Sea por condiciones propias del registro arqueológico o por sesgos de las investigaciones desarrolladas en el área, los macrorrestos vegetales no son abundantes en los sitios tempranos del NOA -salvo excepciones como la de la localidad de Pampa Grande (Pochettino 1985)- sin que se cuente con grandes cantidades de restos arqueobotánicos por sitio, ni con secuencias completas de los mismos a través del tiempo en una región determinada. Por lo tanto el registro arqueobotánico 
de los momentos precerámico y formativo del NOA sigue siendo en gran parte discontinuo y fragmentario.

A pesar de los recientes avances en estudios de macro y microrrestos vegetales todavía no se ha logrado entender de manera acabada cómo ha sido la dinámica social que llevó al surgimiento de modos de vida agrícolas en el NOA, siendo las investigaciones de Antofagasta de la Sierra uno de los primeros indicios que indicarían la presencia temprana de posibles formas vegetales domesticadas en la puna meridional. En lo que respecta a domesticación vegetal, se está aún lejos de asumir un proceso local, tal como se hace actualmente para los camélidos (Yacobaccio 2007). En este sentido se considera que los avances en el entendimiento de la domesticación de camélidos en el NOA se vieron propiciados por un planteo tendiente a identificar formas de relación entre grupos humanos y poblaciones de guanacos silvestres (Yacobaccio 2001, 2007). Por el contrario, en arqueobotánica no se ha avanzado mucho más allá de indicar la presencia o ausencia de ciertas especies vegetales en diversos contextos arqueológicos de cronologías más o menos tempranas, sin que se indague acerca del grado de asociación con las comunidades humanas generadoras del registro arqueológico (vg. plantas silvestre, domesticadas, cultivadas, malezas) más allá de indicar su carácter local o alóctono.

La perspectiva paleoetnobotánica que se asume en esta tesis será empleada como una vía alternativa para el entendimiento de los procesos de domesticación vegetal en el pasado del NOA, buscando superar dicotomías como las de silvestre-domesticado, cazador recolector-agricultor, alóctonoautóctono, a través de las posibles huellas dejadas por las prácticas de manejo de poblaciones vegetales en los (escasos) macrorrestos recuperados en los sitios arqueológicos del NOA. 


\section{SITIOS ARQUEOLÓGICOS ANALIZADOS EN ESTA TESIS}

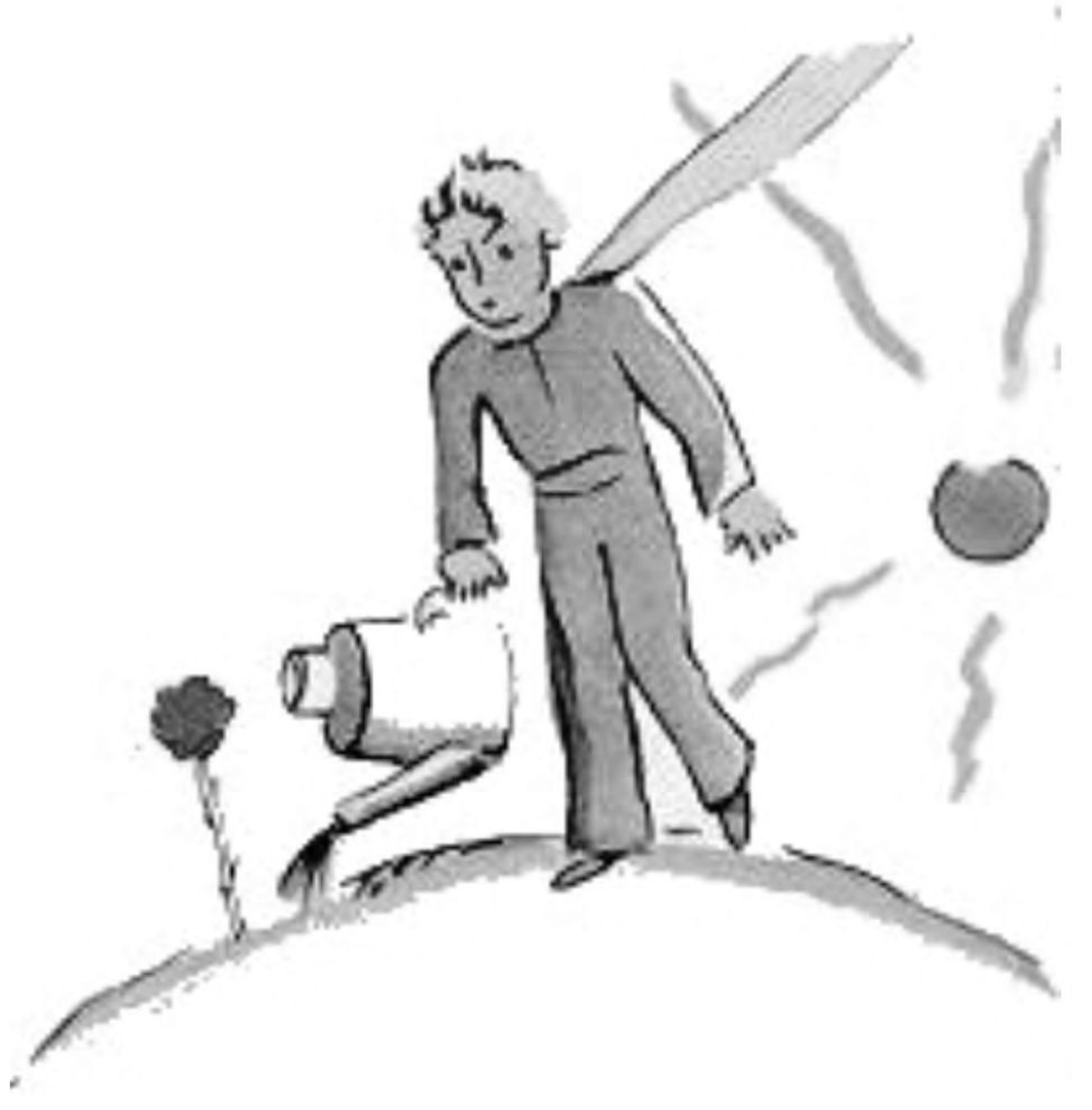




\section{3-SITIOS ARQUEOLOGICOS ANALIZADOS EN ESTA TESIS}

\section{Introducción}

Para el estudio de los procesos de domesticación y formas de manejo de poblaciones vegetales en el pasado prehispánico del NOA se optó por el estudio de macrorrestos de los géneros Cucurbita y Phaseolus. Tal como se mencionó en el capítulo 1 estos dos géneros fueron seleccionados puesto que en el caso de Cucurbita varios autores han sugerido su temprana domesticación en territorio argentino (Millán 1945, Whitaker y Bemis 1965, Brücher 1989, Nee 1990, Decker Walters y Walters 2000, Albeck 2001) y porque en el caso de Phaseolus vulgaris L. se han recuperado gran cantidad de restos de la variedad silvestre y domesticada de dicha especie en sitios tempranos del noroeste argentino (Pochettino y Scattolin 1991, Carrizo et al 1999, Oliszewski 2004). El estudio de los macrorrestos de estos dos géneros se realizó a través del análisis de ejemplares recuperados en diversas excavaciones arqueológicas a lo largo del NOA principalmente, considerándose también algunos ejemplares procedentes de sitios peruanos y chilenos en el caso de Cucurbita sp. En este capítulo se presenta la selección de sitios realizada y el análisis arqueológico de colecciones cuyo registro era parcial o incompleto.

\section{Materiales y método}

Primeramente se realizó un rastreo bibliográfico exhaustivo de la literatura arqueológica referida al NOA a fin de detectar la mención a macrorrestos de Cucurbita spp. o Phaseolus spp. El lapso cronológico considerado abarcó desde los sitios más tempranos registrados en el NOA hasta los del período formativo, siendo estos últimos los representantes más tempranos de formas agrícolas plenas en la región, prestándose especial atención a aquellos sitios 
mencionados en la literatura como "claves" en el estudio de la problemática de la domesticación temprana de especies vegetales en el NOA. De forma menos sistemática se procuró incorporar restos arqueobotánicos de sitios con cronología más tardía dentro del NOA y sitios arcaicos o formativos de Chile y Perú, también se analizaron datos bibliográficos para restos de ambos taxa recuperados en sitios del área centro-oeste argentina (COA) de cronología temprana. La información obtenida de esta última clase de restos se empleó principalmente para contrastar los rasgos de los mismos con los sitios tempranos del NOA.

Una vez realizada la selección de sitios se buscaron los medios que permitieran el acceso a los restos arqueobotánicos, arqueológicos asociados e informes no publicados referidos a los primeros. Se procedió tanto a la consulta directa con los investigadores involucrados en las excavaciones de los sitios, con los investigadores responsables de las identificaciones botánicas o bien con las instituciones (principalmente museos) donde se informó que estaba depositada la colección arqueológica del sitio en consideración.

\section{Resultados}

1) Restos arqueobotánicos informados en la bibliografía, no analizados en esta tesis.

Existe una serie de sitios tempranos en el NOA para los cuales se menciona la presencia de macrorrestos de Cucurbita spp. o Phaseolus spp. en la bibliografía, los que no pudieron ser ubicados tras la consulta en instituciones o con los responsables de su extracción y/o identificación, cuando fue posible. Estos sitios son: Cerro El Dique y Potrero Grande (Quebrada del Toro, Salta) con restos de "calabazas" (Tarragó 1980); Martínez I (Valle de Ambato, Catamarca) con restos de "zapallo" (Laguens et al. 2007); La Poma (Salta) con restos de C. maxima (Pochettino 1985); Costa de Reyes (Tinogasta, Catamarca) con restos de C. maxima (González y Pérez 1968); Alamito (Catamarca) con 
restos de Cucurbita sp. y Phaseolus sp. (Tarragó 1980); Punta Colorada (Catamarca) con restos de Cucurbita sp. (Sempé de Gómez Llanez 1975, Tarragó 1980); Cuesta de Zapata (Catamarca) con restos de C. maxima (González y Pérez 1968).

Gracias a la gentileza de la Dra. A. Callegari se tuvo acceso a los macrorrestos recuperados en el sitio El Carmen, entre los cuales se encuentran fragmentos de pericarpios y semillas de Cucurbita sp (Callegari 2003, Callegari 2004). Este sitio se ubica en el valle de Vinchina (La Rioja) y posee ocupaciones Aguada y Sanagasta dentro de un período cronológico que abarca desde el 950 al 1650 DC (Callegari y Campos 1996, Callegari 2004). El sitio está integrado por 10 recintos y tres montículos de descarte de 16x18m., habiéndose recuperado los macrorrestos referidos de Cucurbita sp del montículo II (Callegari y Campos 1996, Callegari 2004). Los informes publicados indican que dichos macrorrestos fueron recuperados de recolecciones superficiales o primera capa de excavación en todos los casos (Callegari 2003). El examen de la totalidad de los restos arqueobotánicos permitió constatar que, en tanto macrorrestos de otros taxa como Prosopis sp. y Geoffroea decorticans se encuentran carbonizados, los de Cucurbita sp. son restos secos en excelente estado de preservación. Tomando en consideración ambos factores (contexto y tipo de preservación diferencial) se decidió descartar el análisis de estos restos por existir una alta probabilidad de que los mismos sean de origen moderno y formen parte del registro arqueológico por factores postdeposicionales.

\section{2) Análisis de restos arqueobotánicos exclusivamente.}

A través del contacto con diversos investigadores se tuvo acceso a restos de Cucurbita sp. de tres sitios formativos: Los Viscos, Campo del Pucará y La Viña (Figura 3). El interés de los hallazgos de Huachichocana III donde se reporta la presencia temprana de restos de C. maxima y P. vulgaris (Fernández 
Distel 1975, 1986) (ver capítulo 2) y la falta de un reestudio de los mismos llevó a que ejemplares de ambos taxa se consultaran en el Instituto Interdisciplinario Tilcara (FFyL-UBA). Los restos del sitio inkaico- hispano indígena de El Shincal (Figura 3) fueron analizados a fin de compararlos con los provenientes de sitios más tempranos y evaluar así grados de similitud y diferencia, mediante la presencia/ausencia de rasgos significativos en sitios de la misma región.

En el caso de otros sitios del Área Andina Central y Meridional se tuvo acceso a semillas y restos de pericarpios de los sitios arcaicos peruanos de Bandurria, Curayacu, Chavin, Jahuay y Cerro Lampay, obteniéndose las muestras a través de un convenio de intercambio con el Departamento de Etnobotánica y Botánica Económica del Museo de Historia Natural, Universidad Nacional Mayor de San Marcos (Lima, Perú). Se estudiaron también dos muestras de pericarpios de cucurbitáceas recuperados en el sitio arcaico chileno de Tulan 85, remitidos por la Dra. Virginia Mc Rostie de la Universidad de Chile.

A continuación se describen los sitios a partir de la bibliografía publicada hasta el presente y se detalla el material arqueobotánico al cual se accedió para su estudio.

\section{Los Viscos (SCatBe 6)}

Este sitio se ubica en el valle del Bolsón (Dpto. Belén, Pcia de Catamarca), el mismo es un alero de grandes dimensiones $\left(380 \mathrm{~m}^{2}\right)$ con estructuras de piedra en forma cuadrangular en la superficie que presentaba, al momento de ser excavado, tanto evidencias de saqueo como sectores no alterados (Korstanje y Wurschmidt. 1998). Gracias a la buena predisposición de la Dra. Korstanje se pudieron analizar los restos secos de tres semillas de Cucurbita (dos a nivel microscópico), recuperadas en dichas excavaciones. Por intermedio de la Dra. Korstanje se tuvo acceso al informe realizado por Maloberti y Zapatiel (2003) 
sobre la totalidad de restos de Cucurbita recuperados en este sitio (semillas, pericarpios y pedúnculos).

Las dos excavaciones arqueológicas que se realizaron, comprendieron la limpieza de los perfiles y la excavación de áreas aledañas a un pozo de huaqueo (sectores P-Q-R) y una excavación por decapage en una zona sellada por una capa de guano compacta (sectores L-LL-M ), los materiales exhumados indican al menos dos momentos en la ocupación del abrigo, uno asignable al Período Formativo (desde ca 500 a.C) y otro entre el Período de Desarrollos Regionales y el momento de contacto Colonial (entre ca 1000 1536 d.C) (Korstanje y Wurschmidt. 1998).

De los dos grandes sectores excavados se recuperaron:

-Sector P-Q-R.: se recuperaron instrumentos de caza, de guerra e indicadores de tumbas cavadas sobre ocupaciones más antiguas. (Korstanje y Wurschmidt 1998). Según informe de Maloberti y Zapatiel (2003) en la unidad P sólo fue hallada una semilla de C. maxima en el nivel 6, en la unidad $\mathrm{R}$ fueron recuperados 4 fragmentos de pericarpio pertenecientes a $C$. moschata, todos ellos provenientes de la capa 2 y asociados a huesos, marlos, cordeles y madera, en la unidad Q fue hallada una semilla de C. maxima en la capa 2, asociada a marlos, artefactos y una calabaza pirograbada, por último y como producto de la limpieza del perfil de las unidades $\mathrm{R}$ y $\mathrm{Q}$, se recuperó una semilla de C. maxima.

-Sector L-Ll-M: se recuperaron instrumentos en hueso que por su morfología y por los rasgos estilísticos de los grabados realizados sobre calabazas, se propuso una ocupación colonial (Hispano Indígena) sobre la misma ocupación formativa (más tardía dentro del formativo) (Korstanje y Wurschmidt 1998). De acuerdo con Maloberti y Zapatiel (2003) en la unidad $\mathrm{L}$ se recuperaron tres pedúnculos: un pedúnculo de C. maxima, proveniente de la capa 4, asociado a paja, maíz y lascas de cuarzo, en una matriz constituida por sedimento limoso compacto; los otros dos pedúnculos (uno de C. maxima 
y el otro sin identificar) fueron exhumados de la capa 5, asociados a huesos, marlos y cordeles. Se recuperaron además siete fragmentos de pericarpio pertenecientes al mismo fruto, identificado como L. siceraria, provenientes de la capa 4, asociados a maíz, artefactos, paja, palitos, huesos y caracoles. En la unidad Ll se hallaron ocho pedúnculos, cinco provenientes de la capa 4 (dos pertenecientes a $C$. pepo o moschata y tres a $C$. maxima) asociados a paja, maíz, maíz morado, vellones, cordeles, paja pintada, lascas de cuarzo y cerámica; dos de la capa 3 (ambos identificados como C. pepo o moschata), asociados a porotos, marlos, maíz, cordeles y cerámica negra incisa, el pedúnculo restante fue identificado como C. maxima y fue encontrado en la capa 1 asociado a cordeles, fragmentos cerámicos y a una estructura de cañizo, que parece ser una especie de muro; se hallaron también dos fragmentos de pericarpio en la capa 4, identificados como pertenecientes a $C$. moschata., asociados a paja, maíz, lascas de cuarzo y fragmentos cerámicos. En la unidad M se recuperaron dos pedúnculos: uno identificado como C. maxima, hallado en la capa 3 , en una matriz constituida por guano compactado, asociado a maíz, cordeles, una aguja y fragmentos cerámicos, algunos de ellos decorados, el otro pedúnculo, identificado como C. moschata, se encontró en la capa 1, en una matriz compuesta por un sedimento arenoso con ceniza; asociado a cerámica, huesos y marlos (Maloberti y Zapatiel 2003).

Las excavaciones pusieron al descubierto una compleja estratigrafía que indica no solo distintas ocupaciones sino también distintas funcionalidades. A $21 \mathrm{~cm}$ de profundidad se halló una estructura de acumulación que puede ser considerada como un rincón dentro de un piso de habitación o bien una zona de descarte de alimentos y basura, apoya la primera hipótesis la presencia de la pared de cañizo (ya descripta) y varios fragmentos de cerámica en posición horizontal; mientras que la abundancia de vestigios vegetales consumidos y agotados, sustentan la segunda hipótesis (Korstanje 1998). 
Los componentes arqueológicos más tempranos del sitio corresponderían a las capas 3b a 7 donde se hallaron restos de cerámica Aguada (Maloberti y Zapatiel 2003).

Las semillas analizadas en esta tesis son las recuperadas en la unidad P, capa 6 (semilla $\mathrm{n}^{\circ} 25$ ) y en la unidad Q, capa 4 (semilla ${ }^{\circ} 13$ ), ambas posiblemente correspondientes al período Aguada. Pedúnculos y pericarpios sólo fueron estudiados por medio de las fotografías cedidas por la Dra. Korstanje y las descripciones efectuadas por Maloberti y Zapatiel (2003).

\section{Sitio Puente Río La Viña I}

Este sitio se ubica al sudoeste de la ruta nacional $\mathrm{N}^{\circ} 9$ en las planicies de inundación del río La Viña (Figura 4), cerca de la localidad de La Viña en el sector meridional del Valle de Lerma (Escobar ms $a$ y $b$ ). El mismo no posee estructuras de superficie, habiéndose excavado una cuadrícula cuya profundidad alcanzó los 1,7 m (Escobar msa). Este sitio posee un fechado de 1440 +-60 AP (510+-60DC), correspondiendo sus ocupaciones a la Fase La Viña (460- 730 DC) (Escobar 2008). En el mencionado sitio se recuperaron restos carbonizados de Zea mays, Phaseolus vulgaris y Cucurbita maxima identificados por M.L. Pochettino (Escobar 1994). La colección de restos arqueobotánicos de este sitio se encontraba depositada en el Laboratorio de Etnobotánica y Botánica Aplicada (LEBA, FCNYM - UNLP), donde fue consultada. Gracias al Lic. J.M. Escobar pudimos tener acceso a sus informes inéditos.

En el valle de Lerma, previa a la fase La Viña, se encuentra la fase Tilián (200 AC- 300 DC) (Escobar 2008). No se han recuperado restos vegetales vinculados a esta fase, pero la presencia de improntas de marlos en la cerámica recuperada en el sitio Las Garzas (el más temprano del valle con un fechado de 200 AC) indicaría la disponibilidad local de Zea mays (Escobar ms.b). En 
este período se reporta la explotación de Lama guanicoe-glama y Mazama sp., siendo menor el registro de aves, peces, anfibios y mamíferos pequeños como armadillos (Escobar 2008). Esta fase se vincularía con el formativo inferior de la Quebrada del Toro y con la cultura San Francisco de Selvas Occidentales (Escobar 2008).

Los elementos cerámicos de la fase La Viña poseen una amplia distribución en el sector meridional del Valle de Lerma, ubicándose los sitios en los pedemontes occidental y oriental de dicho valle entre los 1150 y 1300 msm (Escobar 2008). No se han reconocido hasta el momento estructuras residenciales o productivas vinculadas a esta fase o a la precedente, sí se han detectado, en cambio, enterratorios de adultos individuales y directos, con escaso ajuar y un único caso de un niño tapado con un puco (Escobar ms a). A pesar de que esta fase está estrechamente vinculada con el período Candelaria III (400- 700 DC) de las Selvas Occidentales meridionales, y por consiguiente, también, con la ocupación funeraria de las cuevas de Pampa Grande, donde es muy frecuente el entierro de adultos en grandes urnas (Escobar $2008 \mathrm{~ms}$ a), las grandes vasijas de la fase La Viña no parecen haber sido destinadas al entierro humano sino al almacenamiento (Escobar ms a). Al igual que la fase Tilian, La Viña se vincula con la Quebrada del Toro, salvo que lo hace con las ocupaciones correspondientes al formativo superior de dicha quebrada; La Viña se vincula también con San Pedro de Atacama y con ocupaciones de los valles Calchaquí y Santa María (Escobar 2008). Las vinculaciones de ambas fases son establecidas por Escobar, fundamentalmente, a partir de las características de los restos cerámicos recuperados.

A nivel regional (Valle de Lerma, Quebrada del Toro y región de Selvas Occidentales) la fase Tilián representaría el formativo temprano con desarrollos locales a nivel aldeano y escasos contactos fuera del valle (Escobar 2008). La fase La Viña posee una clara discontinuidad con la fase Tilián y un 
vínculo muy marcado con Candelaria III y también, en menor medida, con ocupaciones de otros valles como Santa María y Calchaquí (Escobar 2008). En esta fase parecería suceder un aumento demográfico evidenciado por un mayor número de sitios y una ampliación de la base productiva a partir de una mayor diversidad de especies vegetales domesticas y la explotación de llamas para diversos fines (Escobar 2008). En opinión de este investigador éste es un momento de desarrollo acelerado, donde aumentan los contactos culturales y el conflicto social, lo cual integra a nivel regional las fases La Viña y Candelaria III, coincidiendo este período con la expansión Aguada más al sur y cuyas influencias llegan a esta zona pero sin lograr un lugar preponderante en el conjunto de prácticas sociales (Escobar 2008).

Los macrorrestos arqueobotánicos del sitio Puente Río La Viña I depositados en el LEBA consisten en restos carbonizados provenientes de los niveles entre 1,3 y 1,6 $\mathrm{m}$ de profundidad asociados a un gran lente de cenizas detectado en dichos niveles, según consta en las etiquetas junto al material. La revisión del material arqueobotánico confirmó las determinaciones de Pochettino habiéndose identificado restos de Prosopis sp (vainas, endocarpos y semillas) y endocarpios de Geoffroea decorticans en gran número, semillas enteras y fragmentadas de Cucurbita sp., fragmentos de marlos y granos de Zea mays, tallos de monocotiledóneas y cotiledones de Phaseolus sp.

\section{Campo del Pucará}

Esta localidad se ubica en Andalgalá, Catamarca, y consiste en cincuenta unidades arqueológicas distribuidas en tres terrazas de 1700, 1800 y 1900 msm. (Tartusi y Núñez Regueiro 1993, Oliszewski 2004). Cada una de estas unidades posee un área central rodeada por dos plataformas ceremoniales y estructuras vinculadas a actividades metalúrgicas y de habitación junto a un gran montículo ubicado siempre al oeste (Tartusi y Núñez Regueiro 1993). 
Se considera que los sitios arqueológicos de Campo del Pucará fueron centros ceremoniales vinculados culturalmente a Condorhuasi-Alamito (facie de Condorhuasi) (Tartusi y Núñez Regueiro 1993, Oliszewski 2004). Tras un estudio arqueobotánico exhaustivo de Campo del Pucará Oliszewski (2004) reporta la identificación de restos de Zea mays var mínima, Acacia sp., Prosopis sp., P. nigra o P. alba, P. torquata, Phaseolus sp., P. vulgaris var vulgaris, P. vulgaris var aborigineus y Cucurbita maxima. Esta última especie fue identificada por medio del análisis macroscópico de una semilla recuperada en el montículo mayor H-0, en la meseta de 1700 msm y corresponde a la Fase II de Alamito (360-480 DC). Gracias a la Dra. Oliszewski se pudo acceder a los restos de esta semilla carbonizada para su análisis microscópico.

\section{Huachichocana III}

Las cuevas de Huachichocana se ubican en las cabeceras de la quebrada de Purmamarca, tributaria de la quebrada de Humahuaca (Jujuy). De este conjunto de cuevas destaca la número III excavada por A. Fernández Distel en la década de 1970 (Fernández Distel 1974). Como se mencionó en el capítulo 2, los hallazgos efectuados destacaron por la presencia de ejemplares de plantas domesticadas -o sus antecesores silvestres- en contextos próximos al 10.000 AP. En esta cueva se detectaron ocupaciones correspondientes a distintos períodos del desarrollo cultural del área: la capa B corresponde a un asentamiento Hispano-Indígena posterior al 1536 DC, la capa C a un asentamiento humahuaca-inka de entre 1475 y 1536 DC, la capa D a un asentamiento humahuaca-atacameño de entre 1000 y 1400 DC, la capa E1 al cerámico inicial (500 AC-500 DC), la capa E2 al precerámico final entre 1000 y 2500 AC y la capa E3 a un precerámico agrícola incipiente entre 6500 y 8200 AC.(Fernández Distel 1986). En esta cueva se recuperaron restos de cinco inhumaciones y gran número de restos culturales de muy diverso tipo de 
acuerdo con los distintos períodos ocupacionales, una descripción detallada de los contextos y hallazgos puede verse en Fernández Distel (1986) y las implicancias regionales de estos hallazgos fueron discutidas en el capítulo precedente.

En cuanto a los taxa vegetales, se encontraron restos de los siguientes "cultivos": Phaseolus vulgaris (capa E3 y C), Oxalis tuberosa Mol (capa E1), Capsicum baccatum L. var baccatum o C. chacoense (capa E3), Capsicum annuum L o Capsicum baccatum var pendulum o Capsicum frutescens (capa C), restos de Zea mays de distintas variedades fueron recuperados en todos los niveles, restos de Arachis hipogaea en la capa E2 y C, restos de Lagenaria siceraria en capas E1,E2 y E3 y C, Cucurbita maxima en capa C y Erythroxylum coca Lam. var. coca en capa B. Otros restos vegetales silvestres recuperados en la cueva fueron Canna edulis (capa C), Prosopis alba y nigra (capas C,D, E1, E2 y E3), Juglans australis (capa C) y Trichocereus pasacana en todas las capas, entre otros no comestibles (Fernandez Distel 1986)

La colección correspondiente a esta cueva se encuentra depositada actualmente en el Instituto Interdisciplinario Tilcara (FFyL, Tilcara, Jujuy). Si bien se permitió la consulta de los restos arqueobotánicos en las instalaciones del museo, no se autorizó el traslado de los mismos ni la extracción de muestras para su estudio microscópico. Por lo cual restos de pericarpios de cucurbitáceas y las dos semillas de Phaseolus sp. fueron fotografiadas y caracterizadas sólo a nivel macroscópico en las instalaciones del mencionado instituto.

\section{El Shincal}

El sitio arqueológico "El Shincal de Quimivil" se ubica a los $27^{\circ} 41^{\prime} 14$ ” S y $67^{\circ} 10^{\prime} 31^{\prime}$ W, en la localidad de Londres, Departamento de Belén, Provincia de Catamarca, Argentina, a una altitud de $1302 \mathrm{msm}$. Dicho sitio ha sido 
interpretado como un centro administrativo regional erigido en un "lugar de reunión" o tinkuy en la confluencia de los ríos Quimivil y Hondo, en el extremo meridional del Valle de Hualfín (Capparelli et al 2004). En el mismo se han reconocido numerosas estructuras arquitectónicas de piedra y mampostería entre las que sobresalen en el sector principal cinco kallankas estructuras rectangulares de piedra labrada-, un sinchiwasi -complejo arquitectónico compuesto por recintos menores, posiblemente habitacionales, recintos circulares o qollqas para almacenamiento, numerosos RPC -Recinto Perimetral Compuesto- y dos cerros aterrazados de unos $25 \mathrm{~m}$ de altura flanqueando la aukaipata - plaza central de carácter público. Esta última construcción contiene en su interior, coincidiendo con el centro geográfico del sitio, uno de los edificios simbólicamente más importantes y significativos del Tawantinsuyu: el ushnu. (Raffino 2004). El mismo consiste en una plataforma de $16 \mathrm{~m}$ de lado por $2 \mathrm{~m}$ de altura que contiene en su porción superior, sobre el sector norte, una tiana o banqueta de piedra. El acceso a esta estructura se realiza por medio de una escalinata de nueve peldaños (Raffino 2004). En esta estructura se recuperaron restos carbonizados de taxa americanos (Prosopis sp., Geoffroea decorticans, Ziquphbus mistol, Gossypium sp., Zea mays, Phaseolus lunatus, P vulgaris, Cucurbita sp.) y restos originarios del Viejo Mundo (Triticum sp., Hordeum sp y Prunas persica) ingresados al sitio durante las ocupaciones del período Hispano Indígena (Capparelli et al. 2005). Se estudiaron restos carbonizados correspondientes a una semilla y a un pedúnculo de Cucurbita sp.

\section{Sitios arqueológicos del Área Andina Centro-meridional, fuera de territorio argentino.}

Los sitios correspondientes a estas áreas (Figura 5) se describen de manera somera con el único fin de caracterizarlos a nivel general. No es el objetivo de 
esta tesis abordar la compleja problemática de los Andes centro- meridionales a nivel general, tomándose las muestras arqueobotánicas de estos sitios tempranos como referencia para contrastar con la evidencia de sitios arqueológicos del NOA.

Los sitios de Bandurria, Curayacu, Chavin, y Jahuay pertenecen a las primeras manifestaciones de arquitectura pública en Perú. Bandurria esta situado en el Valle de Huaura, próximo a la costa. El mismo fue excavado por la Dra. R. Fung en la decada del '70 quien identificó dos ocupaciones precerámicas (4530-3740 AP/3300 $1700 \mathrm{AC}$ ), ambas asociadas a montículos ceremoniales rodeados en un radio de $250 \mathrm{~m}$ por unidades residenciales. En lo que respecta a restos vegetales se recuperaron restos de algodón (Gossypium barbadense), ají (Capsicum sp.), zapallo (Cucurbita sp.), guayaba (Psidium guajaba), lúcuma (Lucuma bifera), maní (Arachis hipogaea), mate (Lagenaria siceraria) y pacae (Inga fenillet) (Vega-Centeno Sara-Lafosse 2005, Haas y Creamer 2006).

Chavín de Huantar se ubica en el callejón de Huaylas y consiste en uno de los centros ceremoniales de carácter publico más tempranos del Perú, con fechados próximos a los señalados para Bandurria

Cerro Lampay se localiza en el Valle de Fortaleza, a aproximadamente $220 \mathrm{~km}$ al norte de Lima. El mismo consiste en un sitio de arquitectura pública del período intermedio tardío (900-1400 DC) y del período arcaico tardío (30001500 BC) en las terrazas bajas y altas respectivamente (Vega-Centeno SaraLafosse 2005). Entre los restos vegetales de este sitio se identificaron frutos de Inga feullei, Prosopis pallida, Phaseolus vulgaris y Gossypium barbadense, fragmentos de pericarpios de Lagenaria siceraria y Crescentia cujete, semillas de Psidium guajaba, Capsicum sp., Sapinus saponaria, Lagenaria siceraria, Inga feullei, Gossypium barbadense y Cucurbita pepo, marlos de Zea mays y rizomas de Canna edulis y posiblemente Manibot esculenta (Vega-Centeno Sara-Lafosse 2005)

El sitio Tulan 85 se ubica al sur del salar de Atacama (Chile) y corresponde al Formativo temprano del área. 
De todos estos sitios se estudiaron muestras de pericarpios de cucurbitáceas y de Bandurria y Cerro Lampay se analizaron además semillas de Cucurbita sp.

\section{3) Análisis de restos arqueobotánicos y colecciones arqueológicas.}

Sólo en el caso de dos sitios se procedió a un análisis integral de las colecciones arqueológicas. En el caso de Puente del Diablo el registro completo se realizó debido a que no se contaba con información publicada sobre los hallazgos, salvo menciones breves en distintas publicaciones. Si bien Pampa Grande contaba con mayor número de publicaciones y análisis, el volumen considerable de macrorrestos hizo necesario un registro más cuidadoso y pormenorizado de sus contextos de hallazgo. Los macrorrestos de Pampa Grande constituyen, además, un componente esencial de la tesis aquí presentada y es por ello también que se realiza un análisis pormenorizado de esta localidad arqueológica.

\section{Puente del Diablo (SSalLap20)}

\section{El sitio}

La cueva se ubica a $4 \mathrm{~km}$. al sur de la localidad de La Poma, Salta, en el sector norte de los Valles Calchaquíes (Figura 3). La misma está emplazada en la zona conocida como Campo Negro en la margen izquierda del río Calchaquí aproximadamente a $3000 \mathrm{msm}\left(24^{\circ} 46^{\prime}\right.$ lat., $63^{\circ} 13^{\prime}$ long.)

El sitio se descubre a principios de 1973 a partir del hallazgo de un cuerpo momificado por parte de Sergio Saravia, presidente de la Asociación Amigos del Museo de Cachi, quien da aviso inmediato del hallazgo a esta institución.

\section{Historia de las excavaciones. Relevancia de los hallazgos.}


El sitio fue excavado por personal del Museo de Arqueología de Cachi con la asistencia de Monica De Lorenzi y Maria Delia Arena. Lamentablemente la situación política del momento impidió la continuación de la investigación, pero se elaboraron informes de campo y dirigidos a las autoridades provinciales muy completos de los cuales disponemos gracias a la amabilidad de la Lic. María Delia Arena interesada en la continuación de los trabajos. Asimismo la posibilidad de acceder a la colección arqueológica-ubicada actualmente en el Museo Arqueológico de Cachi- y que la misma se encontrara en buen estado de preservación y con registro acompañante permitió avanzar en los estudios aquí presentados.

La escasa información que circuló en el medio académico bastó para reconocer la relevancia de los hallazgos efectuados considerándolos como representativos de cazadores recolectores vallistas en transición hacia la producción de alimentos (Nuñez Regueiro 1974, Tarragó 1980, Schóbinger 1988, Castro y Tarragó 1992, Albeck 2000). En este sentido Fernández Distel (1980) coloca a este sitio junto al conjunto fúnebre de la capa E2 de Huachichocana III en el arcaico regional; Schóbinger (1988) incluye estos hallazgos junto a los de Inca Cueva, Huachichocana y Peña Aujero como "Complejo cultural con agricultura arcaica del borde oriental y meridional de la puna caracterizado por puntas de proyectil triangulares y lanceoladas pequeñas" (Schóbinger 1988:416) en el rango temporal de 2500 a 500 AC Para Tarragó (1980) es el único representante del Arcaico Tardío en el sector septentrional del valle Calchaquí.

En cuanto a la información publicada sobre los hallazgos en sí, se consignan "siete enterratorios, algunos parcial o totalmente disecados (...). Los cadáveres, envueltos en cueros, y enfardados con paja y cuerdas, yacían bajo maderas de cardón que se distribuyeron a manera de techo" (Nuñez Regueiro 1974), Scóbinger (1980) aclara que "los restos humanos corresponden a un 
niño y seis adultos, entre estos una mujer joven con indicios de haber sido golpeada" (Schóbinger 1988:416). Respecto a los artefactos hallados se mencionan puntas de proyectil triangulares y un gancho de propulsor de hueso (Nuñez Regueiro 1974, Tarragó 1980, Schóbinger 1988). Sólo Núñez Regueiro (1974) menciona que se hallaron tres fragmentos de cerámica en la parte superior del relleno de la gruta, aunque considera que no guardan relación con los entierros. En referencia a los restos vegetales se mencionan restos de algarroba, semillas de Cucurbita sp. (probablemente cultivadas, en opinión de Castro y Tarragó 1992) y un ejemplar dudoso de poroto (Nuñez Regueiro 1974, Tarragó 1980, Schóbinger 1988, Castro y Tarragó 1992, Albeck 2000).

\section{Análisis de la colección arqueológica, diario de campo e informes.}

La cueva posee $7 \mathrm{~m}$ de profundidad, el ancho máximo de 4, $75 \mathrm{~m}$ se ubica en la entrada, la cual se orienta al oeste y se encuentra delimitada con piedras. Su altura máxima es de 1,8 m. (Díaz et al. ms.).

Partiendo de una perturbación inicial efectuada al extraerse el cuerpo y manos momificadas ("sector removido" en figura 6) la cueva se excavó mediante un sistema de coordenadas que totalizaron 17 cuadrículas, las cuales se excavaron en niveles de $10 \mathrm{~cm}$ hasta alcanzar la roca de base. Las cuadrículas correspondientes a la columna 1 no fueron excavadas -salvo la cuadrícula E1permaneciendo como testigos. El sector removido tras la extracción de los restos momificados correspondería a la cuadrícula B2 y la intersección de las cuadrículas B2/B3/C2/C3, la cual se excavo como unidad aparte debido a la complejidad de la estratigrafía (figuras 7 y 8 ).

Estas excavaciones representan el primer registro que se posee de la extracción de muestras de sedimento para flotación, representando esto una estrategia metodológica pionera respecto de las prácticas de excavación que se 
venían realizando hasta el momento en el NOA. Asimismo se extrajeron muestras para análisis polínico, las cuales fueron analizadas por el Dr. D’Antoni sin que se detectara la presencia de restos de polen (Díaz et al ms.)

\section{a) Los entierros ${ }^{1}$}

En los informes de campo y libreta se reporta el hallazgo de siete cuerpos, siendo uno de ellos el cuerpo momificado conocido hoy como "La dama de Cachi". De acuerdo con los mencionados informes en las proximidades de la entrada de la cueva y por debajo de rocas ubicadas a $15 \mathrm{~cm}$. de profundidad se recuperan los restos de los entierros $\mathrm{E} 5 / \mathrm{E} 4^{2}$ asociado a restos de un fogón delimitado con piedras. La posición en que se halló al mismo era boca abajo, conservando ambos miembros superiores, uno flexionado con la mano articulada por debajo del húmero, el otro estirado sin una posición clara. Por debajo del miembro superior flexionado se halló el inferior también flexionado y entre fémur, tibia y peroné se recuperó una lasca o posible raspador y restos de carbón. Próximo a estos hallazgos aparecieron, junto a pequeñas lascas, otros restos muy alterados de otro esqueleto (E6) aparentemente asociado también a restos de un fogón delimitado con piedras. En el sector central de la cueva se halló un colchón de paja y por debajo una consolidación de tierra y ceniza, en el extremo de esta consolidación aparecen dos maderas de cardón cruzadas en el nivel donde termina dicha consolidación. Estas formarían parte de un conjunto con otra madera de cardón hallada previamente, que se ubica en el lugar donde se halló el cráneo del E3. Este esqueleto fue hallado articulado en posición genupectoral a menos de $10 \mathrm{~cm}$ de profundidad con orientación este-oeste. Conservaba unos mechones de cabello aún adheridos al cráneo, el cual estaba casi tocando la

\footnotetext{
${ }^{1}$ La descripción de los restos humanos fue realizada con el apoyo de la Dra. P. González a partir de imágenes digitales de los mismos (FCNYM-UNLP)

${ }^{2}$ Los restos humanos que se consignan con la letra $\mathrm{E}$ y un número son los que fueron registrados de éste modo en la libreta de campo e informes.
} 
pared de la cueva. Casi pegado al cráneo se halló un enorme trozo de carbón, a la altura de las vértebras cervicales se halló un manojo de fibras vegetales y rodeando al cráneo había paja. El esqueleto estaba incluido en la mencionada consolidación compacta de guano, paja y ceniza.

En la cuadrícula C3, a los $30 \mathrm{~cm}$ de profundidad, se halla una capa de paja, por debajo de la misma se descubre un fogón y por debajo de éste varias maderas de cardón entrecruzadas y superpuestas -algunas con restos de corteza- formando una capa de aproximadamente $15 \mathrm{~cm}$ de espesor. Aledaños a los mismos se detecta una capa compacta de sedimento, ceniza y paja. Incluidos en esta matriz de paja aparecieron huesos de roedor y huesos humanos (E7) fracturados y termoalterados correspondientes al cráneo, estando la porción correspondiente a la base del mismo orientada hacia la superficie. El resto del esqueleto se halló también incluido en el colchón de paja y junto a restos de carbón de gran tamaño, todo delimitado por piedras. Los restos corresponderían a un niño enterrado en posición genupectoral. Entre las costillas se recuperó una punta triangular de base recta. Los restos del individuo apoyan sobre un colchón de paja y por encima del mismo se ubica una plancha de maderas de cardón. Cercano a este hallazgo y en las proximidades donde se recuperaron los restos momificados se hallo una punta triangular pequeña.

Los restos del cuerpo momificado y del E3 fueron luego estudiados por Marcellino (1981). De acuerdo con este autor el E3 correspondería a los restos de una mujer de 1,5 $\mathrm{m}$ de altura aproximadamente que habría muerto entre los 40 y 43 años. El autor destaca la pérdida temprana de varias piezas dentarias lo cual habría ocasionado una alteración del plano masticatorio, evidenciándose en las piezas restantes una fuerte atrición "al punto de ser verdaderos muñones dentarios" (Marcellino 1981:49). A pesar de ser el único cuerpo hallado sin modificaciones posdeposicionales y de que Marcellino (1981) describe cráneo y esqueleto postcraneal, se hallaron solamente restos 
del primero en las instalaciones del Museo Arqueológico de Cachi. El cráneo conserva restos de tejido blando correspondiente al cuero cabelludo, junto a unos pocos mechones de cabello. En cuanto a las piezas dentarias llama la atención -tal como lo destaca Marcellino (1981)- su elevado grado de desgaste, teniendo todos la corona removida y sin presencia de esmalte. Sólo conserva piezas dentales el maxilar superior donde persisten los caninos de ambos lados y los dos premolares del lado derecho, se reconocen al menos dos perdidas antemortem (PM2 y M1 izquierdo) y abscesos en la cara lingual, en la base de la raíz de los premolares y caninos. En la mandíbula se produjo la perdida pre-mortem de los premolares y molares y post-mortem de todos los dientes anteriores (incisivos y caninos)

Formando parte de la colección del sitio también se encuentran restos del E7. Se trataría efectivamente de un individuo subadulto (posiblemente femenino) dado que el húmero izquierdo posee la epífisis proximal soldada, pero no totalmente fusionada. Se identificaron en la colección: escápula derecha, dos vértebras cervicales, una dorsal y dos lumbares, un fragmento de pubis con señales de carbonización, hueso temporal que conserva la porción petrosa, una porción del proceso zigomático y parte de la escama y una porción de bóveda craneana. En cuanto a restos de dentición se halló un premolar superior con elevado grado de desgaste en la superficie oclusal y desgaste interproximal, cúspides completamente removidas, un parche de dentina y posible hoyo carioso en la superficie oclusal. Se halló también un incisivo central superior con desgaste moderado, con una gran área de dentina aunque conserva los bordes de esmalte completos. Por último se puede señalar que presenta dientes "en pala" que es una forma muy común en los dientes de los amerindios.

Del E4/E5/E6 se identificaron nueve falanges y siete huesos metacarpianos, un molar (probablemente M3) con bastante desgaste oclusal, remoción completa de las cúspides y un pequeño parche de dentina, con gran área de 
desgaste en una de las superficies interproximales. También se recuperó un incisivo central superior con desgaste moderado, con una gran área de dentina aunque conserva los bordes de esmalte completos. Presenta también dientes "en pala".

Lamentablemente la escasa cantidad de restos óseos identificados en la colección impiden despejar la duda inicial señalada en las libretas de campo acerca de si estos restos corresponden a uno o más individuos dado lo alterado del deposito y la ausencia de análisis antropológico posterior a la excavación. Por el momento sólo podemos afirmar la presencia cierta de un único cuerpo.

\section{La dama de Cachi}

Primeras descripciones: No existen precisiones acerca del modo de hallazgo de este cuerpo ni de los objetos asociados al mismo al momento de su extracción de la cueva. En su trabajo de 1981 Marcelino nos ofrece una descripción del mismo: se encuentra parcialmente momificado naturalmente, en posición genupectoral con manos en el rostro y decúbito lateral izquierdo faltando solamente la mandíbula inferior. El cadáver fue acondicionado apoyando el borde inferior de la mandíbula sobre el dorso de la mano izquierda, y el lado derecho del rostro sobre la cara palmar y el dorso de los dedos de la mano del mismo lado; los miembros inferiores se hallaban flexionados sobre el torso, el pie izquierdo hiperflexionado y el derecho en posición natural. Sobre el tórax y parte de los miembros inferiores se ubican restos de una cubierta de cuero, la cual cuenta con huellas superficiales producidas por los cordeles que habrían colaborado en mantener la posición inhumatoria. En su porción distal el fémur derecho presenta evidencias de calcinación.

En la colección del Museo Arqueológico de Cachi se identificó, además del cuerpo de la Dama de Cachi, un par de manos momificadas correspondientes 
a las falanges y huesos metacarpianos de lateralidad izquierda y derecha. Las mismas pertenecen evidentemente a otro cuerpo, pero esto no es mencionado ni en los informes ni en las libretas de campo, aunque figura un segundo hallazgo de cuerpos momificados en el plano de excavación de la cueva (Fig. 6).

En cuanto al cuerpo momificado, este se halla en un estado de deterioro respecto de lo informado por Marcellino (1981). Se registró por separado: el miembro superior izquierdo (escápula, húmero, radio-cubito, huesos metacarpianos y falanges) articulado; escápula, húmero y radio-cúbito-huesos metacarpianos-falanges miembro superior derecho; esternón; fragmento del lado derecho del maxilar inferior; miembro inferior derecho (falanges, huesos metatarsianos, tibia, peroné, rótula y epífisis distal del fémur) articulado; porción de la parrilla costal derecha; porción de la parrilla costal izquierda; porción abdominal del tórax-región lumbar/coxal con miembros inferior izquierdo completo y parte del fémur derecho fracturado y termoalterado. El cráneo con faltante de piezas óseas del lado derecho y las piezas dentarias del maxilar superior con el tercer molar izquierdo y crecimiento aberrante de canino superior derecho coinciden con lo descripto por Marcellino (1981). Se conserva también un canino superior con la corona removida por desgaste, presentando un fuerte plano de desgaste linguo-bucal. Se conservan las primeras once vértebras.

Junto a estos restos se conservan porciones de corteza y madera de una Cactácea columnar (Trichocereus sp.) que habrían sido parte del entierro. Tal como dice Marcellino (1981) se conservan sobre la parrilla costal derecha restos de cuero curtido. Según este autor corresponderían a parte de la vestimenta dada la presencia de un ojal. Tras el examen de los restos no se detectó la presencia del mismo, por lo cual es más factible que sea parte de un fardo de cuero que habría envuelto al cuerpo como lo menciona Nuñez Regueiro (1974) 


\section{b) Los contextos (Anexo I)}

Las cuadrículas A2 y A3 fueron excavadas hasta los $40 \mathrm{~cm}$ de profundidad. Se hallaron abundantes restos de frutos de Prosopis sp., identificándose al menos cuatro especies. La mayor abundancia se detectó en los primeros niveles. Estos restos son endocarpos que conservan en varios casos restos de mesocarpio y epicarpio por lo cual se descarta que sean el producto de la defecación de mamíferos como el zorro, el cual es un agente dispersor de dichos frutos. Se recuperaron también restos de ovarios de Lobivia sp (identificados por R. Kiesling, según datos de etiquetas del Instituto Botánico Darwinion depositadas junto a los restos) y semillas de Tephrocactus sp., una posible semilla de quínoa, un ovario/receptáculo, una flor y seis espinas de una cactácea indeterminada, fragmentos pequeños de madera (uno es madera de Cactácea) algunos de ellos termoalterados y cinco pequeños carbones. En la capa 1 de A2 y en la capa 2 de A3 se recuperaron restos de cubiertas seminales de Cucurbita sp. (C) y en el primero de estos contextos restos de lo que podrían ser fragmentos de pericarpios de este mismo género o de Lagenaria sp.

De estas cuadrículas se recuperaron también restos de cáscara de huevo blanco y otro de color verde correspondiente a Eudromia elegans (determinación que constaba en las etiquetas depositadas junto al material), un ave corredora de la zona. Restos de placas móviles de Chaetophractus sp y huesos de aves. Abundan los restos de Lagidium sp. algunos con señales de exposición al fuego. Se identificaron también restos de Cervidae sp. y Lama sp $^{3}$ y otros huesos con señales de corte y exposición al fuego. También hay huesos con marcas de roído. Otros restos corresponden a cordones de lana

\footnotetext{
${ }^{3}$ Salvo algunas identificaciones realizadas con anterioridad a las investigaciones desarrolladas aquí (las cuales son señaladas cuando corresponde), la determinación de restos faunísticos fue realizada por Sergio Bogan a partir de imágenes digitales de los restos.
} 
color castaño, una lasca secundaria de desecho de metacuarcita gris y un coprolito.

Estos hallazgos parecerían indicar un evento de ocupación en el fondo de la cueva con consumo de recursos vegetales y animales.

De la cuadrícula B3, próxima al sector donde se hallaron los restos momificados, se obtuvieron restos de mamíferos pequeños (Lagidium sp., Cricetidae y un Xenartro juvenil) y restos de Lama sp. Algunos de estos restos presentan señales de meteorización que los distinguen de los restantes restos óseos que conforman la colección, esto probablemente se deba a su exposición superficial tras la remoción para extraer los cuerpos momificados. También hay abundantes restos de frutos y semillas de tres especies de Prosopis sp. y un fruto con semillas de Tephrocactus sp.

El sector B2/B3/C2/C3 presenta un registro escaso hasta los $60 \mathrm{~cm}$ de profundidad compuesto por huesos de un mamífero mediano a grande cuya fragmentación intensa hizo imposible su reconocimiento, también hay restos de Lagidium sp. Se halló un endocarpo de Prosopis sp y una flor de cactácea. Entre los 60 y $70 \mathrm{~cm}$ (capa 6 y 7) de profundidad se hallaron una punta triangular de base recta y de lados convexos, talla bifacial y retoques a presión muy similar y de igual materia prima que la recuperada en C3, capa 8, junto a una preforma (posiblemente de una punta con morfología similar a la de la cuadrícula D2) con rasgos de rebaje bifacial trabajada en una cuarcita grisviolácea. En la cuadrícula C3 hasta los $60 \mathrm{~cm}$ de profundidad se recuperaron también endocarpos de dos especies de Prosopis sp., algunos con restos de epicarpo. Restos de Lagidium sp. con marcas de mordidas, astillas de hueso largo de mamífero grande termoalteradas y un canino de Pseudalopex gymnocercus o P. griseus (determinaciones realizadas por E. Tonni Museo de Ciencias Naturales de La Plata, según consta en etiqueta acompañante). Restos de insecto (Ortóptero) y una lasca secundaria de metacuarcita gris (mismo tipo 
que punta 2-204 y 2-205). A los $60 \mathrm{~cm}$. se recuperó una semilla de Tephrocactus sp. roída, restos de Lagidium sp y de Lama sp (vértebras, costillas, autopodio, hueso largo) con marcas de corte y de roído. Entre los 60 y $80 \mathrm{~cm}$. se produjo el hallazgo del E7, asociado al mismo se recuperó una rama mandibular y piezas dentales de Canidae indet. posiblemente Psendalopex culpaeus (zorro colorado). En este contexto se hallaron también restos de insectos, Lagidium sp, cricétidos, aves y Lama sp. junto a restos de otros de mamíferos grandes con marcas de corte y carbonización. Semillas de Tephrocactus sp y dos endocarpos de Prosopis sp. También se halló un fragmento de ocre rojo. Se recuperaron gran cantidad de lascas de diversas materias primas: tres lascas de rebaje bifacial, dos de basalto/metacuarcita negra (ninguna de las puntas recuperadas posee similar materia prima) y una de calcedonia/arenita verde; una lasca de desecho secundario de metacuarcita verde (mat. prima similar a la de la punta de la cuadrícula E1, capa 2) con marcas de lascado previo en cara dorsal y dos lascas de metacuarcita gris-marronácea, una partida por extracción, con filos potencialmente útiles.

Una punta triangular de basalto con base recta y lados convexos, talla bifacial, a presión fue hallada entre las costillas del E7.

La mayor concentración de restos de talla fue encontrada en las cuadrículas C3 y D3 evidenciando una posible área de talla con gran diversidad de materias primas y pasos en la cadena operativa.

Entre los restos hallados en asociación al cuerpo momificado se destaca un conjunto de fragmentos de cordones de dos y cuatro cabos que no superan los $9 \mathrm{~cm}$ de largo. Los mismos son de lana sin teñir y algunos presentan evidencias de nudos, posiblemente los mismos formaron parte del fardo funerario de la momia. Destaca también el hallazgo de una semilla de Phaseolus sp. , y un gancho de propulsor de hueso, posiblemente realizado en hueso de Cervidae debido al canal medular que lo cruza. Se halló también un ovario de Lobivia sp. y una aparente cuenta efectuada en una semilla o fruto 
indeterminado. También se recuperaron huesos de mamífero mediano-grande, posiblemente un artiodáctilo, y un coprolito.

La cuadrícula D2 corresponde al hallazgo del E3, destacándose un conjunto de cinco haces de gramíneas dobladas sobre sí mismas halladas a la altura de las vértebras cervicales, estas serían probablemente parte del acondicionamiento inhumatorio hecho para la depositación del cadáver. También se encontró un pequeño cordón de lana color castaño claro. En cuanto al material lítico se recuperó una preforma de posible punta triangular de base recta con dos aletas insinuadas y una punta con el extremo fracturado. Esta última posee adherido hacia el extremo y algo sobre los filos una sustancia castaño-oscura, fue recuperada de la consolidación debajo del E3, asociado -según información de libreta de campo- a un posible cúbito partido en su extremo distal. Lamentablemente este último hueso no lo hallamos en la colección.

Por lo tanto los sectores $\mathrm{B}, \mathrm{C}$ y D de la cueva corresponden a inhumaciones asociadas a puntas de flechas, fardos funerarios hechos en cuero y ajustados con cordones de lana, acondicionados con colchones de paja y cubiertos con maderas de cardón

Las cuadrículas E1, E2 y E3 corresponden a la entrada de la cueva, en el sector del hallazgo del esqueleto 5. En las primeras dos capas (hasta $20 \mathrm{~cm}$ de profundidad), correspondientes al hallazgo de los restos óseos humanos, se recuperaron restos de endocarpos y frutos de Prosopis sp. de al menos cuatro especies distintas, los endocarpos poseen restos de epicarpio y mesocarpio, un receptáculo de Lobivia sp., una semilla de Tephrocactus sp. y raíces de cactáceas. En la capa dos de E1 se halló dentro del fogón próximo a E5 una punta triangular de base recta, bifacial y con retoque a presión. También se recuperaron fragmentos de dos cordones de lana, uno de $9 \mathrm{~cm}$ y el otro de 15 $\mathrm{cm}$. En la primera capa de la cuadrícula E2 se hallaron tres fragmentos de cerámica que remontan entre sí, corresponden a una pieza de cocción 
reductora, superficie externa gris pulida y superficie interna alisada con restos de hollín, sin adherencias. En la capa dos se recuperó un tiesto de superficies interna y externa alisadas, no pulidas, de color más oscuro y factura algo más tosca que los tiestos de capa 1 y 4 . El tiesto de la capa 4 es de las mismas características que el de la capa 1, pero no remonta con el mismo. Asociado al mismo se recuperó un resto de cubierta seminal de Cucurbita sp. (A y B) junto a endocarpos de Prosopis torquata y P. chilensis/alba y a un fruto termoalterado de P. ferox. También un cordón de lana de $21 \mathrm{~cm}$ de largo y una punta triangular de base recta y lados convexos, talla bifacial y retoque a presión de la misma materia prima que la punta de la cuadrícula D2. En la capa tres de E1 y E2 se recuperaron también endocarpos de tres especies de Prosopis sp., restos de insectos y del esqueleto postcraneal de un ejemplar identificado como Lagidium sp.

El entierro del sector E también se asocia a puntas de flecha y al hallazgo de cordones, pero en este caso también se asocia a cerámica, por lo cual quedaría sin efecto lo enunciado por Núñez Regueiro (1974) en cuanto a que los restos cerámicos se encuentran en niveles superiores, sin relación con los entierros. Por el contrario, los mismos se hallaron a igual nivel o más profundos que el esqueleto 5. Los fragmentos de cerámica se asemejan en su acabado superficial y morfología a la del período temprano del sector norte del Valle Calchaquí, tal como los identificados por Tarragó en Campo Colorado (Tarragó 1974, 1996, Tarragó y De Lorenzi 1976).Por lo tanto estas ocupaciones se vinculan posiblemente al formativo temprano.

\section{C) Los restos vegetales}

Todos los restos vegetales de SSalLap20 se encuentran secos, sin que se hayan detectado la presencia de restos carbonizados, salvo algunos casos donde hay termoalteración, ya señalados. 
Resultaron muy abundantes los restos de Prosopis sp. La asignación a distintas especies fue en base a caracteres macroscópicos de los restos siguiendo a Burkart (1940, 1952, 1976a y b) Boelcke (1946), Solbrig y Cantino (1975) y Trobok (1985).

El fruto de Prosopis es una legumbre indehiscente clasificada por Burkart (1952:126, 1976) como un lomento drupáceo. El mesocarpo es dulce y comestible, el endocarpo es duro y segmentado en compartimentos que corresponden a cada semilla (Capparelli 2008). Este último debe ser removido para que ocurra la germinación de la semilla, lo cual ocurre a través de propagación endozoica (Trobok 1985, Solbrig y Cantino 1975, Campos y Ojeda 1997).

En Argentina el género Prosopis se distribuye entre $25^{\circ}-40^{\circ} \mathrm{S}$ a través de diferentes regiones biogeográficas como Puna, Monte, Espinal, Chaco y Patagonia (Palacios y Bravo 1981, Burkart 1952, Morello 1958) en las provincias de Jujuy, Salta, Catamarca, La Rioja, Tucumán, Santiago del Estero, San Juan y Mendoza (D’Antoni 1970, Burkart 1952, 1976). Su rango de distribución incluye zonas con una media de temperatura anual mayor a los $12^{\circ} \mathrm{C}$ y delimitado por isoyetas de 50 (por ejemplo en Puna) a $1000 \mathrm{~mm}$ (por ejemplo en Chaco). Las especies de Prosopis pueden ser freatófitas obligadas o facultativas, lo cual les permite sobrevivir en zonas áridas (Burkart 1976a, b, Cavagnaro y Passera 1993). La abundancia de estos restos se señala en los gráficos 1 y 2.

El consumo de cactáceas pertenecientes al género Tephrocactus fue constatada en varios sitios de diversa cronología en la provincia de Mendoza desde el período precerámico tal como lo atestiguan los restos de Jaguel III (Roig y Bárcena 1983). Este género es propio de las zonas puneñas y prepuneñas donde se dispone formando cojines apretados de hasta $60 \mathrm{~cm}$ de diámetro siendo sus frutos y tubérculos comestibles (Roig y Bárcena 1983). Se distribuye en el oeste de Argentina (provincias de Salta, Catamarca, oeste de 
Tucumán, La Rioja, Santiago del Estero, Córdoba, San Juan, San Luis y Mendoza), estas plantas crecen en laderas mas o menos suaves o en llanuras pedregosas o arenosas muy secas, entre los 500 y 2500 msm (Kiesling 1984) este hábitat coincide con el área de emplazamiento de SSalLap20.

En la colección se determinó un fruto completo conteniendo semillas y cerca de 98 semillas sueltas en distintos contextos (ver Anexo I). También se recuperaron restos de ovarios de Lobivia sp. y flores y espinas de cactáceas indeterminadas.

Lobivia ferox crece en una franja altitudinal muy estrecha entre los 3.700 y 4.000 m. Habita laderas de 20 a $30^{\circ}$ de inclinación, de orientación N, NE y E, en suelos de roca volcánica blanca, en grietas de rocas o en suelo abierto pedregoso. También se la encuentra bajo arbustos como Baccharis, Senecio, Fabiana. Comparte su hábitat con otras cactáceas como Echinopsis atacamensis y tres especies de Opuntia; O. echinaceae, O. ignescens y O. soehrensii. (Pinto 2002). Al igual que en el caso de Tephrocactus sp. el ambiente de distribución coincide con el de la cueva. Lobivia ferox es un cactus de grandes y hermosas flores, que produce un rico fruto comestible de un agradable sabor fresco, de pulpa blanca y semillas negras crujientes (Pinto 2002). Por lo que podemos pensar que estas especies de cactáceas estaban siendo consumidas por los antiguos habitantes de esta cueva.

La importancia de las cactáceas queda atestiguada también en los contextos funerarios de esta cueva ya que madera y fragmentos de corteza de especies columnares fueron empleadas en el acondicionamiento de los cuerpos.

Por último se hará mención a que varios de estos restos, incluyendo los macrorrestos de Cucurbita sp y Phaseolus sp. fueron extraviados en las instalaciones del Museo Arqueológico de Cachi, por lo cual no se pudo avanzar en el analisis microscópico de los mismos.

\section{Cronología}


Fragmentos del húmero del E7 fueron datados por AMS arrojando una edad radiocarbónica convencional de 9960+/-90 AP (AA82782). Este fechado resulta sumamente importante ya que ubicaría a las ocupaciones de Puente del Diablo como las más tempranas de los Valles Calchaquíes. Esta cueva posee evidencias de ocupaciones posteriores en la cerámica asociada al E5. Estos fragmentos cerámicos indicarían una ocupación correspondiente probablemente al formativo temprano, dada su similitud con la recuperada por Tarragó (1974, 1996, Tarragó y De Lorenzi 1976) en el sitio próximo de Campo Colorado.

\section{Sitios E1 Puente I y Barranca del Puente}

Estos sitios fueron estudiados a partir de los informes inéditos de la Lic. Flavia Carrión quien en la década de 1990 realizó prospecciones y excavaciones en el sector norte de los Valles Calchaquíes en el área próxima a la localidad de La Poma en busca de ocupaciones humanas tempranas en cuevas y aleros. El interés en estas investigaciones surge por ser próximas a la de Puente del Diablo. Gracias a la amabilidad de las Lic. Clara García, F. Carrión y Mirta Santoni pudimos acceder a los informes inéditos y gracias a las Dras. B. Ventura y V. Williams se pudo tener acceso a parte de la colección de estos sitios depositada en instalaciones de la Facultad de Filosofia y Letras (UBA, Buenos Aires).

Los datos volcados a continuación fueron obtenidos de los informes inéditos y anotaciones de campo cedidos desinteresadamente por la Lic. F. Carrión y de los informes depositados en el Museo Antropológico de Salta.

Tras prospecciones en quebradas laterales del valle Calchaquí (sector norte) se localizaron 27 sitios arqueológicos, de los cuales 12 corresponden a aleros y cuevas, en seis de los sitios se efectuaron sondeos habiéndose excavado cuatro 
(El Puente 1, Cardonal 2, Cueva Laime y El Puente 2). Se registraron evidencias de ocupación humana en cinco de los seis aleros sondeados. El sitio El Puente 1 se encuentra ubicado sobre el encajonamiento del Río Calchaquí que forma la colada basáltica de antiguas erupciones de los volcanes "Los Gemelos" (Campo Negro). Se trata de un pequeño refugio, formado por la caída de un bloque de la Formación Santa Bárbara (areniscas), se orienta al Este y cuenta con una superficie cubierta pequeña, de unos $7 \mathrm{~m}^{2}$. Se encuentra a $50 \mathrm{~m}$ del río y a una altura de $2950 \mathrm{msm}$. Como resultado de la excavación se detectaron 13 niveles de depositación. Las capas 1, 2 y del 5 al 10a presentan proporciones variables de fragmentos cerámicos, desechos de talla y escasos instrumentos líticos. Los restos óseos (camélidos y aves) son igualmente escasos y en su mayoría presentan una notable disgregación. Las capas 10b y 11 evidenciaron contextos acerámicos. En ellas se ha registrado la presencia de desechos de talla, que por sus características se relacionan probablemente con actividades de reducción final o de reactivación de instrumentos en vidrio volcánico, una materia prima no local. Los carbones extraídos de una estructura de combustión en la capa 11 fueron fechados en 3140+/-60 AP (Beta-81649).

En cuanto a las características de la ocupación de esta cueva en la capa 6 hay abundancia de lascas de retoque bifacial en obsidiana y de lascas planas, pero estas no habrían sido formas base debido a su pequeño tamaño (menor a 2 cm.) por lo que se asocian también a la confección de instrumentos. En la capa 7 aumenta la materia prima local (metacuarcita). Las estructuras de combustión son de escaso espesor y sin formatización por lo que las ocupaciones no fueron prolongadas. Si bien no se identificaron restos vegetales no se descarta el posible consumo de algarrobo ya que hay ejemplares en el área. Desde la capa 9b hasta la capa 7 aumenta la materia prima local (metacuarcita) lo que puede indicar una progresiva mayor permanencia en el sitio o que los sitios complementarios se encuentran en la 
zona donde esta materia prima es abundante y no en la zona de Saladillo. Esto se asocia además a una mayor aridez a partir de este nivel.

El sitio Barranca del Puente, próximo al anterior, presenta diferentes evidencias de ocupación. La relativa predominancia de puntas de obsidiana en la capa 1, el hecho de que se hallen fragmentadas o con sus filos embotados sugiere que el reemplazo de proyectiles pudo haber sido una actividad importante en este sito. Hay además gran cantidad de lascas de retoque bifacial en la misma materia prima por lo que los proyectiles de reemplazo habrían sido terminados en el sitio. Al no haber núcleos o lascas de extracción primaria junto al carácter no local de la materia prima se supone que las puntas habrían ingresado con cierto grado de formatización al sitio. La reactivación fue una actividad importante como lo indica la gran cantidad de desechos. El carácter conservado de este instrumento explicaría la ausencia de puntas enteras en el sitio. La abundancia de la obsidiana junto a la presencia de sílice sigue en la capa 2 junto a restos de azadas y conanas. No son claras la

relaciones cronológicas de este sitio con el anterior ya que no existen fechados del mismo.

A pesar de que en los informes de la Lic. Carrión se consigna la presencia de restos vegetales (semillas), los mismos no fueron detectados en el material depositado en las instalaciones de la Facultad de Filosofía y Letras (UBA).

\section{Pampa Grande}

El área se ubica en el departamento de Guachipas, Salta. Geográficamente corresponde a la serranía de Las Pirguas, la cual es una cadena oriental de la Sierra de Carahuasi y el límite oeste del bolsón de la Pampa Grande (Figura 3). Las cuevas se ubican entre 2500 y 3000 msm en las serranías de Las Pirguas y El Rodeo en la región recorrida por el río Grande de La Pampa, más específicamente entre los cerros Pirgua Grande, Pirgua Chica y el Alto del Rodeo ( $25^{\circ} 46^{\prime} \mathrm{S}$ y $\left.65^{\circ} 24^{\prime} \mathrm{O}\right)$ También se exploró la Quebrada de Lampazar, 
la cual se une a la de Las Cuevitas. Esta área corresponde a la porción de la Subárea de Selvas Occidentales adyacente a los valles Calchaquíes representando una zona de contacto entre la región Valliserrana y la de Selvas Occidentales (Baffi et al. 1996; Baldini y Baffi 1996; Baldini et al. 1998; Baldini et al. 2003). Pampa Grande se ubica en el Distrito de Selvas, que ocupa las llanuras al pie de montañas y cerros de los contrafuertes cordilleranos, el clima es templado y húmedo durante el verano con inviernos fríos y secos con abundantes nevadas, las cuales tornan inaccesibles a las cuevas entre mayo y fines de septiembre (Oller et al. 1984-1985)

\section{Antecedentes de trabajos en la zona y la expedición del Museo de La Plata}

Las primeras exploraciones de la zona fueron llevadas a cabo por Ambrosetti (1906) quien investiga al noreste de los cerros Pirgua Grande y Pirgua Chica, en cotas más bajas (zona llana) encontrando cementerios de las culturas Candelaria y Santa María (González 1972, Baldini et al. 2003).

Casi cuarenta años después Aparicio recorre abrigos rocosos situados mas al sur y realiza someras excavaciones en la cueva El Pilón recuperando restos humanos momificados y restos de vegetales junto con ollas usadas como urnas funerarias, recuperando diez cráneos y ocho mandíbulas estudiadas por Constanzó (1941) y restos vegetales estudiados por Hunziker (1943), lamentablemente Aparicio sólo publica un breve artículo en el diario (Aparicio 1941) (Baldini et al. 2003) En opinión de González (1972) la alfarería hallada por Aparicio correspondería a Tafí II

Entre 1969 y 1971 (abril a mayo) se reanudan las exploraciones en esta zona a cargo del Dr. A.R. González, auxiliado por Domingo García, técnico de la División Arqueología del Museo de Ciencias Naturales de La Plata y por José Togo, estudiante de arqueología en ese entonces (González 1972, Baffi et al. 1996, Baldini et al. 1998). 
Esta expedición realiza las primeras excavaciones sistemáticas y extensivas en varias cuevas saqueadas previamente por aficionados (González 1972):

Cueva Los Aparejos: se ubica en el cerro Pirgua Chica a unos 8-9 km al SSO de la estancia de Pampa Grande. Se encuentra emplazada en una quebrada afluente al río Grande de la Pampa, a unos $80 \mathrm{~m}$ sobre el nivel de su cauce y a $400 \mathrm{~m}$ de la cumbre (Baldini y Baffi 1996; Baffi y Torres 1996; Baldini et al. 1998). Posee $60 \mathrm{~m}$ de largo y la entrada, con forma de gran arco se orienta al norte, en su interior hay desniveles pronunciados y acumulaciones de rocas por el desprendimiento de paredes y techo. (González 1972, Baldini et al. 1998). Se practicaron excavaciones en tres sectores, en uno de los cuales se encontraron abundantes restos óseos humanos quemados (Baffi y Torres 1996). Se identificaron contextos de ocupación y funerarios (González 1972).

Quebrada de las Cuevitas (faldeos del alto del Rodeo):

Cueva El Litro: ubicada 15-16 km en línea recta de la estancia de Pampa Grande, sobre un faldeo del cerro El Rodeo, a 50-60 m sobre el río de la quebrada de Las Cuevitas (Baffi y Torres 1996). Entrada pequeña en relación al tamaño del abrigo que se orienta al norte, interior oscuro y con gran declive en la parte media (Baldini et al. 1998). El nivel de ocupación es de reducida potencia (Baffi y Torres 1996). La zona próxima a la entrada correspondería a una ocupación temporaria, habiendo otra zona de entierros (González 1972).

Caverna II: a $12 \mathrm{~m}$ por encima de El Litro, un poco desplazada hacia el oeste (Baffi y Torres 1996). Posee la entrada orientada hacia el norte (Baldini et al. 1998). Cuenta con malas condiciones de habitabilidad por lo empinado del faldeo, el reducido talud, escasa luz y por la distancia hasta el agua, de allí que su uso sea prácticamente funerario (González 1972; Baldini et al. 1998). Las 
condiciones de sequedad optimizaron la conservación de los restos (Baldini et al. 1998)

Caverna III: algo al sudoeste de la anterior y a $25 \mathrm{~m}$ por encima, con gran espesor de sedimentos y abundantes restos culturales (Baffi y Torres 1996). Abertura bastante amplia contando con mucha iluminación. En el lado sur hay una pirca formada por bloques de arenisca paralela a la entrada. Hay indicios de ocupación temporaria, pero es fundamentalmente funeraria (Baldini et al. 1998)

Caverna V: situada a la entrada de la Quebrada de Las Cuevitas, frente a la Quebrada del Lampazar con abertura orientada hacia la misma. En la entrada hay un pequeño talud de $3 \mathrm{~m}$ que desciende abruptamente hacia la mencionada quebrada. No hay evidencias de ocupación temporaria, pero hay conanas tanto sueltas como en bloques de piedra (Baldini et al. 1998)

\section{Quebrada de Lampazar:}

Esta quebrada posee paredes abruptas y verticales con varios abrigos de difícil acceso (Baldini et al. 1998)

Caverna I: entrada amplia hacia el norte $(2,5 \mathrm{~m}$. de ancho y 1,5 m de altura) con entierros depositados directamente sobre la superficie del suelo (Baldini et al. 1998)

Caverna IV: se ubica en la margen derecha de la quebrada, es un conjunto de abrigos con una entrada principal y varias secundarias. Se realizaron sondeos estratigráficos a ambos lados de la entrada de la galería principal. La abertura de la izquierda corresponde a un pequeño abrigo cuya entrada estaba pircada 
hasta 1,15 m. Posee evidencias de ocupaciones alternadas durante un cierto tiempo además de su uso funerario (Baldini et al. 1998).

Las excavaciones más extensas fueron realizadas en El Litro, Los Aparejos, Caverna II y III (Baldini y Baffi 1996)

\section{Datos ambientales y paleoambientales}

En las zonas elevadas el clima es templado y húmero durante la temporada estival, mientras que los inviernos son fríos y secos con abundantes nevadas debido al deslizamiento del aire frío cordillerano, por lo que las cuevas permanecen inaccesibles por la nieve desde mayo hasta fines de septiembre (Oller et al. 1984-1985). D'antoni y Togo (1975) analizaron 5 niveles de sedimento de El Litro, hallando representantes de los dos distritos que Cabrera (1976) incluye en la Provincia de las Yungas (distrito de los bosques montanos y de las praderas montanas). Dichos autores consideran que los hallazgos reflejan el momento en que los Bosques Montanos ascienden por el gradiente topográfico acercándose a la cueva, lo cual puede interpretarse como un momento de mayor temperatura media (Oller et al. 1984-1985).

\section{Los restos recuperados}

De las excavaciones se obtuvieron gran cantidad de restos humanos y culturales, siendo excepcional su estado de conservación así como también la gran diversidad de los mismos:

\section{Cerámica}


Destacan las ollas de gran tamaño (algunas de hasta casi un metro de alto) globulares, de base redondeada y generalmente con cuello (en varios casos la separación entre cuello y cuerpo es bien marcada y presenta un reborde saliente), son mayormente grises o gris-negras, alisadas o escasamente pulidas (Baldini et al. 2003; Baldini et al. 1998). Poseen escasa decoración que consiste en incisiones en la zona del cuello y tiras agregadas en la unión cuello-cuerpo que pueden presentar depresiones circulares. Dos casos excepcionales donde, mediante modelado e incisión, se representó una cara antropomorfa en el cuello (González 1972; Baldini et al. 2003). Las ollas se encontraron asentadas sobre paja y piedra o dispuestas en forma invertida con la base rota, posiblemente para introducir los cuerpos, muchas reparadas y atadas con cuerdas. Varias urnas funerarias se encontraron cerradas con piedras, musgo o fragmentos de alfarería a veces con agregado de barro para sellarlas (Baldini et al. 2003). Numerosos ejemplares fueron atados con sogas y cubiertos con una sustancia blanca calcárea, esta sustancia se usó también para cubrir los restos de los individuos inhumados, para rellenar los diseños grabados o incisos de algunas piezas depositadas como ajuar fúnebre, cubriendo las paredes internas de las urnas y en alguna oportunidad se depositaron en el interior de las urnas como panes (Baldini et al. 1998). También se encontraron piezas de menor tamaño como ajuar (en algunos casos con vegetales en su interior) las que, de acuerdo con la morfología y técnicas de manufactura, se pueden clasificar en dos tipos:

-gris o negra, superficie alisada o pulida, son generalmente pucos, vasijas y jarros. Generalmente decoradas con diseños incisos geométricos (Baldini et al. 2003).

-pintura roja sobre superficie ante o rojiza (Baldini et al. 2003), son mayormente vasijas y jarros. 
Se hallaron también ejemplares con una perforación circular en la porción central de la base realizados sobre la pasta fresca ("agujero de muerte") (Baldini et al. 1998).

La cerámica Candelaria se clasificó de acuerdo con la propuesta de Heredia (1970) en las fases Molleyaco (Candelaria III 400-700 DC) y Rupachico (Candelaria IV 700-1000 DC), contemporáneas a Ciénaga y Aguada, habiendo también ejemplares de momentos previos (Baldini et al. 2003; Baldini y Baffi 1996). Por lo tanto se considera que esta localidad representaría ocupaciones Candelaria de entre 500 y 600 DC (Baldini y Baffi 1996, Baldini et al. 2003). Se identificaron piezas con relaciones estilístico formales con Ciénaga en la Caverna I y III y otras con Aguada en la Caverna I y en El Litro, entre estas últimas hay piezas negras bruñidas con decoración grabada (afines a Aguada del Ambato aunque de paredes más gruesas y pesadas) o grises grabadas; en ambos casos hay piezas halladas como ajuar en el interior de urnas funerarias (Baldini et al. 2003). Entre las piezas con relaciones estilístico formales con Aguada, Baldini y colaboradores (2003) mencionan un jarro pintado en rojo sobre fondo crema $\left(\mathrm{N}^{\circ}\right.$ 50146) que fue colocado junto al niño del entierro $\mathrm{N}^{\circ}$ 38 de la Caverna II de la Quebrada de Las Cuevitas. La revisión de la pieza en la colección indica que la misma es estilo Vaquerías.

Entre los escasos ejemplares con decoración en el interior, aquellos que presentan una línea incisa alrededor del borde interno, se asemejan a las piezas que aparecen con frecuencia en el Valle de Lerma (Escobar 2008), y que identifica también Heredia (1971) en el sitio Amblado (Salta), asociado en superficie a fragmentos Candelaria y Aguada pintados en rojo y negro (Baldini et al. 2003).

Por lo tanto la evidencia cerámica indica influencias desde el área Valliserrana que se plasma en manifestaciones cerámicas locales.

\section{Restos humanos}


De las excavaciones se obtuvieron gran cantidad de restos humanos ya sea momificados, como entierros primarios o bien secundarios (Baldini et al. 2003). El número exacto de cuerpos no está claro en la bibliografía, sobretodo debido a que durante el período en que la colección arqueológica permaneció en el Museo de La Plata sin la supervisión del Dr. González, los restos óseos fueron tratados como osario, perdiéndose la unidad de esqueleto (Baffi y Torres 1996) En su publicación, González (1972) informa el hallazgo de 80 enterratorios que totalizan 120 individuos. Baldini y Baffi (1996) y Baldini et al. (1998) mencionan esta última cantidad aclarando que 15 son cadáveres momificados. Baffi et al. (1996) a través del conteo de cráneos totalizan 80 individuos, 55 adultos y 25 subadultos (también se mencionan estos datos en Baldini et al. 2003 y en Torres y Baffi 1996), pero por esqueleto postcraneal se llegó a un NMI de 85 adultos: 42 masculinos y 43 femeninos. Pero en otras publicaciones se mencionan restos esqueletales de 75 individuos adultos (34 varones y 37 mujeres) y 24 ejemplares de edades pre reproductivas (Baffi y Torres 1996, Baldini et al. 1998)

Un aspecto sumamente interesante es el que refiere a las deformaciones craneales, de acuerdo con Baffi et al. (1996), las mismas se distribuyen de la siguiente forma:

-29 adultos maduros femeninos: 15 con deformación tabular erecta -26 adultos maduros masculinos: 17 con deformación tabular erecta -25 subadultos (habría más, de acuerdo con las libretas): 13 con deformación tabular erecta y 2 con deformación tabular oblicua (en el grupo de edad de hasta 6 años, Torres y Baffi 1996)

Se cuenta con un muy buen registro en cuanto a las paleopatologías presentes en esta población. Entre las mismas, en la población de adultos, se registraron patologías artrósicas en miembros superiores, patologías infecciosas (periostitis en $9 \%$ de tibias y $7 \%$ de radios, a veces asociados con fracturas) y 
entre las patologías dentarias: caries, tártaro, abscesos, retracción ósea del alveolo, pérdida de dientes ante-mortem y desgaste marcado en cara lingual anterior de molares y premolares (Baffi et al. 1996)

El registro de indicadores de carencias nutricionales fue también abundante: criba orbitalia en 8 de 27 individuos femeninos, en 8 de 23 masculinos y en 14 de 23 subadultos; hiperostosis porótica (tanto estado activo como recuperado): en 9 de 27 individuos femeninos, en 14 de 23 masculinos y en 12 de 23 subadultos; estos dos indicadores señalan la carencia de hierro (Baffi et al. 1996). Hay 22 ejemplares adultos-maduros de ambos sexos con evidencia de hundimiento de hueso en senos maxilares, lo cual, junto con engrosamiento de diáfisis de tibias, podría estar indicando carencia de vitamina C y D (Baffi et al. 1996). El dimorfismo sexual no muy marcado de esta población estaría posiblemente relacionado a estrés nutricional prolongado y severo (Baffi et al. 1996)

En cuanto a la relación entre estos indicadores y el tipo de deformación se vió que esta última variable no es significativa entre las mujeres de más de 30 años, pero en ejemplares deformados de hasta 20 años hay mayor incidencia de anemia y más elevada perdida dental ante mortem (Torres y Baffi 1996). En el caso de los hombres con deformación, la mayor mortandad se da entre los 20 y 30 años con mayor hiperostosis porótica y problemas dento bucales, los que superan esta edad poseen también hiperostosis porótica pero mayor criba orbitaria (Torres y Baffi 1996). Por lo tanto la anemia es mas frecuente entre individuos deformados (Torres y Baffi 1996).

Los indicadores de violencia son abundantes en esta población y se ha detectado una alta frecuencia de golpes en el cráneo comparada a los registros para el resto del NOA (Baldini et al. 1998). El registro de los mismos es de 10 cráneos sobre 23 adultos masculinos, 11 de 27 adultos femeninos y 3 de 24 subadultos, registrándose hundimientos circulares en los parietales, rotura y golpes en huesos nasales, etc., habiendo incluso ejemplares con varios golpes 
(Baffi et al. 1996). En relación a la violencia vinculada a la edad no se registraron golpes en ejemplares de hasta 20 años (Torres y Baffi 1996), habiendo un caso de golpes intencionales causantes de muerte en un niño de 6-12 años no deformado y dos casos en ejemplares de misma edad con deformación tabular erecta (Baldini et al. 2003). En muestras de subadultos no se detectaron diferencias por deformación, sino que los episodios de agresión se vinculan mas con el rango etario (entre 6 y 12 años) (Torres y Baffi 1996) En el caso de los adultos la presencia de golpes en cráneo es más abundante en aquellos con deformación tabular erecta y más abundante aun entre ejemplares masculinos de más de treinta años respecto de mujeres de menos de veinte años (Torres y Baffi 1996; Baldini et al. 2003).

Entre las causas no violentas de muerte se detectó septicemia por infección en el maxilar superior (posibles casos de mieloma) y osteomas (Baffi et al. 1996) La expectativa de vida promedio es de 22 años, registrándose la mayor mortandad en el grupo de 20-30 años, principalmente entre las mujeres con deformación (Baffi et al. 1996, Torres y Baffi 1996).

Resulta de gran interés la vinculación de ciertas patologías a posibles actividades recurrentes que estas poblaciones desarrollaron en el pasado. Así, las patologías artrósicas indican el uso intensivo de miembros superiores (con uso exigido de la articulación del codo), los que muestran además el mayor porcentaje de fracturas, inserciones marcadas -con desarrollo de crestas óseas en antebrazo- y casos de dislocación de clavículas (Baffi et al. 1996) Estas últimas se asocian a desgarramiento por levantar objetos pesados (piedras, troncos) y las crestas en zona de inserción de músculos flexores de los dedos se relaciona a tareas cotidianas de amasado u otra actividad que involucra un movimiento flexor de los dedos (Baffi y Torres 1996). En miembros inferiores aparecen patologías vinculadas a transitar por terrenos irregulares: exigencia en articulación de rodilla con inserción muscular marcada en el caso de los gemelos (Baffi et al. 1996) Se identificaron exigencias de la región coxo 
femoral resultado de actividades cotidianas que implican estar acuclillado, las evidencias en huesos coxales también están vinculadas al levantamiento de peso (Baffi y Torres 1996).

Modalidades de entierro.

Se registraron distintas modalidades inhumatorias cuya distribución por cueva es diferencial (Gráfico3). Ente dichas modalidad se cuenta con:

- Entierros directos: directamente en tierra, posición extendida o con piernas flexionadas, se da mayormente en adultos pero también en niños, fetos y adultos con niños (Baldini y Baffi 1996). Hay casos sin ajuar y a veces se colocó un gran fragmento de alfarería sobre el cuerpo (Baldini y Baffi 1996). Esta modalidad de entierro es casi exclusiva en las cavernas de la quebrada de El Lampazar con una excepción en la caverna IV (Baldini y Baffi 1996, Baldini et al. 2003) (recordar que en El Lampazar hay abundancia de cerámica afín a Cienaga y a Aguada). En Los Aparejos esta modalidad se encuentra en casi igual proporción que los entierros en olla, en la caverna $\mathrm{V}$ las inhumaciones directas están en las capas superiores y por debajo se hallaron entierros de adultos y niños en grandes ollas (Baldini y Baffi 1996)

Existen casos también de entierro secundario en tierra (varios en El Lampazar) y en Los Aparejos hay paquete funerario con inhumación de adulto y niño (Baldini y Baffi 1996).

-Entierros en ollas: Mayormente en niños, pero también en adultos, fetos, adultos y niños, adultos y fetos y niño y feto (Baldini y Baffi 1996). Hay individuales, de dos o tres individuos y múltiples (de 5 a 8 individuos, en este caso hay solamente de adultos y de adultos y niños) con o sin ajuar (Baldini y Baffi 1996). Puede haber individuos completos o partes de ellos, hay 
evidencias de cortes en los huesos y desmembrado de cuerpos tras su momificación (Baldini y Baffi 1996). Ambas costumbres se registraron incluso en una misma olla: en el hallazgo 16 (El Litro) se recuperó una primera inhumación en el fondo de la olla, por encima sedimentos, por encima un individuo desmembrado aunque articulado y por encima uno articulado, sin cráneo y en posición flexionada (Baldini y Baffi 1996).

-Entierros en cista: Es exclusiva de Los Aparejos, donde se halló un niño y un adulto (por separado) ambos flexionados y sin ajuar. El adulto se halló en un cista rectangular formada por piedras chatas puestas de canto, con tres lajas a modo de tapa sobre cabeza y torax del cuerpo. La cista del niño esta constituida por cuatro lajas y una para cubrir (Baldini y Baffi 1996).

-Incineración: Exclusiva de Los Aparejos, consiste en un sector del abrigo de $2 \mathrm{~m}$ de diámetro y $0.30-0.40$ de espesor donde se hallaron fragmentos de huesos de adultos y subadultos calcinados, cenizas y carbón, no se halló alfarería asociada pero sí lo que probablemente serían restos de ajuares: fragmentos quemados de cestos, tejidos, cuentas de collar y parte de un brazalete de cobre, por debajo había una capa de paja carbonizada bien conservada (Baldini y Baffi 1996).

La relación entre estas distintas modalidades de entierro no está del todo clara. La modalidad de entierro de adultos en urna es propia de Candelaria y el entierro directo y en cistas se da en Aguada (González 1998). Esto último es sugestivo en cuanto al tipo de influencia que hubo en el área, máxime si tenemos en cuenta que en la quebrada de Lampazar, donde se hallaron piezas cerámicas con afinidades estilísticas con Aguada, son casi exclusivos los entierros directos. Una primera hipótesis seria que esto esté representando dos momentos de ocupación. Si tomamos en cuenta la evidencia de la Caverna V ya mencionada podemos pensar en una primera ocupación Candelaria seguida 
por otra Aguada, pero el hallazgo 11 de El Litro muestra lo opuesto, habiendo un entierro directo por debajo de uno en olla. La otra única entidad que registra entierros directos es San Francisco. Si bien no se han identificado restos de esta entidad en Pampa Grande, sí se han hallado sus restos junto a los del Valle de Lerma (Escobar 2008) los cuales guardan relación con dicha localidad arqueológica.

A las modalidades antes descriptas se cuenta con indicios de sacrificios vinculados al ritual mortuorio como el caso de niño inhumado en urna que presenta fractura de cráneo y extremidades y un esqueleto de adulto depositado directamente en tierra, al que le falta el cráneo y fue seccionado a la altura de la octava vértebra lumbar (Baldini et al. 1998)

Tras analizar los contextos de las cavernas II y III Baldini y colaboradores (2003) detectan que hay entierros sin ajuar o con ajuar escaso se da en inhumaciones de adultos o adultos y niños, en tanto los ajuares diferenciales se dan en estos casos, pero también en el caso de niños solos. En opinión de Baffi y Baldini (1997) esto último puede indicar una incipiente jerarquización. Niños pequeños con ajuar diferencial indicaría incluso status heredado.

\section{Restos culturales.}

Se hallaron cestos decorados o no conteniendo en varias oportunidades ofrendas vegetales, también adornos de plumas, narigueras de cerámica, etc. (Baldini et al. 2003) En su única publicación sobre esta localidad González (1972) destaca el hallazgo de cestos fabricados con técnica de aduja (tan apretada que uno aún retenía agua al ser hallado) y otros de tipo "wicker", textiles de lana burdos de un solo color y casos de tejidos polícromos de factura más compleja, un colgante oval de oro con una cruz de malta grabada y unos pocos anillos de cobre (posiblemente importados desde el NOA), hachas pulidas con cuello completo, un kero de madera, una bola de piedra 
perfectamente pulida de $12,5 \mathrm{~cm}$ de diámetro, un espejo de galena en su marco de madera tallado, un adorno pulido en crisocola, varias cuentas de malaquita o turquesa, una valva de un gran gasterópodo terrestre con tubo adosado posiblemente para aspirar alucinógenos y valvas de Oliva sp. provenientes del Atlántico, finalmente menciona "Arcos simples con cuerda vegetal y flechas de puntas de madera; solo un caso lleva punta de piedra" (González 1972:391)

\section{Dieta}

González derivó las muestras vegetales para que fueran identificadas por reconocidos expertos en distintos taxa. Así, T. Whitaker analizó los restos de cucurbitáceas, Burkart los de leguminosas, A. Krapovickas los de maní y a E. Zardini los de tubérculos. De los informes correspondientes a estos taxa solo pudimos acceder al de T. Whitaker gracias a la amabilidad del Dr. González y de la Lic. M.D. Arena, el cual analizaremos en detalle en la sección correspondiente a cucurbitáceas. En su publicación, González (1972) menciona la presencia de dos variedades de porotos (Phaseolus vulgaris y $P$. lunatus), dos de zapallos (Cucurbita maxima y C. andreana), maní de una variedad común en la costa peruana (Arachis hirsuta), Lagenaria siceraria y tubérculos.

Señala también la presencia de gran cantidad de restos de algarrobo a pesar de que los árboles se hallan bastante alejados y a muchas horas de camino de las cuevas (González 1972)

El análisis de coprolitos humanos recuperados en estratigrafía y en urnas confirma el consumo de maíz, cucúrbitas, porotos y restos de hueso de mamíferos y proteína animal (Hall 1975 en Baldini et al. 2003). El estudio específico de restos vegetales de esta localidad estuvo a cargo de M.L. Pochettino (1985) quien identificó en las distintas cuevas y niveles que las componen restos de diez especies silvestres: semillas de Acacia aroma Gill. Sp. 
Hook. Et. Arn, frutos de Acacia caven (Mol.) Mol., semillas de Canna compacta (?) Resc., racimo de frutos de Dioscorea glomerulata Hauman, fragmentos de frutos y endocarpos de Geoffroea decorticans (Hook. Et Arn.) Burk., endocarpos y fragmentos de legumbres de Prosopis alba (?) Griseb., cápsulas y racimos de frutos de Puya harmsii (Castell.) Castellanos, capítulo fructificado de Viguiera tucumanensis (Hook et Arn.) Griseb. var. dioscoidea (Blake) Cabr. y fragmentos de endocarpos de Zisyphus mistol Griseb. Entre las especies domesticadas se identificaron restos de frutos y semillas de Arachis hypogaea L., fragmentos de pericarpios, semillas y pedúnculos de Cucurbita maxima Duch. y Cucurbita sp., fragmentos de frutos de Lagenaria siceraria (Mol) Standl., fragmentos de frutos y semillas de Phaseolus vulgaris L. junto a vainas con dehiscencia espiralada del tipo presente en $P$ vulgaris var. aborigneus Burk. ex Burk., una semilla de $P$. lunatus L. var. macrospermus Benth. y mazorcas y granos de Zea mays L.. Tiempo después Miante Alzogaray y Cámara Hernández (1996) estudiaron un grupo de maíces reconociendo representantes de las razas actuales "Culli" (hoy día empleada casi con exclusividad para la fabricación de chicha morada), "Chullpi”, "Chaucha", "Amarillo", "Pisingallo", "Azul”, "Capia rosado" y "Capia púrpura", estas dos últimas con posible origen en la raza "Capia blanco" introducida desde Bolivia al igual que la raza "Azul". Si bien los autores no indican contexto puesto que los mismos estaban removidos, el análisis de la colección permitió constatar que al menos dos de las seis muestras proceden del sector III de Los Aparejos, una de la cuadrícula E2 a $60 \mathrm{~cm}$. de profundidad y la otra de la cuadrícula F2 a $25 \mathrm{~cm}$. Finalmente se reportó la presencia también de restos "yacon" Smallanthus sonchifolium, (sub Polymnia sonchifolia) por Zardini (1991).

D'Antoni y Togo analizaron 30 coprolitos de camélidos provenientes de estratigrafía y ollas selladas con tapa (D'Antoni 2008) de los cuales seis eran ofrendas funerarias halladas en urnas selladas de Caverna II de Quebrada de Las Cuevitas (Baldini et al. 1998). La presencia de Zea mays en dichos 
coprolitos indicaría el cultivo local de esta especie (Baldini et al. 2003). Por otro lado el análisis de coprolitos de murciélago de Los Aparejos realizado por estos investigadores mostró que la máxima frecuencia correspondía a Chenopodiaceae/ Amaranthaceae (Baldini et al. 2003). Esta información se relaciona con los hallazgos realizados por Aparicio. Hunziker (1943) realizó el análisis de restos vegetales hallados en una urna funeraria (totalizando 270 grs.) identificando restos de Chenopodium quinoa (Willd.), Chenopodium sp., Amaranthus sp., Amaranthus caudatus Linn. var. leucospermus Thell. y Amaranthus caudatus Linn.,var. alopecurus (Moq.). Esta última variedad presenta testa negra y borde sub agudo "idéntica a la de las especies salvajes de Amaranthus" (Hunziker 1943: 149). En este sentido, también habría ejemplares de "ataco y ajara, dos comunes malezas de los cultivos del noroeste argentino" (ídem) que solo pudo determinar a nivel de género (Chenopodium sp y Amaranthus sp). Finalmente otra semilla no identificada taxonómicamente sería también, en opinión del autor, una maleza de cultivo. También identificó nueve marlos de Zea mays los cuales son de pequeño tamaño (3 a $7 \mathrm{~cm}$.) sugiriendo que se trataría de la subespecie microsperma Koernicke (Hunziker 1943). Por último se menciona también la presencia de una única semilla de Phaseolus vulgaris de 1,2 cm de largo y 0,7 de ancho (Hunziker 1943).

Retomando el análisis de los coprolitos de camélidos realizados por D’Antoni y Togo vemos que se obtuvieron dos conjuntos diferentes. Uno coincide con la dieta de un herbívoro silvestre que se alimenta en los prados locales, el otro conjunto destaca con un $67 \%$ del polen correspondiente a Plantago sp., una maleza de los cultivos (D’Antoni 2008). A este espectro polínico poco diverso se suma la ausencia de plantas cultivadas como el maíz, lo cual lleva a pensar en animales que, si bien se alimentaban de malezas, tenían vedado el acceso a los cultivos. Finalmente los autores concluyen provisoriamente que "había animales salvajes, tal vez guanacos, que visitaban los abrigos rocosos en primavera, buscando refugio en las noches frescas. Había también animales 
domésticos (posiblemente llamas) que comían preferentemente malezas agrícolas" (D’Antoni 2008: 124). Este último conjunto de coprolitos fueron los hallados en las urnas funerarias, lo cual podría indicar que los excrementos de los animales domesticados estaban siendo elegidos especialmente para ser colocados como ajuar u ofrenda fúnebre debido a que, en opinión de D’Antoni (2008), al emplearse como abono indicaban riqueza. La inclusión de estos coprolitos de animales domesticados como ajuares, junto a la inclusión de restos óseos y vegetales en los mismos, sugiere un vínculo entre una posible jerarquía hereditaria en Pampa Grande y las actividades productivas desarrolladas por sus antiguos pobladores. Otro dato que se desprende del polen hallado en este conjunto de coprolitos es que los ritos fúnebres tuvieron lugar en primavera (Oller et al. 1984-1985). Por último la presencia de polen de "malezas" indicaría áreas cultivadas próximas a las cuevas, las cuales no fueron detectadas por medio de rasgos superficiales.

\section{Interpretaciones}

Los estudios físicos demostraron que la población incipientemente jerárquica de Pampa Grande sufría de estrés nutricional prolongado y severo, la evidencia de golpes indica una situación generalizada de tensión grupal o intergrupal, lo cual se relaciona con ocupaciones emplazadas en cuevas de difícil acceso y la presencia de cerámica Aguada en versiones locales y sin la representación del felino distintivo de dicha entidad: "una posible hipótesis que explicaría la situación de estrés social y nutricional de la población de Las Pirguas sería la presión ejercida por las sociedades Aguada que habitaban el valle de Ambato durante la época de ocupación de estos sitios, quienes les habrían limitado el acceso a los recursos disponibles. En esta relación de conflicto los grupos que habitaron estos sitios, si bien modificaron algunas pautas a partir del contacto, intentaron preservar su identidad al no incorporar 
la iconografía que denota la pertenencia a otro grupo social, y además al demarcar diferencias respecto a ese grupo, pudiendo obstaculizar la ocupación efectiva del territorio por parte de las sociedades Aguada." (Baldini et al. 2003: 146).

Análisis de la Colección arqueológica de la localidad de Pampa Grande (Departamento científico de Arqueología. Museo de Ciencias Naturales de La Plata).

Lamentablemente y pese al permiso expreso manifestado por el Dr. A.R. González no se pudo tener acceso a las libretas y notas de campo, por lo tanto la información volcada en este apartado se desprende exclusivamente del análisis de los restos que conforman la colección arqueológica y de las etiquetas originales que acompañan al material. El trabajo de registro de esta colección fue hecho en conjunto con la Lic. M.D. Arena. Las figuras 9 y 10 muestran los ejes de coordenadas empleados para la excavación de las cuevas Los Aparejos y El Litro según se deduce de la información contenida en las etiquetas que acompañan al material arqueológico en depósito.

En este apartado no se analizan los restos óseos humanos ni la cerámica, salvo en sus relaciones contextuales, dado que han sido los restos ya estudiados en las publicaciones antes citadas.

Restos óseos animales.

Hasta el presente no existen datos publicados acerca de los restos animales presentes en Pampa Grande. Se analizó la totalidad de los restos óseos presentes en la colección, los cuales fueron identificados taxonómicamente por el Sr. Sergio Bogan. Los restos más abundantes corresponden a Lama sp. habiéndose identificado tanto ejemplares adultos como juveniles en las cuevas Los Aparejos, caverna III y en El Litro. En esta última los restos de Lama sp. 
se encuentran siempre asociados a restos humanos que también pueden ser adultos o juveniles. En dicha cueva se identificaron además restos de roedores: cricétidos y un ejemplar afín a Lagidium sp. En Los Aparejos se identificaron los mismos taxa pudiendo estar o no acompañados por restos óseos humanos. También se identificaron restos de Iguanide indet. y de aves. En cuanto a las asociaciones con restos humanos llama la atención el hallazgo en la cuadrícula 3 de restos momificados, restos óseos humanos correspondientes a un adulto senil y placas cefálicas articuladas de Dasypodidae. Consideramos que estos últimos pudieron haber sido colocados como ajuar, no así los restos de Rodentia que acompañan a los restos óseos humanos de la olla $\mathrm{N}^{\circ} 1$ recuperada en el sector II que pueden corresponder a un animal que ingresa a dicho recipiente funerario tras su depositación. En el hallazgo $\mathrm{N}^{0} 7$ vemos la asociación también entre restos de óseos humanos de un niño y de un neonato de Lama sp. Esto es particularmente interesante ya que, como vimos, los niños fueron sepultados con ajuares diferenciales en esta localidad, la depositación de un neonato de Lama sp junto a un infante podría estar indicando prácticas sociales de manejo de los camélidos por grupos o líneas familiares. Esto guarda relación también con la depositación de coprolitos de camélidos domesticados exclusivamente como acompañamiento mortuorio en las urnas funerarias, ya comentado. La presencia de ejemplares juveniles y neonatos de Lama sp. indicaría también el manejo de animales en cautiverio (Dransart 1999).

En la caverna III, además de huesos de ejemplares adultos y juveniles se hallaron restos de Pimelodus sp. cff. P. albicans ("bagre blanco"). Este hallazgo se suma al de restos de una vértebra caudal de un osteictio aff. Siluriforme en la cuadrícula 1 de El Litro. Esto indica el aprovechamiento de recursos hídricos que podrían corresponder al curso del río Grande de La Pampa, próximo a las cuevas. 
Finalmente consta en etiquetas junto al material restos de un cráneo de Canidae el cual fue extraído de la colección para su análisis.

\section{Restos malacológicos.}

La mayoría de las valvas no identificadas taxonómicamente fueron halladas en Los Aparejos, cinco de ellas asociadas a un cuerpo momificado depositado en una gran olla Candelaria con decoración antropomorfa en cuello (Hallazgo $\mathrm{N}^{\mathrm{o}}$ 8 , olla 50186) y otros en la olla $\mathrm{N}^{\circ} 1$. Hay un solo ejemplar en la capa 2 de la cuadrícula 1 de El Litro. A estos se suman los restos de Oliva sp. y los empleados para confeccionar artefactos para consumo presumiblemente de alucinógenos mencionados por González (1972)

\section{Insectos.}

El hallazgo más llamativo es un collar confeccionado con más de cien exoesqueletos de escarabajos depositado como ajuar en la urna $\mathrm{N}^{\circ} 7$ de El Litro. En otro contexto funerario se hallaron restos de insectos en un cesto depositados en el interior de la urna $\mathrm{N}^{\circ} 70$ en la caverna V. Se encontraron también restos de Ortópteros.

\section{Cuentas.}

Las mismas forman mayormente parte de los ajuares funerarios, se hallaron también en la olla $\mathrm{N}^{\circ} 1$ (un collar de cuentas de piedra verde y de valvas) y en la $N^{o} 5$ de Los Aparejos. En esta cueva se encontraron también cuentas de malaquita asociadas a restos de un niño en el hallazgo $\mathrm{N}^{\circ}$ 3, sector II. Gran cantidad de cuentas se recuperó de la urna $\mathrm{N}^{\circ} 43$ de La Caverna II y en el hallazgo $\mathrm{N}^{\circ} 42$. 


\section{Cestería.}

Se recuperó gran cantidad de restos de cestería y de cestos completos, muchos con decoración geométrica similar a la que presenta la alfarería. Fueron analizados en 1982 por M. A. Torres restos provenientes de la cueva El Litro (Hallazgo $\mathrm{N}^{\circ} 12 / 14$ ) y de la Caverna II (Hallazgo $\mathrm{N}^{\circ} 44$ ) y se identificó la especie con que fueron confeccionados: Sporobolus rigens (Trin.) Desv.

\section{Restos líticos.}

En lo que respecta a piedra tallada se recuperaron en los contextos de ocupación lascas de cuarzo tanto primarias como secundarias en la cueva Los Aparejos. En el sector III de esta cueva, junto al hallazgo $N^{\circ} 5$, se recuperó una lasca de obsidiana. Esta materia prima se identificó también en las puntas de las flechas pintadas y con plumas recuperadas en la Caverna V.

También se recuperaron restos de minerales como mica en el hallazgo $\mathrm{N}^{\mathrm{o}} 36 \mathrm{y}$ un cristal de granate maclado en el hallazgo $\mathrm{N}^{\circ} 8$ de Los Aparejos, ya mencionado. A esto se suma el espejo de galena en su estuche de madera mencionado por González (1972). Este autor menciona también dos objetos de piedra pulida, únicos representantes de esta técnica identificados en la colección. Uno es una esfera de piedra pulida hallada en superficie, por lo cual no podemos avanzar mucho en su interpretación, y el otro es una pequeña hacha de piedra con cuello completo confeccionada en roca ígnea. La misma fue colocada como ajuar dentro de la urna $\mathrm{N}^{0} 43$ hallada en la caverna II. Además de su importancia como ajuar fúnebre, este hallazgo puede estar indicando tala de árboles, vinculado quizá a prácticas agrícolas de roza y quema. Es en este sentido que hachas de piedra pulida halladas en las tierras 
bajas bolivianas son interpretadas: "La mención frecuente de hachas de piedra (particularmente la variedad en forma de "T") en la literatura arqueológica de la zona y las que se hallaron durante el estudio de la región del monte de San Ignacio, San Borja, y el río Matos, indican la importancia del sistema de cultivo de roza, junto con la utilización de pastizales mediante la construcción de campos elevados. Eder (1888:30), Lizarazu (1906) y Castillo (1906) mencionan el uso de hachas de piedra para limpiar el monte." (Erickson 1980)

\section{Artefactos en madera.}

Se recuperaron varios instrumentos activos para realizar fuego por fricción en las cuadrículas 1 y 4 de El Litro y también en la cuadrícula 3 del sector II de Los Aparejos, próximo a restos momificados de adultos, no se reconocieron partes pasivas. Se vieron en la colección gran cantidad de fragmentos de piezas de madera pulida que posiblemente hayan sido parte de artefactos. Algunos de estos fragmentos parecen ser, por su morfología, parte de implementos para el trabajo en telar tales como palas. Varios de estos fragmentos fueron recuperados en el interior de urnas de las cuevas El Litro (hallazgo $\mathrm{N}^{\circ}$ 5), Los Aparejos (hallazgo $\mathrm{N}^{\circ}$ 4) y en varias de la Caverna II como una posible cuchara junto al hallazgo $\mathrm{N}^{\circ} 43$ y palitos pulidos dentro de la olla $\mathrm{N}^{\circ} 30$. También se recuperaron en el hallazgo $\mathrm{N}^{\circ} 42$.

Se recuperó una pulsera en la Caverna IV y en la Caverna III, un kero de tamaño medio con una talla en su borde, lo cual arroja dudas acerca de la cronología de esta cueva tal como lo manifiesta González (1972).

La madera fue empleada en la confección de puntas ahusadas destacándose un ejemplar con barbas dobles. Este último llama la atención no sólo por su carácter único en todo el NOA, sino también porque coincide con representaciones de la iconografía cerámica Aguada (González 1998) y también con las representaciones rupestres de las armas de esta entidad 
cultural. En este caso existe una figura entre las famosas representaciones de La Tunita (Catamarca) donde un personaje porta un arco donde tensa una flecha barbada que, de acuerdo con la interpretación de los autores, sería usada para cazar aves (de la Fuente et al 2005). En este mismo conjunto de pinturas hay representaciones de estas mismas flechas barbadas (o con “espolones"), pero de mayor tamaño y con sobrepeso en su porción distal, junto a propulsores.

Se recuperaron gran cantidad de astiles de madera. En la Caverna V se recuperaron nueve astiles, dos de ellos con restos de plumas, pintados y con restos de puntas líticas de obsidiana. En la Caverna II se recuperaron en el interior de las urnas $\mathrm{N}^{0} 44$ y 36 como parte de los ajuares. También se recuperaron diez en la Caverna IV y un fragmento en la cuadrícula 4 de El Litro. Existe un conjunto de diecinueve astiles sin referencia contextual. Lamentablemente no se halló en la colección los arcos mencionados por González en su publicación de 1972.

\section{Artefactos en bueso.}

Entre las cuentas recuperadas se identificó con seguridad un conjunto confeccionado en hueso recuperado en el gran fogón de cremación excavado en las cuadrículas F0-F1 del sector III de Los Aparejos. Estas cuentas fueron confeccionadas aparentemente en huesos largos de aves. En huesos de aves se confeccionaron también una punta de proyectil y una pequeña flauta, ambas recuperadas en la primera capa de la cuadrícula D5 de la cueva El Litro. Hay también gran cantidad de fragmentos de huesos pulidos y formatizados pertenecientes a artefactos de uso desconocido.

\section{Metales.}


González (1972) menciona el hallazgo de un colgante oval de oro con una cruz de malta grabada y unos pocos anillos de cobre. En la colección se identificaron restos muy desechos de una pieza de cobre correspondiente al ajuar del niño sepultado en la urna $\mathrm{N}^{\circ} 3$ del sector II de Los Aparejos.

\section{Restos textiles.}

Los restos textiles son muy abundantes habiendo tejidos, trenzados y cordones confeccionados tanto en lana como en fibra vegetal. En el caso de los tejidos, los mismos pertenecen en su mayoría a ajuares fúnebres, habiendo piezas de tejido mas fino y otras de factura más burda, son por lo general monócromas, habiendo escasos ejemplares polícromos. No se halló una distribución diferencial de esta clase de restos por cueva, sector o cuadrícula.

Adorno de plumas.

Se hallaron restos de dos gargantillas confeccionadas con plumas, de las cuales se conservaban solo los ráquis y escasos restos de las bárbaras. Dichos restos fueron analizados por personal de la División Ornitología del Museo de Ciencias Naturales de La Plata quienes tras un minucioso análisis consideraron de manera preliminar que las plumas habrían correspondido a alas de Psitácidos. Una de las gargantillas estaba completa, por lo cual se constató que el diámetro de la misma es pequeño, por lo cual no podría haber sido empleada por un adulto sino por un joven o un niño. Lamentablemente estos restos no estaban acompañados por datos contextuales. Estas piezas (al igual que un conjunto de valvas de caracoles que pudieron ser parte de un sonajero) son muy similares a los implementos de uso chamánico chamacoco registrados por Cordeu (1986). 
Se registró la totalidad de los restos vegetales de la colección (ver Anexo II) estudiados previamente por Pochettino (1985), habiéndose estudiado en profundidad sólo los correspondientes a los géneros Cucurbita sp. y Phaseolus sp. La mayoría de los macrorrestos se encuentran desecados, salvo contadas excepciones.

Un análisis de la tabla presentada en el Anexo II permite ver que no hay una diferenciación por contextos entre especies vinculadas a la recolección (vg. restos de Prosopis sp., Geoffroea decorticans) y especies domesticadas (vg. Zea mays, Phaseolus vulgaris) habiéndose recuperado por igual ambos en contextos funerarios y domésticos de estas cuevas.

\section{Cronología de las ocupaciones}

Si bien las ocupaciones de las cuevas de Pampa Grande se establecieron, en base a la tipología cerámica Candelaria, entre 500 y 600 DC (Baldini y Baffi 1996, Baldini et al. 2003), esta localidad arqueológica no contaba hasta el presente con fechados radiocarbónicos absolutos. Restos de pericarpios (C5) identificados como C. maxima ssp. andreana (ver capítulo 411c) recuperados en Los Aparejos, sector I, cuadrícula 1 se fecharon por AMS obteniéndose una edad radiocarbónica convencional de 1720 +-50 AP (AA82783) correspondiente a una edad calibrada de entre el 259 y 433 DC (1 sigma).

Si bien se reconoce que un único fechado radiocarbónico para toda una localidad arqueológica es por demás insuficiente, el mismo resulta interesante ya que evidencia una cronología más temprana que la que se asumía para estas cuevas.

Si bien la estratigrafía de estas cuevas es compleja, se han recuperado restos culturales correspondientes a sus ocupantes desde la superficie hasta 
aproximadamente un metro de profundidad. A pesar de que las mismas sufrieron diversos saqueos en tiempos recientes, los trabajos llevados a cabo por el Dr. González y equipo fueron cuidadosos en discriminar los contextos vinculados a dichos eventos con los correspondientes a las ocupaciones originales (los cuales se señalan en las etiquetas junto al material, ver anexo II). Por lo que se desprende del análisis de la colección, muchos restos que se hallaban enterrados fueron depositados en superficie tras los saqueos, por lo cual los mismos corresponderían a las ocupaciones prehispánicas, aunque desvinculados de su contexto arqueológico original. 
Figura 3: sitios arqueológicos del NOA cuyos restos han sido estudiados en esta tesis:1: Huachichocana III; 2: Puente del Diablo (SSalLap20); 3: Puente Río La Viña 1; 4: Pampa Grande; 5: Campo del Pucará; 6: El Shincal; 7: Los Viscos (SCatBe6)

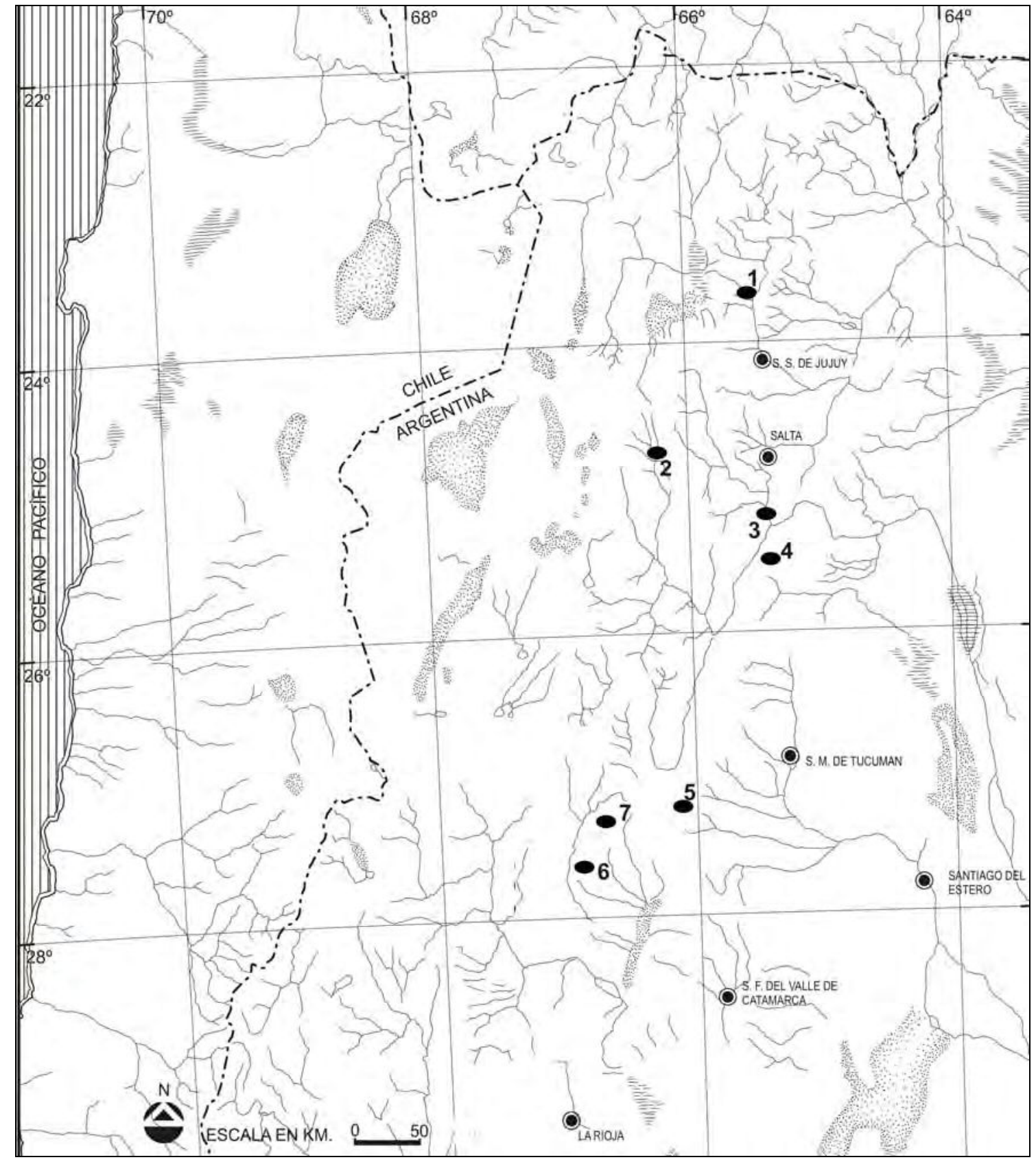


Figura 4: plano de la cuadrícula 1, sitio 1, de Puente Río La Viña I y de la cuadrícula 1, sitio 2, de Puente Río La Viña II, ambos pertenecientes a la fase La Viña del Valle de Lerma. Plano obtenido de Escobar (ms) (autorizada su reproducción)

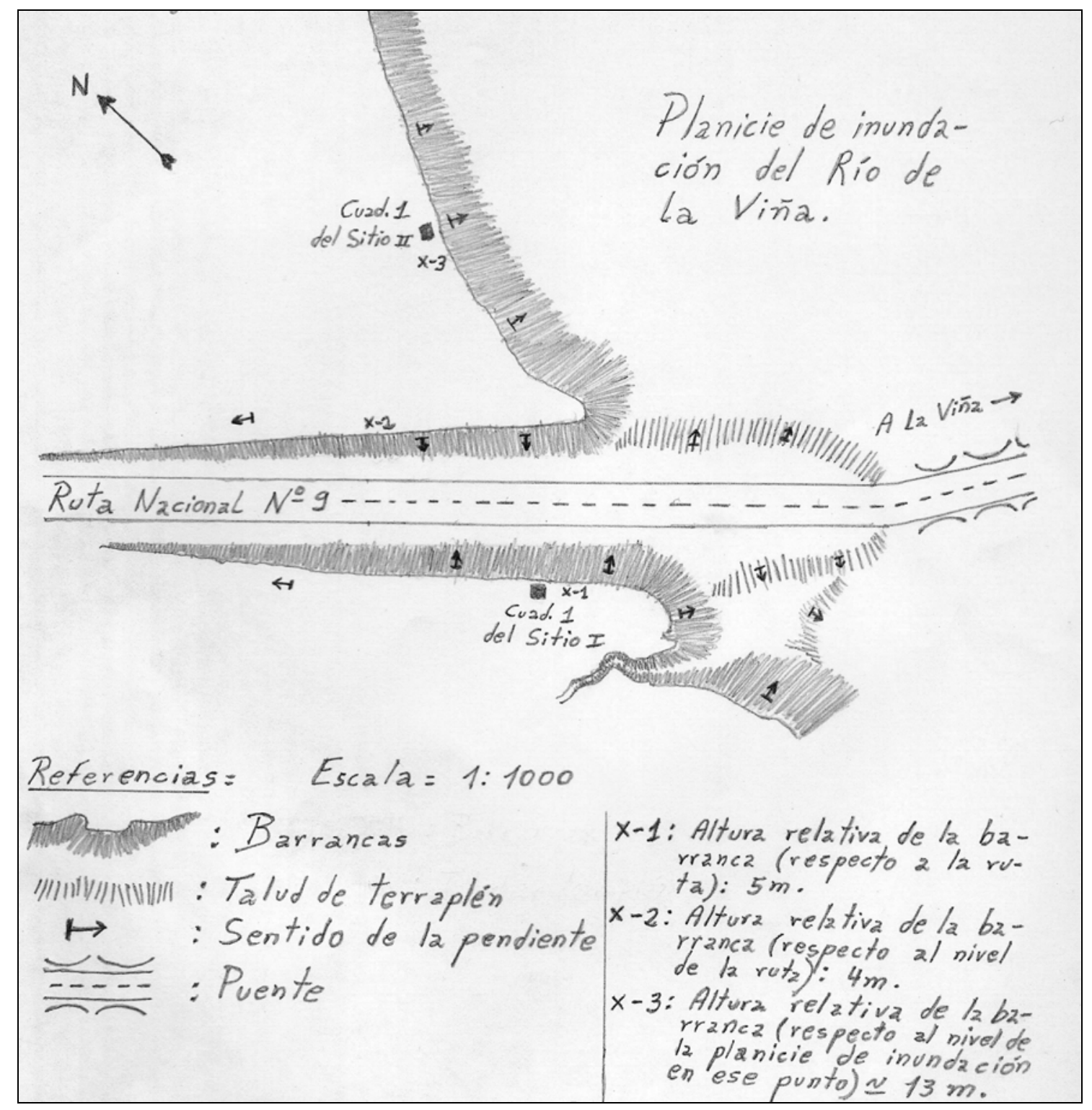


Figura 5: ubicación de los sitios arqueológicos del Área Andina Central y Meridional (fuera de territorio argentina) de los cuales se estudiaron macrorrestos de Cucurbita spp.

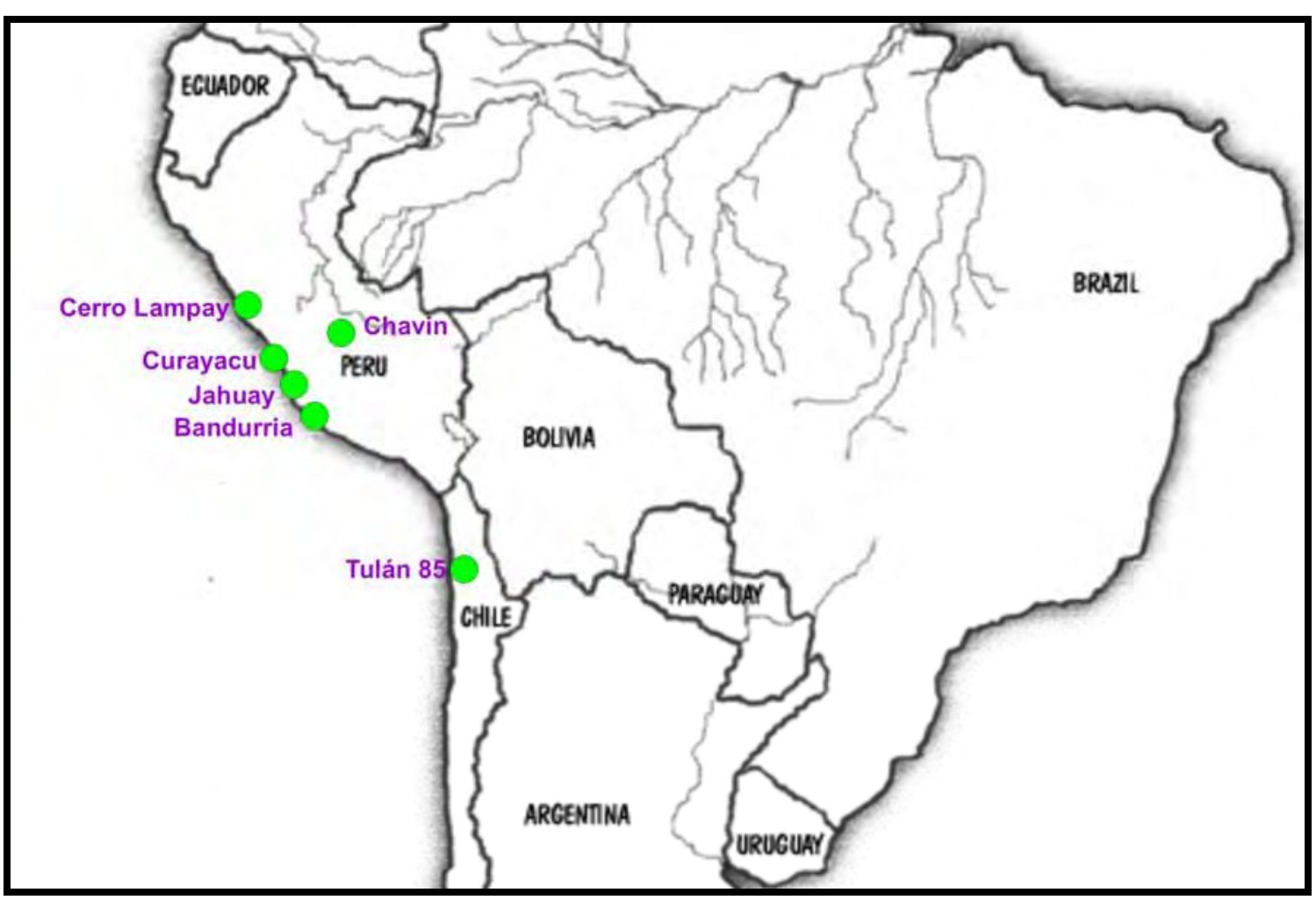


Figura 6: planta de excavación original de la cueva Puente del Diablo (SSalLap20) obtenida de los diarios de campo de la Lic. M.D. Arena (autorizada su reproducción)
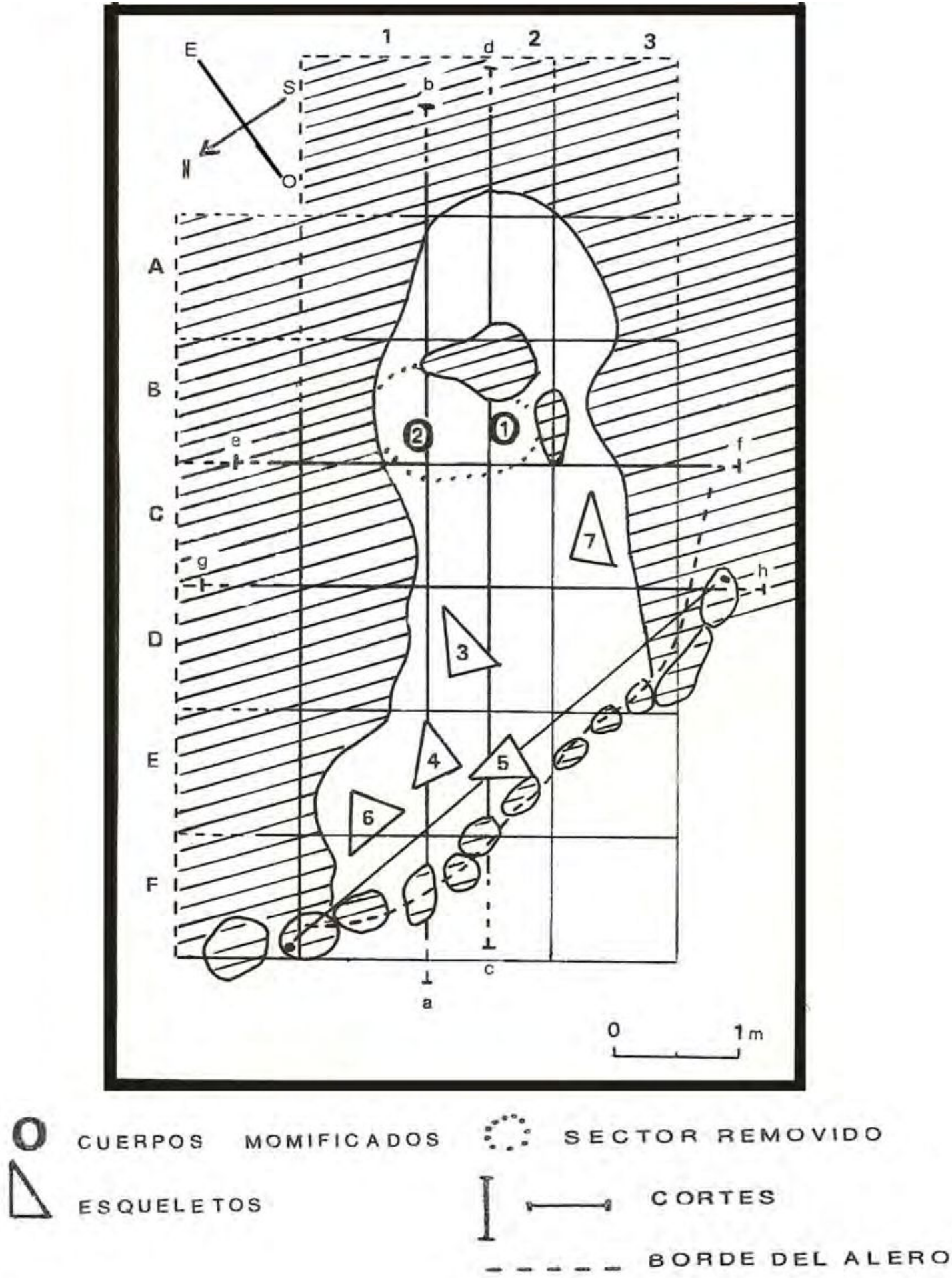
Figura 7: corte g-h de la excavación original de la cueva Puente del Diablo (SSalLap20) obtenida de los diarios de campo de la Lic. M.D. Arena (autorizada su reproducción)

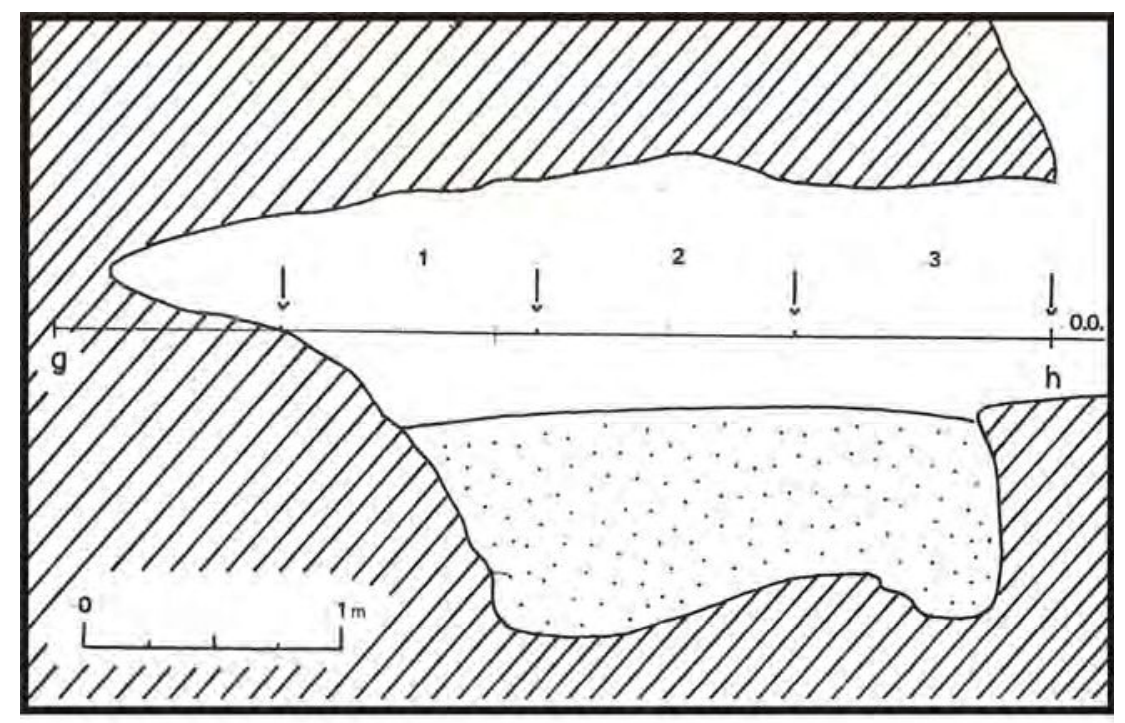

Corte transversal $\mathrm{g}-\mathrm{h}$

Figura 8: Cortes a-b y c-d de la excavación original de la cueva Puente del Diablo (SSalLap20) obtenida de los diarios de campo de la Lic. M.D. Arena (autorizada su reproducción)

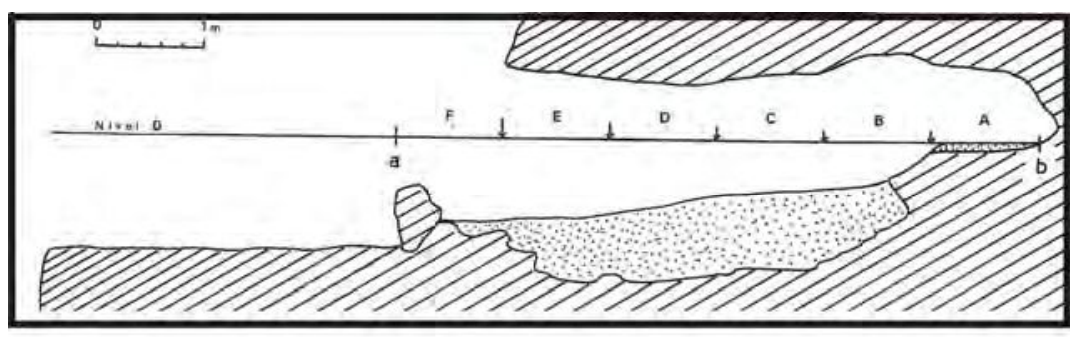

Corte longitudinal $a-b$

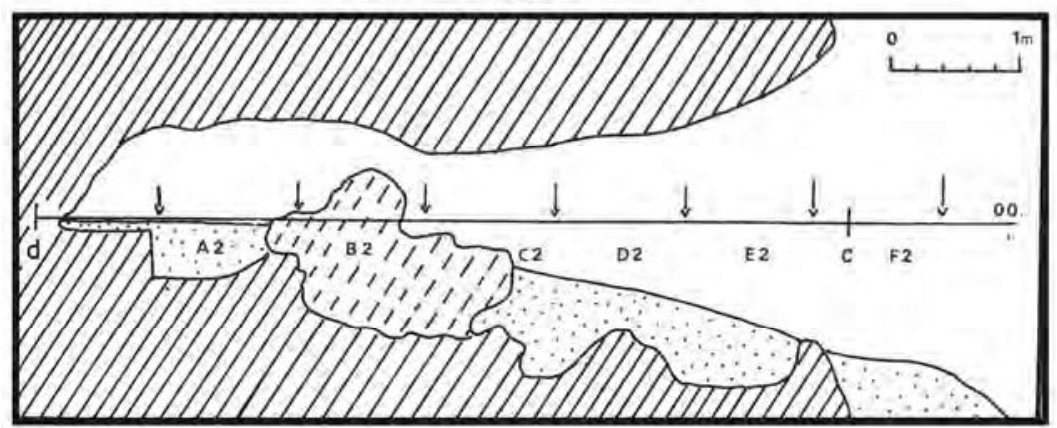

Corte longitudinal $c-d$ 
Figura 9: plano de la planta de excavación de la cueva Los Aparejos. El área donde están ubicadas las letras correspondería a la entrada de la cueva.

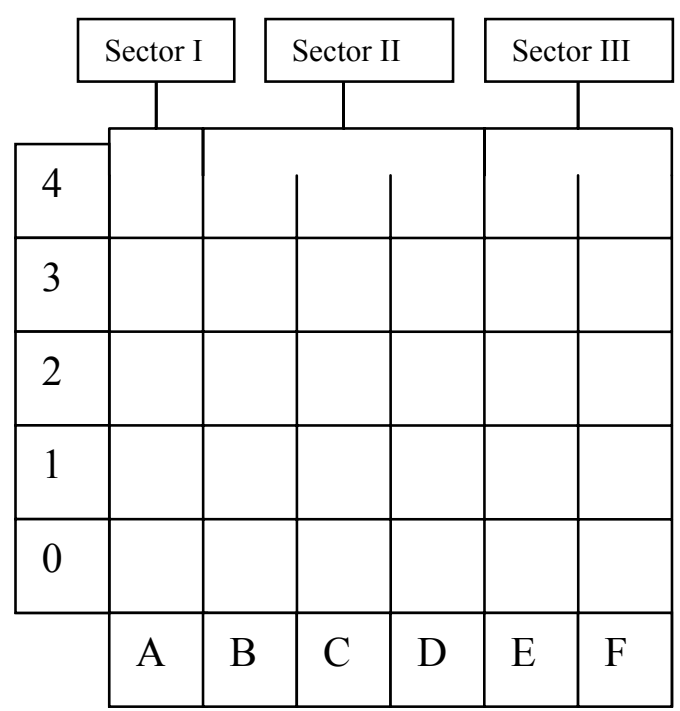

Figura 10: plano de la planta de excavación de la cueva El Litro. El área donde están ubicadas las letras correspondería a la entrada de la cueva.

\begin{tabular}{|l|l|l|l|l|}
\hline 5 & & & & \\
\hline 4 & & & & \\
\hline 3 & & & & \\
\hline 2 & & & & \\
\hline 1 & & & & \\
\hline 0 & & & & \\
\hline & A & B & C & D \\
\hline
\end{tabular}


Gráfico 1: endocarpios de distintas especies del género Prosopis sp. recuperados en el sitio Puente del Diablo (SSalLap20, La Poma, Salta)

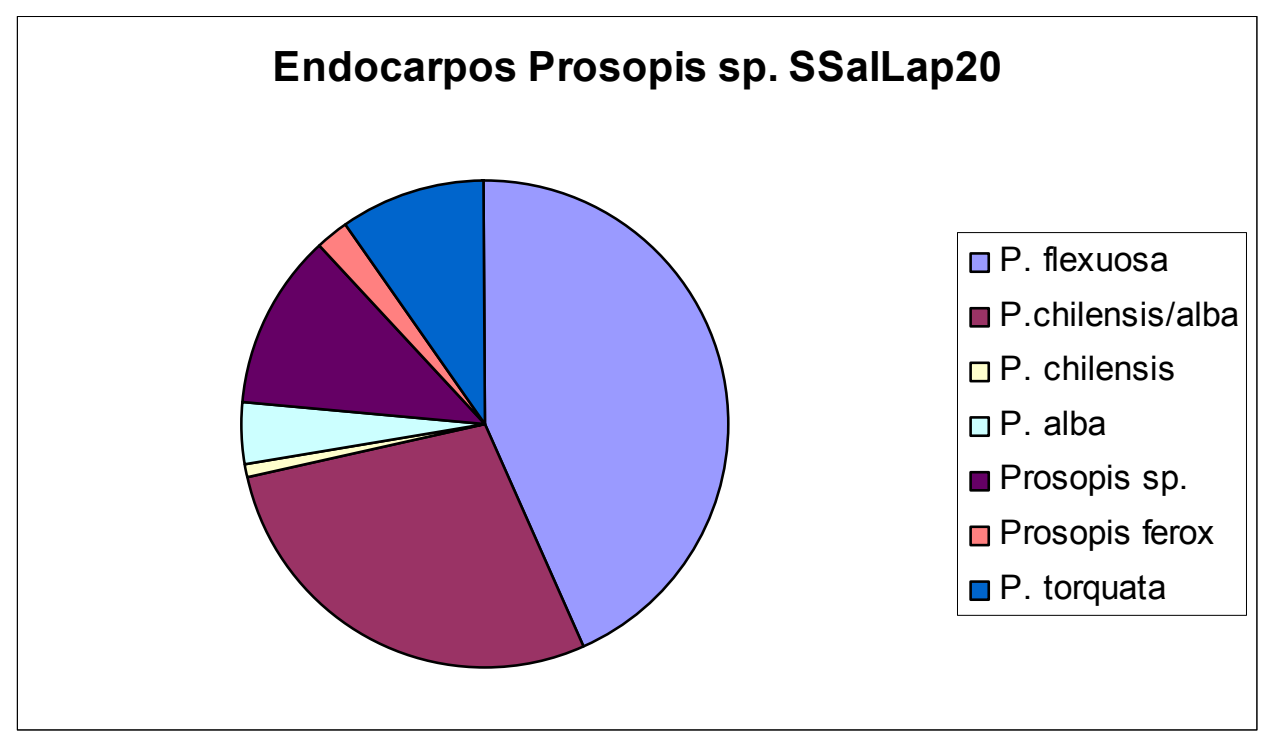

Gráfico 2: endocarpios del género Prosopis sp. recuperados en el sitio Puente del Diablo (SSalLap20, La Poma, Salta) agrupados de acuerdo con la sección algarobia serie chilensis, discriminando aquellos restos pertenecientes a las especies $P$. torquata y $P$. ferox

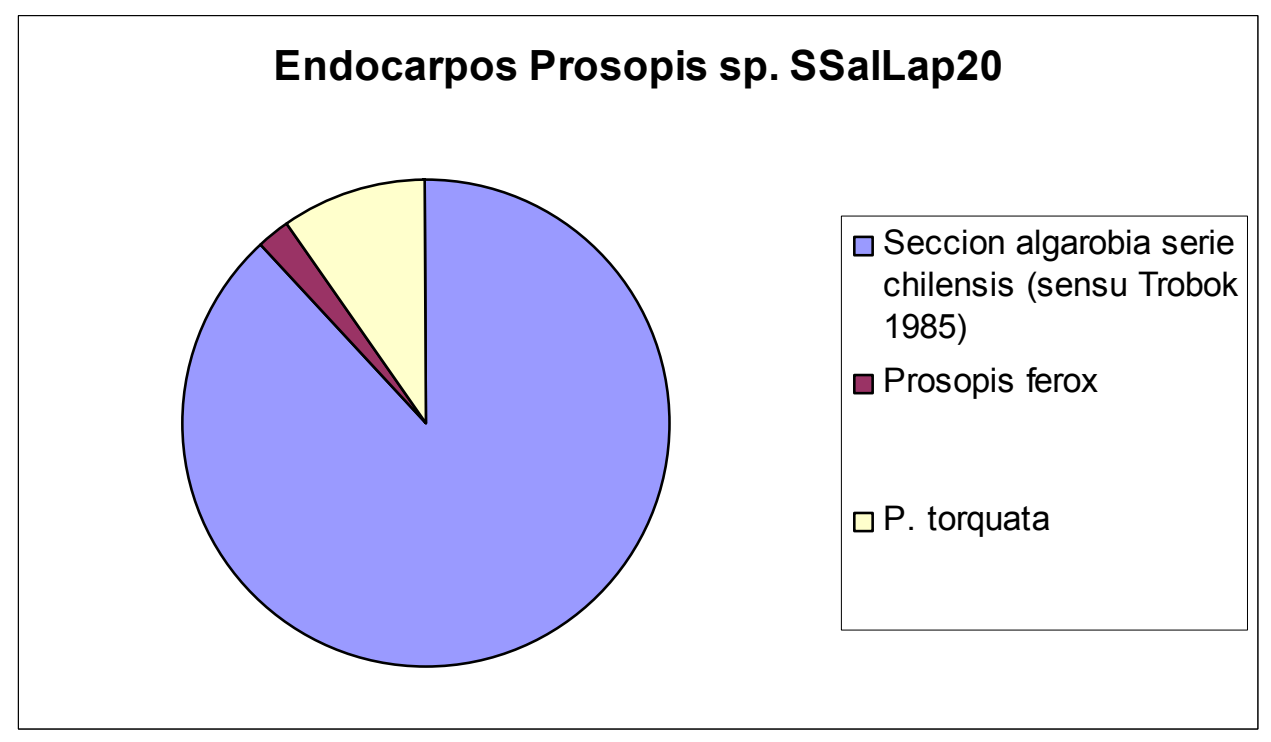


Gráfico 3: modalidades de entierro en las cuevas de la localidad arqueológica de Pampa Grande (Guachipas, Salta). Datos tomados de Baldini y Baffi (1996)

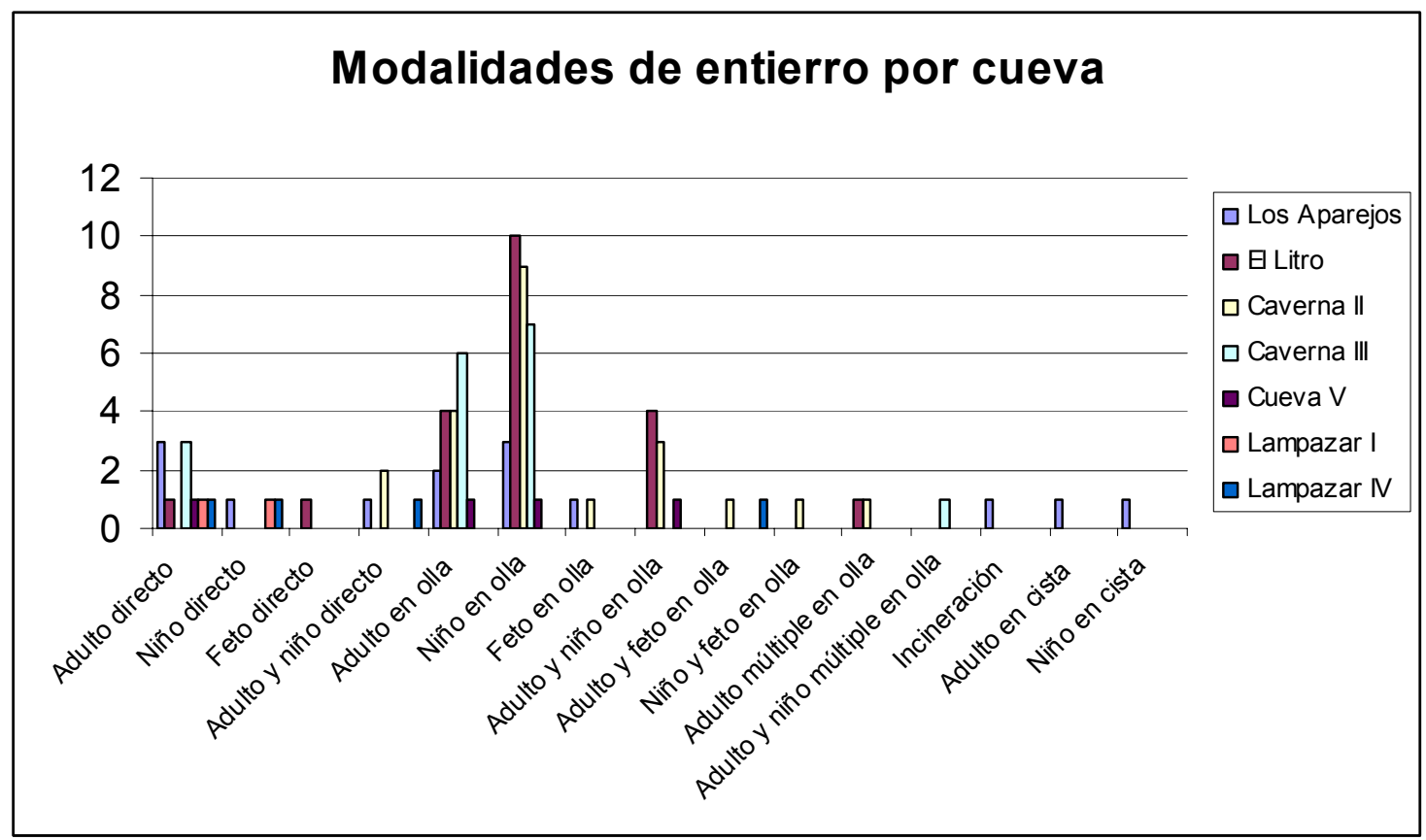


EL ABORDAJE PALEOETNOBOTÁNICO: EVOLUCIÓN BAJO DOMESTICACIÓN 


\section{4-EL ABORDAJE PALEOETNOBOTÁNICO: EVOLUCIÓN BAJO DOMESTICACIÓN.}

En paleoetnobotánica se han desarrollado diversas estrategias metodologías para la identificación y caracterización del proceso de domesticación vegetal. Podemos reconocer entre las mismas dos vías complementarias. Una se centra en el análisis del conjunto de restos arqueobotánicos de una región bajo estudio, siendo sus principales intereses los taxa presentes y sus frecuencias relativas en tiempo y espacio, pudiendo tener un grado de resolución a mayor o menor escala espacial y/o temporal (Mc Neish 1976, Minnis 1978, Pearsall 1978, Watson 1985, Asch y Asch 1985, Ford 1985b, Harris 1990, McCorrison y Hole 1991, Dennel 1992, Smith 1992, McClung de Tapia 1992, Pearsall 1992, Riehl 2007). Por lo general esta clase de abordaje se complementa con análisis paleoambientales, palinológicos, ecológicos y arqueológicos, a fin de caracterizar el proceso de domesticación y advenimiento de sistemas agrícolas en el pasado de una región determinada.

La otra vía metodológica consiste en analizar los caracteres anatómicos, morfológicos y biométricos de los restos botánicos recuperados, en particular de los macrorrestos (Kay et al 1980, Smith 1985, Galinat 1985, Butler 1989, 1995, 1996, 2002; Mangafa y Kotsakis 1996, Lepofsky et al. 1998, Pickersgill 1999, Gremillion 1993, Hillman et al. 1993, Cowan y Smith 1997, Smith 1997, 2000, 2006b; Jacquat y Martinolli 1999, Bruno y Whitehead 2003, Ericsson et al 2005, Bruno 2006, Fuller 2007, Isemura et al. 2007, Lentz et al. 2008), si bien recientemente se han aplicado estos mismos criterios en el estudio de microrrestos (Piperno et al. 2000, Piperno et al. 2002, Stothert et al. 2003, Perry et al 2007, Piperno 2008, Piperno y Stothert 2008). Generalmente esta clase de abordaje se complementa con datos etnobotánicos, botánicos y genéticos, teniendo como objetivo trazar la historia evolutiva de las 
transformaciones en las relaciones entre poblaciones humanas y un taxón en particular.

Si bien podríamos asociar la primera de las vías mencionadas a los estudios de tipo arqueobotánico y la segunda a los de tipo paleoetnobotánico (Archila et al .2008, Giovannetti et al. 2008), ambas son totalmente complementarias, como puede verse en trabajos tales como los de Hillman y Davies (1990). En esta tesis -si bien no de manera excluyente- se desarrolla principalmente la segunda de estas vías metodológicas por dos razones principales. La primera radica en el objetivo mismo de las investigaciones aquí presentadas, el cual se orienta a la identificación de modos de relación humano-planta en el pasado, para lo cual, como se mencionó previamente, resulta más apropiado el estudio de caracteres anatómicos, morfológicos y biométricos de macrorrestos. El segundo motivo recae en los rasgos propios del registro arqueobotánico del NOA, el cual se caracteriza por ser discontinuo y fragmentario (ver capítulo 2), poco propicio para la primera de las vías metodológicas anunciadas anteriormente.

Como se analizó en el capítulo 1 (tabla 1, figura 2), existen formas muy distintas de relación entre comunidades humanas y poblaciones vegetales, las cuales implican a su vez grados de dependencia diferentes. Estos diversos tipos de relación poseen además un reflejo material diferencial, en particular en los órganos de las plantas implicadas en estas interacciones, lo cual posee una clara implicancia en los estudios de restos arqueobotánicos.

Las plantas domesticadas son relativamente fáciles de reconocer en el registro arqueológico ya que poseen modificaciones en los órganos y/o tejidos involucrados en sus sistemas de propagación, las cuales le impiden dispersarse y/o reproducirse por sí solas. Las plantas silvestres, en cambio, pueden reconocerse por carecer de estas modificaciones, y si bien en muchas ocasiones derivan de prácticas como la recolección, pueden estar enmascarando -ante una aparente ausencia de cambio- prácticas de cultivo 
(Buxó y Piqué 2008). Aquí se está ante una disyuntiva: si las plantas cultivadas (no domesticadas) poseen o no modificaciones morfológicas. Este es un dilema crucial puesto que, como se vio en el capítulo 1, el comienzo del cultivo marca un cambio significativo en las relaciones entre seres humanos y plantas que puede eventualmente llevar a la domesticación.

Gremillion (1997) considera que los cultivos pueden o no exhibir cambios morfológicos y/o anatómicos. Para Ford (1979) en el continuum de interacciones humano- planta, entre la recolección y el cultivo, existe el cuidado ("tend"), en donde el hombre interviene en el ciclo de crecimiento de la planta aunque sin que ocurran cambios genéticos detectables (ni morfológicos), aumentándose solamente las ventajas competitivas y las oportunidades de éxito reproductivo de la planta. Para este autor, las plantas bajo cultivo serán las primeras en exhibir cambios morfológicos y/o fisiológicos por las presiones de la selección cultural. Ford (1979) considera que cultivar implica sembrar o transplantar y almacenar, lo cual causará cambios morfológicos (como variaciones en la cubierta seminal) que indican la intervención humana en los ciclos de reproducción de la planta, si bien la misma puede reproducirse sin dicha clase de intervención. Yernell (1983 en Smith 1985) opina, en cambio, que por más que se asuma que el cultivo comienza a partir de un límite claro, como la siembra intencional de semillas o propágulos, esta clase de comportamientos no será fácil de detectar arqueológicamente. Para Gepts (2005) las presiones selectivas ejercidas sobre los cultivos generarán cambios en los rasgos morfológicos y fisiológicos de las plantas, si la planta muestra cambios sólo en sus frutos -ya sea en tamaño, color u otro rasgo- la misma se considera una planta "semidomesticada". Estos cambios son los que, precisamente, detecta Alejandro Casas en sus estudios etnobotánicos de manipulación de cactáceas columnares (Casas et al 1991, Casas et al 1997, Casas 2001, Arellano y Casas 2003), habiendo diferencias morfológicas y biométricas entre los frutos y semillas de formas 
silvestres, por un lado y de formas manipuladas in situ, por otro. Murray (1984) menciona que un cultivo prolongado del girasol (Helianthus annuus L.) aumenta el tamaño de las semillas del mismo sin que éste pierda su capacidad de reproducirse por sí solo. En opinión de Asch y Asch (1985) bajo cultivo las plantas van acumulando cambios genéticos y morfológicos que luego aumentaran la utilidad de la planta. Otro indicador de cultivo mencionado por estos autores es el reconocimiento de un cambio en el rango geográfico de dispersión de una planta, consecuencia de su introducción más allá de la región donde prospera naturalmente. Para Heiser (1989) y Chikwendu y Okezie (1989) entre la forma silvestre y la domesticada hay sólo cambios fenotípicos reversibles y plásticos que no se fijan en el genotipo. Smith (2006) señala que esta problemática se debe interpretar en el marco de un proceso, por lo cual las diferencias serán sólo de grado, siendo altamente probable que en las primeras etapas de cultivo y presión selectiva, los cambios no sean evidentes. Tanto Ford (1979) como Hillman y Davies (1990) acuerdan en que es muy difícil reconocer el paso de formas silvestres a domesticadas en el registro arqueológico. En opinión de estos dos últimos autores, entre los restos arqueobotánicos sólo se pueden reconocer formas silvestres y domesticadas y no la progresión entre las mismas dada la escala de resolución del registro arqueológico para un proceso que puede demorar, en algunos casos, no más de 200 o 300 años, siendo por ende imposible identificar sus pasos a nivel local.

A estas dificultades se suma el hecho de que el análisis de macrorrestos vegetales bajo un tratamiento taxonómico tradicional, obstaculizará el reconocimiento de la posible conexión filogenética entre la forma silvestre y domesticada, enmascarando grandes cambios como, por ejemplo, los ocurridos en el aspecto de una semilla, tales como mecanismos de dispersión, apariencia y propiedades de la cubierta seminal, tamaño y composición, entre otros (Murray 1984). 
En todos los casos de análisis de cambios morfo-anatómicos en plantas domesticadas -sean éstos producto de la selección natural o cultural- se debe asumir que, como en todo proceso evolutivo, primero se produce la generación de variabilidad y luego la fijación de ciertos caracteres. Por lo tanto, todos los rasgos que se atribuyen a las plantas domesticadas, debieron haber estado necesariamente presentes en el acervo genético de las poblaciones silvestres o bien haber surgido en un punto dado del proceso evolutivo por mutaciones (somáticas, pleiotrópicas y/o poliploidía) o por hibridación (Parodi 1938, León 1969).

En la sección siguiente analizaremos puntualmente las estrategias seguidas en estudios paleoetnobotánicos para identificar a nivel arqueológico las distintas formas de manipulación de especies vegetales. 


\section{1- LA BÚSQUEDA DEL CAMBIO EN LOS RESTOS VEGETALES: ESTUDIO DE CARACTERES MORFO- ANATÓMICOS EN MACRORRESTOS.}

El análisis de la domesticación vegetal adquiere matices diferentes de acuerdo con las características de la especie analizada, su modo de reproducción (sexual o vegetativo), ciclo reproductivo (anual o perenne), polinización, fotoperíodo, etc. Pero en general -para el caso de plantas con reproducción por medio de semillas- se ha reconocido que existen ciertos cambios morfológicos asociados a la manipulación humana deliberada como: aumento en el tamaño de las estructuras reproductivas (fruto y semilla), modificaciones en el tipo de dispersión ( $v g$. pérdida de la dehiscencia), modificaciones en el período de dormancia de las semillas (vg. modificación de las cubiertas seminales) y maximización de unidades fértiles (León 1968, De Wet y Harlan 1975, Murray 1984), entre otras de carácter más específico.

Desde una perspectiva distinta, Smith (2006) asume que domesticar implica la siembra en lugares delimitados de semillas previamente cosechadas y guardadas para tal fin, lo que ocasiona cambios en la morfología de la planta debido a una intervención en su ciclo vital. De acuerdo con este autor, los cambios sufridos por las plantas no son propiciados sino que son inconscientes, siendo el producto de la adaptación natural de las mismas al ambiente creado por el hombre. Al ser el resultado de un proceso de selección natural, los cambios que se fijan son aquellos que otorgan ventajas adaptativas a las plantas en este nuevo ambiente, en términos de aporte al próximo stock de semillas. Estos cambios involucran: semillas más grandes, con mayor cantidad de reservas y cubierta seminal delgada que aseguran una germinación rápida y simultánea por pérdida de la dormancia, empaquetamiento de las semillas en la porción terminal del tallo y pérdida de los mecanismos naturales de dispersión de las semillas, rasgos que, en su conjunto, constituyen para 
Smith (2006 a) el "síndrome adaptativo de la domesticación". Siguiendo a Hillman y Davies (1990) se asume que la domesticación requiere necesariamente de la intencionalidad humana para fijar los caracteres propios de este tipo de relación a nivel poblacional, la cual no implica negar la presencia conjunta de procesos de selección natural.

Para Butler (1989) los primeros estadios en la domesticación implican un mayor control sobre dos aspectos del ciclo de vida de la planta: dispersión y germinación de la semilla. En el primer caso se busca mayor eficacia en la recolección o cosecha al mantener el grano maduro en la planta (lo mismo asumen Hillman y Davies 1990) mientras que, en el segundo, se elimina la dormancia a fin de obtener semillas que maduren de forma homogénea ${ }^{1}$. El cultivo puede propiciar también una germinación uniforme luego de la siembra, con un tiempo más breve en la aparición de las semillas, cambios que pueden ser resultado de una alteración en la estructura de la cubierta seminal que afecte la permeabilidad de la misma, o de un cambio metabólico y hormonal (Murria 1984). Obviamente la primera causa cuenta con mayor visibilidad arqueológica dado que puede detectarse dicho cambio mediante estudios morfo-anatómicos en macrorrestos, la segunda causa requiere, en cambio, de estudios químicos no siempre aplicables a los restos arqueobotánicos.

A continuación se describen los tres principales indicadores arqueológicos empleados para el reconocimiento de la domesticación en macrorrestos vegetales de diversas especies.

\section{$\underline{\text { a- Modificaciones en los mecanismos de dispersión }}$}

\footnotetext{
${ }^{1}$ La autora señala que si son plantas domesticadas cuya finalidad es ser empleadas como forraje, el mantenimiento de la dormancia puede ser una ventaja. En el caso de estudios para el NOA esta posibilidad no se aborda dado que no existen evidencias acerca de la alimentación de animales domésticos por medio de formas vegetales modificadas o cuidadas específicamente para tal fin, siendo la única referencia las vegas naturales alentadas por riego actualmente en la puna argentina (García et al 2002)
} 
En las formas ancestrales del género Triticum (T. monococcum L. y T. dicoccum L.) los raquis eran frágiles y se rompían fácilmente a fin de asegurar la dispersión de las semillas; tras la domesticación, los raquis ya no fueron frágiles, permitiendo que la semilla no se separe de la planta a su madurez, facilitando su colecta (Murray 1984). La rigidez del raquis fue un carácter elegido por Hillman y Davies (1990) en sus estudios paleoetnobotánicos, dado que el mismo es reconocible en los restos arqueobotánicos. En el caso de las legumbres, la modificación en el mecanismo de dispersión viene dado por la pérdida de la dehiscencia de la vaina (Kaplan 1965; Murray 1984; Gepts y Gebouck 1991; Epimaki et al 1996; Smartt 1988 en Galvan 2006). Sin embargo, Butler (2002), tras sus análisis en vainas de Vicieae, no halló diferencias anatómicas o morfológicas que indiquen el carácter indehiscente o dehiscente de los frutos, imposibilitando su reconocimiento arqueológico.

\section{$\underline{\text { b- Modificaciones en el tamaño de órganos }}$}

Uno de los cambios más frecuentemente mencionado como resultado de la domesticación es el aumento en el tamaño de las semillas. Aunque hemos visto que este rasgo puede hallarse en cultivos no domesticados (Murray 1984, Casas 2001). El aumento en el tamaño de la semilla puede deberse al aumento del tamaño del embrión, como en el caso de las arvejas, o del endosperma que lo alimenta, como en el caso del paso de trigos diploides a triploides (Murray 1984). Además la mayoría de los estudios biométricos se ha centrado en las semillas, ya que se consideran las menos afectadas por factores ambientales en relación al fruto y otros órganos vegetativos (Decker \& Wilson 1986).

El estudio del incremento del tamaño de órganos como semillas y frutos ha seguido, por lo general, una metodología consistente en el análisis de dichas estructuras en poblaciones vegetales actuales de las formas silvestre y domesticada del taxón bajo estudio, con el fin de obtener un rango de tamaño 
que caracterice a cada una. El resultado de la aplicación de dicha metodología puede evidenciar, en algunos casos, un área de solapamiento entre ambas formas, por lo cual su distinción se torna menos nítida (Gremillion 1993, Cowan y Smith 1993; Smith 1997, 2000, 2006b; Ericsson et al. 2005; Bruno 2006). Ante esto se han procurado rasgos complementarios a los biométricos. Así, en el caso del género Chenopodium se ha constatado que la reducción en el grosor de la testa, junto a cambios en la textura de la misma y en la configuración del margen de la semilla, resultan indicadores confiables de domesticación (Bruno 2006). En otros casos, se ha visto que existe una diferencia de tamaño entre los órganos de las poblaciones silvestres y domesticadas actuales, pero que involucran tejidos de difícil preservación en el registro arqueológico: "este es a menudo el caso de las drupas, donde la selección esta dirigida hacia cambios en la calidad de la porción carnosa del fruto. Por ejemplo, los olivos domesticados (Olea europaea L.) y los dátiles (Phoenix dactylifera L.) tienen una porción carnosa más desarrollada y de mejor calidad que sus contrapartes silvestres, pero esto no se refleja en los endocarpos arqueológicamente preservados" (Zohary \& Hopf 1994 en Lepofsky et al. 1998: 1002).

En los estudios biométricos distintos autores (Mangafa \& Kotsakis 1996, Kay et al. 1980) asumen que la forma es un rasgo genético más conservador, y por lo tanto menos variable, que el tamaño, recomendando por lo tanto el empleo de índices para identificar distintos taxa en macrorrestos.

\section{$\underline{\text { c-Modificaciones en la cubierta seminal }}$}

Como vimos en la sección precedente, la reducción en el grosor de las cubiertas seminales de los ejemplares recuperados, respecto de las formas silvestres, es un rasgo frecuentemente empleado para identificar plantas domesticadas. Este cambio involucra transformaciones anatómicas en el 
tamaño y grado de engrosamiento de las células así como también en su textura y estructura, y conlleva modificaciones físico-químicas como, por ejemplo, un aumento en la permeabilidad de las semillas, lo que contribuye, en casos como el de las legumbres, a una germinación más uniforme y predecible (Murray 1984; Gepts y Gebouck 1991; Epimaki et al 1996; Smartt 1988 en Galvan 2006).

Cambios metabólicos que afectan la síntesis de pigmentos de las cubiertas pueden tener consecuencias más allá de un cambio de aspecto externo. En el caso de Phaseolus vulgaris L. la selección tendiente a la pérdida de pigmentación, por la que se obtuvieron cubiertas blancas, si bien ha mejorado la palatabilidad de las semillas, ha tenido como consecuencia la pérdida de la resistencia al calor y de la defensa contra predadores que estaba dada por la presencia de taninos en las cubiertas de porotos coloreados (Murray 1984; Epimaki et al 1996; Smartt 1988 en Galvan 2006).

En la tabla 3 se han compilado diferentes indicadores morfológicos, anatómicos y biométricos empleados para establecer si macrorrestos hallados en el registro arqueológico corresponden o no a especies domesticadas. Como puede verse en la misma, estos indicadores se han buscado fundamentalmente en estructuras vinculadas con la dispersión y reproducción de las plantas como frutos y semillas, lo cual es coherente con la noción de que estas estructuras serán las que exhiban mayor modificación en plantas domesticadas incapaces de reproducirse por sí solas.

\section{Estudios micromorfológicos.}

Bajo este nombre agrupamos aquellos estudios que analizan caracteres cualitativos o cuantitativos de los tejidos que componen los macrorrestos arqueológicos. Butler (1989, 1996, 2002) ha sido pionera en esta clase de 
análisis aplicándolo a frutos y semillas de leguminosas del Viejo Mundo (ver tabla 3) Asimismo Smith (1985) llevó a cabo estudios micromorfológicos de cubiertas seminales en macrorrestos de Chenopodim sp recuperados en sitios norteamericanos a fin de caracterizar el proceso de domesticación de dicho género. Gordon Hillman, tras un primer intento fallido (Hillman y Davies 1990), logra identificar, analizando a nivel microscópico los tejidos que componen los granos de centeno silvestre perenne (Secale montanum Guss.), de centeno silvestre anual (S. cereale ssp. vavilovii Grossh.) y trigo einkorn silvestre (Triticum urartu Tumanian ex Gandilyan), cuatro caracteres que permiten su identificación arqueológica los cuales, además, sobreviven a la carbonización (Hillman et al 1993).

\section{$\underline{\text { Identificación de cultivos }}$}

De acuerdo con Hillman y Davies (1990) la secuencia de eventos existente entre el cultivo de formas morfológicamente silvestres y la domesticación plena de las mismas no es detectable en el registro arqueológico como una progresión reconocible dado el escaso tiempo que implica dicho proceso (los autores estiman que entre 20 y 300 años, un lapso muy breve para la escala de resolución arqueológica). Restos de un cultivo en vías de ser domesticado o ya en su estado inicial de domesticación (caracterizado, según estos autores, por una mezcla de caracteres silvestres y domesticados) se pueden llegar a recuperar por azar, pero en la mayoría de los sitios donde ocurrió la domesticación es más probable que recuperemos restos de formas silvestres en un nivel y de formas totalmente domesticados en un nivel superior, sin manera de reconocer si los domesticados fueron importados o desarrollados localmente (Hillman y Davies 1990). A pesar de estas afirmaciones creemos que es necesario desarrollar vías metodológicas para detectar cultivos no domesticados en el registro arqueológico no sólo para constatar si, 
efectivamente, la progresión de silvestre a domesticado no es detectable arqueológicamente en todas las especies, sino también para poder identificar complejos maleza-cultivo-domesticados.

Si asumimos que cultivar implica cambios morfológicos en las plantas, la siguiente dificultad es discriminar dichos cambios de los que son propios de una maleza, cuya diferencia con el cultivo es que los cambios que posee se deben a su adaptación a un medio antrópico (Harlan y de Wet 1965, de Wet y Harlan 1975), sin que los seres humanos seleccionen caracteres puntuales de las mismas. Entre los indicadores de cultivo se han mencionado principalmente dos: aumento en el tamaño de frutos y semillas (Murray 1984, Casas 2001, Gepts 2005) y la presencia de plantas fuera de su rango natural de distribución (Asch y Asch 1985). Pero, sin embargo, estos rasgos están también presentes en plantas cultivadas domesticadas, por lo cual la identificación de los mismos en el registro arqueológico no es definitoria para asignar el status de cultivo sin domesticar a los restos de una determinada planta. En el caso del primero de los indicadores enunciados, esta clase de cambios no están fijados genéticamente a nivel poblacional, a diferencia de lo que ocurre en las plantas domesticadas (Hillman y Davies 1990, Casas 2001). Por lo tanto estos cambios son reversibles (Heiser 1989), por lo que si estas poblaciones son abandonadas, los mismos se pierden al adaptarse las plantas nuevamente a condiciones naturales (Clement 1999). Ahora bien, si estos cambios en frutos y semillas alcanzan un grado tal que modifican el mecanismo de dispersión natural de la planta, se estará ante una planta domesticada que depende totalmente de la mano humana. Por lo tanto, tal como lo anunciara Smith (2006), las diferencias entre cultivos transicionales y plantas domesticadas son de grado.

Clement (1999) ve en la secuencia desde plantas "incipientemente domesticadas", plantas "semi-domesticadas" (estas dos analogables a lo que en esta tesis entendemos como cultivos transicionales, ver capítulo 1) y plantas 
domesticadas un grado cada vez mayor de intervención humana. En el primer tipo de plantas mencionadas el fenotipo promedio está aún dentro de los rangos de variación hallados en las poblaciones silvestres para los rasgos sujetos a selección y las variaciones de este promedio son menores que las de la población silvestre original; en el segundo tipo de plantas el fenotipo promedio diverge totalmente del rango de variación hallado en las poblaciones silvestres para los rasgos sujetos a selección y la varianza de este fenotipo promedio puede ser mayor que en la población silvestre, dado que el fenotipo promedio incluye ahora ambos tipos: los comúnmente hallados en la población silvestre y los nuevos; finalmente con la domesticación la variabilidad genética decrece respecto de las plantas "semi-domesticadas" por el aumento en las presiones selectivas y la pérdida de adaptaciones ecológicas que le permitían reproducirse sin la intervención humana (Clement 1999). Esto es compartido por Harlan (1992) y Gremillion (1993) para quienes las plantas domesticadas poseen menor diversidad genética que las plantas silvestres ya que el proceso de domesticación habría llevado a la selección y fijación de una serie limitada de rasgos deseados por el hombre en detrimento de la variabilidad total de las poblaciones silvestres, aunque al desarrollarse cultivares morfológicamente distintos la diversidad aumentaría. Por lo tanto el aumento del control humano sobre el hábitat de las plantas reduce la ventaja selectiva de la flexibilidad al disminuir la incertidumbre ambiental (Rindos 1980).

Para evaluar estas diferencias en diversidad o variabilidad Gremillion (1993) analiza diferencias en el coeficiente de variación (CV), el cual es un buen indicador ya que expresa el desvío estándar como porcentaje de la media permitiendo comparar muestras que difieren en la cantidad de ejemplares. Los valores de C.V. bajos indican homogeneidad morfológica, existiendo uno o pocos morfotipos en las poblaciones silvestres, estos valores aumentarán con los procesos de domesticación por la presencia de más de un tipo de fruto y/o 
los efectos iniciales de la hibridación, cultivo y cría selectiva: "El coeficiente de variación puede ser usado [en arqueología] indirectamente para verificar el advenimiento de la horticultura o la intensificación de prácticas hortícolas y quizá la selección humana dirigida de caracteres del fruto" (Newsom 1993:87, n.t.). La persistencia de una alta variabilidad a lo largo de una secuencia arqueológica señalaría que prácticas como el aislamiento reproductivo y la cría selectiva estaban probablemente limitadas en frecuencia o grado (Gremillion 1993). Sin embargo Cowan \& Smith (1993) verifican que el CV aumenta cuando se consideran diversos cultivares actuales de morfología muy diferente al interior de una especie domesticada por lo cual, en este caso, un aumento en el $\mathrm{CV}$ o un $\mathrm{CV}$ alto en conjuntos arqueológicos puede indicar la presencia de cultivares con frutos de morfología muy diferente.

Resumiendo, la etapa inicial de domesticación estaría caracterizada por una tendencia a la disminución en el CV respecto de las poblaciones silvestres, luego este tenderá a aumentar por la coexistencia de formas silvestres y otras que exhiben rasgos novedosos, con la domesticación la variabilidad disminuiría por la presencia de fuertes presiones selectivas, pero con la generación de diversos cultivares la diversidad aumentaría nuevamente. Puede verse que no hay una tendencia lineal en la diversidad morfológica y que sus valores no son absolutos, sino relativos. A pesar de ello el empleo del CV ha demostrado ser de gran utilidad en estudios morfo-anatómicos y biométricos de domesticación vegetal (Cowan y Smith 1993, Gremillion 1993, Newson 1993).

Saber si estamos ante cultivos transicionales o cultivos que no lo son (es decir, si estamos ante el cultivo previo a la domesticación o al cultivo sin domesticación, en términos de Hillman y Davies 1990) es sumamente difícil ante la ausencia de tendencias lineales en la variabilidad de los rasgos implicados en este proceso de cambio, pudiendo solamente inferirse si se está ante uno u otro tipo mediante el empleo de vías complementarias de análisis. 
Vías complementarias de análisis.

Hillman y Davies (1990) consideran que en depósitos de ocupación con restos morfológicamente silvestres es posible distinguir si estos son el resultado de prácticas de cultivo o de recolección usando la evidencia asociada de restos de otras especies de plantas que son diagnósticas de hábitats naturales o antrópicos. Las prácticas de recolección pueden ocasionar cambios incidentales en las plantas involucradas tales como modificaciones en la abundancia y las frecuencias genéticas de las poblaciones silvestres (Casas 2001, Hather y Mason 2002). En este último caso se debe recurrir indefectiblemente a estudios genéticos. Para analizar modificaciones en la abundancia se puede analizar si existe a lo largo del tiempo un aumento notable en la cantidad de semillas colectadas que supere la producción media natural de las poblaciones naturales locales.

El registro e identificación de las especies presentes en la totalidad del registro arqueobotánico también es una vía útil para distinguir cultivos transicionales de plantas en su primera etapa de domesticación. Si en el conjunto arqueológico aparecen unos pocos ejemplares del cultivo transicional junto con la forma silvestre es probable que todavía no se haya producido la domesticación. Si, en cambio, los ejemplares de cultivo transicional aparecen junto a una gran cantidad de ejemplares domesticados, probablemente estos ejemplares no sean formas transicionales sino ejemplares domesticados entre los cuales persisten caracteres ancestrales o existe aún una alta taza de cruzamiento con poblaciones silvestres o con malezas ante la ausencia de un grado mayor de selección o aislamiento reproductivo. En este sentido las frecuencias relativas de los tipos de plantas que pueden identificarse en la totalidad del registro arqueobotánico se vuelve fundamental. 
Otra vía propuesta por Hillman y Davies (1990) es el análisis de artefactos asociados que habrían estado involucrados en la cosecha o en la recolección, como las hoces microlíticas o de madera vinculadas con la cosecha de trigo, las azuelas y los palos cavadores, éstos últimos generalmente difíciles de reconocer (Unger-Hamilton 1985, Buxó y Piqué 2008).

Para muchos autores cultivar implica la preparación de áreas específicas para la propagación de las plantas (Ford 1979, Yernell 1983 en Smith 1985, Asch y Asch 1985, Piperno y Pearsall 1998, Hather J. y Mason S. 2002), por lo cual la aparición de huertos en el registro arqueológico podría ser otro indicador de cultivo sin domesticación. Sin embargo este rasgo estaría también presente en relación a plantas domesticadas. Los huertos son, además, espacios donde suelen coexistir gran diversidad de especies con distinto grado de asociación con las comunidades humanas, siendo frecuentes los complejos "malezacultivo-domesticado" (Harris 1989, Vogl et al. 2002, Vogl-Lukasser et al. 2002). Por lo tanto los huertos indican asociaciones complejas y no se vinculan directa o únicamente con un tipo de planta o modo de relación.

\section{Identificación de prácticas.}

En la selección cultural que opera sobre plantas cultivadas intervienen acciones conscientes cuando, por ejemplo, se procuran ciertos caracteres o inconciente cuando se modifica el medio donde estas plantas se desarrollan. A pesar de ello, en ambientes modificados por el hombre no deja de operar la selección natural. Distinguir si las modificaciones presentes en las plantas domesticadas se deben a uno u otro tipo de selección resulta sumamente difícil (Decker y Wilson 1986). Un ejemplo claro al respecto son los cambios que sufren las semillas, principalmente un aumento en su tamaño por incremento en el tamaño del embrión y sustancias de reserva y un adelgazamiento de las cubiertas seminales. Este conjunto de cambios puede 
interpretarse como un mecanismo que permite una germinación más rápida y un establecimiento también más rápido del embrión tras la misma, lo cual es una clara ventaja adaptativa en ambientes densamente poblados como los antrópicos (Murray 1984, Kaplan 1965, Smith 2006). Pero estos rasgos pueden ser también interpretados como el resultado de la selección cultural en pro de obtener semillas más nutritivas, palatables (Whitaker y Cutler 1968) y fáciles de procesar. En este sentido creemos que para asegurar que estos rasgos se deben a selección cultural y no natural solamente, se deben identificar cambios que necesariamente impidan la reproducción de la planta sin la intervención del hombre, los cuales afectan principalmente a los frutos (Butler 1989, Hillman y Davies 1990), y son necesariamente fijados en las poblaciones por una selección consciente de los humanos que resiembran estos tipos generación tras generación.

Tomando en cuenta los aspectos desarrollados en este capítulo se considera apropiado para identificar distintas formas de relación humano-planta en los macrorrestos vegetales aplicar:

-análisis morfológicos macroscópicos.

-análisis anatómicos-histológicos micromorfológicos.

-análisis biométricos macro y microscópicos: atendiendo principalmente al empleo de índices y a los coeficientes de variación de los parámetros métricos empleados en el análisis. En este caso restos arqueobotánicos que exhiban caracteres métricos presentes tanto en la forma silvestre como en la domesticada de un mismo taxa serán considerados transicionales en tanto se ajusten a los parámetros señalados por Hillman y Davies (1990) y Clement (1999) previamente descritos, sumado a la caracterización del conjunto arqueobotánico asociado. 
Tabla 3: recopilación de trabajos donde se emplean indicadores de domesticación, tanto cualtitativos como cuantitativos, en relación a la morfología de macrorrestos. Todos ellos toman como base de comparación caracteres presentes en poblaciones actuales de formas tanto silvestre como domesticada del taxón bajo estudio.

\begin{tabular}{|c|c|c|c|c|c|}
\hline Tipo de estudio & Taxa & Estructura & Análisis aplicado & Observaciones & Referencia \\
\hline Cuantitativo & Cucurbita sp & Pericarpio & Espesor & $\begin{array}{c}\text { Más de } 2 \mathrm{~mm} \\
\text { es } \\
\text { domesticada, } \\
\text { pero menos no } \\
\text { indica silvestre }\end{array}$ & $\begin{array}{c}\text { Cowan y } \\
\text { Smith } \\
1993 ; \\
\text { Cowan } \\
1997 ; \\
\text { Smith 1997 }\end{array}$ \\
\hline Cualitativo & Cucurbita sp & Pericarpio & Aspecto externo & $\begin{array}{c}\text { Presencia de } \\
\text { lóbulos y } \\
\text { verrugas indica } \\
\text { domesticación }\end{array}$ & $\begin{array}{l}\text { Cowan y } \\
\text { Smith } \\
1993 ; \\
\text { Cowan } \\
1997 ; \\
\text { Smith 1997 }\end{array}$ \\
\hline Cuantitativo & Cucurbita sp & Semilla & Largo y ancho. & \begin{tabular}{|c|} 
Más de $11 \mathrm{~mm}$ \\
es domesticada \\
pero no se \\
puede asegurar \\
que menos de \\
esta medida \\
sea silvestre \\
\end{tabular} & $\begin{array}{l}\text { Cowan y } \\
\text { Smith } \\
1993 ; \\
\text { Cowan } \\
1997 \\
\text { Smith 1997 }\end{array}$ \\
\hline Cuantitativo & Cucurbita sp & Pedúnculo & Diámetro del pedúnculo. & $\begin{array}{l}\text { Más de } 8 \mathrm{~mm} \\
\text { es } \\
\text { domesticado, } \\
\text { menos es } \\
\text { silvestre }\end{array}$ & $\begin{array}{c}\text { Cowan y } \\
\text { Smith } \\
1993 ; \\
\text { Cowan } \\
1997 \\
\text { Smith 1997 }\end{array}$ \\
\hline Cualitativo & Cucurbita sp & Fruto & Forma y color. & $\begin{array}{l}\text { Forma y color } \\
\text { son } \\
\text { diagnósticas }\end{array}$ & \begin{tabular}{|c|} 
Cowan y \\
Smith \\
$1993 ;$ \\
Cowan \\
$1997 ;$ \\
Smith 1997
\end{tabular} \\
\hline Cuantitativo & Vitis sp & Semilla & $\begin{array}{c}\text { Largo y ancho. Relación } \\
\text { ancho/largo }\end{array}$ & $\begin{array}{c}\text { No se altera la } \\
\text { forma, sí el } \\
\text { tamaño }\end{array}$ & $\begin{array}{c}\text { Kay et al } \\
1980\end{array}$ \\
\hline Cuantitativo & Vitis sp. & Semilla & $\begin{array}{l}\text { Índice ancho/largox100; } \\
\text { grosor/anchox100; } \\
\text { grosor/largox100 }\end{array}$ & \begin{tabular}{|c|} 
Índices son \\
diagnósticos. \\
Tienen en \\
cuenta cambios \\
con \\
carbonización \\
de distintos \\
tipos \\
\end{tabular} & $\begin{array}{c}\text { Mangafa y } \\
\text { Kotsakis } \\
1996\end{array}$ \\
\hline Cuantitativo & \begin{tabular}{|} 
Géneros Canarium \\
Dracontomelon \\
Pandanus \\
y Spondias
\end{tabular} & Endocarpio & $\begin{array}{c}\text { Diámetro y largo. } \\
\text { Diametro/largo y } \\
\text { Largo/diámetro. Analisis uni } \\
\text { y bivariado }\end{array}$ & $\begin{array}{l}\text { Aumento en el } \\
\text { tamaño de } \\
\text { semillas por } \\
\text { selección } \\
\text { cultural }\end{array}$ & $\begin{array}{l}\text { Lepofsky et } \\
\text { al. } 1998\end{array}$ \\
\hline Cuantitativo & Chenopodium sp. & Semilla & $\begin{array}{c}\text { Espesor de la testa/diámetro } \\
\text { de la semilla }\end{array}$ & $\begin{array}{l}\text { Indicador } \\
\text { directo de } \\
\text { manejo } \\
\text { humano. }\end{array}$ & $\begin{array}{c}\text { Bruno y } \\
\text { Whitehead } \\
2003\end{array}$ \\
\hline
\end{tabular}




\begin{tabular}{|c|c|c|c|c|c|}
\hline Cualitativo & Chenopodium sp. & Semilla & $\begin{array}{l}\text { Margen y textura de la } \\
\text { cubierta seminal }\end{array}$ & $\begin{array}{l}\text { Indicador } \\
\text { directo de } \\
\text { manejo } \\
\text { humano. }\end{array}$ & $\begin{array}{c}\text { Bruno y } \\
\text { Whitehead } \\
2003\end{array}$ \\
\hline Cuantitativo & Chenopodium sp. & Semilla & $\begin{array}{l}\text { Espesor de la testa y } \\
\text { diámetro de la semilla }\end{array}$ & $\begin{array}{c}\text { Unido a } \\
\text { factores } \\
\text { ambientales y } \\
\text { culturales } \\
\text { (manejo) } \\
\end{array}$ & \multirow{2}{*}{$\begin{array}{l}\text { Gremillion } \\
1993 \\
\\
\\
\text { Gremillion } \\
1993\end{array}$} \\
\hline Cualitativo & Chenopodium sp. & Semilla & Margen & $\begin{array}{c}\text { Unido a } \\
\text { factores } \\
\text { ambientales y } \\
\text { culturales } \\
\text { (manejo) }\end{array}$ & \\
\hline Cualitativo & $\begin{array}{l}\text { Géneros } \\
\text { Lathyrus.;Lens.; } \\
\text { Pisum y Vicia } \\
\text { (Familia Vicieae) }\end{array}$ & Semilla & $\begin{array}{l}\text { Morfología superficial de la } \\
\text { testa y micromorfologia } \\
\text { interna de la cubierta } \\
\text { seminal. Quimiotaxonomia, } \\
\text { presencia de ciertas } \\
\text { sustancias químicas } \\
\text { asociadas a la dormancia. }\end{array}$ & \begin{tabular}{|c|} 
No encuentra \\
caracteres \\
diagnósticos \\
salvo testas \\
más gruesas en \\
cultivares de \\
Pisum \\
\end{tabular} & Butler 1989 \\
\hline $\begin{array}{l}\text { Cualitativo y } \\
\text { cuantitativo }\end{array}$ & $\begin{array}{c}\text { Géneros Medicago } \\
\text {, Melilotus, } \\
\text { Trifolium y } \\
\text { Trigonella (Familia } \\
\text { Faboideae) }\end{array}$ & Semilla & $\begin{array}{c}\text { Morfología general y } \\
\text { micromorfología de la testa. } \\
\text { Carbonización experimental } \\
\text { y análisis multivariado }\end{array}$ & \begin{tabular}{|c|} 
Forma y \\
tamaño de las \\
semillas son \\
diagnósticos. \\
La \\
micromorfologia \\
de la testa \\
difiere entre \\
Trifolium y \\
Medicago \\
respecto de \\
Melilotus y \\
Trigonella \\
\end{tabular} & Butler 1996 \\
\hline Cualitativo & $\begin{array}{l}\text { Géneros: Lens; } \\
\text { Pisum y Vicia } \\
\text { (Familia Vicieae) }\end{array}$ & Fruto & $\begin{array}{l}\text { Morfología superficial de la } \\
\text { vaina y de los tejidos que la } \\
\text { componen. }\end{array}$ & $\begin{array}{l}\text { No encuentra } \\
\text { caracteres } \\
\text { diagnósticos }\end{array}$ & Butler 2002 \\
\hline Cualitativo & $\begin{array}{c}\text { Géneros Triticum y } \\
\text { Hordeum }\end{array}$ & Fruto & Morfología de raquis & $\begin{array}{c}\text { La morfología } \\
\text { difiere si son } \\
\text { caedizos o fijos }\end{array}$ & $\begin{array}{l}\text { Hillman y } \\
\text { Davies } \\
1990\end{array}$ \\
\hline $\begin{array}{l}\text { Cualitativo y } \\
\text { cuantitativo }\end{array}$ & Helianthus annuus & $\begin{array}{l}\text { Fruto y } \\
\text { semillas }\end{array}$ & $\begin{array}{c}\text { Morfología de la base de los } \\
\text { aquenios y tamaño de los } \\
\text { mismos }\end{array}$ & \begin{tabular}{|c|} 
La morfología y \\
tamaño de los \\
aquenios indica \\
frutos con \\
mayor o menor \\
concentración \\
de aquenios \\
\end{tabular} & $\begin{array}{c}\text { Lentz et al. } \\
2008\end{array}$ \\
\hline Cuantitativo & $\begin{array}{l}\text { Lagenaria } \\
\text { siceraria }\end{array}$ & Pericarpio & Espesor & $\begin{array}{c}\text { Mayor a } 2 \mathrm{~mm} \\
\text { indica } \\
\text { domesticación }\end{array}$ & $\begin{array}{c}\text { Erickson et } \\
\text { al. } 2005\end{array}$ \\
\hline
\end{tabular}




\subsection{1 - GÉNERO CUCURBITA.}

El género Cucurbita (familia Cucurbitaceae, subfamilia Cucurbitoideae) es estrictamente americano e incluye una serie variable de especies tanto silvestres como domesticadas cuyo número varia entre 12 y 26 de acuerdo con las diferentes taxonomías que se tomen en cuenta (Whitaker y Bemis 1976, Jeffrey 1980, Nee 1990, Lira Saade 1995). La mayoría son anuales, habiendo algunas perennes (Hurd et. al. 1971).

Las Cucurbitáceas son una familia marcadamente homogénea, los taxa que la componen son muy similares en morfología, función, plagas que los atacan, condiciones para el cultivo, además de su intolerancia a las bajas temperaturas (Whitaker 1982). Esta familia es esencialmente tropical y es por ello que sus miembros se han adaptado bien a climas templados con baja incidencia de heladas, aunque se han desarrollado también unos pocos cultivares con tolerancia a bajas temperaturas y con capacidad para crecer rápidamente en suelos fríos (Whitaker 1974). No tienen una preferencia marcada por un tipo particular de suelo ya que demandan cantidades moderadas de humedad y nutrientes, aunque su cultivo rinde más si el suelo se encuentra bien drenado y cae en un rango entre levemente ácido a levemente alcalino (Whitaker 1968). Responden a condiciones áridas desarrollando una gran raíz de almacenamiento; el follaje, flores y frutos se desarrollan en un período muy corto, mientras que la raíz grande y carnosa es perenne (Whitaker 1974). Como las Cucurbitáceas son sensibles al frío, las pocas que se extienden hacia regiones templado-frías pasan el invierno bajo tierra como tubérculos o son anuales y pasan el invierno como semillas (Jeffrey 1980 en Ashworth y Galetto 2001).

Las especies cultivadas del género Cucurbita reconocidas por todos los autores mencionados son cinco: 
-C. pepo L.: anual, sensible a la helada pero tolerante a temperaturas bajas, enredadera o arbusto. Se distribuye desde el centro de México hasta el sur de Canadá. ${ }^{1}$

-C. moschata (Duch ex Lam) Duch. ex Poir..: anual, sensible a la helada e intolerante a temperaturas bajas, enredadera. Desde sudoeste de EE.UU. hasta el centro-oeste de Argentina.

-C. argyrosperma Huber: anual, sensible a la helada e intolerante a temperaturas bajas, enredadera. Desde el sudeste de México a sudoeste de EE.UU.

-C. maxima ssp. maxima Duch. ex Lam.: anual, es sensible a las heladas pero es la más tolerante a temperaturas bajas luego de C. ficifolia, enredadera o arbusto (C. maxima ssp. maxima cv. zapallito como arbustiva). Su fruto presenta a veces la típica forma de turbante debido a que el ovario queda por fuera del receptáculo. Cultivares: Mammoth, Mammoth Chili, Hubbard, Delicious, Boston Marrow, Banana, Buttercup Essex Hybrid, Olive, Marblehead, entre muchos otros. Distribución: oeste de Argentina, norte de Chile y Perú.

-C. ficifolia Bouché: tolerante a temperaturas bajas aunque no resiste las heladas, enredadera. Su distribución sigue la línea de los Andes y otras cadenas montañosas desde México a Chile. Es de zonas altas pero requiere un fotoperíodo corto para reproducirse.

En cuanto a las especies silvestres, existen varias identificadas en la zona comprendida entre el sudoeste de Estados Unidos y noroeste de México (Bailey 1943, Lira Saade 1995), las mismas poseen muchas ecoespecies separadas geográficamente pero que se cruzan entre sí, pudiendo haber anuales o perennes, xerofíticas o mesofíticas (Bemis y Whitaker 1969 Whitaker y Bemis 1976).

En cuanto a Sudamérica existen dos taxa silvestres identificados: Cucurbita maxima Duch. ex Lam. ssp. andreana (Naudin) Filov y Cucurbita ecuadorensis Cutler \& Whitaker. Esta última fue considerada por Whitaker y Cutler (1968)

\footnotetext{
${ }^{1}$ Todas las distribuciones que se consignan para las cinco especies son previas al conquista europea y se han establecido en base a hallazgos arqueológicos.
} 
como la primera especie silvestre descripta para el norte de Sudamérica, y la definieron taxonómicamente a partir de ejemplares colectados en 1965 a 5 millas al oeste de Guayaquil y de otros colectados en un valle profundo y cálido a una altura de 2500 pies aproximadamente cerca de Ambuqui al noreste de Ibarra, también en Ecuador. Esta especie difiere de C. maxima ssp. andreana y de otras cucúrbitas silvestres americanas por poseer un fruto relativamente más grande, algunos de ellos no amargos (Nee 1990). En su trabajo de 1990, M. Nee propone que sería una forma semidomesticada con caracteres que la alejarían de otras formas silvestres o malezoides, mientras que en opinión de Piperno y Pearsall (1998) sería una especie domesticada y luego "perdida". Nee ingresa un ejemplar de esta especie al New York Botanical Garden en 1997 procedente de Manabí, Ecuador, donde localmente recibe el nombre de "chía" e indica que los frutos no son muy amargos. En cuanto a su relación con otras especies de Cucurbita, Whitaker y Cutler (1968) señalan que se hibrida fácilmente con C. maxima ssp. maxima, pero la descendencia pierde fertilidad, y que es simpátrica en su distribución con $C$. ficifolia. Estudios genéticos la agrupan con C. maxima ssp. maxima y C. maxima ssp. andreana, pudiendo las tres especies compartir un antecesor común (Wilson et al. 1992 en Piperno y Pearsall 1998).

C. maxima ssp. andreana es una hierba anual muy variable en tamaño y de tallos rastreros (Ashworth y Galetto 1999). Sus flores son color amarillo fuerte, siendo las masculinas más abundantes en la zona central de la planta y las femeninas en la zona terminal de las guías vegetativas, la floración se produce de diciembre a mediados de abril (Ashworth y Galetto 1999, 2001). Esta subespecie es muy propensa a variar, sobre todo en el tamaño de los frutos, los cuales pueden ser ovoides, oblongos, esféricos o deprimidos, su longitud varía de 6 a 21,5 cm; la cáscara es dura, pudiendo ser de un solo color (verde claro, verde amarillento o anaranjada) o puede poseer franjas longitudinales anchas verde oscuro entre las cuales hay otras más angostas verde claro o 
crema, a veces con lunares; mesocarpio verde, blanco o anaranjado, muy amargo, el cual suele reabsorberse y quedar reducido a un conjunto de fibras, constituyendo un fruto seco y liviano que se conserva indefinidamente. El pedúnculo no es corchoso como en C. máxima ssp. maxima sino más o menos herbáceo o fibroso y por lo general caduco (Millán 1945, Martínez Crovetto en Burkart 1974, Ashworth 1997). La mayoría de las poblaciones actuales de este taxón se ubican en el centro-este de Argentina y Uruguay (Nee 1990, Lira Saade 1995), aunque recientemente se han encontrado poblaciones en Bolivia (Andres y Nee 2005) y Perú (Valega Rosas et al. 2004). En cuanto a sus relaciones evolutivas, gran cantidad de autores (Whitaker y Bemis 1965, Millan 1945, Nee 1990, Brücher 1989, Decker Walters y Walters 2000, Albeck 2001, Sanjur et al. 2002) coinciden en señalarla como el antecesor de C. maxima ssp maxima

Para las especies $C$ ficifolia y $C$. moschata se desconocen hasta el presente sus antecesores silvestres. En el caso de C. moschata hallazgos arqueológicos recientes en Ecuador, Colombia y el norte de Perú parecerían establecer una relación estrecha entre ésta y C. ecuadorensis (Piperno et al. 2000, Stothert et al 2003, Piperno et al 2003, Dillehay et al 2007, Piperno et al 2008). Análisis genéticos han vinculado esta especie con C. argyrosperma ssp. sororia (L.H. Bailey) Merrick \& Bates del área centroamericana, por lo cual un área de origen en el norte de Colombia (donde se registra la mayor diversidad actual de C. moschata) se considera, hasta el momento, lo más probable (Piperno y Pearsall 1998, Sanjur et al. 2002, Dillehay et al. 2007, Piperno et al. 2008).

Si bien se desconoce aún al antecesor silvestre de C. ficifolia, Andres (1990) sugiere que el mismo no se hallaría en las zonas altas, frías y húmedas donde suele encontrarse esta especie ya que ninguna Cucurbita silvestre se da naturalmente bajo estas condiciones. Este autor sugiere que la preponderancia de poblaciones que florecen en días cortos hablaría a favor de un antecesor silvestre ubicado en la zona tórrida americana. Si bien Andres (1990) se vuelca 
a favor del área norte de Sudamérica, reconoce que las menciones de ejemplares asilvestrados o naturalizados son escasas. Cárdenas (1969) reporta que en algunas cabeceras de Yungas en Bolivia existen frutos de esta especie de apariencia silvestre por ser espontáneos y estar en posición colgante de las pendientes montañosas. Nee (1990) cuenta también con reportes sobre la presencia de poblaciones de C. ficifolia aparentemente silvestres en la localidad de Inquisivi en el Departamento La Paz, Bolivia, en un área de selva nublada en la ladera oriental andina a 3000 m.s.n.m.

Por lo tanto, de las tres especies de Cucurbita americanas domesticadas, solo se conoce al antecesor silvestre de C. maxima ssp maxima, el cual prospera en territorio argentino. Es por ello que en los capítulos correspondientes a esta sección analizaremos el hipotético proceso de domesticación que llevo de $C$. maxima ssp andreana a $C$. maxima ssp maxima analizando múltiples y complementarios tipos de evidencia. 


\subsection{1a- Características que avalan o rechazan la concepción de $C$. maxima Duch. ex Lam. ssp. andreana (Naudin) Filov como posible antecesor de C. maxima ssp. maxima Duch. ex Lam}

\section{Introducción}

La utilización de sistemas de clasificación taxonómicos resultan problemáticos al intentar trazar las líneas de evolución y cambio de los organismos biológicos. Los límites que necesariamente se deben establecer para poder emplear ciertas categorías $-\mathrm{y}$ por ende otorgarles los nombres correspondientes- obstaculizan muchas veces la denominación apropiada de ciertos organismos que no respetan claramente dichas delimitaciones. Este es el caso de la "yerma", “yukería” o "cháncara" (Pochettino 1985) de Argentina, la cual fue identificada taxonómicamente por primera vez en 1896 por Naudin quien la denominara Cucurbita andreana Naud. (Millán 1945). Desde entonces el "zapallito amargo" -como es conocido en Buenos Aires- pasó a ser identificado como una especie distinta y en años sucesivos quienes se ocuparon de su estudio lo denominaron tal como lo propuso Naudin. Posteriormente, se reconocieron ciertas fallas en la propuesta del mencionado autor tales como el error en considerar que este tipo de zapallo poseía semillas negras, pero sólo Grebenscikov propuso cambiar la taxonomía de esta especie en la década del cincuenta al incluirla como una variedad de Cucurbita maxima. ssp. maxima:: Cucurbita maxima Duch var. parvifurutina Grebenscikov (Martínez Crovetto 1947). Esto resulta correcto desde el punto de vista de que ambos taxones son interfértiles y por lo tanto responderían a una misma especie biológica, siendo sus diferencias significativas sólo para establecer una división infraespecífica. Sin embargo, autores como Hunziker y Subils (1975) proponen sobre la base de caracteres morfológicos como la ausencia de nectarios hipofoliares en $C$. maxima ssp. andreana, junto a caracteres 
carpológicos y areográficos que los mismos "permite(n) mantener a $C$. andreana como una especie independiente de C. maxima." (1975: 46). Este punto introduce el difícil problema de los caracteres que se consideran apropiados para establecer los límites taxonómicos entre organismos cercanamente emparentados. Si bien durante gran parte del siglo XX se mantuvo en uso la propuesta de Naudin, trabajos recientes han optado por considerar a la "cháncara" como una subespecie: Cucurbita maxima subsp. andreana (Lira Saade 1995, Ashworth y Galetto 1999, 2001, Sanjur et.al. 2002). Lira Saade (1995), quien ha realizado una de las más recientes y actualizadas caracterizaciones taxonómicas de las Cucurbitáceas, considera que algunos de los taxa que ubica a nivel de especie "deberían estar en una categoría infraespecífica, pero en la mayoría de los casos su transferencia taxonómica formal aún no ha sido realizada" (Lira Saade 1995:17). El autor establece seis grupos dentro del género Cucurbita, siendo uno de ellos el grupo maxima el cual comprende a C. maxima con dos subespecies: C. maxima ssp. maxima y $C$. maxima ssp andreana., además de C. moschata.

En este capítulo analizaremos distintas características propias de C. maxima ssp. andreana que apoyan o rechazan su carácter de planta silvestre o maleza, considerando las consecuencias que esto trae aparejado tanto en lo referente a su adscripción taxonómica como a su posición evolutiva relativa respecto de C. maxima ssp. maxima. Se evaluará también la posibilidad mayormente aceptada de que C. maxima ssp andreana haya evolucionado hacia C. maxima ssp maxima (Parodi 1935, 1966, Millán 1945, Whitaker y Bemis 1965, Albeck 2001, Millán 1945, Nee 1990, Decker Walters y Walters 2000, Sanjur et al. 2002), y también la propuesta que refiere a que ambas evolucionaron a partir de un hipotético ancestro común actualmente desaparecido o aún no identificado (Wilson et al. 1992, en Piperno y Pearsall 1998).

\section{Materiales y métodos.}


La dificultad taxonómica que han presentado los organismos domesticados ya sean animales o vegetales- ha sido destacada con anterioridad por distintos autores (Clutton Brock 1989, Harlan 1992), sin embargo, han sido escasas las propuestas tendientes a superar visiones dicotómicas como las del tipo silvestre/domesticado. Este tipo de abordaje binario ha obstaculizado la clasificación de ejemplares o poblaciones cuyas características derivan de distintos grados de asociación con comunidades humanas (ver capítulo 1) tanto hallados actualmente, como recuperados en sitios arqueológicos. En este último caso, la ausencia de criterios más apropiados generó el uso de clasificaciones ad hoc confusas, poco acertadas y cuya aplicación no superaba muchas veces la del propio sitio arqueológico donde se recuperaban sus restos. En lo referente a la taxonomía de C. maxima ssp. andreana no se pretende realizar una propuesta de clasificación u optar por una de las ya existentes, el objetivo de este capitulo es realizar una aproximación crítica a las categorías que están siendo utilizadas actualmente para abordar el estudio de los procesos de domesticación en los que se ha visto envuelta esta subespecie, a través de una revisión y análisis de la bibliografía de referencia en el tema.

\section{Resultados}

Para comenzar a entender mejor las dificultades implicadas en el estudio de los procesos de domesticación de especies vegetales, comenzaremos por ampliar la dicotomía silvestre/domesticado introduciendo la categoría de "maleza" ("weed") propuesta por Harlan y de Wet (1965 y 1975). Si bien

reconocemos que seguimos dentro de un pensamiento clasificatorio tipológico, intentaremos relativizar las categorías luego de definirlas para ir difuminando los límites de las mismas e intentar comprender la dinámica del 
cambio en el mundo vegetal cuando éste entra en interacción con sociedades humanas.

De acuerdo con Harlan (1992) las plantas cultivadas y domésticas requieren un tratamiento taxonómico especial puesto que se caracterizan, a diferencia de las plantas silvestres, por grandes afinidades genéticas (sin la existencia de claras barreras reproductivas) junto a marcadas diferencias morfológicas, obteniéndose como resultado una enorme cantidad de variación entre formas muy cercanamente relacionadas. Este resultado sería el producto de la combinación de períodos cortos - pero intensos- de manipulación humana junto con frecuentes retrocruzas con organismos emparentados (silvestres o malezas). Ante esto, el autor propone un sistema novedoso de clasificación basado en el uso de pooles genéticos y categorías como "raza" o "subraza" en lugar de la taxonomía linneana tradicional, ya que ésta -según su opinióntiende a la sobreclasificación cuando se enfrenta a plantas cultivadas. Este autor opina además que la clasificación infraespecífica debería ser simple, de modo tal que sea equiparable a la que -de forma pragmática- establecen quienes lidian cotidianamente con cultivos y formas relacionadas. En el caso de las cucúrbitas esto se manifiesta claramente en las clasificaciones que han hecho los granjeros estadounidenses. Esta clasificación es de tipo agronómica y principalmente gastronómica agrupando a las variedades estivales de cucúrbitas que se consumen inmaduras (“summer squash"), diferenciándolas de aquellas invernales que se consumen fisiológicamente maduras, pueden conservarse por más tiempo, son usadas como forraje y permiten una mayor variedad de procesamientos y modos de consumo ("winter squash" o “pumpkins") (Whitaker y Jagger 1937; Whitaker y Bohn 1950). Esta clasificación se aplica a cuatro de las cinco especies cultivadas, ya que C. ficifolia posee una distribución geográfica más restringida y es empleada principalmente para elaborar dulces (Andres 1990). A su vez, la diferenciación entre las cinco especies cultivadas quedaría evidenciada en la ausencia de 
cruzas espontáneas entre ellas con descendencia viable (Whitaker y Bohn 1950). Otra clasificación folk es aquella realizada por la gente que siembra estas plantas en nuestro país. La misma viene dada por el hábito de estas plantas, distinguiendo entre formas rastreras ("zapallo de guía") y arbustivas ("tronquero", "zapallito de tronco"). Esta división se corresponde a su vez con el hecho de que sus frutos se consumen maduros e inmaduros respectivamente (Millán 1947). En el último caso existe además la alusión, mediante un diminutivo, al tamaño del fruto. Otras referencias que tienen que ver con la morfología del fruto se encuentran en nombres como "cabeza de turco" o "cuello de cisne" que se le dan respectivamente a variedades de $C$. maxima ssp. maxima y de C. moschata por las formas particulares de sus frutos.

Por lo tanto si deseamos analizar el lugar que ocupa un organismo manipulado por el hombre dentro de un sistema de clasificaciones -el cual necesariamente será arbitrario- deberán considerarse distintos aspectos tales como morfología, distribución geográfica, caracteres organolépticos, adaptaciones ecológicas y, por supuesto, el comportamiento de dicho organismo ante el accionar humano. A continuación analizaremos y discutiremos estos aspectos para el caso de C. maxima ssp. andreana.

Cuando se ha caracterizado el hábitat donde suele prosperar C. maxima ssp. andreana la gran mayoría de los autores han coincidido en que es en los suelos disturbados por la acción humana donde más se la suele encontrar. Así, Hunziker y Subils (1975:44) dicen que habita en "campos bajos o sobre los arbustos que bordean los alambrados, o en maizales y vizcacheras"; lo mismo opinan Ashworth y Galetto (2001:398): "Es una especie adaptada a crecer en suelos disturbados como los suelos agrícolas, por ello se la encuentra en campos de cultivo de maíz o soja o bien en antiguos campos agrícolas abandonados". Esta misma observación ya la había realizado Burkart tras observar que en Tapiales (Bs.As.) "abundan mucho en un campo bajo 
cultivado con maíz, estando el rastrojo lleno de zapallitos maduros" (Contardi 1939:343). Todas estas apreciaciones hallan explicación en parte en una peculiaridad que ya fuera señalada por Parodi (1935). Este autor notó que esta especie "no tiene un "hábitat" de planta silvestre; más bien parece una planta doméstica o lo más adventicia, pues crece en suelos modificados, maizales, antiguas taperas, viejos corrales, vizcacheras, etc.” (Parodi 1935 en Contardi 1939:333). Cárdenas (1944) nota la ausencia de cucúrbitas silvestres sudamericanas y niega este estado a C. maxima ssp. andreana ya que crece en suelos modificados por el hombre. Posteriormente este autor se refiere directamente a la misma como maleza o planta adventicia (Cárdenas 1969). Las apreciaciones de estos autores llevan a pensar en C. maxima ssp. andreana como una maleza, lo cual implica serias reconsideraciones al momento de evaluar cuál sería el hábitat de esta especie, ya que la influencia del accionar humano a través del tiempo diversificará necesariamente al mismo. Pero si bien Parodi había vislumbrado en la década del treinta que C. maxima ssp. andreana poseían un status poco definido, esto no produjo una reconsideración profunda de la posición de esta planta, y en décadas sucesivas -incluso en la actualidad- se sigue hablando de C. maxima ssp. andreana como una planta silvestre (Millán 1945, Hunziker y Subils 1975, Sanjur et. al. 2002, Ashworth y Galetto 2002, Boelcke 1981, Brücher 1989, Piperno y Pearsall 1998, Teppner 2004, Valega Rosas et al. 2004, Andres y Nee 2005) o incluso se la denomina indistintamente como maleza o planta silvestre (Carreras et al. 1989, Hurd et. al. 1970). Otros autores utilizan para caracterizarla términos más imprecisos como "weedy" (Decker Walters y Walters 2000: 347, Nee 1990:59) que podríamos traducir como "malezoide". Brücher (1989) es claro en su postura de que $C$. maxima ssp. andreana es una planta silvestre y no un escape de cultivo de C. maxima ssp. maxima, lo cual no quita -de acuerdo con el autorque se la pueda hallar como maleza en campos de cultivo. Cutler y Whitaker (1961) hablan de un carácter malezoide o bien le asignan directamente la 
categoría de maleza. Algo similar escribe Pozner quien, retomando a Parodi (1935), señala que: "habita terrenos modificados en los que se comporta como maleza" (Pozner 1998 en Ashworth y Galetto 1999:188). En opinión de Hernández (1985 en Altieri y Merric 1987) como C. maxima ssp andreana no se encuentra restringida en su distribución a medios agrícolas exclusivamente, no sería una planta arvense en sentido estricto.

La paradoja que le presentó C. maxima ssp. andreana a Parodi se refleja en la dificultad del autor para asignarla a una categoría definida: no es una planta nativa, parece doméstica pero no lo es del todo, es "a lo más adventicia" (Parodi 1935 en Contardi 1939). Pero todo aquello que posee esta especie que la hace extraña a muchas clasificaciones, la acerca a la categoría de maleza propuesta por Harlan y de Wet $(1965,1975)$ (ver capítulo 1). Por ende, para analizar si estamos o no ante una maleza, analizaremos a continuación distintos aspectos de C. maxima ssp. andreana y su grado de ajuste a las definiciones de estos y otros autores (Chhandak et al. 2004).

El modo de propagación es un carácter crucial para diferenciar una maleza de una planta domesticada dado que indica diferencias en el tipo e intensidad de intervención humana en el ciclo reproductivo de la planta. El mecanismo que permite la dispersión de las semillas de C. maxima ssp andreana no ha sido aún dilucidado, ya que el fruto es un pepo indehiscente (Lira Saade 1995) y los compuestos amargos y tóxicos que posee evitan que sea consumida por los animales (Ashworth 1997, Decker Walters y Walters 2000, Bisognin 2002). Debido a estos caracteres se ha considerado indispensable la intervención del hombre para permitir su dispersión (Ashworth 1997). Una posibilidad podría ser la propagación de las semillas junto con el fruto al presentar el mismo una separación asegurada del pedúnculo a la madurez, el cual no es corchoso como en C. maxima ssp maxima sino más o menos herbáceo o fibroso y por lo general caduco (Millán 1945), siendo el fruto trasladado luego por factores 
abióticos tales como cursos de agua o pendientes. A este tipo de dispersión contribuiría también un mesocarpio que se reabsorbe a la madurez dejando un fruto muy liviano, así como también una cáscara delgada (Millán 1945). Si aceptamos esta propuesta, vemos un modo de dispersión que sería acorde a medios naturalmente disturbados (con pendientes pronunciadas o inundables) que permitirían el traslado de esta especie a distancias tanto cortas como largas, dependiendo de la dinámica del ambiente y no de la mano del hombre. Este tipo de dispersión es el que, de acuerdo con Cowan (1997), poseen las especies silvestres norteamericanas del género. Además, la intervención de un gran número de polinizadores en la reproducción sexual de este taxón, todos los cuales aseguran una buena producción, es un carácter tomado por Ashworth (1997) como señal de buena adaptación a hábitats disturbados.

Entre las adaptaciones características de las malezas anuales se halla la gran producción de semillas, generalmente pequeñas, con dormancia prolongada que previenen su germinación simultánea (Harlan y de Wet 1965). C. maxima ssp andreana es anual y posee un gran número de semillas pequeñas, pudiendo tener entre 153 y 448 por fruto, dependiendo del tamaño de éste último (Ashworth 1997). El dispositivo de dormancia y tasa de maduración de sus semillas no son aún conocidos (ver capítulo 4.1.1c). Los autores citados establecen que "otro síndrome adaptativo es aquél en el que la maleza se mimetiza con el cultivo lo suficientemente bien como para ser cosechada junto con el cultivo y sembrada con él en la próxima estación de siembra" (Harlan y de Wet 1965:21, nuestra traducción). Existe una distinción clara entre C. maxima ssp andreana y C. maxima ssp maxima a partir del color y forma de sus frutos (ver capítulo 4.1.1d). A pesar de esto último se ha dicho que la semejanza entre los frutos de C. maxima ssp andreana y los de C. maxima ssp maxima cv. zapallito ("zapallito de tronco") ha provocado que "...algunos engañados de su semejanza los han echado alguna vez en la olla, y es tanta su amargura, que una tajada pequeña ha sido bastante para viciar una olla 
grande" (Pérez Castellano 1914 en Millán 1945:86). Esta semejanza pude llegar a producirse en el caso de algunas poblaciones del cultivar Zapallito que poseen frutos pequeños, globosos, lisos y de color verde claro (Contardi 1939, Millán 1945, Lopez-Anido et al 2003). Sin embargo, un fenómeno muy común es la presencia de "zapallitos de tronco" cuya apariencia es la usual para este cultivar, pero que al probarlos son amargos, sugiriendo esto su cruza con $C$. maxima ssp andreana. Este fenómeno es frecuente puesto que "el carácter amargo es heredable, dominante y regido por un factor simple" (Contardi 1939) y se transmite directamente a C. maxima ssp maxima manifestándose la presencia de cucurbitacina en los frutos de la primera generación híbrida ${ }^{1}$. Esta particularidad permitiría separar, mediante un test organoléptico simple de los frutos, las formas híbridas y detectar la presencia de C. maxima ssp andreana en las plantaciones o sus inmediaciones. Sin embargo, frutos dulces de C. maxima ssp maxima no garantizan semillas puras, Contardi (1939) estudió cruzamientos naturales donde un $23 \%$ de las semillas de zapallos dulces dieron al verano siguiente plantas con frutos de sabor amargo. Por lo tanto, la presencia de frutos amargos en plantas domesticadas puede darse por motivos genéticos intrínsecos a las mismas sin que haya hibridación con C. maxima ssp andreana. A lo anterior se suma el hecho de que la diferencia entre ambas subespecies se vuelve patente al momento de la fructificación, pero cuando el fruto está ausente "los caracteres de los tallos, hojas y flores son indiferenciables" (Millán 1945:90). Esto es señalado por los indios Sonora del noroeste de Méjico, quienes no pueden distinguir sus cucúrbitas domésticas (C. argyrosperma) de la maleza que circunda sus campos (C. argyrosperma ssp sororia) hasta la época de fructificación de las mismas (Merrick y Nabhan

\footnotetext{
${ }^{1}$ Los casos de intoxicación por consumo de "zapallitos de tronco" son muy conocidos, tanto es así que la muerte de algunas personas alérgicas tras la ingestión de sus frutos comprados en el circuito comercial llevó a que se estableciera obligatoriamente una franja de separación sanitaria en los cultivos comerciales de esta especie para evitar la hibridación con C. maxima ssp andreana (A. Nico com. pers.). Este fenómeno no se ha registrado casi para el "zapallo criollo" (C. maxima ssp maxima), el cual -a diferencia del anterior- se consume fisiológicamente maduro, pudiendo llegar a ser ésta la causa de la ausencia de casos de intoxicación. Sin embargo, Contardi (1939) ha demostrado experimentalmente que el sabor amargo se transmite a los frutos de C. maxima ssp maxima, si bien no especifica en qué punto de maduración de los frutos llevó a cabo dicha comprobación.
} 
1984). Por lo tanto, C. maxima ssp andreana lograría en parte mimetizarse con su contraparte domesticada, cruzándose con ella y aprovechando -aunque más no sea esporádicamente- las ventajas que la misma obtiene del cuidado del hombre. Una vez que fructifican las plantas pueden ser erradicadas, sin embargo, Brücher (1989) señala que los frutos de pericarpio duro de esta subespecie pueden sobrevivir en el suelo por muchos meses, incluso años, produciendo constantemente nuevas poblaciones. Este carácter le permitiría también permanecer en los campos cultivados, o sus inmediaciones, generación tras generación. Dicho carácter de persistencia es propio también de las malezas, de acuerdo con Harlan y de Wet (1965).

Las especies silvestres de los géneros Lagenaria, Cucumis, Cucurbita y Citrullus poseen cucurbitacinas (Robinson et al 1976), un conjunto de triterpenos tetracíclicos oxigenados (Martínez Crovetto1974, Jeffrey 1980, Decker Walters y Walters 2000). Varios autores consideran que la presencia de este principio tóxico y amargo cumple la función de evitar la herbivoría como forma de propagación de las semillas (Ashworth 1997, Decker Walters y Walters 2000, Bisognin 2002). ${ }^{2}$ En opinión de Bisognin (2002) la presencia de cucurbitacinas en los frutos del género Cucurbita sería un carácter silvestre-ancestral producto de la coevolución con el escarabajo de la cucurbita, el cual se alimenta de sus frutos amargos. Harlan y de Wet (1965) mencionan la presencia de principios tóxicos en ciertas malezas perennes cuya función sería aumentar la persistencia de las mismas en los campos cultivados. Por lo tanto la presencia de cucurbitacinas en C. maxima ssp andreana podría ser un carácter ancestral que las poblaciones que evolucionaron como maleza mantuvieron puesto que era ventajoso también en su nuevo hábitat.

\footnotetext{
${ }^{2}$ Por su parte Jeffrey (1980) sugiere que los aminoácidos libres de las semillas de las cucurbitáceas podrían también funcionar como mecanismos de defensa química, ya que los embriones que contienen estas sustancias son altamente nutritivos y carecen de cucurbitacinas.
} 
En la tabla 4 puede verse la correspondencia entre ciertos caracteres de $C$. maxima ssp andreana y los propuestos por Chhandak et al. (2004) para las malezas, entendidas éstas en el sentido ecológico del término.

El caracterizar a escala específica una planta de naturaleza malezoide implica prestar especial atención al fenómeno de introgresión o retrocruza -ya que las malezas son por lo general interfértiles con su contraparte domesticada- a fin de discriminar cuáles de los caracteres que presenta le son propios o distintivos y cuáles son el resultado de cruzamientos con poblaciones domesticadas afines. La incidencia de este fenómeno ha sido particularmente problemática en el caso de C. maxima ssp. andreana y generó discusiones y replanteos que aún hoy no están resueltos definitivamente. Este fenómeno se manifiesta a menudo en la diversidad morfológica de los frutos de distintas poblaciones de esta subespecie, fenómeno destacado ya por otros autores (Decker Walters y Walters 2000), quienes suponen incluso que algunos cultivares podrían haberse desarrollado a partir de selecciones hechas sobre poblaciones de C. maxima ssp andreana que ya contaban con un cierto grado de introgresión.

En un principio se pensó que C. maxima ssp. andreana era un escape de cultivo, una forma asilvestrada de C. maxima ssp. maxima. Whitaker y Bemis (1965) son los primeros en proponer esta posibilidad señalando que C. maxima ssp. andreana es: "una maleza de Argentina y Bolivia probablemente ingresada por el hombre junto a C. maxima. Muchos de los zapallos cultivados en Argentina y Bolivia parecen ser híbridos de Cucurbita andreana y Cucurbita maxima y formas similares han resultado de cruces hechos por Whitaker en California (datos sin publicar)" (Cutler y Whitaker 1961:474, n. t.). Sin embargo estos autores reconocen la falta de evidencia para sostener esta propuesta. Recientemente Nee (1990) da al problema un abordaje interesante, comentando que "se ha considerado a veces a $C$. andreana como un escape de cultivo de C. maxima, pero esto solo lo forzaría a uno a buscar en otra parte de 
Sudamérica por especies silvestres ancestrales cuyas características serían todas precisamente aquellas de C. andreana", a esto agrega que "cada Cucurbita domesticada parece haber surgido de diferentes especies silvestres (o de dos especies silvestres cercanamente emparentadas) y estos progenitores aun existen como especies silvestres, incluso si interactúan con sus descendientes cultivados" (Nee 1990:59, n.t.). Recordemos que este autor clasifica a $C$. maxima ssp. andreana como una forma "malezoide" ("weedy"), distinta de $C$. ecuadorensis que sería una forma silvestre (Whitaker y Cutler 1968) o semidomesticada (Nee 1990, Piperno et al. 2008). Recientemente la Goldman Cucurbit Collecting Expedition corroboró la existencia de escapes de cultivo de C. maxima ssp. maxima en el sur de Bolivia y NOA (Andres y Nee 2005). Hurd et al. (1971) considerando la marcada especialización que exhibe la abeja Peponapis fervens, producto de una larga historia de co-evolución con una Cucurbita silvestre de la flora sudamericana, sugieren que "especies que han sido consideradas como escapes de cultivo (ferales) (por ej,. C. andreana) pueden de hecho no ser asilvestradas sino ancestrales a las especies cultivadas" (1970:227, n. t.). Parodi (1935, 1966), Millán (1945) y Brücher (1989) también consideran a C. maxima ssp. andreana como antecesor silvestre.

Pensar el proceso en sentido inverso es también válido, ya que ciertas poblaciones de C. maxima ssp. maxima pueden asimismo obtener ciertos caracteres por retrocruza con la subespecie malezoide. Resultan muy ejemplificadores en este sentido los casos ya mencionados de frutos del cultivar Zapallito que presentan gusto amargo. Un caso que resulta paradigmático a este respecto es el de la población de Cruz del Eje, Córdoba, reportada por Millán (1945). Esta población de C. maxima ssp. andreana, de acuerdo a la determinación del autor, poseía frutos amargos que eran lobulados o tenían la particular forma del tipo denominado "cabeza de turco" provocada al emerger el ovario del receptáculo, un rasgo característico y específico de C. maxima ssp. maxima (Whitaker y Bohn 1950, Lira Saade 
1995). Estos rasgos morfológicos del fruto, tan atípicos para C. maxima ssp. andreana y propios de su contraparte domesticada llevarían a considerar que se trataría de poblaciones de $C$. maxima ssp. maxima, fuera de cultivo que posiblemente se hibridaron con C. maxima ssp. andreana adquiriendo así el sabor amargo (Lira Saade 1995). Pero, por otra parte, debe considerarse que dichos rasgos tenían que estar presentes en el pool génico del antecesor silvestre a fin de que, al manifestarse fenotípicamente, fueran luego seleccionados y fijados bajo poblaciones domesticadas (R. Pozner com. pers.). Por lo tanto más que conformar dos entidades separadas, al no poseer barreras genéticas las dos subespecies de C. maxima, conformarían un complejo cultivo-maleza, tal como lo propusieron Whitaker y Cutler en su trabajo de 1961. Si asumimos que C. maxima ssp. andreana es una maleza asociada a la domesticada C. maxima ssp. maxima entendemos que no es por lo tanto su "antecesor silvestre" en sentido estricto. Harlan y de Wet (1975, 1965) son muy claros al establecer que las malezas tienen sus propias historias evolutivas y que éstas muchas veces van de la mano de sus contrapartes domésticas con las cuales suelen coexistir e hibridarse. En distintas especies, luego de una divergencia inicial entre poblaciones, los cambios adaptativos comienzan a actuar como mecanismos de aislamiento, sin embargo una cierta transferencia de genes por hibridación e introgresión son deseables debido al vigor híbrido; por lo tanto se puede decir que el ideal es un cierto equilibrio entre la divergencia y la introgresión, dos procesos evolutivos opuestos (de Wet y Harlan 1975). La presencia de cruzamientos entre formas silvestres y cultivadas fue reconocida incluso en poblaciones bajo siembra de cucúrbitas norteamericanas modernas como mecanismo aplicado para generar variabilidad (Beebe et a. 1997). También se ha registrado el cruzamiento incidental entre poblaciones de C. argyrosperma y C. argyrosperam ssp. sororia, considerada una maleza, en los terrenos cultivados por los indos Pima en el noroeste de Méjico (Nabhan 1984). 
Por lo tanto se considera que no sería conveniente buscar en las poblaciones actuales del zapallito amargo caracteres "silvestres" o "ancestrales" desde una mirada ecológica y filética, ya que parte de los rasgos que actualmente presentan las mismas son el resultado de su historia evolutiva como maleza. Al tomar esto en consideración, podemos llegar a decir que contamos con al menos tres protagonistas en esta historia de cambios evolutivos: una forma domesticada (C. maxima ssp. maxima), una maleza (C. maxima ssp. andreana) y una hipotética forma silvestre, antecesora de $a_{m b a s}{ }^{3}$. Intentaremos recrear entonces un posible escenario en el que estas tres formas vayan haciendo aparición a partir de la entrada del hombre a escena.

El establecimiento de grupos humanos en un área habría ocasionado una primera perturbación de la misma, esta área perturbada habría sido ocupada en primer lugar por especies silvestres, las cuales suelen ser colonizadoras agresivas. Si la utilización de esta supuesta área por grupos humanos no se mantiene en el tiempo, estas primeras formas colonizadoras posibilitarán el establecimiento de poblaciones estables que prosperarán sin sufrir cambios adaptativos o morfológicos notables, pudiendo ser incluso protegidas por las comunidades humanas. En cambio, si la ocupación humana es persistente, surgirán las primeras formas malezoides. Este escenario -modificado parcialmente del propuesto por de Wet y Harlan (1975)- llevaría entonces, ante una primera perturbación del medio, sólo a la expansión del área de distribución de las especies silvestres, pero de continuar la perturbación irían apareciendo las malezas, las cuales evolucionarían dentro del hábitat antrópico en tres formas principales: “(1) a partir de colonizadores silvestres y, a través de la selección, hacia una adaptación a perturbaciones continuas del ambiente; (2) derivadas a partir de la hibridación entre razas silvestres y domesticadas de especies cultivadas y (3) desde formas domesticadas abandonadas y, a través

\footnotetext{
${ }^{3}$ Recordemos que también se ha propuesto, a partir de estudios genéticos, que estas dos subespecies junto con C. ecuadorensis compartirían un antecesor común (Wilson et al.1992, en Piperno y Pearsall 1998) (ver capitulo 4.1.1b).
} 
de la selección, hacia una asociación menos íntima con el hombre." (de Wet y Harlan 1975:100, n.t.).

La introgresión entre formas domesticadas y silvestres de una misma especie ocurre, obviamente, donde las mismas son simpátricas. Los híbridos resultantes raramente logran invadir hábitats naturales ya que heredan de su progenitor domesticado alguno de los caracteres que el mismo obtuvo por selección cultural, los cuales no suelen ser ventajosos en un medio prístino, por lo cual seguirán ocupando los hábitats modificados por el hombre volviéndose malezas (de Wet y Harlan 1975). Esto explicaría por qué los registros de poblaciones de C. maxima ssp andreana provienen casi exclusivamente de ambientes con signos notables de intervención humana como campos de cultivo, veras de caminos, etc (ver capitulo 4.1.1 b)

Las poblaciones cultivadas que son luego abandonadas pueden seguir subsistiendo en un ambiente disturbado, aunque sin ser atendidas por el hombre; o bien adaptarse a ambientes que, progresivamente, van recuperando su carácter natural primigenio. En ambos casos pueden generar formas novedosas o bien volver a manifestar caracteres ancestrales que habían sufrido una selección negativa por parte del hombre, pero que no fueron definitivamente eliminados del pool génico de la población y ahora son nuevamente seleccionados a favor por selección natural. Como mencionáramos anteriormente, la presencia de cucurbitacinas sería un carácter ancestral en C. maxima ssp. andreana, por lo cual es factible suponer que en poblaciones asilvestradas dichos principios tóxicos se manifestarán nuevamente, tras haber sido su presencia desalentada por las poblaciones humanas. En el caso del paso directo de formas silvestres a malezas, la presencia de cucurbitacinas perdurará a través de este proceso como carácter dominante ya que su función, como vimos anteriormente, justifica su presencia también en plantas que son malezas. Para el caso puntual de $C$. maxima ssp. andreana esta parecería responder a los tipos 2 y 3 de malezas que 
surgen luego de los procesos de domesticación, pero tampoco podemos descartar - a partir de la evidencia disponible- que sea del tipo 1 y haya surgido directamente de la forma silvestre.

La posibilidad de diferenciación morfológica entre las tres formas (silvestre, maleza y domesticada) suele ser difícil, es por ello que Harlan y de Wet (1965) consideran que "la secuencia de plantas silvestres adaptadas a hábitats naturalmente perturbados, a malezas adaptadas a ambientes disturbados por el hombre, a cultivos domesticados, será difícilmente visualizada a través de análisis morfológicos y citogenéticos" (Harlan y de Wet 1965:20 n.t.). Los autores opinan que esto generalmente ocurre porque la historia evolutiva de la maleza la ha llevado a tal grado de especialización que produce una progresiva separación de su antecesor silvestre y su contraparte doméstica en tal medida que no parecieran estar relacionadas entre sí. Esta divergencia evolutiva depende del tipo y grado de aislamiento, el cual puede ser espacial (las tres formas no deben ser simpátricas), estacional o resultado de barreras gametofíticas (de Wet y Harlan 1975). No existe barrera alguna a nivel gametofítico entre C. maxima ssp. andreana y C. maxima ssp. maxima ya que ambas son interfértiles. También ambas presentan una misma estacionalidad en sus ciclos vitales, Cucurbita maxima ssp. andreana florece de diciembre a mediados de abril (Asworth y Galetto 2001) y Cucurbita maxima ssp. maxima desde mediados de noviembre a mediados de abril (Passarelli 2002). Tampoco podemos hablar de separación espacial ya que -al menos actualmente- ambas formas ocupan ambientes similares y comparten los mismos polinizadores, por lo cual una separación efectiva entre ambas debería darse a una distancia tal que no se pueda realizar el cruce polínico, sobre todo el realizado por las abejas, las que poseen rangos de acción amplios. Por lo tanto, en el caso de la historia evolutiva de C. maxima se mantiene la asunción de Harlan y de Wet (1975) sobre la dificultad de reconocer el paso de formas silvestres a malezas y formas domesticadas desde lo morfológico, pero no por 
las abrumadoras diferencias entre éstas como manifiestan estos autores, sino, por el contrario, por las estrechas semejanzas que exhiben.

Sumando todas las características que hemos mencionado estaríamos en condiciones de afirmar que C. maxima ssp. andreana no es una planta silvestre que subsiste solo en hábitats primarios, sino una maleza adaptada a sobrevivir en hábitats disturbados por la acción humana. Esto hace que las características presentes en la misma no se puedan considerar directamente como caracteres ancestrales respecto de C. maxima ssp. maxima, sino más bien como rasgos de una maleza con su propia historia evolutiva. A esto se suman los sucesivos eventos de introgresión entre ambas subespecies que habrían moldeado en gran parte los caracteres que actualmente exhibe C. maxima ssp. andreana Por lo tanto el problema radica en que se desconoce cómo eran las poblaciones de C. maxima ssp andreana previo a la domesticación de C. maxima ssp. maxima y la consecuente hibridación entre ambas. Estas poblaciones sólo serían factibles de ser hallados en el registro arqueológico, aunque ya hemos analizado las dificultades implicadas en su reconocimiento en los restos arqueobotánicos (capítulo 4.1).

Una consideración importante en relación a la historia evolutiva de C. maxima ssp maxima es que la forma cultivada transicional que habría llevado a la forma domesticada (ver figura 2) debería presentar algunas características malezoides -en el sentido de que son plantas adaptadas a crecer en ambientes antrópicos con capacidad de reproducción autónoma- careciendo de otras no deseadas por el hombre, y presentes en las malezas, como los compuestos tóxicos. Por lo tanto, algunos caracteres de C. maxima ssp. andreana podrían haber sido compartidos también por el cultivo transicional que luego dio lugar a C. maxima ssp. maxima.

Hipótesis en torno a los motivos para la domesticación de poblaciones de Cucurbita silvestre 
Un primer paso necesario en el estudio de la domesticación de una especie es analizar cuál podría haber sido el interés inicial que motivó su manipulación. Esto si asumimos que existió intencionalidad, ya que también pudo existir, en un principio, un manejo incidental (inconsciente) de la misma.

Uno de los primeros rasgos que surgen al pensar en una manipulación inicial de una Cucurbita silvestre es la presencia de compuestos tóxicos en la misma. El elevado contenido de cucurbitacina que presentan los frutos de C. maxima ssp. andreana ha llevado a descartar su consumo, aunque deja abierta la posibilidad para otras estructuras como flores o semillas (Whitaker y Cutler 1968, Millán1968). Sin embargo, existe gran cantidad de frutos tóxicos que son consumidos por grupos horticultores o cazadores-recolectores tras ser procesados para eliminar sus compuestos nocivos (Johns y Kubo 1988, Harlan 1992).

De acuerdo con Bemis y Whitaker (1975) un rasgo común a todas las especies silvestres de Cucurbita es que, si bien el mesocarpio del fruto es amargo debido a la presencia de cucurbitacinas, las semillas no son amargas siendo comestibles en la mayoría de las especies, por lo cual el hombre habría colectado primeramente las cucúrbitas para consumir sus semillas hasta haber hallado un fruto no amargo, comenzando luego su cultivo. Autores como Nee (1990), Cowan y Smith (1993), Decker Walters y Walters (2000), Robinson y Decker-Walters (1997en Bisognin 2002), Cowan (1997) y Lira Saade (1995) mencionan también la presencia de cucurbitacinas exclusivamente en el mesocarpio, a diferencia de otros autores que explícitamente sostienen la presencia de este principio en las semillas. Entre estos últimos se encuentran Hart (2004) quien establece que se hallaría en la cubierta seminal de C. pepo o Sharma y Hall (1971 en Robinson et al. 1976) quienes hallaron que un solo gen domina la presencia de cucurbitacina en el cotiledón de esta misma especie. Por lo tanto el área de localización y los factores que regulan la 
presencia de este compuesto químico son aún en gran parte desconocidos. Paulsen (1936) efectuó análisis químicos sobre frutos maduros o casi maduros de C. maxima ssp andreana, determinando así la presencia de cucurbitacinas y saponinas de gusto amargo a partir del análisis de destilados. Si bien el autor no es explícito a este respecto, su estudio parecería indicar que estos principios de gusto amargo se ubican en el mesocarpio del fruto, sin embargo pudo haber incluido semillas en los destilados que elaboró, dato que, lamentablemente, no se especifica en su trabajo. Estudios más recientes de este compuesto orgánico con fines médicos (Jayaprakasam et al. 2003) tampoco son explícitos en cuanto al órgano o tejido de C. maxima ssp. andreana del cual extraen la cucurbitacina.

Como se mencionó anteriormente, el hombre a lo largo de los siglos ha podido consumir frutos tóxicos aplicando distintos procedimientos previos a su consumo. Tomemos como ejemplo el caso de Citrullus colocynthis (L.) Schard, también de la familia Cucurbitaceae, donde primeramente se descubrió la cucurbitacina (Millán 1945). Johns y Kubo (1988) mencionan que el empleo de esta especie se extiende por vastas regiones de África donde es tratada principalmente con métodos de desintoxicación por solución y por calor. Los autores mencionan que en el sur de África se usa el hervido sucesivo con cambios de agua junto con la desintoxicación por cambios de $\mathrm{PH}$, lo cual se logra agregando sal, cenizas, lejía u otro producto; en esta área se emplean además métodos que utilizan el calor. En África occidental también se usan estos últimos, principalmente el tratamiento por medio del vapor junto con desintoxicación por solución, la que involucra el uso de agua para la lixiviación o remojo luego de moler los frutos (Johns y Kubo1988). Otros métodos usados en combinación con los anteriores son el secado -el cual es útil para toxinas volátiles y se emplea usando hornos o simplemente la radiación solar- y los métodos físicos, principalmente la molienda, cuyo 
principal fin es destruir ciertos tejidos a fin de liberar los principios amargos que contienen (Johns y Kubo 1988).

Si bien actualmente no se ha registrado el consumo de C. maxima ssp andreana, se cree que Charrúas, Puelches y Tehuelches comían los frutos de esta subespecie tostados, costumbre registrada también entre los gauchos, quienes tostaban los frutos en el rescoldo del fogón ${ }^{4}$ (Millán 1968, Brücher 1989) (ver capitulo 4.1.1b) Aunque Millán (1968) intentó este tipo de procedimiento sin éxito alguno, Hart (2004) menciona casos en que otros investigadores tampoco lograron reproducir experiencias para desintoxicar semillas de $C$ pepo atribuyendo esto no sólo a fallas en los procedimientos realizados, sino también a las variaciones interpoblacionales con respecto a este principio amargo. Las especies silvestres del género Cucurbita de América del Norte son objeto de diversos tratamientos. Las semillas de Cucurbita foetidissima H.B.K. ("buffalo gourd", "coyote melon" o "calabacilla") eran colectadas por varios grupos indígenas siendo hervidas o tostadas previo a su consumo, los frutos jóvenes eran hervidos sucesivamente con cenizas y en la actualidad los indios Hopi consumen las flores (Cutler y Whitaker 1961). Nee (1990) ve en los procesos de desintoxicación de C. argyrosperma ssp. sororia por medio de repetidos hervidos de la pulpa en sucesivos cambios de agua, la vigencia de procesos de domesticación contemporáneos llevados adelante por las poblaciones del oeste mexicano. Experimentos llevados a cabo en formas asilvestradas de $C$. pepo demostraron la presencia de sustancias amargas en las cubiertas seminales de Cucurbita pepo ssp. ovifera var. ozarkana (Scheele) D.S. Decker que pueden ser removidas sumergiendo o hirviendo sucesivamente las semillas en agua junto con cenizas, proceso que se ve favorecido si las semillas son quebradas (Hart, 2004) ${ }^{5}$. El Pbro. Don Manuel Pérez Castellano refiere a

\footnotetext{
${ }^{4}$ Lira Saade (1995) reporta en su trabajo estos mismos datos agregándole que estos grupos también consumían los frutos de C. maxima ssp. andreana crudos. La consulta de las fuentes originales citadas por el autor nos ha llevado a ver que esta referencia es inexistente.

${ }^{5}$ Cowan y Smith (1993) consideran que el sabor amargo de las semillas de C. pepo ssp. ovifera se debe a que el tejido de la placenta permanece adherido fuertemente a la cubierta seminal, opinión compartida por
} 
unos "calabazos" que, como son amargos, se dulcifican poniéndolos en agua y sometiéndolos luego a varios lavados (Millán 1945). Esta sea probablemente una referencia a la desintoxicación de frutos de L. siceraria. (ver capitulo 4.1.1b).

En territorio argentino, entre los grupos Wichi del Chaco árido se han desarrollado métodos de desintoxicación para diversas plantas recolectadas. Para los frutos inmaduros de Capparis salicifolia Griseb., C. retusa Griseb. y C. speciosa Griseb. y las semillas y flores con brotes tiernos de esta última, se emplea la técnica de hervores sucesivos con cambios de agua. En el caso de las semillas de C. speciosa estas se hierven, se secan al sol, luego son molidas en mortero para separarlas de las cubiertas seminales y antes de consumirlas se aplica el mismo tratamiento con cambios de agua. Los tubérculos de Synandrospadix vermitoxicus (Griseb) Engl y las raíces de Cissus sicyoides L. se desintoxican también con hervores y con cuatro a seis cambios de agua, además de ser primeramente carbonizados parcialmente en el fogón (Maranta 1987, Arenas 2003).

Por lo tanto, habría dos formas de desintoxicación de órganos vegetales: por hervidos sucesivos o por tostado. Esta ultima técnica sería la registrada por Millán (1968) y Brücher (1989) para los frutos de C. maxima ssp. andreana .

Las partes vegetativas de ciertas Cucurbitáceas poseen también cucurbitacina (Cutler y Whitaker 1961), sin embargo la presencia de pedúnculos inmaduros en el registro arqueológico ha llevado a considerar el consumo de los frutos inmaduros y tiernos, probablemente eliminando la toxina tras sucesivos hervidos (Decker Walters y Walters 2000). Un patrón similar de consumo de frutos inmaduros tras sucesivos hervores es también comentado por Lira Saade (1995) quien atribuye la presencia de cucurbitacina sólo a la pulpa del fruto, sosteniendo que existen datos que indican que las semillas tostadas o asadas son ocasionalmente empleadas como alimento.

Nee (1990) para las cucúrbitas silvestres en general. Asimismo Cowan y Smith (1993) consideran que los ejemplares no amargos son evidencia de hibridación con la doméstica C. pepo. 
Las semillas del zapallito amargo son ricas en aceites y proteínas como sucede en la mayoría de las especies de cucúrbitas domesticadas (Pochettino 1985), por lo cual su consumo traería aparejado ciertos beneficios a escala nutricional. Análisis químicos llevados a cabo en once especies de los géneros Cucurbita, Lagenaria, Cucumis y Citrullus revelaron que las semillas de C. maxima ssp. andreana son las que poseen mayor contenido en aceites, lo cual va aparejado también con el hecho de que es la especie con semillas más pequeñas (Carreras et al. 1989). Por lo tanto si se analiza la relación tamaño de la semilla/cantidad de lípidos en C. maxima ssp. andreana y en C. maxima ssp. máxima se ve que $100 \mathrm{~g}$ de semillas de ambas especies proveen casi la misma cantidad de lípidos (55.09\% y 50.91\% respectivamente, Carreras et al. 1989), pero para llegar a 100 g. se necesitan 343 semillas de C. maxima ssp. máxima pero 3115 de C. maxima ssp. andreana aproximadamente. Esta última posee en promedio unas 320 semillas por fruto, pudiendo llegar a 450 aproximadamente (Ashworth 1997), en la especie domesticada, en cambio, el número varía de acuerdo con el tipo de polinización, entre 676 semillas por fruto en el peor de los casos, a 2700 en el mejor, de acuerdo con los resultados de Passarelli (2002). Por lo tanto resulta evidente que se pueden adquirir más expeditivamente una mayor cantidad de semillas en el caso de $C$. maxima ssp. maxima obteniéndose como consecuencia mayor cantidad de lípidos por fruto. De las especies silvestres del género, C. maxima ssp. andreana es también la que mayor contenido de aceites posee: 39,4\%, correspondiendo el 19\% a palmítico, $34 \%$ a oleico y $42 \%$ a linoleico (Lira Saade 1995).

Existen, además, ciertos usos en los cuales la presencia de principios amargos como las saponinas (las cuales se hallan presentes en los frutos de C. maxima ssp andreana según Paulsen 1936) se verían propiciados. Entre éstos se encuentra el uso de la pulpa del fruto o las raíces como jabón, tal como hacen ciertos aborígenes mejicanos con C. okeechobeensis (Small) L.H. Bailey ssp.martinezzi (L.H. Bailey), C. foetidissima H-B.K., C. pedatifolia L.H. Bailey, C. 
argyrosperma ssp. sororia y C. lundelliana L.H. Bailey (Cutler y Whitaker 1961, Pochettino 1985, Lira Saade 1995). Para Nee (1990) esto habría actuado, sin embargo, como una razón subsidiaria en la domesticación de Cucurbita. La presencia de cucurbitacina pudo verse propiciada si se usaron los frutos de $C$. maxima ssp andreana como "planta-trampa" (Contardi 1939), una utilidad posiblemente empleada una vez establecidos cultivos permanentes que proteger ${ }^{6}$. Otro uso donde posiblemente también se vean implicadas estas sustancias amargas es en el empleo de los frutos machacados de C. maxima ssp. andreana como mordiente para teñir lana, un empleo registrado actualmente en las comunidades rurales de Córdoba (Ashworth com. pers.). Finalmente, se sabe que la cucurbitacina fue usada en el pasado como purgante, vermífuga y abortiva (Valderas 2000) y actualmente se ha estudiado el efecto antitumoral de los distintos tipos de cucurbitacina (Jayaprakasam et al. 2003) por lo cual no debe desestimarse su uso medicinal en el pasado.

El pericarpio de los frutos secos de C. maxima ssp andreana es usado actualmente por los indios Ashaninkas para elaborar artesanías para su venta a los turistas en Perú (Valega Rosas et al. 2004). El uso de los frutos como recipientes es reportado para especies silvestres de Cucurbita en América del Norte (Cutler y Whitaker 1961, Lira Saade 1995). Cowan (1997), sin embargo, descarta de lleno la posibilidad de que los frutos de Cucurbita silvestres hayan sido empleados como contenedores, cucharas o flotadores no sólo porque no existe evidencia arqueológica al respecto, sino porque considera que el hecho de que las paredes del fruto se enrollen y el reducido tamaño de los mismos basta para descartar esta clase de empleo. Si bien el tamaño puede no considerarse en sí mismo un aspecto desfavorable, el hecho de que las paredes

\footnotetext{
${ }^{6}$ El uso de C. maxima ssp. andreana como planta-trampa se halla vinculado a proteger a las hortalizas del ataque de Diabrotica speciosa (conocida como "vaquita de San Antonio") la cual no solo polinizan al zapallito amargo sino que también sienten una fuerte atracción por sus frutos debido al principio amargo que poseen, ya que rechazan las formas dulces (Contardi 1939). Si bien no se sabe la distribución originaria de esta especie, la misma se encuentra actualmente en Brasil, Perú, Paraguay, Uruguay y Argentina (ver: Cartes de Répartition Géographique des Organismes de Quarantaine pour l'Europe) y además de hortalizas ataca plantas americanas como el maíz, maní, porotos y papa (Cabrera Walsh 2003), por lo cual es factible extrapolar el uso del zapallito amargo como planta-trampa al pasado prehispánico sudamericano.
} 
se enrollen sí puede serlo. Esta característica de los frutos tiene relación con el grado de lignificación del pericarpio, el cual es variable entre especies de Cucurbita así como también al interior de las mismas (Piperno et al. 2002) y depende también del grado de domesticación (ver capitulo 4.1.1d). Si el fruto se deja madurar y secar entero el pericarpio no se enrolla, pero se vuelve muy frágil dado su escaso espesor.

Es probable, por lo tanto, que en un principio no se hayan manejado los frutos para su empleo como recipiente, prefiriéndose el consumo de las semillas y/o fruto previa aplicación de procesos de desintoxicación, hasta lograr aislar poblaciones sin cucurbitacina.

La intervención de polinizadores en el proceso de domesticación de C. maxima ssp. maxima

Los géneros de abejas Peponapis y Xenoglosa (conocidas como "abejas del zapallo") son polinizadores específicos del género Cucurbita y derivan toda su economía del polen y néctar de este género (Hurd et. al. 1971). Estos autores mencionan que el género Xenoglosa se distribuye en América del norte y central y el género Peponapis se distribuye tanto en América del norte (10 especies) como en América del sur (3 especies). El género Peponapis posee seis subgéneros entre los cuales sólo el subgénero Peponapis s.str. está representado en Sudamérica y posee tres especies con distribución disyunta: $P$. (Colocynthophila) fervens ocupa gran parte del área centro sur de Sudamérica; $P$. (Austropeponapis) melonis está limitada a las tierras bajas y en los alrededores de Guayaquil, Ecuador, y P. (P.) citrullina se distribuye desde Ecuador hacia el sur hasta la provincia de Tarapacá, Chile y hacia el norte a través de Colombia y Venezuela hasta Trinidad (Hurd et. al. 1971).

Tal como hemos argumentado, al comenzar el consumo de frutos y/o semillas de C. maxima ssp. andreana se debieron haber seleccionado 
poblaciones libres de cucurbitacina. Dado que la presencia de esta última es causada por un único gen dominante (Robinson et al. 1976), una posibilidad sería que ciertos grupos humanos dieran con poblaciones recesivas no amargas de C. maxima ssp. andreana y las mantuvieran mediante una reproducción controlada ${ }^{7}$. Sin embargo surge la duda de cómo se mantendría este carácter ante la presencia de polinizadores como las abejas del género Peponapis que cubren grandes distancias y favorecen la cruza entre poblaciones distantes y diversas. De hecho, la gran expansión del área que abarcan las abejas americanas del género Peponapis y Xenoglosa a partir de su hipotética área de distribución original, se vincula con su capacidad de extender sus rangos de acción hacia nuevas áreas siguiendo "rutas de polen" demarcadas por las plantaciones de Cucurbita spp. (Hurd et al. 1970). Whitaker y Jagger (1937) llamaron la atención sobre la adaptabilidad de las cucúrbitas a la polinización por insectos, siendo difícil mantener líneas puras ya que ésta es una fuente importante de variabilidad. Es por ello que actualmente las estaciones experimentales emplean la retrocruza para obtener líneas aisladas más uniformes realizando luego, a partir de las poblaciones obtenidas, una selección dirigida hacia variedades con caracteres específicos (Whitaker y Jagger 1937).

Una posibilidad es que las poblaciones humanas hayan utilizado los medios de propagación asexual de C. maxima ssp. andreana -carácter mencionado por Ashworth (1997)- generando "clones" a partir de formas que reunieran caracteres deseados. Sin embargo, una vez generados estos clones, habría cierta incidencia de polinización por insectos que generaría formas no

\footnotetext{
${ }^{7}$ La regulación genética de este carácter en $C$. maxima ssp. andreana y C. maxima ssp. máxima no se encuentra exhaustivamente estudiada. Por ejemplo, no se explica de manera satisfactoria si los ejemplares amargos de esta última especie responden exclusivamente a la cruza con la maleza o puede ocurrir que dicho carácter se manifieste por combinaciones genéticas intraespecíficas. La regulación de este carácter debe poseer además relación con mecanismos fisiológicos ya que en las cruzas de C. maxima ssp. andreana con C. maxima ssp. maxima cv zapallito el sabor amargo se presenta en los frutos de zapallito obtenidos en la primera generación, lo cual se hace patente al consumírselos inmaduros. Sin embargo este mismo fenómeno jamás ha sido reportado para otros cultivares de C. maxima ssp. maxima cuyos frutos se consumen fisiológicamente maduros y cuyas cruzas con C. maxima ssp. andreana son altamente probables, al igual que ocurre con los zapallitos de tronco.
} 
deseadas que deberían ser controladas a fin de que no se vuelvan dominantes con el transcurso del tiempo. Esta fue probablemente una etapa donde la protección de poblaciones no amargas y el control de su reproducción resultó fundamental para mantener los caracteres deseados. Ashworth (1997) considera que el hecho de que C. maxima ssp. andreana presente un gran número de polinizadores igualmente eficientes (coleópteros, lepidópteros y dípteros, ver capitulo 4.1.1b) es un signo de que se halla bien adaptada a los hábitats disturbados donde crece. Este carácter generalizado y oportunista propio de una maleza- se encuentra en parte regulado por ciertas particularidades del ambiente como la diversidad de especies vegetales, aunque en este caso el factor principal es el grado de perturbación del mismo, ya que por ejemplo las abejas solitarias más especializadas son sensibles a los hábitats disturbados, en cambio los escarabajos menos especializados son ubicuos en hábitats más perturbados como los campos de cultivo (Ashworth y Galetto 2001). Si bien C. maxima ssp. andreana y C. maxima ssp. maxima comparten gran número de polinizadores como Astylus sp., Diabrotica speciosa, Peponapis sp. y Apis mellifera ${ }^{8}$ (Contardi 1939, Ashworth y Galetto 2001, Passarelli 2002) que dificultarían el mantenimiento de poblaciones aisladas, la probable ausencia de las abejas en áreas perturbadas por la acción humana facilitaría, en principio, el control del aislamiento de la población alentada por la selección cultural. Sin embargo, la pérdida en mayor medida de los polinizadores especializados que ocurre en los hábitats fragmentados (Ashworth et al. 2004) puede acarrear pérdidas en cantidad y calidad de componentes tales como las semillas (Aizen et.al. 2002). A pesar de este principio general, en el caso de C. maxima ssp. andreana, la calidad y cantidad de frutos y semillas no se ve afectado por la acción de distintos polinizadores (Ashworth y Galetto 2001). Estos resultados coinciden con la propuesta de Whitaker y Jagger (1937) quienes mencionan que en las cucúrbitas las cruzas no producen vigor híbrido y que tampoco hay

\footnotetext{
${ }^{8}$ Cabe aclarar que Apis mellifera es una especie del Viejo Mundo de introducción reciente (principios del siglo XX) en Argentina (Dr. Abramovich, com.pers.)
} 
pérdida de vigor o esterilidad por sucesivas retrocruzas. Sin embargo, la presencia o no de estos caracteres sí es significativa en estudios realizados en poblaciones de C. maxima ssp. maxima (Pasarelli 2002).

Por lo tanto es probable que a medida que avanzó el proceso de domesticación cambiara la asociación de insectos polinizadores de estas cucúrbitas, apareciendo los propios de hábitats perturbados y desapareciendo las abejas a medida que la perturbación del ambiente era mayor, favoreciéndose así el aislamiento y mantenimiento de poblaciones con caracteres deseados.

C. maxima ssp. andreana en relación a sociedades cazadoras recolectoras: posibles comportamientos humanos implicados en la domesticación de $C$. maxima ssp. maxima

En lo que respecta a accesibilidad, las formas silvestres del género Cucurbita crecen en conjuntos conformados por pocos individuos relativamente aislados entre sí (Lira Saade 1995), por lo cual el acceso a estas poblaciones es fácil al hallarse bastante localizadas en el paisaje y ser persistentes en su ubicación geográfica. Incluso si las condiciones son favorables pueden ser muy abundantes, algo que nota Harlan (1992) para los distintos miembros de la familia Cucurbitaceae y que, en su opinión, las ha hecho atractivas para los grupos cazadores-recolectores. C. foetidissima, por ejemplo, se reproduce asexualmente por medio de raíces que salen de los estolones, observándose en el campo grandes colonias homocigóticas todas vástagos de una misma planta madre (Whitaker 1980).

En opinión de Nee (1990) las especies silvestres de Cucurbita tuvieron varias ventajas que pudieron haber sido apreciadas tempranamente por los grupos cazadores-recolectores: grandes frutos conspicuos y fáciles de recolectar durante estaciones secas e invernales que pueden incluso -al igual que las 
semillas- ser almacenados. En esto coincide Cowan (1997) para quien la visibilidad dentro del entorno natural, su alta productividad y la facilidad con la cual estas poblaciones pueden ser manipuladas resultaron los principales factores por los cuales las antiguas sociedades humanas comenzaron su empleo intensivo. En opinión del autor esto habría creado primeramente un "huerto de zapallos" el cual habría sido empleado a manera de reaseguro ante las variaciones en la producción de otros recursos no tan susceptibles de ser manipulados como los frutos de especies arbóreas. El modelo de Cowan (1997) de que estos huertos serían abandonados de acuerdo con el tipo de nomadismo de la banda, la cual regresaría para la cosecha de los frutos maduros en una estrategia de reaseguro de acuerdo con la producción vegetal local, encuentra su homólogo en la propuesta de trashumancia y cosecha inoportuna propuesta por Lynch (1986) para la región andina. De manera similar McNeish caracteriza la producción durante la fase El Riego de Tehuacán como representada por el cultivo de calabazas en pequeñas parcelas, en las barrancas cercanas a las cuevas que habitaba la gente, sistema que denominó "horticultura de barranca" (McNeish 1967 en Casas 2001).

Las cucúrbitas son típicas plantas "seguidoras de campamento" y su distribución obedece en gran medida a la acción humana más que a la expansión natural de la especie (Bemis y Whitaker 1975, Asch y Asch 1978), por lo cual pueden incorporarse accidentalmente a la vida de cazadores recolectores y ser informalmente manejadas en parcelas con poco cuidado, sin implicar siquiera grandes cambios en las estrategias de subsistencia y patrones de movilidad del grupo (Monaghan et al. 2005). Si pensamos en la dinámica propia de los primeros grupos cazadores-recolectores, la aparición de malezas en el registro arqueológico indicara una perturbación del medio sostenida en el tiempo (Harlan y de Wet 1965). Las cucúrbitas silvestres crecen en hábitats naturalmente disturbados, por lo cual la dispersión natural de sus semillas a lo largo de, por ejemplo, cursos de agua habría favorecido su interacción con 
poblaciones humanas, luego su dispersión incidental hacia los campamentos de cazadores recolectores habría sido altamente probable (Cowan 1997). Si estos campamentos eran estables en el tiempo, estas cucurbitas silvestres podrían haber prosperado como malezas en un hábitat antrópico, pudiendo eventualmente domesticarse.

\section{Cambios en la tecnología}

Además del estudio específico de los cambios acaecidos en las poblaciones vegetales tanto en sus caracteres ecológicos como también fisiológicos y anatómicos, formas diferentes de relación humano-planta pueden ir asociadas a cambios en la tecnología implicada en dicha clase de relación (Hayden 1981, Unger- Hamilton 1985, Hillman y Davies 1990, Wright 1994). Así, a nivel arqueológico, se ha visto que en la transición de sociedades cazadorasrecolectoras a sociedad productoras en la microrregión de Antofagasta de la Sierra (puna catamarqueña), ocurrieron cambios en la morfología y uso de los artefactos líticos (Hocsman 2006). Sin embargo, a escala arqueológica no existe una identificación clara de los implementos vinculados a la recolección de especies vegetales. Por lo general se asocia esta actividad a la presencia de morteros -si el sitio es acerámico- y de bolsas tejidas -que se infieren a partir de restos de trenzados- cuyo supuesto uso fue el acarreo de productos de recolección (King 1994). Como puede verse es evidente que estos restos no implican necesariamente la manipulación de especies vegetales y mucho menos nos indican su carácter silvestre. En este sentido la información etnográfica señala que los implementos asociados a la recolección suelen ser de carácter muy simple (como palos o varas empleados en la recolección de pasacana, por ejemplo, o los "palos horqueta" y las bolsas tejidas de los

grupos chaqueños, ver Arenas 2003), por lo que pueden ser subestimados por los arqueólogos a la hora de interpretar los hallazgos efectuados en los sitios 
(Fernández Distel 1997, Arenas 2003). Puede ocurrir también que no exista una tecnología asociada y que la recolección sea simplemente manual. Este fue probablemente el caso para las cucúrbitas silvestres. Las mismas no requieren de una tecnología necesaria para su manipulación, a lo sumo algún elemento cortante para abrir los frutos -ya que el mismo se separa fácilmente del pedúnculo- el cual podría haber sido simplemente un artefacto lítico generalizado como una lasca. Si asumimos procesos de desintoxicación como los enunciados anteriormente, es probable el uso de morteros y recipientes. En este sentido es interesante el dato de que los restos más antiguos de Cucurbita reportados para el NOA son fitolitos hallados en artefactos de molienda en sitios de Antofagasta de la Sierra, puna de Catamarca (Hocsman 2006). Pero sin embargo, como se ve, no hay ningún implemento que se vincule de forma directa y necesaria al manejo de cucurbitas silvestres, por lo que el análisis de la tecnología como una vía alternativa para detectar procesos de domesticación en el pasado tal como sugieren Hillman y Davies (1990) se ve dificultada en el estudio de C. maxima.

\section{Discusión}

La principal dificultad con que contamos al intentar el análisis y reconstrucción del proceso de domesticación que llevo a $C$ maxima ssp maxima, es que las poblaciones actuales de su posible antecesor, C. maxima ssp andreana, son el resultado de la evolución de esta subespecie como maleza y de las sucesivas cruzas de ésta con la subespecie domesticada. Asumiendo esto, se acuerda con la propuesta de Nee (1990) de que ante el panorama ecológico actual la única alternativa que resta es tomar los caracteres de C. maxima ssp andreana $-\mathrm{y}$, en menor medida, de otras silvestres del género- y emplearlos como referencia en la reconstrucción del proceso de domesticación. Por lo tanto en esta tesis se tomaran los caracteres de este taxón como "línea de 
base" (Cowan y Smith 1993) para el estudio de los cambios que operaron tras el manejo humano de poblaciones espontáneas (no cultivadas), aunque con los recaudos ya indicados atendiendo a que la misma es actualmente una maleza. Entre los caracteres que conformarían dicha "línea de base"estarían los vinculados a la dispersión de semillas en el zapallito amargo, los cuales son muy similares a los de otras especies silvestres del género (Lira Saade 1995, Cowan 1997). El mecanismo de dispersión de C. maxima ssp. andreana es mediante un pedúnculo caduco, un fruto de pericarpio delgado, con un mesocarpio que se reabsorbe a la madurez y semillas pequeñas, lo cual permite un fruto maduro liviano independiente de la planta madre que puede trasladarse a largas distancias, especialmente en ambientes disturbados. La domesticación aumentó el tamaño del fruto, el espesor del pericarpio, evitó un mesocarpio que se reabsorbe y favoreció uno de mayor consistencia e incrementó el tamaño de las semillas. El pedúnculo puede o no separarse del fruto a la madurez, pero éste es de un tamaño y peso tal que no puede trasladarse lejos de la planta madre.

En este proceso de cambio también intervendría un tercer componente que son los polinizadores. A fin de aislar los primeros cultivos de Cucurbita sin cucurbitacina (posiblemente derivados de poblaciones silvestres recesivas) y fijar por consiguiente este carácter en la población, se habría modificado la asociación de insectos polinizadores, contribuyendo una mayor alteración del hábitat a la desaparición de las abejas como visitantes florales.

La persistencia de C. maxima ssp andreana tras la domesticación de C. maxima ssp. maxima en ambientes antrópicos, generaría un complejo cultivo-maleza hasta el desarrollo de comportamientos tendientes a su erradicación, en épocas relativamente recientes.

Este proceso por medio del cual se obtuvieron formas domesticadas de $C$. maxima ssp. maxima, no parece haber estado acompañado por cambios o adquisiciones notorias a nivel tecnológico, debiendo sustentarse la ocurrencia 
de modificaciones en la relación ser humano-planta en otra clase de evidencia. En capítulos subsiguientes analizaremos la posibilidad de que la anatomía y morfología de restos de C. maxima recuperadas en el registro arqueológico revelen este proceso de cambio. 
Tabla 4: características malezoides de acuerdo Chhandak et al. 2004 (traducción literal del artículo original y su correspondencia con caracteres presentes en C. maxima ssp. andreana. de acuerdo con. La descripción de dichas características es.

\begin{tabular}{|c|c|c|}
\hline $\begin{array}{l}\text { Características } \\
\text { malezoides } \\
\text { (Chhandak et } \\
\text { al. 2004) }\end{array}$ & $\begin{array}{l}\text { Descripción de las } \\
\text { características }\end{array}$ & Características de C. maxima ssp. andreana \\
\hline $\begin{array}{l}\text { Rápido } \\
\text { crecimiento }\end{array}$ & $\begin{array}{l}\text { Permite una captura maxima de } \\
\text { factores limitantes del crecimiento } \\
\text { como luz, agua y nutrientes }\end{array}$ & \\
\hline $\begin{array}{c}\text { Fase vegetativa } \\
\text { corta }\end{array}$ & $\begin{array}{l}\text { Bajo situaciones que hacen que } \\
\text { una planta germine tardíamente } \\
\text { dentro del período de germinación, } \\
\text { la planta puede aún completar su } \\
\text { ciclo de vida y dar semillas viables }\end{array}$ & \\
\hline Indeterminante & $\begin{array}{l}\text { Florece a través de la estación } \\
\text { mientras que crece } \\
\text { vegetativamente durante un } \\
\text { extenso período de tiempo }\end{array}$ & \\
\hline Auto-compatible & $\begin{array}{l}\text { Permite la divergencia génica } \\
\text { desde generaciones previas, pero } \\
\text { las plantas no requieren } \\
\text { polinizadores especiales como } \\
\text { abejas u otros insectos para } \\
\text { producir semillas viables. }\end{array}$ & $\begin{array}{l}\text { Posee gran número de polinizadores igualmente } \\
\text { eficientes. La cantidad o fuente del polen recibido } \\
\text { (propia o cruzada) o el agente polinizador no influyen } \\
\text { en el vigor o productividad. Carácter generalizado y } \\
\text { oportunista (Ashworth 1997, Ashworth y Galetto 2001). }\end{array}$ \\
\hline $\begin{array}{l}\text { Alta producción } \\
\text { de semillas }\end{array}$ & $\begin{array}{l}\text { La planta produce muchas semillas } \\
\text { que son dispersadas tanto temporal } \\
\text { como espacialmente a tantos } \\
\text { lugares favorables como sea } \\
\text { posible para su posterior } \\
\text { crecimiento }\end{array}$ & $\begin{array}{c}\text { El promedio de semillas por fruto es de } 322,05+/-9.45 \\
\text { pero con un rango de variación muy amplio que va de } \\
153 \text { a } 448 \text {. Correlación entre el aumento del ancho y } \\
\text { largo del fruto y el incremento en el número de semillas } \\
\text { (Ashworth, 1997). }\end{array}$ \\
\hline $\begin{array}{l}\text { Dispersión de } \\
\text { las semillas a } \\
\text { larga distancia }\end{array}$ & $\begin{array}{l}\text { Dado que las plantas terrestres no } \\
\text { son móviles, la única posibilidad } \\
\text { para una dispersión a larga } \\
\text { distancia es por semillas u otros } \\
\text { propágulos. Las semillas que flotan } \\
\text { en el agua o son llevadas por el } \\
\text { viento son más ampliamente } \\
\text { distribuidas }\end{array}$ & $\begin{array}{c}\text { Un mesocarpio que se reabsorbe y una cáscara } \\
\text { delgada aseguran un fruto muy liviano, el cual se } \\
\text { separa del pedúnculo a la madurez. Esto llevaría a una } \\
\text { dispersión del fruto a largas distancias por medio de } \\
\text { cursos de agua o pendientes (Millán 1945; Lira Saade } \\
\text { 1995). }\end{array}$ \\
\hline $\begin{array}{l}\text { Competencia } \\
\text { con cultivos }\end{array}$ & $\begin{array}{l}\text { Las malezas compiten por luz, agua } \\
\text { y nutrientes haciendo decrecer la } \\
\text { producción de los cultivos }\end{array}$ & \\
\hline $\begin{array}{l}\text { Sistemas } \\
\text { radiculares } \\
\text { profundos }\end{array}$ & $\begin{array}{l}\text { Los sistemas radiculares profundos } \\
\text { permiten que las malezas subsistan } \\
\text { en condiciones de sequía. }\end{array}$ & \\
\hline $\begin{array}{l}\text { Dormancia } \\
\text { discontinua }\end{array}$ & $\begin{array}{l}\text { Las semillas de las malezas } \\
\text { pueden permanecer dormentes en } \\
\text { medios poco favorables } \\
\text { asegurándose la germinación } \\
\text { cuando las condiciones son } \\
\text { nuevamente favorables Ej: } \\
\text { Chenopodium album }\end{array}$ & \\
\hline $\begin{array}{l}\text { Plasticidad } \\
\text { ambiental }\end{array}$ & $\begin{array}{l}\text { Una planta puede cambiar su forma } \\
\text { de crecimiento en respuesta a } \\
\text { factores ambientales u otras } \\
\text { estrategias de control. }\end{array}$ & $\begin{array}{c}\text { Prospera en hábitats perturbados en distintos } \\
\text { ambientes de Perú, Bolivia, Argentina y Uruguay (ver } \\
\text { capítulo } 4.1 .2 \text { b) }\end{array}$ \\
\hline $\begin{array}{l}\text { Modelos duales } \\
\text { de reproducción }\end{array}$ & $\begin{array}{l}\text { Las malezas pueden reproducirse } \\
\text { sexualmente o asexualmente }\end{array}$ & Propagación sexual y asexual (Ashworth 1997) \\
\hline Alelopatía & $\begin{array}{l}\text { Las plantas producen químicos que } \\
\text { evitan el crecimiento de otras } \\
\text { plantas o las matan }\end{array}$ & \\
\hline
\end{tabular}




\subsection{1b- IDENTIFICACIÓN Y DELIMITACIÓN DEL ÁREA DE ORIGEN DE $C$. maxima ssp maxima y $C$. maxima ssp andreana}

\section{Introducción.}

Si bien la relación antecesor -forma domesticada entre Cucurbita maxima ssp. andreana y Cucurbita maxima ssp maxima es ampliamente aceptada, habiéndosela constatado a través de ensayos de hibridación y estudios genéticos (Parodi 1935, 1966, Millán 1945, Whitaker y Bemis 1965, Albeck 2001, Millán 1945, Nee 1990, Decker Walters y Walters 2000, Sanjur et al. 2002), existen dos inconvenientes principales al reconstruir el proceso de domesticación que vinculó ambos taxones. El primero de ellos es la disyunción existente entre la distribución actual de C. maxima ssp. andreana y los restos arqueológicos más tempranos de C. maxima ssp. maxima recuperados en sitios arqueológicos sudamericanos. El segundo inconveniente es la carencia de restos arqueológicos de C. maxima ssp andreana que permitan comparar su distribución original con respecto a la de C. maxima ssp. maxima. En el caso de esta última subespecie, su distribución actual es resultado de la combinación de la adaptación propia de la planta a distintos ambientes y la manipulación humana que amplió cada vez más su nicho. A pesar de ello, basándonos en la evidencia arqueológica, podemos decir que el área de distribución original de C. maxima ssp maxima fue el noroeste argentino (NOA), centro-oeste argentino (COA), sur de Perú y norte y centro de Chile (ver capitulo 4.1.1c,d,e).

En el caso de C. maxima ssp. andreana o "zapallito amargo", su distribución actual corresponde principalmente al área centro- este de Argentina y Uruguay (Parodi 1935 en Contradí 1939, Martínez Crovetto en Burkart 1974, Hunziker y Subils 1975, Nee 1990, Piperno y Pearsall 1998, Ashworth y Galetto 1999, Sanjur et.al. 2002) (Figuras 11 y 12). Recientemente los hallazgos florísticos de 
la "Goldman Cucurbit Collecting Expedition" (GCCE) han demostrado fehacientemente su presencia en Bolivia y Perú (Andres y Nee 2005). Sin embargo, las poblaciones siguen siendo mayoritarias en el centro-este de Argentina y por lo tanto persiste una separación importante entre las áreas de distribución de ambas subespecies de C. maxima.

A pesar de que el nexo filogenético entre C. maxima ssp. andreana y C. maxima ssp. maxima está establecido, el proceso evolutivo que llevó a la formación de estos dos taxones no es aún claro. En este capítulo analizaremos el problema de la disyunción en el área de distribución de estas dos subespecies, aspecto que ha sido escasamente considerado por los autores que las vinculan filogenéticamente. En este sentido Brücher (1989) comenta que "C. maxima tuvo su origen fuera de las verdaderas latitudes tropicales, porque su forma silvestre $C$. andreana crece en las zonas templadas de Argentina y Uruguay. Desde allí diferentes tribus indígenas pudieron en tiempos remotos haber dispersado las semillas hacia Bolivia/Perú" (Brücher 1989: 263). Por su parte Piperno y Pearsall (1998), siguiendo la idea de Wilson y colaboradores (1992) de que C. maxima ssp. maxima, C. maxima ssp. andreana y C. ecuadorensis tuvieron un ancestro común, proponen que "una especie tolerante al frío ancestral con respecto al grupo de especies sudamericanas estuvo distribuida ampliamente en las elevaciones medias andinas y en las zonas templadas más calidas del sur, la cual fue domesticada más de una vez convirtiéndose en $C$. maxima en las elevaciones medias occidentales y en C. ecuadorensis en la costa oeste" (Piperno y Pearsall 1998: 147). Para estas autoras, C. maxima ssp. andrena es una forma silvestre de las regiones templadas que dio origen a C. maxima ssp. maxima. En este capítulo se evaluará la incidencia de distintos factores a través del tiempo en la delimitación del área de distribución de C. maxima ssp. andreana:, señalando tanto los naturales (climáticos, edáficos, polinizadores, eventos poblacionales puntuales) como los antrópicos (ampliación del rango de cultivo, modificaciones en la capacidad de adaptación a diversas condiciones, 
establecimiento de nuevas poblaciones bajo control humano y erradicación de poblaciones no deseadas).

\section{Materiales y método}

En su trabajo de 1973, Harlan y de Wet establecen distintas fuentes de evidencia que deben considerarse a fin de estudiar el origen y dispersión de plantas cultivadas. Dichas fuentes son: la evidencia aportada por las plantas mismas, tanto actuales (análisis de distribución geográfica, del comportamiento ecológico, de los centros de diversificación y distribución y de su morfología general), como del pasado (restos arqueobotánicos) y la evidencia del Hombre y sus actividades tanto en el presente (análisis lingüístico, de técnicas agrícolas y manipulación de poblaciones vegetales) como en el pasado (análisis del registro arqueológico en general, de manifestaciones plásticas o artísticas y de fuentes históricas) (Harlan y de Wet 1975). En este capítulo analizaremos todas estas fuentes de información, si bien algunas son sólo mencionadas someramente (vg. morfología y análisis arqueológico), ya que son el objeto de capítulos específicos de amplio desarrollo en el cuerpo de esta tesis.

Los distintos aspectos analizados implicaron estrategias metodológicas y fuentes de información diversas. Para la localización de poblaciones actuales (siglo XX- XXI) de C. maxima ssp. andreana y de distintos cultivares de $C$. maxima ssp. maxima se consultaron herbarios, floras regionales, bases de datos de distintos organismos (ej: Universidades, I.N.T.A., Museos) y publicaciones científicas. En el caso del registro de poblaciones antiguas (que cuentan con registro escrito) de C. maxima ssp. andreana y C. maxima ssp. maxima (siglo XVI a XIX) se emplearon fundamentalmente fuentes escritas de distinta índole : comunicaciones personales (vg. cartas), informes de personal eclesiástico, de funcionarios públicos, militares, escritos de naturalistas y viajeros. Para el 
registro de restos arqueológicos de C. maxima ssp. andreana y de C. maxima ssp. maxima se recurrió de manera exclusiva a información ya publicada. Este tipo de fuente se empleó también en la delimitación de un área potencial de distribución de C. maxima ssp. andreana de acuerdo con requerimientos específicos de suelo y clima, área fitogeográfica, tipo de dispersión y asociación con polinizadores.

\section{Resultados}

Localización de poblaciones actuales (siglo XX- XXI) de C. maxima ssp. andreana y C. maxima ssp. maxima

El área de distribución de C. maxima ssp. andreana de acuerdo con la bibliografía consultada fue la siguiente:

- Centro -este de Argentina y Uruguay : centro de Argentina, parte del litoral y área del Río de La Plata, incluyendo Uruguay, exclusivamente (Martínez Crovetto en Burkart 1974, Hunziker y Subils 1975, Nee 1990, Piperno y Pearsall 1998, Ashworth y Galetto 1999, Sanjur et.al. 2002). Martínez Crovetto (en Burkart 1974) menciona para la década del '70 que en la región central de Entre Ríos esta especie es ya poco frecuente.

- Centro -este de Argentina, Uruguay y Noroeste de Argentina (Millán 1945, Cabrera y Zardini 1978, Lira Saade 1995, Raffo 1997 en Fernández et.al 2004, Pozner 1999, Decker Walters y Walters 2000).

-Centro -este de Argentina, Uruguay, Mendoza y San Luis: Parodi (1935, 1966) menciona a las provincias argentinas de Entre Ríos, Santa Fe, Córdoba, San Luis y la mitad septentrional de la provincia de Buenos Aires, ademas de Uruguay. Contardi (1939) propone toda la franja central del país incluyendo 
Mendoza, estableciendo que esta Cucurbita se encuentra en las formaciones fitogeográficas de Pradera Pampeana y parte media y sur del Parque Mesopotámico, según definición de Parodi (1934), con las excepciones propias de una planta que es una maleza. Brücher (1989) si bien primero dice que es una planta extra-tropical propia de la pampa húmeda de Argentina y Uruguay, menciona luego que se la puede encontrara en Mendoza y San Luis. Esta última provincia también es mencionada por Ashworth (1997).

-Bolivia: La presencia de C. maxima ssp. andreana en Bolivia ha sido motivo de debate desde hace tiempo. La primera noticia de su existencia procede de los trabajos de M. Cárdenas (1969) quien identificó frutos amargos procedentes de La Loma, localidad próxima a Trinidad (Depto. de Beni) como C. maxima ssp. andreana. Transcribimos a continuación el relato del propio Cárdenas: "Hace unos 20 años recibimos de La Loma, localidad próxima de Trinidad (Beni) dos frutos de una Cucurbita espontánea o maleza llamada joko amargo'. Estos frutos eran pequeños de 8 x $6 \mathrm{~cm}$. aplastados y cóncavos en la parte de la inserción del pedúnculo. Al sembrar las semillas de estos frutos, obtuvimos una gran variación de pepos en relación al espesor de la cáscara y el color de las semillas aunque el sabor amargo de la carne quedó invariable. Las semillas fueron unas de color castaño y gruesas y otras blancas delgadas como ocurre en las formas de C. maxima de Sud América y la mayoría del Hemisferio Norte. De todas maneras, el 'joko amargo' era C. andreana, especie espontánea procedente hasta entonces solo de la Hoya del Plata" (Cárdenas 1969:164). Cárdenas consultó en su momento a T. Whitaker, destacado especialista en la familia Cucurbitaceae, enviándole semillas de estos frutos. Cabe mencionar que si bien "joko" es el nombre vernáculo dado a formas de C. moschata cultivadas en el oriente boliviano, Whitaker las identificó como híbridos entre C. maxima ssp. maxima y C. maxima ssp. andreana (Cárdenas 1969). Probablemente de allí venga la inclusión de Bolivia en el área de 
distribución de C. maxima ssp. andreana en sus obras posteriores (Cuttler y Whitaker 1961). Según informa R. Lira Saade (1995) estos ejemplares mencionados por Cárdenas se hallan depositados en la colección de germoplasma del Dr. Whitaker en California sin haber sido nuevamente estudiados. Trabajos posteriores de la década del ' 90 desestiman este dato y descartan a Bolivia como un área donde habría poblaciones de C. maxima ssp. andreana ya sea porque no se confirmó con hallazgos posteriores (Lira Saade 1995) o bien porque la ubicaría muy lejos de su área de dispersión en el centro este de Argentina y Uruguay donde imperan condiciones ecológicas disímiles (Nee 1990). Sin embargo este panorama se revertirá con el cambio de milenio ya que aparecen trabajos como el de Sanjur y colaboradores (2002) donde se mencionan recientes hallazgos de M. Nee en las tierras bajas del centro de Bolivia y la concordancia de los haplotipos de estos ejemplares con los de C. maxima ssp. maxima ${ }^{1}$. Incluso se menciona a Paraguay como otra área más donde probablemente se halle C. maxima ssp. andreana, aunque no se informa de ningún hallazgo puntual (Decker Walters y Walters 2000). Finalmente se consultó al Dr. D. A. Bisognin de la Universidad Federal de Santa María, Brasil, acerca de la presencia de esta subespecie en dicho país, quien informó que no existen registros de la misma hasta el presente.

Los resultados de los datos relevados en distintos herbarios pueden verse en la tabla 5, constatándose que las áreas de colecta de los ejemplares coinciden con las señaladas en la bibliografía, lo cual ocurre también con los escasos registros presentes en las floras (Tabla 6).

Al consultar al Herbario Nacional de Bolivia acerca de la presencia de ejemplares de C. maxima ssp. andreana en el mismo, se nos informó que este herbario forma parte del proyecto GEF sobre parientes silvestres de plantas cultivadas, por lo que los ejemplares de este taxón fueron colectados por M. Nee. Por lo tanto se contactó al Dr. Nee (New York Botanical Garden) quien

\footnotetext{
${ }^{1}$ C. maxima ssp. maxima y C. maxima ssp. andreana comparten los mismos haplotipos.
} 
gentilmente brindó información sobre un hallazgo cerca de Santa Cruz de la Sierra (Ver Tabla 7).

Este investigador sugiere se contacte al Dr. T. Andres (Cornell University, EE.UU) quien cuenta con mayor cantidad de información. Desinteresadamente el Dr. Andres brinda su base de datos para Argentina, dando detalles sobre la "Goldman Cucurbit collecting expedition" (GCCE) donde ambos investigadores participaron en el 2004 y 2005 (Ver Tabla7). Los datos para Bolivia, si bien coinciden en líneas generales con los de los ejemplares del New York Botanical Garden, son posteriores, por lo cual los registros de poblaciones de C. maxima ssp. andreana en la zona de Santa Cruz de la Sierra se habría producido entre 1998 y 2005. El objetivo de la GCCE fue documentar la diversidad de formas silvestres y domesticadas de Cucurbitaceae en Perú, Bolivia y NOA, con especial énfasis en la búsqueda de poblaciones de C. maxima ssp. andreana y de algún posible antecesor silvestre de C. ficifolia. Cabe destacar que ni una ni otro fueron registrados en el noroeste argentino, aunque el Dr. Nee aclara que en esta área el énfasis estuvo puesto mayormente en C. ficifolia. Sí mencionan, en cambio, escapes de cultivo de C. maxima ssp. maxima en el sur de Bolivia y NOA (Andres y Nee 2005). Lo más destacado de esta expedición son los hallazgos que reportan para Perú (Tabla 7) en el área correspondiente al departamento de Junín, únicos hasta el momento, si bien parece ser una planta identificada claramente por los pobladores locales con un nombre en lengua nativa: "ishcopiqui" o "ishicopé" (Valega Rosas et al. 2004) (Lámina 1, mapa 1). Otro resultado interesante de esta expedición es que los ejemplares de C. maxima ssp. andreana hallados en Bolivia son muy distintos a aquellos hallados en Perú, tanto en lo que respecta al fruto como a la morfología de las hojas, siendo los frutos hallados en el primer país más parecidos a un zapallito de tronco y los hallados en el segundo más similares a la variedad ornamental de C. pepo llamada "white egg" (Andres y Nee 2005). Estos investigadores hallaron también en territorio 
peruano poblaciones de C. ecuadorensis en Zamba, Depto. de Piura, a 656 metros sobre el mar (m.s.m.) denominada localmente como "zambobilla". Este hallazgo es también novedoso ya que, como vimos, sólo se había registrado esta especie en territorio ecuatoriano.

Para el área del NOA hallamos sólo dos referencias (Tabla7). La primera es para la provincia de La Rioja, se trata de un hallazgo consignado por Millán (1945) y que será desestimado por Hunziker y Subils (1975) por no haber sido corroborado con posterioridad y no contar con un ejemplar de herbario que lo certifique. Algo similar ocurre con la única referencia para la provincia de Salta, informada por el Ing. Novara del Herbario del Museo de Ciencias Naturales de Salta. Este investigador reconoció ejemplares de C. maxima ssp. andreana en una plantación de zapallos en la zona del Dique Cabra Corral, aunque lamentablemente no colectó muestras (Novara com. pers.). Por lo tanto las referencias que tenemos para la región del NOA no poseen respaldo en ejemplares de herbario $y$, al menos una de ellas, está asociada estrechamente a la mano del hombre. En este sentido M. Nee (com. pers.) no cree que haya poblaciones de C. maxima ssp. andreana en el noroeste argentino. A fin de unificar los registros de herbarios y floras para C. maxima ssp. andreana se elaboró el mapa 2 (lámina 1). El mapa 3 (lámina 1) se elaboró a partir de las referencias en la tabla 7, las cuales poseen un menor grado de confiabilidad en los datos que brindan dado que, en muchos casos, no cuentan con ejemplares de herbario que las respalden, como ya señalamos.

En cuanto al registro de C. maxima ssp. maxima se analizará puntualmente la situación de la provincia de Córdoba, dado que la misma cuenta con varios registros interesantes (Tabla 8). Los ejemplares colectados en esta provincia evidencian la presencia de plantas con frutos dulces creciendo en baldíos, sobretodo en Córdoba capital, estos ejemplares (CORD Ariza Espinar 2885, Hunziker 22831, Hunziker 23057, Hunziker 23070) se tratarian, en efecto, de la subespecie domesticada. Existe, en cambio, otro conjunto de ejemplares, 
todos pertenecientes también al herbario de Córdoba (Hunziker 11563, 22894; Hunziker y Subils 19355; Subils 2043, 2044 y 2048; Antón 16), colectados en diversas localidades de dicha provincia, cuya identificación ha sido problemática. Estos ejemplares fueron registrados a través de las bases de datos electrónicas de dos instituciones: el Missouri Botanical Garden (EE.UU) y el Instituto de Botánica Darwinion (Argentina), figurando en el primero de ellos sólo a nivel de especie como C. maxima y en el segundo a nivel subespecifico como C. maxima ssp andreana. Ante esta situación, se consultó al responsable de la determinación de dichos ejemplares, el Dr. Raul Pozner, quien nos informó que probablemente se trate de la subespecie señalada, pero que la distinción a nivel subespecifico es difícil de asegurar a través de ejemplares de herbario en este taxón. Se consultó también al Dr. M. Nee quien cabalmente señaló que, teniendo en cuenta el carácter amargo de los frutos de los ejemplares Hunziker 11563, Subils 2043 y Subils 2048 se puede estar ante plantas de C. maxima ssp. andreana o bien ante híbridos de esa subespecie con su contraparte domesticada. El registro de poblaciones híbridas en la provincia de Cordoba ha sido muy frecuente (Burkart 1974), tal como se comentó para el caso de la población de Cruz del Eje reportada por Millán (1945) en el capítulo 4.1.1a. Si bien podría pensarse, a partir de estos datos, que la provincia de Córdoba actuó como un centro de hibridación (lo cual se reflejaría en el mapa 8 , lámina 3), es probable también que esto no sea más que una impresión causada por efectos del muestreo. En primer lugar todos estos ejemplares proceden del herbario de la misma provincia, aportados por investigadores (como A. Hunziker y R. Subils) interesados en el estudio de ambas subespecies. En segundo lugar, en Buenos Aires también hay gran número de casos de hibridación entre $C$. maxima ssp andreana y $C$. maxima ssp maxima (ver capitulo 4.1.1a), solo que los mismos quedan registrados a nivel agronómico como un fenómeno vinculado a malezas perjudiciales, sin que se registren estas poblaciones en herbarios. A este 
respecto cabe hacer un comentario a partir del trabajo de Cowan y Smith (1993), quienes notan que en las distintas floras de Estados Unidos las cucurbitas silvestres no eran incluidas, lo que en opinión de los autores puede deberse a que los colectores consideraban a estas plantas como escapes de cultivo de cucurbitas cultivadas, por lo cual no las incluían en sus colecciones de especies silvestres. La inclusión de taxones cultivados o con señales de hibridación en los herbarios de acuerdo a los criterios de colecta utilizados, resulta por lo tanto un factor decisivo. Teniendo esto en cuenta, se considera que los registros de Cucurbita en herbarios serán forzosamente incompletos, arrojando por lo tanto una visión sesgada de las poblaciones de dicho género. Confirmar que la provincia de Córdoba sea o no un centro de hibridación depende exclusivamente de estudios geneticos en poblaciones actuales.

C. maxima ssp. maxima es una de las especies cultivadas más diversas del género, con 52 cultivares que difieren entre sí por sus características morfológicas y por aspectos agronómicos, como la duración del ciclo anual, productividad y plasticidad adaptativa (Lira Saade 1995). Algunos de los cultivares más conocidos a nivel mundial son:

1) Buttercup: desarrollada por Yeager y Latzke en el siglo XX como substituto a la batata en climas muy fríos donde esta última no crece (Whitaker y Bohn 1950).

2) Acorn: variedad con forma de turbante que aparece hace más de cien años en EE.UU. (Whitaker y Jagger 1937)

3) Boston Marrow o Autumnal Marrow: descrito por Burr en 1865, variedad producida extensamente en EEUU y Europa hace un siglo. J.M. Ives de Salem (Massachussets) obtiene la semilla en 1831 de un conocido en Buffalo (New York) quien a su vez la adquirió de grupos indígenas que visitaban Buffalo periódicamente, Ives populariza los méritos de esta variedad que luego llega a Europa (Whitaker y Jagger 1937). 
4) Hubbard: introducida al circuito comercial por J.J.H. Gregory, un vendedor de semillas de Marblehead, Massachussets en 1855 aproximadamente, quien aseguraba que la variedad había sido introducida en las vecindades de Marblehead hacia unos 60 años atrás. Por lo tanto la variedad posee unos 150 años o más. Delicious -probable variedad a partir de Hubbard- fue introducido por Gregory en 1905. Golden Hubbard introducido en 1896 por Harrison de Painesville, Ohio fue hallado como una "chance plant" en una plantación de Hubbard (Whitaker y Jagger 1937).

5) Vermont Hubbard: variedad obtenida en las estaciones experimentales estatales de Vermont, EE.UU, en 1914. Línea uniforme obtenida por retrocruzas. Seis años después se obtuvo la variedad Long storage Hubbard, una línea desarrollada para tener mayor capacidad de almacenamiento.

6) Marblehead: también introducida al circuito comercial por J.J.H. Gregory. Se cree que se importó directamente de las indias occidentales cerca de 1865 (Whitaker y Jagger 1937).

7) Winter Crookneck: descripta en 1686 aunque no bajo ese nombre, aparece en catálogo de semillas por más de un siglo (Whitaker y Jagger 1937).

Pero los cultivares que más nos interesan a los fines de este trabajo son aquellos que se encuentran restringidos, en su origen y distribución, a Sudamérica. Estos son cuatro:

1) C. maxima Duch. ssp. maxima cv. zapallito (Carrière) nov. comb.

2) C. maxima Duch. ssp. maxima cv. ripinka nov. var.

3) C. maxima Duch. ssp. maxima cv. triloba nov. var.

4) C. maxima Duch. ssp. maxima cv. boliviana Zhit.

Todos estos cultivares (los cuales son formas arbustivas) son conocidos gracias a la obra de Millán (1947), por lo que toda la información que se presenta a continuación proviene de la misma. 
El "zapallito de tronco" (en Salta conocido con el nombre de "tronquero") es registrado entre aborígenes chaqueños en el siglo XVIII y en Buenos Aires en el siglo XX. Este cultivar no se registra ni en Bolivia ni en Perú, siendo propio de Argentina. El cultivar "zipinka" se distingue porque sus frutos lobulados que desarrollan una cáscara muy dura a los pocos días de formarse el fruto, lo cual lleva a que no sean consumidos en estado inmaduro como los zapallitos de tronco. Los frutos pueden tener un ápice más o menos pronunciado y verrugas corchosas (ver lámina 14). Este cultivar es más heterogéneo que el anterior y puede desarrollar plantas con guías. Propio de Argentina, su distribución abarca las provincias de Salta, La Rioja, Santiago del Estero, Catamarca y Tucumán. Este cultivar es ya citado en 1889 por Solá en Salta. El cultivar "triloba" posee, tal como su nombre lo indica, un fruto trilobado de color verde oscuro. El mismo se restringe en su distribución al territorio chileno donde es conocido bajo el nombre de "hollito" u "ollita". El cultivar "boliviana" es tan distinto que Millán lo considera una subespecie, son plantas vigorosas de hojas grandes con frutos color castaño-rojizo de maduración tardía.

Por lo tanto, de los tres cultivares reconocidos como originarios de Sudamérica, dos se habrían desarrollado en el área andina y uno en la zona chaqueña de Argentina.

Localización de poblaciones no actuales de C. maxima ssp. andreana y $C$. maxima ssp. maxima

a. Localización de poblaciones prehispánicas de C. maxima ssp. andreana y $C$. maxima ssp. maxima a través de evidencias directas recuperadas en contextos arqueológicos.

En la tabla 9 y mapa 4 (lámina 2) se consignan los hallazgos de restos de Cucurbita spp. sudamericanos fuera de territorio argentino. Los registros más 
antiguos corresponen a la costa ecuatoriana y consisten en fitolitos de Cucurbita sp. cuyos tamaños sugieren una secuencia de formas silvestres, aunque modificadas por la acción del hombre (cultivadas), a domesticadas; correspondiendo estas últimas a C. ecuadorensis y C. moschata respectivamente (Piperno et al. 2000, Stothert et al 2003, Piperno et al 2003, Piperno et al. 2008) (ver capitulo 4.1.1d). A este respecto resulta muy interesante el registro del sitio Isla Larga, siendo la evidencia más temprana (3600 AP, ver tabla 9) del género para territorio uruguayo (Iriarte et al. 2001). Dicho sitio se ubica en el extremo oeste de la Sierra de San Miguel y, en opinión de los autores citados quienes se basan en el trabajo de Piperno y Pearsall (1998), el tamaño de los fitolitos recuperados indicaría que se trata de ejemplares domesticados. Las posibilidades que brindan los fitolitos de Cucurbita para identificar especies y su grado de modificación por manejo humano, se discute extensamente en otro capítulo de esta tesis (ver capitulo 4.1.1d), por lo que sólo se señala aquí que la asociación entre características de estos microrrestos y el grado de asociación humano-planta no es tan directa como podria suponerse en un principio, habiendo numerosos factores intervenientes que deben considerarse antes de establecer tal clase de relación.

En lo que respecta a macrorrestos de especies silvestres, existen dos hallazgos: el de los sitios Pampa de Ventanilla (costa central de Perú) y Quebrada de Las Pircas (costa norte de Perú). Con respecto al primero de estos sitios, Lanning (1967 en Whitaker y Cutler 1968) considera que los restos de pericarpios, semillas y pedúnculos hallados corresponderían a una cucúrbita silvestre, posiblemente C. maxima ssp. andreana. Whitaker y Cutler (1968), sin embargo, consideran que podría tratarse de C. ecuadorensis, especie definida taxonómicamente por ellos un año después del descubrimiento arqueológico. A esto contribuirían los hallazgos recientes de la GCCE, los cuales confirmaron la existencia de poblaciones naturales de esta última especie en el centro de Perú (Lámina 1, mapa 1). Un reexamen de este material resolvería 
este problema ya que el registro arqueobotánico es abundante y las diferencias morfológicas entre C.maxima ssp. andreana y C. ecuadorensis son notorias (Whitaker y Cutler 1968). Por otra parte, el material del sitio Quebrada de las Pircas 1, fue analizado por T. Andres (Lámina 2, mapa 4) y representa no sólo los macrorrestos de C. moschata más antiguos hasta el presente, sino también su evidencia más temprana en Sudamérica dado que las ocupaciones datarían entre 9240 y 7660 AP (Dillehay et al. 2007). Se trata de pequeñas semillas de entre 6 y $7 \mathrm{~mm}$ de largo y 2,5 a $4 \mathrm{~mm}$ de ancho de color marrón oscuro con márgenes bien marcados y forma elíptica, todo lo cual coincide con cultivares modernos de esta especie que crecen en Colombia (Dillehay et al. 2007).

Cronológicamente, las especies que siguen en su aparición en el registro arqueológico sudamericano, fuera del territorio argentino, son C. ficifolia (66803720 AC) y C. maxima ssp. maxima (4200 - 2500 AC) (Tabla 9).

Dentro del territorio argentino, y hasta el presente, existe una única evidencia arqueológica de la existencia de C. maxima ssp. andreana. La misma fue recuperada en la localidad arqueológica de Pampa Grande ubicada en la serranía de Las Pirguas, Guachipas, al este de Salta (González 1972, González 1998) (Ver capítulo 3) (Ver Tabla 10 y mapa 5 en lámina 2). El material corresponde a un conjunto de fragmentos de pericarpios, con un promedio de $1,5 \mathrm{~mm}$ de espesor, identificados por T. Whitaker, tras ser enviados para su análisis por el Dr. A. Rex González en 1972. Los mismos se hallaron en el Sector I, capa 1 de la caverna V (Tarragó 1980). Sin embargo Whitaker consigna que puede tratarse tanto de $C$. maxima ssp. maxima como de $C$. maxima ssp. andreana (Tarragó 1980). En su trabajo de 1983, este investigador hace referencia explícita a los hallazgos de Pampa Grande y a las identificaciones hechas por él y Carter y no menciona en lo absoluto a $C$. maxima ssp. andreana o una forma cercana a ésta, asegurando tan sólo que podría haber entre los restos de dicha localidad arqueológica distintos cultivares de C. maxima ssp. maxima (Whitaker 1983). Por lo tanto, la 
identificación taxonómica original se vuelve más dudosa aún con respecto a la presencia de C. maxima ssp andreana. ${ }^{2}$

En la tabla 10 puede verse que en el NOA y COA se han identificado tres especies del género Cucurbita. Los restos más tempranos corresponden a $C$. maxima ssp maxima con un fechado de entre 500 AC y 650 DC para ambas regiones $^{3}$. Le siguen los restos de C. moschata con una edad estimada de entre 280 y 375 DC para el COA y de aproximadamente 500 AC para el NOA, si es que las muestras de Los Viscos corresponden al Formativo y no al periodo de Desarrollos Regionales-contacto Hispano Indígena detectado también en esta cueva (Korstanje y Würschmidt 1999) (ver capítulo 3). C ficifolia posee un único registro, el cual es de fecha tardía: 1200 a 1420 DC.

$\mathrm{Si}$ bien en todos estos casos los restos cuentan con identificaciones certeras llevadas a cabo por especialistas, todos adolescen de fechados precisos. Ninguno de los restos ha sido fechado por AMS y en algunos casos la cronología general del contexto asociado no es clara (vg. Cueva El Toro y Los Viscos). Al igual que en el área andina norte, los registros más tempranos del género en el NOA corresponden a fitolitos, aunque en este caso no se llegó a una identificación a nivel específico. En el COA los restos más tempranos corresponden a macrorrestos, pero lamentablemente no se ha profundizado aún en su identificación taxonómica.

La propuesta de una domesticación, en territorio argentino, de C. maxima ssp. maxima a partir C. maxima ssp. andreana, ha recibido amplio apoyo (Millán 1945, Whitaker y Bemis 1965, Brücher 1989, Nee 1990, Decker Walters y Walters 2000, Albeck 2001). Pero esta idea -aunque no explícita en los textos anteriormente citados- parecería basarse en el hecho de que las poblaciones de "zapallito amargo" se encuentran en este país (nótese que todas las

\footnotetext{
${ }^{2}$ Los estudios llevados a cabo en esta tesis confirmaron su presencia mediante el análisis de caracteres microscopicos en restos de pericarpios de la colección de Pampa Grande (ver capítulo 4.1.1d)

${ }^{3}$ Si bien la Cueva del Toro no cuenta con fechados radiocarbónicos, indicándose sólo que la misma corresponde al período temprano (Whitaker 1983), una estimación conservadora de su cronología la equipararía con las fechas de La Poma, dentro del formativo temprano para el NOA y COA (Caggiano y Sempé 1994, Lagiglia 1997)
} 
publicaciones son previas a los hallazgos de la GCCE), sin considerar que los datos del registro arqueológico indican que los restos de C. maxima ssp. maxima son más tempranos en territorio peruano. En territorio argentino los restos de esta subespecie se circunscriben al NOA y COA (con un único registro fuera de estas áreas para el período post-hispánico) ubicándose los sitios en diversos ambientes naturales desde la prepuna al pedemonte andino (Lámina 2, mapa 5).

La tabla 10 nos permite ver también que los restos de Cucurbita spp. fueron recuperados tanto en contextos domésticos como funerarios en sitios de cronología diversa y emplazamiento disímil.

b. Localización de poblaciones de C. maxima ssp. andreana y C. maxima ssp. maxima desde el siglos XVI a principios del siglo XX a través del análisis de su registro escrito

En esta sección se presentan los registros escritos donde existen menciones a cucúrbitas en general, pero es muy usual que dichas menciones incluyan también referencias a Lagenaria siceraria, la cual posee frutos similares a los de las cucúrbitas. El género Lagenaria (familia Cucurbitaceae, subfamilia Cucurbitoideae) incluye cinco especies silvestres perennes en África tropical además de la especie cultivada Lagenaria siceraria (Molina) Standley, la cual es una planta anual distribuida en los trópicos de casi todo el planeta (Teppner 2004). Dicha especie incluye a su vez a dos subespecies: L. siceraria ssp. siceraria (Kobiak.) Heiser y L. siceraria ssp. asiatica (Kobiak.) Heiser, las cuales poseen diferencias en los caracteres de sus hojas, flores y semillas, siendo la primera propia de África y América y la segunda de Asia y el Pacífico Occidental (Whitaker 1948, Teppner 2004, Erickson et al. 2005). Hasta el presente en los registros arqueológicos americanos se han reconocido restos sólo de Lagenaria siceraria, por lo cual se cree que esta especie estuvo presente de forma 
exclusiva a lo largo del desarrollo cultural del continente (Whitaker 1948, Erickson et al. 2005). Es por ello que en los análisis siguientes nos referiremos siempre a ella a nivel específico y no sólo genérico.

\section{$\underline{\text { Siglos XVI a XVIII }}$}

Al considerar escritos antiguos nos encontramos obviamente con el problema de saber a qué especie se están refiriendo los cronistas en sus menciones. Esto se relaciona no sólo con referencias poco precisas o que mencionan caracteres que no son diagnósticos, sino también con la problemática propia de los nombres vulgares dados a las plantas que aparecen en los escritos, los cuales pueden ser de naturaleza diversa. Entre los nombres dados a los vegetales, en general, podemos reconocer aquellos que son voces nativas tomadas por los europeos para referirse a estas plantas que les eran ajenas, produciéndose con frecuencia deformaciones de la voz nativa original (como "mate", derivado de "mati”, voz originalmente quichua, Yacovleff y Herrera 1934). También se adoptan nombres oídos en un grupo étnico que luego se usan de manera extensiva en otras partes (como "maíz" que es deformación de una voz caribe, usada por los cronistas en zonas tan alejadas como el sur andino donde la vOz quichua que designa a esta planta es "sara" y su nombe en guaraní es "abatí", por mencionar sólo algunos, Warman 1988). Otra modalidad corriente era analogar lo desconocido a lo conocido por relaciones de semejanza en forma o uso, de allí por ejemplo la designación de "trigo de las indias" para el maíz. (Warman 1988). Este parecería ser el caso de la referencia más temprana a cucúrbitas que tenemos para la región del río de La Plata. Se trata del testimonio del navegante Acarete du Biscay, en su primer viaje al Río de la Plata en 1657. Este cronista dice haber visto en Buenos Aires "melones", los cuales son "excelentes pues la tierra es muy fértil y buena" (Acarete du Biscay en Busaniche 1971: 94). Existe una referencia previa a ésta que menciona la 
siembra de "calabazas y melones" en Asunción en 1537 (Martín de Orúe en Busaniche 1971:53). A fin de interpretar estas menciones, nos encontramos ante un par de opciones. La primera sería que efectivamente se trate de melones (Cucumis melo L.), especie originaria del Viejo Mundo, alternativa que es relativamente viable ya que en Europa se aconsejaba llevar en los barcos que emprendían grandes viajes -sobre todo los de exploración que iban a las "Indias orientales" u "occidentales"- cítricos y melones a fin de evitar el escorbuto (Millán 1943). Quizás los primeros barcos que anclaron en las costas rioplatenses llevaban melones, los cuales encontraron un terreno apto para prosperar en la rivera del Plata. Ademas, en el caso de la referencia de Acarete du Biscay, el cronista refiere junto a los "melones" la siembra de "coles, cebollas, lechugas, ajos, arvejas y habas" " (Acarete du Biscay en Busaniche 1971: 94), todas especies originarias del Viejo Mundo. La segunda opción es que se tratara en realidad de ejemplares de Cucurbita spp. ya cultivada en Buenos Aires desde su fundación.

Ninguno de los relatos que refieren a los primeros viajes a la zona del Río de La Plata y el posterior ascenso por el Paraná hasta Asunción mencionan la presencia de alguna planta que pudiera asociarse con las características de $C$. maxima ssp. andreana. En los relatos que refieren a la situación que se vivía en estos primeros poblados como Sancti Spiritu, fundada por Caboto en 1527; Nuestra Sra. Del Buen Aire, fundada por Mendoza en 1536; Corpus Christi y La Candelaria, por Ayolas en 1537; y hasta en las referencias al despoblamiento de Buenos Aires y el traslado de la población a Asunción, ordenado por Irala en 1541, en ningún momento se menciona el consumo de algo que remotamente se asemeje a una Cucurbita (Capparelli et al. 2005). Esto es notable si tenemos en cuenta que la posibilidad de morir de inanición, junto al constante ataque nativo, fueron los principales motivos por los que todos estos intentos de asentamiento permanente fallaron. El caso más notorio es el de Ulrico Schmidl, un soldado que viajó con Mendoza, cuyas referencias al 
canibalismo que existió en la primera Buenos Aires le dieron trascendencia hasta la actualidad. Sin embargo en su relato tampoco se menciona nada similar a una cucurbitácea (Schmidl [1567] 1993). En otros relatos donde se señala el hambre padecido en estos efímeros poblados se hace alusión a la fauna, mencionándose en lo que respecta al consumo de vegetales, solo "hierbas y cardos" (Luis Ramírez (1527) en Busaniche 1971).

En cuanto a las referencias a los grupos nativos del litoral del río de La Plata y Paraná el panorama se divide entre grupos nativos cazadores-recolectores (como Querandíes y Charrúas) y otros horticultores, principalmente de filiación guaranítica. Entre estos últimos están los Carcaraís y Timbús de quien se dice que siembran "abatis y calabazas y habas" (Luis Ramírez (1527) en Busaniche 1971). El término "calabaza" es un vocablo que constantemente se nos presenta a lo largo de los escritos de cronistas y viajeros, siendo problemático ya que actualmente se refiere tanto a los frutos de C. moschata como a los de L. siceraria (Lira Saade 1995) ${ }^{4}$, esta última muy usada por los pueblos indígenas del centro y norte de Sudamérica en la época de estos escritos e incluso en la actualidad. Así, el padre jesuita Dobrizhoffer menciona para el siglo XVIII "calabazas" entre los abipones asentados, en distintos momentos, entre el Bermejo occidental y el norte de Santa Fe. Probablemente se esté refiriendo a los frutos de Lagenaria siceraria ya que no menciona su consumo como alimento, sino su uso como recipientes y para la confección de sonajeros para uso shamánico, un empleo muy extendido para los frutos de esta especie entre los grupos chaqueños y guaraníes (Sosa Veron 1948, Arenas 2003). Algo similar ocurre con las referencia de Lozano en su viaje de 1733, quien menciona el uso de "un pedazo de calabaza para beber" (Lozano (1733) 1941: 62) entre los nativos del Gran Chaco. Lozano también dice que los

\footnotetext{
${ }^{4}$ El termino "calabaza" también es empleado para designar a los frutos de C. moschata de forma elongada y también de C. argyrosperma (Millán 1968, Andres y Nee 2005), especie de América del Norte que se cree es de introducción muy reciente en Sudamérica, siendo la publicación de Millán la primera en notificarla.

${ }^{5}$ Resulta notable el hallazgo arqueológico en Cueva Cacao A1 en Antofagasta de la Sierra de un sonajero hecho con el fruto de Lagenaria siceraria fechado en 3000 A.P.
} 
abipones para ocultarse de los españoles en los campos se "cubrían sus cabezas con cortezas de calabazos, que allí se crían muy grandes" (Lozano (1733) 1941: 97). Menciona además cascabeles y tambores de calabaza entre los Guaycurúes. Cuando se refiere a los Lules (grupo asentado en el este de Santiago del Estero culturalmente de filiación chaqueña, pero con estrechas relaciones con los grupos andinos) dice que "hacen sus cortas sementeras de maíz, calabazas y legumbres" (Lozano (1733) 1941:105). En esta oportunidad parecería ser que se hace referencia a la tríada americana: maíz, zapallo y poroto, tan común en las chacras andinas, y por lo tanto se usaría "calabaza" para referir a un miembro del género Cucurbita. Es también en referencia a grupos de indígenas mataguayos del occidente chaqueño que el Jesuita Gaspar de Osorio (citado por Lozano (1733) 1941) dice que siembran "zapallos y maíz". Esta referencia no sólo es valiosa porque usa la voz zapallo, por lo que estaríamos ante ejemplares de Cucurbita sp. y no de L. siceraria, sino también porque es bastante temprana, ya que este Padre jesuita describe lo que vio en 1630 aproximadamente.

Una mención especial merece la obra del padre José Jolís quien recorre el oriente salteño y jujeño entre 1762 y 1767 (Torres et al. 2007). En referencia a los Matarás comenta "Ocho especies de calabazas domésticas siembran y cultivan los Indígenas; pero las cualidades de ellas son varias y numerosísimas, según el P. Acosta, y ascienden a mas de 1.000 [...] se pueden reducir a tres Clases: de flor amarilla, blanca y azul. Las primeras se comen verdes y también maduras, pero las calabazas de las otras Clases, sólo se comen cuando están muy tiernas, pero se vuelven incomibles cuando están maduras, tanto porque se vuelve dura su cáscara, como también porque quedan vacías adentro y casi desprovistas de pulpa; por eso los Salvajes las usan como jarros y otros vasos. Entre las de flor amarilla, solo dos especies naturales [...] crecen y maduran en 25 o 30 días y se pueden obtener de ellas, más cosechas que del maíz [...] Antes de la llegada de los Españoles [...] se cultivaban dos especies de Sandías 
y también dos de Melones, poco diferentes de las nuestras" (Jolís 1972: 93 en Torres et al 2007: 28). Si bien no se sabe de la existencia de una especie de cucurbitaceae con flor azul, las de flores amarillas corresponderían al género Cucurbita y las de flor blanca a L. siceraria (Cutler y Whitaker 1961). La presencia de L. siceraria quedaria evidenciada también al mencionar Jolís que un tipo de calabaza debe consumirse cuando sus frutos se encuentran inmaduros, dado que al madurar su mesocarpio se reabsorve y su pericarpio se endurece de modo tal que se lo emplea para elaborar recipientes, todas caracteristicas propias de dicha especie (Whitaker 1948, Teppner 2004). En cuanto a las referencias a Cucurbita sp., habla de la presencia de dos especies, y menciona el consumo de sus frutos inmaduros, por lo cual es probable que una de éstas sea C. maxima ssp. maxima var. zapallito. Por ultimo cabe señalar que este cronista emplea el término "calabaza" en un sentido genérico, incluyendo en él especies de Cucurbita.

A esta confusión de voces diversas se suma la de "porongo", voz usada por los Padres Ruiz y Solinas (1683 citados por Lozano (1733) 1941) para los cántaros donde contenían sus bebidas los habitantes del valle de Ledesma en el actual oriente salteño. Estos padres se están refiriendo probablemente a $L$. siceraria y están usando voces no locales ya que dicen que la bebida que contenían estos cántaros era "guarapo", voz quichua que se refiere a la bebida fermentada de los frutos de Prosopis sp. y que en el noroeste y noreste argentino se denominó desde las primeras crónicas hasta la actualidad como "aloja”. El término "puru" es una voz quichua empleada para denominar a los frutos de Lagenaria siceraria con forma de botella, en contraste con la vOz "mati" empleada para los frutos esferoidales, del primero se deriva el término "puruncu" que Holguin traduce como "ceramio de barro cuellilargo" y que transformado en "porongo" se usa en Lima para denominar los ceramios con forma de botella (Yacovleff y Herrera 1934). Por lo tanto las referencias de los Padres Ruiz y Solinas no serían de frutos del género Cucúrbita. 
El sacerdote jesuita G. Patiño, en el transcurso de su viaje por el Pilcomayo en 1721, ve cultivada por los Tobas una "especie de zapallos que dan junto al tronco, unos cercanos a otros amontonados, son de buen sabor" (Millán 1947: 335). En opinión de Millán (1947) esta referencia correspondería a C. maxima ssp maxima cr zapallito, lo cual concuerda con lo observado por Jolís entre los Matará aproximadamente para la misma fecha.

Analicemos ahora el testimonio de Félix de Azara en el viaje que realizó desde el río de la Plata hasta Asunción en 1781, fecha cercana a la del viaje de Lozano. La primera referencia en la tabla 11 es interesante ya que podría estar refiriéndose a frutos de C. maxima ssp. andreana creciendo en áreas de cultivo abandonadas. Azara usa indistintamente las voces "porongo" y "calabaza" para referirse a estos ejemplares. Como vimos, la primera se encuentra reservada para los frutos de L. siceraria. La segunda es usada por el mismo cronista para referirse en otras ocasiones al "mate" (L. siceraria) y para frutos comestibles de agradable sabor. Estos frutos pueden pertenecer a los géneros Cucurbita o Lagenaria ya que esta última posee frutos tanto amargos como dulces (Dymock 1972), estos últimos por lo general hallados bajo cultivo (León 1987). A pesar de esto, los wichí no consumen actualmene sus frutos cultivados, asegurando que su sabor es fuerte y desagradable (Arenas 2003).

Por lo tanto al no ser el gusto amargo patrimonio exclusivo de C. maxima ssp. andreana y al haber frutos de L. siceraria que se consumen, no podemos tomar las referencias de Félix de Azara como propias de uno u otro taxón.

Los nombres vulgares tampoco ayudan a una clara diferenciación. Storni (1937) menciona para Lagenaria vulgaris los siguientes nombres vernáculos: mate, purú, porongo, purunco, caiguá, poró y yerúa. Este último nombre vulgar es también asignado a C. maxima ssp. andreana de acuerdo con Báez (1938 en Burkart 1974), y también es mencionado por Ashworth y Galetto (1999 y 2001) como nombre vulgar en Entre Ríos y Uruguay, aunque con acentuación distinta: "Yeruá". Dacunda Díaz (1987) menciona en su 
diccionario guaraní los terminos "Caiguá" y "Yeruá" para "calabacera" y para el vocablo "calabaza" señala: "Caiguá (mate), Yeruá. Variedades: Curapepé (zapallo); Andaí (dulce)" (Dacunda Díaz 1987:35). Storni (1944) da el siguiente significado para el vocablo "Yeruá": "Cucurbita leucantha. Dch- Cucurbitaceas Calabaza guaraní, muy regional, tipo mati, o mate. Interpretación: Ye: dicen que, afirmación, etc.; Ru: tener algo en si; $A$ : granos, tolombones, hinchazón, etc. La corteza de esta Cucurbitacea es llena de rugosidades así como queda dicho; de ahí su nombre" (1944:240). Esto sólo hace que la situación se vuelva más confusa aún ya que tanto los frutos de Lagenaria como los de $C$. maxima ssp. andreana carecen de verrugas, las cuales sí estan presentes en algunos cultivares de C. maxima ssp maxima y C. moschata. Por lo tanto es posible que Storni esté atribuyendo dicho nombre vulgar a frutos de una Cucurbita domesticada, quizá a alguna poblacion de C. maxima ssp maxima de frutos verrucosos y sabor amargo (ver capitulo 4.1.1a). A pesar de ésto hay que considerar que Cucurbita leucantha es el nombre antiguo de Lagenaria siceraria (Cutler y Whitaker 1961). Por lo tanto la correspondencia del nombre "yerúa" o "yeruá" con los taxa actualmente reconocidos permanece oscura.

El trabajo más claro y explícito de todos los consultados es el elaborado por el Padre Jesuita F. Paucke que vivió entre los mocovíes asentados en el sur del Chaco y norte de Santa Fe, también en la segunda mitad del siglo XVIII. La obra de este jesuita se caracteriza por ilustraciones que representan de manera muy fiel la vida en las misiones. Entre dichas ilustraciones que acompañan sus escritos hay dos láminas donde se ilustran cucurbitáceas cultivadas en dichas misiones (Figura 13). De acuerdo con Millán (1947) se trataría de: L. siceraria, Citrullus vulgaris Schard., Cucumis melo, Cucumis melo (L.) var. dudaim (L.) Naudin, C. moschata y C. maxima ssp. máxima. Esta última con la típica forma de "turbante" que, en opinión de Millán (1947) podría tratarse de C. maxima ssp máxima cv. zapallito. Si bien esta referencia es contundente por la posibilidad de identificación que dan las ilustraciones y referencias escritas, se trata de la 
realidad al interior de las Misiones Jesuíticas, por lo cual es dable que todas las especies mencionadas, incluso las americanas, hayan sido ingresadas por los religiosos, ya que eran ellos quienes ordenaban y controlaban la vida en estos asentamientos (Fradkin 2000).

La dinámica dada por el movimiento de población indígena en todo el norte del país desde la llegada del Inka y sobre todo a partir de la conquista europea (Lorandi y Boixadós 1987-1988, Lorandi 1988), generó también desplazamientos de especies vegetales. A esto se suma el robo frecuente de las cosechas de un grupo por parte de otro vecino, por lo general cazador recolector, lo cual es referido en varias de las crónicas del litoral mesopotámico y Gran Chaco (Busaniche 1971). Esto ocasionaría no sólo la ampliación del área de distribución de un cultivo como C. maxima ssp maxima sino también el abandono de semillas (ya que los grupos que robaban los frutos no eran cultivadores) y en consecuencia la posible generación de formas asilvestradas o malezas como C. maxima ssp. andreana. A esto se suma la práctica de varios grupos del Gran Chaco de incendiar grandes áreas de pradera ya sea como método de caza o bien para anunciar a grupos vecinos el arribo de tropas españolas (Lozano (1733) 1941). Esta práctica ocasionaría grandes áreas disturbadas, las cuales podrían ser luego ocupadas por plantas exitosas en sucesión secundaria, algo que caracteriza a las malezas (Harlan y de Wet 1965). Finalmente la introducción de ganado bovino y caballar generó una dinámica totalmente distinta en varios ecosistemas americanos ocasionando alteraciones en la conformación de las poblaciones vegetales así como también el traslado de especies fuera de su área de distribución originaria (Morello y Saravia Toledo 1959). Por lo tanto existen varios factores que habrían intervenido en la distribución -intencional o no- de $C$. maxima ssp. andreana en la región chaqueña, mesopotámica y pampeana de Argentina. 
En cuanto a los testimonios que refieren al territorio del actual noroeste argentino sólo mencionaremos los más tempranos, ya que posteriormente son muy abundantes las referencias precisas al cultivo de Cucurbita sp. entre las poblaciones nativas de la zona. El primero corresponde a la Probanza de Méritos de Núñez del Prado, quien fundara la ciudad de Barco de Ybatín en 1550, la cual pasará a ser, tras sucesivas relocalizaciones y cambios de nombre, Santiago del Estero. En dicho documento se dice que en este poblado que duró apenas un año “... se recogió poca cantidad de maiz frisoles e çapallos e quinoa (...) e sabe que de la primera sementera se cogio poco maiz e de la postrera nenguno..." (Capparelli et al. 2005). Más interesante aún es el testimonio de 1582 del Padre Sotelo de Narváez referido a los indígenas asentados en los Valles Calchaquíes, zona que no estuvo bajo sujeción española sino hasta 1666. Al contrario de lo que ocurrió en el primer poblado español de Argentina, los habitantes de estos valles cultivaban gran cantidad de especies, tanto foráneas (trigo y cebada) como nativas: papa, maíz, porotos, quinoa y zapallo (Capparelli et al. 2005). Por lo tanto la referencia clara al cultivo de Cucurbita sp. en el NOA está presente desde finales del silgo XVI.

\section{Siglo XIX y principios del XX}

Entre las referencias del siglo XIX se encuentra la propia identificación taxonómica de Cucurbita andreana por Naudín en Francia alrededor del año 1896, a partir de semillas que le enviaran desde Uruguay. Pero para este siglo existen referencias previas como la de Lameé quien, en 1887, aconseja su destrucción porque afecta la calidad de los zapallos, ya que al hibridarse les pasa el gusto amargo; lo llama zapallo "chirigua" (Millán 1945). Lamentablemente la obra de Lameé, un tratado de agricultura para la Argentina en su conjunto, no cuenta con una mayor precisión geográfica de su testimonio. Otra referencia corresponde a Saac -1881- quien dice que "en el 
campo existe una especie de curga salvaje vivaz", en opinión de Contardi (1939) se está refiriendo a C. maxima ssp. andreana, pero al igual que en el caso anterior no se dan mayores precisiones. Millán (1968) considera que la referencia de William Mac Cann, quien habría visto cómo asaban un zapallo en las cenizas de un fogón cerca de Dolores en 1847, correspondería a un intento de desintoxicar frutos de C. maxima ssp. andreana. Si bien éste es un metodo de cocción tradicional de los frutos de zapallos domesticados (Arenas 2003), es también un modo de desintoxicar cucúrbitas silvestres como vimos en el capítulo 4.1.1a, por lo que efectivamente el testimonio mencionado por Millán (1968) para el siglo XIX en Dolores podría estar refiriéndose al “zapallito amargo". En 1926 Parodi dice de esta cucúrbita: "se me asegura que antes de los años 1890 y 1900 era sumamente común en la tierra removida de las vizcacheras" (Contardi 1939). Por último se estima que la especie consignada como Cucurbita lagenaria en la Flora Argentina de 1898 (Bettfreund 1898) podría corresponder, teniendo en cuenta la morfología de la flor (estigma bilobado, corola de cinco lóbulos) y hojas (trilobuladas), a C. maxima ssp. andreana (Martínez Crovetto 1965), diferenciándose en estos mismos rasgos de Lagenaria vulgaris presente también en la esta flora del siglo XIX. Lamentablemente tampoco se consigna en este caso la ubicación geográfica del ejemplar.

Entrando ya en el siglo XX nos encontramos con el testimonio del Pbro. Don Manuel Pérez Castellano quien refiere a unos "calabazos que llaman aquí porongos" que crecen en taperas, corrales o poblaciones abandonadas; son de corteza dura al madurar y usados por tanto como recipientes; como son amargos se dulcifican poniéndolos en agua y sometiéndolos luego a varios lavados. Este testimonio es de 1914 para una estancia en Miguelete, Uruguay. Millán (1945) es quien recopila este comentario y no duda en asignarlo a $C$. maxima ssp. andreana a pesar de que Pérez Castellano habla de "calabazo" y "porongo", dos nombres que, como vimos, son asignados por lo general a $L$. 
siceraria, si bien no de manera unívoca. Además menciona que poseen una corteza dura, lo cual no es propio de los frutos de C. maxima ssp. andreana y sí de los de L. siceraria.

En la Flora Uruguaya de 1905 escrita por Arechavaleta habría, en opinión tanto de Millán (1945) como de Contardi (1939), una mención a C. maxima ssp andreana. En la flora de la provincia de Buenos Aires (1965) Martínez Crovetto cita dos ejemplares de herbario, uno del año 1904 (Domínguez s/ $\mathrm{N}^{\circ}$ en BAF) y otro de 1939 (Burkart s/ $\mathrm{N}^{\circ}$ en SI), anunciando que la misma ya es inusual en la provincia de Buenos Aires (ver tabla 5). Resulta interesante que casi en el mismo año las floras de Uruguay y de Buenos Aires estén incluyendo a $C$. maxima ssp. andreana en sus registros.

Lamentablemente los registros de herbario no arrojaron ejemplares de gran antigüedad, sin embargo pueden darnos una idea relativa del momento en que estos "zapallitos amargos" son colectados por primera vez en las distintas provincias de Argentina (Ver Tabla 5). En Córdoba el registro más temprano es de 1924 y corresponde a la colección Scala del Museo de La Plata (LP s/No Scala), en San Luis el más temprano es de 1939 y también se halla depositado en el herbario del Museo de La Plata, correspondiendo a la colección Vignati (Vignati 545 (LP). El ejemplar más temprano para Entre Ríos lo hallamos citado en la Flora elaborada para dicha provincia y se halla consignado bajo el $n^{\circ} 2622$ del Herbario del Instituto Darwinion, (el cual no hallamos en el catálogo electrónico de dicha institución, por lo cual no figura en la tabla 5), el mismo corresponde a la zona de Gualeguay y es del año 1968.

Evaluación de los factores que posibilitarían la delimitación de un área potencial de distribución de Cucurbita maxima ssp. andreana durante tiempos prehispánicos 
Los distintos factores naturales que hacen a los requerimientos de esta subespecie fueron considerados a fin de trazar una posible área de distribución original para la misma.

1) Requerimientos específicos de suelo.

No hemos encontrado referencias acerca del tipo de suelo donde prospera $C$. maxima ssp. andreana, pero recordemos que, en general, las cucurbitáceas crecen en suelos bien drenados, no inundables, neutros o moderadamente ácidos o alcalinos (Whitaker 1968, 1974). Sin embargo al poseer esta subespecie caracteres malezoides, es frecuentemente reportada en suelos agrícolas activos o abandonados y áreas similares como corrales o basureros, registrándose poblaciones más vigorosas en suelos regados artificialmente (Contardi 1939, Ashwort y Galetto 2001) (ver capitulo 4.1.1a). Por lo tanto $C$. maxima ssp. andreana no tendría un requerimiento estricto de suelo donde desarrollarse.

2) Requerimientos específicos de clima.

El género Cucurbita se considera en líneas generales como tropical, sin embargo, existen dos divisiones dentro del mismo, organizadas de acuerdo a caracteres morfo-ecológicos, con especies mesofíticas (consideradas ancestrales) una y especies xerofíticas (consideradas derivadas) la otra (Bemis y Whitaker 1969, Nee 1990, Ashworth 1997). En cuanto al tipo de adaptación específico de C. maxima ssp. andreana hemos encontrado dos posturas:

- Mesofitica de clima templado a semi-tropical: Singh y Dathan (1972) Nee (1990) Decker Walters y Walters (2000) y Sanjur et al. (2002) consideran que este taxón es mesofítico, propio de regiones templadas cálidas. Hurd et al. (1971), 
sobre la base de la hipotética coevolución entre las cucúrbitas y sus polinizadores, también proponen un carácter tropical a semi-tropical para el mismo.

- Xerofitica: Esta postura es sostenida por Ashworth (1997) tras observaciones y experimentaciones en poblaciones de la provincia de San Luis (Tilisarao) y Córdoba (Capilla de los Remedios). Esta autora considera que C. maxima ssp. andreana sería más de tipo xerofítico ya que la población de San Luis presentó, en comparación con la de Córdoba, individuos más vigorosos, menos afectados por hongos e insectos, de crecimiento más rápido y con reproducción asexual. La reproducción asexual se encuentra presente en otras cucúrbitas silvestres como C. foetidissima la cual, por adaptación al ambiente seco y árido del sudoeste de EEUU y noroeste de México, se reproduce asexualmente por medio de raíces que salen de los estolones (Whitaker 1980). Sin embargo C. maxima ssp. andreana no presenta a nivel morfológico los caracteres xerofíticos exhibidos por poblaciones silvestres del género que crecen en el noroeste mexicano-sudoeste estadounidense, como por ejemplo gruesas raíces de almacenamiento (Bemis y Whitaker 1969). Brücher (1989) considera que esta especie es silvestre y crece en suelos no perturbados tanto en ambientes mesofíticos como xerofíticos. Probablemente se esté refiriendo en este último caso a las poblaciones de las provincias de San Luis y Mendoza que menciona dentro del área de distribución natural de esta subespecie.

3) Tipo de dispersión.

Como vimos en el capítulo $4.11 \mathrm{~b}$, luego de la reproducción sexual de $C$. maxima ssp andreana, la dispersión de sus semillas se daría mediante la generación de un fruto liviano que se desprende del pedúnculo a la madurez (Millán 1945, Lira Saade 1995), el cual sería transportado por pendientes o 
corrientes de agua (Cowan 1997). En el mapa 6 (Lámina 2) puede verse que varias poblaciones registradas en la provincia de Buenos Aires se distribuyen en la zona de la planicie de inundación del Salado y zona de "Las Encadenadas", conjunto de lagunas de tamaño variable en el centro-este de la provincia. La distribución de poblaciones en esta área podría tener que ver con una dinámica hídrica muy particular que llevaría a inundaciones periódicas que facilitarían la dispersión de los frutos de esta subespecie. En el área norte de la provincia (ver mapa 7 en lámina 2) la dispersión parecería vincularse más con el impacto antrópico sobre el paisaje, ya que esta es una zona con un desarrollo agrícola-ganadero muy profundo en el tiempo.

4) Asociación con polinizadores específicos

Los rasgos anatómicos y etológicos específicos de las abejas sudamericanas del género Peponapis indican un estrecho vínculo con especies silvestres de Cucurbita, producto de una historia de coevolución muy antigua entre ambas, previa al arribo del hombre al continente americano, habiéndose extendido luego esta relación a las formas domesticadas (Michelbacher et al. 1964, Hurd et al 1971) (ver capítulo 4.1.1b). Esto indica que debió haber existido una íntima asociación entre Peponapis fervens -el miembro más especializado de su género- y una Cucurbita silvestre sudamericana la cual, en opinión de Hurd et al. (1971), sería C. maxima ssp. andreana. Lamentablemente no se conoce el área original de distribución de esta abeja, ya que ésta -al igual que todas las "abejas de zapallo"- ha seguido las rutas de polen de las distintas cucúrbitas domesticadas, y actualmente posee un rango de distribución muy amplio desde Argentina a Brasil y desde el frente de los Andes al océano Atlántico (Hurd et al. 1971). Los registros actualizados de Peponapis fervens la ubican en Bolivia (Cochabamba, Santa Cruz), Brasil (Paraná), Chile (Santiago), Costa Rica (San José), Paraguay, Uruguay y Argentina (Moure et al. 2007). En el caso 
específico de los registros argentinos los mismos corresponden a las provincias de Buenos Aires, Cordoba, Entre Ríos, La Pampa, Santa Fe, Chaco, Misiones, Río Negro, San Luis, Mendoza, San Juan, Jujuy, La Rioja, Salta, Santiago del Estero, Catamarca y Tucumán (Hurd y Linsley 1967, Moure et al. 2007, Catalogo División Entomologia-MLP) (Figura 14). Puede verse que el área de distribución de esta abeja es más amplia incluso que la de C. maxima ssp. andreana posiblemente por su asociación con cucurbitas ya domesticadas. En cuanto a la antigüedad de los registros argentinos de éste polinizador, todos corresponden al siglo XX (la especie fue definida por Smith en 1879, Moure et al. 2007), principalmente a partir de la década del treinta, por lo cual un análisis cronológico de los mismos tampoco aportaría a la delimitación de un área de origen para la especie. Por lo tanto, las áreas originales de distribución de ambos, planta y polinizador, se definirían mutuamente sin que esto por sí solo solucione el problema de la distribución original de ninguno. Por su parte P. (Austropeponapis) melonis estaría asociada a las rutas de polen de C. ecuadorensis y $P$. (P.) citrullina a las rutas de polen de $C$. moschata y C. ficifolia (Hurd et al. 1971).

Sin embargo, a diferencia de las abejas Peponapis, que dependen exclusivamente de este género, las cucúrbitas suelen aceptar otros polinizadores (Free 1970) por lo que pueden reproducirse y prosperar fuera del área de distribución de los géneros de abejas Peponapis y Xenoglosa, característica que permitió su rápida expansión hacia otros continentes.

La reproducción sexual de C. maxima ssp. andreana se halla mediada por diversos visitantes florales que incluyen abejas (Hurd et al. 1971, Ashworth 1997, Ashworth y Galetto 2001, Passarelli 2002) o coleópteros como Diabrotica speciosa (Contardi 1939, Ashworth 1997) o Astylus atromaculatus y, en menor medida, lepidópteros de la familia Pyraustidae: Eudiopthis hyalinata Stoll ("palomita transparente del zapallo") y Spodoptera latifascia, y dípteros de la familia Chloropidae (Ashworth 1997). Todos estos insectos participan en la 
polinización asegurando indistintamente una buena producción, lo cual le da un carácter generalista a este taxón, rasgo tomado por Ashworth (1997) como señal de buena adaptación a hábitats disturbados. Sin embargo estos visitantes florales no se asocian de manera exclusiva a las cucúrbitas como sí lo hacen las "abejas del zapallo" y por ende no son útiles para definir una posible área de distribución original.

5) Área biogeográfica.

Como puede verse en el mapa 8 (Lámina 3) la disyunción entre el área de distribución de las poblaciones actuales de C. maxima ssp. andreana y los hallazgos arqueológicos identificados como C. maxima ssp. maxima o Cucurbita sp., tiene su correlato en las divisiones biogeográficas establecidas por Cabrera y Wiilink (1973) (Figura 15).

-Poblaciones actuales de C. maxima ssp. andreana: la mayor parte de estas poblaciones se ubican en la Provincia Pampeana, tanto en territorio argentino como uruguayo (ver mapa 9 en lámina3), siguiendo en grado de representatividad la Provincia del Espinal. En la Provincia del Monte se ubicaría la población reportada por Contardi (1939) para Mendoza y en la de las Yungas la que viera el ingeniero Novara unos treinta años atrás (tabla 7). Recordemos que para Contardi (1939) esta Cucurbita se encuentra en las formaciones fitogeográficas de Pradera Pampeana y parte media y sur del Parque Mesopotámico, según definición de Parodi (1934), con las excepciones propias de una planta que es una maleza.

En Bolivia y Perú las poblaciones se ubicarían en la Provincia de las Yungas, próxima a la provincia Chaqueña en el primer país (ver mapa 10 en lámina 3) y próxima a la Provincia Amazónica en el segundo (ver mapa 11 en lámina 3). 
-Ejemplares arqueológicos del género Cucurbita: los correspondientes al NOA fueron recuperados mayormente en sitios que se ubicarían en la Provincia del Monte (Alamito, Costa de Reyes, Cuesta de Zapata, El Shincal, Los Viscos, El Carmen, Loma sobre Puente río La Viña. Sitio I), aunque algunos en zonas con microclimas más húmedos que el promedio general para esta provincia (El Shincal) y otros en áreas próximas a las Yungas (Alamito). Otros sitios se ubican en la Provincia Puneña (Doncellas, Los Amarillos y los sitios de la microrregión de Antofagasta de la Sierra) y en la Provincia Prepuneña, específicamente en quebradas de acceso a la puna (Puente del Diablo, Juella, Huachichocana III, Sarahuaico). Sólo Pampa Grande se ubicaría en la Provincia de las Yungas, aunque también en un área transicional con la Provincia del Monte. Los ejemplares recuperados en sitios del COA se ubican todos entre la Provincia Patagónica y la del Monte, aunque algunos son más cercanos a la primera (Los Morillos y Cueva del Toro, por ejemplo) y otros a la segunda (vg. Agua de la Tinaja I). Los sitios de Perú y Chile se encuentran emplazados mayormente en la Provincia del Desierto, con dos excepciones en Perú (Cueva de Guitarrero en el Callejón de Huaylas y sitios de Ayacucho, el primero en la Provincia Prepuneña y los dos últimos en la Provincia Puneña) y una en Chile (sitio Pellines 1 en Bahía de las Cañas que estaría entre la Provincia Chilena y la Provincia Subantártica).

Obviamente los restos que se encuentran en un sitio arqueológico no representan necesariamente recursos obtenidos localmente, lo cual ha sido demostrado innumerables veces en las investigaciones arqueológicas de las áreas aquí analizadas, habiéndose detectado desde muy temprano, por ejemplo, objetos del Pacífico o de las Yungas en sitios puneños (Fernández Distel 1986, Hocsman 2006). Es por ello que el hallazgo de restos de una especie no tolerante a las heladas y de carácter mesofítico como C. maxima ssp. maxima en varios sitios de la Puna o del Desierto no debe llamar la atención, ya que probablemente los hallazgos son más frecuentes en estas 
áreas debido a las excelentes condiciones de preservación de restos perecederos que allí imperan y no porque hayan sido necesariamente un recurso de carácter local. Este es incluso el caso para los dos sitios que podrían contener restos de una Cucurbita silvestre, ya que se ubican en el desierto de la costa pacifica peruana. Para el del Valle de la Ventanilla, excavado por Lanning en la década del '60, no contamos con información paleoambiental, sin embargo para el sitio Quebrada de las Pircas 1 sabemos que en el pasado se emplazaba en una selva montana tropical (Rossen et al. 1996). Esto no sólo nos señala un clima y vegetación distintos a los actuales en el pasado para el caso de sitios de fines del Pleistoceno u Holoceno temprano como Quebrada de las Pircas 1, sino también la necesidad de considerar los microambientes generados por diferencias en topografía y vegetación, que se traducen en mesoclimas y microclimas distintos respectivamente (ver por ejemplo Capparelli et al 2006 para el caso del sitio El Shincal).

En cuanto al hábitat de C. maxima ssp. andreana todas las referencias que tenemos hasta el momento (Tablas 5, 6 y 7) indican medios antrópicos, lo cual coincide con la caracterización que hemos hecho de esta planta como una maleza (ver capítulo 4.1.1a). Este carácter le brinda una plasticidad tal que le permite prosperar en zonas con diverso tipo de suelo y clima, lo cual impide delimitar una posible area de distribución de la misma en base a los caracteres enunciados.

\section{Discusión}

De los resultados obtenidos explorando distintas líneas de evidencia podemos obtener una serie de derivaciones que nos han llevado a concluir los siguientes puntos: 
1) El análisis de factores naturales como suelo, polinizadores, tipo de adaptación, hábitat y modo de dispersión no ha sido útil para delimitar un área específica de distribución de C. maxima ssp. andreana, lo cual se vincula con el carácter malezoide de la misma.

2) En lo que respecta a la profundidad temporal de C. maxima ssp. andreana no existe hasta el momento evidencia arqueológica confiable y las referencias escritas de los primeros viajeros y cronistas de los siglos XVI a XVIII carecen de la precisión necesaria como para adjudicar con seguridad una descripción o comentario realizado por los mismos a esta subespecie. Las primeras menciones de la misma se darían a partir del siglo XIX en la zona rioplatense. Si se considera solamente la cronología de herbarios y floras, el área de distribución original de esta subespecie sería la zona del río de la Plata (Buenos Aires y Uruguay), irradiándose luego a otras áreas del país como Entre Ríos, Santa Fe, Mendoza o San Luis donde son identificadas por los investigadores del siglo XX, y más tarde a Perú y Bolivia donde fueron recientemente reportadas por la GCCE. Este mismo sentido de difusión es el que, como vimos, asume Brücher (1989). Evidentemente este razonamiento no es apropiado ya que lo que se visualiza es la cronología de aparición de los registros, pero no de las poblaciones que les dieron origen. La antigüedad de éstas últimas y sus relaciones como poblaciones madre y derivadas sólo puede llegar a estimarse mediante estudios genéticos (Andres y Nee 2005).

3) Los registros históricos nos indican el cultivo de "zapallos" en el NOA hacia finales del siglo XVI, luego se menciona la presencia de éstos entre los Mataguayos del occidente chaqueño en el siglo XVII y en el siglo XVIII entre los Matarás del oriente salteño, los Tobas del Pilcomayo y los Mocovíes del Chaco Oriental y norte santafecino. En el siglo XIX ya existen poblaciones de C. maxima ssp andreana. Esto indicaría que probablemente los grupos cazadores recolectores chaqueños obtuvieron los zapallos domesticados de sus vecinos andinos para luego sembrarlos ellos mismos. Actualmente estos 
grupos poseen una horticultura de pequeña escala, siendo notable el cultivo de zapallos, los cuales poseen gran diversidad y nombres propios en lengua nativa (Martínez Crovetto 1964 a y b, Maranta 1987, Arenas 2003). Incluso los tobas mencionan zapallos propios distintos a los foráneos -sobre todo en las características del mesocarpio- y los wichí destacan que el "zapallito de tronco" es propio de ellos (Arenas 2003). Por lo tanto la evidencia indicaría un derrotero oeste- este y norte- sur en la dispersión de poblaciones cultivadas de las especies de Cucurbita (Figura 16). Esta dispersión de ejemplares cultivados probablemente incluyó a C. maxima ssp. maxima e incidentalmente -mediante un proceso aún no del todo esclarecido- pudo incluir a $C$ maxima ssp andreana, ya que ambas formarían parte de un complejo cultivo-maleza. Esta dispersión desde el área andina por la cuenca del Pilcomayo-Bermejo y luego por la del Paraná-Río de La Plata coincide en gran medida con las rutas seguidas por los exploradores y colonos españoles en sus primeros momentos en lo que sería luego suelo argentino. Esto habría generado una dinámica de alta movilidad de poblaciones, tanto nativas como extranjeras, sucesivos abandonos de pueblos y sementeras, hurto de cosechas y traslado de ganado con su posterior abandono. Creemos que es en este escenario en el que C. maxima ssp andreana se dispersó y asentó en el área centro-este argentina cruzándose con poblaciones de C. maxima ssp maxima abandonadas hasta llegar a ser una maleza próspera en la región centro-este del país. La ausencia actual de ejemplares en zonas de esta hipotética vía de dispersión como la región chaqueña es llamativa, pudiendo deberse a falta de investigaciones más sistemáticas en el área. Debe considerarse también que el área de distribución actual de C. maxima ssp andreana resulta en gran parte del control humano sobre la misma, tanto porque habita en áreas perturbadas antrópicamente, como porque al ser considerada una maleza agronómica tóxica (Molina 2005) se la combate y erradica "recortando" su área de distribución de acuerdo a las zonas sembradas. Esta via de dispersión estaria también reflejada en que los 
cultivares sudamericanos reconocidos hasta el presente provienen del área andina y chaqueña.

4) El sentido de dispersión del complejo cultivo- maleza habría sido desde el área andina hacia el centro de Argentina y Uruguay. Esta dirección sería opuesta a la propuesta por Brücher (1989) y otros autores (como Piperno y Pearsall 1998), quienes consideran a C.maxima ssp. andreana como silvestre. De acuerdo con la propuesta aquí presentada, las poblaciones actuales de esta subespecie que se hallan presentes en el centro - este argentino y Uruguay son malezas derivadas y no formas ancestrales. En este sentido los resultados aquí obtenidos acuerdan con lo manifestado por Harris y Hillman (1989), quienes establecen que los patrones de distribución actuales no pueden ser usados como guía para evaluar el área donde los progenitores silvestres fueron primeramente cultivados. Para estos autores el principal valor de estudiar los patrones de distribución actual de las comunidades vegetales yace en lo que pueden decirnos acerca de las preferencias de hábitat de los progenitores. Como se analizó en éste y el anterior capítulo, el hábitat de C. maxima ssp andreana es el de una maleza, por lo cual su aporte a la delimitación del área de distribución del progenitor de C maxima ssp maxima es relativo, debiendo recurrirse a otro tipo de evidencia (principalmente arqueológica) para estimar la ubicación de dicha área. 
Tabla 5: registro de C. maxima ssp andreana en herbarios. En la primera columna se señala exsiccata, número de ejemplar y colector (leggitur). Las determinaciones taxonómicas, ubicación y observaciones se transcriben textuales de las fichas.

\begin{tabular}{|c|c|c|c|c|c|}
\hline Ejemplar & Fecha colecta & Identificacion taxonomica & Determinó & Ubicación & Observaciones \\
\hline $\begin{array}{l}\text { Vignatti y.Martínez Crovetto } \\
545 \text { (LP) }\end{array}$ & $25 / 02 / 1939$ & Cucurbita andreana Naud. & R. Martinez Crovetto & San Luis. Paso de las Carretas & \\
\hline Boffa s/n (LP) & 1964 & aff. Cucurbita andreana & R. Pozner & $\begin{array}{l}\text { Buenos Aires, Berisso, Los } \\
\text { Talas, camino a La Balandra }\end{array}$ & \\
\hline Dawson s/n (LP) & $27 / 02 / 1980$ & Cucurbita andreana Naudin & & $\begin{array}{c}\text { Buenos Aires, Partido General } \\
\text { Paz: Villanueva. Almacen "El } \\
\text { descanso" en intersección con } \\
\text { ruta } 29\end{array}$ & Borde de camino \\
\hline Dawson s/n (LP) & $27 / 02 / 1980$ & Cucurbita andreana Naudin & & $\begin{array}{l}\text { Buenos Aires. Partido de } \\
\text { Chascomus.Puente entre } \\
\text { Laguna del Medio y Laguna } \\
\text { Esquivel camino a estancia "El } \\
\text { Tajamar" }\end{array}$ & \\
\hline Scala s/n (LP) & $01 / 12 / 1924$ & Cucurbita andreana Naud. & R. Martinez Crovetto & $\begin{array}{c}\text { Córdoba. Tancacha, orillas río } \\
\text { tercero }\end{array}$ & \\
\hline Pozner 66 (BAB) & $23 / 12 / 1987$ & $\begin{array}{l}\text { Cucurbita maxima Duchesne } \\
\text { subsp.andreana (Naudin) Filov }\end{array}$ & R. Pozner & Buenos Aires. Vicente Lopez & \\
\hline $\begin{array}{l}\text { Burkart y Troncoso } 27387 \\
\text { (SI) }\end{array}$ & & $\begin{array}{l}\text { Cucurbita maxima Duchesne } \\
\text { subsp.andreana (Naudin) Filov }\end{array}$ & R. Martinez Crovetto & $\begin{array}{l}\text { Entre Ríos. Concepcion del } \\
\text { Uruguay. San José }\end{array}$ & $\begin{array}{l}\text { En borde de camino. Citado en } \\
\text { Flora I.I Entre Rios } 6 \text { (6a): } 84\end{array}$ \\
\hline Pozner 58 (BAB) & $29 / 11 / 1987$ & $\begin{array}{l}\text { Cucurbita maxima Duchesne } \\
\text { subsp.andreana (Naudin) }\end{array}$ & R. Pozner & Buenos Aires. Chascomus & $\begin{array}{c}\text { Material cultivado en Olivos a } \\
\text { partir de semillas de } \\
\text { Chascomús }\end{array}$ \\
\hline Pozner 67 (BAB) & $23 / 12 / 1987$ & $\begin{array}{l}\text { Cucurbita maxima Duchesne } \\
\text { subsp.andreana (Naudin) }\end{array}$ & R. Pozner & Buenos Aires. Vicente Lopez & $\begin{array}{l}\text { Material cultivado a partir de } \\
\text { semillas provenientes de la Ea. } \\
\text { del Vasco Arrieta, Chascomús }\end{array}$ \\
\hline
\end{tabular}




\section{Hunziker 9904 (CORD)}

23/03/1952

Hunziker 11563 (CORD)

Gallinal 5106 (LIL MVM)

Krapovickas, Vanni, D.

Williams, K. Williams 47649 (CTES)

Hunziker 24547 (CORD)

Nee 48836 Barcode ID 382258 (NYBG)
$18 / 01 / 1956$

determinacion

en 1954

$19 / 03 / 1999$

$26 / 02 / 1983$

05/04/1998
Cucurbita maxima Duchesne subsp.andreana (Naudin) Filov

Cucurbita maxima Duchesne subsp.andreana (Naudin)

Cucurbita maxima Duchesne subsp.andreana (Naudin) Filov

Cucurbita andreana Naudin

Cucurbita andreana Naudin

Córdoba. Colon

Poco frecuente. Hojas

R. Martinez Crovetto Córdoba. General San Martin

R. Martinez Crovetto

Krapovickas, A.,

Hunziker, A. T.

Córdoba

San Luis. General Pedernera
Cucurbita maxima (Lam.) Poir. subsp. andreana Santiesteban.7.5 km by road
Bolivia, Santa Cruz, NW of bridge at Chané Independencia. marmoreadas; frutos amargos.

En campos bajos, cerca del algarrobal

Citado en Notul Syst. 15: 52

Rastrera, radicante en los nudos

Trailing over short grasses nea abandoned sugar-workers shelter, with Luffa cylindrica, but of the several plants, the one with the larger, $8 \mathrm{~cm}$ diam., soft, non-bitter fruit may be an escape, but the others are more slender and have uniformly smaller fruits with very bitter flesh and are undoubtedly wild. Seeds tan. Corollas open (11:00 A.M., mostly overcast). 
Nee 48864 Barcode ID

390565 (NYBG)
05/04/1998
Cucurbita maxima (Lam.) Poir. subsp. andreana
Bolivia, Santa Cruz, Santiesteban.Ca. $5 \mathrm{~km} \mathrm{~N}$ of bridge at Chané Independencia on road to Colonia Hardiman
Habitat: Along edge of waterfilled roadside ditch, without shrubs but with grasses.

Vegetation: Flat, mostly cleared

for crops. A number of plants

over short grasses between tall grasses and edge of shallow water of roadside ditch. No

open flowers (2:00 P.M., mostly sunny); buds yellow.. Fruit light sunny); buds yellow.. Fruit light
green, faintly spotted, then tannish; rind hard; flesh very bitter; a number seen floating in the shallow water. 
Tabla 6: registro de C. maxima ssp andreana y C. maxima ssp. maxima "subespontánea" en floras. Para la mención de los ejemplares se aplica el mismo criterio que en la tabla 5.

\begin{tabular}{|c|c|c|c|c|c|c|}
\hline $\begin{array}{c}\text { Flora (región y } \\
\text { año) }\end{array}$ & $\begin{array}{c}\text { Autor de la } \\
\text { sección }\end{array}$ & Determinación taxonómica & Observaciones & Ejemplar & Localidad y fecha & Observaciones \\
\hline \multirow[t]{2}{*}{ Entre Ríos 1974} & $\begin{array}{l}\text { R. Martínez } \\
\text { Crovetto }\end{array}$ & Cucurbita andreana Naudin & $\begin{array}{c}\text { En la zona centra de Entre } \\
\text { Ríos, poco frecuente en la } \\
\text { actualidad }\end{array}$ & $\begin{array}{l}\text { SI } 26222 \\
\text { A. Maudet }\end{array}$ & Gualeguay 1968 & $\begin{array}{l}\text { Frutos, plantas } \\
\text { cultivadas }\end{array}$ \\
\hline & & & & $\begin{array}{l}\text { SI } 27387 \\
\text { Burkart y } \\
\text { Troncoso }\end{array}$ & $\begin{array}{c}\text { Concepción del Uruguay, San } \\
\text { José }\end{array}$ & Borde de camino \\
\hline \multirow[t]{2}{*}{ Entre Ríos 1974} & $\begin{array}{l}\text { R. Martínez } \\
\text { Crovetto }\end{array}$ & $\begin{array}{c}\text { Cucurbita maxima Duch. ex } \\
\text { Lam. }\end{array}$ & $\begin{array}{l}\text { En Entre Ríos se la } \\
\text { encuentra subespontánea } \\
\text { en baldíos, basurales, } \\
\text { orillas de caminos, etc. }\end{array}$ & $\begin{array}{l}\text { SI } 24264 \\
\text { Burkart y } \\
\text { Troncoso }\end{array}$ & $\begin{array}{c}\text { Gualeguaychú, arroyo Brazo } \\
\text { Largo }\end{array}$ & \\
\hline & & & & $\begin{array}{l}\text { SI } 26759 \\
\text { Burkart }\end{array}$ & Paraná & $\begin{array}{l}\text { Borde de camino en e } \\
\text { embarcadero }\end{array}$ \\
\hline \multirow[t]{2}{*}{ Buenos Aires 1965} & $\begin{array}{l}\text { R. Martínez } \\
\text { Crovetto }\end{array}$ & Cucurbita andreana Naudin & $\begin{array}{c}\text { Especie originaria del } \\
\text { centro y norte del país y } \\
\text { del Uruguay, rara en la } \\
\text { provincia. }\end{array}$ & $\begin{array}{c}\text { SI s/No } \\
\text { Burkart II } \\
1939\end{array}$ & & \\
\hline & & & & $\begin{array}{l}\text { BAF s/No } \\
\text { Dominguez } \\
\text { II } 1904\end{array}$ & & \\
\hline
\end{tabular}


Tabla 7: datos bibliográficos y obtenidos por consulta con distintos investigadores sobre poblaciones actuales de C. maxima ssp andreana. Las denominaciones taxonómicas se transcriben de manera textual.

\begin{tabular}{|c|c|c|c|c|}
\hline Bibliografía & Identificación taxonómica & Ubicación & Fecha colecta & Otros datos \\
\hline Millán 1945 & Cucurbita andreana & $\begin{array}{l}\text { Estación Juan Jackson } \\
\text { (Uruguay) }\end{array}$ & $17 / 4 / 1942$ у $23 / 7 / 1942$ & \\
\hline Millán 1945 & Cucurbita andreana & $\begin{array}{l}\text { Córdoba, Depto. Cruz } \\
\text { del Eje, Tuclame }\end{array}$ & $30 / 09 / 1942$ & \\
\hline Millán 1945 & Cucurbita andreana & $\begin{array}{l}\text { Cordoba, Depto. San } \\
\text { Javier, La Población }\end{array}$ & jun-42 & \\
\hline Millán 1945 & Cucurbita andreana & $\begin{array}{l}\text { Córdoba, Dique San } \\
\text { Roque (chacras) }\end{array}$ & 1942 & \\
\hline Millán 1945 & Cucurbita andreana & $\begin{array}{l}\text { Córdoba, Manfredi y } \\
\text { Laguna Larga }\end{array}$ & 04/06/1942 & \\
\hline Millán 1945 & Cucurbita andreana & $\begin{array}{l}\text { La Rioja, Dep. } \\
\text { Independencia }\end{array}$ & $12 / 03 / 1943$ & $\begin{array}{l}\text { Hallazgo no corroborado, criticado por Hunziker } \\
\text { y Subils (1975) }\end{array}$ \\
\hline Millán 1968 & Cucurbita andreana & $\begin{array}{l}\text { Buenos Aires, } \\
\text { Pergamino }\end{array}$ & & Frutos dulces \\
\hline Cárdenas 1969 & Cucurbita andreana & $\begin{array}{l}\text { Bolivia, Depto del Beni, } \\
\text { La Loma (proxima a } \\
\text { Trinidad) }\end{array}$ & 1950 aprox. & Maleza amarga "joko silvestre" \\
\hline Base de datos T. Andres & Cucurbita maxima ssp. andreana & $\begin{array}{c}\text { Buenos Aires, cerca de } \\
\text { Laguna Alsina y } \\
\text { tambien cerca de } \\
\text { Laguna Esquivel }\end{array}$ & 1980 & Colectada por T. Whitaker. Silvestre \\
\hline Base de datos T. Andres & Cucurbita maxima ssp. andreana & $\begin{array}{l}\text { Córdoba. Dep. Río } \\
\text { Segundo }\end{array}$ & $12 / 04 / 1978$ & $\begin{array}{c}\text { Colectada por A. Krapovickas. Comunidad } \\
\text { arbustiva }\end{array}$ \\
\hline Base de datos T. Andres & Cucurbita maxima ssp. andreana & Córdoba. Jesus María & $22 / 12 / 1978$ & $\begin{array}{l}\text { En un area de praderas con maleza a los lados } \\
\text { de un camino. }\end{array}$ \\
\hline
\end{tabular}


Base de datos T. Andres

Base de datos T. Andres

Ing. Novara (com. pers)

M. Nee (com. pers.)

Base de datos G.C.C.E.

Base de datos G.C.C.E.

Base de datos G.C.C.E.

Ashworth y Galetto 2001
Cucurbita maxima ssp. andreana

Cucurbita maxima ssp. andreana

Cucurbita andreana

Cucurbita andreana

Cucurbita maxima Duchesne ssp. andreana (Naud.) A. I. Filov

Cucurbita maxima Duchesne ssp. andreana (Naud.) A. I. Filov

Cucurbita maxima Duchesne ssp. andreana (Naud.) A. I. Filov

Cucurbita maxima ssp. andreana
Córdoba Lozada, a 15

$\mathrm{km}$ al oeste de la ciudad de Córdoba

San Luis.

Salta, paraje "El Coro" entre ruta 34 y Dique Cabra Corral

Boliva. Alrededores de

Mineros, al norte de

Santa Cruz de la Sierra

Bolivia. Depto de Santa Cruz, Prov.

Santiestebam, $7 \mathrm{~km} \mathrm{~N}$

of Aguaí, $21.5 \mathrm{~km} \mathrm{~N}$ of bridge at Chané

$\left(16^{\circ} 51.39^{\prime} \mathrm{S}, 63^{\circ} 21.82\right.$ W)

Perú. Marankiari Bajo,

Prov. Chanchamayo, Dep. Junín (S $10^{\circ} 56.2^{\prime}$ W $75^{\circ} 12.1^{\prime}$

Perú. Yurinaki, Dept Junín (S $10^{\circ} 52.4^{\prime}$ W $\left.75^{\circ} 05.1^{\prime}\right)$

Tilisarao, Depto. Chacabuco, San Luis
$07 / 04 / 1944$

1970 aprox.

700-800 m.s.m. en un cultivo de zapallo.

Growing up bank from roadside ditch into a harvested rice field, covering a dilapidated shed in a weedy lot. Large sugar cane fields nearby. C. maxima ssp. maxima and C. moschata grown in area, but not in the immediate vicinity. Vines bearing numerous fruits and a few flowersaround 20 fruits collected. Fruits extremely bitter; rind hard; flesh creamy yellow. Altura: 228 m.s.m.

N.V.: "zapallito de monte"

$17 / 05 / 2004$

A 624 m.s.m. Nombre vulgar: "huevo de pato", "zapallo pouaiquito" "ishicopé"

$18 / 05 / 2004$

Altura: 589 m.s.m. N.V.:“ishcopiqui”

Dos poblaciones, una en un campo de maíz, la otra en un terreno agricola abandonado. Rodeado de bosque chaqueño 
Buenos Aires: Pla,

Timote, Maza, General

Pinto, Tandil,

Contardi 1939

Contardi 1939

Contardi 1939

Contardi 1939

Contardi 1939

Contardi 1939
Cucurbita andreana

\section{Cucurbita andreana}

Cucurbita andreana

Cucurbita andreana

Cucurbita andreana

Cucurbita andreana
Chascomús, Villanueva,

Junín, Chacabuco,

Salto, Rojas, Alfonso,

Pergamino

Córdoba: Jesus María,

R.J. Cárcano

San Luis: San luis,

Naschel

Santa Fe: San Javier

Entre Ríos: Yeruá

Mendoza: Junin 
Tabla 8: registro de C. maxima ssp maxima en herbarios. En la primera columna se señala exsiccata, número de ejemplar y colector (leggitur). Las determinaciones taxonómicas, ubicación y observaciones se transcriben textuales de las fichas.

\begin{tabular}{|c|c|c|c|c|c|}
\hline Ejemplar & Fecha de colecta & Identificacion taxonomica & Determinó & Ubicación & Otros datos en ficha \\
\hline $\begin{array}{l}\text { Ariza Espinar } \\
2885 \text { (CORD) }\end{array}$ & 20/03/1975 & $\begin{array}{l}\text { Cucurbita maxima Duchesne } \\
\text { subsp.maxima }\end{array}$ & R. Pozner & Córdoba. Capital & En baldios \\
\hline $\begin{array}{c}\text { Hunziker } \\
22831 \text { (CORD) }\end{array}$ & $27 / 11 / 1975$ & $\begin{array}{l}\text { Cucurbita maxima Duchesne } \\
\text { subsp. maxima }\end{array}$ & R. Pozner & Córdoba. Capital & $\begin{array}{l}\text { Hojas suaves al tacto, marmoreadeas, } \\
\text { pedicelos fructificados sin costillas }\end{array}$ \\
\hline $\begin{array}{c}\text { Hunziker } \\
23057 \text { (CORD) }\end{array}$ & $25 / 02 / 1975$ & $\begin{array}{l}\text { Cucurbita maxima Duchesne } \\
\text { subsp. maxima }\end{array}$ & R. Pozner & Córdoba. Capital & $\begin{array}{c}\text { En terrenos baldíos vecinos. Hojas sin } \\
\text { manchas blanco- grisáceas. Frutos } \\
\text { dulces (sin colocintina) Hojas con } \\
\text { nectarios }\end{array}$ \\
\hline $\begin{array}{l}\text { Hunziker23070 } \\
\text { (CORD) }\end{array}$ & $11 / 04 / 1975$ & $\begin{array}{l}\text { Cucurbita maxima Duchesne } \\
\text { subsp. maxima }\end{array}$ & R. Pozner & Córdoba. Capital & $\begin{array}{c}\text { En baldío. Frutos con el pedicelo no } \\
\text { engrosado y sin costillas }\end{array}$ \\
\hline $\begin{array}{l}\text { Scarpa } 693 \\
\quad(\mathrm{SI})\end{array}$ & mar-99 & Cucurbita maxima L. & G. Scarpa & Formosa. Depto. Matacos & Cultivada \\
\hline $\begin{array}{l}\text { Elgueta s/n } \\
\text { (SI) }\end{array}$ & $21 / 07 / 1942$ & $\begin{array}{l}\text { Cucurbita maxima Duchesne var. } \\
\text { triloba Millán }\end{array}$ & & $\begin{array}{l}\text { Chile. Region Metropolitana. } \\
\text { Santiago }\end{array}$ & Cultivada. Holotipo SI-15692 \\
\hline Viada s/n (SI) & sep-42 & $\begin{array}{l}\text { Cucurbita maxima Duchesne var. } \\
\text { zipinka Millán }\end{array}$ & & Salta. Chicoana & $\begin{array}{l}\text { Cultivado. N.v. "sipingo" Holotipo SI- } \\
15689\end{array}$ \\
\hline $\begin{array}{c}\text { Hunziker } \\
11563 \text { (CORD) }\end{array}$ & $18 / 01 / 1956$ & Cucurbita maxima Duchesne & Pozner, R. & Córdoba. General San Martin. & $\begin{array}{l}\text { Poco frecuente. Hojas marmoreadas; } \\
\text { frutos amargos. En campos bajos, cerca } \\
\text { del algarrobal }\end{array}$ \\
\hline $\begin{array}{l}\text { Antón } 16 \\
\text { (CORD) }\end{array}$ & 23/03/1975 & Cucurbita maxima Duchesne & Pozner, R. & Córdoba, Río Segundo & Proximidades de casa deshabitada \\
\hline
\end{tabular}


Hunziker y

Subils 19355

(CORD)

Subils 2048

(CORD)

Subils 2043

(CORD)

Subils 2044

(CORD)

Hunziker

22894 (CORD)

Burkart

26759 (SI)

Vargas 937

(LPB, NY

USZ)
24/03/1967

Cucurbita maxima Duchesne

Pozner, R.

Córdoba. Santa María

23/02/1975

Cucurbita maxima Duchesne

23/02/1975

Cucurbita maxima Duchesne

Cucurbita maxima Duchesne

23/02/1975

$24 / 12 / 1975$

Cucurbita maxima Duchesne

Cucurbita maxima Duchesne

11/02/1995

Cucurbita maxima Duchesne
Pozner, R.

Pozner, R.

Pozner, R.

Pozner, R.

Martínez Crovetto

I.G. Vargas

Bolivia, Santa Cruz, Valle Grande (18.31.5S 64.5.8W )
Entre dos departamentos: Santa María/Río Segundo. Frecuente a lo largo del camino de tierra paralelo a la ruta

N v : Zapallo Amargo. En la casa de A. Subils, cerca de los corrales. Guías de

$1.20 \mathrm{~m}$ de long. Hojas con manchas; ovario de $3 \mathrm{~cm}$ long. cuando la flor abre

N.v.:Zapallo amargo En el campo de A. Mármol. Planta completa (long. $2.10 \mathrm{~cm}$ ) Hojas manchadas

N.v.: Zapallo Amargo Guías de 2 a 2.50 m. Hojas manchadas. En campo de A. Mármol

Citado en Flora I.I Entre Rios 6 (6a): 85

Elevaciòn: 2050 mtrs Planta guiadura extendida $4-5 \mathrm{~m}$ de largo, $35 \mathrm{~cm}$ diámetro basal; flores amarillas, frutos verde-amarillento, cas, comestibles.

$$
\text { Cultivada. N.V.: zapallo }
$$


Elevaciòn: 430 mtrs.N Acc. 65. Crece extendida más de $3 \mathrm{~m}$ de largo con

tallos ramificados en la base, ramas de

USZ 5424

Cucurbita maxima Duchesne

T. Andres y M. Nee
Bolivia, Santa Cruz, Andrés Ibañez (17.50S 63.14W)

-2 cm de diámetro con flores femenin

y masculinas de pétalos amarillo-

naranja, frutos inmaduros verdes $y$

esféricos que alcanzan $8 \mathrm{~cm}$ de

diámetro, cáscara dura. N.V :

Chile. Biobio. VIII Región 
Tabla 9: registro arqueológico de restos sudamericanos del género Cucurbita sp. fuera del territorio argentino. El orden es cronológico: desde los registros más tempranos a los más tardíos. Los datos están transcriptos textuales de la bibliografía consultada.

\begin{tabular}{|c|c|c|c|c|c|}
\hline Sitio & Cronología & Ubicación & $\begin{array}{c}\text { IDENTIFICACIÓN Y PARTE } \\
\text { DEL VEGETAL }\end{array}$ & Identificado por & Bibliografía \\
\hline Las Vegas & Previo a $10000 \mathrm{AP}$ & Santa Elena, Costa de Ecuador & $\begin{array}{l}\text { Fitolitos de Cucurbita sp } \\
\text { silvestre }\end{array}$ & D. Piperno & Stothert et al. 2003 \\
\hline Las Vegas & $10130-9320$ AP & Santa Elena, Costa de Ecuador & $\begin{array}{c}\text { Fitolitos de Cucurbita } \\
\text { sp.domesticada, posiblemente } \\
\text { C. ecuadorensis }\end{array}$ & D. Piperno & $\begin{array}{l}\text { Piperno et al 2003, Piperno et al. } \\
2008\end{array}$ \\
\hline Las Vegas & 9800-8000 AP & Santa Elena, Costa de Ecuador & $\begin{array}{c}\text { Fitolitos de Cucurbita sp } \\
\text { modificada posiblemente } C \text {. } \\
\text { ecuadorensis }\end{array}$ & D. Piperno & Stothert et al. 2003 \\
\hline Las Vegas & 8000-6600 AP & Santa Elena, Costa de Ecuador & $\begin{array}{c}\text { Fitolitos de Cucurbita } \\
\text { sp.domesticada, posiblemente } \\
\text { C. moschata }\end{array}$ & D. Piperno & Stothert et al. 2003 \\
\hline Guitarrero & $9390-200 \mathrm{AC}$ & Callejón de Huaylas, Peru (t.altas) & Cucurbita sp. & & Chevallier2002 \\
\hline $\begin{array}{l}\text { Quebrada de las } \\
\text { Pircas } 1\end{array}$ & $\begin{array}{c}9240+/-50 \text { a } 7660+/- \\
40 \mathrm{AP}\end{array}$ & $\begin{array}{l}\text { Valle de Nanchoc, costa norte de } \\
\text { Perú }\end{array}$ & C. moschata & T. Andres & Dillehay et al. 2007 \\
\hline La Paloma & 6680-3720 AC & $\begin{array}{c}\text { Sur de Lima, a } 7 \mathrm{~km} \text { del Valle de } \\
\text { Chilca }\end{array}$ & Cucurbita ficifolia & & Chevallier 2002 \\
\hline La Paloma & $6680-6450$ AC & $\begin{array}{l}\text { Sur de Lima, a } 7 \mathrm{~km} \text { del Valle de } \\
\text { Chilca }\end{array}$ & Cucurbita sp. & & Chevallier2002 \\
\hline Complejo Chihua & $4200-3100$ AC & Valle de Ayacucho, Perú (t. altas) & Cucurbita sp. & & Mc Neish 1975 en Whitaker 1983 \\
\hline Pampa & $4200-2500$ AC & Costa central. Peru & Cucurbita maxima & & Pearsall 1992 \\
\hline Pampa & $4200-2500 \mathrm{AC}$ & Costa central. Peru & Cucurbita ficifolia & & Pearsall 1992 \\
\hline Encanto & $4200-2500 \mathrm{AC}$ & Costa central. Peru & Cucurbita sp. & & $\begin{array}{c}\text { Cutler y Whitaker 1961, Pearsall } \\
1992\end{array}$ \\
\hline Chilca I & $3780-3540 \mathrm{AC}$ & Chilca, al sur de Lima & Cucurbita sp. & & Chevallier2002 \\
\hline
\end{tabular}




\begin{tabular}{|cc} 
Isla Larga & 3600 AP \\
Complejo Cachi & $3400-3100$ AC \\
Huaca Prieta & $3400-2100$ AC \\
Pampa de & $3300-2960$ AC \\
Ventanilla & \\
$\begin{array}{c}\text { Pampa de } \\
\text { Ventanilla PV45- }\end{array}$ & 3000 AC \\
136 (corte 1, nivel 7 \\
y corte 1A, nivel 6) & \\
Cerro Lampay & $3000-1500$ AC \\
Huaca Prieta & $3000-1000$ AC \\
Los Gavilanes & 2900 BC - 60 AC \\
Los Gavilanes & 2900 BC - 60 AC \\
La Galgada & $2870-1920$ AC \\
& \\
La Galgada & $2870-1920$ AC \\
Huaca Prieta & $2700-300$ AC \\
Huaca Prieta & $2700-300$ AC \\
Caral & $2500-2000$ AC \\
El Paraiso & $2450-1410$ AC \\
El Paraiso & $2450-1410$ AC \\
El Paraiso & $2450-1410$ AC \\
Huaynuma & 2000 AC
\end{tabular}

Este de Uruguay, proximo a limite con Brasil

Valle de Ayacucho, Perú (t. altas)

Chicama, costa norte, Perú

Valle de la Ventanilla. Costa central. Peru

Valle de la Ventanilla. Costa central. Peru

Valle Fortaleza, costa norcentral,

$$
\text { Perú }
$$

Chicama, costa norte, Perú

Huarmey, costa norte de Perú

Huarmey, costa norte de Perú

Margen del río Tablachaca, en su

union con el río Santa, costa norcentral de Perú

Margen del río Tablachaca, en su union con el río Santa, costa norcentral de Perú

Chicama, Perú, costa norte

Chicama, Perú, costa norte

Valle de Supe, costa norcentral de Perú

Valle del río Chillón al norte de Lima, Perú

Valle del río Chillón al norte de

$$
\text { Lima, Perú }
$$

Valle del río Chillón, al norte de Lima, Perú

Valle de Casma, Peru (costa)
Fitolitos de Cucurbita ssp. domesticadas

Cucurbita sp.

Cucúrbita maxima

Cucurbita ficifolia

Cucurbita andreana

Cucurbita pepo

Cucurbita moschata

Cucurbita moschata

Cucurbita sp.

Cucurbita maxima

Cucurbita moschata

Cucurbita moschata

Cucurbita ficifolia

Cucurbita sp.

Cucurbita ficifolia

Cucurbita maxima

Cucurbita moschata

Cucurbita maxima
Iriarte et al 2001

Mc Neish 1975 en Whitaker 1983

Chevallier 2002

Chevallier 2002

Pearsall 1992

R. Vega-Centeno 2005

Cutler y Whitaker 1961

Chevallier 2002

Chevallier 2002

Chevallier 2002

Chevallier 2002

Whitaker 1983

Whitaker 1983

R. Vega-Centeno 2005

Chevallier 2002

Chevallier 2002

Chevallier 2002

Whitaker 1983 


\begin{tabular}{|c|c|c|c|c|c|}
\hline Huaynuma & $2000 \mathrm{AC}$ & Valle de Casma, Peru (costa) & Cucurbita ficifolia & T. Whitaker & Whitaker 1983 \\
\hline Huaca Prieta & $2000 \mathrm{AC}$ & Chicama, costa norte, Perú & Cucurbita ficifolia & & Whitaker y Bohn 1950 \\
\hline Huaca Prieta & $2000 \mathrm{AC}$ & Chicama, costa norte, Perú & Cucurbita moschata & & Whitaker y Bohn 1950 \\
\hline Pampa Llamas & $1800-1500 \mathrm{AC}$ & Valle de Casma, Peru (costa) & Cucurbita maxima & T. Whitaker & Whitaker 1983 \\
\hline Tortugas & $1800-1500 \mathrm{AC}$ & Valle de Casma, Peru (costa) & Cucurbita maxima & T. Whitaker & Whitaker 1983 \\
\hline Tortugas & $1800-1500 \mathrm{AC}$ & Valle de Casma, Peru (costa) & Cucurbita ficifolia & T. Whitaker & Whitaker 1983 \\
\hline $\begin{array}{l}\text { Ocho sitios } \\
\text { arqueológicos sin } \\
\text { especificar }\end{array}$ & $1800 \mathrm{BC}-100 \mathrm{AC}$ & Valle de Virú, Perú (costa) & Cucurbita maxima & T. Whitaker & $\begin{array}{c}\text { West y Whitaker } 1979 \\
\text { Whitaker } 1981\end{array}$ \\
\hline $\begin{array}{l}\text { La Capilla } 1 \text { Quiani } \\
\qquad 7\end{array}$ & $1750-1500 \mathrm{AC}$ & Costa. Norte Grande. Arica. Chile & Cucurbita sp. & & Castro y Tarragó 1992 \\
\hline Las Haldas & $1600-1200 \mathrm{AC}$ & Valle de Casma, Peru (costa) & Cucurbita maxima & T. Whitaker & Whitaker 1983 \\
\hline Cementerio AZ-14 & $1650 \mathrm{AC}$ & Costa Norte Grande, Arica, Chile & Cucurbita sp & & Santoro 1980 \\
\hline Las Morrenas & $1050 \mathrm{AC}$ & Chile Zona central & Cucurbitaceae & M. T Planella & Planella 2005 \\
\hline San Diego & $500 \mathrm{AC}$ & Valle de Casma, Perú (costa) & Cucurbita maxima & T. Whitaker & Whitaker 1983 \\
\hline San Diego & $500 \mathrm{AC}$ & Valle de Casma, Perú (costa) & Cucurbita moschata & T. Whitaker & Whitaker 1983 \\
\hline Cueva Guitarrero & $500 \mathrm{AC}$ a $500 \mathrm{DC}$ & Callejón de Huaylas, Peru (t.altas) & Cucurbita sp. & Smith & Whitaker 1983 \\
\hline Pellines 1 & $230+210 \mathrm{DC}$ & Bahía Las Cañas, Chile & Cucurbita sp. & & Seelenfreund, A. 1995-1996 \\
\hline $\begin{array}{l}\text { Cementerio } \\
\text { Tarapacá } 40\end{array}$ & 290 y $360 \mathrm{DC}$ & $\begin{array}{c}\text { Costa Norte Grande, Tarapacá, } \\
\text { Chile }\end{array}$ & C. maxima y C. moschata & Cárdenas & Núñez Atencio 1982 \\
\hline Sitio F & $500-600$ DC & Valle de Ica, Perú (costa) & Cucurbita maxima & Carter 1945 & $\begin{array}{c}\text { Whitaker 1983, Cutler y Whitaker } \\
1961\end{array}$ \\
\hline $\begin{array}{l}\text { Ocho sitios } \\
\text { arqueológicos sin } \\
\text { especificar }\end{array}$ & $600-1100$ DC & Valle de Virú, Perú (costa) & Cucurbita moschata & T. Whitaker & $\begin{array}{l}\text { West y Whitaker } 1979 \\
\text { Whitaker } 1981\end{array}$ \\
\hline
\end{tabular}




\begin{tabular}{|cccccc|c} 
La Granja & $600-1000 \mathrm{DC}$ & Curso medio rio Cachapoal, Chile & Cucurbita sp. & Planella y Tagle & Planella y Tagle 1998 \\
Ancón & $900-1200 \mathrm{DC}$ & Ancón, norte de Lima, Perú & Cucurbita moschata & Wittmack & Whitaker y Bohn 1950 \\
San Nicolas & $1200 \mathrm{DC}$ & Proximo a Supe Perú (costa) & Cucurbita maxima & Carter 1945 & Cutler y Whitaker 1961, Whitaker y \\
Sitio M & $1300-1400 \mathrm{DC}$ & Valle de Ica, Perú (costa) & Cucurbita maxima & Carter 1945 & Bohn 1950 \\
Sitio D & $1300-1530$ DC & Chincha, Perú (costa) & Cucurbita moschata & Carter 1945 & Cutler y Whitaker 1961 \\
\hline
\end{tabular}


Tabla 10: registro arqueológico de restos del género Cucurbita sp. en territorio argentino. El orden es cronológico: desde los registros más tempranos a los más tardíos. Los datos están transcriptos textuales de la bibliografía consultada. Los casilleros en blanco representan falta de información publicada al respecto.

\begin{tabular}{|c|c|c|c|c|c|c|c|}
\hline SITIO & CRONOLOGÍA & UBICACIÓN & $\begin{array}{c}\text { IDENTIFICACION } \\
\text { Y PARTE DEL } \\
\text { VEGETAL }\end{array}$ & $\begin{array}{l}\text { IDENTIFICADO } \\
\text { POR }\end{array}$ & $\begin{array}{c}\text { CONTEXTO } \\
\text { DE } \\
\text { HALLAZGO }\end{array}$ & $\begin{array}{c}\text { OTROS VEGETALES } \\
\text { ASOCIADOS }\end{array}$ & BIBLIOGRAFIA \\
\hline $\begin{array}{l}\text { Quebrada } \\
\text { Seca } 3\end{array}$ & $\begin{array}{c}\text { Arcaico } \\
4930+/-110 \\
4410+/-60 \text { AP }\end{array}$ & $\begin{array}{l}\text { Antofagasta de la } \\
\text { Sierra. Puna de } \\
\text { Catamarca }\end{array}$ & $\begin{array}{l}\text { Silicofitolitos de } \\
\text { Cucurbita sp en } \\
\text { artefacto de } \\
\text { molienda y mano } \\
\text { de molino }\end{array}$ & P. Babot & $\begin{array}{l}\text { Capas } 2 \mathrm{~b} 2 \text { y } \\
2 \mathrm{~b} 3 \\
\text { Contexto } \\
\text { residencial o } \\
\text { doméstico }\end{array}$ & $\begin{array}{c}\text { Microfósiles de Zea mays, } \\
\text { Acrocomia sp.,Chenopodium } \\
\text { sp aff. C. quinoa y de } \\
\text { Opuntia sp. }\end{array}$ & Hocsman 2006 \\
\hline $\begin{array}{l}\text { Punta de la } \\
\text { Peña } 4\end{array}$ & $\begin{array}{c}\text { Arcaico } \\
\text { 4060+/-90; } \\
3820+/-100 \text { AP }\end{array}$ & $\begin{array}{l}\text { Antofagasta de la } \\
\text { Sierra. Puna de } \\
\text { Catamarca }\end{array}$ & $\begin{array}{l}\text { Silicofitolitos de } \\
\text { Cucurbita sp en } \\
\text { mano de moler }\end{array}$ & P. Babot & $\begin{array}{l}\text { Capa } 5\left(5^{\circ}\right) \\
\text { Contexto } \\
\text { residencial o } \\
\text { doméstico }\end{array}$ & $\begin{array}{l}\text { Microfósiles de Oxalis } \\
\text { tuberosa, Solanum } \\
\text { tuberosum, Lagenaria } \\
\text { siceraria, Zea mays, } \\
\text { Prosopis sp., Opuntia sp y de } \\
\text { tubérculo de Ciperaceae }\end{array}$ & Hocsman 2006 \\
\hline $\begin{array}{c}\text { Peñas Chicas } \\
1.3\end{array}$ & $\begin{array}{c}\text { Arcaico } \\
3680+/-50 \text { AP }\end{array}$ & $\begin{array}{l}\text { Antofagasta de la } \\
\text { Sierra. Puna de } \\
\text { Catamarca }\end{array}$ & $\begin{array}{l}\text { Silicofitolitos de } \\
\text { Cucurbita sp en } \\
\text { mano de moler }\end{array}$ & P. Babot & $\begin{array}{l}\text { Capa } \\
\text { 7.Contexto } \\
\text { residencial o } \\
\text { doméstico }\end{array}$ & $\begin{array}{c}\text { Microfósiles de Oxalis } \\
\text { tuberosa, Ullucus tuberosus, } \\
\text { Canna edulis y de Prosopis } \\
\text { sp }\end{array}$ & Hocsman 2006 \\
\hline $\begin{array}{l}\text { Puente del } \\
\text { Diablo }\end{array}$ & Arcaico & $\begin{array}{l}\text { Cabecera norte valles } \\
\text { calchaquies Salta } \\
3000 \text { msnm }\end{array}$ & $\begin{array}{l}\text { Semillas de } \\
\text { Cucurbita sp. }\end{array}$ & & $\begin{array}{l}\text { (para más } \\
\text { detalle ver } \\
\text { capitulo 3) }\end{array}$ & (Ver capitulo 3) & Tarragó 1980 \\
\hline $\begin{array}{l}\text { Gruta del Indio } \\
\text { del Rincón del } \\
\text { Atuel }\end{array}$ & $\begin{array}{l}\text { Atuel II 2200- } \\
1900 \mathrm{AP}\end{array}$ & Atuel, Mendoza & $\begin{array}{l}\text { Semillas de } \\
\text { Cucurbita sp. }\end{array}$ & & & $\begin{array}{c}\text { Phaseolus vulgaris, Zea } \\
\text { mays, Chenopodium quinoa, } \\
\text { Geoffroea decorticans, } \\
\text { Prosopis sp., Ximenia } \\
\text { americana, Myzodendron sp. } \\
\text { y Chusquea culeou }\end{array}$ & $\begin{array}{l}\text { Lagiglia } 1999, \\
\text { Castro y } \\
\text { Tarragó } 1992 \\
\text { Gil } 2005\end{array}$ \\
\hline
\end{tabular}


Cueva

Ponontrehu

Pájaro bobo

$2010+/-40$ AP

$=60 \mathrm{dC}$

Región del Nevado, Mendoza

"zapallo"

Ocupacion

en cueva

\section{Cueva de los}

Corrales

$2060+/-200$

AP

Abra de El Infiernillo, norte del sistema del Aconquija

Pericarpio de

Cucurbita sp.

Personal del Instituto Miguel Lillo

Ocupación

en Cueva

Cuenca del río

Mendoza, depto Las

Heras, sur

precordillera de

Mendoza

\section{Cucurbita maxima $\quad$ T. Whitaker}

Cueva del Toro Temprano

Formativo

inferior

La Poma

500a.C.-650

$\mathrm{DC})$

Salta

Formativo

inferior.

Ciénaga 224

$+/-105$ DC

Alamito

250dC a 450

DC
Camino Tinogasta-

Chilecito (ruta

40). Catamarca

Semillas de

Cucurbita maxima

Cucurbita sp.
Catamarca

\section{Semillas de \\ Cucurbita maxima \\ M.L. Pochettino}

Material en

museo de

Cachi, no se

indica

contexto de

hallazgo

Sitio 1 , nivel

4. Lente de

cenizas

Basurero
Semillas de Phaseolus vulgaris y diversas

variedades de Zea mays

Oliszewski et al en prensa

Whitaker 1983

Prosopis sp.

Pochettino

1985

Marlos de Zea mays var. microsperma, endocarpos de Geoffroea decorticans, frutos de Prosopis alba, semillas de Bixa orellana, semillas de Arachis hipogea, semillas de

González y Opuntia quimilo, posibles frutos de Capparis cynophallaphora

Zea mays var microsperma, Prosopis nigra, Arachis sp. Geoffroea decorticans y Phaseolus sp.
Nuñez

Regueiro 1971

en Tarragó 
Cerro El Dique

otrero Grande

Reparo de las pinturas rojas

Agua de la

mula-1

Campo de

Pucará

Fase II de

Alamito (360-

$480 \mathrm{DC})$

Punta de

Barro.

Basurero $\mathrm{N}^{\circ} 2$
Quebrada del Toro,

$$
\text { Salta }
$$

"Calabaza"

Quebrada del Toro, Salta

Atuel, Mendoza

próximo a gruta de

$$
\text { indio) }
$$

Región de La

Payunia, Mendoza

"zapallo"

Semilla de $C$. maxima

N. Oliszewski

Pedúnculos, semillas y cáscaras de $C$.

$$
\text { maxima. }
$$

Cáscaras de

Cucurbita maxima

var. turbaniformis

$$
\text { Alef. }
$$

Basurero

Basurero

Ocupacion

en cueva

Maíz

Maiz

Maiz

Raffino y Togo

1975 en

Tarragó 1980

Cigliano,Raffino

y Calandra

1976 en

Tarragó 1980

Lagiglia 1999 ,

Gil 2005

Maíz

Gil 2005

Monticulo

ceremonial

$\mathrm{H}-\mathrm{O}$

Restos de Zea mays var minima Acacia sp., Prosopis sp., Prosopis torquata, $P$.

Oliszewski alba o P. nigra, Phaseolus sp.

Lagenaria siceraria,

Phragmites australis (trozos

de cañas), Zea mays var

indurata, var amylacea y var.

microsperma, Acacia aroma,

Geoffroea decorticans,

Roig 1992 Prosopis strombulifera 


\begin{tabular}{|c|c|c|c|c|c|c|c|}
\hline Los Morrillos & $\begin{array}{l}\text { Temprano 0- } \\
375 \text { DC }\end{array}$ & $\begin{array}{l}\text { Serranía de Ansilta, } \\
\text { Calingasta. S.O. De } \\
\text { San Juan } 2000 \text { a } \\
3000 \text { m.s.n.m. (oasis) }\end{array}$ & $\begin{array}{c}\text { Semillas y } \\
\text { pericarpios de } \\
\text { frutos de } \\
\text { Cucurbita maxima }\end{array}$ & F. Roig & & $\begin{array}{l}\text { Zea mays var indurata, } \\
\text { Chenopodium quinoa var } \\
\text { quinoa, Ch. quinoa var } \\
\text { melanospermum, Phaseolus } \\
\text { vulgaris var sphericus, } P \text {. } \\
\text { vulgaris var gonospermus, } P \text {. } \\
\text { vulgaris var subcompressus, } \\
P \text { vulgaris var ellipticus }\end{array}$ & Gambier 1977 \\
\hline Los Morrillos & $\begin{array}{c}\text { Temprano } 280- \\
375 \text { DC }\end{array}$ & $\begin{array}{l}\text { Serranía de Ansilta, } \\
\text { Calingasta. S.O. De } \\
\text { San Juan } 2000 \text { a } \\
3000 \text { m.s.n.m. (oasis) }\end{array}$ & $\begin{array}{l}\text { Pedúnculo y parte } \\
\text { del pericarpio de } \\
\text { Cucurbita } \\
\text { moschata }\end{array}$ & F. Roig & & $\begin{array}{l}\text { Zea mays var indurata, } \\
\text { Chenopodium quinoa var } \\
\text { quinoa, Ch. quinoa var } \\
\text { melanospermum, Phaseolus } \\
\text { vulgaris var sphericus, } P \text {. } \\
\text { vulgaris var gonospermus, } P \text {. } \\
\text { vulgaris var subcompressus, } \\
P \text { vulgaris var ellipticus }\end{array}$ & Gambier 1977 \\
\hline $\begin{array}{l}\text { Vega de los } \\
\text { Pingos }\end{array}$ & $\begin{array}{l}\text { Ocupaciones } \\
\text { Ansilta }\end{array}$ & $\begin{array}{c}\text { Provincia de San } \\
\text { Juan }\end{array}$ & $\begin{array}{c}\text { Fruto de } C . \\
\text { maxima }\end{array}$ & & & & $\begin{array}{c}\text { Gambier 1977, } \\
\text { Lagiglia } 2001\end{array}$ \\
\hline $\begin{array}{l}\text { Loma sobre } \\
\text { Puente río La } \\
\text { Viña. Sitio I }\end{array}$ & $\begin{array}{c}\text { Formativo } \\
\text { Medio. Fase } \\
\text { La Viña (460 } \\
\text { D.C - } 730 \text { D.C) }\end{array}$ & Valle de Lerma. Salta & $\begin{array}{c}\text { Semillas } \\
\text { carbonizadas de } \\
\text { Cucurbita maxima }\end{array}$ & M.L. Pochettino & $\begin{array}{c}\text { (Ver capitulo } \\
3 \text { ) }\end{array}$ & (Ver capitulo 3) & Escobar 2007 \\
\hline $\begin{array}{l}\text { Punta de la } \\
\text { Peña } 9\end{array}$ & ca. $1400 \mathrm{AP}$ & $\begin{array}{l}\text { Antofagasta de la } \\
\text { Sierra. Puna de } \\
\text { Catamarca }\end{array}$ & $\begin{array}{l}\text { Silicofitolitos de } \\
\text { Cucurbita sp en } \\
\text { artefacto de } \\
\text { molienda }\end{array}$ & P. Babot & $\begin{array}{l}\text { Sector I. } \\
\text { Contexto } \\
\text { residencial o } \\
\text { doméstico }\end{array}$ & $\begin{array}{c}\text { Microfósiles de Amaranthus } \\
\text { caudatus/mantegazzianus, } \\
\text { Phaseolus vulgaris, Canna } \\
\text { edulis, Opuntia sp. Prosopis } \\
\text { sp y Lagenaria siceraria }\end{array}$ & Hocsman 2006 \\
\hline
\end{tabular}


Siglo VI dC

Agua de la

Tinaja

590+/-70 d.C

$=1360+/-70$

A.P.)
Semillas y

cáscara de

Cucurbita maxima

F. Roig

2050 m.s.n.m.

Agua de Los Caballos-1

Punta

Colorada. Sitio 3 (cementerio)

Atuel, Mendoza (próximo a gruta de indio)

$1360+/-60$

$\mathrm{AP}=590 \mathrm{DC}$

1200 AP

Área El Nevado, Mendoza

$720+/-85$ DC
Catamarca

\section{Pericarpios de}

"zapallo"

"zapallo"

Semillas de

"zapallo"
Chenopodium quinoa,

Lagenaria siceraria, Zea

mays var amylacea; Z. mays

var indurata, Maihueniopsis

glomerata, Denmoza

Nivel I y II rhodacantha, Notocactus

$\begin{array}{cc}\text { Asociado a } & \text { atrospinus, Prosopis } \\ \text { lítico } & \text { flexuosa, Schinus sp., Setaria }\end{array}$

flexuosa, Schinus sp., Setaria

cerámica y mendocina, Larrea divarica

de animales vergarae, L fuscum,

Ocupación

doméstica

de etapa

agro-alfarera

$$
\text { local }
$$

Chuquiraga oppositifolia

Barcena, Roig

Adesmia horrida,
Aduiraga oppositifolia,

y Roig 1985

Bougainvillea spinosa,

Phragmites australis,

Sporobolus cryptandrus,

Ephedra sp., Atriplex sp., A.

lampa, Stipa debilis,

Tillandsia pedicellata,

Eupatorium patens, Bromus

sp.

\section{Ocupación}

en cueva

Maíz

Lagiglia 1999,

Gil 2005

Maíz

Gil 2005

Semillas alrededor de pieza cerámica tosca: zapallo,

Cementerio algarrobo, chañar, marlos de maíz var. microsperma y otra variedad de grano más

$$
\text { grande }
$$

Sempé de Gomez Llanez $1975 y$ Gonzalez y Sempé 1975 en Tarragó 1980 


\begin{tabular}{|c|c|c|c|}
\hline $\begin{array}{l}\text { Cuesta de } \\
\text { Zapata }\end{array}$ & $\begin{array}{c}\text { Formativo } \\
\text { medio. Aguada }\end{array}$ & $\begin{array}{c}\text { Camino Belén- } \\
\text { Tinogasta Catamarca }\end{array}$ & urbita maxima \\
\hline
\end{tabular}

Acumulación

de ceniza

por debajo

de la línea

de piedras

$$
\text { que }
$$

Marlos de Zea mays var.

microsperma

González y

Pérez 1968

delimitaba el

contorno de

la estructura

2

Formativo (800 Entre serrania de Las

DC.) Fase Pirguas y El Rodeo,

Pampa Grande Candelaria III, Salta $\left(25^{\circ} 46^{\prime} \mathrm{S}\right.$;

influencias $\quad 65^{\circ} 24$ Ó) 2500-3000

Aguada

m.s.n.m

Semillas de T. Whitaker,

(Ver capítulo

3)

(Ver capitulo 3)

Pochettino

1985

Formativo (800 Entre serrania de Las

DC) Fase Pirguas y El Rodeo,

Pampa Grande

andelaria III

Salta $\left(25^{\circ} 46^{\prime} \mathrm{S}\right.$;

Epicarpio fruto de

Cucurbita sp.

(Ver capítulo

3)

(Ver capitulo 3)

Pochettino

Aguada

m.s.n.m

Formativo (800 Entre serrania de Las

DC) Fase Pirguas y El Rodeo

Pampa Grande Candelaria III, Salta (25\%46'S

influencias $\quad 65^{\circ} 240$ ) 2500-3000

Epicarpio fruto

posiblemente $C$.

T. Whitaker

(Ver capítulo

3)

m.s.n.m 
El Carmen $\quad \begin{gathered}\text { Formativo } \\ \text { (Aguada) a } \\ \text { Tardío }\end{gathered}$

(Sanagasta)

La Rioja $28^{\circ} 59^{\prime}$ L.s.; $68^{\circ} 12^{\prime}$ L.O. A 6 km. al NE de Villa Castelli

Semillas de

Cucurbita sp.

posiblemente $C$. maxima

Formativo

Tardío

La Rioja $28^{\circ} 59^{\prime}$ L.s.; $68^{\circ} 12^{\prime}$ L.O. A 6 km.

Pericarpio fruto

NE de Villa Castelli Cucurbita sp.

Formativo

(Aguada, ca

500 AC) o

entre el

Período de

Desarrollos

Los Viscos

Regionales y

momento de

contacto

Colonial (entre

ca 1000 -

1536 DC)

Tardio 710+/- Quebrada de

70 AP (1240 Sarahuaico. Q. de

DC)

Valle del Bolsón,

Depto. Belén,

Catamarca

mahuaca. Depto. Tilcara. Jujuy

entre 984-1024

Arroyo Tala DC y $1028-$

$\begin{array}{cl}\text { DC y 1028- } & \text { Salsacate, Córdoba } \\ 1219 \text { DC } & \end{array}$

pedúnculos de
Semillas,

pericarpios y

Cucurbita maxima

y C. moschata

A.E.

Würschmidt, M. (Ver capítulo

Maloberti, J.

3)

Piso de

ocupación

de recinto

Fitolitos de

Cucurbita sp en

una antigua

M. L. Lopez

parcela de
(Ver capitulo 3)

Prosopis ssp, Geoffroea decorticans, Zea mays

Prosopis ssp, Geoffroea decorticans, Zea mays

Korstanje y

Würschmidt

1999, Maloberti y Zapatiel 2003 Campos 1996

Callegari 2003

Callegari y Campos 1996 Callegari 2003
Callegari y

Espinas de cactáceas

Rivolta 1996

Semillas carbonizadas de Phaseolus vulgaris 


\begin{tabular}{|c|c|c|c|c|}
\hline CPun39 & Tardío & $\begin{array}{l}\text { Valle de Punilla, } \\
\text { Córdoba }\end{array}$ & $\begin{array}{c}\text { Fitolitos de } \\
\text { Cucurbita sp en } \\
\text { adherencias de } \\
\text { tiestos }\end{array}$ & M. L. Lopez \\
\hline Doncellas & Tardío & Puna de Jujuy & $\begin{array}{l}\text { Fruto pequeño de } \\
\text { Cucurbita maxima }\end{array}$ & M.L. Pochettinc \\
\hline Los Amarillos & $\begin{array}{l}\text { Tardío (1200- } \\
1420 \text { DC). } \\
\text { Humahuaca }\end{array}$ & Tilcara. Jujuy & $\begin{array}{l}\text { Semillas de } \\
\text { Cucurbita ficifolia }\end{array}$ & $\begin{array}{c}\text { A.E. } \\
\text { Würschmidt }\end{array}$ \\
\hline Juella & $\begin{array}{c}\text { Tardío Cultura } \\
\text { Humahuca } \\
1335 \text { DC }\end{array}$ & $\begin{array}{l}\text { Q. de Juella. Depto } \\
\text { Tilcara.Jujuy }\end{array}$ & $\begin{array}{l}\text { Semillas de } \\
\text { Cucurbita sp de } \\
\text { tipo "anco" }\end{array}$ & Victor Robles \\
\hline $\begin{array}{l}\text { Santa Rosa de } \\
\text { Tastil }\end{array}$ & $\begin{array}{l}\text { Tardío1362- } \\
\text { 1439 DC }\end{array}$ & Tastil, Salta & $\begin{array}{c}\text { "Calabaza" (C. } \\
\text { pepo según } \\
\text { Raffino 1972) }\end{array}$ & \\
\hline Morohuasi & Tardío & Salta & $\begin{array}{c}\text { "Calabaza", } \\
\text { aparentemente } C . \\
\text { pepo }\end{array}$ & \\
\hline
\end{tabular}

Semillas carbonizadas de

Phaseolus vulgaris y $\mathrm{Ph}$. lunatus

López 2005

Sitio

excavado

por

Casanova.

Material en

Museo

Etnográfico

Lagenaria siceraria, Juglans Pochettino

australis

1985

Würschmidt

2003

Dentro de

una

escudilla de

un ajuar

Zea mays (tipo Capia) Cigliano 1967

$$
\text { en }
$$

Tarragó1980,

Lagiglia 2001

Zea mays (razas perla, rosita

Basurales y

Tumba

o miniatura), Juglans

australis, Canna sp.,

Phaseolus vulgaris.

Basurales y Zea mays (razas morocho,

Tumba pisingallo, perla o rosita, capia y chullpi)
Raffino 1972 en

Tarrago 1980,

Lagiglia 2001

Raffino 1972 en Tarragó 1980 
Huachichocana

III

Inka

Q.de Purmamarca. Depto. Tumbaya.
Jujuy

Ocupación Inka- Hipano Indígena 14351550 DC

Valle de Hualfín-

Bolsón de

El Shincal
Semillas de

Cucurbita maxima

Semilla de

Cucurbita maxima

ssp. maxima

pedúnculo

A. Capparelli,

Pipanaco.Catamaraca
V. Lema, M.L.

Pochettino
Contexto específico:

mazorcas de Zea mays,

acullicos de masticación y semillas completas de Prosopis nigra, restos de crisetidos, de auquénidos, hojas y troncos y tiestos

cerámicos junto a entierro de hurón con collar de sonajero de nuez (Juglans australis)

capa: Zea mays de las razas:

Amarillo (indentata), pisincho

(oryzaea), morocho (indurata)

$$
\text { chullpi o azucarado }
$$

(amyleasacharata)y capia

(amylacea), Arachis sp., fruto

de Lagenaria, Capsicum sp.,

Canna edulis, Prosopis alba y

Prosopis nigra, Juglans

australis, Trichocereus

pasacana, Tipha sp. (totora),

Sporobolus rigens (Pasto

espuro), Liliflorales varias,

Cortaderia sp. Parastrephia

lepidophylla. Restos óseos, cerámicos, fogones,

crustáceos. Inhumación en refugio pircado junto a

ofrendas alimenticias.

Prosopis sp., Geoffroea

decorticans, Zizyphus mistol,

Rhamnaceae/Capparidaceae,

Plataforma

Gossypium sp., Juncus sp.,

ceremonial o Solanum sp., Zea mays,

Phaseolus vulgaris,

Phaseolus Iunatus, Triticum

sp., Hordeum sp., Prunus persica
Pochettino

1985,

Fernández

Distel 1986
Capparelli en prensa,

Capparelli et al 2005, Lema et al 2008 


\begin{tabular}{|c|c|c|c|c|c|c|c|}
\hline El Shincal & $\begin{array}{l}\text { Ocupación } \\
\text { Inka- Hipano } \\
\text { Indígena 1435- } \\
1550 \text { DC }\end{array}$ & $\begin{array}{l}\text { Valle de Hualfín- } \\
\text { Bolsón de } \\
\text { Pipanaco.Catamaraca }\end{array}$ & $\begin{array}{c}\text { Semilla de } \\
\text { Cucurbita sp. }\end{array}$ & A. Capparelli & $\begin{array}{c}\text { Estructura } \\
5 \mathrm{CIII}\end{array}$ & $\begin{array}{c}\text { Prosopis sp., Geoffroea } \\
\text { decorticans, Juncus sp., } \\
\text { Solanum sp., Zea mays, } \\
\text { Phaseolus vulgaris, }\end{array}$ & $\begin{array}{c}\text { Capparelli et al. } \\
2005\end{array}$ \\
\hline $\begin{array}{l}\text { Jueva Epullan } \\
\text { Grande }\end{array}$ & Posthispánico & Neuquen & Cucurbita maxima & $\begin{array}{l}\text { Urrutia, } \\
\text { Bogazzi y } \\
\text { Pozner }\end{array}$ & & & $\begin{array}{c}\text { Urrutia y } \\
\text { Bogazzi } 1996\end{array}$ \\
\hline
\end{tabular}


Tabla 11: referencias a Cucurbitáceas en la crónica de Félix de Azara 1781.

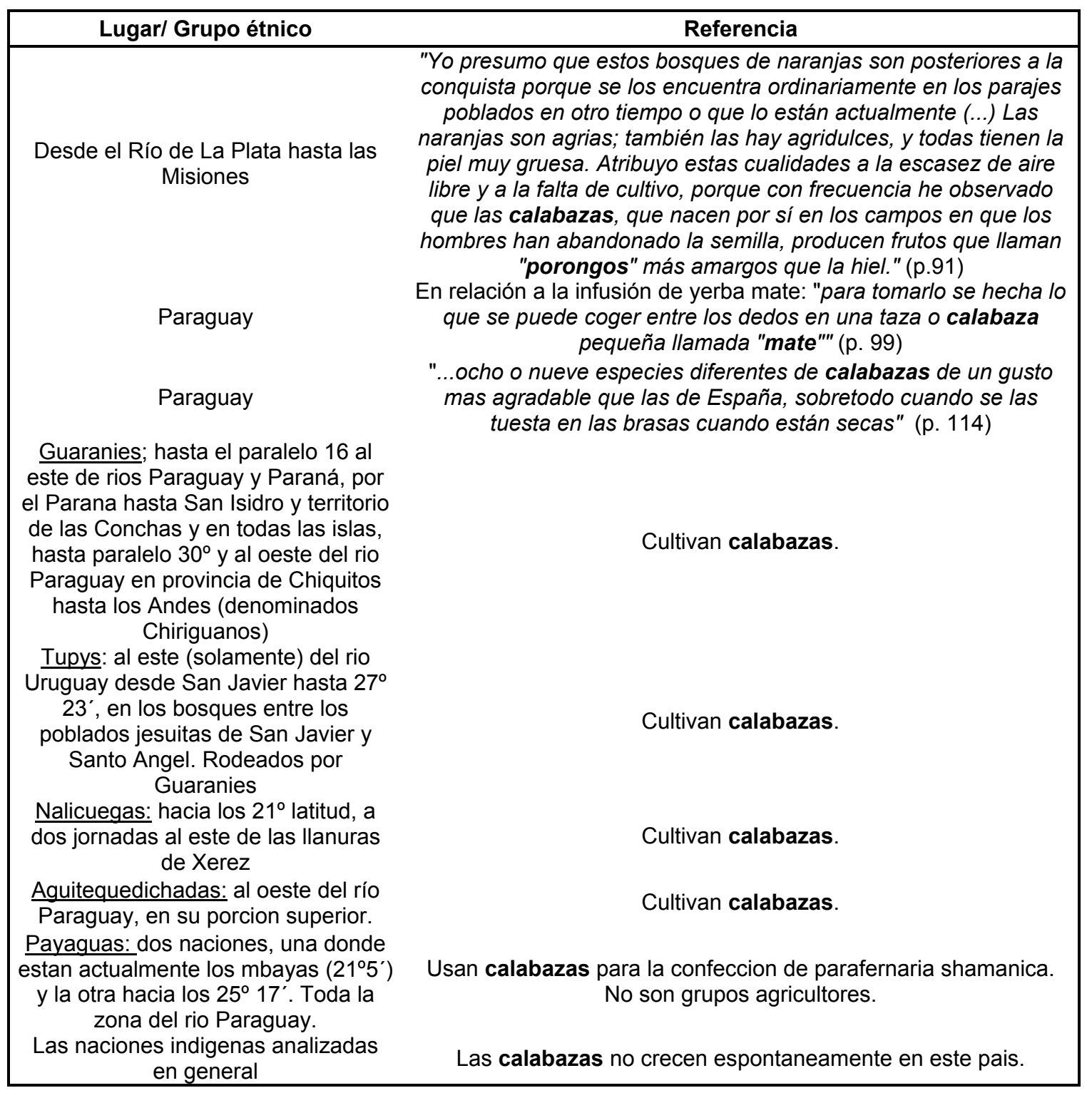


Figura 11: área de distribución de $C$. ecuadorensis, una posible $C$. moschata silvestre y $C$. andreana según las investigaciones efectuadas por Nee (1990, Fig.1).

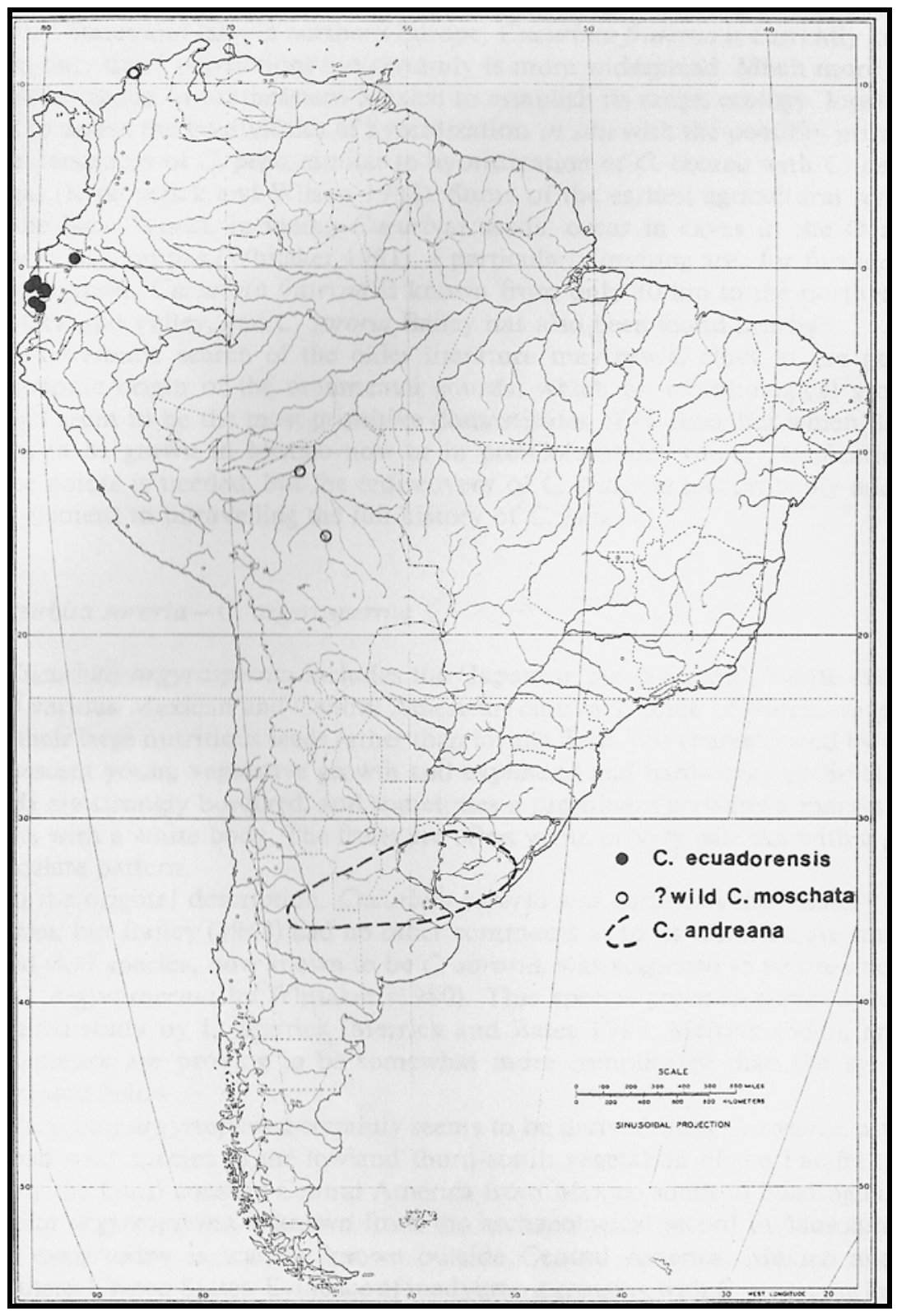


Figura 12: distribución de C maxima ssp. andreana de acuerdo con Lira Saade (1995, capitulo 1, figura 10).

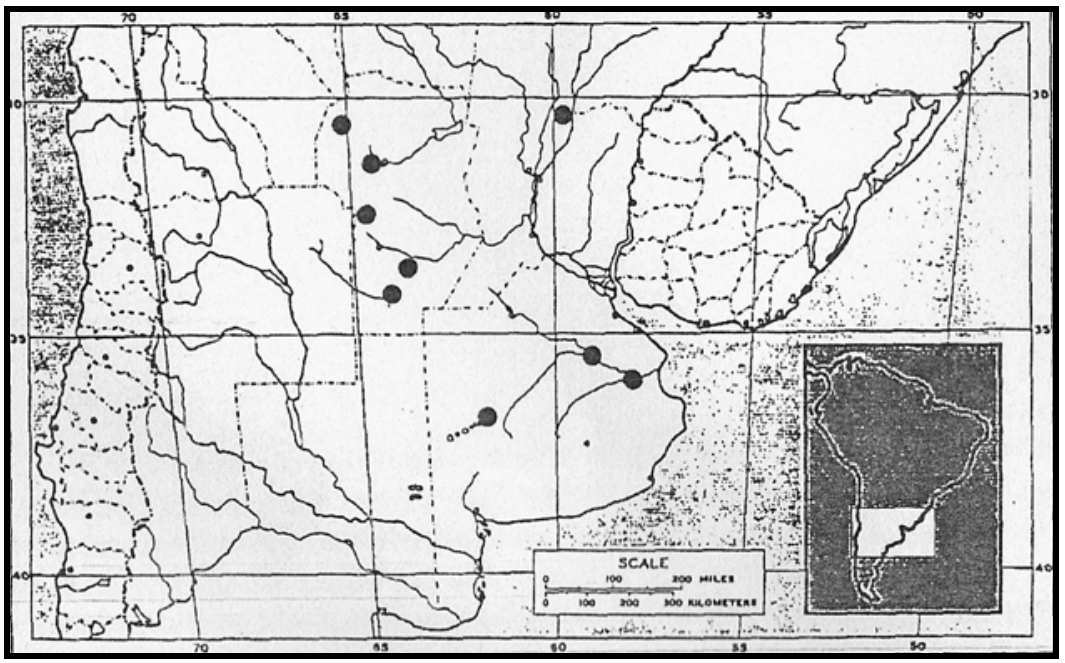

Figura 13: imágenes del libro de F. Paucke indicadas como "clases de plantas que los españoles llaman rapallos y los indios laguil?’

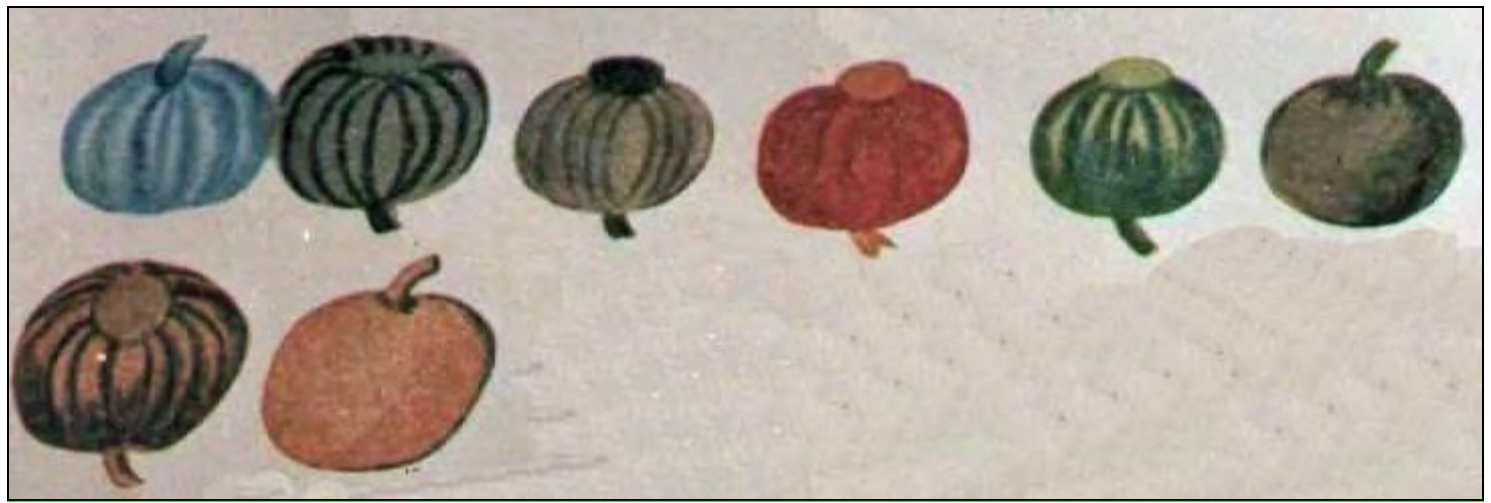


Figura 14: ubicación geográfica de los registros de Peponapis fervens en Argentina. Mapa elaborado por el Dr. A. Abramovich de la División Entomología del Museo de Ciencias Naturales de La Plata a partir de los registros con que cuenta la mencionada División y de los datos aportados por Hurd y Linsley (1967).

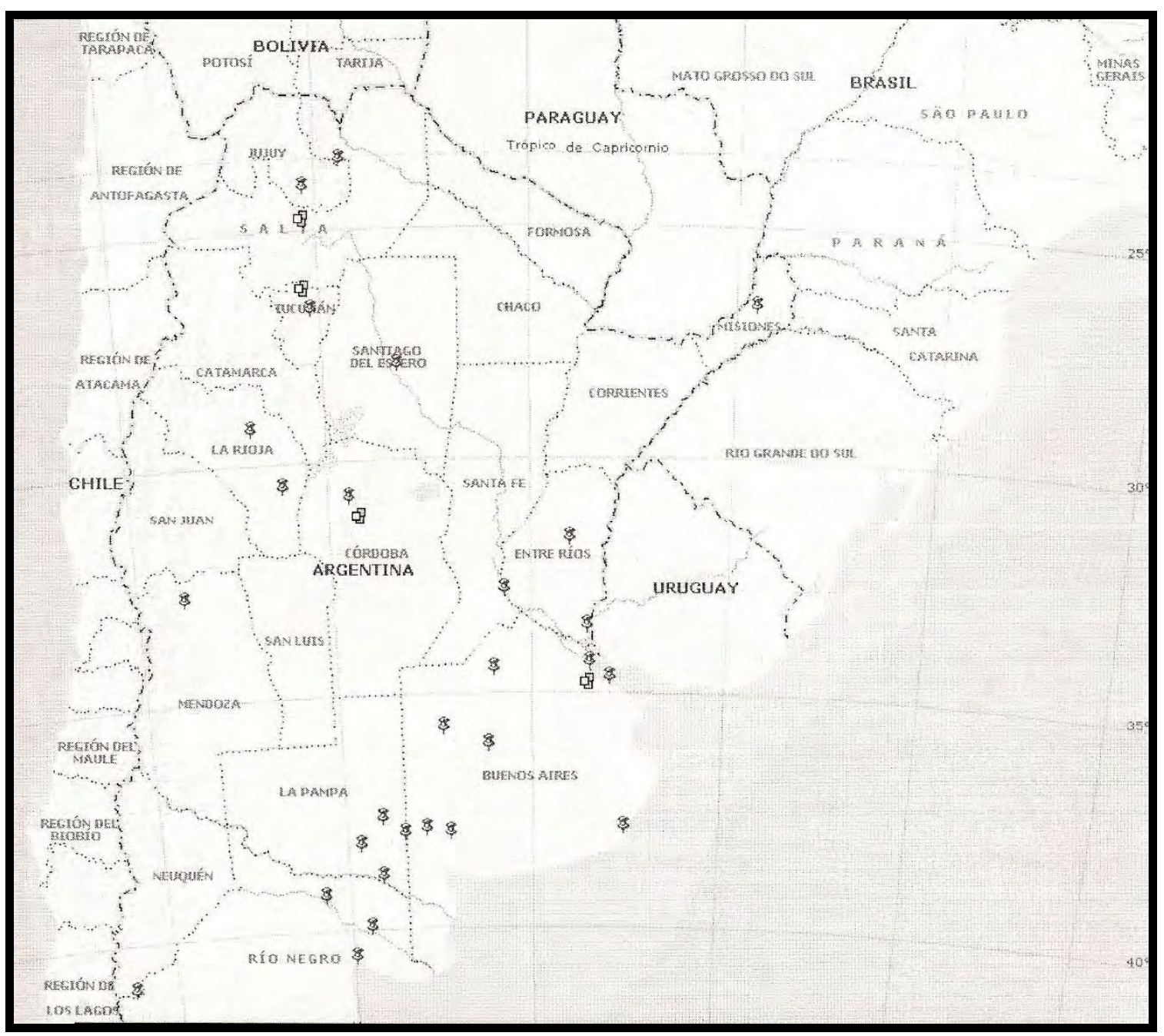


Figura 15: áreas biogeográficas de Sudamérica (Cabrera y Willink 1973).

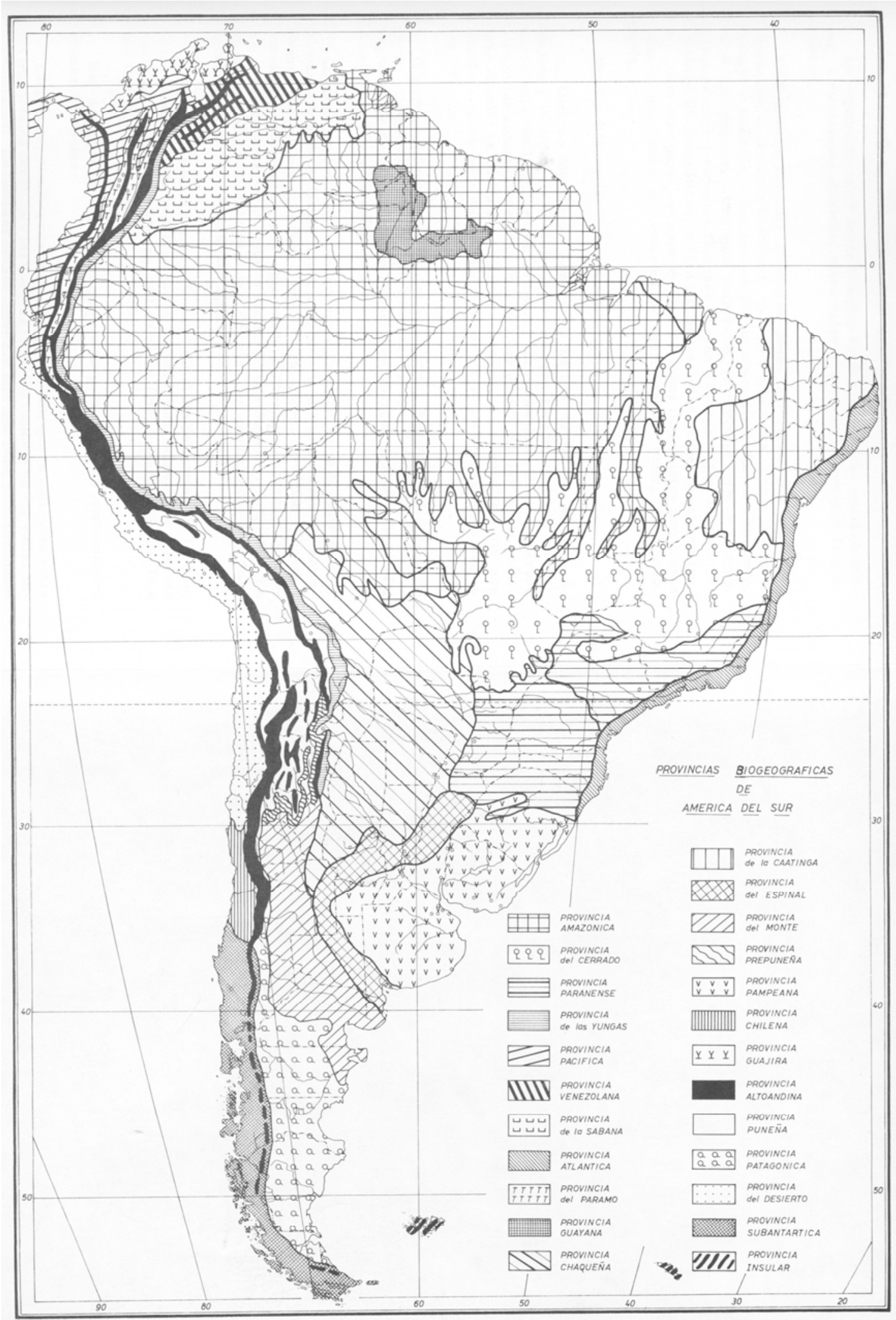


Figura 16: vía de dispersión del complejo C. maxima ssp maxima- C. maxima ssp. andreana propuesta en esta tesis. El área marcada con un círculo verde corresponde al área de distribución hipotética del antecesor silvestre. El área marcada con un círculo azul corresponde al área donde actualmente hay mayor número de poblaciones registradas de $C$. maxima ssp. andreana. Las flechas indican el sentido de la dispersión del complejo cultivomaleza. Los números indican las menciones de los cronistas en sentido cronológico (1: "çapallos" en Barco de Ybatín (Núñez del Prado 1550 en Capparelli et al 2005); y "zapallos" en Valles Calchaquíes (Sotelo de Narváez 1582 en Capparelli et al. 2005); 2: “zapallos" entre los Mataguayos del occidente chaqueño (Gaspar de Osorio en Lozano (1733) 1941); 3: "calabaza doméstica de flores amarillas", posiblemente C. maxima ssp maxima cv zapallito entre los Matarás del oriente salteño-jujeño (Jolís 1972 en Torres et al 2007); 4: C. maxima ssp maxima cv rapallito entre los Tobas del Pilcomayo (Patiño 1721 en Millán 1947); 5: C. maxima ssp maxima cv rapallito entre los Mocovíes del sur del Chaco y norte de Santa Fe (Paucke 1749-1767 en Millán 1947); 6: Registros de C. maxima ssp. andreana del siglo XIX en provincia de Buenos Aires.

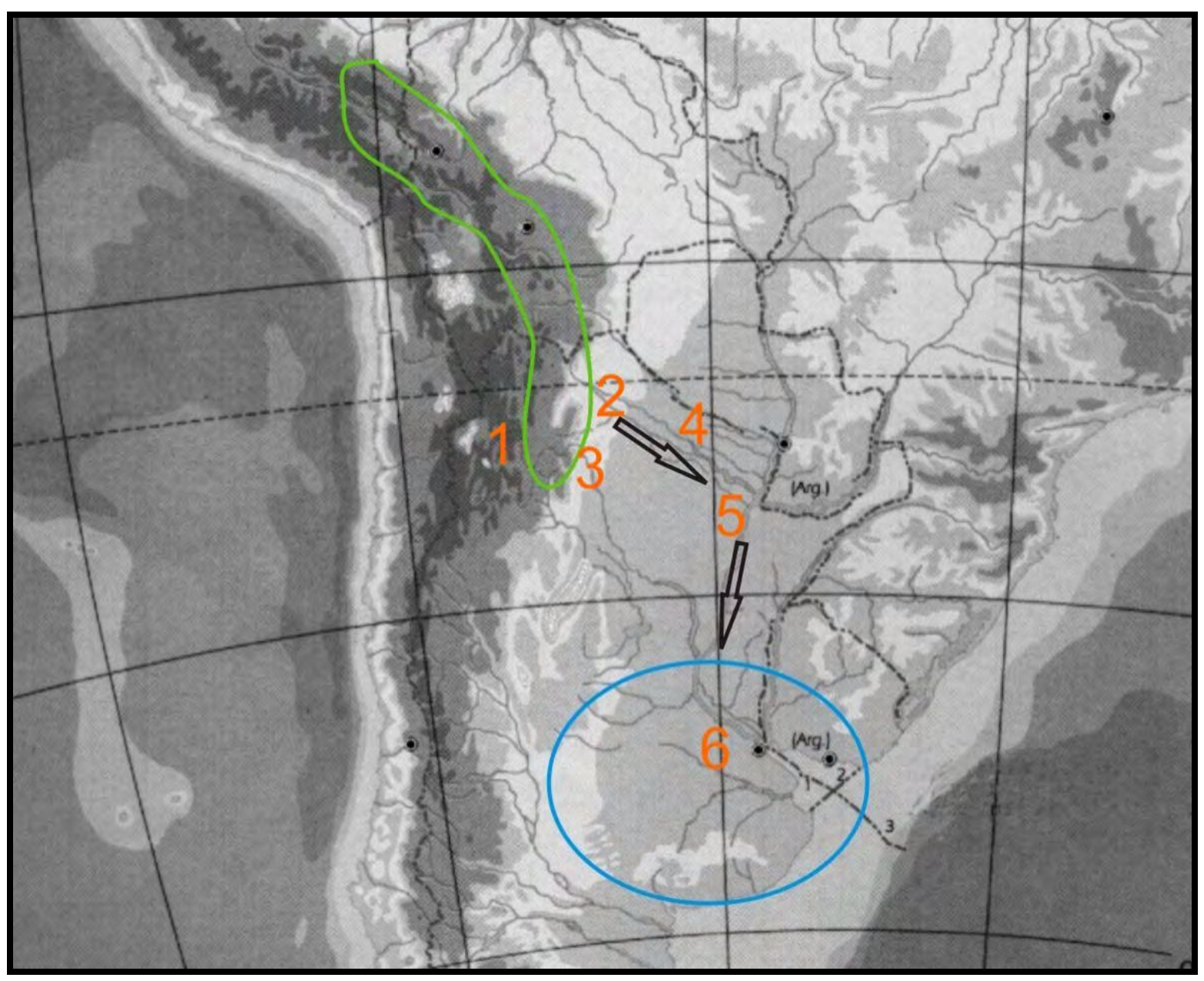



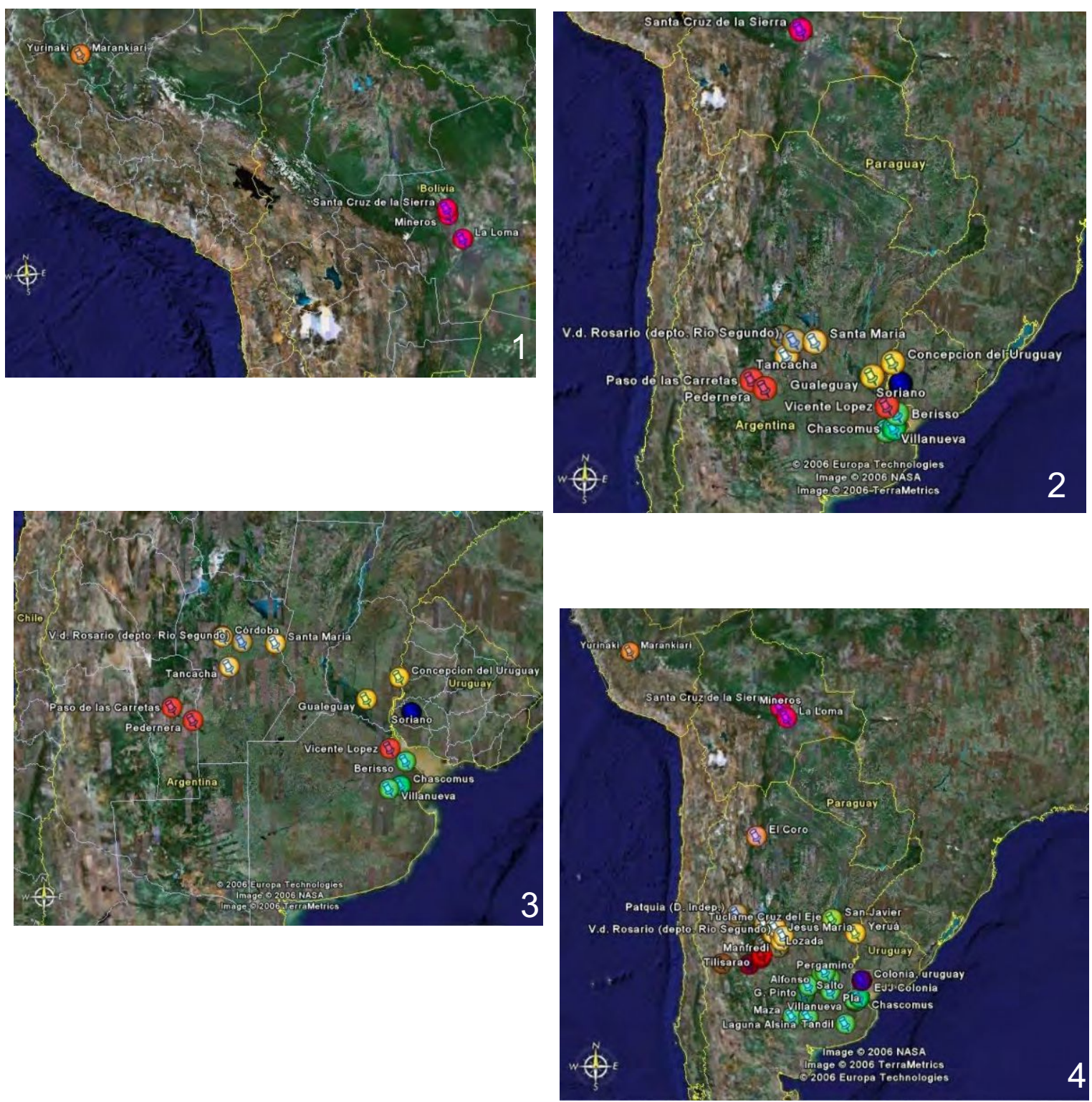

Delimitación y área de origen de C maxima ssp maxima, 1: Mapa 1 señalando el registro actual de $C$ maxima ssp andreana en ladera andina; 2: Mapa 2 con registro actual de $C$ maxima ssp andreana a partir de registro de herbarios y floras; 3: detalle de mapa 2; 4: Mapa 3 con registro actual de $C$ maxima ssp andreana a partir de bibliografía consultada. 

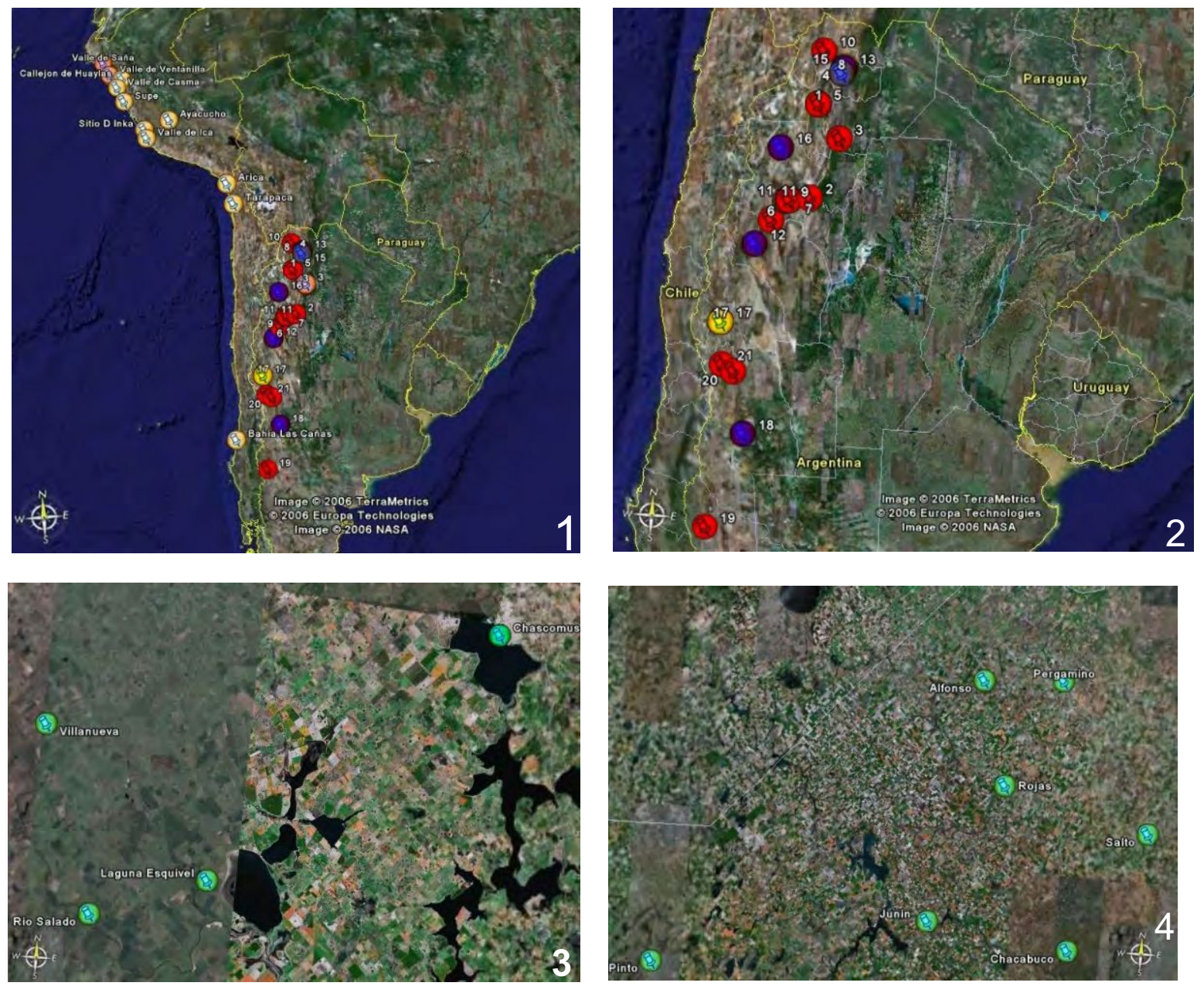

Delimitación y área de origen de C maxima ssp maxima, 1: Mapa 4 con distribución de hallazgos arqueológicos de Cucurbita sp en Sudamérica, azul: Cucurbita sp, rojo: C maxima ssp maxima, amarillo: $C$ moschata, verde: $C$ ficifolia, rosa: posibles formas silvestres de Cucurbita sp; 2: Mapa 5 señalando la distribución de hallazgos arqueológicos de Cucurbita sp en Argentina; 3: Mapa 6 donde se aprecian las poblaciones de $C$ maxima ssp andreana en la planicie de inundación del Salado- Encadenadas (provincia de Buenos Aires, Argentina); 4: Mapa 7 indicando poblaciones de $C$ maxima ssp andreana en el norte de Buenos Aires (Argentina), área de alto impacto antrópico. 

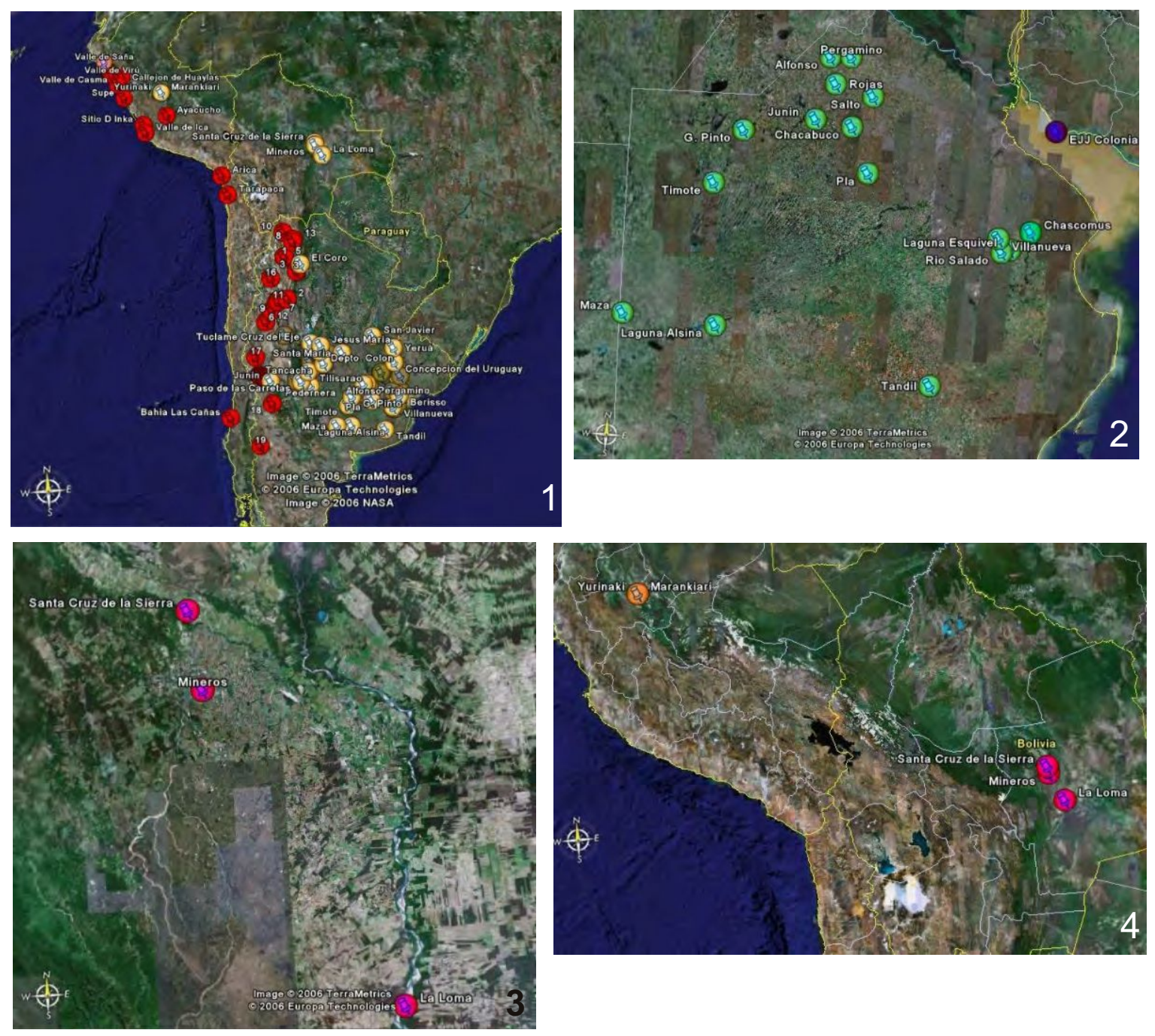

Delimitación y área de origen de $C$ maxima ssp maxima, 1: Mapa 8 señalando la disyunción en el área de distribución entre los sitios con restos arqueológicos de Cucurbita sp domesticadas (rojo) y silvestres (rosa) y las poblaciones actuales de $C$ maxima ssp andreana (amarillo)

2: Mapa 9 con ubicación de poblaciones de $C$ maxima ssp andreana en provincia de Buenos Aires (Argentina); 3: Mapa 10 con detalle del área donde se hallan las poblaciones de $C$ maxima ssp andreana en Bolivia; 4: Mapa 11 con detalle del área donde se hallan las poblaciones de $C$ maxima ssp andreana en Perú. 


\subsection{1c- ESTUDIO MORFO-ANATOMICO EN MACRORRESTOS DE Cucurbita sp.: SEMILLA}

\section{Introducción}

En este capítulo analizaremos las semillas de Cucurbita sp. de distintos sitios arqueológicos (ver capítulo 3) tanto macroscópicamente como en la micromorfología de la cubierta seminal. Para llevar a cabo estos análisis resultó fundamental el armado y estudio de la colección de referencia a fin de hallar caracteres cualitativos y cuantitativos diagnósticos que permitieran diferenciar las distintas especies sudamericanas del género Cucurbita. Dado que parte de los macrorrestos a ser analizados se encontraban carbonizados, se llevó a cabo un estudio de carbonización experimental a fin de indagar las modificaciones sufridas por los caracteres diagnósticos observados en ejemplares frescos.

Tal como fue mencionado en el capítulo 1, un conocimiento profundo basado en el análisis de gran número de ejemplares actuales (tanto experimentales como sin procesar o "frescos") es lo que permite reconocer en los restos arqueobotánicos un cierto conjunto de variables con las que el investigador se halla familiarizado, así como también aspectos novedosos no observados en los ejemplares de referencia (Hillman et al. 1993, Pochettino y Capparelli en prensa).

Las semillas tienen las ventajas de ser las menos afectadas por factores ambientales con relación al fruto y otros órganos vegetativos (Decker \& Wilson 1986) y además de ser abundantes en el registro arqueológico (Cutler \& Whitaker 1961).

En la primer parte de este capítulo se analizará la conformación de la colección de referencia tanto de ejemplares frescos como carbonizados, en la segunda parte se estudiarán los caracteres diagnósticos a nivel microscópico de la cubierta seminal y en la tercera parte del mismo, los caracteres 
macroscópicos de las semillas de los taxa sudamericanos del género Cucurbita. En cada una de estas instancias el objetivo consistió en la identificación taxonómica de los ejemplares arqueológicos, el reconocimiento de rasgos sujetos a modificación por la interacción con poblaciones humanas (identificación de cultivos transicionales, principalmente) y la evaluación de la preservación diferencial de los mismos en ejemplares carbonizados.

\section{I- Conformación de la colección de referencia de semillas de Cucurbita sp.}

\section{Colección de ejemplares frescos}

Para el armado de esta colección se seleccionaron especies y subespecies del género Cucurbita de origen sudamericano (ver capítulo 4.1.2), dado que son las más factibles de ser recuperadas en sitios arqueológicos del Área Andina Meridional. Se reunió un total de siete taxa: C. ficifolia (número de semillas estudiadas $(\mathrm{N})=18), C$. moschata $(\mathrm{N}=18)$, C. maxima ssp. andreana $(\mathrm{N}=66), C$. maxima. ssp. maxima $\mathrm{cv}$. rapallito $(\mathrm{N}=34)$; C. maxima ssp. maxima $\mathrm{cv}$. hubbard $(\mathrm{N}=47)$; C. maxima ssp. maxima $\mathrm{cv}$. ingles $(\mathrm{N}=27)$ y C. maxima ssp. maxima $\mathrm{cv}$. criollo $(\mathrm{N}=11)^{1}$. La inclusión de distintos cultivares en el caso de C. maxima ssp maxima se debe a que la misma es de particular interés en esta tesis puesto que se ha sugerido su domesticación en el NOA (Millán 1945, Whitaker y Bemis 1965, Brücher 1989, Nee 1990, Decker Walters y Walters 2000, Albeck 2001) (ver capítulos 411a y 411b), por lo cual se ha querido abarcar el mayor rango de variación posible para dicha subespecie. Atendiendo a dicha finalidad se han incluido también muestras de los llamados "zapallos bolivianos" o "cochabambinos" (C. maxima ssp. maxima cv. criollo) $(\mathrm{N}=63)$ obtenidos

\footnotetext{
${ }^{1}$ La taxonomía de los cultivares de C. maxima ssp. maxima se consigna siguiendo las sugerencias del Dr. Pozner (com.pers.)
} 
durante los trabajos etnobotánicos en el mercado de La Quiaca (Jujuy, Argentina) (ver capítulos 5 y 6) dado que se distinguen por el gran tamaño de sus semillas. También se incluyeron semillas de zapallos procedentes de Salta (LQM3, C. maxima ssp maxima, cultivar local) adquiridos en el mencionado mercado. Las muestras de los restantes cultivares fueron provistas por la cátedra de Horticultura, Facultad de Ciencias Agrarias y Forestales, UNLP. En el caso de C. maxima ssp andreana las semillas fueron cedidas por la Dra. Lorena Ashworth de la Universidad de Córdoba, quien proveyó tres grupos resultante cada uno de diferente forma de polinización (libre, cruzada y autógama). Esto permitió controlar la permanencia de los rasgos diagnósticos en frutos obtenidos por diferentes vías reproductivas.

La totalidad de estos ejemplares $(\mathrm{N}=284)$ corresponden a semillas de frutos maduros y se encuentran depositados en el Laboratorio de Etnobotánica y Botánica Aplicada (FCNYM - UNLP).

\section{Carbonización experimental de semillas}

En este apartado se analizarán los resultados obtenidos de la carbonización experimental de semillas de C. maxima ssp maxima cv criollo, C. maxima ssp. andreana, C. ficifolia y C. moschata . Este ensayo experimental respondió a dos objetivos principales. El primero de éstos consistió en estudiar la incidencia del proceso de carbonización en la preservación de semillas de este género en el registro arqueológico y, por lo tanto, la factibilidad de su recuperación en el presente como macrorrestos arqueobotánicos. El segundo de los objetivos fue determinar en estos ejemplares carbonizados caracteres que resulten diagnósticos a nivel específico, sean dichos rasgos los mismos que se establecieron para ejemplares frescos u otros distintos.

Al analizar la importancia de un recurso específico en la dieta de las poblaciones prehispánicas de un área dada, resulta fundamental tomar en 
consideración los factores que actúan en la formación del registro arqueológico y que pueden incidir en la preservación de los restos materiales del recurso bajo estudio. En este sentido, los procesos de formación de sitio en general (Schiffer 1979), y la tafonomía en particular, han tenido un notable desarrollo en el campo de la zooarqueología, no siendo tan notorio su estudio en el de la arqueobotánica, particularmente en Argentina. Ambos tipos de estudios -tafonómicos y de formación de sitio- requieren por lo general estudios de campo específicos para la zona bajo estudio, ya que las variables geomorfológicas -fundamentales en esta clase de abordajes- pueden ser correctamente caracterizadas y comprendidas sólo tras un exhaustivo estudio regional (Borella y Dubois 2003). En el caso de los macrorrestos, si bien los mismos son incididos por los mismos factores que el resto del registro arqueológico, su fragilidad y labilidad suelen ser caracteres de riesgo, que afectan su conservación (Buxó y Piqué 2008). La frecuente carbonización de esta clase de resto arqueológico suele aumentar en algunos casos la fragilidad del mismo, lo cual resulta en su desintegración en elementos mínimos, ya sea por procesos tafonómicos naturales o por procesos culturales que hacen a la formación del registro arqueológico, teniendo la excavación arqueológica en sí misma especial incidencia. La contracara de este fenómeno es que la carbonización favorece la preservación de restos de origen vegetal ya que evita los procesos naturales de descomposición que llevan -salvo en ambientes excepcionales- a que los restos no se incorporen al registro arqueológico o lo hagan por un tiempo muy breve susceptible de dejar, en el mejor de los casos, microrrestos tales como fitolitos.

Los macrorrestos de Cucurbita spp. que se recuperan con mayor frecuencia en las excavaciones pueden dividirse en tres clases: semillas, pericarpio (fruto) y pedúnculos, las partes vegetativas de la planta no suelen conservarse, salvo en zonas con condiciones especiales de preservación como abrigos rocosos en regiones de extrema aridez (Whitaker 1981, 1983; Cowan 1997). En lo que 
respecta puntualmente a los efectos de la carbonización en macrorrestos del género Cucurbita resultan particularmente interesantes las afirmaciones de Cowan (1997): "El proceso de carbonización es particularmente poco probable en las cucúrbitas. Las cáscaras de los frutos tanto de las calabazas como de Cucurbita están compuestas mayormente por hileras poco organizadas de células parenquimáticas (que son suaves, de paredes delgadas y fácilmente deformadas y corroídas) y capas externas de células esclerenquimáticas más resistentes y de paredes gruesas. Ambas son fácilmente consumidas por el calor. La excavación y flotación de los sedimentos promueve la degradación de los especimenes arqueológicos carbonizados de Cucurbita. La combinación de estos factores a menudo reduce las cáscaras arqueológicas de Cucurbita a pequeños trozos ennegrecidos que no son de mucha utilidad más allá de la simple identificación. Otras partes de la planta (e.g. semillas, pedúnculos, verrugas de la corteza, y marcas de los pedúnculos o pimpollos) son menos frecuentemente recuperados $\mathrm{O}$ reconocidos. Afortunadamente, las Cucurbita se preservan también en estado no carbonizado en depósitos de cuevas o abrigos rocosos secos o en sedimentos perpetuamente inundados. En estas situaciones la preservación puede ser bastante espectacular (ej. Gilmore 1931: imagen XXIV; Watson 1969: imagen 12B) y las partes de Cucurbita pueden ser abundantes. Los restos recuperados de esta clase de ambientes depositacionales son de gran valor para ayudar a comprender la evolución del género Cucurbita porque retienen caracteres que generalmente faltan en sus contrapartes carbonizadas. Las pérdidas y distorsiones de la carbonización se hallan reducidas y más partes de la planta pueden ser conservadas" (Cowan 1997: 64-65; nuestra traducción). Se pueden destacar dos aspectos primordiales a partir de esta cita. En primer lugar, el autor señala que las probabilidades que existen de que se conserven partes carbonizadas de cucúrbitas son escasas y que, aunque esto suceda, las probabilidades de recuperación son reducidas debido a la agresión causada 
por los procedimientos de excavación y flotación sobre los restos arqueobotánicos. En segundo lugar considera que la carbonización supone deformaciones e incluso pérdidas de partes o rasgos que resultan de interés si se desea profundizar en el estudio de las cucúrbitas más allá de su identificación. Este último punto, resaltado también por otros investigadores (Wright 2003), resulta de fundamental interés para nosotros ya que se pueden ver afectados caracteres morfológicos, anatómicos o biométricos que se utilizan en el estudio de los procesos de domesticación. Sólo se realizaron carbonizaciones experimentales en semilla, y no en pericarpio, dado que éste es el único órgano hallado en dicho estado en los sitios arqueológicos analizados en la presente tesis ${ }^{2}$.

\section{Materiales y método.}

Como primera instancia se realizaron sucesivas carbonizaciones de semillas secas de C. maxima ssp. maxima en un medio anaerobio a $300^{\circ} \mathrm{C}$ dado que el resultado de medidas de reflectancia estudiadas en muestras arqueológicas señala que la mayoría fueron carbonizadas alrededor de esta temperatura en el pasado (Braadbaart 2008). Esto se llevó a cabo como punto de inicio establecido de forma convencional a fin de evaluar el tiempo de exposición necesario para obtener restos carbonizados con buenas posibilidades de preservación en el registro arqueológico. Se obtuvo como resultado que 120 minutos de exposición arrojaba restos con buena consistencia, aumentando la fragilidad de los mismos a medida que transcurría más tiempo. Esta experiencia coincidió con la de otros autores como Butler (2002) quien carbonizó vainas maduras de Vicieae frescas a $300^{\circ} \mathrm{C}$ por dos horas con el fin

\footnotetext{
${ }^{2}$ Para el caso del pericarpio, contamos con el trabajo de Wright (2003) quien analizó los efectos de la carbonización en el espesor del mismo en C. pepo y Lagenaria siceraria. Los resultados indican una marcada tendencia a la reducción de dicho parámetro tras la exposición al calor, siendo mayor en los ejemplares que conservan más humedad (reducciones del $32 \%$ para C. pepo y $38 \%$ para L. siceraria) - los cuales además se ondularon- comparados a ejemplares secos (con reducciones del 27\% y $36 \%$ respectivamente)
} 
de simular material arqueobotánico bien preservado, o Wright (2003) quien aplicó la misma temperatura durante 50 minutos para obtener pericarpios de Cucurbitaceae con buen potencial de preservación e identificación. Cabe aclarar que cada estructura vegetal analizada es particular ya que los tejidos que la componen difieren en gran medida haciendo variar por lo tanto las condiciones óptimas de temperatura y tiempo que generen una buena preservación del material carbonizado. A pesar de ello se ha constatado en la bibliografía consultada que por lo general se aplican temperaturas de $300^{\circ} \mathrm{C}$ variando el tiempo de exposición- a fin de obtener ejemplares carbonizados que tendrían buenas posibilidades de conservación (por ejemplo Jacomet et al. 2002, Butler 2002, Wright 2003, Braadbaart 2008).

Partiendo por lo tanto de la relación original $300^{\circ} \mathrm{C} / 120$ min que aseguraba ejemplares carbonizados de semillas de Cucurbita sp. con una consistencia tal que sugería su buena preservación en el registro arqueológico, se buscó reproducir experimentalmente este estado del material manteniendo constante la relación entre temperatura y tiempo de exposición. Con este fin $-\mathrm{y}$ partiendo de la relación conocida $300^{\circ} \mathrm{C} / 120$ min- se obtuvo la siguiente constante matemática donde la temperatura es la variable independiente y el tiempo la variable dependiente:

$$
36000 / \mathrm{X}^{\mathrm{o}}=\mathrm{Xt}
$$

Expresión matemática (constante) que muestra la relación proporcional entre los grados centígrados $\left(\mathrm{X}^{\circ}\right)$ y el tiempo de exposición $(\mathrm{Xt})$ para semillas de Cucurbita

Una vez obtenida esta constante entre variables se procedió a efectuar las carbonizaciones a tres temperaturas y tiempos correspondientes:

$300^{\circ} \mathrm{C} / 120^{\prime}$

$600^{\circ} \mathrm{C} / 60^{\prime}$

$800^{\circ} \mathrm{C} / 45^{\prime}$ 
Protocolo de experimentación:

a) Variables consideradas para la carbonización.

En todos los casos se emplearon semillas secas y maduras, por lo tanto estas variables pueden tomarse como constantes. Las variables que no resultaron constantes fueron, entre las variables continuas: temperatura y tiempo (siendo el tiempo la variable dependiente respecto de la temperatura) y entre las variables discontinuas: estado de las semillas (enteras o fragmentadas) y atmósfera de carbonización (oxidante o reductora).

b) Semillas empleadas.

Se analizó un total de 62 semillas enteras y 30 mitades de semillas distribuidas según se indica en la tabla 12. Las mismas proceden de la colección de referencia.

c) Variables consideradas para el estudio de caracteres morfológicos en las semillas.

Previo a la carbonización se tomaron en consideración fundamentalmente caracteres métricos: largo, ancho y alto máximos de las semillas. Dado que se carbonizaron conjuntos de semillas de un mismo taxón y no semillas individuales, estas variables métricas se expresaron como promedio por conjunto taxonómico y no como valores individuales.

d) Instrumental empleado en la carbonización.

Las carbonizaciones se llevaron a cabo en las instalaciones del Laboratorio de Tritio y Radiocarbono (LATYR-CONICET-UNLP). Las semillas fueron carbonizadas en una mufla circular abierta con termocupla incorporada, testeándose además la temperatura con una termocupla manual. Las semillas fueron colocadas en crisoles de porcelana. 
e) Atmósfera de carbonización.

-Carbonización anaeróbica: las semillas -enteras y en mitades- se envolvieron en papel aluminio y fueron cubiertas con arena para generar un medio sin oxígeno (Kislev y Rosenzweig 1991). Los ejemplares fueron dispuestos dentro de la matriz arenosa de modo tal que no entraran en contacto directo entre sí. El hecho de envolverlos en papel aluminio no sólo sirvió para acentuar la falta de contacto directo con el oxígeno, sino que también tuvo un fin práctico al impedir que la arena se adhiriera a los ejemplares.

-Carbonización aeróbica: en este caso tanto las semillas enteras como las mitades fueron colocadas directamente en los crisoles, entrando en contacto directo entre sí.

\section{Resultados}

\section{a) $300^{\circ} \mathrm{C} / 120^{\prime}$}

En la carbonización anaeróbica se obtuvieron semillas con buen estado de preservación. En el caso de C. maxima sp. maxima se hallaron conglomerados de arena más oscura adheridos al papel aluminio que rodeaba las semillas, posiblemente debido a las secreciones de soluciones carbonosas de la misma. En el caso de C. moschata los conglomerados eran más escasos. C. maxima ssp. andreana y $C$. ficifolia no presentaron adherencias.

Los ejemplares aeróbicos de C. maxima ssp. andreana se presentaron en perfecto estado, las semillas estaban sueltas, sin ninguna secreción. En el caso de C. maxima ssp. maxima se hallaron restos de la solución carbonosa negroamarronado brillante adherida al fondo del crisol, cubriendo a todas las semillas, las cuales presentaban por ende un aspecto negro brillante también. La excepción fue una semilla que saltó y se depositó en uno de los crisoles con arena próximo a éste. Las dos mitades presentaron soluciones carbonosas 
(con aspecto de alquitrán) en la parte abierta, con burbujas huecas de hasta 3 $\mathrm{mm}$ de diámetro, estas secreciones produjeron que se adhirieran las mitades entre sí, aunque no de manera muy fuerte. De los ejemplares enteros, uno se abrió por el extremo micropilar y otros se abrieron por las grietas de las caras mayores, con secreción por las mismas en mayor o menos medida. Un caso extremo es un ejemplar en el que se levantó la cubierta seminal por una de estas grietas, abriéndose y levantándose una de las mitades de la cara mayor quedando unida por el margen, el cual actuó a modo de "bisagra", mostrando así la mayor resistencia de la cubierta en esta porción de la semilla.

En el caso de C. moschata todas las semillas estaban muy adheridas entre sí y al fondo del crisol por la presencia de gran cantidad de solución carbonosa. Todas las semillas presentan un aspecto negro-brillante por estar recubiertas por dicha solución, excepto una que saltó y cayo en un crisol con arena ubicado al lado. El comportamiento de los ejemplares resultó muy similar al de C. maxima ssp. maxima, aunque la solución carbonosa parece ser más abundante en C. moschata.

La media semilla de C. ficifolia derramó solución carbonosa, adhiriéndose al crisol, el resto de las semillas se presentaron en buen estado, con aspecto hinchado y algunas burbujas pequeñas en la cubierta, la cual tenía en algunos ejemplares algunas porciones de color marrón. Uno de los ejemplares enteros perdió parte de la cubierta seminal, la cual quedó adherida a una de las mitades. En el caso de las mitades, sus caras poseen un aspecto más uniforme negro-opaco liso. Ninguna de las muestras posee adherido el típico depósito carbonoso negro brillante que se vio en los casos anteriores, tampoco se detectó que el mismo saliera de la parte abierta de la semilla fragmentada.

$600^{\circ} \mathrm{C} / 60^{\prime}$ 
En el caso de las semillas de C. maxima ssp. maxima, C. moschata y C. ficifolia expuestas a un medio aeróbico, las mismas quedaron blancas por fuera y negras por dentro y muy frágiles, fragmentándose ante el más mínimo contacto. Las semillas partidas de C. maxima ssp. maxima y C. moschata despidieron soluciones carbonosas oscuras por la parte abierta la cual se adhirió a las paredes del crisol, y en el extremo micropilar de una de las semillas enteras de C. maxima ssp. maxima se halló adherido un residuo carbonoso amorfo. En general todo el conjunto estaba levemente adherido al fondo del crisol. En el caso anaeróbico no se hallaron adherencias sobre el papel aluminio, aunque la media semilla de C. maxima ssp. maxima segregó por la parte abierta una solución carbonosa oscura que quedó adherida al papel. Las semillas en general presentaron una coloración superficial blanca y negra, correspondiendo la primera a una ceniza que, en algunos casos, se separó fácilmente de los restos carbonizados de las semillas al retirar el papel metálico.

En el caso de C. maxima ssp. andreana sólo quedaron residuos blancos muy lábiles, deshaciéndose por completo en algunos casos. En ambiente aeróbico estos residuos se presentaron huecos, salvo la mitad en cuyo interior se ve un residuo negro. A esta última se le separó la cubierta seminal al ser cortada previo a su carbonización. A pesar de lo escaso de los restos recuperados, todo el conjunto se halló levemente adherido al fondo del crisol.

$800^{\circ} \mathrm{C} / 45^{\prime}$

En el caso de C. maxima ssp. andreana no quedó resto alguno, ni en atmósfera aeróbica ni en la anaeróbica. En la primera sólo se ven tres residuos blancos, uno conservando la forma de semilla, en la segunda no quedó absolutamente nada dentro del papel. De las semillas de C. moschata aeróbica quedaron residuos carbonosos en el fondo del crisol, de los ejemplares anaeróbicos sólo se recuperaron dos pequeños residuos amorfos. Lo mismo ocurrió con $C$. 
ficifolia. En el caso de C. maxima ssp. maxima se recuperaron restos en ambas condiciones, en la aeróbica quedaron tres residuos carbonosos amorfos, dos de ellos muy brillosos y adheridos al fondo del crisol, el tercero se deshizo al menor contacto. En el caso anaeróbico quedaron tres residuos dentro del papel aluminio, la media semilla permaneció como un residuo resistente y reconocible. De los otros dos restos uno es irreconocible y el restante es sólo el extremo micropilar con parte de uno de los márgenes hasta la mitad de la semilla aproximadamente.

Por lo tanto, y en líneas generales, se ha visto que:

-una buena preservación de semillas de Cucurbita sp. se logra a los $300^{\circ} \mathrm{C} / 120^{\prime}$ ya sea en condiciones aeróbicas como anaeróbicas. Braadbaart (2008) señala que $600^{\circ} \mathrm{C}$ es la máxima temperatura que se alcanza cuando los restos son carbonizados a fuego abierto, lo cual sería aquí asimilable a las condiciones aeróbicas de carbonización. Los resultados aquí obtenidos indican que, tras 60 minutos de exposición a $600^{\circ} \mathrm{C}$, las semillas de C. maxima ssp. andreana se destruyen por completo, obteniéndose sólo residuos carbonizados amorfos en el caso de los restantes taxa. Las carbonizaciones experimentales llevadas a cabo por Wright (2003) demostraron que $500^{\circ} \mathrm{C} / 50^{\prime}$ es una condición perjudicial para los pericarpios de cucurbitáceas. Finalmente, a $800^{\circ} \mathrm{C} / 45^{\prime}$ sólo se obtuvieron escasos residuos carbonizados amorfos y cenizas.

-de todas las especies C. maxima ssp. maxima fue la que mayor resistencia mostró a la exposición a temperaturas elevadas, fundamentalmente en el caso de semillas partidas.

- la cubierta seminal en general y los márgenes y extremo micropilar en particular, exhibieron una buena preservación.

-C. maxima ssp maxima y C. moschata exudaron soluciones carbonosas en ambos tipos de atmósfera, lo cual podría dificultar la visibilidad de los tejidos 
internos de la semilla. Esta dificultad no se registró en las otras especies analizadas. Esta diferencia puede deberse al elevado contenido de almidón en las células epidérmicas de C. maxima ssp maxima y C. moschata (Winton y Winton 1935, Singh y Dathan 1972) puesto que se ha constatado que esta clase de secreciones se debe al alto contenido de almidón de los órganos expuestos a carbonizaciones experimentales (Western 2008). 


\section{II- Análisis micromorfológico de semillas de Cucurbita spp.}

\section{Introducción}

La semilla -que se desarrolla a partir del óvulo fecundado- consta de un embrión protegido por la cubierta seminal o testa que lo envuelve, el cual está provisto de nutrientes que pueden estar almacenados fuera del embrión en el endosperma o perisperma (Esau 1977). La cubierta seminal -de gran valor para determinar relaciones taxonómicas- varía en su estructura con relación a los caracteres específicos del óvulo y a los cambios producios por el desarrollo en los tegumentos durante la maduración de la semilla (Esau 1977).

La cubierta seminal o testa de las semillas de Cucurbitaceae deriva por completo del tegumento externo del óvulo (Singh 1953, Jeffrey 1980). La epidermis externa de este tegumento forma, por medio de dos divisiones sucesivas, tres capas: e, $\mathrm{e}^{\mathrm{n}} \mathrm{y} \mathrm{e}^{1}$, de afuera hacia adentro (Singh y Dathan 1972). Estas tres capas se dividen tangencialmente a medida que la semilla crece, produciéndose mas divisiones en los extremos tanto basal como micropilar. En la capa $\mathrm{e}^{1}$ una vez terminadas las divisiones, las células se alargan tangencialmente y se vuelven esclerenquimáticas formando la principal capa mecánica de la cubierta seminal. De las capas e y e $\mathrm{e}^{\mathrm{n}}$ se derivan respectivamente la epidermis y la hipodermis (Singh y Dathan 1972). En definitiva, a la madurez la semilla queda conformada por una cubierta seminal, un perisperma, una o dos capas de endosperma y un gran embrión.

\section{$\underline{\text { Rasgos generales de las semillas de Cucurbita }}$}

Las semillas de Cucurbita son chatas, ovaladas y con márgenes más o menos pronunciados de acuerdo con la especie. Siguiendo a Singh y Dathan (1972) su cubierta seminal consta de cinco capas (desde el exterior hacia el interior): 
epidermis, hipodermis, capa esclerenquimática, aerénquima y una "zona interna". Para estos autores esta última zona puede ser clorenquimática con células ensanchadas y de paredes delgadas en especies mesofíticas y cultivadas; o constar de células anchas y poligonales con leves engrosamientos de celulosa y sin cloroplastos, constituyendo por lo tanto un tejido parenquimático no colenquimatico, en especies xerofíticas. Lott (1973) considera los tejidos de esta zona como un parénquima esponjoso conformado por células muertas irregulares con varias excrecencias. Este autor declara que este parénquima posee una delgada capa verde adherida al cotiledón cuya estructura no pudo determinar al MEB. Por su parte, Singh y Dathan (1972) y Teppner (2000) reconocen a esta capa como clorénquima. Finalmente Agbagwa y Ndukwu (2005) consideran sólo cuatro capas, siguiéndole a la capa de esclereidas un parénquima clorenquimatoso, sin que haya aerénquima. Lamentablemente, la distinción entre parénquima y clorénquima es imposible a nivel arqueológico ya que el segundo de estos tejidos se diferencia del primero por la presencia de cloroplastos, los cuales no se conservan en material arqueobotánico desecado y/o carbonizado. Por lo tanto, su valor como carácter diagnóstico para identificar tipos de adaptación en ejemplares arqueológicos decrece.

A pesar de la diversidad de terminologías aplicadas, en esta tesis se adoptará la propuesta de Singh y Dathan $(1972,1990)$ ya que se halla sustentada en el análisis de gran número de especies de Cucurbita mediante un análisis riguroso de numerosos ejemplares.

\section{Materiales y Método.}

Se estudiaron a nivel microscópico cuarenta y dos semillas de C. ficifolia, C. moschata, C. maxima ssp. andreana, C. maxima. maxima cv. rapallito; C. maxima ssp. maxima cv. hubbard; C. maxima ssp. maxima cv. ingles and C. maxima ssp. maxima cv. criollo. 
Estas cuarenta y dos semillas fueron divididas en dos grupos a fin de realizar distintos tipos de análisis. El primer grupo de 35 semillas fue hidratado a fin de realizar cortes delgados de tres tipos (figura 17).

I) Corte transversal $(\mathrm{Tr})$ : éste se realizó en tres partes distintas de la semilla: en la región micropilar (C1), en la región media (C2) y en la región basal o de la chalaza (C3); cortes sucesivos que se fueron aproximando desde C1 y C3 hacia C2 se indicaron con el agregado de "a" y "b" a medida que se acentuaba dicha proximidad. Este tipo de corte se efectuó tanto a mano alzada como con ayuda de un micrótomo de mano. En este plano se observaron entre cinco y once semillas por taxa y como resultado un total de ciento tres secciones delgadas se obtuvieron de todos los taxa analizados. Una vez efectuados los cortes los ejemplares fueron observados bajo microscopio estereoscópico a fin de caracterizar márgenes y espesor de la cubierta seminal, y luego fueron observados bajo microcopio de transparencia para analizar los tejidos de la cubierta.

2) Corte tangencial longitudinal (TgLg): efectuado en la zona media o C2 de una semilla de C. maxima ssp. maxima cv criollo y en una de C. maxima ssp. andreana a fin de apreciar la capa esclerenquimática en un plano distinto que permitiera estudiar mejor su morfología. Se procedió en dos etapas. La primera de ellas consistió en un corte a mano alzada en la región señalada, separando la testa del resto de los tejidos de la semilla. En la segunda etapa se sometió dicho corte de la cubierta seminal a un macerado químico a fin de separar el tejido esclerenquimática de las otras capas tisulares. El proceso consistió en sumergir dicho corte en un preparado compuesto en un 50\% por agua oxigenada 100 volúmenes y en un 50\% por ácido acético, el mismo se expuso al fuego hasta que alcanzara el punto de hervor, dejándoselo hervir entre diez y quince minutos. La capa esclerenquimática se separó de las otras capas tisulares, pero manteniendo la integridad y unión entre las células que la componen. 
3) Corte radial longitudinal ( $R d L g)$ : Se siguió el mismo procedimiento que en el caso del corte tangencial longitudinal a fin de obtener una vista radial de las células del esclerénquima de una semilla de C. maxima ssp. maxima cv criollo.

El segundo grupo de siete semillas fueron desecadas directamente al aire y se fracturaron manualmente en la región C2 a fin de ser estudiadas tanto por medio de microscopio de incidencia como a través de MEB a diferentes magnificaciones (80, 370 y $700 \mathrm{X})$.

Desde el inicio de los análisis se realizó un abordaje cualitativo, prestando especial atención a las características intrínsecas de cada uno de los tejidos que conforman la cubierta seminal y al margen de la semilla. No obstante, en el caso de especies cercanamente emparentadas como subespecies o cultivares de C. maxima se recurrió a caracteres cuantitativos para su análisis, tales como: ancho y largo de células epidérmicas, número de capas y espesor del tejido hipodérmico, tamaño de células hipodérmicas, largo, ancho y espesor de células esclerenquimáicas, espesor del aerénquima. En este último caso las medidas realizadas sobre las células de la cubierta seminal se efectuaron sobre imágenes de las mismas tomadas con una cámara marca Motic Image Plus 2.0, aplicando luego su correspondiente software de medición. Cuando fue necesario se corroboraron los resultados obtenidos por este medio con medidas obtenidas a través del empleo de una cámara clara incorporada al microscopio Leica (DM/LM). Sobre fotografías de MEB las medidas fueron obtenidas con el programa Image Tool 3.0. Se calcularon media, desvío, coeficiente de variación y rango de tamaño de los tejidos diagnósticos, este último se consigna ente paréntesis. Dependiendo del caso, las medias obtenidas resultaron de un promedio de entre veinte y cincuenta medidas por tejido de cada taxa. Cuando se mencionan datos correspondientes a C. maxima ssp. maxima se está considerando un promedio del conjunto de los cuatro cultivares mencionados. 
Cabe mencionar que a medida que se realiza la descripción de los caracteres observados, se los compara con las apreciaciones realizadas para los mismos taxa de Cucurbita por Singh y Danthan (1972) y Teppner (2004).

Tras el análisis de la colección de referencia, y una vez identificados los rasgos diagnósticos cualitativos y cuantitativos tanto para semillas frescas como carbonizadas, se analizaron los restos arqueológicos de semillas a fin de constatar la presencia o ausencia de dichos rasgos y hacer una evaluación taxonómica de los mismos. Los restos arqueobotánicos fueron observados bajo microscopio estereoscópico, por transparencia y al MEB a diversos aumentos. Se analizaron 22 semillas arqueológicas secas: dos semillas (LV 25 y LV13) del sitio Los Viscos, la totalidad ( $N=11)$ de las semillas recuperadas en la localidad de Pampa Grande (Q1, QA, QB, QC, QD, O85, S1, S2, S3, S4 y S5), cuatro semillas del sitio Bandurria (372F, 425FA, 425FB y 409F) y cinco de Cerro Lampay (1059; 17/1248; 18/1235A; 18/1235B y 13/1200). Se analizaron además ejemplares carbonizados: tres semillas carbonizadas y cuatro fragmentos de distintas semillas del sitio Puente Río La Viña I (Salta, Argentina) y fragmentos de la única semilla recuperada en la localidad de Campo del Pucará (Tucumán, Argentina) (Figura 18).

\section{Resultados.}

\section{1) Espesor de la cubierta seminal}

El espesor de la cubierta seminal se acrecienta notablemente de C. maxima ssp. andreana a C. maxima ssp. maxima, siendo generalmente del doble en el caso de ésta última, y aún más en el caso del cultivar Criollo. Tras el análisis bajo microscopio estereoscópico se detectó una clara diferencia entre dos de los tres tipos de semillas de C. maxima ssp. maxima reconocidos por Teppner (2000) -siguiendo a Harz (1885)- de acuerdo con los caracteres de su cubierta 
seminal. Vale la pena aquí, en pos de un mejor entendimiento de nuestras descripciones, realizar una breve mención a los tres tipos de semillas reconocidos por Teppner

El primero (I) está constituido por semillas de superficie castaña, cubiertas gruesas, epidermis muy gruesa y una superficie de fractura suave (Teppner 2000). En este grupo incluimos al cultivar Criollo, el cual posee una cubierta cuyo espesor es once veces mayor al de C. maxima ssp. andreana y es casi tres veces mayor con respecto a los restantes cultivares de su misma especie (ver tabla 13). A este grupo de semillas se refiere probablemente Lira Saade (1995) cuando afirma que las semillas de C. maxima ssp. maxima se destacan respecto de otras especies cultivadas por poseer una testa muy engrosada de 1 a $2 \mathrm{~mm}$ de altura.

El segundo grupo (II) es el de cubiertas semi-gruesas y esta constituido por semillas de superficies sedosas y blancas, de epidermis más delgada y una superficie de fractura fibrosa. Teppner (2000) incluye en este grupo a los cultivares Hubbard y Zapallito. Ambos poseen, junto con el cultivar Inglés, cubiertas casi tres veces más delgadas que el cultivar Criollo. Para caracterizar el incremento en el espesor de la cubierta seminal se decidió utilizar el valor del espesor de la cubierta como valor \% del espesor total de la semilla y no como valor absoluto, dado que la semilla también acrecienta su tamaño general. En la última columna de la tabla 13 puede verse que en la semilla de C. maxima ssp. andreana la cubierta seminal representa un $8,9 \%$ del espesor total de la semilla y que el cultivar Criollo sigue destacándose ya que en este caso la cubierta representa casi un 30\%. Hubbard y Zapallito mantienen cubiertas cuya proporción respecto del total sigue siendo mayor que lo obtenido para C. maxima ssp. andreana. El caso llamativo es el del cultivar Ingles, ya que proporcionalmente su cubierta seminal es más pequeña que la de C. maxima ssp. andreana., revirtiendo la tendencia observada en los otros cultivares. Este cultivar presenta varias similitudes con C. maxima ssp. andreana 
en lo que respecta a los tejidos que componen la cubierta seminal, lo cual se discutirá en los próximos apartados.

Hasta aquí, podríamos decir que la tendencia entre C. maxima ssp. andreana y C. maxima ssp. maxima -salvo la excepción del cultivar Inglés- es el aumento del grosor de la testa, lo cual entra en contraposición con la opinión generalmente asumida de que los procesos de domesticación llevan a la reducción del espesor de las cubiertas seminales para mejorar la palatabilidad de la semilla, o bien como ventaja adaptativa en ambientes antrópicos (ver capitulo 4.1). Este fenómeno inverso observado entre las subespecies de $C$. maxima podría ser el resultado de la selección cultural de semillas más grandes y nutritivas, con un incremento en la cantidad de endosperma, caracteres que pudieron haber estado ligados a un aumento del espesor de la cubierta seminal. Lamentablemente hasta tanto no se cuente con estudios genéticos referidos al ligamiento de genes que regulan la expresión de caracteres vinculados al proceso de domesticación en C. maxima no es posible avanzar en este sentido.

\section{2) Micromorfología de la cubierta seminal en corte transversal}

Los cortes a la altura media de la semilla (C2) permiten una mejor comparación interespecífica ya que no sufren las deformaciones propias ocurridas en los tejidos de los extremos micropilar o chalazar (cortes C1 y C3). Por lo tanto todas las observaciones descriptas en lo sucesivo corresponden a las realizadas en el sector $\mathrm{C} 2$.

\section{2a_Morfología del margen}

El primer rasgo que distingue a las distintas especies es la morfología microscópica general de los márgenes que puede observarse en un corte transversal a bajas magnitudes. Los márgenes de C. maxima ssp. maxima, $C$. 
maxima ssp. andreana y C. moschata describen un arco redondeado, en el caso del primer taxón este es algo más aplanado, a manera de meseta. Los márgenes de C. ficifolia presentan una morfología bastante disímil a la de otras cucúrbitas ya que el margen no presenta una forma de arco sino que es rectangular a trapezoidal. Esta característica, que ya había sido observada antes por Teppner 2004, permite su fácil identificación.

C. moschata presenta un arco submarginal el cual se encuentra también en $C$. ficifolia y en el tipo III de cubierta seminal de C. maxima ssp. maxima, pero, tal como fue observado antes por Teppner (2004), está ausente en los tipos I y II. El mismo también se halla ausente en C. maxima ssp. andreana.

A continuación se presenta una clave dicotómica elaborada para diferenciar las distintas especies de Cucurbita sudamericanas en base a caracteres del margen:

A-Morfología del margen en corte transversal (Lámina 4)

A.1- Morfología rectangular/trapezoidal-------------------------C. ficifolia

A.2- Morfología a manera de arco

A.2. 1. Morfología a manera de arco redondeado

A.2.1.1- Con arco submarginal---on moschata

A.2.1.2- Sin arco submarginal--------------------- C. maxima ssp. andreana

A.2.2- Morfología a manera de arco aplanado ("meseta")

A.2.2.1.- Con arco submarginal-------------------- C. maxima ssp. maxima (tipo III de Teppner 2004)

A.2.2.2.- Sin arco submarginal------------------ C. maxima ssp. maxima (tipo I y II de Teppner 2004) 


\section{2b_Epidermis}

La epidermis de las cucúrbitas consiste en células radialmente elongadas engrosadas pero no lignificadas (Esau 1977) ${ }^{3}$. Las células epidérmicas pueden dividirse entre aquellas que son de forma rectangular, poseen paredes engrosadas y se hallan dispuestas en empalizada como ocurre en C. moschata y C. maxima ssp. maxima cv. criollo, y aquellas que también son de forma rectangular y dispuestas en empalizada, pero que -dado que poseen paredes delgadas- luego de ser manipuladas para su análisis microscópico (corte delgado con instrumental de corte o fractura manual) su disposición original se pierde adquiriendo una disposición laxa y desarreglada. Este último tipo de célula epidérmica se encuentra en los restantes cultivares de $C$. maxima ssp. maxima (tipos II y III), en C. maxima ssp. andreana y en C. ficifolia.

Además de estas diferencias, se distinguen células largas y cortas, pudiendo las primeras rodear o no a las segundas en el margen. Esto fue señalado por Singh y Dathan (1972) quienes notaron que las células largas rodean completamente a las cortas en C. moschata y C. ficifolia y que en C. maxima ssp. maxima las células epidérmicas largas son solamente un poco más largas que las células cortas y por tanto no las rodean. En esta última especie las células largas describen solamente una protuberancia en la zona próxima al margen, lo cual -de acuerdo con los autores citados- ocurre también en C. maxima ssp. andreana, aunque dicha protuberancia es poco pronunciada. Teppner (2004) manifiesta que en $C$. maxima ssp. andreana estas células epidérmicas largas apenas cubren el margen o sólo lo hacen en una tercera parte del mismo, sin embargo tanto en observaciones bajo microscopio de transparencia como al MEB, este carácter no pudo ser observado. A diferencia de Singh y Dathan (1972), Teppner (2004) distingue tres tipos de cubiertas seminales en $C$.

\footnotetext{
${ }^{3}$ Lott (1973) explícitamente dice que las células de la epidermis no están radialmente elongadas, esta discrepancia puede ser aparente ya que existe una falta de precisión en los planos de referencia empleados por los autores en sus observaciones.
} 
maxima ssp. maxima. Estos tipos fueron reconocidos en los ejemplares observados, aunque con algunas variaciones. El tipo I se caracteriza por células largas que no rodean a las cortas en el margen, describiendo sólo una protuberancia (esto coincide con lo que mencionan Singh y Dathan (1972) para la subespecie en genera), las células epidérmicas poseen paredes engrosadas y carece de arco submarginal (Teppner 2004). Este tipo I se correspondería con el cultivar Criollo. El tipo II en el que Teppner (2004) incluye a los cultivares Hubbard y Zapallito coincide plenamente con las observaciones realizadas aquí respecto de que comparte las mismas características que el tipo I, salvo que las células epidérmicas son lábiles y de paredes delgadas. El tipo III (que posee células largas que rodean al margen, células epidérmicas de paredes delgadas y un pequeño arco submarginal, según Teppner 2004) fue reconocido en cultivares locales de C. maxima ssp. maxima vendidos en el mercado municipal de La Quiaca (Jujuy) procedentes de Salta (LQM3) (ver capitulo 6). Nuevamente el cultivar Inglés representa una excepción ya que posee los mismos caracteres que el tipo II, salvo que en este caso también las células largas cubren un tercio del margen. En este sentido Teppner (2004) señala la necesidad de profundizar el estudio de tipos intermedios entre el grupo II y III.

En los cortes transversales de C. ficifolia observamos que las células largas rodean a las cortas en el margen, tal como lo proponen Singh y Dathan (1972). Si bien en C. moschata las células largas rodean totalmente a las cortas cuando el corte se realiza en la sección C2, leves variaciones en la altura del corte dentro de dicha sección pueden arrojan un resultado distinto donde las células largas pueden no llegar a cubrir totalmente a las cortas en el margen. En este último caso, la disposició de las células largas se denomina a manera de "cuerno" -y no de "protuberancia" como en el caso de C. maxima ssp. maxima- ya que es mayor el largo de las células y se arquean más sobre las cortas (Lámina 5). Es importante, por ende, la altura a la cual se efectúa el 
corte, ya que esto posee efectos notables sobre la apariencia de las células de la cubierta seminal. El punto a partir del cual surgen estas células epidérmicas largas coincide con el arco submarginal. Esto mismo ocurre con las células largas de C. ficifolia y de C. maxima ssp. maxima de tipo III, tal como ya fue observado por Teppner (2004) para este ultimo tipo. Singh y Dathan (1972) enfatizan en su trabajo los tipos de engrosamientos presentes en las células epidérmicas de las diferentes especies, los cuales están ausentes en las células de los extremos, que son más pequeñas (Singh 1953). El tamaño de las células epidérmicas, así como su engrosamiento, gradualmente disminuye hacia las caras mayores de la semilla donde éstos últimos pueden estar incluso ausentes (Singh 1953). Dado que será esta región de las caras mayores la que consideraremos principalmente para el estudio arqueológico de las semillas de Cucurbita, no se tendrán en cuenta los engrosamientos como rasgo diagnóstico ya que pueden faltar en la misma.

Singh y Dathan (1972) mencionan que en C. moschata las células epidérmicas poseen abundantes granos de almidón. Las observaciones desarrolladas aquí han constatado que no sólo en dicha especie sino también en la epidermis de C. maxima ssp. maxima cr bubbard hay gran cantidad de granos de almidón pequeños $[7,10 \mu \mathrm{m}(4-9,2 \mu \mathrm{m})]$ y esféricos (promedio de relación entre dos medidas de diámetro por grano: $0,93 \mu \mathrm{m})$.

Otro rasgo que se suma a los cualitativos es el largo y ancho de las células epidérmicas. En opinión de Singh y Dathan (1972) C. maxima ssp. maxima se destaca por poseer las células epidérmicas más largas del género, tal y como se desprende de las medidas que publican (ver tabla 14).

Probablemente Singh y Dathan (1972) se estén refiriendo a C. maxima ssp. maxima cv. criollo, cultivar que destaca entre los restantes taxa por el notable largo de sus células epidérmicas (tabla 15). Este cultivar se caracteriza también por poseer la superficie de la semilla color castaño y no blanco como los restantes cultivares aquí analizados (lo cual coincide con la caracterización del 
tipo I de Teppner). C. moschata posee, en cambio, las células epidérmicas más anchas (tabla 16).

En cuanto a los caracteres cuantitativos que distinguen la subespecie domesticada de la espontánea vemos que para el caso del largo los valores obtenidos para C. maxima ssp. maxima incluyen a los de C. maxima ssp. andreana (tabla 15). Por lo tanto, en lo que respecta a este parámetro, los valores comprendidos entre 242 y $315 \mu \mathrm{m}$ pueden ser de cualquiera de ambas subespecies ya que los valores del cultivar Inglés se asemejan a los de $C$. maxima ssp. andreana, los valores por debajo de $213 \mu \mathrm{m}$ corresponderían a cultivares de C. maxima ssp. maxima como Zapallito y Hubbard y aquellos por sobre $315 \mu \mathrm{m}$ corresponderían a cultivares como Criollo.

En el caso del ancho el solapamiento se da nuevamente entre C. maxima ssp andreana y C. maxima ssp. maxima cv. ingles con valores ambos entre 22 y 40 $\mu \mathrm{m}$, los valores mayores a $40 \mu \mathrm{m}$ corresponderían a los cultivares Hubbard o Criollo (tabla 16).

Como puede verse entonces, C. maxima ssp maxima se podría distinguir de $C$. maxima ssp andreana en ejemplares cuyas células epidérmicas en sus caras mayores presenten un largo mayor a $315 \mu \mathrm{m}$ o uno menor a $213 \mu \mathrm{m}$, y en aquellos cuyo ancho sea mayor a $40 \mu \mathrm{m}$. Los valores de esta última subespecie, en cambio, coinciden para alto y largo con los del cultivar Inglés, sin que se la pueda distinguir del mismo. Este solapamiento que se observa entre ambas subespecies de C. maxima en lo que respecta a valores cuantitativos se debe a la inclusión de diversos cultivares en el análisis, a fin de hacer éste más representativo. Gracias a ello se puede apreciar lo mencionado por otros autores en cuanto a que la variabilidad de la especie domesticada incluye generalmente a la de la variedad silvestre (Galván 2006), cuyo caso extremo se observa entre la subespecie espontánea y el cultivar Inglés. Sin embargo, el cultivar Inglés se distingue de C. maxima ssp andreana por la disposición de las células epidérmicas en el margen, por lo que ambos taxa podrían diferenciarse 
en este aspecto. Teniendo en cuenta este último carácter en conjunto con los caracteres métricos, se podría distinguir la subespecie silvestre de los cultivares Inglés, por un lado, y Hubbard y Zapallito, con los que comparte rasgos morfológicos cualitativos, por otro, tal como se señala en la Tabla 17 y en la clave que se presenta a continuación.

\section{A- Epidermis (Lámina 5)}

A.1- Las células largas rodean a las cortas en el margen

A.1.1- Las células largas cubren al margen por completo

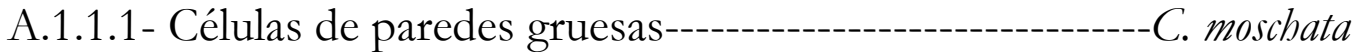

A.1.1.2- Células de paredes delgadas-------------------- C. ficifolia

A.1.2- Las células largas cubren un tercio del margen --------------- $C$. maxima ssp. maxima $\mathrm{cv}$. inglés.

A.2- Las células largas no rodean a las cortas en el margen sino que constituyen sólo una protuberancia

A.2.1- Células de paredes gruesas-----------C. maxima ssp. maxima cv. criollo

A.2.2- Células de paredes delgadas

A.2.2.1- Caras mayores con células cuyo largo es menor a $222 \mu \mathrm{m}$ y su ancho mayor a $40 \mu \mathrm{m}----C$. maxima ssp. maxima cv. rapallito; C. maxima ssp. maxima cv. bubbard

A.2.2.2- Caras mayores con células cuyo largo es mayor a $242 \mu \mathrm{m}$ y su ancho menor a $30 \mu \mathrm{m}---------------------$ C. maxima ssp. andreana

En principio por lo tanto una distinción taxonómica a partir de células epidérmicas podría llevarse a cabo teniendo en cuenta la disposición de las células largas en el margen, el grosor relativo de las paredes de las mismas y sus caracteres métricos en caras mayores.

\section{2c_Hipodermis}

La hipodermis consiste en pequeñas células con paredes moderadamente gruesas, lignificadas, con el engrosamiento formando un retículo (Esau 1977). La hipodermis es compacta y posee escaso espacio intercelular (Lott 1973). Singh y Dathan (1972) señalan que el número de células en la parte media de 
la semilla es constante para cada especie. Sin embargo en los datos que publican, de las cuatro especies sudamericanas, tres poseen cuatro capas siendo C. maxima ssp. andreana la excepción debido a que no es una forma domesticada (ver tabla 18). En la comparación que llevan a cabo Agbagwa y Ndukwu (2005) entre C. maxima ssp. maxima y C. moschata tampoco encuentran diferencias en el número de capas de células hipodérmica variando, en ambos casos, de 3 a 4 capas en las caras mayores a 6 ó 7 en los márgenes.

De acuerdo con Singh y Dathan (1972) la cantidad de capas hipodérmicas se halla más desarrollada a lo largo de los márgenes en la mayoría de las especies mesofíticas y domesticadas, excepto en C. maxima ssp. maxima. Tras las observaciones llevadas a cabo en esta tesis se constató, en cambio, que el número de capas de células también aumenta en dicha subespecie, como en todas las cucúrbitas, aunque en menor medida (no más de siete u ocho capas dispuestas irregularmente) y de manera mucho menos abrupta y notoria que en C. moschata o C. ficifolia. Esto mismo ocurre con C. maxima ssp. andreana donde incluso es menos notorio el paso de las caras mayores al margen.

La hipodermis puede poseer límites irregulares o no en su zona de contacto con la epidermis, lo cual produce que el número de capas pueda variar en una misma semilla. Así, si bien hemos confirmado en gran medida las cantidades mencionadas por Singh y Dathan (1972), en C. maxima ssp. maxima hemos encontrado casos donde en una porción de las caras mayores se divisan tres capas de células en la hipodermis, aunque en otra porción dentro de la misma cubierta se ven cuatro. También se han encontrado casos con cinco capas (tabla 19).

La irregularidad antes mencionada de la hipodermis en su área de contacto con la epidermis es muy notoria en C. moschata (Singh y Dathan 1972). Dicha irregularidad se debe a que las bases de las células epidérmicas se insertan a distintas alturas en la hipodermis. El número de células en la parte media de 
las caras mayores varía entre dos y cuatro, lo cual es dependiente de la heterogeneidad de la capa (tabla 19). En casos extremos de irregularidad el número de capas puede ser cinco. A medida que nos aproximamos al margen la cantidad aumenta a siete pudiendo llegar a nueve o diez.

Singh y Dathan (1972) dicen que la hipodermis de C. ficifolia posee entre cuatro y seis capas en sus caras mayores. En las observaciones realizadas aquí siempre se registraron entre tres y cuatro, pudiendo en algunos casos ser cinco (tabla 19). En el margen la cantidad de células aumenta hasta nueve o diez. Se destaca una marcada diferencia en el tamaño de las células que constituyen la hipodermis, siendo generalmente de tamaño mayor las próximas a las esclereidas y menores las próximas a la epidermis, a pesar de que Singh y Dathan (1972) hablan de que la hipodermis de C. ficifolia es uniforme. Otro rasgo constante observado mediante los analisis microscopicos efectuados es que la capa de células de la hipodermis en contacto con la epidermis es irregular -algo ya señalado, pero no caracterizado, por Singh y Dathan 1972describiendo una serie de "ondas" regulares que se corresponden con la inserción de las bases de las células epidérmicas.

En el caso de $C$. maxima ssp andreana el número de capas en las caras mayores es bastante constante siendo de dos o tres (lo cual coincide con lo observado por Singh y Dathan 1972) y muy raramente de cuatro (tabla 19), en los extremos aumenta a cinco o siete, no más. La hipodermis se presenta como un tejido bastante regular en su zona de contacto con la epidermis.

Las especies xerofíticas - principalmente del área del sudoeste norteamericano a noroeste mexicano- tienen en general hipodermis amplias con muchas capas y las células de las capas internas suelen estar más lignificadas. Por lo tanto los rasgos de la hipodermis podrían estar señalando xerofismo. De todas maneras, estos datos aportado por Singh y Dathan (1972) se contraponen con las dos capas de células de C. foetidissima que los mismos autores publican, por lo cual por el momento se desestima aquí este indicador de xeromorfísmo 
hasta tanto se lo corrobore con un estudio exhaustivo de las especies silvestres norteamericanas.

La información publicada señala que en C. moschata, C. ficifolia y C. maxima ssp. andreana estas células se hallan moderadamente engrosadas, en tanto en $C$. maxima ssp. maxima se hallan muy engrosadas (Singh y Dathan 1972, Lott 1973). Las observaciones realizadas aquí señalan, en cambio, que los engrosamientos de la hipodermis son similares en las cuatro especies.

Entre los cultivares de C. maxima ssp. maxima el tamaño de las células hipodérmicas no es diagnóstico ya que todas poseen diámetros similares (tabla 20). El espesor de la capa tampoco lo es (tabla 21), si bien algunos cultivares exhibieron tamaños únicos. Así, en C. maxima ssp. maxima cv. zapallito la misma tiende a ser delgada con medidas entre los 26 y $43 \mu \mathrm{m}$-asemejándose a las medidas obtenidas para C. maxima ssp. andreana - en tanto que en el cultivar Inglés es mayor que el resto, habiéndose registrado medidas entre 40 y $75 \mu \mathrm{m}$. Estos rasgos cuantitativos (alto de la capa y tamaño de las células) tampoco permiten distinguir de forma absoluta C. maxima ssp. maxima de C. maxima ssp. andreana, pudiendo considerarse tan sólo que las muestras con hipodermis de un espesor mayor a $47 \mu \mathrm{m}$ corresponderían a $C$. maxima ssp. maxima, mas no pudiendo asegurarse si las que poseen medidas menores corresponden a $C$. maxima ssp. maxima o C. maxima ssp. andreana. Si bien la variación en las medidas de las células es mucho mayor que en el espesor de la hipodermis, puede afirmarse que la subespecie domesticada posee células de más de $10 \mu \mathrm{m}$ de diámetro. Estas consideraciones se presentan en la tabla 22 y en la clave dicotómica subsiguiente.

B- Hipodermis (Lámina 6)

B1- Capa no irregular en su contacto con la epidermis

B1.1 - De 3 a 5 capas en caras mayores y de 7 a 8 en márgenes.

C. maxima ssp. maxima

B1.2- De 2 a 3 capas en capas mayores y de 5 a 7 en márgenes --------C. maxima ssp. andreana 
B2- Capa irregular en su contacto con la epidermis

B2.1- Base de células epidérmicas a distintas alturas ---------C. moschata

B2.2- Base de células epidérmicas describen "ondas" en zona donde

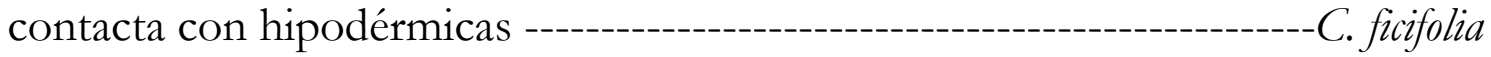

Por lo tanto la sinuosidad de la capa establece una primera distinción, siendo luego necesario recurrir a la cantidad de capas en caras mayores y margen en el caso de que no exista sinuosidad y, en el caso de haberla, a la forma que adopta dicha irregularidad.

\section{2d_Esclerénquima}

La región esclerenquimática da firmeza a la cubierta seminal (Hayward 1953). Las esclereidas se hallan levemente ramificadas y poseen gruesas paredes lignificadas (Esau 1977). Singh y Dathan (1972) caracterizan a estas esclereidas como astroesclereidas ${ }^{4}$, que pueden ser más o menos isodiamétricas o irregulares, elongadas radialmente; disponiéndose de forma oblicua o transversal al eje mayor de la semilla (Singh 1953). De acuerdo con Hayward (1953:585) "las paredes muy gruesas parecen sinuosas, con repliegues que se superponen". Esto puede apreciarse claramente en el corte longitudinal radial. Este carácter sinuoso de las paredes posee cierto valor diagnóstico ya que en C. moschata, por ejemplo, Singh y Dathan (1972: fig. 3G) mencionan la presencia de ramificaciones unifaciales características ${ }^{5}$.

Lott (1973) afirma que, en general, las esclereidas poseen gruesas paredes y escaso lumen. En corte transversal podemos ver que esta relación varía entre especies. C. moschata posee paredes mucho más gruesas que las de otras

\footnotetext{
${ }^{4}$ A pesar de que Stuart y Loy (1983) también caracterizan las esclereidas de C. pepo como astroesclereidas, no se considera del todo apropiada esta asignación, tomando la definición de éstas como células ramificadas en tres dimensiones partiendo desde un punto central (Hather 2000; ver el dibujo que la caracteriza en Esau 1977: 70). Parecería ajustarse más (según Esau 1977) a la caracterización de las esclereidas columnares o macroesclereidas, siendo las de Cucurbita particularmente sinuosas.

${ }^{5}$ Nuevamente, la ausencia de indicación de plano de corte o de observación de las células lleva a que la información volcada por los autores no pueda ser apreciada en todo su potencial. A partir de los gráficos que publican Singh y Dathan (1972), y de las observaciones realizadas aquí, se considera que esta "ramificación unifacial" de las esclereidas de C. moschata se aprecia en corte longitudinal.
} 
cucurbitas analizadas, una morfología similar mostraron las esclereidas de semillas de C. maxima ssp. andreana, pero sólo las obtenidas por polinización cruzada. C. ficifolia posee paredes delgadas y una morfología muy irregular. Por el contrario, C. maxima ssp. maxima y C. maxima ssp. andreana poseen esclereidas de morfología homogénea que describen círculos regulares en corte transversal.

Las esclereidas conforman una única capa en las caras mayores aumentando su número a dos o tres en los márgenes (Hayward 1953, Stuart y Loy 1983). En esta última región el espesor del tejido esclerenquimático no aumenta notoriamente ya que el incremento en el número de capas suele ir acompañado por una disminución en el tamaño de las células y cuando el número no aumenta las esclereidas aumentan escasamente su tamaño. Tanto en uno como en otro caso (los cuales se dan a veces en el mismo margen) las esclereidas sufren notorias deformaciones respecto de la morfología que exhiben en las caras mayores, área donde son mucho más uniformes. A esto se suma que la disposición de las esclereidas en el margen no mostró un patrón de acuerdo a cada taxa analizado. Un fenómeno parecido al observado en los márgenes ocurre en las regiones próximas a la micrópila y a la chalaza (cortes C1 y C3), pero las células se deforman y /o aumentan en cantidad a todo lo largo del tejido esclerenquimático y no sólo en los márgenes. Cortes a través de la micrópila muestran, además, que la capa esclerenquimática no forma un anillo completo aquí como en la chalaza y en todo el resto de la semilla (Singh 1953). Por estas razones, y al igual que para otros tejidos, el esclerénquima presente en región media (C2) de las caras mayores de la semilla es el que emplearemos en la evaluación de caracteres diagnósticos específicos.

En cuanto a los caracteres métricos de las esclereidas de las caras mayores (C2), puede verse en la tabla 23 que las medidas de ancho y largo tomadas en corte longitudinal tangencial no son diagnósticas para distinguir a C. moschata y 
C. ficifolia. Tomando en cuenta este plano de análisis Singh y Dathan (1972) manifiestan que C. maxima ssp. andreana y otras silvestres tienen esclereidas muy pequeñas. Las observaciones efectuadas en corte longitudinal corroboraron que en este plano las esclereidas de C. maxima ssp. andreana son más cortas que las de C. maxima ssp. maxima (ver tabla 24), si bien las medidas obtenidas difieren de las publicadas por los mencionados autores. Finalmente, se puede decir que en este plano de corte, esclereidas con una longitud de entre $146 \mu \mathrm{m}$ y $209 \mu \mathrm{m}$ corresponderían a la subespecie espontánea y aquellas con una longitud de entre $366 \mu \mathrm{m}$ y $587 \mu \mathrm{m}$ a la domesticada (Lámina 7).

En corte longitudinal tangencial las esclereidas de C. maxima ssp. andreana-al igual que las de C. ficifolia- son oblicuas al eje mayor de la semilla (Singh y Dathan 1972).

En corte transversal las esclereidas de C. moschata poseen escaso alto, cuyo promedio es incluso menor a formas no domesticadas como C. maxima ssp andreana (tabla 25). En este plano de corte puede verse que la distribución de medidas de esta última subespecie queda incluida dentro de la de C. maxima ssp. maxima, pudiendo afirmarse la presencia de la forma domesticada sólo ante esclereidas de más de $95 \mu \mathrm{m}$ de alto en dicho corte.

C. ficifolia posee esclereidas muy angostas (10,3 $\mu \mathrm{m}$ de promedio) en comparación con las otras especies (tabla 26). Le sigue C. moschata, aunque ya con valores mayores $(49,6 \mu \mathrm{m}$ de promedio). El rango de variación de $C$. maxima ssp. maxima se encuentra incluido dentro del de C. maxima ssp. andreana, pudiendo diferenciarse sólo esta última subespecie ante esclereidas más angostas de entre $48,8 \mu \mathrm{m}$ y $52,8 \mu \mathrm{m}$.

Por lo tanto vemos que en el caso de las esclereidas deben considerarse tanto caracteres cualitativos como cuantitativos, En el primer caso resulta diagnóstica la relación del lumen con el ancho de la pared y su homogeneidad o heterogeneidad en corte transversal. En el segundo caso resultaron diagnósticos para distinguir algunos taxa el ancho y el largo de estas células 
vistas tanto en corte longitudinal como transversal, aunque sólo en el caso de que los mismos presenten valores extremos (ver tabla 27 y clave a continuación).

C- Esclerénquima (Lámina 8)

C.1- Paredes delgadas y lumen amplio

C.1.1- Morfología homogénea (circular en Tr) y paredes uniformes

C.1.1.1 - Largo de las esclereidas en TgLg entre 366 y $587 \mu \mathrm{m}$. En Tr largo mayor a $95 \mu \mathrm{m}$.

C. maxima ssp.maxima.

C.1.1.2- Largo de las esclereida en TgLg entre 146 y $209 \mu \mathrm{m}$. En

Tr ancho entre 49 y $53 \mu \mathrm{m}$. ------C. maxima ssp. andreana

C.1.2- Morfología heterogénea (no circular en CT) y paredes irregulares C. ficifolia

C.2- Paredes gruesas y lumen estrecho

C. moschata

2e_Aerénquima

Esau (1977) considera al aerénquima como un parénquima lagunoso con células ramificadas, Stuart y Loy (1983) y Lott (1973) hablan directamente de parénquima y Singh y Dathan (1972) definen esta capa como compuesta por células estrelladas con engrosamientos lignificados reticulados o en espiral en las paredes y con prominentes espacios aéreos.

Este tejido se deriva de la hipodermis del óvulo y puede constar de sólo dos a cuatro capas u ocasionalmente de ocho a diez aunque en el extremo de la semilla el aerénquima está pobremente desarrollado de modo tal que las capas esclerenquimáticas de los dos lados de la semilla se acercan entre sí (Singh 1953). Por ello para apreciar este tejido también resulta más adecuada la porción media de la semilla (C2).

En cuanto al valor diagnóstico de este tejido, Singh y Dathan (1972) establecen que las especies silvestres tienen de una a dos capas a lo largo de las 
caras mayores constituidas por células pequeñas; los ejemplares cultivados poseen en cambio células grandes y varias capas.

En cuanto a los caracteres morfológicos, las células del aerénquima son muy heterogéneas en su forma, por lo cual los caracteres métricos son muy variables también. En las observaciones realizadas en todas las especies se pudo notar que las células de este tejido siempre son más pequeñas en su zona de contacto con las esclereidas, aspecto ya señalado por Winton y Winton (1935), Lott (1973) y Essau (1977).

En cuanto al número de capas, dada la irregularidad de estas células se vuelve muy difícil poder cuantificarlas, por ello se optó por tomar la altura total de la capa en corte transversal. Sólo en el caso de C. maxima ssp. andreana pudo constatarse que el aerénquima está compuesto por dos capas de células solamente. Esto es coherente con lo expresado por Singh y Dathan (1972) sobre que esta subespecie posee un aerénquima escasamente desarrollado, siendo éste un carácter primitivo.

Por lo tanto en esta capa serán los caracteres cuantitativos (altura del tejido y, en menor medida, cantidad de capas de células) y no los cualitativos los que resultan diagnósticos, tal como se demuestra en la tabla 28 y clave que se presenta a continuación.

D- Aerénquima (Lámina 9)

D.1- Dos capas de células. Alto del tejido en corte transversal menor a $55 \mu \mathrm{m}--$ C. maxima ssp. andreana

D.2- Más de dos capas de células. Alto del tejido en corte transversal mayor a $55 \mu \mathrm{m}$

D.2.1 - Alto del tejido en corte transversal menor a $150 \mu \mathrm{m}$

D.2.1.1 Alto del tejido en corte transversal entre 55 y $100 \mu \mathrm{m}-----$ C. ficifolia

D.2.1.2 Alto del tejido en corte transversal entre 100 y $150 \mu \mathrm{m}----$ C. moschata

D.2.2- Alto del tejido en corte transversal entre 150 y $200 \mu \mathrm{m}$

C. maxima ssp. maxima 
Clave dicotómica para la diferenciación de especies basada en el conjunto de los caracteres analizados de semilla.

A. Con arco submarginal notorio. Células epidérmicas largas rodean a las cortas en el margen. La hipodermis es una capa sinuosa en caras mayores aumentando su grosor (siete a diez capas) en los márgenes. Esclereidas homogéneas o heterogéneas.

B. Margen rectangular a trapezoidal. Células epidérmicas rectangulares de paredes finas dispuestas en empalizada que adquieren una disposición laxa

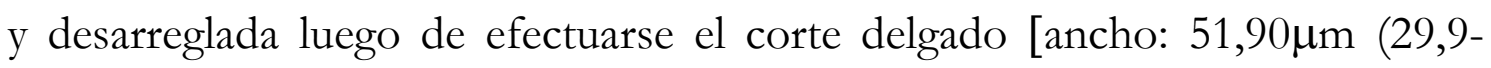
$80 \mu \mathrm{m})$; largo: $128,37 \mu \mathrm{m}(105,7-157,1 \mu \mathrm{m})]$. En su área de contacto con la epidermis la hipodermis presenta un límite irregular con ondulaciones que corresponden a la base de las células epidermicas. Hipodermis constituida por tres a cinco capas en las caras mayores presentando ondulaciones en el límite

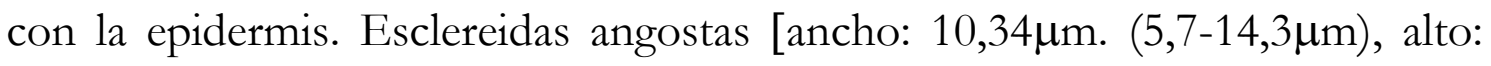
65,57 $\mu \mathrm{m}(56,3-74,8 \mu \mathrm{m})]$ con paredes delgadas y lumen amplio, morfología heterogénea. Alto del aerénquima entre 55 y $100 \mu \mathrm{m}$

C. ficifolia

BB. Margen redondeado en forma de arco. Células epidérmicas rectangulares de paredes gruesas dispuestas en empalizada [ancho: $65,6 \mu \mathrm{m}$

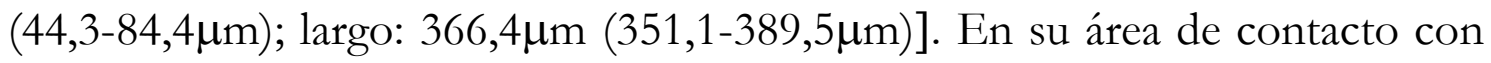
la epidermis la hipodermis presenta un límite irregular dado por las bases de las células epidérmicas a distintas alturas. Hipodermis constituida por dos a cuatro capas en caras mayores. Esclereidas con paredes gruesas y lumen estrecho, morfología homogénea [ancho:49,6 $\mu \mathrm{m}(44,3-53,6 \mu \mathrm{m})$; alto: 
$58,32 \mu \mathrm{m}(50,4-67,3 \mu \mathrm{m})]$. Alto del aerénquima entre 100 y $150 \mu \mathrm{m}$

C. moschata

AA. Sin arco submarginal o con arco marginal poco pronunciado. Las células largas rodean a las cortas en un tercio del margen o forman sólo una protuberancia. La hipodermis no es una capa sinuosa. Esclereidas homogéneas con paredes delgadas y lumen amplio de morfología y paredes uniformes.

C. Margen a manera de arco aplanado ("meseta"). Hipodermis de tres a cinco capas en caras mayores y siete a ocho en el margen. Espesor de la hipodermis: 44, $07 \mu \mathrm{m}(26,5-75,1 \mu \mathrm{m})$, diámetro de las células hipodérmicas: 9,68 $\mu \mathrm{m}(4,7-15,3 \mu \mathrm{m})$. Alto de las esclereidas 91,16 $\mu \mathrm{m}(66,8-125,4 \mu \mathrm{m})$; ancho: $68,88 \mu \mathrm{m}(52,8-85,9 \mu \mathrm{m})$. Alto del aerénquima entre $150 \mu \mathrm{m}$ y 200 $\mu \mathrm{m}$, tejido constituido por más de dos capas de células

C. maxima ssp.

\section{maxima}

D- Las células epidérmicas largas cubren un tercio de las células cortas en el margen C. maxima ssp. maxima cv. inglés.

DD- Las células epidérmicas largas no rodean a las cortas en el margen sino que constituyen sólo una protuberancia

E- Células epidérmicas de paredes gruesas-----C. maxima ssp. maxima cv. criollo

EE- Células epidérmicas de paredes delgadas

C. maxima ssp. maxima cv. zapallito; C. maxima ssp. maxima cv. hubbard

CC. Margen a manera de arco redondeado. Hipodermis de dos a cuatro capas en caras mayores y cinco a siete en el margen. Espesor de la hipodermis:

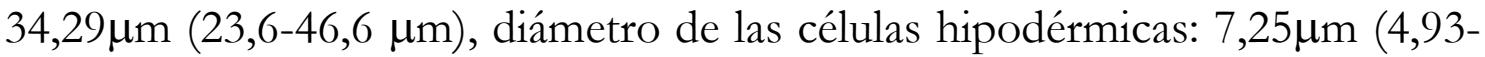


9,76 $\mu \mathrm{m})$. Alto de las esclereidas $81,25 \mu \mathrm{m}(65,4-95,4 \mu \mathrm{m})$; ancho: $62,88 \mu \mathrm{m}$ (48,8-89,2 $\mu \mathrm{m})$. Alto del aerénquima menor a $55 \mu \mathrm{m}$, tejido constituido sólo por dos capas de células

C. maxima ssp. andreana

\section{3) Cambios sufridos con la carbonización $\left(300^{\circ} / 120^{\prime}\right)$}

Bajo atmósfera aeróbica la morfología general de los tejidos de la cubierta seminal y la morfología del margen se mantienen sin alteraciones, excepto en casos donde la epidermis consiste en células de paredes delgadas tales como C. maxima ssp. andreana y C. ficifolia (Lámina 10). En estos casos sólo perduran las bases de las células epidérmicas pudiendo medirse el ancho de las mismas. Así se constató que en tanto el ancho de las células epidérmicas de $\quad$ C. ficifolia aumentan tras la carbonización, las de C. maxima ssp. andreana, en cambio, se reducen significativamente (Tabla 29). En $C$ moschata y $C$ maxima ssp. maxima tanto el largo como el ancho de las células epidérmicas se reducen, principalmente en la primera. A pesar de ello las células epidérmicas de $C$. maxima ssp. maxima siguen siendo las más largas. Por lo tanto, contrariamente a lo que sucede con muestras secas, el ancho de las células epidérmicas puede ser usado para distinguir C. maxima ssp. maxima de C. maxima ssp andreana en muestras carbonizadas, ya que sus rangos de medidas no se solapan.

La hipodermis no sufre cambios notables en la morfología o cantidad de células que la componen. Tampoco varía la morfología de las esclereidas, pero se reduce su alto en corte transversal. Como en el caso de las células epidérmicas, la diferencia en el alto de las esclereidas entre C. maxima ssp. maxima y C. maxima ssp andreana aumenta con la carbonización sin que ambos rangos de medidas se solapen.

El aerénquima mostró buena preservación luego de la carbonización, sin embargo se observaron alteraciones en la disposición de las células que lo 
componen, las cuales mostraron mayor agrupamiento por una reducción en el espacio intercelular lo cual produce una reducción general de este tejido. La excepción fue nuevamente $C$. ficifolia, la cual aumentó el alto del aerénquima.

\section{4) Análisis microscópico de semillas arqueológicas}

Dado que los rasgos diagnósticos varían de acuerdo con el estado desecado o carbonizado de las semillas se optó por seguir este criterio y separar las semillas arqueológicas en dos grupos para su análisis.

\section{4a_Semillas arqueológicas desecadas}

En primer lugar se analizaron los restos de semillas secas recuperadas en sitios arqueológicos peruanos y argentinos (tabla 30). En las identificaciones taxonómicas se ha aplicado el término affinis para indicar que el material observado correspondería al taxa mencionado o a uno cercano a éste, la imprecisión se debe a la falta de un número mayor de rasgos diagnósticos para asegurar la identificación taxonómica. En los casos analizados aquí, esta ausencia de rasgos se debió mayormente al estado de conservación de los macrorrestos.

El análisis del conjunto analizado permite derivar una serie de apreciaciones en cuanto a la conservación del material:

-a pesar de tratarse de semillas en buen estado de conservación las células epidérmicas no se preservan, salvo vestigios de sus bases. Esto resulta particularmente llamativo en los casos donde se observa claramente la presencia de células epidérmicas largas en los márgenes bajo microscopio estereoscópico, pero tras los cortes delgados para observación al microscopio óptico o los cortes para observación al MEB, las mismas no se hallan presentes (Lámina 11). Esto señalaría al tratamiento del material para su 
observación microscópica como una posible causa de la ausencia de dichas células.

En algunos ejemplares se observó una capa amorfa sobre la hipodermis posiblemente conformada por las células epidérmicas rotas y colapsadas. En las semillas recuperadas en Cerro Lampay y la número 085 de Pampa Grande pudieron observarse algunas células largas en el margen (Lámina 11).

-si bien en general la hipodermis se conserva en buen estado, en gran cantidad de ejemplares la misma se encuentra colapsada, por lo cual no se pudo registrar el tamaño de las células individuales, siendo el alto del tejido un carater menos confiable que la cantidad de capas que lo componen (Lámina 12).

-en todos los casos observados las esclereidas se hallaron en buen estado de preservación. El único factor que incidió en la apreciación de la morfología de las mismas fue el ocasional desgarramiento de la pared celular, probablemente por efecto de los cortes de la semilla para la observación microscópica y el estado de conservación de la mismas (Lámina 12).

-las capas de aerénquima resultaron ser muy variables en un mismo ejemplar incluso en el caso de semillas enteras bien preservadas- tal como era de esperarse de un tejido tan lábil.. En la tabla 30 se consigna la cantidad de capas de aerénquima y el alto del mismo observado en las semillas arqueológicas, pero su valor diagnóstico es dudoso, puesto que puede estar distorsionando los valores reales. El único caso donde este tejido brinda información fiable es en los ejemplares donde se registran más de dos capas, señalando de esta manera que no se trata de C. maxima ssp. andreana (Lámina 12).

Ninguna de las semillas analizadas corresponde a C. ficifolia, siendo todas afines a C. moschata, C. maxima o alguna de las subespecies de ésta última. El conjunto de semillas de Pampa Grande, afines a C. maxima ssp maxima en todos los casos, poseen en general esclereidas muy pequeñas, con rangos de medidas menores a las observadas en el material de referencia. Este menor 
tamaño se registra en ambos valores (alto y ancho) de las esclereidas, salvo en S2, S3 y S4 donde los valores son menores sólo para el ancho. La hipodermis también mostró una cantidad de capas muy reducida tanto en caras mayores como en margen, pudiendo asemejarse o ser menor a la cantidad registrada en C. maxima ssp andreana. Esto se condice con un escaso espesor para este tejido, aunque la presencia de células hipodérmicas colapsadas puede estar distorsionando este carácter. El limite entre hipodermis y epidermis si bien no muestra la marcada irregularidad que se detecta en ejemplares de C. moschata, tampoco es totalmente regular, mostrando un ingreso más o menos marcado de las células de la epidermis en la hipodermis. La presencia de arco submarginal en cuatro ejemplares $(\mathrm{QB}, \mathrm{QD}, 085$ y S5) indicaría que se trata de semillas semejantes al tipo III propuesto por Teppner (2004). Esto mismo se observó en la semilla 13 de Puento Rio La Viña I. A pesar de ello en ninguna de las semillas de Pampa Grande se observaron células largas a distintos aumentos, salvo en el caso de la semilla 085, única que podría corresponder a C. moschata y única recuperada en la caverna III.

El conjunto de semillas recuperadas en los sitios peruanos de Bandurria y Cerro Lampay posee una variabilidad de rasgos mucho mayor, por lo cual su identificación taxonómica se torna más imprecisa. A pesar de ello, en este grupo también se constató la presencia de esclereidas de tamaño pequeño e hipodermis con escasas capas de células tanto en margen como en caras mayores. En el caso de las esclereidas, ninguna posee paredes claramente más anchas que el lumen, siendo todas muy homogéneas. A pesar de ello, otros rasgos presentes en epidermis e hipodermis, se asemejan a lo observado en ejemplares actuales de C. moschata, por lo cual las semillas 425FA y 425FB de Bandurria y 1059 y 18/1235B de Cerro Lampay son afines tanto a esta especie como a C. maxima ssp maxima ante la ausencia de otros rasgos diagnósticos que permitan precisar la identificación. En el caso de la semilla 425FB de Bandurria llama la atención la presencia clara de células epidérmicas largas en 
el margen sin la presencia de arco submarginal, rasgo ausente en la colección de referencia estudiada y no mencionado en la bibliografía consultada. Este carácter no puede atribuirse a alteraciones sufridas por el material arqueológico, dado que las células epidérmicas largas se ubican por sobre el arco submarginal, por lo que si las primeras se conservaron, también debería haberlo hecho el segundo.

A pesar de las diferencias observadas con respecto al material de referencia, los conjuntos de semillas procedentes de un mismo sitio guardan una estrecha similitud entre sí, lo cual indica que no se está ante hechos excepcionales o aislados sino ante posibles patrones morfológicos diferentes a los actuales.

Finalmente cabe destacar que sólo en Cerro Lampay se recuperó una semilla identificada como C. maxima aff. ssp. andreana (Tabla 30, Lámina 11).

4b_Semillas arqueológicas carbonizadas.

Sitio Puente Río La Viña I (Tabla 31)

Este sitio formativo del Valle de Lerma destaca por el hallazgo de gran número de semillas y fragmentos de semillas de Cucurbita sp. carbonizadas. Dentro del conjunto se recuperaron cinco fragmentos correspondientes a extremos micropilares, los cuales no fueron analizados a nivel microscópico puesto que los rasgos diagnósticos se encuentran en la región C2 de la semilla de Cucurbita sp. Estos hallazgos coinciden con los resultados de la carbonización experimental donde se pudo ver que el extremo micropilar de las semillas es resistente a la degradación por exposición a altas temperaturas. En el caso de la semilla entera LV1 quedó expuesta la capa esclerenquimática, por lo cual no hay restos de hipodermis ni epidermis, en cambio en los 
fragmentos MA y MB se conservaron todos los tejidos constitutivos de la cubierta seminal.

En el caso de los fragmentos MA y MB el rango de valores para el alto de las esclereidas abarca los exhibidos tanto en muestras carbonizadas experimentalmente de C. maxima ssp. maxima como de C. maxima ssp. andreana. La cantidad de capas de hipodermis en el margen es similar a la hallada en esta última subespecie, en tanto la cantidad en caras mayores se encuentra en el rango registrado en la subespecie domesticada. En el fragmento $\mathrm{SD}$, en cambio, los rasgos para ambos tejidos (esclerénquima e hipodermis) coinciden con lo observado en C. maxima ssp. andreana. (Lámina 13). Las otras dos semillas enteras y el fragmento FA fueron identificados como C. maxima aff. ssp. maxima.

\section{El Shincal (Tabla 31)}

En este caso la preservación de la semilla recuperada en la plataforma ceremonial o ushnu es excepcional, lo cual se deba probablemente al carácter ritual del depósito, habiéndose interpretado que los restos vegetales fueron arrojados intencionalmente a un fogón realizado en una oquedad en el suelo que luego fue tapado con piedras (Capparelli et al 2007). Esto habría generado una atmósfera anaeróbica que permitió que se preservara -a diferencia de lo observado en las semillas del sitio Puente Río La Viña Irestos carbonizados amorfos de lo que probablemente fue una epidermis con células de paredes delgadas de C. maxima ssp. maxima, similar a la que se registra en ejemplares actuales del cultivar Zapallito (Lámina 13). Las evidencias de la buena preservación de esta semilla carbonizada hablan a favor de una atmósfera anaeróbica a partir de los ensayos experimentales de carbonización. 


\section{Campo del Pucará}

Tras el análisis arqueobotánico exhaustivo realizado por Oliszewski (2004) de los macrorrestos recuperados en Campo del Pucará (Andalgalá, Catamarca) la autora identifica un único ejemplar afín a Cucurbita sp. La semilla fue recuperada en el montículo mayor correspondiente a un sitio "Patrón Alamito" que por cronología relativa (seriación cerámica) y dataciones radiocarbónicas se ubica en la Fase II de Alamito (360-480 DC) (Oliszewaki 2004). Se trata de una pequeña semilla carbonizada (4 mm de longitud x $3 \mathrm{~mm}$ de latitud) en buen estado de conservación. Considerando la morfología general de la semilla, su tamaño y la presencia de células "arborescentes" en la cubierta seminal, la autora la identifica como C. maxima (Oliszewaki 2004). Este constituiría el registro más temprano de un macrorresto de Cucurbita sp. en el NOA. Gracias a la gentileza de la Dra. Oliszewski, se tuvo acceso a este ejemplar. Al realizar las observaciones de la micromorfología interna de la cubierta seminal (Figura 19a) se concluyó que el resto no corresponde al género Cucúrbita.

La semilla se determinó como aff a Solanum elaeagnifolium Cav. (Solanaceae), en base a caracteres de morfología externa, tamaño y cubierta seminal descriptos ya por otros autores (Edmonds 1983, Capparelli 1997, Dottori y Cosa 2003, 2007). A nivel microscópico se destaca la presencia de esclereidas prismáticas onduladas de gruesas paredes radiales totalmente lignificadas sin pseudopelos (figura 19a y b).

Por lo tanto a partir de este reestudio se descarta la pertenencia al género Cucurbita del material publicado hasta el presente para la localidad arqueológica de Campo del Pucará. 


\section{III- Análisis macroscópico de semillas de Cucurbita sp.}

\section{Introducción}

Caracteres cualitativos externos de las semillas de Cucurbita sp. (principalmente color y caracteres del margen y morfología del extremo micropilar) han sido empleados para identificar especies domesticadas (Lira Saade 1995). Los mismos fueron aplicados también para la identificación taxonómica de ejemplares arqueológicos en el caso de semillas no carbonizadas y en buen estado de preservación (Cutler and Whitaker 1961, Whitaker y Cutler 1971, Whitaker 1981, 1983, Decker y Wilson 1986). A pesar de ello, investigadores especializados en este género y autoridades reconocidas en la materia han afirmado que muchas veces estos caracteres no son adecuados para una distinción certera entre especies de Cucurbita ya que existe una enorme variabilidad en la morfología de las semillas dentro de una única especie (Cutler and Whitaker 1961, Whitaker 1980) y su aplicación a ejemplares arqueológicos sin el apoyo de caracteres cuantitativos puede llevar a identificaciones erróneas (Smith 2000).

En estudios arqueobotánicos posteriores de semillas de Cucurbita spp. se ha recurrido al empleo de medidas lineales tales como largo, ancho y espesor de las mismas para diferenciar formas silvestres de domesticadas (Decker y Wilson 1986, Cowan y Smith 1993, Newsom et. al 1993, Cowan 1997, Smith 2000, 2006), asumiéndose que existe una tendencia a que las semillas aumenten de tamaño a través de la evolución bajo domesticación. En el caso particular de Cucurbita spp. se planteó que el aumento en el tamaño podía ser el resultado de la selección cultural dirigida hacia semillas más grandes dado que las mismas eran consumidas (Decker y Wilson 1986), o bien que semillas más grandes están indirectamente reflejando la selección cultural de frutos de 
mayor tamaño, considerando que se ha comprobado que existe una correlación entre tamaño de semilla y de fruto (Cowan 1997). En este sentido Bisognin (2002) invierte los términos de la relación afirmando que entre los cambios sufridos bajo domesticación la selección de semillas más grandes pudo haber resultado en frutos más grandes. Como se mencionó en el capítulo 4.1 se asume también que semillas más grandes poseen embriones de mayor tamaño, lo cual representa una ventaja adaptativa en la siguiente estación de germinación en medios antrópicos (Decker y Wilson 1986). Otra posibilidad no mencionada en la bibliografía es la poliploidía, la cual tiene como consecuencia generalmente el aumento en el tamaño de los órganos (León 1968).

En cuanto al empleo de medidas lineales para el estudio de la domesticación, se ha procedido por lo general analizando en primer lugar el rango de medidas que exhiben ejemplares modernos de los taxa silvestres y domesticados, estableciendo una "línea de base" a partir de los mismos (Smith 2000) (ver capítulo 4.1). De esta manera semillas arqueológicas más grandes que el rango de medidas que exhiben las semillas silvestres actuales indicarían formas domesticadas (Smith 1997). Sin embargo cuando se amplía la base de referencia con mayor cantidad de ejemplares y se cuenta, por el contrario, con conjuntos pequeños de semillas arqueológicas, se reconoce que esta distinción no es tan taxativa: "El tamaño de la semilla por sí solo no le permite a uno distinguir las semillas actuales o arqueológicas de los zapallos pepo cultivados de los de poblaciones silvestres. Dado que el tamaño de las semillas de las ornamentales cultivadas parece más variable (como lo expresa el desvío estándar y el coeficiente de variación) ésta es una medida que difícilmente sea útil si uno se enfrenta a colecciones arqueológicas de una o unas pocas semillas. Nuevamente, mientras que es posible sugerir que las semillas arqueológicas de C. pepo más largas que $11 \mathrm{~mm}$ representan formas domesticadas (Smith 1992:45), una sola semilla más pequeña que $10 \mathrm{~mm}$ de 
largo puede venir tanto de un fruto silvestre como domesticado. En tales casos, el contexto arqueológico y el fechado directo juegan un rol importante en asignar un status silvestre versus domesticado" (Cowan y Smith 1993:43, n. t.). Por lo tanto en estos casos donde la variabilidad de valores de un carácter de la forma domesticada incluye a aquélla de la forma silvestre o la espontánea (algo muy usual como vimos en la sección precedente), es común que sólo una parte de dicho rango de valores de referencia (la que no presente solapamiento) permita afirmar con seguridad la presencia de la forma domesticada, mientras que la franja de solapamiento de valores impide afirmar si se trata de una forma silvestre o domesticada.

Otro caso es cuando las medidas de los ejemplares arqueológicos poseen un valor intermedio al registrado entre poblaciones silvestres y domesticadas en el presente, o bien cuando el rango de medidas de ejemplares arqueológicos abarca el de ambas poblaciones actuales. En estas situaciones se interpreta que se está ante formas malezoides resultado de la hibridación entre poblaciones silvestres y domesticadas (Gremillion 1993) o ante formas transcionales en un continuum de transformaciones (Pearsall 1989, Hillman y Davies 1999) (ver capíitulo 4.1).

Las medidas lineales también se han empleado para diferenciar cultivares pasados (Whitaker 1983), analizándose fundamentalmente la variabilidad presente en las mismas. Como se vió en el capítulo 4.1.1 la etapa inicial de domesticación estaría caracterizada por una tendencia a la disminución en el $\mathrm{CV}$ respecto de las poblaciones silvestres, luego este tenderá a aumentar por la coexistencia de formas silvestres y otras que exhiben rasgos novedosos, con la domesticación la variabilidad disminuiría por la presencia de fuertes presiones selectiva, pero con la generación de diversos cultivares la diversidad aumentaría nuevamente. Puede verse que no hay una tendencia lineal en la diversidad morfológica y que sus valores no son absolutos, sino relativos. A pesar de ello el empleo del CV ha demostrado ser de gran utilidad en estudios 
morfo-anatómicos y biométricos de domesticación vegetal (Cowan y Smith 1993, Gremillion 1993, Newson 1993).

Varios autores consideran sin embargo, que en poblaciones vegetales naturales la forma es menos variable y está menos sujeta a factores ambientales que el tamaño, por lo cual es más adecuado el uso de índices que el de medidas lineales (Mangafa y Kotsakis 1996). Esto se aplicaría particularmente a las semillas ya que en las mismas la forma es un rasgo genético más conservador que el tamaño (Kay et al. 1980).

Un estudio adecuado que utilice parámetros lineales debe considerar la variabilidad intrínseca de las poblaciones de la especie en estudio analizando cuáles pueden ser los factores que la determinan. Lamentablemente, este aspecto no ha sido plenamente desarrollado para las especies sudamericanas de este género (no así en el caso de C. pepo, ver por ejemplo Decker y Wilson 1986 y Smith 2000), ya sea con un registro apropiado de la variabilidad biométrica presente en las poblaciones actuales de diversas especies del género Cucurbita, como a través del análisis de factores ecológicos, fisiológicos y genéticos que generan o regulan dicha variabilidad. En el análisis morfométrico llevado a cabo en esta tesis se atenderá a la variabilidad infraespecífica presente en C. maxima ssp. andreana y C. maxima ssp. maxima. Con ello se pretende establecer criterios morfométricos válidos en la determinación taxonómica de material arqueobotánico atendiendo a la posibilidad de detectar formas transicionales en el registro arqueológico.

\section{Caracteres morfométricos de C. maxima ssp andreana.}

Estudios llevados a cabo en semillas de esta subespecie (Tabla 32) registraron valores que van de 6 a $10 \mathrm{~mm}$ de largo, llegando a $16 \mathrm{~mm}$ (Millán 1945) ${ }^{6} \mathrm{o}$

\footnotetext{
${ }^{6}$ Este autor incorpora en su muestra ejemplares de la localidad de Cruz del Eje que probablemente sean híbridos entre la subespecie espontánea y la domesticada (Lira Saade 1995, ver capitulo 4.1.1a), por lo tanto ciertos rasgos o medidas de las semillas mencionadas por este autor deben ser considerados con precaución.
} 
bien entre 8 y $9 \mathrm{~mm}$ de largo y $5 \mathrm{~mm}$ de ancho (Martínez Crovetto en Burkart 1974). Mucho más variable es la cantidad de semillas por fruto, de acuerdo con Ashworth (1997) el promedio es de 322,05 +/- 9.45, pero con un rango de variación muy amplio que va de 153 a 448 semillas por fruto. Esta variabilidad puede llegar a relacionarse con la correlación hallada por esta autora entre el aumento del ancho y largo del fruto de C. maxima ssp. andreana y el incremento en el número de semillas (Ashworth 1997).

En cuanto a la relación entre el tamaño del fruto y el tamaño de las semillas existen posiciones encontradas, afirmándose tanto la presencia de dicha correlación (Cowan 1997), como su ausencia (Cowan y Smith 1993).

También se exploró la posibilidad de que los tipos de polinización afectaran el vigor, peso, tamaño o cantidad de semillas de C. maxima ssp andreana, sin embargo a este respecto no se hallaron diferencias significativas ni en las características del fruto ni en las de las semillas (Ashworth y Galetto 2001). Estos mismos autores pudieron comprobar que frutos más grandes con más semillas se dan en suelos más fértiles (específicamente suelos cultivados) y que el mayor número de simientes se debe a este factor sin que esté influyendo la cantidad o fuente del polen recibido (propia o cruzada), el agente polinizador, o el número de óvulos por flores (Ashworth y Galetto 2001).

\section{Caracteres morfométricos de C. maxima ssp maxima.}

Los caracteres externos de las semillas de la subespecie domesticada pueden verse en la tabla 33, donde se aprecia que son mucho más variables que en la subespecie espontánea.

Whitaker y Jagger (1937) afiman que no hay evidencia de metaxenia (un efecto inmediato del polen sobre las características del fruto o de los caracteres generales de la semilla) en los zapallos y otras cucúrbitas. Esto mismo se confirmó en el caso de C. maxima ssp. andreana, como vimos 
anteriormente. Por el contrario estudios llevados a cabo en C. maxima ssp. maxima demostraron que la ausencia de polinización por parte de la abeja Apis mellifera en poblaciones de esta especie ocasionan resultados marcadamente negativos (Pasarelli 2002) (Tabla 34).

Como puede apreciarse, entonces, tanto para C. maxima ssp. andreana como para C. maxima ssp. maxima los datos métricos y cuantitativos son muy variables, siendo afectados por distintos caracteres medioambientales (principalmente suelo en el primer caso y polinizadores en el segundo). Separar este tipo de modificaciones de las acarreadas por la manipulación humana es por lo tanto crucial, por lo cual los resultados obtenidos de los estudios arqueobotánicos deben estar complementados en todo momento por información obtenida del resto del registro arqueológico.

En esta sección se explorará el potencial de rasgos biométricos macroscópicos en la discriminación de formas espontáneas no cultivadas, formas domesticadas y cultivos transicionales entre los restos de semillas arqueológicas de C. maxima ssp maxima y C maxima ssp andreana.

\section{Materiales y método.}

Para el estudio de la evolución bajo domesticación de C. maxima a través del análisis macroscópico de restos de semillas arqueológicas y de semillas de poblaciones actuales del mismo taxón tomadas como referencia, se siguió la metodología propuesta por Decker y Wilson (1986), Cowan y Smith (1993), Cowan (1997) y Smith (2000) quienes la emplearon para este tipo de análisis en C. реро. Por lo tanto los rasgos biométricos macroscópicos seleccionados para el análisis de semillas actuales y arqueológicas de C. maxima ssp maxima y $C$ maxima ssp andreana fueron el largo y el ancho como indicadores de tamaño y la relación entre ambos (ancho/largo) como indicador de forma. El espesor 
de la semilla es un rasgo que no resulta apropiado para el estudio de restos arqueológicos, sea porque sólo se preservan las cubiertas seminales o, en el caso de semillas enteras, porque dicho rasgo se modifica tanto por degradación y/o desecación en restos secos como por la exposición al fuego en restos carbonizados.

1) Análisis de semillas secas actuales.

De la colección de referencia se estudiaron un total de 212 semillas, consignándose el largo, ancho, e índice ancho/largo de cada una. De $C$. maxima ssp. maxima se estudiaron 152 semillas de distintos cultivares distribuidos según se indica en el gráfico 4. Se analizaron ademas 60 semillas de C. maxima ssp andreana, 20 por cada tipo de polinización (cruzada, autogama y libre).

2) Análisis de ejemplares experimentalmente carbonizados.

Se analizaron los cambios sufridos en los rasgos biométricos de semillas enteras y fragmentadas de C. maxima ssp. maxima y C. maxima ssp andreana tras la carbonización experimental de ejemplares expuestos a $300^{\circ} \mathrm{C}$ por 120 minutos en atmósfera aeróbica y anaeróbica (tabla 12).

3) Análisis de ejemplares arqueológicos.

3.a_Análisis de información bibliografica.

Se analizó la bibliografía publicada a fin de recopilar datos referidos a largo y ancho de semillas recuperadas en sitios arqueológicos del Area Andina Cento- 
Meridional identificadas como C. maxima, C. maxima ssp. maxima o C. maxima ssp. andreana.

3.b_Análisis de restos arqueobotánicos.

A partir de la identificación botánica de semillas arqueológicas secas y carbonizadas lograda tras el análisis micromorfológico (ver sección II de este capítulo), se seleccionaron aquellas afines a C. maxima, C. maxima ssp maxima o a C. maxima ssp andreana para su análisis macroscópico.Con tal fin se consideraron todas las semillas recuperadas en Pampa Grande y en Puente Río La Viña I, la semilla 13 de Los Viscos, un ejemplar de Bandurria (372F) y tres de Cerro Lampay (17/1248; 18/1235A y 13/1200). Se incluyeron en el análisis los tres restos de semillas de Cucurbita sp recuperados en el Sitio Puente del Diablo (SSalLap20, La Poma, Salta) (ver capítulo 3). Si bien no se pudieron efectuar análisis microscópicos de los restos de semillas de este último sitio, por sus caracteres externos (margen no pronunciado, extremo micropilar obtuso y ausencia de células largas bajo microscopio estereoscópico) se consideraron semejantes a $C$. maxima, por lo cual provisionalmente serán considerados como afines a dicha especie y, por lo tanto, incluidos en el análisis macroscópico. De estos 17 restos se midió el largo y ancho y se calculó el índice producto de la relación entre ambas medidas.

\section{Resultados}

1) Análisis de semillas secas actuales.

\section{1_ C. maxima ssp andreana}


Los resultados de las medidas lineales pueden verse en la tabla 35. La discriminación por tipo de polinización permitió ver que las semillas procedentes de frutos obtenidos por autogamia son menos largas y anchas, que las de polinización libre o cruzada. Esto no se refleja en el índice ancho/largo el cual es muy similar para los tres casos (0,66 para autógama; 0,67 para cruzada y 0,61 para libre) siendo el valor obtenido para la subespecie en general: $0,64+/-0,05$.

En los tres tipos de polinización el ancho ha resultado ser el carácter más homogéneo en C. maxima ssp. andreana (Gráfico 5). Esto coincide con lo expresado por Cowan y Smith (1993) en cuanto a que, en general, el ancho de la semilla es menos variable que el largo.

\section{2_ C. maxima ssp maxima}

En la tabla 36 se volcaron los datos obtenidos de las medidas de distintos cultivares de C. maxima ssp. maxima. Como puede apreciarse en la misma, los rangos de valores del cultivar Boliviano para el largo superan a los valores de los otros cuatro cultivares de la misma subespecie. Sin embargo, en el ancho hay solapamiento con los cultivares Criollo e Inglés. Lo contrario ocurre para los cultivares Zapallito y Hubbard, los cuales comparten valores en el rango de medidas del largo con otros cultivares, en tanto en el ancho se separan del resto de los cultivares, mostrando valores muy bajos, sin que haya solapamiento alguno con los restantes tres cultivares. Por lo tanto el ancho y el largo son igualmente heterogénos (gráfico 6).

En lo que respecta al índice ancho/largo, el mismo es también muy variable (0,69 para el cultivar Inglés; 065 para el cultivar Criollo; 052 para Hubbard; 061 para Zapallito y 052 para Boliviano), coincidendo incluso en el caso de los cultivares Criollo y Zapallito con los valores obtenidos para C. maxima ssp. 
andreana. El valor obtenido para C. maxima ssp maxima en general es de 0,56 $+/-0,08$.

Por lo tanto C. maxima ssp maxima destaca por una alta diversidad en tamaño y forma, lo cual lógicamente surge de considerar varios cultivares de rasgos disímiles.

1.3_ Comparación de los datos obtenidos para semillas actuales de ambas subespecies de $C$. maxima.

Los gráficos 7 y 8 muestran que ninguna de las medidas lineales se solapa entre ambas subespecies de C. maxima, por lo cual semillas de entre 13 y 30 $\mathrm{mm}$ de largo y entre 7 y y $17 \mathrm{~mm}$ de ancho corresponderán a $C$. maxima ssp maxima, en tanto semillas de entre 6,5 y $10 \mathrm{~mm}$ de largo y 4 y $6,5 \mathrm{~mm}$ de ancho corresponderan a C. maxima ssp. andreana.

Los gráficos 7 y 8 muestran también que la dispersión para las dos medidas lineales es mayor en C. maxima ssp. maxima, la cual posee además coeficientes de variación para ambas medidas mayores a lo registrado para C. maxima ssp. andreana (tablas 35 y 36). Si bien se ha señalado que la reducción en los coeficientes de variación de las medidas (es decir, medidas más estandarizadas, más homogéneas, con menor dispersión) es propia de las especies domesticadas, dicha tendencia se revierte cuando en el análisis de la forma domesticada se incluyen distintos cultivares morfológicamente disímiles (Cowan y Smith 1993, Newsom 1993) como los que caracterizan a C. maxima ssp. maxima. Para De Wet y Harlan (1975) la subespecie silvestre es frecuentemente tan variable morfológicamente como la subespecie cultivada. Esto se confirma cuando se comparan los valores de $\mathrm{CV}$ obtenidos para ancho y largo en C. maxima ssp andreana con cada cultivar de C. maxima ssp. maxima por separado. 
En el caso del índice ancho/largo los valores obtenidos para C. maxima ssp. maxima incluyen a los obtenidos para C. maxima ssp andreana. En este sentido parecería haber una contradicción con lo que se asume en la bibliografía en cuanto a que la "forma" es más constante en las poblaciones vegetales naturales que el "tamaño” (Mangafa y Kotsakis 1996, Kay et al. 1980). Sin embargo, el hecho de que ambos taxa sean parte de una misma especie, siendo además interfértiles, puede estar ocasionando una separación menos clara en lo que a "forma" se refiere.

Por lo tanto el ancho y el largo serán elementos útiles en la discriminación de semillas entre ambas variedades de C. maxima, no así el indice obtenido de la relación entre ambas medidas. Luego, valores de CV similares entre los conjuntos de semillas asignados a la subespecie espontánea y a la domesticada pueden indicar que en la segunda no hay más que un único cultivar. Por el contrario valores elevados de CV en la segunda pueden indicar la presencia de diversos cultivares formando parte de las poblaciones domesticadas.

2) Análisis de ejemplares experimentalmente carbonizados.

Tras una carbonización a $300^{\circ} \mathrm{C}$ por $120^{\prime}$-que, como vimos en la sección I, representan una carbonización con buenas posibilidades de conservación- se observaron reducciones en ambos parámetros métricos independientemente del tipo de atmósfera a la que fueron sometidos los ejemplares (Tabla 37).

Ambas subespecies sufren una reducción más acentuada en atmósfera aeróbica comparada con la registrada en atmósfera anaerobica, C. maxima ssp. andreana se reduce de forma más marcada en el ancho. En dicha subespecie, salvo en el largo bajo atmósfera anaeróbica, las reducciones son más acentuadas en el caso de semillas fragmentadas. En C. maxima ssp maxima, en cambio, las semillas fragmentadas se reducen en igual proporción o menos que las enteras, salvo en el caso del ancho bajo atmósfera aeróbica. 
Si se aplican los porcentajes de reducción obtenidos tras las carbonizaciones experimentales a las medidas de los ejemplares secos de referencia se obtiene una serie de rangos de tamaño (Tabla 38) que puede aplicarse en el reconocimiento de restos de semillas arqueológicas carbonizadas. De esta manera, semillas carbonizadas con un largo de entre 5 y $8 \mathrm{~mm}$ y un ancho de entre 3 y $6 \mathrm{~mm}$ corresponderán a la subespecie espontánea, en tanto aquellas con un largo de entre 10,5 y $25 \mathrm{~mm}$ y un ancho de entre 6 y $14 \mathrm{~mm}$ a la subespecie domesticada.

3) Análisis de ejemplares arqueológicos.

Los resultados de la aplicación de caracteres biométricos externos a semillas arqueológicas secas y carbonizadas pueden verse en la tabla 39. La información bibliografica se encuentra presentada en la tabla 40, habiéndose hallado datos métricos sólo para semillas de C. maxima ssp. maxima recuperadas en diversos sitos arqueológicos sudamericanos.

En la mayoría de los ejemplares consignados en las tablas 39 y 40 las medidas de ancho y largo coinciden con las registradas actualmente para C. maxima ssp maxima. Sólo en el caso del ejemplar de la Cueva Epullán Grande (tabla 40) ambas medidas coinciden con las actuales de C. maxima ssp. andreana. $\mathrm{La}$ cronología de esta cueva asignada al período colonial temprano a partir del hallazgo arqueológico de elementos posthispánicos (Urrutia y Bogáis 1996) hace pensar que esta semilla represente probablemente una población de la subespecie espontánea. De ser así -y si la semilla no fue transportada a esta localidad por factores antrópicos- este sería el registro más meridional de la subespecie andreana (ver capitulo 4.1.1b).

Se consignó la presencia de ejemplares (Co. Lampay 13/1200, Los Morrillos $\mathrm{N}^{\circ}$ 4, Sitio $\mathrm{M} \mathrm{N}^{\circ}$ 7) con rasgos métricos de posición intermedia respecto de la registrada actualmente en las dos subespecies de C. maxima, pero sólo en lo 
que refiere al largo de los mismos. También hay varias semillas arqueológicas, todas provenientes de sitios arqueológicos en territorio argentino (SSalLap20 C; LVi3; Los Morrillos $\mathrm{N}^{\circ}$, Cueva del Toro $\mathrm{N}^{\circ} 1$ ), donde cada una de las medidas lineales se corresponde con distintas subespecies, generalmente presentando valores que se corresponden con los valores extremos de las distribuciones actuales de C. maxima ssp. maxima o C. maxima ssp andreana. Estos siete ejemplares se pueden considerar por lo tanto como transicionales o intermedios en su posición relativa con respecto a las subespecies espontánea y domesticada. De este conjunto destaca la semilla 13/1200 de Cerro Lampay, la cual presenta rasgos microscópicos afines a C. maxima ssp andreana y rasgos macroscópicos intermedios entre los de ambas subespecies actuales.

En cuanto a las tendencias cronológicas, los gráficos 9 y 10 muestran que no hay una tendencia lineal o uniforme en ambas medidas analizadas a lo largo del tiempo.En el mismo sentido, ejemplares intermedios o transicionales tampoco se disponen en un lapso cronológico determinado estando presentes a todo lo largo de la secuencia temporal.

Por lo tanto la presencia de semillas con rasgos correspondientes tanto a la subespecie espontánea como a la domesticada, o intermedios entre ambas, no ocuparía un lugar fijo a lo largo de un continuum de transformaciones en la evolución bajo domesticación de C. maxima, hallándose este tipo de resto todo a lo largo de la secuencia cronológica indicada por los sitios arqueológicos.

En cuanto a los coeficientes de variaciación, se analizaron los sitios con conjuntos de cuatro o más semillas (Tabla 41). El sitio Los Morrillos resulta un caso interesante ya que no sólo cuenta con conjuntos de varias semillas de C. maxima, sino también con una cronología clara entre los mismos. Esto permite ver la presencia de una tendencia hacia la reducción del CV, la cual no es totalmente lineal sino que muestra reversiones en algunos lapsos temporales. Esta tendencia general se ve también en los sitios peruanos, ya 
que a medida que la cronología de los mismos es más reciente el CV tiende de manera no lineal- a disminuir, salvo en el último período previo a la conquista incaica donde aumenta notablemente, sobre todo en el largo. La tendencia a la disminución podría estar indicando una selección cultural tendiente a la fijación de un cierto conjunto limitado de rasgos en detrimento de una mayor diversidad inicial. En los valores de CV podría estar incidiendo también la presencia de ejemplares con caracteres intermedios como ocurre con el sitio Gruta de los Morrillos y el sitio M Chulpaca.

Los valores de CV para Pampa Grande son moderadamente elevados (valores intermedios entre los registrados en ejemplares de referencia de la subespecie espontánea y domesticada) lo cual podría estar indicando la presencia de más de un cultivar o de ejemplares con distinto grado de asociación con el Hombre.

\section{Discusión}

Los análisis llevados a cabo en este capítulo han permitido el estudio de semillas arqueológicas de Cucurbita spp. a partir de una colección de referencia con numerosos ejemplares representativos de los cuatro taxa susceptibles de ser hallados en el registro arqueológico de sitios del Área Andina Meridional. Los restos de semillas arqueológicas de éste genero no son particularmente abundantes en los sitios arqueológicos de Argentina, siendo por el contrario su número bastante elevado en sitios de la costa peruana (Bertone com. pers). Esta diferencia se debe probablemente a las excepcionales condiciones de preservación de la costa árida de Perú, donde se recupera una gran diversidad de restos en un estado de preservación excepcional (Caggiano y Sempé 1994). En el NOA, en cambio, la preservación de los macrorrestos es más variable, dependiendo fundamentalmente del área geográfica (puna, valles, faldeos orientales andinos, llanuras orientales) donde se emplazan los sitios 
arqueológicos. En este sentido los ensayos experimentales de carbonización realizados han permitido ver que las semillas de Cucurbita presentan una buena preservación a $300^{\circ} \mathrm{C}$, pero al elevarse la temperatura al doble, las mismas sufren una mayor alteración, transformándose en restos compuestos mayormente por cenizas. De acuerdo con los estudios de Braadbaart (2008), los fogones alcanzan temperaturas de entre $300^{\circ}$ a $600^{\circ}$, por lo cual cabe la posibilidad de que la escasez de restos de semillas en sitios del NOA se deba a su desaparición por contacto con el fuego. En esto se acordaría con la apreciaciones de Cowan (1997) acerca de que los restos de Cucurbita sp. son destruidos -más que preservados- por la carbonización. Asimismo esto explicaría los escasos restos de semillas carbonizadas de Cucurbita en sitios del NOA, habiéndose reportado hasta el momento hallazgos sólo en los sitios Puente Río La Viña I (Escobar 2008) y El Shincal (Capparelli 1997). En este último caso las condiciones anaeróbicas excepcionales de carbonización de la plataforma ritual o Ushnu habrían favorecido la conservación de este ejemplar junto a restos de un pedúnculo de Cucurbita sp. (ver capítulo 4.1.1e) y abundantes restos vegetales (Capparelli et al 2005). Finalmente puede considerarse un rol menor en el espectro de especies vegetales manipuladas en el pasado prehispánico del área.

El análisis de los tejidos que componen la cubierta seminal de las semillas de Cucurbita se mostró como una buena vía para identificarlas a nivel específico y subespecífico. Sin embargo, no todos los rasgos diagnósticos se preservan en los ejemplares arqueológicos, incluso en semillas secas y enteras con un buen estado de preservación como las recuperadas en sitios arqueológicos de la costa peruana. Así se constató que por lo general epidermis y aerénquima no se conservan, o lo hacen sólo parcialmente, perdurando en los restos algunas bases de células epidérmicas y las primeras capas de aerénquima. En otros casos la epidermis no se ha perdido, pero se presenta como una capa amorfa conformada por el conjunto de celulas rotas, de las cuales sólo quedan sus 
paredes colapsadas. En el caso de la hipodermis, las células son más resistentes, no se rompen, pero sufren una compresión que lleva a que las paredes celulares entren en contacto entre sí. El esclerénquima es el tejido que mostró mejor preservación, estando presente en todos los restos analizados y sin sufrir deformaciones notables. Estos rasgos de los diversos tejidos de la cubierta seminal se constataron por igual en ejemplares secos y carbonizados. Por lo tanto, empleando caracteres microscopicos se puede realizar la asignación taxónomica de los restos carbonizados del género Cucurbita salvando las dificultades señaladas por Cowan (1997) respecto a las posibilidades de identificación de los mismos.

El análisis microscópico de cubiertas seminales permitió ajustar identificaciones arqueológicas previas, confirmándose algunas (como en el caso de Pampa Grande) y modificándose otras (Los Viscos y Campo del Pucará). Esto, sumado a nuevas identificaciones, permitió el ajuste de la cronología de C. maxima en el NOA, siendo los restos más antiguos para el área Valliserrana los de Pampa Grande (con fechad directo AMS, ver capítulo 3) y no los de Campo del Pucará, de los publicados hasta el presente.

La micromorfología de la cubierta seminal de semillas arqueológicas identificadas como C. aff maxima, C. maxima aff ssp maxima o C. maxima aff ssp andreana permitió tambien la detección de rasgos que no estaban presentes en el material actual de referencia, fundamentalmente esclereidas e hipodermis reducidas. El análisis macroscópico de estas semillas arqueológicas a partir del registro biométrico en conjuntos de semillas actuales de referencia permitió ver que muchos de éstos macrorrestos poseen combinación de caracteres de ambas subespecies actuales o valores intermedios entre ambas. La combinación de abordajes de tipo macro y microscópico permitió no sólo la identificación taxonómica sino también el reconocimiento de formas intermedias que combinan rasgos presentes en sus referentes actuales o exhiben caracteres novedosos. En el caso del NOA los restos de la cueva Los 
Aparejos (sector III) y El Litro de Pampa Grande poseen caracteres microscópicos cercanos a $C$. maxima ssp. maxima y un rango de tamaño en largo y ancho de la semilla que coincide plenamente con la de esta subespecie. La unica excepción es el ejemplar 085 recuperado en la Caverna III, afin a $C$. moschata.o a C. maxima ssp maxima. El ejemplar C/2-224 de Puente del Diablo posee rasgos macroscópicos intermedios, el ejemplar SD de Puente Río La Viña I posee rasgos de su cubierta seminal afines a C. maxima ssp. andreana, en tanto el ejemplares LVi3 posee rasgos microscópicos afines a la subespecie domesticada y macroscópicos intermedios.

En el estudio de la domesticación vegetal existen rasgos que permiten distinguir entre especies o variedades ( $v g$. margen y extremo micropilar), y rasgos que -a la vez que permiten esto- dan información acerca de la asociación entre plantas y seres humanos en el pasado. Entre estos últimos se encuentra el tamaño de la semilla y de la cubierta seminal, los cuales pueden estar vinculados con la selección cultural tendiente a fijar caracteres deseados en semillas que se consumen, o bien ser el resultado de la adaptación de la planta a ambientes antrópicos de alta competencia por aumento en la densidad de ejemplares. La presencia de semillas arqueológicas de sitios del Area Andina Meridional con rasgos correspondientes tanto a la subespecie espontánea como a la domesticada, o intermedios entre ambas, no ocuparía un lugar fijo a lo largo de un continuum de transformaciones en la evolución bajo domesticación de C. maxima, hallándose este tipo de restos a lo largo de toda la secuencia cronológica indicada por los sitios arqueológicos aquí analizados. Por lo tanto la presencia de estas formas intermedias o transicionales a lo largo del tiempo indicaría la permanencia de posibles complejos maleza-cultivo-domesticado. Sí se detectó, en cambio, una tendencia a la disminución del $\mathrm{CV}$ en el tiempo. Esto último podría estar indicando la fijación de un número reducido de caracteres culturalmente 
seleccionados sin que ello implique la eliminación de formas intermedias o transicionales. 
Tabla 12: cantidad de semillas enteras y fragmentadas (en mitades) empleadas en la carbonización experimental, según temperatura/tiempo y atmósfera. Aer= atmósfera aeróbica; $\mathrm{An}=$ atmósfera anaeróbica.

\begin{tabular}{|c|c|c|c|c|c|c|c|}
\hline \multirow{2}{*}{\multicolumn{2}{|c|}{$\begin{array}{l}{ }^{\circ} \mathrm{C} / \text { tiempo } \\
\text { Atmósfera }\end{array}$}} & \multicolumn{2}{|c|}{$300 \% 120^{\prime}$} & \multicolumn{2}{|c|}{$600^{\circ} / 60^{\prime}$} & \multicolumn{2}{|c|}{$800^{\circ} / 45^{\prime}$} \\
\hline & & Aer & An & Aer & An & Aer & An \\
\hline \multirow{2}{*}{ C. maxima ssp maxima cv criollo } & Enteras & 3 & 3 & 3 & 3 & 2 & 2 \\
\hline & Fragmentadas & 2 & 2 & 1 & 1 & 1 & 1 \\
\hline \multirow{2}{*}{ C. maxima ssp. andreana } & Enteras & 3 & 3 & 3 & 3 & 2 & 2 \\
\hline & Fragmentadas & 2 & 2 & 1 & 1 & 1 & 1 \\
\hline \multirow{2}{*}{ C. moschata } & Enteras & 3 & 3 & 3 & 3 & 2 & 2 \\
\hline & Fragmentadas & 2 & 2 & 1 & 1 & 1 & 1 \\
\hline \multirow{2}{*}{ C. ficifolia } & Enteras & 2 & 2 & 3 & 3 & 2 & 2 \\
\hline & Fragmentadas & 1 & 1 & 1 & 1 & 1 & 1 \\
\hline
\end{tabular}

Tabla 13: análisis del espesor proporcional de las cubiertas seminales. Las medidas presentadas son promedio de dos medidas en el caso del espesor de la semilla y de seis medidas en el caso del espesor de la cubierta seminal.

\begin{tabular}{|c|c|c|c|}
\hline Taxa & Variables & mm & $\begin{array}{c}\text { \% de cubierta } \\
\text { seminal }\end{array}$ \\
\hline $\begin{array}{c}\text { C. maxima ssp. } \\
\text { andreana }\end{array}$ & $\begin{array}{c}\text { espesor de la semilla en corte transversal } \\
\text { espesor de la cubierta en corte transversal }\end{array}$ & 1,46 & 0,13 \\
\hline $\begin{array}{c}\text { C. maxima ssp. } \\
\text { maxima cv. criollo }\end{array}$ & espesor de la semilla en corte transversal & 5,13 & $29,04 \%$ \\
\hline $\begin{array}{c}\text { C. maxima ssp. } \\
\text { maxima cv. } \\
\text { hubbard }\end{array}$ & espesor de la semilla en corte transversal & 1,49 & $12,91 \%$ \\
\hline $\begin{array}{c}\text { C. maxima ssp. } \\
\text { maxima cv.ingles }\end{array}$ & espesor de la cubierta en corte transversal & 4,26 & $7,50 \%$ \\
\hline $\begin{array}{c}\text { C. maxima ssp. } \\
\text { maxima }\end{array}$ & espespor de la cubierta en corte transversal & 0,55 & $13,36 \%$ \\
\hline
\end{tabular}


Tabla 14: caracteres cuantitativos de células epidermicas. Tomado de Singh y Dathan 1972. $\mathrm{L}=\operatorname{largo} ; \mathrm{B}=$ ancho.

\begin{tabular}{|c|c|}
\hline Taxa & Epidermis Lx B en $\mu \mathrm{m}$ (caras mayores) \\
\hline C. moschata & $250 \times 30$ \\
\hline C. maxima ssp. maxima & $625 \times 60$ \\
\hline C. maxima ssp. andreana & $125 \times 25$ \\
\hline C. ficifolia & $230 \times 75$ \\
\hline
\end{tabular}

Tabla 15: largo de células epidérmicas. Las medidas están en micrones (um); d.s.: desvío estándar; max.: valores máximos dentro del rango de distribución de medidas; min.: valores mínimos dentro del rango de distribución de medidas; cv: coeficiente de variación.

\begin{tabular}{|c|cccccc|}
\hline Taxa & $\begin{array}{c}\text { Cantidad } \\
\text { de } \\
\text { medidas }\end{array}$ & Promedio & d.s. & max. & min. & cv. \\
\hline C. maxima ssp. maxima cv. ingles & 20 & 258,97 & 20,81 & 303,5 & 216,9 & 8,04 \\
C. maxima ssp. maxima cv.criollo & 10 & 725,72 & 11,94 & 743,7 & 705,4 & 1,64 \\
C. maxima ssp. maxima cv. hubbard & 17 & 186,74 & 19,27 & 221,6 & 157,2 & 10,32 \\
C. maxima ssp. maxima cv. zapallito & 5 & 152,24 & 4,14 & 158,1 & 147,4 & 2,72 \\
C. maxima ssp. maxima (gral.) & 52 & 314,85 & 206,62 & 743,7 & 147,4 & 65,62 \\
C. maxima ssp. andreana & 7 & 270,07 & 39,3 & 314,9 & 241,6 & 14,55 \\
C. moschata & 5 & 366,4 & 16,57 & 389,5 & 351,1 & 4,52 \\
C. ficifolia & 14 & 128,37 & 13,47 & 157,1 & 105,7 & 10,49 \\
\hline
\end{tabular}

Tabla 16: ancho de células epidérmicas Las medidas están en micrones (um); d.s.: desvío estándar; max.: valores máximos dentro del rango de distribución de medidas; min.: valores mínimos dentro del rango de distribución de medidas; cv: coeficiente de variación

\begin{tabular}{|c|cccccc|}
\hline Taxa & $\begin{array}{c}\text { Cantidad } \\
\text { de medidas }\end{array}$ & Promedio & d.s. & max. & min. & cv. \\
\hline C. maxima ssp. maxima cv. ingles & 19 & 34,19 & 4,91 & 40,2 & 24,4 & 14,36 \\
C. maxima ssp. maxima cv.criollo & 22 & 43,87 & 8,44 & 67,7 & 28 & 19,24 \\
C. maxima ssp. maxima cv. hubbard & 21 & 41,93 & 7,37 & 56,1 & 29,3 & 17,58 \\
C. maxima ssp. maxima (gral.) & 62 & 40,25 & 8,16 & 67,7 & 24,4 & 20,27 \\
C. maxima ssp. andreana & 6 & 30,33 & 6,36 & 40 & 22 & 20,98 \\
C. moschata & 6 & 65,65 & 13,7 & 84,4 & 44,3 & 20,84 \\
C. ficifolia & 15 & 51,97 & 14,4 & 80 & 29,9 & 27,66 \\
\hline
\end{tabular}


Tabla 17: caracteres de la epidermis de la cubierta seminal útiles en la distinción de taxa sudamericanos de Cucurbita sp.

\begin{tabular}{|c|c|c|c|c|}
\hline & $\begin{array}{l}\text { Cucurbita maxima } \\
\text { ssp. maxima }\end{array}$ & $\begin{array}{l}\text { Cucurbita maxima } \\
\text { ssp. andreana }\end{array}$ & $\begin{array}{l}\text { Cucurbita } \\
\text { moschata }\end{array}$ & Cucurbita ficifolia \\
\hline Epidermis & $\begin{array}{l}\text { Las células largas } \\
\text { forman una } \\
\text { protuberancia, } \\
\text { cubren un tercio del } \\
\text { margen o lo rodean } \\
\text { por completo. } \\
\text { Células } \\
\text { rectangulares y en } \\
\text { empalizada de } \\
\text { paredes gruesas o } \\
\text { delgadas. } \\
\text { Con o sin arco } \\
\text { submarginal } \\
\text { Largo: } 147-744 \mu \mathrm{m} \\
\text { Ancho: } 24-68 \mu \mathrm{m}\end{array}$ & $\begin{array}{c}\text { Las células largas no } \\
\text { rodean a las células } \\
\text { cortas en el margen } \\
\text { y hacen una } \\
\text { protuberancia } \\
\text { pequeña que puede } \\
\text { ser imperceptible. } \\
\text { Células } \\
\text { rectangulares y en } \\
\text { empalizada de } \\
\text { paredes delgadas. } \\
\text { Largo: } 242-315 \mu \mathrm{m} \\
\text { Ancho: } 22-40 \mu \mathrm{m}\end{array}$ & $\begin{array}{c}\text { Las células largas } \\
\text { rodean } \\
\text { completamente a las } \\
\text { cortas. En cortes } \\
\text { más cercanos a los } \\
\text { extremos de la } \\
\text { semilla estas células } \\
\text { largas pueden } \\
\text { disponerse a manera } \\
\text { de "cuernos" que no } \\
\text { cubren a las células } \\
\text { cortas. Células } \\
\text { rectangulares y } \\
\text { dispuestas en } \\
\text { empalizada de } \\
\text { paredes gruesas. } \\
\text { Largo: } 351-389 \mu \mathrm{m} \\
\text { Ancho: } 44-84 \mu \mathrm{m}\end{array}$ & $\begin{array}{l}\text { Las células largas } \\
\text { rodean por completo a } \\
\text { las cortas. Células } \\
\text { rectangulares en } \\
\text { empalizada de paredes } \\
\text { delgadas. } \\
\text { Largo: } 106-157 \mu \mathrm{m} \\
\text { Ancho: } 30-80 \mu \mathrm{m}\end{array}$ \\
\hline
\end{tabular}

Tabla 18: Cantidad de capas celulares que constituyen el tejido hipodermico. Tomado de Singh y Dathan 1972

\begin{tabular}{|c|c|}
\hline Especies & $\mathbf{N}^{\mathbf{0}}$ de capas en hipodermis (caras mayores) \\
\hline C. moschata & 2 a 4 \\
\hline C. maxima ssp. maxima & 4 a 5 \\
\hline C. maxima ssp. andreana & 2 a 3 \\
\hline C. ficifolia & 4 a 6 \\
\hline
\end{tabular}

Tabla 19: cantidad de capas en el tejido hipodérmico observadas en caras mayores, las cantidades menos frecuentes se señalan entre paréntesis

\begin{tabular}{|c|c|}
\hline Especies & $\mathbf{N}^{\circ}$ de capas en hipodermis \\
\hline C. moschata & 2 a $4(5)$ \\
\hline C. maxima ssp. maxima & 3 a $4(5)$ \\
\hline C. maxima ssp. andreana & 2 a $3(4)$ \\
\hline C. ficifolia & 3 a $4(5)$ \\
\hline
\end{tabular}


Tabla 20: diámetro de células hipodérmicas. Medidas en en micrones; d.s.: desvío estándar; max.: valores máximos dentro del rango de distribución de medidas; min.: valores mínimos dentro del rango de distribución de medidas; cv: coeficiente de variación

\begin{tabular}{|c|c|c|c|c|c|c|}
\hline \multirow[b]{3}{*}{ C. maxima ssp. maxima cv. ingles } & \multirow{2}{*}{$\begin{array}{l}\text { Cantidad de } \\
\text { medidas }\end{array}$} & \multicolumn{5}{|c|}{ Diámetro de células hipodérmicas } \\
\hline & & Promedio & d.s. & $\max$. & $\min$. & cv. \\
\hline & 10 & 10,11 & 2,88 & 14,2 & 5,9 & 28,5 \\
\hline C. maxima ssp. maxima cv.criollo & 15 & 10 & 2,71 & 15,3 & 4,7 & 27,15 \\
\hline C. maxima ssp. maxima cv. hubbard & 11 & 8,99 & 1,76 & 11,3 & 6,2 & 19,59 \\
\hline C. maxima ssp. maxima cv.zapallito & 11 & 9,55 & 3,11 & 13,7 & 5,7 & 32,58 \\
\hline C. maxima ssp. maxima (gral.) & 47 & 9,68 & 2,62 & 15,3 & 4,7 & 27,01 \\
\hline C. maxima ssp. andreana & 11 & 7,25 & 1,78 & 9,76 & 4,93 & 24,6 \\
\hline
\end{tabular}

Tabla 21: espesor del tejido hipodérmico en caras mayores. Medidas en $\mu \mathrm{m}$ Las medidas están en micrones $(\mu \mathrm{m})$; d.s.: desvío estándar; max.: valores máximos dentro del rango de distribución de medidas; min.: valores mínimos dentro del rango de distribución de medidas; cv: coeficiente de variación

\begin{tabular}{|c|c|c|c|c|c|c|}
\hline \multirow{4}{*}{$\begin{array}{l}\text { C. maxima ssp. maxima cv. ingles } \\
\text { C. maxima ssp. maxima cv.criollo }\end{array}$} & \multirow{2}{*}{$\begin{array}{l}\text { Cantidad de } \\
\text { medidas }\end{array}$} & \multicolumn{5}{|c|}{ Espesor del tejido hipodérmico } \\
\hline & & Promedio & d.s. & $\max$. & $\min$. & CV. \\
\hline & 9 & 56,22 & 12,1 & 75,1 & 40,5 & 21,43 \\
\hline & 10 & 46,9 & 9,14 & 58,7 & 32,8 & 19,48 \\
\hline C. maxima ssp. maxima cv. hubbard & 10 & 41,1 & 7,4 & 50 & 27,2 & 17,99 \\
\hline C. maxima ssp. maxima cv.zapallito & 12 & 35,08 & 5,43 & 43,3 & 26,5 & 15,48 \\
\hline C. maxima ssp. maxima (gral.) & 41 & 44,07 & 11,4 & 75,1 & 26,5 & 25,87 \\
\hline C. maxima ssp. andreana & 19 & 34,29 & 6,45 & 46,6 & 23,6 & 18,82 \\
\hline
\end{tabular}


Tabla 22: caracteres de la hipodermis de la cubierta seminal útiles en la distinción de taxa sudamericanos de Cucurbita sp.

\begin{tabular}{|c|c|c|c|c|}
\hline & $\begin{array}{c}\text { Cucurbita } \\
\text { máxima ssp. } \\
\text { maxima }\end{array}$ & $\begin{array}{c}\text { Cucurbita } \\
\text { maxima ssp. } \\
\text { andreana }\end{array}$ & Cucurbita moschata & Cucurbita ficifolia \\
\hline Hipodermis & $\begin{array}{c}\text { Márgenes: La } \\
\text { transición entre las } \\
\text { capas de células } \\
\text { en las caras } \\
\text { mayores y el } \\
\text { margen no es } \\
\text { abrupta. Capas: } 7 \\
\text { a } 8 \\
\text { Caras mayores: el } \\
\text { límite con la } \\
\text { epidermis es } \\
\text { regular. Capas: } 3 \text { a } \\
4 \text { (5). Espesor } \\
\text { tejido: } 26-75 \mu \mathrm{m} \\
\text { Diámetro de las } \\
\text { células: } 5-15 \mu \mathrm{m}\end{array}$ & $\begin{array}{c}\text { Márgenes: La } \\
\text { transición entre las } \\
\text { capas de células } \\
\text { en las caras } \\
\text { mayores y el } \\
\text { margen no es } \\
\text { abrupta. Capas: } 5 \\
\text { a } 7 \\
\text { Caras mayores: el } \\
\text { límite con la } \\
\text { epidermis es } \\
\text { regular. Capas: } 2 \text { a } \\
3 \text { (4). Espesor } \\
\text { tejido: } 24-47 \mu \mathrm{m} \\
\text { Diámetro de las } \\
\text { células: } 5-10 \mu \mathrm{m}\end{array}$ & $\begin{array}{c}\text { Márgenes: Notorio } \\
\text { aumento de la cantidad } \\
\text { de células en el } \\
\text { margen. Capas: } 7 \text { ( } 9 \text { a } \\
\text { 10) } \\
\text { Caras mayores: El } \\
\text { contacto con la } \\
\text { epidermis es sinuoso } \\
\text { ya que las bases de las } \\
\text { células epidérmicas se } \\
\text { hallan a alturas muy } \\
\text { variables. Capas: } 2 \text { a } 4 \\
\text { (5). }\end{array}$ & $\begin{array}{c}\text { Márgenes: Notorio } \\
\text { aumento de la cantidad } \\
\text { de células en el } \\
\text { margen. Capas: } 7 \text { (9 a } \\
10) \\
\text { Caras mayores: El } \\
\text { límite con la epidermis } \\
\text { es irregular } \\
\text { describiendo "ondas" } \\
\text { que coinciden con las } \\
\text { bases de las células } \\
\text { epidérmicas. Capas: } 3 \text { a } \\
4(5) \text {. }\end{array}$ \\
\hline
\end{tabular}

Tabla 23: $\operatorname{largo}(\mathrm{L})$ y ancho (B) de esclereidas. Tomado de Singh y Dathan 1972 (se asume que estas medidas debieron ser tomadas en corte longitudinal tangencial de la semilla)

\begin{tabular}{|l|c|c|c|c|}
\hline & C. maxima ssp. maxima & C. maxima ssp. andreana & C. moschata & C. ficifolia \\
\hline L & $550+/-50$ & 175 & $400+/-50$ & $400+/-50$ \\
\hline B & $100+/-25$ & 50 & $100+/-25$ & $100+/-25$ \\
\hline
\end{tabular}


Tabla 24: largo de esclereidas en corte longitudinal tangencial. Medidas en $\mu \mathrm{m}$ Las medidas están en micrones (um); d.s.: desvío estándar; max.: valores máximos dentro del rango de distribución de medidas; min.: valores mínimos dentro del rango de distribución de medidas; cv: coeficiente de variación

\begin{tabular}{|c|cccccc|}
\hline Taxa & $\begin{array}{c}\text { Cantidad } \\
\text { de } \\
\text { medidas }\end{array}$ & Promedio & d.s. & max. & min. & cv. \\
\hline C. maxima ssp. maxima cv.criollo & 39 & 349,01 & 76,03 & 587,88 & 208,69 & 21,78 \\
C. maxima ssp. andreana & 39 & 233,55 & 51,3 & 365,64 & 146,12 & 21,97 \\
\hline
\end{tabular}

Tabla 25: alto de esclereidas en corte transversal. Las medidas están en micrones (um); d.s.: desvío estándar; max.: valores máximos dentro del rango de distribución de medidas; min.: valores mínimos dentro del rango de distribución de medidas; cv: coeficiente de variación

\begin{tabular}{|c|cccccc|}
\hline Taxa & Cantidad de & Promedio & d.s. & max. & min. & cv. \\
& medidas & & & & & \\
\hline C. maxima ssp. maxima (gral.) & 73 & 91,16 & 15,29 & 125,4 & 66,8 & 16,77 \\
C. maxima ssp. andreana & 32 & 81,25 & 7,89 & 95,4 & 65,4 & 9,71 \\
C. moschata & 53 & 58,32 & 4,03 & 67,3 & 50,4 & 6,9 \\
C. ficifolia & 35 & 65,57 & 4,88 & 74,8 & 56,3 & 7,44 \\
\hline
\end{tabular}

Tabla 26: ancho de esclereidas en corte transversal. Las medidas están en micrones (um); d.s.: desvío estándar; max.: valores máximos dentro del rango de distribución de medidas; min.: valores mínimos dentro del rango de distribución de medidas; cv: coeficiente de variación.

\begin{tabular}{|c|cccccc|}
\hline Taxa & $\begin{array}{c}\text { Cantidad de } \\
\text { medidas }\end{array}$ & Promedio & d.s. & max. & min. & cv. \\
\hline C. maxima ssp. maxima (gral.) & 16 & 68,88 & 11,2 & 85,9 & 52,8 & 16,32 \\
C. maxima ssp. andreana & 12 & 62,88 & 12,8 & 89,2 & 48,8 & 20,27 \\
C. moschata & 7 & 49,63 & 3,43 & 53,6 & 44,3 & 6,91 \\
C. ficifolia & 16 & 10,34 & 2,45 & 14,3 & 5,7 & 23,73 \\
\hline
\end{tabular}


Tabla 27: caracteres del esclerénquima de la cubierta seminal útiles en la distinción de taxa sudamericanos de Cucurbita sp.

\begin{tabular}{|c|c|c|c|c|}
\hline & $\begin{array}{l}\text { Cucurbita máxima } \\
\text { ssp. maxima }\end{array}$ & $\begin{array}{c}\text { Cucurbita } \\
\text { maxima ssp. } \\
\text { andreana }\end{array}$ & $\begin{array}{l}\text { Cucurbita } \\
\text { moschata }\end{array}$ & $\begin{array}{l}\text { Cucurbita } \\
\text { ficifolia }\end{array}$ \\
\hline Esclerenquima & $\begin{array}{c}\text { Corte longitudinal: } \\
\text { esclereidas largas 209- } \\
588 \mu \mathrm{m} \\
\text { Corte transversal: } \\
\text { esclereidas regulares } \\
\text { (círculos).Paredes } \\
\text { uniformes y lumen } \\
\text { amplio. Alto: } 67-125 \mu \mathrm{m} \\
\text { Ancho: } 53-86 \mu \mathrm{m}\end{array}$ & 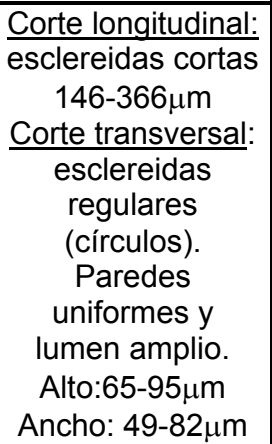 & $\begin{array}{l}\text { Corte transversal: } \\
\text { esclereidas de } \\
\text { escaso lumen y } \\
\text { paredes muy } \\
\text { engrosadas, } \\
\text { regulares y de } \\
\text { escaso alto. } \\
\text { Alto:50-67 } \mu \mathrm{m} \\
\text { Ancho: } 44-54 \mu \mathrm{m}\end{array}$ & $\begin{array}{c}\text { Corte transversal: } \\
\text { esclereidas de } \\
\text { paredes muy } \\
\text { delgadas y lumen } \\
\text { amplio. Muy } \\
\text { irregulares (no } \\
\text { circulares) } \\
\text { Muy angostas. } \\
\text { Alto: } 56-75 \mu \mathrm{m} \\
\text { Ancho: } 6-14 \mu \mathrm{m}\end{array}$ \\
\hline
\end{tabular}

Tabla 28: caracteres del aerénquima de la cubierta seminal útiles en la distinción de taxa sudamericanos de Cucurbita sp. Las medidas están en micrones (um); d.s.: desvío estándar; max.: valores máximos dentro del rango de distribución de medidas; min.: valores mínimos dentro del rango de distribución de medidas; cv: coeficiente de variación

\begin{tabular}{|c|cccccc|}
\hline Taxa & $\begin{array}{c}\text { Cantidad de } \\
\text { medidas }\end{array}$ & Promedio & d.s. & max. & min. & cv. \\
\hline C. maxima ssp. maxima (gral.) & 37 & 179,16 & 54,02 & 208 & 149,6 & 25,83 \\
C. maxima ssp. andreana & 22 & 45,77 & 8,34 & 54,2 & 31,5 & 18,17 \\
C. moschata & 18 & 135,69 & 47,83 & 149,7 & 100,5 & 22,4 \\
C. ficifolia & 29 & 78,92 & 50,05 & 98,9 & 55,4 & 20,62 \\
\hline
\end{tabular}


Tabla 29: cambios sufridos en los tejidos de la cubierta seminal de diversas especies de Cucúrbita sudamericanas tras carbonización aeróbica a $300^{\circ}$ por 120 minutos. En la columna "reducción/aumento" se indica el porcentaje de incremento (señalado con un signo +) o disminución (señalado con un signo -) respecto a los valores promedios obtenidos en ejemplares secos.

\begin{tabular}{|c|c|c|c|c|c|c|c|c|}
\hline & \multicolumn{4}{|c|}{ Epidermis } & \multicolumn{2}{|c|}{ Esclereidas } & \multicolumn{2}{|c|}{ Aerénquima } \\
\hline & Largo & $\begin{array}{c}\text { Reducció } \\
\text { n/aument } \\
0\end{array}$ & $\begin{array}{c}\text { Anch } \\
0\end{array}$ & $\begin{array}{l}\text { Reducción/ } \\
\text { aumento }\end{array}$ & Alto & $\begin{array}{l}\text { Reduc } \\
\text { ción/au } \\
\text { mento }\end{array}$ & Alto & $\begin{array}{l}\text { Reducción/ } \\
\text { aumento }\end{array}$ \\
\hline C. moschata & $\begin{array}{c}276+/- \\
8 \mu \mathrm{m} \\
(260- \\
288 \\
\mu \mathrm{m})\end{array}$ & $-24.5 \%$ & $\begin{array}{l}43+/- \\
5 \mu \mathrm{m} \\
(35- \\
50 \mu \mathrm{m})\end{array}$ & $-35 \%$ & $\begin{array}{c}46+/-2 \\
\mu \mathrm{m}(42- \\
50 \mu \mathrm{m})\end{array}$ & $-21,6 \%$ & $\begin{array}{l}66+/-13 \mu \mathrm{m} \\
(50-85 \mu \mathrm{m})\end{array}$ & $-48,7 \%$ \\
\hline $\begin{array}{l}\text { C. maxima } \\
\text { ssp. maxima } \\
\text { cv. criollo }\end{array}$ & $\begin{array}{c}573+/- \\
40 \mu \mathrm{m} \\
(506- \\
618 \\
\mu \mathrm{m}) \\
\end{array}$ & $-21 \%$ & $\begin{array}{l}37+/- \\
5 \mu \mathrm{m} \\
(24- \\
48 \mu \mathrm{m})\end{array}$ & $-16 \%$ & $\begin{array}{c}80+/-8 \\
\mu \mathrm{m}(68- \\
94 \mu \mathrm{m})\end{array}$ & $-12,1 \%$ & $\begin{array}{l}94+/-22 \mu \mathrm{m} \\
(59-127 \mu \mathrm{m})\end{array}$ & $-47,4 \%$ \\
\hline $\begin{array}{c}\text { C. maxima } \\
\text { ssp. } \\
\text { andreana }\end{array}$ & $\begin{array}{c}\text { Sin } \\
\text { datos }\end{array}$ & Sin datos & $\begin{array}{c}13+/- \\
3 \mu \mathrm{m} \\
(9- \\
16 \mu \mathrm{m})\end{array}$ & $-58 \%$ & $\begin{array}{c}55+/-2 \\
\mu \mathrm{m}(50- \\
60 \mu \mathrm{m})\end{array}$ & $-32,2 \%$ & $\begin{array}{l}36+/-6 \mu \mathrm{m} \\
(26-47 \mu \mathrm{m})\end{array}$ & $-21,7 \%$ \\
\hline C. ficifolia & $\begin{array}{c}\text { Sin } \\
\text { datos }\end{array}$ & Sin datos & $\begin{array}{l}63+/- \\
5 \mu \mathrm{m} \\
(59- \\
66 \mu \mathrm{m})\end{array}$ & $+17 \%$ & $\begin{array}{c}50+/-3 \\
\mu \mathrm{m}(45- \\
54 \mu \mathrm{m})\end{array}$ & $-23,5 \%$ & $\begin{array}{l}83+/-4 \mu \mathrm{m} \\
(80-88 \mu \mathrm{m})\end{array}$ & $+5,2 \%$ \\
\hline
\end{tabular}


Tabla 30: caracterización del margen y tejidos de la cubierta seminal de semillas arqueológicas desecadas recuperadas en sitios argentinos y peruanos. En el caso de la hipodermis, tanto en margen como en caras mayores, se consigna la cantidad de capas observadas entre corchetes, colocándose entre paréntesis la cantidad más inusual. En el caso de alto y ancho de esclereidas, alto y ancho de células epidérmicas y alto del aerénquima e hipodermis se consigna el valor promedio y entre paréntesis el rango. En el caso de que se consigne un único valor sin rango entre paréntesis es debido a la existencia de una única medida ante la imposibilidad de realizar un mayor número de mediciones dado el estado de preservación del ejemplar analizado

\begin{tabular}{|c|c|c|c|c|c|c|c|c|c|c|c|}
\hline \multirow{3}{*}{ Muestra } & \multicolumn{4}{|c|}{ Margen } & \multicolumn{6}{|c|}{ Caras mayores } & \multirow{3}{*}{$\begin{array}{c}\text { Identificación } \\
\text { taxonómica }\end{array}$} \\
\hline & \multirow{2}{*}{$\begin{array}{l}\text { Morfología } \\
\text { general }\end{array}$} & \multirow{2}{*}{$\begin{array}{c}\text { Cel. largas/cel. } \\
\text { cortas } \\
\text { epidérmicas }\end{array}$} & \multirow{2}{*}{$\begin{array}{c}\text { Arco } \\
\text { submarginal }\end{array}$} & \multirow[t]{2}{*}{ Hipodermis } & \multicolumn{2}{|c|}{$\begin{array}{c}\text { Células } \\
\text { epidérmicas }\end{array}$} & \multirow[t]{2}{*}{ Hipodermis } & \multicolumn{2}{|c|}{ Esclereidas } & \multirow[t]{2}{*}{ Aerénquima } & \\
\hline & & & & & Alto & Ancho & & Alto & Ancho & & \\
\hline $\begin{array}{l}\text { Los } \\
\text { Viscos } 25 \\
\text { (Lámina } \\
12)\end{array}$ & Redondeado & $\begin{array}{l}\text { Cel largas bajo } \\
\text { microscopio } \\
\text { estereoscópico } \\
\text { No se observan } \\
\text { cel. } \\
\text { epidérmicas en } \\
\text { MEB }\end{array}$ & $\mathrm{Si}$ & 4 & No s & onserva & $\begin{array}{c}38,6 \mu \mathrm{m}(28- \\
54,5 \mu \mathrm{m}) \\
{[5]} \\
\text { Limite } \\
\text { irregular con } \\
\text { epidermis }\end{array}$ & $\begin{array}{c}68 \mu \mathrm{m}(64- \\
72 \mu \mathrm{m})\end{array}$ & $\begin{array}{c}35,4 \mu \mathrm{m} \\
(32,6- \\
38,4 \mu \mathrm{m})\end{array}$ & $\begin{array}{c}\text { Más de dos } \\
\text { capas } \\
109,1 \mu \mathrm{m} \\
(90,8- \\
133,9 \mu \mathrm{m})\end{array}$ & $\begin{array}{c}\text { C. aff. } \\
\text { moschata }\end{array}$ \\
\hline $\begin{array}{l}\text { Los } \\
\text { Viscos } 13\end{array}$ & $\begin{array}{l}\text { Redondeado } \\
\text { aplanado }\end{array}$ & $\begin{array}{c}\text { Cel largas bajo } \\
\text { microscopio } \\
\text { estereoscópico } \\
\text { No se observan } \\
\text { cel. } \\
\text { epidérmicas en } \\
\text { MEB }\end{array}$ & $\mathrm{Si}$ & 5 & $\begin{array}{r}\text { Célula } \\
\text { delg } \\
\text { to } \\
\mathrm{cc}\end{array}$ & $\begin{array}{l}\text { e paredes } \\
\text { s, capa } \\
\text { nente } \\
\text { sada }\end{array}$ & $\begin{array}{c}62,6 \mu \mathrm{m}(28- \\
97 \mu \mathrm{m}) \\
{[3]} \\
\text { Limite } \\
\text { regular con } \\
\text { epidermis }\end{array}$ & $\begin{array}{c}64,1 \mu \mathrm{m} \\
(58- \\
70,5 \mu \mathrm{m})\end{array}$ & $\begin{array}{c}41,2 \mu \mathrm{m} \\
(37-45 \mu \mathrm{m})\end{array}$ & $\begin{array}{c}\text { Más de dos } \\
\text { capas } \\
46,2 \mu \mathrm{m}(41,9- \\
54,4 \mu \mathrm{m})\end{array}$ & $\begin{array}{l}\text { C. maxima aff } \\
\text { ssp. maxima }\end{array}$ \\
\hline $\begin{array}{l}\text { Pampa } \\
\text { Grande } \\
\text { Los } \\
\text { Aparejos } \\
\text { Sector } \\
\text { III/E1/20- } \\
40 \mathrm{~cm} \\
\text { Q1 }\end{array}$ & $\begin{array}{c}\text { Redondeado } \\
\text { aplanado }\end{array}$ & \begin{tabular}{|c|} 
No se observan \\
cel. largas bajo \\
microscopio \\
estereoscópico \\
No se observan \\
cel. \\
epidérmicas \\
bajo \\
microscopio de \\
transparencia
\end{tabular} & No & $5-6$ & $\begin{array}{r}\text { Célula } \\
\text { delg } \\
\text { to } \\
\text { co }\end{array}$ & $\begin{array}{l}\text { e paredes } \\
\text { s, capa } \\
\text { nente } \\
\text { sada. }\end{array}$ & $\begin{array}{c}41,9 \mu \mathrm{m} \\
(18,4- \\
60,9 \mu \mathrm{m}) \\
{[4(3-5)]} \\
\text { Limite con } \\
\text { epidermis } \\
\text { algo irregular }\end{array}$ & $\begin{array}{c}69,5 \mu \mathrm{m} \\
(62,3- \\
82,2 \mathrm{~m})\end{array}$ & $\begin{array}{c}47,4 \mu \mathrm{m} \\
(33,5- \\
64 \mu \mathrm{m})\end{array}$ & $\begin{array}{c}\text { Más de dos } \\
\text { capas } \\
133,3 \mu \mathrm{m} \\
(128,5- \\
137,1 \mu \mathrm{m})\end{array}$ & $\begin{array}{l}\text { C. maxima aff } \\
\text { ssp. maxima }\end{array}$ \\
\hline
\end{tabular}




\begin{tabular}{|c|c|c|c|c|c|c|c|c|c|c|c|}
\hline $\begin{array}{c}\text { Pampa } \\
\text { Grande } \\
\text { Los } \\
\text { Aparejos } \\
\text { Sector } \\
\text { III/E1/20- } \\
40 \mathrm{~cm} . \\
\text { QA }\end{array}$ & $\begin{array}{l}\text { Redondeado } \\
\text { aplanado }\end{array}$ & $\begin{array}{c}\text { No se observan } \\
\text { cel. largas bajo } \\
\text { microscopio } \\
\text { estereoscópico. } \\
\text { No se observan } \\
\text { cel. } \\
\text { epidérmicas } \\
\text { bajo } \\
\text { microscopio de } \\
\text { transparencia }\end{array}$ & No & $4-5$ & \multicolumn{2}{|c|}{ No se conserva } & $\begin{array}{c}24,5 \mu \mathrm{m} \\
(16,2- \\
33,5 \mu \mathrm{m}) \\
{[3]} \\
\text { Limite } \\
\text { regular con } \\
\text { epidermis }\end{array}$ & $\begin{array}{c}67,2 \mu \mathrm{m} \\
(59,1- \\
78,7 \mathrm{~m})\end{array}$ & $\begin{array}{c}50,8 \mu \mathrm{m} \\
(43,8- \\
57,4 \mathrm{~m})\end{array}$ & $\begin{array}{c}\text { Más de dos } \\
\text { capas } \\
54,3 \mu \mathrm{m} \\
(45,4-63,3 \mu \mathrm{m})\end{array}$ & $\begin{array}{l}\text { C. maxima aff } \\
\text { ssp. maxima }\end{array}$ \\
\hline $\begin{array}{l}\text { Pampa } \\
\text { Grande } \\
\text { Los } \\
\text { Aparejos } \\
\text { Sector } \\
\text { III/E1/20- } \\
40 \mathrm{~cm} . \\
\text { QB }\end{array}$ & Redondeado & $\begin{array}{c}\text { No se observan } \\
\text { cel. largas bajo } \\
\text { microscopio } \\
\text { estereoscópico. } \\
\text { No se observan } \\
\text { cel. } \\
\text { epidérmicas } \\
\text { bajo } \\
\text { microscopio de } \\
\text { transparencia }\end{array}$ & $\mathrm{Si}$ & $5(4)$ & -- & $\begin{array}{c}26,8 \mu \mathrm{m} \\
(16,6- \\
34,8 \mu \mathrm{m})\end{array}$ & $\begin{array}{c}26,6 \mu \mathrm{m} \\
(18,8- \\
34,6 \mu \mathrm{m}) \\
{[3]} \\
\text { Limite con } \\
\text { epidermis } \\
\text { algo irregular }\end{array}$ & $\begin{array}{c}12,2 \mu \mathrm{m} \\
(10,8-13 \\
\mu \mathrm{m})\end{array}$ & $\begin{array}{c}9 \mu \mathrm{m}(7,8- \\
9,7 \mu \mathrm{m})\end{array}$ & $\begin{array}{c}\text { Sólo se } \\
\text { conserva capa } \\
\text { de cel. } \\
\text { pequeñas } \\
\text { cercanas al } \\
\text { esclerénquima }\end{array}$ & $\begin{array}{l}\text { C. maxima aff } \\
\text { ssp. maxima }\end{array}$ \\
\hline $\begin{array}{l}\text { Pampa } \\
\text { Grande } \\
\text { Los } \\
\text { Aparejos } \\
\text { Sector } \\
\text { III/E1/20- } \\
40 \mathrm{~cm} . \\
\text { QC }\end{array}$ & Redondeado & $\begin{array}{c}\text { No se observan } \\
\text { cel. largas bajo } \\
\text { microscopio } \\
\text { estereoscópico. } \\
\text { No se observan } \\
\text { cel. } \\
\text { epidérmicas } \\
\text { bajo } \\
\text { microscopio de } \\
\text { transparencia }\end{array}$ & No & $5-6$ & -- & $38,5 \mu \mathrm{m}$ & $\begin{array}{c}49,4 \mu \mathrm{m} \\
(44,4- \\
54,7 \mu \mathrm{m}) \\
{[4]} \\
\text { Limite con } \\
\text { epidermis } \\
\text { algo irregular }\end{array}$ & $\begin{array}{c}72,4 \mu \mathrm{m} \\
(65,5-80,1 \\
\mu \mathrm{m})\end{array}$ & $\begin{array}{c}63,9 \mu \mathrm{m} \\
(46,1-72,5 \\
\mu \mathrm{m})\end{array}$ & $\begin{array}{c}\text { Más de dos } \\
\text { capas } \\
77,3 \mu \mathrm{m} \\
(71,6-80,5 \mu \mathrm{m})\end{array}$ & $\begin{array}{l}\text { C. maxima aff } \\
\text { ssp. maxima }\end{array}$ \\
\hline $\begin{array}{l}\text { Pampa } \\
\text { Grande. } \\
\text { Los } \\
\text { Aparejos } \\
\text { Sector } \\
\text { III/E1/20- } \\
40 \mathrm{~cm} . \\
\text { QD }\end{array}$ & Redondeado & $\begin{array}{c}\text { No se observan } \\
\text { cel. largas bajo } \\
\text { microscopio } \\
\text { estereoscópico. } \\
\text { No se observan } \\
\text { cel. } \\
\text { epidérmicas } \\
\text { bajo } \\
\text { microscopio de } \\
\text { transparencia } \\
\end{array}$ & $\mathrm{Si}$ & 6-8 (9) & -- & 15,3 & $\begin{array}{c}26,1 \mu \mathrm{m} \\
(16,9- \\
31,6 \mu \mathrm{m}) \\
{[3]} \\
\text { Limite con } \\
\text { epidermis } \\
\text { algo irregular }\end{array}$ & $\begin{array}{c}12,1 \mu \mathrm{m} \\
(10,6-12,9 \\
\mu \mathrm{m})\end{array}$ & $\begin{array}{c}10 \mu \mathrm{m} \\
(9,5- \\
10,6 \mathrm{~m})\end{array}$ & $\begin{array}{c}\text { No se } \\
\text { conserva }\end{array}$ & $\begin{array}{l}\text { C. maxima aff } \\
\text { ssp. maxima }\end{array}$ \\
\hline
\end{tabular}




\begin{tabular}{|c|c|c|c|c|c|c|c|c|c|c|c|}
\hline $\begin{array}{c}\text { Pampa } \\
\text { Grande } \\
\text { Caverna } \\
\text { III } \\
085\end{array}$ & Redondeado & $\begin{array}{l}\text { Cel largas bajo } \\
\text { microscopio } \\
\text { estereoscópico } \\
\text { Cel. largas } \\
\text { rodean } \\
\text { completamente } \\
\text { a las cortas en } \\
\text { el margen bajo } \\
\text { microscopio de } \\
\text { transparencia }\end{array}$ & $\mathrm{Si}$ & $6-7$ & -- & $\begin{array}{c}52,21 \\
\mu \mathrm{m} \\
(45,7- \\
62,1 \mu \mathrm{m})\end{array}$ & $\begin{array}{c}54,7 \mu \mathrm{m} \\
(28,5-82 \mu \mathrm{m}) \\
{[4-5(6)]} \\
\text { Limite con } \\
\text { epidermis } \\
\text { irregular }\end{array}$ & $\begin{array}{c}88,1 \mu \mathrm{m} \\
(81,1-99,3 \\
\mu \mathrm{m})\end{array}$ & $\begin{array}{c}57,3 \mu \mathrm{m} \\
(48,4-71,2 \\
\mu \mathrm{m})\end{array}$ & $\begin{array}{c}\text { Más de dos } \\
\text { capas } \\
210,4 \mu \mathrm{m} \\
(196,9-219,7 \\
\mu \mathrm{m})\end{array}$ & $\begin{array}{l}\text { C. aff. maxima } \\
\text { ssp. maxima o } \\
\text { moschata }\end{array}$ \\
\hline $\begin{array}{l}\text { Pampa } \\
\text { Grande } \\
\text { Los } \\
\text { Aparejos } \\
\text { Sector } \\
\text { III/E1/60- } \\
80 \mathrm{~cm} . \\
\text { S1 }\end{array}$ & Redondeado & $\begin{array}{c}\text { No se observan } \\
\text { cel. largas bajo } \\
\text { microscopio } \\
\text { estereoscópico } \\
\text { No se observan } \\
\text { cel. } \\
\text { epidérmicas en } \\
\text { MEB }\end{array}$ & No & $3-4$ & -- & $\begin{array}{c}35,6 \mu \mathrm{m} \\
(30,2- \\
45,9 \mu \mathrm{m})\end{array}$ & $\begin{array}{c}33,1 \mu \mathrm{m} \\
(13,6- \\
92,5 \mu \mathrm{m}) \\
{[3(2-4)]} \\
\text { Limite con } \\
\text { epidermis } \\
\text { algo irregular }\end{array}$ & $\begin{array}{c}55,5 \mu \mathrm{m} \\
(49,2-62,7 \\
\mu \mathrm{m})\end{array}$ & $\begin{array}{c}35,8 \mu \mathrm{m} \\
(29,8-47,3 \\
\mu \mathrm{m})\end{array}$ & $\begin{array}{c}\text { Más de dos } \\
\text { capas } \\
163,2 \mu \mathrm{m} \\
(146-178,2 \\
\mu \mathrm{m})\end{array}$ & $\begin{array}{l}\text { C. maxima aff. } \\
\text { ssp. maxima }\end{array}$ \\
\hline $\begin{array}{l}\text { Pampa } \\
\text { Grande } \\
\text { Los } \\
\text { Aparejos } \\
\text { Sector } \\
\text { III/F1 } \\
\text { S2 }\end{array}$ & Redondeado & $\begin{array}{c}\text { No se observan } \\
\text { células largas } \\
\text { bajo } \\
\text { microscopio } \\
\text { estereoscópico } \\
\text { No se observan } \\
\text { células } \\
\text { epidérmicas en } \\
\text { el margen. }\end{array}$ & No & $4-5$ & -- & $40,8 \mu \mathrm{m}$ & $\begin{array}{c}33 \mu \mathrm{m}(28- \\
43,4 \mu \mathrm{m}) \\
{[3-4]} \\
\text { Límite } \\
\text { regular con } \\
\text { epidermis }\end{array}$ & $\begin{array}{c}75,7 \mu \mathrm{m} \\
(62,5-90,6 \\
\mu \mathrm{m})\end{array}$ & $\begin{array}{c}47 \mu \mathrm{m} \\
(36,4-54,3 \\
\mu \mathrm{m})\end{array}$ & $\begin{array}{c}\text { Más de dos } \\
\text { capas } \\
37,4 \mu \mathrm{m}(20,4- \\
113,4 \mu \mathrm{m})\end{array}$ & $\begin{array}{l}\text { C. maxima aff. } \\
\text { ssp. maxima }\end{array}$ \\
\hline $\begin{array}{l}\text { Pampa } \\
\text { Grande } \\
\text { Los } \\
\text { Aparejos } \\
\text { Sector } \\
\text { III/F1 } \\
\text { S3 } \\
\text { (Lámina } \\
\text { 12) }\end{array}$ & $\begin{array}{l}\text { Redondeado } \\
\text { aplanado }\end{array}$ & $\begin{array}{c}\text { No se observan } \\
\text { cel. largas bajo } \\
\text { microscopio } \\
\text { estereoscópico } \\
\text { No se observan } \\
\text { cel. } \\
\text { epidérmicas en } \\
\text { MEB }\end{array}$ & No & $4-5$ & \multicolumn{2}{|c|}{ No se conserva } & $\begin{array}{c}38,9 \mu \mathrm{m} \\
(27,9- \\
61,1 \mu \mathrm{m}) \\
{[3(4-5)]} \\
\text { Límite } \\
\text { regular con } \\
\text { epidermis }\end{array}$ & $\begin{array}{c}72,6 \mu \mathrm{m} \\
(60,8-82,2 \\
\mu \mathrm{m})\end{array}$ & $\begin{array}{c}43,5 \mu \mathrm{m} \\
(35-60 \mu \mathrm{m})\end{array}$ & $\begin{array}{c}\text { Más de dos } \\
\text { capas } \\
161,6 \mu \mathrm{m} \\
(125,6-214,2 \\
\mu \mathrm{m})\end{array}$ & $\begin{array}{l}\text { C. maxima aff. } \\
\text { ssp. maxima }\end{array}$ \\
\hline $\begin{array}{l}\text { Pampa } \\
\text { Grande. } \\
\text { Los }\end{array}$ & $\begin{array}{l}\text { Redondeado } \\
\text { aplanado }\end{array}$ & $\begin{array}{l}\text { No se observan } \\
\text { cel. largas bajo } \\
\text { microscopio }\end{array}$ & No & $\begin{array}{l}\text { No se } \\
\text { conserva }\end{array}$ & \multicolumn{2}{|c|}{ No se conserva } & $\begin{array}{c}17 \mu \mathrm{m}(14- \\
20,6 \mu \mathrm{m}) \\
{[3]}\end{array}$ & $\begin{array}{c}80,2 \mu \mathrm{m} \\
(74-85 \\
\mu \mathrm{m})\end{array}$ & $\begin{array}{c}37,2 \mu \mathrm{m} \\
(30-42,8 \\
\mu \mathrm{m})\end{array}$ & $\begin{array}{c}\text { Más de dos } \\
\text { capas } \\
109,7 \mu \mathrm{m}\end{array}$ & $\begin{array}{l}\text { C. maxima aff. } \\
\text { ssp. maxima }\end{array}$ \\
\hline
\end{tabular}




\begin{tabular}{|c|c|c|c|c|c|c|c|c|c|c|c|}
\hline $\begin{array}{l}\text { Aparejos } \\
\text { Sector } \\
\text { III/F2/40- } \\
60 \mathrm{~cm} . \\
\text { S4 } \\
\text { (Lámina } \\
12 \text { ) }\end{array}$ & & $\begin{array}{c}\text { estereoscópico. } \\
\text { No se observan } \\
\text { cel. } \\
\text { epidérmicas al } \\
\text { MEB }\end{array}$ & & & & & $\begin{array}{c}\text { Limite con } \\
\text { epidermis } \\
\text { posiblemente } \\
\text { regular }\end{array}$ & & & $\begin{array}{c}(84,6-131,7 \\
\mu \mathrm{m})\end{array}$ & \\
\hline $\begin{array}{c}\text { Pampa } \\
\text { Grande } \\
\text { El Litro } \\
\text { C1, capa } \\
1 \\
\text { S5 } \\
\text { (Lámina } \\
12 \text { ) }\end{array}$ & Redondeado & $\begin{array}{c}\text { No se observan } \\
\text { cel. largas bajo } \\
\text { microscopio } \\
\text { estereoscópico. } \\
\text { No se observan } \\
\text { cel. } \\
\text { epidérmicas al } \\
\text { MEB }\end{array}$ & $\mathrm{Si}$ & $4-6$ & \multicolumn{2}{|c|}{ No se conserva } & $\begin{array}{c}26,6 \mu \mathrm{m} \\
(18,2- \\
36,6 \mu \mathrm{m}) \\
{[2-3]} \\
\text { Límite } \\
\text { regular con } \\
\text { epidermis }\end{array}$ & $\begin{array}{c}64,3 \mu \mathrm{m} \\
(53,3-71,7 \\
\mu \mathrm{m})\end{array}$ & $\begin{array}{c}37,9 \mu \mathrm{m} \\
(30,5-42,6 \\
\mu \mathrm{m})\end{array}$ & $\begin{array}{c}\text { Más de dos } \\
\text { capas } \\
63,9 \mu \mathrm{m}(36,8- \\
99,4 \mu \mathrm{m})\end{array}$ & $\begin{array}{l}\text { C. maxima aff. } \\
\text { ssp. maxima }\end{array}$ \\
\hline $\begin{array}{c}\text { Bandurria } \\
372 \mathrm{~F}\end{array}$ & Redondeado & $\begin{array}{c}\text { No se observan } \\
\text { cel. largas bajo } \\
\text { microscopio } \\
\text { estereoscópico } \\
\text { No se observan } \\
\text { cel. } \\
\text { epidérmicas } \\
\text { bajo } \\
\text { microscopio de } \\
\text { transparencia }\end{array}$ & No & 3 & -- & $48,5 \mu \mathrm{m}$ & $\begin{array}{l}\text { No se } \\
\text { distingue } \\
\text { cantidad de } \\
\text { capas. } \\
\text { Limite con } \\
\text { epidermis } \\
\text { regular. }\end{array}$ & $\begin{array}{c}72,8 \mu \mathrm{m} \\
(59,5- \\
125,9 \mu \mathrm{m})\end{array}$ & $\begin{array}{c}39,8 \mu \mathrm{m} \\
(32,9- \\
75,4 \mu \mathrm{m})\end{array}$ & $\begin{array}{c}\text { Una o dos } \\
\text { capas }\end{array}$ & C. aff. maxima \\
\hline $\begin{array}{c}\text { Bandurria } \\
\text { 425FA } \\
\text { (Lámina } \\
11)\end{array}$ & Redondeado & $\begin{array}{l}\text { Cel largas bajo } \\
\text { microscopio } \\
\text { estereoscópico } \\
\text { No se observan } \\
\text { cel. } \\
\text { epidérmicas en } \\
\text { MEB }\end{array}$ & $\mathrm{Si}$ & $5-6$ & -- & $\begin{array}{c}44,5 \mu \mathrm{m} \\
(38,7- \\
57 \mu \mathrm{m})\end{array}$ & $\begin{array}{c}21,3 \mu \mathrm{m} \\
(10,4- \\
34,4 \mu \mathrm{m}) \\
{[1-3]} \\
\text { Limite con } \\
\text { epidermis } \\
\text { irregular }\end{array}$ & $\begin{array}{c}37,9 \mu \mathrm{m} \\
(11,5- \\
47,7 \mu \mathrm{m})\end{array}$ & $\begin{array}{c}23,8 \mu \mathrm{m} \\
(18,3- \\
31,1 \mu \mathrm{m})\end{array}$ & $\begin{array}{l}\text { Una o dos } \\
\text { capas }\end{array}$ & $\begin{array}{c}\text { C. aff. maxima } \\
\text { ssp. maxima o } \\
\text { C. aff. } \\
\text { moschata }\end{array}$ \\
\hline $\begin{array}{c}\text { Bandurria } \\
\text { 425FB }\end{array}$ & Redondeado & \begin{tabular}{|c|} 
Cel largas bajo \\
microscopio \\
estereoscópico \\
Solo se \\
observan \\
restos de \\
paredes de las \\
cel. largas en \\
\end{tabular} & No & $8-9$ & -- & $\begin{array}{c}38,2 \mu \mathrm{m} \\
(24- \\
54,3 \mu \mathrm{m})\end{array}$ & $\begin{array}{c}23,2 \mu \mathrm{m} \\
(10,6- \\
56,8 \mu \mathrm{m}) \\
{[1-3]} \\
\text { Limite con } \\
\text { epidermis } \\
\text { irregular }\end{array}$ & $\begin{array}{c}50,1 \mu \mathrm{m} \\
(43,7- \\
63,5 \mu \mathrm{m})\end{array}$ & $\begin{array}{c}34 \mu \mathrm{m} \\
(23,7- \\
39,4 \mu \mathrm{m})\end{array}$ & $\begin{array}{c}\text { Más de dos } \\
\text { capas } \\
56,1 \mu \mathrm{m}\end{array}$ & $\begin{array}{c}\text { C. aff. maxima } \\
\text { ssp. maxima o } \\
\text { C. aff. } \\
\text { moschata }\end{array}$ \\
\hline
\end{tabular}




\begin{tabular}{|c|c|c|c|c|c|c|c|c|c|c|c|}
\hline & & MEB & & & & & & & & & \\
\hline $\begin{array}{c}\text { Co. } \\
\text { Lampay } \\
1059 \\
\text { (Lámina } \\
11)\end{array}$ & Redondeado & $\begin{array}{l}\text { Cel largas bajo } \\
\text { microscopio } \\
\text { estereoscópico } \\
\text { Cel. largas } \\
\text { rodean } \\
\text { completamente } \\
\text { a las cortas en } \\
\text { el margen al } \\
\text { MEB }\end{array}$ & $\mathrm{Si}$ & $5-6$ & -- & $\begin{array}{c}26,5 \mu \mathrm{m} \\
(18,2- \\
32,8 \mu \mathrm{m})\end{array}$ & $\begin{array}{c}16 \mu \mathrm{m} \\
(7,2-27,1 \mu \mathrm{m}) \\
{[2-3(4)]} \\
\text { Limite con } \\
\text { epidermis } \\
\text { irregular }\end{array}$ & $\begin{array}{c}43,7 \mu \mathrm{m} \\
(38,3- \\
49,3 \mu \mathrm{m})\end{array}$ & $\begin{array}{c}23,8 \mu \mathrm{m} \\
(18- \\
31,8 \mu \mathrm{m})\end{array}$ & No conserva & $\begin{array}{c}\text { C. aff. maxima } \\
\text { ssp. maxima o } \\
\text { C. aff. } \\
\text { moschata }\end{array}$ \\
\hline $\begin{array}{c}\text { Co. } \\
\text { Lampay } \\
17 / 1248\end{array}$ & $\begin{array}{l}\text { Redondeado } \\
\text { aplanado }\end{array}$ & $\begin{array}{l}\text { Cel largas bajo } \\
\text { microscopio } \\
\text { estereoscópico } \\
\text { Cel. largas } \\
\text { rodean } \\
\text { completamente } \\
\text { a las cortas en } \\
\text { el margen bajo } \\
\text { microscopio de } \\
\text { transparencia }\end{array}$ & $\mathrm{Si}$ & $5-6$ & -- & $23,8 \mu \mathrm{m}$ & $\begin{array}{c}32,6 \mu \mathrm{m} \\
(27,2- \\
35,6 \mu \mathrm{m}) \\
{[3]} \\
\text { Limite con } \\
\text { epidermis } \\
\text { regular }\end{array}$ & $\begin{array}{c}72,7 \mu \mathrm{m} \\
(67,4- \\
82,4 \mu \mathrm{m})\end{array}$ & $\begin{array}{c}53,3 \mu \mathrm{m} \\
(33,8- \\
88,6 \mu \mathrm{m})\end{array}$ & $\begin{array}{c}\text { Más de dos } \\
\text { capas } \\
145,1 \mu \mathrm{m} \\
(43,2- \\
351,7 \mu \mathrm{m})\end{array}$ & $\begin{array}{l}\text { C. maxima aff. } \\
\text { ssp. maxima }\end{array}$ \\
\hline $\begin{array}{c}\text { Co } \\
\text { Lampay } \\
\text { 18/1235A }\end{array}$ & $\begin{array}{l}\text { Redondeado } \\
\text { aplanado }\end{array}$ & $\begin{array}{l}\text { Cel largas bajo } \\
\text { microscopio } \\
\text { estereoscópico } \\
\text { Cel. largas } \\
\text { rodean } \\
\text { completamente } \\
\text { a las cortas en } \\
\text { el margen bajo } \\
\text { microscopio de } \\
\text { transparencia }\end{array}$ & $\mathrm{Si}$ & $6-7$ & -- & $\begin{array}{c}35,9 \mu \mathrm{m} \\
(22,8- \\
57,3 \mu \mathrm{m})\end{array}$ & $\begin{array}{c}34,28 \mu \mathrm{m} \\
(22,6- \\
52,2 \mu \mathrm{m}) \\
{[3]} \\
\text { Limite con } \\
\text { epidermis } \\
\text { levemente } \\
\text { irregular }\end{array}$ & $\begin{array}{c}86,7 \mu \mathrm{m} \\
(78,9- \\
98,4 \mu \mathrm{m})\end{array}$ & $\begin{array}{c}63,1 \mu \mathrm{m} \\
(46,1- \\
81,1 \mu \mathrm{m})\end{array}$ & $\begin{array}{c}\text { Tres capas } \\
118,2 \mu \mathrm{m} \\
(100,7- \\
150,7 \mu \mathrm{m})\end{array}$ & $\begin{array}{l}\text { C. maxima aff. } \\
\text { ssp. maxima }\end{array}$ \\
\hline $\begin{array}{c}\text { Co } \\
\text { Lampay } \\
\text { 18/1235B }\end{array}$ & $\begin{array}{l}\text { Redondeado } \\
\text { aplanado }\end{array}$ & $\begin{array}{l}\text { Cel largas bajo } \\
\text { microscopio } \\
\text { estereoscópico } \\
\text { Cel. largas } \\
\text { rodean } \\
\text { completamente } \\
\text { a las cortas en } \\
\text { el margen bajo } \\
\text { microscopio de } \\
\text { transparencia }\end{array}$ & $\mathrm{Si}$ & 5 & -- & $\begin{array}{c}80,2 \mu \mathrm{m} \\
(65,8- \\
88,5 \mu \mathrm{m})\end{array}$ & $\begin{array}{c}26,4 \mu \mathrm{m} \\
(23,3- \\
33,9 \mu \mathrm{m}) \\
{[2-3]} \\
\text { Limite con } \\
\text { epidermis } \\
\text { levemente } \\
\text { irregular }\end{array}$ & $\begin{array}{c}45,8 \mu \mathrm{m} \\
(30,9- \\
50,9 \mu \mathrm{m})\end{array}$ & $\begin{array}{c}31,6 \mu \mathrm{m} \\
(28- \\
34,8 \mu \mathrm{m})\end{array}$ & No conserva & $\begin{array}{c}\text { C. aff. maxima } \\
\text { ssp. maxima o } \\
\text { C. aff. } \\
\text { moschata }\end{array}$ \\
\hline
\end{tabular}




\begin{tabular}{|c|c|c|c|c|c|c|c|c|c|c|c|}
\hline $\begin{array}{c}\text { Co } \\
\text { Lampay } \\
13 / 1200 \\
\text { (Lámina } \\
11)\end{array}$ & $\begin{array}{l}\text { Redondeado } \\
\text { aplanado }\end{array}$ & $\begin{array}{l}\text { No se observan } \\
\text { cel. largas bajo } \\
\text { microscopio } \\
\text { estereoscópico }\end{array}$ & No & $3-4$ & -- & $\begin{array}{c}37,8 \mu \mathrm{m} \\
(36,6- \\
39,5 \mu \mathrm{m})\end{array}$ & $\begin{array}{c}21,2 \mu \mathrm{m} \\
(13,1- \\
38,9 \mu \mathrm{m}) \\
{[2-3(4)]} \\
\text { Limite con } \\
\text { epidermis } \\
\text { regular } \\
\end{array}$ & $\begin{array}{c}66,6 \mu \mathrm{m} \\
(59,1- \\
77,5 \mu \mathrm{m})\end{array}$ & $\begin{array}{c}36,1 \mu \mathrm{m} \\
(30,3- \\
41,5 \mu \mathrm{m})\end{array}$ & $\begin{array}{c}\text { Dos capas } \\
30,67 \mu \mathrm{m} \\
(14,4-56,9 \mu \mathrm{m})\end{array}$ & $\begin{array}{l}\text { C. maxima aff. } \\
\text { ssp. andreana }\end{array}$ \\
\hline
\end{tabular}


Tabla 31: caracterización del margen y tejidos de la cubierta seminal de semillas arqueológicas carbonizadas recuperadas en el sitio Puente Río La Viña I (Valle de Lerma, Salta, 460-730DC) y El Shincal (Valle de Hualfín, Catamarca, 1430-1550AD). En el caso de la hipodermis, tanto en margen como en caras mayores, se consigna la cantidad de capas observadas y entre paréntesis la cantidad más inusual. En el caso de alto y ancho de esclereidas, alto y ancho de células epidérmicas y alto del aerénquima se consigna el valor promedio y entre paréntesis el rango de tamaños. En el caso de que se consigne un único valor sin rango entre paréntesis es debido a la existencia de una única medida ante la imposibilidad de realizar un mayor número de mediciones por ausencia del carácter en el ejemplar analizado

\begin{tabular}{|c|c|c|c|c|c|c|c|c|c|c|c|c|c|}
\hline \multirow{3}{*}{ Sitio } & \multirow{3}{*}{ Muestra } & \multirow{3}{*}{ Estado } & \multicolumn{4}{|c|}{ Margen } & \multicolumn{6}{|c|}{ Caras mayores } & \multirow{3}{*}{$\begin{array}{c}\text { Identificación } \\
\text { taxonómica }\end{array}$} \\
\hline & & & \multirow{2}{*}{$\begin{array}{l}\text { Morfología } \\
\text { general }\end{array}$} & \multirow{2}{*}{$\begin{array}{c}\text { Cel. } \\
\text { largas/ } \\
\text { cel. } \\
\text { cortas } \\
\text { epidermis }\end{array}$} & \multirow{2}{*}{$\begin{array}{c}\text { Arco } \\
\text { submarginal }\end{array}$} & \multirow{2}{*}{ Hipodermis } & \multicolumn{2}{|c|}{$\begin{array}{c}\text { Células } \\
\text { epidérmicas }\end{array}$} & \multirow{2}{*}{ Hipodermis } & \multicolumn{2}{|c|}{ Esclereidas } & \multirow[b]{2}{*}{ Aerénquima } & \\
\hline & & & & & & & Alto & Ancho & & Alto & Ancho & & \\
\hline \multirow[t]{4}{*}{$\begin{array}{l}\text { Puente } \\
\text { Río La } \\
\text { Viña }\end{array}$} & L.Vi. 1 & $\begin{array}{l}\text { Semilla } \\
\text { entera }\end{array}$ & Redondeado & $\begin{array}{c}\text { No se } \\
\text { conservan }\end{array}$ & $\begin{array}{c}\text { No se } \\
\text { conserva }\end{array}$ & $\begin{array}{l}\text { No se } \\
\text { conserva }\end{array}$ & \multicolumn{2}{|c|}{$\begin{array}{l}\text { No se } \\
\text { conservan }\end{array}$} & $\begin{array}{l}\text { No se } \\
\text { conserva }\end{array}$ & $\begin{array}{c}73,4 \\
\mu \mathrm{m}\end{array}$ & $\begin{array}{c}27,8 \\
\mu \mathrm{m} \\
(25,4- \\
29,7 \\
\mu \mathrm{m})\end{array}$ & $\begin{array}{c}\text { Más de dos } \\
\text { capas } 50,9 \\
\mu \mathrm{m}\end{array}$ & $\begin{array}{l}\text { C. maxima aff. } \\
\text { ssp. maxima }\end{array}$ \\
\hline & L. Vi. 2 & $\begin{array}{l}\text { Semilla } \\
\text { entera }\end{array}$ & Redondeado & $\begin{array}{c}\text { No se } \\
\text { conservan }\end{array}$ & $\begin{array}{c}\text { No se } \\
\text { conserva }\end{array}$ & $5-6$ & \multicolumn{2}{|c|}{$\begin{array}{c}\text { No se } \\
\text { conservan }\end{array}$} & $4-5$ & $\begin{array}{l}77 \\
\mu \mathrm{m}\end{array}$ & $\begin{array}{c}28 \mu \mathrm{m} \\
(26,3- \\
29,7 \\
\mu \mathrm{m})\end{array}$ & $\begin{array}{c}\text { Más de dos } \\
\text { capas } 70,5 \\
\mu \mathrm{m}\end{array}$ & $\begin{array}{l}\text { C. maxima aff. } \\
\text { ssp. maxima }\end{array}$ \\
\hline & $\begin{array}{l}\text { MA y } \\
\text { MB }\end{array}$ & $\begin{array}{l}\text { Fragmentos } \\
\text { de margen } \\
\text { y caras } \\
\text { mayores de } \\
\text { una misma } \\
\text { semilla }\end{array}$ & Redondeado & & $\mathrm{Si}$ & $5-6$ & & $\begin{array}{c}46,9 \\
\mu \mathrm{m}\end{array}$ & $\begin{array}{l}\text { 3-4 } \\
\text { Limite con } \\
\text { epidermis } \\
\text { irregular }\end{array}$ & $\begin{array}{c}63,5 \\
\mu \mathrm{m} \\
(53,4- \\
76,5 \\
\mu \mathrm{m})\end{array}$ & $\begin{array}{c}39,4 \\
\mu \mathrm{m} \\
(34,9- \\
42,4 \\
\mu \mathrm{m})\end{array}$ & $\begin{array}{c}\text { Dos capas } \\
35,3 \mu \mathrm{m} \\
(25,4-29,7 \\
\mu \mathrm{m})\end{array}$ & C. aff. maxima \\
\hline & $\begin{array}{c}\text { SD } \\
\text { (Lámina } \\
13)\end{array}$ & $\begin{array}{l}\text { Fragmento } \\
\text { muy } \\
\text { pequeño de } \\
\text { cara mayor }\end{array}$ & ---- & --- & --- & ---- & & $\begin{array}{c}28,6 \\
\mu \mathrm{m}\end{array}$ & $1-2$ & $\begin{array}{c}58,6 \\
\mu \mathrm{m} \\
(52,8- \\
67,1 \\
\mu \mathrm{m})\end{array}$ & $\begin{array}{c}28,6 \\
\mu \mathrm{m}\end{array}$ & $\begin{array}{c}\text { Dos capas } \\
30,4 \mu \mathrm{m} \\
(28,6-32,8 \\
\mu \mathrm{m})\end{array}$ & $\begin{array}{l}\text { C. maxima aff. } \\
\text { ssp. andreana }\end{array}$ \\
\hline
\end{tabular}




\begin{tabular}{|c|c|c|c|c|c|c|c|c|c|c|c|c|}
\hline & L.Vi.3 & $\begin{array}{l}\text { Semilla } \\
\text { entera }\end{array}$ & Redondeado & $\begin{array}{l}\text { No se } \\
\text { conservan }\end{array}$ & $\begin{array}{c}\text { No se } \\
\text { conserva }\end{array}$ & $6-7$ & $\begin{array}{l}\text { No se } \\
\text { conservan }\end{array}$ & $2-3$ & $\begin{array}{c}68,9 \\
\mu \mathrm{m} \\
(62,5- \\
73 \\
\mu \mathrm{m})\end{array}$ & $\begin{array}{c}27 \mu \mathrm{m} \\
(24,8- \\
28,9 \\
\mu \mathrm{m})\end{array}$ & $\begin{array}{c}\text { Más de dos } \\
\text { capas } 50,9 \\
\mu \mathrm{m}\end{array}$ & $\begin{array}{l}\text { C. maxima aff. } \\
\text { ssp. maxima }\end{array}$ \\
\hline & FA & $\begin{array}{c}\text { Fragmento } \\
\text { de margen } \\
\text { y parte de } \\
\text { caras } \\
\text { mayores }\end{array}$ & Redondeado & $\begin{array}{c}\text { No se } \\
\text { conservan }\end{array}$ & $\begin{array}{c}\text { No se } \\
\text { conserva }\end{array}$ & $4-5$ & $\begin{array}{l}\text { No se } \\
\text { conservan }\end{array}$ & $4-5$ & $\begin{array}{l}75 \\
\mu \mathrm{m}\end{array}$ & $\begin{array}{c}28,7 \\
\mu \mathrm{m}\end{array}$ & $\begin{array}{l}\text { Más de dos } \\
\text { capas } 63 \mu \mathrm{m}\end{array}$ & $\begin{array}{l}\text { C. maxima aff. } \\
\text { ssp. maxima }\end{array}$ \\
\hline $\begin{array}{c}\text { El } \\
\text { Shincal }\end{array}$ & $\begin{array}{l}\text { Ushnu } \\
\text { (Lámina } \\
\text { 13) }\end{array}$ & $\begin{array}{l}\text { Semilla } \\
\text { entera }\end{array}$ & Redondeado & -- & No & 6 & Colapsadas & $\begin{array}{c}4-5(3) \\
\text { Contacto } \\
\text { regular con } \\
\text { la epidermis }\end{array}$ & $\begin{array}{c}58,6 \\
\mu \mathrm{m} \\
(53- \\
59 \\
\mu \mathrm{m})\end{array}$ & $\begin{array}{c}43,3 \\
\mu \mathrm{m} \\
(40-50 \\
\mu \mathrm{m})\end{array}$ & $\begin{array}{l}\text { Más de dos } \\
\text { capas } 105 \\
\mu \mathrm{m}\end{array}$ & $\begin{array}{l}\text { C. maxima } \\
\text { ssp. maxima } \\
\text { aff. } \mathrm{cv} \text {. } \\
\text { zapallito }\end{array}$ \\
\hline
\end{tabular}


Tabla 32: caracteres de la semilla de C. maxima ssp. andreana según la bibliografía consultada.

\begin{tabular}{|c|c|c|c|c|c|}
\hline Autor/año & Forma & Cantidad & Medidas & Peso & Color \\
\hline $\begin{array}{l}\text { Martinez Crovetto } \\
\text { en Burkart } 1974\end{array}$ & ovales complanadas & & $\begin{array}{c}8 \text { a } 9 \mathrm{~mm} \text { de largo } \\
5 \mathrm{~mm} \text { de ancho }\end{array}$ & & blanquecinas \\
\hline Millán 1945(*) & & & $\begin{array}{c}6 \text { a } 10 \mathrm{~mm} \text { de largo } \\
\text { llegando a } 16 \mathrm{~mm}\end{array}$ & & $\begin{array}{l}\text { blancas, } \\
\text { grises o } \\
\text { castañas }\end{array}$ \\
\hline Contardi 1939 & & 190 por fruto & & & \\
\hline Ashworth 1997 & ovales complanadas & $\begin{array}{c}\text { promedio de } \\
322,05+/-9,45 \\
\text { por fruto, con } \\
\text { rango de } \\
\text { variación muy } \\
\text { amplio (entre } \\
153 y 448)\end{array}$ & & & $\begin{array}{c}\text { blanquecina } \\
\text { de sup. lisa } \\
\text { brillante a } \\
\text { algo rugosa }\end{array}$ \\
\hline Carreras et al. 1989 & & & & 0,032 grs. & \\
\hline Lira Saade 1995 & $\begin{array}{c}\text { Ovado-elipticas, } \\
\text { comprimidas. Centro } \\
\text { liso, margenes muy } \\
\text { delgados no } \\
\text { resaltados. Apice } \\
\text { truncado y } \\
\text { ligeramente oblicuo }\end{array}$ & & $\begin{array}{l}\text { 6-8 } \mathrm{mm} \text { de largo } \\
5-6 \mathrm{~mm} \text { de ancho }\end{array}$ & & \\
\hline \multicolumn{2}{|l|}{ Teppner 2004} & & 6 a $8 \mathrm{~mm}$ de largo & & blanca a ocre \\
\hline
\end{tabular}


Tabla 33: caracteres de la semilla de C. maxima ssp. maxima según la bibliografía consultada.

\begin{tabular}{|c|c|c|c|}
\hline Autor/año & Forma & Medidas & Color \\
\hline $\begin{array}{c}\text { Whitaker y Bohn } \\
1950\end{array}$ & $\begin{array}{c}\text { Superficie regular o } \\
\text { finamente estriada o } \\
\text { punteada aunque } \\
\text { raramente, cubierta } \\
\text { seminal gruesa, margen } \\
\text { suave, obtuso, contorno } \\
\text { regular, delgado a } \\
\text { moderadamente grueso. }\end{array}$ & & \\
\hline Parodi 1966 & $\begin{array}{c}\text { Reborde periférico poco } \\
\text { notable }\end{array}$ & $\begin{array}{c}18 \mathrm{~mm} \text { de } \\
\text { largo, } 10 \mathrm{~mm} \\
\text { de ancho }\end{array}$ & $\begin{array}{c}\text { Ocráceas a } \\
\text { blancas }\end{array}$ \\
\hline Lira Saade 1995 & $\begin{array}{c}\text { Elípticas, infladas o } \\
\text { tumescentes. Superficie } \\
\text { lisa, levemente estriada o } \\
\text { punteada. Margenes } \\
\text { redondeados no realzados } \\
\text { o delimitados por surco. } \\
\text { Apice truncado y oblicuo. } \\
\text { Testa muy engrosada de } \\
1-2 \mathrm{~mm} \\
\end{array}$ & $\begin{array}{l}13-24 \mathrm{~mm} \\
\text { largo, } 8-12 \mathrm{~mm} \\
\text { ancho }\end{array}$ & $\begin{array}{l}\text { Blancas a } \\
\text { pardas. } \\
\text { Margenes de } \\
\text { distinto color que } \\
\text { el centro. }\end{array}$ \\
\hline Teppner 2004 & $\begin{array}{c}\text { Margen redondeado de } \\
\text { color diferente a la } \\
\text { superficie la cual es } \\
\text { blanca o marronacea. Tres } \\
\text { tipos según cubierta } \\
\text { seminal }\end{array}$ & $\begin{array}{l}\text { 13-32 mm de } \\
\text { largo }\end{array}$ & \\
\hline
\end{tabular}

Tabla 34: efectos de tipos diferenciales de polinización en los frutos y semillas de C. maxima ssp. maxima. Datos tomados de Pasarelli (2002). Referencias: 1) plantas polinizadas por Apis mellifera 2) plantas con polinización abierta.

\begin{tabular}{|c|c|}
\hline 1 & $82 \%$ produjeron frutos normales $(\mathrm{n}=121)$. Sin frutos abortados. \\
\hline 2 & $0.4 \%$ produjeron frutos normales $(\mathrm{n}=238) .204$ frutos abortados. \\
\hline 1 & frutos más pesados (530 grs. promedio) y uniformes. \\
\hline 2 & frutos de menor peso y con valores más heterogéneos cuyo promedio es de 188 grs. \\
\hline 1 & más semillas $(2700)$ \\
\hline 2 & menos semillas $(676)$ \\
\hline
\end{tabular}


Tabla 35: valores obtenidos del largo y ancho de semillas actuales de C. maxima ssp andreana. Autógama, cruzada y libre indican las semillas procedentes de frutos obtenidos por diversas vias de polinización, la fila C. maxima ssp andreana general consigna los valores generales para las tres muestras de distinta polinización. DS: desvío estándar, CV: coeficiente de variación; MIN: valores mínimos; MAX: valores máximos. Medidas expresadas en milímetros.

\begin{tabular}{|cc|c|c|c|c|c|}
\hline & & PROMEDIO & DS & CV & MIN & MAX \\
\hline $\begin{array}{c}\text { C. maxima ssp. } \\
\text { andreana } \\
\text { General }\end{array}$ & LARGO & 8,26 & 0,80 & 9,66 & 6,57 & 9,64 \\
\hline \multirow{2}{*}{ Autogama } & ANCHO & 5,31 & 0,54 & 10,09 & 4,36 & 6,53 \\
\hline \multirow{2}{*}{ Cruzada } & LARGO & 7,37 & 0,38 & 5,14 & 6,57 & 7,86 \\
& ANCHO & 4,82 & 0,23 & 4,77 & 4,36 & 5,25 \\
\hline \multirow{2}{*}{ Libre } & LARGO & 8,88 & 0,45 & 5,02 & 8,06 & 9,52 \\
& ANCHO & 5,89 & 0,34 & 5,81 & 5,27 & 6,53 \\
\hline
\end{tabular}

Tabla 36: Valores obtenidos del largo y ancho de semillas actuales de C. maxima ssp maxima. En la primer columna se indican los nombres de los cinco cultivares analizados, en la fila C. maxima ssp. maxima general se consignan los valores obtenidos al considerar los cinco cultivares en su conjunto . DS: desvío estándar, CV: coeficiente de variación; MIN: valores mínimos; MAX: valores máximos. Medidas expresadas en milímetros.

\begin{tabular}{|c|c|c|c|c|c|c|}
\hline & & PROMEDIO & DS & $\mathrm{CV}$ & MIN & MAX \\
\hline \multirow{2}{*}{$\begin{array}{c}\text { C. maxima ssp. maxima } \\
\text { General }\end{array}$} & LARGO & 21,70 & 5,11 & 23,56 & 13,28 & 30,25 \\
\hline & ANCHO & 11,94 & 2,29 & 19,15 & 7,28 & 17,12 \\
\hline \multirow{2}{*}{$\begin{array}{l}\text { C. maxima ssp. maxima } \\
\text { cv. ingles }\end{array}$} & LARGO & 17,96 & 1,25 & 6,98 & 15,46 & 20,52 \\
\hline & ANCHO & 12,32 & 1,01 & 8,22 & 10,96 & 13,89 \\
\hline \multirow{2}{*}{$\begin{array}{l}\text { C. maxima ssp. maxima } \\
\text { cv. criollo }\end{array}$} & LARGO & 20,28 & 0,76 & 3,74 & 19,35 & 21,02 \\
\hline & ANCHO & 13,2 & 0,77 & 5,81 & 11,87 & 13,7 \\
\hline \multirow{2}{*}{$\begin{array}{c}\text { C. maxima ssp. maxima } \\
\text { cv. hubbard }\end{array}$} & LARGO & 19,42 & 1,4 & 7,2 & 16,06 & 21,77 \\
\hline & ANCHO & 9,96 & 0,67 & 6,76 & 8,67 & 11,66 \\
\hline \multirow{2}{*}{$\begin{array}{c}\text { C. maxima ssp. maxima } \\
\text { cv. zapallito }\end{array}$} & LARGO & 15,59 & 1,41 & 9,07 & 13,28 & 18,06 \\
\hline & ANCHO & 9,46 & 1,02 & 10,8 & 7,28 & 11,14 \\
\hline \multirow{2}{*}{$\begin{array}{l}\text { C. maxima ssp. maxima } \\
\text { cv. boliviano }\end{array}$} & LARGO & 27,84 & 1,12 & 4,01 & 25,25 & 30,25 \\
\hline & ANCHO & 14,34 & 0,95 & 6,61 & 12,28 & 17,12 \\
\hline
\end{tabular}


Tabla 37: cambios tras carbonización a $300^{\circ}$ por $120^{\prime}$ en semillas enteras y fragmentadas de C. maxima ssp. maxima y C. maxima ssp. andreana en atmófera aneróbica y aeróbica. En las columna "secas" se consigna el valor promediado de las semillas previo a su carbonización, en la columna "carbonizadas" se consigna el valor promediado de las semillas tras la carbonización, en ambas columnas los valores se expresan en milímetros. En la columna "reducción" se indica en qué porcentaje se redujo la semilla respecto a los ejemplares secos tras la carbonización.

\begin{tabular}{|c|c|c|c|c|c|c|c|c|c|c|c|c|c|}
\hline & & \multicolumn{6}{|c|}{ Atmósfera anaeróbica } & \multicolumn{6}{|c|}{ Atmósfera aeróbica } \\
\hline & & \multicolumn{3}{|c|}{ Enteras } & \multicolumn{3}{|c|}{ Fragmentadas } & \multicolumn{3}{|c|}{ Enteras } & \multicolumn{3}{|c|}{ Fragmentadas } \\
\hline & & Secas & Carbonizadas & Reducción & Secas & Carbonizadas & Reducción & Secas & Carbonizadas & Reducción & Secas & Carbonizadas & Reducción \\
\hline \multirow{2}{*}{$\begin{array}{c}C . \\
\text { maxima } \\
\text { ssp. } \\
\text { andreana }\end{array}$} & largo & 8 & 6,6 & $18 \%$ & 4,4 & 4 & $16 \%$ & 8 & 6,5 & $19 \%$ & 4,3 & 3,40 & $21 \%$ \\
\hline & ancho & 5,1 & 4,6 & $10 \%$ & 5 & 4 & $20 \%$ & 5,6 & 4,2 & $25 \%$ & 5,6 & 3,80 & $32 \%$ \\
\hline \multirow{2}{*}{$\begin{array}{c}C . \\
\text { maxima } \\
\text { ssp. } \\
\text { maxima }\end{array}$} & largo & 15,7 & 13,1 & $17 \%$ & 7,5 & 7 & $7 \%$ & 15,5 & 12,2 & $21 \%$ & 8,4 & 7,20 & $14 \%$ \\
\hline & ancho & 8,5 & 7 & $18 \%$ & 9,5 & 7,9 & $17 \%$ & 8,8 & 7,1 & $19 \%$ & 8,9 & 7,00 & $21 \%$ \\
\hline
\end{tabular}


Tabla 38: rangos de tamaño obtenidos tras aplicar los porcentajes de reducción en atmósfera aeróbica (Aer) y anaeróbica (An) de forma individual a cada uno de los ejemplares secos de referencia de C. maxima ssp. maxima y C. maxima ssp. andreana, los valores calculados tras la suma de los resultados obtenidos para ambas atmósferas se consignan en la fila "Gral." DS: desvío estandar, CV: coeficiente de variación; MIN: valores mínimos; MAX: valores máximos. Medidas expresadas en milímetros.

\begin{tabular}{|c|c|c|c|c|c|c|c|}
\hline & & & PROMEDIO & DS & CV & MIN & MAX \\
\hline \multirow[t]{2}{*}{$\begin{array}{c}\text { C. maxima } \\
\text { ssp } \\
\text { andreana }\end{array}$} & LARGO & $\begin{array}{l}\text { Aer } \\
\text { An } \\
\text { Gral }\end{array}$ & $\begin{array}{l}6,69 \\
6,78 \\
6,74\end{array}$ & $\begin{array}{l}0,65 \\
0,65 \\
0,65\end{array}$ & $\begin{array}{l}9,66 \\
9,66 \\
9,64\end{array}$ & $\begin{array}{l}5,32 \\
5,39 \\
5,32\end{array}$ & $\begin{array}{r}7,81 \\
7,9 \\
7,9\end{array}$ \\
\hline & ANCHO & $\begin{array}{l}\text { Aer } \\
\text { An } \\
\text { Gral }\end{array}$ & $\begin{array}{l}3,98 \\
4,78 \\
4,38\end{array}$ & $\begin{array}{c}0,4 \\
0,48 \\
0,6\end{array}$ & $\begin{array}{l}10,09 \\
10,09 \\
13,61\end{array}$ & $\begin{array}{l}3,27 \\
3,92 \\
3,27\end{array}$ & $\begin{array}{c}4,9 \\
5,88 \\
5,88\end{array}$ \\
\hline \multirow{2}{*}{$\begin{array}{c}\text { C. maxima } \\
\text { ssp } \\
\text { maxima }\end{array}$} & LARGO & $\begin{array}{l}\text { Aer } \\
\text { An } \\
\text { Gral }\end{array}$ & $\begin{array}{c}18,46 \\
19,4 \\
18,93\end{array}$ & $\begin{array}{c}4,09 \\
4,3 \\
4,22\end{array}$ & $\begin{array}{l}22,16 \\
22,16 \\
22,27\end{array}$ & $\begin{array}{l}10,49 \\
11,02 \\
10,49\end{array}$ & $\begin{array}{r}23,9 \\
25,11 \\
25,11\end{array}$ \\
\hline & ANCHO & $\begin{array}{l}\text { Aer } \\
\text { An } \\
\text { Gral }\end{array}$ & $\begin{array}{c}10,2 \\
10,33 \\
10,27\end{array}$ & $\begin{array}{l}1,84 \\
1,87 \\
1,85\end{array}$ & $\begin{array}{l}18,07 \\
18,07 \\
18,06\end{array}$ & $\begin{array}{c}5,9 \\
5,97 \\
5,9\end{array}$ & $\begin{array}{r}13,9 \\
14,04 \\
14,04\end{array}$ \\
\hline
\end{tabular}

Tabla 39: medidas para diversas semillas arqueológicas de sitios del Area Andina Meridional. En la columna "identificación" se consigna la determinación taxonómica asignada tras el análisis microscópico de sus cubiertas seminales (ver sección II). En la columna "correspondencia con rangos actuales" se consigna la subespecie en cuyo rango de medidas actuales se ubica la medida de la semilla arqueológica. Las medidas estan en milímetros.

\begin{tabular}{|c|c|c|c|c|c|c|c|}
\hline Sitio & Ejemplar & Identificación & Estado & Largo & Ancho & Observaciones & $\begin{array}{l}\text { Correspondencia } \\
\text { con rangos } \\
\text { actuales }\end{array}$ \\
\hline \multirow[b]{3}{*}{ SSalLap20 } & A & C. aff. maxima & $\begin{array}{c}\text { Cubierta } \\
\text { seminal } \\
\text { seca }\end{array}$ & 16,9 & 9,5 & & $\begin{array}{l}\text { C. maxima ssp. } \\
\text { maxima }\end{array}$ \\
\hline & B & & $\begin{array}{c}\text { Cubierta } \\
\text { seminal } \\
\text { seca }\end{array}$ & rota & 9 & & $\begin{array}{l}\text { C. maxima ssp. } \\
\text { maxima }\end{array}$ \\
\hline & $\begin{array}{c}C \\
(2-224)\end{array}$ & & $\begin{array}{l}\text { Semilla } \\
\text { seca }\end{array}$ & 12,5 & 6,5 & & $\begin{array}{l}\text { Largo en el limite } \\
\text { inferior de } C \text {. } \\
\text { maxima ssp. } \\
\text { maxima; ancho en } \\
\text { el limite inferior de } \\
\text { C. maxima ssp. } \\
\text { andreana }\end{array}$ \\
\hline \multirow{3}{*}{$\begin{array}{l}\text { Puente } \\
\text { Río La } \\
\text { Viña I }\end{array}$} & L.Vi 1 & $\begin{array}{l}\text { C. maxima aff. } \\
\text { ssp. maxima }\end{array}$ & $\begin{array}{c}\text { Semilla } \\
\text { carbonizada }\end{array}$ & 12,52 & 6,52 & & $\begin{array}{l}\text { C. maxima ssp. } \\
\text { maxima }\end{array}$ \\
\hline & L.Vi 2 & $\begin{array}{l}\text { C. maxima aff. } \\
\text { ssp. maxima }\end{array}$ & $\begin{array}{c}\text { Semilla } \\
\text { carbonizada }\end{array}$ & 13,63 & 5,76 & & $\begin{array}{l}\text { C. maxima ssp. } \\
\text { maxima }\end{array}$ \\
\hline & L.Vi. 3 & $\begin{array}{l}\text { C. maxima aff. } \\
\text { ssp. maxima }\end{array}$ & $\begin{array}{c}\text { Semilla } \\
\text { carbonizada }\end{array}$ & 11 & 5 & & $\begin{array}{l}\text { Largo: C. maxima } \\
\text { ssp. maxima } \\
\text { Ancho: C. maxima } \\
\text { ssp andreana }\end{array}$ \\
\hline Los Viscos & LV13 & $\begin{array}{l}\text { C. maxima aff. } \\
\text { ssp. maxima }\end{array}$ & $\begin{array}{l}\text { Semilla } \\
\text { seca }\end{array}$ & 20,26 & 8,45 & & $\begin{array}{l}\text { C. maxima ssp. } \\
\text { maxima }\end{array}$ \\
\hline
\end{tabular}




\begin{tabular}{|c|c|c|c|c|c|c|c|}
\hline \multirow[t]{10}{*}{$\begin{array}{l}\text { Pampa } \\
\text { Grande }\end{array}$} & $\begin{array}{c}\text { Los } \\
\text { Aparejos } \\
\text { Sector } \\
\text { III/E1/20- } \\
40 \mathrm{~cm} . \\
\text { Q1 }\end{array}$ & $\begin{array}{l}\text { C. maxima aff. } \\
\text { ssp. maxima }\end{array}$ & $\begin{array}{l}\text { Semilla } \\
\text { seca }\end{array}$ & 20,29 & 9,79 & & $\begin{array}{l}\text { C. } \operatorname{maxima}_{\text {maxima }} \\
\text { asp. }\end{array}$ \\
\hline & $\begin{array}{l}\text { Los } \\
\text { Aparejos } \\
\text { Sector } \\
\text { III/E1/20- } \\
40 \mathrm{~cm} . \\
\text { QA }\end{array}$ & $\begin{array}{l}\text { C. maxima aff. } \\
\text { ssp. maxima }\end{array}$ & $\begin{array}{l}\text { Cubierta } \\
\text { seminal } \\
\text { seca }\end{array}$ & 16,88 & 6,55 & $\begin{array}{l}\text { Plegada sobre } \\
\text { el eje } \\
\text { longitudinal por } \\
\text { lo cual el valor } \\
\text { del ancho } \\
\text { puede estar } \\
\text { alterado }\end{array}$ & $\begin{array}{l}\text { C. maxima ssp. } \\
\text { maxima }\end{array}$ \\
\hline & $\begin{array}{l}\text { Los } \\
\text { Aparejos } \\
\text { Sector } \\
\text { III/E1/20- } \\
40 \mathrm{~cm} . \\
\text { QB }\end{array}$ & $\begin{array}{l}\text { C. maxima aff. } \\
\text { ssp. maxima }\end{array}$ & $\begin{array}{l}\text { Cubierta } \\
\text { seminal } \\
\text { seca }\end{array}$ & 16,27 & 7,39 & $\begin{array}{l}\text { Plegada sobre } \\
\text { el eje } \\
\text { longitudinal por } \\
\text { lo cual el valor } \\
\text { del ancho } \\
\text { puede estar } \\
\text { alterado }\end{array}$ & $\begin{array}{l}\text { C. maxima ssp. } \\
\text { maxima }\end{array}$ \\
\hline & $\begin{array}{l}\text { Los } \\
\text { Aparejos } \\
\text { Sector } \\
\text { III/E1/20- } \\
40 \mathrm{~cm} \text {. } \\
\text { QC }\end{array}$ & $\begin{array}{l}\text { C. maxima aff. } \\
\text { ssp. maxima }\end{array}$ & $\begin{array}{c}\text { Cubierta } \\
\text { seminal } \\
\text { seca }\end{array}$ & 16,86 & 8,2 & $\begin{array}{l}\text { Plegada sobre } \\
\text { el eje } \\
\text { longitudinal por } \\
\text { lo cual el valor } \\
\text { del ancho } \\
\text { puede estar } \\
\text { alterado }\end{array}$ & $\begin{array}{l}\text { C. } \operatorname{maxima}_{\text {maxima }} \text { ssp. } \\
\text { a }\end{array}$ \\
\hline & $\begin{array}{l}\text { Los } \\
\text { Aparejos } \\
\text { Sector } \\
\text { III/E1/20- } \\
40 \mathrm{~cm} \text {. } \\
\text { QD }\end{array}$ & $\begin{array}{l}\text { C. maxima aff. } \\
\text { ssp. maxima }\end{array}$ & $\begin{array}{l}\text { Cubierta } \\
\text { seminal } \\
\text { seca }\end{array}$ & -- & 9,28 & $\begin{array}{l}\text { Muy plegada } \\
\text { sobre el eje } \\
\text { transversal por } \\
\text { lo cual es } \\
\text { imposible } \\
\text { tomarle el largo. } \\
\text { Plegada sobre } \\
\text { el eje } \\
\text { longitudinal por } \\
\text { lo cual el valor } \\
\text { del ancho } \\
\text { puede estar } \\
\text { alterado }\end{array}$ & $\begin{array}{l}\text { C. maxima ssp. } \\
\text { maxima }\end{array}$ \\
\hline & $\begin{array}{c}\text { Caverna } \\
\text { III } \\
085\end{array}$ & $\begin{array}{l}\text { C. maxima aff. } \\
\text { ssp. maxima }\end{array}$ & $\begin{array}{l}\text { Semilla } \\
\text { Seca }\end{array}$ & 21,5 & 10,18 & & $\begin{array}{l}\text { C. maxima ssp. } \\
\text { maxima }\end{array}$ \\
\hline & $\begin{array}{l}\text { Los } \\
\text { Aparejos } \\
\text { Sector } \\
\text { III/E1/60- } \\
80 \mathrm{~cm} . \\
\text { S1 }\end{array}$ & $\begin{array}{l}\text { C. maxima aff. } \\
\text { ssp. maxima }\end{array}$ & $\begin{array}{c}\text { Dos } \\
\text { cubiertas } \\
\text { seminales } \\
\text { secas } \\
\text { unidas por } \\
\text { el borde }\end{array}$ & 14,1 & 9 & & $\begin{array}{l}\text { C. maxima ssp. } \\
\text { maxima }\end{array}$ \\
\hline & $\begin{array}{c}\text { Los } \\
\text { Aparejos } \\
\text { Sector } \\
\text { III/F1 } \\
\text { S2 }\end{array}$ & $\begin{array}{l}\text { C. maxima aff. } \\
\text { ssp. maxima }\end{array}$ & $\begin{array}{l}\text { Semilla } \\
\text { Seca }\end{array}$ & 17,63 & 9,84 & & $\begin{array}{l}\text { C. } \operatorname{maxima}_{\text {maxima }} \mathrm{ssp} \text {. } \\
\text { mate }\end{array}$ \\
\hline & $\begin{array}{c}\text { Los } \\
\text { Aparejos } \\
\text { Sector } \\
\text { III/F1 } \\
\text { S3 }\end{array}$ & $\begin{array}{l}\text { C. maxima aff. } \\
\text { ssp. maxima }\end{array}$ & $\begin{array}{l}\text { Semilla } \\
\text { Seca }\end{array}$ & 16,65 & 8,75 & & $\begin{array}{l}\text { C. maxima ssp. } \\
\text { maxima }\end{array}$ \\
\hline & $\begin{array}{l}\text { Los } \\
\text { Aparejos } \\
\text { Sector } \\
\text { III/F2/40- } \\
60 \mathrm{~cm} . \\
\text { S4 }\end{array}$ & $\begin{array}{l}\text { C. maxima aff. } \\
\text { ssp. maxima }\end{array}$ & $\begin{array}{l}\text { Semilla } \\
\text { Seca }\end{array}$ & 19,13 & 8,54 & & $\begin{array}{l}\text { C. } \operatorname{maxima}_{\text {maxima }} \text { ssp. } \\
\text {. }\end{array}$ \\
\hline
\end{tabular}




\begin{tabular}{|c|c|c|c|c|c|c|c|}
\hline & $\begin{array}{c}\text { El Litro } \\
\text { C1, capa } \\
1 \\
\text { S5 }\end{array}$ & $\begin{array}{l}\text { C. maxima aff. } \\
\text { ssp. maxima }\end{array}$ & $\begin{array}{l}\text { Semilla } \\
\text { Seca }\end{array}$ & 20,91 & 10,47 & & $\begin{array}{l}\text { C. maxima ssp. } \\
\text { maxima }\end{array}$ \\
\hline El Shincal & Ushnu & $\begin{array}{c}\text { C. maxima } \\
\text { ssp. maxima }\end{array}$ & $\begin{array}{c}\text { Semilla } \\
\text { carbonizada }\end{array}$ & 12,9 & 8,9 & & $\begin{array}{l}\text { C. maxima ssp. } \\
\text { maxima }\end{array}$ \\
\hline Bandurria & $372 F$ & C. aff. maxima & $\begin{array}{l}\text { Semilla } \\
\text { Seca }\end{array}$ & & 5,93 & Semilla rota & $\begin{array}{l}\text { C.maxima ssp. } \\
\text { andreana }\end{array}$ \\
\hline \multirow[b]{3}{*}{$\begin{array}{c}\text { Co. } \\
\text { Lampay }\end{array}$} & $17 / 1248$ & $\begin{array}{l}\text { C. aff. maxima } \\
\text { ssp. maxima }\end{array}$ & $\begin{array}{l}\text { Semilla } \\
\text { Seca }\end{array}$ & 14,87 & 10,39 & & $\begin{array}{l}\text { C. maxima ssp. } \\
\text { maxima }\end{array}$ \\
\hline & $18 / 1235 A$ & $\begin{array}{l}\text { C. aff. maxima } \\
\text { ssp. maxima }\end{array}$ & $\begin{array}{l}\text { Semilla } \\
\text { Seca }\end{array}$ & 15,62 & 12,46 & & $\begin{array}{l}\text { C. maxima ssp. } \\
\text { maxima }\end{array}$ \\
\hline & $13 / 1200$ & $\begin{array}{l}\text { C. aff. maxima } \\
\text { ssp. andreana }\end{array}$ & $\begin{array}{l}\text { Semilla } \\
\text { Seca }\end{array}$ & 11,3 & 7,12 & & $\begin{array}{c}\text { Largo: valor } \\
\text { intermedio entre } \\
\text { los registrados } \\
\text { para ambas } \\
\text { subespecies } \\
\text { Ancho: en el limite } \\
\text { inferior de } C \text {. } \\
\text { maxima ssp } \\
\text { maxima }\end{array}$ \\
\hline
\end{tabular}

Tabla 40: datos métricos publicados para semillas de C. maxima ssp. maxima recuperadas en sitios del Area Andina Meridional. En la columna "correspondencia con rangos actuales" se consigna la subespecie en cuyo rango de medidas actuales se ubica la medida de la semilla arqueológica. Las medidas estan en milímetros.

\begin{tabular}{|c|c|c|c|c|c|c|c|}
\hline País & Sitio & Cronología & Bibliografía & $\begin{array}{c}\text { Ejemplar } \\
\mathrm{N}^{\mathrm{O}}\end{array}$ & Largo & Ancho & $\begin{array}{c}\text { Correspondencia } \\
\text { con rangos } \\
\text { actuales }\end{array}$ \\
\hline \multirow{4}{*}{$\begin{array}{l}\text { Perú Valle } \\
\text { de Casma } \\
\text { (costa) }\end{array}$} & \multirow{4}{*}{$\begin{array}{l}\text { Huaynum } \\
\text { a }\end{array}$} & \multirow{4}{*}{$2000 B C$} & \multirow{4}{*}{ Whitaker 1980} & 1 & 20,8 & 13 & $\begin{array}{l}\text { C. maxima ssp. } \\
\text { maxima }\end{array}$ \\
\hline & & & & 2 & 23,4 & 14,3 & $\begin{array}{l}\text { C. maxima ssp. } \\
\text { maxima }\end{array}$ \\
\hline & & & & 3 & 26 & 16,9 & $\begin{array}{l}\text { C. maxima ssp. } \\
\text { maxima }\end{array}$ \\
\hline & & & & 4 & 20,8 & 13 & $\begin{array}{l}\text { C. maxima ssp. } \\
\text { maxima }\end{array}$ \\
\hline \multirow{4}{*}{$\begin{array}{l}\text { Argentina, } \\
\text { San Juan, } \\
\text { Calingasta }\end{array}$} & \multirow{4}{*}{$\begin{array}{l}\text { Gruta de } \\
\text { los } \\
\text { Morillos }\end{array}$} & \multirow{4}{*}{$\begin{array}{c}\text { Ansilta } 0-50 \\
\text { DC }\end{array}$} & \multirow{4}{*}{ Roig 1977} & 1 & 24 & 12 & $\begin{array}{l}\text { C. maxima ssp. } \\
\text { maxima }\end{array}$ \\
\hline & & & & 2 & 16 & 10 & $\begin{array}{l}\text { C. maxima ssp. } \\
\text { maxima }\end{array}$ \\
\hline & & & & 3 & 17 & 11 & $\begin{array}{l}\text { C. maxima ssp. } \\
\text { maxima }\end{array}$ \\
\hline & & & & 4 & 12 & 8 & $\begin{array}{c}\text { Largo: valor } \\
\text { intermedio entre } \\
\text { los registrados } \\
\text { para ambas } \\
\text { subespecies } \\
\text { Ancho: C. maxima } \\
\text { ssp. maxima }\end{array}$ \\
\hline \multirow[t]{2}{*}{$\begin{array}{l}\text { Argentina, } \\
\text { San Juan, } \\
\text { Calingasta }\end{array}$} & \multirow[t]{2}{*}{$\begin{array}{l}\text { Gruta de } \\
\text { los } \\
\text { Morillos }\end{array}$} & \multirow[t]{2}{*}{$\begin{array}{l}\text { Ansilta 50- } \\
210 \text { DC }\end{array}$} & \multirow[t]{2}{*}{ Roig 1977} & 5 & 17 & 10 & $\begin{array}{l}\text { C. maxima ssp. } \\
\text { maxima }\end{array}$ \\
\hline & & & & 6 & 19 & 10 & $\begin{array}{l}\text { C. maxima ssp. } \\
\text { maxima }\end{array}$ \\
\hline
\end{tabular}




\begin{tabular}{|c|c|c|c|c|c|c|c|}
\hline & & & & 7 & 16 & 11 & $\begin{array}{l}\text { C. maxima ssp. } \\
\text { maxima }\end{array}$ \\
\hline & & & & 8 & 13 & 6 & $\begin{array}{l}\text { Largo: en el límite } \\
\text { inferior de } C . \\
\text { maxima ssp. } \\
\text { maxima } \\
\text { Ancho: en el límite } \\
\text { superior de } C \text {. } \\
\text { maxima ssp. } \\
\text { andreana }\end{array}$ \\
\hline $\begin{array}{l}\text { Argentina, } \\
\text { San Juan, } \\
\text { Calingasta }\end{array}$ & $\begin{array}{c}\text { Gruta de } \\
\text { los } \\
\text { Morillos } \\
\end{array}$ & $\begin{array}{l}\text { Ansilta 210- } \\
375 \text { DC }\end{array}$ & Roig 1977 & 9 & 15 & 8 & $\begin{array}{l}\text { C. maxima ssp. } \\
\text { maxima }\end{array}$ \\
\hline \multirow{3}{*}{$\begin{array}{l}\text { Argentina, } \\
\text { San Juan, } \\
\text { Calingasta }\end{array}$} & \multirow{3}{*}{$\begin{array}{c}\text { Gruta de } \\
\text { los } \\
\text { Morillos }\end{array}$} & \multirow{3}{*}{$\begin{array}{l}\text { Ansilta 280- } \\
375 \text { DC }\end{array}$} & \multirow{3}{*}{ Roig 1977} & 10 & 20 & 9 & $\begin{array}{l}\text { C. maxima ssp. } \\
\text { maxima }\end{array}$ \\
\hline & & & & 11 & 21 & 10 & $\begin{array}{l}\text { C. maxima ssp. } \\
\text { maxima }\end{array}$ \\
\hline & & & & 12 & 17 & 10 & $\begin{array}{l}\text { C. maxima ssp. } \\
\text { maxima }\end{array}$ \\
\hline \multirow{10}{*}{$\begin{array}{l}\text { Perú, Valle } \\
\text { de Ica }\end{array}$} & \multirow{10}{*}{ Sitio F } & \multirow{10}{*}{$\begin{array}{c}\text { Ocucaje } \\
\text { Período } \\
\text { Medio Proto- } \\
\text { Nazca } 500 \\
\text { AD }\end{array}$} & \multirow{10}{*}{ Carter 1945} & 1 & 20 & 12 & $\begin{array}{l}\text { C. maxima ssp. } \\
\text { maxima }\end{array}$ \\
\hline & & & & 2 & 20 & 12 & $\begin{array}{l}\text { C. maxima ssp. } \\
\text { maxima }\end{array}$ \\
\hline & & & & 3 & 20 & 13 & $\begin{array}{l}\text { C. maxima ssp. } \\
\text { maxima }\end{array}$ \\
\hline & & & & 4 & 19 & 12 & $\begin{array}{c}\text { C. maxima ssp. } \\
\text { maxima }\end{array}$ \\
\hline & & & & 5 & 19 & 11 & $\begin{array}{c}\text { C. maxima ssp. } \\
\text { maxima }\end{array}$ \\
\hline & & & & 6 & 18 & 9 & $\begin{array}{l}\text { C. maxima ssp. } \\
\text { maxima }\end{array}$ \\
\hline & & & & 7 & 19 & 9 & $\begin{array}{l}\text { C. maxima ssp. } \\
\text { maxima }\end{array}$ \\
\hline & & & & 8 & 16 & 10 & $\begin{array}{l}\text { C. maxima ssp. } \\
\text { maxima }\end{array}$ \\
\hline & & & & 9 & 17 & 8 & $\begin{array}{l}\text { C. maxima ssp. } \\
\text { maxima }\end{array}$ \\
\hline & & & & 10 & 16 & 9 & $\begin{array}{l}\text { C. maxima ssp. } \\
\text { maxima }\end{array}$ \\
\hline \multirow{4}{*}{$\begin{array}{l}\text { Perú, San } \\
\text { Nicolas, } \\
\text { cerca de } \\
\text { Supe }\end{array}$} & \multirow{4}{*}{$\begin{array}{c}\text { San } \\
\text { Nicolas }\end{array}$} & \multirow{4}{*}{$\begin{array}{c}\text { Período } \\
\text { Medio } 1200 \\
\text { AD }\end{array}$} & \multirow{4}{*}{ Carter 1945} & 1 & 26 & 12 & $\begin{array}{l}\text { C. maxima ssp. } \\
\text { maxima }\end{array}$ \\
\hline & & & & 2 & 27 & 14 & $\begin{array}{c}\text { C. maxima ssp. } \\
\text { maxima }\end{array}$ \\
\hline & & & & 3 & 28 & 14 & $\begin{array}{l}\text { C. maxima ssp. } \\
\text { maxima }\end{array}$ \\
\hline & & & & 4 & 25 & 13 & $\begin{array}{l}\text { C. maxima ssp. } \\
\text { maxima }\end{array}$ \\
\hline \multirow[t]{6}{*}{$\begin{array}{l}\text { Perú, Valle } \\
\text { de Ica }\end{array}$} & \multirow[t]{6}{*}{ Sitio M } & \multirow[t]{6}{*}{$\begin{array}{c}\text { Chulpaca } \\
\text { Período } \\
\text { Medio Ica II, } \\
1300-1400 \\
\text { AD }\end{array}$} & \multirow[t]{6}{*}{ Carter 1945} & 1 & 26 & 13 & $\begin{array}{l}\text { C. maxima ssp. } \\
\text { maxima }\end{array}$ \\
\hline & & & & 2 & 25 & 13 & $\begin{array}{l}\text { C. maxima ssp. } \\
\text { maxima }\end{array}$ \\
\hline & & & & 3 & 25 & 12 & $\begin{array}{l}\text { C. maxima ssp. } \\
\text { maxima }\end{array}$ \\
\hline & & & & 4 & 21 & 13 & $\begin{array}{l}\text { C. maxima ssp. } \\
\text { maxima }\end{array}$ \\
\hline & & & & 5 & 20 & 13 & $\begin{array}{l}\text { C. maxima ssp. } \\
\text { maxima }\end{array}$ \\
\hline & & & & 6 & 20 & 10 & $\begin{array}{l}\text { C. maxima ssp. } \\
\text { maxima }\end{array}$ \\
\hline
\end{tabular}




\begin{tabular}{|c|c|c|c|c|c|c|c|}
\hline & & & & 7 & 12 & 12 & $\begin{array}{c}\text { Largo: valor } \\
\text { intermedio entre } \\
\text { los registrados } \\
\text { para ambas } \\
\text { subespecies } \\
\text { Ancho: C. maxima } \\
\text { ssp. maxima }\end{array}$ \\
\hline \multirow[t]{2}{*}{$\begin{array}{c}\text { Argentina, } \\
\text { Mendoza }\end{array}$} & \multirow[t]{2}{*}{$\begin{array}{c}\text { Cueva del } \\
\text { Toro }\end{array}$} & & \multirow[t]{2}{*}{$\begin{array}{l}\text { Whitaker } 1983 \\
\text { (material } \\
\text { excavado por } \\
\text { Prieto en } \\
1978 \text { ) }\end{array}$} & 1 & 20 & 6 & $\begin{array}{l}\text { Largo: C. maxima } \\
\text { ssp. maxima } \\
\text { Ancho: en el limite } \\
\text { superior de } C \text {. } \\
\text { maxima ssp. } \\
\text { andreana }\end{array}$ \\
\hline & & & & 2 & 15 & 8 & $\begin{array}{l}\text { C. maxima ssp. } \\
\text { maxima }\end{array}$ \\
\hline $\begin{array}{c}\text { Argentina, } \\
\text { Neuquen }\end{array}$ & $\begin{array}{l}\text { Cueva } \\
\text { Epullan } \\
\text { Grande }\end{array}$ & $\begin{array}{l}\text { Colonial } \\
\text { temprano }\end{array}$ & $\begin{array}{c}\text { Urrutia y } \\
\text { Bogazzi } 1996\end{array}$ & 1 & 9 & 6 & $\begin{array}{l}\text { C. maxima ssp. } \\
\text { andreana }\end{array}$ \\
\hline
\end{tabular}

Tabla 41: valores de CV para largo y ancho de sitios arqueológicos con conjuntos de semillas de C. maxima, la cantidad de semillas por sitio se señala en la columna "N".

\begin{tabular}{|c|c|c|c|}
\hline $\begin{array}{c}\text { Sitio y } \\
\text { cronología }\end{array}$ & N & CV Largo & CV Ancho \\
\hline $\begin{array}{c}\text { Pampa } \\
\text { Grande } \\
260-430 \text { DC }\end{array}$ & 11 & 13,15 & 13,46 \\
\hline $\begin{array}{c}\text { Gruta de los } \\
\text { Morillos. } \\
\text { Ansilta 0-50 } \\
\text { DC }\end{array}$ & 4 & 28,94 & 16,66 \\
\hline $\begin{array}{c}\text { Gruta de los } \\
\text { Morillos. } \\
\text { Ansilta 50- } \\
\text { 210 DC }\end{array}$ & 4 & 15,38 & 23,97 \\
\hline $\begin{array}{c}\text { Gruta de los } \\
\text { Morillos. }\end{array}$ & 3 & 10,77 & 5,97 \\
$\begin{array}{c}\text { Ansitta 280- } \\
375 \text { DC }\end{array}$ & 4 & 10,94 & 12,86 \\
\hline $\begin{array}{c}\text { Huaynuma } \\
\text { 2000 AC }\end{array}$ & 10 & 8,57 & 16,34 \\
\hline $\begin{array}{c}\text { Sitio F. } \\
\text { Ocucaje } \\
\text { Proto- } \\
\text { Nazca 500 } \\
\text { AD }\end{array}$ & 1 & 4,87 & 7,23 \\
\hline $\begin{array}{c}\text { San } \\
\text { Nicolás. } \\
\text { Periodo } \\
\text { Medio 1200 } \\
\text { AD }\end{array}$ & 4 & 22,65 & 9,06 \\
\hline $\begin{array}{c}\text { Sitio M } \\
\text { Chulpaca } \\
1300-1400 \\
\text { AD }\end{array}$ & 7 & & \\
\hline
\end{tabular}


Figura 17: terminología de referencia para el estudio de semillas de Cucurbita sp. En la imagen de la izquierda se señalan las áreas principales de la semilla. En la imagen de la derecha se señalan los planos de corte efectuados para el estudio micromorfológico.
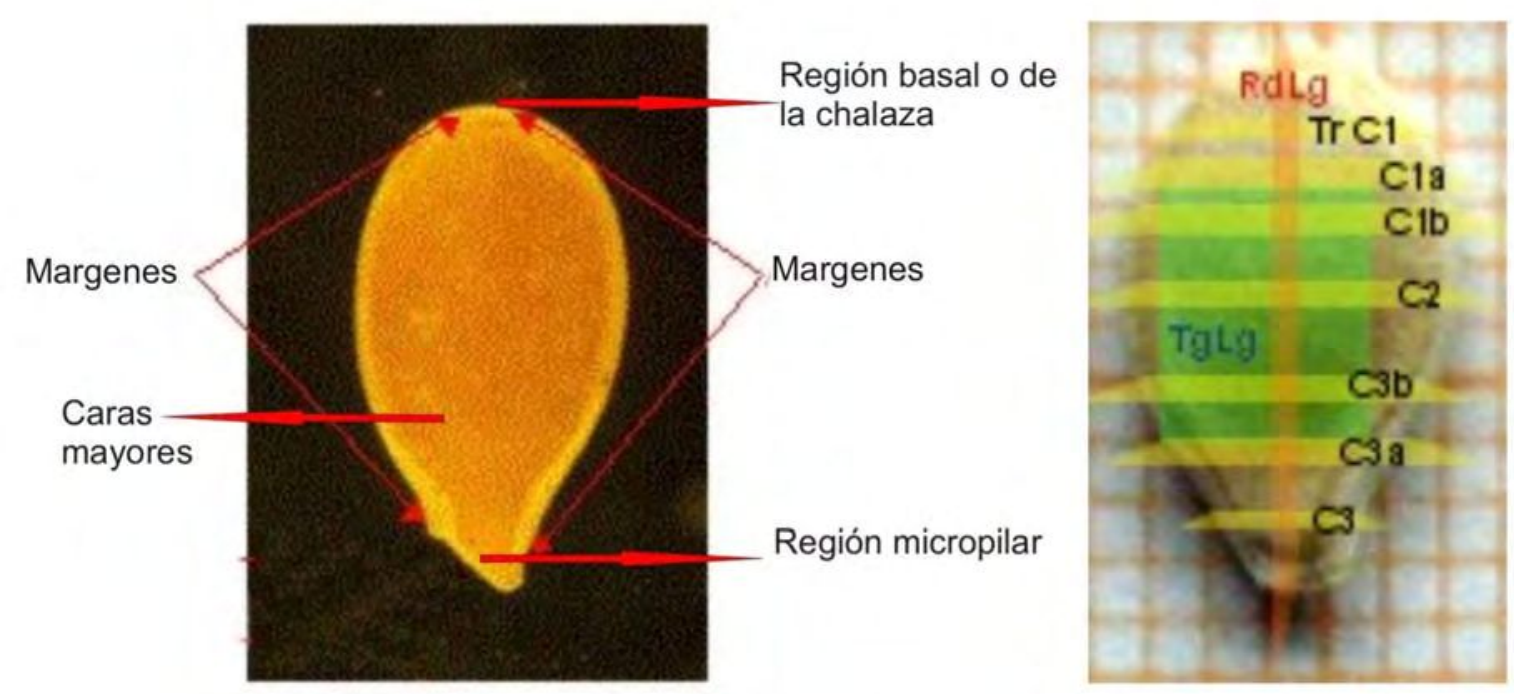

Figura 18: ubicación de sitios arqueológicos con restos de semillas de Cucurbita spp. mencionados en este capítulo.

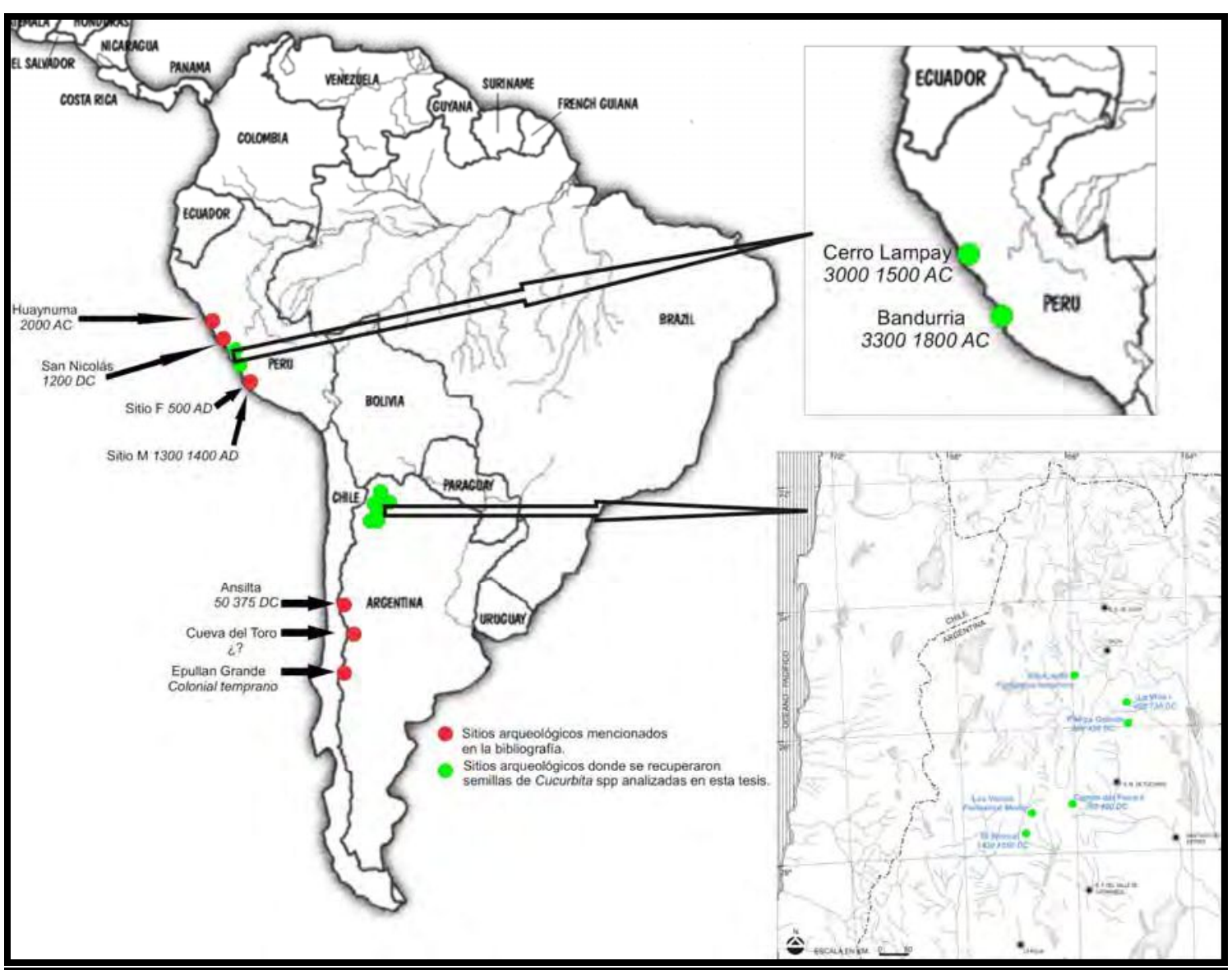


Figura 19: comparación de las cubiertas seminales de la semilla carbonizada identificada por Oliszewski (2004) como C. maxima (A) y de una semilla de Solanum elaeagnifolium carbonizada experimentalmente (tomada de Capparelli 1997) (B)

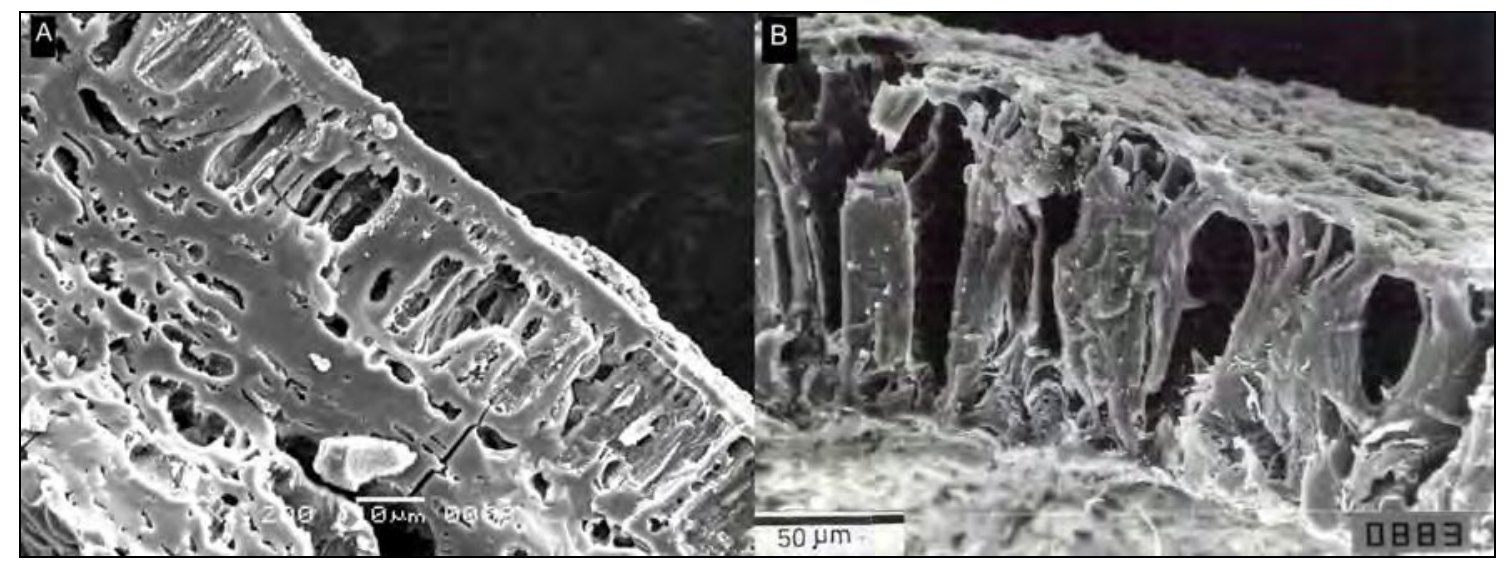

Gráfico 4: Cantidad de semillas de cinco cultivares de C. maxima ssp maxima macroscópicamente analizados.

Bolivianos; 57 ; $38 \%$

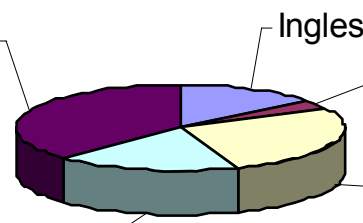

Zapallito; 28;

$18 \%$ ngles; $21 ; 14 \%$

Criollo; $5 ; 3 \%$

Hubbard; 41;

$27 \%$ 
Gráfico 5: dispersión de las medidas para largo y ancho en los tres conjuntos de semillas de C. maxima ssp andreana agrupados de acuerdo al tipo de polinización.

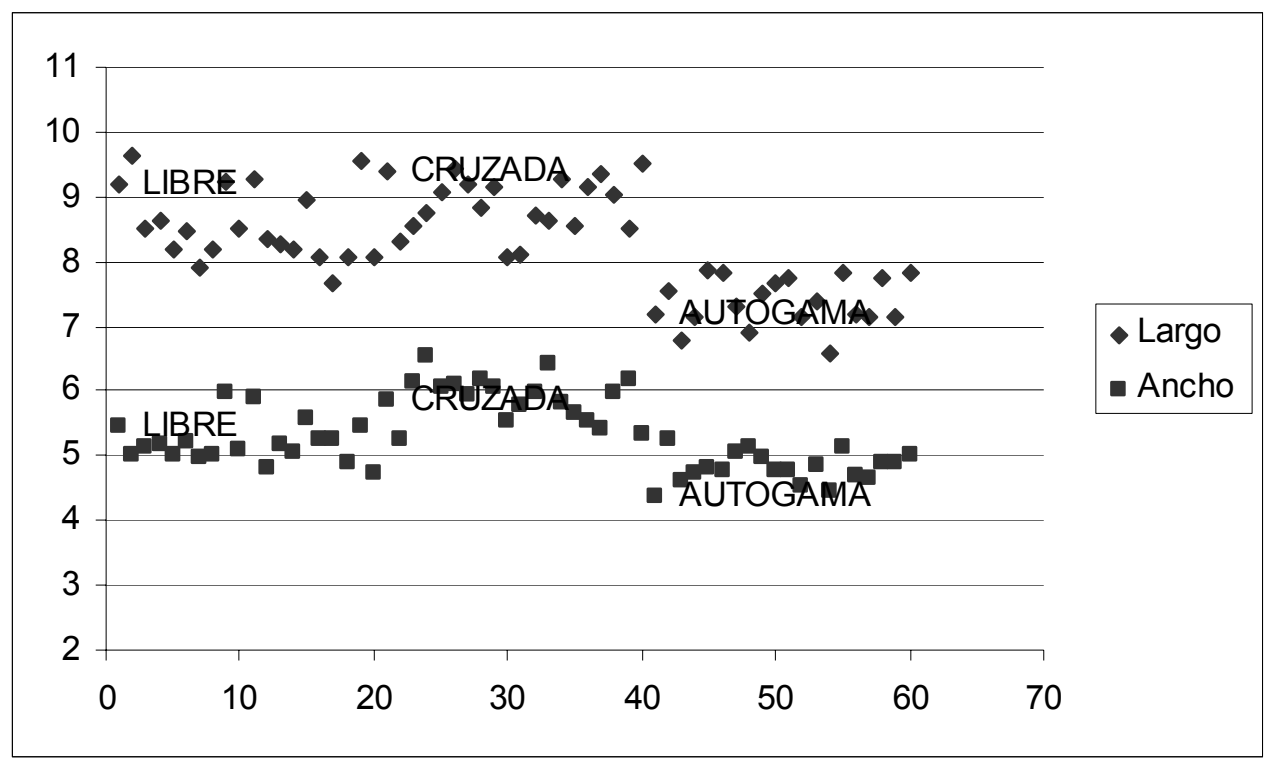

Gráfico 6: dispersión de las medidas para largo y ancho en los cinco cultivares de C. maxima ssp maxima.

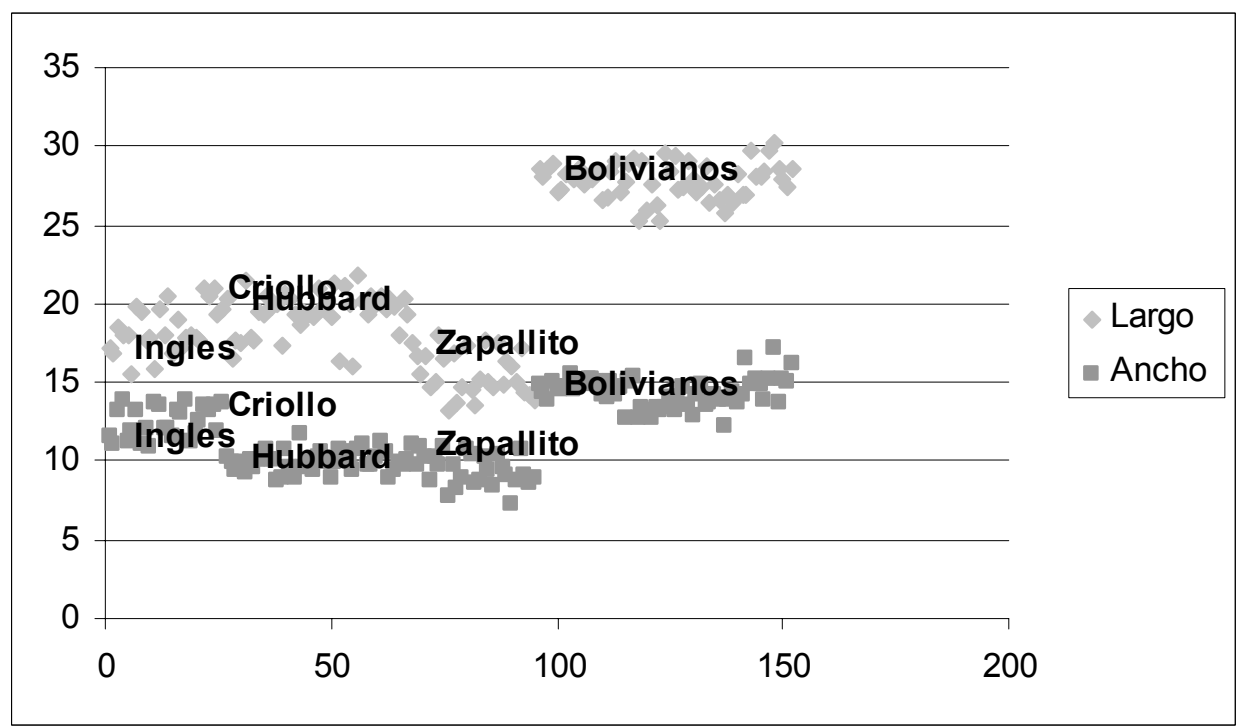


Gráfico 7: rango de tamaño para el largo de semillas actuales de C. maxima ssp maxima y $C$. maxima ssp. andreana.

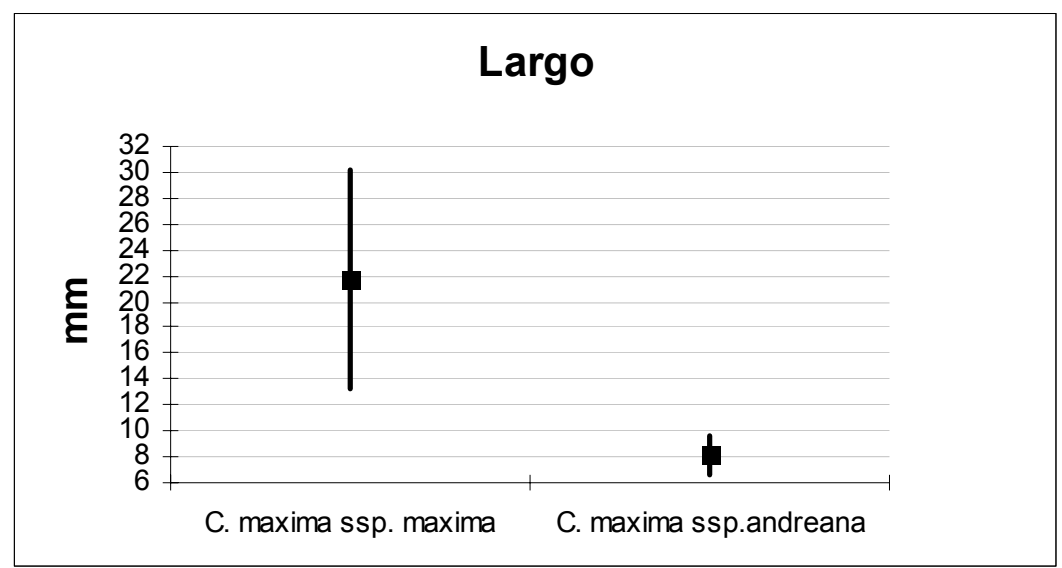

Gráfico 8: rango de tamaño para el ancho de semillas actuales de C. maxima ssp maxima y $C$. maxima ssp. andreana.

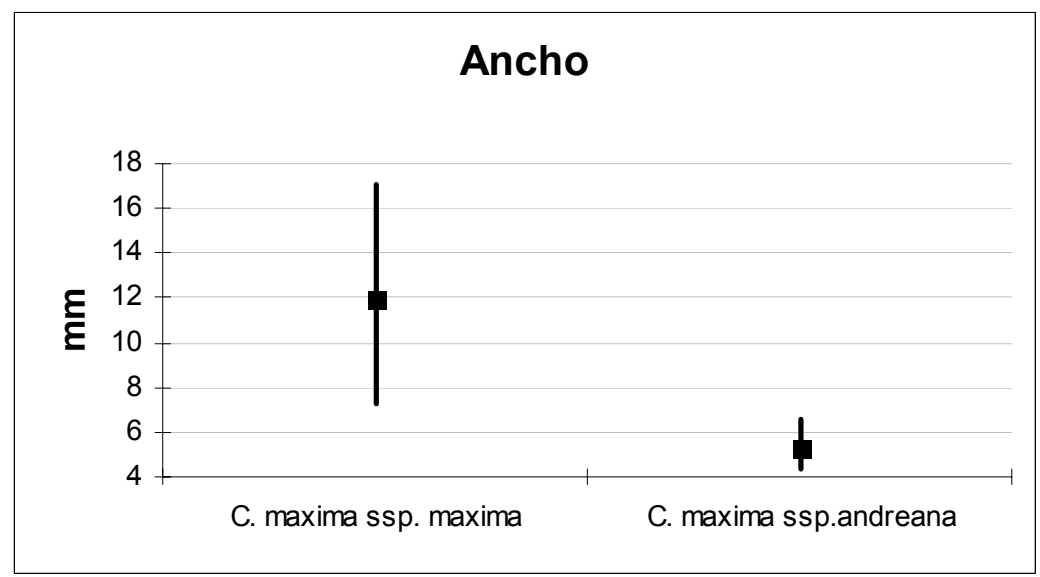


Gráfico 9: dispersión de las medidas correspondientes al largo las semillas desecadas analizadas en las tablas 24 y 25 . Se consignan los rangos de valores de C. maxima ssp maxima $(\mathrm{Cmm})$ y C. maxima ssp andreana (Cma) como referencia general. La cronología aumenta de izquierda a derecha. Iniciales de los sitios y cronología: CL: Cerro Lampay (3000-1500 AC); H: sitio Huaynuma (2000 AC); AI: Gruta de los Morrillos Ansilta I (050DC); AII: Gruta de los Morrillos Ansilta II (50-120 DC); AIII: Gruta de los Morrillos Ansilta III (210-375 DC); AIV: Gruta de los Morrillos Ansilta IV (280-375 DC); PG: Pampa Grande (260-430DC); PD: Puente del Diablo (Formativo Temprano); FI: sitio Fv (500 DC); LV: Los Viscos (Formativo medio); CT: Cueva del Toro (Formativo Medio); SN: San Nicolás (1200 DC); M: Sitio F (1300-1400 DC); CEG: Cueva Epullen Grande (Colonial temprano).

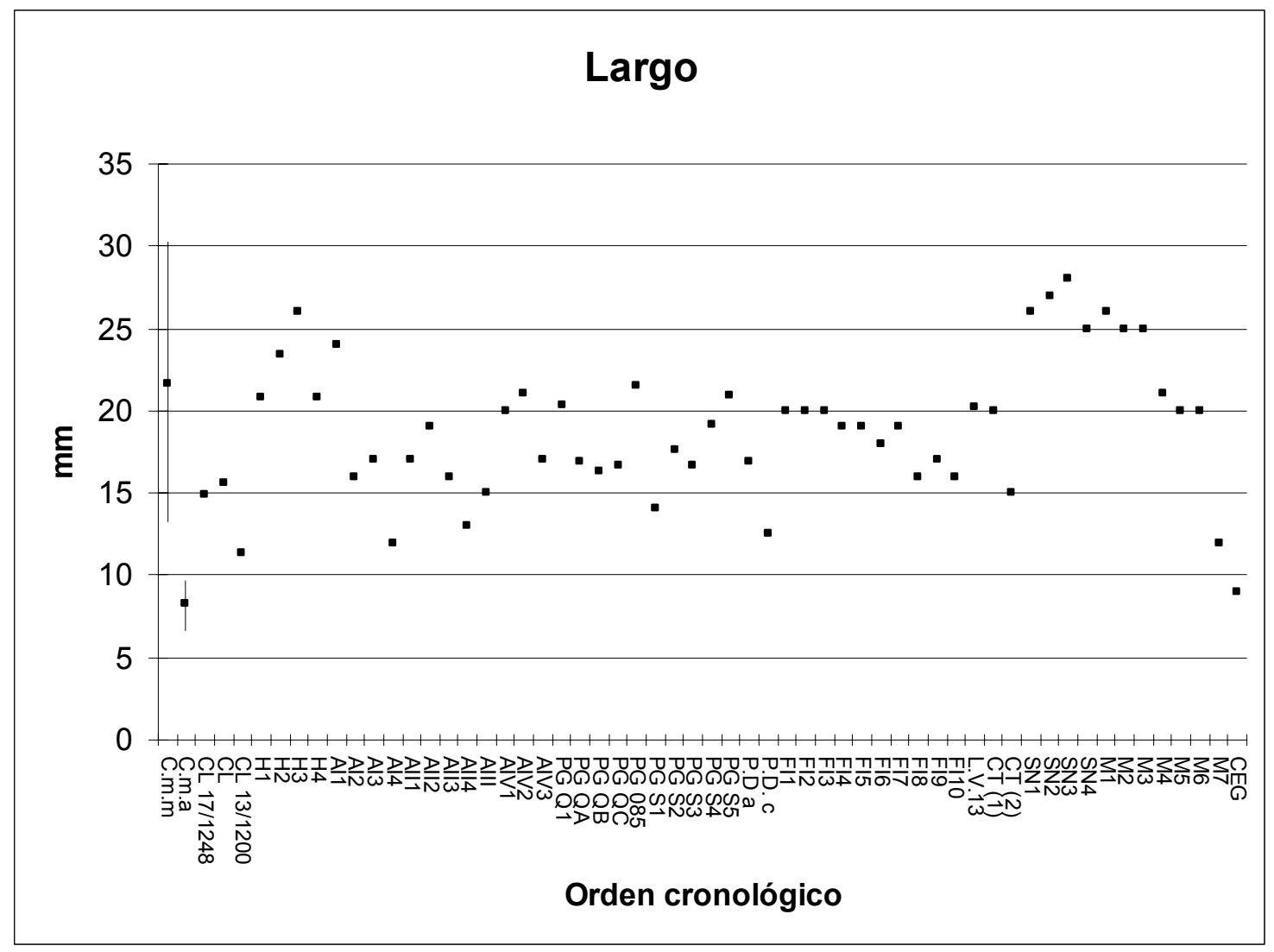


Gráfico 10: dispersión de las medidas correspondientes al ancho de las semillas desecadas analizadas en las tablas 24 y 25 . Se consignan los rangos de valores de C. maxima ssp maxima $(\mathrm{Cmm})$ y C. maxima ssp andreana $(\mathrm{Cma})$ como referencia general. La cronología aumenta de izquierda a derecha. Iniciales de los sitios y cronología: B: Bandurria (33001800AC); CL: Cerro Lampay (3000-1500 AC); H: sitio Huaynuma (2000 AC); AI: Gruta de los Morrillos Ansilta I (0-50DC); AII: Gruta de los Morrillos Ansilta II (50-120 DC); AIII: Gruta de los Morrillos Ansilta III (210-375 DC); AIV: Gruta de los Morrillos Ansilta IV (280-375 DC); PG: Pampa Grande (260-430DC); PD: Puente del Diablo (Formativo Temprano); FI: sitio Fv (500 DC); LV: Los Viscos (Formativo medio); CT: Cueva del Toro (Formativo Medio); SN: San Nicolás (1200 DC); M: Sitio F (1300-1400 DC); CEG: Cueva Epullen Grande (Colonial temprano).

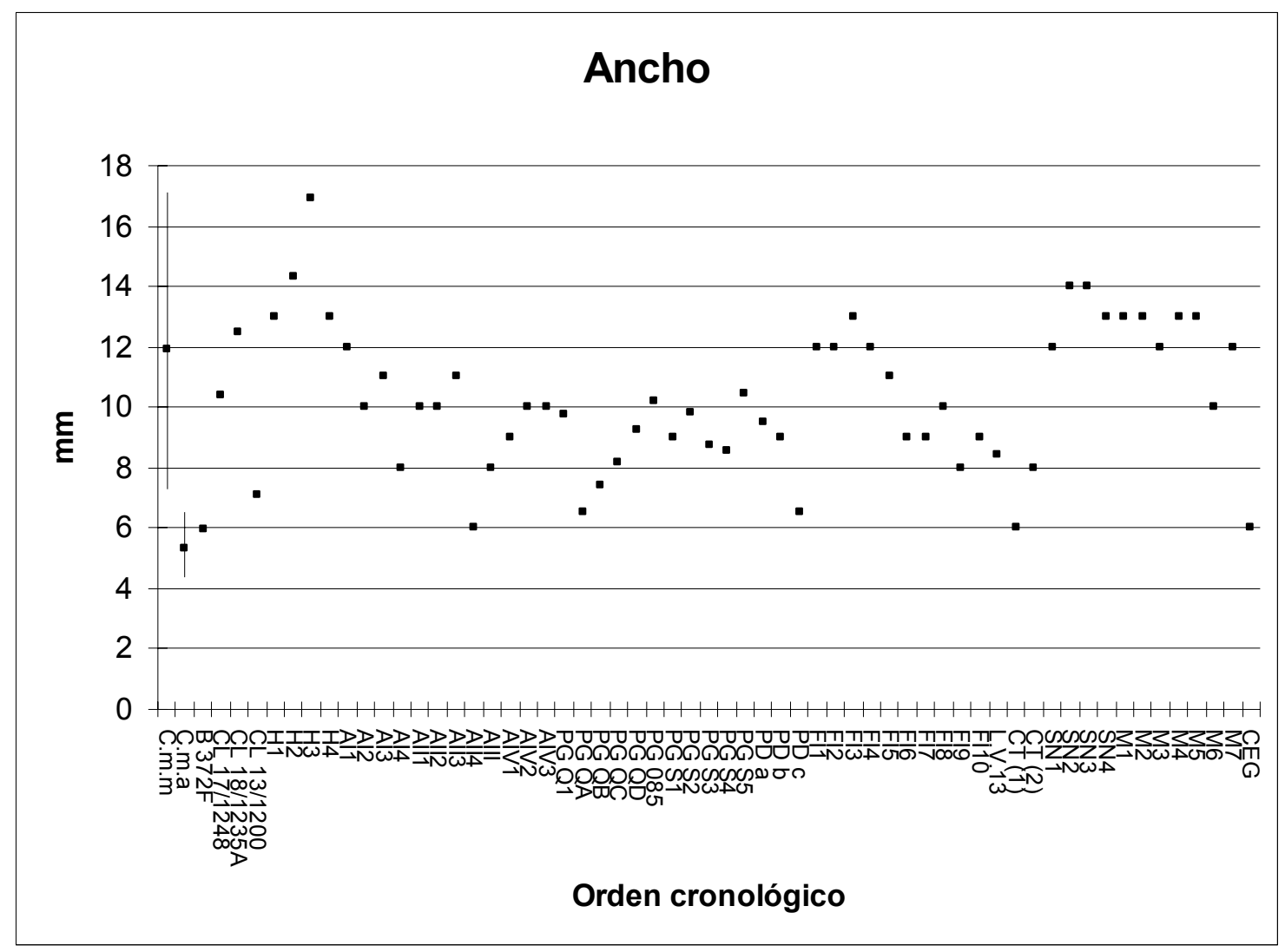



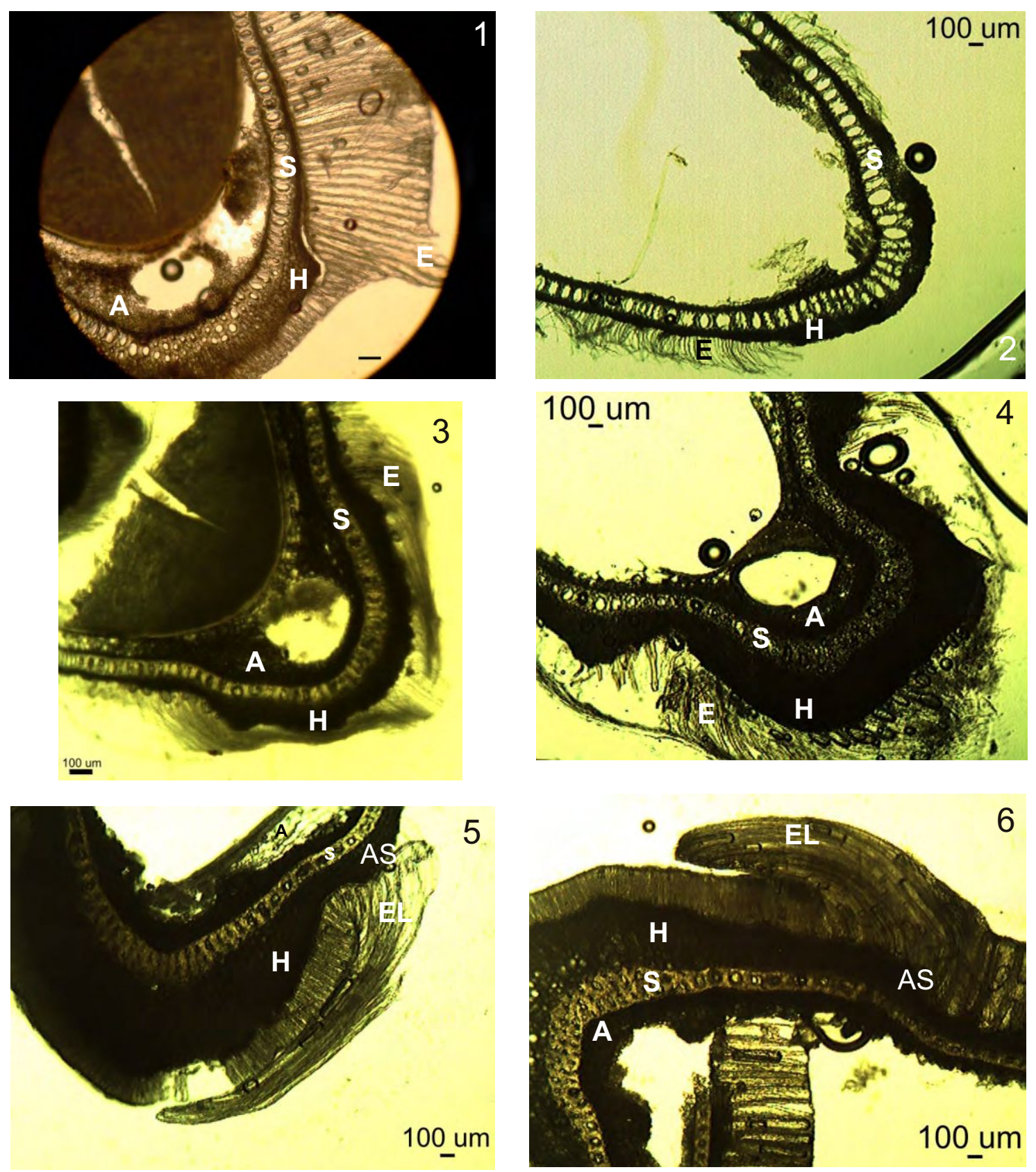

Márgenes de taxa sudamericanos de Cucurbita sp., Cortes transversales en $\mathrm{C} 2$

1: C maxima ssp maxima cv criollo; 2: C maxima ssp andreana;

3: C maxima ssp maxima, ejemplar de los valles de Salta; 4: C ficifolia; 5 y 6: C moschata; E: epidermis, EL: células epidérmicas largas, $\mathrm{H}$ : hipodermis, $\mathrm{S}$ : esclerénquima, A: aerénquima, AS: arco submarginal. 

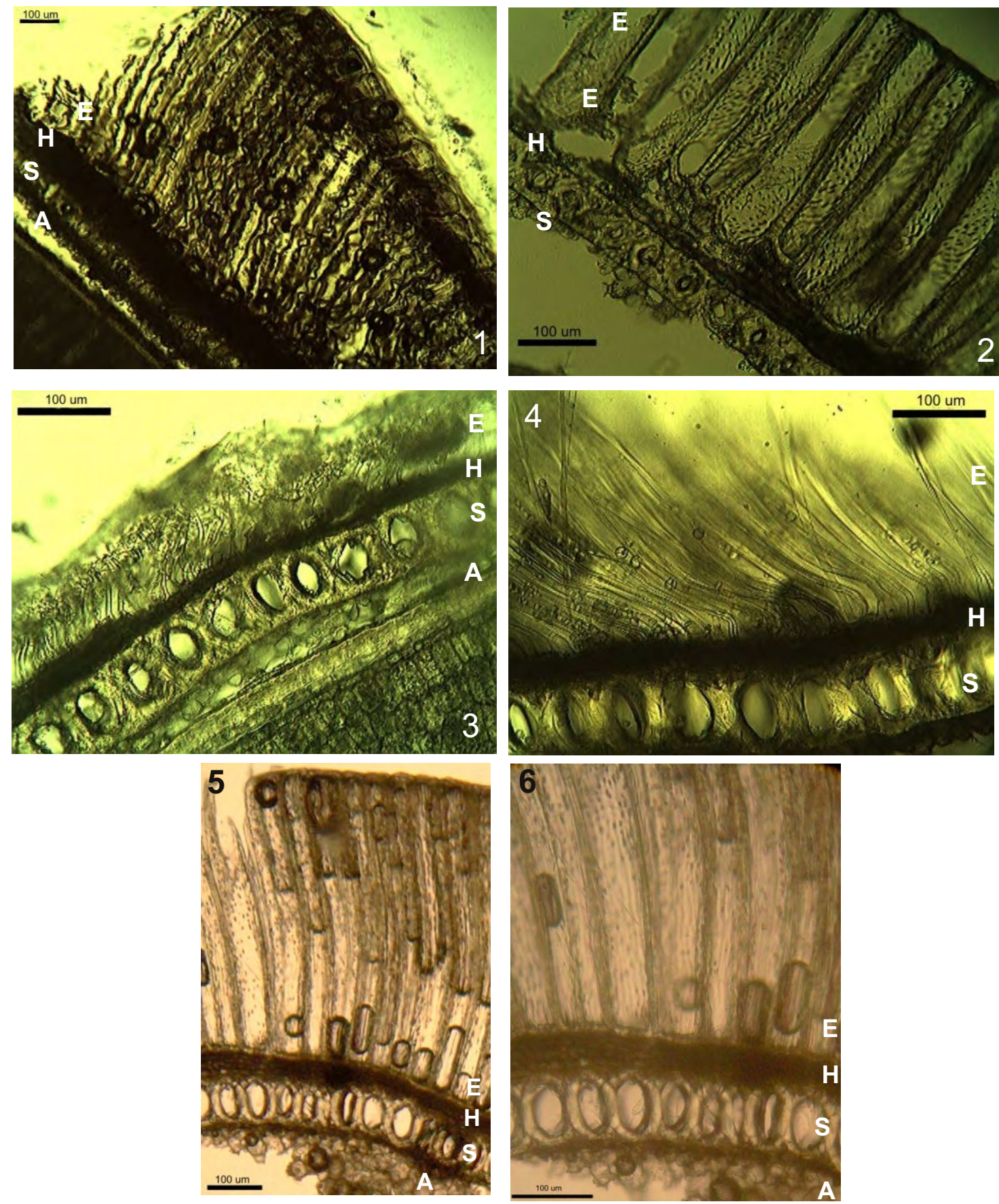

Caracteres de la epidermis de taxa sudamericanos de Cucurbita sp. Cortes transversales en C2.

1: C ficifolia; 2:C moschata; 3: C maxima ssp andreana;

4: $C$ maxima ssp maxima cv hubbard; 5 y 6: $C$ maxima ssp maxima cv criollo; E: epidermis, H: hipodermis, $S$ : esclerénquima, $A$ : aerénquima, 

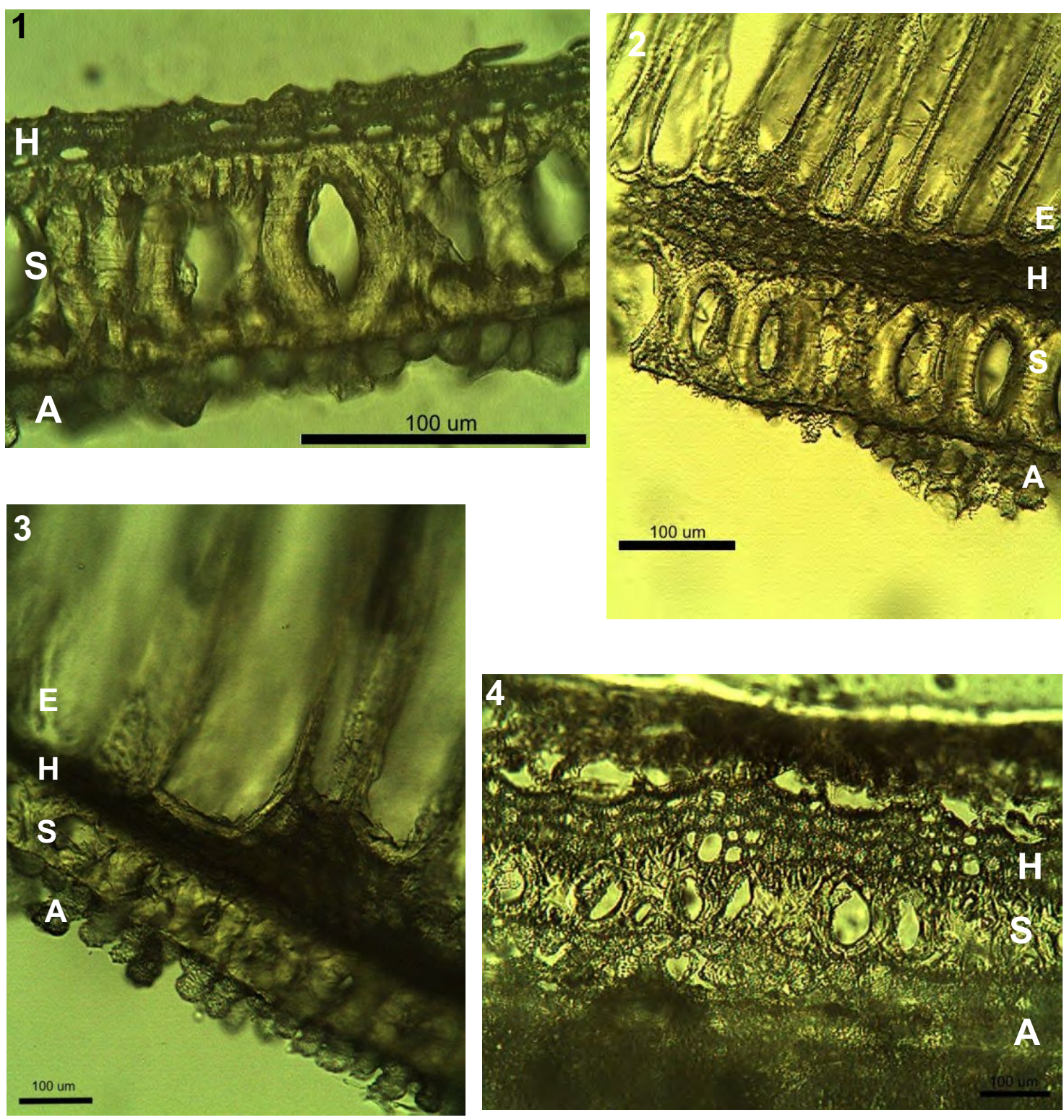

Caracteres de la hipodermis de taxa sudamericanos de Cucurbita sp. Cortes transversales en C2.

1: C maxima ssp andreana; 2:C maxima ssp maxima cv criollo ; 3: C moschata; 4: C ficifolia;

$\mathrm{E}$ : epidermis, $\mathrm{H}$ : hipodermis, $S$ : esclénquima, $A$ : aerénquima, 

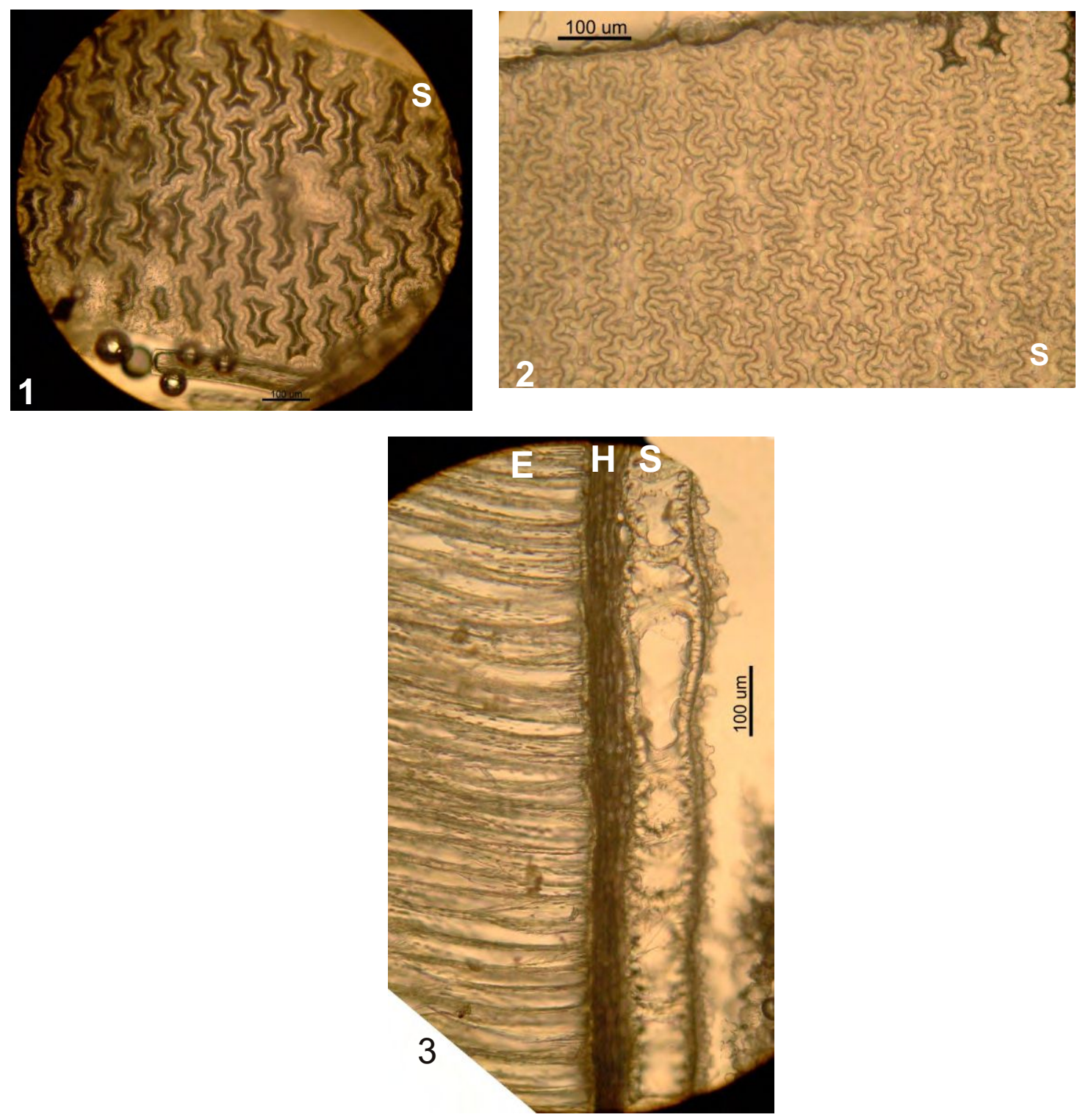

Caracteres del esclerénquima de taxa sudamericanos de Cucurbita $\mathrm{sp}$ en corte tangencial longitudinal (1 y 2) y longitudinal radial (3) en C2. 1 y 3: C maxima ssp maxima cv criollo; 2 : C maxima ssp andreana: $\mathrm{E}$ : epidermis, $\mathrm{H}$ : hipodermis, $\mathrm{S}$ : esclerénquima 

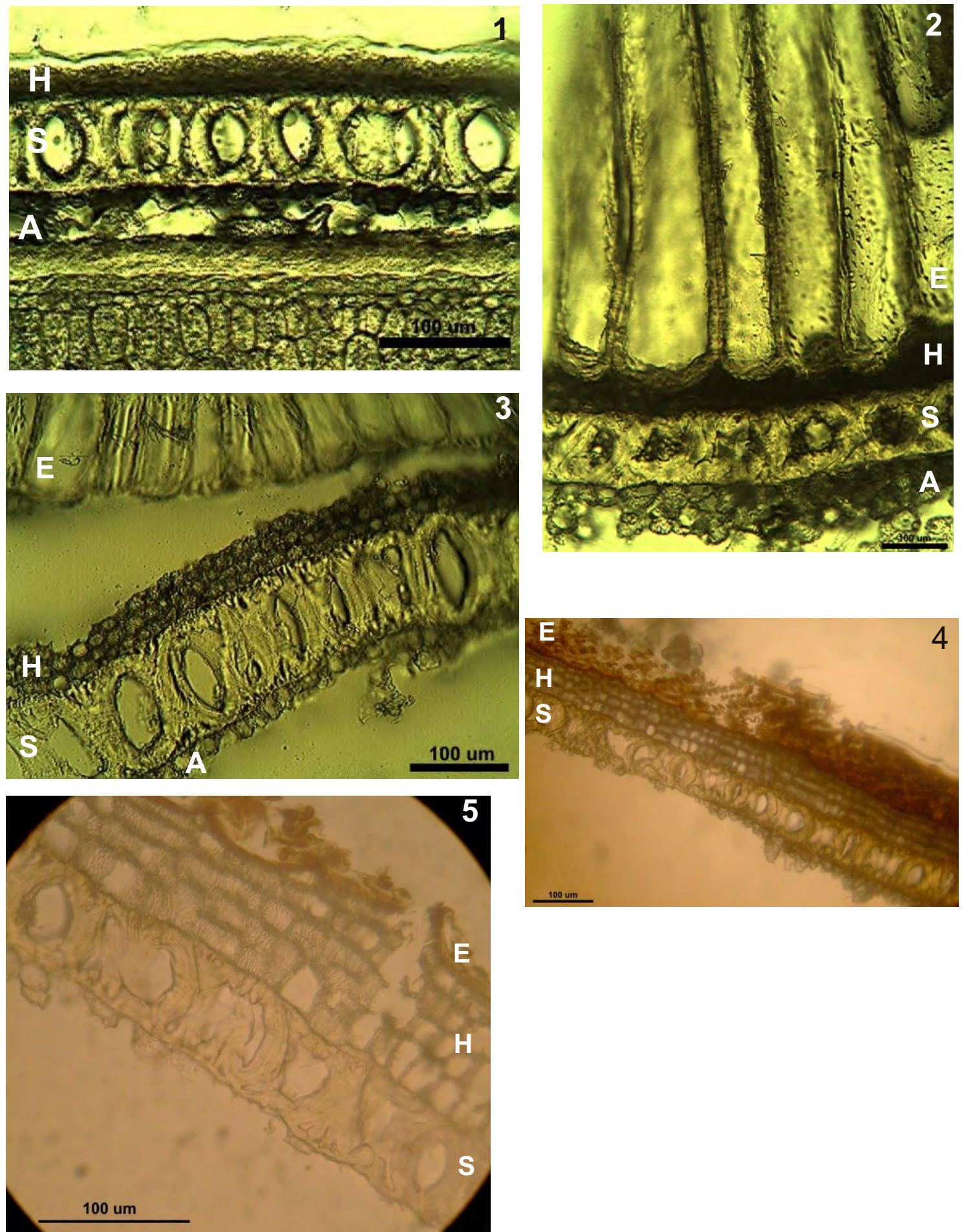

Caracteres del esclerénquima de taxa sudamericanos de Cucurbita sp. Cortes transversales en C2.1: C maxima ssp andreana; 2:C moschata; 3:C maxima ssp maxima cv criollo ; 4 y 5: C ficifolia; $\mathrm{E}$ : epidermis, $\mathrm{H}$ : hipodermis,S: esclerénquima, A: aerénquima, 
LAMINA 9
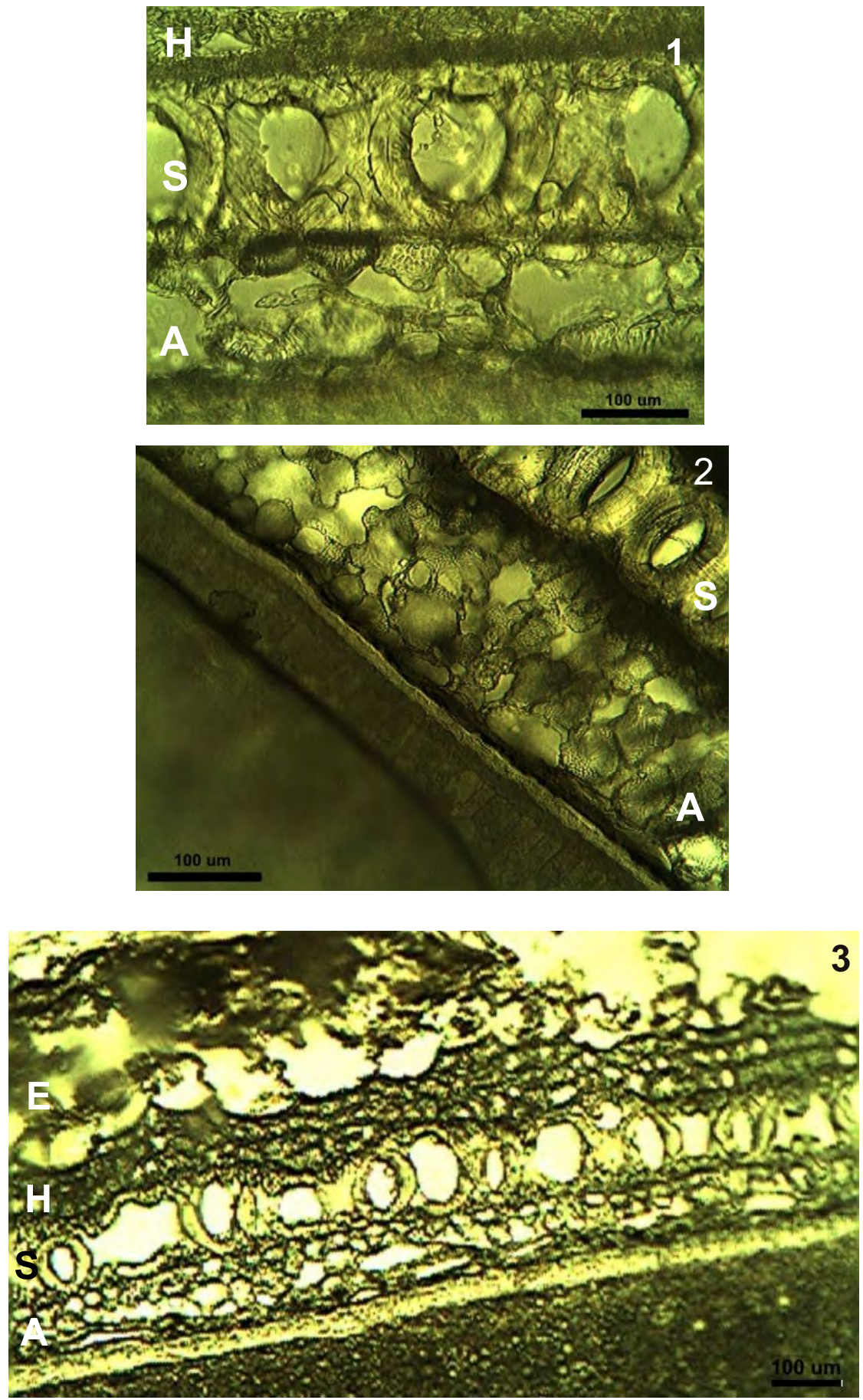

Caracteres del aerénquima de taxa sudamericanos de Cucurbita sp. Cortes transversales en C2.1: C maxima ssp andreana; 2: C maxima ssp maxima cv hubbard ;3:C ficifolia $\mathrm{E}$ : epidermis, $\mathrm{H}$ : hipodermis, $\mathrm{S}$ : esclerénquima, $A$ : aerénquima, 

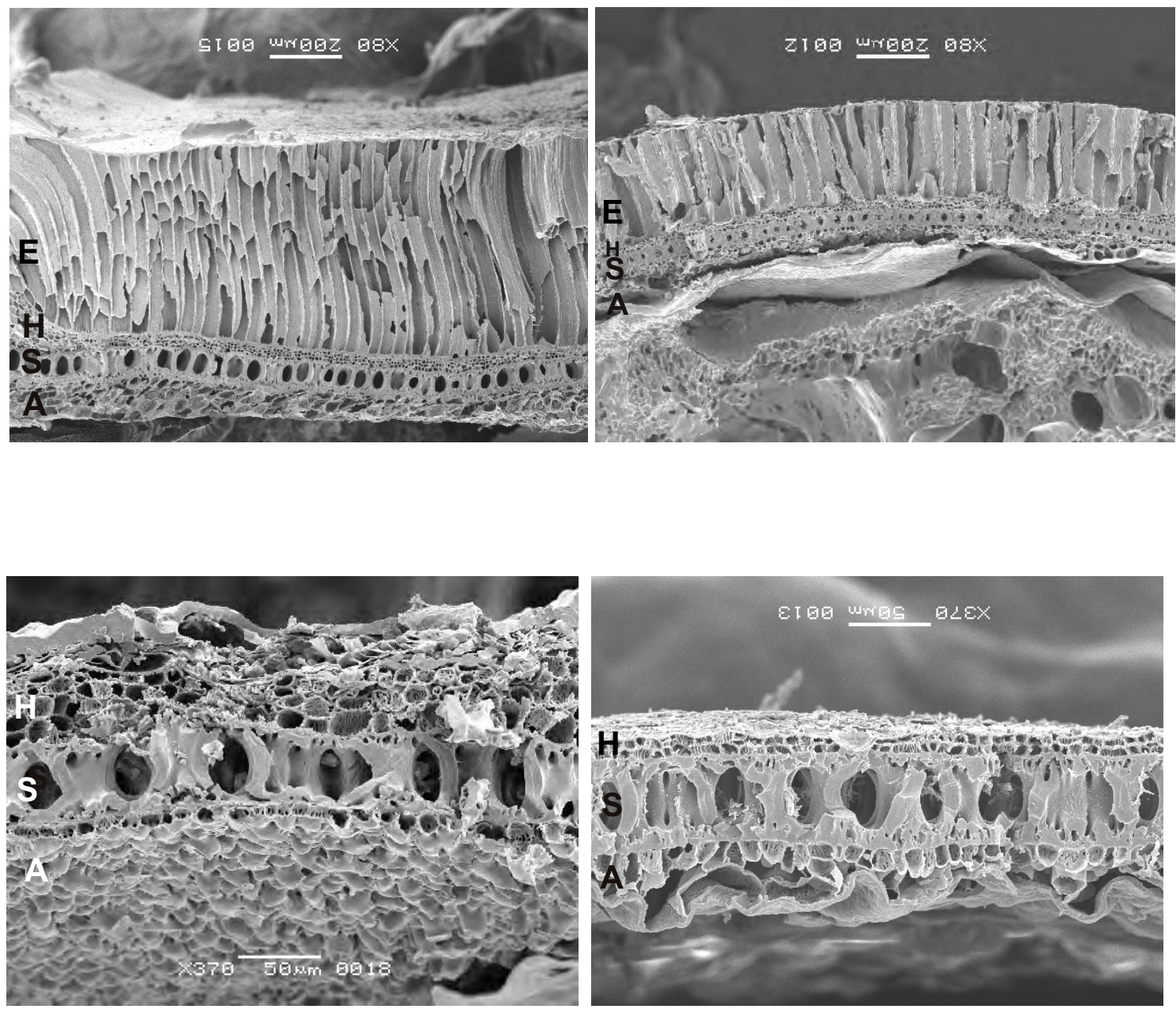

Caracteres de las cubiertas seminales de cinco taxa sudamericanos tras carbonización experimental a $300^{\circ} \mathrm{C}$ por $120^{\prime}$

Cortes transversales (C2)

1: C maxima ssp maxima cv criollo; 2: C moschata; 3: C ficifolia; 4: C maxima ssp andreana 

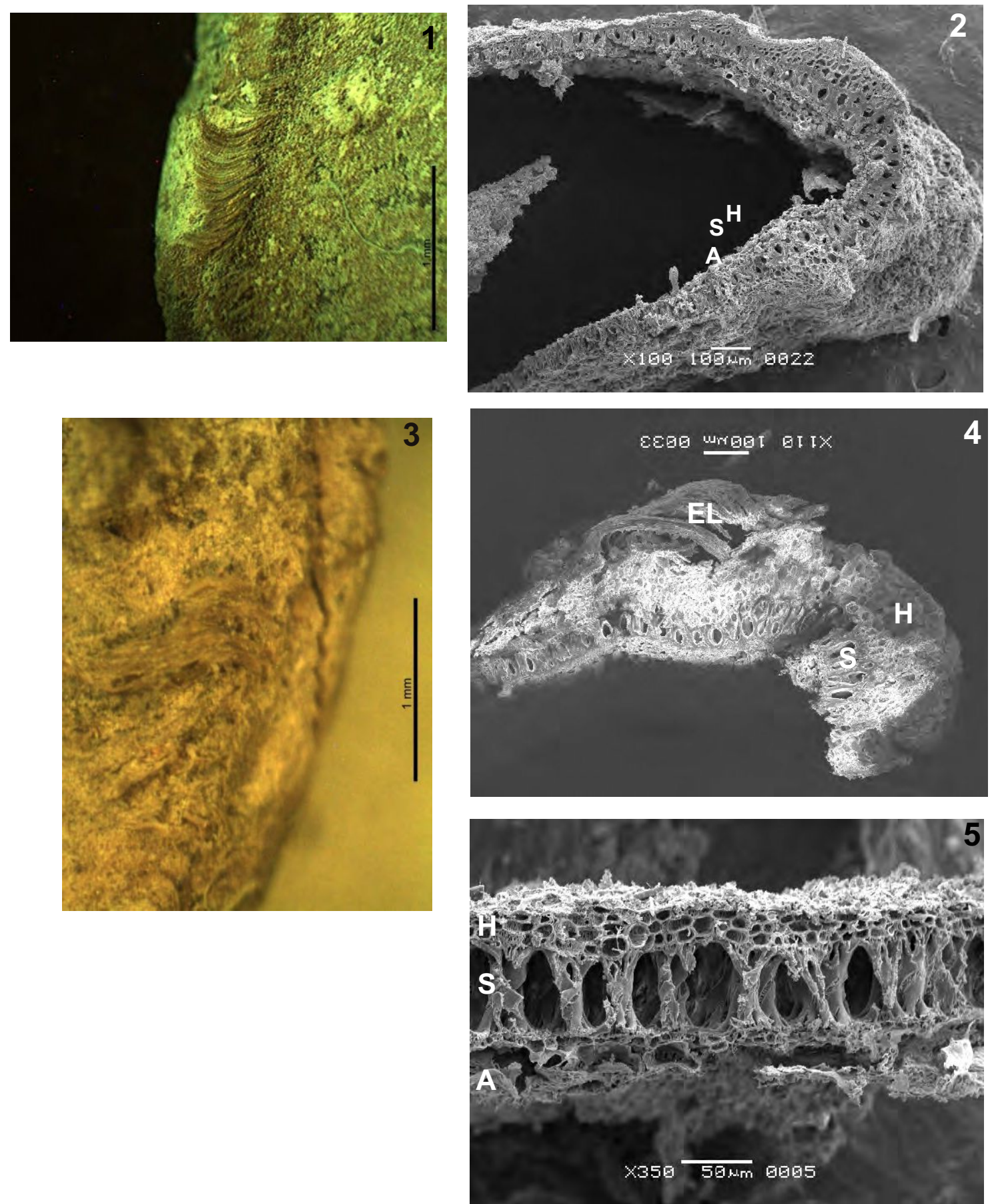

Semillas de arqueológicas desecadas, 1 y 2: Bandurria 425FA C aff maxima ssp maxima o $C$ aff moschata, semilla que presenta células epidérmicas largas en el margen observables bajo microscopio estereoscópico (1), pero ausentes al MEB (2); 3 y 4: Co. Lampay 1059 C aff maxima ssp maxima o C aff moschata, semilla que presenta células epidérmicas largas en el margen observables bajo microscopio estereoscópico (3) y al MEB (4); 5: Co. Lampay 13!1200 C maxima aff andreana, semilla que ha perdido por completo las células epidérmicas en caras mayores. 

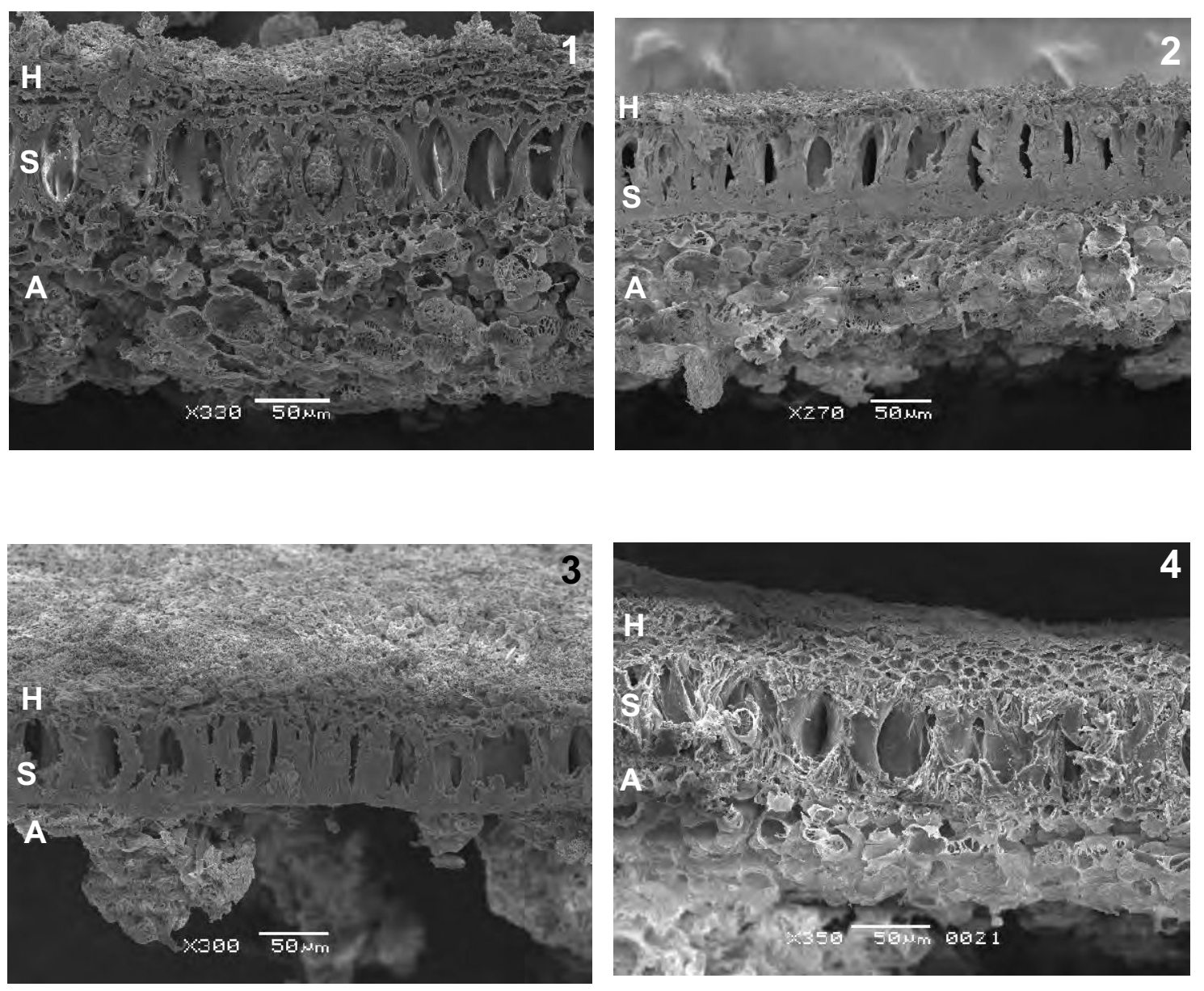

Semillas arqueológicas desecadas donde puede verse el buen estado de preservación de la capa esclerenquimática, la ausencia de la epidermis, la preservación diferencial del aerénquima y las células hipodérmicas colapsadas en mayor o menor grado. 1: Pampa Grande S3 C maxima aff spp maxima; 2: Pampa Grande S4 C maxima aff spp maxima; 3: Pampa Grande S5 C maxima aff ssp maxima; 4: Los Viscos 25 C aff moschata. 

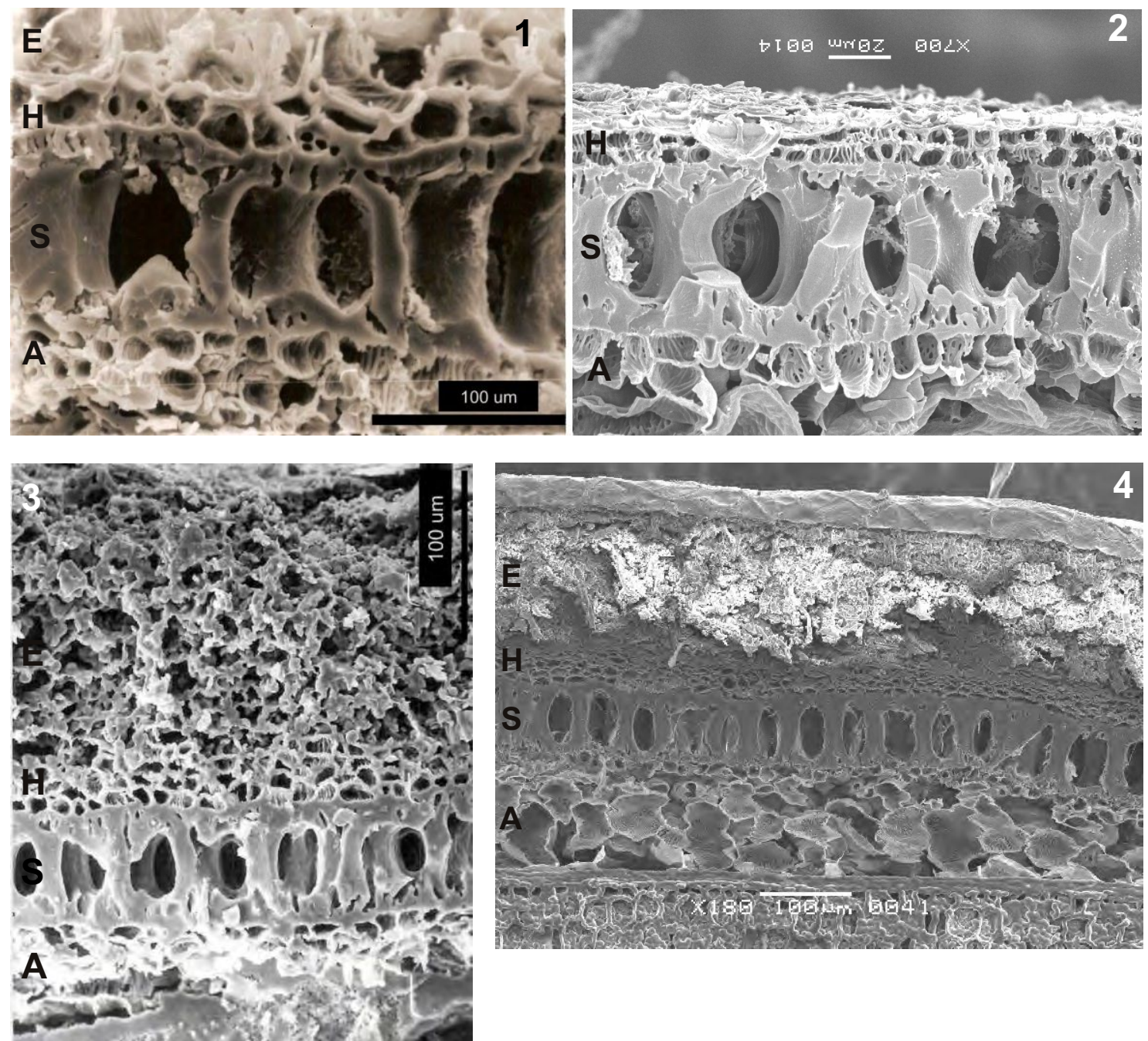

Semillas arqueológicas carbonizadas y su comparación con ejemplares actuales del taxón al cual fueron asignadas.

1: Puente Río La Viña I SD C. maxima aff ssp andreana; 2: semilla carbonizada (300/120') de C maxima ssp andreana; 3: El Shincal

C maxima ssp maxima aff cv zapallito; 4: semilla fresca de C maxima ssp maxima cv zapallito. 


\subsection{1d- ESTUDIO MORFO-ANATOMICO EN MACRORRESTOS DE CUCURBITÁCEAS: FRUTO}

\section{Introducción}

Dentro de los estudios de domesticación del género Cucurbita, el análisis de los cambios sufridos en la morfología del fruto han sido fundamentales puesto que se cree que fue principalmente sobre este órgano que operaron presiones selectivas ejercidas por las poblaciones humanas durante el proceso de domesticación (Smith 2000, Cowan y Smith 1993, Cowan 1997).

Si bien los frutos de las especies silvestres de dicho género son generalmente globosos y lisos, los de las especies domesticadas son muy variables (Tabla 42, láminas 14 y 15), lo cual disipa su valor diagnóstico en la identificación taxonómica. En este sentido debemos destacar como excepción la forma "turbante", "turbaniforme" o "cabeza de turco" exclusivo de C. maxima ssp. maxima que se produce cuando el ovario sale por fuera del receptáculo (Lira Saade 1995) (lámina 14).

De todas las especies sudamericanas del género Cucurbita, C. moschata es la que posee mayor diversidad en la morfología del fruto, en tanto $C$. ficifolia es la más homogénea (Tabla 42, lámina 15). Esta última especie posee siempre frutos redondeados a oblongos de superficie lisa con sólo dos colores: verde y/o blanco, lo que redunda en el hecho de que no hay cultivares bien definidos dentro de esta especie (León 1987). Entre las explicaciones que dan cuenta del motivo por el cual C. ficifolia permaneció genética y morfológicamente monomórfica se incluyen:1) una variación genética inicialmente baja dentro de la especie; 2) un único evento de domesticación que resultó en un taxón aislado de su progenitor silvestre; 3) un único genotipo que se popularizó en las distintas áreas de distribución; 4) baja intensidad en la selección de cultivares; 5) la domesticación ocurrió en un único tipo de hábitat; 6) su 
domesticación es reciente y por lo tanto el tiempo de diversificación es escaso comparado con otras especies de Cucurbita (Andres 1990). Lagenaria siceraria posee una diversidad muy marcada en la morfología de sus frutos, siendo además destacable el enorme rango de medidas que pueden exhibir los mismos (Whitaker 1948, Teppner 2004) (Tabla 42, lámina 16)

Resultan de gran importancia los caracteres del mesocarpio (Tabla 42) ya que es la porción del fruto que -junto con las semillas- se consumen con mayor frecuencia. Los caracteres del mismo son generalmente mencionados por los cultivadores al momento de seleccionar formas deseadas (ver capitulo 5), puesto que sus características resultan fundamentales en lo que respecta a las preparaciones culinarias en las cuales intervienen las distintas especies de zapallos. Además tanto las características del mesocarpio como el grosor del pericarpio resultan claves para determinar las posibilidades de conservación y almacenaje de los frutos.

El objetivo de este capítulo radica principalmente en analizar los cambios que se irán produciendo en las poblaciones vegetales de C. maxima sujetas a manejo humano a través del análisis arqueológico de restos de fruto de este taxón. Es por ello que se considerará específicamente los caracteres de los frutos de la subespecie espontánea (C. maxima ssp andreana), puesto que es el representante actual no cultivado más cercano a C. maxima ssp. maxima.

Los frutos de C. maxima ssp andreana son particularmente diversos en forma, pudiendo ser ovoides, oblongos, globosos, piriformes, esféricos o deprimidos (Tabla 43, lámina 17), incluso una misma planta puede dar frutos ovoides y globosos (Ashworth 1997). El color varía entre verde claro y amarillento y posee estrías longitudinales generalmente más claras (Millán 1945, Martínez Crovetto en Burkart 1974, Lira Saade 1995, Ashworth y Galetto 2001). En general todos los autores concuerdan en que los frutos de esta especie son lisos, la única referencia a frutos con lóbulos es reportada por Millán (1945) en ejemplares procedentes de Cruz del Eje, provincia de Córdoba, Argentina. Sin 
embargo este rasgo, junto con otros que poseían estos frutos (vg. espesor de la cáscara, tamaño del fruto y presencia de lóbulos) ha llevado a autores como Lira Saade (1995) a considerar estos caracteres como producto de la cruza de poblaciones de C. maxima ssp andreana con otras de C. maxima ssp maxima, catalogando por lo tanto a esta población cordobesa como híbrida. Sin embargo, no debemos pensar que la presencia de lóbulos es ajena a la subespecie C. maxima ssp andreana ya que la posibilidad de producir frutos lobulados tendría que haber estado presente en el acervo génico de la misma para ser luego seleccionada y fijada por selección cultural (R. Pozner com. pers.), sea que la misma haya estado dirigida a la permanencia de este carácter o que se fijara de manera incidental como carácter ligado a otro conscientemente fomentado. No se ha registrado hasta el presente la presencia de verrugas en frutos de este taxon, por lo cual se lo considera también como un carácter fijado en poblaciones ya bajo cultivo.

Este taxón es muy variable también en tamaño. Ashworth (1997) estableció, tras el análisis de varios ejemplares, que los frutos de esta especie poseen en promedio 71,63 +/-2,86 $\mathrm{mm}$. de longitud y $67,80+/-2,27 \mathrm{~mm}$. de ancho, aunque otros autores registran entre 6 y $21,5 \mathrm{~cm}$. de longitud y entre 5 y 9,5 cm. de diámetro (Millán 1945; Martinez Crovetto en Burkart 1974). En cuanto al peso del fruto el mismo varía de acuerdo con el estado del mismo ya que a la madurez el mesocarpio se reabsorbe; por lo tanto, en promedio, el peso del fruto fresco sería de $160 \mathrm{~g}$ (un 7,2\% correspondiente a las semillas) y seco disminuiría a $20 \mathrm{mg}$. (un 32\% correspondiente a las semillas) (Ashworth y Galetto 2001).

En lo que respecta al espesor del pericarpio existen pocas referencias al respecto (Tabla 44). Al comparar los escasos datos publicados puede verse que existe un amplio solapamiento de medidas y que por lo tanto las mismas no serían diagnósticas. 


\section{Micromorfología de pericarpios de Cucurbita sp. y Lagenaria siceraria.}

Cutler y Whitaker (1961) enumeran caracteres que permiten diferenciar anatómicamente el pericarpio de L. siceraria de los de Cucúrbita spp., pero mencionan que no existen caracteres que contribuyan a diferenciar a las distintas especies de Cucurbita entre sí. Estos autores señalan que en L. siceraria las células superficiales de la epidermis por lo general se encuentran ausentes, en tanto en Cucurbita están presentes. Por debajo de esta capa en L. siceraria existe una pequeña capa de células pétreas cortas y de paredes engrosadas, seguida por células parenquimáticas pequeñas, laxas y de paredes delgadas. En Cucurbita, en cambio, existen varias capas de células pétreas de paredes engrosadas. Por último las capas más internas están compuestas por células parenquimáticas largas y de disposición laxa en L. siceraria, en tanto en Cucurbita estas células son isodiamétricas, de paredes delgadas y con una disposición más o menos regular (Figura 20). En opinión de León (1987) estas capas más internas son parenquimáticas, con células de paredes finas llenas de punteaduras que absorben líquidos muy lentamente.

Winton y Winton (1935) y Hayward (1953) describen -siguiendo a Barber (1909)- seis capas de tejidos en el pericarpio de las especies cultivadas de Cucurbita (fundamentalmente C. maxima ssp. maxima y $C$. pepo): el epicarpio o epidermis consiste en células prismáticas que en vista superficial son poligonales y forman una capa en empalizada, con paredes externas y radiales muy engrosadas y una espesa cutícula estriada. En algunos cultivares ("verrucoso" en C. pepo por ejemplo) las paredes externas presentan una depresión, lo que le da una apariencia ondulada en corte transversal. En la superficie del fruto se aprecian manchas blancas, las cuales son estomas en cuyo derredor las células son alargadas y curvadas; y a partir de ellos se extienden hileras radiadas de células alargadas tangencialmente que carecen de color (Figura 21). En el cultivar "verrucoso" de C. pepo los estomas están hundidos (Winton y Winton 1935). La distribución de los estomas no es 
uniforme y a veces dos de ellos pueden estar rodeados por el mismo grupo de células radiadas. En esta superficie epidérmica se forman dos tipos de pelos cuando el fruto es inmaduro, ambos con células basales que son un poco más redondeadas que las células epidérmicas adyacentes. Estos pelos no persisten y se secan cuando el fruto aun es pequeño, dejando intacta la célula basal. El tipo grande y articulado es acuminado, cónico y multicelular, alcanzando frecuentemente una longitud de 1,5 - 2 milímetros. El otro tipo es más pequeño y capitado, consistiendo en una estructura articulada de cuatro o cinco células, y una cabeza globular grande de una o más células (Figura 22). Luego de la epidermis o epicarpio sigue la hipodermis ${ }^{1}$ la cual estaría formada por muchas capas de pequeñas células isodiamétricas de paredes gruesas, con pequeños espacios intercelulares. El mesocarpio externo sigue a la hipodermis y consiste en células cuyos tamaños se escalonan entre las más pequeñas de la región hipodérmica y las más grandes del mesocarpio medio. Son isodiamétricas y de paredes gruesas, en el cultivar "verrucoso" la región se caracteriza por muchas capas de células pétreas poligonales que irradian desde grandes espacios intercelulares ${ }^{2}$, gracias a este tejido el fruto maduro posee una cáscara dura y rígida que resiste la degradación. El mesocarpio medio esta formado por células progresivamente más grandes y con disposición más laxa que las del mesocarpio externo. Las células más externas contienen abundantes granos de almidón cuya cantidad decrece hacia los límites internos de esta zona. Estos granos de almidón llegan hasta $10 \mu \mathrm{m}$ y ocurren simples, en pareja o triples (Figura 23).

El mesocarpio interno consta de grandes células parenquimáticas sin mucho contenido celular. Por este mesocarpio se extienden haces vasculares y tubos cribosos aislados, así como tubos de látex que se anastomosan entre sí. La porción central del fruto está ocupada por fibras duras, rodeadas de células parenquimáticas desintegradas. La zona más interna o endocarpio está

\footnotetext{
${ }^{1}$ Los autores no son claros respecto a si la hipodermis pertenece al epicarpio o al mesocarpio del fruto.

${ }^{2}$ Estos "grandes espacios intercelulares" corresponderían al desprendimiento de fitolitos.
} 
formada por células muy pequeñas, de paredes delgadas, alargadas longitudinalmente, que forman un fino tejido membranoso que se adhiere a las semillas. Este tejido se une firmemente a la cubierta seminal, pero puede desprenderse en las semillas secas en forma de película incolora, transparente. (Figura 24).

Si bien estos caracteres han sido empleados para discriminar entre L. siceraria y Cucurbita en restos de pericarpio arqueológicos (Pochettino 1985; Pochettino et al. 1998; Smith 2000), un estudio más reciente (Piperno et al. 2002) nos permite ver caracteres diferenciales en los pericarpios de diversas especies del género Cucurbita que hacen que las diferencias tan claras mencionadas por Cutler y Whitaker (1961) entre este género y L. siceraria se vuelvan más sutiles. En primer lugar resulta crucial el hecho de que en una misma especie las células pétreas pueden o no estar presentes, dependiendo del grado de lignificación del fruto (Piperno et al. 2002). Los frutos lignificados presentan fitolitos en la capa más externa de las células pétreas en una "zona de formación de fitolitos" en la interfase hipodermis/mesocarpio (externo) cuya formación está regida por un único gen $(H r)$ que codifica tanto la producción de lignina como de fitolitos en Cucurbita (Piperno 2008). Estos fitolitos están totalmente ausentes en frutos no lignificados. Puede haber también casos intermedios donde la lignificación del fruto es moderada -probablemente por una dominancia incompleta del locus $\mathrm{Hr}$ - lo cual se refleja en una disminución de las capas de células pétreas (Piperno et al. 2002). Así, en frutos no lignificados de C. moschata luego de la epidermis existe entre la hipodermis y el mesocarpio externo una graduación regular de células parenquimáticas isodiamétricas de paredes delgadas de más pequeñas a más grandes, estando totalmente ausentes las células pétreas (Piperno et al. 2002, fig. 3). En cambio en los frutos lignificados de esta especie se ven células pétreas marcadamente elongadas en el mesocarpio más externo junto a fitolitos elípticos (Piperno et al. 2002, fig. 2). Como vimos previamente la presencia o ausencia de células 
pétreas en distintas variedades de una misma especie es mencionada por Winton y Winton (1935) para C. pepo.

Según Piperno (2008) en todas las especies silvestres de Cucurbita el gen $\mathrm{Hr}$ causa la depositación de una densa capa de células pétreas y fitolitos (miles por $\mathrm{cm}^{2}$ ), la cual protege al fruto de herbívoros y hongos patógenos y permite -a nivel arqueológico- la detección de estas especies gracias a la abundancia de estas células y cuerpos silíceos que resisten la degradación. La autora destaca que el tamaño también es diagnóstico ya que los fitolitos de taxones silvestres poseen un tamaño máximo de $60 \mu \mathrm{m}$ a $70 \mu \mathrm{m}$, en tanto los taxa domesticados suelen superar dicha medida, dependiendo del tamaño de fruto que alcancen (Piperno y Pearsall 1998; Piperno et al. 2000, Piperno 2008, Piperno y Stothert 2008). Los fitolitos de C. maxima ssp. maxima poseen un largo de entre 56 y $134 \mu \mathrm{m}$ y un espesor de entre 56 y $136 \mu \mathrm{m}$; los de C. maxima ssp. andreana, en cambio, poseen un largo de entre 64 y $120 \mu \mathrm{m}$ y un espesor de entre 28 y $64 \mu \mathrm{m}$ (Piperno y Stothert 2008). Por lo cual los fitolitos de la forma domesticada son isodiamétricos y los de la forma espontánea son alargados. Los fitolitos de C. ecuadorensis poseen un tamaño $(82-86 \mu \mathrm{m}$ de largo y 68$90 \mu \mathrm{m}$ de grosor) intermedio entre los de las especies silvestres $C$. argyrosperma ssp. sororia y C. foetidissima y las domesticadas de C. moschata y Cficifolia (Stothert et al 2003, Piperno y Stothert 2008), lo cual es coherente con el carácter de especie semi-domesticada que le han atribuido Nee y Andres (Piperno y Pearsall 1998).

C. maxima ssp. andreana se caracteriza por tener en el mesocarpio más externo células pétreas aplanadas con paredes celulares más largas y lineales, lo cual es propio y exclusivo de esta subespecie (Piperno et al. 2002, fig. 7). Esto ocasiona que los fitolitos sean planos, con tres o cuatro facetas rectas (Piperno et al. 2002, fig. 6) y no esféricos como en C. maxima ssp. maxima, la cual posee un tejido hipodérmico denso, de varias capas y engrosado en ciertas áreas característico (Piperno et al. 2002, fig. 8). En L. siceraria, a diferencia de lo que 
ocurre en Cucurbita, las células pétreas poseen una disposición irregular, siendo algunas largas y elongadas y otras bastante pequeñas, pudiendo incluso estar horizontalmente elongadas (Piperno et al. 2002, fig. 9), esto genera fitolitos semiesféricos y semielípticos (Piperno et al. 2002, Piperno 2008).

Por lo tanto, todas las especies de Cucurbita analizadas hasta el momento así como también L. siceraria poseen fitolitos facetados (con concavidades de diversa profundidad en su superficie), que pueden ser esféricos, semiesféricos o irregulares. Estos son exclusivos de ambos géneros, aunque L. siceraria produce muchos menos fitolitos que Cucúrbita, y no se encuentran fitolitos similares en otras especies vegetales analizadas hasta el momento (Piperno y Pearsall 1998).

El ambiente puede determinar si los fitolitos se encuentran silicificados solo en parte -resultando en fitolitos con oquedades profundas- o si están totalmente silicificados (Bozarth 1987). Los factores ambientales inciden también en el tamaño de estos cuerpos silicificados (Tabla 45) durante distintos momentos del desarrollo de la planta, por lo que una misma variedad de Cucurbita creciendo en distintos ambientes puede generar fitolitos de muy diverso tamaño (Bozarth 1987).

Piperno y Pearsall (1998) encuentran una fuerte correlación positiva entre el aumento en el tamaño del fruto y semilla y el aumento en el tamaño de los fitolitos, lo cual sería el resultado de que estos últimos posean mayor espacio en los tejidos para desarrollarse.

\section{Materiales y método.}

\section{$\underline{\text { Colección de referencia de frutos }}$}

\section{a. Procedencia del material}


Se conformó una colección de referencia de frutos procedentes de cuatro taxa de Cucurbita sudamericanos susceptibles de ser hallados en el registro arqueológico de los Andes Meridionales, de acuerdo con la distribución del género en esta región (ver sección 4.1.1.a): C. maxima ssp. maxima, C. maxima ssp. andreana, C. ficifolia y C. moschata. Se observaron también muestras de $L$. siceraria a fin de establecer los caracteres que permitan su discriminación con respecto a Cucurbita.

En el caso de C. maxima ssp. maxima se observó un fruto no lignificado adquirido en el circuito comercial bonaerense y un ejemplar del cultivar de fruto lignificado, C. maxima ssp. maxima cv. zinpinka (Millán 1947), obtenido mediante los trabajos etnobotánicos en el poblado de El Shincal (Catamarca) donde le dan el nombre de "Silpingo".

No se pudieron obtener frutos de pericarpio lignificado de C. moschata, analizándose sólo un ejemplar de pericarpio no lignificado procedente del circuito comercial bonaerense.

El fruto analizado de C. ficifolia procede de la provincia Tucumán, en tanto que el ejemplar de L. siceraria y los once frutos de C. maxima ssp. andreana (ver Tabla 46) provienen de distintas localidades de la provincia de Buenos Aires. El énfasis puesto en esta última subespecie se debe a que la misma ha sido estudiada por otros investigadores en menor profundidad que su contraparte domesticada.

\section{b. Caracteres de diagnóstico observados}

En el caso particular de los frutos de C. maxima ssp andreana, y por las razones expuestas en el acápite anterior, se registraron la forma y el tamaño de seis de los once frutos de la colección de referencia. El registro se realizó tomando en consideración los indicadores propuestos por Cowan y Smith (1993, figura 3) para el estudio de caracteres de frutos arqueológicos a partir de frutos actuales 
de referencia. Se registraron diversas medidas que se describen a continuación. Dos medidas del diámetro del fruto: una desde el pedúnculo a la corola y otra transversal a dicho eje; cinco medidas del espesor del pericarpio en distintos puntos a lo largo del fruto: el espesor del pericarpio en la zona de inserción del pedúnculo y dos a los lados de la misma; por último el espesor del pericarpio en la zona de la corola y dos a ambos lados de la misma. En algunos casos el estado de preservación de las muestras no permitió obtener datos para todos los parámetros considerados.

En el resto de los taxa, incluida C. maxima ssp. andreana, se analizó la micromorfología de los tejidos que componen el pericarpio. Dichos caracteres son los que resultan de mayor utilidad al momento de identificar restos arqueobotánicos de frutos de Cucúrbita, que en general, se recuperan fragmentados.

Para el análisis micromorfológico se efectuaron cortes transversales, los cuales se analizaron bajo microscopio de transparencia e incidencia. En algunos casos se realizó una decoloración previa con hipoclorito de sodio al 50\% antes de la observación por transparencia.

\section{$\underline{\text { Registro arqueobotánico. }}$}

\section{a. Análisis bibliográfico}

Se recopiló la información existente en la bibliografía arqueológica de Argentina, Chile y Perú referida a caracteres cualitativos y cuantitativos de restos arqueobotánicos correspondientes a frutos, o partes de frutos, de los géneros Cucurbita y Lagenaria

\section{b. Análisis de restos arqueológicos de pericarpio}

\section{b.1. Procedencia del material}


Se analizaron muestras procedentes de sitios tempranos localizados en distintos países de Sudamérica: Argentina, Perú y Chile (Figuras 25 y 26). Con respecto a los correspondientes a Argentina, se analizaron restos arqueológicos de pericarpios procedentes de la cueva III de Huachichocana $(\mathrm{N}=3)$ y Pampa Grande $(\mathrm{N}=95)$. Con respecto a Perú, se realizaron análisis sobre restos procedentes de los sitios: Chavin $(\mathrm{N}=1)$, Curayacu $(\mathrm{N}=1)$, Jahuay $(\mathrm{N}=1)$, Bandurria $(\mathrm{N}=2)$ y Cerro Lampay $(\mathrm{N}=15)$. Finalmente se analizaron dos ejemplares procedentes del sitio chileno Tulan 85.

\section{b.2. Caracteres de diagnóstico observados}

Se registraron características externas superficiales del epicarpio, como color y textura, así como características generales del pericarpio, como su consistencia, la existencia o no de enrollamiento, y el espesor en cada espécimen arqueológico. Para estimar esta última variable se tomaron varias medidas en cada fragmento arqueológico (entre 3 y 5 medidas, dependiendo del tamaño del fragmento) ya que el mismo era altamente variable debido a la degradación diferencial del material por ataque de microorganismos, o a la presencia de distintos sectores del fruto representados en un mismo fragmento. $\mathrm{Al}$ ser los pericarpios materiales no rígidos sino esponjosos, una mínima presión diferencial del calibre causaba variaciones en la medición, por eso tomar varias medidas de un mismo ejemplar fue una forma de minimizar este tipo de error. Finalmente se consideró el promedio de las distintas medidas como el valor del espesor del pericarpio de cada espécimen, siendo este valor el consignado en las tablas correspondientes. Las medidas se obtuvieron empleando calibre digital TESA junto a software acompañante. Todos los valores se hallan expresados en milímetros.

El análisis micromorfológico del pericarpio se efectuó bajo microscopio óptico de luz incidente y transmitida. En un solo caso (muestra C5 de Pampa 
Grande) se empleó MEB para un mayor detalle de los tejidos. Para todas las observaciones microscópicas se efectuaron pequeños levantados en las caras laterales de los fragmentos de pericarpios arqueológicos, a fin de extraer del área residuos que dificultaran la observación. Dichos levantados se efectuaron con hojas de bisturí nuevas.

\section{b.3. Criterios empleados para las determinaciones taxonómicas}

Teniendo en cuenta la información bibliográfica y el análisis de material actual de referencia, se adoptaron los siguientes criterios de identificación del material arqueológico. Cuando dice "aff C. moschata variedad lignificada" o "aff L. siceraria" es debido a que ambas presentan células pétreas alargadas en sentido radial en el mesocarpio externo. En el primer caso la identificación aproximada se justifica por la presencia de células angostas y largas con disposición homogénea; en el segundo por la presencia de células más elongadas y angostas, junto a células pequeñas redondeadas, todas con disposición heterogénea. En el caso de C. maxima, se consigna "C.maxima aff ssp andreana" o "C. maxima aff ssp. maxima", atendiendo principalmente a las características de las células pétreas del mesocarpio externo que, en el primer caso, poseen paredes rectas y se hallan elongadas en sentido transversal al eje del fruto y en el segundo son circulares y de paredes más delgadas. C. maxima ssp. maxima aff cv. zipinka se considera cuando el mesocarpio externo posee células de paredes engrosadas y rectas, mayormente isodiamétricas. El término aff. (affinis) se emplea para indicar que el material observado correspondería al taxón o taxa mencionado o a uno cercano a este, la imprecisión se debe a la falta de un número mayor de rasgos diagnósticos para asegurar la identificación taxonómica. En los casos analizados aquí, esta ausencia de rasgos se debió mayormente al estado de conservación de los macrorrestos. 


\section{b.4. Análisis de fitolitos}

Si bien esta tesis no incluye el estudio de microrrestos, su análisis es someramente abordado en el caso de Cucurbita a los fines de complementar información procedente de macrorrestos. Ni el tamaño ni la morfología de los fitolitos se pueden apreciar cuando éstos están aún incluidos en los tejidos del fruto. Para ello debería realizarse un procedimiento de digestión química (Bozarth 1987) el cual liberaría al fitolito, pero destruiría en gran parte al macrorresto. Por tal motivo, y dado que se optó por preservar los restos de pericarpios arqueológicos, el tamaño de los fitolitos encontrados dentro de los restos de pericarpio arqueológicos analizados fue determinado sólo en forma aproximada. A pesar de que las medidas tomadas no son las reales de los fitolitos, el hecho de que este sesgo esté dado tanto en las muestras de referencia como en las arqueológicas hizo a ambas muestras comparables. Si bien esta es una vía más para aproximarse a la variabilidad taxonómica que puede desprenderse de los estudios de pericarpios arqueológicos, no puede considerarse en forma individual como indicativa de taxa o estadios evolutivos en sí misma.

Se midieron seis fitolitos de pericarpios de seis frutos de C. maxima ssp. andreana de referencia procedentes de la provincia de Buenos Aires y dos fitolitos de un mismo fruto de C. maxima ssp. maxima cv zipinka colectado como parte de los estudios etnobotánicos llevados a cabo en El Shincal, Catamarca. Estas medidas se compararon con las de veinte fitolitos aún incluidos en trece pericarpios arqueológicos de Pampa Grande. En el caso de que se conservara el fitolito en la muestra de pericarpio se consignan dos medidas de diámetro, en el caso de que sólo quedara el orificio donde el mismo estaba incluido, y de que el resto careciera de la hipodermis que marcaría el límite superior del fitolito, se consigna una sola medida de diámetro. 


\section{Resultados}

\section{Colección de referencia}

\section{a-Morfología externa de frutos de C. maxima ssp andreana}

En la tabla 47 se presentan los resultados del análisis cuantitativo macroscópico de los frutos y pericarpios de C. maxima spp andreana. En la misma puede verse que los frutos poseen un diámetro de 56,24 mm, la relación entre ambos diámetros permite ver que son frutos esféricos. El pericarpio posee en las paredes laterales del fruto un alto de 1,28 mm (rango: 0,79 a 1,82 mm) que aumenta hacia la zona de inserción del pedúnculo y hacia la corola -puesto que en las mismas hay un incremento notable del tejido subepidérmico- alcanzando en estas áreas un promedio de 5,19 mm (rango: 3,97 a 5,97 mm) y 4,09 $\mathrm{mm}$. (rango: 3,6 a 4,85 $\mathrm{mm}$ ) respectivamente.

A los lados del pedúnculo el pericarpio posee un alto de 1,49 mm (rango: 0,91 a 1,89 mm) y a los lados de la corola 2, $31 \mathrm{~mm}$ (rango: 1,93 a 2,62 mm). Por lo tanto el espesor del pericarpio en esta subespecie puede ir desde 0,79 a 5,97 $\mathrm{mm}$, siendo el CV es muy elevado (65,15\%). La media general de todas las medidas tomadas es 1,85 mm. Este análisis ofrece una apreciación más exacta del rango de medidas que puede exhibir C. maxima ssp. andreana a comparación de la única medida publicada hasta el presente para el alto del pericarpio de la misma (ver tabla 44).

Todos los frutos de la colección de referencia son lisos y de superficie suave, sin verrugas. Los colores de los frutos varían de verde claro o oscuro con franjas más claras en los ejemplares maduros no secos, a amarillo y castaño claro en los ejemplares maduros y secos. 


\section{b-Micromorfología del pericarpio de cada taxon de referencia estudiado.}

C. maxima ssp. andreana (Lámina 18): La epidermis consiste en células cuadrangulares de paredes engrosadas con leves depresiones en su cara externa. La hipodermis posee varias capas de células redondeadas de disposición desordenada, lo cual dificulta contabilizar cuantas capas de células posee este tejido. Entre la hipodermis y el mesocarpio externo se detectó la presencia de fitolitos. Se confirmaron los caracteres mencionados por Piperno et al. 2002 en cuanto a que el mesocarpio externo consiste en células pétreas aplanadas de paredes largas y lineales. Estas células pétreas pueden ser isodiamétricas o bien elongadas, en este último caso el eje mayor de las mismas se dispone de manera transversal al eje principal ${ }^{3}$ del fruto. En el mesocarpio medio las células son de paredes engrosadas también, pero progresivamente más grandes que las del externo. El mesocarpio interno posee células grandes, de paredes delgadas y disposición laxa con haces vasculares y tubos cribosos.

C. maxima ssp. maxima: Primeramente se efectuaron cortes en el pericarpio de un fruto no lignificado (Lámina 19). En el mismo se observó que la epidermis es similar a la de C. maxima ssp. andreana, pero con depresiones más acentuadas en la pared externa. La hipodermis posee menos capas (entre $5 \mathrm{y}$ 6) respecto a C. maxima ssp. andreana, contrariamente a lo manifestado por Piperno et al (2002). No se observó un límite marcado entre mesocarpio externo, medio e interno, registrándose una graduación de células redondeadas de menor a mayor tamaño, estando ausentes las células pétreas y los fitolitos. El mesocarpio interno presentó abundantes granos de almidón. En segundo lugar se observó una muestra de C. maxima ssp. maxima cv. zinpinka (Lámina 20). En este ejemplar se observó un mesocarpio externo con

\footnotetext{
${ }^{3}$ Línea imaginaria que une el área de inserción del pedúnculo con la corola.
} 
células lignificadas de paredes engrosadas, facetadas y mayormente isodiamétricas, detectándose la presencia de fitolitos. Los mesocarpios medio e interno poseen células de mayor tamaño y más redondeadas, en este último se observaron tubos cribosos. De acuerdo con las imágenes publicadas por Piperno et al. (2002) se puede apreciar que el mesocarpio externo del ejemplar de C. maxima ssp. maxima que analizan posee células elongadas de paredes rectas, similares a las de $C$. moschata, tratándose posiblemente de un ejemplar lignificado, semejante a C. maxima ssp. maxima cv ripinka.

Las diferencias que exhiben estas dos variedades de un mismo taxon serían el resultado de procesos de selección distintos. El cultivar Zipinka se caracteriza por poseer un pericarpio muy grueso que se constituye a los pocos días de formarse el fruto, lo cual alarga su vida post-cosecha (Millán 1947) (tabla 42). El ejemplar obtenido en el circuito comercial, en cambio, corresponde a zapallos seleccionados por su fácil cocción, en detrimento a la conservación prolongada del fruto, que está relacionada con un pericarpio compuesto por tejidos menos engrosados y correosos.

C. moschata (Lámina 21): La epidermis no difiere de la observada en el ejemplar no lignificado de C. maxima ssp. maxima, salvo una forma rectangular más que cuadrangular. La hipodermis posee más capas que las de ésta última subespecie. Entre mesocarpio externo, medio e interno se observaron células circulares de paredes delgadas progresivamente más grandes. En el mesocarpio interno se observaron haces vasculares, tubos cribosos y granos de almidón.

Esta descripción es propia de un fruto no lignificado (Piperno et al 2002, Piperno 2008). El pericarpio de frutos lignificados de esta especie descrito por Piperno y colaboradores (2002) se asemeja en cambio al cultivar Zipinka de $C$. maxima ssp. maxima, diferenciándose de éste -de acuerdo con las imágenes 
publicadas por Piperno et al. (2002)- por poseer células más angostas y largas cuyo eje mayor se dispone de manera radial al eje principal del fruto.

C. ficifolia (Lámina 22): En esta especie se observó una epidermis de células rectangulares sin depresión en su cara externa y una hipodermis de varias capas (entre 5 y 6 ). Las células pétreas del mesocarpio externo se hallan fuertemente engrosadas, junto a abundantes fitolitos. De estas células pétreas las más externas que se encuentran en la zona de formación de fitolitos son circulares, y desde pequeñas a muy grandes, las más internas son, en cambio, elongadas (eje mayor transversal al eje principal del fruto) y de paredes rectas. El mesocarpio medio consiste en células sub-circulares facetadas de paredes engrosadas y el mesocarpio interno posee células circulares facetadas de paredes más finas

Lagenaria siceraria (Lámina 23): La epidermis e hipodermis constituyen una capa casi indiferenciable. El mesocarpio externo está constituido por células pétreas de morfología diversa (mayormente angostas y largas) y con disposición heterogénea presentando fitolitos semiesféricos, tal como lo manifiestan Piperno et al. (2002). Una diferencia que notamos es que en este género no se observa una organización radial de células del mesocarpio alrededor de los fitolitos como ocurre en todas las especies aquí analizadas del género Cucurbita. El mesocarpio medio posee células elongadas de paredes finas con granos de almidón. En el mesocarpio interno, de células irregulares y laxas, se detectó la presencia de haces vasculares espiralados.

\section{$\underline{\text { Registro arqueobotánico }}$}

a. Análisis bibliográfico 
En Argentina (Figura 26), restos de fitolitos de frutos de Cucurbita sp. de la microrregión de Antofagasta de la Sierra (puna de Catamarca), constituirían el registro más temprano de este género en el país, siendo los recuperados en sitios cordobeses (más tardíos) muy pequeños, teniendo entre 20 y $22 \mu \mathrm{m}$ de diámetro (López com. pers.) (ver tabla 10).

El macrorresto más temprano corresponde a un fragmento de pericarpio recuperado en Cueva de Los Corrales I, ubicada en el Abra de El Infiernillo al norte del sistema del Aconquija y a 3000 msm (Oliszewski et al en prensa) (Figura 27). El resto fue identificado por personal del Instituto Miguel Lillo como Cucurbita sp., posee un espesor de 1,50 $\mathrm{mm}$ y se halló en la capa datada en $2060+/-200$ AP (Oliszewski com. pers.). El espacio ocupacional de la cueva se articula sincrónicamente con un área productiva dominada por andenes agrícolas en un espacio próximo, de la cueva se recuperaron también semillas de Phaseolus vulgaris y diversas variedades de Zea mays (Oliszewski et al en prensa). El escaso espesor de este ejemplar lo ubicaría dentro del rango de medidas propio de C. maxima ssp. andreana, sin embargo se requeriría un análisis minucioso del mismo a fin de evaluar el grado de degradación que posee, así como también un análisis microscópico de su estructura interna.

Del sitio Los Viscos (ScatBe6(1), Catamarca) se recuperaron doce restos, siete de ellos identificados como pericarpios de L. siceraria debido a su escaso espesor por Maloberti y Zapatiel (2003), cuatro como C. moschata debido a la presencia de costillas y un fragmento no determinado, aunque según las mencionadas autoras correspondería a la familia de las Cucurbitáceas (Tabla 48 , figura 28).

Estas mismas autoras nos aportan los datos contextuales de los hallazgos: de las excavaciones aledañas a un pozo de huaqueo se recuperaron cuatro fragmentos de pericarpio pertenecientes a C. moschata, todos ellos provenientes de la capa 2 de la unidad $\mathrm{R}$ y asociados a huesos, marlos, cordeles y madera. En la unidad Q fue hallada una semilla -que se ha identificado en esta tesis 
como de C. maxima aff. ssp. maxima- en la capa 2, asociada a marlos, artefactos y una calabaza pirograbada. Tras la excavación de una zona sellada por una capa de guano compacta (sectores L-LL-M ), los materiales exhumados indican al menos dos momentos en la ocupación del abrigo, uno asignable al Período Formativo (desde ca 500 a.C) y otro a un lapso comprendido entre el Período de Desarrollos Regionales y el momento de contacto Colonial (entre ca 1000 - 1536 d.C), este último identificado por los rasgos estilísticos presentes en los instrumentos en hueso y calabazas pirograbadas (Korstanje y Wurschmidt. 1998). De la unidad L (capa 4), proceden los siete fragmentos de pericarpio identificados como L. siceraria, asociados a maíz, artefactos, paja, palitos, huesos y caracoles. En la unidad Ll (capa 4) se hallaron dos fragmentos de pericarpio, identificados como pertenecientes a C. moschata asociados a paja, maíz, lascas de cuarzo y fragmentos cerámicos. Estos dos últimos conjuntos corresponderían a la ocupación Aguada del abrigo (Maloberti y Zapatiel 2003).

Si bien no se tuvo acceso a estos restos, gracias a los informes y fotografías cedidos por la Dra. A. Korstanje pueden realizarse los siguientes comentarios. El ejemplar $1 \mathrm{~b}$ se halla aún adherido al pedúnculo, el cual exhibe un ensanchamiento en esta zona de contacto con el fruto. Esta característica permitiría asegurar que se trata de restos de $C$. moschata, de acuerdo con lo establecido en la bibliografía (Whitaker y Bohn 1950, Cutler y Whitaker 1961, Lira Saade 1995). Si bien todos los ejemplares recuperados en este sitio son de escaso espesor, el ejemplar $\mathrm{N}^{\mathrm{o}} 14$ es particularmente interesante por lo escaso del mismo $(0.5 \mathrm{~mm})$, carácter que lo destaca de los otros ejemplares hallados y de lo registrado para cucurbitas en general, poseyendo un grosor menor aún que lo registrado para C. maxima ssp. andreana. Estamos en condiciones de afirmar que los criterios usados por Maloberti y Zapatiel (2003) basados en morfología externa y espesor del pericarpio no son totalmente confiables algo reconocido por las propias autoras- ya que si bien ocasionalmente son 
acertados en el reconocimiento taxonómico, con mucha frecuencia resultan engañosos. Pensamos que un análisis microscópico de corte delgado podría asegurar la identificación taxonómica de estos restos.

Los hallazgos efectuados en Los Morrillos de Ansilta (50 AC - 900 DC) resultan excepcionales. Allí se encontraron, en la gruta $\mathrm{N}^{\circ} 1$, dos frutos de Cucurbita que fueron empleados como recipientes, uno de ellos aovadoaplanado de $175 \mathrm{~cm}$ de diámetro y otro piriforme con una abertura irregular identificado como perteneciente a C. maxima ssp. maxima conteniendo $2.200 \mathrm{~g}$ de semillas de Chenopodium quinoa (Gambier 1977, Lagiglia 2001). También se recuperó un fruto piriforme de L. siceraria con orificio lateral formando parte del ajuar del cuerpo $\mathrm{N}^{\circ} 2$ de dicha gruta, datado en el año 40 DC (Gambier 1977, Lagiglia 2001). En la gruta Vega de Los Pingos -también con ocupaciones Ansilta, ubicada en la provincia de San Juan- se halló un fruto de C.maxima ssp maxima con un orificio para ser empleado como recipiente (Gambier 1977, Lagiglia 2001).

Entre los restos de pericarpio de C. maxima ssp. maxima recuperados en Los Morillos se cuenta con ejemplares lisos y rugosos "con producciones corchosas irregulares" (Roig 1977: 217). Se recuperaron también restos de pericarpio con el pedúnculo ensanchado en su base característico de $C$. moschata con un fechado de entre 280 y 375 DC (Roig 1977). Lamentablemente no contamos con datos sobre el grosor de estos restos de pericarpios; para el área próxima de Mendoza, contamos con los datos aportados por Whitaker (1983) quien señala que restos de Cucurbita, posiblemente C. maxima ssp maxima recuperados en la Cueva del Toro poseían un alto de entre 2 a 5 milímetros.

Restos de L. siceraria. están presentes a lo largo de toda la secuencia de Los Morillos, correspondiendo los mismos siempre a frutos o fragmentos de pericarpios, sin que se recuperaran semillas (Roig 1977). 
En el caso del Área Andina Meridional, se registraron los restos de pericarpios donde se consigna su alto, sean estos del género Cucurbita o Lagenaria (Tabla 49, Figura 25)

En cuanto al registro de datos cuantitativos de frutos arqueológicos completos, la bibliografía sólo ofrece datos para L. siceraria (Whitaker 1948, Whitaker y Bird 1949, Yacovleff y Herrera 1934).

En el caso de los restos de pericarpios de C. moschata de Huaca Prieta, un examen reciente de los fitolitos contenidos en los mismos evidenció la presencia de morfotipos ausentes en frutos actuales de dicha especie, lo cual indicaría la presencia de algún cultivar actualmente desaparecido (Piperno 2008)

Para el territorio chileno contamos con diversos trabajos que mencionan la presencia de "calabazas" en sitios costeros tempranos del Norte Grande. Destaca el cementerio de Camarones 15 donde se recuperaron gran cantidad de calabazas pirograbadas empleadas como contenedores de colorantes, otras modificadas para su empleo como sonajero y otras envueltas en bolsas de punto red (Focacci 1974, Rivera et al 1974). Esto podría indicar una "horticultura de cucurbitáceas hacia el 1100 AC" (Castro y Tarragó 1992: 98). En el cementerio de Quiani, Dauselberg (1974) recupera como parte del ajuar de una momia de adulto en la tumba 7 una cucurbitácea de $12 \mathrm{~cm}$ de diámetro y $8 \mathrm{~cm}$ de alto abierta en la parte superior para darle forma de recipiente con restos de carbonización. En opinión del autor "pudo haber sido utilizada para calentar y cocer alimentos por medio de la inmersión de piedras calientes" (Dauselberg 1974: 28). En cementerios de la fase Azapa -considerada como transicional entre la tradición marítima costera y la agrícola aldeana- también abundan los restos de L. siceraria junto a restos de Cucurbita formando parte de los ajuares hacia el $1650 \mathrm{AC}$; en el cementerio AZ-14 se recuperaron calabazas grabadas y otras sin decoración conteniendo restos de harina vegetal (Santoro 1980). En el cementerio Tarapacá 40 se identificaron restos de C. maxima ssp. 
maxima y C. moschata (identificaciones realizadas por Cárdenas) en dos tumbas y de calabazas en otras 8 tumbas con un fechado de entre 290 y 360 DC (Núñez Atencio 1982) En el caso del cementerio Playa Miller en Arica asignado a la fase El Laucho (300 AC) correspondiente al "período de agricultura incipiente" (Focacci 1974:27) se recuperaron calabazas acompañando restos momificados de adultos, varias de ellas pirograbadas y otras rotas y emparchadas. Algunas de estas calabazas son pequeñas y globosas, otras piriformes y otras se encuentran cortadas a modo de pucos. Los tamaños de las mismas son similares a los de frutos de L. siceraria de Huaca Prieta. Lamentablemente, salvo el caso del cementerio Tarapacá 40, no se cuenta con identificaciones taxonómicas de estos restos, usándose denominaciones como "calabaza" sin que se aclare si se hace referencia a frutos del género Lagenaria o Cucurbita.

\section{b. Análisis de restos arqueológicos de pericarpio}

De la cueva III de Huachichocana capa C se recuperó un fragmento de pericarpio de Cucurbita sp. identificado por Whitaker (Fernández Distel 1986), el cual pudimos medir y fotografiar en el Instituto Interdisciplinario Tilcara, siendo su alto de 5,24 mm. El mismo es color castaño oscuro con líneas negras y presenta claras marcas de roído (Figura 29). Fernández Distel (1986) reporta el hallazgo de quince fragmentos de L. siceraria de la misma capa C, uno de ellos con decoración pirograbada e incisa (motivo de banda en zig-zag en el borde), un fragmento con perforación cercana al borde y varios con pigmento externo rojizo, en tanto que otros presentan restos de hollín en cara interna y/o externa. Vale recordar que esta capa corresponde a una ocupación humahuaca-inca. De las capas que representan ocupaciones precerámicas se recuperaron también 15 fragmentos de $L$. siceraria de acuerdo con lo informado por Whitaker (Fernández Distel 1986), representando cinco de 
ellos a un recipiente muy pequeño, de unos $10 \mathrm{~cm}$ de diámetro. Pudimos analizar uno de los restos asociados al esqueleto 3 en capa E2, el cual posee un alto de 5,16 mm (Figura 29). Lamentablemente no puede asignársele ninguna clasificación taxonómica al mismo en tanto no se cuente con análisis microscópicos, a pesar de ello el fragmento pertenece a las paredes laterales del fruto y posee un alto considerable, lo cual habla a favor de un fruto ya domesticado.

El análisis de la colección nos permitió detectar los restos de un pericarpio de fruto indeterminado recuperado en la capa D (ocupación humahuacaatacameña) de escaso espesor $(0,6 \mathrm{~mm})$. El mismo no corresponde a ningún tipo de Cucurbitácea ni por su estructura externa ni por la interna.

En el caso de la muestra de sitios peruanos, la mayor cantidad de fragmentos son del sitio Cerro Lampay (Tabla 50) y los restantes corresponden a escasos ejemplares de sitios distribuidos a la largo de la costa peruana (Tabla 51). En este último caso, tras el análisis microscópico de los restos se constató que todas las muestras correspondieron a L. siceraria, al igual que las dos muestras del sitio chileno Tulan 85 (Tabla 52). En ningún caso se observaron ejemplares que claramente pertenecieran a C. maxima ssp. maxima salvo una muestra de Cerro Lampay con mesocarpio externo afín al cultivar Zipinka, aunque se debe considerar que el aspecto general de éste es muy similar también al publicado para frutos lignificados de C. moschata, por lo cual la identificación no puede ser definitoria. Por ahora postulamos que en Cerro Lampay es probable que hubiera variedades lignificadas de C. moschata de paredes delgadas (media de ejemplares medidos: 2,08 mm; rango: 0,94-3,81 $\mathrm{mm}$ ) junto con frutos de L. siceraria de paredes más gruesas (media: 3,47 mm; rango: 2,92- 4,22 $\mathrm{mm}$.).

El registro de restos de pericarpios del sitio Pampa Grande es uno de los más completos de los reportados hasta el momento para el NOA. Si bien estos restos arqueobotánicos fueron identificados primeramente por Whitaker en 
un informe al Dr. González publicado parcialmente por Tarragó (1978) y luego por Pochettino (1985), en ambos casos la identificación se hizo en base a caracteres cualitativos externos. En nuestras investigaciones realizamos la identificación a partir del análisis de caracteres de los tejidos que conforman el pericarpio, pudiendo determinar nuevos taxa presentes y reclasificar otros (Tabla 53). El hallazgo más interesante es el de cinco restos de pericarpios (número de registro: C5, ver tabla 53) que por caracteres anatómicos internos fueron clasificados como C. maxima ssp. andreana. Los mismos fueron descritos como dudosamente pertenecientes a este taxón por Whitaker (Tarragó 1978) ${ }^{4}$, el análisis de los tejidos del pericarpio confirmó esta identificación mediante comparación con material actual de referencia, atendiendo a las características ya señaladas. En la lámina 24 pueden verse las células pétreas de paredes rectas y elongadas transversales al eje principal del fruto y la epidermis de células cuadrangulares de paredes engrosadas y con leves depresiones en su cara externa. La hipodermis se encuentra colapsada, pero a pesar de ello puede verse que está constituida por varias capas. Asimismo se observa la impronta dejada por un fitolito desprendido en la zona de formación de fitolitos entre la hipodermis y el mesocarpio externo. La impronta permite ver que se trataría de un fitolito de paredes rectas, tal como lo señalan Piperno y colaboradores (2002) para esta especie. También se observa el mesocarpio medio de células más grandes que el externo.

El alto promedio de los ejemplares identificados como C. maxima ssp. andreana o afines a ésta (11 restos) es de 1,58 $\mu \mathrm{m}$ con un rango de entre 0,95 y 2,38 $\mu \mathrm{m}$. Este último valor excede al registrado en la colección de referencia (en lo que respecta al alto del pericarpio en las paredes del fruto) y se solapa con los valores registrados para C. maxima ssp. maxima (Gráfico 11).

\footnotetext{
${ }^{4}$ Whitaker menciona estos hallazgos con referencia a igual sector y cuadrícula que los registrados para los restos C5, pero asignándolos a la Caverna V (Tarragó 1980), lo cual consideramos un probable error cometido por éste investigador al transcribir los datos originales de la excavación.
} 
Los pericarpios pertenecientes a C. maxima ssp. maxima (45 restos) poseerían un alto de entre 2,08 y 6,64 $\mu \mathrm{m}$. Existiría un área de solapamiento entre estas

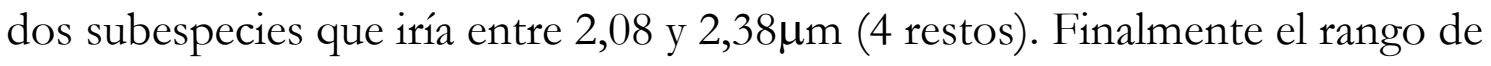
medidas de los restos identificados como Cucurbita sp $(\mathrm{N}=6)$ no se solapan con el de C. maxima ssp. andreana, siendo bastante similar al de la subespecie domesticada.

Como mencionáramos anteriormente, los pericarpios exhiben, en algunos casos, una clara alteración de su estructura original por el ataque de distintos agentes (principalmente hongos), lo cual dificulta en algunos casos el análisis anatómico de las distintas capas que lo componen, así como también altera las medidas correspondientes al alto de los mismos. Nuestras observaciones han detectado que esta alteración afecta principalmente al mesocarpio interno el cual, al estar compuesto por células no lignificadas, es más sensible al ataque de microorganismos y al deterioro físico. Epidermis e hipodermis suelen estar ausentes también, siendo la causa de ello posiblemente la alteración física por roce y abrasión del material. Esto hace que estudios donde se evalúa el incremento del alto del pericarpio como indicador de domesticación (Smith 2000) sean poco confiables si no cuentan con una evaluación microscópica de los restos, en la que se vea que todos conservan sus capas constitutivas inalteradas. Incluso cuando se identifica la totalidad de los tejidos no es posible precisar si el mesocarpio interno presenta todas sus capas o no, ya que la cantidad de capas de células que componen éste tejido es indeterminada. Por lo tanto no sería válido realizar un estudio transversal que compare directamente el alto de fragmentos de pericarpios arqueológicos en el caso de que posean preservación diferencial de sus capas constitutivas. En cambio los análisis microscópicos aquí realizados han permitido constatar que en el caso de Pampa Grande, la mayoría de los restos poseen todos los tejidos del pericarpio salvo el mesocarpio interno (con la excepción de algunos casos como $\mathrm{C} 4 \mathrm{c}$ y $\mathrm{C} 8$ ) el cual posee en todos los taxa analizados células de paredes 
delgadas que no favorecen su conservación. En algunos ejemplares no se ha conservado la epidermis e hipodermis, pero como estos tejidos aportan muy poco (entre 120 y $300 \mu \mathrm{m}$ ) al alto total del pericarpio -y aquí se evalúan diferencias significativas a partir de rangos de tamaño y no de valores absolutos- su ausencia no resulta significativa en cuanto a ocasionar confusión en la asignación taxonómica.

Los restos de pericarpios correspondientes a C. maxima ssp. andreana cuyo alto se encuentra entre 0,95 y $2,08 \mu \mathrm{m}$ son todos lisos y de color amarillo o castaño (Tabla 53) Algunos se encuentran enrollados sobre sí mismos, una característica observada también en los frutos actuales de C. maxima ssp. andreana, los cuales tras ser abiertos frescos, enrollan sus paredes a medida que se secan. El grupo de fragmentos registrados como C5 (a-e) se encontraba asociado a un pedúnculo $\left(\mathrm{n}^{\circ} 4\right)$ identificado como perteneciente a $C$. maxima ssp. maxima, el cual junto con el pedúnculo $\mathrm{n}^{\circ} 2$, se destacan del resto de los hallazgos por ser más delgados y fibrosos (ver capítulo 4.1.1e). Este conjunto se hallaba también en asociación a un fragmento de pericarpio identificado como C. maxima ssp. maxima (C6). Esto último ocurre también en el caso de C9(b), 089, C11(b) y C1(b) asociados a fragmentos de frutos lobulados de $C$. maxima ssp. maxima en los dos primeros casos, y lisos en los dos últimos; C1(b) asociado también a pericarpio ubicado en el área de solapamiento de subespecies de C. maxima. El fragmento de pericarpio de la caja 067(b) se halla justo en el inicio del área de solapamiento y corresponde ya a un fruto lobulado de C. maxima ssp. maxima moderadamente lignificado. El mismo está asociado a brácteas de maíz y vainas de Phaseolus vulgaris y Arachis sp. Todos estos restos correspondientes o afines a C. maxima ssp. andreana fueron recuperados en la cueva Los Aparejos.

Todos los fragmentos de pericarpios ubicados en el área de solapamiento entre C. maxima ssp. andreana y C. maxima ssp. maxima corresponden a frutos sin verrugas de color ocre o castaño. En este caso todos proceden también de 
la cueva Los Aparejos, estando dos de los restos asociados a enterratorios. De los cuatro fragmentos de pericarpio, tres se encuentran asociados a otros restos de pericarpio de C. maxima ssp. maxima, uno de los cuales se encuentra también asociado a un ejemplar afín a C. maxima ssp. andreana (Tabla 53).

Finalmente entre los pericarpios identificados como C. maxima ssp. maxima cuyo alto se encuentra entre los 2,38 y $6,64 \mu \mathrm{m}$ - es donde encontramos mayor diversidad. Se encuentran restos de frutos lobulados (13 fragmentos), con verrugas ( 3 fragmentos), lisos (22 fragmentos) y lobulados con verrugas ( 7 fragmentos). Los colores de los epicarpios son: amarillo, ocre, castaño, castaño-rojizo y ceniciento-grisáceo. Algunos restos muestran indicios de exposición al fuego, ya sea porque están tiznados, carbonizados o bien termoalterados tanto en cara externa como interna. Resulta interesante el caso del resto J'/II(b), el cual presenta el área del mesocarpio teñida de color rojo, como si el fruto hubiese contenido un líquido de dicho color que fue absorbido por las paredes del mismo. Otro caso interesante es el del fragmento $\mathrm{C} 17$, el cual presenta próximo al borde un orificio de unos $7 \mathrm{~mm}$. de diámetro el cual pudo haber servido probablemente para enhebrar correas de suspensión. Esta interpretación se sustenta también en el hecho de que en los mismos contextos de estas cuevas se han hallado restos de frutos de $L$. siceraria y tiestos cerámicos con orificios de similar morfología conteniendo aún restos de cordeles (tabla 54, lámina 25). Dentro de la diversidad señalada hay frutos lignificados y otros que no lo están, aunque todos aquellos que superan los $3 \mathrm{~mm}$ de espesor se encuentran lignificados. Probablemente estos últimos, más que los primeros, hayan sido utilizados como contenedores por la resistencia otorgada por la lignificación y por sus paredes más gruesas. Los lugares de hallazgo también aumentan, ya que estos restos proceden de la cueva Los Aparejos, de El Litro y de la Caverna II. En este último caso asociado al hallazgo $\mathrm{n}^{\circ} 42$ junto a un estuche de cuero, textiles, restos de redes, cuentas y coprolitos. En el caso de los fragmentos catalogados como 
C18 (a-e) los mismos fueron hallados en el interior de un gran cesto. Esta dispersión de los hallazgos habla a favor de la popularización del uso de contenedores de Cucurbita maxima ssp maxima en la localidad de Pampa Grande. No existe una diferencia de contexto de acuerdo con los caracteres del pericarpio de esta especie, lo cual indicaría que las diversas clases de frutos se emplearon de manera similar.

Por lo tanto podemos ver que en Pampa Grande los restos de C. maxima ssp. andreana se encuentran asociados a los de la subespecie domesticada. Entre los ejemplares que caen dentro del área de solapamiento de medidas de alto de ambas subespecies -los cuales podemos considerar como intermedios $\mathrm{O}$ transicionales- hay ejemplares que ya poseen lóbulos y están moderadamente lignificados junto a otros totalmente lisos, apareciendo en contextos de enterratorios. En el conjunto de ejemplares ya plenamente domesticados vemos una alta diversidad en lo que respecta al color, habiendo frutos lignificados y no lignificados, con o sin verrugas, lobulados o lisos. Esta misma tendencia en el aumento de la diversidad morfológica, es la que observó Smith (2000) para el caso de la domesticación de C. pepo. Lamentablemente, por los problemas ya señalados (ver capítulo 3) no se pueden correlacionar estos cambios morfológicos con diferencias cronológicas. Sin embargo resulta interesante que los restos identificados como C. maxima ssp andreana y los transicionales se hallaron exclusivamente en Los Aparejos. En El Litro y Cueva II, en cambio, sólo se hallaron restos de C. maxima ssp maxima. En el caso de El Litro contamos con restos presentes en dos niveles contiguos de una misma cuadrícula (C1). Como puede verse en el gráfico 12 , hay una tendencia al aumento en el grosor de los pericarpios al aumentar la profundidad del hallazgo, sin embargo el fragmento hallado en la capa 1 supera en alto a dos de los pericarpios hallados en la capa 2. Por lo tanto no hay una tendencia constante y lineal hacia el aumento del alto de los 
pericarpios de Cucurbita maxima ssp. maxima con el aumento de la profundidad en esta cuadrícula.

En cuanto a la presencia de frutos enteros de Cucurbita sp., en el informe de T. Whitaker figura un fruto entero bajo el $\mathrm{N}^{\circ} 3$, hallado en el Sector II, cuadrícula B4 de Los Aparejos. Se trataría de un fruto turbaniforme con 10 lóbulos (8 mayores y 2 menores) de $8,2 \mathrm{~cm}$ de alto y una apertura en el área de la corola de $9,3 \mathrm{~cm}$ de diámetro. Whitaker señala también que el pericarpio posee $5 \mathrm{~mm}$ de grosor máximo y que, en sección transversal, posee células de apariencia circular. Los restos de pericarpio C14 proceden de igual contexto, pero no son evidentemente restos de este fruto ya que no muestran indicios de lóbulos. Este fruto $\mathrm{N}^{0} 3$ no fue localizados en depósito ni fue registrado por Pochettino (1985).

En su informe, Whitaker interpreta los restos C12 como parte de medio fruto el cual, según su estimación, habría tenido aproximadamente $28 \mathrm{~cm}$. de largo, asemejándose a los frutos del cultivar "banana" actual. Por último interpreta los restos C17 como pertenecientes a un fruto de $21 \mathrm{~cm}$ de diámetro y $16 \mathrm{~cm}$ de alto, levemente lobulado. El análisis de los fragmentos que actualmente conforman la colección ha permitido corroborar estos datos brindados por Whitaker y dar apoyo a sus interpretaciones.

El análisis microscópico efectuado permitió constatar que seis restos identificados previamente como C. maxima pertenecían a la especie Lagenaria siceraria (Tabla 54). La distribución de los hallazgos es amplia, habiendo restos tanto en la cueva Los Aparejos y El Litro como en otras menores: caverna III, IV y V. En estas últimas cavernas no se recuperaron restos de Cucurbita y, por el contrario, no se recuperaron restos de L. siceraria en la Caverna II. Todos los restos son de colores uniformes, principalmente castaño oscuro o bordó y en menor medida castaño claro. Se registró un solo caso (Lag 7) con moteado blanco sobre fondo bordó oscuro. Este último carácter estaría gobernado en Lagenaria por un par de genes (Robinson et al 1976). 
El alto de los restos es sumamente variable, con un promedio general de 2,81 $\mathrm{mm}$, un rango de entre 1,78 y 4,52 $\mathrm{mm}$ y un coeficiente de variación del $25 \%$. En el caso de este género es difícil evaluar esta alta variabilidad. A pesar de que la historia evolutiva del mismo estuvo durante mucho tiempo bajo debate (Cutler y Whitaker 1961, Teppner 2004), hallazgos recientes (Ericsson et al. 2005) parecerían indicar que la domesticación del género Lagenaria implicó -al igual que la de Cucurbita- un aumento en el grosor del pericarpio. En opinión de estos investigadores dicho aumento habría implicado la perdida de los mecanismos naturales de dispersión de este taxón al obtenerse un fruto resistente y perdurable. El análisis de poblaciones silvestres de Lagenaria indicaría que los pericarpios de sus frutos no superan los $1,4 \mathrm{~mm}$, convirtiéndose éste valor en una línea de base para distinguir formas silvestres de domesticadas, el análisis de restos de sitios tempranos con 8.000 a 10.000 años de antigüedad de Mesoamérica y Sudamérica revela que todos los restos corresponden a frutos domesticados, lo cual lleva a Erickson y colaboradores (2005) a asumir un ingreso de este taxón con los primeros pobladores del continente americano. Sin embargo, como puede verse en las tablas 50 y 54, no existe correspondencia entre el aumento del alto del pericarpio y fechas más recientes de los hallazgos. Por lo tanto, a pesar de que la propuesta de Erickson et al. (2005) resulta interesante, no han analizado en mayor profundidad la relación existente entre la enorme variabilidad de los frutos, tanto en morfología como en tamaño, de Lagenaria siceraria (Whitaker 1948, Leon 1987, Teppner 2004) y las características del pericarpio. Ante esto podemos asumir - con cierto recaudo- que la alta variabilidad registrada en Pampa Grande para ésta especie indicaría la coexistencia de diversos morfotipos, tal como ocurre para el caso de Cucurbita.

En su informe Whitaker interpreta a los restos Lag-1 como parte de un pequeño fruto probablemente periforme de unos 6 a $7 \mathrm{~cm}$ de diámetro. Los restos de Lag-5 también corresponderían a un fruto piriforme de $9 \mathrm{~cm}$ de 
diámetro y $12 \mathrm{~cm}$ de alto con una apertura en uno de sus lados. El trabajo en depósito mostró este fruto roto, acompañado por restos de cordelería, hojas secas y paja. De acuerdo con el informe de Whitaker estos restos habrían estado dentro del fruto. Se reportan también restos del "cuello" de un fruto con forma de botella, cuyo tamaño estimado a partir del fragmento es de unos $20 \mathrm{~cm}$ de alto y $12 \mathrm{~cm}$ de diámetro. Este fragmento figura como cuadrícula 36 de El Litro, lo cual no es acertado, tratándose posiblemente de restos vinculados al hallazgo 36 de la Caverna II de Las Cuevitas. Finalmente Whitaker menciona el hallazgo de un fruto cortado por la mitad con un pericarpio de 3,4 $\mathrm{mm}$ de espesor. El mismo fue hallado en la Caverna $\mathrm{V}$ vinculado al hallazgo 71 y su imagen se encuentra en el trabajo que el autor publica en 1983. Este fruto no fue hallado en depósito y tampoco fue registrado por Pochettino (1985).

A pesar de la conservación de frutos enteros, fue en los fragmentos donde se detectó la presencia de orificios conteniendo aún restos de cordelería. Destaca el conjunto registrado como Lag-7 (Tabla 54, lámina 25), cuyos fragmentos a, b y c remontan conformando un único resto de pericarpio delgado color bordó con manchas blancas que posee bordes cortados en línea recta en los cuales se ubican orificios muy pequeños. Los mismos son equidistantes con una separación aproximada de $9 \mathrm{~mm}$ ubicándose aproximadamente a $3 \mathrm{~mm}$ del borde. Se conservan restos de un cordón muy fino (menos de $1 \mathrm{~mm}$ ) que une los mencionados orificios recorriendo el borde recto del fragmento. El material fue analizado por Graciela Suarez -a cargo del registro y conservación de textiles en el Departamento Científico de Arqueología del Museo de Ciencias Naturales de La Plata- quien señaló que la técnica empleada es la de festón invertido ya que alterna el lugar de entrada del cordón (de forma alternada por fuera y dentro del pericarpio), siendo sumamente inusual en el registro arqueológico. También señaló que posiblemente se haya empleado una aguja dado que los orificios tienen el 
diámetro exacto del cordón y que es un tipo de trabajo que no puede cumplir la función de unión, siendo sólo una decoración sobre el borde. El fragmento e posee, además de tres orificios como los ya descritos, un ojal en uno de sus bordes (un ojal del mismo tipo está presente en el fragmento f) de $2 \mathrm{~mm}$ de largo y menos de uno de ancho por el cual pasa una tira de fibra vegetal. Estos fragmentos no son mayores a $5 \mathrm{~cm}$, pero poseen curvatura, por lo cual podría tratarse de un fruto pequeño, como los ya mencionados. Lo único que sabemos del conjunto Lag-7 es que estaba contenido en un cesto, sin más referencia contextual. El fragmento 067 posee un orificio pequeño con restos de un cordón y un ojal de $1 \mathrm{~cm}$ de largo conteniendo restos de varias fibras vegetales. Los restos 071 son muy interesantes también (Tabla 54, lámina 25). El fragmento b, de menor espesor, posee un borde recto con pequeños orificios al igual que $\operatorname{Lag} 7$ a-c, aunque en este caso son fibras vegetales las que atraviesan los orificios y no cordones, siendo nuevamente el diámetro de la apertura de los mismos exactamente igual al del material que los atraviesa. En el caso del fragmento $a$ el mismo es parte de la base del fruto, el cual se habría cortado en el sentido del eje mayor del mismo por sobre la línea corolapedúnculo. Por debajo del borde formado por dicho corte se efectuaron varios orificios de $1 \mathrm{~mm}$ de diámetro aproximadamente. El fragmento conserva restos de un cordón de fibra vegetal teñido de rojo, el cual pasa por dos orificios y luego esta anudado. En este caso es posible que estemos ante un dispositivo efectuado para suspender al fruto, el cual habría oficiado como recipiente.

Recordemos que en el caso de Cucurbita, un único fragmento (C17) presentó un orificio, pero éste no contenía resto alguno en su interior. En este sentido, cabe mencionar que los contextos de hallazgo de pericarpios de L. siceraria son muy similares a los de Cucurbita sp., como puede constatarse al comparar los contextos señalados en las tablas 53 y 54 . Por lo tanto es posible proponer que no hubo una diferenciación entre ambos géneros en lo referente a uso y 
contexto, ya que ambos se emplearon como contenedores tanto en ámbitos domésticos como funerarios.

\section{Análisis de fitolitos}

El rango de medidas de los fitolitos de C. maxima ssp. andreana de referencia se encuentra entre los $39 \mu \mathrm{m}$ y $67,5 \mu \mathrm{m}$, en tanto los de la subespecie domesticada entre $50 \mu \mathrm{m}$ y $90 \mu \mathrm{m}$ (Tabla 55). Estas medidas se compararon con las de veinte fitolitos aún incluidos en pericarpios arqueológicos de Pampa Grande (Lámina 26). De estos últimos cuatro fueron identificados como C. maxima ssp. andreana, siete como C. maxima ssp. maxima y el resto sólo a nivel genérico como Cucurbita sp. (Tabla 56).

En el caso de pericarpios arqueológicos identificados como C. maxima ssp. andreana, los fitolitos poseen un CV mayor al registrado en ejemplares de referencia (ambas subespecies) y un rango de medidas mayor al que poseen los frutos de poblaciones actuales de C. maxima ssp. andreana (Tabla 56 y 57). Los fitolitos de pericarpios arqueológicos identificados como C. maxima ssp. maxima y Cucurbita sp. exhibieron rangos de medidas menores a los de fitolitos actuales de C. maxima ssp. maxima y un coeficiente de variación similar a los fitolitos de C. maxima ssp. andreana actuales (Tablas 57 y 58).

Por lo tanto la evidencia de estos cuerpos cristalinos nos indica que los frutos arqueológicos de C. maxima ssp. andreana eran morfológicamente más grandes y más variables que los actuales (recordemos que fitolitos más grandes se producen en frutos más grandes según Piperno y Pearsall 1998). Asimismo, los restos de C. maxima ssp. maxima y Cucurbita sp. indican frutos de mayor diversidad que los actuales de esta última subespecie. Por lo tanto podemos asumir que en Pampa Grande había poblaciones domesticadas morfométricamente variables coexistiendo con formas malezoides que eran más variables aún, probablemente porque esporádicamente se cruzaban con 
las poblaciones cultivadas sin que luego operara una selección cultural sobre ellas.

Si bien estas ideas son interesantes, no debemos dejar de tener en cuenta las apreciaciones de Bozarth (1987) ya mencionadas acerca de que plantas de una misma especie creciendo en ambientes disímiles pueden producir fitolitos de distinto tamaño. Tanto en el caso de los frutos actuales de C. maxima ssp. andreana como de C. maxima ssp. maxima cv zipinka empleados como referencia, los ambientes de los que proceden difieren del que caracteriza a la región de Pampa Grande, por lo que -si los resultados obtenidos por Bozarth (1987) se aplican a nivel de subespecie- éste es un factor que podría incidir en las diferencias observadas entre las muestras arqueológicas respecto a las actuales de referencia.

\section{Discusión}

El análisis microscópico de los tejidos que constituyen al pericarpio y una evaluación más precisa del rango de medidas que posee el espesor del mismo en ejemplares actuales nos indica que es muy difícil identificar correctamente restos arqueológicos -incluso a nivel genérico- si no se efectúan análisis de su estructura interna. Esto trae como consecuencia la dificultad de evaluar la información procedente de la bibliografía. En el caso de restos de pericarpios tempranos del NOA (Los Corrales y Los Viscos), sabemos que los mismos poseen escaso espesor, sin embargo no estamos en condiciones de asegurar a qué género pertenecen y mucho menos si corresponden a ejemplares silvestres o domesticados. En el caso de los restos recuperados en los niveles precerámicos de Huachichocana tampoco podemos asignarlos taxonómicamente, sin embargo por su elevado espesor podemos desestimar que se esté ante restos de una forma silvestre. Lo mismo ocurre con bibliografía referida a hallazgos tempranos en Chile y Perú. Por lo tanto el 
registro de Pampa Grande en el NOA es el primero en contar con una identificación clara y justificada de la presencia de restos de C. maxima ssp. andreana. Estos restos se hallaron asociados a otros de C. maxima ssp. maxima plenamente domesticados y a posibles formas transicionales entre ambas subespecies, lo cual indica que no habría diferencias temporales entre los mismos, sino una coexistencia. Sí es de destacar, sin embargo, que dicha coexistencia se constató solamente en la cueva Los Aparejos. Las denominadas "formas transicionales" son pericarpios con valores de alto compartidos por la forma silvestre y domesticada de C. maxima. Pero estos ejemplares no serían "transicionales" en el sentido estricto de la palabra ya que no ocupan un lugar intermedio en un proceso de cambio, tratándose posiblemente de formas híbridas, malezoides. En este sentido resulta interesante la propuesta de Decker Walters y Walters (2000) de que ciertos cultivares podrían haberse desarrollado a partir de selecciones hechas sobre poblaciones de C. maxima ssp andreana con cierto grado de introgresión (ver capítulo 4.1 .1 a). La alta diversidad de tamaños de fruto indicada por el análisis de fitolitos de pericarpios de Pampa Grande identificados como C. maxima ssp. andreana señalaría que este taxón era más diverso que lo que es actualmente, posiblemente por no representar estos restos a poblaciones espontáneas, sino a otras con cierto grado de alteración antrópica.

Los restos de C. maxima ssp. maxima de Pampa Grande exhiben una gran diversidad morfológica, indicando la existencia de diversos morfotipos que, probablemente, estén representando distintos cultivares. El análisis de los fitolitos indica también una diversidad elevada de los mismos. Los frutos de esta subespecie habrían sido empleados como recipientes y empleados en todas las cuevas de esta localidad arqueológica tanto en contextos domésticos como funerarios. Esto mismo ocurre con los frutos de L. siceraria -cuyos pericarpios estarían indicando la existencia de distintos morfotipos- aunque no se han recuperado semillas de este género, al contrario de lo registrado para 
Cucurbita. Esta diferencia en los tipos de restos recuperados indicaría que, si bien los frutos de ambos géneros poseían un tipo de uso y un contexto de empleo similar, los mismos eran procesados de manera distinta. Posiblemente los frutos de Lagenaria sp. eran cortados y vaciados fuera del sitio descartándose semillas (y la mayoría de los pedúnculos) fuera de las cuevas. A este respecto resulta muy interesante una observación hecha por Arenas (2003) tras sus estudios etnobotánicos entre los wichí del chaco central. Este autor menciona respecto de L. siceraria: "lo preferían sembrar en un huerto del monte porque los frutos deben crecer en la planta hasta que maduren; esto es así porque la enredadera se desarrolla y en estas condiciones ahoga a las otras del huerto. También se cultivaba alguna que otra planta en las periferias del huerto, siempre en las inmediaciones de algún árbol donde pueda treparse. Aseguran que es arriba donde da sus mejores frutos y se toma cuidado que la planta crezca en esas condiciones" (Arenas 2003: 342). Tomando en consideración esta referencia, podemos pensar que L. siceraria se sembró en un espacio distinto al de Cucurbita, si bien no estamos en condiciones de asegurar -aunque es altamente probable- que los habitantes de Pampa Grande tuvieran huertos para el cultivo de éstas últimas. Esta diferencia habría llevado a rutas distintas en el procesamiento de ambos taxa. Esto se vincula al hecho de que las semillas, al igual que los pedúnculos, no se consumían, a diferencia de las semillas de Cucurbita. Actualmente, tanto tobas como wichí no consumen ni los frutos ni las semillas de esta especie (Arenas 2003).En este sentido no concordamos con la propuesta de que las semillas de L. siceraria no suelen recuperarse en los sitios americanos ya que eran consumidas (Cutler y Whitaker 1961). Es probable entonces que las poblaciones de L siceraria fueran sembradas en espacios alejados del ámbito habitacional, siendo sus frutos procesados in situ tras ser cosechados, descartándose semillas y pedúnculos. La ausencia de semillas trae aparejadas también dudas acerca de si las mismas se 
guardaban o no para ser sembradas. Es posible que el descarte in situ de semillas generara la base para el próximo ciclo de germinación de plantas.

La presencia de orificios con restos de cordelería en frutos de L. siceraria podría llevar a suponer que los mismos eran remendados luego de romperse, asumiéndose una actitud conservadora de estos objetos. El propio Whitaker asume esto cuando dice refiriéndose a los restos de Pampa Grande: "La estima que tenían por las calabazas se ve sustentada por el hecho de que muchos contenedores fracturados fueron emparchados usando fibras de plantas (probablemente una gramínea) o una tira de cuero" (Whitaker 1983:.583). Sin embargo, un análisis del tipo de técnica empleada indica que estos trabajos en cordelería poseían una función principalmente decorativa o de sostén. Por lo tanto estos frutos, si bien no eran objetos conservados, sí eran apreciados y embellecidos.

En opinión de Piperno (2008) durante el proceso de domesticación de Cucurbita la selección humana habría estado dirigida a la obtención de pericarpios más suaves, no lignificados y por lo tanto sin fitolitos, de allí que el hallazgo de estos microrrestos no se efectúe en sitios arqueológicos donde la domesticación de Cucurbita es plena con poblaciones homocigotas hr. Sin embargo, la autora reconoce que actualmente existen cultivares de pericarpios duros en las distintas especies domesticadas de Cucurbita, los cuales podrían estar representando la selección a favor de frutos más durables en el tiempo, con mayor capacidad de almacenamiento. En el caso de Pampa Grande habría frutos tanto de pericarpio duro como suave, los primeros aptos para ser empleados como recipientes y con mayor capacidad de almacenamiento, y los segundos posiblemente más palatables. El empleo de los frutos de Cucurbita como recipientes se halla extendido en las ocupaciones tempranas del Área Andina Meridional tal como vimos para sitios chilenos, peruanos, del COA y NOA. Estos no sólo habrían sido empleados para contener restos diversos (semillas, harinas, colorantes), sino que también fueron empleados para 
calentar o cocinar restos en su interior. Consideramos que su presencia en ajuares funerarios no debe destacarse, ya que el empleo dado a los mismos cotidianamente se habría hecho extensivo al ámbito funerario donde fueron empleados para contener ofrendas.

Esta tradición de empleo de los frutos lignificados de Cucurbita como recipientes, a semejanza de lo registrado en L. siceraria, está presente en Pampa Grande junto a frutos no lignificados. Estos últimos estarían representando otra línea de selección, que habría operado a favor de otros caracteres vinculados posiblemente a atributos gastronómicos, desestimando la capacidad de almacenaje o el uso como recipiente de los frutos. En este sentido cabe considerar que si se están seleccionando, por ejemplo, ciertas características del mesocarpio (vg. color, sabor, etc.) sin que ello altere el tamaño del fruto o la lignificación del pericarpio, difícilmente este proceso de selección se refleje en los macrorrestos ni en los fitolitos, ya que estos se modifican respondiendo a estas dos últimas variables (tamaño del fruto y grado de lignificación del mismo).

La gran diversidad de restos llamó la atención del propio Whitaker quien señala la presencia de "Cucúrbitas abundantes y hermosamente conservadas (...) Sugerimos que C. maxima fue intensamente cultivada en Pampa Grande por un período de al menos 1500 años antes del contacto con los españoles. (...) Comienza a aparecer material similar a los modernos cultivares por ej. tipo Hubbard, Turbante, Banana y quizá otros (Whitaker 1983:.583). En este sentido, de los cultivares argentinos de C maxima ssp maxima (ver capítulo 4.1.1a), los restos de frutos lobulados con verrugas y de paredes gruesas en esta localidad arqueológica se asemejan al cultivar Zipinka, propio del NOA.

A pesar de la gran diversidad de Cucurbitáceas presente en Pampa Grande, con distintos cultivares y formas malezoides, no se constató la presencia de $C$. moschata. Restos de frutos de dicha especie fueron identificados en Los Morillos hacia el 280-375 dC y en Los Viscos hacia el 770 -980 dC. En el 
Norte Grande de Chile se encuentran también presente este taxón con una fecha similar, junto a C. maxima ssp maxima y L. siceraria. Esta especie es la primera en hacer su aparición en sitios peruanos junto a restos de L. siceraria (Dillehay et al. 2007). Los análisis aquí efectuados de sitios tempranos peruanos confirman esta tendencia. En el caso de Cerro Lampay pudo constatarse la coexistencia de una variedad de $C$. moschata lignificada de paredes delgadas junto a restos de pericarpios de L. siceraria más gruesos. Esta misma asociación se constata en Huaca Prieta. En cuanto a la presencia de otras especies, en este último sitio habría restos de pericarpio de C. ficifolia y en Cerro Lampay habría un ejemplar dudoso de C. maxima ssp. maxima lignificado. Por lo tanto la costa peruana, el litoral pacífico chileno y el área del Centro Oeste en Argentina habrían compartido una tradición temprana en el empleo y manipulación de frutos de C. moschata, no compartido por el área de transición hacia las tierras bajas del NOA durante el Formativo, donde fue más popular el empleo de frutos de $C$. maxima ssp. maxima cultivados localmente. 
Tabla 42: caracteres de los frutos de especies sudamericanas de Cucurbita domesticadas y de Lagenaria siceraria

\begin{tabular}{|c|c|c|c|c|c|c|}
\hline \multirow[b]{2}{*}{$\begin{array}{l}\text { C. maxima ssp. } \\
\text { maxima }\end{array}$} & \multicolumn{2}{|c|}{ Fruto } & \multicolumn{2}{|c|}{ Epicarpio } & \multicolumn{2}{|r|}{ Mesocarpio } \\
\hline & Forma & Dimensiones & Color & Consistencia & Color & Otras características. \\
\hline Millán 1947 & $\begin{array}{l}\text { Cultivar zipinka: frutos } \\
\text { lobulados de forma esférica } \\
\text { a deprimida con el ápice } \\
\text { romo o algo puntiagudo } \\
\text { Cultivar zapallito: redondos } \\
\text { cuando inmaduros algo } \\
\text { lobulados al madurar. } \\
\text { Cultivar triloba: trilobulados } \\
\text { con un ombligo más o } \\
\text { menos desarrollado en el } \\
\text { extremo distal }\end{array}$ & & \begin{tabular}{|c|} 
Cultivar zipinka: \\
Verde uniforme o con \\
retículos de un verde \\
pálido. Superficie lisa \\
o con verrugas \\
corchosas Cultivar \\
zapallito: cuando \\
inmaduro totalmente \\
verde o verde con \\
líneas más claras, \\
cuando maduro \\
verde obscuro o \\
ceniza. Cultivar \\
triloba: verde oscuro, \\
superficie rugosa \\
\end{tabular} & $\begin{array}{c}\text { Cultivar zipinka: } \\
\text { durísima desde muy } \\
\text { joven el fruto } \\
\text { Cultivar zapallito: suave } \\
\text { cuando inmaduro y } \\
\text { durísima al madurar el } \\
\text { fruto }\end{array}$ & $\begin{array}{l}\text { Cultivar } \\
\text { zapallito: verde } \\
\text { amarillento a } \\
\text { anaranjado }\end{array}$ & \\
\hline Whitaker y Bohn 1950 & $\begin{array}{c}\text { Variable. Forma de } \\
\text { turbante (ovario por fuera } \\
\text { del receptáculo). Pericarpio } \\
\text { duro o blando }\end{array}$ & & Brillantes u opacos & $\begin{array}{l}\text { Granulado fino, sin } \\
\text { fibras distintivas }\end{array}$ & $\begin{array}{c}\text { Amarillo pálido a } \\
\text { amarillo- } \\
\text { anaranjado }\end{array}$ & $\begin{array}{l}\text { Moderadamente húmedo a } \\
\text { seco }\end{array}$ \\
\hline Parodi 1966 & $\begin{array}{l}\text { Cultivar zapallito: frutos } \\
\text { globosos más o menos } \\
\text { comprimidos por los } \\
\text { extremos. Cultivar zipinka: } \\
\text { frutos con forma de trompo }\end{array}$ & $\begin{array}{c}\text { Cultivar Criollo : } 20 \text { a } 40 \\
\text { cm de diámetro. Cultivar } \\
\text { zipinka: de } 10 \text { a } 15 \mathrm{~cm} \text { de } \\
\text { diámetro }\end{array}$ & $\begin{array}{c}\text { Cultivar Criollo: } \\
\text { anaranjado o plomizo } \\
\text { Cultivar zipinka: } \\
\text { verdoso o anaranjado }\end{array}$ & $\begin{array}{l}\text { Cultivar zipinka: } \\
\text { durísima Cultivar } \\
\text { zapallito: t Cultivar } \\
\text { zapallito tierna y } \\
\text { delgada cuando } \\
\text { inmaduros }\end{array}$ & $\begin{array}{l}\text { Cultivar Criollo } \\
\text { anaranjada: }\end{array}$ & $\begin{array}{l}\text { Cultivar Criollo : espeso y } \\
\text { dulce }\end{array}$ \\
\hline
\end{tabular}




\begin{tabular}{|c|c|c|c|c|c|c|}
\hline Lira Saade 1995 & $\begin{array}{l}\text { Elíptico, oblado, oblongo a } \\
\text { veces piriforme, nunca } \\
\text { claviforme. Turbaniforme. } \\
\text { Liso o lobulado, a veces } \\
\text { con protuberancias leñosas }\end{array}$ & Muy variable. Hasta $100 \mathrm{~kg}$ & \begin{tabular}{|} 
Tonalidades de \\
blanco, amarillo o \\
verde, a veces rojizo \\
anaranjado, azul- \\
grisáceo o verde \\
parduzco
\end{tabular} & Rígida o suave & $\begin{array}{c}\text { Amarillo pálido o } \\
\text { anaranjado } \\
\text { brillante. }\end{array}$ & Poco o nada fibroso. \\
\hline Teppner 2004 & $\begin{array}{c}\text { Muy diverso. El receptáculo } \\
\text { a menudo no se cierra } \\
\text { alrededor del estilo, de } \\
\text { manera que en los frutos } \\
\text { las puntas de los carpelos } \\
\text { son más (tipo turbante) o } \\
\text { menos (anillo corchoso a } \\
\text { cierta distancia de la base } \\
\text { del estilo) evidentes }\end{array}$ & & Muy diverso & & & \\
\hline \multicolumn{7}{|l|}{ C. moschata } \\
\hline Whitaker y Bohn 1950 & $\begin{array}{l}\text { Variable, pero nunca con } \\
\text { pericarpio duro }\end{array}$ & & Colores mate & $\begin{array}{c}\text { Granulado fino a } \\
\text { grueso con fibras } \\
\text { gelatinosas }\end{array}$ & $\begin{array}{c}\text { Amarillo a } \\
\text { naranja fuerte }\end{array}$ & $\begin{array}{c}\text { Moderadamente seco a } \\
\text { húmedo }\end{array}$ \\
\hline $\begin{array}{c}\text { Lira Saade 1995, Lira } \\
\text { Saade FAO }\end{array}$ & $\begin{array}{c}\text { Muy variable: globoso, } \\
\text { ovoide, oblado, cónico, } \\
\text { obcónico, piriforme, } \\
\text { claviforme, lageniforme, } \\
\text { oblongo, cilíndrico, nunca } \\
\text { turbaniforme. Comúnmente } \\
\text { con costillas o surcos } \\
\text { longitudinales, liso, } \\
\text { moderada a densamente } \\
\text { verrucoso. Pericarpio } \\
\text { blando y suave o duro y } \\
\text { durable }\end{array}$ & & \begin{tabular}{|} 
Diversos sombreados \\
o patrones de verde, \\
pardo o menos \\
comúnmente \\
anaranjado, \\
usualmente con capa \\
cerosa glauco- \\
grisácea. Mate o \\
brillante
\end{tabular} & $\begin{array}{l}\text { Ligeramente a nada } \\
\text { fibrosa }\end{array}$ & $\begin{array}{c}\text { Amarillo pálido a } \\
\text { anaranjado } \\
\text { brillante, } \\
\text { puede tener } \\
\text { color } \\
\text { oscuro en la } \\
\text { placenta }\end{array}$ & \\
\hline Teppner 2004 & $\begin{array}{c}\text { Forma y tamaño muy } \\
\text { variable }\end{array}$ & & $\begin{array}{c}\text { Muy variable, } \\
\text { cubierto con capa } \\
\text { cerosa }\end{array}$ & & & \\
\hline
\end{tabular}




\begin{tabular}{|c|c|c|c|c|c|c|}
\hline Leon 1987 & $\begin{array}{c}\text { fruto de formas muy } \\
\text { distintas incluso en la } \\
\text { misma planta: esférico, } \\
\text { elipsoidal, oblado, } \\
\text { piriforme, en forma de } \\
\text { botella con el cuello recto o } \\
\text { curvo, superficie lisa o con } \\
\text { rebordes o costillas } \\
\text { longitudinales, uniforme o } \\
\text { verrucosa, gran variación } \\
\text { en tamaño. }\end{array}$ & & Muy variable & & & \\
\hline Parodi (1978) & $\begin{array}{l}\text { Fruto alargado y curvo, } \\
\text { algunos aplanados mucho } \\
\text { más anchos que largos, } \\
\text { otros son oblongos, liso, } \\
\text { angostado en la inserción } \\
\text { con el pedúnculo }\end{array}$ & & Amarillento o verdoso & & & \\
\hline \multicolumn{7}{|l|}{ C. ficifolia } \\
\hline Whitaker y Bohn 1950 & $\begin{array}{c}\text { Globular a oblonga con } \\
\text { pericarpio duro }\end{array}$ & & $\begin{array}{c}\text { Blanco, marfil o verde } \\
\text { pálido, opaco, a } \\
\text { menudo con } \\
\text { manchas verdes }\end{array}$ & $\begin{array}{l}\text { Granulado grueso, } \\
\text { firme, fibroso }\end{array}$ & Blanco & Moderadamente seco \\
\hline Lira Saade 1995 & $\begin{array}{l}\text { Globoso a ovado-elíptico, } \\
\text { nunca oblado, piriforme o } \\
\text { claviforme. Liso, con } \\
\text { abundantes y muy } \\
\text { diminutas depresiones u } \\
\text { ondulaciones }\end{array}$ & $\begin{array}{c}15-50 \mathrm{~cm} \text { de largo y más o } \\
\text { menos la mitad de diámetro }\end{array}$ & \begin{tabular}{|} 
Generalmente verde \\
con manchas y/o \\
franjas blancas \\
irregulares o densa y \\
diminutamente \\
manchados en \\
blanco y verde, a \\
veces totalmente \\
blancos o verdes
\end{tabular} & $\begin{array}{c}\text { Fibrosa, no fácilmente } \\
\text { delicuescente }\end{array}$ & Siempre blanco & \\
\hline Teppner 2004 & Ovado a redondeado & $15-50 \mathrm{~cm}$ de largo & $\begin{array}{c}\text { Verde con jaspeado } \\
\text { blanco o blanco }\end{array}$ & Fibrosa & & \\
\hline Leon 1987 & $\begin{array}{c}\text { Fruto esférico o elipsoidal } \\
\text { sin surcos de pericarpio } \\
\text { delgado y duro }\end{array}$ & & $\begin{array}{l}\text { Color verde con } \\
\text { manchas blancas } \\
\text { irregulares }\end{array}$ & Fibrosa & Blanco & \\
\hline
\end{tabular}




\begin{tabular}{|c|c|c|c|c|c|c|}
\hline Parodi (1978) & $\begin{array}{l}\text { Frutos aovados, } \\
\text { elipsoideos o } \\
\text { suborbiculares, con el } \\
\text { clamidorcarpo duro } \\
\end{array}$ & $20-30 \mathrm{~cm}$ de largo & & & & \\
\hline \multicolumn{7}{|c|}{ Lagenaria siceraria } \\
\hline Teppner 2004 & $\begin{array}{l}\text { Muy variable, pericarpio } \\
\text { duro }\end{array}$ & Hasta 1-2 m & & & & $\begin{array}{l}\text { La placenta puede estar } \\
\text { firmemente unida al } \\
\text { pericarpio o separarse de } \\
\text { éste a la madurez }\end{array}$ \\
\hline Leon 1987 & $\begin{array}{l}\text { Fruto mas variable que en } \\
\text { cualquier otra } \\
\text { cucurbitáceas: cilíndricos, } \\
\text { angostos, esféricos, } \\
\text { piriformes, cuello recto o } \\
\text { curvo. }\end{array}$ & $\begin{array}{c}\text { Cilíndricos hasta } 1 \mathrm{~m} \text { de } \\
\text { largo; esféricos hasta } 0.5 \mathrm{~m} \\
\text { de diámetro }\end{array}$ & & & & \\
\hline Dymock 1972 & & & & Esponjosa & Blanca & \\
\hline Whitaker 1948 & $\begin{array}{c}\text { Más de una docena e } \\
\text { formas: forma de campana, } \\
\text { de clava, de botella, de } \\
\text { cucharón, entre otras. }\end{array}$ & $\begin{array}{c}\text { Desde } 7,6 \text { a } 91,4 \mathrm{~cm} . \mathrm{La} \\
\text { subespecie asiática seria } \\
\text { mayor que la africana }\end{array}$ & \begin{tabular}{|c|} 
La subespecie \\
asiática con fruto \\
verde pálido a \\
blanco, africana con \\
color verde oscuro \\
\end{tabular} & $\begin{array}{l}\text { Duro, subespecie } \\
\text { asiática más grueso } \\
\text { que la africana }\end{array}$ & & \\
\hline
\end{tabular}


Tabla 43: caracteres de los frutos de C. maxima ssp. andreana.

\begin{tabular}{|c|c|c|c|c|c|c|c|c|}
\hline \multirow[t]{2}{*}{ Autor/Año } & \multicolumn{3}{|c|}{ Fruto } & \multicolumn{3}{|l|}{ Epicarpio } & \multicolumn{2}{|l|}{ Mesocarpio } \\
\hline & Forma & Peso & Dimensiones & Color & Consistencia & Espesor & Color & Otras características \\
\hline Millán 1945 & $\begin{array}{c}\text { ovoide, oblongo, esférico } \\
\text { o deprimido liso o } \\
\text { lobulado }\end{array}$ & & $6-21,5 \mathrm{~cm}$ de largo & \begin{tabular}{|c|} 
verde \\
claro/amarillento o \\
anaranjado con \\
franjas longitudinales \\
anchas verde oscuro \\
con otras más \\
angostas \\
intercaladas verde \\
claro o crema, a \\
veces con lunares. \\
\end{tabular} & $\begin{array}{c}\text { leñosa y dura, a } \\
\text { veces mas } \\
\text { blanda }\end{array}$ & & $\begin{array}{l}\text { verde, blanco } \\
\text { o anaranjado }\end{array}$ & $\begin{array}{c}\text { se reabsorbe y queda } \\
\text { como fibras }\end{array}$ \\
\hline $\begin{array}{c}\text { Martínez } \\
\text { Crovetto en } \\
\text { Burkart } 1974 \\
\end{array}$ & globoso-ovoide liso & & $\begin{array}{c}\text { 8-20 cm de largo, 5- 9,5 } \\
\mathrm{cm} \text { diám }\end{array}$ & $\begin{array}{c}\text { verdoso con } 10 \\
\text { estrías longitudinales } \\
\text { más claras. }\end{array}$ & dura y lignificada & $2,5 \mathrm{~mm}$ & blanco & escaso y amargo \\
\hline $\begin{array}{c}\text { Cabrera y } \\
\text { Zardini } 1978 \\
\end{array}$ & $\begin{array}{l}\text { globoso-ovoide o } \\
\text { globoso-oblongo }\end{array}$ & & $12-20 \mathrm{~cm}$ de largo & $\begin{array}{l}\text { verdoso, con } 10 \\
\text { estrías mas claras }\end{array}$ & & & & \\
\hline Lira Saade 1995 & $\begin{array}{c}\text { Ovoide-elípticos, } \\
\text { oblongo-piriformes, } \\
\text { raramente subglobosos u } \\
\text { oblados }\end{array}$ & & $\begin{array}{c}\text { 8-16 } \mathrm{cm} \text { de largo, } 5-7.5 \\
\mathrm{~cm} . \text { de diámetro }\end{array}$ & $\begin{array}{l}\text { Verde a amarillento. } \\
\text { A veces con rayas } \\
\text { delgadas } \\
\text { longitudinales verde } \\
\text { claro a crema y } \\
\text { manchas pequeñas } \\
\text { de color crema a } \\
\text { blanquecino }\end{array}$ & $\begin{array}{c}\text { Rígida y } \\
\text { durable, lisa }\end{array}$ & & $\begin{array}{c}\text { Blanquecina a } \\
\text { amarillo } \\
\text { pálido }\end{array}$ & $\begin{array}{c}\text { Escaso, fibroso y muy } \\
\text { amargo }\end{array}$ \\
\hline Ashworth 1997 & $\begin{array}{c}\text { generalmente ovoide hay } \\
\text { globosos (pueden darse } \\
\text { ambos casos en una } \\
\text { misma planta) }\end{array}$ & & $\begin{array}{c}71,63+/-2,86 \mathrm{~mm} \text { de } \\
\text { largo } 67,80+/-2,27 \mathrm{~mm} \\
\text { de ancho }\end{array}$ & & & & & \\
\hline $\begin{array}{l}\text { Ashworth y } \\
\text { Galetto } 2001\end{array}$ & & $\begin{array}{c}\text { Seco: } 20 \mathrm{mg} \text { ( } 38 \% \text { es } \\
\text { de las semillas) } \\
\text { Fresco: } 160 \mathrm{~g}(7,2 \% \\
\text { es de las semillas) }\end{array}$ & & & & & $\begin{array}{c}\text { blanco o } \\
\text { amarillento, } \\
\text { naranja pálido }\end{array}$ & $\begin{array}{l}\text { se reabsorbe a la } \\
\text { madurez }\end{array}$ \\
\hline Teppner 2004 & alargado-oval & & 6,5-16 cm de largo & & & & & \\
\hline
\end{tabular}


Tabla 44: medidas de espesor del pericarpio de diversos taxa de acuerdo con la bibliografía consultada.

\begin{tabular}{|ccc|}
\hline TAXA & $\begin{array}{c}\text { ESPESOR }(\text { en } \\
\text { mm })\end{array}$ & BIBLIOGRAFÍA \\
\hline $\begin{array}{c}\text { Lagenaria siceraria } \\
\text { Cucurbita maxima ssp. } \\
\text { andreana }\end{array}$ & 1 a 16 & Whitaker 1948; Cutler y Whitaker \\
& 2,5 & Martinez Crovetto en Burkart 1974 \\
Cucurbita sp. & $\begin{array}{c}1,5 \text { a } 10 \\
\text { (generalmente } \\
\text { menos de 4, de 2 } \\
\text { a 3) }\end{array}$ & Whitaker 1948; Cutler y Whitaker \\
& 1961
\end{tabular}

Tabla 45: diámetro (en micrones) de fitolitos esféricos facetados de dos cultivares estadounidenses de C. maxima ssp. maxima. Modificado de tabla 2 en Bozarth 1987

\begin{tabular}{|c|c|c|c|c|}
\hline Cultivar & Rango & Media & Varianza & Desvío Estándar \\
\hline Banquet squash & $50-90$ & 68,5 & 76,4 & 8,7 \\
\hline $\begin{array}{c}\text { Kampsville orange } \\
\text { squash }\end{array}$ & $45-68$ & 55,4 & 23,7 & 4,9 \\
\hline
\end{tabular}

Tabla 46: colección de referencia de frutos de C. maxima ssp andreana de provincia de Buenos Aires.

\begin{tabular}{|c|c|c|c|}
\hline Procedencia & Cantidad & Colectó & Observaciones \\
\hline $\begin{array}{c}\text { Gonnet. } \\
\text { Buenos Aires }\end{array}$ & 1 & A. Capparelli & $\begin{array}{c}\text { Fruto esférico } \\
\text { pequeño. }\end{array}$ \\
\hline $\begin{array}{c}\text { Mones Cazón } \\
\text { Buenos Aires }\end{array}$ & 3 & M. Arriaga & $\begin{array}{c}\text { Frutos esféricos } \\
\text { pequeños. }\end{array}$ \\
\hline $\begin{array}{c}\text { Mones Cazón } \\
\text { Buenos Aires }\end{array}$ & 3 & M. Arriaga & $\begin{array}{c}\text { Frutos de alargados } \\
\text { de gran tamaño. }\end{array}$ \\
\hline $\begin{array}{c}\text { Orillas del } \\
\text { Salado. Buenos } \\
\text { Aires }\end{array}$ & 1 & S. Bogan & $\begin{array}{c}\text { Fruto esférico } \\
\text { pequeño. }\end{array}$ \\
\hline $\begin{array}{c}\text { Orillas del } \\
\text { Salado. Buenos } \\
\text { Aires }\end{array}$ & 2 & S. Bogan & $\begin{array}{c}\text { Frutos de alargados } \\
\text { de gran tamaño. }\end{array}$ \\
\hline $\begin{array}{c}\text { LEBA } \\
\text { Material no } \\
\text { etiquetado, } \\
\text { colección de } \\
\text { futos y semillas } \\
\text { Laboratorio de } \\
\text { Etnobotánica y } \\
\text { botánica } \\
\text { Aplicada, FCNYM }\end{array}$ & 1 & & \\
\hline
\end{tabular}


Tabla 47: medidas (mm) de frutos de C. maxima ssp. andreana colectados en diversas localidades de la provincia de Buenos Aires siguiendo los parámetros propuestos por Cowan y Smith (1193). Diam: diámetro del fruto.

\begin{tabular}{|c|c|c|c|c|c|c|c|c|c|c|c|c|c|c|c|c|c|c|}
\hline MUESTRA & $\mid \begin{array}{c}\text { DIAM. } \\
1\end{array}$ & $\begin{array}{c}\text { DIAM. } \\
2\end{array}$ & MEDIA & $\mid \begin{array}{c}\text { Rel. } \\
\text { Diam } \\
\text { 1/diam2 }\end{array}$ & $\begin{array}{c}\text { ESPESOR } \\
1\end{array}$ & $\begin{array}{c}\text { ESPESOR } \\
2\end{array}$ & $\begin{array}{c}\text { ESPESOR } \\
3\end{array}$ & $\begin{array}{c}\text { ESPESOR } \\
4\end{array}$ & $\begin{array}{c}\text { ESPESOR } \\
5\end{array}$ & MEDIA & $\begin{array}{c}\text { ESPESOR } \\
\text { ZONA } \\
\text { PEDUNCULO }\end{array}$ & $\begin{array}{c}\text { ESPESOR } \\
\text { ZONA LADO } \\
\text { DEL } \\
\text { PEDUNCULO } \\
1\end{array}$ & $\mid \begin{array}{c}\text { ESPESOR } \\
\text { ZONA LADO } \\
\text { DEL } \\
\text { PEDUNCULO } \\
\mathbf{2}\end{array}$ & MEDIA & $\begin{array}{c}\text { ESPESOR } \\
\text { ZONA } \\
\text { COROLA }\end{array}$ & $\mid \begin{array}{c}\text { ESPESOR } \\
\text { ZONA } \\
\text { LADO DE } \\
\text { LA } \\
\text { COROLA } \\
1\end{array}$ & \begin{tabular}{|c|} 
ESPESOR \\
ZONA \\
LADO DE \\
LA \\
COROLA \\
2
\end{tabular} & MEDIA \\
\hline Montes Casón 1 & 151,79 & 53,78 & 52,79 & 0,96 & 1,36 & 1,21 & 1,55 & 1,42 & 1,39 & 1,39 & 5,22 & 1,56 & 1,62 & 1,59 & 3,83 & 1,93 & 2,33 & 2,13 \\
\hline Montes Casón 2 & 256,7 & 57,54 & 57,12 & 0,99 & 1,56 & 1,67 & 1,82 & 1,59 & 1,64 & 1,66 & 5,97 & 1,69 & 1,89 & 1,79 & 4,85 & 2,62 & 2,54 & 2,58 \\
\hline Montes Casón 3 & & & & & 0,9 & 1,32 & 1,72 & 1,79 & 0,87 & 1,32 & & & & & & & & \\
\hline Salado 1 & 59,29 & 58,34 & 58,82 & 1,02 & 0,88 & 1,02 & 0,9 & 1,01 & 0,93 & 0,95 & 5,6 & 1,02 & 0,91 & 0,97 & 3,6 & 2,34 & 2,12 & 2,23 \\
\hline Gonnet 1 & & & & & 1,41 & 0,89 & 0,91 & 1,2 & 1,81 & 1,24 & & & & & & & & \\
\hline LEBA & & & & & 0,89 & 1,12 & 1,44 & 1,26 & 0,79 & 1,10 & 3,97 & 1,52 & 1,7 & 1,61 & & & & \\
\hline Media Gral. & & & 56,24 & & & & & & & 1,28 & 5,19 & & & 1,49 & 4,09 & & & 2,31 \\
\hline
\end{tabular}


Tabla 48: restos de pericarpios del sitio Los Viscos. Información procedente de Maloberti y Zapatiel (2003)

\begin{tabular}{|c|c|c|c|c|c|}
\hline Ejemplar $\mathbf{N}^{\circ}$ & $\begin{array}{c}\text { Espesor } \\
(\mathrm{mm})\end{array}$ & $\begin{array}{c}\text { Superficie } \\
\text { externa }\end{array}$ & $\begin{array}{c}\text { Superficie } \\
\text { interna }\end{array}$ & Color & Observaciones \\
\hline $1 b$ & 2 & Estrías & & Alutaceo & \\
\hline 5 & 3 & lisa + pocas irregularidades & estriada & Ocráceo & \\
\hline 6 & 1 & Lisa & lisa & Amarillo azufre & \\
\hline 7 & 1 & Lisa & lisa & Amarillo azufre & mismo fruto que 6 \\
\hline 8 & 1 & Lisa & lisa & Amarillo azufre & mismo fruto que 6 y 7 \\
\hline 9 & 3 & Lisa & lisa & Ocráceo & mismo fruto que 6,7 y 8 \\
\hline 10 & 3 & Lisa & lisa & Ocráceo & $\begin{array}{c}\text { mismo fruto que } 6,7,8 \\
\text { y } 9 \\
\end{array}$ \\
\hline 11 & 3 & Lisa & - & Damasco & $\begin{array}{c}\text { Posible carbonización } \\
\text { interna }\end{array}$ \\
\hline 12 & 2 & Lisa & - & Alutaceo & $\begin{array}{c}\begin{array}{c}\text { Adherencia carbonosa } \\
\text { externa }\end{array} \\
\end{array}$ \\
\hline 14 & 0,5 & $\begin{array}{c}\text { lisa con burbujas ("por } \\
\text { calor") }\end{array}$ & lisa + brillante & Rojizo & \\
\hline 19 & 1 & lisa con cicatrices/estrías & - & Amarillo pálido & símil $6,7,8,9,10$ \\
\hline
\end{tabular}

Tabla 49: recopilación de información publicada sobre el alto de pericarpios arqueológicos de Cucurbitaceae para el Área Andina Meridional.

\begin{tabular}{|c|c|c|c|c|c|}
\hline TAXA & SITIO & CONTEXTO & $\begin{array}{l}\text { MEDIDAS } \\
(\mathrm{mm})\end{array}$ & $\begin{array}{l}\text { VALORES } \\
\text { EXTREMOS }\end{array}$ & BIBLIOGRAFIA \\
\hline $\begin{array}{c}\text { Cucurbita } \\
\text { (probablemente } \\
\text { C. ficifolia) }\end{array}$ & Huaca Prieta & $\begin{array}{c}\text { HP-3-M } \\
\text { preceramico }\end{array}$ & 2 a 3 & 1,5 a 5 & $\begin{array}{c}\text { Whitaker y Bird } \\
1949\end{array}$ \\
\hline $\begin{array}{c}\text { Cucurbita } \\
\text { (probablemente } \\
\text { C. moschata) }\end{array}$ & Huaca Prieta & HP-5-B Cupisnique & 1,5 a 3 & & $\begin{array}{c}\text { Whitaker y Bird } \\
1949\end{array}$ \\
\hline L. siceraria & Huaca Prieta & $\begin{array}{c}\text { HP-3-M } \\
\text { preceramico }\end{array}$ & $\begin{array}{c}3.5 \text { a } 4 ; 8 ; 5 \\
\text { a } 6\end{array}$ & 1,5 a $10(14)$ & $\begin{array}{c}\text { Whitaker y Bird } \\
1949 \\
\end{array}$ \\
\hline L. siceraria & Huaca Prieta & HP-5-A1 Cupisnique & $5,6,10$ & & $\begin{array}{c}\text { Whitaker y Bird } \\
1949\end{array}$ \\
\hline L. siceraria & Huaca Prieta & $\begin{array}{l}\text { HP-5-(varios) } \\
\text { Cupisnique }\end{array}$ & $\begin{array}{c}1.5 ; 3 ; 4 ; 5 \text { y } \\
6 \\
\end{array}$ & & $\begin{array}{c}\text { Whitaker y Bird } \\
1949\end{array}$ \\
\hline L. siceraria & $\begin{array}{c}\text { (Costa } \\
\text { central de } \\
\text { Peru, cerca } \\
\text { de Chilca a } \\
50 \mathrm{~km} \text {. al sur } \\
\text { de Lima) }\end{array}$ & $\begin{array}{c}\text { Montículos } \\
\text { asociados con } \\
\text { sistemas agrícolas } \\
\text { sobreelevados }\end{array}$ & $\begin{array}{l}2 \text { a } 14 \text { (mas } \\
\text { frecuente } \\
\text { entre } 4 \text { y } 7)\end{array}$ & & Whitaker 1983 \\
\hline L. siceraria & Chincha & Chincha tardío & 8 & & Whitaker 1948 \\
\hline L. siceraria & Chincha & Inka & 2 a 4 & & Whitaker 1948 \\
\hline
\end{tabular}




\begin{tabular}{|c|c|c|c|c|c|}
\hline L. siceraria & Valle de Ica & Ica & 4,8 & Whitaker 1948 \\
\hline L. siceraria & Valle de Ica & Ica Medio & 4 & Whitaker 1948 \\
\hline L. siceraria & Valle de Ica & Ica Tardío & 3 & Whitaker 1948 \\
\hline L. siceraria & Valle de Ica & Ica Epigonal & 3 & Whitaker 1948 \\
\hline L. siceraria & Valle de Ica & Inka & 2 & Whitaker 1948 \\
\hline L. siceraria & Valle de Ica & Inka Tardío & 6 & Whitaker 1948 \\
\hline L. siceraria & Ancón & Chincha Medio & 4 & Whitaker 1948 \\
\hline
\end{tabular}

Tabla 50: análisis de fragmentos de pericarpio del sitio Cerro Lampay.

\begin{tabular}{|c|c|c|c|c|c|}
\hline $\mathbf{N}^{\circ}$ & FRAGMENTO & $\begin{array}{c}\text { INVENTARI } \\
0\end{array}$ & ESPESOR & IDENTIFICACION & OBSERVACIONES \\
\hline \multirow[t]{2}{*}{1} & $A$ & 14 & 3,81 & $\begin{array}{l}\text { aff. C. moschata } \\
\text { lignificada }\end{array}$ & \\
\hline & $b$ & 14 & 3,20 & $\begin{array}{l}\text { aff. C. moschata } \\
\text { lignificada }\end{array}$ & \\
\hline 2 & & 134 & 1,92 & $\begin{array}{l}\text { aff. C. moschata } \\
\text { lignificada }\end{array}$ & \\
\hline 4 & & 56 & 2,92 & L. siceraria & \\
\hline 5 & & 91 & 3,12 & $\begin{array}{c}\text { Mesocarpio } \\
\text { externo simil C. } \\
\text { maxima ssp } \\
\text { maxima aff. cv. } \\
\text { zipinka }\end{array}$ & $\begin{array}{l}\text { Posee orificio (posible origen } \\
\text { animal) }\end{array}$ \\
\hline 6 & & Bolsa 515 & 1,89 & $\begin{array}{l}\text { aff. C. moschata } \\
\text { lignificada }\end{array}$ & \\
\hline 7 & & Bolsa 697 & 1,71 & $\begin{array}{l}\text { aff. C. moschata } \\
\text { lignificada }\end{array}$ & \\
\hline 8 & & 713 & 4,22 & L. siceraria & \\
\hline 9 & & 959 & 3,42 & aff. L. siceraria & Con aparente muesca \\
\hline 10 & & 1072 & 3,62 & L. siceraria & \\
\hline 11 & & 1137 & 3,36 & L. siceraria & \\
\hline \multirow[t]{2}{*}{15} & a & 1230 & 0,94 & $\begin{array}{l}\text { aff. C. moschata } \\
\text { lignificada }\end{array}$ & \\
\hline & $\mathrm{b}$ & 1230 & 2,00 & $\begin{array}{l}\text { aff. C. moschata } \\
\text { lignificada }\end{array}$ & \\
\hline 14 & & 1210 & 3,30 & aff. L. siceraria & \\
\hline 16 & & 1243 & 1,2 & $\begin{array}{l}\text { aff. C. moschata } \\
\text { lignificada }\end{array}$ & $\begin{array}{c}\text { Junto a semilla de Lagenaria } \\
\text { siceraria }\end{array}$ \\
\hline
\end{tabular}


Tabla 51: análisis de fragmentos de pericarpio de cuatro sitios peruanos.

\begin{tabular}{|c|c|c|c|c|}
\hline SITIO & DATOS & ESPESOR & IDENTIFICACION & OBSERVACIONES \\
\hline Jahuay & $\begin{array}{c}\text { Caja } 126 \mathrm{~F} / \\
\text { Lanning } \\
1957\end{array}$ & 5,28 & aff. L. siceraria & \\
\hline $\begin{array}{c}\text { Complejo } \\
\text { Chavin }\end{array}$ & $\begin{array}{c}\text { Zona } \\
\text { (ilegible) del } \\
\text { fogón hacia } \\
\text { el piso. } \\
\text { Bolsa 3B } \\
\text { 370F }\end{array}$ & 4,46 & aff. L. siceraria & \\
\hline $\begin{array}{c}\text { Curayacu } \\
\text { (PV 49) }\end{array}$ & Caja 232 F & 5,92 & aff. L. siceraria & \\
\hline Bandurria & $\begin{array}{c}\text { Sector N } \\
\text { Cuadric A1- } \\
\text { A2, capa 15, } \\
\text { Nivel I, } \\
\text { Exc.:RFP, } \\
\text { 18/09/77 } \\
372 F, 37 b \\
\text { mate }\end{array}$ & 5,29 & L. siceraria & $\begin{array}{c}\text { Se deshace al tacto. } \\
\text { Posee abundante } \\
\text { mesocarpio medio. }\end{array}$ \\
\hline Bandurria & $\begin{array}{l}34 \mathrm{~F} / \mathrm{N} 71 / \\
\text { N46 (mate } \\
\text { trabajado) }\end{array}$ & 2,23 & L. siceraria & $\begin{array}{l}\text { En etiqueta: "mate } \\
\text { trabajado". Mejor } \\
\text { consistencia, no se } \\
\text { deshace al tacto }\end{array}$ \\
\hline
\end{tabular}

Tabla 52: análisis de dos muestras de pericarpios del sitio chileno Tulan 85

\begin{tabular}{|c|c|c|c|c|}
\hline SITIO & DATOS & ESPESOR & IDENTIFICACION & OBSERVACIONES \\
\hline Tulan 85 & Nivel 7 & 3,31 & L. siceraria & \\
\hline Tulan 85 & Nivel 8 & 3,9 & aff. L. siceraria & $\begin{array}{c}\text { Curvatura cerrada, } \\
\text { probablemente fruto } \\
\text { pequeño }\end{array}$ \\
\hline
\end{tabular}


Tabla 53: pericarpios de la localidad arqueológica Pampa Grande identificados como pertenecientes al género Cucurbita. La tabla se encuentra organizada desde los restos con menor a los de mayor espesor. En la columna denominada "identificación previa" se consigna la determinación taxonómica de los resto efectuada por Pochettino (1985), en columna "identificación actual mediante caracteres microscópicos" se consigna la determinación realizada tras el análisis de los tejidos que conforman el pericarpio.

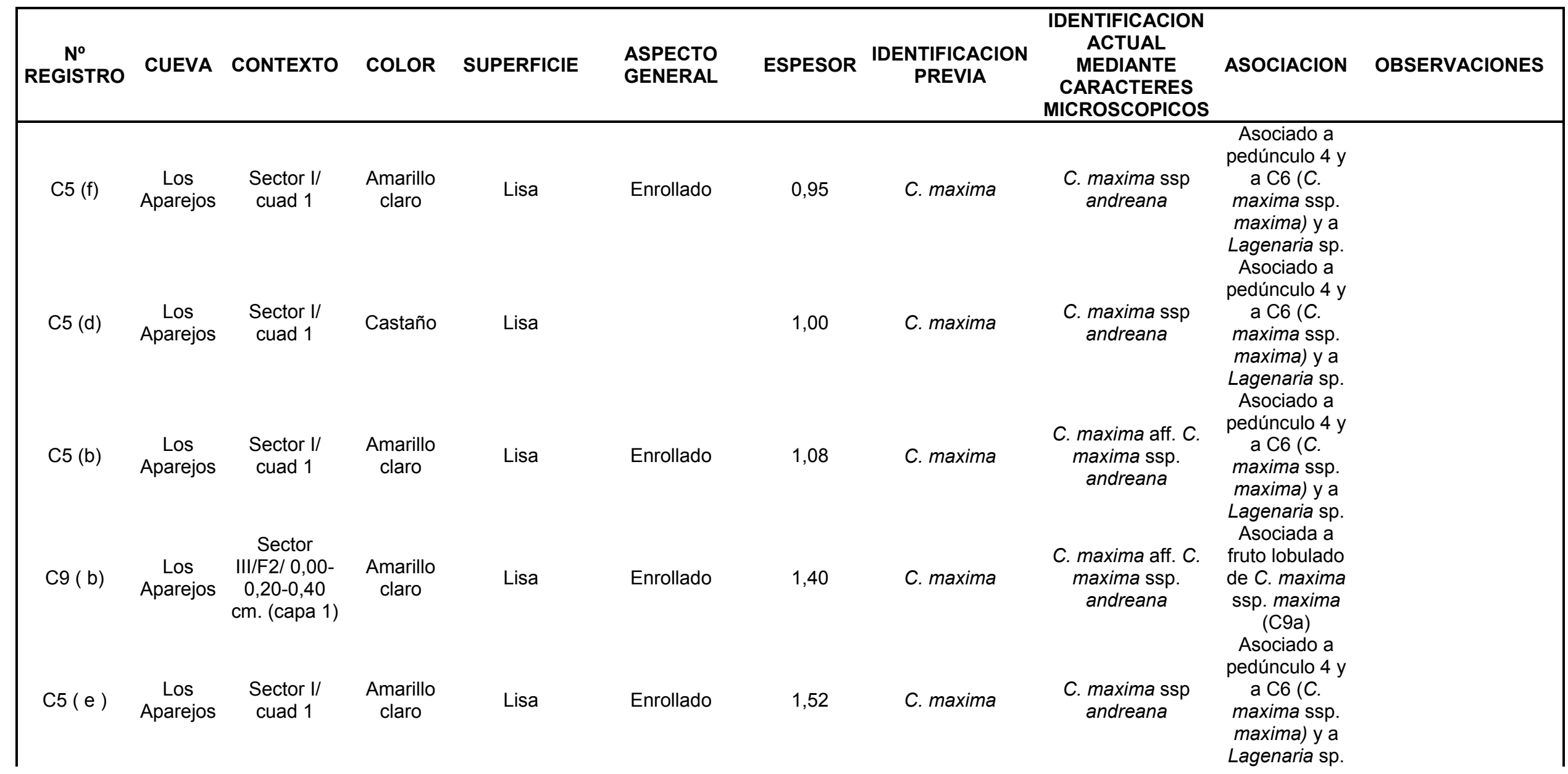




\begin{tabular}{|c|c|c|c|c|c|c|c|c|c|c|}
\hline Саја 089 & $\begin{array}{c}\text { Los } \\
\text { Aparejos }\end{array}$ & $\begin{array}{c}\text { Sector II/ } \\
\text { D1/ capa2 } \\
(0.20-0.40)\end{array}$ & Castaño & Lisa & Compacta & 1,73 & Indet. & $\begin{array}{l}\text { C. maxima ssp } \\
\text { andreana }\end{array}$ & $\begin{array}{c}\text { Junto a } \\
\text { endocarpos } \\
\text { de Prosopis } \\
\text { sp., Geoffroea } \\
\text { decorticans, } \\
\text { marlos, } \\
\text { vainas de } \\
\text { Phaseolus sp. } \\
\text { y de Arachis } \\
\text { sp., textiles. }\end{array}$ & \\
\hline C5 (a) & $\begin{array}{c}\text { Los } \\
\text { Aparejos }\end{array}$ & $\begin{array}{l}\text { Sector 1/ } \\
\text { cuad } 1\end{array}$ & $\begin{array}{l}\text { Amarillo } \\
\text { claro }\end{array}$ & Lisa & Enrollado & 1,80 & C. maxima & $\begin{array}{c}\text { C. maxima aff. C. } \\
\text { maxima ssp. } \\
\text { andreana }\end{array}$ & $\begin{array}{c}\text { Asociado a } \\
\text { pedúnculo } 4 \text { y } \\
\text { a C6 (C. } \\
\text { maxima ssp. } \\
\text { maxima) y a } \\
\text { Lagenaria sp. }\end{array}$ & \\
\hline C1 (b) & $\begin{array}{c}\text { Los } \\
\text { Aparejos }\end{array}$ & $\begin{array}{l}\text { Sector I/ } \\
\text { cuad Al } \\
\text { capa 3a }\end{array}$ & $\begin{array}{l}\text { Castaño } \\
\text { claro }\end{array}$ & Lisa & & 1,83 & C. maxima & $\begin{array}{c}\text { C. maxima aff. C. } \\
\text { maxima ssp. } \\
\text { andreana }\end{array}$ & & $\begin{array}{l}\text { Rota en dos partes. } \\
\text { Fragmentos muy } \\
\text { pequeños, no se } \\
\text { puede estimar } \\
\text { curvatura }\end{array}$ \\
\hline C11 (b) & $\begin{array}{l}\text { Los } \\
\text { Aparejos }\end{array}$ & $\begin{array}{l}\text { Sector III. } \\
\text { Junto a la } \\
\text { urna No5 }\end{array}$ & $\begin{array}{l}\text { Amarillo- } \\
\text { ocre }\end{array}$ & Lisa & Enrollado & 1,85 & C. maxima & $\begin{array}{c}\text { C. maxima aff. C. } \\
\text { maxima ssp. } \\
\text { andreana }\end{array}$ & $\begin{array}{l}\text { Asociado a } \\
\text { pericarpio de } \\
\text { C. maxima }\end{array}$ & \\
\hline C5 (c) & $\begin{array}{l}\text { Los } \\
\text { Aparejos }\end{array}$ & $\begin{array}{l}\text { Sector } 1 / \\
\text { cuad } 1\end{array}$ & $\begin{array}{l}\text { Amarillo } \\
\text { claro }\end{array}$ & Lisa & Enrollado & 1,86 & C. maxima & $\begin{array}{l}\text { C. maxima ssp } \\
\text { andreana }\end{array}$ & $\begin{array}{c}\text { Asociado a } \\
\text { pedúnculo } 4 \text { y } \\
\text { a C6 (C. } \\
\text { maxima ssp. } \\
\text { maxima) y a } \\
\text { Lagenaria sp. }\end{array}$ & \\
\hline
\end{tabular}



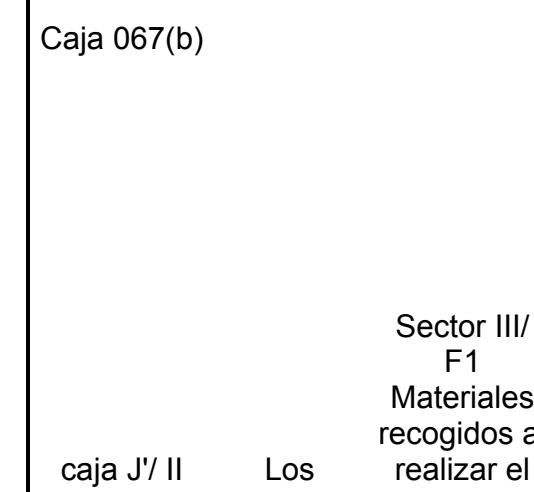

Amarillo

Lisa

Compacta

2,08

Indet.

C. maxima ssp.

maxima

Asociado a

restos de

brácteas de

Zea mays,

vainas de

Phaseolus sp

Arachis sp.y

a fruto

moderadamente

lignificada. Fruto

lobulado

C. maxima

ssp maxima

Junto a

tejidos,

trenzados

cerámica,

Materiales

recogidos al

caja J'/ II Los realizar el

(c) Aparejos perfil junto a

Castaño Lisa

Finas y

compactas

$$
\text { con }
$$

con

anterior.

sin datos Los Sector III

$\begin{array}{ccc}\text { 8h } & \text { Los } & \text { Hallazgo } \\ & \text { Aparejos } & \text { No5 }\end{array}$

Ocre claro

Lisa

No5 Urna

Compacta

2,11

Indet.

estos óseos

y cabello

C. maxima

ssp.maxima

dos frag. de

pericarpio de

C. maxima

ssp. maxima.

Materiales

proximos al

hallazgo $\mathrm{N}^{\circ} 5$

Asociado a

enterratorio

(hallazgo $\mathrm{N}^{\circ}$

5) junto a

granos de

Zea mays,

semillas de

Phaseolus

$\mathrm{sp}$.,

endocarpos

de Prosopis

sp. y textiles. 
$\begin{array}{lll}\text { Caja I / Los Sector II/ } & \text { C3/ 0,10- }\end{array}$

Bolsa 5 (a) Aparejos $\quad$ C3/ 0,10-

C1 (c ) Aparejos

Sector I/

cuad A

capa $3 a$

Amarillo-

ocre

Lisa

Caja I/L Los

Sector II/

C3/0,10$0,40 \mathrm{~cm}$.

Sector III/ F1

\section{Materiales}

recogidos al

caja J'/ L Los realizar el

(b) Aparejos perfil junto la urna $n^{\circ} 5$,

con

remoción

anterior.

Ocre claro

Lisa

Castaño

Lisa

\section{Ocre claro \\ Lisa \\ Corchosa pero}

compacta

2,38

Indet.

Cucurbita sp.

Finas y

compactas

2,38

C. maxima

Corchosa pero

2,40

Indet.

C. maxima

ssp.maxima

C. maxima

ssp.maxima
Asociado a

pericarpio de

C. maxima

ssp maxima,

endocarpos

de Prosopis

sp. y

Geoffroea

decorticans,

marlo y

brácteas de

Zea mays,

semillas de

Phaseolus sp.

restos oseos

humanos,

textiles y una

lasca

Asociado a

pericarpio de

C. maxima

C. maxima $\mathrm{ssp}$

aff. ssp.

andreana y de

C. maxima

ssp. maxima

Bolsa 5(a))

Interior y exterior

tiznados. Parece

conservar hasta la

capa más interna del

pericarpio.Mesocarpio

(Ver Caja J'/II

(c))

ido de rojo, como

si hubiese contenido

liquido rojo que fue absorbido por el tejido del pericarpio. Parece ser una variedad poco o no lignificada 
Sector

15 (b) Los III/E1/0,60- Castaño Aparejos $\quad 0,80 \mathrm{~cm}$. claro

(capa 4)

Lisa

Compacta

2,61

Los
Aparejos
$(00-0.20)$

$\begin{array}{cc}\text { Los } & \text { E1/ capa } 1 \\ \text { Aparejos } & (00-0.20)\end{array}$

Ocre claro

Lisa

Material que

estaba

dentro del

cesto de

tejido

Amarillo

ocre

Rugosa

Con pequeñas

verrugas

Wiqueboy

doble borde.

C10 (c) El Litro C1-capa 2 Castaño-

(0070-0090) amarillenta
Lisa
Asociada a

S1 y C15 (a):

C. maxima

ssp. maxima

Junto a

semillas de

Phaseolus sp.

(una bicolor),

pedúnculo,

endocarpos

C. maxima de Prosopis

ssp.maxima sp. y

sp. y

decorticans,

marlo y

granos de

Zea mays.

Asociado a

otros cuatro

fragmentos de

pericarpio de

C. maxima

ssp. maxima

angulo cerrado.

C. maxima

compañan cierto

lobulado apenas esbozado.

Asociado a

otros dos

C. maxima

ssp.maxima

agmentos de

pericarpio de

C. maxima

Células del

mesocarpio externo

engrosadas 


\begin{tabular}{|c|c|c|c|c|c|c|c|c|c|c|}
\hline $\begin{array}{l}\text { Caja } 092 \text { I } \\
\text { Bolsa } 6\end{array}$ & EI Litro & $\begin{array}{l}\text { C5/ capa1 } \\
(00-0.20)\end{array}$ & $\begin{array}{c}\text { Claro, } \\
\text { ceniciento }\end{array}$ & $\begin{array}{l}\text { Lisa con } \\
\text { vetas mas } \\
\text { oscuras }\end{array}$ & Compacta & 2,86 & Indet. & $\begin{array}{l}\text { C. maxima } \\
\text { ssp.maxima }\end{array}$ & $\begin{array}{l}\text { Asociado a } \\
\text { restos oseos } \\
\text { humanos, de } \\
\text { roedores y de } \\
\text { Lama sp., } \\
\text { trenzados, un } \\
\text { tiesto, } \\
\text { madera, } \\
\text { cuero y marlo }\end{array}$ & $\begin{array}{c}\text { Moderadamente } \\
\text { lignificada, hipodermis } \\
\text { de varias capas }\end{array}$ \\
\hline C11 (a) & $\begin{array}{l}\text { Los } \\
\text { Aparejos }\end{array}$ & $\begin{array}{l}\text { Sector III. } \\
\text { Junto a la } \\
\text { urna N } 55\end{array}$ & $\begin{array}{l}\text { Amarillo } \\
\text { claro }\end{array}$ & Lisa & $\begin{array}{c}\text { Consistencia } \\
\text { superficial } \\
\text { compacta, interior } \\
\text { poroso. }\end{array}$ & 3,00 & C. maxima & $\begin{array}{l}\text { C. maxima } \\
\text { ssp.maxima }\end{array}$ & $\begin{array}{l}\text { Asociado a } \\
\text { pericarpio de } \\
\text { C. maxima } \\
\text { ssp. andreana }\end{array}$ & $\begin{array}{l}\text { Células del } \\
\text { mesocarpio externo } \\
\text { engrosadas }\end{array}$ \\
\hline C6 (a) & $\begin{array}{l}\text { Los } \\
\text { Aparejos }\end{array}$ & $\begin{array}{l}\text { Sector I/ } \\
\text { cuad } 1\end{array}$ & $\begin{array}{l}\text { Castaño- } \\
\text { rojizo }\end{array}$ & Rugosa & & 3,06 & C. maxima & $\begin{array}{c}\text { C. maxima } \\
\text { ssp.maxima }\end{array}$ & $\begin{array}{l}\text { Asociado a } \\
\mathrm{P} 4, \text { a C5 y a } \\
\text { Lagenaria sp. }\end{array}$ & \\
\hline C3 (b) & EI Litro & $\begin{array}{c}\text { C1- capa } 2 \\
\text { (hasta 0,90- } \\
70-90)\end{array}$ & $\begin{array}{l}\text { Amarillo- } \\
\text { ocre }\end{array}$ & Rugosa & & 3,08 & C. maxima & $\begin{array}{l}\text { C. maxima } \\
\text { ssp.maxima }\end{array}$ & $\begin{array}{l}\text { Asociado a } \\
\text { P3 }\end{array}$ & $\begin{array}{l}\text { No lognificado. Fruto } \\
\text { con verrugas. }\end{array}$ \\
\hline
\end{tabular}




\begin{tabular}{|c|c|c|}
\hline $\begin{array}{c}\text { Sin datos } \\
10 \text { (a) }\end{array}$ & $\begin{array}{c}\text { Los } \\
\text { Aparejos }\end{array}$ & Superficial \\
\hline
\end{tabular}

Sector III/

$$
\text { F1 }
$$

\section{Materiales}

recogidos al

caja J'/ II Los realizar el

(a) Aparejos perfil junto a

\section{Amarillo}

con

remoción

anterior.

claro
Finas y

compactas

3,15

Lisa
Corchosa

3,20
C. maxima ssp.maxima

Asociado a

otro resto de

pericarpio de

C. maxima

ssp. maxima,

restos óseos

humanos,

tiesto, textiles,

endocarpos

de Prosopis

sp. y de

Geoffroea

decorticans,

carbonizado en un

extremo

semillas de

Phaseolus

sp., marlos y

granos de

Zea mays,

cestería,

carbón,

coprolitos.

C. maxima

(Ver Caja J'/II

(c))

Posibles marcas de

roído 


\begin{tabular}{|c|c|c|c|c|c|c|c|c|c|c|}
\hline C13 (d) & El Litro & $\begin{array}{c}\text { C1- capa } 1 \\
(00-0,70)\end{array}$ & $\begin{array}{l}\text { Amarillo- } \\
\text { ocre }\end{array}$ & Rugosa & $\begin{array}{l}\text { Rugosidad } \\
\text { debida a tejido } \\
\text { superficial } \\
\text { amarillo-ocre. } \\
\text { Interior muy } \\
\text { poroso. Alto sin } \\
\text { interior poroso: } \\
1,2 \mathrm{~mm}\end{array}$ & 3,38 & $\begin{array}{l}\text { L. siceraria- } C . \\
\text { maxima }\end{array}$ & Cucurbita sp. & $\begin{array}{c}\text { Asociado a } \\
\text { P7 }\end{array}$ & \\
\hline $\begin{array}{l}\text { Sin datos } \\
10(b)\end{array}$ & $\begin{array}{l}\text { Los } \\
\text { Aparejos }\end{array}$ & Superficial & $\begin{array}{c}\text { Castaño } \\
\text { claro }\end{array}$ & Lisa & $\begin{array}{c}\text { Finas y } \\
\text { compactas }\end{array}$ & 3,41 & Indet. & $\begin{array}{l}\text { C. maxima } \\
\text { ssp.maxima }\end{array}$ & $\begin{array}{l}\text { (VerSin datos } \\
10(a))\end{array}$ & $\begin{array}{l}\text { Lignificado. Bordes } \\
\text { redondeados }\end{array}$ \\
\hline C3 (a) & El Litro & $\begin{array}{c}\text { C1- capa } 2 \\
\text { (hasta 0,90- } \\
70-90 \text { ) }\end{array}$ & $\begin{array}{l}\text { Amarillo- } \\
\text { ocre }\end{array}$ & Rugosa & & 3,51 & C. maxima & $\begin{array}{l}\text { C. maxima } \\
\text { ssp.maxima }\end{array}$ & & $\begin{array}{c}\text { Células del } \\
\text { mesocarpio externo } \\
\text { engrosadas. } \\
\text { Posiblemente } \\
\text { expuesta al fuego. }\end{array}$ \\
\hline Caja 070 & $\begin{array}{l}\text { Los } \\
\text { Aparejos }\end{array}$ & $\begin{array}{c}\text { sector II/ } \\
\text { D1/ capa2 } \\
(0.20-0.40)\end{array}$ & $\begin{array}{l}\text { Claro, } \\
\text { ceniciento }\end{array}$ & $\begin{array}{l}\text { Lisa, restos } \\
\text { de un tejido } \\
\text { superficial } \\
\text { blanquecino }\end{array}$ & Compacta & 3,59 & Indet. & Cucurbita sp. & $\begin{array}{l}\text { Restos óseos } \\
\text { humanos, de } \\
\text { Lama sp. y } \\
\text { Pimelodus } \\
\text { sp., marlo y } \\
\text { trenzado de } \\
\text { cabello. }\end{array}$ & Fruto lobulado \\
\hline $\begin{array}{l}\text { Caja 067( } \\
\text { c) }\end{array}$ & & & Ocre claro & $\begin{array}{l}\text { Lisa con } \\
\text { verrugas }\end{array}$ & $\begin{array}{l}\text { Corchosa } \\
\text { compacta }\end{array}$ & 3,72 & Indet. & $\begin{array}{l}\text { C. maxima } \\
\text { ssp.maxima }\end{array}$ & $\begin{array}{l}\text { (Ver Caja } 067 \\
\text { (b)) }\end{array}$ & $\begin{array}{c}\text { Fragmento partido en } \\
\text { tres partes. } \\
\text { Corresponderia a } \\
\text { porción de } \\
\text { lobulo.Ancho minimo } \\
\text { del lobulo: } 33 \mathrm{~mm} \\
\text { Fruto lignificado }\end{array}$ \\
\hline
\end{tabular}




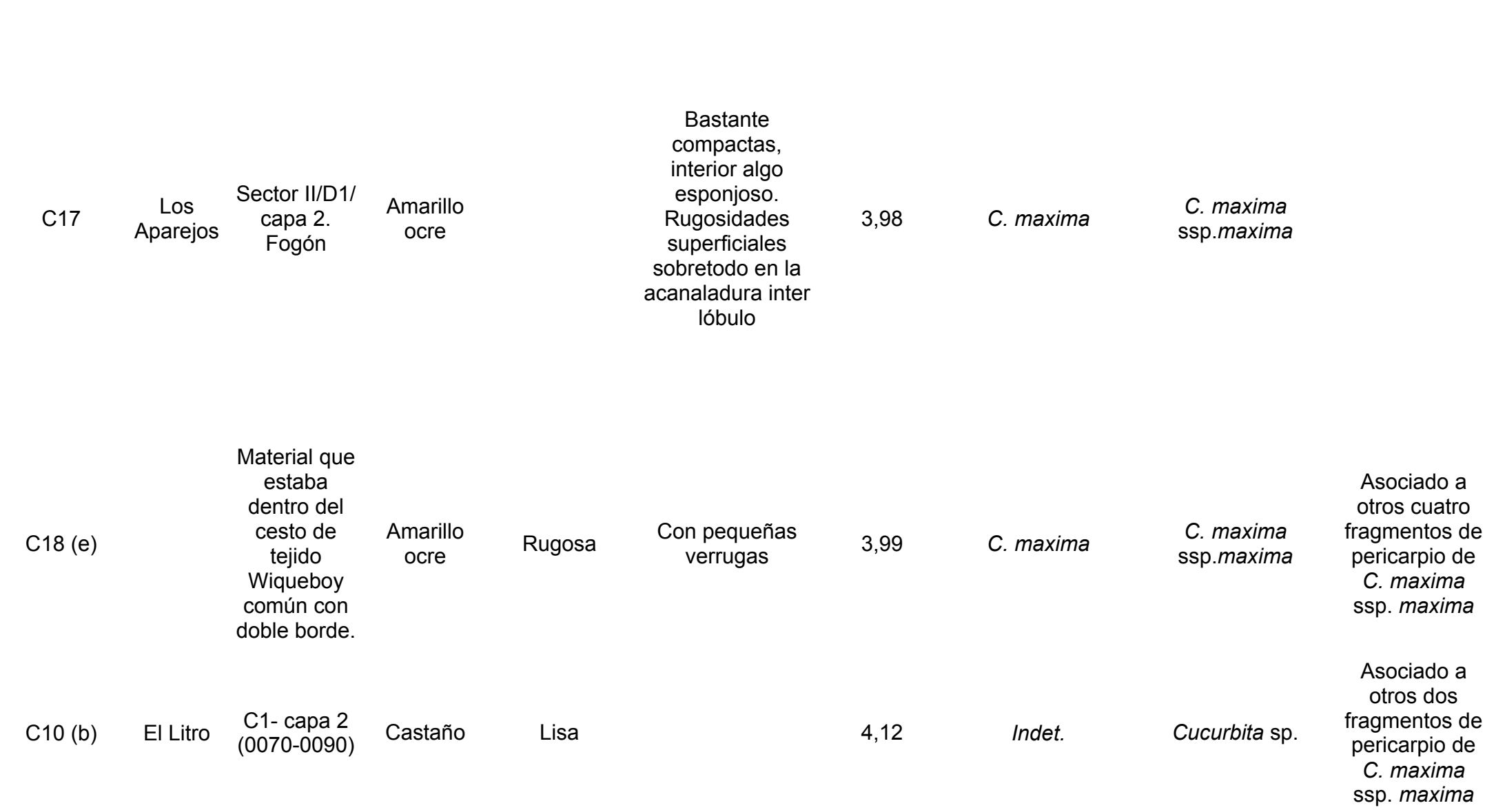

Siete fragmentos del mismo tipo, tres

remontan. Con restos de tierra rojiza adherida. Fruto

lobulado (ancho

aproximado del lóbulo $4,7 \mathrm{~cm}$ ) y con bastante curvatura. Células del

mesocarpio externo engrosadas. Uno de los fragmentos posee próximo al borde un orificio circular de unos $7 \mathrm{~mm}$ de diámetro

Fragmentos con ángulo cerrado. Estrías internas que acompañan cierto lobulado apenas esbozado. Células de mesocarpio externo engrosadas 


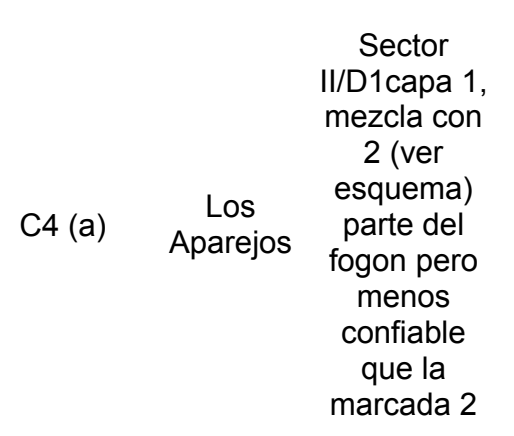

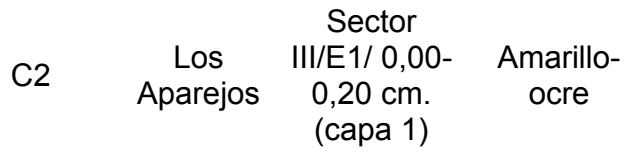

Superficie

cubierta por tejido delgado amarillo

(parece que en

su momento

cubrió toda la

cáscara), posee también

pequeñas

verrugas o llagas

de escasísima

altura y desarrollo

Compacta. Posee marcas de

curvatura como

si fuera de un

fruto lobulado.

Uno de los

lóbulos tendría

aproximadamente

$2,8 \mathrm{~cm}$ de ancho
Asociado a

otros tres

C. maxima

ssp.maxima

C. maxima

fragmentos de

pericarpio de

C. maxima

ssp maxima $\mathrm{cm}$ aproximadamente y casi sin curvatura, probablemente fruto de tamaño grande.
4,24

C. maxima
C. maxima

ssp.maxima
Células del mesocarpio externo engrosadas 


\begin{tabular}{|c|c|c|c|c|c|c|c|c|}
\hline C4 (c ) & $\begin{array}{l}\text { Los } \\
\text { Aparejos }\end{array}$ & $\begin{array}{c}\text { Sector } \\
\text { II/D1capa 1, } \\
\text { mezcla con } \\
2 \text { (ver } \\
\text { esquema) } \\
\text { parte del } \\
\text { fogón pero } \\
\text { menos } \\
\text { confiable } \\
\text { que la } \\
\text { marcada 2 }\end{array}$ & $\begin{array}{l}\text { Castaño- } \\
\text { grisáceo }\end{array}$ & Rugosa & $\begin{array}{l}\text { Con adherencias } \\
\text { de tejido amarillo }\end{array}$ & 4,24 & C. maxima & $\begin{array}{l}\text { C. maxima } \\
\text { ssp.maxima }\end{array}$ \\
\hline C12 (b) & $\begin{array}{l}\text { Caverna } \\
\text { II- Las } \\
\text { cuevitas }\end{array}$ & Hallazgo 42 & $\begin{array}{l}\text { Amarillo- } \\
\text { ocre }\end{array}$ & Rugosa & $\begin{array}{c}\text { Llagas } \\
\text { superficiales de } 3 \\
\text { a } 5 \mathrm{~mm} \text { de ancho } \\
\text { y } 1 \mathrm{~cm} \text { de largo } \\
\text { aprox. }\end{array}$ & 4,40 & C. maxima & $\begin{array}{l}\text { C. maxima } \\
\text { ssp.maxima }\end{array}$ \\
\hline Caja 089 & $\begin{array}{c}\text { Los } \\
\text { Aparejos }\end{array}$ & $\begin{array}{c}\text { Sector II/ } \\
\text { D1/ capa2 } \\
(0.20-0.40)\end{array}$ & Amarillo & $\begin{array}{c}\text { Liso, el color } \\
\text { amarillo se } \\
\text { infiere por } \\
\text { restos muy } \\
\text { diminutos de } \\
\text { tejido } \\
\text { superficial }\end{array}$ & $\begin{array}{l}\text { Corchosa pero } \\
\text { compacta }\end{array}$ & 4,53 & Indet. & $\begin{array}{l}\text { C. maxima } \\
\text { ssp.maxima }\end{array}$ \\
\hline Саја 089 & $\begin{array}{l}\text { Los } \\
\text { Aparejos }\end{array}$ & $\begin{array}{c}\text { Sector II/ } \\
\text { D1/ capa2 } \\
(0.20-0.40)\end{array}$ & Amarillo & $\begin{array}{c}\text { Liso, el color } \\
\text { amarillo se } \\
\text { infiere por } \\
\text { restos muy } \\
\text { diminutos de } \\
\text { tejido } \\
\text { superficial }\end{array}$ & $\begin{array}{l}\text { Corchosa pero } \\
\text { compacta }\end{array}$ & 4,64 & Indet. & $\begin{array}{l}\text { C. maxima } \\
\text { ssp.maxima }\end{array}$ \\
\hline
\end{tabular}

Asociado a otros tres

fragmentos de pericarpio de

C. maxima

ssp maxima

Asociado a

P6 y a otro

fragmento de

pericarpio de

C. maxima

ssp maxima
(Ver mención
previa a caja
089)

grande y de gran

curvatura. Células del mesocarpio externo engrosadas.

Fruto lobulado,

$\begin{array}{cc}\text { (Ver mención } & \text { grande y de gran } \\ \text { previa a caja } & \text { curvatura. Células del }\end{array}$ 089)

mesocarpio externo

engrosadas. 
Material que

estaba

dentro del

C18 (a)

cesto de

tejido

Amarillo

Wiqueboy

común con

doble borde.

Sector

$\begin{array}{ccc}\text { C15 (a) } \quad \begin{array}{c}\text { Los } \\ \text { AlI/E1/ 0,60 } / E \text { arejos }\end{array} & 0,80 \mathrm{~cm} \text {. }\end{array}$

(capa 4)

ocre

Muy rugosa

Con verrugas

4,76

. maxima

Pequeñas

verrugas (de 2 a

$5 \mathrm{~mm}$ ) y llagas (5 $\mathrm{mm}$ en

promedio). Pared

\section{Caverna}

C12 (a) cuevitas
Hallazgo 42 Amarillo-

ocre dividida

Rugosa

claramente

dos partes una mas rígida y

superficial y otra

mas interna y

corchosa
Asociado a

otros cuatro

C. maxima

ssp.maxima

fragmentos de

pericarpio de

C. maxima

ssp. maxima

angulo cerrado.

Estrías internas que

acompañan cierto

lobulado apenas

esbozado.

Asociada a

S1 y C15 (b): Interior termoalterado

c. maxima

ssp. maxima

y quemado

ssp maxima

Asociado a

P6 y a otro

Fruto lobulado (ancho

pericarpio de máximo de los lóbulos

C. maxima

ssp maxima

entre 21,8 y $19 \mathrm{~mm}$ )

ssp.maxima 
Sobre la

superficie

castaña tejido

amarillo-ocre que

$$
\text { forma }
$$

4,84

C. maxima

rugosidades y

sobre éste restos

de tejido castaño oscuro.

Lisa, el color

amarillo se

ve a traves

Los Sector II/ D1

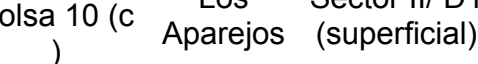

Corchosa pero

compacta
5,07

Indet.

\section{C. maxima}

ssp.maxima de restos de

un tejido

superficial.

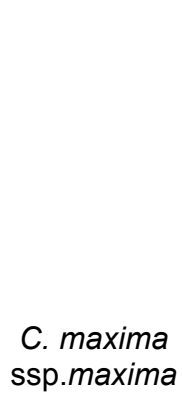

Asociado a restos de fruto de Lagenaria sp.,

endocarpo de Geoffroea

decorticans,

semillas y

vainas de

Phaseolus

sp., marlos y

brácteas de

Zea mays

restos óseos

humanos,

coprolitos de

animales,

cordones de

fibra vegetal,

tiesto.
Leve indicio de

lóbulos. Células del mesocarpio externo

engrosadas

Células del

mesocarpio externo y medio

engrosadas.Pericarpio

muy duro. Fruto

lobulado. 


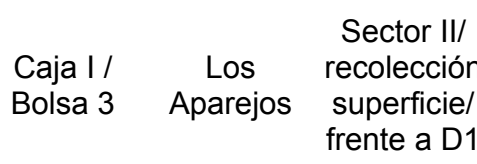

\section{Caja 067 (}

a)

Caja 084

C7 (b)

$\begin{array}{cc} & \text { Superficial y } \\ \text { Los } & \text { hasta 10 } \\ \text { Aparejos } & \mathrm{cm} \text {. Terreno }\end{array}$

Amarillo-

ocre

removido

y oscuro

Castaño

2/ capa1

(0.20-0.40)

Lisa, parece
Amarillo $\quad \begin{gathered}\text { tener restos } \\ \text { de surco del } \\ \text { lobulado }\end{gathered}$

C8

$\begin{array}{ccc}\text { Los } & \text { Sector III/ } & \text { Amarillo } \\ \text { Aparejos } & \text { superficial } & \text { claro }\end{array}$

corchosa sobre

pared mas

5,08

compacta
Compacta

\section{Lisa}

Lisa

Lisa

Rugosidad dada por restos de tejido amarilloocre en superficie

$$
\begin{aligned}
& \text { Superficie interna } \\
& \text { muy irregular }
\end{aligned}
$$

Indet.

Rugosa
C. maxima

ssp.maxima

Restos óseos

humanos y de

Lama sp.,

cordón de

lana, semillas

Escasamente a no
lignificado. Evidencias

sp., marlo y

ndocarpo de

Geoffroea

decorticans.

(Ver Caja 067

(b))

ssp.maxima

C. maxima

ssp.maxima

Asociado a

restos oseos

humanos, marlo y lasca

de roído.

\section{Asociado a}

otro

fragmento de

pericarpio de

C maxima ssp

maxima

Células del mesocarpio externo engrosadas

Células del mesocarpio externo engrosadas. Posible fruto lobulado.

\section{C. maxima}

ssp.maxima

Células del mesocarpio externo engrosadas 


\begin{tabular}{|c|c|c|c|c|c|c|c|c|c|c|}
\hline C4 (b) & $\begin{array}{c}\text { Los } \\
\text { Aparejos }\end{array}$ & $\begin{array}{c}\text { Sector } \\
\text { II/D1capa 1, } \\
\text { mezcla con } \\
2 \text { (ver } \\
\text { esquema) } \\
\text { parte del } \\
\text { fogon pero } \\
\text { menos } \\
\text { confiable } \\
\text { que la } \\
\text { marcada } 2\end{array}$ & Castaño & Rugosa & Compacta & 5,32 & C. maxima & $\begin{array}{l}\text { C. maxima } \\
\text { ssp.maxima }\end{array}$ & $\begin{array}{l}\text { Asociado a } \\
\text { otros tres } \\
\text { fragmentos de } \\
\text { pericarpio de } \\
\text { C. maxima } \\
\text { ssp maxima }\end{array}$ & \\
\hline $\begin{array}{l}\text { Caja } 092 \text { I } \\
\text { Bolsa } 19\end{array}$ & & $\begin{array}{l}\text { Siglado: } \\
\text { D1/C1-2 }\end{array}$ & Ocre claro & Lisa & Compacta & 5,38 & Indet. & $\begin{array}{l}\text { C. maxima } \\
\text { ssp.maxima }\end{array}$ & $\begin{array}{c}\text { Asociado a } \\
\text { tiesto y marlo }\end{array}$ & $\begin{array}{c}\text { Células del } \\
\text { mesocarpio externo } \\
\text { engrosadas y del } \\
\text { medio elongadas. } \\
\text { Fruto lobulado }\end{array}$ \\
\hline C9 (a) & $\begin{array}{c}\text { Los } \\
\text { Aparejos }\end{array}$ & $\begin{array}{c}\text { Sector } \\
\text { III/F2/ 0,00- } \\
0,20-0,40 \\
\text { cm. (capa 1) }\end{array}$ & $\begin{array}{l}\text { Amarillo } \\
\text { claro }\end{array}$ & Rugosa & $\begin{array}{l}\text { Rugosidad dada } \\
\text { por restos de } \\
\text { tejido amarillo } \\
\text { grueso en } \\
\text { superficie }\end{array}$ & 5,44 & C. maxima & $\begin{array}{l}\text { C. maxima } \\
\text { ssp.maxima }\end{array}$ & $\begin{array}{l}\text { Asociada a } C \text {. } \\
\text { maxima ssp. } \\
\text { andreana } \\
\text { (C9b) }\end{array}$ & $\begin{array}{l}\text { Células del } \\
\text { mesocarpio externo } \\
\text { engrosadas. Presenta } \\
\text { leve indicio de } \\
\text { lobulado. }\end{array}$ \\
\hline C10 (a) & $\begin{array}{c}\text { Los } \\
\text { Aparejos }\end{array}$ & $\begin{array}{l}\text { Sector I/ } \\
\text { cuad A/ } \\
\text { capa } 3 a\end{array}$ & $\begin{array}{l}\text { Amarillo- } \\
\text { ocre }\end{array}$ & $\begin{array}{l}\text { Lisa, leves } \\
\text { rugosidades }\end{array}$ & $\begin{array}{l}\text { Tejido superficial } \\
\text { castaño oscuro. }\end{array}$ & 5,59 & C. maxima & $\begin{array}{l}\text { C. maxima } \\
\text { ssp.maxima }\end{array}$ & $\begin{array}{l}\text { Asociado a } \\
\text { pericarpio de } \\
\text { C. maxima } \\
\text { aff. ssp. } \\
\text { andreana y de } \\
\text { C. maxima } \\
\text { ssp. maxima } \\
\text { (intermedia) } \\
\text { Asociado a } \\
\text { otros dos } \\
\text { fragmentos de } \\
\text { pericarpio de } \\
\text { C. maxima } \\
\text { ssp. maxima }\end{array}$ & $\begin{array}{c}\text { Células del } \\
\text { mesocarpio externo } \\
\text { engrosadas }\end{array}$ \\
\hline
\end{tabular}


Sector
II/D1capa 1

mezcla con

$$
2 \text { (ver }
$$

C4 (d)

Los
Aparejos

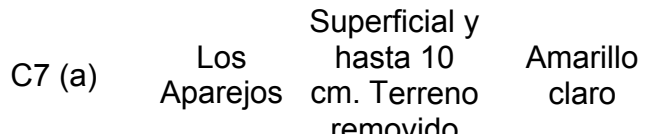

C18 (c) esquema)

parte del

fogón pero

menos

confiable

que la

marcada 2

Material que

estaba

dentro del

Castañogrisáceo

$$
\begin{aligned}
& \text { cesto de } \\
& \text { tejido }
\end{aligned}
$$

Wiquebo

común con

doble borde.

ocre
Con adherencias de tejido amarillo, y por sobre éste un pequeño

fragmento de

tejido castaño

oscuro. Algunas

llagas. Cascara

muy ancha y

compacta.

Superficie

cubierta por tejido

amarillo-ocre.

Suprficie

6,26

C. maxima

compacta, interio

mas corchoso.

Con pequeñas

verrugas

6,37

Rugosa
6,00

C. maxima

C. maxima ssp.maxima

C. maxima

ssp maxima

Células del

mesocarpio externo

engrosadas

ton

otro

ragmento de

pericarpio de

C maxima ssp

maxima

Asociado a

otros cuatro

C. maxima

ssp.maxima ragmentos de

pericarpio de

C. maxima

ssp. maxima
Fruto lobulado, ancho mínimo del lóbulo: 14 $\mathrm{mm}$

Fragmentos con ángulo cerrado. Estrías internas que acompañan cierto lobulado apenas esbozado. 
Material que

estaba

C18 (b)

cesto de

tejido

Amarillo

ocre

Capa extern

compacta e

Wiqueboy

comun con

terna corchosa.

Con pequeñas

6,64

verrugas

C. maxima

Asociado a

otros cuatro

ragmentos de

Fragmentos con

ángulo cerrado.

c. maxima

lobulado apenas

doble borde.

$$
\text { esbozado. }
$$


Tabla 54: pericarpios de la localidad arqueológica de Pampa Grande identificados como $L$. siceraria En la columna denominada "identificación previa" se consigna la determinación del resto efectuada por Pochettino (1985).

\begin{tabular}{|c|c|c|c|c|}
\hline $\begin{array}{c}\text { IDENTIFICACIÓN } \\
\text { PREVIA } \\
\end{array}$ & No REGISTRO & CUEVA & CONTEXTO & ESPESOR \\
\hline L. siceraria & Lag-7(a) & El Litro & C1- capa $1(00-0,70)$ & 1,78 \\
\hline L. siceraria & $\operatorname{Lag}-7(d)$ & El Litro & C1- capa $1(00-0,70)$ & 1,81 \\
\hline $\begin{array}{l}\text { L. siceraria- } C . \\
\text { maxima }\end{array}$ & C13 (c) & El Litro & C1- capa $1(00-0,70)$ & 2,08 \\
\hline L. siceraria & $\operatorname{Lag}-7(\mathrm{e})$ & El Litro & C1- capa $1(00-0,70)$ & 2,08 \\
\hline \multirow[t]{2}{*}{ L. siceraria } & $\operatorname{Lag}-2(d)$ & El Litro & C1- capa 2 (hasta 0,90-70-90) & 2,12 \\
\hline & C16 & El Litro & B4- capa $1(00-0,25)$ & 2,14 \\
\hline L. siceraria & Lag-7(c) & El Litro & C1- capa $1(00-0,70)$ & 2,15 \\
\hline L. siceraria & Caja I / Bolsa 10 (b) & Los Aparejos & Sector II/ D1 (superficial) & 2,20 \\
\hline L. siceraria & Lag-7(b) & El Litro & C1- capa $1(00-0,70)$ & 2,24 \\
\hline L. siceraria & $\operatorname{Lag}-1(a)$ & Los Aparejos & Sector II/superficial y hasta $40 \mathrm{~cm}$. & 2,31 \\
\hline $\begin{array}{l}\text { L. siceraria- } C . \\
\text { maxima }\end{array}$ & C13 (a) & El Litro & C1- capa $1(00-0,70)$ & 2,38 \\
\hline L. siceraria & Caja 067 & & & 2,41 \\
\hline L. siceraria & $\operatorname{Lag}-7(f)$ & El Litro & C1- capa $1(00-0,70)$ & 2,43 \\
\hline L. siceraria & Caja I / Bolsa 5 & Los Aparejos & Sector II/ C3/ 0,10-0,40 cm. & 2,49 \\
\hline L. siceraria & Caja 071(b) & Caverna IV / I & & 2,49 \\
\hline C. maxima & $\mathrm{C} 4(\mathrm{e})$ & Los Aparejos & $\begin{array}{l}\text { Sector II/D1capa } 1 \text {, mezcla con } 2 \text { (ver } \\
\text { esquema) parte del fogon pero menos } \\
\text { confiable que la marcada } 2\end{array}$ & 2,54 \\
\hline L. siceraria & Lag-1(b) & Los Aparejos & Sector II/superficial y hasta $40 \mathrm{~cm}$. & 2,63 \\
\hline & C19 (a) & El Litro & C5/ capa2 (0.20-0.40) & 2,65 \\
\hline
\end{tabular}




\begin{tabular}{|c|c|c|c|c|}
\hline & C19 (b) & EI Litro & C5/ capa2 $(0.20-0.40)$ & 2,72 \\
\hline & Caja 092 / Bolsa 12 & El Litro & C5/ capa1 (00-0.20) & 2,79 \\
\hline L. siceraria & Lag-3 & El Litro & C1- capa $1(00-0,70)$ & 2,84 \\
\hline C. maxima & C6 (b) & Los Aparejos & Sector I/ cuad 1 & 2,88 \\
\hline L. siceraria & Lag-7(g) & EI Litro & C1- capa $1(00-0,70)$ & 2,94 \\
\hline C. maxima & C14 (a) & Los Aparejos & Sector II/B4/ capa 2 & 2,96 \\
\hline L. siceraria & Lag-2 (c) & El Litro & C1- capa 2 (hasta 0,90-70-90) & 3,11 \\
\hline L. siceraria & Caja I / Bolsa 10 (a) & Los Aparejos & Sector II/ D1 (superficial) & 3,17 \\
\hline Lagenaria sp.? & Bolsa 085 & $\begin{array}{l}\text { Caverna III/ } \\
\text { Las Cuevitas }\end{array}$ & Superficial y nivel ocupacional & 3,21 \\
\hline Lagenaria sp.? & Bolsa 085 & $\begin{array}{l}\text { Caverna IIII/ } \\
\text { Las Cuevitas }\end{array}$ & Superficial y nivel ocupacional & 3,35 \\
\hline \multirow[t]{2}{*}{ Lagenaria sp.? } & Sin datos 22 & El Litro & E5. Hallazgo $\mathrm{N}^{\circ} 21$ & 3,38 \\
\hline & C10 (d) & El Litro & C1- capa 2 (0070-0090) & 3,60 \\
\hline L. siceraria & Lag-6 & Caverna V & Superficial & 3,60 \\
\hline L. siceraria & Lag-2 (b) & El Litro & C1- capa 2 (hasta 0,90-70-90) & 3,67 \\
\hline \multirow[t]{2}{*}{ L. siceraria } & Lag-2 (a) & El Litro & C1- capa 2 (hasta 0,90-70-90) & 4,23 \\
\hline & Caja 071 (a) & Caverna IV / I & & 4,35 \\
\hline $\begin{array}{l}\text { L. Siceraria- C. } \\
\text { maxima }\end{array}$ & C13 (b) & El Litro & C1- capa $1(00-0,70)$ & 4,52 \\
\hline
\end{tabular}

Tabla 55: medidas de fitolitos obtenidos en ejemplares actuales de referencia.

\begin{tabular}{|lccc|}
\hline & Diámetro 1 & Diámetro 2 & Promedio \\
\cline { 2 - 4 } C. maxima ssp. andreana & 31,5 & 47,5 & $\mathbf{3 9 , 5}$ \\
& 37,1 & 41 & $\mathbf{3 9}$ \\
& 57,3 & 50 & $\mathbf{5 3 , 6}$ \\
& 59,7 & 75,4 & $\mathbf{6 7 , 5}$ \\
& 53,2 & 49,2 & $\mathbf{5 1 , 2}$ \\
& 60,6 & 62,6 & $\mathbf{6 1 , 6}$ \\
\hline \multirow{4}{*}{. maxima ssp. maxima } & 90,4 & & $\mathbf{9 0 , 4}$ \\
& 71,5 & & $\mathbf{7 1 , 5}$ \\
& 50,6 & 49,8 & $\mathbf{5 0 , 2}$ \\
& 50,5 & 52 & $\mathbf{5 1 , 2}$ \\
& 66,9 & 70,1 & $\mathbf{6 8 , 5}$ \\
& 74,2 & 60,3 & $\mathbf{6 7 , 2}$ \\
\hline
\end{tabular}


Tabla 56: medidas de fitolitos de pericarpios arqueológicos de Pampa Grande.

\begin{tabular}{|c|c|c|c|c|}
\hline Ejemplar & Taxa & Diámetro 1 & Diámetro 2 & Promedio \\
\hline C5d & $\begin{array}{c}\text { C. maxima } \\
\text { ssp andreana }\end{array}$ & 53,7 & 45,1 & 49,4 \\
\hline $\mathrm{C} 9 \mathrm{~b}$ & $\begin{array}{l}\text { C. maxima aff. } \\
\text { ssp. andreana }\end{array}$ & 74,9 & 46,5 & 60,7 \\
\hline C11b & $\begin{array}{l}\text { C. maxima aff. } \\
\text { ssp. andreana }\end{array}$ & 43,4 & 15,3 & 29,3 \\
\hline C11b & $\begin{array}{l}\text { C. maxima aff. } \\
\text { ssp. andreana }\end{array}$ & 48,4 & 24,2 & 36,3 \\
\hline C3a & $\begin{array}{c}\text { C. maxima } \\
\text { ssp.maxima }\end{array}$ & 53,2 & 61,5 & 57,3 \\
\hline $\mathrm{C} 3 \mathrm{~b}$ & $\begin{array}{c}\text { C. maxima } \\
\text { ssp.maxima }\end{array}$ & 44,4 & 52,5 & 48,4 \\
\hline $\mathrm{C} 18 \mathrm{e}$ & $\begin{array}{l}\text { C. maxima } \\
\text { ssp.maxima }\end{array}$ & 77 & 47,6 & 62,3 \\
\hline C10b & Cucurbita sp. & 79,4 & 71,7 & 75,5 \\
\hline C10b & Cucurbita sp. & 37,1 & 63,1 & 50,1 \\
\hline C10b & Cucurbita sp. & 70,5 & 60,5 & 65,5 \\
\hline C10b & Cucurbita sp. & 43,3 & 63,5 & 53,4 \\
\hline C10b & Cucurbita sp. & 53,2 & 73,8 & 63,5 \\
\hline C10b & Cucurbita sp. & 34,7 & 50 & 42,3 \\
\hline 089 Grueso & $\begin{array}{c}\text { C. maxima } \\
\text { ssp.maxima }\end{array}$ & 56,5 & 82,8 & 69,6 \\
\hline C15a & $\begin{array}{c}\text { C. maxima } \\
\text { ssp.maxima }\end{array}$ & 52 & 52 & 52 \\
\hline $\mathrm{C} 7 \mathrm{~b}$ & $\begin{array}{c}\text { C. maxima } \\
\text { ssp.maxima }\end{array}$ & 28,2 & 53,3 & 40,7 \\
\hline $\mathrm{C9a}$ & $\begin{array}{l}\text { C. maxima } \\
\text { ssp.maxima }\end{array}$ & 71,3 & 52,4 & 61,8 \\
\hline $\mathrm{C} 7 \mathrm{a}$ & Cucurbita sp. & 63,7 & 82 & 72,8 \\
\hline $\mathrm{C} 7 \mathrm{a}$ & Cucurbita sp. & 53,2 & 69,7 & 61,4 \\
\hline $\mathrm{C} 7 \mathrm{a}$ & Cucurbita sp. & 48,4 & 85,2 & 66,8 \\
\hline
\end{tabular}


Tabla 57: medidas de fitolitos de pericarpios actuales de referencia de C. maxima ssp. andreana. DS: desvío estándar; CV: coeficiente de variación; MIN: valor menor; MAX: valor más alto.

\begin{tabular}{|c|c|c|}
\hline & C. maxima ssp. andreana & C. maxima ssp. maxima \\
\hline & 31,5 & 90,4 \\
& 37,1 & 71,5 \\
& 57,3 & 50,6 \\
& 59,7 & 50,5 \\
& 53,2 & 66,9 \\
& 60,6 & 74,2 \\
& 47,5 & 49,8 \\
& 41 & 52 \\
& 50 & 70,1 \\
& 75,4 & 60,3 \\
PROMEDIO & 49,2 & \\
DS & 62,6 & \\
CV & $\mathbf{5 2 , 0 9}$ & $\mathbf{6 3 , 6 3}$ \\
Min & $\mathbf{1 2 , 1 3}$ & $\mathbf{1 3 , 4 3}$ \\
Max & $\mathbf{2 3 , 2 8}$ & $\mathbf{2 1 , 1 0}$ \\
\hline
\end{tabular}


Tabla 58: medidas de fitolitos de pericarpios arqueológicos de Pampa Grande. DS: desvío estándar; CV: coeficiente de variación; MIN: valor menor; MAX: valor más alto.

\begin{tabular}{|cccc|}
\hline & $\begin{array}{c}\text { C. maxima } \\
\text { ssp andreana }\end{array}$ & $\begin{array}{c}\text { C. maxima } \\
\text { ssp.maxima }\end{array}$ & Cucurbita sp. \\
& 53,7 & 53,2 & 79,4 \\
& 74,9 & 44,4 & 37,1 \\
& 43,4 & 77 & 70,5 \\
& 48,4 & 56,5 & 43,3 \\
& 45,1 & 52 & 53,2 \\
& 46,5 & 28,2 & 34,7 \\
& 24,2 & 71,3 & 63,7 \\
& & 61,5 & 53,2 \\
& & 52,5 & 48,4 \\
& & 47,6 & 71,7 \\
& & 82,8 & 63,1 \\
& & 52 & 60,5 \\
& & 53,3 & 63,5 \\
& & 52,4 & 73,8 \\
& & & 50 \\
& & & 82 \\
D.S. & & & 69,7 \\
Min. & & & 85,2 \\
Max. & $\mathbf{4 1 , 2 8}$ & $\mathbf{2 4 , 6 1}$ & $\mathbf{2 4 , 4 1}$ \\
& $\mathbf{2 4 , 2}$ & $\mathbf{2 8 , 2 0}$ & $\mathbf{3 4 , 7 0}$ \\
& $\mathbf{7 4 , 9}$ & $\mathbf{8 2 , 8 0}$ & $\mathbf{8 5 , 2 0}$ \\
\hline
\end{tabular}


Figura 20: diferencia anatómica en corte transversal entre el pericarpio de Lagenaria siceraria y el de Cucurbita, tomado de Cutler y Whitaker 1961

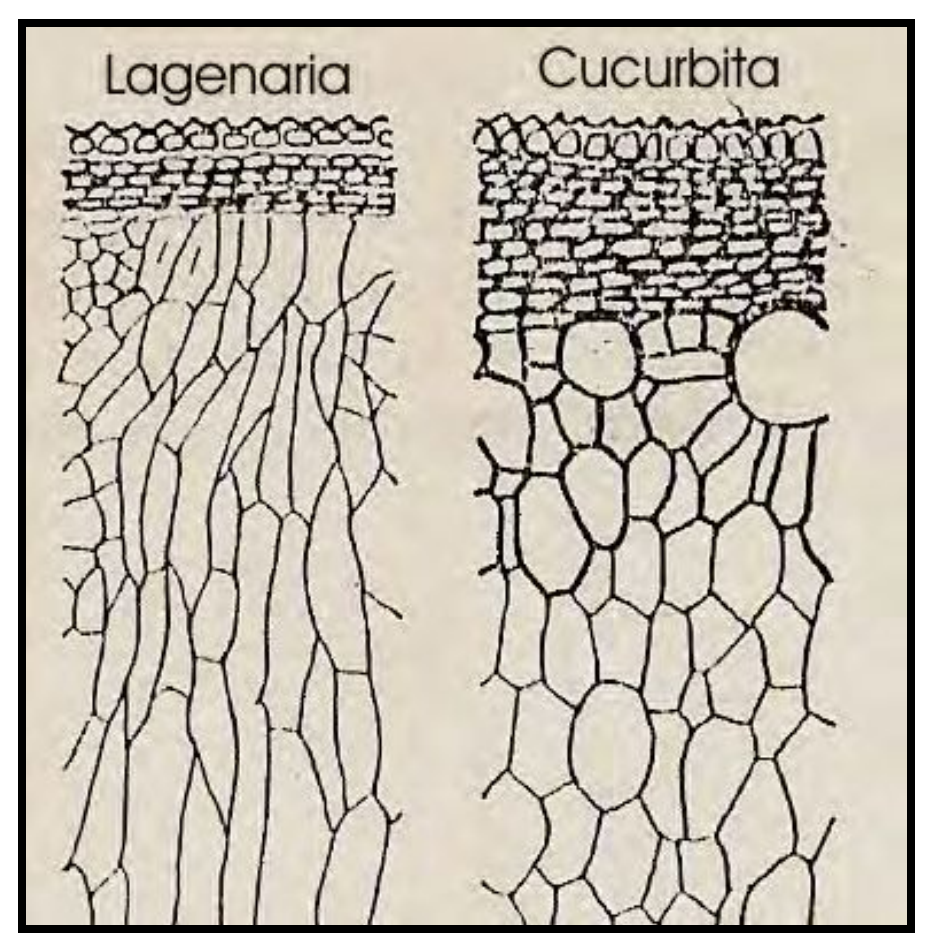

Figura 21: vista superficial del epicarpio X320 (Winton y Winton 1935)

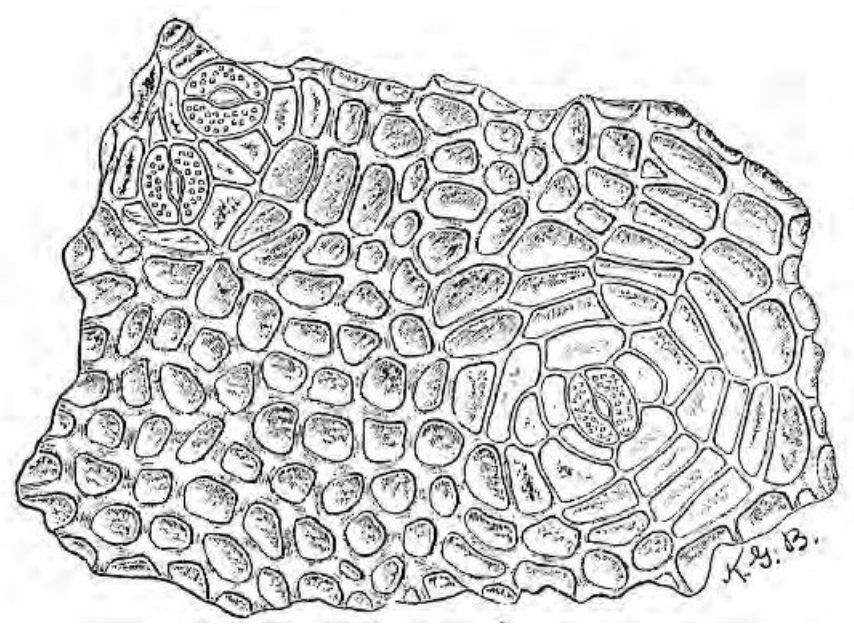


Figura 22: Epi epicarpio inmaduro en vista superficial: $t^{1}$ pelo en punta; $t^{2}$ pelo capitado; sto estoma X 160 (Winton y Winton 1935).

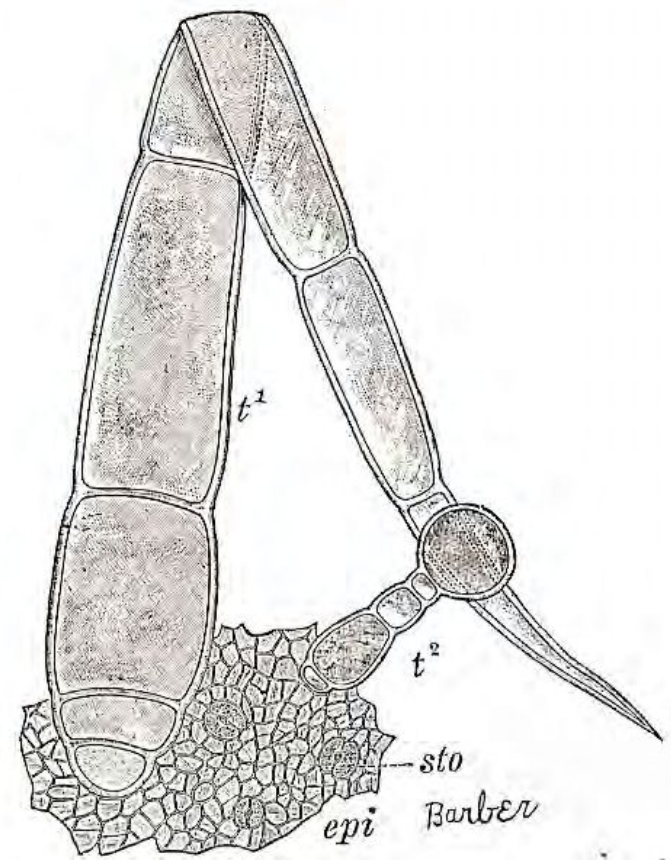

Figura 23: mesocarpio mostrando am granos de almidón y lat tubos laticíferos X 160 (Winton y Winton 1935)

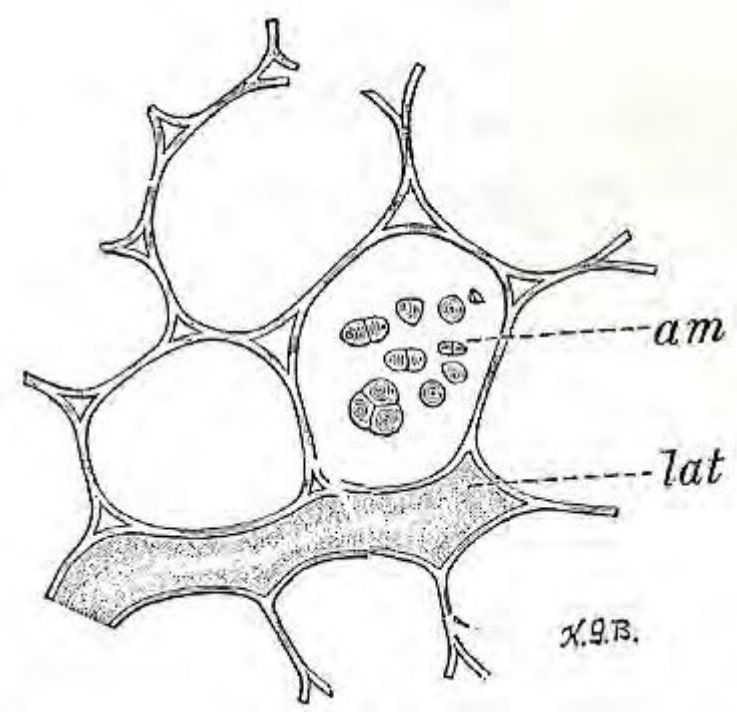


Figura 24: corte transversal del pericarpio externo (epi epicarpio con $t$ pelos y sto estomas; by hipodermis; st mesocarpio externo con $x$ grandes espacios intercelulares; mes mesocarpio medio con $f v$ haces vasculares y am granos de almidón X160 (Winton y Winton 1935)
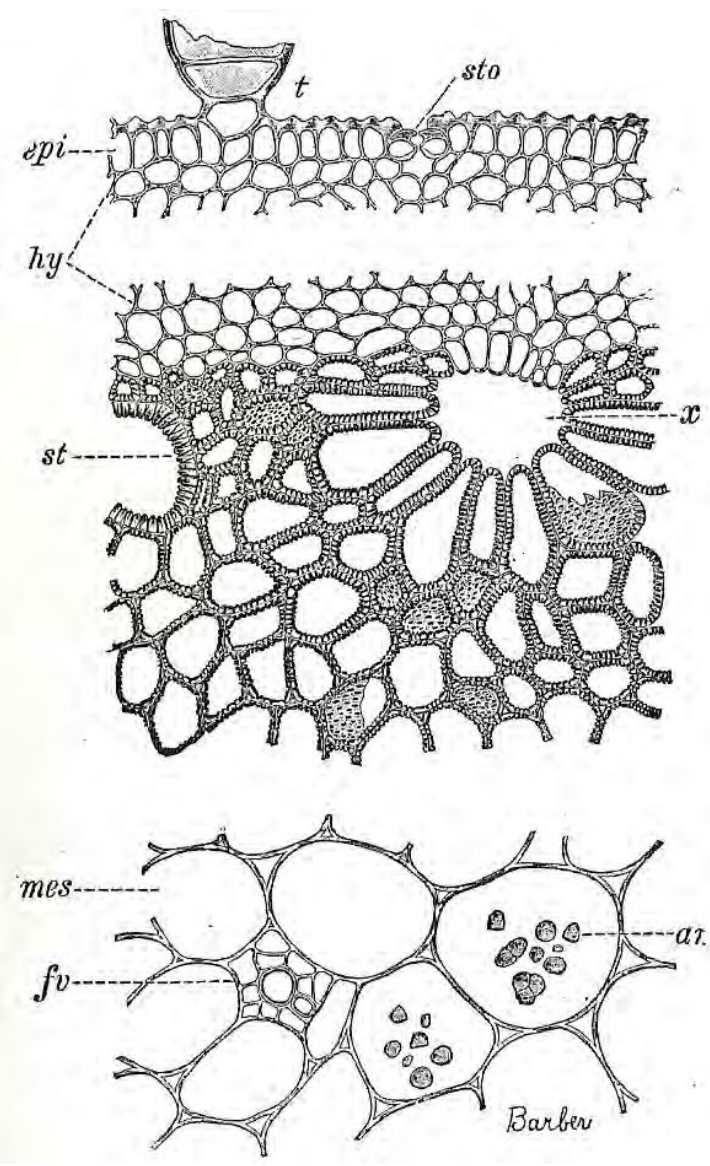

Piperno et al. 2002 Fig. 2. Pericarpio lignificado de C. moschata con epidermis (epi), hipodermis (hy), células pétreas (st), fitoliltos (phy), y zona de formación de fitolitos (pfz). Las células pétreas son elongadas, lo cual produce fitolitos elípticos.

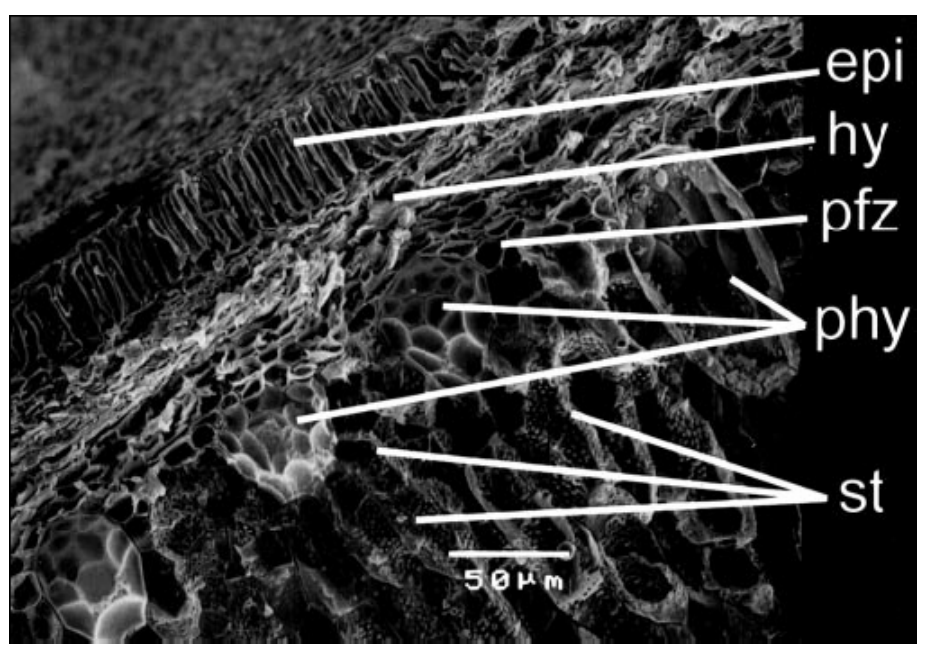


Piperno et al. 2002 Fig. 3. Pericarpio no lignificado de C. moschata, donde se aprecia la ausencia de fitoliltos, zona de formación de fitolitos y células pétreas. A diferencia de las variedades lignificadas, el pericarpio muestra una gradación desde la hipodermis al mesocarpio (mes).

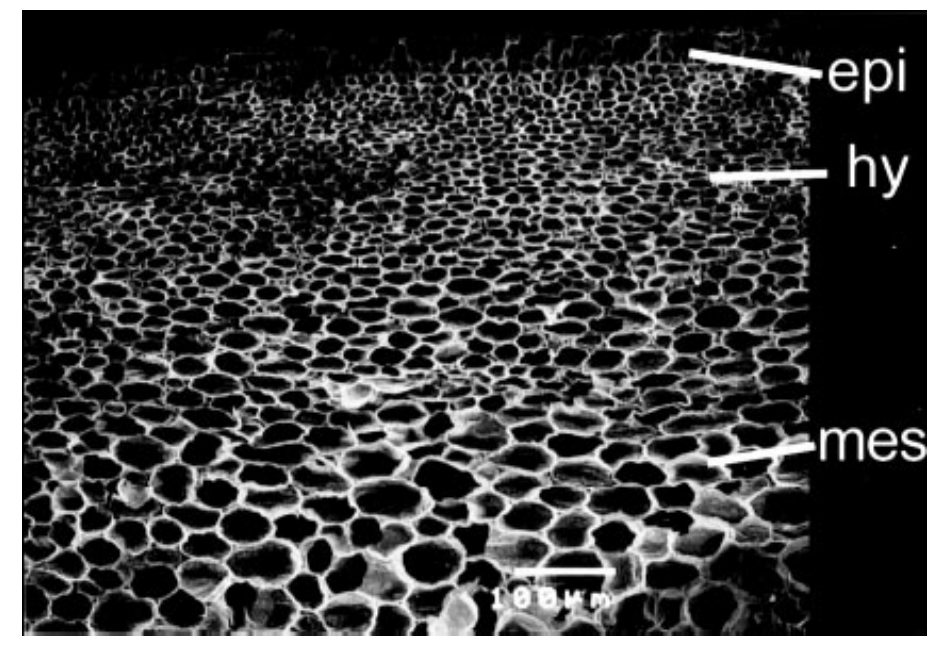

Piperno et al. 2002 Fig. 7. Pericarpio de C. maxima ssp. andreana mostrando células pétreas con bordes relativamente largos y rectos que llevan a la formación de fitolitos como los de la figura 6, pc: cavidad dejada por un fitolito desprendido.

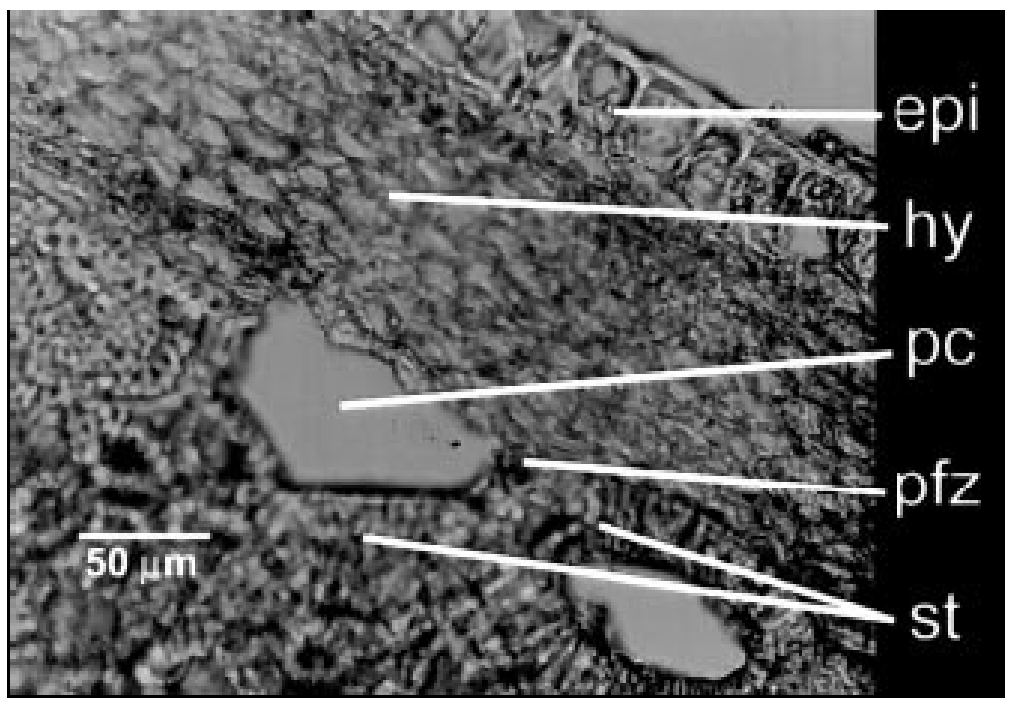


Piperno et al. 2002, Fig. 6. Fitolitos de C. maxima ssp. andreana. Son planos y de bordes rectos.

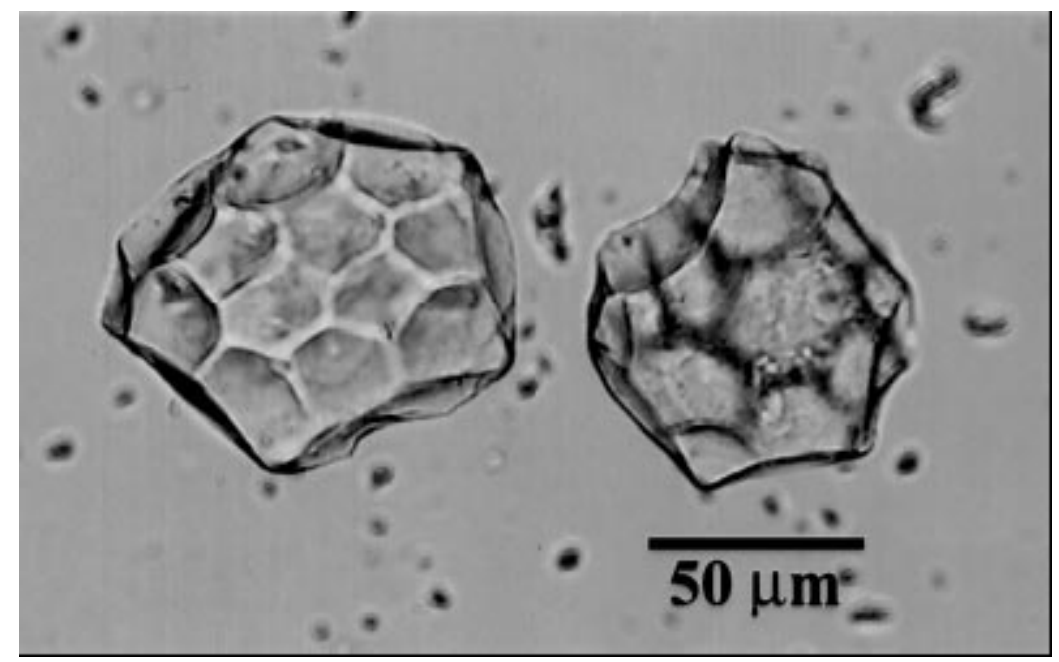

Piperno et al. 2002, Fig. 8. (Iqquierda) Pericarpio de C. maxima ssp. maxima con tejido hipodérmico grueso y denso. (Derecha) Un fitolito de C. maxima ssp. maxima mostrando marcas características en el hemisferio derivado de la hipodermis (hh).

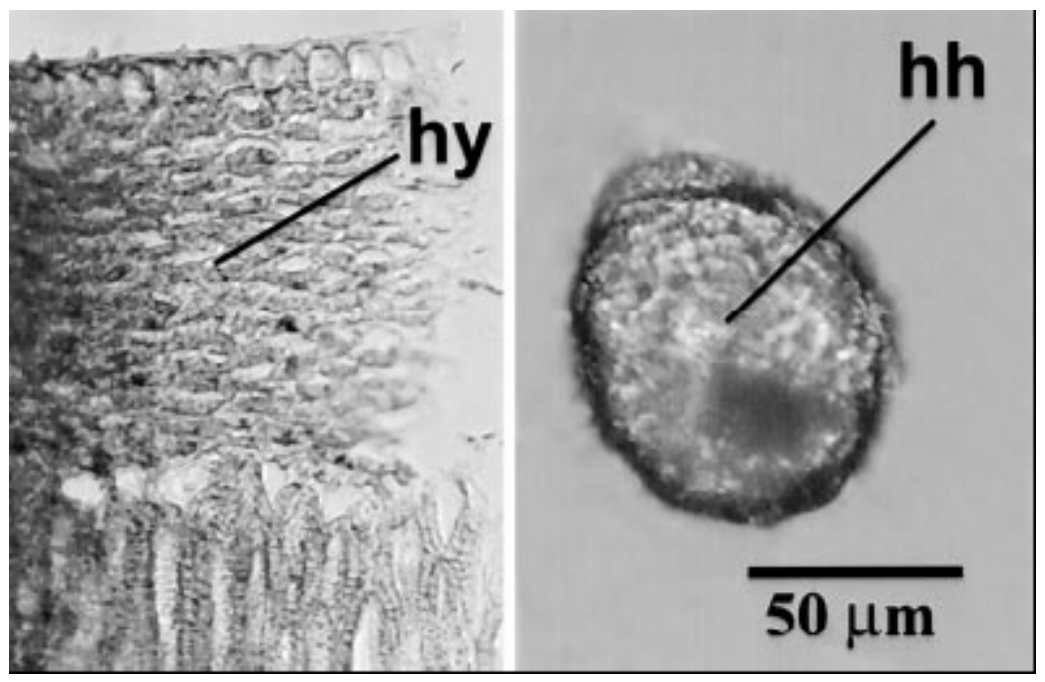


Piperno et al. 2002, Fig. 9. Pericarpio de Lagenaria siceraria mostrando cómo las células pétreas poseen una configuración irregular. El epicarpio y la hipodermis faltan en este ejemplar; hesc: células pétreas horizontalmente elongadas; ssc: pequeñas células pétreas; pc: cavidad dejada por un fitolito desprendido. Insertado: fitolito semi- elíptico mostrando la configuración irregular de las células pétreas horizontalmente elongadas (hesc) y de las pequeñas (ssc) a través de las concavidades formadas por la impresión de estas células.

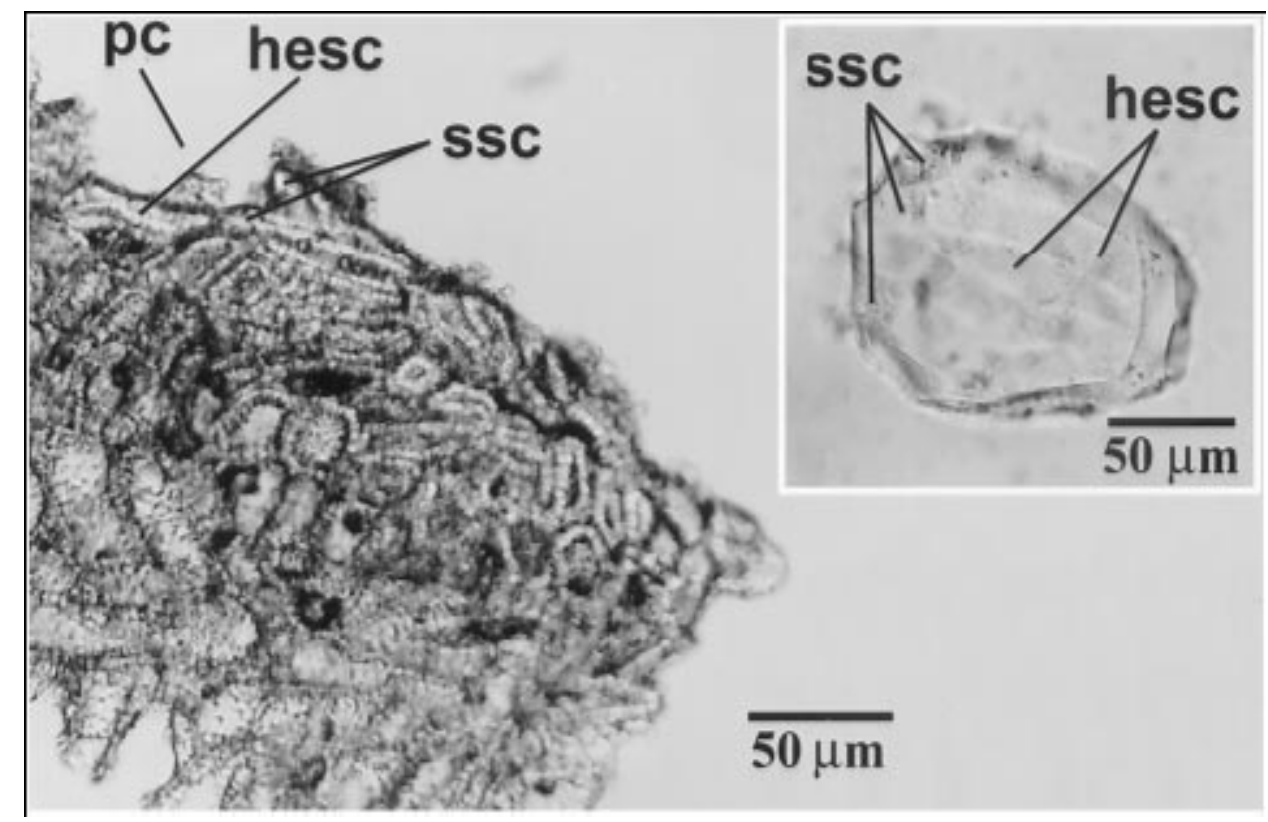


Figura 25: ubicación de sitios arqueológicos y áreas culturales sudamericanas donde se han recuperado restos de frutos y/o pericarpios de Cucurbita sp.

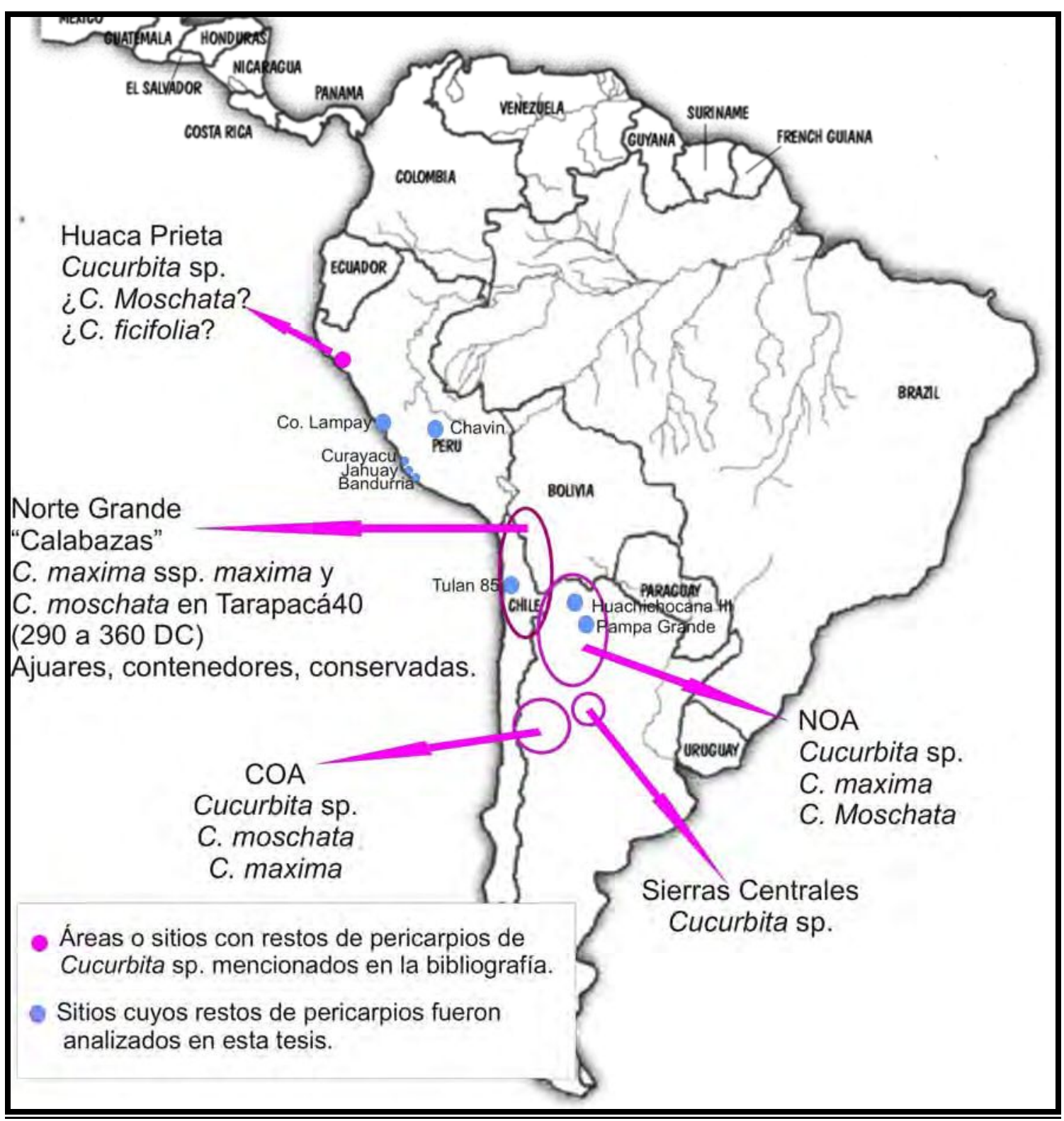


Figura 26: sitios arqueológicos de argentina donde se han recuperado micro y macrorrestos de frutos del género Cucúrbita.

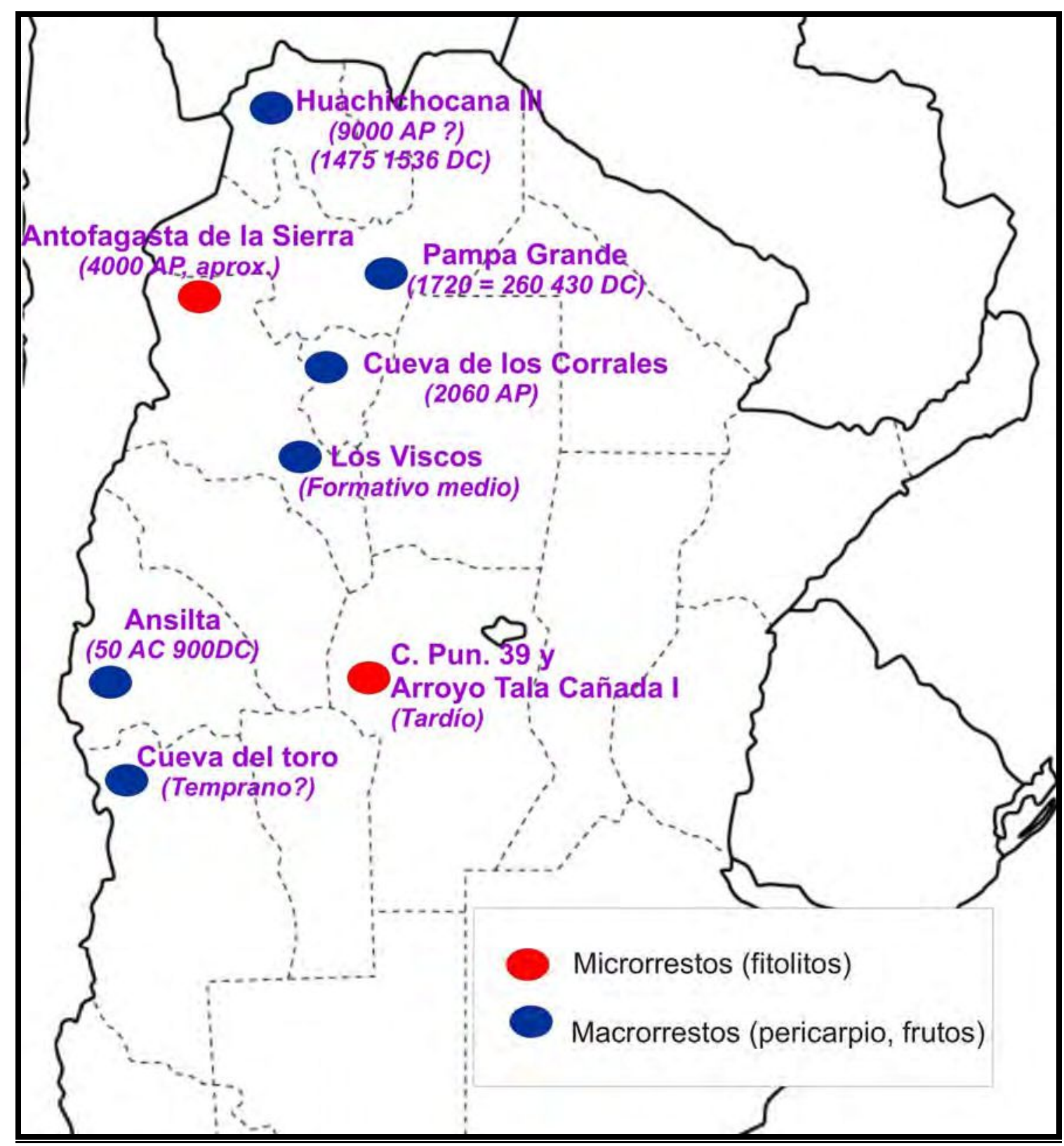


Figura 27: fragmento de pericarpio procedente del sitio Los Corrales. Foto cedida por la Dra. Oliszewski

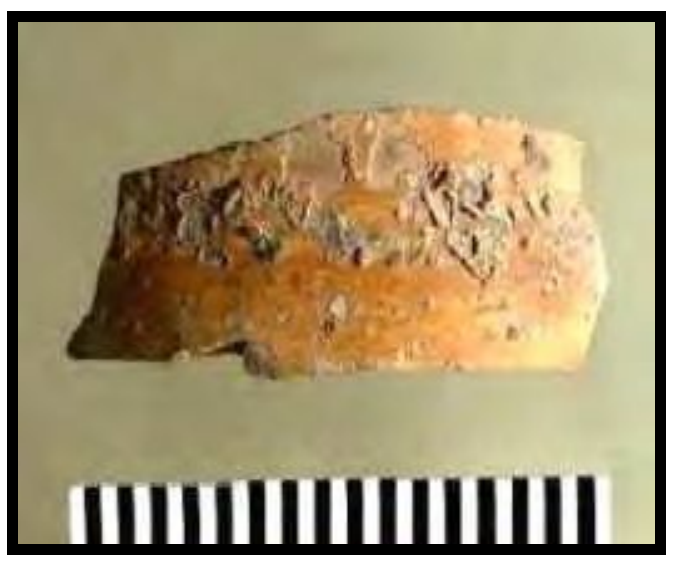

Figura 28: restos de pericarpios del sitio Los Viscos (ScatBe6(1), Catamarca. El número de ejemplar se indica en cada imagen. Imágenes tomadas de Maloberti y Zapatiel (2003).

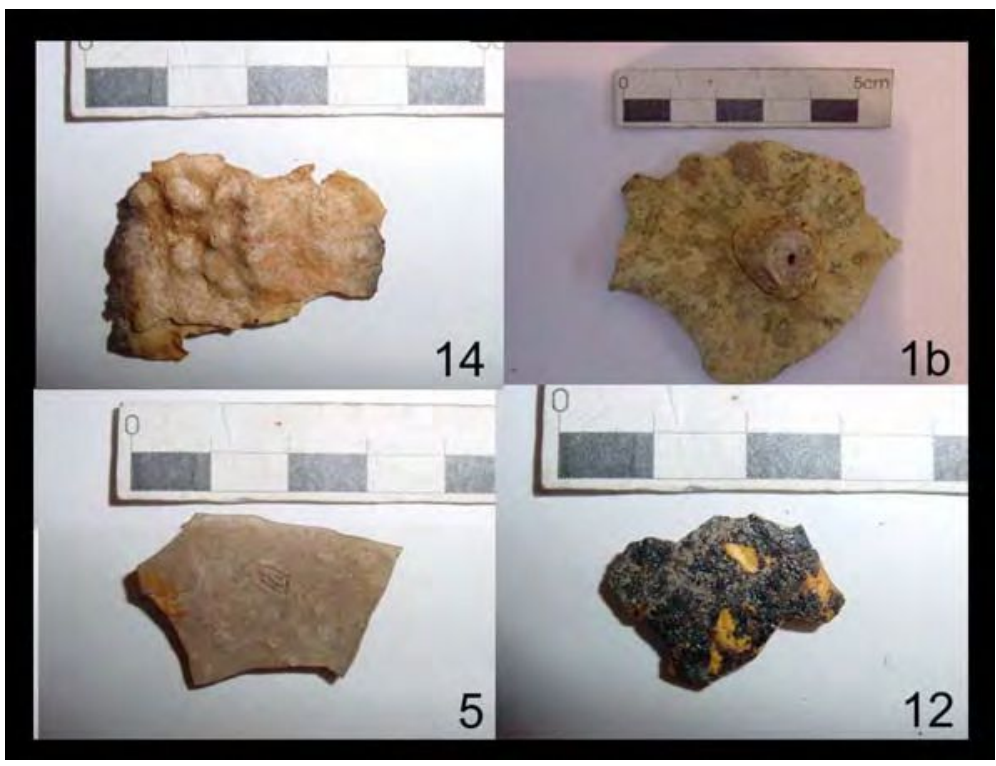


Figura 29: restos de pericarpios de la cueva III de Huachichocana. 1: pericarpio de Cucurbita sp. de capa C; 2: pericarpio de Lagenaria siceraria asociada a inhumación del esqueleto3- capa E2; 3 y 4: pericarpio indeterminado hallado en capa D.

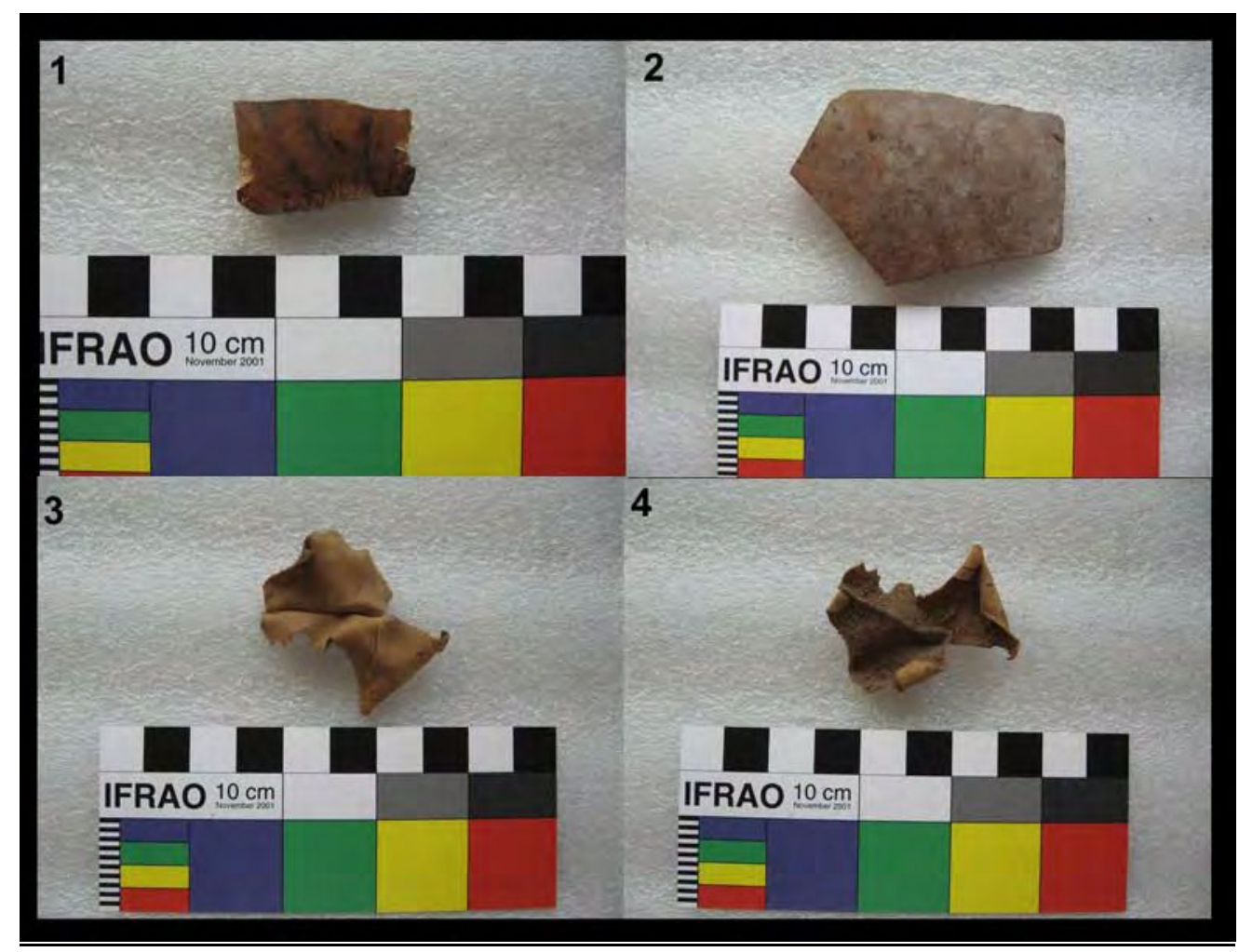

Gráfico 11: rangos de medidas correspondientes al alto del pericarpio de los taxa identificados en restos arqueológicos del sitio Pampa Grande.

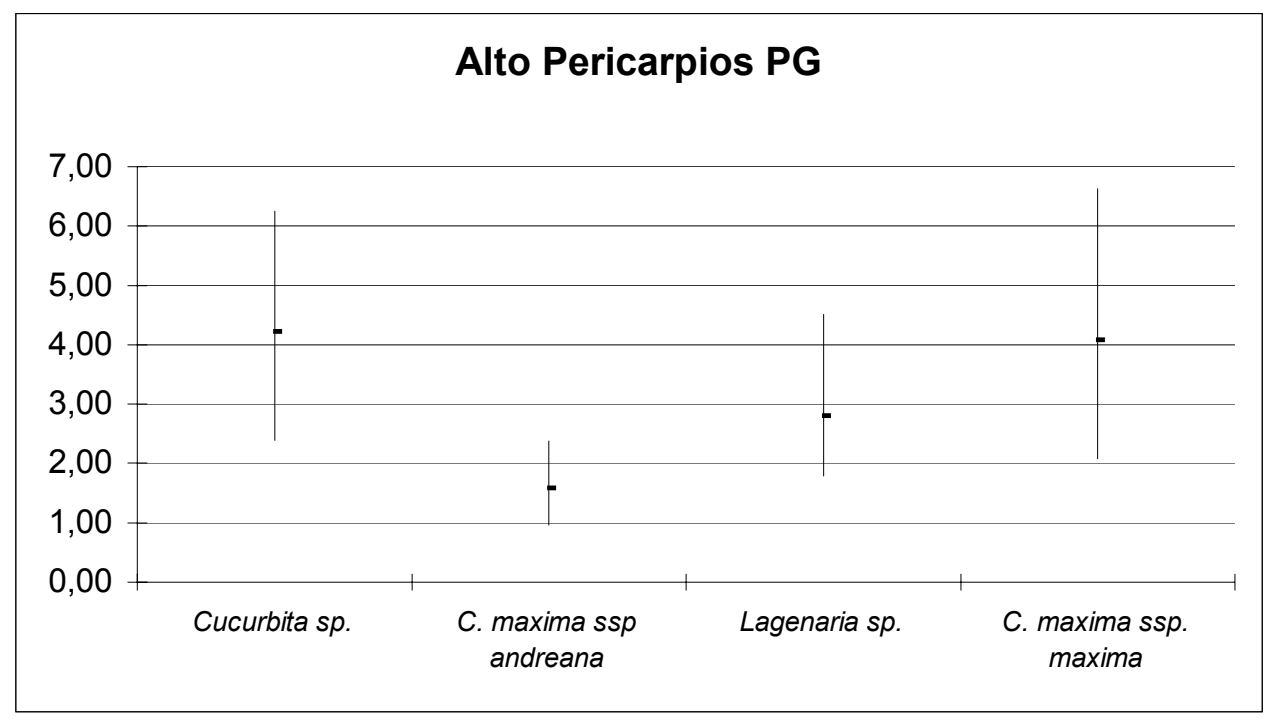


Gráfico 12: distribución de las medidas del alto de pericarpios de Cucurbita maxima ssp maxima recuperados en la cuadricula 1, capas 1 y 2 de El Litro.

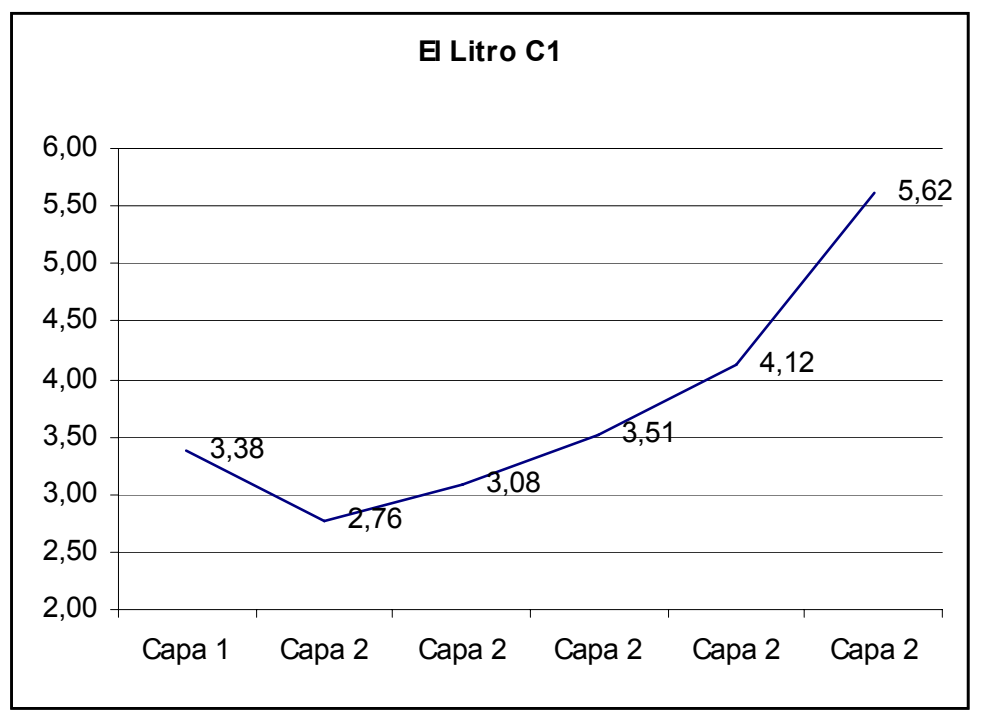



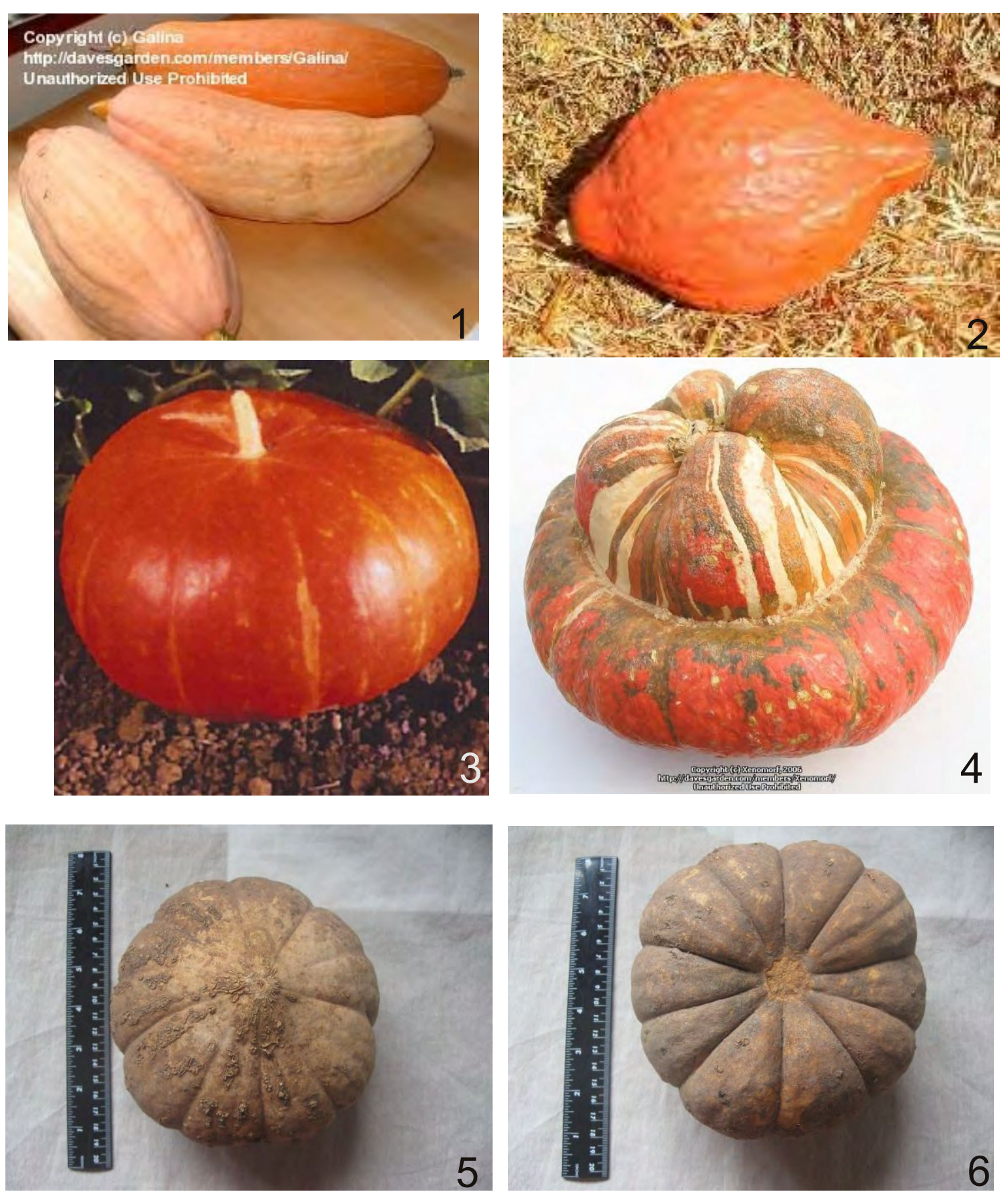

Frutos de diversos cultivares de C maxima ssp maxima, 1: cultivar "Banana" (www.davesgarden.com); 2: cultivar "Golden Hubbard" (www.mobot.org); 3: cultivar "Cinderella" (www.seedbydesign.com); 4: fruto turbaniforme (www.davesgarden.com); 5: cultivar "Zipinka" (fruto obtenido en El Shincal). 

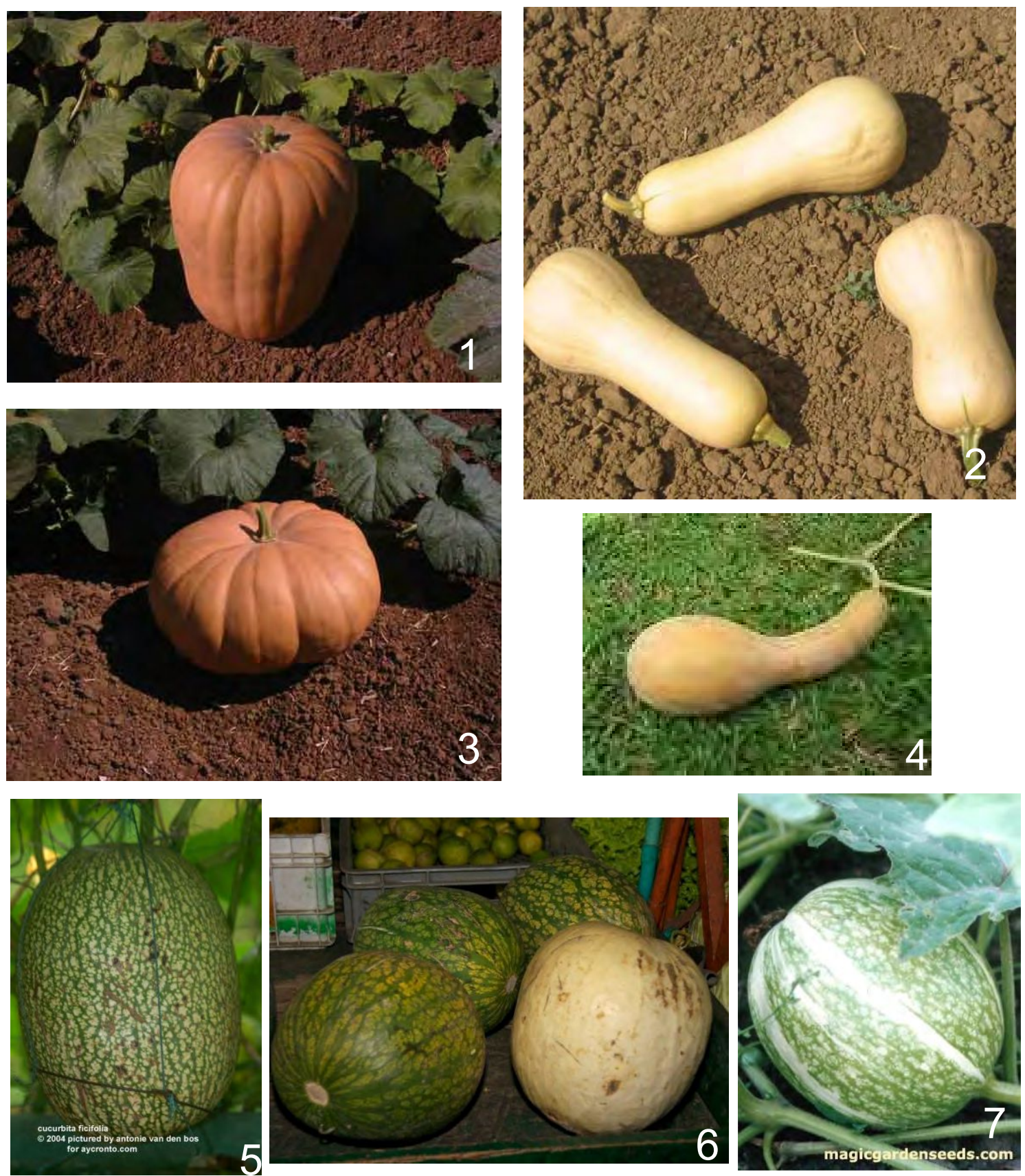

Frutos de C moschata: 1,2 y 4: www.seedsbydesign.com; 3: www.greenculturesg.com

Frutos de C ficifolia: 5: www.aycronto.com; 6: www.picasaweb.com; 7:www.magicgardenseeds.com 

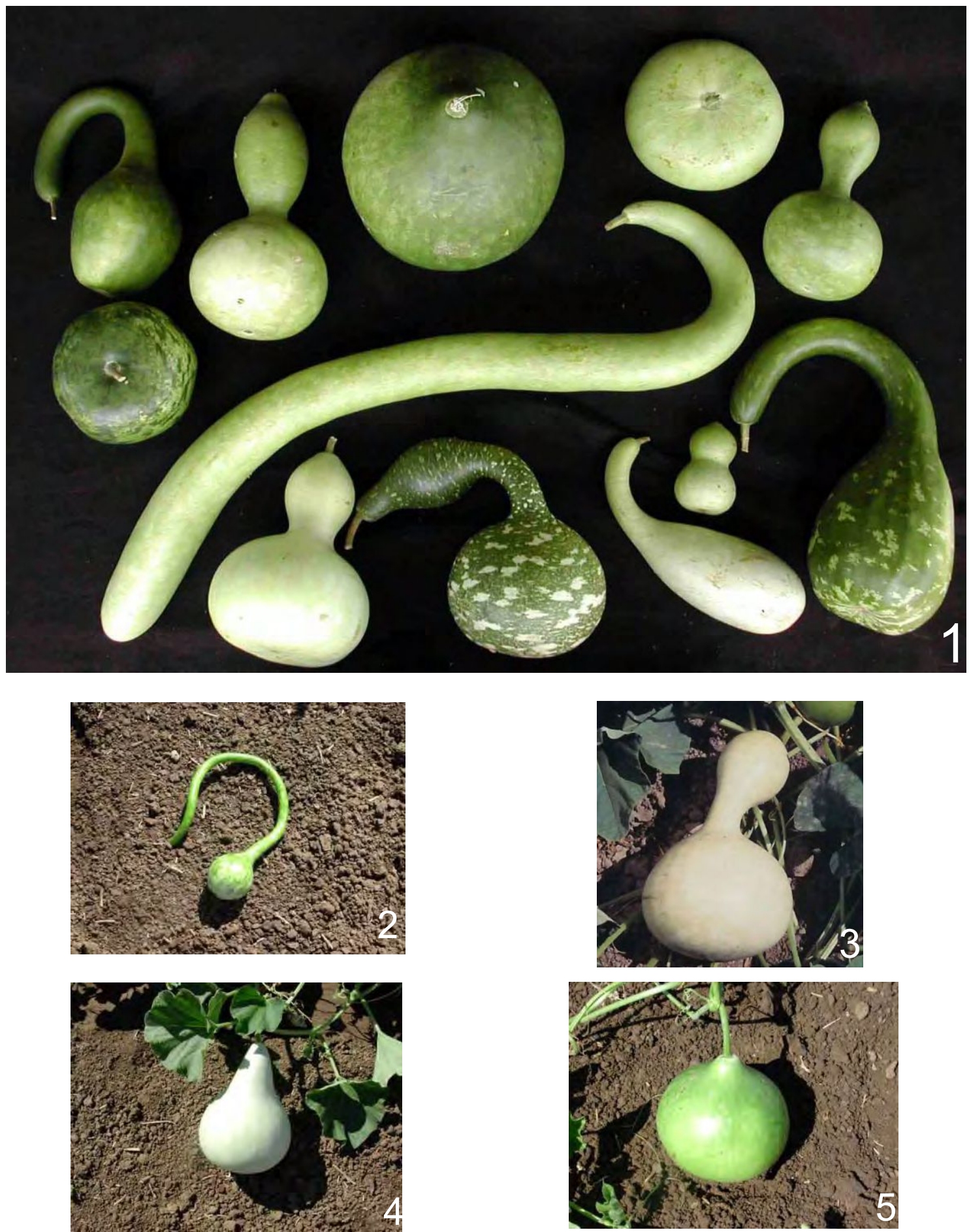

Frutos de Lagenaria siceraria, 1: www.grec.ifas.ufl.edu; 2,3,4 y 5: www.seedsbydesign.com 

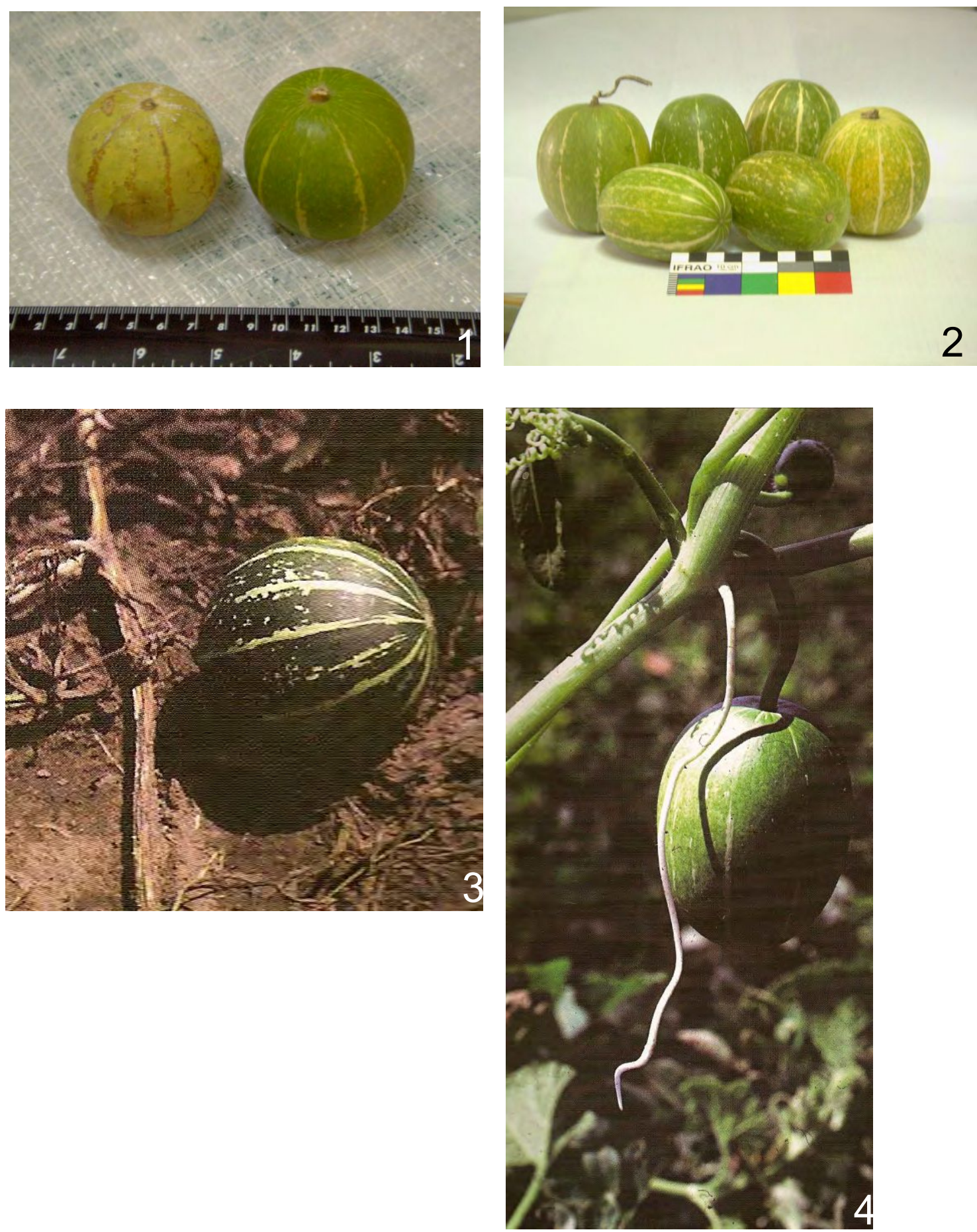

Frutos de $C$ maxima ssp andreana, 1: ejemplares de orillas del río Salado, Buenos Aires (Leg. S. Bogan); 2: ejemplares de Mones Cazón (Buenos Aires) (Leg. M. Arriaga); 3 y 4: frutos en la planta fotos tomadas de Molina 2005. 

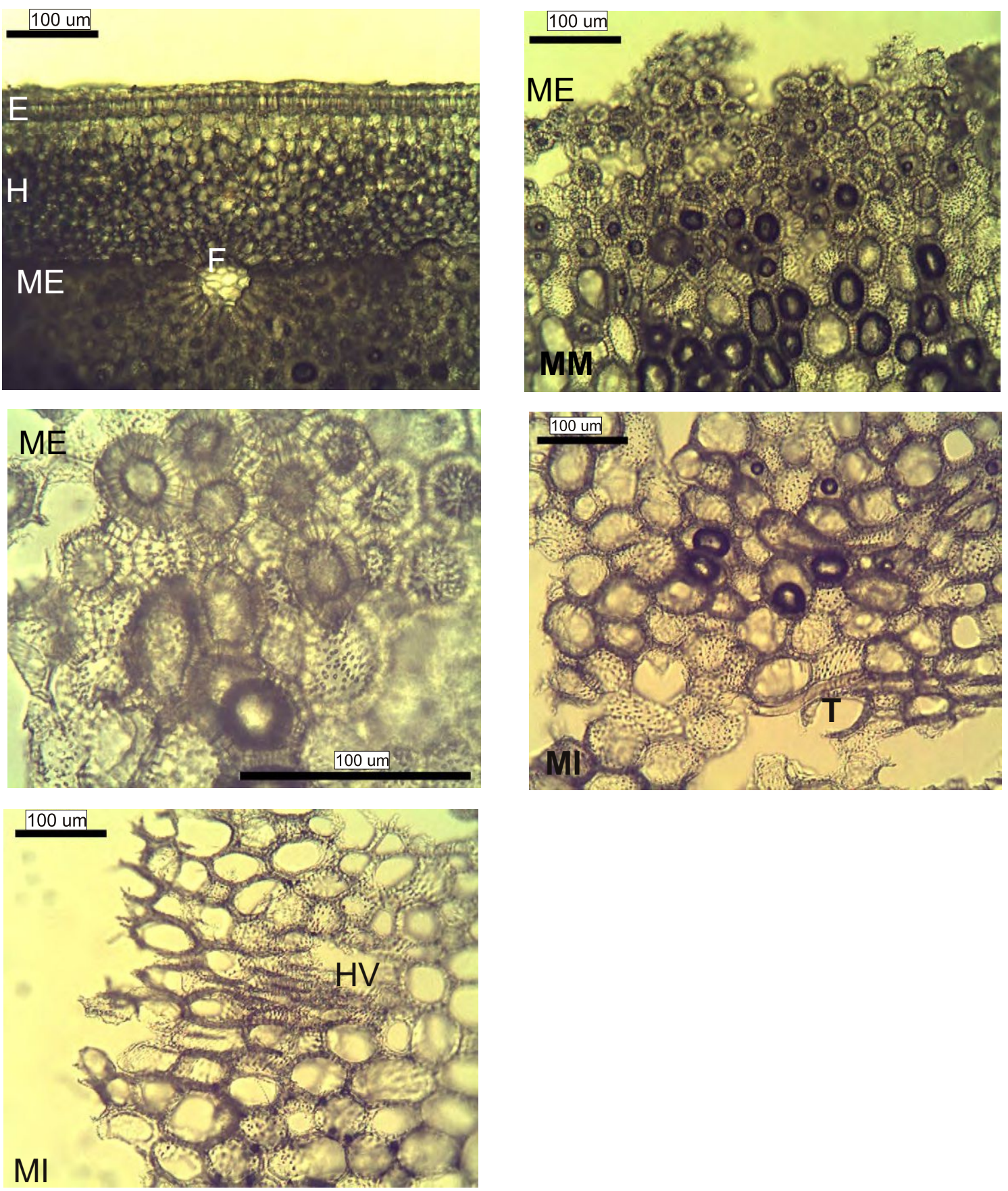

Corte transversal de pericarpio de $C$ maxima ssp andreana observado por transparencia; E: epidermis; $\mathrm{H}$ : hipodermis; ME: mesocarpio externo; MM: mesocarpio medio; MI: mesocarpio interno; $\mathrm{F}$ : fitolito; $\mathrm{T}$ : tubo criboso; $\mathrm{HV}$ : haz vascular. 
LAMINA 19
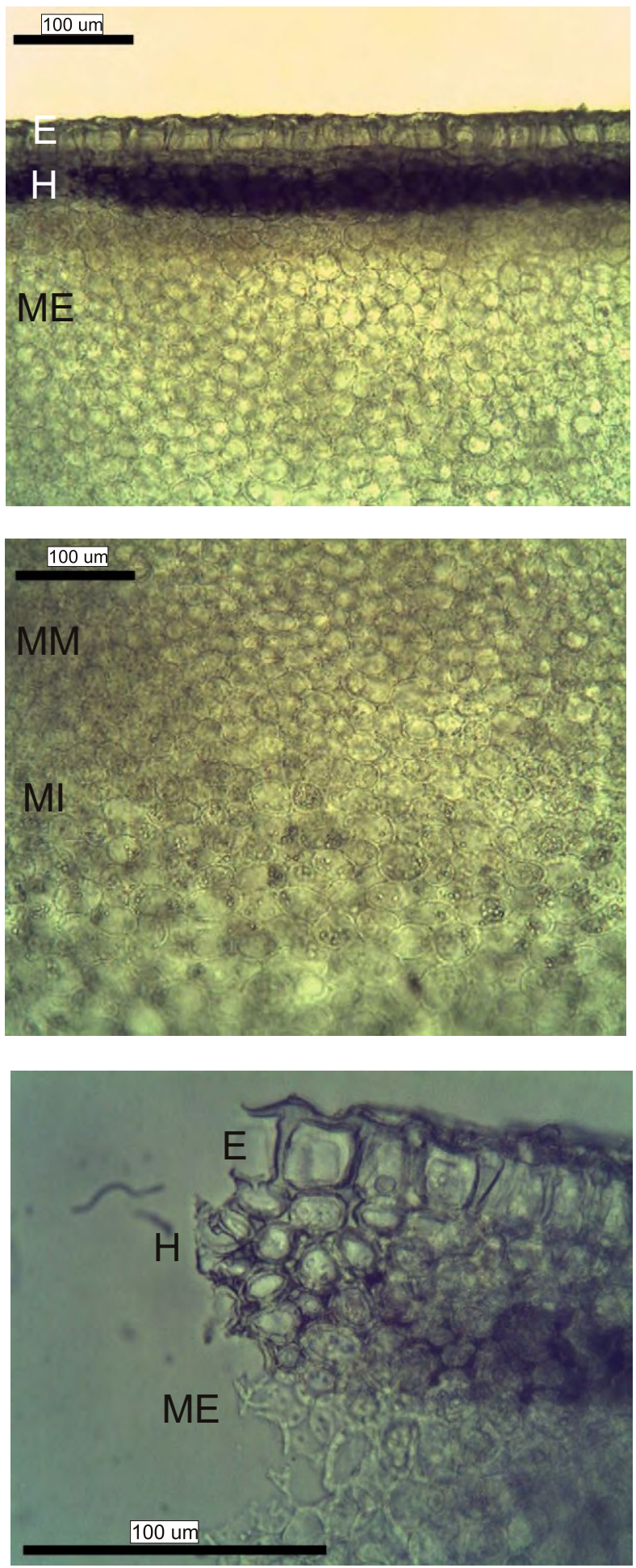

Corte transversal de pericarpio de $C$ maxima ssp maxima (no lignificado) observado por transparencia; $\mathrm{E}$ : epidermis; $\mathrm{H}$ : hipodermis; ME:mesocarpio externo; MM: mesocarpio medio, MI: mesocarpio interno. 

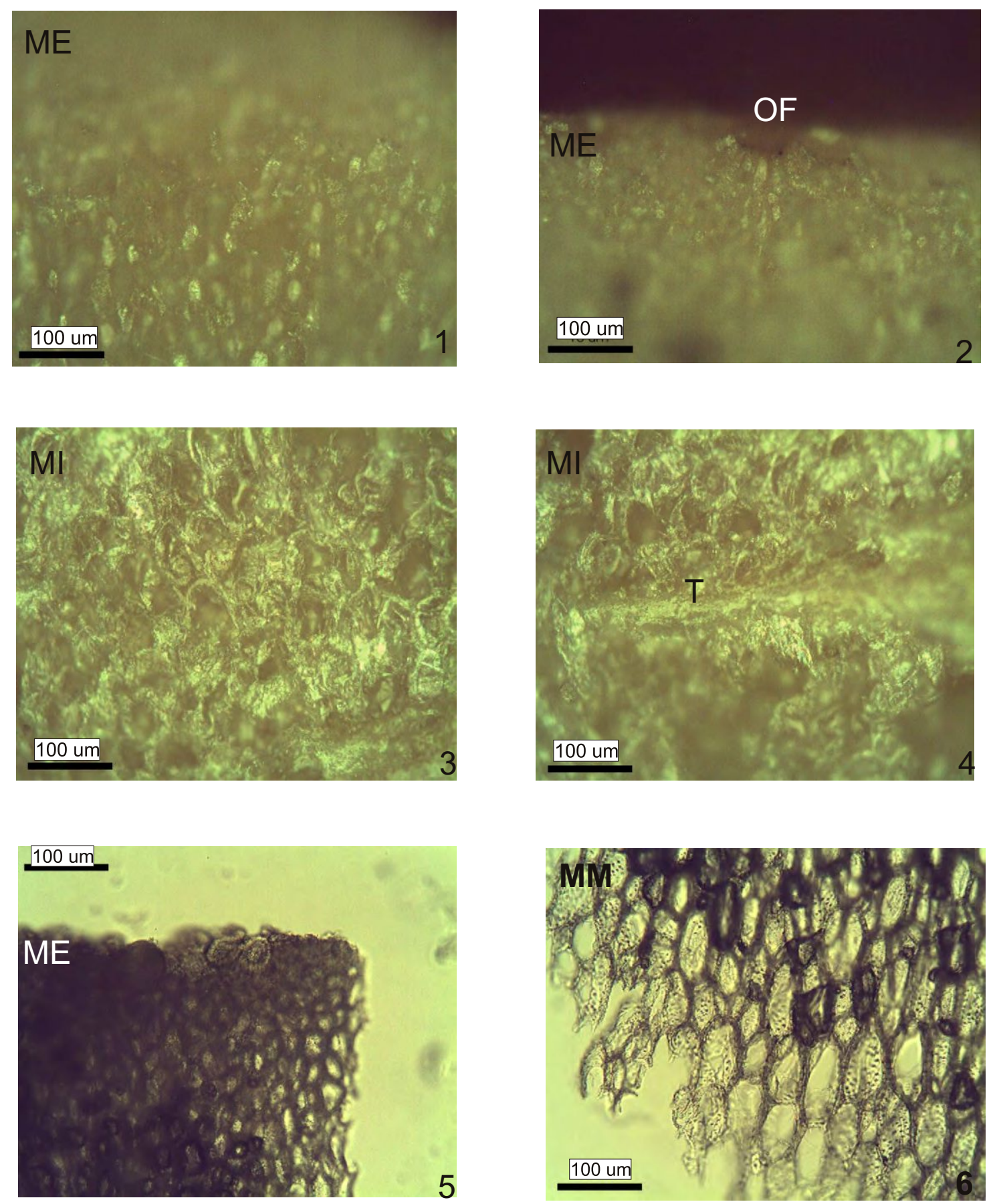

Corte transversal de pericarpio de $C$ maxima ssp maxima cv. zipinka 1 a 4: observado por incidencia, 5 y 6 : observado por transparencia; ME: mesocarpio externo; MM: mesocarpio medio; MI: mesocarpio interno; OF: oquedad correspondiente a fitolito; T: tubo criboso; HV: haz vascular. 

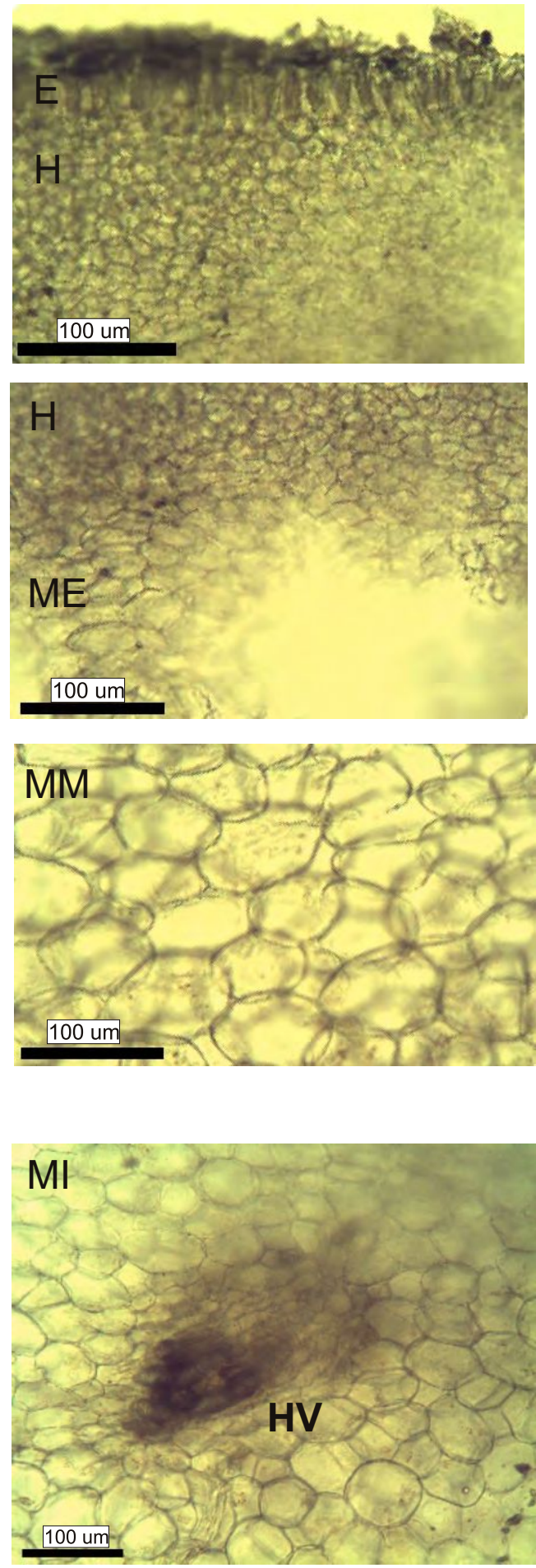
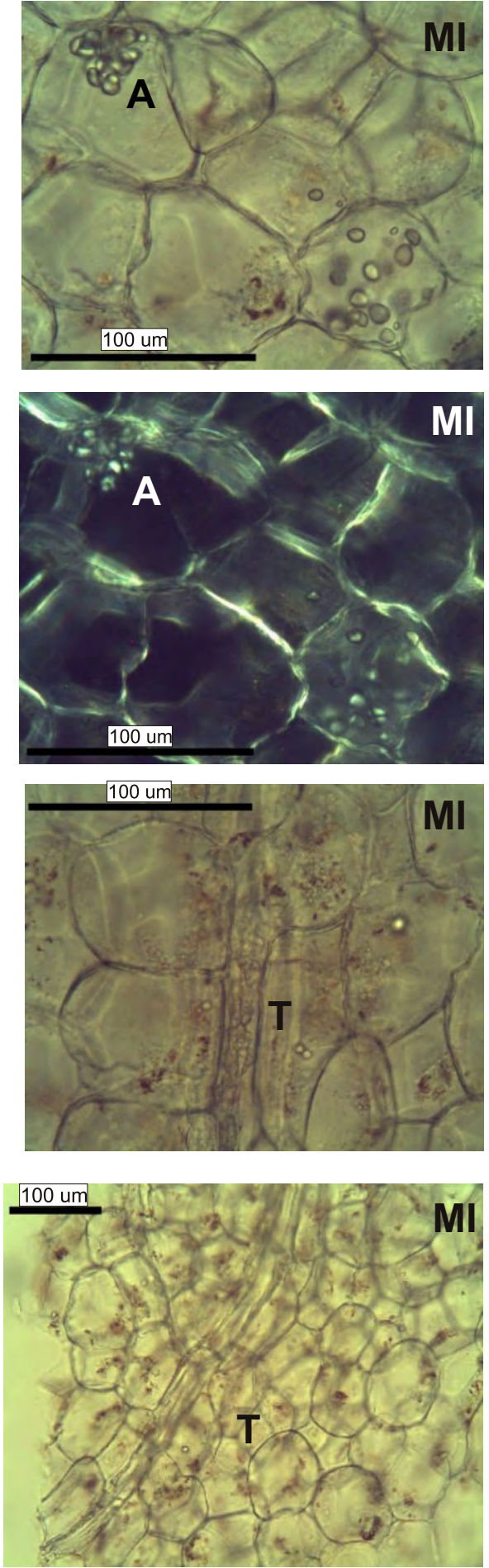

Corte transversal de pericarpio de $C$ moschata (no lignificado) observado por transparencia; E: epidermis; H: hipodermis; ME: mesocarpio externo; MM: mesocarpio medio; MI: mesocarpio interno; A: granos de almidón; T: tubo criboso; HV: haz vascular. 

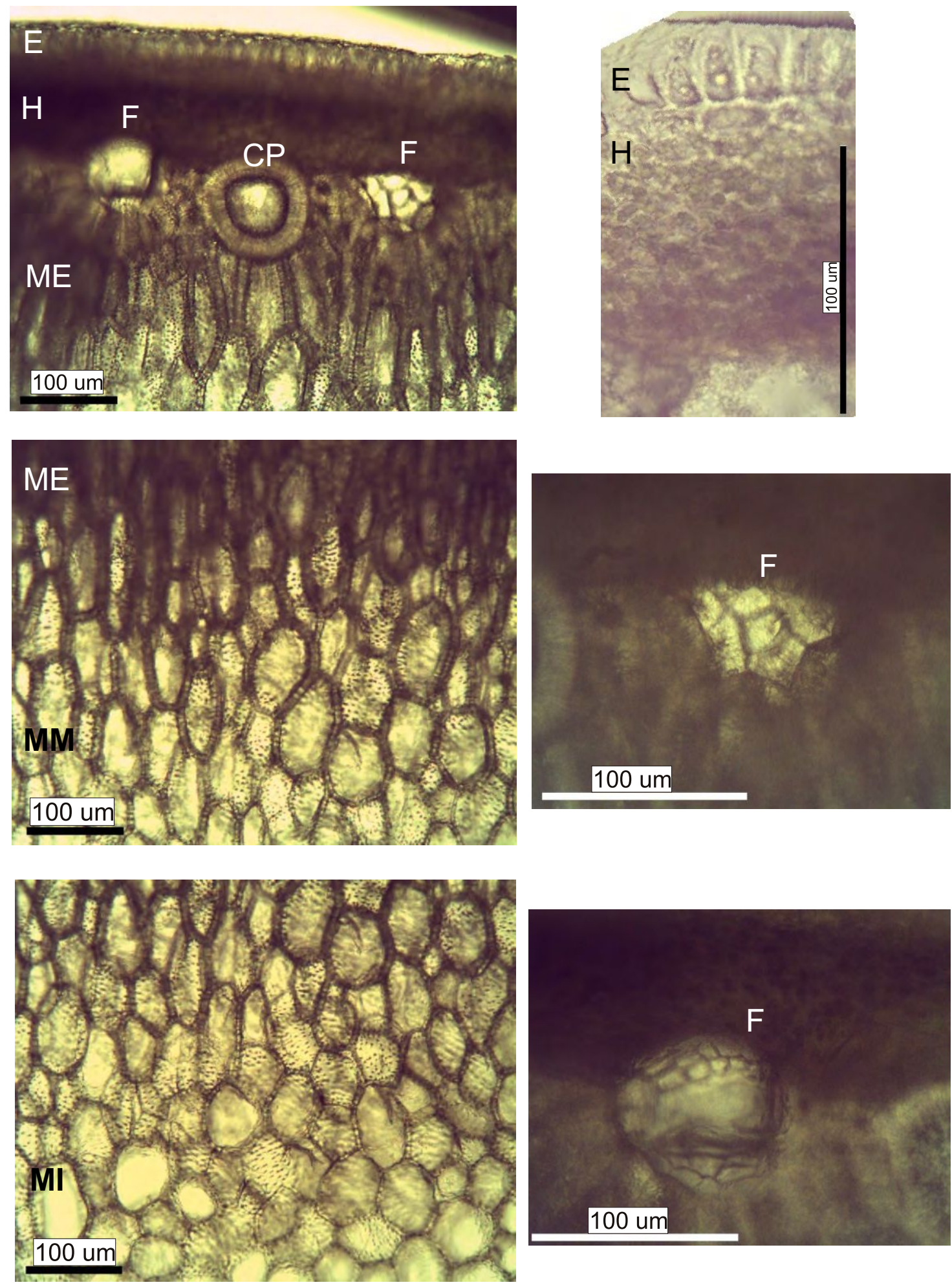

Corte transversal de pericarpio de $C$ ficifolia observado por transparencia; E: epidermis; H: hipodermis; ME: mesocarpio externo; MM: mesocarpio medio; MI: mesocarpio interno; F: fitolito; $\mathrm{CP}$ : célula pétrea. 

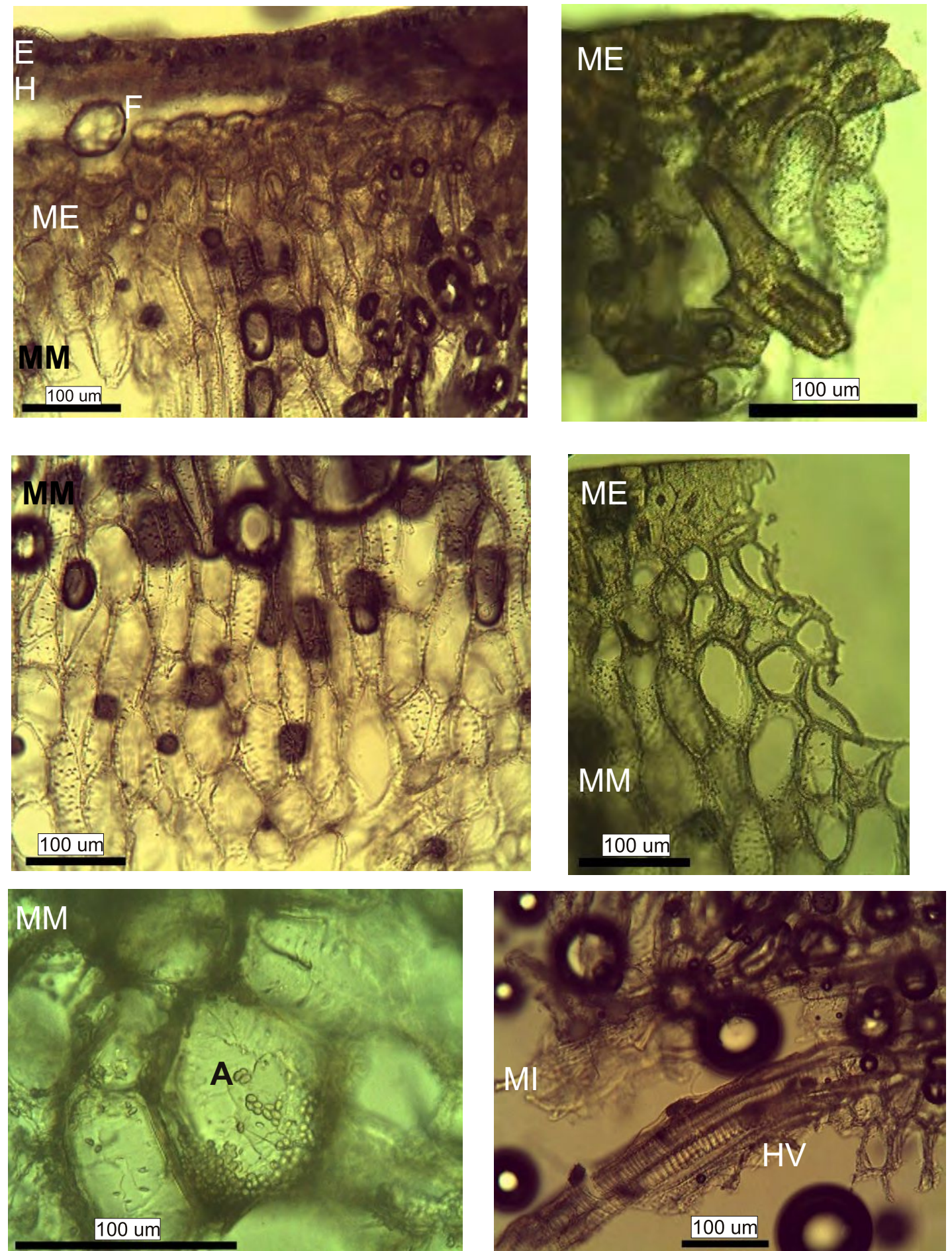

Corte transversal de pericarpio de $L$. siceraria observado por transparencia; E: epidermis; $\mathrm{H}$ : hipodermis; ME: mesocarpio externo; MM: mesocarpio medio; MI: mesocarpio interno; F: fitolito; A: granos de almidón; HV: haz vascular. 

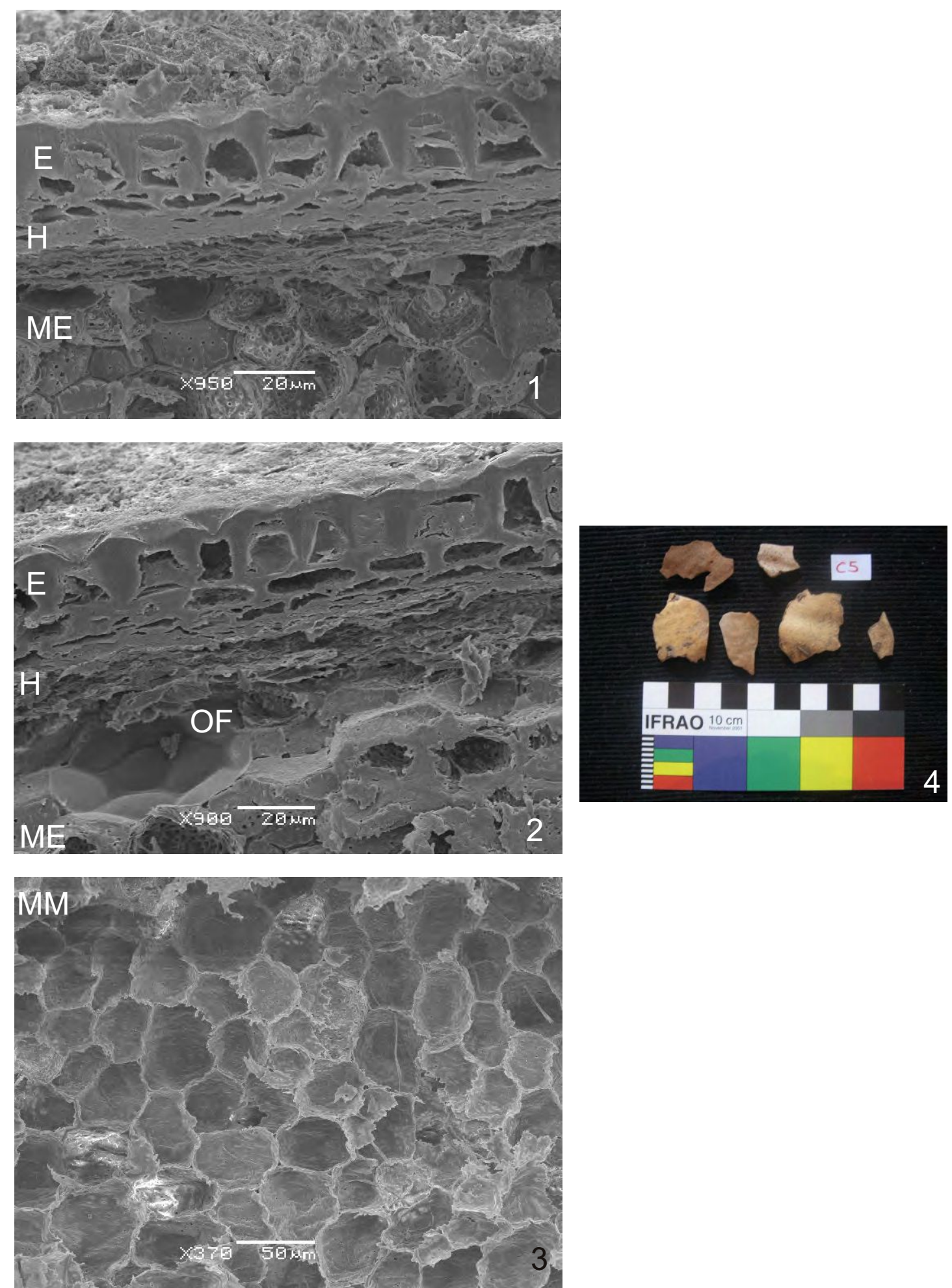

Pericarpios de Pampa Grande identificados como $C$ maxima ssp andreana; 1,2,3: corte transversal de pericarpio C5f observado al MEB; E: epidermis; $\mathrm{H}$ : hipodermis; ME: mesocarpio externo; MM: mesocarpio medio; OF: oquedad dejada por fitolito. 4: conjunto de pericarpios C5, Pampa Grande. 

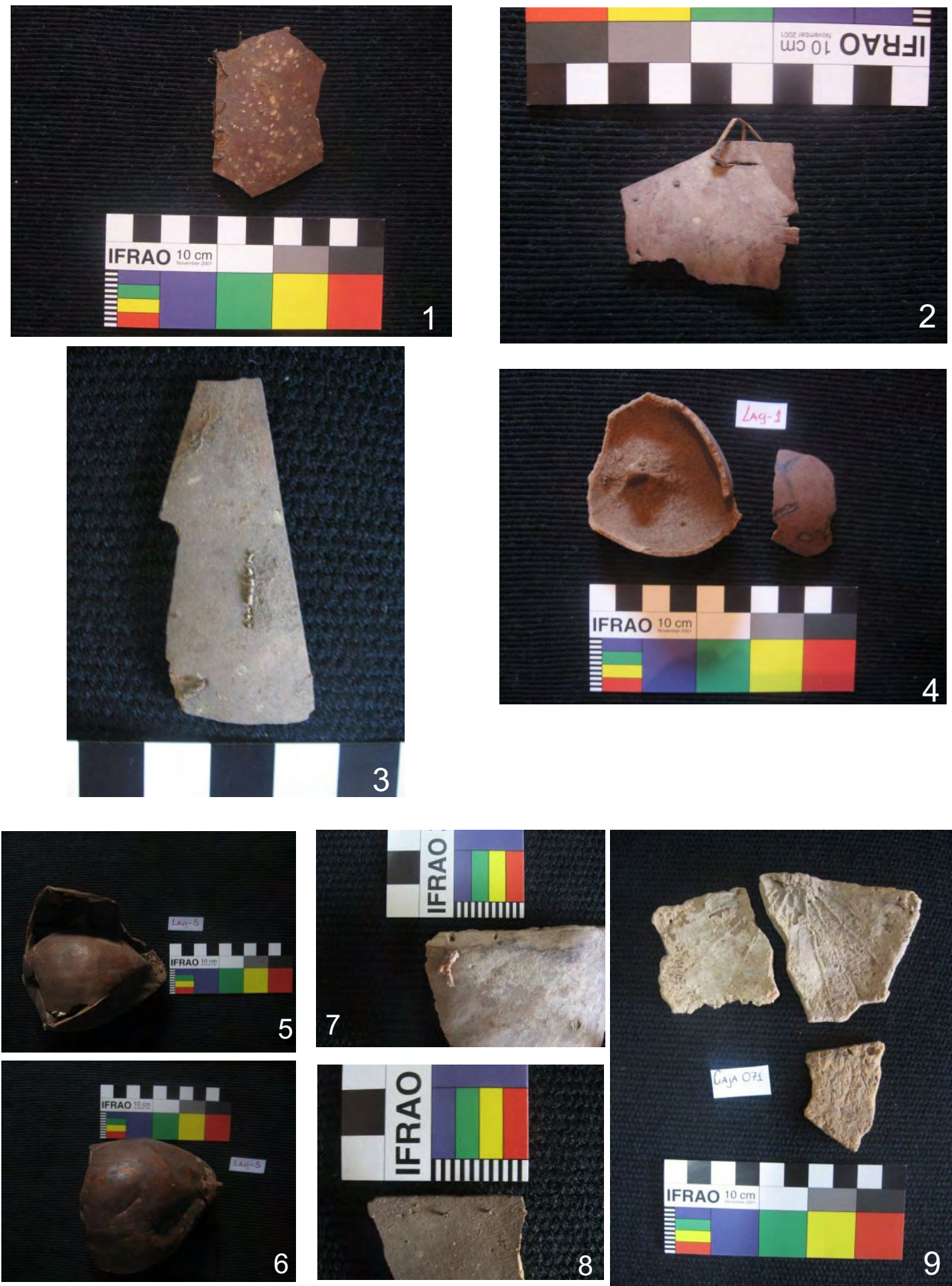

Frutos de Lagenaria siceraria de Pampa Grande, 1y 2: Lag.-7; 3: caja 067; 4: Lag.-1; 5 y 6: Lag.-5; 7,8 y 9: 071. 

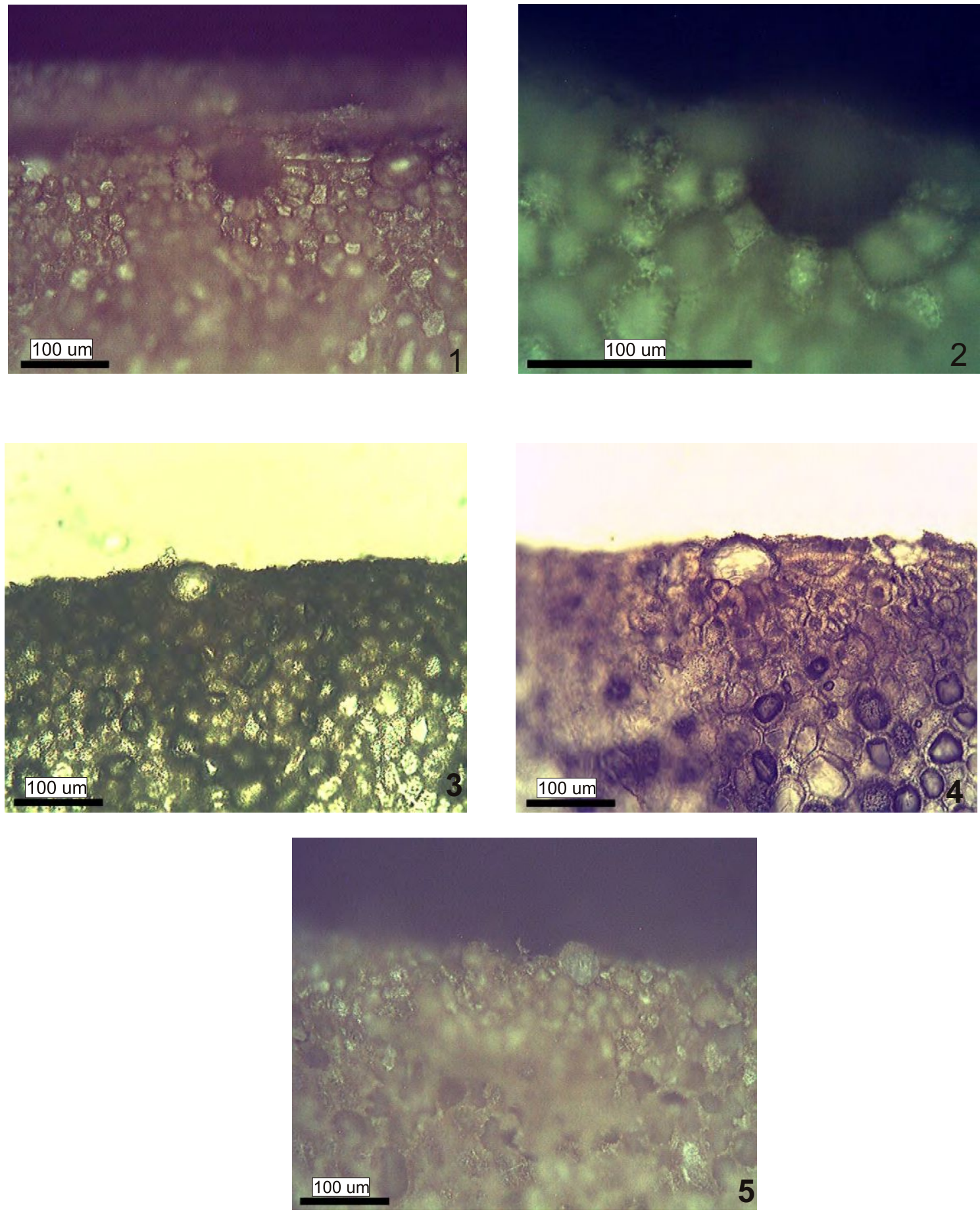

Pericarpios de Pampa Grande donde puede apreciarse la presencia de fitolitos (3,4 y 5 ) o las oquedades dejadas por los mismos (1 y 2 ). 1: Cucurbita sp. (C7a); 2: Cucurbita sp. (C10b); 3: C maxima ssp maxima (C3b); 4: C maxima ssp maxima (Caja 089); 5: C maxima ssp andreana (C5d). 


\subsection{1e- ESTUDIO MORFO-ANATOMICO EN MACRORRESTOS DE CUCURBITÁCEAS: PEDÚNCULO}

\section{Introducción}

De todas las estructuras de las cucúrbitas, los pedúnculos son los más adecuados para la identificación a nivel de especie (Cutler y Whitaker 1961) (Lámina 27) Las características diagnósticas de los mismos son:

-C. moschata: pedúnculo leñoso con cinco costillas obtusas levemente marcadas, se expande en la unión con el fruto formando un disco más o menos pronunciado, las costillas no tienden a escurrirse o extenderse hacia el ápice del fruto (Whitaker y Bohn 1950, Leon 1987, Parodi 1978, Lira Saade 1995, Teppner 2004)

-C. maxima ssp. maxima: pedúnculo corto, corchoso, cilíndrico no anguloso, posee estrías corchosas e irregulares, no ensanchado en la unión con el fruto (Whitaker y Bohn 1950, Lira Saade 1995). Según Teppner (2004) puede exhibir distintos tamaños, pero en sección transversal siempre es redondeado y corchoso.

-C. ficifolia: pedúnculo leñoso no rígido, redondeado a levemente con 5 costillas obtusas, no corchoso, no se agranda o solo lo hace moderadamente en la unión con el fruto, las costillas no tienden a extenderse o escurrirse hacia el ápice del fruto (Whitaker y Bohn 1950, Leon 1987, Lira Saade 1995)

En las especies silvestres de éste género los pedúnculos serían en general más pequeños (Whitaker y Cutler 1971), el de C. maxima ssp. andreana no es corchoso como el de C. máxima ssp. maxima, sino más o menos herbáceo o fibroso y por lo general caduco (Millán 1945, Lira Saade 1995) (Lámina 28). De acuerdo con Teppner (2004) es delicado y se encoge fuertemente cuando madura. No presenta costillas ni se ensancha en el área de inserción con el 
fruto. El pedúnculo de L. siceraria es leñoso y muy variable, pudiendo ser redondeado, levemente anguloso o muy anguloso (Yetsir et al 2008) (Lámina 27).

En concordancia con su valor diagnóstico en ejemplares actuales, los pedúnculos son los mejores elementos para la identificación de cucúrbitas arqueológicas (Whitaker 1980), además sufren escaso daño por el fuego y son muy resistentes al ataque de microorganismos, sobre todo en climas secos (Whitaker y Cutler 1968). La única dificultad se observa cuando los pedúnculos son recuperados fragmentados o inmaduros como los ejemplares recuperados por McNeish en el valle de Ayacucho (Whitaker 1980, 1983).

La identificación arqueológica de pedúnculos a partir de rasgos externos puede reforzarse mediante el análisis microscópico de sus tejidos constitutivos, fundamentalmente los haces vasculares bicolaterales (con floema en el lado interno y externo del xilema) característicos de las Cucurbitaceae (Esau 1976, Metcalfe y Chalk 1983) (Figura 30).

\section{Materiales y método}

Se conformó una colección de referencia con representantes de cinco taxa: siete pedúnculos de C. maxima ssp. andreana procedentes de la provincia de Buenos Aires; cinco de C. maxima ssp. maxima -habiendo tres ejemplares del cultivar Zapallito, uno del cultivar Zipinka (ambos cultivares colectados en El Shincal) y uno de un cultivar no identificado, adquirido en el mercado de La Quiaca, procedente de Salta; tres pedúnculos de C. moschata de frutos adquiridos en el circuito comercial bonaerense, uno de C. ficifolia de fruto colectado en Tucumán y uno de Lagenaria siceraria de provincia de Buenos Aires.

Se realizaron estudios de morfología cuantitativa externa en pedúnculos actuales de referencia de C. maxima ssp. andreana y C. maxima ssp. maxima dado 
el interés que revisten ambos taxa para esta tesis y la ausencia de este tipo de información en la bibliografía consultada. Se empleó un calibre digital de precisión para tomar dos medidas del diámetro basal del pedúnculo, el cual se entiende como la distancia máxima entre dos puntos en la base del pedúnculo (Cowan y Smith 1993), siguiendo la propuesta de Cowan y Smith (1993) y Smith (2000) para el análisis de pedúnculos arqueológicos a partir de ejemplares actuales.

Tomando en cuenta tanto los caracteres cuantitativos registrados en la colección de referencia, como los cualitativos mencionados en la bibliografía (Whitaker y Bohn 1950, Cutler y Whitaker 1961, Leon 1987, Parodi 1978, Lira Saade 1995, Teppner 2004) se analizó información publicada sobre restos de pedúnculos del sitio Los Viscos y se analizaron macroscópicamente once restos secos de pedúnculos de la localidad arqueológica de Pampa Grande. En este último caso los caracteres macroscópicos de uno de los pedúnculos no bastaron para su identificación, por lo que se analizó la estructura interna del mismo comparándolo con material actual de referencia de $C$. ficiolia y $C$. moschata. Para este análisis se realizó un corte en la parte media de los pedúnculos de referencia y se limpió la superficie expuesta del pedúnculo arqueológico fragmentado, realizándose la observación de su estructura interna bajo microscopio estereoscópico.

\section{Resultados}

$\underline{\text { Análisis de ejemplares actuales de referencia }}$

Los pedúnculos de C. maxima ssp. andreana poseen un aspecto fibroso, sin formar ángulos ni costillas, su diámetro promedio es de 5,75 $\mathrm{mm}$ (rango de tamaño: 3,47- 7,99 mm) (Tabla 59) (Lámina 28). 
El cultivar "Zapallito" de C. maxima ssp. maxima se caracteriza por poseer frutos de escaso tamaño, por lo que el análisis de sus pedúnculos amplía las consideraciones sobre la diversidad presente en la subespecie domesticada. El análisis de frutos maduros de referencia de dicho cultivar arrojo un diámetro promedio de los pedúnculos de 19, $5 \mathrm{~mm}$ con un rango de tamaño de entre 17 y 23 milímetros. Si bien estas medidas se alejan bastante de las registradas para C. maxima ssp andreana, son menores a las observadas en otros cultivares de referencia de C. maxima ssp. maxima con un promedio general de 25,2 $\mathrm{mm}$ y un rango de entre $(21,4$ y 27,8 mm) (Tabla 59).

Por lo tanto los tamaños de los pedúnculos de ambas subespecies de $C$. maxima son lo suficientemente disímiles como para poseer valor diagnóstico. Así, puede establecerse que ejemplares con diámetro menor o igual a $8 \mathrm{~mm}$ pertenecerán a la subespecie espontánea y aquellos con diámetros mayores a $17 \mathrm{~mm}$ a la subespecie domesticada.

Se ha comprobado la relación entre el aumento en el tamaño del fruto y el aumento del diámetro basal del pedúnculo en poblaciones de C. pepo (Cowan y Smith 1993), asumiéndose que dichos resultados son aplicables también a poblaciones de C. maxima. Como puede verse en el gráfico 13 si bien la dispersión es amplia, existe una tendencia al aumento conjunto del tamaño del pedúnculo y alto del pericarpio.

\section{Análisis de ejemplares arqueológicos}

Se analizaron restos de pedúnculos de los únicos dos sitios arqueológicos argentinos con representación del periodo temprano donde, hasta el momento, se recuperaron restos de pedúnculos de cucurbitáceas. Se recuperó también un pedúnculo carbonizado en el sitio inkaico-hispano indígena de El Shincal (Catamarca) (Capparelli 1997). El excepcional estado de conservación 
permite estimar por morfología cualitativa externa que el mismo correspondería a C. moschata.

1) Los Viscos

Se emplearon los datos e imágenes presentes en el informe de Maloberti y Zapatiel (2003) a fin de aproximar una identificación taxonómica de los pedúnculos los cuales son, en todos los casos, restos secos:

-Ejemplar $\mathrm{N}^{\circ}$ 1a: Dado que conserva el pedúnculo aún adherido al fruto puede verse la típica expansión que sufre el mismo en esta zona, propio de $C$. moschata..

-Ejemplar $\mathrm{N}^{\circ}$ 2: Se observa que es un pedúnculo corchoso, sin costillas, por lo cual se trataría de restos de C. maxima ssp. maxima.

- Ejemplar $\mathrm{N}^{o}$ 4: dudoso, ápice huidizo y algo ensanchado en la base, puede ser que se trate de C. moschata.

- Ejemplar $\mathrm{N}^{0}$ 15: parecería ser un pedúnculo de C. moschata ya que posee apariencia leñosa y lo que podrían ser costillas levemente marcadas, algo característico de esta especie (Whitaker y Bohn 1950).

- Ejemplar $N^{\circ} 16$ y 18: morfología similar a la del ejemplar $N^{o} 15$, podría tratarse de un pedúnculo de C. moschata.

- Ejemplar $\mathrm{N}^{\circ}$ 3, 21, 22, 23 y 24: morfología similar a la del ejemplar $\mathrm{N}^{\circ} 2$, correspondería a C. maxima ssp. maxima..

- Ejemplar No 27: dudosa su asignación al género Cucurbita.

El diámetro basal de los pedúnculos identificados como C. maxima ssp. maxima varía entre 10 y $19 \mathrm{~mm}$. (Tabla 60), ubicándose los mismos en una posición intermedia entre las medidas registradas en ejemplares actuales de dicha subespecie y C. maxima ssp andrena. 
Lamentablemente no contamos con mayores precisiones sobre las asociaciones contextuales de estos restos, habiéndose recuperado los mismos en los dos sectores excavados de la cueva (Korstanje y Würschmidt 1999).

2) Pampa Grande

En esta localidad se registraron un total de once pedúnculos, todos corresponden a restos secos y ninguno de ellos se encuentra adherido al pericarpio. Cinco de estos pedúnculos fueron analizados por T. Whitaker quien identificó cuatro de ellos como C. maxima ssp. maxima y uno como Lagenaria siceraria.

Nueve pedúnculos fueron identificados debido a su morfología corchosofibrosa, ausencia de costillas, diámetro similar entre la base y el ápice y sección circular como pertenecientes a C. maxima ssp. maxima. (Tabla 61) El pedúnculo No1 (lámina 29), fue identificado por Whitaker como perteneciente a Lagenaria siceraria., con lo cual coincidimos. El pedúnculo de la caja 6 (lámina 29) fue analizado en mayor profundidad dado que por su morfología externa se asemejaba tanto a los pedúnculos de C. ficifolia como de C. moschata. (la similitud que puede haber entre ambos fue señalada por Andres (1990, sobretodo en el caso de ciertos cultivares locales de C. moschata). Por lo tanto se realizó una observación de la estructura interna en la zona media de pedúnculos actuales de referencia de ambas especies. El pedúnculo de $C$. moschata posee una médula central maciza y cinco costillas, con un haz vascular bicolateral presente en cada costilla y uno en cada valle, sumando un total de diez. El pedúnculo de C. ficifolia, en cambio, posee una médula central hueca, presenta también un haz vascular bicolateral por costilla, pero un número variable (entre uno y tres) por valle. Los haces vasculares de esta especie exhiben un floema externo más corto y ancho que el observado en $C$. moschata. Las características de la médula, la disposición de los haces vasculares 
y el aspecto del floema externo registrado en C. ficifolia coincide con lo observado en el pedúnculo de la Caja 6 de Pampa Grande, por lo cual consideramos que el mismo correspondería a esta especie (Tabla 61).

En general el diámetro basal de los pedúnculos identificados como C. maxima ssp. maxima es escaso. Entre los ejemplares que poseen valores de diámetro basal intermedios $(\mathrm{N}=6)$ respecto de los registrados actualmente en C. maxima ssp. andreana y C. maxima ssp. maxima, P2, P4 y P3 son los que poseen el menor diámetro. Los dos primeros proceden del sector I de la cueva Los Aparejos y se encuentra asociados a pericarpios identificados como pertenecientes a C. maxima ssp. andreana (C1 y C5 respectivamente) por lo que, si bien la medida de estos pedúnculos apenas excede a la registrada en ejemplares actuales, podríamos estar también ante pedúnculos de esta subespecie. Los mismos son además de aspecto fibroso (lámina 29) y no corchoso, lo cual los asemeja más a la subespecie espontánea que a la domesticada.

Ante la correlación positiva (aunque débil) entre el aumento en el tamaño del pedúnculo y del pericarpio vemos que P2 -el menor de todo el conjunto- se asocia a $\mathrm{C} 1$ (c) el cual es un pericarpio identificado como C. maxima ssp andreana, pero que supera al rango de medidas actual de dicha subespecie; P4 es de mayor diámetro y se asocia a pericarpios de C. maxima ssp andreana de escaso espesor (C5) y a pericarpios de C. maxima ssp. maxima (C6). Por lo tanto, si asumimos que estos pedúnculos y pericarpios contextualmente asociados pertenecen a un mismo fruto, la correlación débil que se ve en los ejemplares de referencia actuales se halla presente también en los arqueológicos.

El ejemplar P3 de El Litro se encuentra, en cambio, asociado sólo a restos de pericarpio identificados como C. maxima ssp. maxima (C3), al igual que otros pedúnculos con diámetro de valor intermedio aunque más elevado (caja 89). De todas maneras la asociación contextual no es definitoria ya que ejemplares 
como P5 y $\mathrm{P} 4$ se encuentran asociados a restos de pericarpios de C. maxima ssp. maxima y a otros de C. maxima aff. ssp. andreana. Como vimos en el capítulo 4.1.1d en Pampa Grande se evidencia una coexistencia entre formas malezoides y domesticadas de C. maxima., lo cual se ve también reflejado en el caso de los pedúnculos.

Los ejemplares P7, P6 y P8 se encuentran dentro del rango de medidas registrado para C. maxima ssp. maxima cv zapallito. Dado que existe una relación clara entre tamaño de pedúnculo y de fruto (Cowan y Smith 1993), estos pedúnculos podrían estar señalando la presencia de frutos domesticados de tamaño pequeño, similares a los del mencionado cultivar. Existe la posibilidad de que estos pedúnculos de menor tamaño correspondan a ejemplares inmaduros, sin embargo, los rasgos diagnósticos macroscópicos por los cuales se los ha identificado se establecen en ejemplares maduros, siendo difícil la identificación de ejemplares arqueológicos inmaduros (Whitaker 1980, 1983). Esto lleva a que la posibilidad de que se trate de pedúnculos inmaduros pierda fuerza, si bien no se la puede descartar por completo.

Al contrario de lo que ocurre en el sector I de Los Aparejos, en el sector III contamos con restos de diámetro intermedio (caja 89 y P5) en la capa 1 y un ejemplar con diámetro coincidente con el cultivar Zapallito moderno en la capa 2, más profunda. Esta aparente inversión estratigráfica en la tendencia al aumento del tamaño ocurre con otros restos arqueobotánicos de las cuevas de Pampa Grande (ver capítulo 4.1.2). Aparentemente la estratigrafía de estas cavernas no refleja tendencia alguna, lo cual es coherente con la propuesta de una coexistencia - y no de una sucesión en el tiempo- de poblaciones vegetales con distinto grado de relación con grupos humanos.

El único pedúnculo asociado a un hallazgo es el recuperado en la Caverna II. Este forma parte del hallazgo $\mathrm{N}^{\circ} 42$ junto a coprolitos de camélidos, textiles, cuentas, restos de cestos, cerámica y pericarpios de C. maxima ssp maxima 
(ejemplares C12). El fragmento de pericarpio C12b presenta la marca dejada por el desprendimiento del pedúnculo. Esto indicaría que un fruto lobulado con su pedúnculo fue colocado como ajuar fúnebre. Podría pensarse que si el fruto ofició como recipiente, el pedúnculo fue quizá dejado a modo de mango o asa. Sin embargo, sólo se recuperaron dos fragmentos de pericarpio y el pedúnculo por separado, lo cual hace pensar que fueron colocados intencionalmente de esta manera como ajuar fúnebre. La presencia de objetos cerámicos rotos depositados como ajuar se encuentra en piezas de filiación Condorhuasi en tumbas excavadas por las expediciones financiadas por B. Muñiz Barreto (M.D. Arena, com. pers.). Por lo tanto no sería inapropiado asumir la depositación de objetos de origen vegetal fragmentados como ajuar funerario. Recordemos también que en Pampa Grande se depositaron piezas cerámicas con "agujero de muerte" acompañando a los cuerpos sepultados (ver capítulo 3).

\section{Discusión}

No existen, hasta el momento, pedúnculos de C. maxima ssp andreana arqueológicamente reportados, por lo cual no se puede seguir el camino evolutivo que habría llevado de un pedúnculo delgado, fibroso y caduco a uno engrosado, corchoso y persistente, propio de una especie que ha perdido la capacidad de dispersarse por sí sola (ver capítulo 4.1.1a).

El análisis de pedúnculos actuales de C. maxima ssp maxima (distintos cultivares) y $C$ maxima ssp andreana demostró una diferencia muy marcada de tamaño, contrariamente a lo registrado por Cowan y Smith (1993) en C. pepo, donde hay un solapamiento en las medidas de los diámetros basales entre pedúnculos de la subespecie silvestre y la domesticada. Pedúnculos con tamaño intermedio entre $C$. maxima ssp maxima y $C$ maxima ssp andreana se encuentran en el registro arqueológico del NOA, siendo los de Pampa Grande 
los de menor tamaño registrados hasta el momento en esta región. Los mismos se asocian a pericarpios identificados como $C$ maxima ssp andreana, pudiendo corresponderse a formas malezoides o híbridas entre C. maxima ssp. maxima y C. maxima ssp. andreana y no a ejemplares intermedios o transicionales dado que en esta localidad arqueológica hay una coexistencia de plantas con distinto grado de manipulación más que una sucesión en el tiempo de las mismas. Esta caracterización de formas malezoides o híbridas se fundamenta también en que tanto los pedúnculos como los pericarpios exhiben un tamaño levemente mayor al registrado en poblaciones actuales de C. maxima ssp. andreana. Los restantes pedúnculos indican frutos de C. maxima ssp maxima de pequeño tamaño.

Nuevamente a diferencia de otros sitios formativos del NOA como Los Viscos, no se encontraron restos de C. moschata entre los pedúnculo de Pampa Grande. Resulta sin embargo muy llamativa la presencia de restos de $C$. ficifolia, especie que no había sido detectada en los análisis de pericarpios y semillas de esta localidad. Esta especie destaca respecto de sus congéneres domesticados en que crece en altitudes elevadas, donde mantiene el vigor a pesar de las bajas temperaturas, y en que requiere de un fotoperíodo corto para florecer (Whitaker y Bohn 1950). Sin embargo esta generalidad posee matices, ya que existen poblaciones que crecen en latitudes extremas como Noruega y otras que no prosperan fuera de los trópicos (Andres 1990), lo cual señala la alta plasticidad adaptativa de esta especie. El rango altitudinal en el cual se siembra C. ficifolia en las laderas andinas va desde los 2500 a $1800 \mathrm{msm}$ (Nee 1990). Respecto al área donde se ubica Pampa Grande, existe un ejemplar de herbario de esta especie en el Museo de Ciencias Naturales de Salta (12677 Novara, Bruno, de la Fuente y Lusvarghi) colectado a 1650 msm en un área aledaña al río Blanco, ingresando a la Quebrada del Toro y a $2 \mathrm{~km}$ de Campo Quijano (Dpto. Rosario de Lerma). De acuerdo con el Ing. Novara (com. pers.) se trataba de plantas asilvestradas, con frutos de más de $1 \mathrm{~kg}$, casi 
maduros, trepando en árboles a $3 \mathrm{~m}$ del suelo. Existen también reportes sobre la presencia de formas asilvestradas de C. ficifolia en las yungas de Bolivia (Cárdenas 1969, Nee 1990). Lamentablemente la ausencia de un antecesor silvestre definido y la uniformidad morfológica que caracteriza a esta especie (ver capítulos 4.1.1 a y 4.1.1d) hace que sea muy difícil evaluar el grado de manipulación y/o transformación sufrida por la misma tras la intervención humana. El hallazgo de un pedúnculo de C. ficifolia en Pampa Grande constituye un indicador más en el sentido de destacar que esta área poseyó una tradición distinta en el manejo de las cucurbitáceas a la registrada en los valles longitudinales del NOA y en el COA, donde no se ha hallado esta especie. 
Tabla 59: medidas (dos por ejemplar) correspondientes al diámetro basal de pedúnculos de frutos actuales de C. maxima ssp andreana y $C$. maxima ssp maxima cuya procedencia se señala en la columna correspondiente al taxón.

\begin{tabular}{|c|c|c|c|}
\hline C maxima ssp andrena & Medidas (mm) & C. maxima ssp maxima & Medidas (mm) \\
\hline Mones Cazón 1 & 5,18 & Cultivar indet (El Shincal) & 23,58 \\
\hline & 4,33 & & 21,44 \\
\hline Mones Cazón 2 & 5,39 & Cultivar Zipinka (El Shincal) & 27,37 \\
\hline & 6,38 & & 27,79 \\
\hline Mones Cazón 3 & 5,96 & Mercado de La Quiaca & 25,91 \\
\hline & 6,54 & (fruto procedente de Salta) & 25,33 \\
\hline Los Toldos & 5,76 & Cultivar Zapallito (El Shincal) & 21,6 \\
\hline & 4,86 & & 17,18 \\
\hline LEBA & 3,97 & Cultivar Zapallito (El Shincal) & 17,16 \\
\hline & 3,47 & & 19,79 \\
\hline Orillas del Salado 1 & 7,98 & & 23,11 \\
\hline & 7,99 & & 18,06 \\
\hline Orillas del Salado 2 & 5,69 & & \\
\hline & 7 & & 22,36 \\
\hline Promedio & 5,75 & & 3,80 \\
\hline D.S. & 1,37 & & 16,97 \\
\hline C.V & 23,75 & & 17,16 \\
\hline Min & 3,47 & & 27,79 \\
\hline Max & 7,99 & & \\
\hline
\end{tabular}

Tabla 60: diámetro basal de los pedúnculos identificados como pertenecientes a C. maxima ssp. maxima recuperados en el sitio Los Viscos según datos de Maloberti y Zapatiel (2003)

\begin{tabular}{|cc|}
\hline $\begin{array}{c}\text { Especimen } \\
\mathbf{N}^{\mathbf{0}}\end{array}$ & $\begin{array}{c}\text { Diámetro } \\
\text { basal }(\mathbf{m m})\end{array}$ \\
\hline 22 & 10 \\
2 & 11 \\
24 & 11 \\
21 & 15 \\
23 & 15 \\
3 & 19 \\
\hline
\end{tabular}


Tabla 61: pedúnculos recuperados en la localidad arqueológica de Pampa Grande. La medida del diámetro basal corresponde a la media de dos medidas tomadas en dicha área.

\begin{tabular}{|c|c|c|c|c|}
\hline $\begin{array}{c}\mathbf{N}^{\circ} \\
\text { Registro }\end{array}$ & Identificación & Cueva & Contexto & $\begin{array}{c}\text { Diámetro } \\
\text { basal } \\
\text { (mm) }\end{array}$ \\
\hline P-4 & $\begin{array}{l}\text { C. maxima ssp } \\
\text { maxima }\end{array}$ & Los Aparejos & Sector I/ cuad 1 & 9,55 \\
\hline $\mathrm{P}-2$ & $\begin{array}{l}\text { C. maxima ssp } \\
\text { maxima }\end{array}$ & Los Aparejos & Sector I/ cuad A/ capa 3a & 8,45 \\
\hline Caja 89 & $\begin{array}{l}\text { C. maxima ssp } \\
\text { maxima }\end{array}$ & Los Aparejos & Sector III/ E1/ capa $1(00-0.20)$ & 16,61 \\
\hline$P-5$ & $\begin{array}{l}\text { C. maxima ssp } \\
\text { maxima }\end{array}$ & Los Aparejos & $\begin{array}{c}\text { Sector III/F2/ } 0,00-0,20-0,40 \mathrm{~cm} \text {. (capa } \\
\text { 1) }\end{array}$ & 13,35 \\
\hline $\mathrm{P}-8$ & $\begin{array}{l}\text { C. } \operatorname{maxima}_{\text {maxima }} \\
\text { msp }\end{array}$ & Los Aparejos & Sector III/E2/ 0,40-0,60 cm. (capa 2) & 19,25 \\
\hline$P-1$ & Lagenaria siceraria & Los Aparejos & Sector III/F2/ 0,40-0,60 cm. (capa 2) & 10,75 \\
\hline P-7 & $\begin{array}{l}\text { C. } \operatorname{maxima} \mathrm{ssp} \\
\text { maxima }\end{array}$ & El Litro & C1- capa $1(00-0,70)$ & 17,00 \\
\hline P-3 & $\begin{array}{l}\text { C. } \operatorname{maxima}_{\text {maxima }} \\
\text { maxp }\end{array}$ & El Litro & C1- capa 2 (hasta 0,90-70-90) & 9,78 \\
\hline Caja 6 & C. ficifolia & El Litro & C1- capa $2(0070-0090)$ & 17,40 \\
\hline P-6 & $\begin{array}{l}\text { C. } \operatorname{maxima}_{\text {maxima }} \\
\text { map }\end{array}$ & Caverna II & Hallazgo 42 & 17,20 \\
\hline Caja 047 & $\begin{array}{l}\text { C. maxima ssp } \\
\text { maxima }\end{array}$ & Caverna IV & & 12,49 \\
\hline
\end{tabular}

Figura 26: corte transversal de pedúnculo de Cucurbita sp. (izquierda) y detalle de haz vascular (derecha) tomado de Esau 1993.

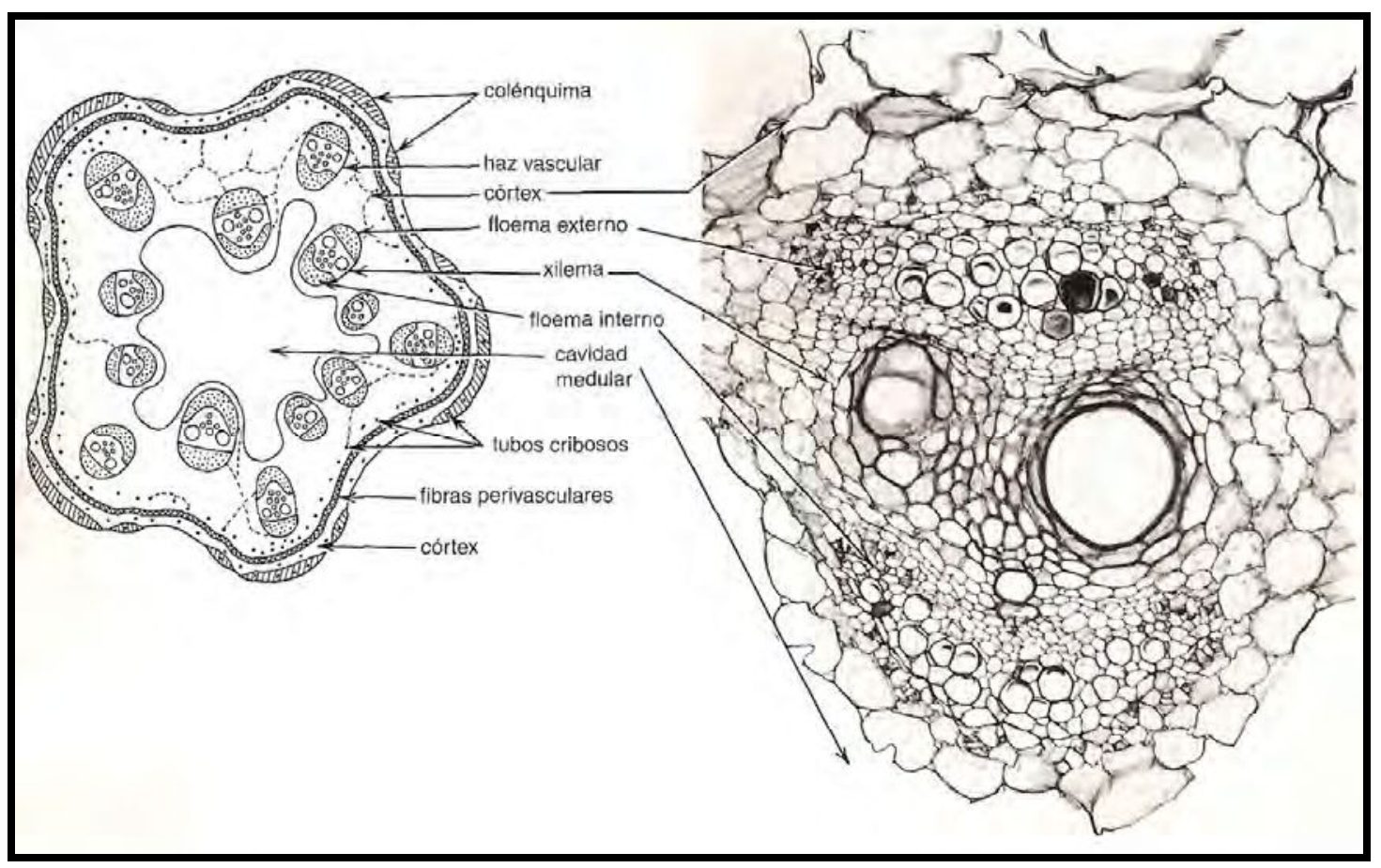


Gráfico 13: diagrama de dispersión de puntos indicando la relación entre diámetro de pedúnculo y alto del pericarpio en frutos actuales de referencia de C. maxima ssp andreana (gráfico generado mediante el software SPSS 15.0)

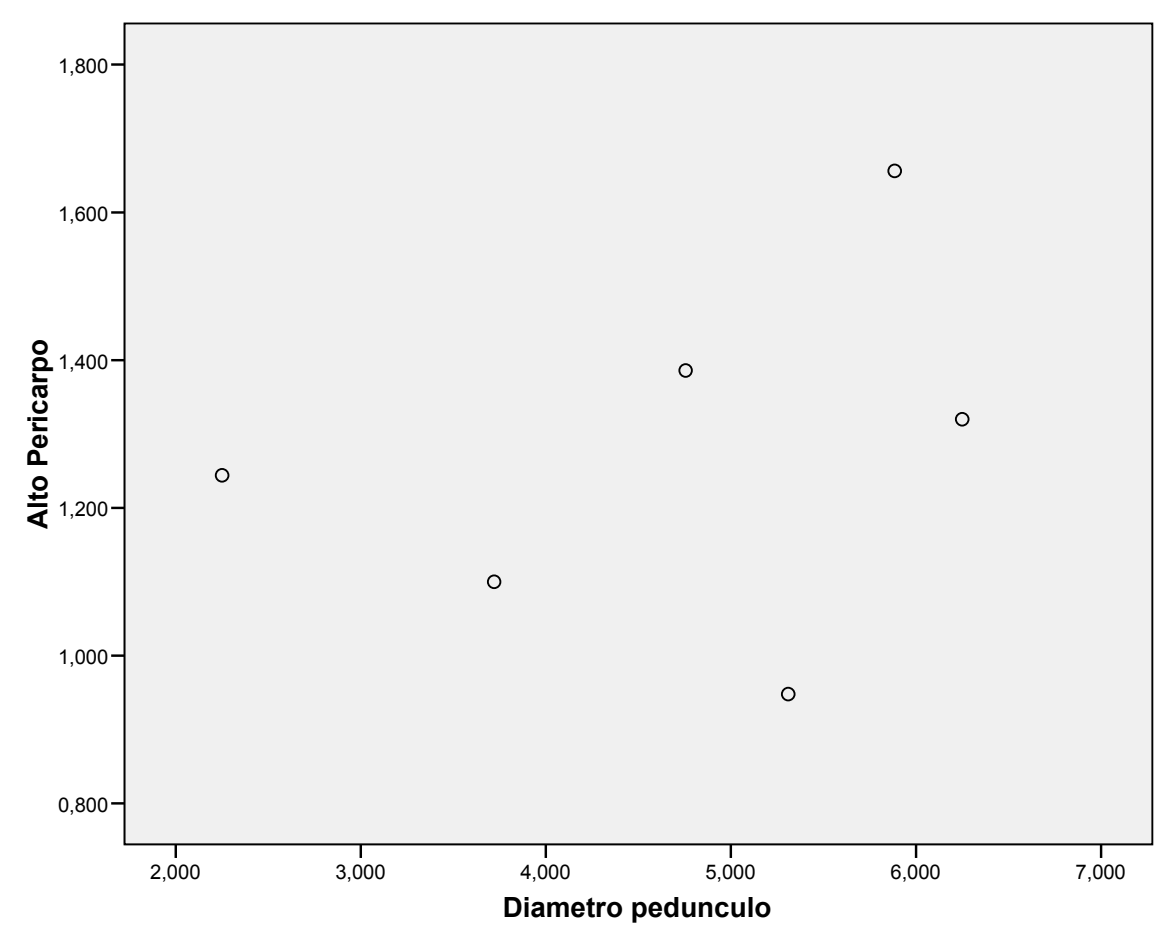



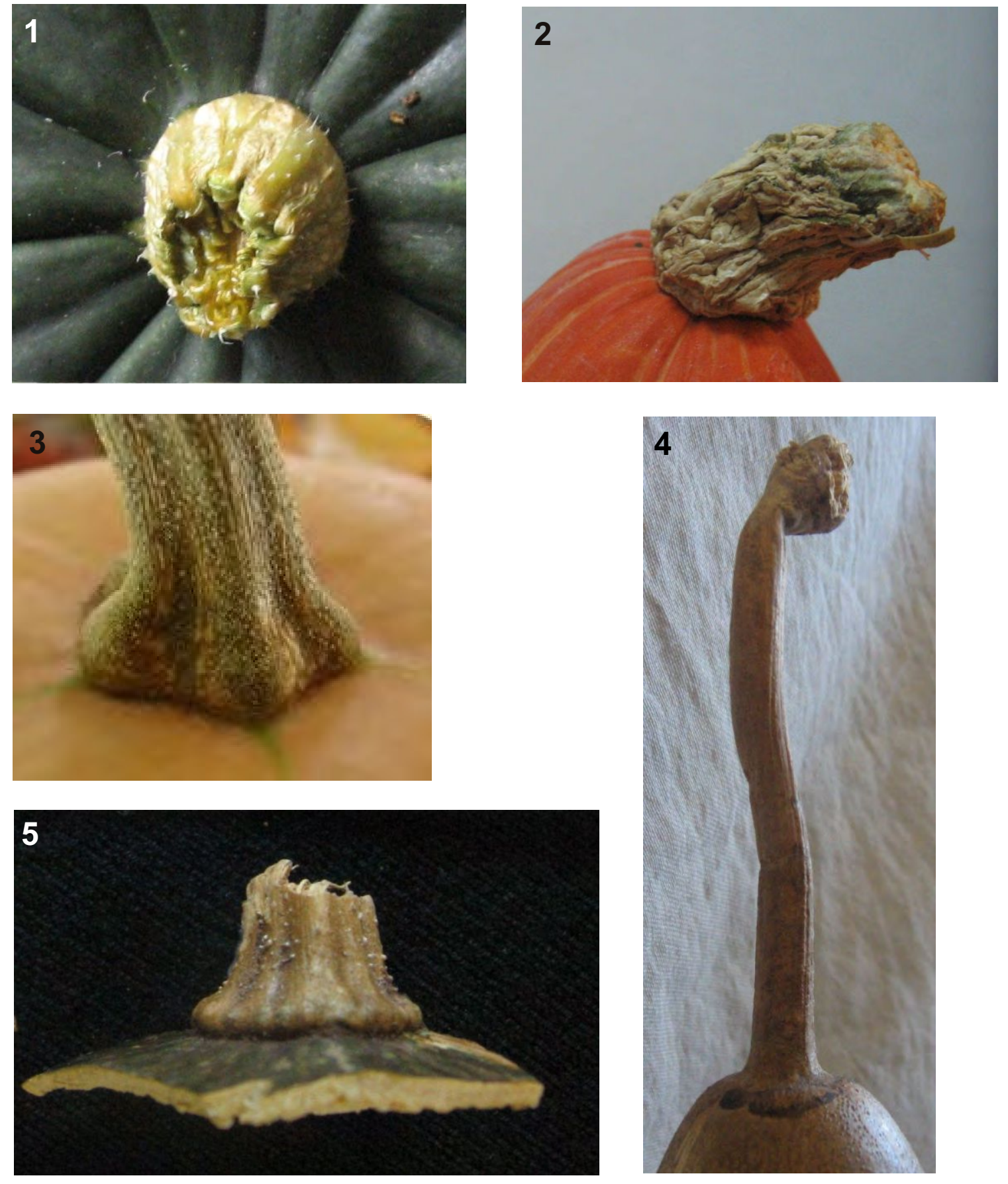

Pedúnculos de $C$ maxima ssp maxima cv zapallito (1); $C$ maxima ssp maxima cv hubbard (2); C moschata (3); Lagenaria siceraria (4); C ficifolia (5) 

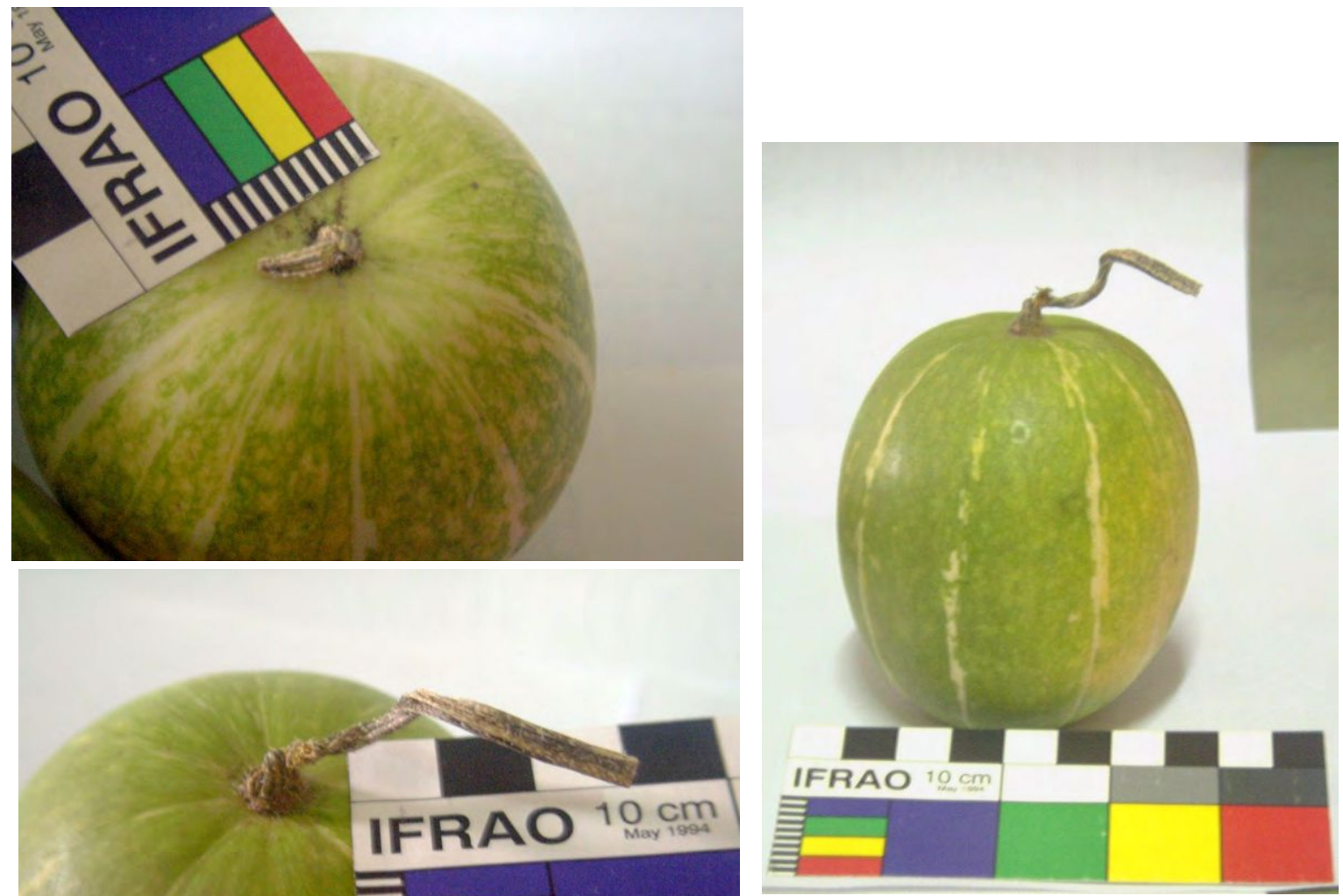

Pedúnculo de C maxima ssp andreana, ejemplares de Mones Cazón, provincia de Buenos Aires, Argentina (Leg. M. Arriaga). 

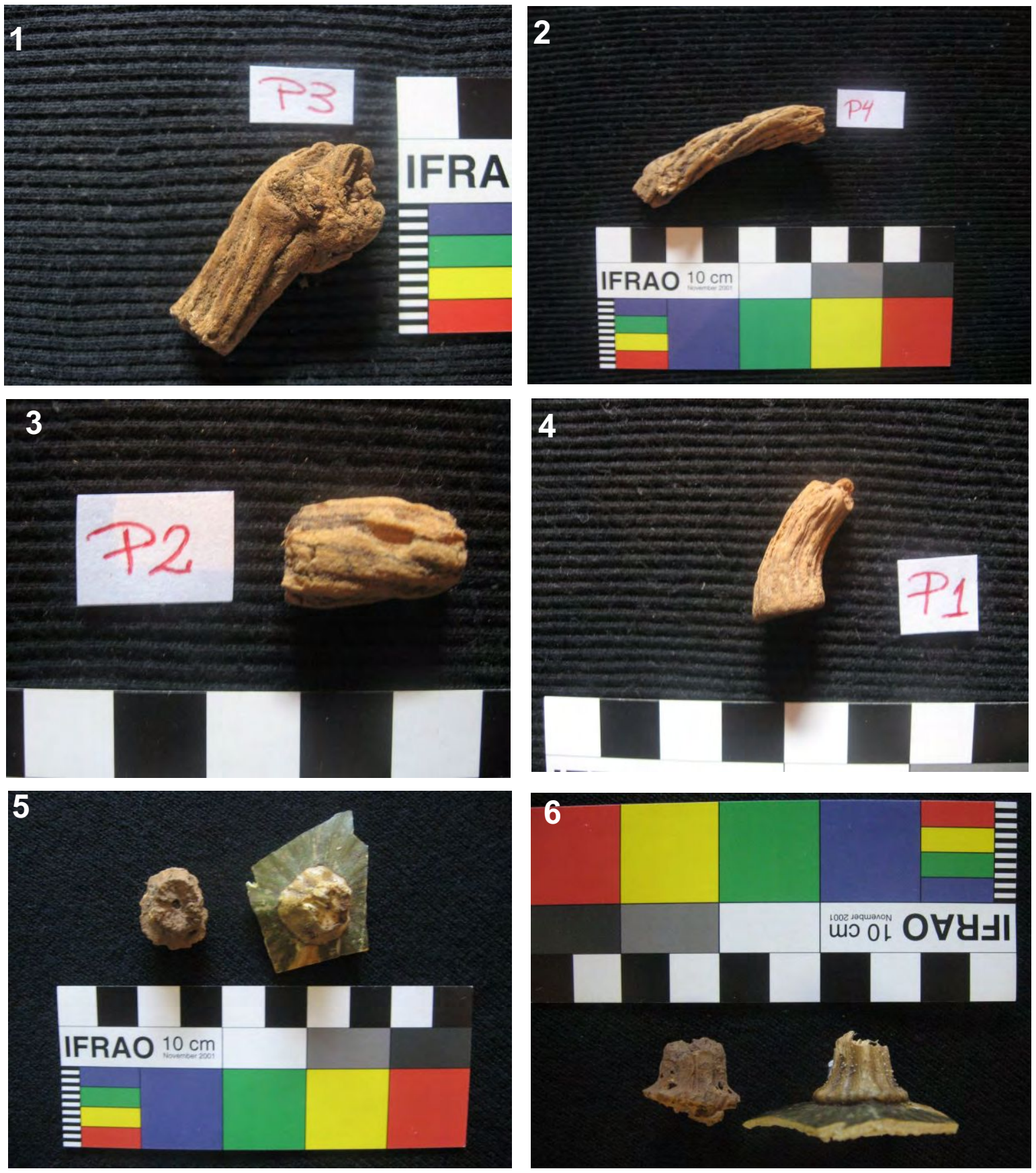

Pedúnculos de Pampa Grande: 1, 2 y 3: pedúnculos de $C$ maxima ssp maxima con menor diámetro basal; 4: pedúnculo de $L$ siceraria; 5 y 6 : pedúnculo arqueológico de $C$ ficifolia (izquierda) y ejemplar actual de dicho taxón (derecha). 


\subsection{1 f- EVIDENCIA DE CERAMIOS FITOMORFOS.}

\section{Introducción}

El estudio de manifestaciones artísticas donde se plasman motivos vegetales ha sido un abordaje emblemático en los estudios paleoetnobotánicos, considerándoselas un tipo de evidencia indirecta acerca de las plantas empleadas por los grupos humanos en el pasado (Pearsall 1989). En este sentido cabe aclarar que si el interés radica en identificar especies a través de manifestaciones artísticas, deben procurarse aquellas donde se realice un tratamiento naturalista de las representaciones, ya que en éstas el artista busca la reproducción fiel de un objeto y no una síntesis del mismo por medio de abstracciones o reemplazos simbólicos (González 1974, Sempé de Gomez Llanes 1984). También se caracteriza a esta clase de representaciones como poseedoras de un alto nivel icónico, ya que las relaciones entre forma y contenido están basadas en una fuerte semejanza formal entre las figuras y sus referentes en el mundo real u objetivo (Berenguer 1996). La utilidad de este tipo de aproximación puede verse en el caso de piezas Moche del periodo Clásico de la costa norte peruana. Esta cultura en particular se caracterizó por representaciones naturalistas de diverso tipo: rostros humanos (los llamados "huaco retratos"), viviendas, animales y plantas, entre otros (Sempé de Gomez Llanes 1984). En el Museo Amano (Lima, Perú) se conserva un molde obtenido de una mazorca, el cual fue empleado en la elaboración de piezas cerámicas; Eubanks (1999 en Eubanks 2001) analizó 129 de estas piezas empleando esquemas de clasificación desarrollados para el análisis de mazorcas logrando identificar siete razas distintas de maíz (Eubanks 2001). 


\section{Representaciones vegetales en el Área Andina Meridional}

Las representaciones de vegetales en las culturas prehispánicas del actual territorio peruano han sido profusas desde el Período Intermedio Temprano, plasmándose las mismas sobre soportes diversos como textiles ( $\mathrm{O}^{\prime}$ Neale y Whitaker 1947), lapidaria (en este sentido destaca el famoso Obelisco Tello, Piperno y Pearsall 1998) y cerámica. En este último caso los vegetales han sido representados tanto pintados como modelados (para una excelente compilación de los mismos ver Yacovleff y Herrera 1934, 1935 y Towle 1961). En el caso particular de las cucurbitáceas las mismas se hallan por lo general modeladas en vasijas. Towle (1961) menciona representaciones de $C$. maxima ssp. maxima en cerámica Moche y Chimú, habiendo reproducciones de zapallos verrugosos Hubbard, aunque son más frecuentes las reproducciones de C. moschata. De esta última especie suelen representarse frutos verrugosos con cuello de cisne, frecuentes en Paracas (Yacovleff y Herrera 1934, Towle 1961, Whitaker y Cutler 1967). En todos los casos la vasija entera o el cuerpo de la misma es un modelado del fruto (lámina 30), conservándose en varias de ellas la representación del pedúnculo, lo cual asegura la identificación taxonómica. En Nazca se habrían empleado los frutos de L. siceraria para dar forma a las piezas cerámicas (Yacovleff y Herrera 1934).

Saliendo de territorio peruano, las representaciones fitomorfas prácticamente desaparecen, salvo las referidas a Cucurbitáceas. En el Norte Grande chileno en una tumba del cementerio Playa Miller de la fase agrícola inicial El Laucho (300 AC) se recuperó junto a una momia de un individuo adulto una pieza sin decoración que "tiene forma de Cucurbitácea" (Focacci 1974:31).

En Chile central existen piezas cerámicas con forma de cucurbitáceas en contextos culturales Bato y Llolleo correspondientes al Período Agroalfarero Temprano con una cronología entre 200 AC y 100 DC (Falabella y Stehberg 
1989, Planella y Tagle 1998). En estos contextos se ha recuperado una jarra con pintura roja cuyo cuerpo posee una serie de líneas gruesas incisas que delimitarían lóbulos, representando a un fruto de Cucurbita sp en el enterratorio $\mathrm{N}^{\mathrm{o}} 4$ del sitio Laguna El Peral y dos ceramios monócromos lisos y de cuerpo globoso con forma de frutos de L. siceraria en el sitio Chacayes (430 DC) (Falabella y Stehberg 1989, Planella y Tagle 1998, fotos 1 y 2). La presencia de ceramios fitomorfos es un elemento, junto a otros, que vinculan a los grupos de tradición Bato con poblaciones tempranas del Norte Chico chileno y del NOA, habiéndose encontrado cerámica típica Llolleo en Mendoza y Neuquén, lo cual evidencia el movimiento de bienes desde la costa pacífica hasta espacios trasandinos (Falabella y Stehberg 1989, Lagiglia 1997). Existe también una pieza cerámica representando un fruto de $L$. siceraria procedente del sitio Huimpil -trabajado por Américo Gordonfechada por termoluminiscencia entre el 640 y 680 DC, la misma correspondería a la cultura Pitrén (M.T. Planella com. pers.).

En el sitio Las Morrenas 1 ubicado en la cuenca del río Maipo en Chile central se constató la presencia de restos carbonizados de Chenopodium quinoa junto a semillas, pericarpios y pedúnculos carbonizados también de Cucurbitaceae para el arcaico tardío, hace aproximadamente 3000 años (Planella et al 2005). La presencia efectiva de restos de Cucurbita sp. y de L. siceraria en está área quedó confirmada tras los trabajos en el sitio La Granja donde se recuperaron restos carbonizados de semillas, pericarpos y pedúnculos junto a restos de Zea mays, Phaseolus vulgaris y Chenopodium quinoa fechados entre el 600 y 1000 dC (Planella y Tagle 1998).

En la arqueología argentina existen escasas menciones a la representación de vegetales en general. Fiadone (2006) interpreta bandas onduladas pintadas en la cerámica Sanagasta del NOA como representaciones de frutos de leguminosas. Scattolin (2003) reporta una pieza de la colección Zavaleta cuyo 
motivo decorativo es una "calabaza", correspondiente al formativo del Valle de Santa María en el NOA.

\section{Materiales y método}

$\underline{\text { Análisis de colecciones arqueológicas. }}$

Se efectuó un registro de piezas cerámicas y líticas con motivos fitomorfos en colecciones arqueológicas del Museo Condorhuasi (Belén, Catamarca) y Museo Adán Quiroga (San Fernando del Valle, Catamarca). Se registraron también piezas, de la colección García Uriburu y de la colección Di Tella del Ministerio de Relaciones Exteriores, Comercio Internacional y Culto.

Criterios empleados en la identificación de piezas fitomorfas.

En la búsqueda de representaciones de objetos de la naturaleza en manifestaciones plásticas del pasado se ha reconocido la utilidad de distinguir criterios basados en las características intrínsecas, de aquellos basados en caracteres extrínsecos de las representaciones, entendiéndose los primeros como rasgos que conforman la imagen mental que el artista se forma del objeto en cuestión, en tanto los segundos son argumentos inferenciales externos a las representaciones, por medio de los cuales el analista identifica una especie (Clottes 1989 en Berenguer 1996). En este capítulo empleamos ambos tipos de criterios a fin de identificar representaciones vegetales.

En primera instancia se recurrió a caracteres de semejanza formal dada la alta calidad naturalista de algunas piezas, tal es el caso de ejemplares identificados como frutos de L. siceraria dado que exhibían formas propias de los frutos de esta especie como la piriforme con cintura, la piriforme asimétrica y con 
protuberancias (ver lámina 16). Este criterio de semejanza formal fue empleado también en la identificación de otros taxa vegetales.

El modelado de lóbulos en los cuerpos de ciertas piezas se interpretó como representación de frutos domesticados de Cucurbita sp., ya que los mismos son los únicos que poseen dicho rasgo. Existen otras piezas que, sin embargo, no poseen modelado de lóbulos y que han sido consideradas aquí como representando también frutos de Cucurbitáceas. Resulta sumamente difícil atribuir la representación de un fruto liso y globoso en piezas cerámicas ya que las mismas suelen tener, por motivos funcionales, dicha morfología en el cuerpo (Orton et al 1997). Ante esta dificultad se consideraron, en primera instancia, las piezas con representación de frutos lobulados observando la morfología general de las mismas (forma y disposición del borde, cuello cuerpo y asa en conjunto) y los motivos plasmados sobre ellas, luego se asumió que piezas con cuerpos globosos o subglobosos que poseyeran igual morfología general y mismos motivos serían representaciones de frutos de cucurbitáceas lisas. También se asumió este criterio cuando el cuerpo globoso o subgloboso de la pieza estuviera decorado con franjas verticales que dividieran espacios a manera de lóbulos, aunque los mismos no estuvieran modelados. Se consideró representación de frutos turbanifomes cuando los lóbulos se representan de forma muy pronunciada y proyectados hacia fuera tal como ocurre en los ejemplares vegetales de esta clase de fruto (ver lámina 14).

\section{Resultados}

El resultado del relevamiento de objetos cerámicos resulto en una gran cantidad de piezas modeladas con forma de Cucurbitáceas según los criterios descriptos precedentemente (Tabla 62), siendo mucho menor el modelado de otras formas vegetales. Entre estas últimas podemos mencionar sólo dos: una 
vasija Río Diablo (MC1407) con cuerpo imitando un tubérculo (lámina 31) y una vasija de gran tamaño, también Río Diablo (MC 1147), cuyo cuerpo imita al tronco de un "palo borracho" (Chorisia speciosa) ${ }^{1}$ (lámina 31). También se reconoció la representación pintada de frutos y semillas de una leguminosa junto a un felino estilizado en una escudilla Aguada bicolor procedente de Pozo de Piedra (Catamarca) (MC 310) (lámina 31).

Entre las piezas que representan cucurbitáceas $(\mathrm{N}=26)$, podemos destacar la presencia de jarros con cuello abierto $(\mathrm{N}=8)$, jarros con cuello restringido $(\mathrm{N}=1)$, vasijas de cuello abierto $(\mathrm{N}=6)$, vasijas de cuello restringido $(\mathrm{N}=6)$, pucos $(\mathrm{N}=1)$ y vasos $(\mathrm{N}=4)$ (láminas 32 y 33). Estos últimos son todos representaciones de frutos de Lagenaria siceraria. Las representaciones de frutos lobulados corresponderían a C. moschata o a C. maxima ssp. maxima ya que son las únicas con esta clase de estructura, sin que se pueda precisar la identificación entre ambas debido a que ninguna de las piezas cerámicas posee representación del pedúnculo, al contrario de lo que ocurre en piezas peruanas. Sin embargo la representación de $C$ maxima ssp maxima estaría dada por la representación de frutos turbaniformes, exclusivos de esta especie.

Los motivos son mayormente incisos lineales y puntiformes, con una única pieza pintada y un sólo caso donde hay representación de un rostro humano al pastillaje. Se trata por lo general de piezas con buen acabado, salvo escasos ejemplares, de paredes delgadas. Muchas de ellas poseen tiznado externo con restos de hollín en el exterior, lo cual indicaría su carácter utilitario, al igual que la presencia de abundante mica en la pasta de algunas piezas, carácter que indica la preparación de la pieza para soportar exposición a altas temperaturas (Orton et al 1997). Es mayor la presencia de piezas con cuello abierto que restringido. Estas últimas poseen también restos de tiznado por lo cual, si se asume que piezas de cuello restringido fueron empleadas para contener líquidos más que para efectuar preparaciones en su interior dado el acceso

\footnotetext{
${ }^{1}$ Una bella pieza Condorhuasi pintada representando claramente el tronco de dicho árbol puede verse en el sitio www.cultura.gov.ar/traficoilicito/imagenes.
} 
restringido al mismo, estas piezas podrían haber sido empleadas para calentar líquidos.

La mayoría de las piezas pertenece a la fase Río Diablo de Condorhuasi, habiéndose registrado también piezas del estilo Aguada (Allpatauca inciso, gris liso y negro inciso tipo Ambato). La fase Río Diablo es la más temprana del estilo Condorhuasi (200 AC- 200 DC), siendo una de las primeras manifestaciones cerámicas del NOA (Caggiano y Sempé 1994). Los estilos Allpatauca inciso y Aguada gris liso representan las primeras manifestaciones de la entidad Aguada en los valles catamarqueños, el tipo Ambato, en cambio, es propio del Aguada clásico más meridional (Caggiano y Sempé 1994, González 1998).

El trabajo en museos permitió advertir también la presencia de representaciones de cucúrbitas en piedra pulida (lámina 34). Nuevamente la presencia de lóbulos hace pensar en la representación de un fruto domesticado de Cucurbita sp. en un recipiente o fuente de piedra (MQ131) Resulta sumamente interesante una mano de mortero pequeña (MC 129) que posee la forma de un pedúnculo de C. moschata (lámina 34). Esta identificación se fundamenta en la presencia de costillas y en la expansión observable en la base de la mano, la cual correspondería a la inserción del pedúnculo con el fruto; estas dos características son propias del pedúnculo de C. moschata (ver capítulo 4.1.1e). La presencia de esta pieza lleva a considerar que otras manos de mortero de forma y tamaño similar como la $\mathrm{N}^{\circ} 144$ del Museo Adan Quiroga (lámina 34) podría representar un pedúnculo de $C$. maxima ssp. maxima dada la ausencia de representación de costillas.

De acuerdo con su morfología todas estas piezas de lapidaria serían de filiación Condorhuasi.

Lamentablemente las piezas analizadas en ambos museos catamarqueños pertenecen a colecciones privadas (colección Cura en el caso del Museo Condorhuasi y colección del Padre Narváez en el caso del Museo Adán 
Quiroga) por lo que no se cuenta con datos de procedencia y mucho menos contextuales. El hecho de que se trate de piezas completas en buen estado de preservación hace pensar que las mismas pudieron haber sido parte de ajuares funerarios. En este último caso la presencia de ceramios cuya forma asemeja a la de frutos lobulados de Cucurbita en la colección Muñiz Barreto del Museo de La Plata confirmaría la depositación de esta clase de piezas como acompañamiento funerario en tumbas de los períodos Condorhuasi y Ciénaga-Aguada. Por otra parte el registro de piezas con restos de hollín indica que probablemente las mismas fueron utilizadas en actividades cotidianas de cocción. La presencia de objetos de uso diario en tumbas, e incluso el empleo como urnas funerarias para niños de piezas con evidencias de exposición al fuego y probable uso en actividades diarias de preparado de alimentos se registra también en Cienaga (González 1979), lo que indica que este no es un carácter excepcional o propio de los ceramios fitomorfos.

\section{Discusión}

A diferencia de lo que ocurre en los Andes centrales, los ceramios fitomorfos son muy escasos en el NOA, existiendo en cambio numerosas referencias a piezas con motivos zoomorfos o antropomorfos asignadas a distintas entidades culturales (Bregante 1926, González 1974, Sempé de Gomez Llanes 1984, Sempé 1993, entre otros).

La representación de frutos de cucurbitáceas y de otros taxa vegetales es una manifestación más de la tradición naturalista de representación mediante modelado que tuvieron las entidades formativas del NOA como Condorhuasi, Vaquerías, Candelaria, las del Valle de Santa María y Aguada (Kusch 1990, Korstanje 1998, Scattolin 2003, González 1998). Estas modelaron también otros objetos de uso cotidiano como hachas (pieza de la fase Río Diablo, MQ 590), además de animales y seres humanos con distintos atributos. El por qué se seleccionaron de manera casi exclusiva las 
cucurbitáceas para su representación constituye un interrogante, sin embargo probablemente se vincule a que éstas eran empleadas como recipientes, tal como vimos en el capítulo 4.1.1.d, función fácilmente analogable a las piezas cerámicas una vez que éstas comienzan a ser producidas.

La representación de cucurbitáceas modeladas en cerámica es patrimonio de entidades propias del área Valliserana del NOA como lo son Condorhuasi y Aguada, sin que se hayan reportado representaciones de esta clase en piezas Candelaria, entidad que también modeló distintas figuras de manera naturalista en sus piezas cerámicas (Scattolin 2003). Las piezas con representaciones de frutos de Cucurbita sp de la fase Río Diablo tendrían una cronología relativa próxima a la registrada para Pampa Grande (ver capítulo 3). Para los sitios del sector meridional del área valliserrana correspondiente a las provincias de Catamarca y La Rioja, estas piezas cerámicas ayudarían a confirmar la edad formativa de los restos de Cucurbita sp. recuperados en sitios con cronologías dudosas como Los Viscos.

Si bien existen representaciones modeladas de Cucurbitáceas en entidades culturales de Chile central que establecieron vínculos trasandinos, las representaciones registradas en las colecciones del NOA son estilísticamente propias de las entidades locales ya señaladas, sin que se evidencien influencias alóctonas en su diseño. Esto hace pensar en un referente natural local, es decir, frutos de C. moschata o de C. maxima ssp. maxima localmente cultivados, más que en la imitación formal de cerámica fitomorfa elaborada por otros grupos sociales. 
Tabla 62: piezas cerámicas registradas en los museos Condorhuasi (MC) y Adan Quiroga (MQ) y en la colección García Uriburu (C.G.U.) que representarían ejemplares de la familia Cucurbitáceae.

\begin{tabular}{|c|c|c|c|c|c|c|}
\hline $\begin{array}{c}\text { No }^{\circ} \\
\text { Pieza }\end{array}$ & $\begin{array}{c}\text { Caracterización } \\
\text { cerámica }\end{array}$ & Procedencia & $\begin{array}{c}\text { Adscripción } \\
\text { cultural }\end{array}$ & $\begin{array}{c}\text { Caracterización } \\
\text { botánica }\end{array}$ & $\begin{array}{l}\text { Taxón } \\
\text { representado }\end{array}$ & Observaciones \\
\hline $\begin{array}{l}\text { MC } \\
1412\end{array}$ & $\begin{array}{c}\text { Pieza modelada } \\
\text { oxidante } \\
\text { globular de } \\
\text { cuello } \\
\text { restringido y } \\
\text { labio evertido. }\end{array}$ & $\begin{array}{l}\text { Las } \\
\text { Barrancas, } \\
\text { Catamarca }\end{array}$ & $\begin{array}{c}\text { Aguada } \\
\text { (Allpatauca } \\
\text { inciso) }\end{array}$ & $\begin{array}{c}\text { Posee siete lóbulos } \\
\text { de } 6 \text { a } 8 \mathrm{~cm} \text { de } \\
\text { ancho. Semeja fruto } \\
\text { turbaniforme }\end{array}$ & $\begin{array}{l}\text { C. maxima } \\
\text { ssp maxima. }\end{array}$ & $\begin{array}{c}\text { Tiznado leve en } \\
\text { base y cuerpo }\end{array}$ \\
\hline $\begin{array}{l}\text { MC } \\
677\end{array}$ & $\begin{array}{l}\text { Pieza reductora, } \\
\text { gris, exterior } \\
\text { pulido, interior } \\
\text { alisado, asa } \\
\text { acintada } \\
\text { vertical, cuello } \\
\text { recto con rostro } \\
\text { humano al } \\
\text { pastillaje }\end{array}$ & & Condorhuasi & $\begin{array}{c}\text { Posee ocho } \\
\text { incisiones verticales } \\
\text { que delimitarían } \\
\text { lóbulos de entre } 4,5 \text { y } \\
6 \mathrm{~cm} \text { de ancho }\end{array}$ & $\begin{array}{l}\text { C. maxima } \\
\text { ssp maxima o } \\
\text { C. moschata }\end{array}$ & \\
\hline $\begin{array}{l}\text { MC } \\
885\end{array}$ & $\begin{array}{c}\text { Jarra reductora } \\
\text { subglobular gris } \\
\text { incisa, cuerpo } \\
\text { modelado, } \\
\text { exterior pulido, } \\
\text { interior alisado, } \\
\text { borde levemente } \\
\text { evertido, asa } \\
\text { acintada } \\
\text { vertical, paredes } \\
\text { finas (3 mm), } \\
\text { gollete anular } \\
\text { entre cuello y } \\
\text { cuerpo }\end{array}$ & & $\begin{array}{l}\text { Condorhuasi } \\
\text { Río Diablo }\end{array}$ & $\begin{array}{l}\text { Posee quince lóbulos } \\
\text { de } 3 \mathrm{~cm} \text { de ancho. } \\
\text { Semeja fruto } \\
\text { turbaniforme }\end{array}$ & $\begin{array}{l}\text { C. maxima } \\
\text { ssp maxima }\end{array}$ & \\
\hline
\end{tabular}


Jarra reductora subglobular gris incisa, cuerpo modelado,

exterior pulido, interior alisado,

MC borde levemente

1084 evertido, asa acintada

vertical, paredes finas $(3 \mathrm{~mm})$, doble gollete anular entre cuello y cuerpo

Vaso modelado reductor gris

MC inciso, exterior pulido, interior alisado

Pieza modelada oxidante, interior marrón alisado exterior rojizo alisado, cuello recto con motivos pintados en color rojo oscuro

Jarra reductora globular gris,

MC exterior pulido,

1141 interior alisado asa acintada vertical, borde evertido.

Vaso reductor gris inciso,

exterior pulido,

1413

interior alisado, asa como

prolongación del cuerpo

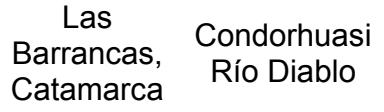

Las

Barrancas,

Catamarca

Condorhuasi

Río Diablo

Condorhuasi
Río Diablo
Representación de fruto piriforme

Lagenaria siceraria

Posee un orificio oval en el tercio inferior del cuerpo
Posee seis lóbulos, entre 6,5 y $8 \mathrm{~cm}$ de ancho

C. maxima ssp maxima o C. moschata
Base muy tiznada, pasta con mucha mica.

\section{Aguada}

\section{Cuatro depresiones}

C. maxima profundas marcarían ssp maxima o C. moschata

Tiznado en el límite de lóbulos
Jarra reductora gris modelada, exterior pulido, interior alisado, cuello recto con MQ motivos incisos,

608 asa acintada vertical, gollete anular entre cuello y cuerpo, paredes finas ( 3 $\mathrm{mm}$.)
Posee veintitrés

Condorhuasi lóbulos, con un ancho Río Diablo de 2,5 a $3 \mathrm{~cm}$ cada uno
Tiznado en todo C. maxima el cuerpo de la ssp maxima o pieza y en un C. moschata sector hasta el 
Jarra reductora gris modelada,

interior alisado,

cuello recto con motivos incisos,

falta el asa

Pieza globular modelada

oxidante de cuello

$M Q$ restringido,

619 exterior pulido, color ante,

motivos incisos, borde levemente evertido

Jarra globular de cuello restringido,

$M Q$ reductora, gris

608 (2) incisa, exterior pulido, asa vertical acintada

Pieza globular modelada oxidante de cuello restringido

MQ evertido con

616 gollete anular entre este ultimo y el cuerpo, decoración mediante peinado

Pieza globular modelada

MQ reductora de cuello recto restringido levemente evertido

Puco reductor gris, exterior pulido, interior alisado

Jarra globular reductora gris, exterior pulido,

MQ interior alisado, incisa, asa vertical

acintada, cuello recto, levemente evertido
Posee treinta y tres

Condorhuasi lóbulos, con un ancho Río Diablo de entre 2 y $2,5 \mathrm{~cm}$. cada uno

C. maxima ssp maxima o C. moschata

Cuatro incisiones profundas marcan

Condorhuasi lóbulos con motivos Río Diablo incisos idénticos, ente 17 y $20 \mathrm{~cm}$ de ancho

Tiznado en todo el cuerpo y

C. maxima sp maxima cuello, parece C. mosinacto de la cocción de la pieza.
Cuerpo globular sin lóbulos con idénticos

Condorhuasi motivos incisos que

Río Diablo los presentes en los lóbulos del cuerpo de la pieza 619

Allpatauca

Posee ocho lóbulos

C. maxima

ssp maxima o Tiznado desde C. moschata
Posee cuatro lóbulos

Formativo temprano

Formativo temprano

Condorhuasi Río Diablo marcados por cuatro incisiones profundas en el cuerpo, ancho entre 15,5 y $17 \mathrm{~cm}$ ssp maxima o en toda la C. moschata superficie de la pieza

Posee veintiún lóbulos insinuados por incisiones gruesas, con un ancho de entre 2 y 3

C. maxima

ssp maxima o

C. moschata
Tiznado en base, cuerpo y cuello, incluso

Representación de fruto liso
Cucurbita sp. tores del interior de la pieza 
Pieza oxidante subglobular

modelada,

MQ cuello evertido

con gollete

anular entre

cuello y cuerpo,

paredes finas ( 3 $\mathrm{mm}$ )

\section{Pieza oxidante} subglobular

modelada,

cuello recto

MQ

levemente

evertido,

decoración

incisa en cuello

y cuerpo, interior

y exterior

alisados

Pieza oxidante globular

modelada,

$\mathrm{MQ}$ cuello evertido

2597 levemente restringido,

interior y exterior alisados

Jarra oxidante globular negra, exterior pulido,

$\mathrm{MQ}$ interior alisado,

2596 decoración

incisa, restos de asa vertical ausente

\section{Pieza negra} pulida con

$\mathrm{MQ}$ decoración incisa y asa como

protuberancia del cuerpo

Pieza globular modelada

oxidante ante con cuello

966 vertical y dos pequeñas asas horizontales a los lados

Formativo temprano

Formativo temprano

Posee ocho lóbulos con un ancho promedio de 4 a 4,5 $\mathrm{cm}$

C. maxima

Tiznado leve en

Posee seis lóbulos

Pasta con mucha mica

Tiznado en parte de la base C. maxima y en un par de ssp maxima o lóbulos. Restos C. moschata escasos de pintura roja
Formativo temprano

Aguada (Ambato)

Formativo temprano
Siete lóbulos insinuados en el tercio superior del cuerpo, posible imitación de fruto

C. maxima ssp maxima o C. moschata

Tiznado en turbaniforme

Diez secciones lisas separadas por bandas incisas, estas secciones no están abultadas, podrían

C. maxima

Belen representar lóbulos

ssp maxima

C. moschata

Fruto con protuberancia

Lagenaria siceraria 
Pieza

subglobular

modelada

$M Q$

oxidante roja

con cuello

999

vertical evertido,

gollete anular

entre cuello y

cuerpo abultado

Jarra

subglobular

oxidante incisa,

MQ exterior pulido,

972 interior alisado,

cuello recto

levemente

evertido

Pieza globular

reductora gris

incisa, exterior

pulido, interior

alisado, boca

amplia, asa

como

protuberancia

del cuerpo
Posee seis lóbulos

muy salientes, podría tratarse también de

Condorhuasi una representación de zapallo

turbaniforme

C. maxima

ssp maxima
Pieza

subglobular

modelada

reductora gris,

exterior pulido,

interior alisado,

C.G.U. cuello recto

evertido con

decoración

incisa, gollete

anular entre

cuello y cuerpo

con decoración

modelada
Condorhuasi
Río Diablo
Cinco secciones lisas separadas por dos

Formativo bandas incisas, estas C. maxima

temprano secciones no están ssp maxima o

C. moschata

representar lóbulos

Condorhuasi Fruto con Lagenaria

Río Diablo protuberancia siceraria 

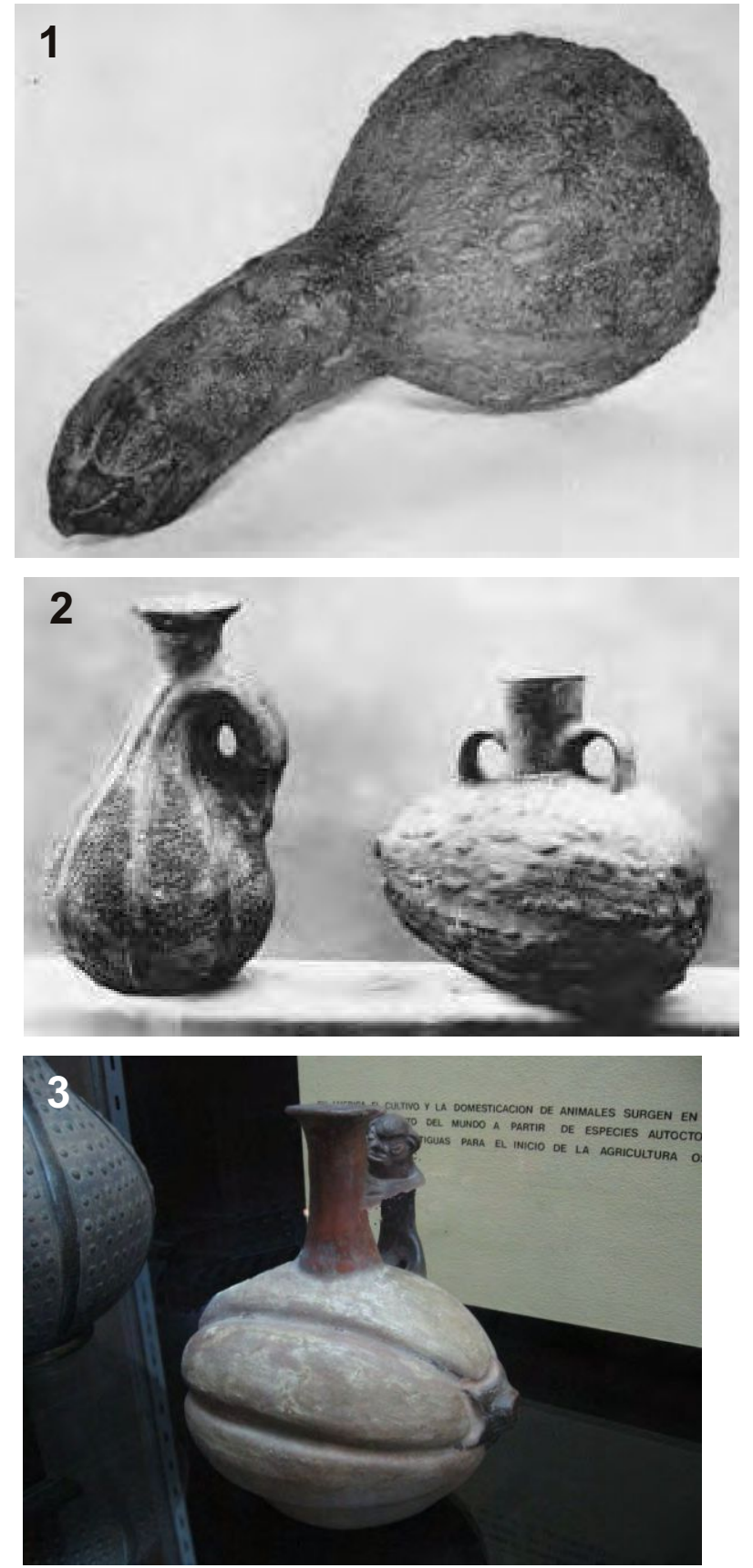

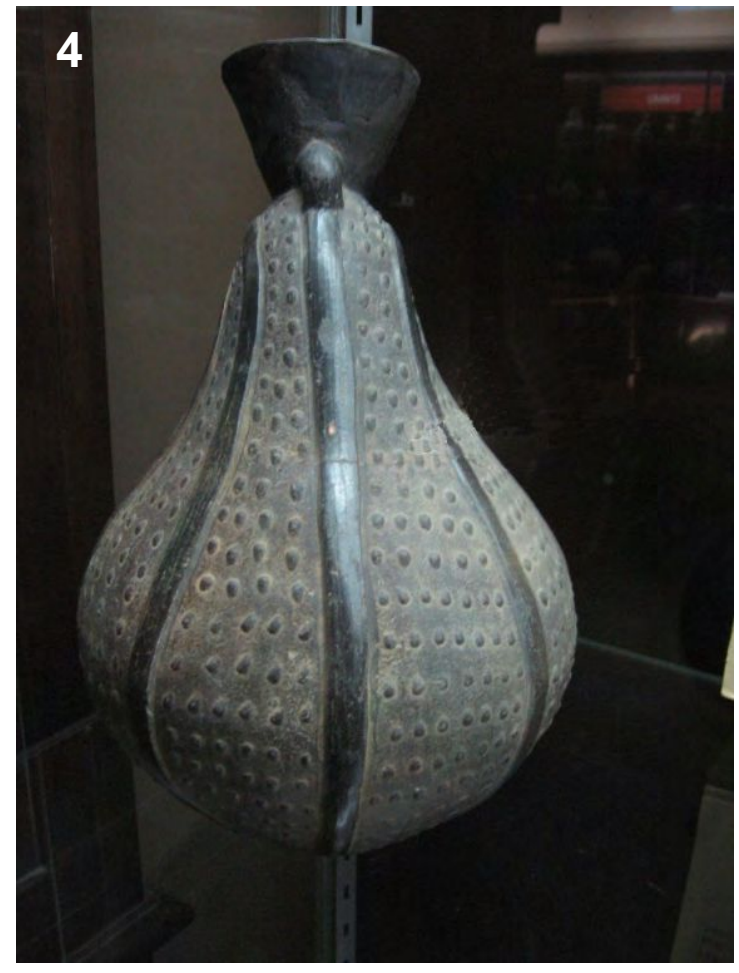

Ceramios fitomorfos de Perú representando frutos de Cucurbitaceae, 1 y 2: piezas modeladas de frutos verrugosos (Towle 1961) 3 y 4: modelado de frutos lobulados en piezas Moche (3) y Chimú (4), Museo de Ciencias Naturales de La Plata. En el caso de las piezas 1 y 3 la representación de pedúnculos coincide con los de $C$ moschata. 

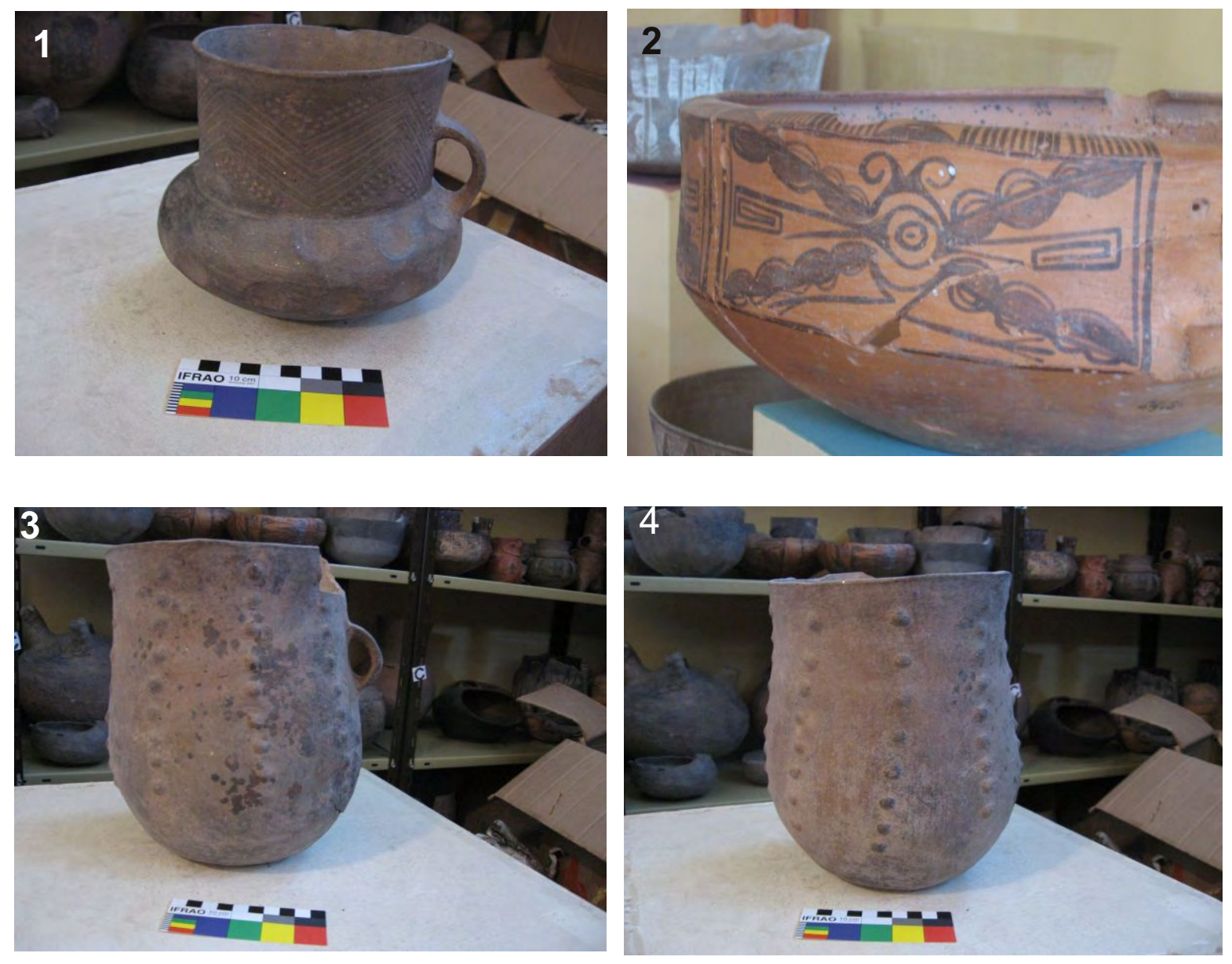

Representaciones vegetales en piezas cerámicas del Noroeste Argentino, 1: modelado de tubérculo (MC 1407); 2: representación pintada de fruto de leguminosa (MC 310); 3 y 4: modelado de tronco de Chorisia speciosa (MC 1147). 

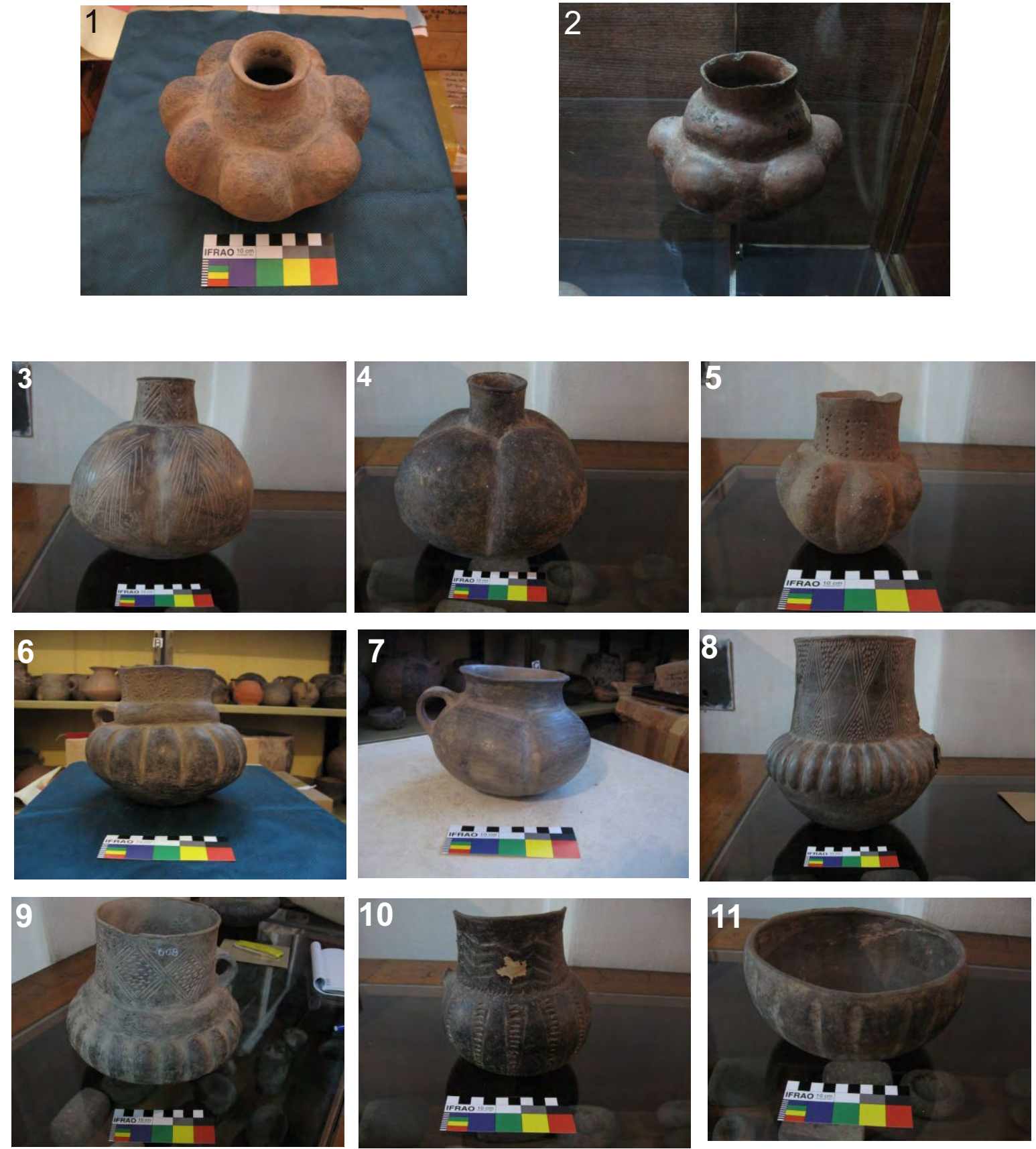

Ceramios del NOA con representaciones modeladas de frutos lobulados de Cucurbita sp, 1 (MC 1412) y 2 (MQ 999) representación de frutos turbaniformes; 3 (MQ 619) y 4 (MQ 3732) vasijas restringidas; 5 (MQ 613) vasija abierta; 6 (MC 885), 7 (MC 1141), 8 (MC 600), 9 (MQ 608) y 10 (MQ 2596) jarras abiertas; 11 (MQ 3078) puco. 

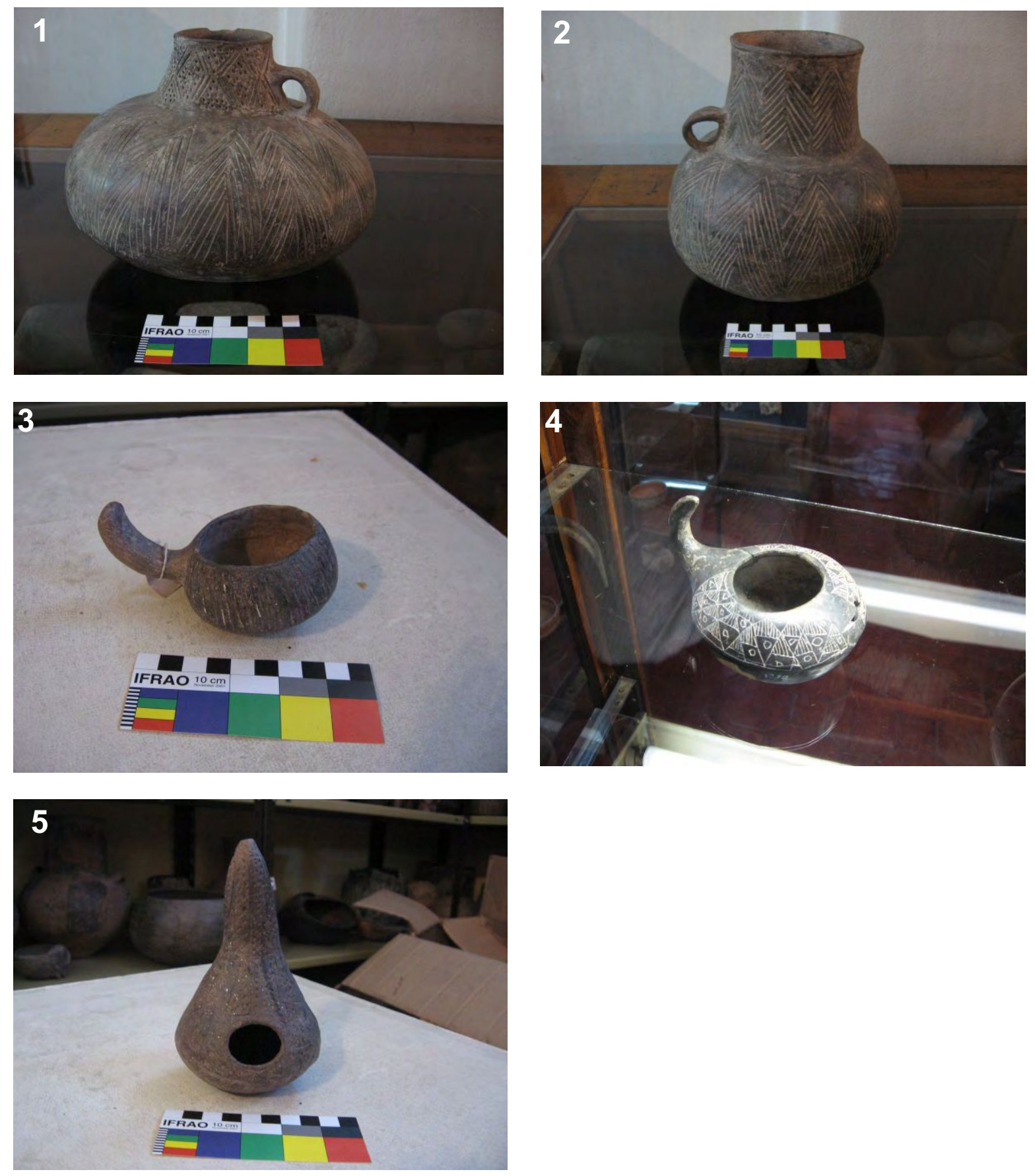

Ceramios fitomorfos del NOA, 1 (MQ 608 2) jarra restringida y 2 (MQ 617 ) jarra abierta representando probablemente frutos no lobulados de Cucurbita sp.; 3 (MC 1413), 4 (MQ 1279) y 5 (MC 515) piezas modeladas representando frutos de Lagenaria siceraria. 

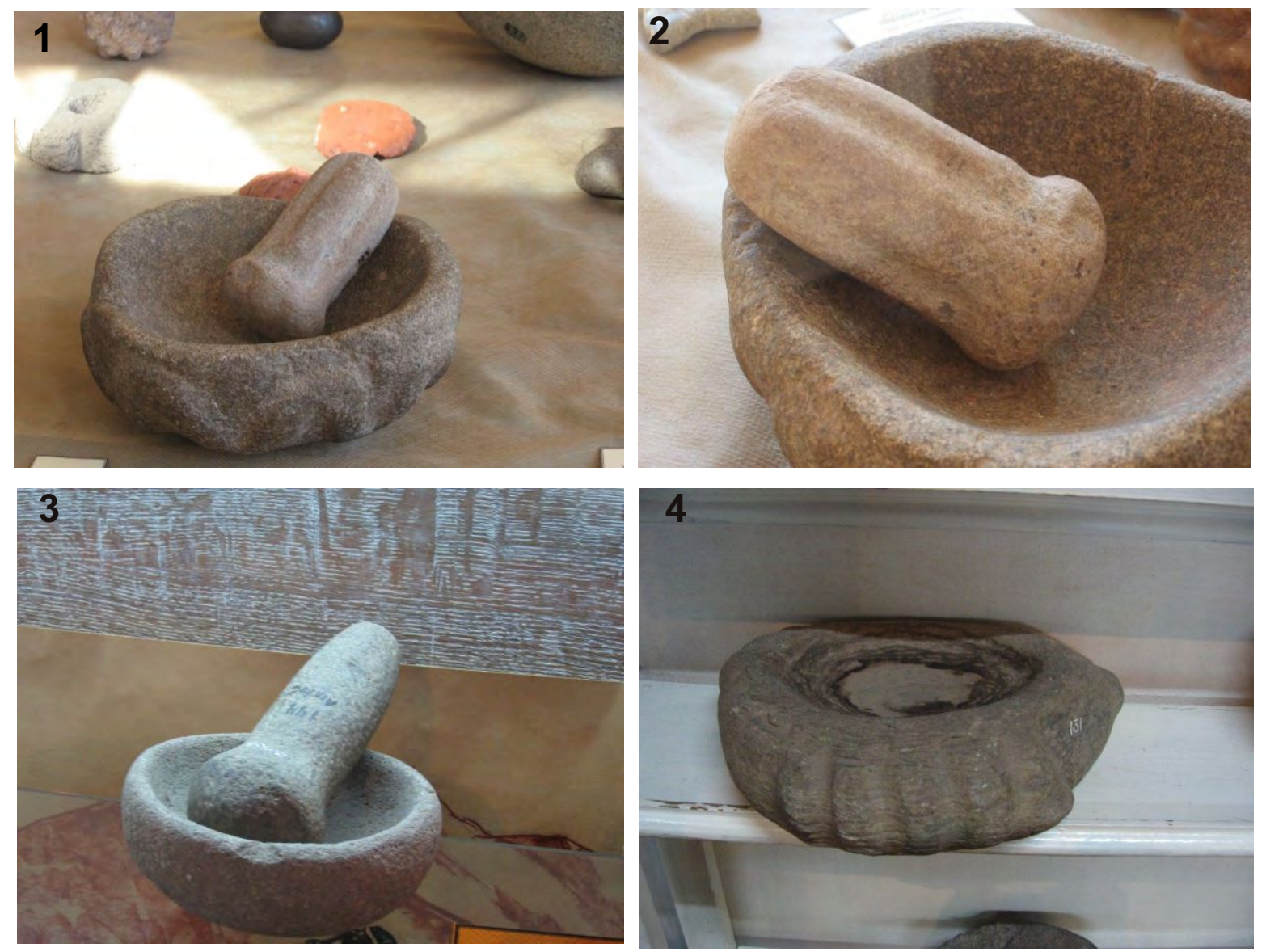

Piezas líticas pulidas con modeladas fitomorfos, 1 y 2 (MC 129): mano de mortero con modelado de pedúnculo de $C$ moschata; 3 (MQ 3035): mano de mortero con posible modelado de pedúnculo de C maxima ssp maxima; 4 (MQ 131) artefacto con modelado de fruto lobulado de Cucurbita sp. 


\subsection{2- GÉNERO PHASEOLUS.}

\section{Introducción}

Los restos arqueológicos del género Phaseolus suelen ser ubicuos en el noroeste argentino, habiéndose identificado tanto formas silvestres como domesticadas en sitios formativos con emplazamientos diversos (Oliszweski 2004, Babot et al 2007). En este capítulo, y a partir de una reinterpretación de evidencia arqueológica ya existente, y del análisis de restos arqueobotánicos correspondientes a semillas y frutos de dicho género, se indagará sobre la existencia de formas diversas de manejo de poblaciones del género Phaseolus en el pasado prehispánico del NOA. Se investigará en particular las modificaciones de las estructuras reproductivas en macrorrestos de este género ya que las mismas brindan datos cruciales para interpretar grados de dependencia ser humano-planta.

\section{La domesticación de Phaseolus sp. en Sudamérica.}

El género Phaseolus es exclusivamente americano, pertenece a la familia Fabaceae e incluye unas cincuenta especies, siendo las domesticadas: Phaseolus vulgaris L var vulgaris ("poroto comun"), Phaseolus lunatus L ("poroto manteca" o "poroto de Lima"), Phaseolus coccineus L ("poroto pallar") y Phaseolus acutifolius A. Gray ("poroto teparí") (Menéndez Sevillano 2002) y algunos autores reconocen también una quinta especie $P$. polyanthus Greeman en Mesoamérica (Debouck www.rlc.fao.org, consultado diciembre 2008). En este capítulo nos centraremos en las dos primeras especies mencionadas puesto que existen antecedentes arqueológicos de su presencia en sitios arqueológicos del NOA. Desde la década del setenta se reconoce la existencia de dos grupos de germoplasma, tanto en formas silvestres como domesticadas de P. vulgaris: uno 
andino (abarcando principalmente los territorios de Perú, Bolivia y Argentina) y uno mesoamericano (fundamentalmente Méjico, Centroamérica y Colombia) (Kami et al. 1995, Piperno y Pearsal 1998, Aguilar et al. 2004). Ambos grupos difieren por caracteres morfológicos, agronómicos, bioquímicos y moleculares, lo cual sugeriría al menos dos centros de domesticación (Menéndez Sevillano 2002). Las poblaciones silvestres andinas, por ejemplo, poseen semillas más grandes respecto de las del grupo mesoamericano, lo cual podría ser el resultado de la adaptación de estas formas a ambientes forestados, puesto que las poblaciones de Phaseolus sp. que habitan en ambientes abiertos poseen semillas más pequeñas (Koenig et al. 1990 en Piperno y Pearsall 1998, Gepts y Debouck 1991).

Recientemente en semillas silvestres de poblaciones ecuatorianas y del norte de Perú se detectó un pool génico intermedio entre ambos grupos y de mayor antigüedad respecto a éstos, sugiriendo que puede tratarse de un relicto del acervo genético original que dio origen a los germoplasmas andino y mesoamericano (Menéndez Sevillano 2002). Los marcadores de faseolina concuerdan en que el sector meridional de los Andes fue el principal centro de domesticación en Sudamérica, siendo el norte de Colombia-Centroamérica un centro menor (Gepts 1990 en Piperno y Pearsall 1998). Estos centros de domesticación y diversificación se evidencian también en que las poblaciones de Phaseolus vulgaris var. aborigineus (Burk.) Baudet de cada uno poseen una historia de simbiosis y coevolución con distintas especies de Rhizobium spp. (Aguilar et al. 2004). Actualmente -teniendo en cuenta evidencias botánicas, arqueológicas, bioquímicas y lingüísticas- se acepta una domesticación múltiple e independiente de este género, reconociéndose al menos tres eventos de domesticación a partir de poblaciones silvestres locales que habrían tenido lugar en el centro-oeste de México o Guatemala, en el norte de Colombia y en el sur de Perú/Bolivia (Gepts y Debouck 1991, Piperno y Pearsall 1998) (Figura 31). 
El NOA representa el límite sur del centro andino de domesticación vegetal, existiendo en dicha región poblaciones silvestres de P. vulgaris var. aborigineus, el antecesor de P. vulgaris var. vulgaris (Brücher y Berglund-Brücher 1976, Menéndez Sevillano 2002). La variedad aborigineus crece en los valles húmedos de la Cordillera Oriental de los Andes, entre los 700 y $2600 \mathrm{msm}$ y entre los $22^{\circ}$ y $27^{\circ} \mathrm{S}$ y $66^{\circ} 30^{\prime}$ y $63^{\circ} 00^{\prime} \mathrm{W}$, abarcando las provincias fitogeográficas de Yungas, Prepuna y Monte, llegando en su distribución más austral hasta las provincia de Córdoba y San Luis (Brücher y Berglund-Brücher 1976, Brücher 1989, Menéndez Sevillano 2002, Drewes 2006). Las poblaciones de porotos silvestres del NOA representan un caso particular dentro del taxón debido al aislamiento ambiental en el cual se encuentran (Aguilar et al 2004).

A pesar de que los porotos domesticados muestran una gran diversidad fenotípica, comparados con los porotos silvestres presentan una baja diversidad genética, lo que en opinión de Gepts (1991 en Piperno y Pearsall 1998) implica que los distintos eventos de domesticación involucraron poblaciones silvestres circunscriptas que representaban sólo una fracción de toda la diversidad presente en el taxón silvestre.

El antecesor silvestre de Phaseolus lunatus L ("poroto manteca" o "poroto Lima"), Phaseolus lunatus L. var sylvester Baudet, crece en altitudes bajas a medias, en ambientes estacionales secos de sabanas y montes en Centroamérica, el Caribe y los Andes, distribuyéndose en esta última región desde Colombia hasta Argentina (provincia de Chaco, Jujuy y Salta) (Piperno y Pearsall 1998, Zuloaga y Morrone 1999). Uno de los principales criterios que se ha utilizado para explicar el origen y la diversidad de Phaseolus lunatus es el estudio de la variación de las características morfológicas en sus semillas, demostrándose que el morfotipo "Lima" o "Pallar", que presenta semillas relativamente grandes, pertenece al reservorio genético andino, en tanto los morfotipos "Potato" (con semillas pequeñas) y "Sieva" (de tamaño intermedio) pertenecen al reservorio de Mesoamérica (Vargas et al 2003) 
(Figura 32). Un aspecto interesante de este taxón silvestre es que posee en sus semillas altos niveles de faseolunatina la cual produce por hidrólisis cianuro, compuesto tóxico que no puede ser completamente eliminado por métodos de desintoxicación tradicionales, volviendo sus semillas imposibles de ser consumidas (Piperno y Pearsall 1998) ${ }^{1}$. Las poblaciones escapadas de cultivo de $P$. lunatus o las malezas producto de su hibridación con poblaciones silvestres, poseen también este principio tóxico por lo cual son erradicados de los campos sembrados por los campesinos peruanos (Debouck et al 1987)

Bajo cultivo $P$. lunatus tolera un gran rango de condiciones climáticas siendo capaz de tolerar ambientes más húmedos que $P$. vulgaris var. vulgaris, aunque requiere de un clima seco para la maduración de sus semillas (Purseglove 1968 en Piperno y Pearsall 1998).

Manejo humano de poblaciones de Phaseolus sp: complejo "maleza -cultivodomesticado"

En los sistemas de siembra tradicionales plantas domesticadas y sus parientes cultivados y/o malezoides co-existen y co-evolucionan a lo largo del tiempo incluidos en una esfera de interacción con comunidades humanas. De manera inadvertida y a través de la estrategia de no mantener campos sembrados "limpios" - es decir, con conjuntos homogéneos de plantas domesticadas aisladas- las poblaciones humanas aumentaron el flujo génico entre las plantas domesticadas y sus parientes no domesticados. Este mantenimiento de complejos donde hay cruza, y por ende intercambio genético, se ha reconocido como un mecanismo para la generación de variabilidad en cultivos locales (Harlan 1992), siendo particularmente frecuente en sistemas hortícolas (Harris 1989). Existen varios casos en Méjico donde se permite adrede que crezcan malezas o plantas silvestres relacionadas a los cultivos a fin de que se

\footnotetext{
${ }^{1}$ P. vulgaris var aborigineus no posee semillas tóxicas o amargas, siendo perfectamente consumibles sin requerir ningún tipo de pre-tratamiento (Brücher y Berglund- Brücher 1976).
} 
hibriden, generándose así una mayor variabilidad sobre la cual poder seleccionar luego. Este fenómeno de alentar la presencia de ciertas malezas sería una domesticación progresiva (Altieri y Merrick 1987), en tanto se comienzan a realizar actividades de cultivo. La domesticación de Phaseolus no sólo se da actualmente por una extensión de los cultivos de la especie domesticada, sino también por una constante cruza con poblaciones silvestres (Beebe et al. 1997, Piperno y Pearsall 1998).

En el caso de P. vulgaris var. aborigineus -y a diferencia de C. maxima ssp. andreana- existen registros claros y abundantes de poblaciones silvestres fuera de los hábitats antrópicos, en las laderas orientales andinas (Brücher y Berglund-Brücher 1976, Menéndez Sevillano 2002, Drewes 2006). Sin embargo, existen también registros de poblaciones que prosperan en áreas cultivadas (Freyre et al 1996, Gepts y Debouck 1991, Menéndez Sevillano 2002). Por lo tanto P. vulgaris var. aborigineus puede considerarse también como una maleza en el sentido dado al término en el capítulo 1 de esta tesis. Al igual que en el caso de las subespecies de C. maxima no existen barreras reproductivas entre las dos variedades de P. vulgaris, lo cual genera frecuentes cruzas entre los mismos con la consecuente generación de descendencia viable, lo cual lleva a que ambos pertenezcan a la misma especie biológica (Gepts y Debouck 1991).

En un trabajo de campo realizado en 1997 Menéndez Sevillano (2002) detecta en las localidades de Arazay, La Misión y Los Toldos, en el oriente salteño, poblaciones de P. vulgaris var aborigineus mezcladas con los cultivos locales, afirmando que se trataría de "variedades silvestres y tipos intermedios en pleno proceso de domesticación” (Menéndez Sevillano 2002:153). La autora considera que esto representa uno de los denominados complejos "malezacultivo-domesticado" tales como los observados en poblaciones de P. vulgaris y P. lunatus del área Andina, principalmente en Bolivia, Perú y Colombia (Freyre et al 1996, Beebe et al 1997) y también en Mesoamérica (Papa y Gepts 
2003, Martínez Castillo et al 2007). La autora halló también "tipos intermedios" en otras localidades salteñas como Campo Quijano y Quebrada del Toro (Menéndez Sevillano 2002). La explicación para las variedades silvestres presentes entre los cultivos locales en Los Toldos sería que los pobladores locales traen ejemplares del cercano Parque Nacional Baritú (Yungas), lo cual justificaría también los tipos intermedios ya que, según los lugareños, "al traer el poroto del zorro (uno de los nombres que le dan a la forma silvestre) de Baritú, a Los Toldos, se engorda" (Menéndez Sevillano 2002:154).

También en Salta otros autores mencionan la frecuente hibridación entre $P$. vulgaris var. aborigineus con P. vulgaris var. vulgaris, P. augustii Harms. y cultivares primitivos de la región (Drewes 2006). Lamentablemente la autora no brinda mayores detalles acerca de los rasgos que caracterizan estos tipos intermedios. Teniendo en cuenta caracteres morfoagronómicos ${ }^{2}$, Menéndez Sevillano (2002) obtiene que las poblaciones de P. vulgaris var aborigineus del NOA se separan en dos grupos, uno aglutina las poblaciones muestreadas de Jujuy y Tucumán y el otro a las de Salta. Esto fue corroborado a nivel genético por Galvan (2006), ya que los análisis moleculares pusieron en evidencia que el patrón de distribución de la variabilidad genética de las muestras silvestres se asocia con la distribución geográfica de las mismas, siendo las de la provincia de Salta diferentes a las de Jujuy y Tucumán. A pesar de la autogamia teórica de P. vulgaris var. vulgaris hay gran cantidad de evidencia que señala que tanto la variedad silvestre como la doméstica exhiben variabilidad en el sistema reproductivo que permite el intercambio genético entre poblaciones (los rangos de cruzamiento pueden llegar a un 66,8\% de acuerdo con Beebe et al 1997), por ello pudo haber un flujo limitado de genes entre poblaciones próximas (en un radio de 100 m o menos, Freyre et al. 1996) que produjera patrones de variación diferentes en lugares distantes aislados por la orografía

\footnotetext{
${ }^{2}$ Caracteres de los cultivos locales salteños: anuales, completan el ciclo de madurez total en no menos de 130 días por lo cual son de ciclo muy largo, lo que es de esperarse ya que son de crecimiento indeterminado trepador. Caracteres de las formas silvestres: anuales, completan el ciclo de madurez total en 148 días o más (Menéndez Sevillano 2002)
} 
del NOA (Menéndez Sevillano 2002). El aislamiento geográfico favorecido por la topografía del NOA habría conducido al mantenimiento de genotipos y morfologías distintivas de cada ecoregión, y cierto grado de fecundación cruzada sumada al flujo génico entre poblaciones cercanas habría mantenido la variabilidad intrapoblacional observada en los porotos silvestres (Galvan 2006).

El análisis de las cultivares locales, procedentes sobre todo de localidades salteñas, mostró un sistema de producción donde se mantiene una alta variabilidad, otorgándosele mayor plasticidad al cultivo (Menendez Sevillano 2002). Esto comprobaría la afirmación de que tasas bajas de cruzamiento son suficientes para generar una amplia variabilidad (Beebe et al. 1997). Sin embargo, tanto en el caso de $P$. lunatus como en el caso de $P$. vulgaris var. vulgaris se ha visto que existe un flujo génico desigual, siendo preponderante la fijación de genes de poblaciones domesticadas en poblaciones silvestres (Papa y Gepts 2003, Martínez Castillo et al 2007). A su vez esta elevada variabilidad genética dentro de las localidades se contrapone a una baja diferenciación entre ellas, pudiendo deberse esto último a una selección homogénea ejercida por los productores en los distintos ambientes y al frecuente intercambio de semillas entre los agricultores del área (Galvan 2006).

Cruzas entre poblaciones silvestres y cultivadas generadoras de complejos "maleza-cultivo-domesticado" fueron identificadas también cerca de Tarija, Bolivia (Freyre et al. 1996). Estas poblaciones poseían ejemplares intermedios de hábito trepador, con semillas del tamaño de las cultivadas, pero de color "agouti" (termino usado para animales pelaje a rayas marrones y blancas) blancas con líneas oscuras o bien marronáceas con puntos o líneas negras; estas plantas son denominadas por los autores como "formas malezoides regresivas" y crecen en ámbitos antrópicos disturbados como basureros y límites de campos de cultivo (Freyre et al. 1996). Estas "formas malezoides" son difíciles de clasificar taxonómicamente sin que esté aún claramente 
establecido si se deben considerar como P. vulgaris var aborigineus (Gepts y Debouck 1991). Estudios genéticos realizados en poblaciones mesoamericanas muestran que estas malezas poseen componentes genéticos tanto de la variedad silvestre como de la especie domesticada, por lo cual serían el resultado de la hibridación entre ambas y no de escapes de cultivo de la especie domesticada (Papa y Gepts 2003). Los escapes de cultivo de hecho existen, pero no logran sobrevivir más de tres años alejados del área de dispersión del taxón silvestre (Gepts y Debouck 1991).

El modelo propuesto por Beebe et al (1997) parte del complejo malezacultivo-domesticado interpretando que las razas malezoides surgen de cruces entre cultivares locales y formas silvestres simpátricas (coexistiendo en un área que puede ir desde $1 \mathrm{~m}$ a $3 \mathrm{~km}$ ); estas malezas (correspondientes al tipo 2 de Harlan y de Wet 1975, ver capitulo 4) se cruzan a su vez con las formas silvestres y domesticadas que les dieron origen, generando lo que los autores denominan un "enjambre de híbridos" (Beebe et al. 1997). Si predomina la selección natural este conjunto puede derivar en o contribuir a la diversidad genética de poblaciones silvestres, si, en cambio, predomina la selección cultural directa (de caracteres deseados) o indirecta (perturbación creciente del medio) el conjunto de híbridos podría derivar en formas cultivadas: "si los agricultores pueden beneficiarse de las variantes así generadas, la presencia de complejos maleza-cultivo-domesticado puede ser indicativo de que está teniendo lugar una actividad de domesticación en progreso" (Beebe et al 1997:74) "en la cual la domesticación no se da en un punto dado del tiempo, sino como un proceso dinámico resultante de selección, hibridación y reselección a lo largo de muchos años" (ibidem:88, n.t.). La evolución de los complejos maleza-cultivo-domesticado depende de que los cultivadores protejan o alienten la presencia de formas híbridas en las áreas cultivadas (actualmente en poblaciones andinas se ha visto que al momento de consumir las semillas y/o vainas no se discrimina entre ejemplares con distinto grado de 
dependencia), y de que dichas áreas posean límites difusos con las zonas de vegetación natural, una intervención limitada del Hombre, así como la aplicación de tecnología rudimentaria (Beebe et al 1997). Los autores mencionados notan que actualmente las influencias externas llevan a que los campesinos dejen este sistema de cultivo tradicional buscando líneas puras de plantas domesticadas con los caracteres deseados por el mercado, lo cual implica la selección desfavorable de híbridos, la erradicación de poblaciones silvestres cercanas a las áreas sembradas y la eliminación de ciertos rasgos morfológicos (como semillas de color oscuro). Esta misma situación es la que se observa actualmente en la comunidad campesina de El Shincal, Catamarca, respecto de los cultivos de P. vulgaris var. vulgaris (ver capítulo 5).

Por lo tanto en el análisis de ejemplares arqueológicos de Phaseolus sp. se buscará detectar este complejo maleza-cultivo-domesticado a fin de inferir procesos de domesticación que probablemente no hayan sido lineales -en el sentido de que no representan una sucesión progresiva de estadíos en un continum unidimensional- en el pasado prehispánico del NOA. Para ello es necesario contar con parámetros para distinguir formas silvestres, domesticadas, malezas y cultivos.

El "síndrome adaptativo de la domesticación" en Phaseolus sp.

El conjunto de modificaciones que se acepta ha ocurrido entre las formas silvestres y domesticadas del género Phaseolus en general y de Phaseolus vulgaris en particular son:

-el hábito de crecimiento pasa de indeterminado a determinado y arbustivo (Brücher y Berglund-Brücher 1976, Smartt 1988 en Galvan 2006, Gepts y Debouck 1991, Epimaki et al 1996). Si bien el hábito arbustivo se encuentra sólo en formas domesticadas, éstas pueden poseer también hábito 
indeterminado tal como sucede en el caso de las poblaciones de P. vulgaris var. vulgaris del NOA (Menéndez Sevillano 2002).

-pasan de ser perennes a anuales (Kaplan 1965).

-insensibilidad al fotoperíodo (Brücher y Berglund-Brücher 1976, Smartt 1988 en Galvan 2006, Gepts y Debouck 1991). P. vulgaris var. aborigineus florece sólo en días cortos, por lo general P. vulgaris var. vulgaris florece y madura antes (Epimaki et al 1996).

-semillas más grandes y con mayor diversidad de colores (Brücher y BerglundBrücher 1976 Epimaki et al 1996; Gepts y Debouck 1991 y Smartt 1988 en Galvan 2006).

-semillas más permeables (Brücher y Berglund-Brücher 1976, Epimaki et al 1996; Gepts y Gebouck 1991 y Smartt 1988 en Galvan 2006), la disminución en las cubiertas ocasiona reducción en la dormancia y crecimiento más rápido (Kaplan 1965).

-vainas indehiscentes debido a la reducción en las fibras que las componen o a su total pérdida (Brücher y Berglund-Brücher 1976, Kaplan 1965, Smartt 1988 en Galvan 2006, Gepts y Debouck 1991, Epimaki et al 1996).

-vainas más grandes (Brücher y Berglund-Brücher 1976, Epimaki et al 1996). Vainas silvestres de 6 a $10 \mathrm{~cm}$ de largo y $1 \mathrm{~cm}$ de ancho y domesticadas entre 4 y $30 \mathrm{~cm}$ de largo (Brücher y Berglund-Brücher 1976, Gepts y Gebouck 1991 y Smartt 1988 en Galvan 2006). En este sentido es común que la variabilidad de la forma domesticada incluya a la silvestre en cuanto a parámetros cuantitativos (Galvan 2006). 
-pérdida de pigmentación (antocianinas) y reducción del contenido de sustancias tóxicas de la cubierta seminal, disminuyendo la protección de las semillas frente a predadores, pero mejorando el sabor (Brücher y BerglundBrücher 1976, Epimaki et al 1996; Smartt 1988 en Galvan 2006).

Las investigaciones genéticas sobre este síndrome realizadas por Epimaki et al. (1996) en Phaseolus indican que los rasgos vinculados a la domesticación son la manifestación de unos pocos genes con grandes efectos, los cuales se concentran en 3 de los 11 grupos de ligamiento que posee $P$. vulgaris. Esto indicaría que el proceso de domesticación en esta especie no habría sido el producto de la acumulación gradual de numerosos genes de efectos limitados, sino la fijación relativamente rápida de unos pocos genes de efectos mayores, suponiendo una alta intensidad de selección (Epimaki et al. 1996). Sin embargo, el hecho de que las formas silvestre y domesticada fueran simpátricas e interfértiles y que por lo tanto haya habido cruzamiento entre ellas, dificultaría la fijación de los rasgos señalados (Epimaki et al 1996). En los complejos maleza-cultivo-domesticado Beebe et al. (1997) distinguen las plantas silvestres por sus vainas cortas y fuertemente dehiscentes y por sus pequeñas semillas blancas, crema, marrones, negras o grises moteadas; las malezas difieren de las plantas silvestres por tener vainas y/o semillas más grandes, a pesar de que las primeras son a menudo también dehiscentes. Freyre et al (1996) señalan también la presencia de semillas del tamaño de las cultivadas en las malezas, pero con patrones de color del tipo silvestre. De acuerdo con Beebe et al. (1997) los signos de introgresión consistirían en semillas de porotos domesticados más chicas que el rango existente en el conjunto cultivado y porotos silvestres con semillas más grandes respecto del rango de tamaño registrado en la población natural. 
En opinión de Gepts y Debouck (1991) existen diversas causas que podrían dar cuenta del aumento en el tamaño de las semillas (y consecuentemente de las vainas, ya que ambas se encuentran correlacionadas según estos autores):

1) Podría ser el resultado de la particularidad del sistema de plantación americano donde la siembra individualizada de escasas semillas habría favorecido la etapa de selección de genotipos con semillas más grandes.

2) Las semillas más grandes tendrían ventajas adaptativas dado el mayor contenido de sustancias de reserva, las cuales son usadas durante la germinación, sobre todo cuando la germinación es lenta como en el caso de climas fríos en latitudes o altitudes elevadas. Esto explicaría la predominancia de plantas domesticadas con semillas grandes en las partes más altas y frías de Sudamérica.

3) Por cruzamientos naturales entre individuos de la misma o de diferentes poblaciones de porotos silvestres, seguido por selección cultural de los recombinantes.

\section{Análisis y caracterización de semillas de Phaseolus sp.}

La tesis de Menéndez Sevillano (2002) constituye un material de inestimable utilidad para el estudio de muestras arqueobotánicas del NOA ya que brinda una muy valiosa información de referencia. Esta autora analiza muestras actuales de cultivares locales (que llama "variedades primitivas") de P. vulgaris var. vulgaris del NOA, así como también de poblaciones silvestres de P. vulgaris var aborigineus de la misma región. Los criterios empleados por esta investigadora para el análisis morfológico de fruto y semillas son tomados de Puerta Romero (1961 en Menéndez Sevillano 2002). A continuación describiremos los resultados obtenidos por esta investigadora, los que constituirán la base de referencia para el análisis de restos arqueobotánicos. 
En el caso de los ejemplares domesticados el 78\% procede de la provincia de Salta (Iruya y Santa Victoria), el 19\% de Jujuy (Humahuaca, Tilcara y Yavi) y el 3\% de la provincia de Catamarca (Belén). Los rasgos que caracterizan las semillas de los mismos son:

Largo: entre 9,9 y $16,3 \mathrm{~mm}$

Ancho: entre 7 y $9,6 \mathrm{~mm}$

Grosor: entre 4,7 y $7,3 \mathrm{~mm}$

El 67\% de las semillas tienen una longitud menor a $13 \mathrm{~mm}$ mientras que el $33 \%$ restante es mayor de $13 \mathrm{~mm}$

Forma: La misma se establece a partir de dos índices (Tabla 63 y 64)

Los resultados obtenidos para las formas domesticadas del NOA fueron:

a) Índice J: 60\% son elípticas

$32 \%$ son oblongas

$8 \%$ son esféricas

b) Índice H: $72 \%$ son semillenas

$18 \%$ son aplanadas

$10 \%$ son llenas

Color: gran variedad, $43 \%$ con color primario blanco, $20 \%$ con tonalidades anaranjadas, $25 \%$ con tonos marrones y $9 \%$ con tonos amarillos. El $71 \%$ presenta algún tipo de diseño.

En el caso de los ejemplares silvestres analizados el 29\% proceden de la provincia de Jujuy (Tumbaya, Tiraxi, Valle Grande y Capital), el 14\% de Salta 
(Santa Victoria, Chicoana, Cerrillos, Orán y Capital) y el 57\% de Tucumán (Trancas, Chiclingasta, Tafí y Burruyaco). Los resultados del análisis de las semillas fueron los siguientes:

Largo: 7,05 a 8,65 mm

Ancho: 4,6 a 5,91 mm

Grosor: 2,47 a 3,74 mm

Forma: mayormente elíptica (en la muestra MCM-147 es levemente arriñonada corta y en la muestra VAV-6364 los valores están por fuera de los límites dados por Puerta Romero 1961, pero se infiere que la forma es esférica). De la observación a ojo desnudo Menendez Sevillano (2002) coincide con lo mencionado por diversos autores de que la forma de la semilla es cuadrangular.

Color: muy uniforme, todas presentaron color amarillo ocre, con moteado y estrías en color oscuro.

Recientemente se han realizado nuevos estudios sobre poblaciones silvestres y domesticadas de este género en el NOA, aunque considerando muestras de menor tamaño. Oliszewski (2004) analiza tres muestras actuales de la variedad silvestre y una de la cultivada (10 ejemplares por muestra) procedentes de la zona conocida como Campo del Pucará en el departamento de Andalgalá, Catamarca ( $27^{\circ} 32^{\prime} 30^{\prime \prime}$ S- $66^{\circ} 00^{\prime} 15^{\prime \prime}$ W). En ambos casos los rangos de medidas señalados para las tres variables (largo, ancho y grosor) son algo menores a los señalados por Menéndez Sevillano (2002), lo cual se deba probablemente a lo reducido y localizado geográficamente de la muestra estudiada. Seguramente por la misma razón la autora asigne a ambos taxa una única forma (reniforme), aunque obtiene para ambos valores diferentes en el 
índice largo/ancho. Si tomamos en cuenta sus resultados y los aplicamos a las formas reconocidas por Menéndez Sevillano (2002) (ver tablas 63 y 64), veremos que el índice obtenido por Oliszewski (2004) para P. vulgaris var aborigineus $(1,3)$ correspondería a la forma esférica, en tanto el obtenido para la muestra de P. vulgaris var. vulgaris $(1,9)$ se correspondería a la forma oblonga o arriñonada media. Recientemente Babot et al. (2007) elevan a nueve el número de muestras actuales analizadas, incluyendo diversas localidades del NOA (San Pedro de Colalao y Tafi del Valle en Tucumán; dos localidades dentro del departamento de Andalgalá, Catamarca y la localidad de Metán en Salta). Los resultados a los que arriban no difieren en gran medida de los mencionados por Oliszewski (2004), salvo en la relación largo/ancho que llamativamente no arroja diferencias significativas entre la forma silvestre y la domesticada, salvo en un único caso. Por otro lado, en cuanto a los caracteres cualitativos, en ambos trabajos se menciona que las semillas domesticadas se distinguen por la presencia clara de la micrópila.

Vale la pena mencionar que existen, aparentemente, factores naturales que pueden estar generando variabilidad natural en la subespecie silvestre. Por ejemplo, Esteves et al. (2005) detectan diferencias en tamaño de las semillas en una misma vaina con relación a su posición relativa dentro de ésta; en este sentido, las semillas de la posición 3 muestran un aumento en el valor ancho con respecto a la posición 1 .

\section{Análisis y caracterización de frutos de Phaseolus sp.}

\section{Caracteres macroscópicos}

Las vainas de P. vulgaris var. vulgaris analizadas por Menéndez Sevillano (2002) son de color amarillo claro, poseyendo el 50\% del conjunto analizado estrías 
color púrpura grisáceo. En lo que respecta a los caracteres métricos, los resultados obtenidos por la autora fueron los siguientes:

Largo: $164,5-86,33 \mathrm{~mm}$

Ancho: 9,1-13,4 mm

Grosor: 7- 10,2 mm

El análisis de los frutos de P. vulgaris var aborigineus efectuado por la citada autora reveló que todos son de color crema con estrías púrpuras, los datos métricos obtenidos fueron los siguientes:

Largo: $57,4-89,4 \mathrm{~mm}$

Ancho: $6,1-7,4 \mathrm{~mm}$

Grosor: 3,7-6,4 mm

\section{Caracteres micromorfológicos}

Tal como se mencionó anteriormente, los caracteres micromorfológicos de la vaina de algunas leguminosas son importantes para determinar su grado de domesticación. De acuerdo con Fahn (1985) la estructura básica del fruto de las leguminosas (Fabaceae) posee las siguientes capas:

-el exocarpo: consiste sólo en epidermis que puede o no ser uniseriada.

-el mesocarpo: puede ser parénquima o colénquima, posee haces vasculares acompañados de tejido esclerenquimático.

-el endocarpo: es un esclerénquima que puede contener epidermis y parénquima. El esclerénquima puede consistir en fibras orientadas todas en una misma dirección o ubicadas en dos zonas en las que la orientación difiere. Butler (2002) menciona la presencia de fibras y de células elongadas de paredes engrosadas en el endocarpo. 
De acuerdo con Esau (1982) la vaina de Phaseolus sp. consiste en una epidermis e hipodermis fuertemente asociadas (la "piel"), a las que le sigue el parénquima con cloroplastos conteniendo gránulos de almidón, el mismo posee una red de pequeños haces vasculares cerca de la capa de esclerénquima que están a su vez rodeados por esclerénquima lignificado (es el caso de los "hilos" en chauchas verdes). Winton y Winton (1935) mencionan seis capas en el pericarpio de Phaseolus sp.: (1) epicarpo con cutícula estriada de células isodiamétricas o algo elongadas, a menudo con paredes con engrosamientos arrosariados y con pelos unicelulares rectos o en gancho, pelos capitados con cabezas multicelulares ${ }^{3}$ y estomas; (2) hipodermis de células colenquimáticas elongadas, muchas engrosadas; (3) mesocarpo externo de parénquima esponjoso conteniendo granos de almidón pequeños y en la porción más interna haces fibro- vasculares; (4) fibras diagonales, algunas engrosadas; (5) mesocarpo interno de parénquima con paredes delgadas y pequeños cristales dispuestos a menudo en grupo y finalmente un endocarpo (6) de células poligonales.

Herrera Flores et al. (2005) menciona que a lo largo de la sutura dorsal existen haces vasculares rodeados de fascículos de esclereidas y que en la sutura ventral de la vaina se ubica el "tejido de dehiscencia". Los autores no son explícitos en cuanto al tipo de células involucrado en este "tejido de dehiscencia" ni a sus particularidades, pero a partir de las imágenes presentadas, parecería que el mismo involucra principalmente a la capa de esclereidas. También se señala que el espesor de la pared de las esclereidas de la capa interna de esclerénquima, así como el diámetro de estas células, es mayor en los genotipos dehiscentes que en los indehiscentes, siendo además el número de hileras de esclereidas internas mayor en las formas silvestres que en los tipos semidomesticados y domesticados (Herrera Flores et al. 2005)

\footnotetext{
${ }^{3}$ De acuerdo con Herrera Flores (2005) los tricomas van desapareciendo con la madurez de la vaina.
} 
Las legumbres pueden tener dehiscencia pasiva, sin movimientos, o activa donde ambas valvas se separan y tuercen en espiral (Burkart 1952)

Burkart (1952) menciona que la dehiscencia activa es provocada, al secarse el fruto maduro, por un tejido de fibras oblicuas ubicado en el endocarpo llamado "pergamino". La importancia de este tejido en la modificación del mecanismo de dehiscencia del fruto de $P$. vulgaris fue destacada también por Kaplan (1965), Brücher y Berglund-Brücher (1976) y por Gepts y Debouck (1991). En opinión de estos dos últimos autores: "El mecanismo de dehiscencia de la vaina [de P. vulgaris] puede ser atribuido a la presencia de fibras que rodean los haces vasculares en las paredes de la vaina así como también a la capa fibrosa de pergamino que reviste la cavidad de la vaina (Roth 1977). En particular, el movimiento giratorio de las paredes de la vaina es causado por la orientación oblicua de las fibras en la capa de pergamino. Una disminución en el contenido de fibras en las paredes de la vaina reducirá o retardará el mecanismo de dehiscencia (...) Luego de la domesticación, la selección en pro de un contenido reducido de fibras en la vaina fue en aumento, llevando eventualmente a un tipo de vaina sin fibras ("snap bean type") que no se abre en lo absoluto, incluso luego de la maduración" (Gepts y Debouck 1991:32). Por lo tanto se pasaría de vainas fuertemente dehiscentes en porotos silvestres a vainas moderadamente dehiscentes en los cultivares de porotos domesticados que se consumen maduros ("dry bean type") a frutos completamente indehiscentes en los cultivares donde se consume la vaina inmadura ("snap bean type") (Gepts y Debouck 1991). Este último tipo parecería ser el resultado de selecciones realizadas fuera de América y en tiempo relativamente reciente en pro de vainas sin fibras para su consumo como vegetal verde ("chauchas", “judías verdes" o “ejotes") (Singh 1989, Silbernagel et al. 1991).

De acuerdo a Fahn (1985) las dos valvas de la legumbre se retuercen debido a la disposición anisotrópica de las paredes engrosadas de las células 
pericárpicas, el retorcimiento resulta de la orientación de las microfibrillas y de los cristales de celulosa en las paredes. La mayor hinchazón de las paredes celulares resulta en ángulo recto con el eje longitudinal de las microfibrillas, por ello el mayor acortamiento ocurre en esta dirección cuando las valvas se secan. En Vicia y otros géneros las células esclerenquimáticas del endocarpo se orientan en un ángulo de $45^{\circ}$ con el eje longitudinal de la legumbre, mientras que los engrosamientos parietales de las células epidérmicas (o epidérmicas e hipodérmicas) se orientan con el mismo ángulo pero en dirección opuesta. En las valvas de estas legumbres, la orientación microfibrilar con relación al eje celular es la misma, tanto en el endocarpo como en el epicarpo, pero como los ejes celulares de estos dos estratos pericárpicos están a su vez diferentemente orientados, se produce tensión al secarse las valvas, la cual produce el retorcimiento de las valvas cuando han cesado las fuerzas que mantienen cerrada la sutura. La legumbre se abre entonces de manera explosiva, las valvas se retuercen y las semillas son arrojadas, proceso de dispersión denominado "espermatobolia".

Otros tipos de dehiscencia pueden ser: 1) el caso del género Lupinus donde las células esclerenquimáticas del endocarpo poseen orientación homogénea pero hay dos regiones donde es diferente la orientación de los cristales de celulosa y la de sus engrosamientos

2) el caso del género Astragalus donde el esclerénquima endocárpico posee dos capas que se diferencian en su orientación celular.

Fahn y Zohary (1955) establecen grupos de acuerdo con la estructura de la capa esclerenquimática (que es el tejido más importante en lo que a dehiscencia concierne, según ambos autores)

-dos capas de fibras dispuestas de manera perpendicular entre sí -dos capas de fibras se cruzan entre sí formando un ángulo agudo 
-una capa de fibras corre tangencial a la superficie de la valva y la otra son células engrosadas o en empalizada

-una capa con fibras orientadas de manera diferente en varias partes de la valva

En resumen, para una activa dehiscencia de las vainas se requieren dos factores: 1) el cruce de las células esclerenquimáticas y/o el cruce de sus micelas celulósicas; 2) la presencia de un tejido de separación que se expande en la región de la sutura desde la epidermis interna a la externa (Fahn y Zohary 1955)

De acuerdo con estos autores la tendencia evolutiva que llevaría hacia la indehiscencia sería desde un estado inicial con legumbres con dos capas esclerenquimáticas a aquellas con una capa, hasta la desaparición de dicha capa. La misma tendencia es observada por Gepts y Debouck (1991) y por Epimaki et al. (1996). Por lo tanto la presencia de fibras del esclerénquima diferencialmente orientadas en vainas indehiscentes serían caracteres relictuales o vestigiales, mientras que la vaina sería indehiscente porque ha perdido el tejido de separación (Fahn y Zohary 1955). También para Burkart (1952) la pérdida de la dehiscencia se produce por la desaparición del tejido de fibras oblicuas del endocarpo. Sin embargo Butler (2002) sostiene que el estado de indehiscencia que sigue a la domesticación puede darse por la reorientación de las micelas más que por una reducción en las capas de fibras. Smartt (1942 en Butler 2002) señaló que en los frijoles cultivados hay una tendencia a reducir la dehiscencia, lo cual no implica cambios anatómicos notables con relación a los tipos silvestres; además, bajo domesticación y que el contenido de fibras puede reducirse más en una especie que en otra (habiendo por ejemplo más reducción de estas fibras en P. vulgaris var. vulgaris que en $P$. coccineus). La cantidad de fibras es un carácter gobernado genéticamente (ligado al gen que regula la dormancia en las semillas), pero es influenciado por factores ambientales como la humedad atmosférica y la 
temperatura (Revé y Brown 1968, Epimaki et al 1996). Butler (2002) analizó rasgos superficiales (tricomas, estomas, depositación de ceras y células del exocarpo) e internos (grosor, cristales del mesocarpo, número y orientación de las fibras del endocarpo) de los frutos de formas domesticadas y silvestres de los géneros Lens, Pisum y Vicia sin encontrar diferencias diagnósticas a nivel morfológico ni anatómico que den cuenta de los distintos mecanismos de dehiscencia. La autora sugiere que quizá la indehiscencia que surge tras la domesticación se deba a la reorientación de las micelas celulares y no a una reducción en la capa de fibras (Butler 2002).

En el caso particular de las poblaciones argentinas de P. vulgaris var aborigineus el mecanismo de dehiscencia se encuentra menos desarrollado que en otras formas silvestres de leguminosas con dehiscencia espiralado-explosiva, pudiendo encontrarse en las poblaciones silvestres gran número de vainas maduras cerradas (Brücher y Berglund-Brücher 1976).

\section{El registro arqueológico de Phaseolus sp.en el área andina}

La antigüedad de este género en Sudamérica ha sido motivo de debate a lo largo de los años siendo un aspecto crucial en lo referente a establecer la antigüedad de los procesos de domesticación vegetal en el área. El reestudio llevado a cabo por Kaplan y Lynch (1999) -consistente en el fechado radiocarbónico por el método de AMS de restos arqueológicos de porotos de antiguas colecciones- ha sido de gran utilidad para esclarecer la cronología del género (Figura 33). Los restos más tempranos corresponden a restos secos de vainas de $P$. lunatus provenientes de Chilca, en la costa peruana, con una edad de 5616+/-57 AP (edad calibrada: 4490-4360 AC). El fechado más tempranos de P. vulgaris var. vulgaris fue obtenido a partir de semillas no carbonizadas de la cueva Guitarrero, en el altiplano peruano, las cuales arrojaron una edad radiocarbónica de 4337+/-55 AP (edad calibrada: 3030-2890 AC). 
Finalmente, los nuevos fechados realizados por Kaplan y Lynch (1999) sobre los que eran los restos más antiguos en territorio chileno procedentes del sitio San Pedro Viejo de Pichasca dieron una edad relativamente temprana de 1420 $+/-83$ AP.

Una particularidad de estos restos sudamericanos más tempranos -compartida por los restos mesoamericanos más tempranos- es que las semillas tanto de $P$. vulgaris var. vulgaris como de $P$. lunatus poseen una morfología y tamaño similar a las encontradas en sitios cronológicamente posteriores y a las de cultivares actuales, sin que existan secuencias donde se vea un cambio gradual a través de la presencia de formas transicionales (Kaplan 1965, Debouck et al 1987). En opinión de Epimaki et al. (1965) esto se debería al control genético que poseen los rasgos asociados al síndrome adaptativo de la domesticación, los cuales obedecen a la acción de pocos genes ligados entre sí. En cuanto a los restos de vainas, las más antiguas de América fueron recuperadas en el sitio mexicano de Ocampo (7500 AP), considerándoselas domesticadas ya que su ancho se corresponde con el de formas domesticadas actuales y porque poseen escasas capas en el tejido denominado "pergamino" de la vaina (Kaplan 1965, Kaplan y Lynch 1999).

La presencia de Phaseolus sp. en sitios arqueológicos del NOA se ha detectado principalmente por medio de la recuperación de semillas o sólo cotiledones tanto secos como carbonizados. Ambas variedades, P. vulgaris var. vulgaris y $P$. vulgaris var aborigineus, se han recuperado en dicha región en contextos agrícolas formativos, desde ca. 2600 años AC en adelante (Tarragó 1980, Pochettino y Scattolin 1991, Albeck 2000, Lagiglia 2001, Oliszewski 2004, Babot et al. 2007), sin que existan hasta el presente fechados AMS realizados directamente sobre restos arqueobotánicos de estos taxa. Por mucho tiempo los ejemplares más tempranos de $P$. vulgaris var. vulgaris en Sudamérica correspondieron a los de la cueva III de Huachichocana (prepuna de Jujuy, 
Argentina) con fechados radiocarbónicos de las ocupaciones del abrigo cercanos al 10.000 AP (Fernández Distel 1974, Aguerre et al. 1975), ocupando los mismos un lugar preponderante en las secuencias regionales (Gepts y Debouck 1991, Pearsall 1992, Lagiglia 2001). Posteriormente estos hallazgos se desestimaron en el ámbito de la arqueología argentina (ver capítulo 2), sin que se publicara un reestudio del material arqueobotánico recuperado. Los hallazgos del sitio Puente del Diablo (La Poma, Salta) también fueron señalados como representativos del período de transición hacia los primeros grupos agricultores, mencionándose la presencia de un ejemplar de "poroto" entre los restos recuperados (Nuñez Regueiro 1974, Tarragó 1980, Schóbinger 1988, Castro y Tarragó 1992, Albeck 2000), el cual nunca fue identificado (ver capítulo 2).

Trabajos posteriores procuraron parámetros que permitieran una identificación más rigurosa de los restos vegetales de Phaseolus sp., tanto a través de la morfología general externa, tanto cualitativa como cuantitativa, de los restos (Pochettino 1985, Capparelli 1997, Oliszewski 2004) o bien, por medio de caracteres microscópicos de los macrorrestos recuperados (Pochettino y Scattolin 1991). Entre los macrorrestos correspondientes a sitios formativos del NOA se encuentran los recuperados en los montículos de Campo del Pucará (Tucumán) por Oliszewski (2004), los del sitio Casas Viejas-El Mollar (Carrizo et al 1999) y los de la ladera occidental del Aconquija, Catamarca (Pochettino y Scattolin 1991). En todos los casos se recuperaron restos de semillas y cotiledones carbonizados. En Campo del Pucará se identificó la presencia de $P$. vulgaris var vulgaris, $P$. vulgaris var aborigineus y un conjunto identificado sólo a nivel especifico y considerado como posibles "híbridos" ya que sus dimensiones son muy pequeñas (largo: 3 $-3,75 \mathrm{~mm}$; ancho: $2-2,5 \mathrm{~mm}$ ), aunque posee almidones propios de la forma domesticada (Oliszewski 2004). En el caso de los restos del Aconquija y Casas Viejas- El Mollar se identificaron también restos de ambas variedades 
(Pochettino y Scattolin 1991, Carrizo et al. 1999). En el caso de la semilla de $P$. vulgaris recuperada en el sitio Punta de la Peña 4 (760-560 AP, Antofagasta de la Sierra) la falta de datos acerca de su estado de conservación, caracteres cualitativos y cuantitativos (Rodríguez et al. 2006) impiden incluirla en la comparación con los hallazgos realizados en el NOA hasta el presente.

La localidad arqueológica de Pampa Grande destaca respecto del resto de los sitios arqueológicos del NOA por la recuperación de gran cantidad de vainas y por el hallazgo de una semilla de P. lunatus (Pochettino 1985) -taxón identificado en el NOA sólo en el sitio inkaico-hispano indígena de El Shincal (Capparelli 1997) y en sitios tardíos de la provincia de Córdoba (López 2005, 2007)- además de abundante cantidad de semillas y vainas de P. vulgaris var vulgaris (Pochettino 1985) que conforman actualmente la colección de esta localidad arqueológica.

\section{Materiales y método.}

\section{1) Colección de referencia}

Se conformó una colección de referencia compuesta por treinta y dos frutos secos y maduros (y sus correspondientes semillas) de P. vulgaris var aborigineus cedidas por el Dr. Roberto Neuman de la estación experimental Cerrillos del INTA colectadas en el oriente salteño en diversas campañas. En el caso de

muestras de frutos secos y maduros de P. vulgaris var vulgaris (cinco frutos y diez semillas) se empleó material identificado depositado en la colección del Laboratorio de Etnobotánica y Botánica Aplicada (FCNYM -UNLP). Se trabajó también con cuatro vainas frescas colectadas de cuatro plantas cultivadas para un ensayo experimental ajeno a las investigaciones realizadas aquí por la Dra. G. Fermoselle (INFIVE, FCAF, Museo de Ciencias Naturales de La Plata, UNLP, CONICET). Para conformar esta colección de referencia 
se buscaron frutos de otras leguminosas del NOA cuyas vainas tuvieran dehiscencia espiralada y aspecto externo similar - una vez abiertas- a P. vulgaris. La única especie que cubría dicho espectro fue Caesalpinia gillesii (Wall ex Hook) Dietrich. Cinco frutos de esta especie colectados en El Shincal, identificados y depositados en la colección del Laboratorio 1 del Departamento Científico de Arqueología del Museo de Ciencias Naturales de La Plata, fueron por ende incluidos en la presente colección de referencia.

\section{1) Análisis de vainas con distinto grado de desarrollo.}

Se realizó un pequeño ensayo experimental para analizar el comportamiento de desecación de cuatro vainas inmaduras de P. vulgaris var vulgaris. Este ensayo se realizó dado que existía la posibilidad de que las valvas que componen las vainas indehiscentes de la variedad domesticada pudieran espiralarse (asemejándose al aspecto de las valvas de frutos dehiscentes tras su apertura) al ser colectadas inmaduras, luego de ser extraídos sus frutos y de secarse la vaina.

Las vainas se colectaron de las plantas en distintos puntos de su desarrollo previo al desecamiento de las mismas. Fueron luego abiertas y, tras removerse las semillas o sus primeros vestigios, se pusieron a secar bajo sol directo a fin de observar el aspecto final adoptado por las valvas tras su desecamiento.

\section{2) Análisis anatómico de vainas.}

El análisis microscópico se efectuó en frutos maduros y secos de P. vulgaris var. aborigineus $(\mathrm{N}=5)$ y de $P$. vulgaris var. vulgaris $(\mathrm{N}=5)$. Se efectuaron cortes transversales al eje longitudinal de la valva en su porción media y levantados superficiales de tejido tangenciales a la superficie de la vaina en dicha parte media. Dado que la orientación de las células de los distintos tejidos de la 
vaina resulta fundamental en la comprensión de los mecanismos de dehiscencia (Fahn y Zahory 1955, Fahn 1985, Butler 2002) se prestó especial atención con respecto a que los cortes realizados mantuvieran una clara relación con los planos de las valvas de procedencia. Así, se adoptó un sistema de planos de referencia $(X, Y, Z)$ que tomara en cuenta las tres dimensiones de las valvas que componen la vaina (Láminas 35 y 36). En opinión de los últimos autores mencionados, los tejidos que se encuentran involucrados en los mecanismos de dehiscencia son el colénquima de la hipodermis y el esclerénquima del endocarpo, por lo cual fueron éstos los tejidos analizados tanto en las caras de la valva como en la sutura dorsal (donde su ubican haces vasculares rodeados de fascículos de esclereidas) y en la sutura ventral (donde, de acuerdo con Herrera Flores et al. (2005), se ubica el tejido de dehiscencia). Los cortes transversales fueron observados en microscopio óptico de transparencia y en MEB, sólo en el primer caso el material fue previamente hidratado. Los levantados superficiales fueron observados sólo por transparencia, realizándose una decoloración previa con hipoclorito de sodio al 50\%. También se observó la epidermis de ambas variedades de vainas en superficie al MEB.

La misma metodología de análisis para observación bajo microscopio óptico de transparencia se aplicó sobre una vaina de Caesalpinia gillesii.

Se midió el espesor del pericarpio de ocho valvas de frutos maduros y secos diferentes de $P$. vulgaris var vulgaris $(\mathrm{N}=4)$ y $P$ vulgaris var aborigineus $(\mathrm{N}=4)$ de la colección de referencia a fin de explorar el valor diagnóstico de este rasgo biométrico.

Asimismo se realizaron estudios de superficie en la epidermis con el fin de diagnosticar su potencial diagnóstico. Se caracterizó la cutícula superficial, los tricomas, pelos glandulares y estomas, midiéndose también éstos últimos.

\section{2) Restos arqueobotánicos: análisis morfológicos macroscópicos}


2.1) Análisis morfológicos macroscópicos aplicados a partir de datos publicados de ejemplares arqueológico.

Si bien los hallazgos de Campo del Pucará (Oliszewski 2004), Casas Viejas-El Mollar (Carrizo et al. 1999) y Aconquija (Pochettino y Scattolin 1991) resultan interesantes para caracterizar los conjuntos de $P$. vulgaris var vulgaris y $P$. vulgaris var aborigineus del formativo del NOA en todos los casos se trata de conjuntos de semillas carbonizadas (Figura 34). En el capítulo 411c se hizo referencia a las variaciones en rasgos biométricos que causa la carbonización de órganos vegetales y la necesidad de realizar estudios experimentales para poder comparar macrorrestos secos con carbonizados de los mismos o distintos taxones. Dado que hasta el presente no existen dichos estudios experimentales, no se considera válido comparar los caracteres métricos de las semillas de Campo del Pucara, Casas Viejas-El Mollar y Aconquija con las semillas secas de los otros sitios arqueológicos analizados en esta tesis. En este sentido se tomaron los datos brindados por Roig (1977) de los restos de Phaseolus sp. recuperados tras la excavaciones efectuadas por Gambier y Sachero en Los Morrillos de Ansilta, conjunto de cuevas ubicadas al oeste del Valle de Calingasta (San Juan) donde encuentran vestigios de agricultores iniciales (Lagiglia 2001). Se trata de 42 restos secos de semillas de Phaseolus sp. fechados entre el 50 AC y 375 DC en excelente estado de preservación lo cual, junto al minucioso registro efectuado por Roig (1977) y la publicación de los datos en bruto de cada ejemplar (color, largo, ancho y grosor), permiten su análisis mediante la aplicación de nuevos parámetros. En consecuencia se aplicaron a estos restos los descriptores morfológicos empleados por Menéndez Sevillano (2002, siguiendo a Puerta Romero 1961), a fin de hacerlos comparables con los datos obtenidos del análisis de restos arqueobotánicos. 
Para los grupos de semillas analizados se calculó media, desvío estándar, coeficiente de variación (CV), y rango de medidas.

2.2) Análisis morfológicos macroscópicos aplicados directamente a ejemplares arqueobotánicos.

Se analizaron ejemplares procedentes de tres sitios ya descritos en los capítulos 2 y 3: la cueva III de Huachichocana en la quebrada de Purmamarca (prepuna jujeña), el sitio SSalLap20 en la cabecera norte del Valle Calchaquí (prepuna salteña) y la localidad arqueológica de Pampa Grande en las serranías de Guachipas (oriente salteño).

\subsection{1) semillas.}

En el caso de Huachichocana y SSalLap20 se registraron caracteres cualitativos y cuantitativos de todas las semillas recuperadas en las excavaciones. En el caso de Pampa Grande se registraron todos los restos de Phaseolus sp. que componen la colección y se analizaron los caracteres cualitativos y cuantitativos de una muestra de 51 semillas de Los Aparejos y 50 procedentes de El Litro.

Para el análisis macroscópico cualitativo y cuantitativo de las semillas arqueológicas se aplicaron los descriptores morfológicos empleados por Menéndez Sevillano (2002) siguiendo a Puerta Romero (1961 en Menéndez Sevillano 2002) ya que al haber sido usados en estudios de muestras actuales del NOA nos permiten contar con un conjunto de referencia constituido por una muestra amplia que consideramos representativa. Además, los resultados métricos de los trabajos de Oliszewski (2004) y Babot et al. (2007) no contradicen a los de la autora, salvo en el caso de los índices y la concomitante asignación de forma, como se discutió previamente. 
Los colores de los ejemplares se consignaron siguiendo la codificación de la carta Earth Colors (1997). Se realizó también un análisis de otros rasgos cualitativos externos (micrópila, hilio y rafe) comparándolo con semillas de $P$. vulgaris var. aborigineus de la colección de referencia por medio del empleo de microscopio estereoscópico.

Los rasgos biométricos y cualitativos externos analizados se señalan en la figura 35 .

\subsection{2) vainas.}

En el caso de Pampa Grande, en donde se registraron todos los restos de Phaseolus sp. que componen la colección, se analizaron los caracteres cualitativos y cuantitativos de cuatro ejemplares distintos, cada una de ellas proveniente de una cueva/caverna distinta (El Litro, Los Aparejos, Caverna III y Caverna IV).

En el caso de los frutos no fue posible aplicar los descriptores empleados por Menéndez Sevillano (2002) para su descripción macroscópica puesto que la colección de Pampa Grande posee sólo restos de vainas abiertas o incluso valvas aisladas, todas ellas espiraladas, lo cual impide cuantificar los descriptores de manera apropiada y comparable con los resultados obtenidos por dicha investigadora. Por lo tanto el único dato externo registrado fue el espesor del pericarpio.

Dado el carácter único de los restos de vaina de la localidad de Pampa Grande y considerando que los restos arqueológicos de frutos pueden arrojar información sobre el mecanismo de dispersión de las semillas -fundamental en el estudio de procesos de domesticación y manejo humano de poblaciones vegetales- se llevó a cabo un estudio de los caracteres microscópicos de estos restos a fin de analizar la presencia o no de cambios en los tejidos que estarían implicados en la dehiscencia de los frutos. 
En las cuatro muestras arqueológicas se realizaron cortes transversales al eje longitudinal de la valva y en la porción media de la misma con hojas de bisturí nuevas, sin hidratación previa. La porción correspondiente a la sutura ventral, sutura dorsal y caras de las vainas fueron observadas empleando MEB. También se analizó la superficie de estas vainas al MEB a fin de caracterizar cutícula, tricomas, pelos glandulares y estomas. En un solo caso (vaina de la Caverna IV) el mal estado de preservación del material y la disgregación de la valva al ser procesada para su observación produjo que las observaciones al MEB resultaran infructuosas. La aplicación de la técnica de electrones retrodifundidos permitió observar sólo algunos rasgos superficiales. Ante esta dificultad se optó por realizar un levantado superficial pudiendo obtenerse muestras sólo en las áreas próximas a la sutura ventral y dorsal, puesto que las muestras correspondientes a las caras mayores se deshacían en fragmentos mínimos ante su manipulación. Las muestras obtenidas se analizaron bajo microscopio de transparencia.

\section{Resultados}

Análisis morfológicos macroscópicos aplicados a datos publicados de ejemplares arqueológicos: semillas de Phaseolus sp.

El análisis de los datos aportados por Roig (1977) para las semillas recuperadas en Ansilta evidenció que todas las medidas caen dentro del rango de distribución de $P$. vulgaris. Este investigador presenta cuatro grupos cronológicos para los restos de semillas, la comparación entre estos conjuntos en lo que respecta a largo, ancho y grosor de las semillas evidenció la ausencia de diferencias significativas (tabla 65). Dado que los grupos de 50AC-200DC; 0-50DC y 50-200/210 DC representarían un mismo lapso, diferente al de 280- 
375 DC se armaron dos grupos de semillas según criterio cronológico: uno con los restos que corresponden al período 50AC-210DC y otro con los restos del período 280-375DC. Nuevamente los valores para ancho, largo y grosor mostraron un grado elevado de solapamiento.

Sin embargo la tabla 65 permite ver que los valores de CV de las tres medidas son mayores en muestras cronológicamente más recientes. Este aumento en los valores de CV indica, de acuerdo con Cowan y Smith (1993) y Newsom (1993) ya comentados en el capítulo 4.1 de esta tesis, una mayor heterogeneidad en los conjuntos, lo cual se asociaría con la presencia de distintos cultivares, que aquí consideraremos como distintas líneas de selección por manejo diferencial, sea el mismo incidental o no.

En períodos cronológicos más tardíos se detecta pérdida (gráficos 14 y 15) o reemplazo (gráficos 16 y 17) de formas respecto a momentos anteriores.

Por lo tanto en el caso de Los Morrillos un aumento en la heterogeneidad del conjunto de semillas se visualiza a través del CV de las medidas lineales, y no por medio de los índices que indican forma.

Análisis morfológicos macroscópicos aplicados directamente a ejemplares arqueológicos: semillas de Phaseolus sp.

\section{HUACHICHOCANA (CH III)}

En la colección depositada en el Instituto Interdisciplinario Tilcara (FFLUBA) pudimos tener acceso a los dos ejemplares de porotos mencionados para la cueva III de la localidad arqueológica de Huachichocana (Fernandez Distel 1986). Los mismos fueron fotografiados y medidos.

-Capa C (asentamiento agro alfarero tardío, Humahuaca-inka, entre 1475 y 1536 DC- Fernández Distel 1986): cutícula blanca; largo: 12 mm; ancho: 8 
$\mathrm{mm}$; grosor: 5,5 mm.; índice J (largo/ancho): 1,5 (elíptico); índice $\mathrm{H}$ (grosor/ancho): 0,687 (aplanada, en el límite) (Figura 36).

-Capa E 3 (precerámico agrícola incipiente, entre 6500 y 8200 AC Fernández Distel 1986): cutícula roja oscura; largo: $16,7 \mathrm{~mm}$; ancho 9,2 mm; grosor: 8,4 mm.; índice J (largo/ancho): 1,81 (oblongo o arriñonado corto); índice $\mathrm{H}$ (grosor/ancho): 0,91 (llena) (Figura 37).

Los mismos fueron determinados por A. Burkart y E. Ulibarri (Instituto de Botánica Darwinion) como Phaseolus vulgaris L. (Fernández Distel 1986). No hemos tenido acceso al informe original, pero transcribimos a continuación una cita que consideramos de interés: "Son tres los probables vegetales cultivados de CH III, capa E3: Ají (Capsicum baccatum o Capsicum chacoense), Poroto (Phaseolus vulgaris) y Maíz (Zea mays). Los dos primeros, según expresa aclaración de los botánicos que los analizaron, pudieron tratarse de ejemplares silvestres, ya que prosperan naturalmente en la zona" (Aguerre, et al. 1975:212, subrayado nuestro).

Se compararon los datos relevados del ejemplar procedente de la capa E3 puesto que es la que se considera correspondiente a un período de agricultura incipiente- con los datos provistos por Menéndez Sevillano (2002) para el taxón silvestre. Los datos de forma y color no coinciden con los de Ph. vulgaris var aborigineus, y en las tres medidas los resultados obtenidos superan ampliamente a los registrados por la autora en poblaciones silvestres. Asimismo, la observación del ejemplar nos permitió constatar que el mismo se asemeja claramente más a la variedad domesticada de $P$. vulgaris que a la silvestre en su morfología general.

PUENTE DEL DIABLO (SsalLap20) 
Se registró la presencia de una semilla de poroto (Phaseolus sp.) bajo el número de catálogo 2-243. La misma se encuentra en asociación con el hallazgo $\mathrm{N}^{\circ} 1$ que es el cuerpo momificado de una mujer conocido como "la dama de Cachi”. La semilla fue medida y fotografiada (Figura 38). A continuación se describe la misma:

Cubierta color castaño-rojiza y ennegrecida en el área del hilum. Este rasgo sería característico de los cultivares de origen andino según Beebe et al (1997) Largo: 8,1 mm; ancho: $7 \mathrm{~mm}$; grosor : $4 \mathrm{~mm}$

Índice J (largo/ancho): 1,15 (por debajo del limite inferior -1,16-de la forma esférica)

Índice H (grosor/ancho): 0,57 (aplanada)

Comparado con los caracteres mencionados por Menéndez Sevillano (2002) para P. vulgaris var. aborigineus vemos que ni el color ni la forma coinciden. A pesar de ello en el caso de las medidas lineales el ancho de la semilla de SsalLap20 es apenas mayor, en tanto el grosor y el largo se encuentran en el límite del rango de las medidas de la variedad silvestre. Por lo tanto esta semilla posee rasgos que se encuentran actualmente sólo en las poblaciones del NOA de la variedad domesticada (color, forma y ancho) y otros exhibidos actualmente por la variedad silvestre (largo y grosor). Esto permitiría ubicar este ejemplar en una posición intermedia respecto de los rasgos observados en las poblaciones actuales de la variedad silvestre y domesticada del NOA.

\section{PAMPA GRANDE}

En las distintas cuevas que conforman esta localidad arqueológica se recuperaron gran cantidad de restos de semillas secas en excelente estado de conservación, habiendo sólo unas pocas carbonizadas. Los restos de Phaseolus spp. de esta localidad fueron analizados por A. Burkart a pedido de A. R. 
González y luego por Pochettino (1985). La distribución de los hallazgos por cueva puede verse en el gráfico 18.

Los Aparejos: Es la cueva en la que se recuperaron mayor cantidad de semillas $(\mathrm{N}=2189)$, aunque se debe tener en cuenta también que es la que se excavó en mayor extensión. Todas las semillas corresponden a $P$. vulgaris var vulgaris y solamente en esta cueva se recuperaron semillas bicolores (Figura $39)$.

La distribución por sector, cuadrícula y capa puede verse en la tabla 66 y la distribución en estratigrafía en el gráfico 19.

Los dos picos principales observados en los niveles $0,20-0,40$ y $0,60-0,80$ corresponden a dos concentraciones ubicadas en el sector III, cuadrícula E1. La primer concentración del nivel 0,20-0,40 suma un total de 840 semillas y, de acuerdo con los excavadores, las mismas formaban un núcleo compacto entre las piedras, rodeado de paja. La concentración del nivel 0,60-0,80 suma un total de 583 semillas, señaladas como "in situ" por los excavadores. A una profundidad intermedia entre las anteriores $(0,40-0,60)$ se encuentra otra concentración de 337 semillas en la cuadrícula F0. Finalmente, en la cuadrícula F1 se recuperó otro conjunto de semillas $(\mathrm{N}=66)$, sesenta de las cuales se recuperaron al realizar el perfil junto a la urna correspondiente al hallazgo $\mathrm{N}^{\circ} 5$ y seis dentro de dicha urna junto a restos humanos, cuentas, cordones de lana, endocarpos de Prosopis sp., granos de Zea mays y pericarpios de C. maxima ssp. maxima.. Por lo tanto en este sector de la cueva se recuperaron un total de 1826 semillas, que representan el $83,4 \%$ del total de semillas recuperadas en toda esta cueva.

En el sector II se recuperaron también restos de semillas de $P$. vulgaris var vulgaris asociadas a restos óseos humanos: ocho semillas en la cuadricula D1 y treinta y dos en la cuadricula C3. 
En general todas las semillas recuperadas se asocian con restos vegetales de recolección (endocarpios de Geoffroea decorticans y de Prosopis sp.) y especies cultivadas (semillas, pedúnculos y restos de pericarpio de Cucurbita sp., granos, marlos y brácteas de Zea mays frutos de Arachis sp. y vainas de Phaseolus sp.).

Por lo tanto esta cueva nos indica que hubo grandes conjunto de semillas dispuestas en sectores delimitados con piedra y paja, quizá representando el almacenamiento de las mismas para consumo o para el próximo período de siembra, así como también un uso funerario de las mismas, dispuestas en enterratorios.

E1 Litro: Se recuperaron semillas sólo en dos cuadrículas, en C1 se halló un total de 493 semillas, una de las cuales fue identificada por A. Burkart como $P$. lunatus var macrocarpus ${ }^{4}$ (Figura 40), la única reportada hasta el momento en la arqueología del noroeste argentino, habiendo hallazgos sólo en la provincia de Córdoba (López 2005, 2007). Junto a esta semilla se halló también el único registro de la especie Cassia hookeriana Gill. ex Hook. et Arn de toda la localidad arqueológica, consistente en una vaina entera, seca, que conserva aún sus semillas en el interior (Pochettino 1985) (Figura 40). Cassia hookeriana es un arbusto de 0,5 a $2 \mathrm{~m}$ de altura que crece actualmente en el área donde se emplaza Pampa Grande (Pochettino 1985).

En la cuadrícula B4 se recuperaron sólo 3 semillas de P. vulgaris var vulgaris asociadas a tiestos ordinarios, restos de vainas de Arachis sp y endocarpios de Geoffroea decorticans. Lamentablemente no contamos con datos estratigráficos precisos para estos hallazgos.

Otras cuevas: Como puede verse en el gráfico 14 se recuperaron escasas semillas de P. vulgaris var vulgaris en otras cuevas de esta localidad: dos en la

\footnotetext{
${ }^{4}$ Todas las determinaciones y comentarios realizados por A. Burkart fueron obtenidos de las etiquetas del instituto Darwinion que acompañan al material arqueológico que conforma esta colección.
} 
Caverna III (una aún dentro de la vaina) y una en la caverna IV asociada a restos óseos humanos.

Estudio morfológico de ejemplares de la colección Pampa Grande.

Los Aparejos: Se analizó un muestra seleccionada al azar de la acumulación del sector III, E1, capa 4 (0,60-0,80) consistente en 21 semillas enteras. (Tabla 67).

Todas las semillas son elípticas llenas o semillenas, poseen un solo color entre el rojo oscuro o rojo ocre habiendo un solo caso de semilla color negra. Como mencionamos antes sólo en esta cueva se recuperó una semilla de Phaseolus vulgaris bicolor blanca y negra. Todas las semillas (excepto la de color negro) presentan la zona de la micrópila más oscurecida (en esto coinciden con la semilla de SSalLap20, siendo un carácter típico de los cultivares andinos, Beebe et al. 1996) y la gran mayoría presenta también veteado o moteado oscuro en el resto de la superficie.

En segunda instancia se realizó un muestreo dirigido dentro del mismo conjunto seleccionándose un grupo de 30 semillas que, a ojo desnudo, parecían ser más pequeñas y redondeadas (Tabla 68).

En este conjunto se pudo constatar la presencia de formas (esférica, oblonga, llena y semillena o arriñonada corta) que no estaban presentes en la selección anterior. El patrón de color, en cambio, es similar al del grupo anterior.

$\mathrm{Si}$ agrupamos ambas muestras podemos ver la distribución en forma (gráfico 20y 21) y color (gráfico 22) del conjunto.

E1 Litro: Se analizó una muestra de 50 semillas seleccionadas al azar procedentes de la cuadrícula 1 entre el nivel de superficie y $0,70 \mathrm{~cm}$. de profundidad (Tabla 69). 
Las formas y colores registrados en este conjunto de semillas son mucho más diversas que las observadas en la cueva Los Aparejos (gráficos 23, 24 y 25). En cuanto al color el tipo "dusky red" es abundante al igual que en Los Aparejos, pero el color negro no registrado en esta última cueva es igualmente abundante en El Litro. En lo que respecta a forma sigue dominando la forma elíptica, pero en este caso -contrariamente a lo que ocurre en Los Aparejos- la forma semillena es más frecuente que la llena y esta última es igual de frecuente que la aplanada, no registrada en Los Aparejos.

En el caso del CV, los resultados son altamente similares para ambos conjuntos (Tabla 70), por lo que este parámetro no indica diferencias en la diversidad entre ambas cuevas.

En el caso de Pampa Grande, contrario a lo observado en Los Morrillos de Ansilta, la heterogeneidad en los conjuntos de semillas se detecta por medio del empleo de índices que indican forma y no a través del CV de medidas lineales que indican tamaño.

Morfología de bilio, micrópila y rafe.

No se observaron diferencias morfologías en la micrópila ni en el hilio entre los distintos ejemplares arqueológicos analizados. Sí se observaron, en cambio, diferencias en el rafe. En ejemplares de $P$. vulgaris var aborigineus esta área presenta sólo dos esferas pequeñas. Las semillas de Pampa Grande de forma redondeada presentan también dichas esferas, en cambio, aquellas con forma más oblonga, presentan excrecencias adicionales en la zona del rafe (Figura 41). Esta ausencia de excrecencias adicionales se observa también en el ejemplar de la capa E3 de Huachichocana (no así en el de la capa C) y en el ejemplar de Puente del Diablo. Si bien interesante, este carácter no resulta lo suficientemente conspicuo como para considerarlo significativo en esta tesis, más allá de la asociación entre morfología general de la semilla y del rafe. 
VAINAS: Análisis macroscópico de frutos de P. vulgaris de la colección de referencia

El conjunto de frutos de $P$. vulgaris var aborigineus resultado de la colectas efectuadas por el personal de la estación Cerrillos (INTA) en el oriente salteño permitió advertir la presencia de vainas con distinto grado de dehiscencia e incluso indehiscentes tal como mencionaran Brücher y Berglund-Brücher (1976).

A diferencia de lo registrado en las poblaciones de esta variedad por Menéndez Sevillano (2002) los frutos de toda la colección de referencia son de color crema a amarillo y no poseen en ningún caso estrías púrpuras.

Los frutos de $P$. vulgaris var vulgaris de la colección son totalmente indehiscentes y coinciden en sus caracteres con los descritos por Menéndez Sevillano (2002).

El espiralamiento post-cosecha en vainas de P. vulgaris var vulgaris con distinto grado de maduración

Las cuatro vainas analizadas representaron tres grados distintos de madurez progresivos:

$a_{-}$dos vainas inmaduras y sin semillas, color verde.

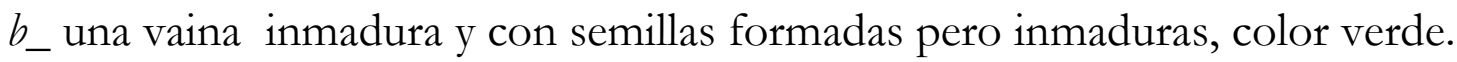

c_ una vaina madura pero no seca, con semillas también maduras, color amarillo.

Tras secarse bajo el sol directo a lo largo de una semana, las valvas de las vainas del tipo $a$ se encogieron y deformaron, pero no se espiralaron, una mantuvo su color verde original, en tanto la otra se tornó amarilla al desecarse. Las valvas del fruto tipo $b$ también se encogieron y deformaron sin espiralarse, manteniendo su color verde original. Finalmente, las valvas del fruto tipo c se 
espiralaron parcialmente adquiriendo una apariencia similar a la de los frutos de P. vulgaris var aborigineus dehiscentes de la colección de referencia.

Análisis anatómico de vainas.

a- P. vulgaris.

Se realizaron cortes transversales y levantados superficiales de las vainas de $P$. vulgaris var vulgaris y de P. vulgaris var aborigineus. Siguiendo a Winton y Winton (1935), Esau (1982) y Herrera Flores et al. (2005) se identificaron en las caras de las valvas las siguientes capas: epicarpio o epidermis, hipodermis colenquimatosa de células elongadas y engrosadas, mesocarpio o parénquima externo con haces vasculares, esclerénquima con esclereidas ${ }^{5}$ alargadas, mesocarpio interno constituido por tejido parenquimático y endocarpio o parénquima interno. Estos dos últimos tejidos se hallan estrechamente relacionados siendo indiferenciables (Figura 42).

Se observaron gran cantidad de diferencias en el tipo de disposición de células del colénquima (hipodermis) y del esclerénquima de las dos variedades de $P$. vulgaris. Estas diferencias fueron detectadas tanto al comparar los tres sectores (cara de la valva, sutura ventral y sutura dorsal) de cada corte transversal realizado, como en la disposición de dichos tejidos en cada uno de los tres sectores.

Las diferencias se detectaron además tanto entre ambos tejidos como a lo largo de un mismo tejido (Tabla 71, láminas 37 a 48). El único caso donde no se observaron diferencias significativas entre $P$. vulgaris var vulgaris y $P$. vulgaris var aborigineus fue en el esclerénquima de las caras de la valva.

\footnotetext{
${ }^{5}$ Si bien todos los autores consultados (Winton y Winton 1935, Esau 1982, Herrera Flores et al. 2005) describen las células de este tejido como fibras, la presencia de plasmodesmos en las paredes celulares de las mismas nos llevan a clasificarlas como esclereidas.
} 
Se observó también la superficie de las vainas de ambas variedades al MEB (lámina 49). Ambas presentan pelos glandulares y tricomas unicelulares con células basales hexagonales y el extremo en forma de gancho. La presencia y frecuencia de tricomas varía con factores ambientales, y se cree que estuvieron bajo selección en respuesta a la predación de insectos, ya que poseen una función de defensa mecánica, en tanto que los pelos glandulares pueden exudar toxinas (Butler 2002). A pesar de esto no se observaron diferencias significativas entre ambos taxa analizados con respecto a este carácter.

P. vulgaris var aborigineus presenta una cutícula más estriada. La tendencia a producir cera epicuticular está genéticamente controlada, pero factores ambientales como temperatura, humedad e intensidad de luz están involucrados en su expresión y pueden darse variaciones en la forma de los cristales de cera (Butler 2002).

Otra diferencia observada es el largo de los estomas siendo mayor en la

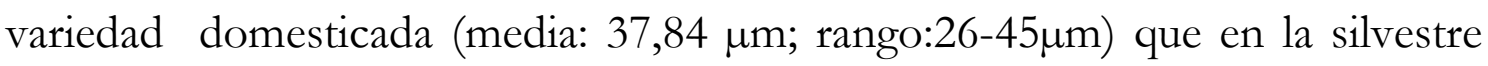

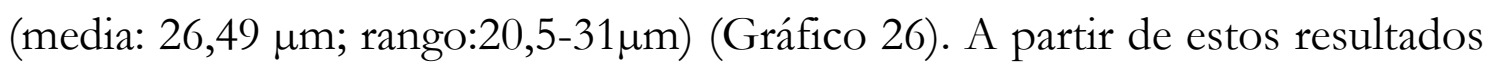
se puede inferir la presencia de la variedad domesticada ante estomas con más de $31 \mu \mathrm{m}$ de largo y la variedad silvestre ante estomas cuyo largo se encuentra entre los 20 y $25 \mu \mathrm{m}$.

Finalmente se midió el espesor del pericarpio en ambas variedades (Gráfico 27), siendo el de la variedad silvestre menor a $0,21 \mathrm{~mm}$, en tanto el de la variedad domesticada es siempre mayor a 0,24 milímetros. Por lo tanto el largo de los estomas, la estriación de la cutícula y el espesor del pericarpio considerados como caracteres útiles para discriminar entre la variedad silvestre y domesticada de $P$. vulgaris en ejemplares arqueológicos.

\section{b- Caesalpinea gillesii}


Las valvas de los frutos de esta leguminosa también están constituidas por un epicarpio o epidermis, hipodermis colenquimatosa de células elongadas y engrosadas, mesocarpio o parénquima externo con haces vasculares, esclerénquima y endocarpio.

Las diferencias observadas respecto de $P$. vulgaris fueron principalmente una hipodermis de células con paredes menos engrosadas y un mesocarpio externo y endocarpio compuesto por un mayor número de células. El endocarpio de esta especie posee dos capas de esclereidas orientadas en sentido distinto.

Respecto a los rasgo superficiales, a diferencia de Phaseolus sp., C. gillesii no presenta una cutícula estriada ni tricomas unicelulares con el extremo en forma de gancho. Posee en cambio pelos uni y biseriados con el extremo aguzado y llagas superficiales (Lámina 50).

\section{ANÁLISIS DE VAINAS ARQUEOLÓGICAS DE LA COLECCIÓN} PAMPA GRANDE.

\section{Análisis de los restos presentes en la colección.}

El hallazgo de vainas secas en excelente estado de conservación constituye el único registro arqueológico de este órgano reportado hasta el momento en el NOA. Su distribución por cueva puede verse en el gráfico 28. Al igual que en el caso de las semillas, las mismas fueron analizadas por A. Burkart quienes las identificó como Phaseolus vulgaris L. La peculiaridad de estos restos es que en todos los casos las valvas se encuentran espiraladas, siendo su tamaño variable aunque, en muchos casos, parecería que el mismo se corresponde con el de frutos domesticados actuales. 
Los Aparejos: La cantidad de vainas recuperadas es mucho menor en comparación con la cantidad de semillas y su frecuencia de distribución según sector, cuadrícula y capa puede verse en la tabla 72 . En el caso de un conjunto superficial del sector I Burkart señala la presencia de "semillas de tres variedades y de una vaina dehiscente de variedad primitiva".

Con relación a las concentraciones de semillas antes analizadas, sólo en la capa $2(0,40-0,60)$ de $\mathrm{F} 0$ y en el perfilado de la urna $\mathrm{N}^{\circ} 5$ se recuperaron vainas, las cuales se hallan ausentes de la cuadrícula E1. En general las vainas se concentran en las dos primeras capas de las cuadrículas D1 y F2.

E1 Litro: Sólo en C1 se recuperaron 21 vainas distribuidas según puede verse en la tabla 73. Si bien esta cueva es la que posee el mayor número de vainas, catorce de ellas proceden de contextos poco definidos.

Otras cuevas: Como puede verse en el gráfico 27 se recuperaron escasas vainas en otras cuevas de esta localidad (tres en Caverna III y una en Caverna IV). En este caso carecemos también de datos estratigráficos y de procedencia más precisos.

\section{Análisis macroscópico y microscópico de vainas P. vulgaris de Pampa Grande}

Del conjunto de vainas recuperadas en esta localidad arqueológica se seleccionó una muestra compuesta por cuatro vainas procedentes de distintas cuevas (tabla 74). En el caso particular de Los Aparejos se seleccionó el fruto señalado por Burkart como una posible forma silvestre. En los cuatro casos las vainas presentan colores que varían entre el castaño al amarillo, sólo la muestra de El Litro posee estrías moradas. (Lámina 51).

Todas las medidas correspondientes al espesor del pericarpio son mayores a las obtenidas en valvas de $P$. vulgaris var vulgaris actuales, sólo la 
correspondiente a El Litro se ubica en el límite inferior del rango de distribución de medidas actuales para esta variedad.

Los resultados de la observación de la superficie y del colénquima y esclerénquima de estas cuatro vainas arqueológicas (Tabla 75, láminas 18 a 66) confirmaron su identificación taxonómica como P. vulgaris. La combinación de rasgos que coinciden con los observados en frutos de referencia de las dos variedades de esta especie, así como también de otros novedosos (Tabla 75), impidió la determinación taxonómica a nivel de variedad. A continuación se detallan los mismos en cada valva arqueológica observada:

Caverna IV: En el área de la sutura dorsal las esclereidas oblicuas (tipo I) respecto al plano $Z$ coinciden aproximadamente con lo observado en $P$. vulgaris var aborigineus, en cambio, su relación con respecto a los otros dos planos no se observó en las muestras de referencia. En el caso de las células colenquimáticas de la hipodermis, también su relación respecto del plano $Z$ coincide con lo observado en $P$. vulgaris var aborigineus, lo mismo sucede con la disposición respecto del eje $X$; la ubicación respecto a $Y$ no coincide en cambio con lo observado en las muestras de referencia.

En el área de la sutura ventral la presencia de esclereidas casi perpendiculares a $\mathrm{X}$ coincide con lo observado en $P$. vulgaris var aborigineus, en cambio su disposición respecto de los otros dos planos se observa en las muestras de referencia de ambas variedades. Esto mismo ocurre con la disposición de las células del colénquima respecto de $X$, siendo su ubicación con respecto a los planos $Y$ y $Z$ la misma que la observada para este tejido en esta área en muestras de P. vulgaris var aborigineus.

En cuanto a los rasgos superficiales se reconocieron bases de tricomas coincidentes con las halladas a nivel específico. Se midió el largo de dos estomas obteniéndose valores de 22,2 y $27 \mu \mathrm{m}$, el primero de ellos está dentro del rango de distribución de valores exhibidos por los estomas de P. vulgaris 
var aborigineus, en tanto el segundo se encuentra en una posición intermedia entre esta variedad y la domesticada.

Por lo tanto, resumiendo lo antes dicho, la valva arqueológica de la Caverna IV posee rasgos similares a $P$. vulgaris var aborigineus, otros presentes en ambas variedades de $P$. vulgaris y otros no observados en ninguna de las muestras de referencia.

Caverna III: La disposición de las células colenquimáticas tanto en caras de la valva como en la sutura dorsal coincide con lo observado en muestras de referencia de $P$. vulgaris var vulgaris En el caso de la sutura ventral posee células del esclerénquima oblicuas a los tres planos, tanto de tipo I (lo que coincide con lo observado en $P$. vulgaris var aborigineus) como de tipo II (lo que coincide con lo observado en $P$. vulgaris var vulgaris). La disposición de las células colenquimáticas de la hipodermis en la sutura ventral no coincide con lo registrado en las muestras de referencia, siendo similar a las oblicuas respecto de los tres planos tipo I observadas en valvas de $P$. vulgaris var aborigineus

Las observaciones de la superficie permitieron ver una cutícula estriada que

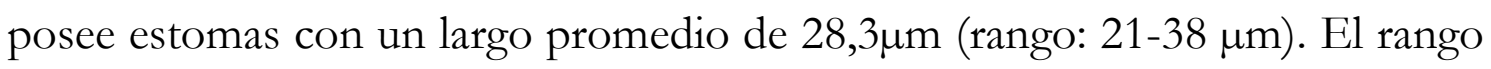
de valores de los estomas de esta vaina arqueológica abarca los registrados actualmente tanto en la variedad silvestre como en la domesticada. También se observaron tricomas con células basales hexagonales con extremo en forma de gancho, tanto uniseriados como biseriados. Este último tipo no fue registrado en material actual de referencia para ninguna de ambas variedades. Resumiendo se puede decir que la valva de la Caverna III posee en la cara y sutura dorsal rasgos similares a los observados en $P$. vulgaris var vulgaris, las medidas de los estomas se ubican en una posición intermedia respecto de las registradas para la variedad silvestre y domesticada actualmente y tanto en los 
tricomas superficiales como en la sutura ventral se observaron rasgos que no se detectaron en las muestra de referencia.

El Litro: Los rasgos de las células que componen la hipodermis en esta valva coinciden totalmente con las observadas en la caverna III, asemejándose por ende a $P$ vulgaris var vulgaris. En lo que respecta a la hipodermis de la sutura dorsal, un grupo de células colenquimáticas (perpendiculares a $X$ y paralelas a $Z$ y a $Y$ ) coincide con lo observado en P. vulgaris var aborigineus, en tanto el otro grupo de células con disposición distinta (oblicuas a los tres planos, tipo I) coincide, con lo observado en P. vulgaris var vulgaris.

Las células del esclerénquima de la sutura ventral son siempre oblicuas respecto de los tres planos, las tipo I coinciden con lo observado en $P$. vulgaris var aborigineus en tanto las tipo II concuerdan con lo observado en P. vulgaris var vulgaris. En las células colenquimáticas de la hipodermis se da una situación similar coincidiendo las oblicuas a los tres planos tipo I con lo observado en P. vulgaris var aborigineus en tanto las de tipo II se asemejan a las de P. vulgaris var vulgaris, las cuales presentan dicha orientación (tipo II) respecto a a $Z$ y a $Y$, siendo en cambio casi paralelas a $X$.

La superficie de esta vaina cuenta con una cutícula marcadamente estriada que conserva solamente las bases hexagonales de los tricomas. Los estomas poseen un largo promedio de $29 \mu \mathrm{m}(22-36 \mu \mathrm{m})$. Estos rangos de valores son muy similares a los registrados en la vaina de la Caverna III abarcando los valores presentes en poblaciones tanto de $P$. vulgaris var vulgaris como de $P$. vulgaris var aborigineus.

Resumiendo los datos obtenidos respecto de esta valva podemos decir que en sus caras presenta rasgos propios de P. vulgaris var vulgaris, en tanto en las medidas de sus estomas y disposición de los tejidos de las suturas exhibe una combinación de caracteres presentes en ambas variedades. 
Los Aparejos: En las caras de la valva un grupo de células colenquimáticas de la hipodermis (paralelas a $X$, levemente oblicuas -tipo II- a $Y$ y a Z) se asemejan en su relación con los planos $Y$ y $Z$ a $P$. vulgaris var aborigineus, en tanto en su relación con el plano X se asemejan a P. vulgaris var vulgaris. Sin embargo en el otro grupo ocurre lo inverso, asemejándose las células de este tejido a $P$. vulgaris var vulgaris en su relación con los planos $Y$ y $Z$, en tanto en el plano $X$ se asemeja a $P$. vulgaris var aborigineus.

Las células colenquimáticas de la hipodermis de ambas suturas y las esclereidas oblicuas a los tres planos (tipo I) de la sutura ventral se asemejan a P. vulgaris var aborigineus. El otro conjunto de esclereidas de la sutura ventral coinciden con esta misma variedad silvestre en su posición relativa al plano $X$, la relación con el plano $Y$ se encuentra en cambio en las muestras actuales de ambas variedades, pero su relación con $Z$ no se observa en ninguna de ellas.

En la superficie se observaron tricomas y cutícula idénticos a lo observado en material actual de referencia de la especie. Se pudo detectar la presencia de un único estoma de 31,4 $\mu \mathrm{m}$ de largo, valor que no puede considerarse por sí solo dado lo variable de este rasgo biométrico.

A modo de resumen podemos decir que esta valva posee rasgos hallados en $P$. vulgaris var vulgaris en la hipodermis de ambas suturas y en algunas esclereidas de la sutura ventral. En cambio posee una combinación de rasgos de ambas variedades en caras de la valva y en algunas esclereidas de la sutura ventral.

\section{Discusión}

Distintas líneas de evidencia se han aplicado en este capítulo para comprender el manejo humano de $P$. vulgaris por parte de poblaciones humanas pretéritas. En lo que respecta a las semillas de esta especie, los análisis de macrorrestos analizados en este capitulo han evidenciado que sólo la semilla arqueológica de SSalLap20 posee rasgos que pueden considerarse intermedios entre aquellos 
que caracterizan actualmente la variedad silvestre y aquellos propios de la variedad domesticada en poblaciones del NOA. Los restos de semillas de Los Morrillos y Pampa Grande son semejantes en todo sentido a los de P. vulgaris var vulgaris, habiéndose detectado en el primer sitio un aumento en la variabilidad del tamaño de las mismas a lo largo del tiempo, en tanto en el segundo sitio se registro una diferencia entre cuevas de la localidad habiendo mayor diversidad en forma y color en El Litro respecto de Los Aparejos.

Las vainas arqueológicas de P. vulgaris de Pampa Grande poseen tamaños similares tanto a las de la variedad silvestre como domesticada, siendo siempre espiraladas. Este rasgo por si sólo no es confiable para determinar el grado de asociación con poblaciones humanas de las plantas productoras de dichas vainas. La existencia, por un lado, de vainas de $P$. vulgaris var aborigineus indehiscentes, y, por otro lado, el aspecto espiralado que adoptan las valvas de la variedad domesticada indehiscente tras ser colectadas frescas y luego desecadas, torna la identificación de vainas arqueológicas extremadamente dudosa si se consideran sólo rasgos macroscópicos. El análisis de la disposición interna de los tejidos de los frutos de Pampa Grande, demostró que los mismos poseen una combinación de rasgos presentes tanto en la variedad domesticada como en la silvestre actual, sobre todo en el área de la sutura ventral correspondiente al tejido de dehiscencia. Esta combinación de caracteres podría indicar la existencia en el pasado de Pampa Grande de formas cultivadas con caracteres intermedios. Esta misma combinación de rasgos (vainas dehiscentes y semillas del tamaño de las domesticadas) es señalada por los autores que han estudiado el complejo maleza-cultivodomesticado en la actualidad como propia de las formas intermedias resultado de los cruzamientos de la variedad silvestre con la domesticada. La ausencia de semillas de $P$. vulgaris var aborigineus en las cuevas de esta localidad arqueológica, indica que las mismas no eran consumidas o empleadas para otros fines, como el de conformar parte de los ajuares funerarios. Las grandes 
acumulaciones de semillas arqueológicas recuperadas en las cuevas de esta localidad como conjuntos discretos y delimitados por rocas o paja fuera de los contextos funerarios podrían estar representando las que fueron seleccionadas y guardadas para el próximo ciclo de siembra. Si bien las semillas pueden presentar caracteres intermedios (como en el caso del ejemplar de SSalLap20), también se ha constatado reiteradamente la presencia de ejemplares con una morfología totalmente similar a la domesticada en los sitios arqueológicos más tempranos de América. Esto hace que las semillas no sean indicadoras confiables de cambio ya que pueden evidenciar o enmascarar al mismo. Por lo tanto en el caso de Pampa Grande las semillas de P. vulgaris se podrían corresponder tanto a formas intermedias (cuya existencia se constata a través del análisis de los restos de frutos) como plenamente domesticadas.

En otros tipos de registro, como el de Los Morrillos, donde no se han recuperado vainas, la situación es mucho más difícil, no pudiendo descartarse a priori la presencia de formas transicionales considerando sólo los rasgos morfológicos de las semillas arqueológicas.

Es probable que los antiguos habitantes de Pampa Grande (y probablemente también los de otros sitios formativos como Campo del Pucará, Casas ViejasEl Mollar y Aconquija) estuvieran manejando los cultivos de P. vulgaris como un complejo maleza-cultivo-domesticado, siendo una estrategia tendiente al aumento de la variabilidad. Esta es una modalidad muy común actualmente en el cultivo de esta especie en el área andina (incluido el NOA) sobre todo a nivel hortícola. Un análisis distinto de este fenómeno desde una perspectiva evolutiva podría indicar la ausencia de una domesticación plena al no existir aislamiento reproductivo y falta de una presión de selección cultural homogeneizadora. Esta baja intensidad de selección y la presencia de cruzamientos habría obstaculizado la rápida fijación de los pocos genes vinculados al "síndrome adaptativo de la domesticación" en P. vulgaris. 
Por ende los complejos maleza-cultivo-domesticado como modelo de "domesticación en progreso" -como los entienden ciertos autores- habrían comenzado a desarrollarse al menos en algunas regiones del NOA desde el formativo temprano, continuando hasta la actualidad. 
Tabla 63: forma de la semilla de $P$. vulgaris var vulgaris en función del índice $\mathrm{J}=$ longitud/anchura según Puerta Romero (1961) en Menéndez Sevillano (2002)

\begin{tabular}{|c|c|}
\hline Forma & Longitud/anchura \\
\hline Esférico & $1,16-1,42$ \\
\hline Elíptico & $1,43-1,65$ \\
\hline Oblongo o arriñonado corto & $1,66-1,85$ \\
\hline Oblongo o arriñonado medio & $1,86-2$ \\
\hline Oblongo o arriñonado largo & $+2,00$ \\
\hline
\end{tabular}

Tabla 64: forma de la semilla de $P$. vulgaris var vulgaris en función del índice H=grosor/anchura según Puerta Romero (1961) en Menéndez Sevillano (2002)

\begin{tabular}{|c|c|}
\hline Forma & Grosor/anchura \\
\hline Aplanada & Menor o igual a 0,69 \\
\hline Semillena & $0,7-0,79$ \\
\hline Llena & Mayor o igual a 0,8 \\
\hline
\end{tabular}

Tabla 65: promedio, desvío estándar (DS), coeficiente de variación (CV), valor mínimo (MIN) y valor máximo (MAX) de los conjuntos de semillas de P. vulgaris var vulgaris analizados por Roig (1977), las medidas están consignadas en milímetros.

\begin{tabular}{|c|c|c|c|c|c|c|c|c|c|c|c|c|}
\hline & \multicolumn{3}{|c|}{$50 \mathrm{AC}-200 \mathrm{DC}$} & \multicolumn{3}{|c|}{ 0-50 DC } & \multicolumn{3}{|c|}{$50-200 / 210 \mathrm{DC}$} & \multicolumn{3}{|c|}{ 280-375 DC } \\
\hline & Ancho & Largo & Grosor & Ancho & Largo & Grosor & Ancho & |Largo & Grosor & Ancho & Largo & Grosor \\
\hline Promedio & 8,66 & 12,07 & 6,96 & 8,13 & 13,49 & 6,30 & 8,59 & 12,25 & 6,60 & 8,18 & 11,72 & 6,95 \\
\hline DS & 1,18 & 1,97 & 0,84 & 1,01 & 1,81 & 0,64 & 1,35 & 1,18 & 1,08 & 1,44 & \begin{tabular}{l|l|}
1,84 \\
\end{tabular} & 1,59 \\
\hline CV & 13,62 & 16,28 & 12,02 & 12,48 & 13,40 & 10,20 & 15,67 & 9,65 & 16,41 & 17,59 & 15,66 & 22,93 \\
\hline MIN & 7,60 & 9,80 & 6,00 & 7,00 & 11,00 & 5,00 & 6,40 & 9,50 & 5,00 & 6,40 & \begin{tabular}{l|l}
8,60 \\
\end{tabular} & 5,10 \\
\hline MAX & 10,50 & 15,00 & 8,00 & 9,80 & 16,00 & 7,00 & 10,80 & 13,50 & 9,50 & 11,00 & 15,00 & 10,00 \\
\hline
\end{tabular}


Tabla 66: distribución de las semillas de Phaseolus vulgaris var vulgaris recuperadas en la cueva Los Aparejos de acuerdo con sector, cuadrícula y capa.

\begin{tabular}{|c|c|}
\hline Datos de etiqueta original & Cantidad \\
\hline Superficial y hasta $10 \mathrm{~cm}$ & 3 \\
\hline Sector I/ superficial & 18 \\
\hline $\begin{array}{l}\text { Sector II/ recolección superficie/ frente } \\
\text { a D1 }\end{array}$ & 3 \\
\hline Sector III/ E2/ superficial & 11 \\
\hline Sector II/ D1 (superficial) & 2 \\
\hline Sector II/ D1/ capa1 $(0,0-0,2)$ & 5 \\
\hline Sector II/ D4 (00- 0.25) & 4 \\
\hline Sector II/ B / capa $1(0,-0,20)$ & 21 \\
\hline Sector III/ E1/ capa 1 (00-0.20) & 45 \\
\hline Sector II/ D1/capa 1, mezcla con 2 & 6 \\
\hline Sector III/ F2/ capa 1 hasta 00-20-40 & 33 \\
\hline Sector III/ E2/ capa1(00-0.20-0.40) & 35 \\
\hline Sector II/ D3/ capa 0.10-0.40 & 1 \\
\hline Sector II/ C3/ 0,10-0,40 cm. & 32 \\
\hline Sector II/ D1/ capa 2 (hasta 0.40) & 7 \\
\hline Sector II/ D1/ capa2 (0.20-0.40) & 8 \\
\hline Sector II/ D4/ capa $2(0.20-0.40)$ & 2 \\
\hline Sector II/ B4/ capa2 (0.20-0.40) & 80 \\
\hline Sector II/ B4/ capa2 (0.20-0.40) & 4 \\
\hline Sector III/ E1/ nivel 2 (0.20-0.40) & 840 \\
\hline Sector II/ D4/ capa3 (0.40-0.60) & 1 \\
\hline Sector III/ F0 (0.40-0.60) & 337 \\
\hline Sector III/ F2/ capa2 (040-060) & 8 \\
\hline Sector III/ E1/ capa4 (0.60-0.80) & 583 \\
\hline Sector III/ E2/ capa $4(0.60-0.80)$ & 1 \\
\hline Sector III/ F2/ capa 5 (0.80-1 m) & 22 \\
\hline
\end{tabular}


Tabla 67: análisis morfológico de 21 semillas de Los Aparejos Sector III, E1, capa4 siguiendo los criterios aplicados por Menéndez Sevillano (2002). Los colores siguen la codificación de la carta Earth Colors (1997).

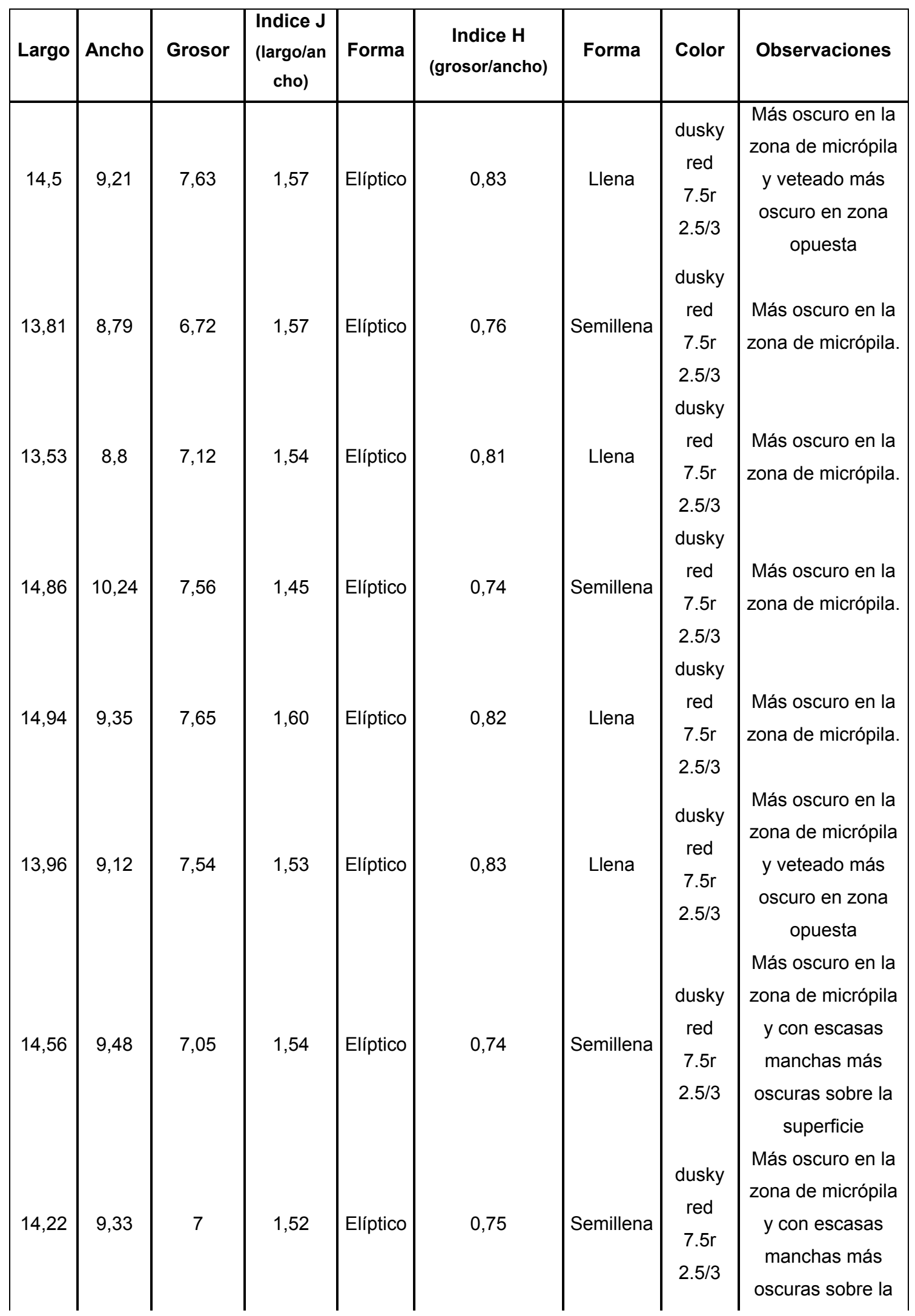




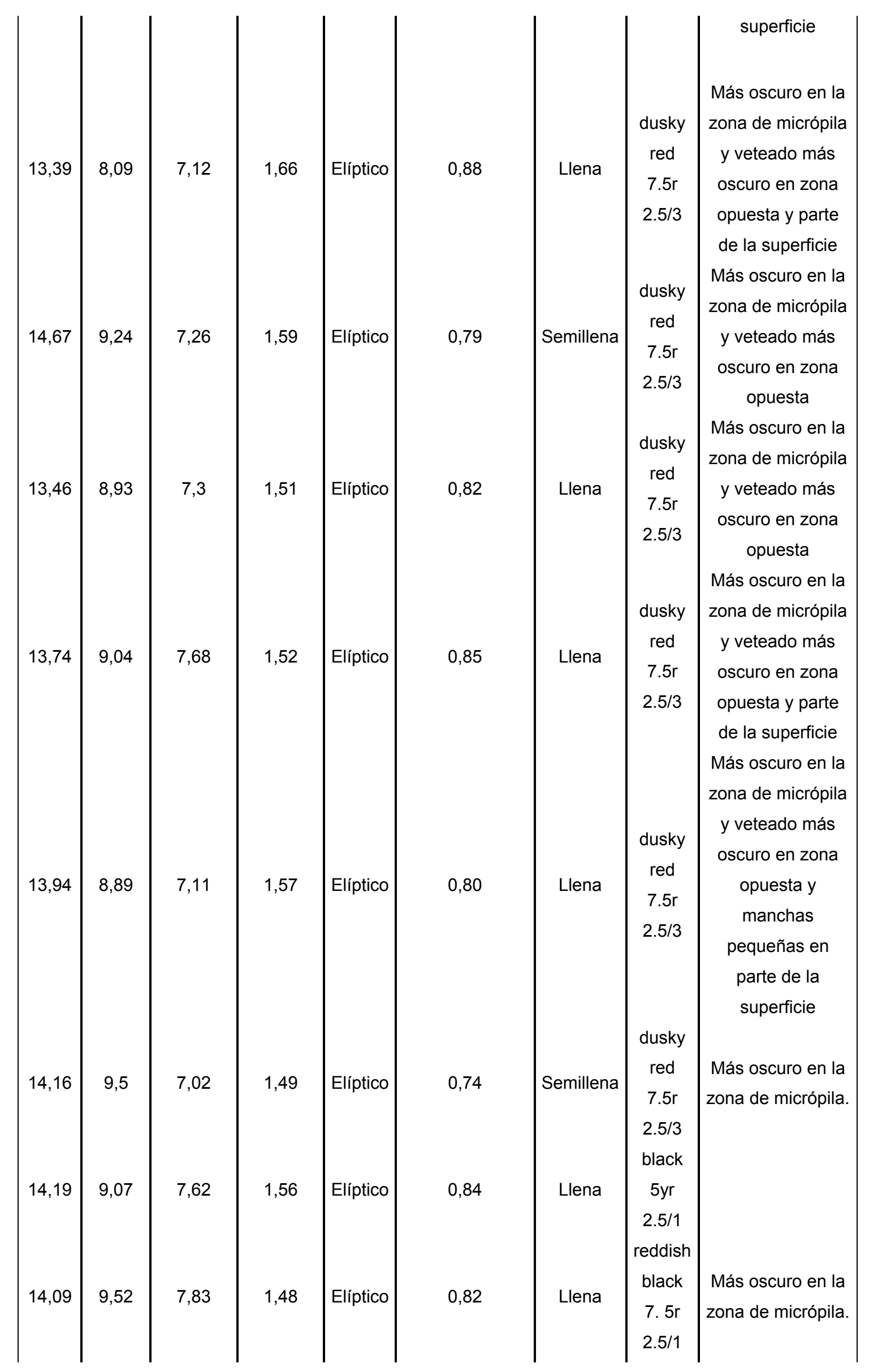




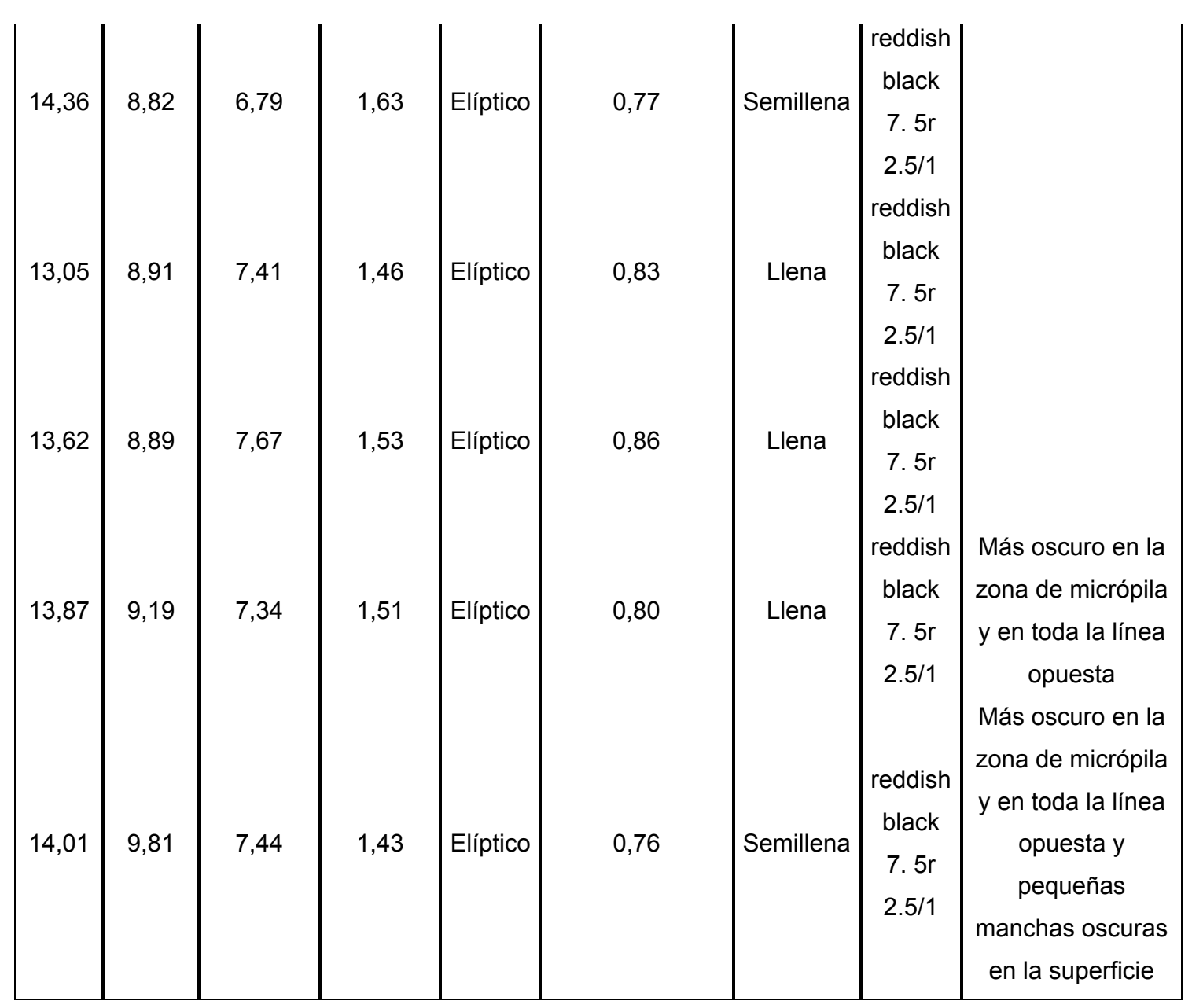


Tabla 68: análisis morfológico de 30 semillas de Los Aparejos Sector III, E1, capa 4 siguiendo los criterios aplicados por Menéndez Sevillano (2002). Los colores siguen la codificación de la carta Earth Colors (1997).

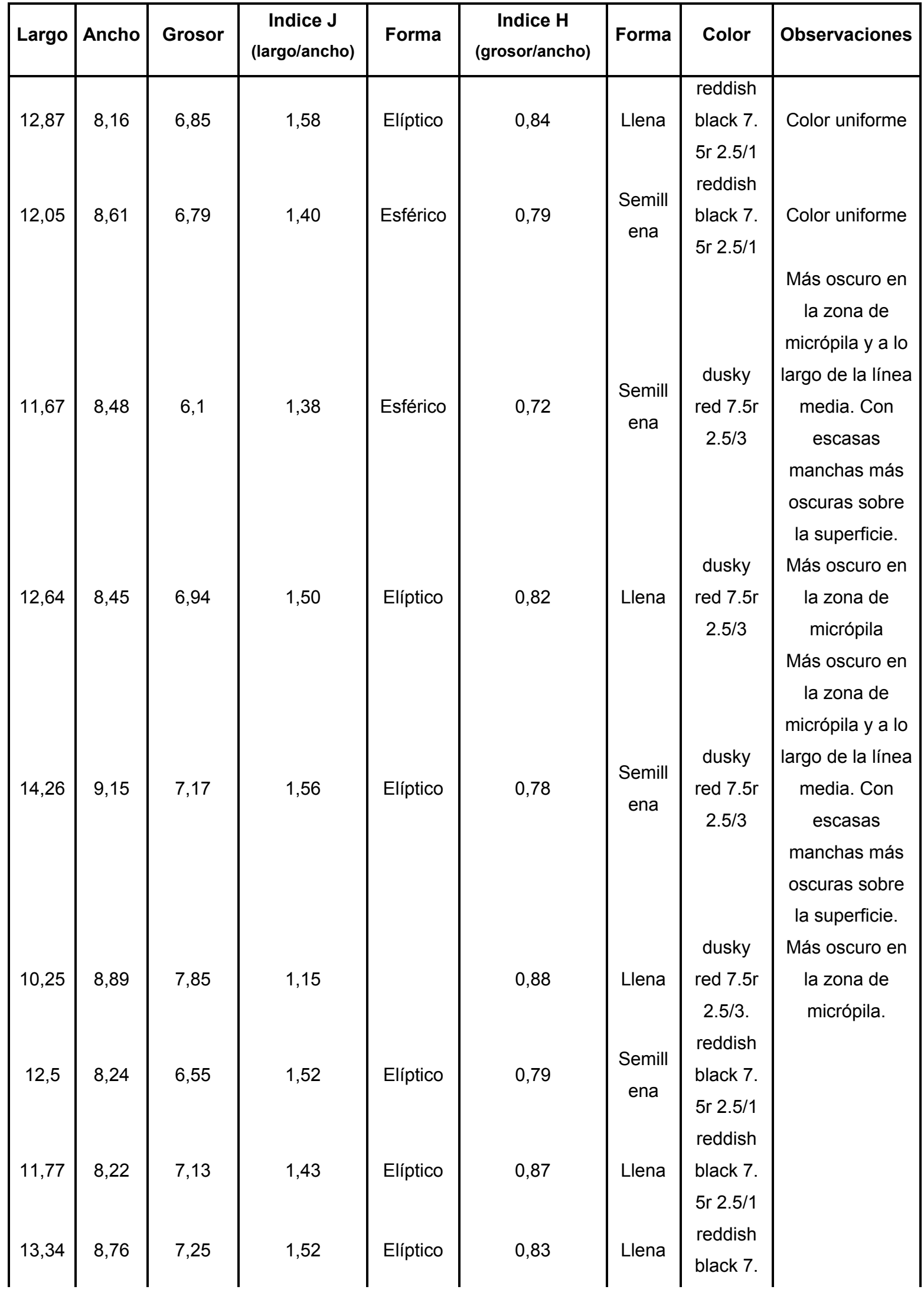




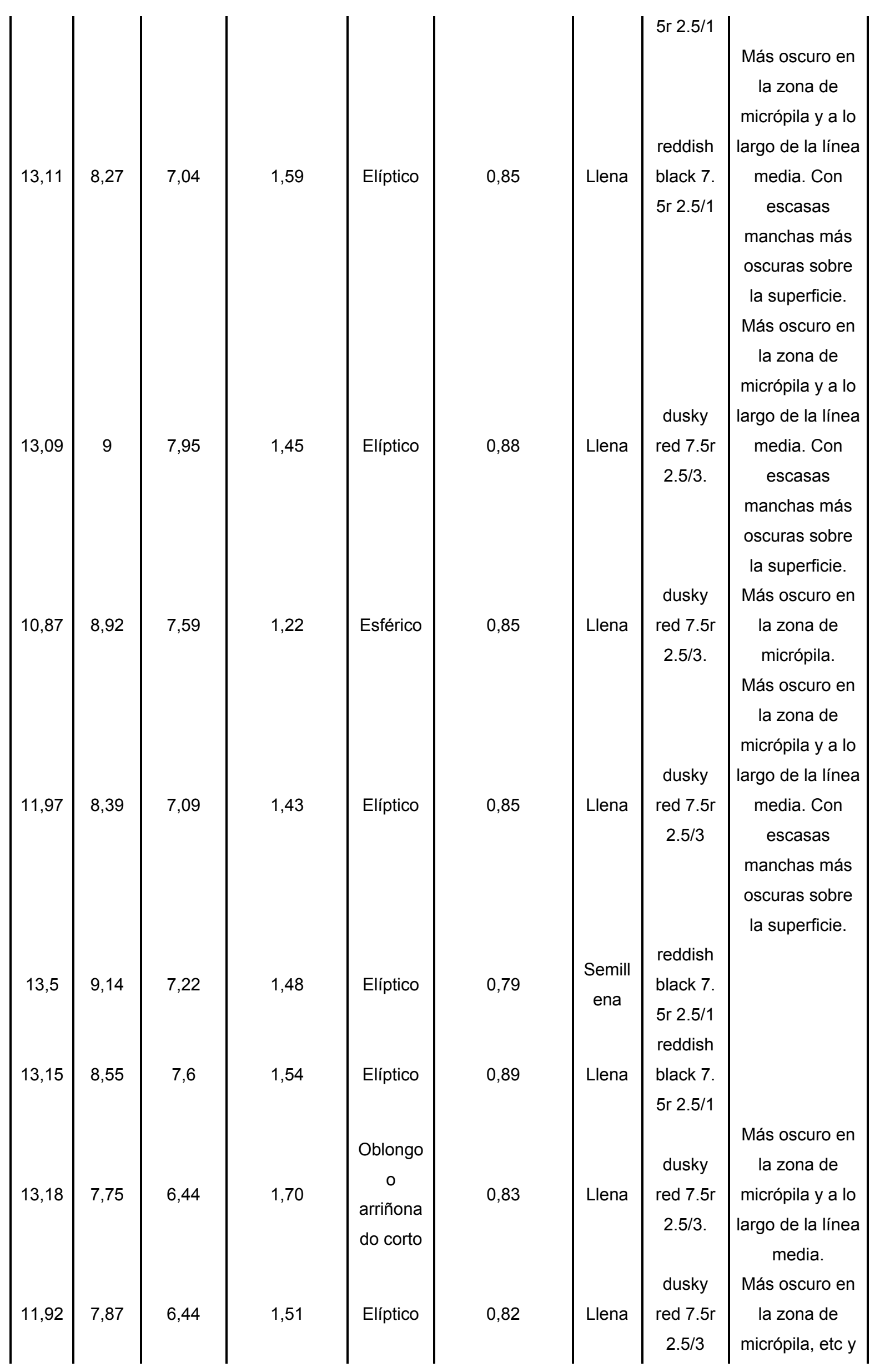




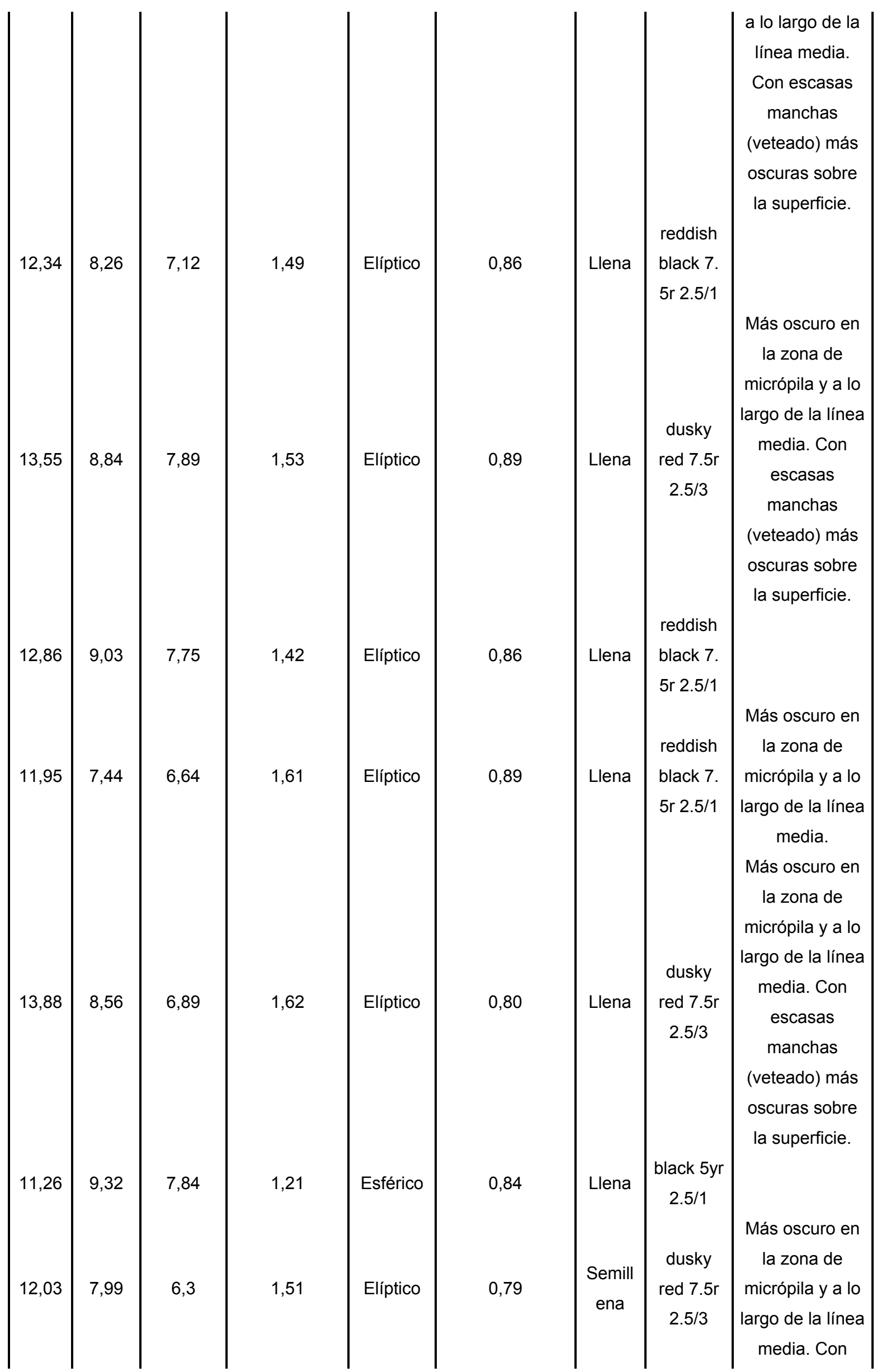




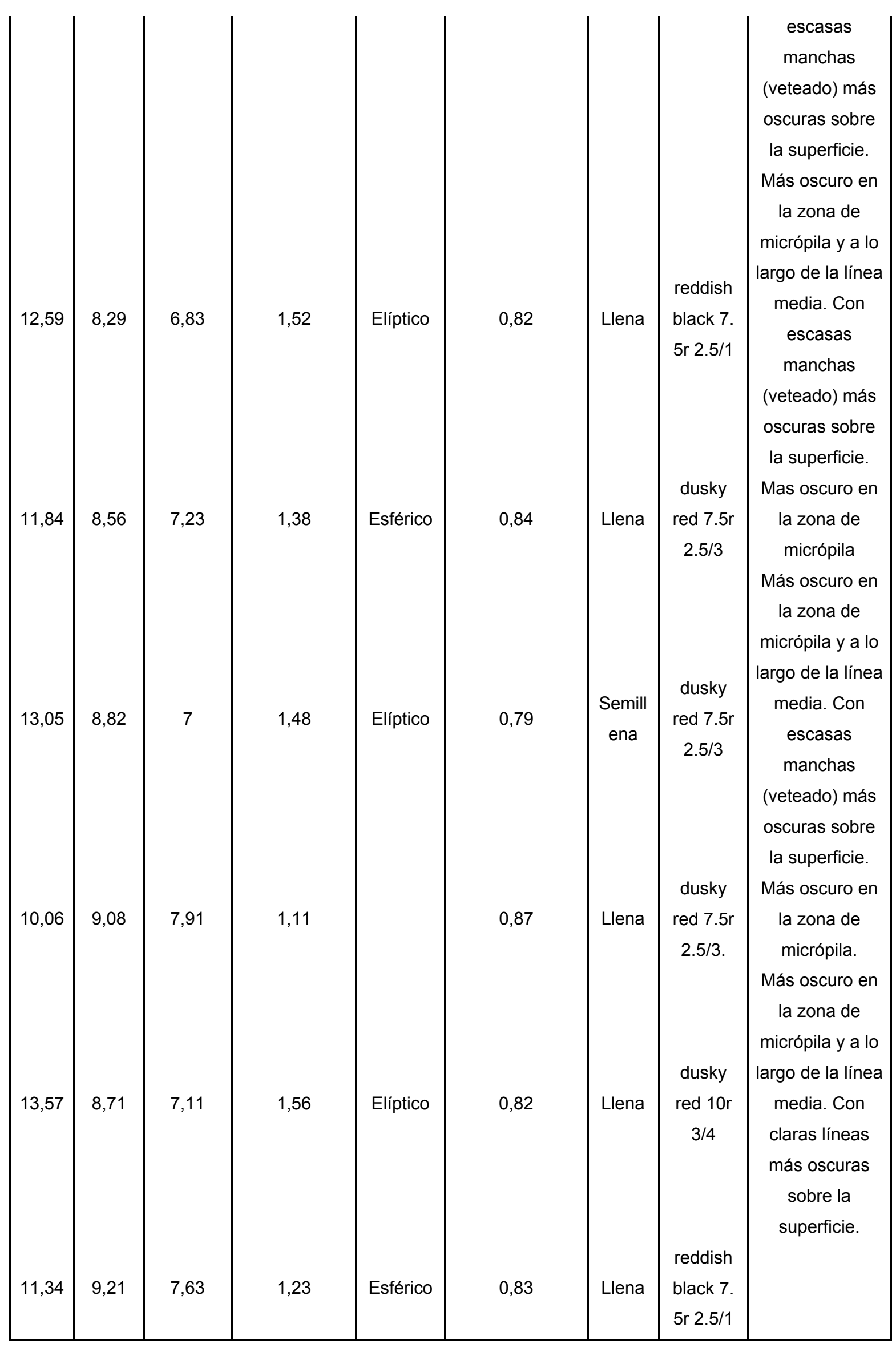


Tabla 69: análisis morfológico de 50 semillas de de la cuadrícula $1(0-0,70 \mathrm{~cm})$ de la cueva El Litro siguiendo los criterios aplicados por Menéndez Sevillano (2002). Los colores siguen la codificación de la carta Earth Colors (1997).

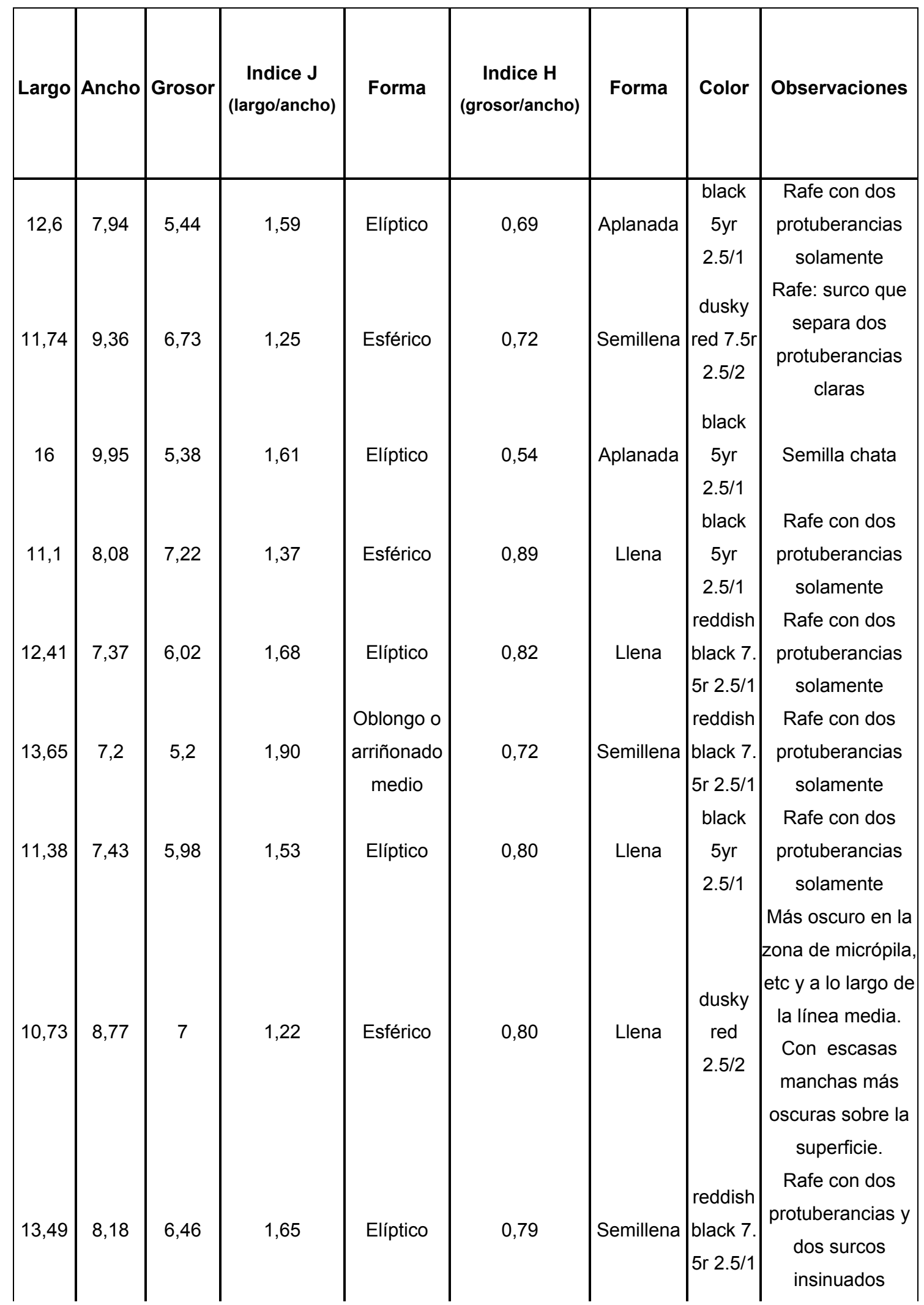




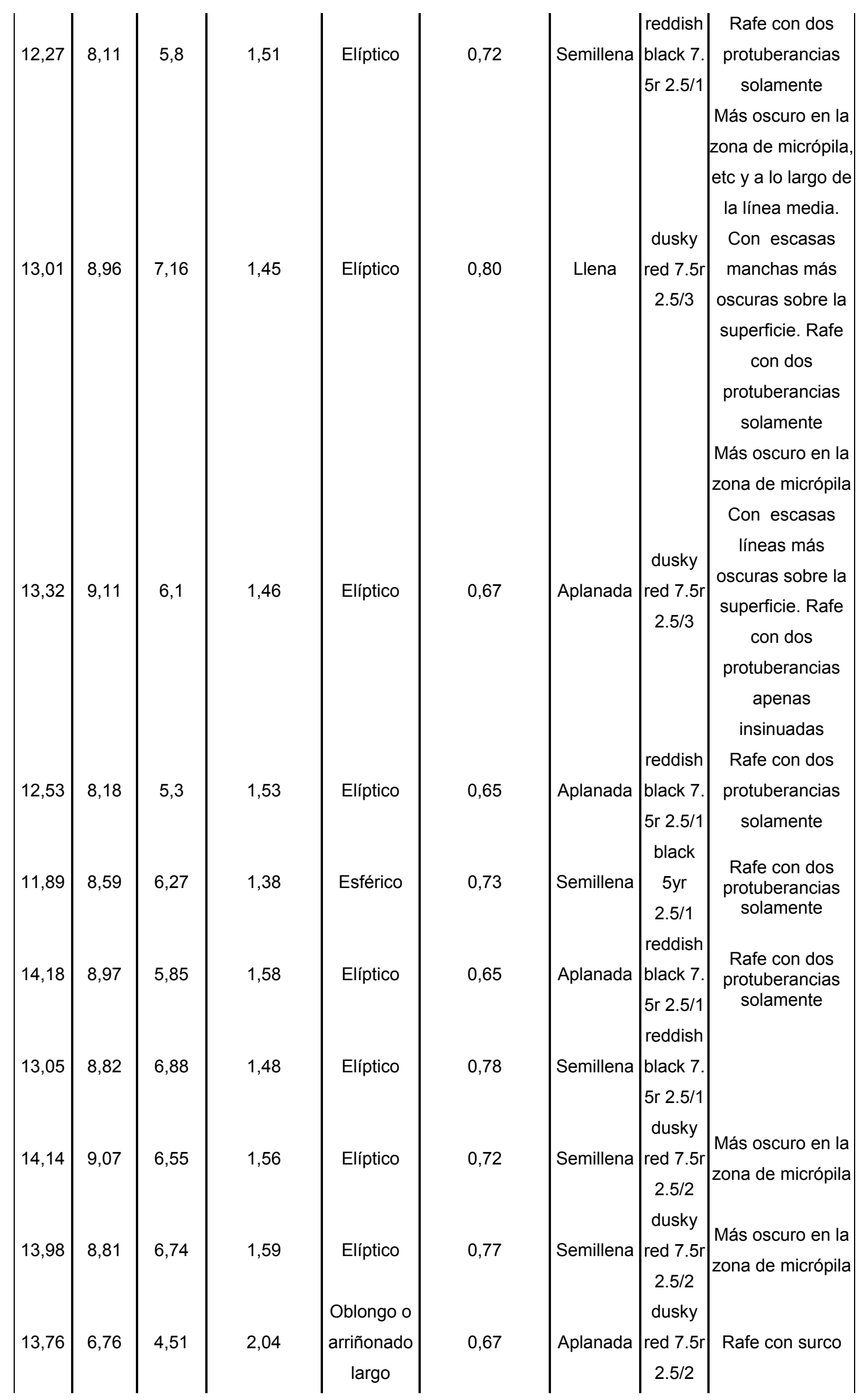




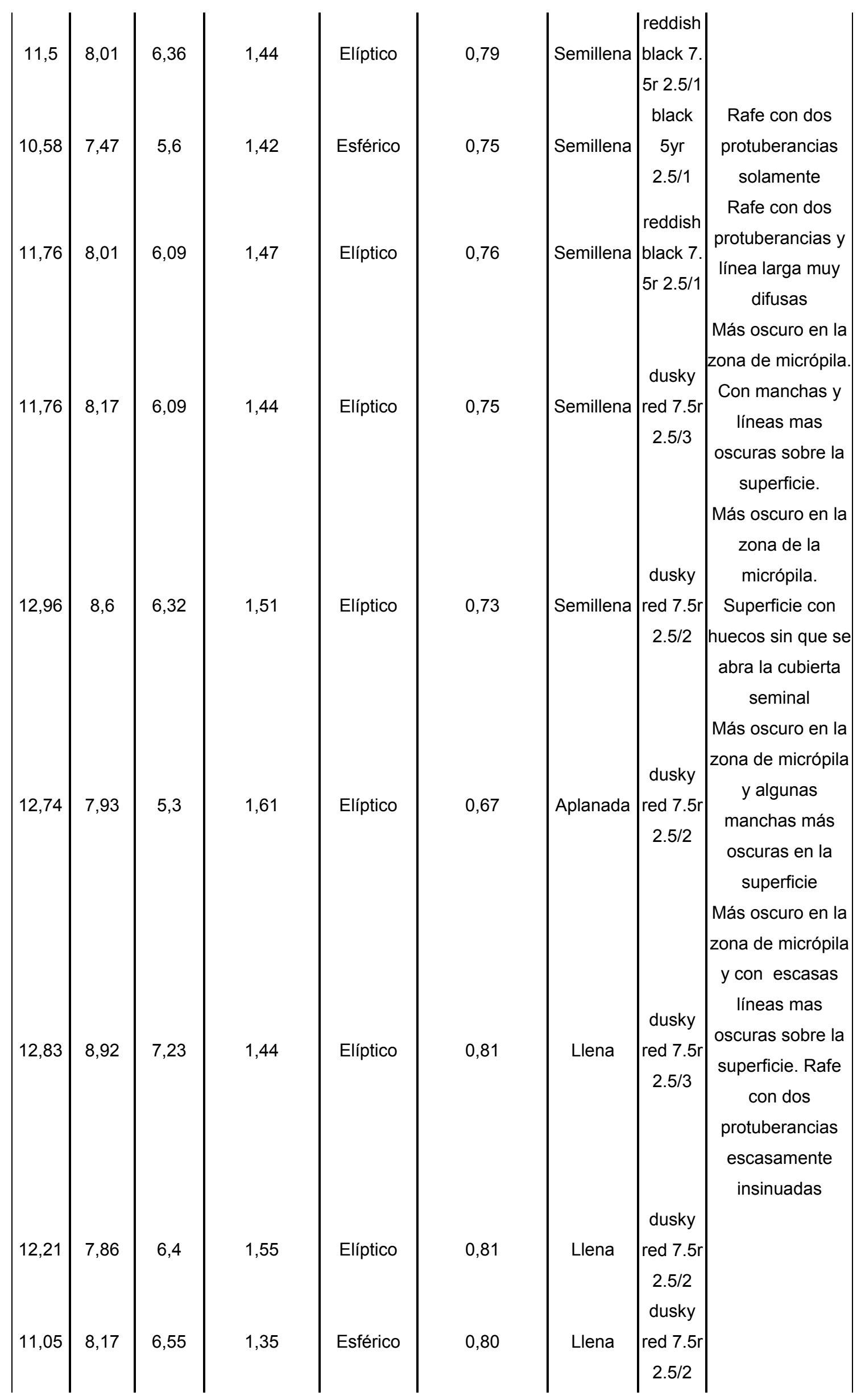




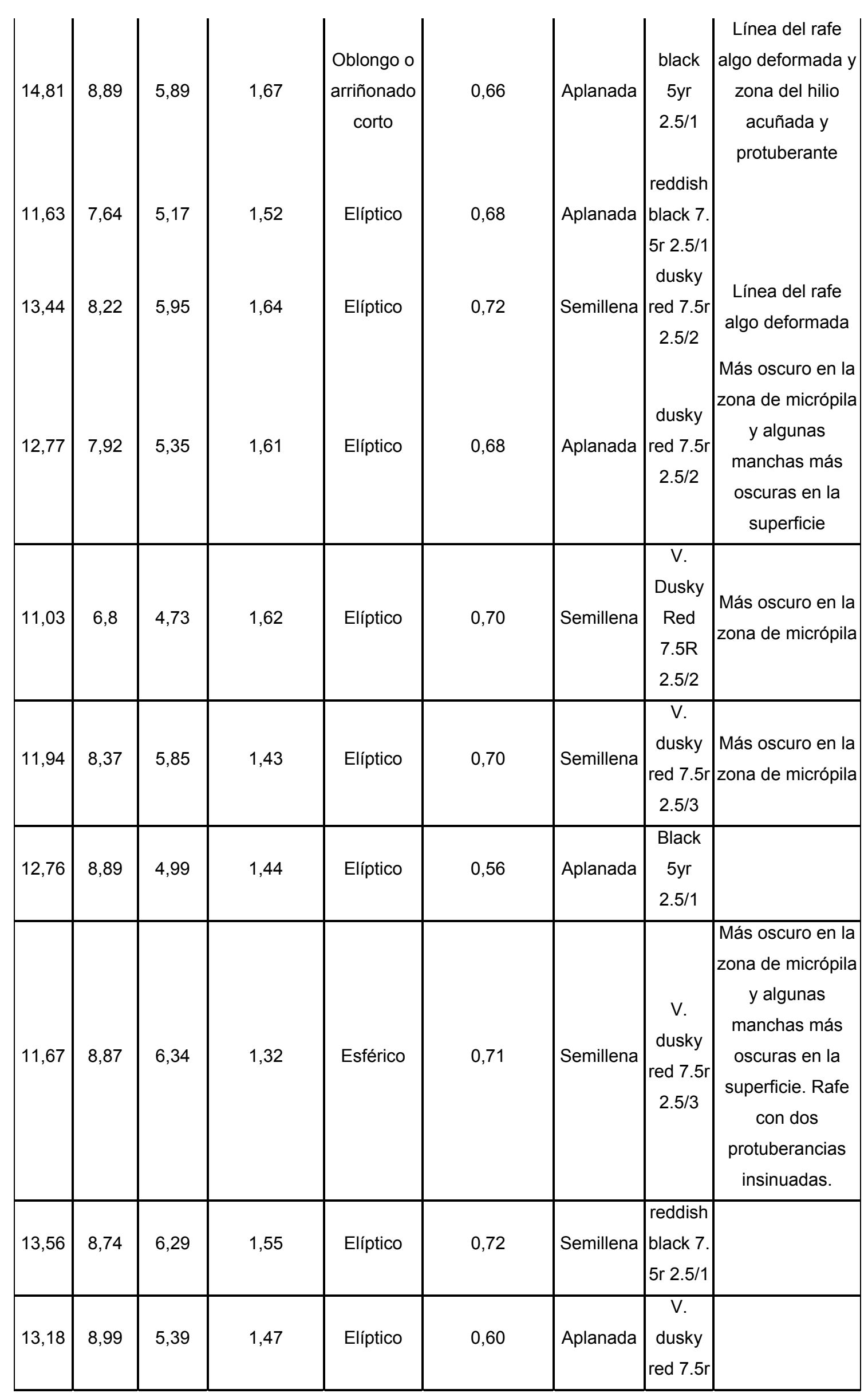




\begin{tabular}{|c|c|c|c|c|c|c|c|c|}
\hline & & & & & & & $2.5 / 3$ & \\
\hline 11,73 & 8,1 & 6,12 & 1,45 & Elíptico & 0,76 & Semillena & \begin{tabular}{|c|} 
Black \\
$5 \mathrm{yr}$ \\
$2.5 / 1$
\end{tabular} & $\begin{array}{c}\text { Rafe con línea } \\
\text { poco clara }\end{array}$ \\
\hline 11,62 & 8,83 & 6,3 & 1,32 & Esférico & 0,71 & Semillena & $\begin{array}{c} \\
\text { V. } \\
\text { dusky } \\
\text { red } 7.5 r \\
2.5 / 3\end{array}$ & $\begin{array}{c}\text { Más oscuro en la } \\
\text { zona de micrópila } \\
\text { y a lo largo de la } \\
\text { línea media. Con } \\
\text { escasas manchas } \\
\text { y líneas más } \\
\text { oscuras sobre la } \\
\text { superficie. Rafe } \\
\text { con dos } \\
\text { protuberancias y } \\
\text { línea como surco } \\
\text { que separa a las } \\
\text { mismas }\end{array}$ \\
\hline 13,87 & 10,69 & 8,32 & 1,30 & Esférico & 0,78 & Semillena & \begin{tabular}{|c|} 
Black \\
$5 \mathrm{yr}$ \\
$2.5 / 1$
\end{tabular} & $\begin{array}{c}\text { Características } \\
\text { del rafe muy } \\
\text { difusas }\end{array}$ \\
\hline 13,91 & 9,11 & 6,96 & 1,53 & Elíptico & 0,76 & Semillena & \begin{tabular}{|c|} 
dusky \\
red $7.5 r$ \\
$2.5 / 2$
\end{tabular} & \\
\hline 13,93 & 9,64 & 8,19 & 1,45 & Elíptico & 0,85 & Llena & \begin{tabular}{|c|} 
Black \\
$5 \mathrm{yr}$ \\
$2.5 / 1$
\end{tabular} & $\begin{array}{l}\text { Rafe con dos } \\
\text { protuberancias }\end{array}$ \\
\hline 12,01 & 9,02 & 7,01 & 1,33 & Esférico & 0,78 & Semillena & $\begin{array}{c} \\
\text { V. } \\
\text { dusky } \\
\text { red } 7.5 r \\
2.5 / 3\end{array}$ & $\begin{array}{c}\text { Más oscuro en la } \\
\text { zona de micrópila } \\
\text { y a lo largo de la } \\
\text { línea media. Con } \\
\text { veteado y } \\
\text { manchas más } \\
\text { oscuras sobre la } \\
\text { superficie. Rafe } \\
\text { con surco que } \\
\text { separa dos } \\
\text { protuberancias } \\
\text { claras }\end{array}$ \\
\hline 11,95 & 9,7 & 6,44 & 1,23 & Esférico & 0,66 & Aplanada & \begin{tabular}{|c|} 
Black \\
$5 \mathrm{yr}$ \\
$2.5 / 1$
\end{tabular} & $\begin{array}{c}\text { Rafe con } \\
\text { protuberancia } \\
\text { lineal que separa } \\
\text { dos surcos }\end{array}$ \\
\hline 10,15 & 8,07 & 6,36 & 1,26 & Esférico & 0,79 & Semillena & \begin{tabular}{|c|} 
Black \\
$5 \mathrm{yr}$
\end{tabular} & $\begin{array}{c}\text { Rafe con dos } \\
\text { protuberancias }\end{array}$ \\
\hline
\end{tabular}




\begin{tabular}{|c|c|c|c|c|c|c|c|c|}
\hline & & & & & & & $2.5 / 1$ & \\
\hline 12,2 & 8,6 & 6,3 & 1,42 & Esférico & 0,73 & Semillena & \begin{tabular}{|c} 
dusky \\
red $7.5 r$ \\
$2.5 / 2$
\end{tabular} & $\begin{array}{c}\text { Rafe con línea } \\
\text { poco clara }\end{array}$ \\
\hline 11,37 & 7,72 & 6,51 & 1,47 & Elíptico & 0,84 & Llena & \begin{tabular}{|c} 
Bm. \\
Yellow \\
$10 y r 5 / 8$
\end{tabular} & $\begin{array}{l}\text { Rafe con línea } \\
\text { como } \\
\text { protuberancia. }\end{array}$ \\
\hline 12,46 & 7,77 & 6,63 & 1,60 & Elíptico & 0,85 & Llena & $\begin{array}{c}\text { Bm. } \\
\text { Yellow } \\
10 y r 5 / 8\end{array}$ & $\begin{array}{c}\text { Rafe con línea } \\
\text { como } \\
\text { protuberancia y } \\
\text { protuberancias } \\
\text { reducidas hasta } \\
\text { casi desaparecer. }\end{array}$ \\
\hline 9,78 & 7,92 & 6,6 & 1,23 & Esférico & 0,83 & Llena & $\begin{array}{c}\text { Bm. } \\
\text { Yellow } \\
10 y r 5 / 8\end{array}$ & $\begin{array}{c}\text { Rafe con línea } \\
\text { apenas insinuada. } \\
\text { Color más oscuro } \\
\text { (Yel.Brown 10yr } \\
5 / 6 \text { ) sobre el area } \\
\text { de la micrópila y } \\
\text { algo en la línea } \\
\text { media. }\end{array}$ \\
\hline
\end{tabular}

Tabla 70:promedio, desvío estándar (DS) y coeficiente de variación (CV), de los conjuntos de semillas de P. vulgaris var vulgaris analizados en las cuevas El Litro $(\mathrm{N}=50)$ y Los Aparejos $(\mathrm{N}=51)$, las medidas están consignadas en milímetros.

\begin{tabular}{|ccccc|}
\hline & & Largo & Ancho & Alto \\
\hline EI Litro & PROMEDIOS & 12,49 & 8,43 & 6,20 \\
& DS & 1,24 & 0,78 & 0,77 \\
& CV & 0,15 & 0,07 & 0,05 \\
\hline Los & PROMEDIOS & 13,09 & 8,81 & 7,22 \\
Aparejos & DS & 1,17 & 0,53 & 0,45 \\
& CV & 0,15 & 0,05 & 0,03 \\
\hline
\end{tabular}


Tabla 71: disposición del eje longitudinal de las células que conforman el esclerénquima y el colénquima en tres áreas de las valvas de $P$. vulgaris var vulgaris y $P$. vulgaris var aborigineus medida en términos del ángulo que dicho eje forma al intersectar los tres planos de referencia (X, Y, Z) estipulados para su ubicación relativa en la valva. Los tipos I y II representan orientaciones en relación a la cara externa o interna de la valva (Lámina 35)

\begin{tabular}{|c|c|c|c|c|c|c|c|c|c|c|}
\hline \multirow{2}{*}{\multicolumn{2}{|c|}{$\begin{array}{c}\text { Área de la valva } \\
\text { Planos }\end{array}$}} & \multicolumn{3}{|c|}{ Caras } & \multicolumn{3}{|c|}{ Sutura dorsal } & \multicolumn{3}{|c|}{ Sutura ventral } \\
\hline & & $\mathbf{X}$ & $\mathbf{Y}$ & $\mathbf{Z}$ & $\mathbf{X}$ & $\mathbf{Y}$ & $\mathbf{Z}$ & $\mathbf{X}$ & $\mathbf{Y}$ & $\mathbf{Z}$ \\
\hline \multirow{6}{*}{$\begin{array}{l}P \text {. vulgaris } \\
\text { var vulgaris }\end{array}$} & \multirow{3}{*}{ Esclerénquima } & Perpendiculares & Paralelos & Paralelas & $\begin{array}{c}\text { Casi } \\
\text { perpendiculares }\end{array}$ & $\begin{array}{l}\text { Oblicuos } \\
\text { (Tipo II) }\end{array}$ & $\begin{array}{l}\text { Oblicuos } \\
\text { (Tipo II) }\end{array}$ & Casi paralelas & $\begin{array}{c}\text { Casi } \\
\text { paralelas }\end{array}$ & $\begin{array}{c}\text { Levemente } \\
\text { oblicuos (Tipo I) }\end{array}$ \\
\hline & & $\begin{array}{l}\text { Levemente } \\
\text { oblicuos (Tipo I) }\end{array}$ & $\begin{array}{l}\text { Levemente } \\
\text { oblicuos } \\
\text { (Tipo I) }\end{array}$ & $\begin{array}{l}\text { Muy oblicuos } \\
\text { (Tipo I) }\end{array}$ & $\begin{array}{l}\text { Muy oblicuos a } \\
\text { casi paralelas }\end{array}$ & $\begin{array}{l}\text { Oblicuos } \\
\text { (Tipo II) }\end{array}$ & $\begin{array}{l}\text { Oblicuos } \\
\text { (Tipo II) }\end{array}$ & $\begin{array}{l}\text { Oblicuos (Tipo } \\
\text { II) }\end{array}$ & $\begin{array}{l}\text { Oblicuos } \\
\text { (Tipo II) }\end{array}$ & $\begin{array}{l}\text { Oblicuos (Tipo } \\
\text { II) }\end{array}$ \\
\hline & & Casi paralelos & $\begin{array}{l}\text { Oblicuos } \\
\text { (Tipo I) }\end{array}$ & $\begin{array}{c}\text { Oblicuos (Tipo } \\
\text { I) }\end{array}$ & & & & & & \\
\hline & \multirow{3}{*}{ Colénquima } & Paralelos & Paralelos & $\begin{array}{c}\text { Casi } \\
\text { perpendiculares }\end{array}$ & $\begin{array}{c}\text { Casi } \\
\text { perpendiculares }\end{array}$ & $\begin{array}{l}\text { Levemente } \\
\text { oblicuos } \\
\text { (Tipo I) }\end{array}$ & $\begin{array}{l}\text { Levemente } \\
\text { oblicuos } \\
\text { (Tipo I) }\end{array}$ & Casi paralelas & $\begin{array}{l}\text { Oblicuos } \\
\text { (Tipo II) }\end{array}$ & $\begin{array}{l}\text { Oblicuos (Tipo } \\
\text { II) }\end{array}$ \\
\hline & & $\begin{array}{c}\text { Oblicuos (Tipo } \\
\text { I) }\end{array}$ & Paralelos & $\begin{array}{c}\text { Oblicuos (Tipo } \\
\text { I) }\end{array}$ & & & & & & \\
\hline & & Paralelos & $\begin{array}{l}\text { Oblicuos } \\
\text { (Tipo I) }\end{array}$ & $\begin{array}{c}\text { Oblicuos (Tipo } \\
\text { I) }\end{array}$ & & & & & & \\
\hline \multirow{5}{*}{$\begin{array}{l}P . \text { vulgaris } \\
\text { var } \\
\text { aborigineus }\end{array}$} & \multirow{3}{*}{ Esclerénquima } & Perpendiculares & Paralelos & Paralelos & Casi paralelos & $\begin{array}{l}\text { Oblicuos } \\
\text { (Tipo I) }\end{array}$ & $\begin{array}{l}\text { Oblicuos } \\
\text { (Tipo I) }\end{array}$ & $\begin{array}{c}\text { Oblicuos (Tipo } \\
\text { I) }\end{array}$ & $\begin{array}{c}\text { Oblicuos } \\
\text { (Tipo I) }\end{array}$ & $\begin{array}{l}\text { Oblicuos (Tipo } \\
\text { I) }\end{array}$ \\
\hline & & $\begin{array}{c}\text { Levemente } \\
\text { oblicuos (Tipo I) }\end{array}$ & $\begin{array}{l}\text { Levemente } \\
\text { oblicuos } \\
\text { (Tipo I) }\end{array}$ & $\begin{array}{l}\text { Muy oblicuos } \\
\text { (Tipo I) }\end{array}$ & & & & $\begin{array}{l}\text { Perpendiculares } \\
\text { a casi paralelos }\end{array}$ & $\begin{array}{c}\text { Casi } \\
\text { paralelos }\end{array}$ & $\begin{array}{l}\text { Oblicuos (Tipo } \\
\text { I) }\end{array}$ \\
\hline & & Casi paralelos & $\begin{array}{l}\text { Oblicuos } \\
\text { (Tipo I) }\end{array}$ & $\begin{array}{l}\text { Oblicuos (Tipo } \\
\text { I) }\end{array}$ & & & & & & \\
\hline & \multirow[t]{2}{*}{ Colénquima } & $\begin{array}{c}\text { Perpendiculares } \\
\text { a casi } \\
\text { perpendiculares }\end{array}$ & $\begin{array}{l}\text { Levemente } \\
\text { oblicuos } \\
\text { (Tipo II) }\end{array}$ & $\begin{array}{c}\text { Levemente } \\
\text { oblicuos (Tipo } \\
\text { II) }\end{array}$ & Perpendiculares & Paralelas & Paralelas & Paralelos & Paralelos & $\begin{array}{c}\text { Casi } \\
\text { perpendiculares }\end{array}$ \\
\hline & & & & & $\begin{array}{c}\text { Oblicuos (Tipo } \\
\text { II) }\end{array}$ & $\begin{array}{l}\text { Oblicuos } \\
\text { (Tipo II) }\end{array}$ & $\begin{array}{l}\text { Oblicuos } \\
\text { (Tipo II) }\end{array}$ & $\begin{array}{c}\text { Oblicuos (Tipo } \\
\text { I) }\end{array}$ & $\begin{array}{l}\text { Oblicuos } \\
\text { (Tipo I) }\end{array}$ & $\begin{array}{l}\text { Oblicuos (Tipo } \\
\text { I) }\end{array}$ \\
\hline
\end{tabular}


Tabla 72: distribución de las vainas de Phaseolus sp recuperadas en la cueva Los Aparejos de acuerdo con sector, cuadrícula y capa según consta en las etiquetas originales de la excavación depositadas junto al material recuperado.

\begin{tabular}{|cc|}
\hline $\begin{array}{c}\text { Datos de etiqueta } \\
\text { original }\end{array}$ & Cantidad \\
\hline $\begin{array}{c}\text { Sector I/ superficial } \\
\text { Sector I/ capa 1 }\end{array}$ & 1 \\
Sector II/ D1 (superficial) & 3 \\
Sector II/ D1/capa 1, & 2 \\
mezcla con 2 & \\
Sector II/ D1/ capa 2 & 3 \\
(hasta 0.40) & \\
Sector II/ D1/ capa2 (0.20- & 1 \\
0.40) & 1 \\
Sector III/ F0 (00-0.40) & 1 \\
Sector III/ F2/ capa1 (0.20- & \\
0.40) & \\
Sector III/ F2/ capa 1 hasta & 1 \\
00-20-40 & 3 \\
060) & \\
\hline Sector III/ F2/ capa2 (040- & \\
\end{tabular}

Tabla 73: distribución de las vainas de Phaseolus sp recuperadas en la cueva El Litro de acuerdo con cuadrícula y capa según consta en las etiquetas originales de la excavación depositadas junto al material recuperado.

\begin{tabular}{|cc|}
\hline Datos de etiqueta original & Cantidad \\
\hline Superficial y capa fértil & 14 \\
varias cuadrículas & 1 \\
C1/ capa1 (00-0.70) & 1 \\
C1/ capa1 (00-0.70) & 1 \\
C1/ capa2 (0070-0090) & 4 \\
C1/ capa2 (0.70-0.90) & \\
\hline
\end{tabular}

Tabla 74: medidas (expresadas en milímetros) del grosor del pericarpio en cuatro vainas P.vulgaris de la localidad arqueológica de Pampa Grande.

\begin{tabular}{|c|c|}
\hline PROCEDENCIA & ESPESOR DEL PERICARPIO \\
\hline Caverna IV & 0,34 \\
\hline Caverna III & 0,47 \\
\hline Los Aparejos Sector I Superficial & 0,31 \\
\hline El Litro C1 capa 2 (0,7-0,9) & 0,24 \\
\hline
\end{tabular}


Tabla 75: disposición de las células que conforman el esclerénquima y colénquima en cuatro valvas arqueológicas procedentes de distintas cuevas de la localidad arqueológica de Pampa Grande de acuerdo a los tres planos de referencia (X, Y, Z) estipulados para su ubicación relativa en la valva.

\begin{tabular}{|c|c|c|c|c|c|c|c|c|c|c|}
\hline \multirow{2}{*}{\multicolumn{2}{|c|}{$\begin{array}{c}\text { Área de la valva } \\
\text { Planos } \\
\end{array}$}} & \multicolumn{3}{|c|}{ Caras } & \multicolumn{3}{|c|}{ Sutura Dorsal } & \multicolumn{3}{|c|}{ Sutura Ventral } \\
\hline & & $\mathbf{X}$ & $\mathbf{Y}$ & $\mathbf{Z}$ & $\mathbf{X}$ & $\mathbf{Y}$ & $\mathbf{Z}$ & $\mathbf{X}$ & $\mathbf{Y}$ & $\mathbf{Z}$ \\
\hline \multirow{2}{*}{$\begin{array}{l}\text { Caverna } \\
\text { IV }\end{array}$} & Esclerénquima & ---------- & ------------- & -------------- & Oblicuas (Tipo I) & Paralelas & $\begin{array}{l}\text { Oblicuas } \\
\text { (Tipo I) }\end{array}$ & $\begin{array}{c}\text { Casi } \\
\text { perpendiculares }\end{array}$ & Paralelas & $\begin{array}{l}\text { Levemente } \\
\text { oblicuas } \\
\text { (Tipo I) }\end{array}$ \\
\hline & Colénquima & ------ & ---- & --- & $\begin{array}{c}\text { Oblicuas (Tipo } \\
\text { II) }\end{array}$ & Paralelas & $\begin{array}{l}\text { Oblicuas } \\
\text { (Tipo II) }\end{array}$ & Casi paralelas & Paralelas & $\begin{array}{l}\text { Levemente } \\
\text { oblicuas } \\
\text { (Tipo I) }\end{array}$ \\
\hline \multirow{3}{*}{$\begin{array}{c}\text { Caverna } \\
\text { III }\end{array}$} & Esclerénquima & Perpendiculares & Paralelas & $\begin{array}{l}\text { Levemente } \\
\text { oblicuas }\end{array}$ & ---------' & -- & & $\begin{array}{c}\text { Oblicuas (casi } \\
\text { perpendiculares) } \\
\text { (Tipo I y II) }\end{array}$ & $\begin{array}{l}\text { Oblicuas } \\
\text { (Tipo I y II) }\end{array}$ & $\begin{array}{l}\text { Oblicuas } \\
\text { (Tipo I y II) }\end{array}$ \\
\hline & \multirow[t]{2}{*}{ Colénquima } & Paralelas & Paralelas & $\begin{array}{c}\text { Casi } \\
\text { perpendiculares }\end{array}$ & $\begin{array}{c}\text { Casi } \\
\text { perpendicular }\end{array}$ & $\begin{array}{l}\text { Levemente } \\
\text { oblicua } \\
\text { (Tipo I) }\end{array}$ & $\begin{array}{l}\text { Levemente } \\
\text { oblicua } \\
\text { (Tipo I) }\end{array}$ & Perpendiculares & Paralelas & Paralelas \\
\hline & & Paralela & $\begin{array}{l}\text { Oblicuas } \\
\text { (Tipo I) }\end{array}$ & $\begin{array}{l}\text { Oblicuas } \\
\text { (Tipo I) }\end{array}$ & & & & & & \\
\hline \multirow{3}{*}{ El Litro } & Esclerénquima & $\begin{array}{c}\text { Casi } \\
\text { perpendiculares }\end{array}$ & $\begin{array}{l}\text { Oblicuas } \\
\text { (Tipo I y II) }\end{array}$ & $\begin{array}{c}\text { Oblicuas (Tipo I } \\
\text { y II) }\end{array}$ & ----- & ----- & ------- & $\begin{array}{c}\text { Oblicuas (Tipo I } \\
\text { y II) }\end{array}$ & $\begin{array}{l}\text { Oblicuas } \\
\text { (Tipo I y II) }\end{array}$ & $\begin{array}{l}\text { Oblicuas } \\
\text { (Tipo I y II) }\end{array}$ \\
\hline & \multirow[b]{2}{*}{ Colénquima } & Paralelas & Paralelas & $\begin{array}{c}\text { Casi } \\
\text { perpendiculares }\end{array}$ & Perpendiculares & Paralelas & Paralelas & Oblicuas (Tipo I) & $\begin{array}{l}\text { Oblicuas } \\
\text { (Tipo I) }\end{array}$ & $\begin{array}{l}\text { Oblicuas } \\
\text { (Tipo I) }\end{array}$ \\
\hline & & Paralelas & $\begin{array}{l}\text { Oblicuas } \\
\text { (Tipo I) }\end{array}$ & $\begin{array}{l}\text { Oblicuas (Tipo } \\
\text { I) }\end{array}$ & $\begin{array}{c}\text { Casi } \\
\text { perpendiculares }\end{array}$ & $\begin{array}{l}\text { Oblicuas } \\
\text { (Tipo I) }\end{array}$ & $\begin{array}{l}\text { Oblicuas } \\
\text { (Tipo I) }\end{array}$ & $\begin{array}{c}\text { Levemente } \\
\text { oblicuas (Tipo II) }\end{array}$ & $\begin{array}{l}\text { Levemente } \\
\text { oblicuas } \\
\text { (Tipo II) }\end{array}$ & $\begin{array}{l}\text { Levemente } \\
\text { oblicuas } \\
\text { (Tipo II) }\end{array}$ \\
\hline \multirow{5}{*}{$\begin{array}{l}\text { Los } \\
\text { Aparejos }\end{array}$} & \multirow{3}{*}{ Esclerénquima } & Perpendiculares & Paralelas & Paralelas & ------------- & ------------- & |----------- & Perpendiculares & Paralelas & Paralelas \\
\hline & & Oblicuas (Tipo I) & $\begin{array}{l}\text { Oblicuas } \\
\text { (Tipo I) }\end{array}$ & $\begin{array}{l}\text { Oblicuas (Tipo } \\
\text { I) }\end{array}$ & & & & $\begin{array}{c}\text { Levemente } \\
\text { oblicuas (Tipo I) }\end{array}$ & $\begin{array}{l}\text { Levemente } \\
\text { oblicuas } \\
\text { (Tipo I) } \\
\end{array}$ & $\begin{array}{l}\text { Levemente } \\
\text { oblicuas } \\
\text { (Tipo I) }\end{array}$ \\
\hline & & $\begin{array}{l}\text { Oblicuas (Tipo } \\
\text { II) }\end{array}$ & $\begin{array}{l}\text { Oblicuas } \\
\text { (Tipo II) }\end{array}$ & $\begin{array}{c}\text { Oblicuas (Tipo } \\
\text { II) }\end{array}$ & & & & & & \\
\hline & \multirow{2}{*}{ Colénquima } & Paralelas & $\begin{array}{l}\text { Levemente } \\
\text { oblicuas } \\
\text { (Tipo II) }\end{array}$ & $\begin{array}{l}\text { Levemente } \\
\text { oblicuas (Tipo } \\
\text { II) }\end{array}$ & Perpendiculares & Paralelas & Paralelas & Oblicuas (Tipo I) & $\begin{array}{l}\text { Oblicuas } \\
\text { (Tipo I) }\end{array}$ & $\begin{array}{l}\text { Oblicuas } \\
\text { (Tipo I) }\end{array}$ \\
\hline & & $\begin{array}{c}\text { Casi } \\
\text { perpendiculares }\end{array}$ & $\begin{array}{l}\text { Levemente } \\
\text { oblicuas } \\
\text { (Tipo I) }\end{array}$ & $\begin{array}{c}\text { Levemente } \\
\text { oblicuas (Tipo I) }\end{array}$ & & & & & & \\
\hline
\end{tabular}


Figura 31: centros de diversificación y áreas de domesticación de Phaseolus vulgaris en América.

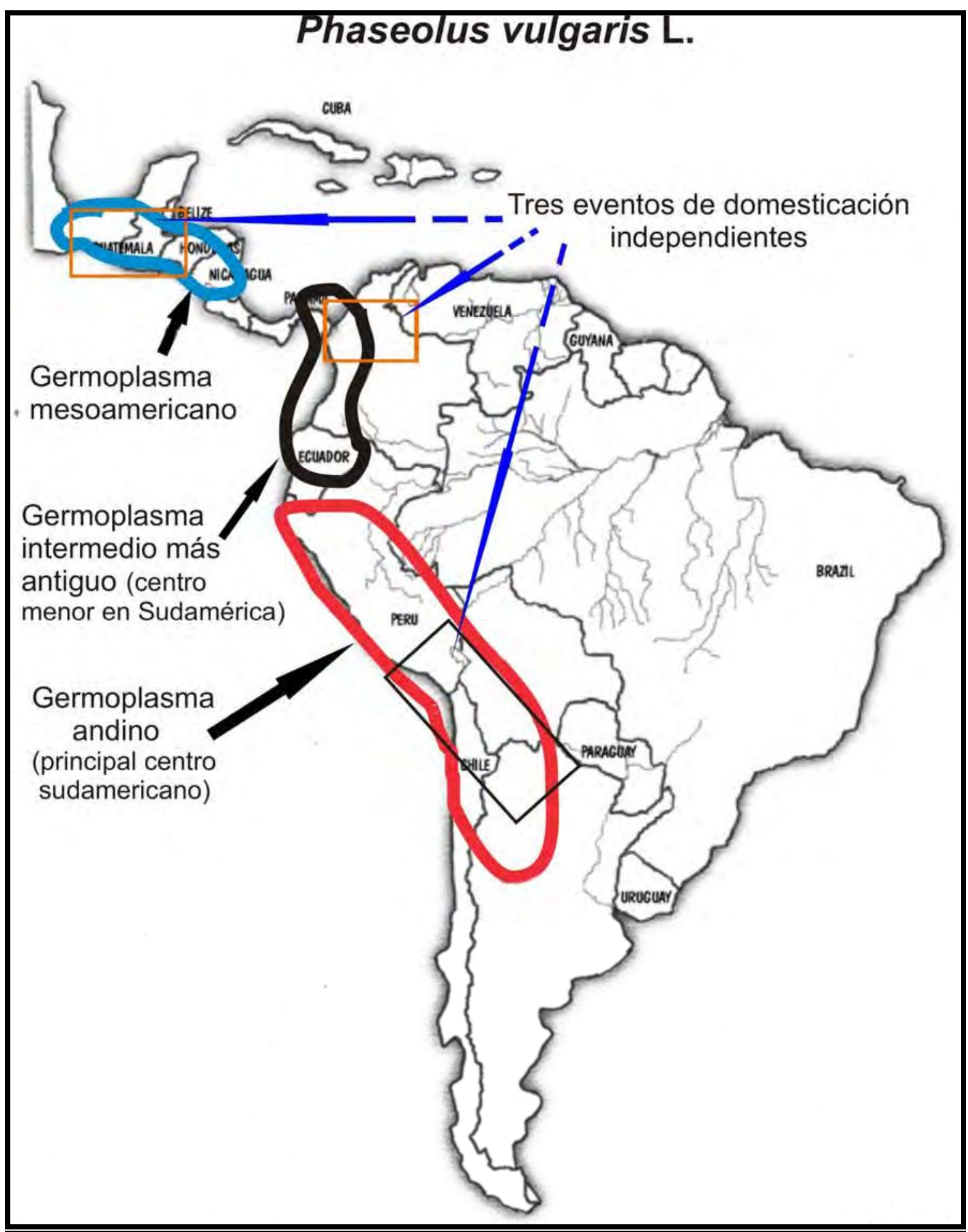


Figura 32: áreas de domesticación de Phaseolus lunatus en América.

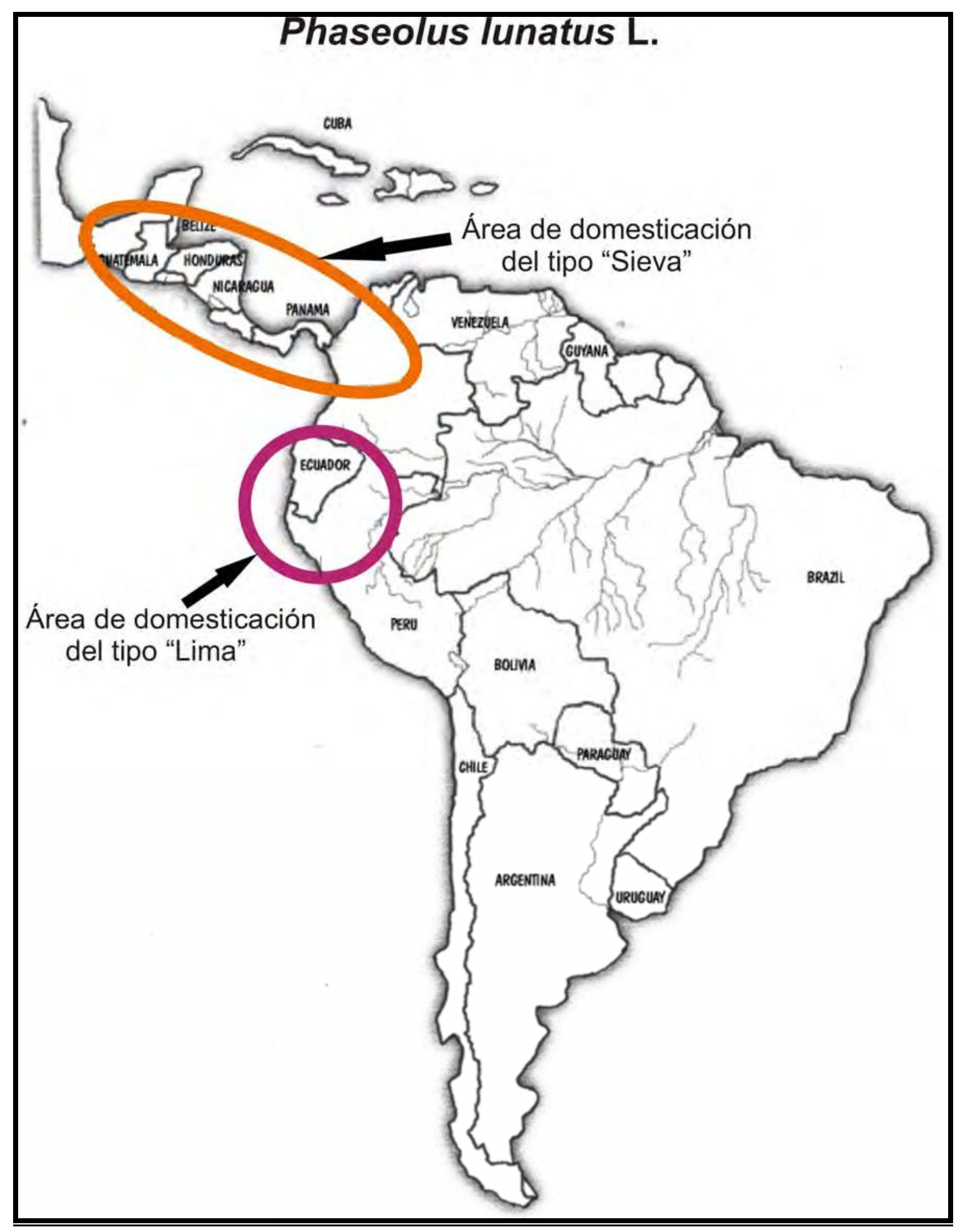


Figura 33: restos arqueológicos más tempranos del género Phaseolus en Sudamérica (datos tomados de Kaplan y Lynch 1999).

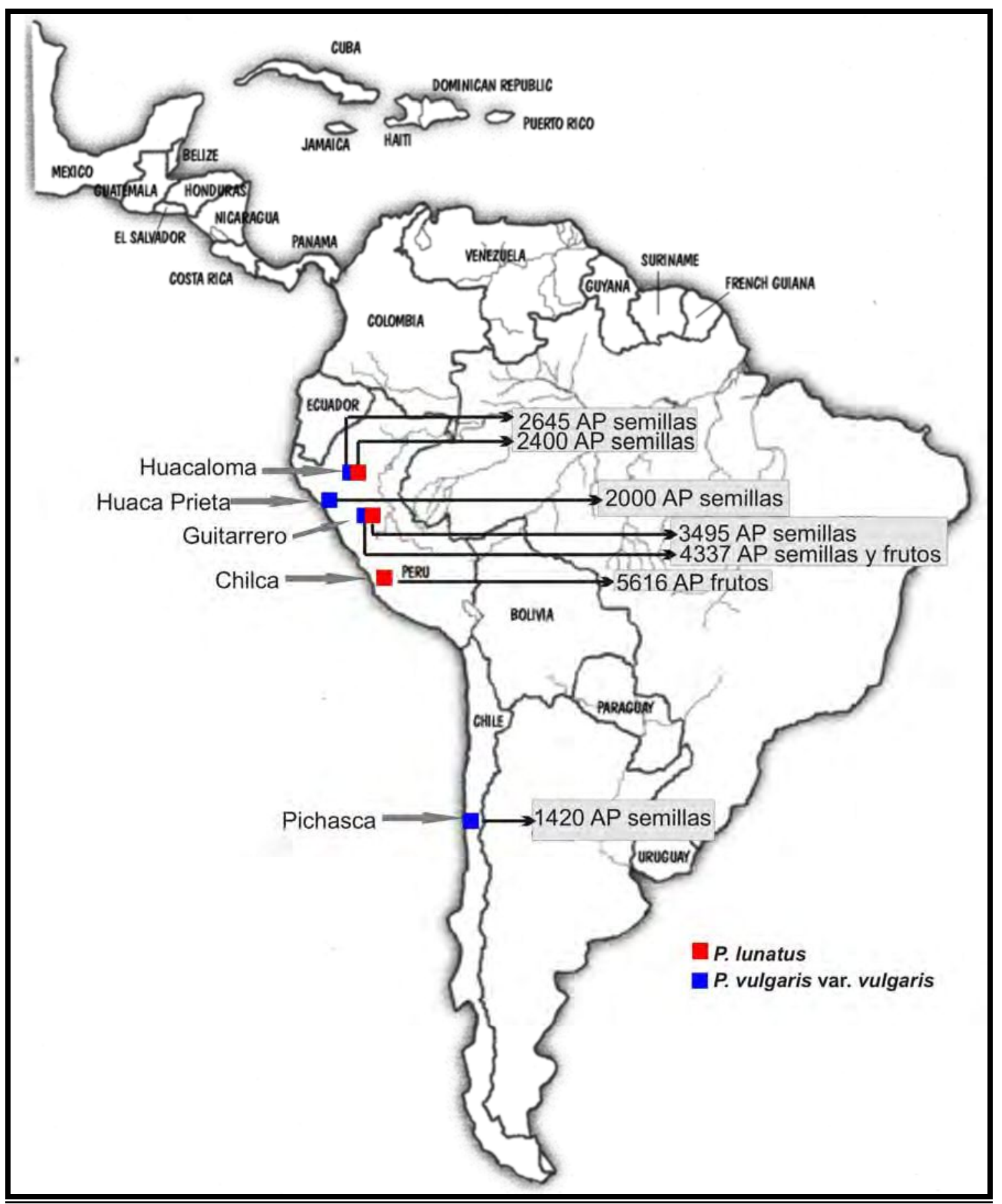


Figura 34: macrorrestos arqueológicos del género Phaseolus en Argentina.

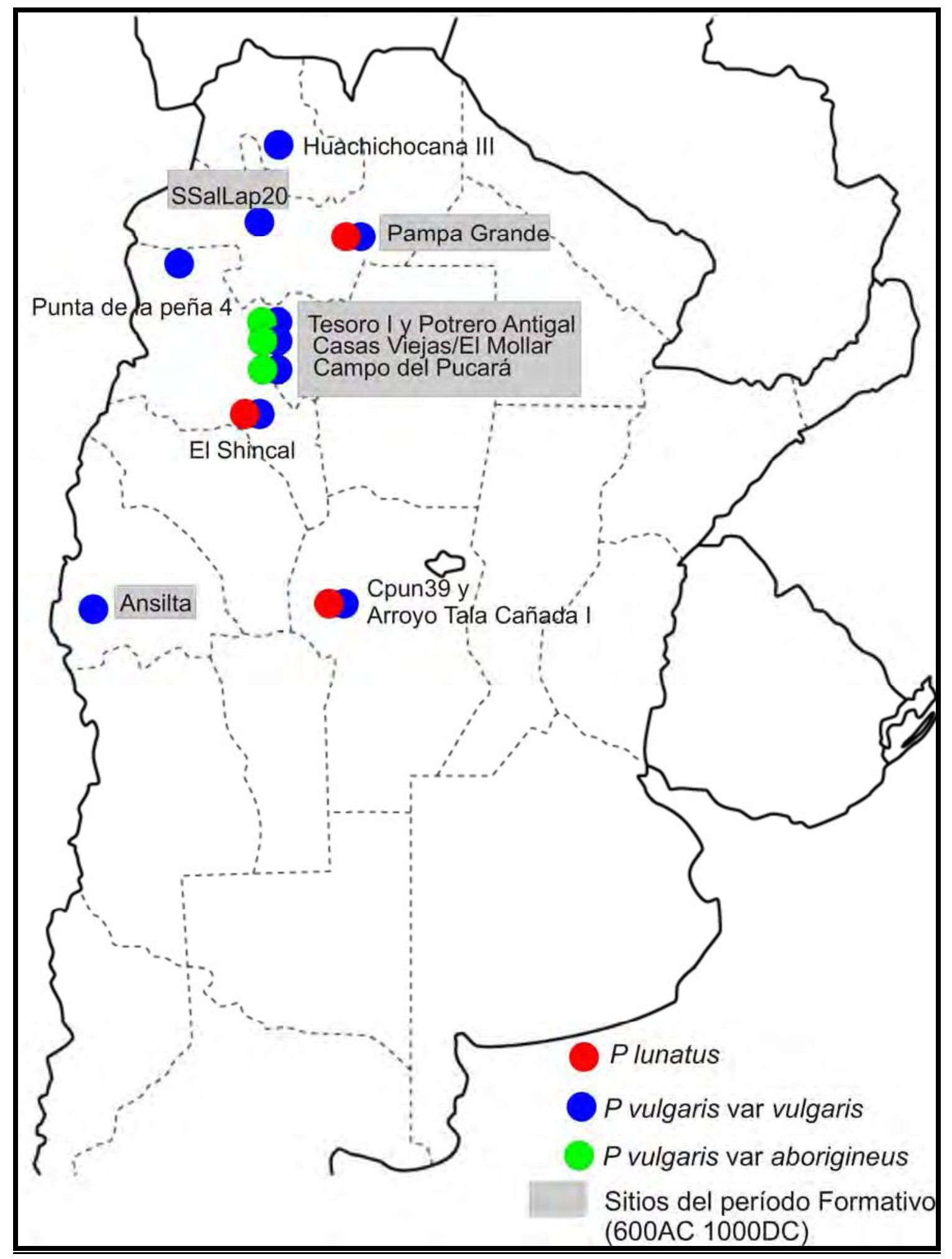


Figura 35: parámetros y rasgos analizados en las semillas de Phaseolus sp.

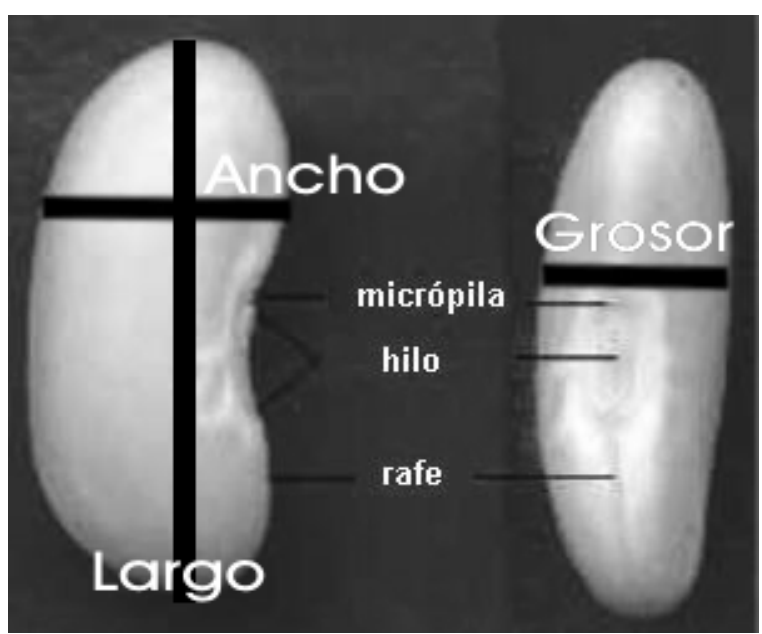

Figura 36: semilla de Phaseolus sp. de Huachichocana, cueva III, capa C.

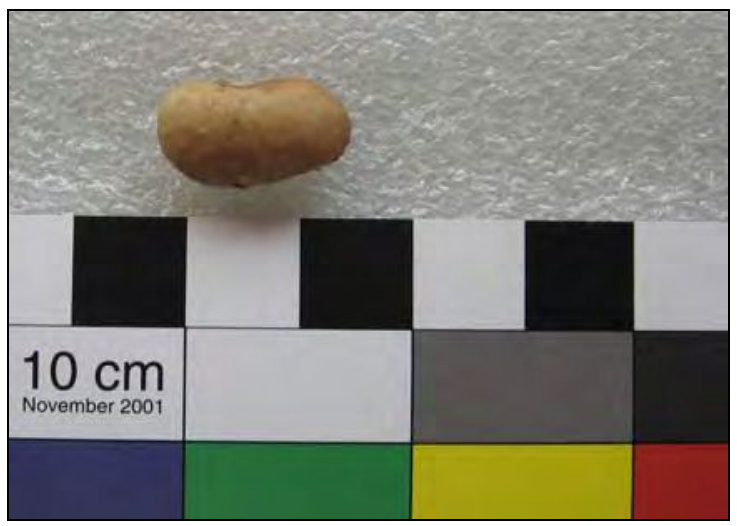

Figura 37: semilla de Phaseolus sp. de Huachichocana, cueva III, capa E3.

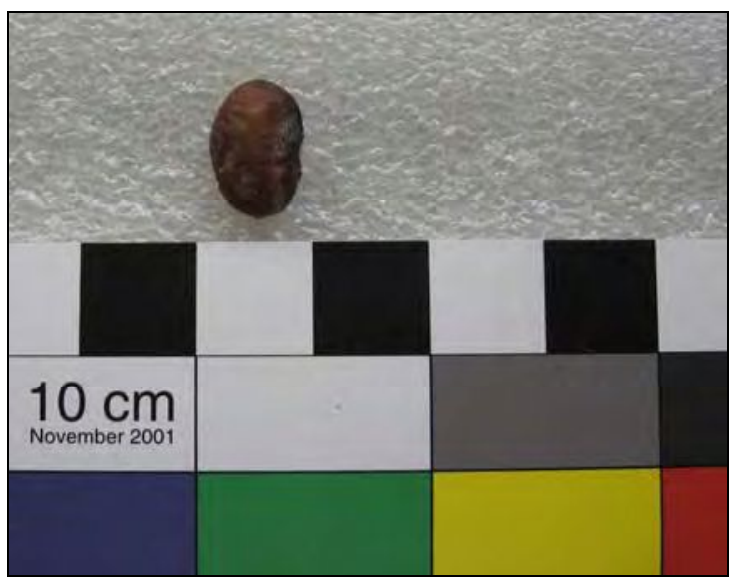


Figura 38: única semilla de P. vulgaris var. vulgaris recuperada en SSalLap20.

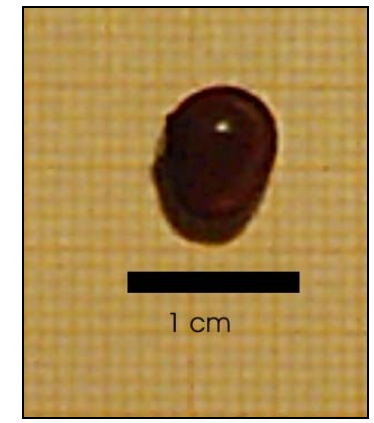

Figura 39: semilla bicolor de Phaseolus vulgaris recuperadas en la cueva Los Aparejos (sector I, superficial) de la localidad de Pampa Grande.

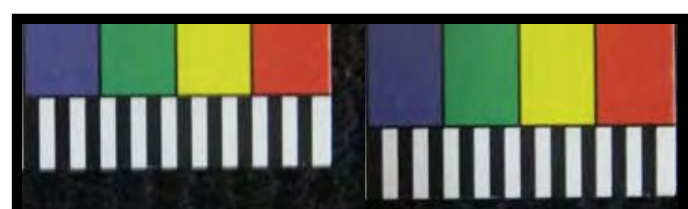

Figura 40: semilla de P. lunatus y vaina de Cassia bookeriana halladas en la cuadricula 1 de la cueva El Litro.

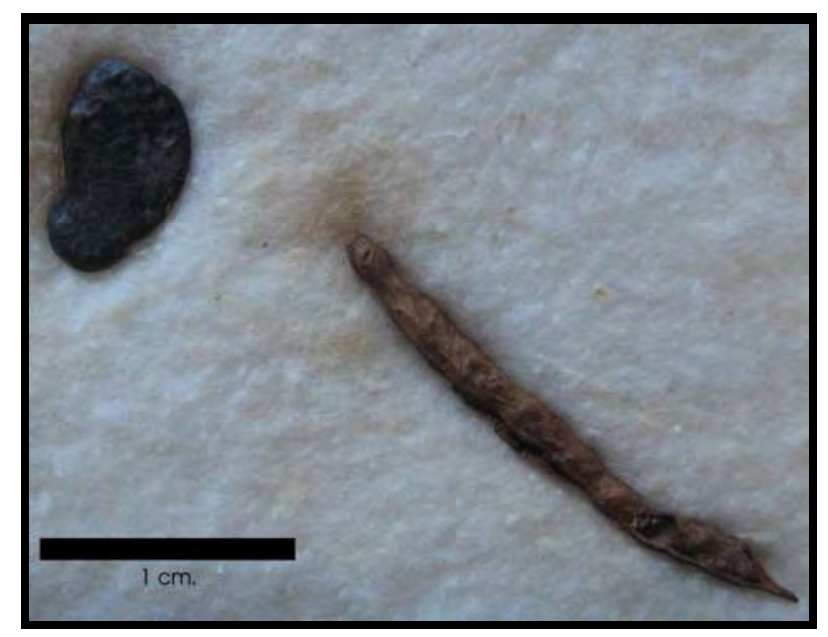


Figura 41: morfología del rafe en P. vulgaris var aborigineus (1) y ejemplares arqueológicos de Los Aparejos con rafe con excrescencias adicionales (2) y con rafe simil forma silvestre (3).
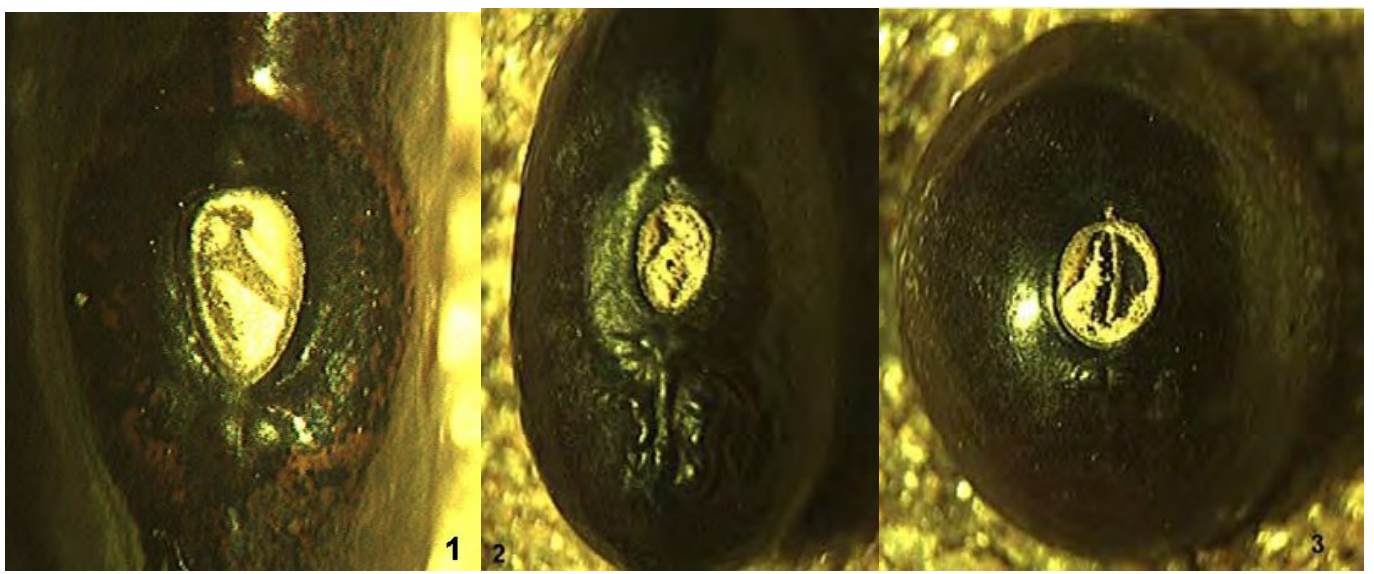

Figura 42: áreas y tejidos que constituyen cada valva del fruto de P. vulgaris (modificado de Esau 1977).

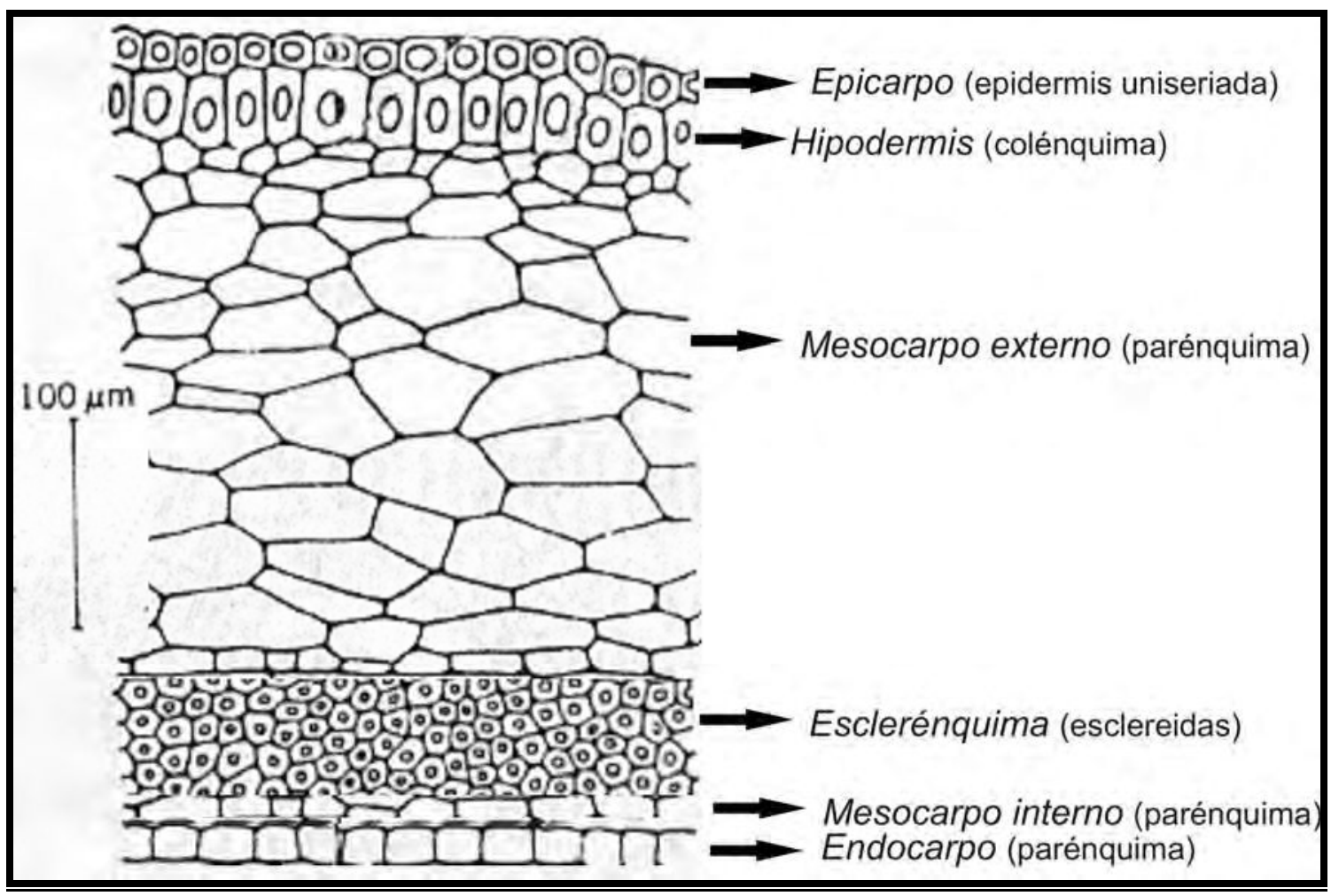


Grafico 14: distribución de semillas de Phaseolus sp. halladas en Los Morrillos correspondientes al período 50 AC- 210 DC de acuerdo con el índice H (grosor/ancho).

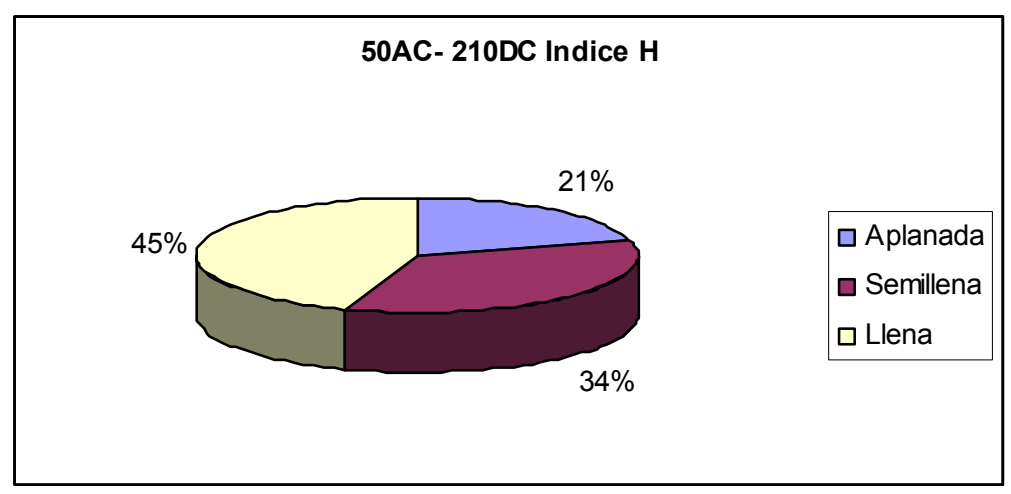

Grafico 15: distribución de semillas de Phaseolus sp. halladas en Los Morrillos correspondientes al período 280-375 DC de acuerdo con el índice H (grosor/ancho).

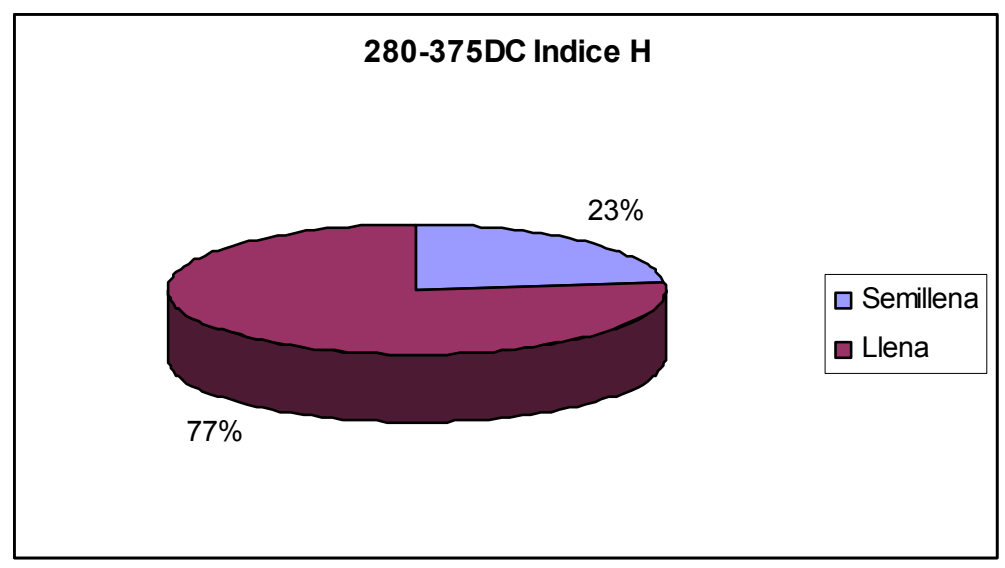

Grafico 16: distribución de semillas de Phaseolus sp. halladas en Los Morrillos correspondientes al período 50 AC- 210 DC de acuerdo con el índice J (largo/ancho).

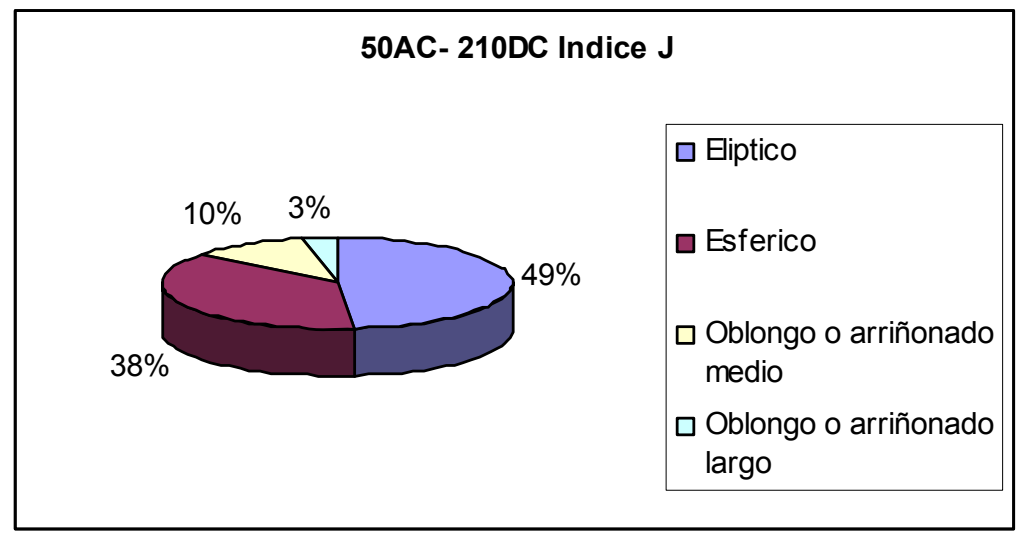


Grafico 17: distribución de semillas de Phaseolus sp. halladas en Los Morrillos correspondientes al período 280- 375 DC de acuerdo con el índice J (largo/ancho).

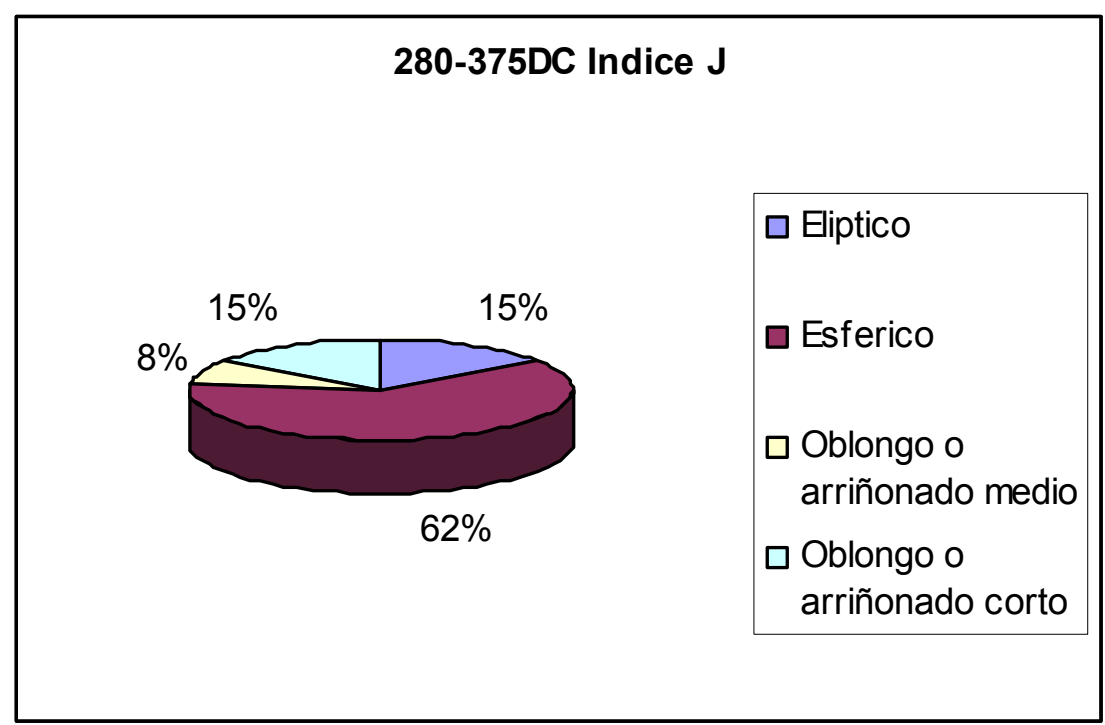

Grafico 18: distribución de semillas de Phaseolus sp. halladas en las distintas cuevas de la localidad arqueológica de Pampa Grande, los números indican la cantidad de semillas en cada cueva.

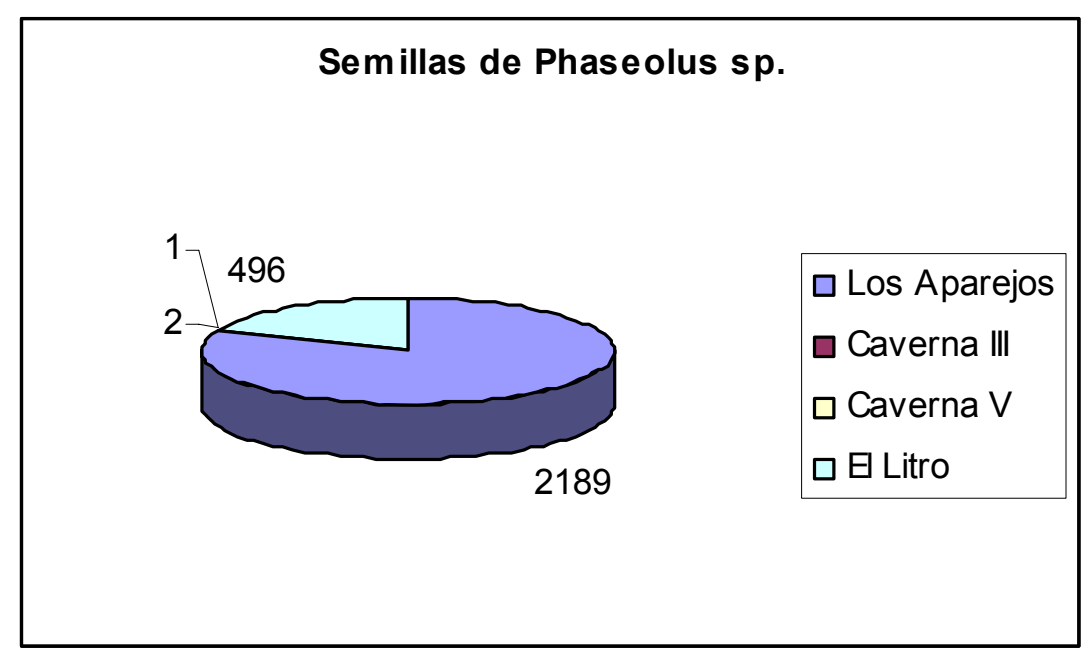


Gráfico 19: distribución en estratigrafía de las semillas de Phaseolus vulgaris var vulgaris recuperadas en la cueva Los Aparejos.

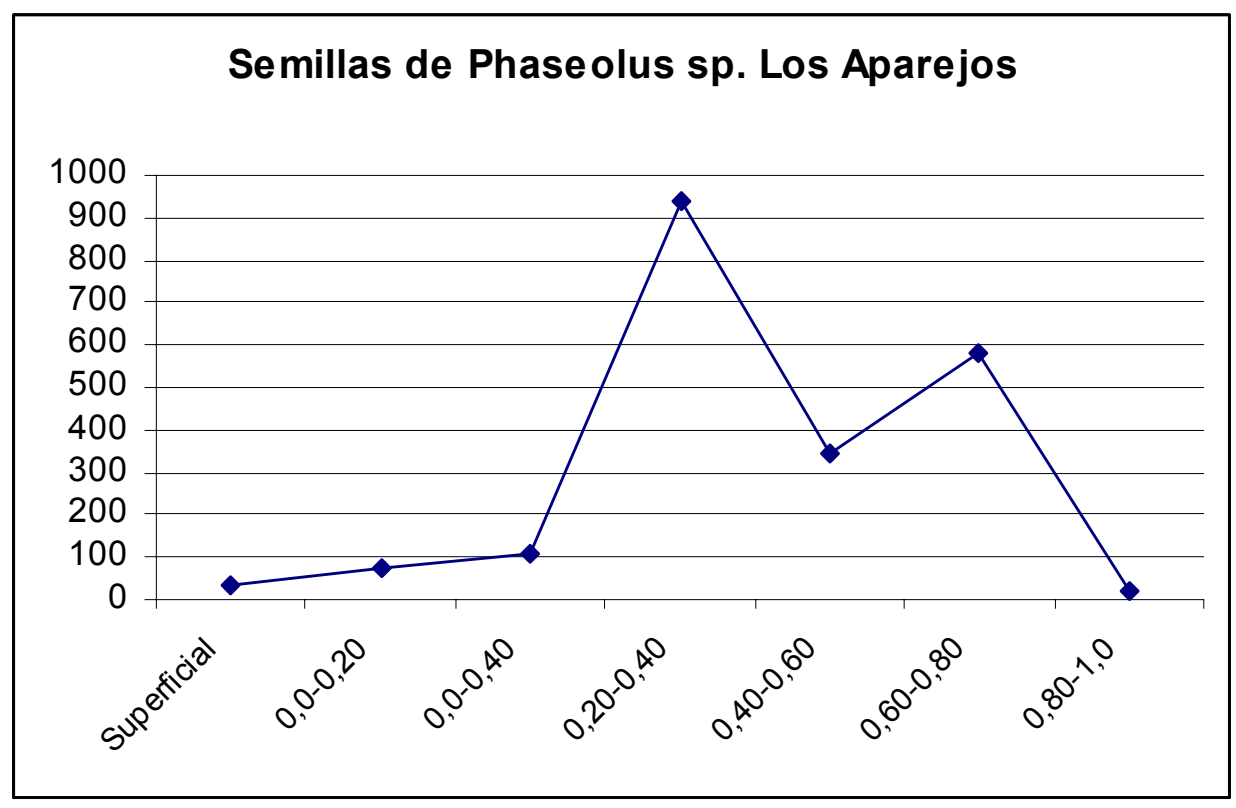

Gráfico 20: distribución del porcentaje de 51 semillas de Los Aparejos Sector III, E1, capa 4 de acuerdo con el índice J (largo/ancho).

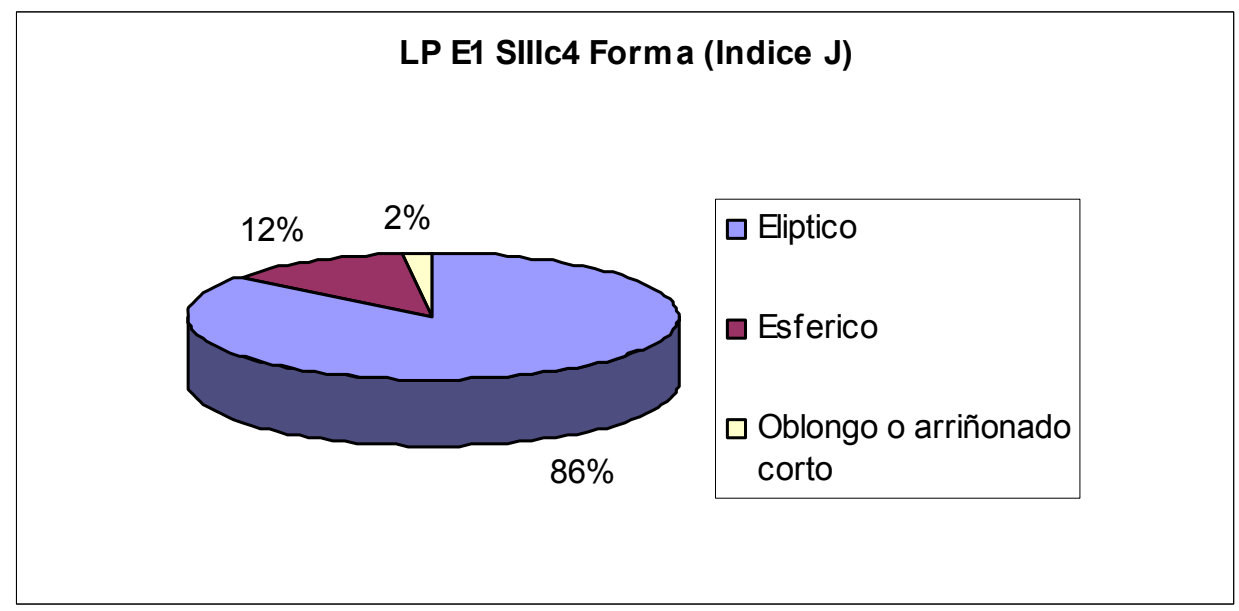


Gráfico 21: distribución del porcentaje de 51 semillas de Los Aparejos Sector III, E1, capa 4 de acuerdo con el índice $\mathrm{H}$ (grosor/ancho).

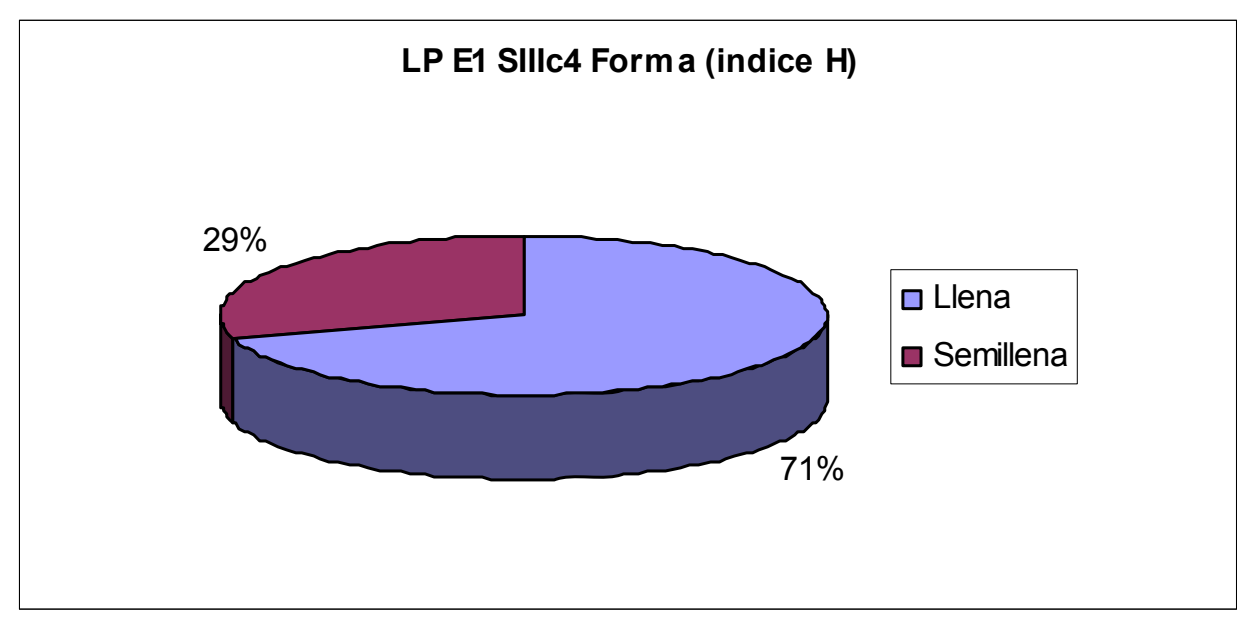

Gráfico 22: Distribución del porcentaje de 51 semillas de Los Aparejos Sector III, E1, capa 4 de acuerdo con el color del epicarpio (Earth Colors 1997).

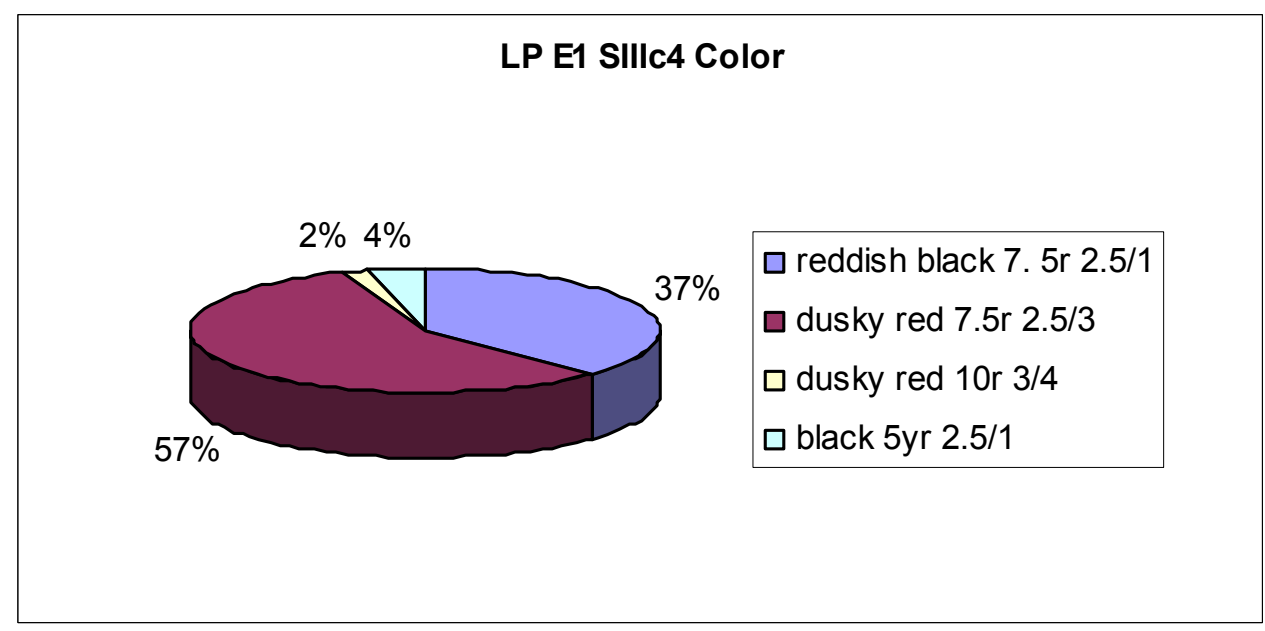


Gráfico 23: distribución del porcentaje de 50 semillas de El Litro C1 (0-0,7) de acuerdo con el índice J (largo/ancho).

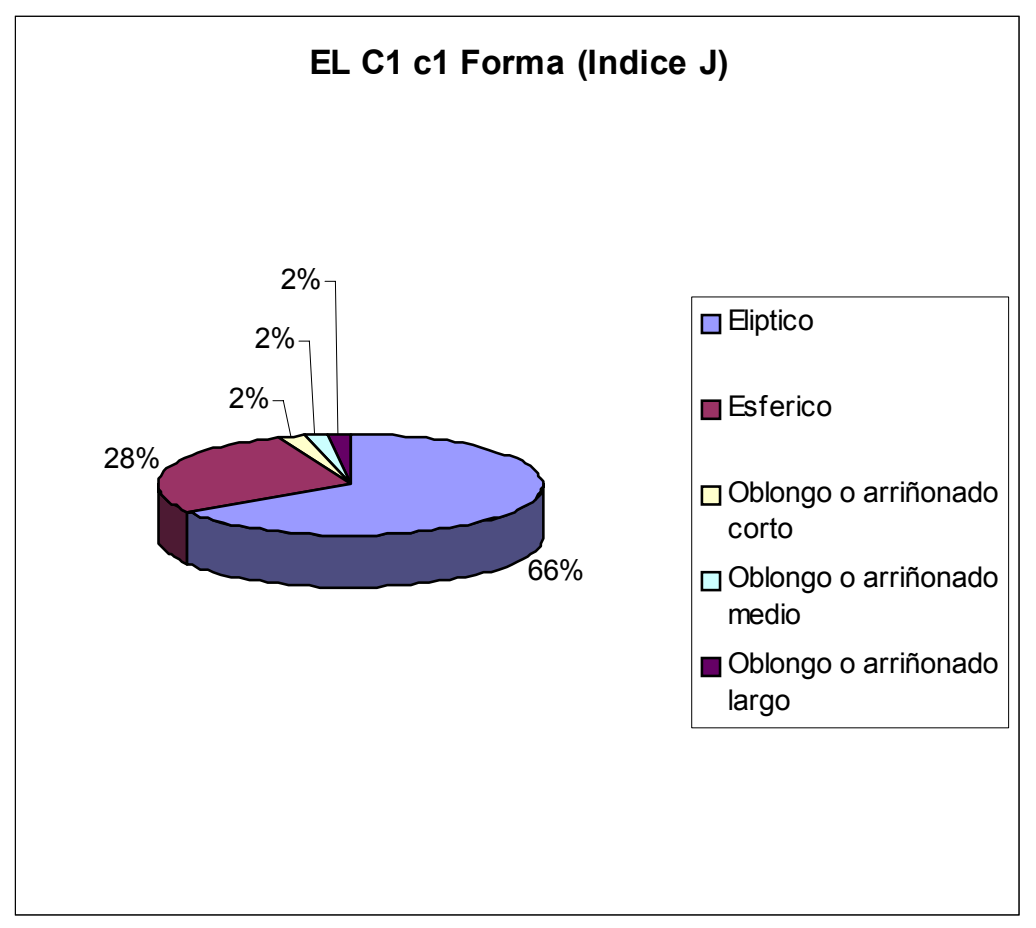

Gráfico 24: distribución del porcentaje de 50 semillas de El Litro C1 (0-0,7) de acuerdo con el índice $\mathrm{H}$ (grosor/ancho).

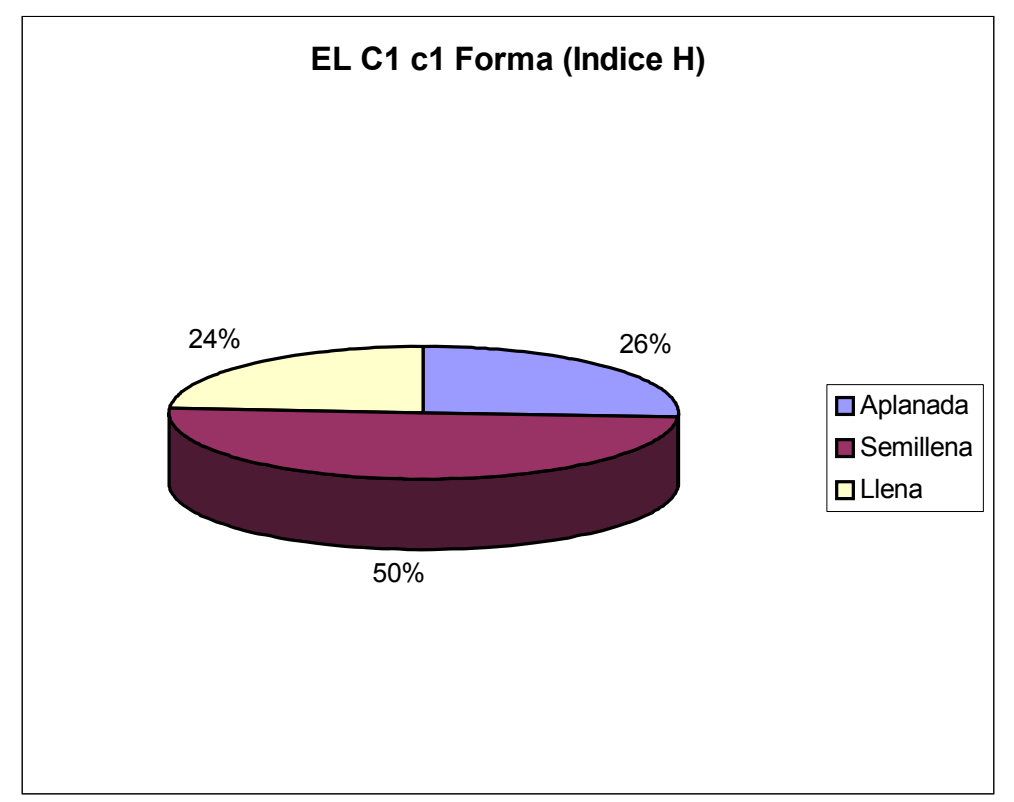


Gráfico 25: distribución del porcentaje de 50 semillas de El Litro, c1 (0-0,7) de acuerdo con el color del epicarpio (Earth Colors 1997).

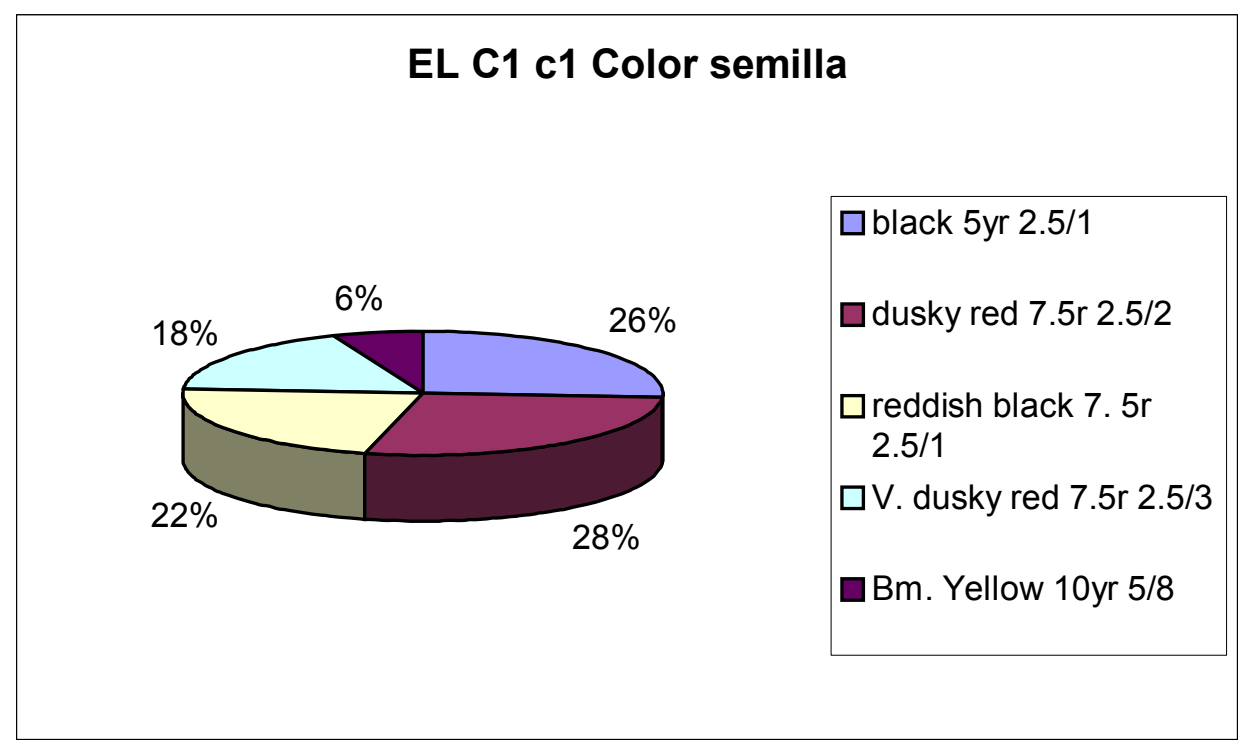

Gráfico 26: diferencia en el largo de estomas entre variedades silvestre y domesticada de $P$. vulgaris de referencia.

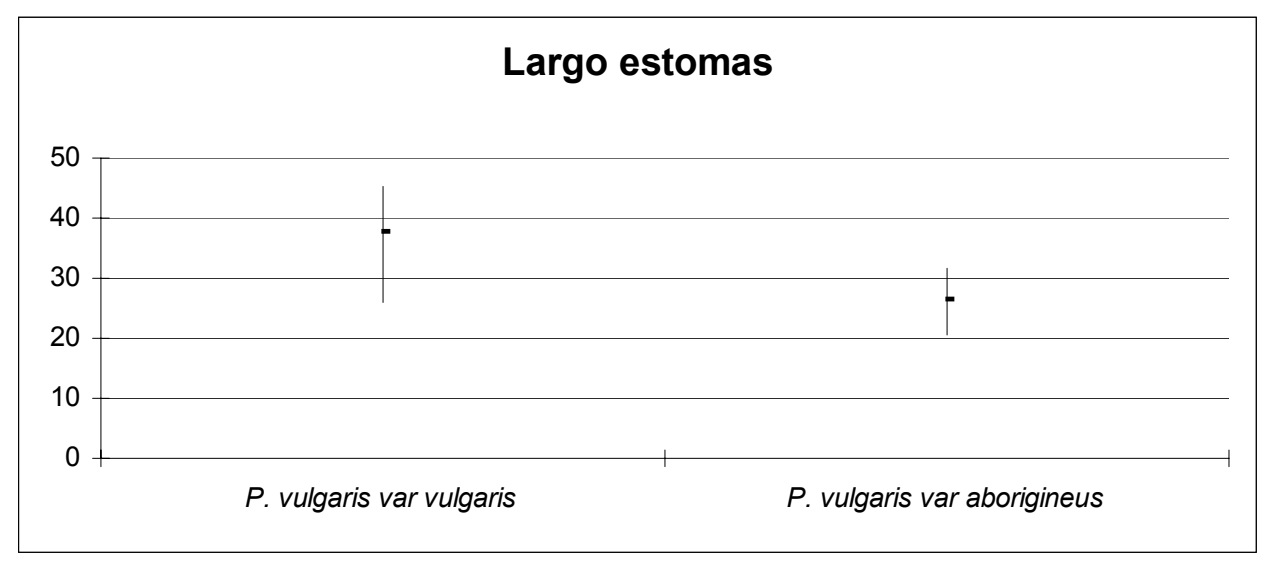


Gráfico 27: diferencia en el espesor del pericarpio entre variedades silvestre y domesticada de $P$. vulgaris de referencia (medidas expresadas en milímetros).

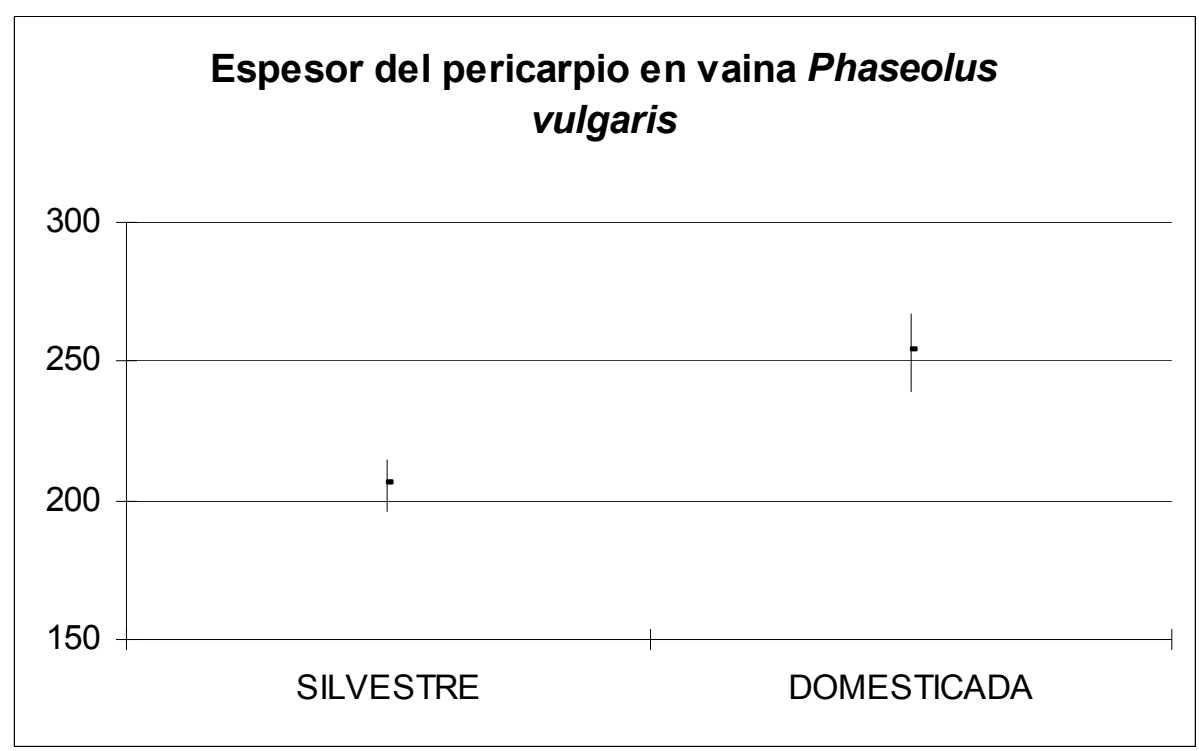

Grafico 28: distribución de vainas de Phaseolus sp. halladas en las distintas cuevas de la localidad arqueológica de Pampa Grande. Los números que figuran junto al gráfico corresponden al número exacto de vainas recuperadas.

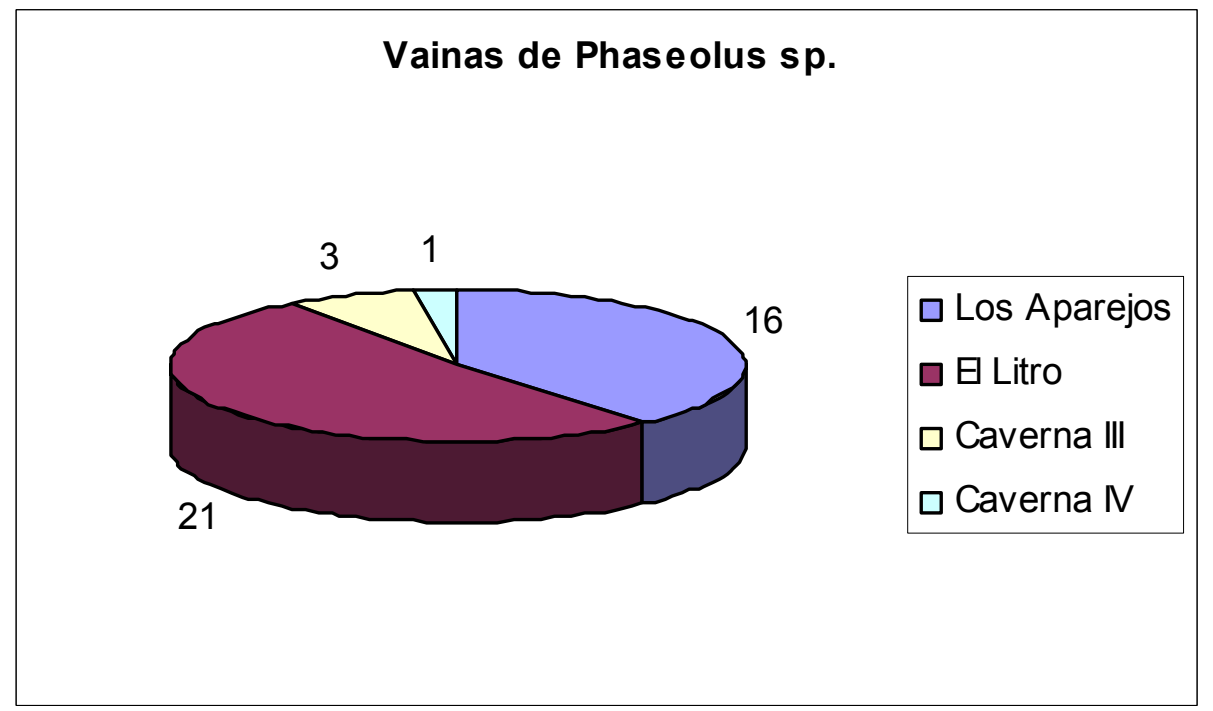




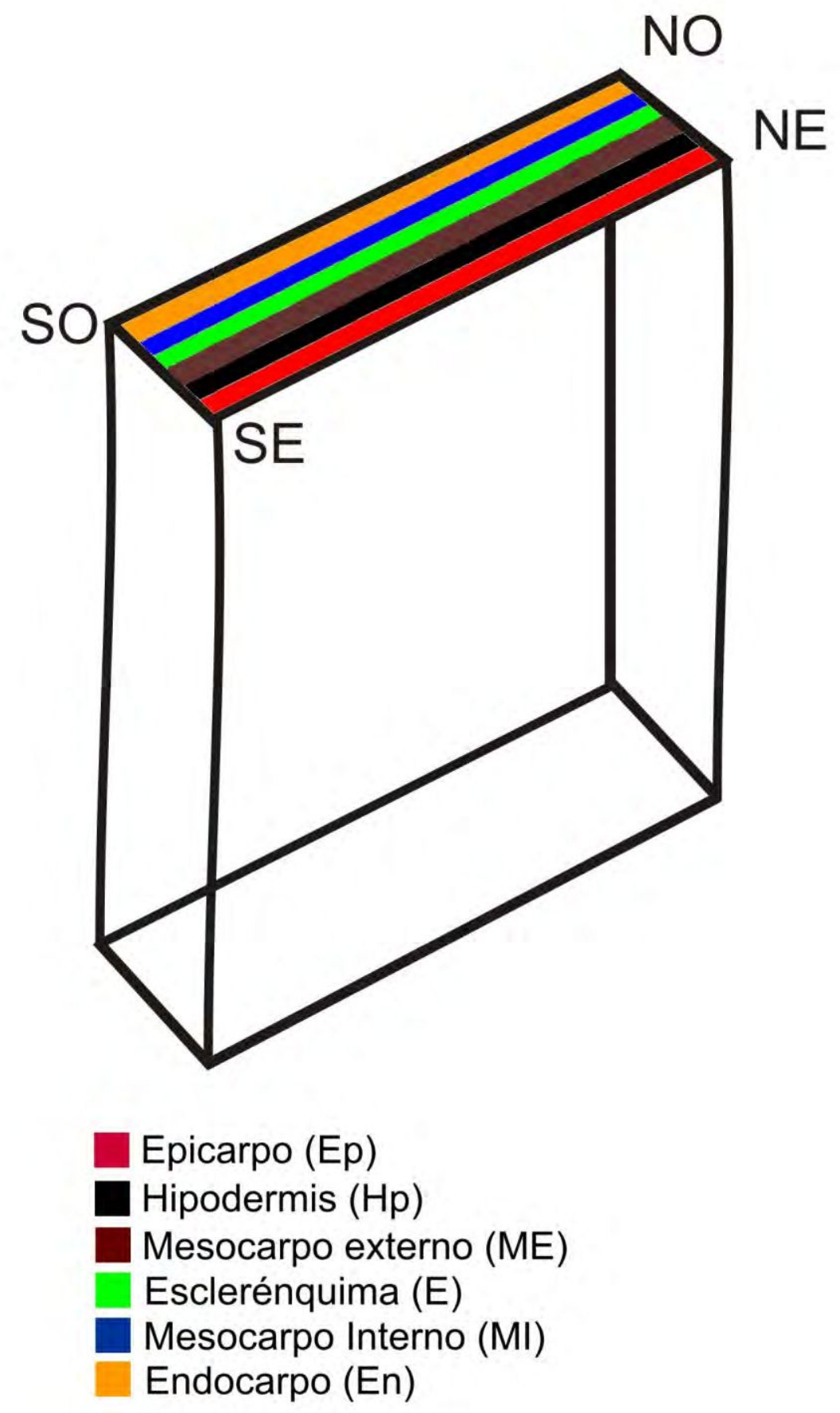

Referencias usadas en el análisis anatómico de vainas de Phaseolus vulgaris. El rectángulo negro representa una valva de $P$. vulgaris . La orientación de tipo I es NO SE, en tanto la de tipo II es NE SO. 


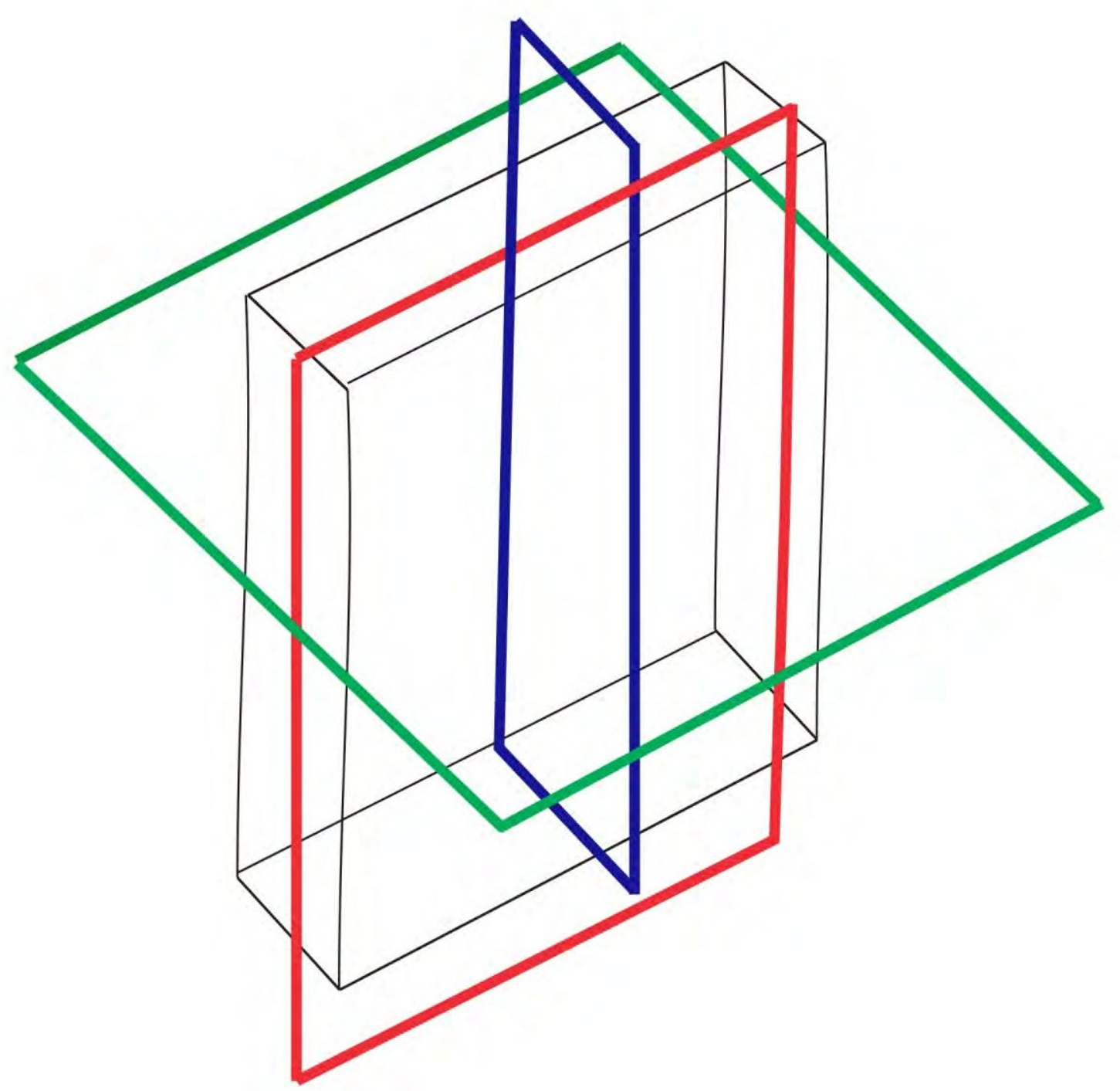

$\square$ Plano $Y$ tangente a la superficie de las caras de la valva. Plano $Z$ que corresponde al espesor de la valva. Plano $X$ que corta transversalmente a la valva.

Planos de referencias usados en el análisis anatómico de vainas de Phaseolus vulgaris . 


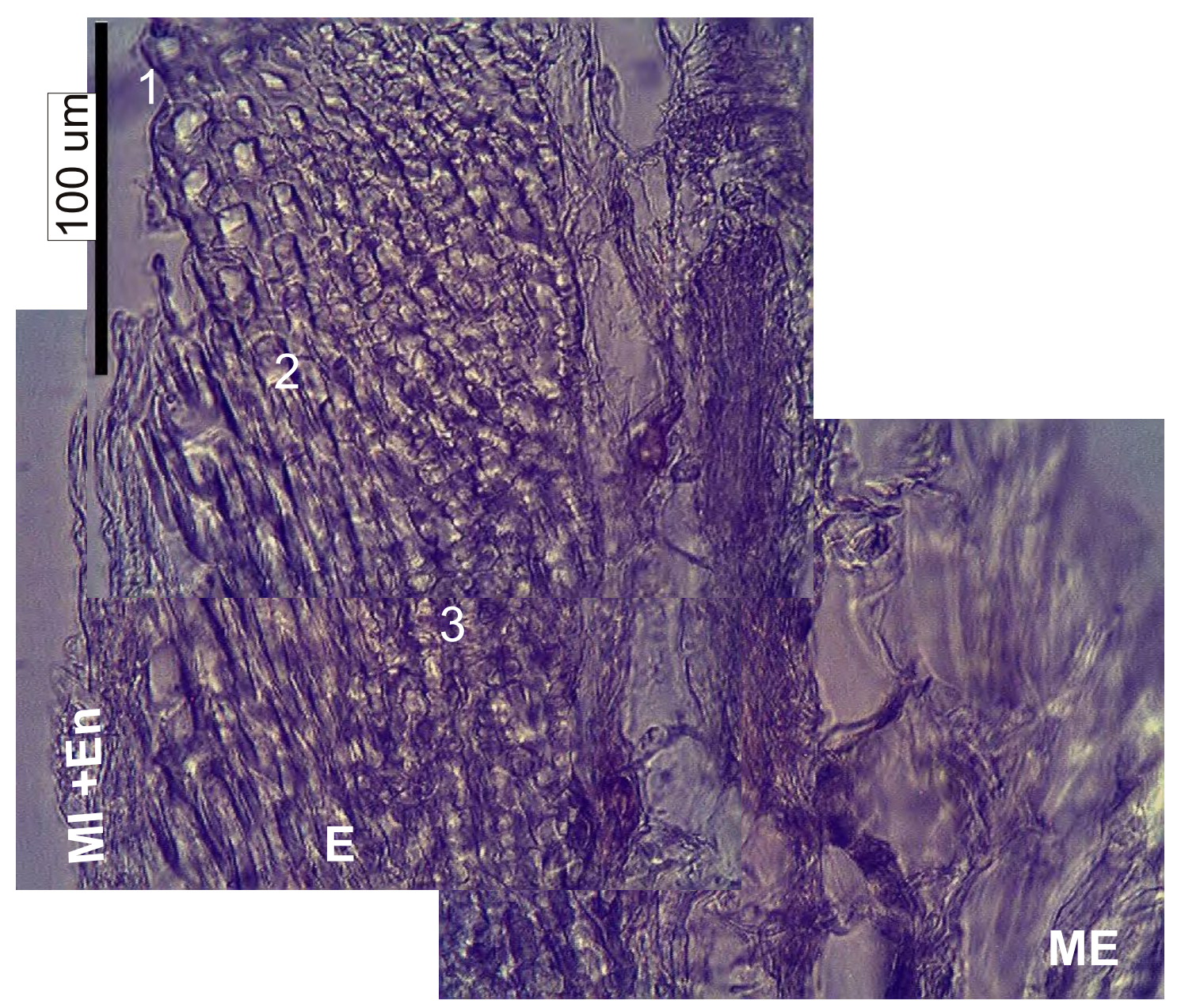

Phaseolus vulgaris var vulgaris Corte transversal, caras mayores Esclereidas cuya disposición varia entre los siguientes tipos:

1) paralelas al eje $Z$ e $Y$ y perpendiculares a $X$

2) levemente oblicuas a $X$ y a $Y$ y muy oblicuas a $Z$ (tipo I)

3) casi paralelo a $X$ y oblicuo a $Z$ y a $Y$ (tipo I) 
LAMINA 38
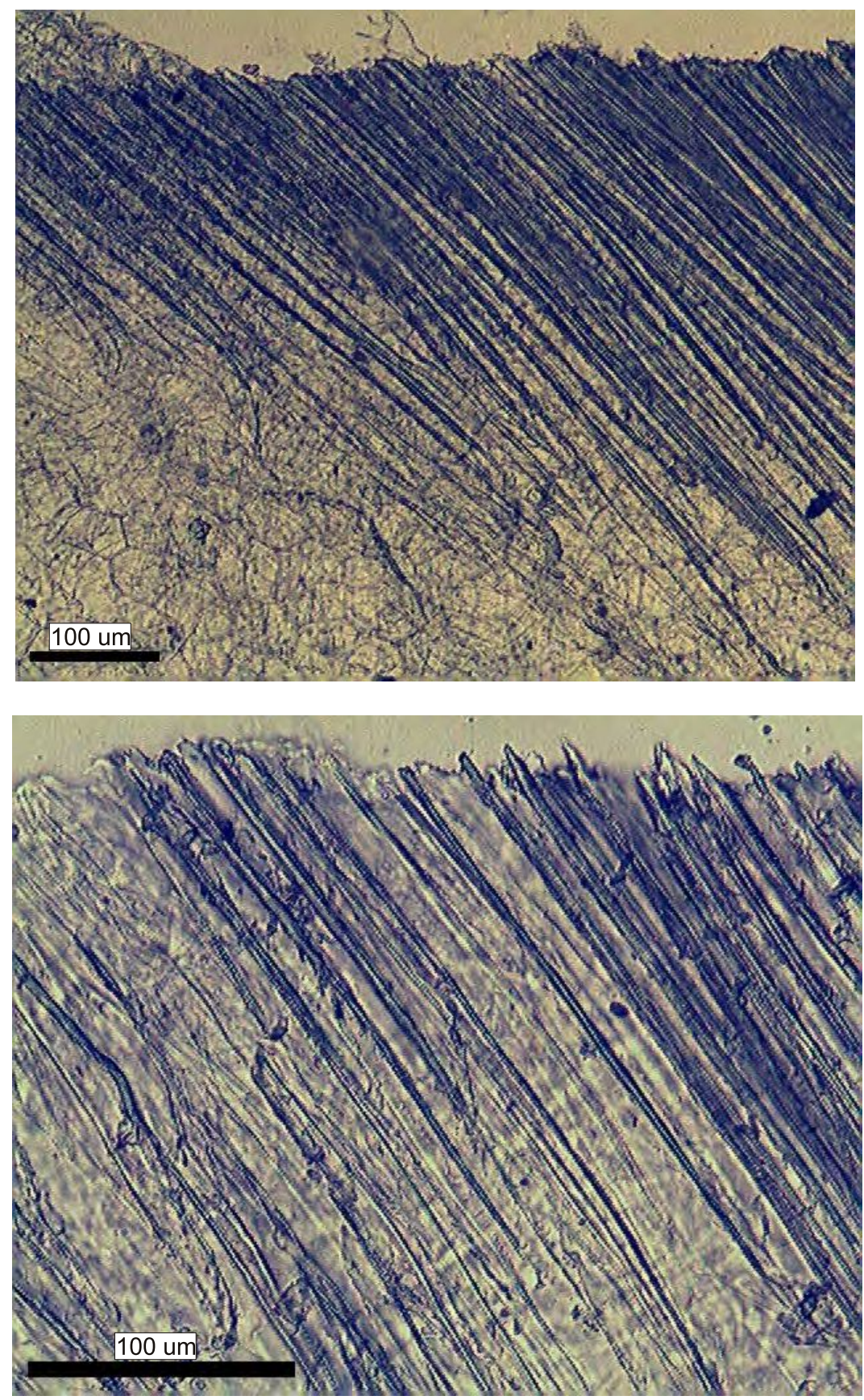

Phaseolus vulgaris var vulgaris Vista superficial, caras mayores donde se aprecian las esclereidas oblicuas (tipo I) respecto a los tres ejes considerados. 


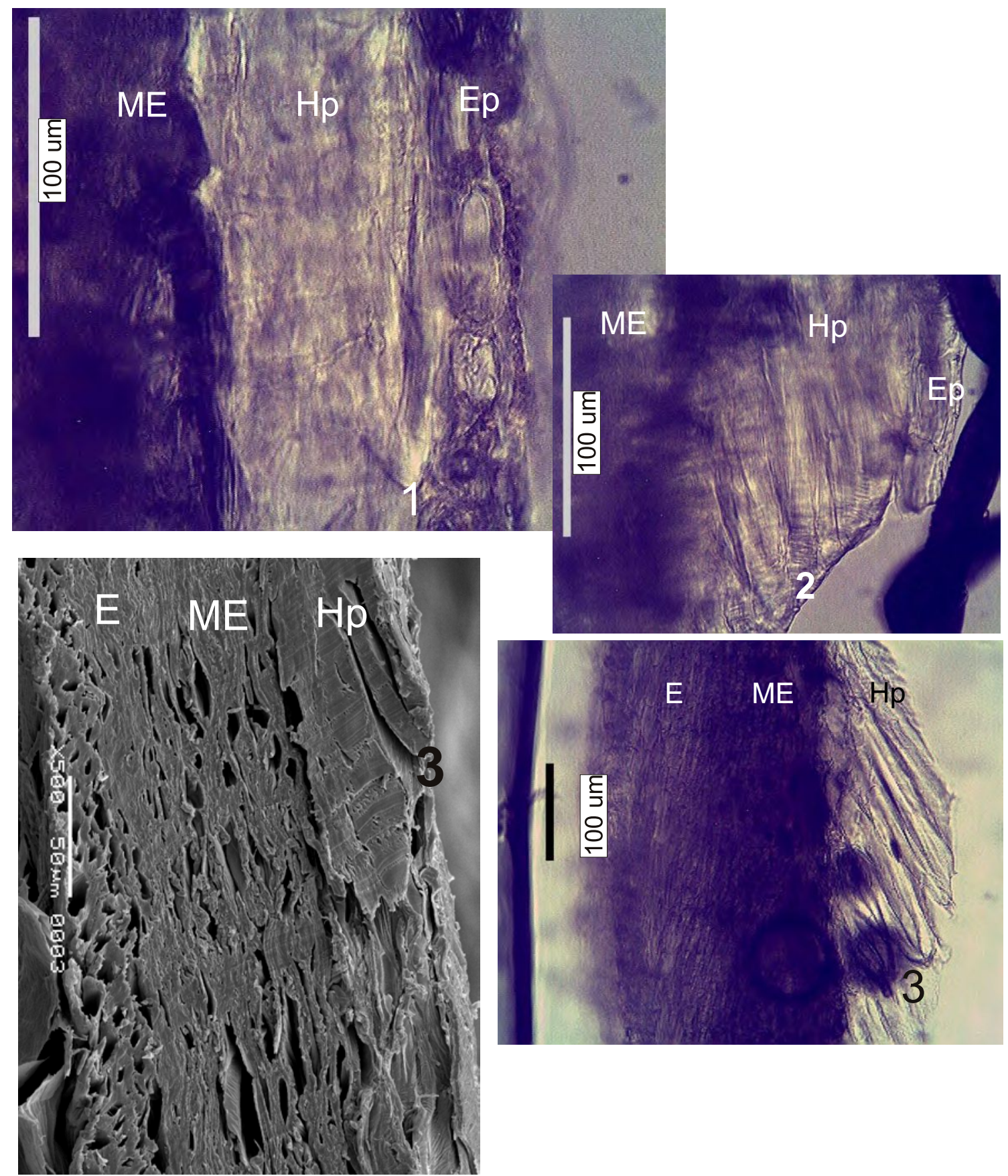

Phaseolus vulgaris var vulgaris Corte transversal en caras Mayores Células colenquimaticas de la hipodermis dispuestas:

1) Paralelas a $X$ y a $Y$ casi perpendiculares a $Z$

2) Oblicuas a $X$ y a $Z$ y paralela a $Y$ (tipo I)

3) Paralelas a $X$, oblicuas a $Z$ y a $Y$ (tipo I) 


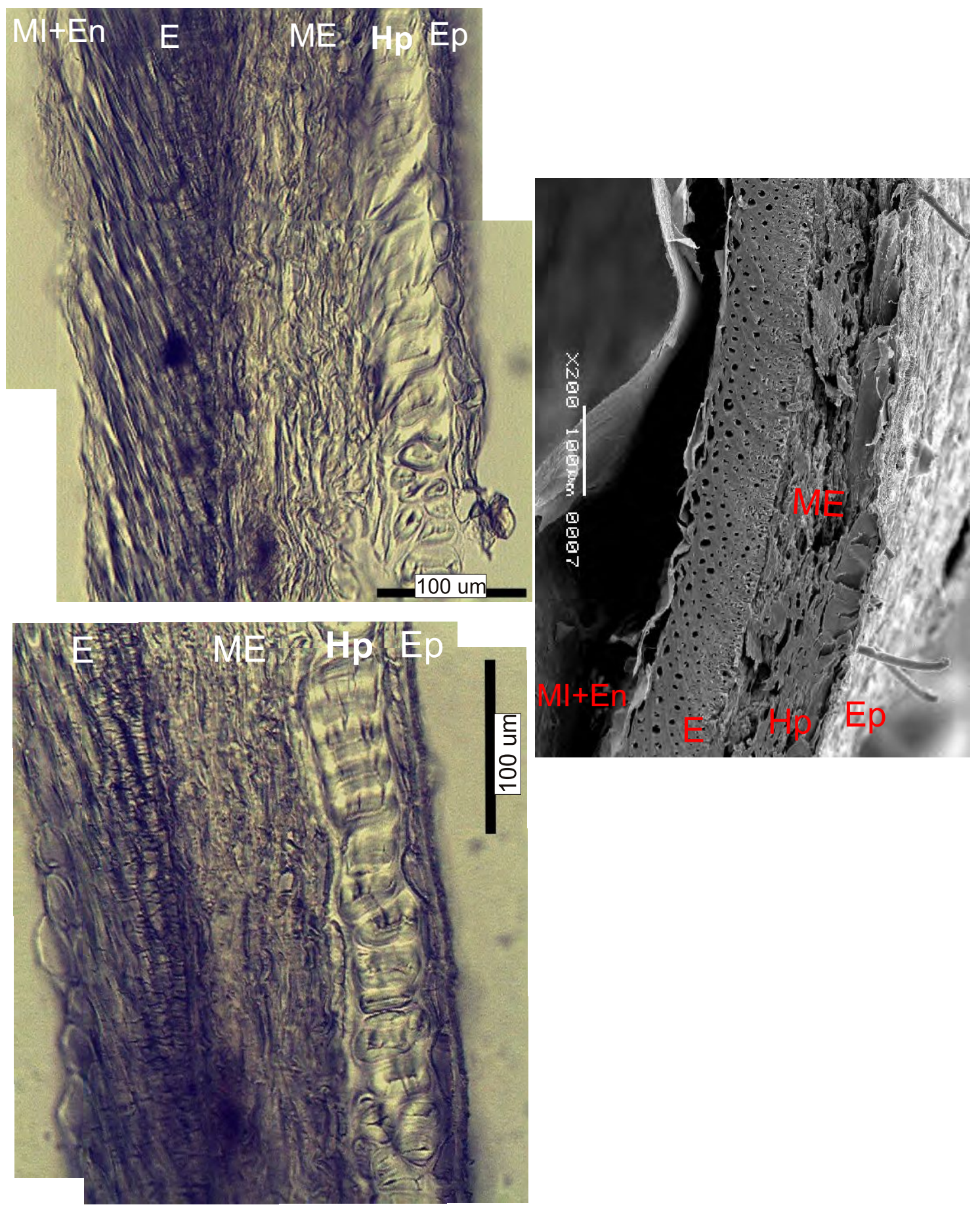

Phaseolus vulgaris var aborigineus. Corte transversal en caras mayores. Células colenquimáticas de la hipodermis: desde perpendiculares a casi perpendiculares a $X$, levemente oblicuas a $Y$ y a $Z$ (tipo II). Las esclereidas poseen las tres mismas orientaciones que las observadas en $P$. vulgaris var vulgaris. 
Lamina 41
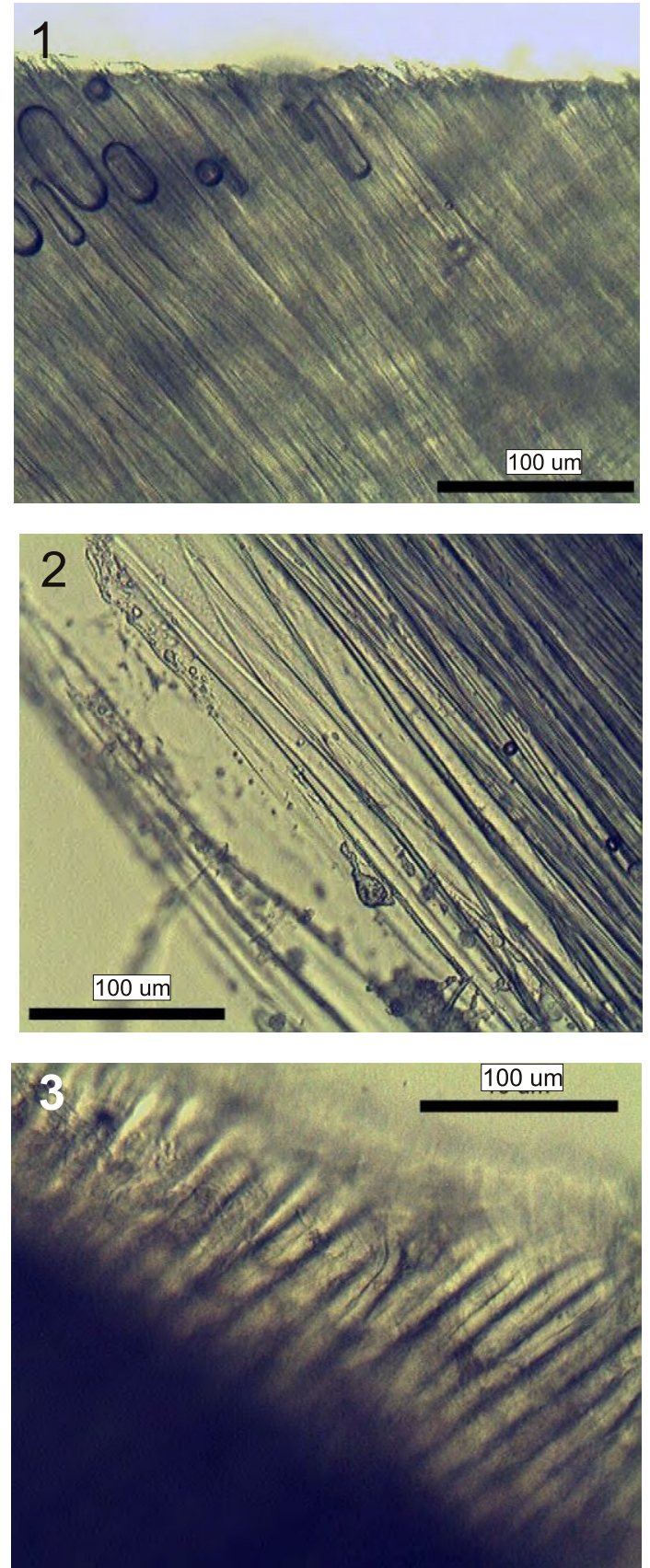

Phaseolus vulgaris var aborigineus Vista superficial en caras mayores donde puede apreciarse la orientación diferencial de esclereidas (tipo I) en las imágenes 1 y 2 y células colenquimáticas (tipo II) en la imagen 3. 


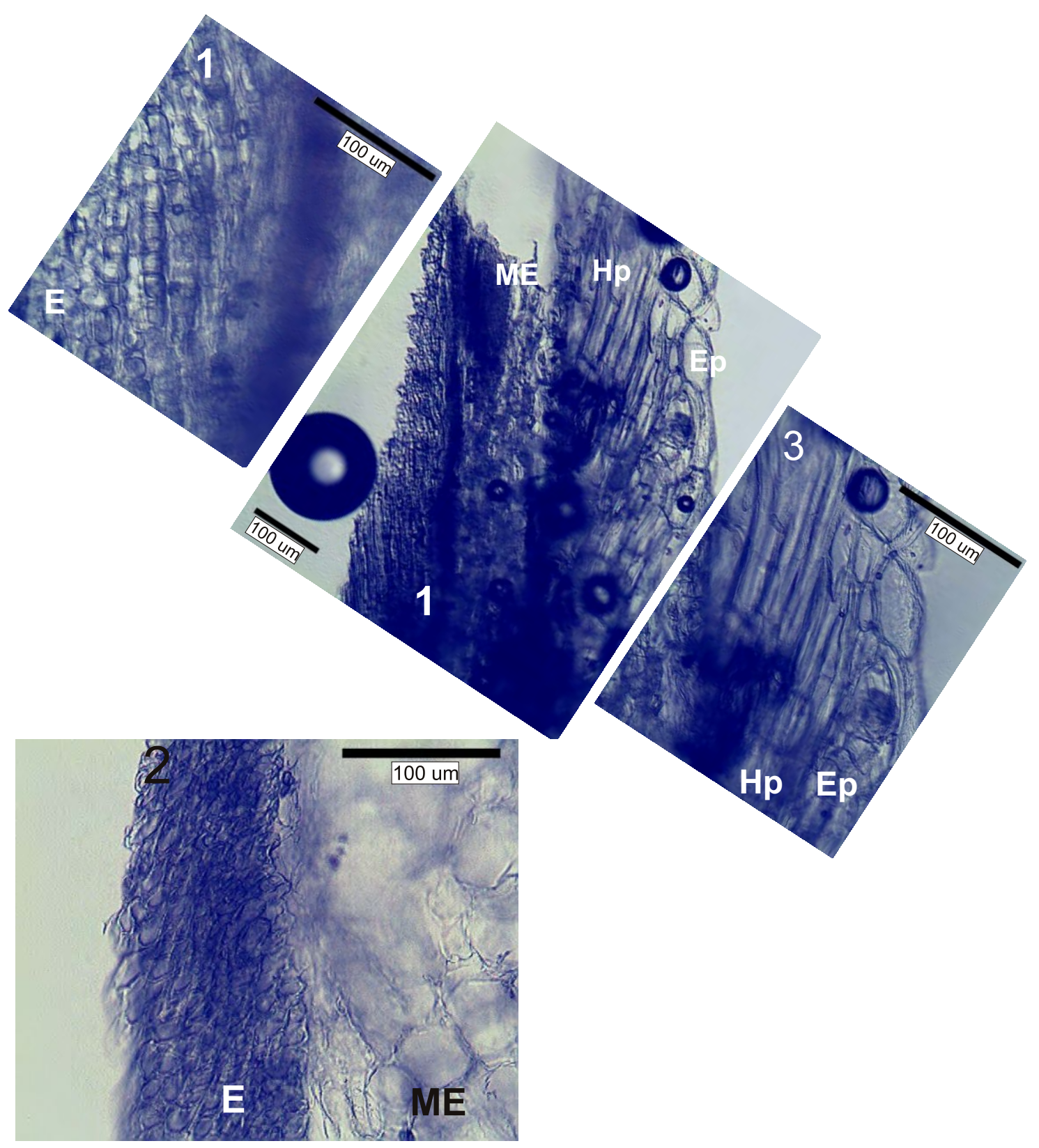

Phaseolus vulgaris var vulgaris Corte transversal Sutura ventral Esclereidas con dos disposiciones espaciales:

1) Casi paralelas a $X$ y a $Y$, levemente oblicuas a $Z$ (tipo I)

2) Oblicuas a los tres planos (tipo II)

Células colenquimaticas de la hipodermis: Casi paralelas a $X$ y oblicuas (tipo II) respecto de ejes $Z$ e $Y$ 
LAMINA 43

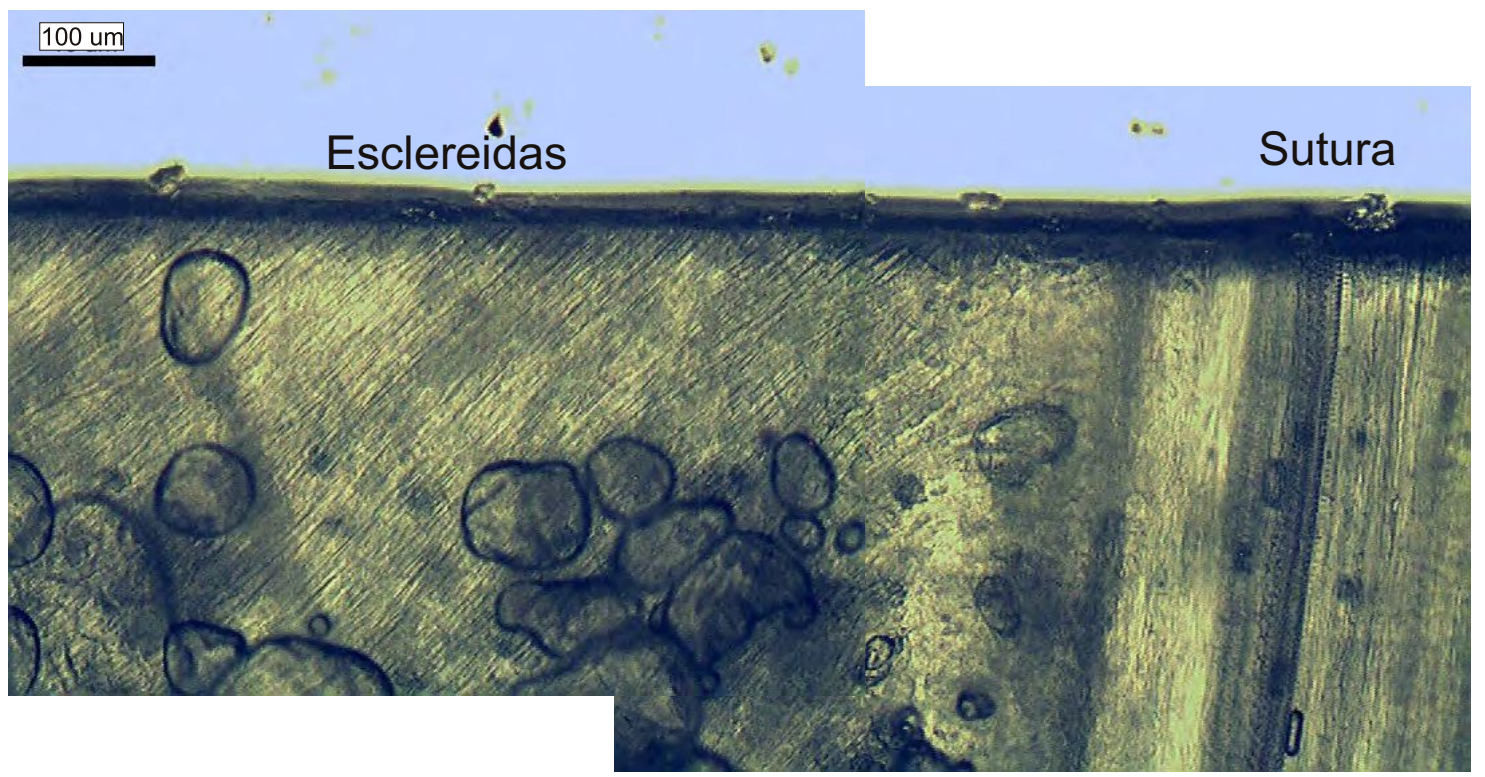

Phaseolus vulgaris var vulgaris Superficial Sutura ventral Esclereidas oblicuas a los tres planos (tipo II) 

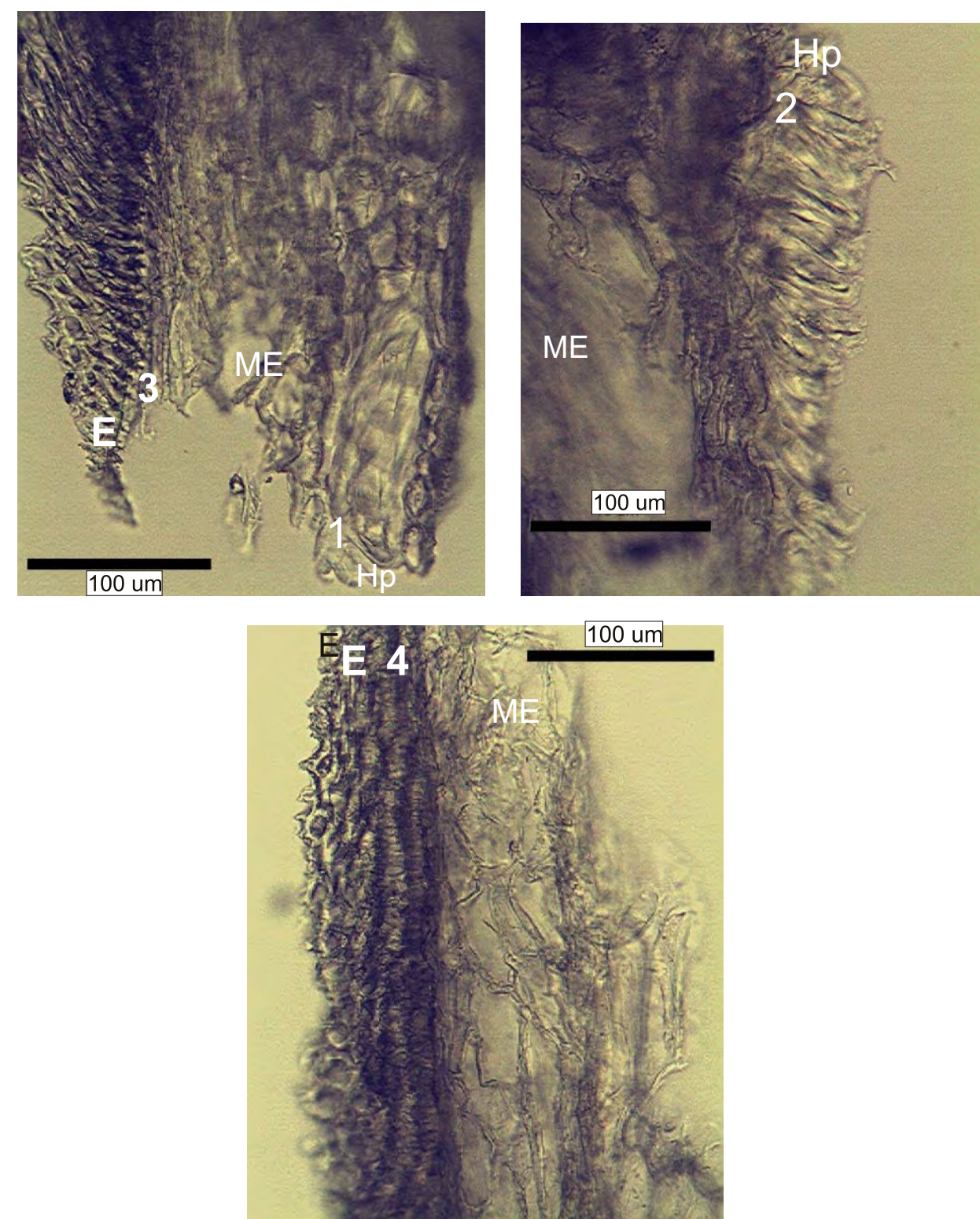

Phaseolus vulgaris var aborigineus Corte transversal en sutura ventral.

Células colenquimaticas de la hipodermis con dos disposiciones:

1) Paralelas a $X$ y a $Y$ casi perpendiculares a $Z$

2) Oblicuas (tipo I) a los tres planos

Esclereidas con dos disposiciones:

3) Oblicuas (tipo I) a los tres planos (igual a $P$. vulgaris var vulgaris pero difiere en el tipo)

4) Perpendiculares a casi paralelas a $X$, casi paralelas a $Y$ y oblicuas a $Z$ (tipo I) (similar a $P$. vulgaris var vulgaris salvo que en este caso hay esclereidas perpendiculares) 
LAMINA 45

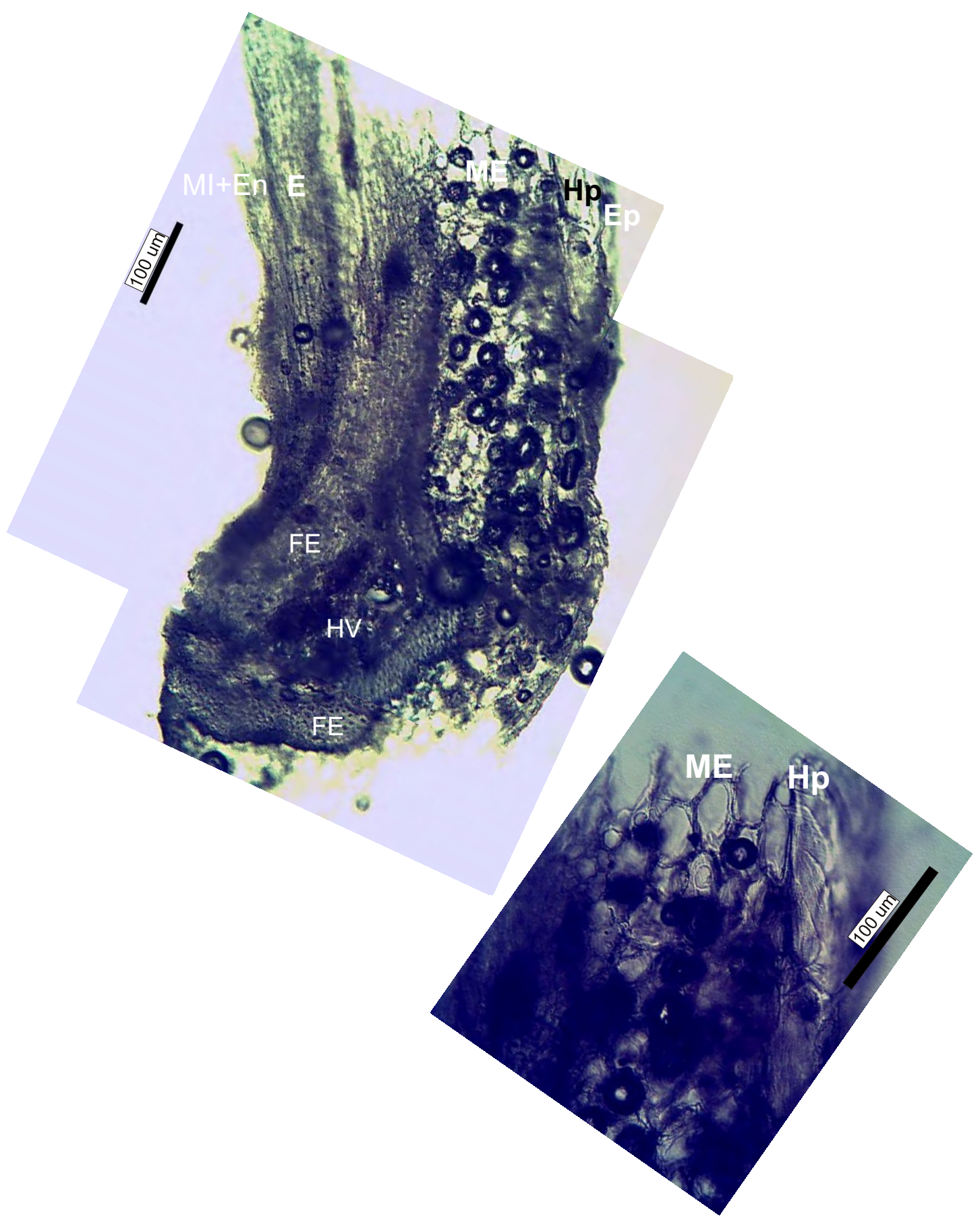

Phaseolus vulgaris var vulgaris Corte transversal en sutura dorsal Células colenquimáticas de la hipodermis casi perpendiculares a $X$, levemente oblicuas a $Y$ y a $Z$ (tipo I). 


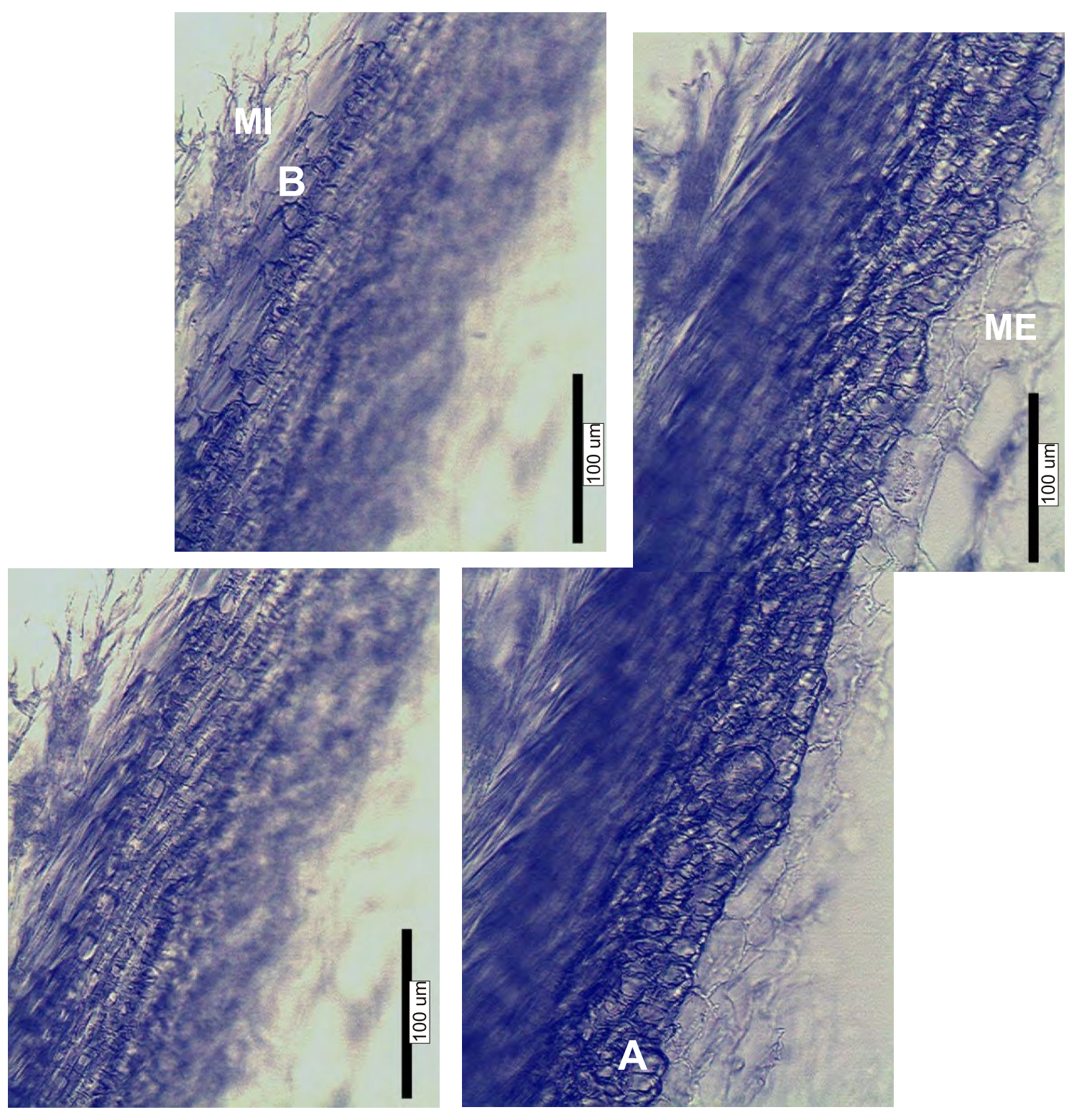

Phaseolus vulgaris var vulgaris Corte transversal en sutura dorsal Esclereidas en dos capas(A: primera, B: segunda) que poseen disposición distinta:

Capa 1: Casi perpendiculares a $X$ y oblicuas a $Z$ y a $Y$ (tipo II) Capa 2: Muy oblicuas a casi paralelas a $X$ y oblicuas a $Z$ y a $Y$ (tipo II) 

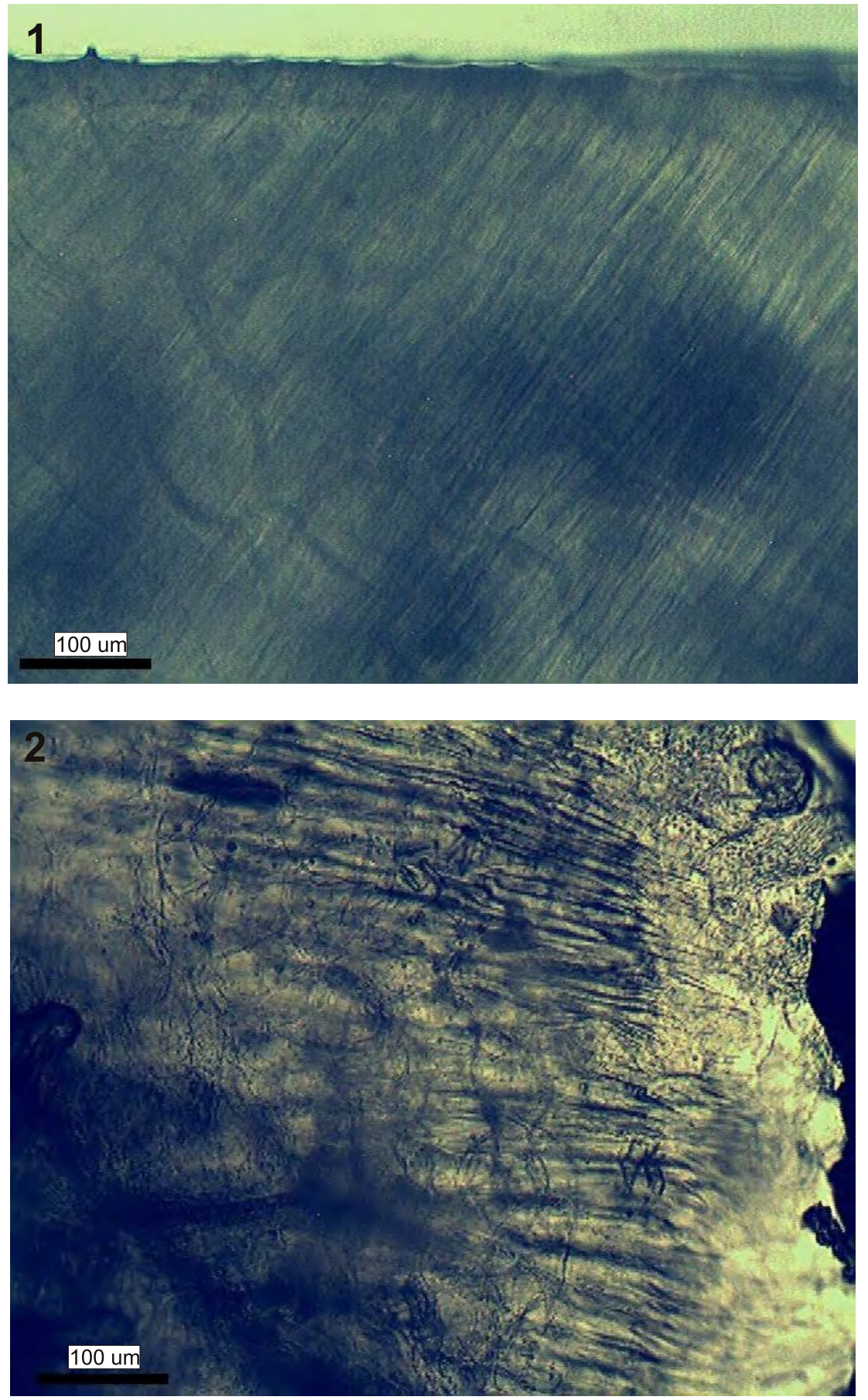

Phaseolus vulgaris var vulgaris, vista superficial de la sutura dorsal, 1: esclereidas oblicuas respecto de los tres planos (tipo II)

2: celulas colenquimaticas de la hipodermis levemente oblicuas (tipo I) respecto a los tres plano., 


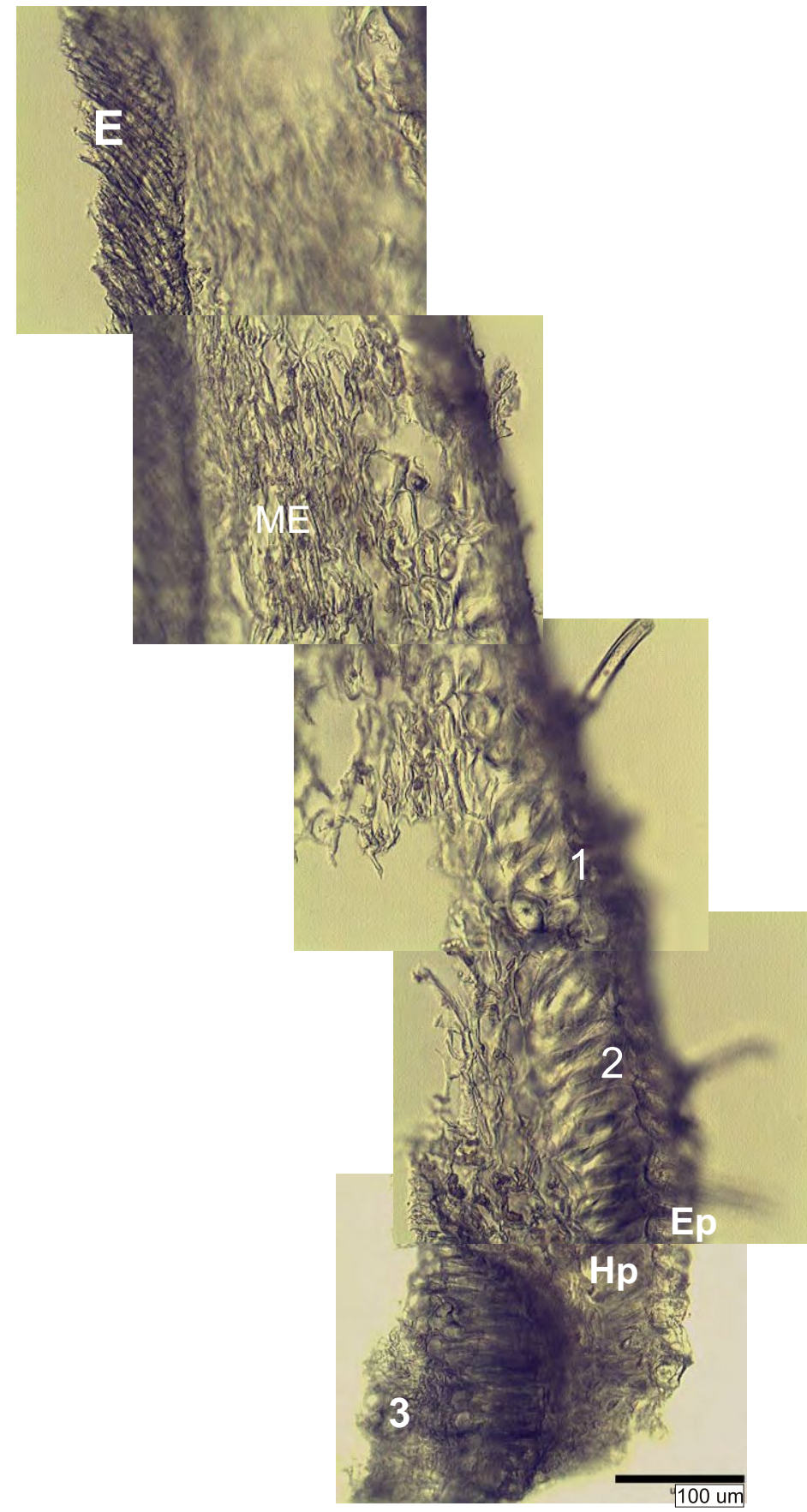

Phaseolus vulgaris var aborigineus Corte transversal en sutura dorsal.Esclereidas casi paralelas a $X$ y oblicuas (tipo I) a $Z$ y a $Y$. Células colenquimatica de la hipodermis con dos disposiciones:

1) Perpendicular a $X$, paralela a $Z$ y a $Y$

2) Oblicua (tipo II) a los tres planos Haz vascular rodeado de fascículos de esclereidas (3) 

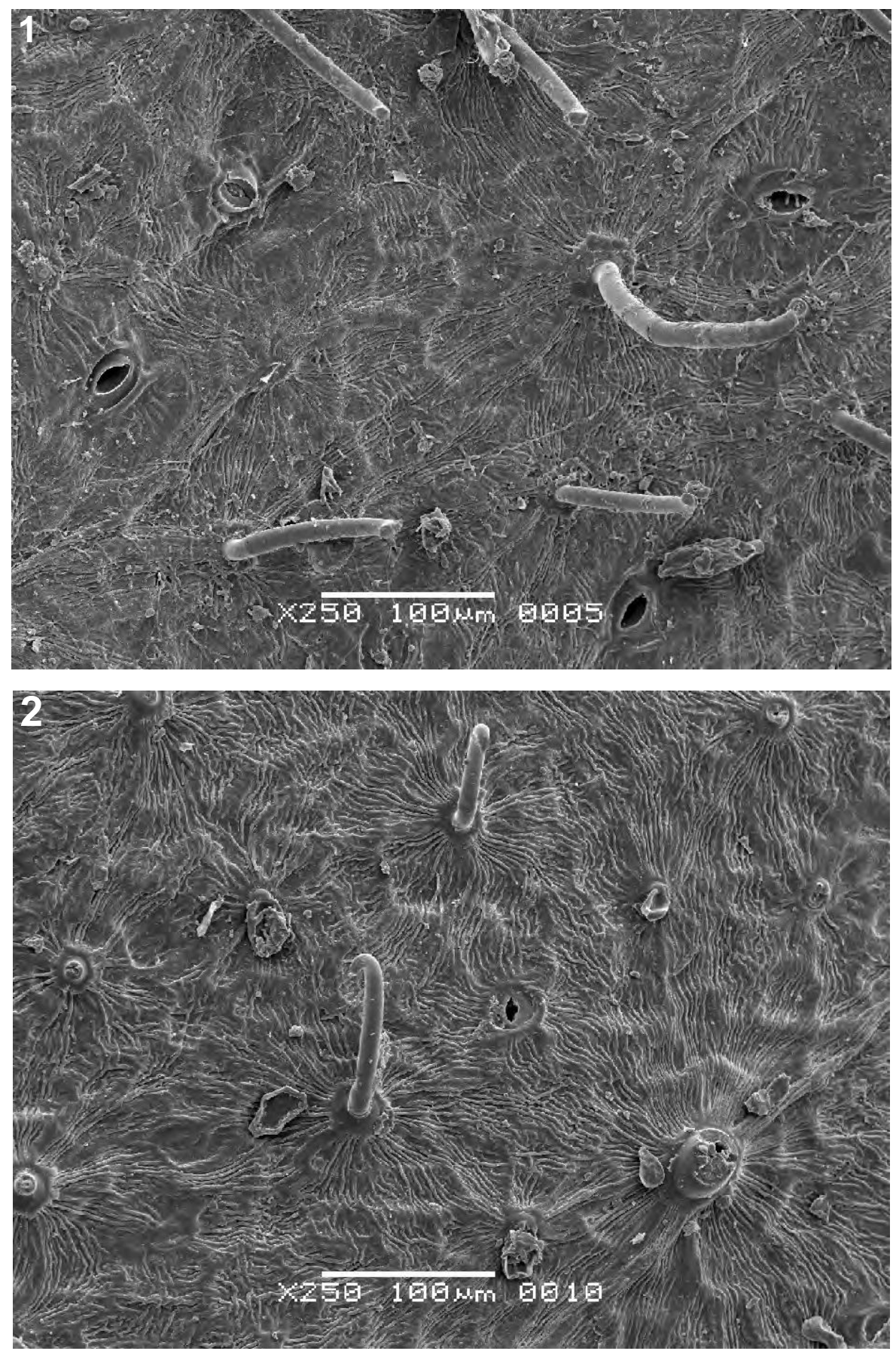

Vista superficial de la vaina de Phaseolus vulgaris var vulgaris con largo de estomas de 37,84um promedio (26-45um) y de Phaseolus vulgaris var. aborigineus (2) con argo de estoma de 26,49 um promedio $(20,5-31$ um) y cutícula mas estriada que la subespecie domesticada. 

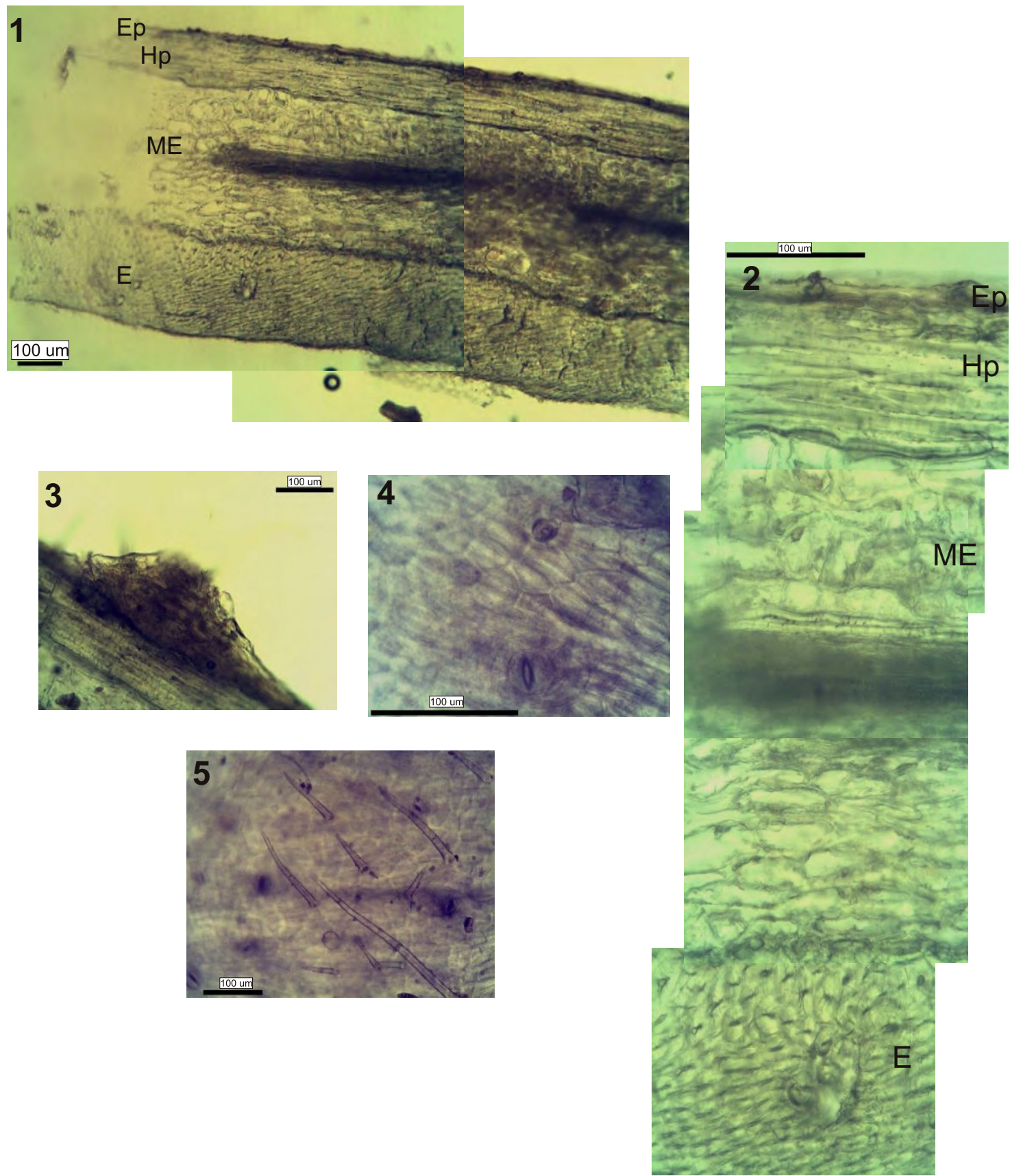

Caesalpinea gillesii, 1 y 2: corte transversal de una valva, 3: llaga superficial, 4: superficie sin cutícula, 5: tricomas uni y biseriados con extremo aguzado. 

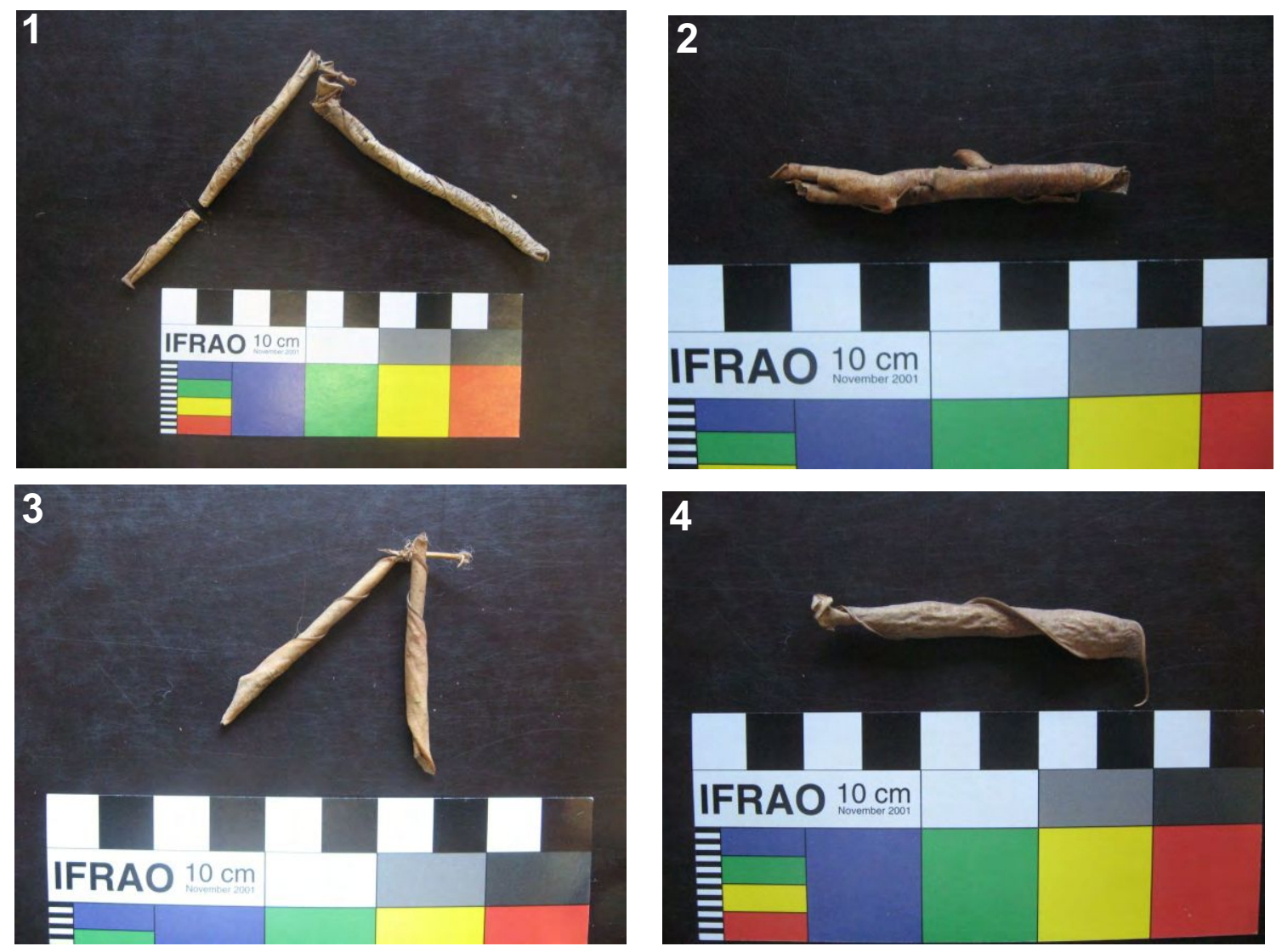

Conjunto de vainas analizado de Pampa Grande, 1: Caverna IV, 2: El Litro, 3: Los Aparejos, 4: Caverna III 

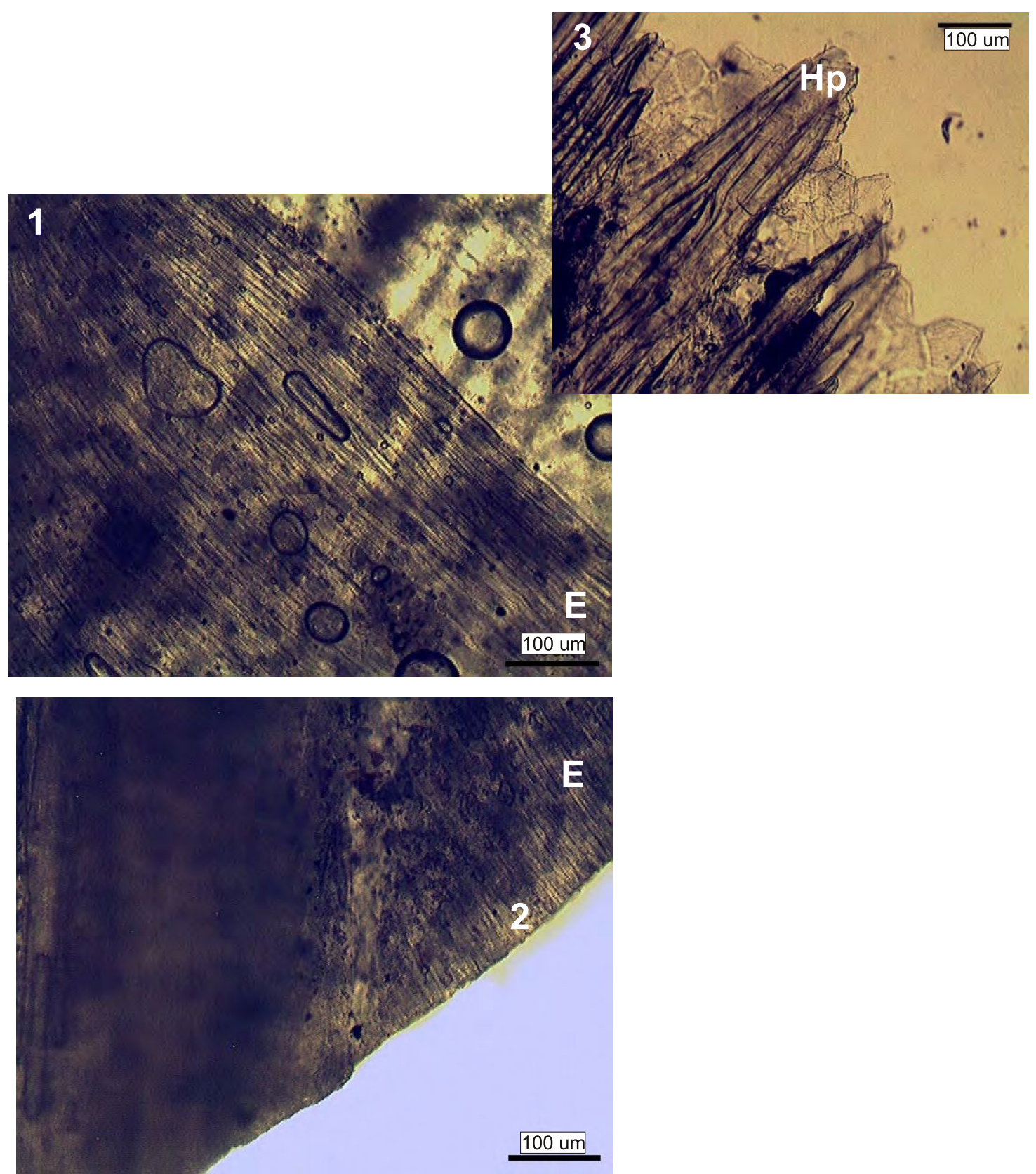

Pampa Grande Vaina Caverna IV Superficial, sutura dorsal

1 y 2) Esclereidas: Oblicuas (tipo I) respecto a $X$ y a $Z$, paralela respecto a $Y$

3) Células colenquimaticas de la hipodermis: oblicuas (tipo II) respecto a $X$ y a $Z$, paralela respecto a $Y$ 


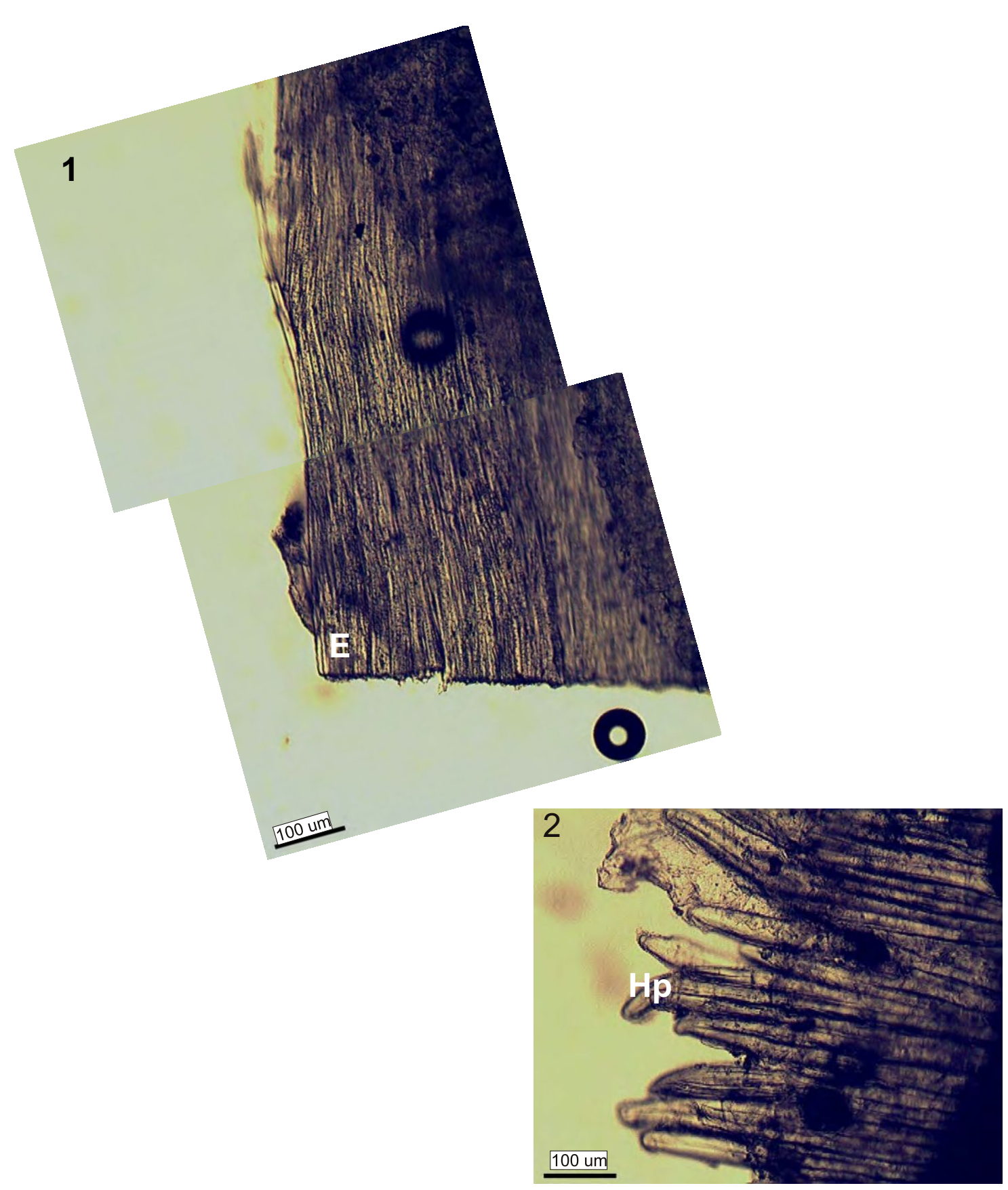

Pampa Grande Vaina Caverna IV Superficial Sutura ventral

1) esclereidas: casi perpendiculares al plano $X$, levemente oblicuas a $Z$ (tipo I) y paralelas a $Y$

2) células colenquimáticas de la hipodermis paralelas a $Y$, casi paralelas a $X$ y levemente oblicuas (tipo I) a $Z$ 


\section{LAMINA 54}
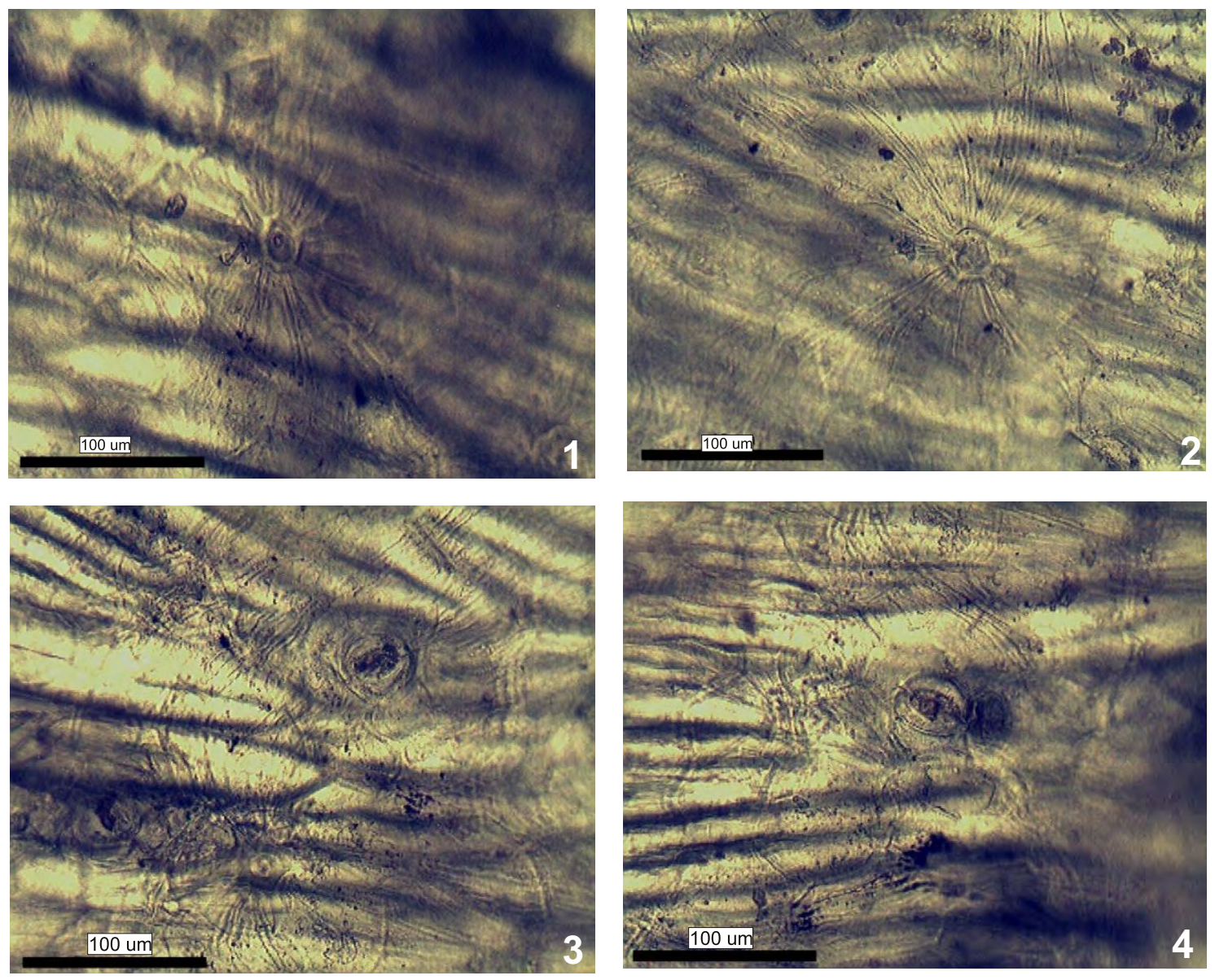

Pampa Grande Vaina Caverna IV, vista superficial, 1 y 2: bases de tricomas; 3 y 4 estomas, 3: largo 22,2um ; 4: largo 27um. 


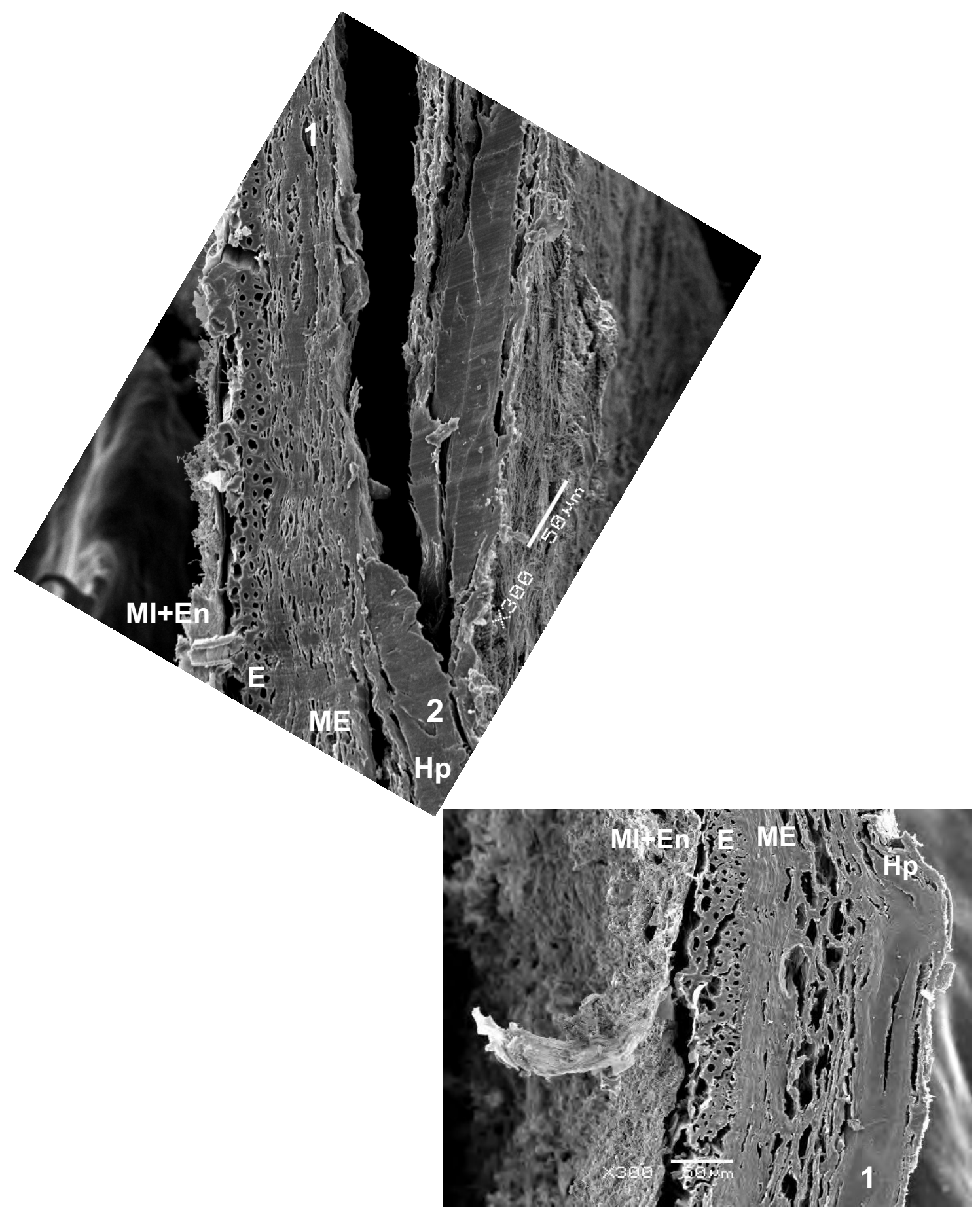

Pampa Grande Vaina Caverna III, Corte transversal en caras de la valva. Células del esclerenquima perpendiculares a $X$, levemente oblicuas a $Z$ y paralelas a $Y$. Celulas del colenquima con dos disposiciones: 1) Paralelas a $X$ y a $Y$ y casi perpendiculares a $Z$

2) Paralela a $X$ y oblicuas (Tipo I) a $Y$ y a $Z$ 


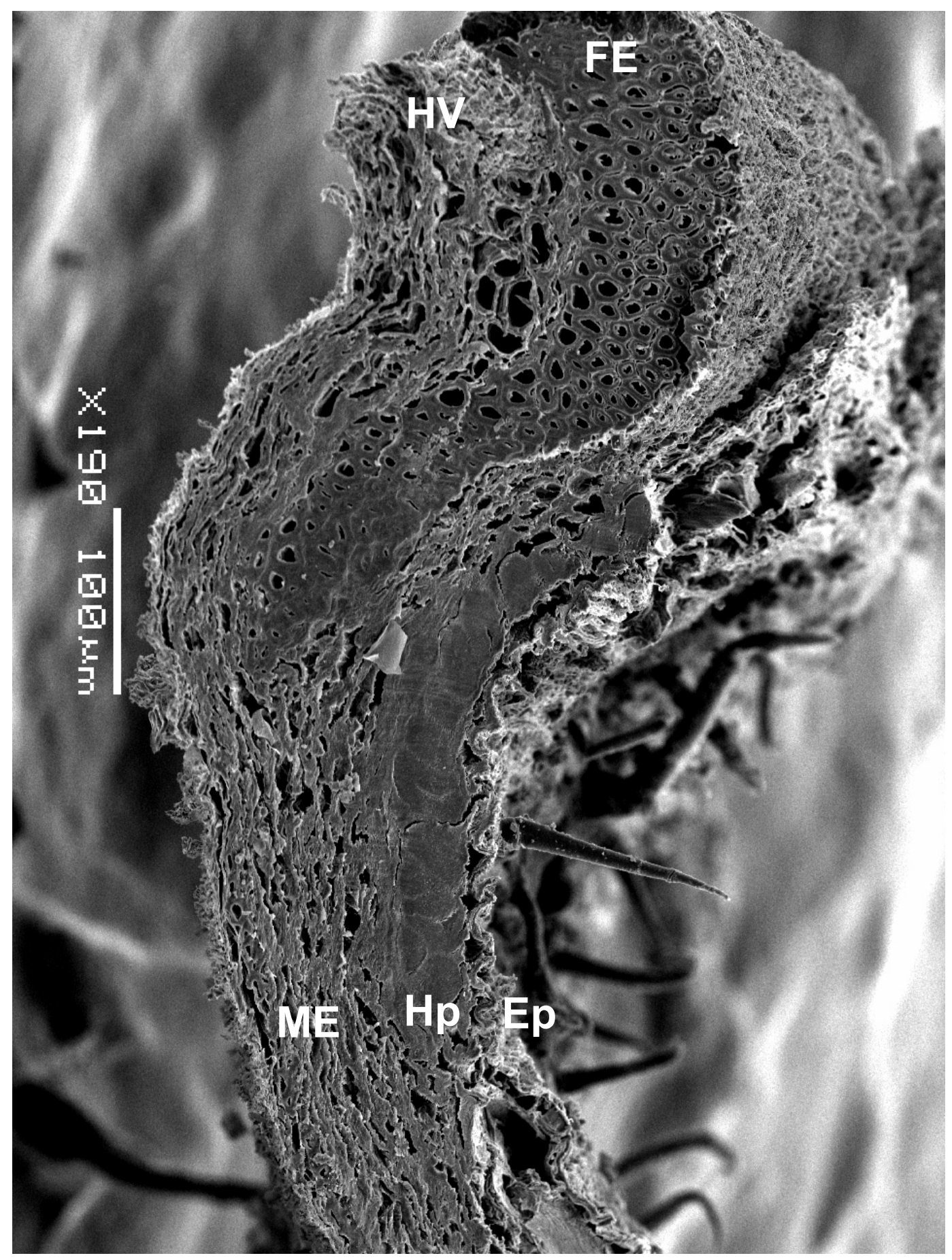

Pampa Grande Vaina Caverna III Corte transversal en sutura dorsal Células colenquimaticas de la hipodermis: casi perpendiculares a $X$, levemente oblicuas a $Y$ y a $Z$ (Tipo I) 


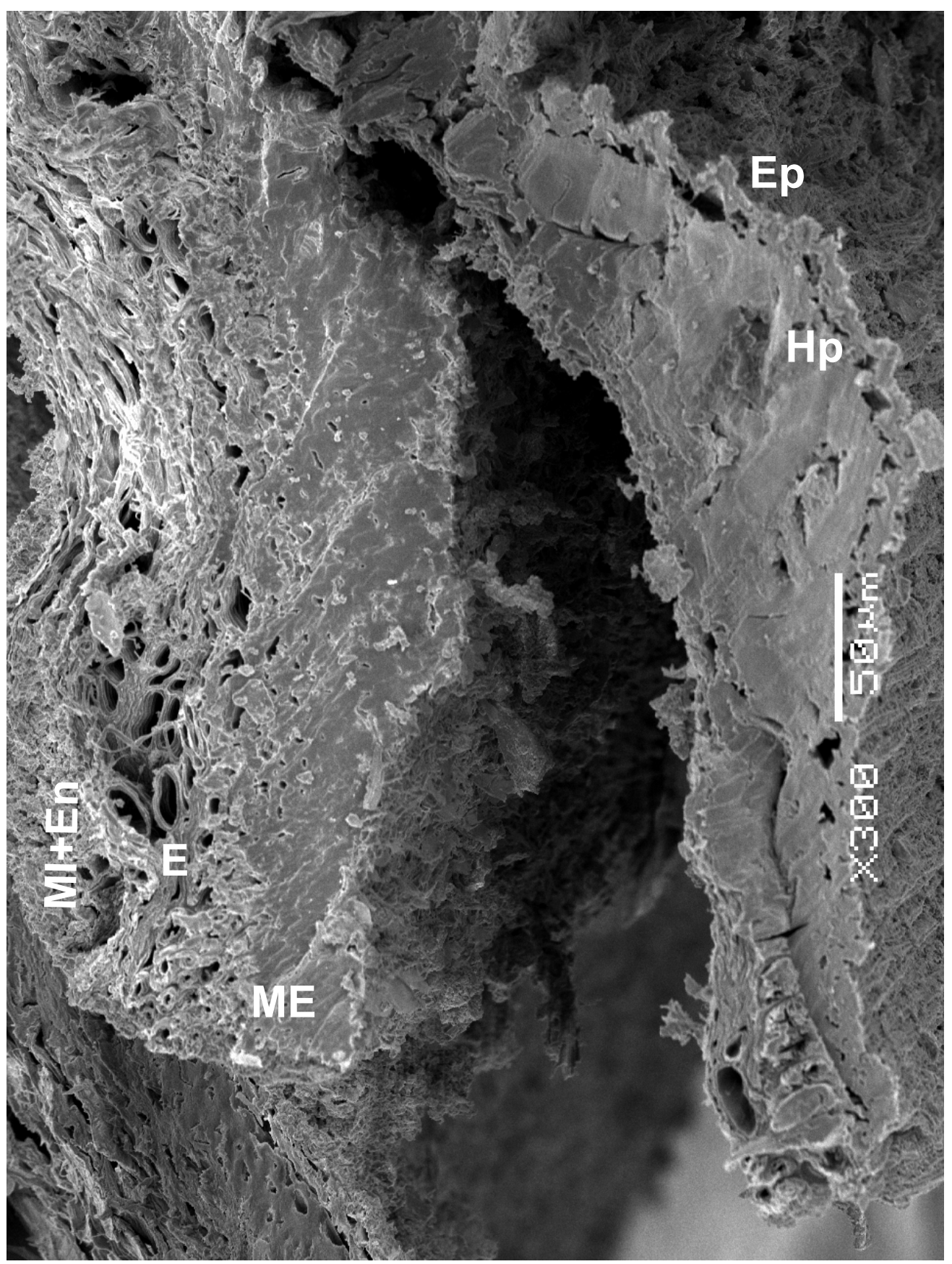

Pampa Grande Vaina Caverna III. Corte transversal en sutura ventral.

Esclereidas: oblicuas (casi perpendiculares) a $X$, oblicuas a $Y$ y a Z (tipos I y II)

Células colenquimaticas de la hipodermis: perpendiculares a $X$, paralelas a $Y$ y a $Z$ 

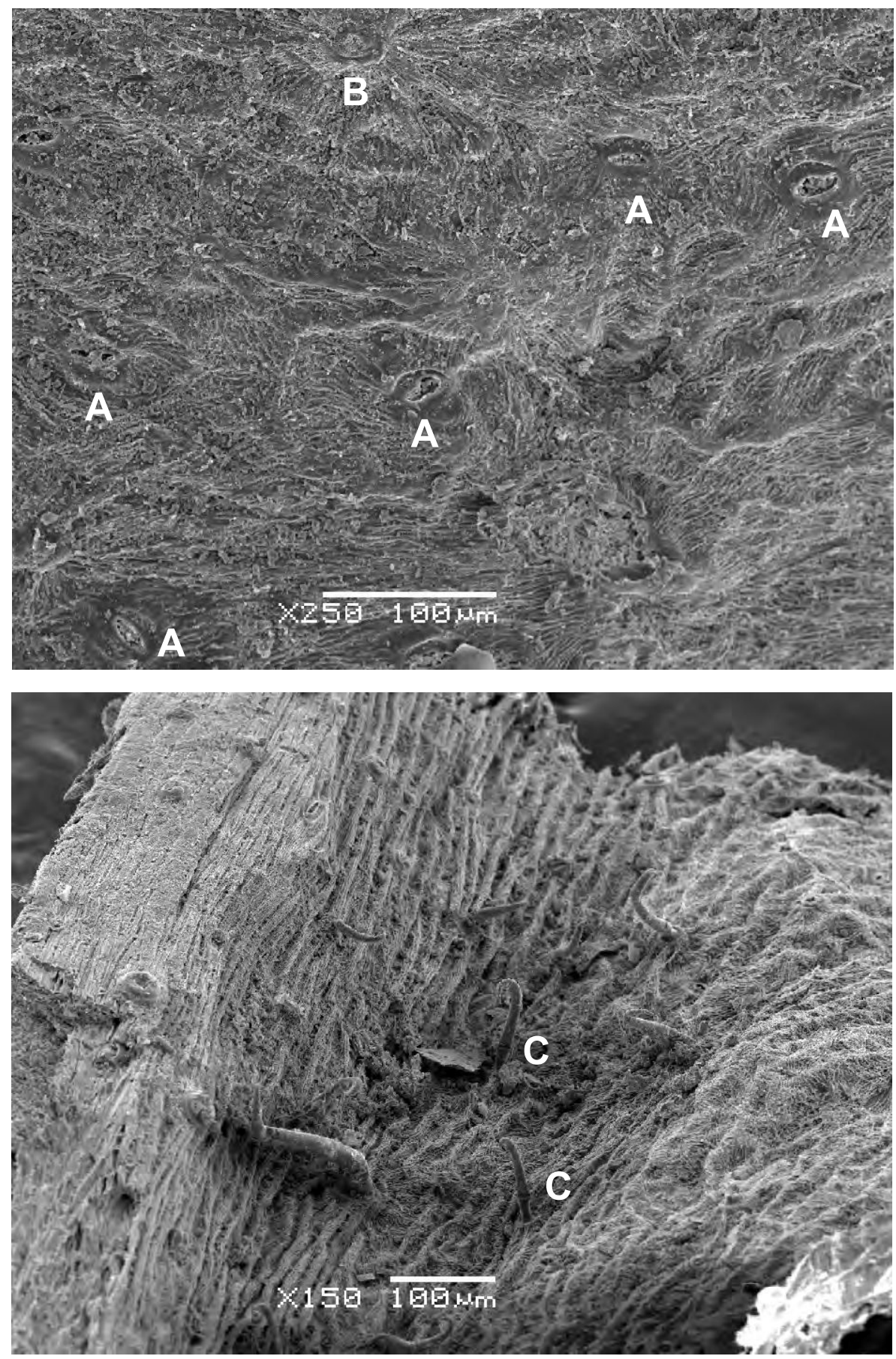

Pampa Grande Vaina Caverna III Vista superficial de las caras de la valva; A: estomas, largo promedio: 28,3um (21-38 um), B: base de tricomas y $\mathrm{C}$ : tricomas biseriados. 


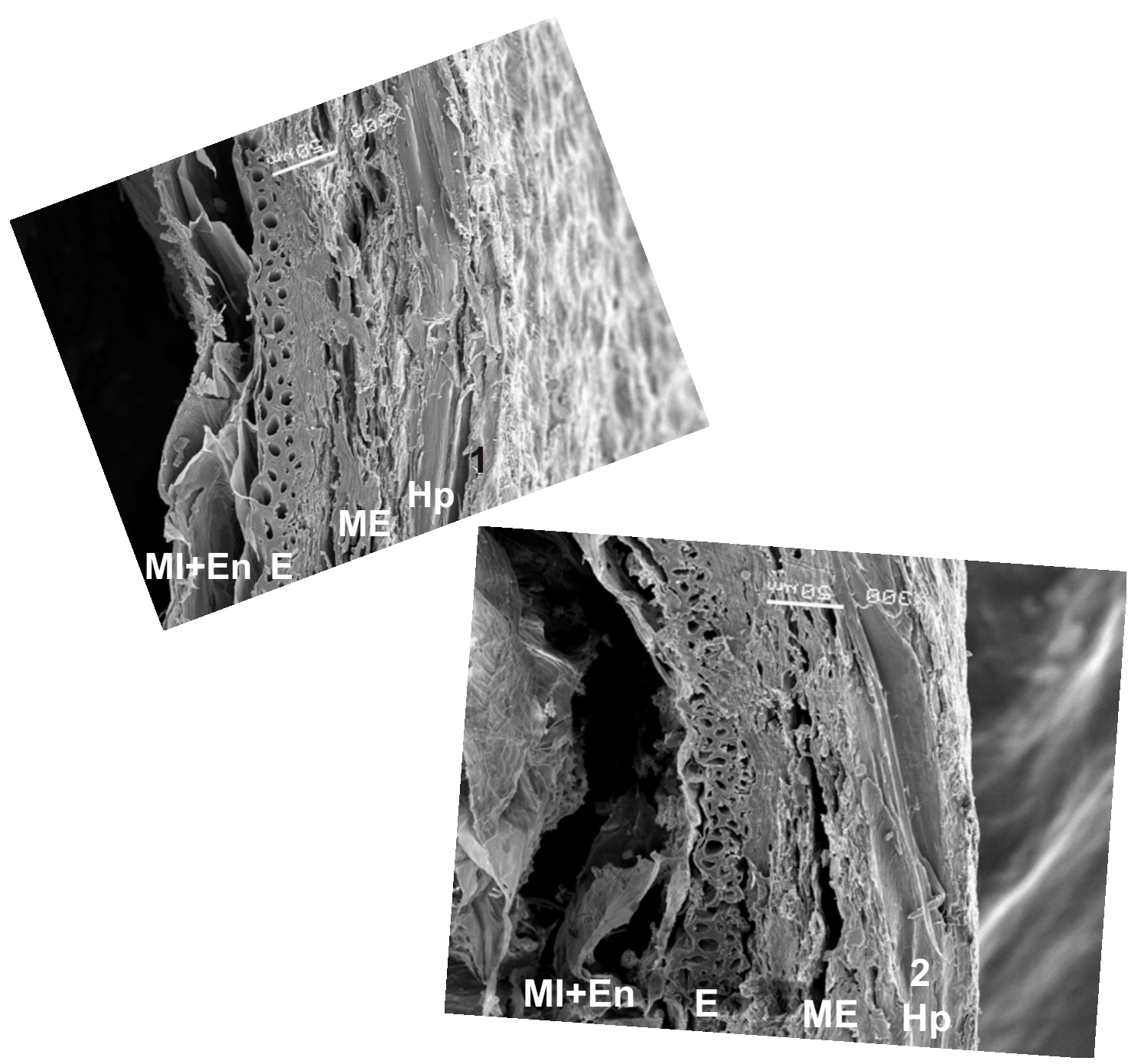

Pampa Grande Vaina El Litro. Corte transversal en caras mayores

Esclereidas: casi perpendiculares a $X$, oblicuas (Tipo I y II) a Z y a $Y$

Células colenquimaticas de la hipodermis con dos disposiciones:

1) Paralelas a $X$ y a $Y$, casi perpendiculares a $Z$

2) Paralelas a $X$ y oblicuas a $Z$ y a $Y$ (Tipo I) 


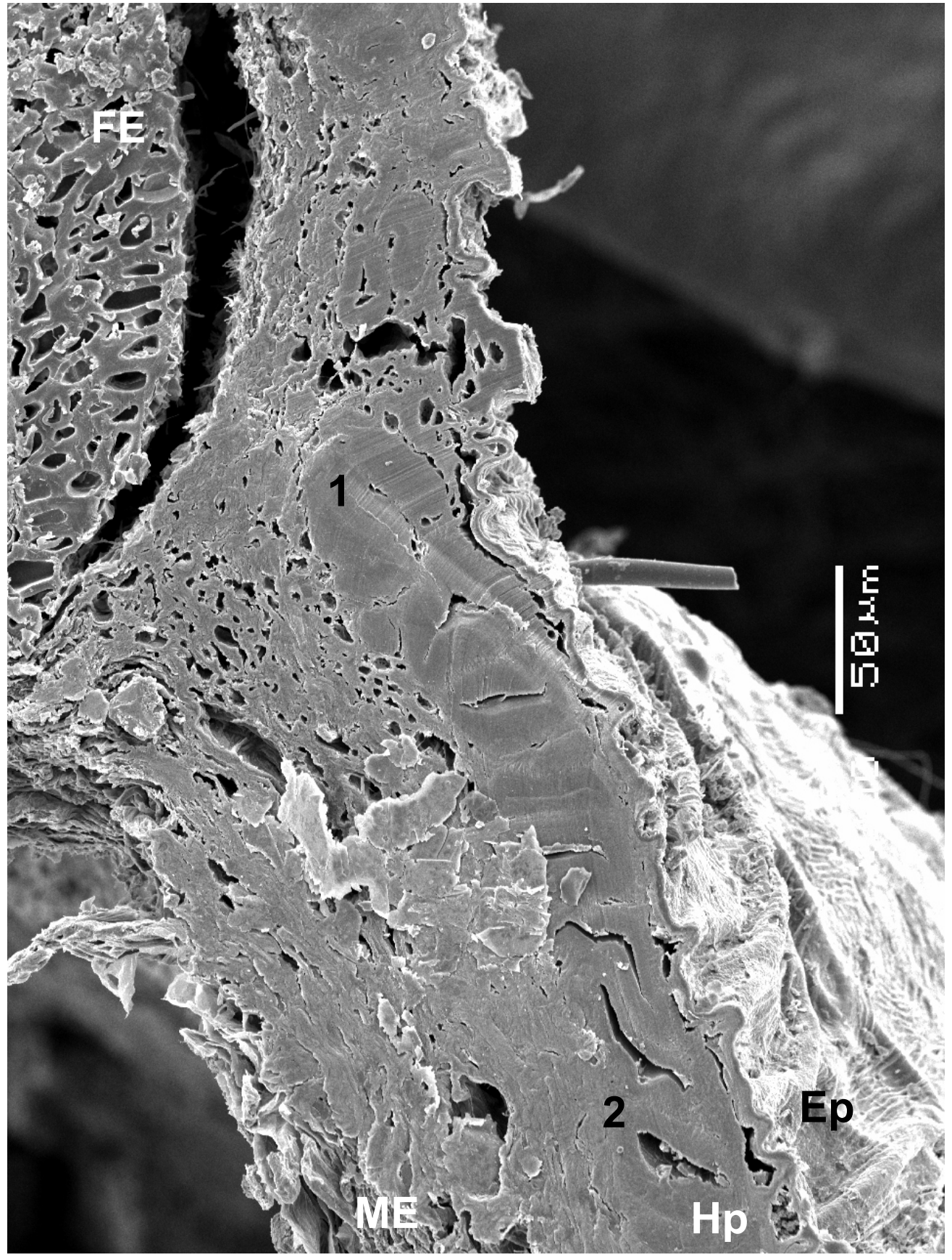

Pampa Grande Vaina El Litro Corte transversal en sutura dorsal Celulas colenquimaticas de la hipodermis:

1) Perpendiculares a $X$ y paralelas a $Z$ e $Y$

2) Casi perpendiculares a $X$ y oblicuas (Tipo I) a $Z$ y a $Y$ 


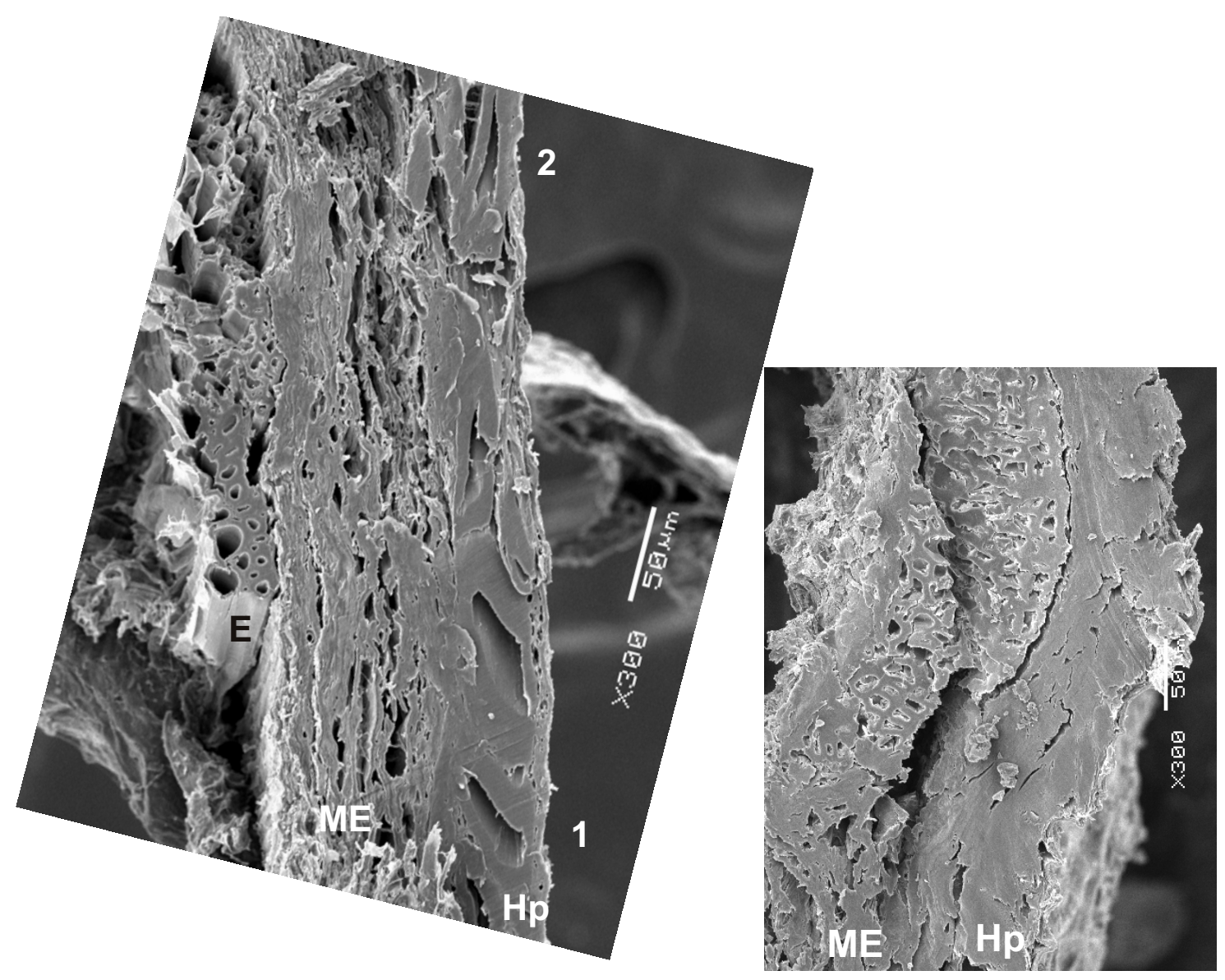

Pampa Grande Vaina El Litro. Corte transversal en sutura ventral

Esclereidas: Oblicuas (Tipo I y II) a los tres planos

Células colenquimaticas de la hipodermis con dos disposiciones;

1) Oblicuas (Tipo I) a los tres planos

2) Levemente oblicuas (Tipo II) a los tres planos 

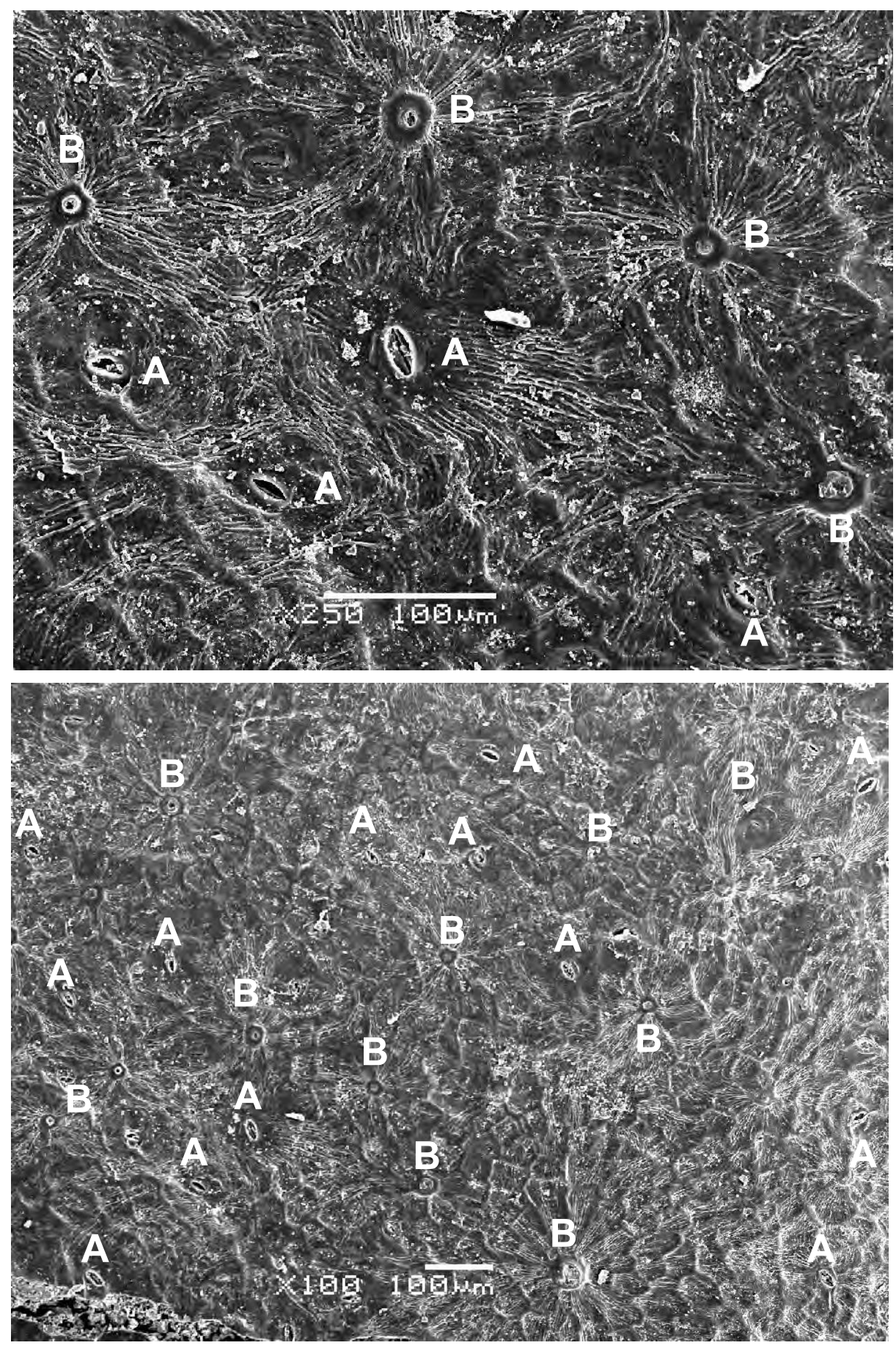

Pampa Grande Vaina El Litro Vista superficial en caras de la valva A: estomas, largo promedio: 29 um (22-36 um); B: base de tricomas 


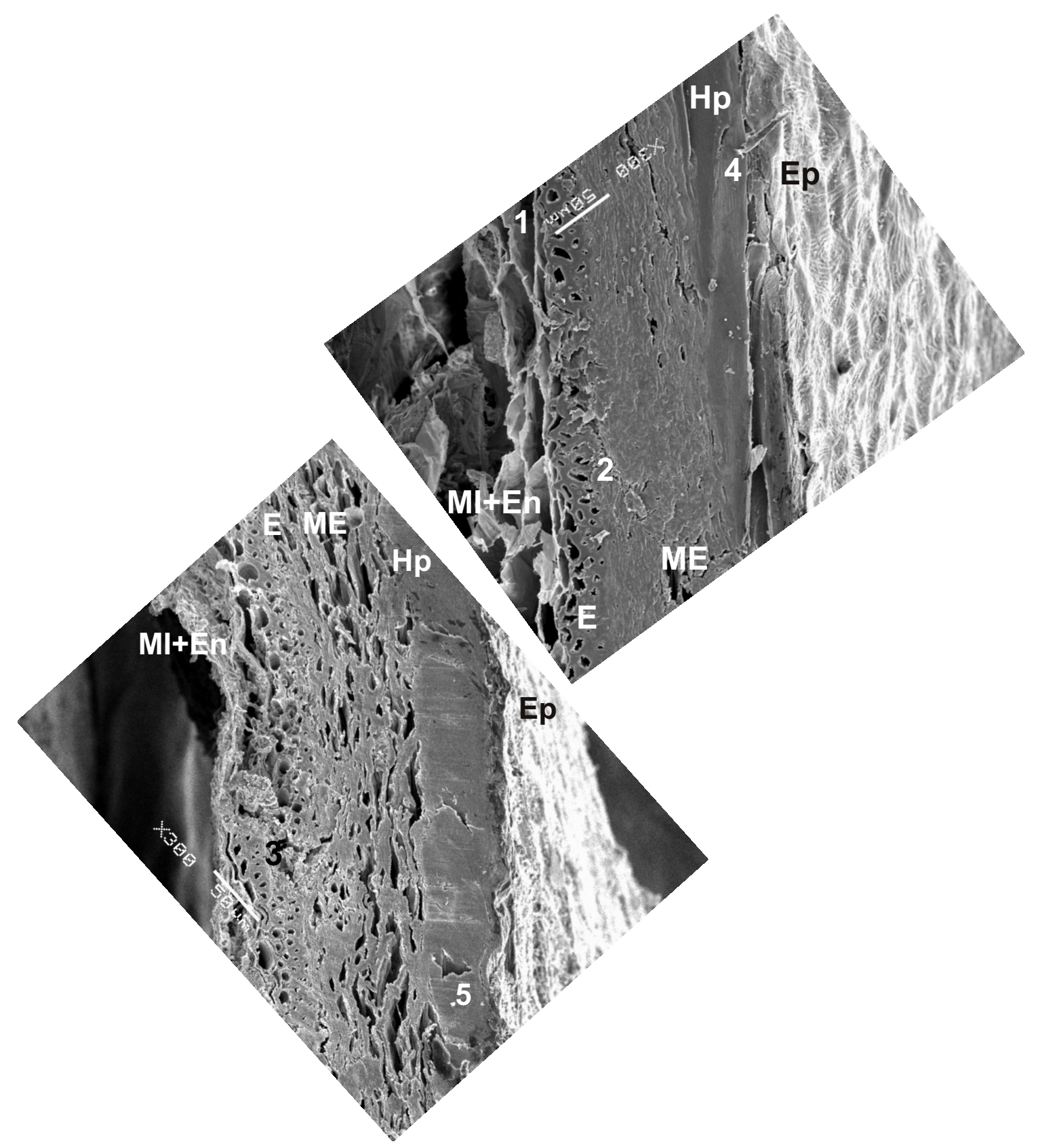

Pampa Grande Vaina Los Aparejos. Corte transversal en caras mayores. Esclereidas con tres disposiciones:

1) Perpendiculares a $X$ y paralelas a $Z$ e $Y$

2) Oblicuas a los tres planos (Tipo I)

3) Oblicuas a los tres planos (Tipo II)

Células colenquimáticas de la hipodermis con dos disposiciones:

4) Paralelas a $X$ y levemente oblicuas a $Y$ y a $Z$ (Tipo II)

5) Casi perpendiculares a $X$, levemente oblicuas a $Y$ y a $Z$ (Tipo I) 


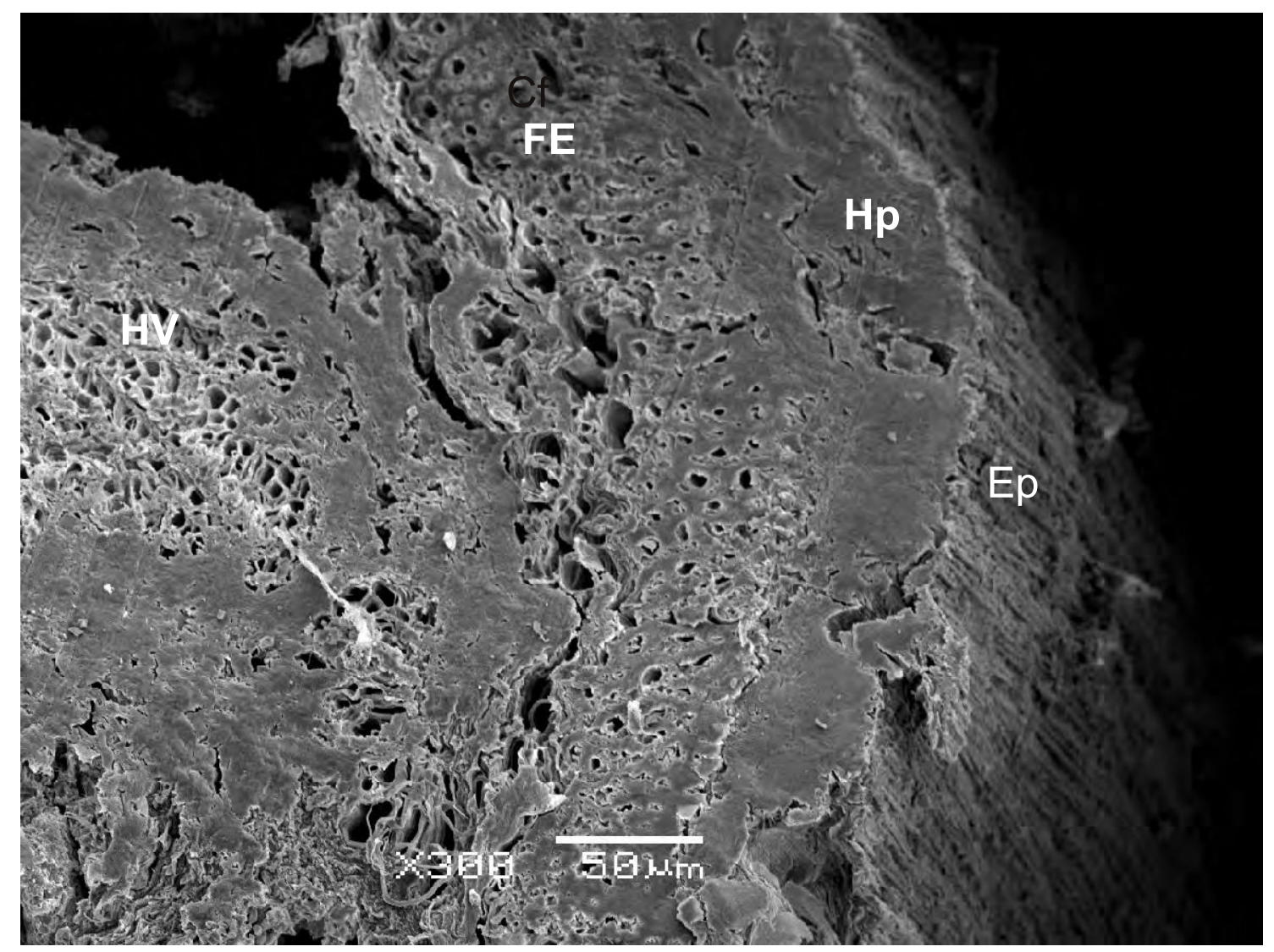

Pampa Grande Vaina Los Aparejos. Corte transversal en sutura dorsal. Células colenquimáticas de la hipodermis: perpendiculares a $X$ y paralelas a $Z$ y a $Y$ 


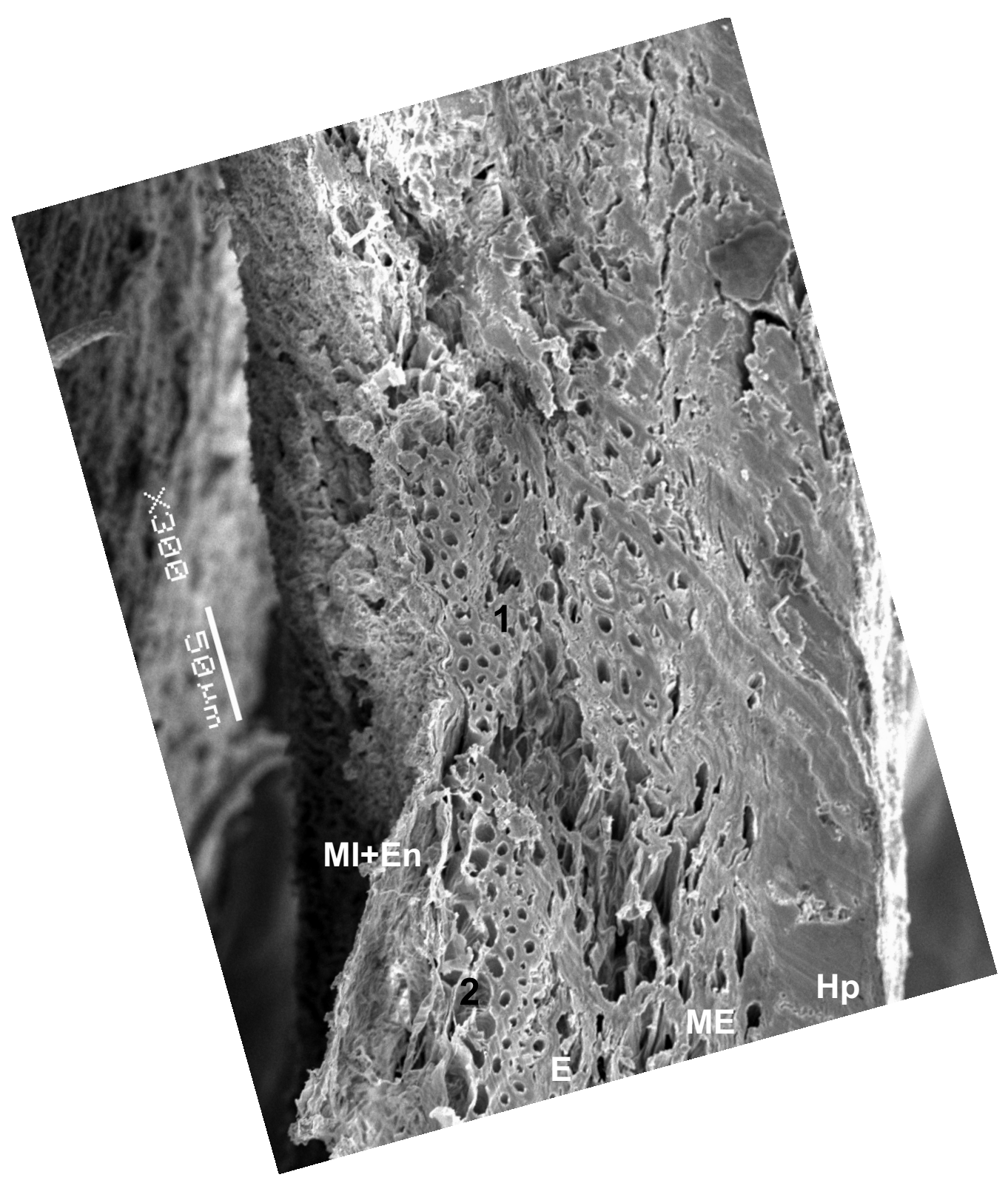

Pampa Grande Vaina Los Aparejos. Corte transversal en sutura vental.

Células colenquimaticas de la hipodermis: oblicuas a $X$ a $Z$ y a $Y$ (Tipo I)

Esclereidas dispuestas de dos modos:

1) Perpendiculares a $X$ y paralelas a $Z$ y a $Y$

2) Levemente oblicua a los tres ejes (Tipo I) 

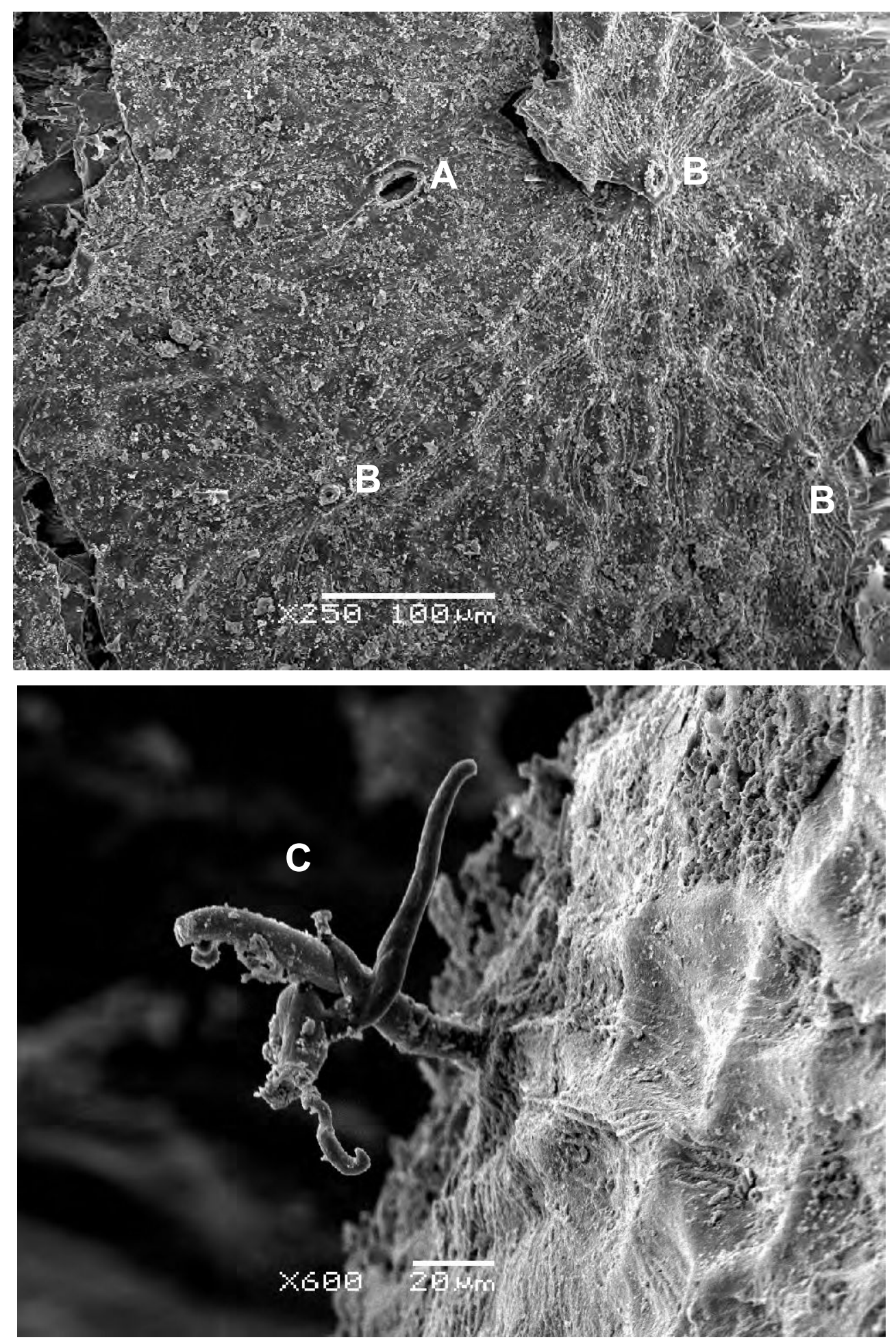

Pampa Grande Vaina Los Aparejos. Vista sSuperficia de caras mayores; A: ILargo estoma: 31,4 um; B: base de tricoma y C: tricoma. 


\section{LAS LECCIONES DE LA ETNOBOTÁNICA: OPCIONES SOCIALES Y TOMA DE DECISIONES EN LOS HUERTOS DEL NOA.}

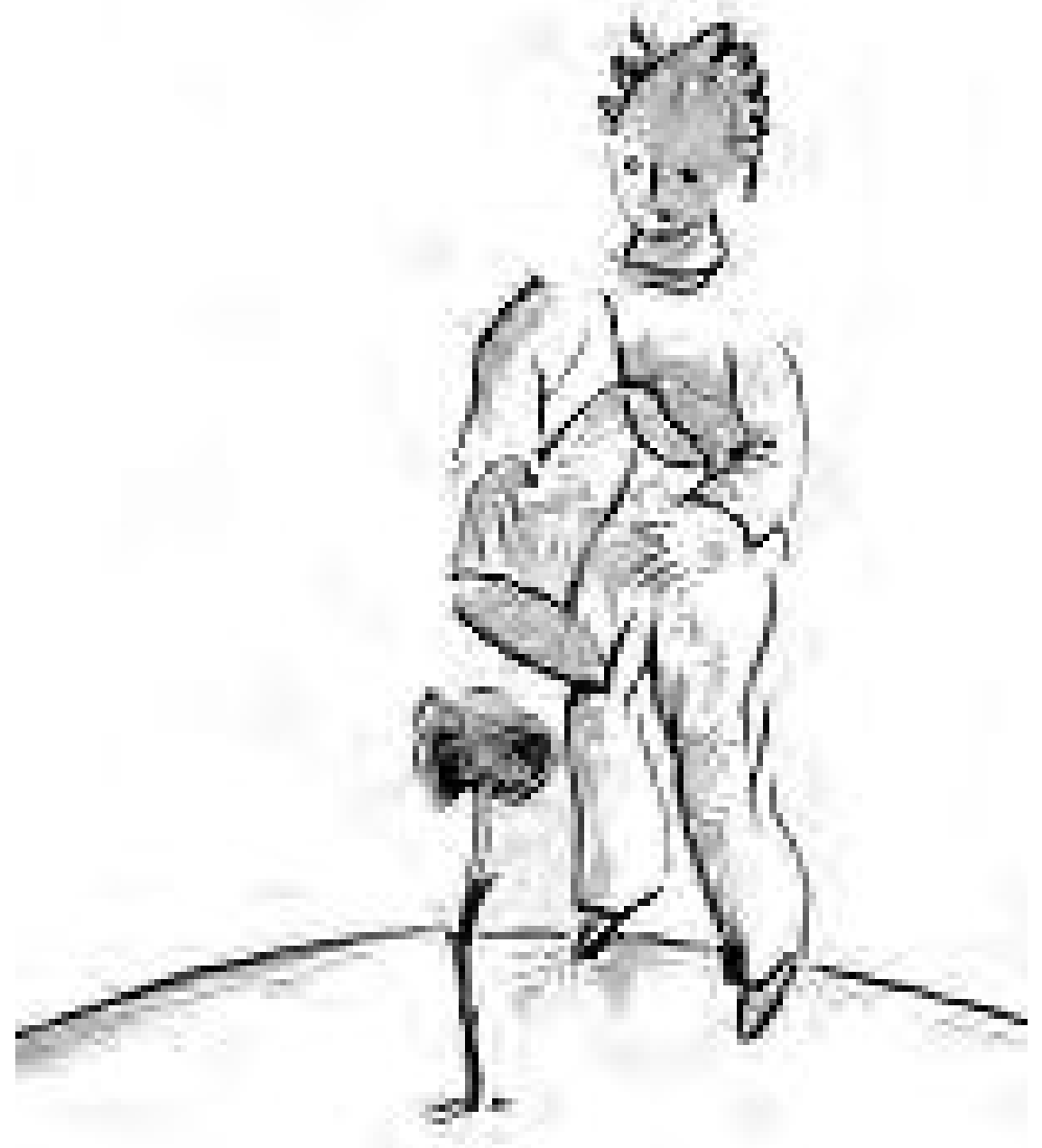




\section{5- LAS LECCIONES DE LA ETNOBOTÁNICA: OPCIONES SOCIALES Y TOMA DE DECISIONES EN LOS HUERTOS DEL NOA.}

\section{Introducción}

Como vimos en la primer sección de esta tesis uno de los abordajes propuestos consiste en el estudio etnobotánico de comunidades campesinas actuales a fin de entender la dinámica social que opera en la relación entre grupos humanos y comunidades vegetales. Entendemos la etnobotánica como "el estudio de las interrelaciones planta-Hombre incluidas en ecosistemas dinámicos con componentes sociales y naturales. Puesto de otra forma, la etnobotánica es el estudio contextualizado del uso de las plantas. El uso de las plantas y las interrelaciones plantas-humanos están moldeados por la historia, por los ambientes físicos y sociales y por las cualidades inherentes de las plantas mismas" (Alcorn 1995:24, n. t.).

Si bien la domesticación de especies vegetales no es un fenómeno actual, es un proceso que perdura y opera aún hoy día, siendo contemporáneo a nosotros y por lo tanto factible de ser estudiado desde un abordaje etnobotánico. Desde dicho abordaje se han llevado a cabo estudios tendientes a analizar la manera en que las poblaciones humanas manipulan especies o comunidades vegetales tanto desde el aspecto comportamental como cognitivo (Seeand 1997, Wetterstrom 1978, Bates 1985, Nazarea 1998, Cotton 1998 , Sthapit et al. 2000, Toledo 2002, Luna-Morales 2002). Los mismos han ayudado a entender en qué medida los criterios de manejo empleados han colaborado tanto con la generación, mantenimiento o merma de una gran diversidad de formas vegetales, así como a comprender de manera más profunda de qué manera los seres humanos nos vinculamos al entorno natural en el cual vivimos. Estos estudios se adentran en el espacio "emic", donde las personas estructuran y 
organizan sus experiencias y acciones y actúan eligiendo entre distintas alternativas (Kessing 1976 en Wetterstrom 1978). Se asume, además, que la percepción del ambiente se encuentra atravesada por múltiples factores: biofísicos (por ejemplo el tamaño relativo y la densidad de ciertas especies de plantas), espirituales, sociológicos y personales (Hallam 1989).

En el caso particular de las formas de manejo y criterios empleados en la domesticación vegetal, existen trabajos cuyo objetivo último es el empleo de los datos registrados en la actualidad para evaluar la evidencia arqueológica (Hillman y Davies 1990, Hildebrand 2003), en tanto otros no poseen tal proyección al pasado (Casas et al 1991, Casas et al 1997, Casas 2001, Arellano y Casas 2003) a pesar de que es factible realizar la misma.

En este capítulo analizaremos la puesta en práctica de criterios de selección y toma de decisiones locales (Nazarea 1998) que guían la acción colectiva o individual de los cultivadores en el caso particular de cuatro comunidades del NOA asentadas en ambientes disímiles. Como se estipuló en el capítulo 1, si bien se asume que el ambiente impone ciertas restricciones por su propia materialidad, la misma no es objetiva sino incorporada al sistema de conocimiento cultural (sistema de cognición) a través de una serie de mediaciones culturales que interpretan esas características materiales contextualizadas con relación a los marcos interpretativos culturales. Se asume que en toda sociedad las prácticas o acciones sociales conjugan conocimientos, conceptos y categorías socialmente compartidos e individualmente aprehendidos y reproducidos o transformados en la acción misma (Toledo 2002).

\section{Materiales y métodos}


Se efectuaron trabajos de campo en cuatro comunidades campesinas del NOA: Rachaite y Coranzulí en la puna jujeña, El Shincal en el Valle de Hualfin, Catamarca y Santa Victoria Oeste en el oriente salteño (figura 43).

Tomando en cuenta las distintas variables que intervienen en el manejo de poblaciones cultivadas se desarrolló una estrategia metodológica aplicando principalmente dos técnicas etnográficas (entrevistas y observación) para registrar las mismas según se ilustra en la figura 44.

La metodología empleada fueron entrevistas abiertas y semiestructuradas y observación directa junto a los pobladores locales con colecta de ejemplares botánicos para ser estudiados en laboratorio (Cotton 1995, Martin 1995, Granai 1962) (ver capitulo 1, sección 1.3). En el caso de El Shincal se realizaron también historias de vida con adultos mayores (Nazarea 1998).

Las entrevistas se llevaron a cabo con individuos adultos de ambos sexos (7 individuos en Coranzulí, 8 en Rachaite $^{1}, 19$ en ESH y 10 en SVO) perteneciendo cada uno a una unidad doméstica (UD) (Crivos y Martínez 1996) distinta. Los nombres de las personas entrevistadas no son mencionados en esta tesis, señalándose solamente sus iniciales, género ("masc." para hombres y "fem." para mujeres) y edad, en el caso de haber sido registrada. Los diversos términos usados localmente así como también las etnoespecies (conjunto discreto de plantas reconocido bajo un nombre vernáculo, Reyes Garcia et al 2006) se presentan entrecomillados. Las observaciones se efectuaron en las unidades domésticas y en las áreas de cultivo, fundamentalmente en las orientadas al autoconsumo. Las entrevistas estuvieron orientadas al relevamiento de prácticas agrícolas, criterios de selección de especies y variedades a sembrar, caracteres deseados y alentados en las distintas etnoespecies sembradas y formas de cultivo, manejo y procesamiento de las mismas.

\footnotetext{
${ }^{1}$ En esta comunidad se realizó una entrevista con niños dado que los mismos cumplen un rol crucial en las tareas agrícolas.
} 


\section{Resultados}

\section{El Shincal (Lámina 67)}

La comunidad rural de El Shincal se encuentra emplazada a $7 \mathrm{~km}$ de la localidad de Londres de Quimivil en el departamento de Belén, Catamarca. Su ubicación se corresponde geográficamente con el bolsón de Pipanaco y fitogeográficamente con la provincia de Monte, siendo su clima cálido, continental árido y de tipo subtropical (Capparelli et al. 2004). Las comunidades actuales del bolsón incluyen: I) entre los 1500 y 1250 m.s.m. bosque abierto de Prosopis flexuosa, Prosopis chilensis, Geoffroea decorticans, Celtis tala y Acacia aroma, con estrato arbustivo de Mimosa farinosa, Condalia microphylla, Porliera microphylla y Ximenia americana y comunidades de Larrea cuneifolia; II) entre los 850 y 750 m.s.m. estepas de Bulnesia retama, Acacia caven y Atamisquea emarginata y III) en las quebradas de los ríos se desarrollan bosques con predominio de Celtis tala (Capparelli 1997).

Esta población consiste en una serie de viviendas ubicadas sobre un camino principal y otras emplazadas en zonas aledañas al mismo. Los habitantes de estas viviendas tienen sus "puestos" en zonas más elevadas (serranías de Belén) por lo cual consideramos aquí como miembros de una misma unidad doméstica (Crivos y Martínez 1996) a las personas que habitan el espacio físico tanto de la vivienda emplazada en la comunidad de El Shincal propiamente dicha, como a las que habitan en el puesto correspondiente en zonas más elevadas. La movilidad entre las viviendas de El Shincal y las del puesto es más o menos fluida dependiendo la época del año, alternándose la residencia de las personas que conforman la UD en uno u otro emplazamiento. Los habitantes de El Shincal poseen en su mayoría huertos para autoconsumo y corrales para la cría de animales menores (fundamentalmente caprinos) en el puesto. Algunas personas poseen además 
fincas donde siembran especies con fines comerciales, principalmente nogales, pero también hortalizas como "lechuga", condimentos ("comino" y "anís") y otros cultivos como el "poroto" (ver tabla 76). "Huerta", "rastrojo" y "finca" son categorías empleadas por los habitantes de El Shincal para designar espacios productivos de distinta magnitud. Las huertas se encuentran anexas a las viviendas y poseen en promedio dos por ocho metros y están delimitadas con elementos perecederos como cañas y ramas, el riego es a mano o a temporal aunque ocasionalmente puede hacerse un desvío desde los canales de riego si la finca se halla próxima al huerto. En las mismas se siembran especies consumidas como comestibles por los miembros de la unidad doméstica y otras ornamentales o medicinales como la "ruda" (ver tabla 76). Las fincas son espacios para la siembra de especies con fines comerciales. Se siembran principalmente nogales, un producto propio de la zona, habiendo una variedad local más pequeña (la "nuez criolla", caracterizada como "primitiva" por P.M., masc.) y otra introducida por organismos gubernamentales (la "nuez mariposa") de mayor tamaño. Las fincas poseen en promedio unas diez hectáreas, variando las dimensiones de acuerdo con el poder adquisitivo de los propietarios. En el caso de hallarse en zona de pendiente se elaboran melgas transversales a la misma a fin de salvar el desnivel existente. Por lo general las fincas se hallan delimitadas con alambrado y son regadas a través de un sistema municipal de distribución del agua por turnos horarios (“derechos de agua" o "turnos"). Una vez ingresada el agua a la finca, el agricultor desvía el curso de la misma con bordos de tierra según los requerimientos particulares de las etnoespecies sembradas. Los rastrojos son terrenos ganados al monte destinados a la siembra extensiva de pocas especies destinadas principalmente al consumo alimenticio de la unidad doméstica $y$, en menor medida, a su venta en el circuito comercial o intercambio con otros miembros de la comunidad. Son pocos los habitantes que cuentan con estos espacios, cuya configuración y fin último son variables 
entre las distintas UD. El riego se hace desde las acequias comunitarias, lo cual muchas veces genera conflictos al interior de la comunidad ya que quienes poseen grandes extensiones de terreno sembrado suelen dejar sin agua de riego a otros miembros de la comunidad.

Algunos conjuntos de etnoespecies sembradas reciben un nombre particular, así, al cultivo de "zapallos" se le llama "zapallar", al de "maíz" "chacra" y al de "porotos" "porotal", independientemente del ámbito donde se hallan sembrados (huerta, finca o rastrojo). Los términos "zapallo", "maíz" y "poroto" son de carácter general e inclusivo respecto de distintas etnoespecies. Si bien el primero de estos se usa mayormente para referirse a $C$. maxima ssp. maxima (incluyendo al "zapallo plomo" y "zapallo silpingo"), también se lo suele usar para referir al "angola", "coreano" o "coreanito" y "anco" o "anquito". El "zapallito de tronco" es por lo general mencionado de manera particular. El termino "poroto" agrupa a las doce etnoespecies listadas en la tabla 76 y el término "maíz" a las ocho etnoespecies señaladas en la misma tabla.

A pesar del gran número de etnoespecies registradas en esta comunidad, la gente menciona la pérdida de varias de ellas -tanto nativas (vg. "papa") como introducidas (vg. "manzana")- por el aumento en las poblaciones de plagas y la escasez de medios para su control. Otras plantas como los diversos tipos de "trigos" y "morrón" o "pimientos", que requieren un aporte de agua mayor al de los otros cultivos locales, se dejaron de sembrar debido a la escasez de agua de riego, según manifestaron los entrevistados. Por último, un factor crucial han sido los distintos momentos económicos por los cuales ha transcurrido el país, afectando esto directamente a esta comunidad. De acuerdo con lo manifestado por varios de los entrevistados, durante la época de la convertibilidad económica (década de 1990, aproximadamente) se dejaron de sembrar varias especies puesto que adquirir los productos en el mercado resultaba sumamente económico a comparación de momentos previos. Por 
ejemplo se dejó de producir trigo para luego hacer harina en el molino municipal como hacían muchos de los habitantes de menores recursos y se pasó a comprar directamente la harina elaborada. Al revertirse la situación económica a principios del año 2000 se debió volver a sembrar, ante lo cual varios pobladores se percataron de que habían perdido las semillas para poder hacerlo, y recurrieron al intercambio y préstamo dentro de la comunidad para reactivar la producción local, prefiriendo las semillas locales a las adquiridas comercialmente dado que consideraban que el rendimiento de estas últimas es menor.

A partir de los registros tomados en el campo se analizó en qué medida diferentes situaciones influyen en los criterios o prácticas en lo que respecta a manipulación de distintos cultivos, distinguiéndose fundamentalmente entre aquellas familias que cultivan para autoconsumo exclusivamente, de aquellas que poseen áreas sembradas destinadas al comercio. Esta discriminación se estableció dado que los patrones de toma de decisión resultaron ser claramente diferentes en cada caso, estando el primero regido exclusivamente por criterios propios de los miembros de la UD tales como gustos personales y costumbres familiares y el segundo por criterios y exigencias ajenas a dicha unidad, ya sea provenientes de particulares (en el caso de que se siembre para intercambios específicos con otros sujetos o familias) o del mercado local (en el caso de que se abastezca comercios). Esta división no solo se tuvo en cuenta entre unidades domésticas, sino también al interior de las mismas, ya que hay casos donde existen espacios separados dentro de una misma UD, siendo las huertas para autoconsumo y las fincas para el comercio. Tras el análisis resultó claro un abandono de ciertas preferencias culinarias propias $-\mathrm{y}$ concomitante pérdida de variedades vegetales- a favor de criterios de mercado.

Un abordaje transversal de los registros tomados permitió ver cambios en los criterios con relación a la composición de cada UD, las actividades que 
desempeñan sus miembros, su situación económica y su relación con otros miembros de la comunidad. Al considerar el género y edad de las personas entrevistadas surgieron también diferencias. En el primer caso se vieron criterios distintos entre hombres y mujeres ya que la siembra y cosecha se halla en manos de los hombres, en tanto el procesamiento para la preparación de alimentos está a cargo de las mujeres. En el segundo caso resultó importante el registro de historias de vida puesto que ello permitió dilucidar el motivo de ciertos comportamientos observados y opiniones vertidas por los entrevistados.

Los criterios de selección registrados fueron principalmente de cuatro tipos: selección por gusto, por criterios de mercado, por criterios gastronómicos, fisiológicos y morfológicos. Estos dos últimos criterios se encuentran siempre junto a los tres anteriores. A continuación analizaremos estos distintos criterios.

a) Selección por gusto

a.1) "Zapallos" (Cucurbita spp)

Este criterio se aplica al interior de las poblaciones sembradas de "zapallo" y no entre las distintas etnoespecies reconocidas. Los habitantes de El Shincal manifestaron que seleccionan para el próximo ciclo de siembra las semillas de los zapallos:

-más dulces o sabrosos (B.C. fem; A.B. fem; M.M. masc; A.M. fem 79; D.C fem 76; R.A. masc 54; J.M. masc 38), en un caso (M.V masc 40) señalaron que se sabe si es sabroso por el color de la "carne".

-de mesocarpio más consistente, no los "aguachentos" (R.A fem 57; M.M. masc; A.M. fem 79; R.A. masc 54; J.M. masc 38). 
-los de "carne" bien amarilla y no blancuzca (A.M. fem 79; M.V. masc 40).

- más grandes (D.S.R masc 77; R.R. masc 53; G.R. fem; L.M masc; J.M. masc 38).

Como puede verse, algunos informantes manifestaron más de un criterio, los cuales se hallan principalmente vinculados al gusto, siendo escasas las referencias a aspectos morfológicos.

Para algunas personas el gusto del "zapallo" depende del suelo, otros señalaron que la gente de antes decía que cuanto más tiempo tenía de guardada la semilla más rico era el fruto, aunque la planta daba menos (L.A. masc; R.F. 68). En opinión de D.S.R. (masc 77) los “zapallos” más grandes se dan cuando se siembran junto a la "sandía". Hay quienes prefieren al "angola" (C. pepo) sobre el "zapallo" (C. maxima ssp. maxima) porque el primero dura más tiempo almacenado una vez maduro (M.M. masc). El "zapallo" se corta además con el "tronco" (pedúnculo) porque si no se pudre (M.V. masc 40).

\section{a.2) "Porotos" (Phaseolus sp.)}

En la totalidad de los casos registrados la selección por gusto de los "porotos" opera en el momento de decidir cuál de las doce etnoespecies reconocidas localmente sembrar. Los habitantes de El Shincal mayormente no escogen las semillas de porotos de una misma etnoespecie (esto mismo fue referido para los "morrones" o "pimientos"). Sólo en dos casos se registraron criterios morfológicos, eligiéndose en un caso las semillas más grandes de "poroto" (P.R. masc 84), y en otro rechazándose la siembra del "poroto alubia" ya que es muy "cascarudo" consumiéndoselo ocasionalmente en guiso antes de que madure (D.S.R. masc 77). También se prefiere el "poroto alubia" porque, además de ser más rico, se cocina más rápido (A.M. fem 79) y porque, aparte 
de cosecharse más pronto, es "el mejor para las comidas" (D.C. fem 76). En estos dos últimos casos el criterio aplicado para la selección de esta etnoespecie está asociado a los roles que cumplen las mujeres dentro de las UD, siendo las encargadas del procesamiento y preparación de los alimentos. Otros criterios mencionados por los cuales se elige al "poroto alubia" para autoconsumo son de tipo fisiológico:

-porque es más "ligero" (madura en menos tiempo) (M.M. masc; DC fem 76 ), lo cual es señalado como un carácter ventajoso ante la posibilidad de heladas tempranas.

-porque posee altos rendimientos (J.M. masc 38)

Existen también criterios morfológicos a la hora de sembrar esta etnoespecie, principalmente sus semillas grandes (M.M. masc).

b) Selección por criterios de mercado- "Porotos" (Phaseolus sp)

Algunos pobladores de El Shincal siembran "alubia" porque tiene "mejor vista" para el mercado, prefiriendo en cambio otras etnoespecies para autoconsumo como el "criollo" o "bola" (L.A. masc; D.S.R. masc 77). El "poroto boca amarilla" se siembra exclusivamente para el mercado de Catamarca, el alubia en cambio posee mercado fuera de dicha provincia. Al "poroto manteca" lo sembraban antes para hacer harina y venderla a los ingenios, guardándose los "porotos" bien maduros y no "chusitos" (M.M fem), refiriéndose con este término tanto a los que no han madurado bien como a los que se encuentran en mal estado.

El problema del poroto que se destina a comercio externo es que si bien no se elige la semilla, éste se híbrida (se "entrevera") muy fácilmente, siendo difícil el mantenimiento de líneas puras. Esta hibridación entre etnoespecies no baja el rendimiento promedio, pero la modificación o pérdida 
de ciertos caracteres como tamaño o color hace que la cosecha no sea vendible. Ante este inconveniente algunos informantes (M.M. fem; J.M. masc 38) reportaron que ellos hacen selección de las semillas guardando "porotos puros" (de un solo color), no mezclados. Para el caso del "poroto boca amarilla" se señala que cuando se hierve sale "tinta" oscura, y por ello no se vende fuera del mercado catamarqueño (D.S.R. masc 77; RF masc 68). Existen además variedades que se conocen, pero no se siembran actualmente como el "poroto negro".

c) Selección por criterios gastronómicos- "Maíz" (Zea mays).

La selección de etnoespecies de maíces se da principalmente por el tipo de comida que se puede hacer con cada una:

-"maíz blanco" para "mote", "mazamorra" o "locro" (se siembra localmente o se compra) (R.A. fem 57; C.R. fem 48; D.C. fem 76; R.C masc 53; R.F masc 68; L.M. masc; M.V. masc 40; J.M. masc 38).

-"maíz capia" para "frangollo" (no se siembra localmente, se trae de los cerros) (M.M. fem; P.M. masc; P.R. masc 84; A.M. fem 79; R.R. masc 53; L.M. masc.).

-"maíz pispo" para "rosita" o "flores" (se siembra localmente, no se compra) (P.M. masc).

-"maíz amarillo" como forraje (R.A. fem 57; C.R. fem 48; M.M. fem; M.V. masc. 40; J.M. masc. 38) o en menor medida para consumo como "choclo" (D.S.R. masc 77; M.M. fem; R.R. masc 53; L.M. masc). En este sentido una mujer mayor (M.M.) dice que el "maíz amarillo" no es bueno porque es "cálido" y por ello sienta mal, siendo preferibles para el consumo los "maíces blancos". 
-"maíz blanco" para "humitas" para Semana Santa (se siembra en diciembre y debe estar maduro para Pascuas, si no es así no se hace esta comida ya que al no estar bien maduro "la humita sale aguada") (G.V. fem)

Varios informantes manifestaron que se guardan los granos de la porción media de la mazorca, no los del ápice ni los de la base (S.Y. masc; R.A.fem 57; L.A. masc; P.R. masc 84; R.A. masc 54), seleccionándose los del medio dado que son más "parejitos" (M.M. masc).

También se guardan las mazorcas enteras, prefiriéndose aquellas que poseen más hileras (criterio morfológico) (L.A. masc), o las que poseen los granos "más parejitos", bien maduros y no "amortiguados" (J.M. masc 38).

Sólo en un caso (A.B. fem) se eligen los granos más grandes (criterio morfológico) para comer y para guardar como semilla, vale aclarar que este caso es el de una mujer que es oriunda de la provincia de Santa Cruz (Argentina), habiéndose instalado en El Shincal hace siete años aproximadamente. El criterio morfológico se aplica también en la selección de mazorcas más grandes (R.R. masc 53; D.C. fem 76; R.F. masc 68) o bien guardando aquellas que poseen granos más grandes (R.A. masc 54; D.C. fem 76; M.V. masc 40; J.M. masc 38).

Del registro de historias de vida, destacamos la de E.E. (masc., 70) dado que de ella se desprenden consideraciones de importancia para los objetivos de este capítulo. E.E. nació en Tinogasta, se crió en Londres, vivió varios años en Caleta Olivia y Comodoro Rivadavia por motivos laborales y luego volvió a Londres. Actualmente sólo realiza plantaciones en su huerta para autoconsumo, siembra poco, sólo para "demostrar lo que hacía antes" de volver del sur. Este hombre destaca por su afición a experimentar y registrar la dinámica de sus plantaciones en el huerto con mucho más detenimiento que el 
manifestado por otros habitantes de El Shincal. En su opinión "Si se es sembrador, hay que observar" por lo cual, entre otras cosas, señala que él realiza un seguimiento tanto diurno como nocturno del comportamiento de las hormigas que atacan sus plantaciones a fin de entender su dinámica y poder así erradicarlas. Lo más destacado son sus prácticas de experimentación, por ejemplo una vez sembró cinco plantas de "maíz" en marzo/ abril para ver si maduraban antes de la helada, todos los días las destapa a la mañana y las tapa después a fin de probar "hasta cuándo tienen fuerza". En otra oportunidad compró frutales a un hombre que venía viajando y sembró perales, "todos se reían, decían que no iba a dar", finalmente crecieron y fructificaron bien, tras lo cual los otros pobladores le pidieron frutos $y / o$ semillas para sembrar en sus terrenos. Al volver recientemente del sur trajo muestras de "poroto manteca" sólo para ver si daba en Londres, él "experimenta, intenta" porque quiere "demostrar lo que se puede hacer en Londres, demostrar la grandura de lo que se da en Londres".

Este caso señala el rol crucial que pueden tener ciertos individuos en una comunidad, movidos sólo por predisposiciones personales y no por la asignación de roles sociales destacados. Gracias a su gusto por la experimentación, E.E. incorporó en toda una comunidad la producción de una nueva etnoespecie ("peras") y ejemplares de poblaciones distantes de etnoespecies ya conocidas localmente ("poroto manteca"). Estas acciones individuales, y su posterior aceptación y generalización dentro de una comunidad, aportaron al aumento de la diversidad de cultivos en toda una localidad.

El estudio llevado a cabo en El Shincal demostró que existe una concentración del conocimiento en el género masculino en lo que respecta a siembra y cosecha, siendo las mujeres depositarias del conocimiento sobre procesamiento y preparación de alimentos. Ciertas exigencias externas a la comunidad (de mercado) han llevado a cambiar hábitos de consumo propios, 
lo cual ha producido la merma o extinción en la producción de ciertos productos como por ejemplo el poroto "bocabaya" y su reemplazo por el alubia. El resultado es que la unidad familiar de producción subsume su toma de decisión a las condiciones del mercado, lo mismo ocurre con la preeminencia del poroto alubia "puro" en desmedro de los híbridos, eliminándolos al seleccionar la semilla para plantar al año siguiente. Lo anterior se podría leer o traducir de la siguiente manera: si la unidad doméstica depende para su subsistencia de redes de intercambio o comercio establecidas con otros núcleos (sobre todo mercados o centros comerciales) va a decidir qué sembrar y qué variedades seleccionar de acuerdo con las categorías ajenas y no con las propias, manteniendo quizá una población menor a nivel hortícola para consumo propio, o bien resignando sus preferencias, valores y categorías ante las ajenas, al punto de dejar de sembrar definitivamente ciertas etnoespecies. Este fenómeno no se registra, en cambio, cuando el intercambio se produce entre unidades domésticas del mismo conjunto poblacional.

\section{$\underline{\text { Rachaite y Coranzulí. }}$}

La puna argentina constituye una planicie sobreelevada que abarca parte de las provincias de Jujuy, Salta y Catamarca, pudiendo accederse a la misma desde los valles longitudinales orientales a través de tres quebradas principales: Humahuaca, del Toro y porción superior de los Valles Calchaquíes (Merlino y Rabey 1978). En líneas generales la puna se caracteriza por ser una estepa herbácea-arbustiva con vegas o "ciénagos" en zonas bajas donde brota el agua (Cabrera1971). Coranzuli y Rachaite son dos comunidades jujeñas ubicadas en quebradas de altura dentro de la cuenca de Guayatayoc a $3800 \mathrm{msm}$ aproximadamente. 
En los estudios en ambas comunidades se constató la existencia de espacios de cultivo denominados "rastrojo" o "huerto", aunque este último término lo registramos en un único caso en Coranzulí. Estos espacios (que reciben aquí el nombre genérico de huertos de altura) son únicos, aledaños o próximos a las viviendas de las familias propietarias. Sus productos se destinan al autoconsumo o al intercambio informal con otras familias sin que tengan injerencia sobre los mismos ningún nivel de organización superior al de la UD, que es la unidad productiva propietaria, constituida en estas comunidades por una familia nuclear o extensa. Por lo tanto no hallamos el ejercicio de una autoridad local o de un control comunitario sobre estos espacios tal como se ha registrado en otros casos dentro del mundo andino (Mayer 2004) o fuera de él (Martínez et al. 2003).

De acuerdo con la disposición sobre el terreno y la presencia o no de estructuras por encima de éste se distinguen tres clases de huertos de altura, los dos primeros se hallan en ambas comunidades, en tanto el tercero es propio de Rachaite.

a) Huertos a cielo descubierto y a nivel.

Se trata de parcelas pequeñas de tamaño variable que no superan los diez metros cuadrados, donde se siembra de forma sectorizada distintas etnoespecies. En el caso de la huerta de la familia de M. T. (fem 40) (Lámina 68, figura a), la misma tenía sembrado al momento de la realización del trabajo de campo plantas alimenticias: "habas" (Vicia faba L), "arvejas" (Pisum sativum L.) y "lechuga" (Lactuca sativa), y otras señaladas como forrajeras: "cebada" (Hordeum sp.) y "alfa" (Medicago sativa L.), aunque la primera también se consume ocasionalmente. El riego es a brazo o con una manguera desde una pileta cercana. Otras especies identificadas en esta clase de huertos fueron 
"quínoa blanca" y "quínoa rosada" (Chenopodium quinoa Willd), "trigo" (Triticum sp) y "maíz" (Zea mays). Por lo general "papas" de distintas clases (Solanum tuberosum L. ssp. tuberosum y ssp andigenum Juz. et Buk.) y otras etnoespecies como el "ajo" (Allium sativum L.) se siembran en los terrenos más amplios que poseen las UD en las laderas de los cerros o quebradas interiores que rodean al poblado. Algunos de estos huertos se hallan delimitados en parte con muros hechos en ladrillos de adobe o bien adobe y piedra ("tapia") en cuya porción superior se coloca barro batido con ramas de "tola" (Parastrephia lepidophylla (Wedd.) Cabrera) para evitar la erosión. Estos se ubican estratégicamente para proteger al huerto de los fuertes vientos locales, estando el resto de la parcela delimitada y protegida de los animales con un alambrado. En los huertos se puede encontrar la presencia de plantas locales ("tola", "cortadera" -Cortaderia sp.-, "coba" - Parastrephia quadrangularis (Meyen) Cabrera- y "añagua" - Adesmia horrida Gillies ex Hook. \& Arn.) que son toleradas en los mismos a menos que se necesite el espacio que ocupan para sembrar. La gente entrevistada explicó que a veces se emplean como forraje, dejando que los animales entren a pastar; otras no le adjudicaron utilidad: al delimitar el huerto ya estaban allí y se dejaron -o bien aparecieron tras su abandono temporal - y no fueron removidas.

b) Huertos en invernaderos.

Su presencia se debe principalmente a los aportes realizados de manera irregular desde la década del ochenta por distintos organismos estatales de desarrollo, los cuales suelen aportar las semillas de algunas especies y los plásticos y maderas necesarios para el armado de la estructura. En estos se halla mayor diversidad específica que en los huertos a cielo descubierto. En el caso de R. M. (masc 33) (Lámina 68, figura b) el invernadero tiene aproximadamente cuatro metros de largo y tres de ancho, las paredes son de 
adobe y el techo consiste en tirantes de madera y nylon transparente. En el interior del invernadero la temperatura es muy elevada debido a la fuerte radiación solar de la zona, por lo cual hay ventanas para eliminar el exceso de calor en verano. Este hombre siembra plantas alimenticias: "lechuga", "tomate" (Lycopersicum esculentum), "zanahoria” (Daucus carota L.), "acelga" (Beta vulgaris L. ssp. cicla (L.) W.Koch) y "cebolla" (Allium cepa) (nos indicó que el "maíz" también se da, pero no lo siembran porque viene muy alto y rompe el plástico del techo) y algunas aromáticas como "perejil" (Petroselinum crispum L.) y "ajenjo" (Artemisia absinthium L.), éste último utilizado con fines medicinales para afecciones del hígado. En el invernadero también se da un gusano llamado "lacato" que lo secan, lo muelen y lo toman para los pulmones. Usa abono de oveja, de cabra o de llama que mezcla con la tierra. A la "papa" y "habas" las siembran fuera del invernadero. En otros casos se ha constatado la presencia de otras plantas medicinales ("Aloe vera"-Aloe sp.-) o aromáticas ("menta" -Mentha sp.-). Un caso notable es el señalado por D. G. (masc 61) quien comentó que como en verano los invernaderos levantan mucha temperatura, reemplazan los plásticos del techo por una zaranda (red metálica) a fin de evitar el ingreso de predadores -aves- permitiendo el empleo del mismo predio ya delimitado. En este caso habría una transmutación de la categoría "b" hacia "a", cambiando la asociación de especies sembradas en el invernadero en invierno respecto de la del verano, ya que cambian las condiciones microambientales del huerto, aprovechándose el espacio y el suelo rico en nutrientes.

Si bien Coranzulí es un poblado más concentrado que Rachaite cuyo patrón es disperso, sus habitantes responden a una movilidad marcada entre asentamientos próximos, algo muy usual en la puna en particular y en los Andes en general (Merlino y Rabey 1978; Goebel 1998, Mayer 2004). Esta movilidad se caracteriza por la sucesiva ocupación de una misma residencia por distintos miembros de la familia extensa a lo largo del año o bien por el 
abandono temporal de la vivienda. Esta dinámica repercute en el desarrollo de los huertos, los cuales pueden pasar por períodos de abandono en los que prosperan las especies nativas silvestres o las formas asilvestradas de los cultivos. En el caso de que la vivienda sea ocupada por miembros distintos de la familia, los huertos pueden ser sometidos a manipulaciones y criterios que, si bien son compartidos en líneas generales por la familia extendida, adquieren ciertas peculiaridades de acuerdo con quien habite la residencia en los distintos momentos del ciclo anual. Por lo general cada UD posee, además del huerto, tierras de siembra en los cerros -en quebradas con aguadas resguardadas del viento- próximas a los corrales de sus animales de pastoreo (llamas, ovejas). Sin embargo se pudo constatar, tanto por observación directa de las áreas de siembra abandonadas como por referencia específica de los propios pobladores, que en líneas generales la siembra en los cerros ha decaído notablemente, un proceso señalado ya por Merlino y Rabey (1978).

A estos sistemas de autoabastecimiento debemos agregar los aportes externos generados por el intercambio esporádico entre familias asentadas en poblados próximos, así como el arribo semanal de un ómnibus procedente de centros poblacionales y comerciales de mayor envergadura (fundamentalmente Abra Pampa) que permite el acceso a mercancías de diversa clase.

c) Huertos a cielo descubierto y a desnivel.

Esta modalidad la hallamos exclusivamente en Rachaite. El caso más notorio fue el de una UD cuya vivienda se emplaza en una quebrada interior, ubicándose el huerto en una ladera protegida de los vientos (Lámina 69). El mismo consta de cuatro pequeñas terrazas de cultivo, delimitado por un pircado periférico junto a un alambrado. Ante la ausencia de adultos, las entrevistas se efectuaron con dos de los cinco hijos que componen la UD: P.T. (masc 14) y J.T. (masc 11). Se opto por entrevistar a los mismos ya que 
en estas comunidades los niños desempeñan tareas agrícolo- ganaderas desde muy corta edad, pudiendo brindar información a partir de sus conocimientos adquiridos. Estos dieron a cada porción de las terrazas con distinta asociación de especies alimenticias sembradas, o bien con una sola especie sembrada, el nombre de "patías", el cual se registró también tras las entrevistas con otros pobladores locales. Las especies que hallamos sembradas fueron: "papas" de distintas clases, "oca" (Oxalis tuberosa Mol.), "habas", "acelga", "cebolla", "arvejas", "quínoa" y "lechuga". El riego se efectúa por medio de una acequia hecha en tierra que toma agua del río próximo, las "patías" se riegan cada dos días. Los hermanos señalaron que cada año van rotando lo que se siembra en cada "patía" para que se "fortalezca más", indicaron asimismo que, por ejemplo, al momento de realización del trabajo de campo las "habas" las habían sembrado ese año, pero las plantas de "lechuga" y la "papa" venían de las siembras del año previo y, si bien ya habían cosechado la "quínoa", algunas todavía no estaban del todo maduras. Esto último se lo adjudicaban a la acción de su hermanita menor a quien se le habían caído semillas luego de que se efectuara la siembra principal. Es interesante la acción supuesta de esta niña quien además había sembrado en la "patía" de más abajo algunas cebollas que ella misma se encargó luego de cosechar, según nos informaron sus hermanos mayores. En las paredes de las terrazas o en las mismas "patías" crecen especies nativas, principalmente "tola" y "cortadera", las cuales no son retiradas a menos que se necesite el espacio que ocupan. Otra huerta de esta clase fue la de H.T. (fem.) quien tenía sembrado además de especies comestibles -principalmente tubérculos: "papa", "осa” y "collareja" Solanum tuberosum. ssp. andigenum - alfalfa (Medicago sativa) para los animales.

Además de estas pequeñas terrazas, varios pobladores de Rachaite realizan terrazas agrícolas de gran extensión, muy similares a las prehispánicas que abundan en la zona. Estas son construidas por los miembros de la unidad doméstica y a veces de forma aledaña a las arqueológicas, reutilizándose 
ocasionalmente estas últimas. Rachaite se caracteriza desde momentos prehispánicos por ser un poblado puneño con abundante actividad agrícola. Actualmente es a nivel regional una de las localidades más ricas en diversidad de tubérculos microtérmicos (aproximadamente catorce etnoespecies). Esto ha ocasionado la intervención de ingenieros agrónomos y personal de la Universidad Nacional de Jujuy, INTA y de la Secretaría de Agricultura, ganadería y pesca de la Nación. Estos agentes elaboran, junto a la gente de Rachaite, planes para la inserción de los productos agrícolas locales en el mercado nacional y extranjero. Esto genera un diálogo entre los requerimientos del mercado y la oferta local, la cual está dada no solo por las variedades vegetales sino por las técnicas que se aplican en su producción. En este sentido resulta llamativo que son los pobladores de Rachaite los que en ocasiones sugieren la implementación de tecnologías no locales tales como los invernaderos, siendo los agentes estatales los que explican el por qué resultaría mas conveniente seguir aplicando tecnologías tradicionales, sugiriendo su continuidad.

Por último se destaca que los tres tipos de huertos se diferencian de las zonas de producción agraria a mayor escala en: mayor diversidad de especies, mayor diversidad de asociaciones vegetales, plantas de uso heterogéneo (alimenticio, medicinal, forrajero), ejemplares pertenecientes a distintos ciclos de siembra y plantas con distinto grado de asociación con el Hombre.

\section{Forrajes y malezas}

El cultivo de forraje es una práctica ampliamente extendida en la puna argentina que se efectúa bajo dos modalidades: la delimitación de espacios artificiales -llamados "potreros" ${ }^{2}$ - donde se siembra, riega y cosecha la especie

\footnotetext{
${ }^{2}$ En El Shincal, en cambio el "llano", que es el terreno que no posee elevaciones, puede ser "potrero" o "campo". El "potrero" es el terreno de cultivo o pastura propio de cada finca, que posee riego; en cambio el "campo" es el terreno de uso común, los fondos de los bolsones, o las áreas de campo abierto que separan una localidad de otra (Capparelli 2007).
} 
forrajera, o bien el cuidado de zonas de pastoreo naturales como el riego de vegas en Antofagasta de la Sierra (García et al. 2002). Incluso hay un cierto solapamiento entre ambas modalidades ya que en Coranzulí "en algunos casos simplemente se deja crecer en ellos [los potreros] los pastos naturales de la zona, con la ayuda de irrigación artificial” (Merlino y Rabey 1978:60), también se trasplanta a estos espacios ejemplares de "chillagua" o "cortadera", donde su crecimiento es propiciado por el riego. Por lo tanto este tipo de cultivo no produce la domesticación de la planta, en tanto la misma no pierde su capacidad de reproducirse por medios propios. Los cuidados dados a las mismas causan un aumento de su productividad, las comunidades fomentan estas plantas seleccionando cuáles sembrar de acuerdo con las preferencias de pasturas que manifiestan sus animales de cría. A pesar de que se alienta el crecimiento de estas plantas -que son trasplantadas o sembradas, regadas y cosechadas en espacios artificiales delimitados (Merlino y Rabey 1978; García et al. 2002)- no hay una selección que opere sobre sus caracteres tras la cosecha siguiendo criterios como sabor o cualidades gastronómicas. El impacto del accionar humano es bajo, manteniéndose la estructura ecológica natural alterándose artificialmente sólo el nivel de humedad relativa por medio del riego y el número de ejemplares por siembra y/o transplante. Esto genera cambios sólo en la abundancia y frecuencias génicas de las poblaciones naturales, las cuales siguen siendo morfológicamente silvestres (ver tabla 1). La producción de especies forrajeras en la puna es por lo tanto un caso de cultivo de plantas silvestres, posibilidad ya señalada por Harlan (1992).

Ciertos autores sugieren que en la puna no hay malezas (Leon 1964 en Ochoa y Ugent 2001), sin embargo en los huertos de altura puneños observamos plantas (como la "tola", "cortadera", "coba" y "añagua") que entrarían en esta categoría si empleamos el sentido ecológico del término, entendiendo a éstas como plantas invasoras de suelos disturbados por la acción humana y que prosperan sin la intervención directa de éste en su ciclo reproductivo (de Wet 
y Harlan 1975). No obstante, una lectura más atenta de la propuesta de estos autores nos deja ver claramente que estas especies nativas que hallamos en los huertos de Rachaite y Coranzulí no son malezas, sino plantas silvestres ubicadas en un ambiente antrópico, ya que carecen de las adaptaciones propias de las malezas que las hace fuertemente competitivas y difíciles de erradicar como producción de gran número de semillas de germinación rápida pero heterogénea en el tiempo, mimetización con cultivo asociado, gran plasticidad fenotípica, longevidad en formas perennes asociado al desarrollo de mecanismos de defensa como principios tóxicos o espinas, entre otros (Harlan y de Wet 1965). Las poblaciones de estas cuatro especies no poseen cambios que las adapten al medio antrópico respecto de las poblaciones que crecen localmente fuera de los espacios de siembra. Estas plantas son toleradas o erradicadas de los huertos, en este ultimo caso sólo se las quita porque ocupan el espacio destinado a otras plantas. La madera de la "coba", la "añagua" y la "tola" se usan como combustible, empleándose además la primera para sahumar en festividades como la de la Pachamama y la segunda como alimento de la "hacienda" (animales de cría) (R.T. fem). A pesar de estos distintos empleos, las observaciones realizadas indican que estas plantas son recolectadas principalmente en los cerros y en menor medida en los huertos.

Sólo en Rachaite se nos mencionó la presencia de la "ajara" y del "ataco" como formas asilvestradas de la "quínoa" y de la "quiwicha" (Amaranthus sp.) respectivamente. Según los pobladores de esta comunidad, si la "quínoa" no es cosechada por dos o tres años, se vuelve "ajara", la cual no se consume, empleándose sólo sus ramas para hacer "lejía" para mascar coca. Sin embargo las observaciones realizadas permitieron ver que una familia tenía guardadas semillas negras de "ajara", lo cual puede relacionarse a su consumo, si bien lo negaron. Otra posibilidad es que se guarde la semilla para la siembra. Una sola informante (MQ fem.) nos refirió que la ajara se cultiva, aunque esto lo 
menciona en relación a lo que observara en casa de parientes y no porque ella o su familia la siembren. En cuanto al "ataco" todos coincidieron en que crece solo fuera de los espacios cultivados, que lo consume la hacienda y que antes se comía, pero ahora no. F. Z. -un anciano que vive hacia los límites del pueblo- nos confió que él aun recolecta "ataco", lo lava y lo echa a la sopa para comerlo ${ }^{3}$. Finalmente también se menciona que si la "papa" se deja sin cosechar por dos o tres años se vuelve "aparoma" que quiere decir "salvaje, silvestre". Finalmente, en ambas comunidades puneñas no se registró la presencia de malezas sistemáticamente desalentadas o erradicadas por los agricultores de la puna jujeña, quienes tampoco se encargan de quitar las especies silvestres que crecen en sus huertos. Esto es coherente con lo registrado en otras localidades altoandinas chilenas donde son escasas las malezas combatidas o desalentadas (Aldunante et al.1981, Villagrán et al. 1999).

\section{$\underline{\text { Santa Victoria Oeste }}$}

La localidad de Santa Victoria Oeste, constituye la cabecera del departamento homónimo y se ubica a 2560 m.s.m. en la quebrada del río que lleva también su mismo nombre dentro de la Alta Cuenca del río Bermejo (Hurrell 1989, Hilgert 2007a). El acceso a esta comunidad se realiza por la ruta nacional $\mathrm{N}^{\circ} 5$ que parte de La Quiaca (Jujuy), pasa por la localidad de Yavi, cruza la Sierra de Santa Victoria por el Abra de Lizoite a 4500 ms.n.m. y, en territorio salteño, recorre las quebradas de los ríos Lizoite y La Huerta hasta llegar a

\footnotetext{
${ }^{3}$ El Ing. R. Neuman de la estación experimental Cerrillos de Salta considera, tras sus años de experiencia entre comunidades campesinas del NOA, que es muy frecuente que la gente adulta niegue el consumo de "ajara" o de "ataco" (señalando incluso que años atrás sucedía lo mismo con la "quínoa"), por vergüenza al considerárselas comida de indios o de pobres, por lo cual la aceptación de su consumo es manifestada generalmente por niños o ancianos. En opinión de Neuman $-\mathrm{y}$ coincidiendo con escasas declaraciones de los entrevistados- la "ajara" y el "ataco" se siembran, lo cual queda señalado por su disposición ordenada $\mathrm{y}$ en hilera en los huertos locales.
} 
SVO, una zona de valles fértiles cuya fisonomía característica es la de pastizales de altura (Hurrell 1989).

Tras su trabajo en la segunda mitad de la década de 1980, Hurrell (1989) destaca el aislamiento de esta comunidad, siendo la mencionada ruta una vía para el intercambio comercial, principalmente de productos alimenticios. A raíz de ello en SVO se concentran todas las mercancías provenientes de La Quiaca para luego distribuirse a las pequeñas comunidades de la zona. Esto mismo fue constatado en el trabajo de campo aquí presentado observándose que periódicamente ciertos pobladores de SVO concurren al mercado municipal de La Quiaca para aprovisionarse de diversas mercancías que ofrecen luego a la venta en su comunidad de origen. Es por ello que nuestro trabajo etnobotánico incluyó también el relevamiento y colecta de ejemplares de C. maxima ssp. maxima vendidos en el mercado municipal de La Quiaca.

Los pobladores de SVO ubican sus viviendas en los fondos de valles o laderas bajas, poseyendo en la cima de los cerros una vivienda menor o "puesto" para la siembra y la cría de ganado, al cual concurren algunos miembros de la familia periódicamente para mantenimiento de la producción. Al igual que en el caso de El Shincal, ambos emplazamientos constituirían parte de una misma UD. El cultivo se realiza en terrazas fluviales aprovechando la capa de suelo negro de unos $40 \mathrm{~cm}$ de espesor (Zardini y Pochettino 1983), existiendo huertas aledañas a las viviendas. Tanto los huertos como las parcelas sembradas ubicadas en los puestos son para autoconsumo y trueque local, siendo la principal fuente de semillas o propágulos vegetativos la propia producción. Estas mismas características de las áreas agrícolas se ha visto en diversas comunidades de la Alta Cuenca del Río Bermejo a través de estudios etnobotánicos recientes (Hilgert y Gil 2005; Hilgert 2007a; 2007b).

Los estudios etnobotánicos llevados a cabo en la década de 1980 evidencian que, si bien los pobladores locales siembran una gran diversidad de plantas nativas americanas, incluso en pequeñas parcelas, desde 1983 existe un 
aumento considerable en la introducción de plantas domesticadas foráneas (principalmente hortalizas) que desplazan a los cultivos autóctonos (Zardini y Pochettino 1983, Hurrell 1989). Esto también fue constatado por nosotros al relevar la composición de los huertos locales de SVO donde el número de especies nativas americanas fue siempre menor al de las originarias del Viejo Mundo. Esta tendencia a la desaparición de cultivos locales constituyó un impedimento en la labor de campo realizada, ya que el interés inicial radicaba en relevar prácticas de manipulación de especies silvestres, sobre todo de Phaseolus vulgaris var aborigineus (Burk.) Baudet reportados para la zona por Menéndez Sevillano (2002) en la década de 1980. Al llegar pudimos constatar rápidamente que dichas prácticas estaban perdidas y que incluso ya no se siembra ninguna clase de porotos debido a que las condiciones de mercado no fueron favorables para su cultivo, manteniéndose el autoconsumo a nivel doméstico con ejemplares traídos desde el mercado municipal de La Quiaca.

Ante la situación en la que se hallaba esta comunidad se optó por registrar el cultivo de diversas etnoespecies correspondientes a taxa originados en Sudamérica, destacándose entre las mismas la producción de distintas especies y cultivares del género Cucurbita spp. Se tomará a manera de ejemplo ilustrativo el caso de D.L.M (fem.) quien administra el huerto (al cual denomina "corralcito") correspondiente a la UD de pertenencia, aledaño a su vivienda. El mismo se encuentra delimitado en uno de sus lados por la roca de base de una pequeña quebrada sobre la cual limita la unidad de vivienda, en tanto el perímetro restante esta demarcado por pirca seca (Lámina 70, figura a). Dos estructuras circulares, también en pirca seca, se encuentran incluidas dentro del espacio subrectangular el huerto. Las mismas poseen unos $60 \mathrm{~cm}$ de altura en promedio, estando rellenas de tierra ya que son empleadas para sembrar los almácigos que luego se transportaban a la porción rectangular del huerto (Lámina 70, figura b). Las etnoespecies sembradas primero como almácigo y luego trasladadas al huerto en sí mismo son: "tomate" (Lycopersicum 
esculentum), "lechuga" (Lactuca sativa), "remolacha" (Beta vulgaris var. conditiva Alef.) "repollo" (Brassica oleracea var capitata L.) y "zapallito tronquero" o "tronquerito" (C. maxima ssp maxima cv zapallito). El espacio del huerto cuenta con una pronunciada pendiente salvada por pequeñas acumulaciones de tierras paralelas entre sí y transversales al eje mayor del huerto. El mismo es regado a mano o por medio de una manguera desde la toma comunitaria, la tierra es carpida y abonada con heces de animales, trayéndose en algunas ocasiones tierra desde otros parajes. En el huerto se siembran, además de las especies alimenticias mencionadas, plantas ornamentales (flores). De acuerdo con D.L.M no se siembran plantas medicinales porque "no se dan" localmente, adquiriéndolas por compra. Las únicas plantas nativas americanas sembradas son dos etnoespecies de Cucurbita sp.: el "tronquerito" ya mencionado y el "angolín” o "angola" (C. pepo). Ambas son distinguidas en las semillas guardadas (las cuales se guardan en conjunto) por el tamaño de las mismas (las semillas de mayor tamaño corresponden al "angolín" o "angola" y las más pequeñas al "tronquerito"). Ambas clases se siembran con la "puntita" (el extremo micropilar) hacia la tierra, primero haciendo almácigo y luego transplantando la plantita al huerto. De acuerdo con D.L.M. no se seleccionan las semillas, cuando se abren los "zapallos" para cocinarlos se sacan las semillas, se secan y luego guardan para el próximo período de siembra.

En el "puesto" se siembra a temporal "papa", "maíz" ("maíz blanco", "maíz pisancalla" y otros cuyos nombres no recordaba la entrevistada) y "trigo". Estos cultivos son cuidados por los hombres, quienes van cada quince días hasta que se realiza la cosecha en mayo. El "maíz blanco" se siembra porque no madura tan rápido como los de otras variedades, permitiendo su consumo inmaduro como "choclo", los que maduran antes se guardan y algunos se usan como forraje. El "maíz pisancalla" se utiliza para hacer "pelado" o "mote". Sólo en el caso del "maíz" se siembran unas pocas plantas en el huerto para complementar la dieta de la UD que consiste frecuentemente en 
arroz y fideos adquiridos comercialmente "porque si no cansa comer siempre lo mismo, [con el "maíz"] se pueden hacer otras comidas". En este caso, al igual que lo señalado para el El Shincal, se eligen las etnoespecies de maíz a sembrar por criterios de gusto y fundamentalmente gastronómicos.

\section{Discusión}

A partir de los resultados obtenidos tras el trabajo de campo etnobotánico pueden desprenderse una serie de "lecciones" a las cuales se debe atender, fundamentalmente al reconstruir comportamientos de manejo de comunidades vegetales en el pasado a partir del registro arqueológico:

I) En lo que respecta a plantas alimenticias los criterios de selección que operan en la elección de etnoespecies a sembrar y, dentro de ellas, de ejemplares destinados al próximo ciclo de siembra, se encuentran principalmente basados en el gusto, en criterios de mercado, gastronómicos, fisiológicos y morfológicos. La presencia y/o combinación de estos criterios variará de acuerdo con: la etnoespecie considerada; la procedencia y edad de las personas que llevan a cabo la selección, el rol social dado a los distintos géneros dentro de una sociedad (en lo que a manejo de comunidades vegetales respecta) y si la cosecha se destina al consumo de la UD o al comercio. Este último caso es muy evidente en la comunidad de El Shincal, donde se constató que en varios casos la UD subsume sus criterios a los del mercado tanto en la selección de los caracteres de las etnoespecies, como en la elección de qué etnoespecie sembrar. Criterios del mismo tipo que los obtenidos tras el trabajo de campo en estas comunidades campesinas del NOA se han reconocido en comunidades campesinas de otras regiones (Jarvis et al 1999).

II) Las acciones individuales pueden acarrear cambios sustanciales en cuanto a la composición y diversidad de cultivos en una comunidad, no estando dichas 
acciones ligadas necesariamente a roles socialmente establecidos sino a predisposiciones personales.

III) Todas las comunidades estudiadas poseen contactos fluidos fuera de sus límites y reciben claras influencias de centros poblacionales mayores y organismos estatales. Esto ha llevado a la incorporación de cultivos previamente desconocidos como nuevas etnoespecies a la diversidad local. Sin embargo, hay sociedades más conservadoras que otras. En este sentido, Rachaite mantiene un gran número de etnoespecies de tubérculos microtérmicos cuya historia de manejo se remonta posiblemente al pasado prehispánico de la región. Por el contrario Santa Victoria Oeste ha perdido variedades locales de plantas cultivadas y prácticas de manejo de especies americanas que fueron registradas hace no más de veinte años en dicha comunidad, siendo más propensa a la pérdida de diversidad local.

IV) El trabajo realizado en las cuatro comunidades indica la importancia de los huertos como espacios de toma de decisión propios de la UD, la cual se constituye, a la vez, en la unidad de producción. Tradicionalmente los estudios sobre horticultura se han centrado en áreas tropicales o subtropicales, lo cual ha orientado el carácter de las propuestas y discusiones hacia problemáticas como el impacto de las prácticas de roza y quema (Harris 1989, Vogl et al. 2002, Martínez et al. 2003), habiendo pocas excepciones recientes (VoglLukasser et al. 2002, Mayer 2004, Pochettino 2007). La horticultura se caracteriza por distintos aspectos. En lo que refiere a su expresión física, es un área de producción de dimensiones reducidas próxima a la zona de residencia de la unidad productiva que es propietaria y/o trabaja la huerta; desde lo biológico por la presencia de gran diversidad de taxa que poseen distintos grados de asociación con el Hombre, siendo abundantes las especies de sucesiones secundarias; y desde las actividades humanas, por la presencia de comportamientos tendientes a producir y reproducir estas asociaciones más o menos estrechas con especies de aplicación diversa, destinadas por lo general 
al autoconsumo de una unidad productiva de carácter doméstico, a través del empleo de tecnologías simples, las cuales -al igual que los criterios que se aplican en el manejo- poseen una fuerte raigambre tradicional (Harris 1989, Vogl et al. 2002, Vogl-Lukasser et al. 2002, Wagner 2002).

El término "huerto" aparece escasamente en los estudios etnográficos del noroeste argentino en general y de la puna en particular (Ottonello y Ruthsatz 1986, García et al. 2002), siendo más frecuentes el de "rastrojo" usado localmente para referir a zonas de cultivo de especies alimenticias que se distingue del "potrero" que es para el de forraje (Merlino y Rabey 1978; Goebel 1998; García et al. 2002; Martínez y Pochettino 2004).

Nos ha interesado caracterizar los pequeños espacios de producción de las unidades domésticas como huertos ya que esta categoría implica ciertos aspectos que habían recibido escasa atención en los estudios del NOA en general y de la puna en particular, considerada esta última como un área de baja diversidad (Muscio 1998/1999). Los resultados obtenidos tras el trabajo de campo señalan que los huertos del NOA son espacios altamente heterogéneos con elevada diversidad específica ya que son ámbitos de producción múltiple donde se propicia el crecimiento de plantas alimenticias, ornamentales, medicinales y/o forrajeras. Son espacios dinámicos también en el tiempo: pueden cambiar su fisonomía ( $v g$. estar cubiertos o no), cambiando por ende su microclima y asociación vegetal, pueden abandonarse durante un período y ser luego reutilizados y es usual que en ellos convivan ejemplares de etnoespecies sembrados en distintos ciclos agrarios. Son ámbitos de experimentación para el cultivo de especies nuevas o de ejemplares alóctonos de etnoespecies locales conocidas. Este último aspecto también se ha registrados en la puna chilena y peruana (Aldunante et al. 1981, Mayer 2004), coincidiendo con la caracterización general de los huertos (Harris 1989). La dinámica de este espacio productivo va de la mano con la de la unidad doméstica, ya que al cambiar sus miembros cambian también los criterios de 
selección que sobre el mismo operan. Es por lo tanto un espacio artificial, un "artefacto" social en términos de Mayer (2004) donde la relación con las formas vegetales es flexible, atada a contingencias locales y a criterios diversos. Esto, en los caso de las comunidades puneñas aquí analizadas, da como resultado el surgimiento de formas asilvestradas consideradas como malezas por muchos autores (Planchuelo 1975, Coons 1982) en el sentido agronómico del término (Harlan y de Wet 1965) tales como el "ataco" o la "ajara", junto a plantas cultivadas y otras silvestres toleradas con empleos diversos. Los huertos de altura de tipo $a$ y $c$ no presentan un microambiente muy distinto al natural que los rodea salvo por la mayor afluencia de agua. Es por ello que en los mismos prosperan especies silvestres toleradas o erradicadas. En el caso de los potreros las plantas son alentadas por medio del riego y empleadas con fines forrajeros. Estas plantas no modifican sus rasgos fenotípicos manteniendo su carácter silvestre como respuesta a una manipulación humana que se limita a favorecer su presencia y el aumento numérico de ejemplares, reproduciendo un hábitat altamente similar al natural que les es propio. Esta clase de cultivo produce, en cambio, cambios a nivel poblacional en lo que respecta a frecuencia génica y número de individuos. Los huertos de altura son un ejemplo claro de espacios productivos donde se manipulan especies vegetales habiendo trasplante, siembra, cosecha, fomento, tolerancia, erradicación y riego, sin que ello produzca una población uniforme de especies domesticadas sino, por el contrario, una gama de formas cuyo vínculo con el ser humano es mayor o menor en términos de autonomía reproductiva y cambios fenotípicos asociados. Creemos que esto es producto de una relación muy particular que sostiene el habitante de la puna con las especies vegetales, caracterizada por el bajo grado de disturbación del medio junto a la propiciación de diversas formas, las cuales son cultivadas o toleradas y en muy pocos casos rechazadas o erradicadas de forma sistemática, 
habiendo por lo tanto en los huertos muchos cultivos y plantas domesticadas, algunas plantas silvestres y pocas malezas.

De estas lecciones se desprenden críticas a ciertas explicaciones de lo que en arqueología se suele llamar "orígenes de la agricultura" refiriéndose con ello a los primeros ensayos de domesticación de vegetales detectados arqueológicamente. Dichas explicaciones apelan a una idea holística, funcionalista y sistémica de sociedad donde la capacidad de los actores sociales individuales para generar o direccionar el cambio tiene escaso o nulo lugar. Esto se encuentra relacionado con los marcos teóricos desde donde se ha pensado la relación entre seres humanos y plantas: estructuralismo, funcionalismo, ecología cultural, teoría sistémica, neodarwinismo y materialismo cultural, todos los cuales son marcos teóricos holísticos donde lo social es dominante y condiciona los comportamientos individuales, los cuales son vistos como epifenómenos (Gillespie 2001). Entendiendo que son los individuos -y no las sociedades- los que manipulan las plantas, comprender qué criterios emplean para seleccionar lo que han de sembrar al año siguiente resulta crucial para pensar la manera en que el proceso de domesticación de cierta especie pudo haberse dado en el pasado. De la misma forma, el impacto a nivel poblacional que pueden tener las acciones individuales en lo que refiere al cambio puede resultar mayor a lo esperado y manifestarse en cambios bruscos a nivel arqueológico. Existen, además, sociedades más conservadoras que otras en lo que respecta al mantenimiento de su diversidad local de cultivos, lo cual también puede tener un impacto diferencial en los procesos de cambio a través del tiempo. Las influencias ejercidas por organizaciones sociales mayores (como los mercados provinciales, cooperativas de productores u organismos estatales) pueden causar el abandono de prácticas locales de manejo, lo cual puede ocasionar en última instancia la pérdida de etnoespecies propias de la comunidad. La identificación arqueológica de esta 
clase de vínculos puede, por ende, resultar importante en la evaluación del cambio.

Los huertos han demostrado ser los espacios destinados al autoconsumo donde se aplican criterios de selección por medio de prácticas de manejo ejercidas exclusivamente por los miembros de la UD, por lo que su detección arqueológica es de gran importancia a fin de caracterizar la relación entre comunidades humanas y plantas cultivadas a nivel doméstico. La importancia de estos espacios en el estudio de la temprana domesticación vegetal fue señalada por Harris (1989), pero, en el caso de la arqueología del NOA, la presencia de huertos no se ha identificado aún a nivel arqueológico.

Finalmente el trabajo etnobotánico realizado advierte sobre criterios que pudieron haber estado operando en el pasado en la relación entre poblaciones humanas y comunidades vegetales y que son imperceptibles en el registro arqueológico ( $v g$. selección por gusto). Estos deben ser tenidos en cuenta al igual que aquellos que sí tienen un correlato material (como por ej. los criterios morfológicos) al momento de realizar interpretaciones de corte paleoetnobotánico. Estos últimos han recibido un tratamiento especial en esta tesis el cual se desarrolla en el capítulo 6. 
Tabla 76: listado de etnoespecies domesticadas reconocidas por los habitantes de El Shincal, nombre científico y área donde se siembran. $(*)=$ etnoespecies mencionadas por los entrevistados, pero no observadas durante el trabajo de campo, por lo cual carecen de identificación científica.

\begin{tabular}{|c|c|c|c|}
\hline & $\begin{array}{l}\text { Nombres vulgares asignados } \\
\text { a las plantas cultivadas }\end{array}$ & Nombre científico & Área donde se cultivan \\
\hline 1 & Maíz blanco & Zea mays L. & Huerta o rastrojo \\
\hline 2 & Maíz blanco chico & Zea mays L. & Huerta o rastrojo \\
\hline 3 & Maíz blanco mediano & Zea mays L. & Huerta o rastrojo \\
\hline 4 & Maíz blanco diente de caballo & Zea mays L. & Huerta o rastrojo \\
\hline 5 & Maíz capia/ capia morado $\left({ }^{*}\right)$ & & En el cerro \\
\hline 6 & Maíz pispo o pichingo & Zea mays L. & Huerta o rastrojo \\
\hline 7 & Maíz socorro o amarillo & Zea mays L. & Huerta o rastrojo \\
\hline 8 & Maíz ocho rayas & Zea mays L. & Huerta o rastrojo \\
\hline 9 & Zapallo de tronco $\left(^{*}\right)$ & & Huerta \\
\hline 10 & (Zapallo) angola & C. pepo & Huerta \\
\hline 11 & Zapallo & C. maxima ssp. maxima & \\
\hline 12 & Zapallo plomo & C. maxima ssp. maxima & Huerta \\
\hline 13 & Zapallo silpingo & $\begin{array}{l}\text { C. maxima ssp. maxima cv. } \\
\text { zipinka }\end{array}$ & Huerta \\
\hline 14 & (Zapallo) anco/ anquito & C. pepo & Huerta \\
\hline 15 & (Zapallo) coreano/coreanito & C. pepo & Huerta \\
\hline 16 & Cayota $\left(^{*}\right)$ & & - \\
\hline 17 & Poroto blanco & Phaseolus vulgaris L. & Finca o rastrojo \\
\hline 18 & Poroto alubia, bilubia rosadito o común & Phaseolus vulgaris L. & Finca o rastrojo \\
\hline 19 & $\begin{array}{c}\text { Poroto boca amarilla, boca baya, poroto } \\
\text { overo o gateado }\end{array}$ & Phaseolus vulgaris L. & Finca o rastrojo \\
\hline 20 & Poroto de Santa Fe & Phaseolus vulgaris L. & Finca o rastrojo \\
\hline 21 & $\begin{array}{c}\text { Poroto chucha, chaucha, chauchita o } \\
\text { triguillo }\end{array}$ & Phaseolus vulgaris $\mathrm{L}$. & Finca o rastrojo \\
\hline 22 & Poroto bola & Phaseolus vulgaris L. & Finca o rastrojo \\
\hline 23 & Poroto vaina morada & Phaseolus vulgaris L. & Finca o rastrojo \\
\hline 24 & Poroto cuarentero & Phaseolus vulgaris L. & Finca o rastrojo \\
\hline 25 & Poroto calcuta $\left(^{*}\right)$ & & - \\
\hline 26 & Poroto virginia $\left({ }^{*}\right)$ & & - \\
\hline 27 & Poroto manteca & Phaseolus lunatus & Huerta \\
\hline 28 & Poroto negro $\left(^{*}\right)$ & & En el cerro \\
\hline 29 & Cebolla & Allium cepa L. & Huerta \\
\hline 30 & Ruda & Ruta graveolens L & Huerta \\
\hline 31 & Muña-muña & $\begin{array}{l}\text { Satureja parvifolia. } \\
\text { (Philippi) Epling }\end{array}$ & Huerta \\
\hline 32 & Tomate & $\begin{array}{c}\text { Lycopersicum esculentum } \\
\text { Mill }\end{array}$ & Huerta \\
\hline 33 & Lechuga & Lactuca sativa $\mathrm{L}$. & Huerta o finca \\
\hline 34 & Acelga $\left({ }^{*}\right)$ & & Huerta \\
\hline 35 & Zanahoria $\left(^{*}\right)$ & & Huerta \\
\hline 36 & Morrón $\left(^{*}\right)$ & & Huerta \\
\hline 37 & Pimiento o ají $\left(^{*}\right)$ & & Huerta \\
\hline 38 & Sandia $\left(^{*}\right)$ & & Finca \\
\hline 39 & Melón $\left(^{*}\right)$ & & Finca \\
\hline 40 & Nuez criolla & Juglans regia & $\begin{array}{l}\text { Finca, ocasionalmente en } \\
\text { huertos }\end{array}$ \\
\hline 41 & Nuez mariposa & Juglans regia & Finca \\
\hline 42 & Durazno & Prunus persica L & $\begin{array}{l}\text { Finca, ocasionalmente en } \\
\text { huertos }\end{array}$ \\
\hline 43 & Membrillo & Cydonia oblonga L & Finca \\
\hline 44 & Manzana & Malus domestica Borkh. & Finca \\
\hline 45 & Higos & Ficus carica L & Finca \\
\hline 46 & Naranjas $\left(^{*}\right)$ & & Finca \\
\hline
\end{tabular}




\begin{tabular}{|c|c|c|c|}
\hline 47 & Comino & Cuminum cyminum $\mathrm{L}$ & Finca o rastrojo \\
\hline 48 & Anís & Pimpinella anisum L. & Finca \\
\hline 49 & Papa & $\begin{array}{c}\text { Solanum tuberosum L. ssp. } \\
\text { tuberosum }\end{array}$ & Rastrojo \\
\hline 50 & Papa colla $\left(^{*}\right)$ & & En el cerro \\
\hline 51 & Papa Granulada $\left(^{*}\right)$ & & En el cerro \\
\hline 52 & Trigo blanco $\left(^{*}\right)$ & & - \\
\hline 53 & Trigo colorado $\left(^{*}\right)$ & & - \\
\hline 54 & Trigo chileno $\left({ }^{*}\right)$ & & - \\
\hline
\end{tabular}


Figura 43: comunidades campesinas del NOA donde se realizaron trabajos de índole etnobotánica.

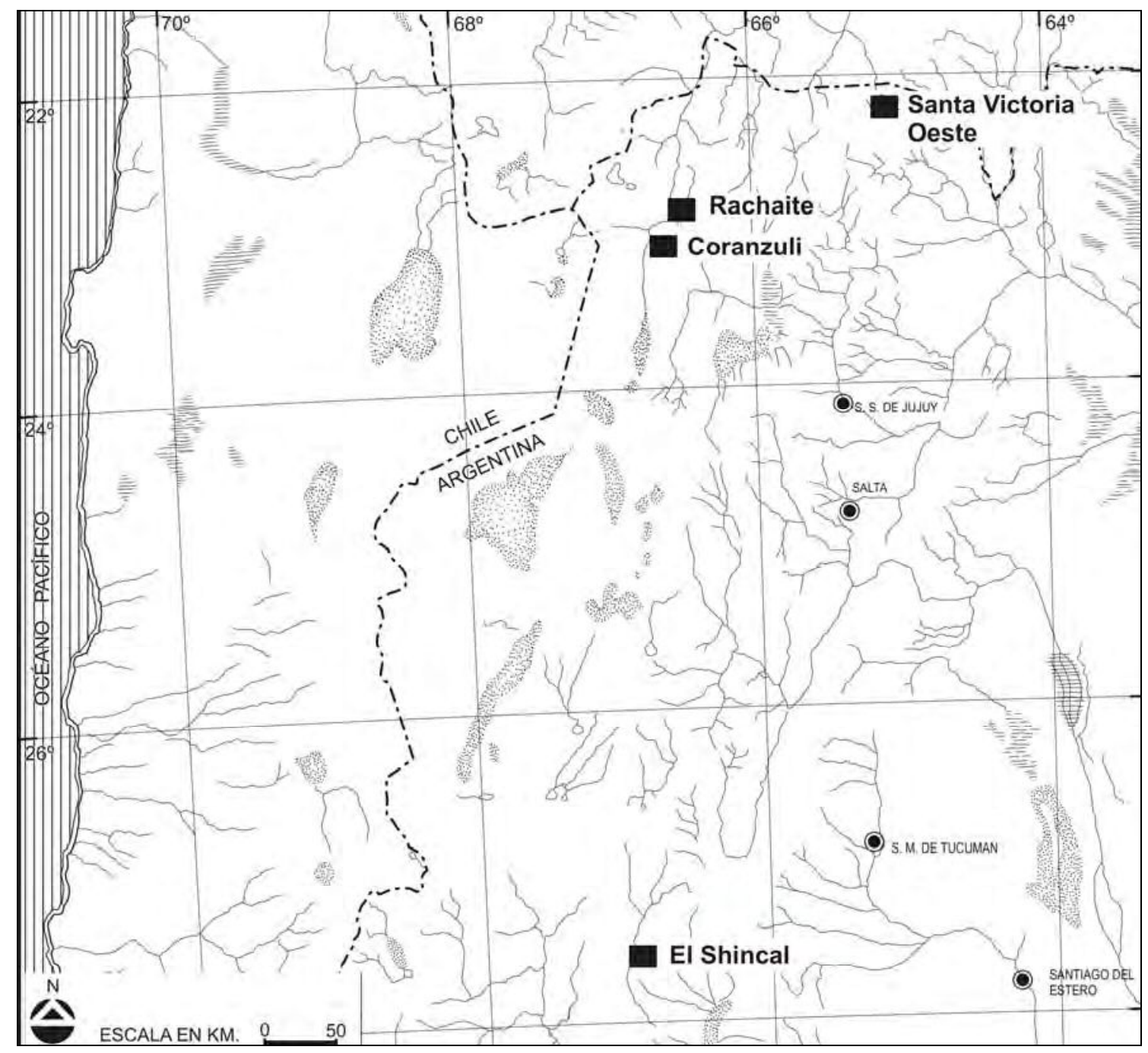


Figura 44: aplicación de técnicas etnográficas (recuadros punteados) para el registro de diversas variables (recuadros enteros) que operan en la conformación de prácticas de manejo de conjuntos de taxones cultivados.

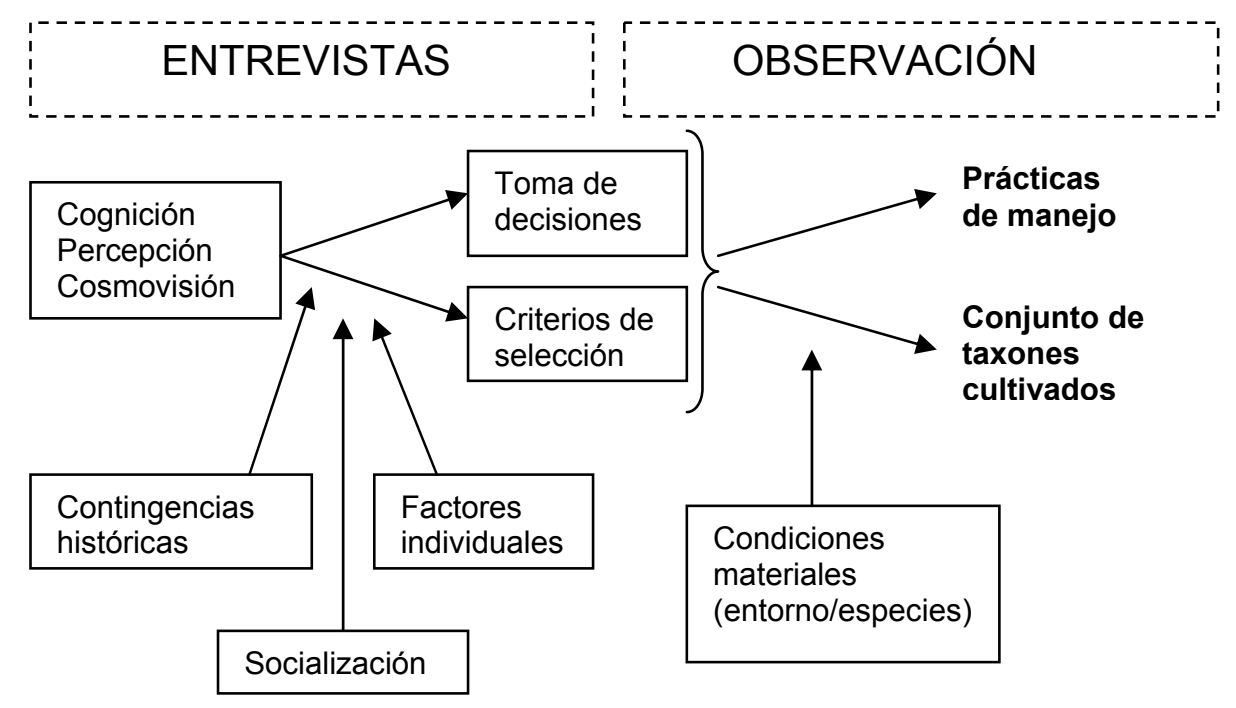



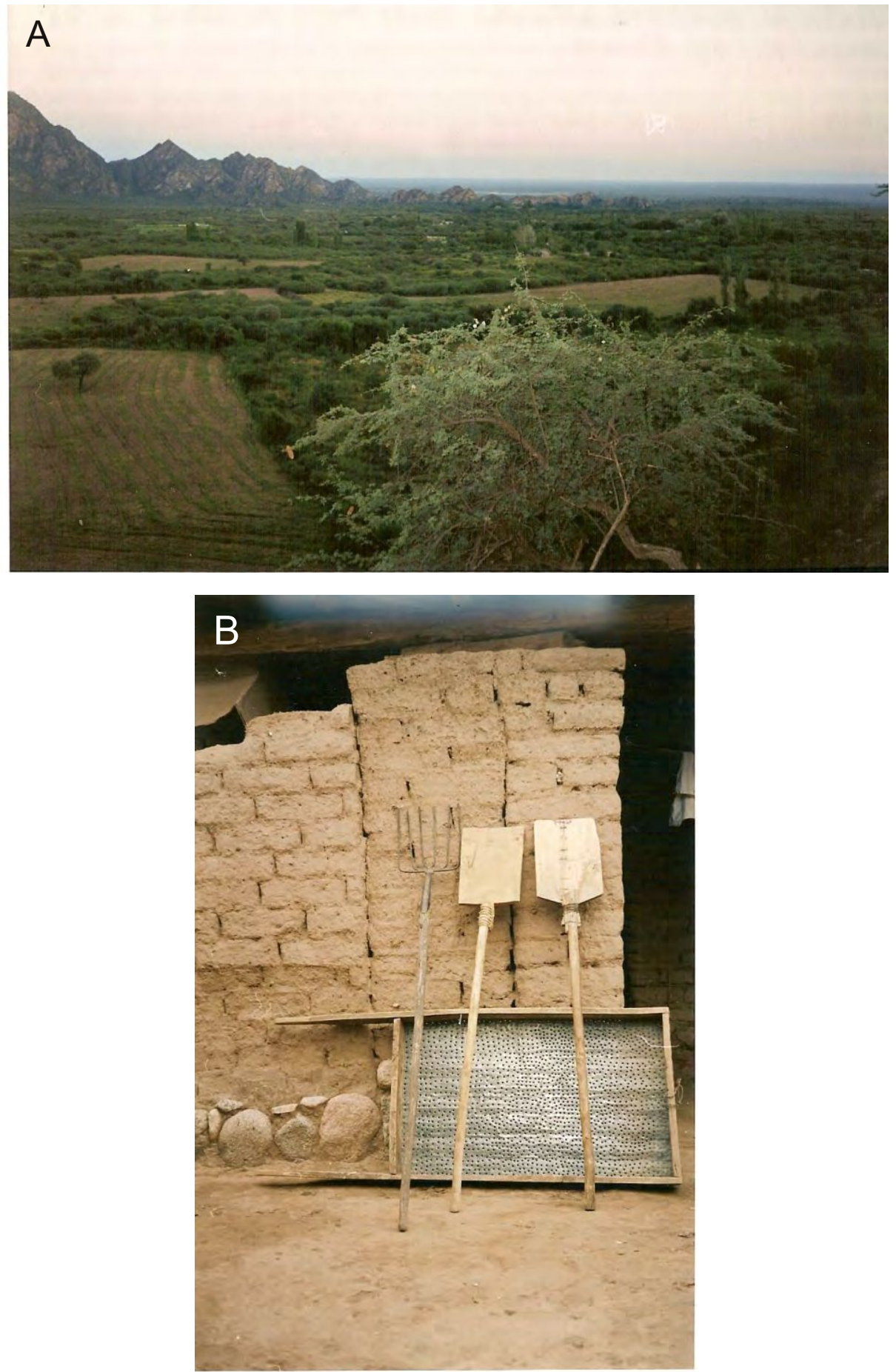

\section{EL SHINCAL (Londres, Catamarca)}

Figura a: Vista panoramica de las fincas de El Shincal Figura b: Elementos usualmente empleados en la cosecha. 

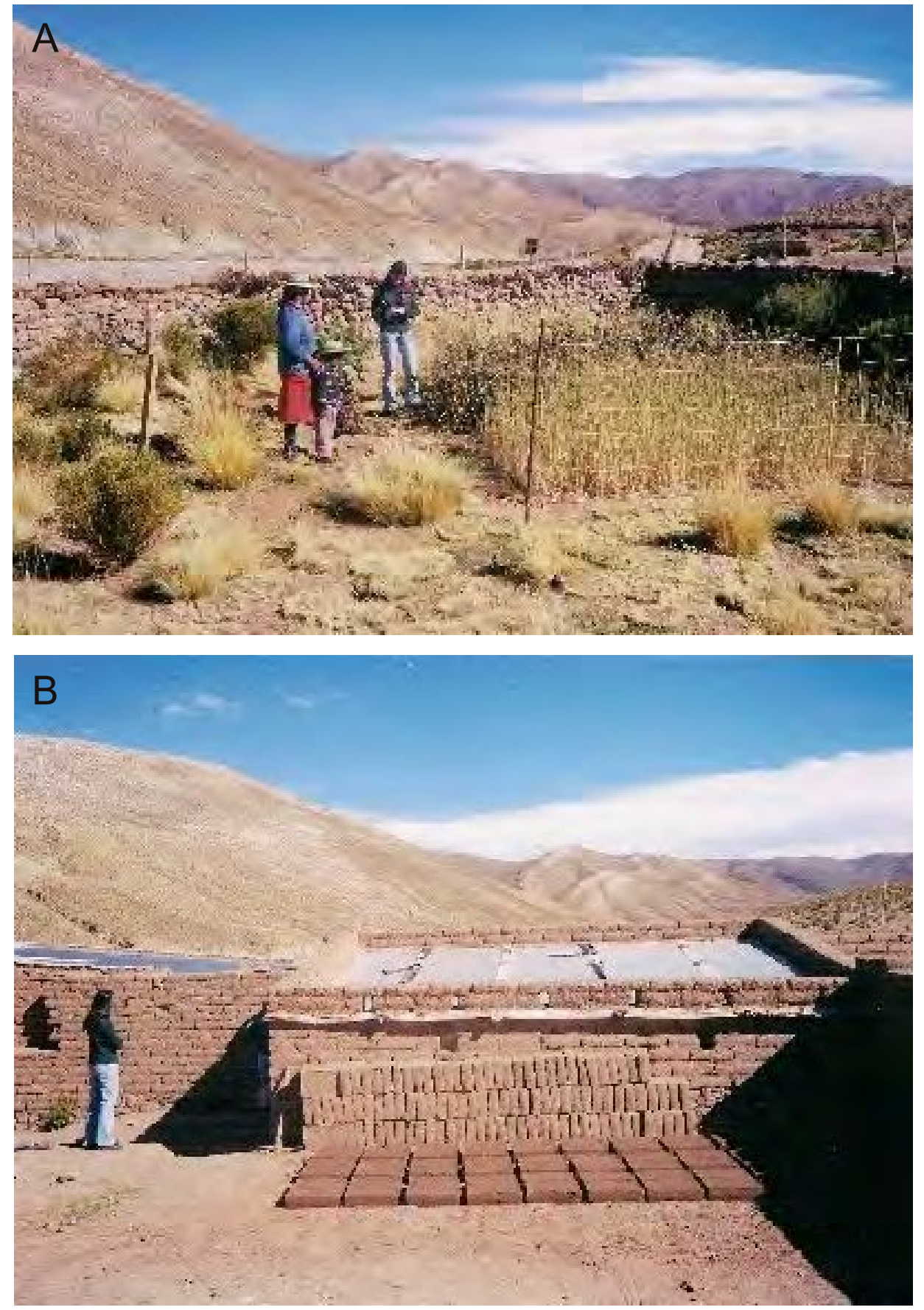

CORANZULI (Jujuy)

Figura a: Huerto de altura tipo a de M.T. (Fem). Notese los ejemplares de plantas dispuestos ordenadamente y la presencia de plantas nativas dentro y fuera del espacio delimitado como "huerta" o "rastrojo".

Figura b: Invernadero (huerta de altura tipo b) de R.M. (Masc) 

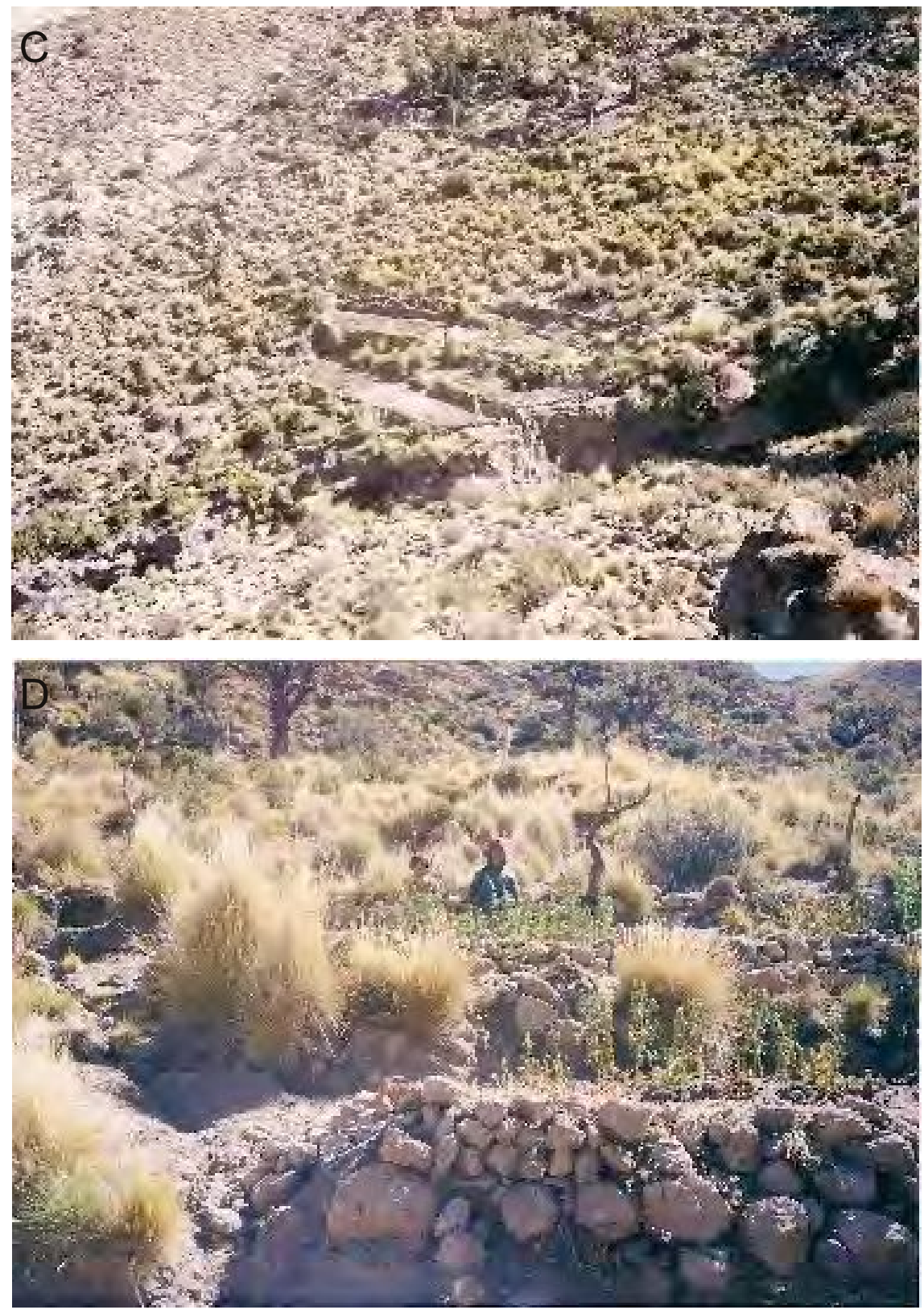

CORANZULI (Jujuy)

Figura a: Huerto de altura tipo $c$ de R.T. (Masc)

Figura b: Detalle del huerto de la foto 4 c. En la foto estan P.T. y J.T a quienes se entrevisto acerca de las caracteristicas de este huerto. En primer plano pueden verse las "patias" a distinto nivel, en las cuales se aprecia la presencia de ejemplares sembrados en distintos momentos del ciclo productivo. Al igual que en la figura 4a puede observarse la presencia de especies nativas que traspasan el limite del huerto sin que sean erradicadas 

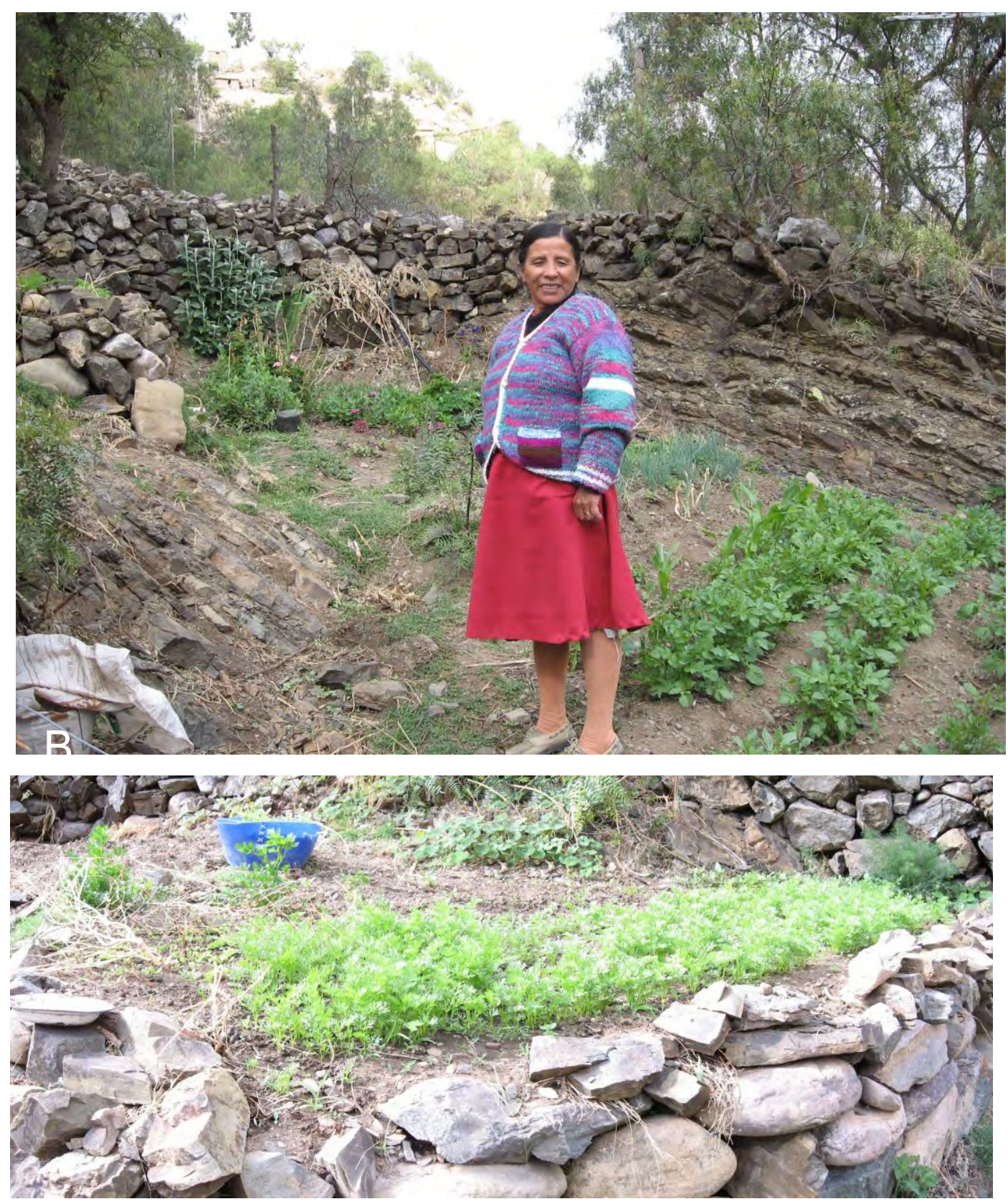

\section{SANTA VICTORIA OESTE (Salta)}

Figura a: Huerto de D.L.M (fem, en la foto) delimitado por las formaciones rocosas de la barranca del rio y por construcciones en pirca seca.

Figura b: Mismo huerto que en la figura 5a. Estructura subcircular de pirca seca dentro del espacio delimitado como huerto destinado a la siembra de almacigos. 


\section{ETNOBOTÁNICA ETNOARQUEOLÓGICA: LOS APORTES DE LOS ESTUDIOS ACTUALES A LA INTERPRETACIÓN DEL PASADO.}

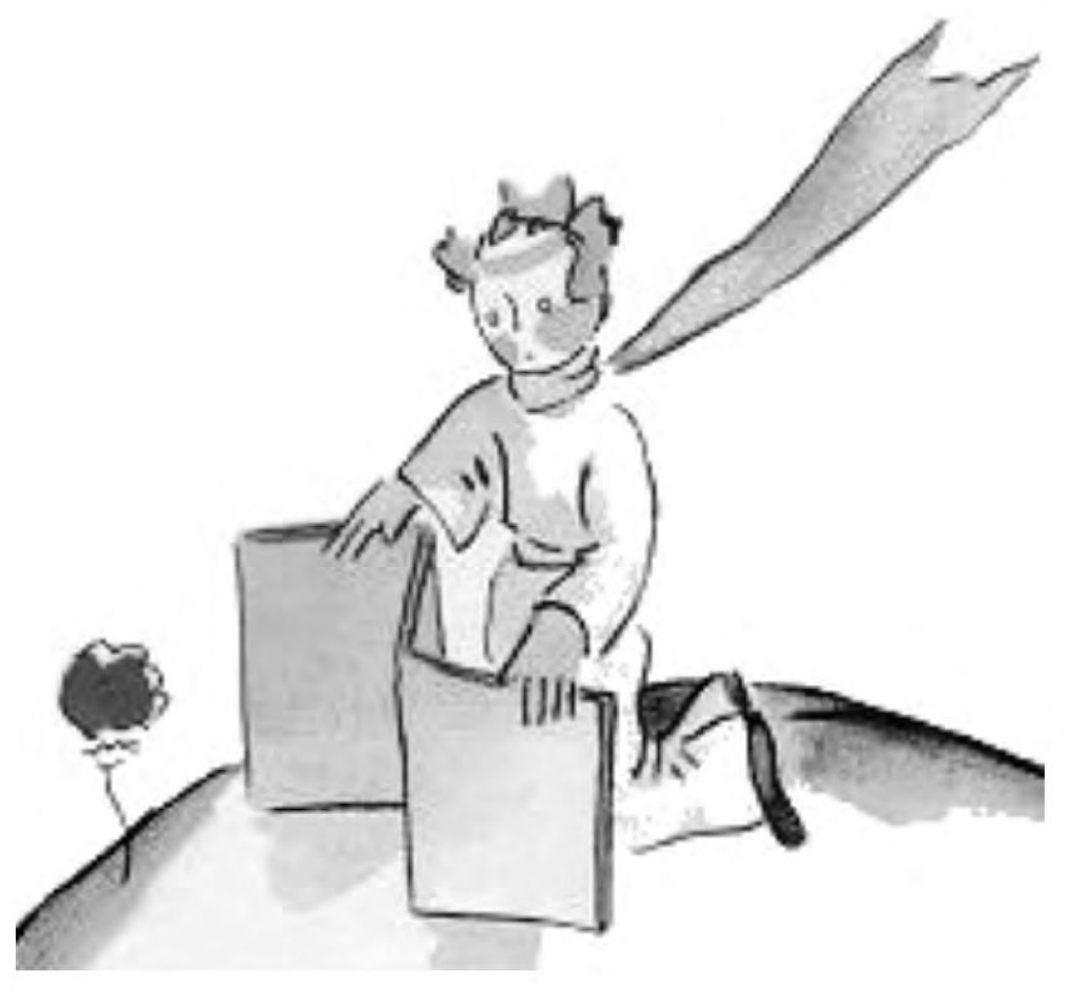




\section{6- ETNOBOTÁNICA ETNOARQUEOLÓGICA: LOS APORTES DE LOS ESTUDIOS ACTUALES A LA INTERPRETACIÓN DEL PASADO}

\section{Introducción}

La problemática de la manipulación humana de poblaciones vegetales y las distintas formas de relación que esto produce ha sido ampliamente abordada en estudios etnobotánicos (Ford 1985a, Harlan 1992, Casas 2001, Hildebrand 2003). Si bien investigadores como G. Hillman han hecho importantes aportes en la generación de modelos etnobotánicos sobre prácticas de procesamiento y manipulación de vegetales que fueron luego aplicados a estudios arqueobotánicos (Hillman 1984, Hillman \& Davies 1990), siguen siendo escasos los intentos por identificar categorías emic o locales en estudios paleoetnobotánicos (Farrington \& Urry 1985, Lema 2008).

En este capítulo se realiza un abordaje etnobotánico-etnoarqueológico de diversos cultivares tradicionales de C. maxima ssp. maxima. El objetivo es constatar si caracteres cuantitativos y cualitativos de las semillas procedentes de los mencionados cultivares, así como también de plantas resultado de prácticas de cultivo o cuidado, se agrupan o no en morfotipos diferenciales que reflejen materialmente la diversidad localmente reconocida y los distintos comportamientos involucrados. Por lo tanto la generación de dichos morfotipos se propone como una vía para explorar si es factible reconocer cultivares locales y distintas formas de relación humano- planta en muestras arqueobotánicas.

La aplicación de la taxonomía linneana a las plantas domesticadas resulta a veces insuficiente, más aún en niveles infraespecíficos, debiendo pensarse en vías alternativas para su agrupamiento y ordenamiento taxonómico, tanto en estudios 
etnobotánicos (Harlan 1992) como arqueobotánicos o paleoetnobotánicos (Murray 1984, Marconetto 2008). Esta complejidad taxonómica aumenta al considerarse los múltiples criterios de evaluación (Nazarea 1998) empleados por los grupos humanos que crean, mediante selección cultural dirigida, diversos cultivares. Estas percepciones locales que generan una gran diversidad de criterios de evaluación sin límites claros (ver capítulo 5) se contraponen con los principios ordenadores reduccionistas de la ciencia occidental que entiende al mundo "en blancos y negros", en tanto la gente lo ve en una amplia "gama de grises" (Nazarea 1998).

Asumiendo esta dificultad, exploraremos vías que permitan reconocer estos criterios múltiples de evaluación y selección en el pasado. La vía que hemos elegido en este capítulo es la realización de trabajos etnobotánicos desde una perspectiva etnoarqueológica.

La posibilidad de una etnobotánica etnoarqueológica.

A pesar de que la etnoarqueología ha recibido distintas denominaciones (disciplina, subdisciplina, abordaje o perspectiva) puede aproximarse una primera idea de la misma diciendo que es el estudio de los correlatos o reflejos materiales de las conductas sociales actuales con el objetivo de lograr un mejor entendimiento de las conductas sociales pasadas estudiadas por medio del registro arqueológico. El mecanismo lógico por el cual se vincula lo observado en la sociedad actual ("fuente") con la interpretación de las sociedades pretéritas ("sujeto" o "meta") es la analogía. Los arqueólogos procesuales fueron los primeros en realizar estudios etnoarqueológicos buscando generar leyes universales ahistóricas y transculturales (Politis 2004) bajo una perspectiva comparativa general que buscaba regularidades en la conducta humana (Fournier 
y Freeman 1991). Esto se lograba fragmentando aspectos culturales que, por lo general, eran conjuntos de acciones concretas y observables (Fournier y Freeman 1991, Frére et al. 2004) - como el faenamiento de presas o la confección de artefactos- que se vinculaban entre la fuente y el sujeto totalmente despojados de su contexto cultural general. Al incluirse la totalidad cultural, tal como ocurrió a partir de los trabajos de arqueólogos posprocesuales (Politis 2004), la posibilidad de generar esta clase de asunciones generales cayó, ya que cuando se consideraban los aspectos superestructurales, las acciones concretas eran más difíciles de universalizar. En esta nueva línea teórica ya no se buscaba generar modelos como en el procesualismo positivista, sino marcos interpretativos desde una postura hermenéutica; tampoco se construían relaciones causales entre comportamiento y consecuencias materiales, ni se hacía de la correlación entre variables una explicación (Politis 2004).

De acuerdo con Politis (2004) toda conducta social posee un correlato material, pero sólo si la misma es recurrente generará un patrón estructurado de dicha materialidad que tendrá posibilidades de ser arqueológicamente detectado. Manuel Gándara (2006) establece con mucha claridad lo que debe cumplirse en la analogía como inferencia inductiva: "la probabilidad de que la(s) propiedad (es) presentes en el conjunto base estén también presentes en el conjunto meta es una función de la probabilidad de que el conjunto base ocurra con una cierta regularidad con todas sus propiedades. De ser cierta esta premisa, entonces se puede postular que las propiedades no observadas en el conjunto meta probablemente estén/estuvieran contenidas en él a partir de que las propiedades generalmente ocurren juntas” (Gándara 2006:16), “determinar cuáles y cuántas de estas propiedades deben de co-ocurrir como para ser una base sólida al momento de formular la hipótesis, o deben de añadirse a ambos conjuntos, en el momento de corroborarla, es un asunto que requiere de una argumentación más profunda, 
teórica, de qué propiedades son las más relevantes" (idem: 19). De acuerdo con este autor, la proyección inductiva requiere de la asunción de un principio general, por lo cual no se puede tener una ontología particularista. Esto no sería lo mismo que aceptar la existencia de leyes ahistóricas, ya que el materialismo histórico asume que hay leyes generales para lo social y otras que se aplican sólo a ciertas formaciones socio-económicas en un momento histórico de su desarrollo. Este problema de historicidad no lo tienen las analogías cuyo principio general involucrado no es social, sino físico o químico: "hay analogías de diferentes órdenes de generalidad, que combinadas con otras que dependen de principios físicos, químicos o biológicos, son menos susceptibles a problemas de distorsión histórica" (Gándara 2006: 22).

La domesticación y generación de cultivares es un fenómeno contemporáneo susceptible de proyectarse al pasado asumiendo que los criterios de selección y el manejo de poblaciones vegetales son operaciones cognitivas y prácticas, respectivamente, que toda sociedad de cultivadores realiza sobre el entorno natural con el que se relaciona. Asimismo, se asume que si actualmente se observa que las poblaciones vegetales cultivadas responden a la manipulación humana generando cambios morfológicos, lo mismo debió de ocurrir en las poblaciones vegetales del pasado.

Al trabajar con restos arqueológicos resulta fundamental corroborar la posibilidad de que estas prácticas de selección cultural se plasmen materialmente en los restos arqueobotánicos. Por ello, a semejanza de lo que ocurre en paleobotánica, en paleoetnobotánica debemos manejarnos con el establecimiento de morfotipos, los cuales son codificaciones de fenotipos particulares por medio del empleo de descriptores morfológicos estandarizados (Lobot et al. 1999). Es en este punto donde es esencial investigar si la acción resultante de la aplicación de criterios de selección y toma de decisiones se materializa en cambios 
morfoanatómicos en los órganos vegetales. De ser así, un morfotipo diferencial en el registro arqueobotánico podría indicar prácticas locales respaldadas en criterios que identifican socialmente a un grupo.

Se deben considerar asimismo otros aspectos tales como la preservación diferencial de los tejidos vegetales. En el caso de C. maxima ssp. maxima existen órganos o tejidos de escasa o nula conservación (i.e. hojas y mesocarpio), en tanto otros se recuperan con frecuencia en los sitios arqueológicos (i.e. semillas, fragmentos de epicarpo y pedúnculos). Por ende el interés se centrará en explorar la posibilidad de que los rasgos de estas últimas estructuras sean susceptibles de reflejar la selección humana sobre poblaciones de la mencionada especie.

\section{Materiales y método}

En otros capítulos de esta tesis hemos señalado las ventajas de trabajar con semillas por sobre otros órganos vegetales, sobre todo cuando se consideran caracteres métricos (ver capítulo 4.1.1c).

Como se ha señalado previamente, en las poblaciones biológicas la categoría "forma" es menos variable y está menos sujeta a factores ambientales que el "tamaño"; como la primera se representa a través de índices y el segundo a través de valores absolutos, los índices serían por ende más adecuados para identificar distintos taxa en ejemplares arqueobotánicos (Mangafa y Kotsakis 1996). En las semillas la forma es un rasgo genético más conservador que el tamaño (Kay et al. 1980), por lo que es aún más aconsejable el empleo de índices para identificar taxa a partir de las mismas.

Se ha mencionado anteriormente en esta tesis (capítulo 4.1.1c) que en el estudio de semillas de Cucurbita sp. los valores métricos lineales de las mismas, el CV de dichos valores y las relaciones entre los mismos como representativas de la 
forma, pueden ser indicadores adecuados para identificar cultivares en los restos arqueobotánicos. (Whitaker 1983, Cowan y Smith 1993, Gremillion 1993, Newsom et al. 1993). Asimismo en el mencionado capítulo se constató la utilidad de los caracteres anatómicos y biométricos de la cubierta seminal de estas semillas para discriminar distintas especies sudamericanas del género.

Trabajo de campo etnobotánico.

El estudio etnobotánico se llevó a cabo en dos comunidades ya descritas en el capítulo 5: Santa Victoria Oeste (SVO) ubicada en el centro de la provincia de Salta, en su extremo norte y El Shincal (ESH) ubicada en el valle de Hualfin, Catamarca. Estas comunidades fueron seleccionadas dado que en ellas se siembran poblaciones de C. maxima ssp maxima y porque se emplazan en dos ambientes fitogeográficos distintos: la primera en la provincia de Yungas, distrito de los Bosques Montanos (Hurrell1989, Hilgert 2007a) y la segunda en la del Monte (Capparelli 2007). La metodología de trabajo en cada comunidad se señala en el capítulo 5. También se llevó a cabo un relevamiento de los ejemplares de Cucurbita vendidos en el mercado municipal de La Quiaca (LQ) dado que muchos de los cultivares que se venden allí son luego trasladados a Santa Victoria por comerciantes locales para su posterior venta. En dicho mercado se efectuaron entrevistas semiestructuradas con las personas que atendían los puestos de venta y observación metódica en los mismos. Ambas técnicas estuvieron dirigidas exclusivamente al relevamiento de información sobre la venta de distintos tipos de "zapallos": nombre asignado, procedencia y compradores más frecuentes. Se obtuvieron ejemplares de los distintos cultivares los cuales fueron tratados de acuerdo con la metodología ya señalada en el capítulo 1, apartado 1.3. 
Trabajo en gabinete y selección de los descriptores morfológicos.

Como descriptores morfológicos macroscópicos se seleccionaron el largo, ancho y altura de las semillas. Se midieron la totalidad de las semillas obtenidas tras el trabajo de campo por medio del empleo de calibre digital. De cada uno de estos descriptores se calculó la media, el desvío estándar, el coeficiente de variación (CV) y los valores máximos y mínimos. A su vez, el CV fue usado específicamente como descriptor en sí mismo. Este descriptor es especialmente valioso ya que permite la comparación de muestras de distinto tamaño $(N)$. Agrupamos los valores de CV en alto, medio y bajo siguiendo los criterios de Newsom (1993): valores de entre 1 y 6 se consideran bajos, valores entre 6 y 10 medios, y de más de 10 son altos.

En segunda instancia se calcularon tres índices (largo/ancho, largo/altura y ancho/altura), empleados también como descriptores morfológicos.

Para el análisis de caracteres microscópicos se siguió la metodología descripta en el capítulo 4.1.1c para el reconocimiento de especies sudamericanas de Cucurbita sp. a partir de rasgos cuali y cuantitativos de la cubierta seminal. Se seleccionó un subconjunto de muestras (LQM3, LQM5, SVMT1, DSR1 y DSR2) y se realizaron cortes delgados de las cubiertas seminales de una semilla por muestra, los cuales fueron observados por transparencia bajo microscopio óptico. Entre los rasgos microscópicos propuestos en el mencionado capítulo para identificar especies de Cucurbita sp. se seleccionaron cinco a ser empleados como descriptores morfológicos: largo y ancho de las células epidérmicas, largo y ancho de las esclereidas y altura de la capa hipodérmica.

Se obtuvieron veinte medidas por descriptor. Los caracteres cuantitativos fueron organizados en una base de datos a fin de poder realizar análisis de 
conglomerados jerárquico con empleo de representación gráfica de diagrama de árbol o dendrograma. Se utilizó el método de Ward y la distancia euclidiana como medida de similitud. El análisis se realizó empleando el software Statistica 6.0. Se seleccionó este tipo de análisis ya que se reconoce su utilidad para evaluar grados de similitud/diferencia en caracteres de semillas de diferentes plantas alimenticias que poseen un valor diferencial asignado por la gente (Höft et al. 1999).

\section{Resultados}

\section{Trabajo de campo etnobotánico.}

De la totalidad de especies registradas se seleccionaron aquellas mencionadas por los entrevistados como "zapallos". De los siete cultivares mencionados en ESH, tres fueron taxonómicamente identificados, por los caracteres de sus semillas, como cultivares de C. pepo y cuatro como cultivares de C. maxima ssp. maxima. Del análisis de las entrevistas referidas a esta última especie se constató que sólo un individuo (D.S.R., masc., 77años) menciona modos distintos de manipulación de poblaciones de la misma. El entrevistado señaló que él cultiva "zapallo criollo" (muestra de semillas aportada por el entrevistado registradas bajo el código DSR1) y guarda la semilla de otro zapallo que también consume, "el cual crece sólo con la llwiva" sin ningún cuidado de su parte, en un campo abandonado ubicado frente a su vivienda (muestra DSR2). Señaló también que el segundo no es tan rico como el criollo, pero su beneficio es que no necesita riego extra para crecer. A pesar de que estas prácticas fueron registradas en un único caso del total analizado, el mismo es significativo ya que del trabajo etnobotánico que se realizó en El Shincal, Rachaite, Coranzulí y Santa Victoria Oeste, esta es la única referencia a cuidados diferenciales para los tipos de "zapallos" reconocidos 
localmente. Por lo tanto el caso de este poblador de ESH es de suma importancia ya que puede ser representativo de formas de manipulación que se han ido perdiendo con el paso del tiempo.

En el caso de los ejemplares adquiridos en el mercado de La Quiaca, todos fueron identificadas como C. maxima ssp. maxima (LQM1 a LQM7). De las dos muestras de semillas de "zapallos" colectadas en SVO, una (localmente denominada "guineo") fue identificada como C. pepo y otra ("tronquero" o "tronquerito") como C. maxima ssp. maxima cv. zapallito (SVMT1). Estas semillas fueron aportadas por una informante (D.L.M., fem., 56 años) y corresponden a los "zapallos" que cultiva en su huerto. Según nos informó, las semillas son guardadas tras la cosecha y son plantadas cada año.

Por lo tanto el trabajo etnobotánico aportó, en primer lugar, muestras que representan modos distintos de relación humano- planta en una comunidad (DSR1 y DSR2) y, en segundo lugar, muestras que representaran cultivares que son reconocidos y circulan en una misma comunidad distinguiéndose entre los que son manipulados localmente en todo su ciclo productivo (SVMT1) de los que ingresan a la comunidad para ser consumidos, pero que no son producidos localmente, por lo que no reflejan criterios locales de manejo (LQM1 a LQM7) (Tabla 77).

\section{La búsqueda de morfotipos.}

En el caso de las semillas, el carácter macroscópico cualitativo más destacado es el color de las mismas, distinguiéndose aquellas de superficie opaca y color castaño (DSR1, LQM1, LQM4 y LQM5, correspondientes al cultivar "criollo") de las que poseen superficie brillante color blanco (DSR2, SVMT1, LQM2, LQM3, LQM6 y LQM7). La utilidad de este carácter para distinguir cultivares 
disminuye al trabajar con restos arqueobotánicos, ya que los mismos se encuentran por lo general desecados y descoloridos, o bien carbonizados. Sin embargo, estos colores de la superficie se correlacionan con tipos de células epidérmicas (Teppner 2004), tal como veremos al analizar caracteres microscópicos.

SANTA VICTORIA OESTE

1) DESCRIPTORES EN MORFOLOGIA MACROSCOPICA

1.1) LARGO, ANCHO Y ALTURA DE LAS SEMILLAS (Tabla 78, Gráficos 29 a 31): para el caso de SVO, los tres descriptores indican la presencia de dos morfotipos. El morfotipo 1 esta compuesto por semillas de zapallos llamados "bolivianos" o "cochabambinos" vendidos en el mercado municipal de La Quiaca (LQM1, LQM4 y LQM5). A simple vista se aprecia que estos zapallos de gran tamaño poseen semillas también de gran tamaño. Esta diferencia queda plasmada en un morfotipo caracterizado por un largo de entre 25 y $30 \mathrm{~mm}$, un ancho de entre 13 y $15 \mathrm{~mm}$ (pudiendo llegar a $17 \mathrm{~mm}$ ) y una altura de 5 a 7,5 milímetros.

El morfotipo 2 es mucho más variable que el anterior, agrupando ejemplares de C. maxima ssp. maxima y de C. maxima ssp. maxima cv. zapallito (LQM2, LQM3, LQM6, LQM7 y SVMT1). En ninguno de los tres descriptores los conglomerados menores dentro del morfotipo 2 lograron reflejar las clasificaciones locales: los valores obtenidos para largo y ancho distinguen ejemplares que los habitantes de la localidad agrupan bajo un mismo nombre (vg. "zapallos de los valles de Salta") y agrupa aquellos que se clasifican localmente por separado y poseen trayectorias distintas (vg. "zapallitos" que vienen de San 
Salvador y se venden en el mercado de La Quiaca con zapallos que responden a un cuidado y cultivo local llamados "tronquero" o "tronquerito" -ambos pertenecientes al cultivar "zapallito"- o bien con zapallos procedentes de Salta). La distancia de ligamiento entre las muestras del morfotipo 1 es menor en la altura, siendo las del largo y ancho similares. La distancia de amalgamiento entre ambos morfotipos es menor también en el caso de la altura, siguiéndoles en orden creciente el largo y el ancho.

1.2) COEFICIENTE DE VARIACIÓN (Tabla 78 y 79 Gráfico 32): En general el CV no se comporta de la misma manera en cada muestra para los tres descriptores considerados (largo, ancho y altura). Si bien en las muestras LQM3, LQM4 y LQM6 los valores de CV se comportan de igual manera para las tres medidas, debemos considerar que cada una de estas muestras representa una parte de una categoría mayor reconocida por los pobladores locales. Por ejemplo LQM3 es un "zapallo de los valles de Salta", pero dentro de esta categoría está también la muestra LQM2 cuyos valores de CV son totalmente distintos, lo mismo ocurre con LQM4 que forma parte del grupo de "zapallos bolivianos" o “cochabambino" y LQM6 que junto con LQM7 son las semillas de "zapallitos" que se venden en el mercado de La Quiaca.

Si quitamos la altura de la tabla 79 veremos que en todos los casos los valores de CV de largo y ancho coinciden en su carácter de bajo, medio o alto, salvo en LQM1. Teniendo esto en cuenta tendríamos entonces tres conjuntos representados por estos tres rangos de medidas, pero que están agrupando a la vez que separando distintos cultivares locales: el grupo de CV bajo agrupa a una muestra de los valles de Salta con dos de zapallos bolivianos, el grupo de CV medio agrupa a un cultivar local, un zapallo de los valles de Salta y zapallitos de 
San Salvador y el CV alto está representado solamente por una muestra de zapallitos del circuito comercial.

El segundo aspecto de interés es el análisis de la variabilidad presente en un cultivar. Si este se encuentra representado por semillas procedentes de diversos frutos, puede ser que el CV aumente, ya que las mismas pueden ser el producto de distintas condiciones a las que estuvieron sometidas las plantas, pudiendo esto generar cambios morfológicos. Pero si consideramos la variabilidad representada por semillas de un mismo fruto, tendremos una visión más ajustada de cuán variable es el cultivar. Cada una de las muestras de los zapallos bolivianos y las de los valles de Salta proceden de frutos distintos, sin embargo los CV de ambos cultivares son muy discrepantes. Las muestras LQM4 y LQM5 presentan valores bajos de CV, por lo que este sería un cultivar bastante homogéneo. Los zapallos salteños, en cambio, presentan valores muy dispares entre uno y otro fruto (LQM2 y LQM3), por lo que éste sería un cultivar heterogéneo. Por lo tanto el mantenimiento de CV altos puede estar presente en un cultivar.

1.3) INDICES (Tabla 80 Gráficos 33 a 35): el análisis de conglomerados de los tres índices indica que, si bien ninguno refleja la diversidad localmente reconocida, el índice largo/ancho acertó en agrupar los zapallitos comerciales (LQM6 y LQM7) y separar el único cultivar no comercial (SVMT1) del resto de ejemplares que se comercializan en La Quiaca. En todos los restantes casos volvemos a encontrar agrupamiento de cultivares diferenciados a nivel local y separación de muestras clasificadas como un único cultivar en las comunidades de origen.

\section{2) DESCRIPTORES EN MORFOLOGIA MICROSCÓPICA}


Entre los caracteres cualitativos la presencia de células epidérmicas largas de paredes engrosadas en las caras mayores de la semilla que no llegan a rodear a las células epidérmicas cortas en el margen de la misma, distinguen a LQM5 como C. maxima ssp. maxima cv. criollo (Fig 45-A y B). Por el contrario, la presencia de células epidérmicas largas de paredes delgadas en las caras mayores que rodean a las células cortas de los márgenes es compartido por LQM3 y SVMT1.

Tras el análisis de los datos cuantitativos (Tabla 81) puede verse que solo el alto de la capa hipodérmica en caras mayores permite diferenciar a los tres cultivares como tres morfotipos distintos dado que las medidas no se solapan entre sí, o lo hacen sólo moderadamente.

Los valores de CV para los distintos descriptores micromorfológicos son muy discrepantes al interior de cada muestra, incluso al considerar dos caracteres de una misma célula, por lo cual no se considera al CV de rasgos microscópicos como un descriptor válido por sí mismo para caracterizar un cultivar.

\section{EL SHINCAL.}

\section{1) DESCRIPTORES EN MORFOLOGIA MACROSCOPICA.}

1.1) LARGO, ANCHO Y ALTURA DE LAS SEMILLAS (Tabla 78): los resultados muestran que ambas muestras poseen valores que se solapan entre sí, por lo cual no se pueden distinguir morfotipos diferentes.

1.2) Coeficiente de variación (CV) (Tabla 78): los valores de CV de la muestra DSR2 son más bajos para las tres medidas lineales. 
1.3) INDICES (Tabla 80): valores muy similares en los índices (con alto grado de solapamiento) impiden distinguir estas dos muestras como unidades distintas.

\section{2) DESCRIPTORES EN MORFOLOGIA MICROSCÓPICA}

Mediante el empleo de caracteres cualitativos se constató que hay dos cultivares: la muestra DSR2 corresponde a C. maxima ssp. maxima cv. criollo y la muestra DSR1 a un cultivar de epidermis de paredes delgadas (Figura 45-C y D).

$\mathrm{Al}$ igual que en el caso de SVO el CV no resultó útil para distinguir cultivares (Tabla 81). En este caso el largo de las células epidérmicas fue el parámetro que mejor diferenció a ambos grupos, sin que haya solapamiento de medidas (Tabla 81).

\section{Discusión}

En el caso de los cultivares el empleo de descriptores macroscópicos puede tanto reducir como aumentar artificiosamente la variabilidad reconocida por una comunidad al agrupar cultivares que la gente considera distintos y separar los que son considerados como uno, tal como se vio aquí para el caso de SVO. Asimismo los valores de CV obtenidos para este último conjunto de cultivares difiere en gran medida de acuerdo con el descriptor elegido, por lo tanto no es indistinto tomar el CV del largo, ancho o altura de una muestra de semillas. En los estudios paleoetnobotánicos, por lo general, se toma como indicador de cambio el CV de una medida lineal (frecuentemente del largo, ver Newsom 1993, por ejemplo) sin justificar esta elección. En el caso de la altura -a pesar de que en los análisis de conglomerados mostró las menores distancias de ligamiento y de 
amalgamiento- no es un carácter de aplicación en estudios de restos arqueobotánicos ya que se ve muy afectado por procesos de desecación, degradación y carbonización (ver capítulo 4.1.1c). El ancho, en cambio, puede ser empleado sin inconvenientes, incluso es mencionado por Cowan \& Smith (1993) como un carácter más conservador en las semillas de cucúrbitas. Pero incluso al no considerar los CV para la altura en los cultivares de SVO, los CV de largo y ancho desagrupan muestras de cultivares que los pobladores locales agrupan. Asimismo la consideración de que sólo valores diferentes de $\mathrm{CV}$ obtenidos en una muestra de una localidad o sitio arqueológico indicarán la presencia de distintos cultivares debe también reconsiderarse, ya que los resultados aquí obtenidos señalan que un mismo rango de valores de CV puede estar agrupando cultivares que los pobladores locales consideran distintos.

En el caso de grupos de plantas sujetos a distintos tipos de manipulación (DSR1 y DSR2), los descriptores macroscópicos tampoco resultaron de utilidad para diferencias dichos tipos.

Finalmente los resultados obtenidos tanto para las muestras de SVO como para las de ESH muestran que el uso exclusivo en paleoetnobotánica de valores bajos de CV como indicadores de cultivos puede llegar a subestimar la presencia de cultivares donde el mantenimiento de una alta diversidad es un rasgo seleccionado por los cultivadores. En este sentido es contundente el hecho de que muestras procedentes de poblaciones con escaso cuidado humano (DSR2) obtengan CV más bajos que las que sí son cuidadas y regadas (DSR1). Esto estaría en contraposición con la idea de que los cuidados humanos tienden a reducir la variabilidad presente en las poblaciones naturales, generando poblaciones homogéneas de acuerdo con los caracteres seleccionados (Harlan 1992, Gremillion 1997, Clement 1999). Este es un punto importante ya que de acuerdo con Cowan \& Smith (1993) las medidas actuales de semillas de 
cucúrbitas que son muy variables no son útiles para ser empleadas en la identificación de material arqueológico con escasas semillas.

El empleo de índices para evaluar si la forma refleja mejor las categorías locales respecto del tamaño, no arrojó resultados favorables para el caso de ESH y sólo resultó útil el índice largo/ancho para dos cultivares de SVO.

En cambio, los descriptores en morfología cuantitativa microscópica generaron morfotipos que reflejan de manera más ajustada los cultivares localmente reconocidos. Sin embargo, no todos fueron igualmente útiles, por lo cual se requiere del análisis de un número elevado de descriptores micromorfológicos a fin de hallar diferencias significativas. Además algunos de los mismos, como caracteres de la epidermis e hipodermis, sufren notables alteraciones en restos arqueobotánicos, pudiendo incluso estar ausente todo el tejido (ver capítulo 4.1.1c).

Siguiendo a Gándara (2006) es posible afirmar que se ha generado a partir de ciertos rasgos cuantitativos macroscópicos y microscópicos de semillas de $C$. maxima ssp. maxima una base inductiva a partir de la cual se ha descartado el empleo de ciertos indicadores, corroborándose (aunque no comprobándose) la utilidad de otros. Esta corroboración irá tomando mayor fuerza a partir del contrastarse con nuevos conjuntos de referencia. En este capítulo se ha procurado la elaboración de un argumento de relevancia, tal como lo entiende Gándara (2006), en el sentido de que la composición y frecuencia del conjunto base sean fundamento suficiente para la inferencia. La aplicación arqueológica de estos resultados etnoarqueológicos requiere que los elementos que conforman la base inductiva vayan en aumento a fin de corroborar las inferencias analógicas aquí desarrolladas. 
Tabla 77: datos correspondientes a las muestras obtenidas tras el trabajo de campo etnobotánico en la localidad de Santa Victoria Oeste e identificación taxonómica de los distintos cultivares

\begin{tabular}{|c|c|c|c|c|c|}
\hline CODIGO & NOMBRE LOCAL & $\begin{array}{l}\text { ZONA DE } \\
\text { COLECTA }\end{array}$ & PROCEDENCIA & $\begin{array}{c}\text { ESTADO DE LA } \\
\text { MUESTRA } \\
\text { COLECTADA }\end{array}$ & ESPECIE \\
\hline LQM1 & Zapallo boliviano & $\begin{array}{c}\text { Mercado } \\
\text { Municipal de La } \\
\text { Quiaca }\end{array}$ & San Salvador & $\begin{array}{c}\text { Semillas } \\
\text { empaquetadas para } \\
\text { siembra. }\end{array}$ & $\begin{array}{l}\text { C. maxima ssp. } \\
\text { maxima cv. criollo }\end{array}$ \\
\hline LQM2 & $\begin{array}{l}\text { Zapallo de los } \\
\text { valles de Salta }\end{array}$ & $\begin{array}{c}\text { Mercado } \\
\text { Municipal de La } \\
\text { Quiaca }\end{array}$ & Salta & $\begin{array}{c}\text { Fruto vendido fresco } \\
\text { para consumo. }\end{array}$ & $\begin{array}{l}\text { C. maxima ssp. } \\
\text { maxima }\end{array}$ \\
\hline LQM3 & $\begin{array}{l}\text { Zapallo de los } \\
\text { valles de Salta }\end{array}$ & $\begin{array}{c}\text { Mercado } \\
\text { Municipal de La } \\
\text { Quiaca }\end{array}$ & Salta & $\begin{array}{c}\text { Fruto vendido fresco } \\
\text { para consumo. }\end{array}$ & $\begin{array}{l}\text { C. maxima ssp. } \\
\text { maxima }\end{array}$ \\
\hline LQM4 & $\begin{array}{c}\text { Zapallo } \\
\text { Cochabambino o } \\
\text { boliviano }\end{array}$ & $\begin{array}{c}\text { Mercado } \\
\text { Municipal de La } \\
\text { Quiaca }\end{array}$ & Bolivia & $\begin{array}{c}\text { Fruto vendido fresco } \\
\text { para consumo. }\end{array}$ & $\begin{array}{l}\text { C. maxima ssp. } \\
\text { maxima cv. criollo }\end{array}$ \\
\hline LQM5 & Zapallo boliviano & $\begin{array}{c}\text { Mercado } \\
\text { Municipal de La } \\
\text { Quiaca }\end{array}$ & Bolivia & $\begin{array}{c}\text { Fruto vendido fresco } \\
\text { para consumo. }\end{array}$ & $\begin{array}{l}\text { C. maxima ssp. } \\
\text { maxima cv. criollo }\end{array}$ \\
\hline LQM6 & Zapallitos & $\begin{array}{c}\text { Mercado } \\
\text { Municipal de La } \\
\text { Quiaca }\end{array}$ & San Salvador & $\begin{array}{c}\text { Semillas } \\
\text { empaquetadas para } \\
\text { siembra. }\end{array}$ & $\begin{array}{l}\text { C. maxima ssp. } \\
\text { maxima cv. } \\
\text { zapallito }\end{array}$ \\
\hline LQM7 & Zapallitos & $\begin{array}{c}\text { Mercado } \\
\text { Municipal de La } \\
\text { Quiaca }\end{array}$ & San Salvador & $\begin{array}{c}\text { Semillas } \\
\text { empaquetadas para } \\
\text { siembra. }\end{array}$ & $\begin{array}{l}\text { C. maxima ssp. } \\
\text { maxima } \mathrm{cv} \text {. } \\
\text { zapallito }\end{array}$ \\
\hline SVMT1 & $\begin{array}{l}\text { Tronquero o } \\
\text { tronquerito }\end{array}$ & $\begin{array}{c}\text { Santa Victoria } \\
\text { Oeste }\end{array}$ & Local & $\begin{array}{c}\text { Semillas guardadas } \\
\text { para sembrar. }\end{array}$ & $\begin{array}{c}\text { C. maxima ssp. } \\
\text { maxima } \mathrm{cv} . \\
\text { zapallito }\end{array}$ \\
\hline
\end{tabular}


Tabla 78: valores de los descriptores en morfología macroscópica cuantitativa correspondientes a las muestras obtenidas en la comunidad de Santa Victoria Oeste y El Shincal.

\begin{tabular}{|c|c|c|c|c|c|c|c|c|c|c|c|c|c|c|c|c|}
\hline & \multirow[b]{2}{*}{$\mathrm{N}$} & \multicolumn{5}{|c|}{ LARGO } & \multicolumn{5}{|c|}{ ANCHO } & \multicolumn{5}{|c|}{ ALTURA } \\
\hline & & Media & DS & CV & Min & Max & Media & DS & $\mathrm{CV}$ & Min & Max & Media & DS & CV & Min & Max \\
\hline SVMT1 & 104 & 16,22 & 1,29 & 7,97 & 13,98 & 19,31 & 7,43 & 0,48 & 6,5 & 6,2 & 8,63 & 2,51 & 0,33 & 13,1 & 3,09 & 1,65 \\
\hline LQM1 & 11 & 28,46 & 1,09 & 3,82 & 26,78 & 30,38 & 15,24 & 1,05 & 6,9 & 14 & 17,2 & 6,35 & 0,49 & 7,66 & 7,5 & 5,98 \\
\hline LQM2 & 10 & 18,98 & 0,5 & 2,62 & 18,03 & 19,57 & 9,73 & 0,43 & 4,4 & 8,9 & 10,2 & 3,62 & 0,42 & 11,68 & 4,03 & 2,62 \\
\hline LQM3 & 23 & 16,74 & 1,08 & 6,47 & 13,67 & 18,53 & 9,33 & 0,77 & 8,2 & 7,2 & 10,2 & 2,65 & 0,23 & 8,55 & 2,95 & 2,11 \\
\hline LQM4 & 22 & 28,04 & 0,74 & 2,65 & 26,55 & 29,9 & 14,65 & 0,6 & 4,1 & 13 & 15,5 & 5,51 & 0,28 & 5,05 & 6,02 & 5,04 \\
\hline LQM5 & 24 & 27,35 & 1,25 & 4,58 & 25,25 & 29,61 & 13,64 & 0,64 & 4,7 & 12 & 14,9 & 6,22 & 0,39 & 6,19 & 6,95 & 5,44 \\
\hline LQM6 & 62 & 15,5 & 1,55 & 10 & 12,06 & 19,14 & 9,67 & 1,04 & 11 & 7,4 & 11,9 & 2,68 & 0,4 & 15,11 & 3,59 & 1,81 \\
\hline LQM7 & 56 & 15,05 & 1,32 & 8,76 & 12,32 & 18,01 & 9,06 & 0,71 & 7,8 & 7,6 & 10,3 & 2,68 & 0,35 & 12,96 & 3,67 & 1,91 \\
\hline DSR1 & 19 & 17,46 & 1,06 & 6,1 & 15,84 & 19,17 & 9,68 & 0,57 & 5,8 & 8,18 & 10,5 & 2,51 & 0,33 & 13,1 & 3,09 & 1,65 \\
\hline DSR2 & 40 & 18,13 & 0,71 & 3,92 & 16,90 & 19,54 & 10,08 & 0,36 & 3,5 & 9,12 & 10,9 & 3,92 & 0,14 & 3,5 & 3,6 & 4,26 \\
\hline
\end{tabular}


Tabla 79: agrupamiento de los valores de CV para las tres medidas lineales de las muestras obtenidas en la comunidad de Santa Victoria Oeste, B: valores bajos; M: valores medios; A: valores altos siguiendo a Newsom (1993).

\begin{tabular}{|cccc|}
\hline CV & LARGO & ANCHO & ALTURA \\
\hline SVMT1 & M & M & A \\
LQM1 & B & M & M \\
LQM2 & B & B & A \\
LQM3 & M & M & M \\
LQM4 & B & B & B \\
LQM5 & B & B & M \\
LQM6 & A & A & A \\
LQM7 & M & M & A \\
\hline
\end{tabular}

Tabla 80: índices correspondientes a los descriptores en morfología macroscópica cuantitativa de las muestras obtenidas en la comunidad de Santa Victoria Oeste y El Shincal.

\begin{tabular}{|c|c|c|c|c|c|c|c|c|c|c|}
\hline & SVMT1 & LQM1 & LQM2 & LQM3 & LQM4 & LQM5 & LQM6 & LQM7 & DSR1 & DSR2 \\
\hline Largo/ancho & 2,18 & 1,87 & 1,95 & 1,79 & 1,91 & 2,01 & 1,6 & 1,66 & 19 & 40 \\
\hline Largo/altura & 6,46 & 4,48 & 5,24 & 6,32 & 5,09 & 4,40 & 5,78 & 5,62 & 17,46 & 18,13 \\
\hline Ancho/altura & 2,96 & 2,4 & 2,69 & 3,52 & 2,66 & 2,19 & 3,61 & 3,38 & 1,06 & 0,71 \\
\hline
\end{tabular}


Tabla 81: Resultados de los descriptores en morfología cuantitativa microscópica para las muestras de Santa Victoria Oeste y El Shincal

$\begin{array}{llll}\text { Largo células epidérmicas } & \begin{array}{c}\text { Ancho células } \\ \text { epidérmicas }\end{array} & \text { Altura capa hipodermis } & \text { Alto esclereidas }\end{array}$ Ancho Esclereidas

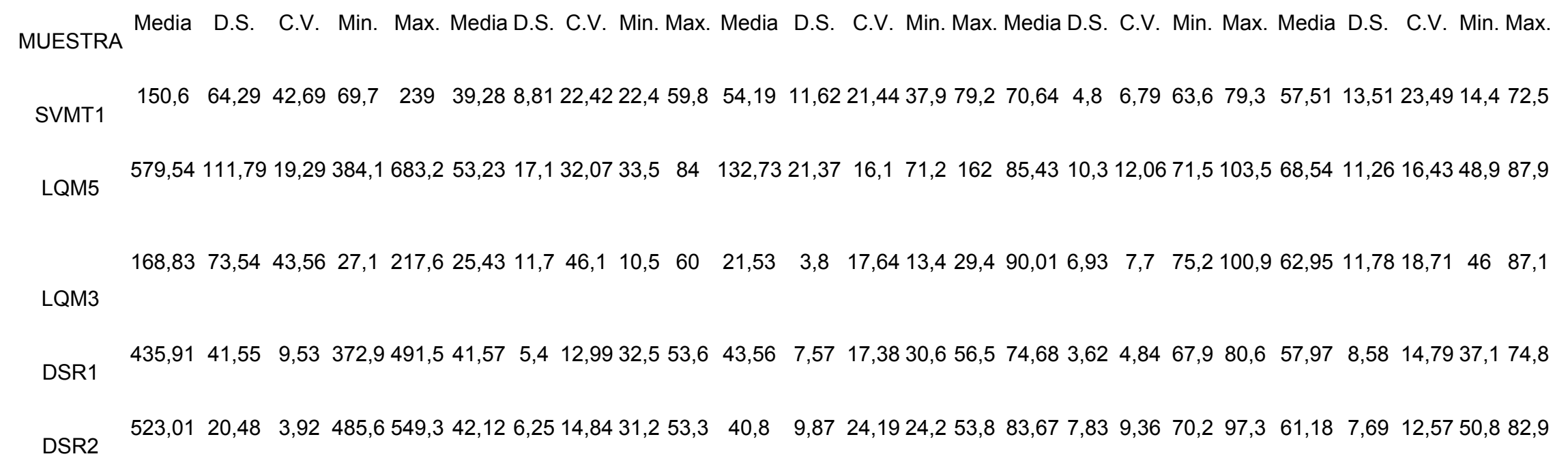


Figura 45: cortes delgados de cubiertas seminales de ejemplares colectados en el trabajo de campo etnobotánico. A-B: muestra LQM5: A, margen; B, cara mayor. C-D: muestra DSR1: C, cara mayor; D, margen. Abreviaturas: Epi, epidermis; Hipo, hipodermis; Scl, esclereidas; Aer, aerénquima.

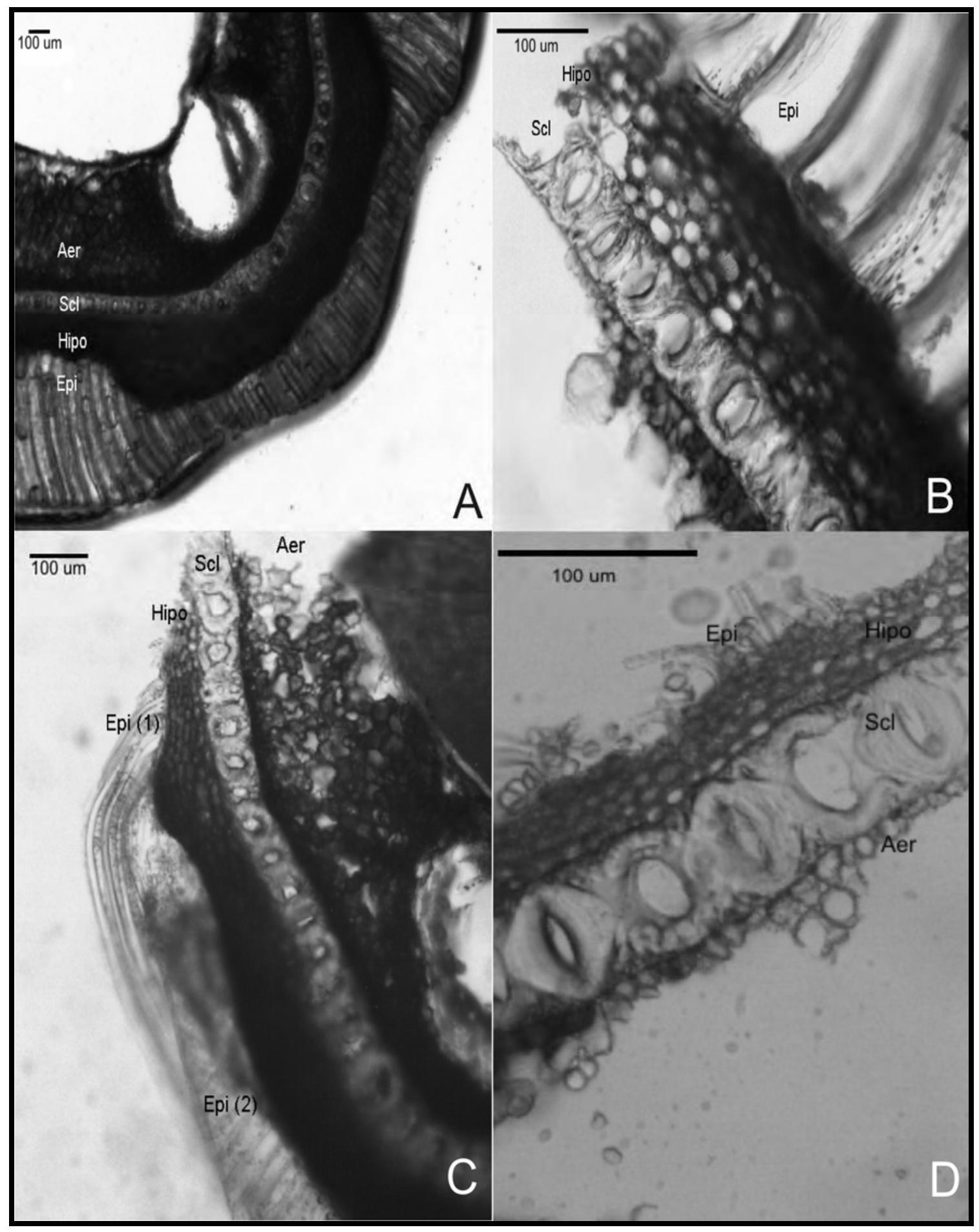


Gráfico 29: análisis de conglomerados del largo de las semillas correspondientes a las muestras de cultivos locales procedentes de la comunidad de SVO

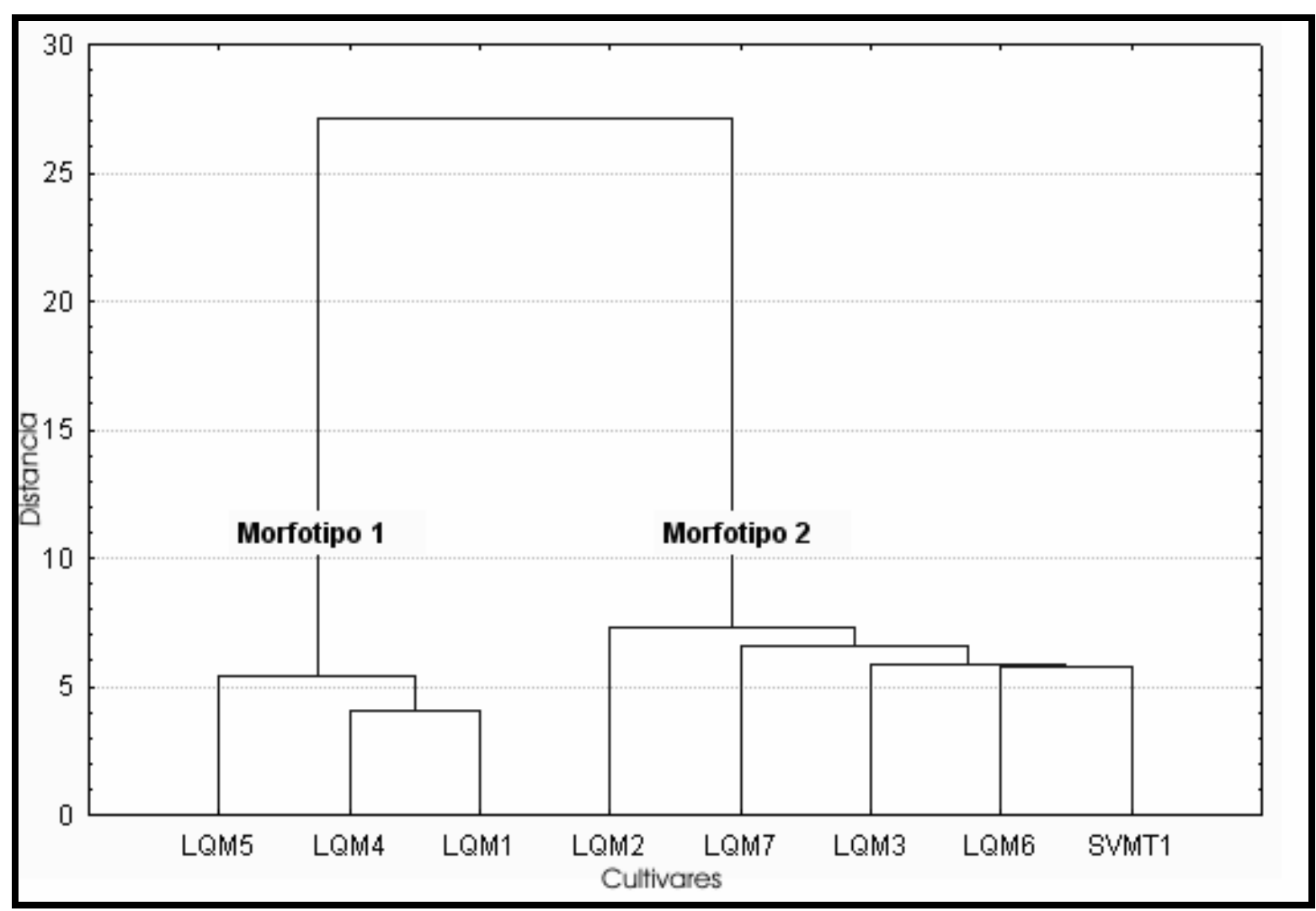


Gráfico 30: análisis de conglomerados del ancho de las semillas correspondientes a las muestras de cultivos locales procedentes de la comunidad de SVO.

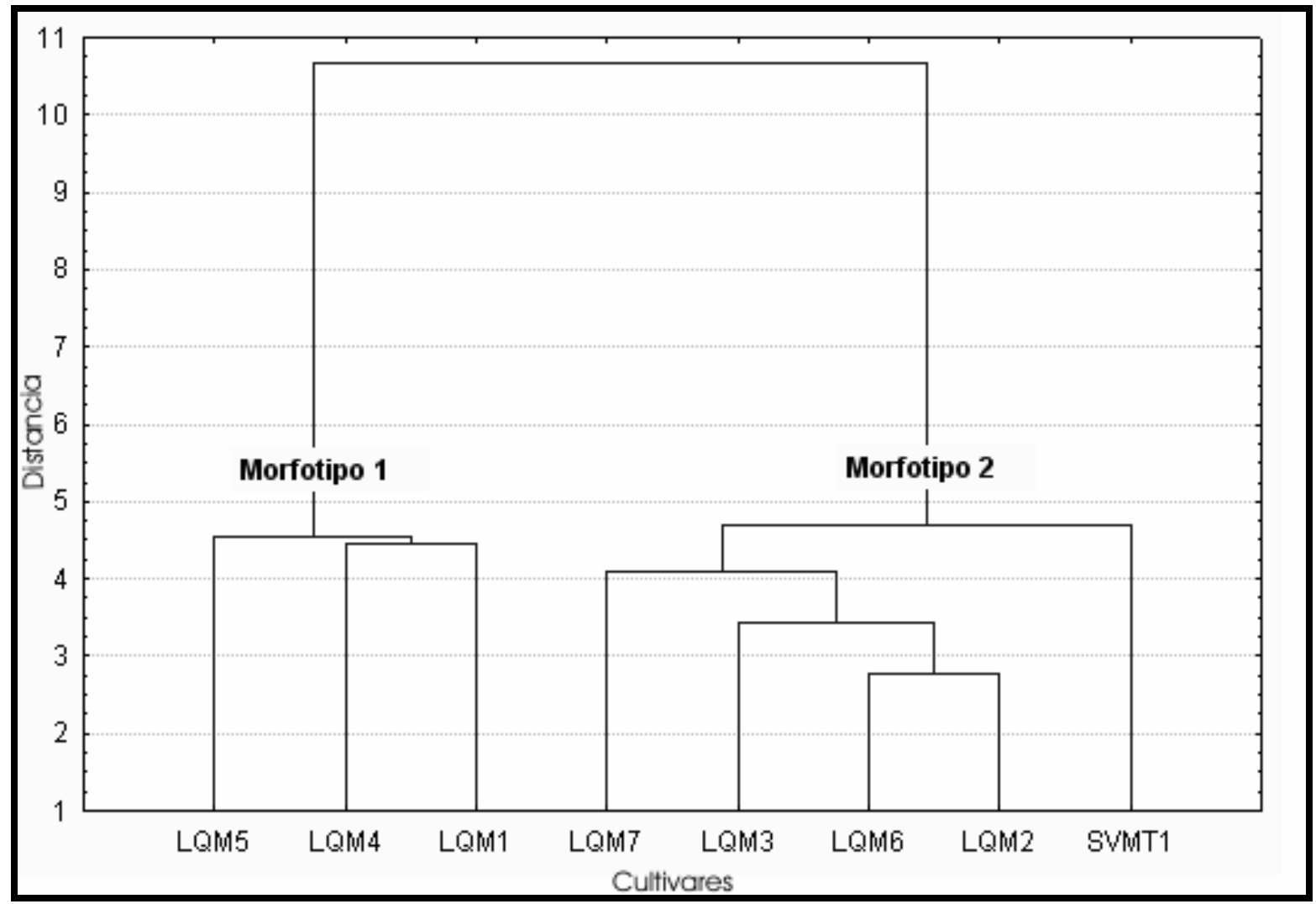


Gráfico 31: análisis de conglomerados de la altura de las semillas correspondientes a las muestras de cultivos locales procedentes de la comunidad de SVO (Salta).

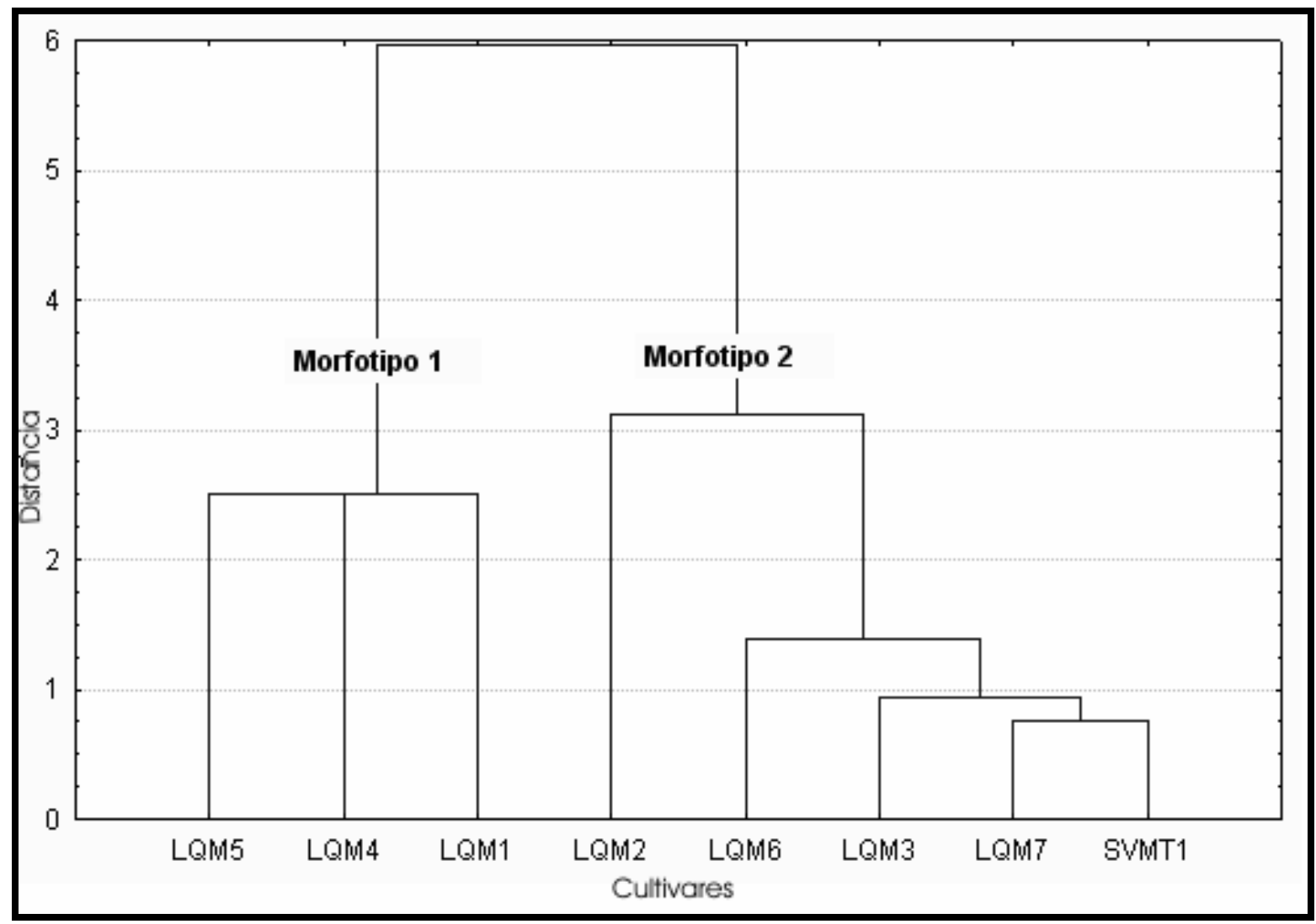


Gráfico 32: gráfico que representa la distribución de los valores de CV para las tres medidas lineales de las muestras obtenidas en la comunidad de Santa Victoria Oeste.

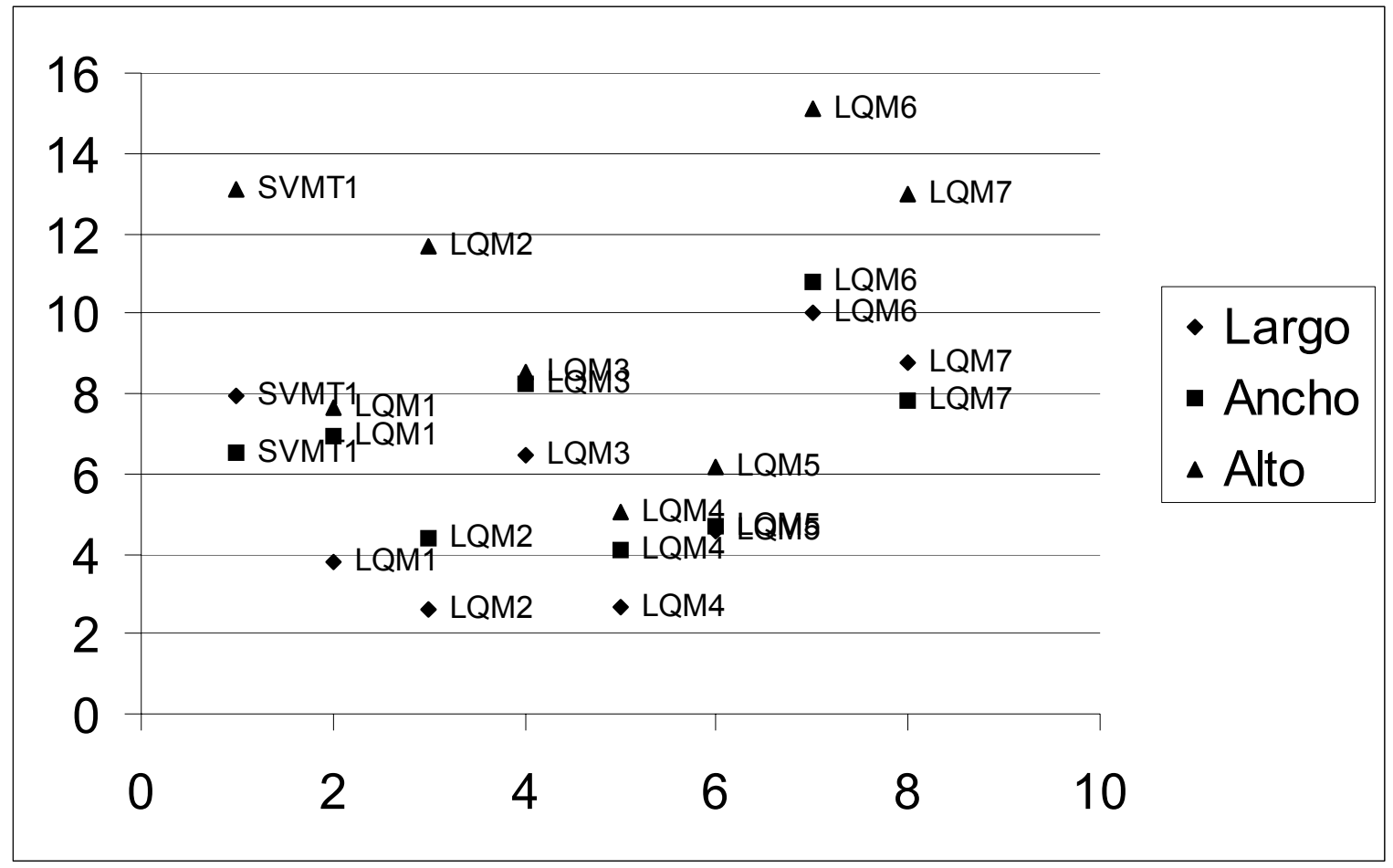


Gráfico 33: análisis de conglomerados del índice largo/ancho de las semillas correspondientes a las muestras de cultivos locales procedentes de la comunidad de SVO.

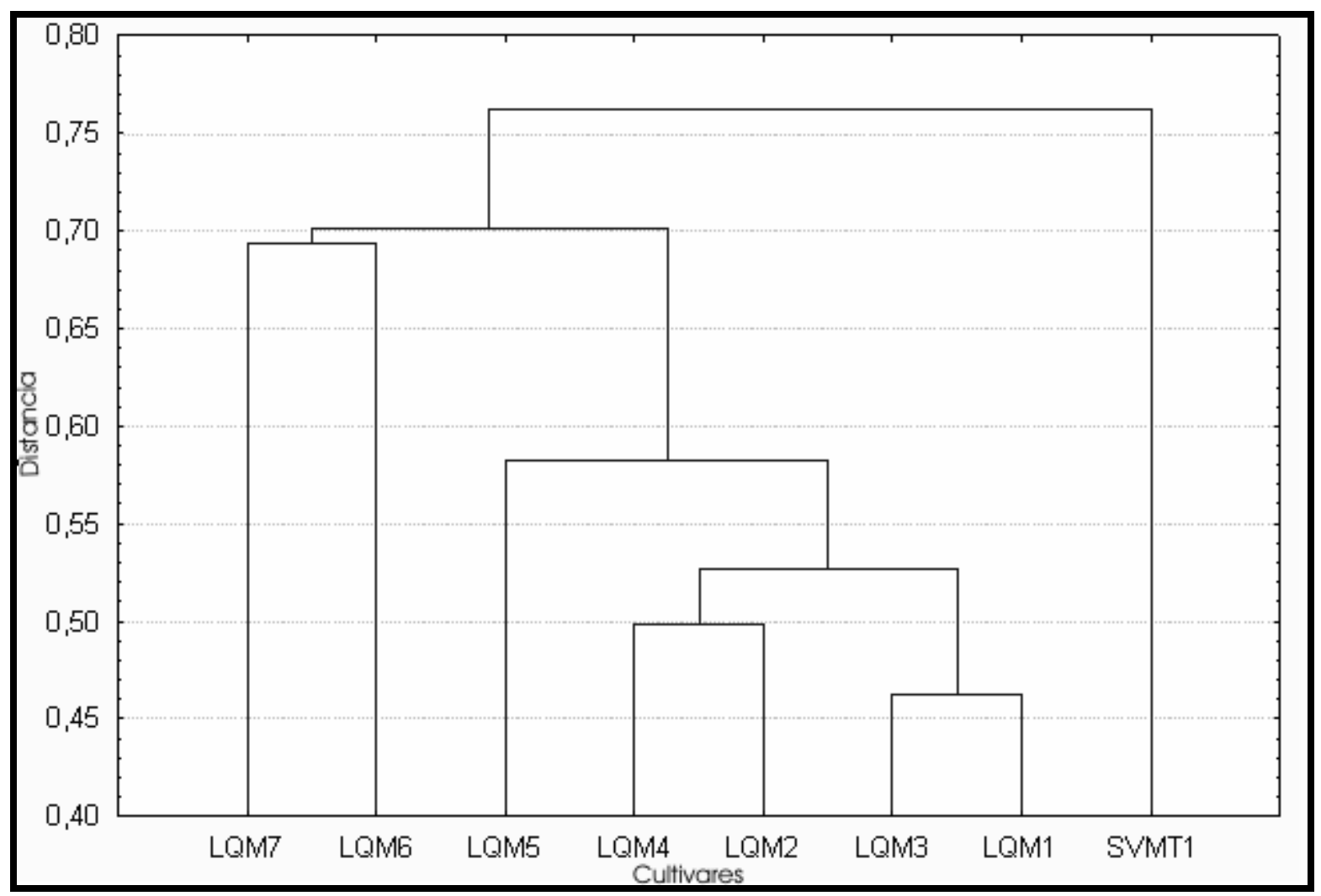


Gráfico 34: análisis de conglomerados del índice largo/altura de las semillas correspondientes a las muestras de cultivos locales procedentes de la comunidad de SVO.

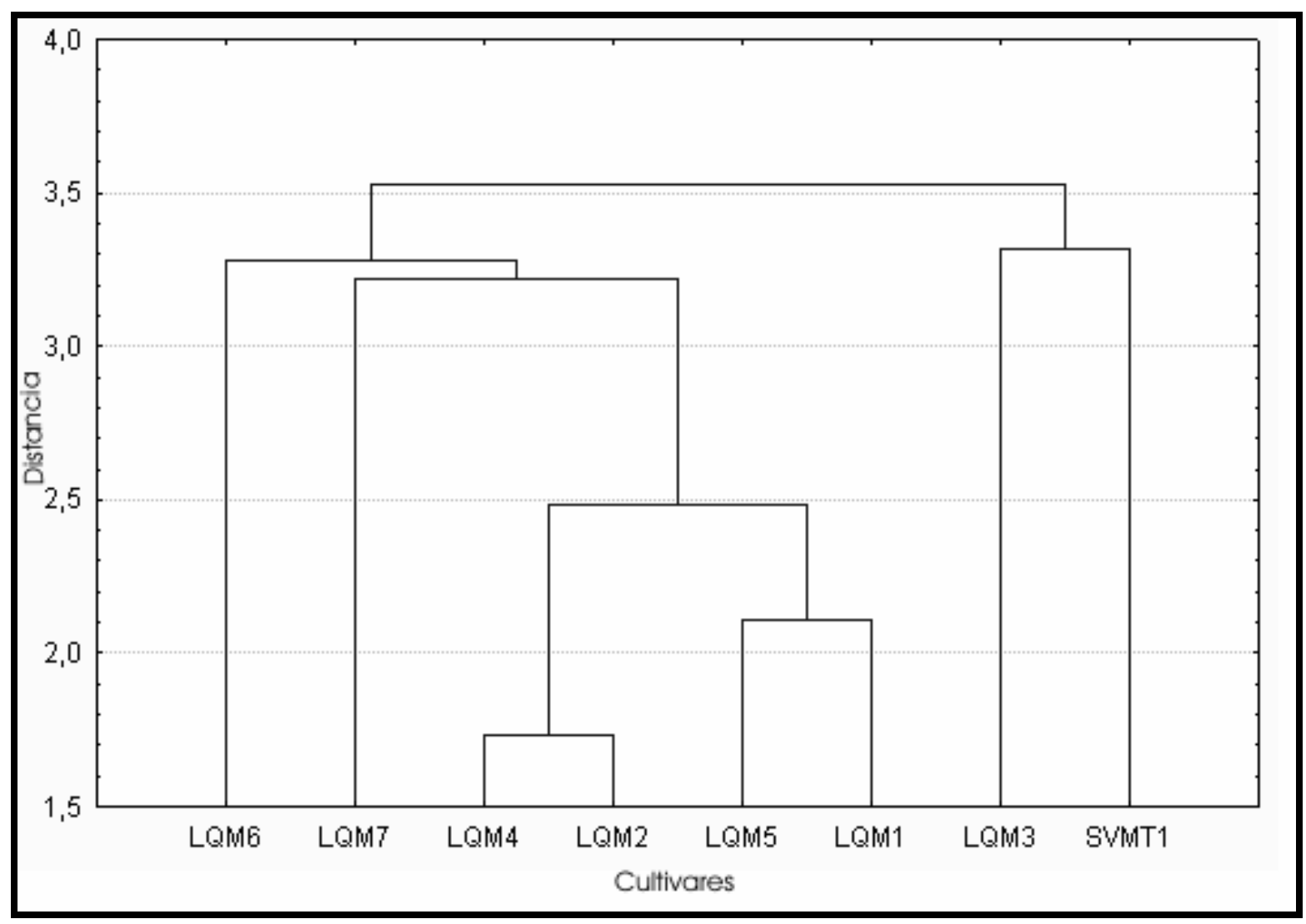


Gráfico 35: análisis de conglomerados del índice ancho/altura de las semillas correspondientes a las muestras de cultivos locales procedentes de la comunidad de SVO.

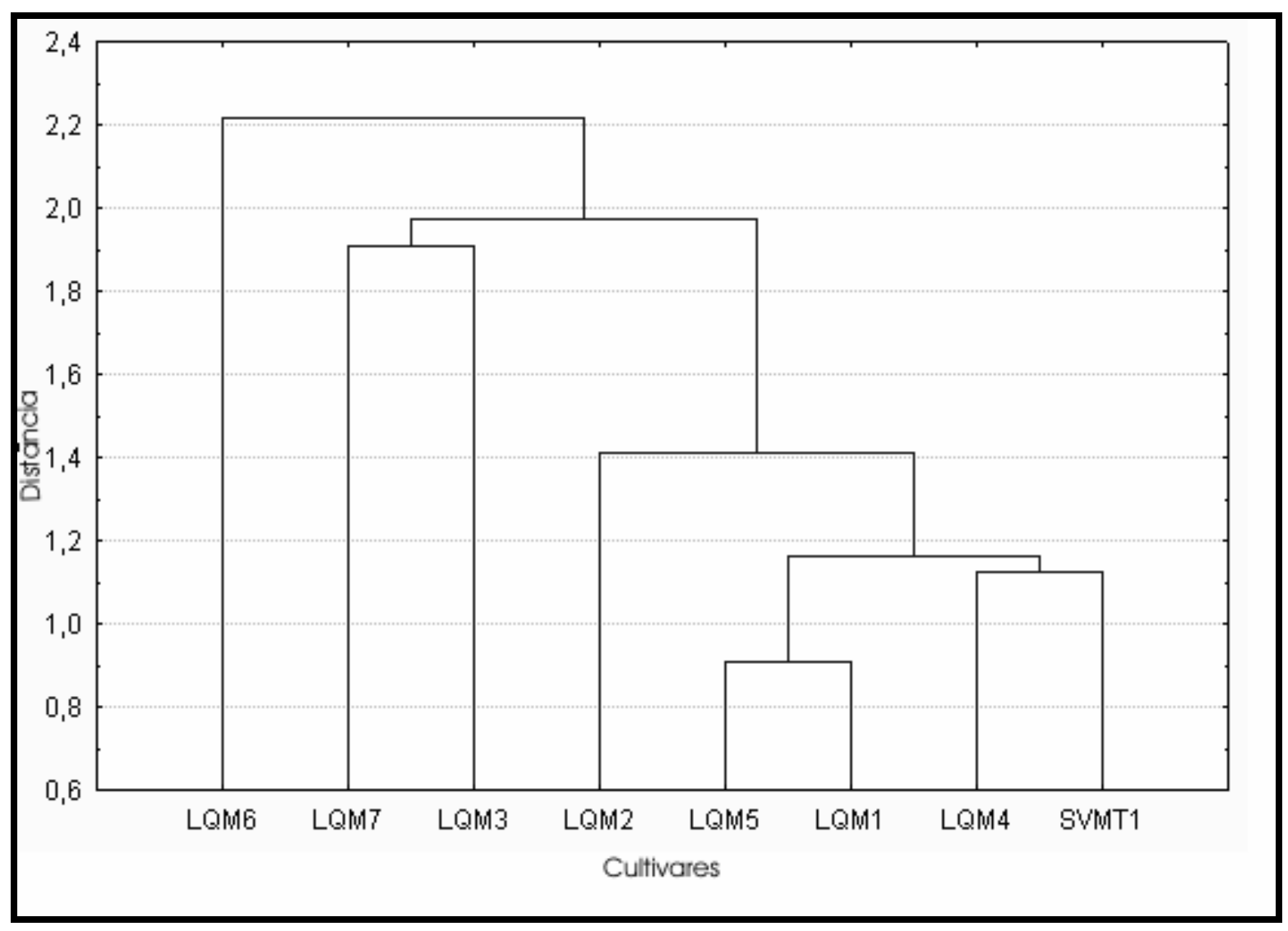




\section{CONCLUSIONES}

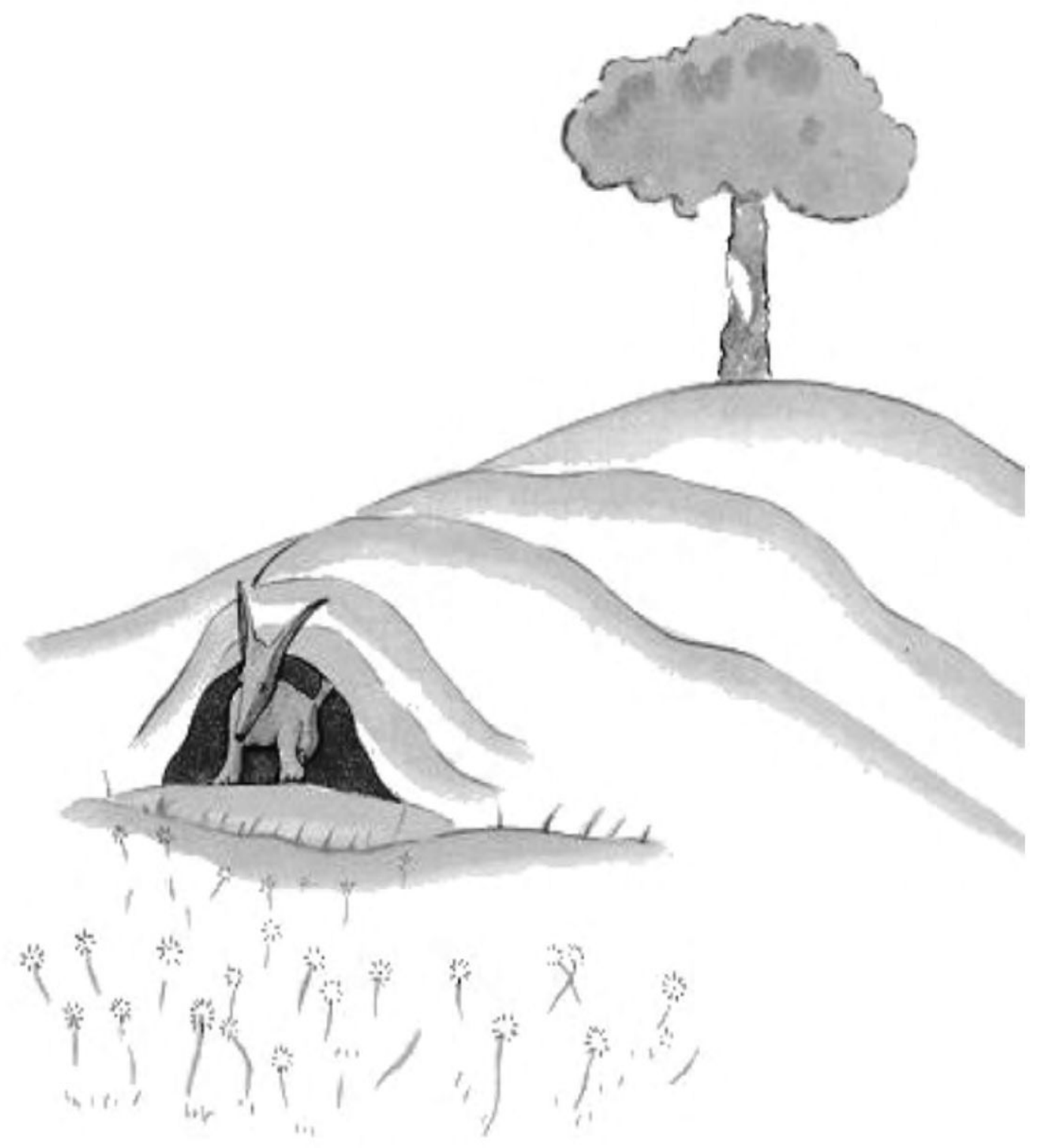




\section{CONCLUSIONES}

\section{RESULTADOS LOGRADOS MEDIANTE EL ABORDAJE PALEOETNOBOTANICO}

El análisis de los procesos de domesticación vegetal desde un abordaje paleoetnobotánico ha permitido dilucidar la presencia de formas de manejo de poblaciones vegetales mucho más diversos que lo que se entendía hasta el presente para el desarrollo cultural prehispánico del NOA.

Los taxa vegetales seleccionados para ser analizados en esta tesis no poseen barreras reproductivas entre sus formas domésticas y silvestres o espontáneas lo que permite la existencia de sucesivas cruzas entre la forma domesticada, cultivada no domesticada, maleza y forma silvestre que se refleja en elevadas similitudes morfológicas entre los ejemplares producto de dichas cruzas. Pero a pesar de ello, tanto en el caso de Cucurbita maxima como de Phaseolus vulgaris se han hallado caracteres morfológicos, anatómicos y biométricos útiles en la distinción de estas diversas formas de relación ser humano-planta en macrorrestos arqueológicos. El reconocimiento de dichos caracteres pudo hacerse gracias a una serie de factores.

En primera instancia el estudio pormenorizado de material actual de una colección de referencia conformado por gran número de ejemplares resultó crucial para hallar caracteres de diagnóstico útiles en la identificación taxonómica de los restos bajo estudio. Esto es particularmente importante cuando se analizan plantas domesticadas, las cuales suelen exhibir una diversidad muy alta en sus órganos útiles (frutos y semillas principalmente) como resultado, precisamente, de los procesos de selección bajo domesticación. Una colección de referencia orientada al estudio de restos vegetales arqueológicos debe, además, contar con ejemplares que resulten de la replicación experimental de los procesos reconocidos en los contextos 
arqueológicos siendo la carbonización, en particular, un proceso que altera notablemente los caracteres diagnósticos reconocidos en material actual fresco. Las carbonizaciones experimentales son la única vía no sólo para identificar restos vegetales carbonizados, sino también para poder comparar los mismos con restos secos recuperados en los mismos u otros contextos arqueológicos. En esta tesis pudo verse la utilidad que reportan dichas experimentaciones en el caso de semillas de Cucurbita maxima y los perjuicios que acarrea su ausencia en el caso de semillas de Phaseolus vulgaris.

En segundo lugar avanzar en el estudio de la anatomía interna de los macrorrestos vegetales resultó clave en dos sentidos: para precisar las identificaciones taxonómicas y para hallar caracteres sujetos a modificación bajo selección cultural. Los análisis microscópicos permiten una apreciación de la diversidad que subyace a una aparente homogeneidad sugerida por el examen exclusivamente macroscópico. Además, esta clase de análisis ha sido útil tanto para confirmar como para desestimar identificaciones previas realizadas en base sólo al aspecto externo de los macrorrestos. La combinación de los estudios macro y microscópicos resulta particularmente fructífera cuando se cuenta con escasos ejemplares arqueológicos como en el caso del NOA.

Finalmente la aplicación combinada de análisis macroscópicos y microscópicos, morfológicos y anatómicos y cualitativos y cuantitativos resultó de vital importancia en la dilucidación de grados de dependencia o asociación entre grupos humanos y poblaciones vegetales al permitir constatar la combinación de rasgos de las distintas formas actuales (malezas, cultivos, silvestres y domesticadas) en un mismo ejemplar arqueobotánico, o bien al permitir detectar rasgos novedosos, ausentes en las poblaciones actuales de referencia. La identificación a nivel específico o subespecífico permitió también ver diferencias espaciales significativas en la distribución prehispánica de los diversos taxa. De esta manera se evidenciaron diferentes tradiciones en 
el uso de ciertas especies y subespecies de los géneros Cucurbita y Phaseolus, pudiendo identificarse una mayor diversidad en las formas de relación de las sociedades prehispánicas con ambos géneros.

En tercer lugar el análisis integral del registro arqueobotánico fue una vía importante para lograr un panorama acabado de la diversidad que puede haber en un mismo sitio arqueológico. Estudiar los distintos órganos (o partes de órganos) correspondientes a un mismo taxón, aportó en gran medida al entendimiento de las prácticas de manejo de las poblaciones vegetales en el pasado que, de lo contrario, habrían permanecido ocultas. Como ejemplo puede mencionarse que entre los resultados obtenidos tras los análisis de macrorrestos realizados en esta tesis el carácter intermedio o transicional de restos de P. vulgaris de Pampa Grande se detectó en sus frutos, pero no en las semillas recuperadas junto a los mismos.

Otras estrategias metodológicas resultaron también claves para dar solución a las problemáticas planteadas en el caso particular de la domesticación de $C$. maxima: El recurso a registros históricos fue lo que permitió hallar una posible explicación a la disyunción que existe entre el área de distribución actual de C.maxima ssp andreana (centro-este de Argentina) y el área de domesticación de C. maxima ssp maxima (Andes centro-meridionales). Asimismo el análisis de representaciones de vegetales en piezas cerámicas y líticas aportó datos esenciales en cuanto a la cronología, dispersión y contextos de uso de esta especie en el NOA.

Un conocimiento pormenorizado de aspectos ecológicos y fisiológios permitió entender las condiciones bajo las cuales se habrían dado las interacciones con las comunidades humanas. $\mathrm{Si}$ bien los restos arqueobotánicos arrojan gran cantidad de información, carecen de la posibilidad de brindar datos sobre otros aspectos de las poblaciones vegetales del pasado. Así, características vinculadas a la fisiología de la planta -cruciales 
en la interacción con comunidades humanas- como la presencia de principios tóxicos o las respuestas ante el fotoperíodo sólo pueden deducirse a partir de datos actuales derivados de investigaciones ecológicas o fisiológicas.

El empleo de estudios etnobotánicos como herramienta etnoarqueológica permite evaluar si es posible identificar comportamientos sociales pasados a través del estudio de restos arqueobotánicos. El traspaso de lo comportamental a lo material es siempre dificultoso y requiere de una constante revisión de los medios que empleamos para hacer esta transformación, puesto que con frecuencia los indicadores que estamos seleccionando para hacerlo no son los más adecuados. El estudio etnobotánico realizado en esta tesis permitió constatar que ciertos atributos empleados en arqueobotánica para hablar de comportamientos pasados con relación al género Cucurbita (vg. caracteres macroscópicos de las semillas) pueden ser engañosos y llevarnos a conclusiones erradas, en tanto otros (vg. caracteres microscópicos de la cubierta seminal) son un reflejo más ajustado de los criterios empleados localmente en el manejo de poblaciones vegetales. Por otra parte, ciertos criterios de selección (principalmente aquellos basados en percepciones referentes al gusto) empleados por los cultivadores modernos poseen escasas posibilidades de ser arqueológicamente detectados.

Los estudios etnobotánicos de aplicación etnoarqueológica son formas de investigar arqueológicamente el cultivo en tanto comportamiento humano en el pasado, desarrollando alternativas de interpretación que nos ayuden a imponer cada vez menos nuestra propia visión del mundo a las comunidades que nos antecedieron.

RELACIONES ENTRE COMUNIDADES HUMANAS Y POBLACIONES DE Cucurbita sp. 
La historia de C. maxima ssp. maxima es particularmente compleja por dos razones: porque ha sido escasamente estudiada y porque su relación con su antecesor silvestre putativo C. maxima ssp andreana es poco clara. El carácter malezoide de esta última le permite adaptarse a las condiciones generadas por la perturbación humana del medio, lo cual, por un lado, la convierte en un buen candidato para haberse asociado tempranamente con el Hombre, pero por el otro, dificulta hoy día su reconocimiento como planta silvestre que prospera en ambientes no antrópicos. Posiblemente como antecesora primero y luego como maleza, C. maxima ssp andreana perduró junto a C. maxima ssp maxima en los campos cultivados por las comunidades humanas durante mucho tiempo. Esta asociación entre planta cultivada (domesticada) y maleza junto a los híbridos resultantes de sus frecuentes cruzas, se habría generado tempranamente en el área centro-meridional andina, dispersándose luego hacia el este por la cuenca del Pilcomayo-Bermejo y hacia el sur por la del Paraná-río de La Plata encontrando en esta última zona un área propicia para la dispersión de poblaciones de C. maxima ssp andreana.

Tras las investigaciones realizadas en esta tesis se identificaron por primera vez de forma fehaciente restos de C. maxima ssp andreana en fragmentos de pericarpios hallados en Pampa Grande fechados por AMS entre el 259 y 433 DC, junto a restos de C. maxima ssp. maxima, C. ficifolia, habiendo incluso distintos cultivares de C. maxima ssp maxima. Asimismo tanto en esta localidad como en otras del formativo temprano del NOA (Puente del Diablo, Puente Río La Viña I), del COA (Los Morrillos, Cueva del Toro) y arcaicos del los Andes Centrales como Cerro Lampay se identificaron restos que combinaban rasgos de las dos subespecies de C. maxima, o bien presentaban caracteres totalmente novedosos. No hay hasta el momento registro de secuencias arqueológicas que indiquen un primer momento de explotación exclusiva de poblaciones C. maxima ssp andreana. Esta ausencia (que puede deberse a dificultades en la preservación de sus restos, muy susceptibles a la 
carbonización) impide caracterizar de forma definitiva el tipo de interacción entre esta subespecie y poblaciones humanas a través del registro arqueológico. Por ende sólo resta tomar los caracteres actuales de ambas subespecies para reconstruir las formas de asociación pasadas. Así, se entiende que las poblaciones silvestres tendrían frutos posiblemente tóxicos, pequeños y livianos a la madurez a fin de dispersarse a través de pendientes pronunciadas o cursos de agua, en tanto las formas domesticadas poseerían frutos no tóxicos, grandes y pesados que habrían perdido sus mecanismos naturales de dispersión volviéndose incapaces de generar poblaciones viables a nivel evolutivo sin la asistencia humana. Todo carácter intermedio entre estos dos extremos sería indicio de plantas cultivadas no domesticadas o bien de malezas. Distinguir entre estas dos últimas se torna un aspecto delicado en paleoetnobotánica puesto que involucra la actitud humana hacia las mismas: siembra, cuidado, protección y fomento en el caso de las plantas cultivadas vs. tolerancia o erradicación en el caso de las malezas. Los resultados obtenidos tras las investigaciones de restos arqueobotánicos indican la presencia de complejos maleza-cultivo-domesticadas en sitios formativos tempranos del NOA, COA y en sitios arcaicos de los Andes Centrales. Parecería ser que en todos los casos analizados las estrategias seguidas por las poblaciones humanas fue la de favorecer la diversidad. El control sobre las poblaciones de Cucurbita fue moderado, estableciéndose posiblemente un aislamiento reproductivo parcial que permitiera la generación de formas deseadas de zapallos domesticados, a la vez que formas híbridas. En el caso de éstas últimas algunas habrían sido alentadas al poseer caracteres deseados convirtiéndose en cultivos, otras habrían sido erradicadas al poseer rasgos considerados nocivos, en tanto aquellas que carecieran de uno u otro tipo de carácter habrían sido toleradas. Lamentablemente no se sabe cómo sigue este proceso luego del formativo, los restos de períodos más tardíos como la semilla del sitio El Shincal indicaría formas plenamente domesticadas, sin 
embargo la ausencia de un mayor número de restos de Cucurbita en sitios posteriores al formativo en el NOA impide, por el momento, avanzar en el conocimiento del desarrollo del proceso de domesticación de este taxón.

La costa peruana, el litoral pacífico chileno y el área del Centro Oeste en Argentina habrían compartido una tradición temprana en el empleo y manipulación de frutos de C. moschata. La presencia de C. moschata en Los Viscos, su ausencia en sitios como Pampa Grande (salvo un ejemplar dudoso afín a esta especie) Puente del Diablo y Puente sobre Río La Viña I, junto a un pedúnculo de C. ficifolia en Pampa Grande -especie registrada sólo en Los Amarillos, sitio tardío de la Quebrada de Humahuaca- podría indicar la presencia de dos tradiciones diferentes en el uso y selección de especies del género Cucurbita en el Área Andina Central y Meridional. Esta es una posibilidad que sólo podrá ser confirmada o descartada con nuevos hallazgos arqueobotánicos.

La diversidad presente en los complejos maleza-cultivo-domesticada se encuentra asociada con los distintos usos dados a las cucúrbitas. El registro de Pampa Grande indicaría la existencia de diversos cultivares de C. maxima ssp. maxima con caracteres diferenciales de sus frutos, habiendo algunos de pericarpio grueso y lignificado, en tanto otros de pericarpio delgado. Estos últimos junto a la presencia de semillas de este taxón en contextos domésticos señalarían su consumo como alimento, a diferencia de L. siceraria cuyas semillas no se han identificado en la numerosa colección de restos vegetales de esta localidad arqueológica. El empleo de frutos de Cucurbita como recipiente al igual que los de L. siceraria constatado en Pampa Grande coincide con lo registrado en varios sitios arcaicos de Chile. En ambos casos, al igual que en sitios del Norte Grande chileno o del COA como los de Gruta del indio (Mendoza, Argentina) y Los Morrillos (San Juan, Argentina) los restos de Cucurbita se hallaron en contextos funerarios. Esta doble presencia en contextos domésticos y mortuorios se registra también en ceramios 
fitomorfos que representan frutos de Cucurbita sp. Estas piezas proceden muy probablemente de contextos funerarios, pero restos de hollín aún adheridos en sus paredes señalan que fueron empleadas también en actividades cotidianas de cocción de alimentos.

Si bien faltan análisis exhaustivos, parecería que en sitios más tardíos solo los frutos de L. siceraria retienen su función como recipientes. Es probable, por lo tanto, que en tiempos posteriores las cucúrbitas hayan sido empleadas sólo para su consumo como alimento. La recuperación de un mayor número de macrorrestos de este género en contextos arqueológicos tardíos del NOA permitirá avanzar en este sentido.

\section{RELACIONES ENTRE COMUNIDADES HUMANAS Y POBLACIONES DE Phaseolus vulgaris.}

Una de las dificultades señaladas puntualmente en el caso del análisis de la domesticación de $P$. vulgaris a través de restos arqueológicos es la ausencia de ejemplares transicionales. En los sitios más tempranos de los Andes y Mesoamérica semillas y vainas de P. vulgaris poseen una morfología en todo similar a la de la variedad domesticada. En el NOA existen, sin embargo, sitios formativos tempranos con restos de semillas o cotiledones carbonizados identificados como $P$. vulgaris var aborigineus. Estos restos proceden en todo los casos de sitios ubicados en las estribaciones orientales de las sierras subandinas donde actualmente existen poblaciones de la subespecie silvestre y han sido recuperados siempre junto a la variedad doméstica, interpretándose en consecuencia la coexistencia de estrategias de recolección y agrícolas en una misma entidad cultural. Los análisis efectuados permitieron constatar que la semilla procedente de la capa precerámica de Huachichocana III y las recuperadas en Pampa Grande se corresponden totalmente en su morfología externa con las de la variedad domesticada. Caracteres morfológicos 
intermedios entre ambas variedades de $P$. vulgaris fueron identificados sólo en la única semilla recuperada en Puente del Diablo, de edad posiblemente precerámica. En el caso de Pampa Grande se pudieron profundizar los análisis gracias a la presencia de restos arqueológicos de frutos. La pérdida de la dehiscencia en las vainas de las leguminosas es un rasgo clave en el estudio de su domesticación ya que es un indicador claro de la incapacidad de la planta para dispersar sus semillas dependiendo de la acción humana para subsistir durante varias generaciones. Las vainas de Pampa Grande presentan una combinación de rasgos de la subespecie silvestre y domesticada, sobre todo en su zona de dehiscencia. Estos restos con caracteres intermedios indicarían la existencia de complejos maleza-cultivos-domesticados también para esta especie en Pampa Grande. Sin embargo en esta localidad no se recuperaron restos de la variedad silvestre, a diferencia de otros sitios formativos del NOA. Esto podría sugerir distintas estrategias de manejo, aunque se debe ser cauto al comparar conjuntos arqueobotánicos disímiles ya que el tipo de resto condiciona las inferencias que se pueden realizar y el nivel de análisis a alcanzar.

\section{COMPLEJOS MALEZA-CULTIVO-DOMESTICADO:}

IDENTIFICACION DE PRACTICAS DE MANEJO MAS ALLA DE LA RECOLECCION Y LA AGRICULTURA.

Los estudios etnobotánicos evidencian que el manejo que las poblaciones humanas hacen de su entorno vegetal puede ser sumamente variable generando distintos grados de dependencia y asociación entre grupos humanos y poblaciones vegetales. El abordaje paleoetnobotánico propuesto en esta tesis resultó apropiado para identificar formas de relación distintas a la recolección y la agricultura entre las poblaciones prehispánicas del NOA a través de la superación de la dicotomía silvestre-domesticado en la 
identificación de restos arqueobotánicos. El resultado no fue la presencia de una u otra forma (silvestre, maleza, cultivo transicional, planta domesticada) en momentos cronológicos distintos, sino su coexistencia como resultado de estrategias de relación con el entorno vegetal tendientes a la generación y mantenimiento de la diversidad. La ausencia de una separación clara y taxativa entre plantas con diverso grado de asociación con el Hombre junto a la ausencia de secuencias arqueológicas que indiquen transición entre un modo de vida cazador recolector a uno de agricultura incipiente generan un escenario donde no hay un continuum de transformaciones en un proceso lineal de evolución y cambio. El escenario que se ha reconstruido es por el contrario diverso, lo cual no se contrapone con lo que actualmente se registra a nivel etnobotánico en comunidades locales. La horticultura es particularmente una forma de producción vegetal donde no hay una actitud seleccionadora homogeneizadora, siendo un espacio donde conviven múltiples formas de relación ser humano-planta. Los estudios llevados a cabo con comunidades campesinas actuales de los valles, la puna y las yungas de Argentina han demostrado que el NOA no es una excepción a esta regla y que los horticultores de estos diversos ambientes -con una historia cultural también disímil- favorecen el mantenimiento de la diversidad en sus espacios cultivados siendo tolerantes ante la emergencia en los mismos de ejemplares de formas diversas, o teniendo una actitud seleccionadora que responde a criterios múltiples (gastronómicos, morfológicos, de gusto o fisiológicos) que se reflejan en la presencia de distintos cultivares en sus huertos.

La horticultura es una posibilidad que prácticamente no se ha considerado en la arqueología del NOA. A pesar de que la misma puede tener escasa visibilidad arqueológica es probable que los canchones y pequeñas terrazas identificados en sitios del formativo temprano sean análogos a los huertos identificados actualmente en Rachaite o Santa Victoria. Una arquitectura simple o realizada en material perecedero junto a una escasa tecnificación son 
caracteres propios de la horticultura que pueden dificultar su reconocimiento a nivel arqueológico.

La identificación de complejos maleza-cultivos-domesticados en macrorrestos arqueobotánicos está probablemente reflejando prácticas hortícolas en el pasado del NOA. Esta clase de prácticas de manejo implica una escala doméstica de toma de decisiones, al ser la unidad doméstica la unidad productiva. Es este carácter familiar de producción el que se ha propuesto para el formativo temprano del NOA, fundamentalmente a partir de la escala de desarrollo arquitectónico, de la infraestructura de regadío y de la destinada a la producción. Esta modalidad cambia durante el formativo-medio a tardío con la integración regional Aguada pasando la producción de una escala familiar a una comunitaria. Se propuso que este cambio habría generado un aumento en la diversidad de los cultivares o "razas" prehispánicas, particularmente en el caso del maíz. Esta es una posibilidad acorde con la noción que se posee actualmente de Aguada como un fenómeno social de integración sin centralización. Cuando existe un criterio de producción supracomunitario ejercido por una entidad central que es dominante en el aspecto económico, las unidades menores que dependen de la misma para su subsistencia tienden a abandonar sus propios criterios de manejo a fin de adecuarse a las nuevas condiciones imperantes. Esto es lo que se ha registrado actualmente en comunidades campesinas como la de El Shincal donde las unidades domésticas productivas adoptan los criterios de mercado al seleccionar sus cultivos. Si bien conservan sus prácticas de manejo en los huertos destinados al autoconsumo, las fuerzas involucradas en los cultivos destinados al mercado terminan siendo dominantes y causan que la horticultura sea cada vez una práctica menos frecuente, perdiéndose las variedades vegetales localmente desarrolladas tanto por pérdida de sus semillas como de las prácticas y criterios que le dieron origen y sustento a través del tiempo. La integración sin centralización Aguada pudo redundar en un 
aumento de la diversidad de cultivos por un mayor contacto entre entidades que, hasta el momento, habían tenido un desarrollo preponderantemente local. Asimismo, las prácticas hortícolas del formativo temprano pudieron dar paso -y coexistir- con sistemas agrícolas comunitarios de mayor producción donde fueran preponderantes otras especies plenamente domesticadas como el maíz (Zea mays).

Las ocupaciones Candelaria III de Pampa Grande indican vínculos con la fase La Viña del Valle de Lerma, e influencias Aguada de Ambato. Las evidencias físicas indican stress social y nutricional lo cual, junto a la ausencia de la iconografía clásica distintiva de Aguada, hace pensar que hubo resistencia por parte de las poblaciones de Pampa Grande a la integración regional del formativo medio. Lamentablemente no se han localizado actualmente restos de Cucurbita o de vainas de P. vulgaris en sitios Aguada del Ambato como para poder hacer una comparación con los resultados obtenidos en Pampa Grande. Los rasgos presentes en los macrorrestos del sitio Puente Río la Viña I fueron consistentes con los de Pampa Grande, indicando prácticas de manejo similares entre estas dos localidades, coincidiendo con las semejanzas previamente registradas a través de otros rasgos culturales.

Tanto los restos de Cucurbita de Puente del Diablo (SSalLap20) como los de Phaseolus poseen un carácter transicional o intermedio entre las formas silvestre y domesticada de ambos taxones, lo que hace que las sospechas originales sobre la importancia de este sitio en cuanto a la agricultura incipiente de la región sean en parte confirmadas. Esta confirmación resulta parcial debido a que los resultados obtenidos en esta tesis tras los análisis efectuados en otras localidades arqueológicas indican que cultivos con caracteres intermedios no son necesariamente transicionales entre la forma silvestre y la domesticada. A pesar de ello el registro de Puente del Diablo sigue siendo interesante puesto que las ocupaciones previas de SSalLap20 y de sitios asociadas como El Puente I y Barranca del Puente poseen elementos de 
desarrollo netamente locales y porque, de haberse intentado el cultivo local de $C$ maxima o de $P$. vulgaris, las condiciones de aislamiento espacial respecto a la subespecie y a la variedad no cultivadas, respectivamente, habría favorecido una fijación más rápida de caracteres deseados en ambos taxa. Si bien interesante, el registro de las ocupaciones precerámicas y formativas de Puente del Diablo es escaso y no se cuenta con restos arqueobotánicos de las mismas especies vegetales en sitios formativos relacionados como Campo Colorado.

\section{CONSIDERACIONES FINALES}

Esta tesis brinda un "estado de la situación" de la problemática de la domesticación vegetal en el NOA para el caso especifico del género Cucurbita y para P. vulgaris. Los restos arqueológicos analizados son los mismos que se han empleado hasta el presente para caracterizar la agricultura temprana en el NOA, pero un cambio en el abordaje y realizar nuevas preguntas a los mismos restos permitió construir un nuevo panorama interpretativo al considerarse las diversas prácticas y relaciones entre seres humanos y comunidades vegetales en el pasado. El reconocimiento de restos vegetales con caracteres transicionales o intermedios en complejos maleza- cultivo- domesticado se relacionaría con procesos locales de domesticación, más que a la difusión de tradiciones o a la introducción de material vegetal foráneo. Como conclusión podemos decir que no se ha establecido un "inicio" de la domesticación en el NOA y tampoco un "final", lográndose en cambio una visión enriquecida de las formas de manejo de poblaciones vegetales en el pasado prehispánico de la región donde priman la diversidad de formas de relación y grados de asociación entre grupos humanos y poblaciones vegetales. 


\section{ADENDA}

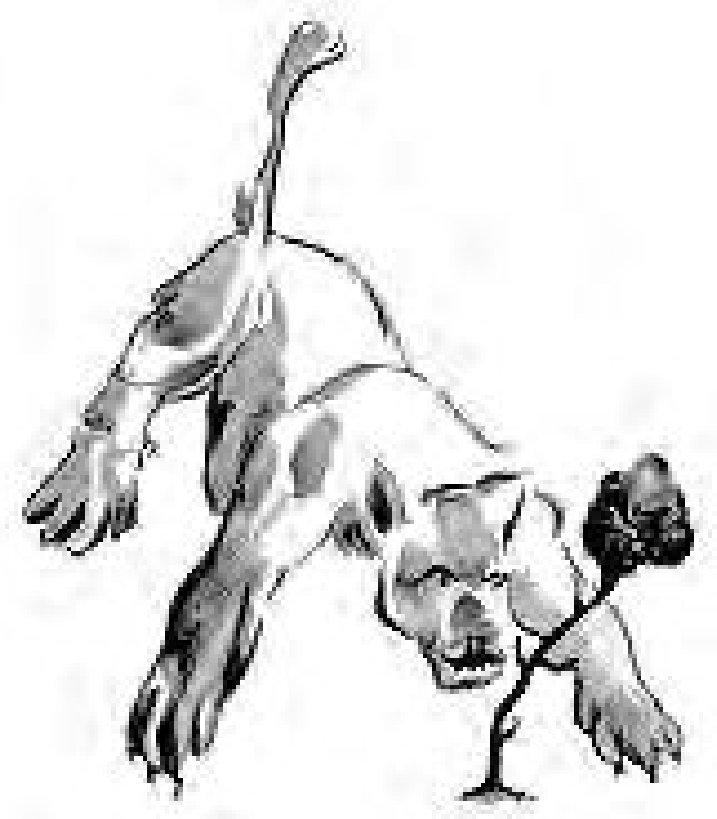




\section{8- ADENDA: CAMBIO Y CONTINUIDAD: DOMESTICACIÓN VEGETAL, BIOTECNOLOGÍA, CAMPESINADO Y LOS APORTES DE ESTA INVESTIGACIÓN A LA PROBLEMÁTICA ACTUAL.}

Las conclusiones a las que se ha arribado en esta tesis son una muestra más de la importancia que poseen los modos de producción locales a baja escala en la generación y mantenimiento de la diversidad biocultural (Maffi 2001). Los complejos maleza-cultivo-domesticado son el resultado de que las comunidades locales -caracterizadas por economías de subsistencia y una relación directa con el entorno natural en el cual habitan- conciban la naturaleza como una entidad compleja, caótica, en un constante estado de cambio, donde ningún componente del ecosistema es más importante que otro, ya que el todo es mayor que la suma de las partes y donde todas las partes (aunque no posean utilidad práctica) cumplen un rol fundamental, incluidas las poblaciones humanas, concebidas como una parte más de ese todo (Merculieff, 2002). Esta concepción y la aplicación de criterios múltiples de selección es lo que permite una división menos rígida entre categorías como silvestre y domesticado, permitiendo una gran gama de formas de asociación ser humano- planta (Nazarea 1998).

La introducción de cultivos transgénicos en los centros de domesticación vegetal ha actuado en detrimento de la diversidad generada no sólo por los procesos locales de manejo de poblaciones vegetales, sino también por la persistencia de formas silvestres, malezas y plantas cultivadas no domesticadas en los mismos (Gepts y Papa 2003). El flujo génico existente entre dichas formas vegetales es la base para la generación de una diversidad creciente, las prácticas de manejo de los horticultores locales ha actuado como salvaguarda en su persistencia a pesar de los embates homogenizadores del monocultivo comercial (Shiva 2006). Sin embargo la biotecnología se ha entendido como una forma de domesticación más avanzada y precisa que la tradicional al 
manipular, ya no plantas, sino genes (Gepts 2002). El impacto de esta nueva y altamente tecnificada forma de manejo de poblaciones vegetales no es aún totalmente comprendida puesto que es un proceso cuyos inicios son recientes -si bien su progreso acelerado- habiendo detractores y partidarios de la misma. Como una forma de "super-domesticación" la producción de cultivos transgénicos por medio de ingeniería genética es promisoria en cubrir la creciente demanda de alimentos a nivel global con el menor impacto ecológico posible (Vaughan et al 2007). Su contracara es la disminución de la diversidad biocultural, no solo por pérdida de genes (Gepts y Papa 2003), sino también de las prácticas locales que generan y reproducen a la misma (Nazarea 1998). Esta altamente tecnificada forma de domesticación no se encuentra, además, al alcance del campesinado y las comunidades locales, por lo cual la toma de decisiones se hace a niveles mayores, tanto en la esfera pública (Estados Nación) como privada (empresas). Esto ha alertado a las comunidades locales en torno a las industrias multinacionales monopolizadoras quienes venden las semillas transgénicas sin que esas comunidades puedan reproducirlas luego por sus propios medios. La deficiencia de la agricultura en suplir la demanda mundial de alimentos no yace en los genes de las plantas: el hambre en ciertos sectores del planeta es un problema ante todo político, fuertemente vinculado con la historia social y económica; en términos de Altieri (2002) la devastación de la naturaleza es un problema ecológico, pero ante todo de ecología política.

La tensión que existe entre los desarrollos en ingeniería genética (biotecnología) y las formas tradicionales de manejo puede verse en el caso de la búsqueda de genes que otorgan resistencia a plagas de los cultivos o que participan en la síntesis de principios químicos de aplicación diversa, entre ellas farmacéutica. Existen dos vías para dar solución a esta búsqueda: la generación de cultivos transgénicos o el mantenimiento de formas de producción locales que favorezcan la persistencia del flujo génico entre formas 
domésticas y formas espontáneas emparentadas (Altieri 2002, Gepts y Papa 2003). Esta tensión entre "agronegocios" y "agroecología" (Altieri 2002) se encuentra en el corazón del debate actual sobre el desarrollo económico mundial y quienes ostentan los derechos sobre la diversidad.

En los últimos años, el conocimiento botánico tradicional ha sido blanco de la búsqueda y apropiación de nuevas fuentes de productos agrícolas, medicinales e industriales en general. Esta práctica -es decir la identificación de materia prima provisoria a partir de la investigación de los conocimientos locales asociados- se denomina etnobioprospección. Ante esta situación surge de inmediato el problema de la protección de los saberes locales y del patentamiento del bien percibido como recurso, sea éste un principio activo, una variedad taxonómica o un órgano vegetal. El patentamiento lleva a su vez a la idea de propiedad individual y sobre todo de origen, pero el conocimiento botánico tradicional no es individual sino colectivo, producto de prácticas propias de la comunidad así como de interacciones con otros grupos vecinos, sus fronteras son difusas y en algunos casos muy extensas (Pochettino et al 2008). La idea de primacía ligada a este tipo de conocimiento carece también de sentido ya que aún cuando fuera posible establecer el origen del uso de determinadas plantas -aspecto donde tiene ingerencia la paleoetnobotánica- ese uso es dinámico y en su expansión se reformula continuamente, por lo tanto no se puede establecer un "inventor", propietario de ese saber, ni concebir dicho saber y su referente como inmutables a lo largo del tiempo. Mediante las investigaciones desarrolladas en esta tesis puede verse que los estudios paleoetnobotánicos en muchos casos no pueden identificar "el origen" de una variedad ni "el pueblo" que la creó, la noción de origen único ligado a un espacio físico delimitado y a una única agrupación humana no es aplicable a los procesos socioculturales en que se enmarca la manipulación de especies vegetales. El dinamismo que las formas de manejo tradicionales imprimen a las comunidades vegetales lleva a que procesos como 
el de la domesticación vegetal no sean unilineales con principio y fin, sino múltiples y dendríticos con la constante generación de formas híbridas que se pierden o mudan hacia nuevas formas vegetales que están más o menos ligadas a las comunidades humanas.

La racionalidad científica debe flexibilizarse ante tal situación y las leyes nacionales han de hacer lo mismo para dar una adecuada protección a los saberes ecológicos locales que conforman parte del patrimonio que identifica a los pueblos que los portan y desarrollan. 
BIBLIOGRAFÍA.

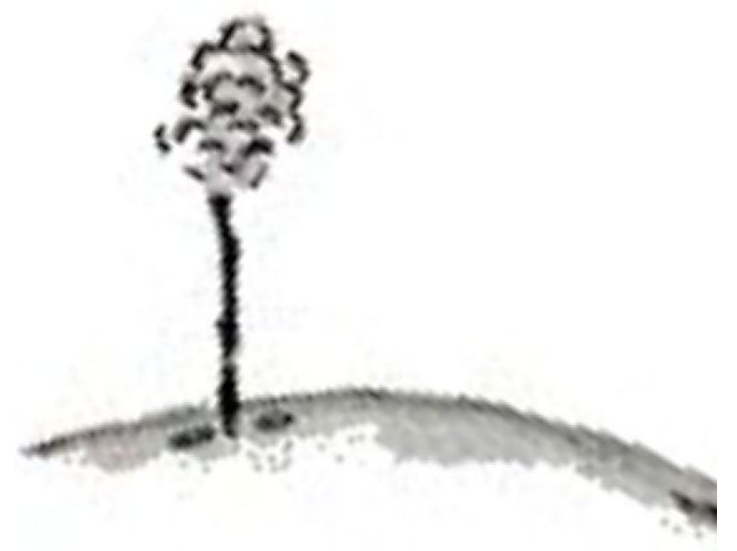




\section{BIBLIOGRAFÍA}

-Abiusso N. y Cámara Hernández J. 1974 Los maíces autóctonos de la Quebrada de Humahuaca (Jujuy), sus niveles nitrogenados y su composición en aminoácidos. Revista de la Facultad de Agronomía (UNLP) (3 época, t.L, entrega 12):1-25

-Agbagwa I. y Ndukwu B. 2005 The value of morpho-anatomical features in the systematics of Cucurbita L. (Cucurbitaceae) species in Nigeria African Journal of Biotechnology 3 (10): 541-546

-Aguerre, A. M., Fernández Distel A. y Aschero C. 1973 Hallazgo de un sitio acerámico en la Quebrada de Inca Cueva. Provincia de Jujuy. Relaciones de la Sociedad Argentina de Antropología n.s. 7: 197-235.

-Aguerre, A. M., Fernández Distel A. y Aschero C. 1975 Comentarios sobre nuevas fechas en la cronología arqueológica precerámica de la provincia de Jujuy. Relaciones de la Sociedad Argentina de Antropologia IX: 211-214

-Aguilar M.; Riva O. Y Peltzer E. 2004 Analysis of Rbizobium elti and of its symbiosis with wild Phaseolus vulgaris supports coevolution in centers of host diversification PNAS 101 (37): 13548-13553

-Albeck, M.A. 2000 La vida agraria en los Andes del Sur En: Nueva Historia Argentina T. 1 Los pueblos originarios y la conquista. Dirección del tomo: M. Tarragó. Ed. Sudamericana. Bs. As.

-Alcorn, J. 1995. Economic Botany, Conservation and Development: what's the connection. Ann. Missouri Bot. Gard. 82 (1):34-46

-Aldunante C., Armesto J., Castro V., Villagrán C. 1981. Estudio etnobotánico en una comunidad precordillerana de Antofagasta: Toconce. Boletín del Museo de Historia Natural de Chile 38: 183-223.

-Altieri M. 2002 Biotecnología agrícola: mitos, riesgos ambientales y alternativas. En: Ecología politica. Cuadernos de debate Internacional No 21 pp: 15-43. Fundación Hogar del Empleado. Ed. Icaria. Barcelona

-Altieri M. y Merrick L. 1987 In situ conservation of crop genetic resources through maintenance of traditional farming systems Economic Botany 41 (1): 86-89 -Andres T 1990 Biosistematics, theories on the origin, and breeding potential of Cucurbita ficifolia En: Bates, Robinson y Jeffrey (Eds.) Biology and utilization of the Cucurbitaceae pp: 102-119. Cornel University Press, Ithaca

-Andres T. y M. Nee 2005 The Goldman Cucurbit Collecting Expedition in southern Boliva and Northwestern Argentina (Informe). www.cucurbit.org

-Araus, JL, Febrero A, Buxo R, Rodríguez-Ariza, MO., Molona F, Camalich MD, Martin D, Voltas J. 1997. Identification of ancient practices base don the carbon 
isotope discrimination of plant seeds: a case of study from the south-east Iberian Peninsula. Journal of Archaeological Sience 24:729-740

-Araus JL, Slafer GA, Buxó R, Romagnosa I. 2003. Productivity in prehistoric agriculture: physiological models for the quantification of cereal yields as na alternative to traditional approaches. Journal of Archaeological Sience 30:681-693 -Archila S., Giovannetti M. y Lema V. (Comp.) 2008 Arqueobotánica y teoría arqueológica. Discusiones desde Sudamérica Ed Uniandes, Bogotá.

-Arellano y Casas 2003 Morphological variation and domestication of Escontria chiotilla (Cactaceae) under silvicultural management in the Tehuacán Valley, Central Mexico. Genetic resources and crop evolution 50: 439-453

-Arenas P 2003 Etnografía y alimentación entre los Toba-Nachilamoleek y WichiLhuku'tas del Chaco Central (Argentina) Latín Gráfica, Buenos Aires.

-Asch N y Asch D 1978 The economic potential of Iva annua and its prehistoric importance in the lower Illinois Valley Anthropological Papers 67: 301-343

- Asch D y Asch N 1985 Prehistoric plant cultivation in West-Central Illinois Anthropological Papers 75: 149-204

Aschero C. 1994 Reflexiones desde el arcaico tardío (6000-3000 AP) Rumitacana 1(1):1317

-Aschero C. y Yacobaccio H. 1998/1999 Veinte años después: Inca Cueva 7 reinterpretado Cuadernos del INAPL 18: 7-18

-Ashworth L. 1997 Estudios sobre la biología reproductiva del zapallo amargo (Cucurbita andreana, Cucurbitaceae). Tesina de licenciatura. F.C.E.F.y N. U.N.C.

-Ashworth L. y Galetto L. 1999 Morfoanatomía cuantitativa de las flores pistiladas y estaminadas de Cucurbita maxima subsp. andreana (Cucurbitaceae). Darwiniana 37 (3-4): 187-198.

-Ashworth L. y Galetto L. 2001 Pollinators and reproductive success of the wild cucurbit Cucurbita maxima ssp. Andreana. Plant Biology 3:398-404

-Ashworth L. y Galetto L. 2002 Differential nectar production between male and female flowers in a wild cucurbit: Cucurbita maxima ssp. Andreana (Cucurbitaceae). Cannadian Journal of Botany 80: 1203-1208

-Babot, M. P. 2005 Plant resource Processing by Argentinean Puna HunterGatherers (ca.. 7000-3200 A.P.): Microfossil Record. The Phytolitharien 17 (2): 910.

-Babot, M. P. 2006 El papel de la molienda en la transición hacia la producción agropastoril: un análisis desde la Puna Meridional argentina. Estudios atacameños 32:75-92

-Babot M., Oliszewski N y Grau A. 2007 Análisis de caracteres macroscópicos y microscópicos de Phaseolus vulgaris (Fabaceae, Faboideae) silvestres y cultivados del noroeste argentino: una aplicación en arqueobotánica. Darwiniana 45(2):149162 
-Baffi E. y Torres M. 1996 Aproximación al análisis de pautas de actividad en una población prehispánica: Las Pirguas (Salta, Argentina) X Congreso Nacional de Arqueología Argentina: 134-148

-Baffi E.I., Torres M.F. y J.A. Cocilovo 1996. La población prehispánica de Las Pirguas (Salta, Argentina) un enfoque integral. Revista argentina de antropología biológica 1(1): 204-218

-Bailey L. H. 1943 Species of Cucurbita Gentes Herbarum Vol. VI Fasc. V New York

-Baldini M. y Baffi E. 1996 Comportamiento mortuorio en la población prehispánica de Las Pirguas (Pampa Grande, Salta). Actas y memorias del XI C.N.A.A. Tomo: Arqueología del temprano en el noroeste argentino. Revista del Museo de Historia Natural de San Rafael T XXIII (1-4): 7-16.

-Baldini M., Baffi E., Togo J. 1998 Abrigos y cavernas que hacen historia: los hallazgos de Las Pirguas (Pampa Grande, Salta) Homenaje a Alberto Rex González. pp: 343-353. FADA-FFyL UBA

-Baldini M., Baffi E., Salaberry M y Torres M. 2003 Candelaria: una aproximación desde un conjunto de sitios localizados entre los cerros de Las Pirguas y El Alto del Rodeo (Dto. Guachitas, Salta, Argentina). En: Ortiz G. y Ventura B (Eds) La mitad verde del mundo andino. Investigaciones arqueológicas en la vertiente oriental de los Andes y las Tierras Bajas de Bolivia y Argentina, pp:131-151 Ed. FHyCS- UNJU

-Barcena R., Roig F y Roig V. 1985 Aportes arqueo-fito-zoologicos para la prehistoria del N.O. de la provincia de Mendoza: la excavación de Agua de la Tinaja 1 Trabajos de Prehistoria 42

- Barrau, J. 1981 La etnobiología. En: Cresswell, R. y M. Godellier (eds.) Útiles de encuesta y de análisis antropológico: 81-92. Fundamentos Madrid

-Bate, F 1998 Proceso de investigación en arqueología Ed Crítica, Barcelona.

-Bates D. 1985 Plant utilization: patterns and prospects Economic Botany 39:241265

-Beebe S., Toro Ch. O., González A., Chacón M. y Debouck D 1997 Wildweedy-crop complexes of common bean (Phaseolus vulgaris L., Fabaceae) in the Andes of Peru and Colombia, and their implications for conservation and breeding. Genetic resources and crop evolution 44: 73- 91

-Bemis W. y Whitaker T. 1969 The xerophytic cucurbita of Northwestern Mexico and Southwestern United States Madroño 20 (2): 33-41

-Berenguer J 1996 Identificación de camélidos en el arte rupestre de Taira: ¿animales silvestres o domésticos? Chungara 28 (1-2): 85-114

-Bettfreund C. 1898 Flora Argentina. Recolección y descripción de plantas vivas. Tomo I Librería Alemana.

-Bisognin D.A. 2002 Origin and evolution of cultivated cucurbits. Ciência Rural 35 (5): 715-723 
-Boelcke, O. 1946. Estudio morfológico de las semillas de Leguminosas Mimosoideas y Caesalpinoideas de interés agronómico en la Argentina. Darwiniana 7 (2): 240-253

-Boelcke O. 1981 Plantas vasculares de la Argentina nativas y exoticas Segunda ed. (1992) Ed. Hemisferio Sur.

-Borella F y Dubois C 2003 Tafonomía y geoarqueología en la interpretación arqueológica: perspectivas integradas En: R. Curtoni y M.L. Endere (Eds.) Análisis, interpretación y gestión en la arqueología de Sudamérica Serie Teórica $\mathrm{N}^{\mathrm{o}} 2$ INCUAPA UNICEN, Olavarría

-Bozarth S.R. 1987 Diagnostic opal phytoliths from rinds of selected cucurbita species American Antiquity 52 (3): 607-615

-Braadbaart F. 2008 Carbonisation and morphological changes in modern dehusked and husked Triticum dicoccum and Triticum aestivum grains Vegetation History and Archaeobotany 17:155-166

-Braadbaart F., Boon J., Veld H., David P., van Bergen P. 2004 Laboratory simulations of the transformation of peas as a result of heat treatment: changes of the physical and chemical properties Journal of Archaeological Science 31: 821-833 -Bregante O 1926 Ensayo de clasificación de la cerámica del Noroeste argentino Ed. Angel Estrada y Cia. Buenos Aires

-Brieger F. 1968 The main ethnobotanical regions of Central and South America Actas y Memorias XXVII Congreso Internacional de Americanistas 2: 547-558

-Brücher, H 1989 Useful plants of Neotropical origin and their wild relatives. Ed.Springer New York.

-Brücher O. y Berglund-Brücher H. 1976 The south american wild bean (Phaseolus aborigineus Burk.) as ancestor of the common bean Economic botany 30: 257-272

-Bruno M. 2006 Morphological approach to documenting the domestication of Chenopodium in the Andes. En: Zeder M, Emshwiller E, Bradley D, Smith B (eds) Documenting domestication: new genetic and archaeological paradigms. University of California Press, Berkeley

-Bruno M. y Whitehead W. 2003 Chenopodium cultivation and formative period agriculture at Chiripa, Bolivia. Latin American Antiquity 14(3): 339-355

-Brush, S.B. 1993. Indigenous knowledge of biological resourses and intellectual property rights: the role of Anthropology. American Anthropologist 95(3):653-86

-Burkart, A. 1940. Materiales para una monografía del género Prosopis (Leguminosae), Darwiniana 4 (1), 57-128.

-Burkart, A., 1952. Las leguminosas argentinas silvestres y cultivadas. Acme agency.

-Burkart A. (ed) 1974 Flora ilustrada de la provincia de Entre Rios Colección Ci. Instituto Nacional de Tecnología Agropecuaria.

-Burkart, A., 1976 (a). A monograph of the genus Prosopis (Leguminosae subfam. Mimosidae) Journal of the Arnold Arboretum. 57 (3-4), 219-249. 
-Burkart, A., 1976 (b). A monograph of the genus Prosopis (Leguminosae subfam. Mimosidae), continuation Journal of the Arnold Arboretum 57 (3-4), 450-523.

-Busaniche J.L. 1971 Estampas del Pasado Biblioteca argentina de Historia y Política

-Butler A.1989. Crytptic anatomical characters as evidence of early cultivation in the grain legumes (pulses). En: Ed. D. Harris y G. Hillman Foraging and Farming. The evolution of plan exploitation. Unwin Hyman, London.

-Butler A. 1995 The small-seeded legumes: an enigmatic prehistoric resource Acta Paleobotanica 35(1): 105-115

-Butler A. 1996 Trifolieae and related seeds from archaeological contexts: problems in identification Vegetation history and archaeobotany 5: 157-167

-Butler A. 2002 Investigations of pod characters in the Vicieae Vegetation History and archaeobotany 11: 127-132

-Buxó R y Piqué R 2008 Arqueobotánica. Los usos de las plantas en la península Ibérica Ed Ariel, Barcelona

-Caballero, J. 1987. Etnobotánica y desarrollo: la búsqueda de nuevos recursos vegetales. 6to Congreso Latinoamericano de Botánica. Simposio de Etnobotánica. Medellín 1986. ICFES, Serie Memorias Eventos Cientificos Colombianos 46:79-95

-Cabrera A.L. (Dir.) 1965 Flora de la provincia de Buenos Aires Colección Científica del INTA.

-Cabrera, A.L. 1971. Fitogeografía de la República Argentina. Bol. Soc. Argent. Bot. 14: 1-42.

-Cabrera, A. L. 1978. Flora de la provincia de Jujuy: República Argentina. INTA, Colección científica. Buenos Aires

-Cabrera A.L. y Zardini E.M. 1978 Manual de la flora de los alrededores de Buenos Aires. Ed. Acme

-Cabrera A. L. y Willink A 1973 Biogeografia de América Latina Serie de biología. Monografía $\mathrm{N}^{\circ} 13$ OEA

-Cabrera Walsh G. 2003 Host range and reproductive traits of Diabrotica speciosa (German) and Diabrotica viridula (L.) (Coleoptera, Chrysomelidae). Two species of South American pest rootworms, with notes in other species of Diabroticina Population ecology 32 (2): 276-285

-Caggiano A. y Sempé C 1994 América Prehistoria y geopolítica Ed Tea Buenos Aires -Calle, R. 1996. Juridical and sociocultural problems on the definition of law concerning property, usage and acces to genetic resources in Colombia. Journal of Ethnopharmacology 51:127-146

-Callegari A. y Campos F. 1996 Nuevas evidencias arqueológicas sobre el sitio El Carmen. En: Actas y memorias del XI Congreso Nacional de Arqueología Argentina. Tomo: Arqueología del noroeste argentino (13). Revista del Museo de Historia Natural de San Rafael'T XXV (1-2): 189-202 
-Callegari A. 2003 Los Procesos de Consolidación del Periodo de Integración y la Transición a los Desarrollos Regionales en el Oeste Riojano. Tesis Doctoral. Facultad de Filosofía y Letras. UBA

-Callegari A. 2004 Las poblaciones precolombinas que habitaron el sector central del valle de Vinchina entre el 900/950 y 1600/1650 d.C. (Depto. Gral. Lamadrid, La Rioja, Argentina) Relaciones de la sociedad argentina de antropología XXIX: 81-110. -Cámara Hernández J 1973 Restos arqueológicos de maíz de Santa Rosa de Tastil En: Cigliano E. M (Ed) Tastil, una ciudad preincaica argentina Cap XI: 559-564. Camargon, Buenos Aires.

-Cámara Hernández J. ms. Informe preliminar sobre el material arqueológico de maíx, coleccionado por la Dra. Alicia Fernández. Distel en Huachichocana, Quebrada de Purmamarca, provincia de Jujuy.

-Cámara Hernández J y Rossi J. 1968 Maíz arqueológico de Cafayate, Salta. Boletín de la Sociedad Argentina de Botánica XII: 234-242 Buenos Aires

-Campos C. y Ojeda R., 1997. Dispersal and germination of Prosopis flexuosa (Fabaceae) seeds by desert mammals in Argentina Journal of Arid Environments 35: 707-714.

-Capparelli A. 1997 Reconstrucción ambiental de la instalación arqueológica Inka El Shincal'. Tesis Doctoral. Facultad de Ciencias Naturales y Museo. Universidad Nacional de La Plata.

-Capparelli A. 2007 Los productos alimenticios derivados de Prosopis chilensis (Mol.) Stuntz y P. flexuosa DC, Fabaceae, en la vida cotidiana de los habitantes del NOA y su paralelismo con el algarrobo europeo Kurtziana 33 (1): 103-120

-Capparelli A. 2008 Caracterización cuantitativa de productos intermedios y residuos derivados de alimentos del algarrobo (Prosopis flexuosa y P. Chilensis, fabaceae): aproximación experimental aplicada a restos arqueobotánicos desecados Darwiniana 46 (2): 175- 201

-Capparelli A. (en prensa) Intra-site comparison of the archaeobotanical evidence of El Shincal: implications about the Inka economy. Treballs d'Etnoarqueologia, editado por el Archaeology and Anthropology Department of the Institute Milà y Fontanals - Consejo Superior de Investigaciones Científicas (CSIC), España -Capparelli A., Lema V. y Giovannetti M. 2004 El poder de las plantas En: R. Raffino (ed.). El Shincal de Quimivil, cap. VII, pp:140-163. Editorial Sarquís. Catamarca.

-Capparelli A., Lema V., Giovannetti M. y Raffino R. 2005 Introduction of European crops (wheat, barley and peach) in Andean Argentina during the 16 th century: archaeobotanical and ethnohistorical evidence. Vegetation History and Archaeobotany 14: 472-484.

-Capparelli A., Pochettino M.L., Andreoni D. e Iturriza R. 2005 Differences between written and archaeological record: the case of plant micro remains recovered at a Northwestern Argentinean Pipe En: Z. Füsun Ertu (ed) Proceedings 
of the IV th International Congress of Ethnobotany (ICEB 2005): 397-406 Yayinlari Estambul

-Capparelli A., Giovannetti M. y Lema V. 2007 Primera evidencia arqueológica de cultivos del Viejo Mundo (trigo, cebada y durazno) en el NOA: su significación a través del registro de El Shincal de Quimivil. En: B. Marconetto, Babot y Oliszewski (comp.) Paleoetnobotanica del Cono Sur: estudios de casos y propuestas metodológicas. pp: 25-49 Ed. Ferreira. Córdoba, Argentina

-Capparelli A., Frangi J. y Kristensen M. 2006 El urbanismo inka y su vinculación con mesoclimas en el sitio "El Shincal de Quimivil" (Provincia de Catamarca, Argentina) Intersecciones en Antropología 7: 163-177

-Capparelli A., Oliszewski N. y Pochettino M. L. (en prensa) Historia y estado actual de las investigaciones arqueobotánicas en argentina. En: Actas del XIV Congreso Nacional de Arqueología Argentina Rosario 2001

-Cárdenas M., 1944 Las cucurbitáceas cultivadas de Bolivia En: Nuevas contribuciones a la Flora Económica de Bolivia $2^{\circ}$ opúsculo

-Cárdenas D. y Politis G. 2000 Territorio, movilidad, etnobotánica y manejo del bosque de los Nukak orientales Estudios Antropológicos 3 Ed Corcas Bogotá

-Cárdenas M., 1969 Manual de plantas económicas de Bolivia. Imprenta Icthus. Cochabamba, Bolivia.

-Carreras M, Fuentes E. y Guzmán C. 1989 Biochemical Systematics and ecology 17(4): 287-291.

-Carrizo J., Cano S., Soler Nixdorff M. 1999 Recursos vegetales comestibles en el Valle de Tafí durante el período formativo: análisis arqueobotánico I del sitio Casas Viejas-El Mollar (S TUC TAV 2) En: C. Diez Marín (Ed.) Actas del XII Congreso Nacional de Arqueología Argentina T. I: 65-73

-Cartes de Répartition Géographique des Organismes de Quarantaine pour l'Europe

-Casas, A. 2001 Silvicultura y domesticación de plantas en Mesoamérica En: Aguilar,B; Domínguez S.; Caballero Nieto J. \& Martínez Alfaro M. Plantas, cultura y sociedad. Estudio sobre la relación entre seres humanos y plantas en los albores del siglo XXI UAM-S.M.A.R.N.yP.- México

-Casas A; Otero-Arnaiz A.; Pérez-Negrón E y Valiente Banuet A. 1991-2003 Manejo y domesticación de cactáceas en Mesoamérica Zonas Áridas 7: 75-104 -Casas A; Pickersgill B.; Caballero J y Valiente Banuet A. 1997 Ethnobotany and domestication in Xoconochtli, Stenocereus stellatus (Cactaceae), in the Tehuacán Valley and La Mixteca Baja, México Economic Botany 51:279-292

-Castro,V y M. Tarragó 1992 Los inicios de la producción de alimentos en el cono sur de América. Revista de Arqueología Americana 6:91-124.

-Cavagnaro, J.B, Passera, C.B., 1993. Relaciones hídricas de Prosopis flexuosa (Algarrobo dulce) en el monte, Argentina En: Unidad de Botánica y Fisiología 
vegetal (eds.) Contribuciones mendocinas a la quinta reunión regional para América Latina y el Caribe de la Red de forestación del CID: conservación y mejoramiento de especies del género Prosopis, pp. 73-77

-Cigliano E. 1964 El precerámico en el N.W. argentino Arqueología de Chile central y áreas vecinas: $191-197$

-Cigliano E. 1968 Panorama general de las industrias precerámicas en el NO argentino. XXVII Congreso Internacional de Americanistas.

-Clement Ch. 19991492 and the loss of Amazonian crop genetic resources. I. The relation between domestication and human population decline Economic Botany 53:188-202

-Contardi D 1939 Estudios genéticos en Cucurbita y consideraciones agronómicas. Phycis 18:331-347

-Coons M. 1982 Relationships of Amaranthus caudatus. Economic Botany 36(2): 129146.

-Cordeu E. J. 1986 Los atuendos shamánicos chamacoco del museo etnográfico: un intento de interpretación simbólica. Runa XVI: 103-136

-Cortella A., Pochettino M. L., Manzo A. y Raviña G. 2001 Erythroxylum coca: Microscopical identification in powered and carbonised archaeological material. Journal of Archaeological Science 28:787-794.

-Cotton C. 1995. Ethnobotany: principles and applications John Willey and Sons, England.

-Cowan C. 1997 Evolutionary changes associated with the domestication of Cucurbita pepo En: K. Gremillion (Ed.) People, plants and landscapes. Studies in Paleoethnobotany pp: 63-85. University of Alabama Press.

-Cowan C.W. y Smith B.D. 1993 New perspectives on a wild gourd in Eastern North America Jounal of ethnobiology 13(1):17-54

-Crespo C. 2006 Entre el "deber" y el "derecho": patrimonio arqueológico y obligaciones sociales en Patagonia Argentina. Intersecciones en Antropología 7: 63-75 -Crivos, M. y M. R. Martínez. 1996. Las estrategias frente a la enfermedad en Molinos (Salta, Argentina). Una propuesta para el relevamiento de información empírica en el dominio de la Etnobiología. En: A. Martínez, L.A. Vargas y C. Serrano (eds.) Contribuciones a la Antropología Fisica Latinoamericana (IV Simposio de Antropología Física "Luis Montané", La Habana, Cuba, 5-9 diciembre, 1994), pp. 99-104. Universidad Nacional Autónoma de México, Instituto de Investigaciones Antropológicas, México.

-Cutler H. y Whitaker T. 1961 History and distribution of the cultivated cucurbits in the Americas. American Antiquity 26 (4): 469-485

-Chevalier A. 2002 L'exploitation des plantes sur la côte péruvienne en contexte formatif. Tesis doctoral en "Archéologie préhistorique", Faculté des Sciences, Département D'anthropologie et d'écologie, Université de Genève. 
-Chhandak B., Halfhill M., Mueller T., Steward C. 2004 Weeds genomics: new tools to understand weed biology. Trend in plant science 9 (8): 391- 398 -Chikwendu V. y Okezie C. 1989 Factors responsible for the ennoblement of African yams: inferences from experiments in yam domestication. En: D. Harris y G. Hillman (Eds.) Foraging and Farming. The evolution of plan exploitation. Unwin Hyman, London.

-D’Antoni, H. L., 1970. Introducción al estudio etnobotánico del Algarrobo Actas del Primer Congreso Nacional de Arqueología Argentina, pp. 23-441. Buenos Aires -D’Antoni 2008 Arqueoecología sistémica y caótica Ed. C.S.I.C. Textos Universitarios 41, Barcelona.

-Dacunda Díaz M. R. 1987 Gran diccionario de lengua guaraní Ediciones Gairacä, Corrientes

-Dauselberg P. 1974 Excavaciones arqueológicas en Quiani, provincia de Tarapacá, Depto. de Arica, Chile. Chungara 4: 7-38

- De Candolle 1959 Origin of cultivated plants US Hafner New York

-De la Fuente N.R.; Nazar D. y Pelli E. Documentación y diagnostico del arte rupestre de La Tunita Provincia de Catamarca-Republica Argentina En: La cultura de La Aguada y sus expresiones regionales pp:227-244. Ed Eudelar, La Rioja

-De Wet, J.M. y Harlan J. R. 1975 Weeds and domesticates: evolution in the manmade habitat. Economic Botany 29: 99-107.

-Debouck D., Jara L., Campana Sierra A., de la Cruz Rojas J 1987 Observations on the domestication of Phaseolus lunatus L. Plant genetic resources newsletter 70: 26-32

-Decker D. y Wilson H. 1986 Numerical analysis of seed morphology in Cucurbita pepo. Systematic Botany (1986) 11 (4): 595-607

-Decker Walters y Walters 2000 "Squash" The Cambridge World History of food Vol.1 K.F. Kiple, K.C. Ornelas (Eds.) Cambridge University Press

-Delfino D. 2005 Entre la dispersión y la periferia. Sentido de presencias. Lagunización de La Aguada En: Martin S., Gonaldi M.E., Ferraris S. y Giordano A. (eds.) La cultura de la Aguada y sus expresiones regionales Eudelar La Rioja

-Dennel R. 1992 The origins of crop agriculture in Europe En: C.W. Cowan y P.J. Watson (Eds.) The origins of agriculture. An international perspective pp: 71-100. Smithsonian Institution Press Washington

-Díaz P., Arena M. D., De Lorenzi M. Ms Informe preliminar sobre las investigaciones arqueológicas realizadas por el Museo Arqueológico de Cachi en el sitio SSalLap20 Puente del Diablo

-Dillehay T, Ardila Calderón G., Politis G. y Moraes Coutinho Beltrao M. 1992 Earliest hunters and gatherers of south america Journal of World Prehistory 6 (2): 145-204

-Dillehay T., Rossen J., Andres T., Williams D. 2007 Preceramic adoption of peanuts, squash and cotton n Northern Peru Science 316: 1890-1893. 
-Dobrizhoffer S.J., Martín 1968 (S. XVIII) Historia de los abipones Vol.II Traducción de la Prof. Clara Vedoya de Guillén Univ. Nac.del Nordeste, Fac.de Humanidades, Dep .de Historia, Resistencia, Chaco.

-Dottori N y Cosa M. T. 2003 Desarrollo de fruto y semilla en Solanum euacanthum (Solanaceae) Kurtziana 30 (1-2): 17-25.

-Dottori N. y Cosa M T. 2007 Anatomía y desarrollo de fruto y semilla de Solanum palinacanthum (Solanaceae) Revista mexicana de biodiversidad 78: 359-3687

-Dransart P. 1999 La domesticación de los camélidos en los Andes centro-sur, una reconsideración Relaciones de la Sociedad Argentina de Antropología, n.s., XXIV: 125-138

-Drewes S. 2006 Sobre Phaseolus vulgaris var. aborigineus (Fabaceae) en Córdoba. Boletin de la Sociedad Argentina de Botánica (3-4) 323-324

-Dymock W. 1972 Pharmacographia Indica. A history of the principal drugs of vegetable origin met with in British India Hamdard Vol XV N $1-2$

-Earth Colors Soil color book 1997 Color Communications, Inc.

-Edmonds J. 1983 Seed coat structure and development in Solanum L. Section Solanum (Solanaceae) Botanical journal of the Linnean Society 87: 229-246

-Erickson C.L. 1980 Sistemas agrícolas prehispánicos en los Llanos de Mojos América Indígena XL (4): 731-756

-Erickson D., Smith B., Clarke A., Sandweiss D y Turss N 2005 An Asian origin for a 10.000-year-old domesticated plant in the Americas PNAS 102 (51): 1831518320

-Esau K. 1977 Anatomia vegetal Ed. Omega, Barcelona

-Esau K. 1993 Anatomia de las plantas con semillas. Ed. Hemisferio Sur, Buenos Aires.

-Escobar J. M. 2008 Periodo formativo inferior del Valle de Salta (Salta, Argentina) Una interpretación. La Terminal Gráfica, Buenos Aires

-Escobar J.M ms (a) Informe final de beca de perfeccionamiento. Becas Internas. CONICET.

-Escobar J. M ms (b) Primer informe de beca de iniciación. Becas Internas. CONICET. -Esteves J., Velásquez C., Drewes S. y Hoc P. 2005 Abortos de semillas de Phaseolus vulgaris var. aborigineus Burk. (Fabaceae) Boletin de la Sociedad Argentina de Botánica 40:35 Suplemento especial, resúmenes de las XXX Jornadas Argentinas de Botánica.

-Eubanks M. 2001 The mysterious origin of maize Economic Botany 55(4): 492-514 -Fahn A. 1985 Anatomía vegetal Ed. Pirámide, Madrid.

-Fahn A y Zohary M. 1955 On the pericarpial structure of the legumen, its evolution and relation to dehiscence. Phytomorphology 5: 99-111

-Falabella F y Stehberg R 1989 Los inicios del desarrollo agrícola y alfarero: zona central (300 aC- $900 \mathrm{dC}$ ) En: Hidalgo, Schiappacasse, Niemeyer, Aldunante y 
Solimano (Eds.) Culturas de Chile. Prehistoria. Desde sus orígenes hasta los albores de la conquista Ed. Andres Bello Santiago

-Farrington, I. y Urry J. 1985 Food and the early history of cultivation. Journal of ethnobiology 5(2): 143-157

-Félix de Azara (1781) 1998 Viajes por la América Meridional T. I y II Ediciones El Elefante Blanco. Bs As.

-Fernández J. 1968a La industria de Mal Paso: materiales de morfología protolítica en las terrazas del Yacoraite Superior (Puna de Jujuy) Anales de arqueología y etnología XXIII: 43-54

-Fernández J. 1968b El Aguilarense Anales de arqueología y etnología XXIII: 55-73

-Fernández J. 1968c Instalaciones humanas en la Gruta del Inca (Jujuy Arg.) Anales de arqueología y etnología XXIII: 75-94

-Fernández J.1969-1970 La recolección de bulbos, rizomas y tubérculos entre los cazadores superiores de la puna Anales de arqueología y etnologia XXIV-XXV: 131 142

-Fernandez N., Aguirre C., Maidana F., Lozada W., Fogar M., Garay M. Cassaro L. 2004 Estudio de la efectividad de Imidacloprid, en zapallito redondo de tronco, aplicado a la semilla. http://www.unne.edu.ar/cyt/2001/5-Agrarias/A036.pdf.

-Fernández Distel, A. 1974 Excavaciones arqueológicas en la cueva de Huachichocana, Departamento de Tumbaya, Prov. De Jujuy. Argentina. Relaciones de la Sociedad Argentina de Antropología 8:101-27

-Fernández Distel A 1975 Restos vegetales de etapa arcaica en yacimientos del NO de la República Argentina (pcia. de Jujuy) Etnia 22: 11-24

-Fernández Distel A. 1986 Las cuevas de Huachichocana, su posición dentro del precerámico con agricultura incipiente del Noroeste argentino. Beitrage zur allgemeinen und vergleichenden Archaologie, band 8, Mainz. pp: 353-430

-Ferrio J.P, Araus J. L., Buxo, R., Voltas J., Bort J. 2005. Water management practices and climate in ancient agriculture: inferences from the stable isotope composition of archaeobotanical remains. Vegetation History and Archaeobotany 14:510-517

-Fiadone, A. 2006. El diseño indígena argentino: una aproximación estética a la iconografía precolombina. Editorial La Marca. Buenos Aires

-Fiedel Stuart 1996 Prehistoria de América Ed. Critica. Barcelona.

-Focacci G 1974 Excavaciones en el cementerio Playa Miller, Arica (Chile) Chungara 3: 23-74

-Font Quer, P. 1979 Diccionario de Botánica. Ed. Labor

-Ford R. 1979 Paleoethnobotany in American Archaeology En Schiffer (ed.) Advances in archaeological method and theory. vol. 2: 285-336 Academic Press. New York 
-Ford, R. 1985a The processes of plant food production in prehistoric north America Anthropological papers 75: 1-18

-Ford R. 1985b Patterns of prehistoric food production in North America Anthropological Papers 75: 341- 364

- Fournier P. y Freeman A. 1991 El razonamiento analógico en etnoarqueología, el caso de la tradición alfarera de Mata Ortiz, Chihuahua, México. Boletín de Antropología Americana 23:109-114

-Fradkin R. 2000 El mundo rural colonial En: Tandeter (Ed.) Nueva historia argentina Tomo II: 241-285 Ed. Sudamericana Buenos Aires.

-Free J. 1970 Insect pollination of crops Washington

-Frére, M.; González M.; Guráieb A. \& Muñoz S. 2004 Etnoarqueología, arqueología experimental y tafonomía En: Aguerre A. \& Lanata J. (comp.) Explorando algunos temas en arqueología. pp 97-120. Ed. Gedisa, Buenos Aires.

-Freyre R., Ríos R., Guzman L., Debouck G., Gepts P. 1996 Ecogeographic distribution of Phaseolus spp.(Fabaceae) in Bolivia Economic Botany 50(2): 195-215.

-Fuller D. 2007 Contrasting patterns in crop domestication and domestication rates: recent archaeobotanical insights from the Old World Annals of Botany 100: 903-924

-Galinat W. 1985 Domestication and diffusion of maize Anthropological Papers 75: 245- 278

-Galvan M.Z. 2006 Análisis de la variabilidad genética en poblaciones primitivas y silvestres de Phaseolus vulgaris, mediante marcadores bioquimicos y moleculares. Tesis para optar al grado de Doctor en Ciencias Naturales FCNYM. UNLP

-Gambier M. 1977 La cultura Ansilta Instituto de Investigaciones arqueológicas y Museo. F.F.H. y A. U.N.S.J. San Juan

-Gambier M. 1980 El proceso de agriculturización en la región de Cuyo. En: Actas del V Congreso Nacional de Arqueología Argentina, T I: 47-54. San Juan.

-Gándara M. 2006 La inferencia por analogía: más allá de la analogía etnográfica Treballs D'Etnoarqueologia 6: 13-23.

-García S., Rolandi D., López M. y Valeri P. 2002 “Alfa”, vega y hortaliza. Riego y siembra en Antofagasta de la Sierra, puna catamarqueña. Relaciones XXVII: 79100

-Gepts P. 2002 A comparision between crop domestication, classical plant breeding and genetic engineering Crop science 42: 1780-1790

-Gepts P. y Debouck D. 1991 Origen, domestication and evolution of the common bean (Phaseolus vulgaris L) En: Schoonhoven y Voysest (Ed) Common beans: research for crop improvement, pp 7-53, Washington.

-Gepts P. y Papa R. 2003 Possible effects of (trans)gene flow from crops on the genetic diversity from landraces and wild relatives Environment biosafety research 2:89-103 
-Gil, A. 1997-1998 Cultígenos prehispánicos en el sur de Mendoza. Discusión en torno al límite meridional de la agricultura andina. Relaciones de la Sociedad Argentina de Antropología XXII-XXIII: 295-318

-Gil, A. 2005 Arqueología de La Payunia (Mendoza, Argentina) El poblamiento bumano en los márgenes de la agricultura www.arqueologiamendoza.com

-Gil A., Tykot R., Neme G., Shelnut N. 2006 Maize on Frontier: Isotopic and macrobotanical data from Central-Western Argentina. En: Staller, Tykot y Benz (Eds.) Histories of Maize. Academic Press.

-Giovannetti M., Capparelli A y Pochettino M.L. 2008 La arqueobotánica en Sudamérica ¿hacia un equilibrio de enfoques? Discusión en torno a las categorías clasificatorias y la práctica arqueobotánica y paleoetnobotánica En: Archila S, Giovannetti M y Lema V. (comp.) Arqueobotánica y teoría arqueologica. Discusiones desde Sudamérica pp: 17-34 UNIANDES, Bogotá.

-Göbel B. 1998 Salir de viaje: producción pastoril e intercambio económico en el noroeste argentino" Publicaciones del BAS 30:867-891.

-Gonzáles A. R. 1972 Descubrimientos arqueológicos en las Serranías de Las Pirguas, Pcia. de Salta. Revista de la Universidad Nacional de La Plata 24: 388-392 -González A.R. 1974 Arte, estructura y arqueología Ed. Nueva Visión, Buenos Aires -González A.R. 1979 Dinámica cultual del N.O. argentino. Evolución e historia en las culturas del N.O. argentino. Antiquitas $\mathrm{N}^{\circ} 28-29$, Bs.As.

-González A.R. 1998 Cultura La Aguada Arqueología y diseños Ed Filmediciones Valero. Buenos Aires

-González A.R. y Pérez J 1968 Una nota sobre etnobotánica del N.O. argentino Actas y Memorias del XXXVII Congreso Internacional de Americanistas 2: 209-233.

-González A.R y Baldini M. 1992 La Aguada y el proceso cultural del NOA. Origen y relaciones con el área andina Boletín del Museo Regional de Atacama 4: 6-24

-Gould S.J. 1980 El pulgar del panda Ed. Hyspamércia, Madrid

-Granai, G. 1962 Técnicas de investigación sociológica. En: Gurvitch, G., ed. Tratado de sociología. : 153-171 Kapeluz Buenos Aires

-Gremillion K. 1993 The evolution of seed morphology in domesticated Chenopodium: an archaeological case study Journal of Ethnobiology 13(21): 149-169

-Gremillion K. 1996 Diffusion and adoption of crops in evolutionary perspective Journal of Anthropological Archaeology 15: 183-204.

-Gremillion K. 1997 Introducción En: Gremillion K. (Ed.) People, plantas and landscapes. Studies in paleoethnobotany. Alabama Press. Tuscaloosa

-Guillespie S. 2001 Personhood, agency, and mortuary ritual: a case study from the ancient maya Journal of anthropological archaeology 20:73-112

-Helbaeck H. 1960 The palaethnobotany of the Near East and Europe En: Braidwood y Howe (eds.) Prehistoric investigations in Iraqi Kurdistan, Studies in Oriental Civilization 31: 99-118 Oriental Institute, Chicago. 
-Haber A. 2006 Una arqueología de los oasis puneños. Domesticidad, interacción e identidad en Antofalla, primer y segundo milenio d.C. Jorge Sarmiento Editor-Universitaslibros, Córdoba

-Hallam S.J. 1989 Plant usage and management in southwest australian aboriginal societies. En: D. Harris y G. Hillman (Eds.) Foraging and Farming, the evolution of plant exploitation Unwin Hyman, London.

-Harlan J., 1992. Crops and man. 2da. Ed. American Society of Agronomy. -Harlan J y de Wet J 1965 Some thoughts about weeds. Economic botany 19 (1): 1624

-Harlan J y de Wet J 1973 On the quality of evidence for origin and dispersal of cultivated plants Current Anthropology 14 (1-2): 51-62

-Harris D. 1989 An evolutionary continuum of people-plan interaction. En: D. Harris y G. Hillman (Eds.) Foraging and Farming. The evolution of plan exploitation. Unwin Hyman, London.

-Harris D. 1990 Settling down and breaking ground: retbinking the Neolitbic Revolution Editado por Twaalfde Kroon-Voordracht, Gehouden Voor De, Stichting Nederlands Museum voor Anthropologie en Prehistory, Amsterdam

-Harris D y Hillman G 1989 Introduction En: D. Harris y G. Hillman (Ed.) Foraging and Farming. The evolution of plan exploitation. pp:1-7. Unwin Hyman, London.

-Hart J. 2004 Can Cucurbita pepo gourd seeds be made edible? Journal of Archaeological Science 31: 1631-1633

-Hastorf C. y Popper V. 1988 (Eds.) Current paleoethnobotany. Analytical methods and cultural interpretations of archaeological plant remains. Chicago Press.

-Hather J. y Mason S. 2002 Introduction: some issues in the archaeobotany of hunter-gatherers. En: Mason S. y Hather J. (Eds.) Hunter- gatherer archaeobotany. Perspectives from the northern temperate zone. Institute of archaeology. University College. Londres

-Hawkes, J.G. 1969 The ecological background of plant domestication. En: Ucko y Dimbleby (eds). The domestication and exploitation of plants and animals. Duckworth \& Co. Londres

-Hayden B. 1981 Research and development in the Stone Age: technological transitions among hunter-gatherers. Current Anthropology 22(5): 519-548.

-Hayward, H. 1953 Estructura de las plantas útiles ACME, Buenos Aires

-Haas J. y Creamer W. Crucible of Andean civilization. The peruvian coast from 3000 to 1800 BC. Current Anthropology 47(5):745-775

-Helbaek H. 1959 The domestication of food plants in the Old World. Science 130:365-372.

-Herrera Flores T., Cárdenas Soriano E., Ortiz Cereceres J., Acosta Gallegos J., Mendoza Castillo M. 2005 Anatomía de la vaina de tres especies del género Phaseolus Agrociencia 39: 595-602 
-Hildebrand E. 2003 Motives and opportunities for domestication: an ethnoarchaeological study in southwest Ethiopia Journal of anthropological archaeology 22:358-375.

-Hilgert, N. I. 2007a Plantas silvestres, ámbito doméstico y subsistencia. En: Brown. A.D.; M. García Moritán; Ventura, B. N.; Hilgert, N.I.; Malizia, L.R. (Eds.). Finca San Andrés. Un espacio de cambios ambientales y sociales en el Alto Bermejo. Ediciones del Subtrópico, Tucumán.

-Hilgert, N. I. 2007b La vinculación del hombre actual con los recursos naturales y el uso de la tierra. En: Brown. A.D.; M. García Moritán; Ventura, B. N.; Hilgert, N.I.; Malizia, L.R. (Eds.). Finca San Andrés. Un espacio de cambios ambientales y sociales en el Alto Bermejo. Ediciones del Subtrópico, Tucumán.

-Hilgert, N.I. y Gil G.E. 2005. Traditional Andean agriculture and changing processes in the Zenta River Basin, Salta, Northwestern Argentina. Darwiniana 43 (1-4): 30-43

-Hillman G. 1984 Interpretation of archaeological plant remains: the application of ethnographic models from Turkey En: Van Zeist W. \& Casparie W. (Eds.) Plant and ancient man. Studies in palaeoethnobotany. A. Balkema, Rotterdam-Boston. -Hillman, G. y Davies M. S. 1990 Measured domestication rates in wild wheats and barley under primitive cultivation, and their archaeological implications. Journal of World Prehistory 4 (2): 157-222.

-Hillman. G, Wales S., McLaren F., Evans J. y Butler A. 1993 Identifying problematic remains of ancient plant foods: a comparison of the role of chemical, histological and morphological criteria World Archaeology 25(1): 94-121. -Hocsman S. 2006 Producción lítica, variabilidad y cambio en Antofagasta de la Sierraca. 5500-1500 AP Tesis para optar al grado académico de Doctor en Ciencias Naturales F.C.N.yM. U.N.L.P.

-Hodder I. 1991 Interpretación en arqueología. Corrientes actuales. Ed. Crítica. Madrid - Höft M.; Barik S \& Lykke A. 1999 Quantitative ethnobotany People and plants working paper $\mathrm{N}^{\mathrm{o}} 6$.

-Horrocks M. Irwin G, Jones M y Sutton D 2004 Starch grains and xylem cells of sweet potato (Ipomoea batatas) and bracken (Pteridium esculentum) in archaeological deposits from northern New Zealand Journal of Archaeological Science 31: 251-258

-Hunziker A. 1943 Granos hallados en el yacimiento arqueológico de Pampa Grande (Salta, Argentina) Revista Argentina de Agronomia 10 (2): 146- 154

-Hunziker A y Subils R 1975 Sobre la importancia taxonómica de los nectarios foliares en especies silvestres y cultivadas de Cucurbita. Kurtiiana 8: 43-47

-Hurd P. y Linsley E. 1967 South american squash and gourd bees of the genus Peponapis Annals of the Entomological Society of America 60 (3): 647-661 
-Hurd P., Gorton Linsley E. y Whitaker T. 1971 Squash and gourd bees (Peponapis, Xenoglosa) and the origin of the cultivated Cucurbita. Evolution 25:218-234

-Hurrell, J. 1987. Las posibilidades de la etnobotánica y un nuevo enfoque a partir de la ecología y su propuesta cibernética. Rev. Esp. Antrop. Amer. 17: 235258.

-Hurrell J. A. 1989 Interpretación de relaciones en ecología a partir de la noción de sistema. Para el referente empirico Santa Victoria e Iruya (Salta,Argentina) Tesis para optar al grado de Doctor en Ciencias Naturales. F.C.N.yM. U.N.L.P.

-Iriarte J., Holst I., López J y Cabrera L. 2001 Subtropical wetland adaptations in Uruguay during the Mid-Holocene: an archaeobotanical perspective En: Purdy B. (ed.) Enduring records. The environmental and cultural heritage of wetlands pp: 61-70. Oxford Books. Oxford.

-Isemura T, Kaga A, Konishi S., Ando T., Tomooka N., Han O. y Vaughan D. 2007 Genome dissection of traits related to domestication in Azuki Bean

(Vigna angularis) and comparison with other warm-season legumes Annals of Botany 100: 1053-1071

-Jacomet, S., Kucăn, D., Ritter A., Suter G, Hagendorn A. 2002. Punica granatum L. (pomegranates) from early Roman contexts in Vindonissa (Switzerland), Vegetation History and Archaeobotany 11(1-2):79-92

-Jacquat C y Martinolli D 1999 Vitis vinifera L.: wild or cultivated? Study of the grape pips found at Petra, Jordan; 150 B.C. - A.D. 40 Vegetation history and archaeobotany 8: 25-30.

-Jarvis D., Sthapit B. y Sears L. 1999 Conserving agricultural biodiversity in situ: a scientific basis for sustainable agriculture. IPGRI publications.

-Jayaprakasam B., Seeram N. y Nair M 2003 Anticancer and antiinflammatory activities of cucurbitacins from Cucurbita andreana. Cancer letters 189:11-16

-Jeffrey C. 1980 A review of the Cucurbitaceae Botanical Journal of the Linnean Society 81: 233-247

-Johns T. y Kubo I. 1988 A survey of traditional methods employed for the detoxification of plant foods. Journal of Ethnobiology 8 (1): 81-129.

-Jones V. 1941 The Nature and Status of Ethnobotany Chronica Botanica VI (10): 219-221

-Kami J., Becerra Velásquez V., Debouck D. y Gepts P. 1995 Identification of presumed ancestral ADN sequences of phaseolin in Phaseolus vulgaris Proc. Natl. Acad. Scl.92: 1101-1104.

-Kaplan L. 1965 Archaeology and domestication in American Phaseolus (Beans) Economic Botany 19(4):358-368

-Kaplan L. y Lynch T. Phaseolus (Fabaceae) in archaeology: AMS radiocarbon dates and their significance for pre-colombian agriculture Economic Botany 53: 261272 
-Kay, S., King A. y Robinson M. 1980 Study of archaeobotanical seeds American Antiquity 35:26-39.

-Kiesling R. Flora de San Juan-República Argentina V.I Ed. Vazquez Mazzini, Buenos Aires

-Kiesling R. 1984 Estudios en cactaceae de Argentina: Maihueniopsis, Tephrocactus y generos afines (opuntioideae) Darwiniana 25(1-4): 171-215

-King F., 1994. Interpreting wild plant foods in the archeological record. En: Nina Etking (Ed).. Eating on the wild side. Arizona series in human ecology. The University of Arizona press.

-Kislev M. y Rosenzweig R 1991 Influence of experimental charring on seed dimensions of pulses Palaeoethnobotany and archaeology. Archaeological Institute of the Slovak Academy of Sciences, Nitra.

-Körber-Grohne U.,1991. Identification methods En: Van Zeist, Wasylikowa y Behre (Eds.) Progress in Old World paleothnobotany. Rotterdam.

-Korstanje M.A. 1998 Desempolvando antigüedades: consideraciones sobre el repertorio cerámico Vaquerías Mundo de Antes 1:69-120

-Korstanje M.A y Würschmidt A. 1999 Producir y recolectar en los valles altos del NOA: Los Viscos como caso de estudio En los tres reinos: prácticas de recolección en el cono sur de América pp: 151-160. Instituto de Arqueología y Museo FCNeIMLUNT.

-Korstanje M. A y Babot M P 2007 Microfossils characterization from south Andean economic plants En: M. Madella y D. Zurro (eds) Plants, people and places Recent studies in phytolith analysis. Oxbow books. Londres

-Krapovickas A 1968 Origen, variabilidad y difusión del maní (Arachis hypogaea) Actas y Memorias XXVII Congreso Internacional de Americanistas 2: 517-534

-Krapovickas P. 1980 La agriculturización prehispánica en la puna En: Actas del $V$ Congreso Nacional de Arqueología Argentina, T I:47-54. San Juan.

-Kusch M. F. 1990 El concepto de humanidad en la alfarería prehispánica del Noroeste argentino Revista de Antropología V (9):13-20

-Ladizinski G., 1989. Origin and domestication of the Southwest Asian grain legumes. En: D. Harris y G. Hillman (Eds.).Foraging and Farming. The evolution of plan exploitation. Unwin Hyman, London.

-Laguens A 2004 Arqueología de la diferenciación social en el Valle de Ambato, Catamarca, Argentina (S II-VI d.C.): el actualismo como metodología de análisis Relaciones de la sociedad argentina de antropología XXIX: 137-161

-Lagiglia H. 1997 Arqueología de cazadores-recolectores cordilleranos de altura Ed. Ciencias y Arte. San Rafael.

-Lagiglia H. 1980 El proceso de agriculturización del Sur de Cuyo. La cultura del Atuel II. En: Actas del V Congreso Nacional de Arqueología Argentina. Vol. I: 231-52. 
-Lagiglia H. 1999 Nuevos fechados radiocarbónicos para los agricultores incipientes del Atuel. Actas XII Congreso Nacional de Arqueologia Argenitna T. III: 239-250

-Lagiglia H. 2001. Los orígenes de la agricultura en Argentina. En: E. Berberián y A. Nielsen (Eds.). Historia Argentina Prehispánica. Ed. Brujas

-Laguens, A., Dantas M., Figueroa G., Gastaldi M., Juez M.S. y Pazzarelli F. 2007 Vasijas+pucos con huesos+agua no son solo sopa: la cerámica de uso domestico en el siglo XI d.C. en el Valle de Ambato, Catamarca, y sus relaciones con otros entramados sociales y materiales Libro de resúmenes expandidos XVI Congreso Nacional de Arqueología Argentina T II: 353-359 Universidad Nacional de Jujuy

-Lanning S 1963 A preagricultural occupation on the central coast of Perú. American Antiquity 28: 360-371

-Lathrap, Donald. W. 1976. Our father the Cayman, Our Mother the Gourd: Spinden Revisited, or a Unitary Model for the Emergence of Agriculture in the New World. En: Ch. Reed (Ed.) Origins of Agriculture. Mouton Publishers, The Hague, Paris.

-Lee R. y De Vore I 1968 (Eds.) Man the bunter Aldine Publishing Company. Chicago

-Lentz D, De Land Pohl M., Alvarado J., Tarighat M. Bye R. 2008 Sunflower (Helianthus annuus L.) as a pre-Columbian domesticate in Mexico PNAS 105 (17):6232-6237

-León J. 1968 Botánica de los cultivos tropicales Instituto interamericano de cooperación para la agricultura. San José. Costa Rica

-Lepofsky D.; Kirch P. y Lertzman K 1998 Metric analysis of prehistoric morphological change in cultivated fruits and nuts: an example from Island Melanesia Journal of archaeological science 25: 1001-1014

-Lira Saade R. 1995 Estudios taxonómicos y ecogeográficos de las Cucurbitacea latinoamericanas de importancia económica. Instituto de Biología. U.N.A.M. México.

-Lobot V., Johnston E., Zheng Q. E; McKern D \& Mc Kenna D 1999 Morphological, phytochemical and genetic variation in Hawaiian Cultivars of 'Awa (Kava, Piper methysticum, Piperaceae) Economic Botany 53 (4): 407-418

-López M.L. 2005 Los pobladores productores de alimentos en las Sierras de Córdoba. Primeras evidencias arqueobotánicas en los sitios Arroyo Tala Cañada I y C. pun. 39 La Zaranda de Ideas I: 89-92

-López M.L. 2007 La producción de alimentos en las sociedades prehispánicas tardías de Córdoba Comechingonia Virtual 1:12-31.

-López-Anido F., Cravero V., Asprelli P., Cointry E., Firpo I. y García S.M. 2003 Inheritance of immature fruti color in Cucurbita maxima var. zapallito (Carriére) Millan. Cucurbit Genetics Cooperative Report 26:48-50 
-Lorandi A.M. 1988 El servicio personal como agente de desestructuración en el Tucumán colonial. Revista Andina 6 (1): 135-173.

-Lorandi A.M., y R. Boixadós. 1987-88. Etnohistoria de los Valles Calchaquíes en los siglos XVI y XVII. Runa XVII-XVIII: 263-420

-Lozano, P. (1733) 1974 Descripción corográfica del Gran Chaco Gualamba. Instituto de Antropología. Publicación especial no 288 Tucumán

-Lumbreras L 1984 La arqueología como ciencia social. Casa de las Américas. La Habana

-Luna Morales C. 2002 Ciencia, conocimiento tradicional y etnobotánica Etnobiologia 2: 120-135

-Lunch T. 1967 The nature of the central Andean preceramic. Ocas. Papers 21

-Mac Neish R. 1992. The Beginning of Agriculture in the New World. Revista de Arqueología Americana $\mathrm{N}^{\circ} 6$.

-Maloberti, M. y Zapatiel, J. 2003 Cucurbitacea. Informe para la cátedra Práctica de Campo IV. U.N.C. Inedito

-Mangafa M y Kotsakis K. 1996 A new method for the identification of wild and cultivated charred grape seeds Journal of archaeological science 23: 409-418

-Maranta A. 1987 Los recursos vegetales alimenticios de la etnia Mataco del Chaco Central occidental. Parodiana 5(1): 161-237

-Marcellino A. 1981 El morfotipo paleoamericano lago-fuéguido en restos humanos del período de agricultura incipiente del noroeste argentino Publicaciones del Instituto de Antropología (Universidad Nacional de Córdoba) 36: 47-67

-Marconetto, M.B. 2008 Linnaeus en el Ambato. El uso de la clasificación taxonómica en arqueobotánica. En: Archila S, Giovannetti M y Lema V. (comp.) Arqueobotánica y teoría arqueológica. Discusiones desde Sudamérica pp: 143-166. UNIANDES, Bogotá.

-Martin G. 1995. Ethnobotany. A method manual. Chapman and Hall, Londres.

-Martínez M.R., Pochettino M.L. y Arenas P.M. 2003 La horticultura: estrategia de subsistencia en contextos pluriculturales, Valle del Cunapiru, Misiones, Argentina. Delpinoa 45: 89-97.

-Martínez M.R. y Pochettino M.L. 2004 Microambientes y recursos vegetales terapeuticos. Conocimiento local en Molinos, Salta, Argentina. Zonas Aridas 8 (distribución por Internet, difundido abril 2005)

-Martínez Crovetto R. 1964a Estudios etnobotánicos I Nombres de plantas y su utilidad, según los indios Tobas del este del Chaco Bonplandia 1(4): 279-333

-Martínez Crovetto R. 1964b Estudios etnobotánicos II Nombres de plantas y su utilidad, según los indios Vilelas del Chaco Bomplandia 2(1): 1-23

-Martínez Crovetto R. 1965 Cucurbitaceae En: Cabrera A.L. (Dir.) Flora de la provincia de Buenos Aires pp:400-401. Colección Cientifica del INTA. 
-Martínez Crovetto R. 1974 Cucurbitaceae En A. Burkart (ed) Flora ilustrada de la provincia de Entre Ríos Colección Científica Instituto Nacional de Tecnología Agropecuaria 4: 63-94

-Mayer E. 2004 Casa, chacra y dinero. Economias domésticas y ecología en los Andes. IEP, Lima.

-McClung de Tapia E. 1992 The origins of agriculture in Mesoamerica and Central America En: C.W. Cowan y P.J. Watson (Eds.) The origins of agriculture. An international perspective pp: 143-172. Smithsonian Institution Press Washington -McCorriston J y Hole F 1991 The ecology of seasonal stress and the origins of agriculture in the Near East American Anthropologist 93 (1): 46-69

-Mc Neish R. 1976 The beginning of agriculture in Central Peru En: C. Reed (Ed.) Origins of Agriculture World Anthropology pp: 753-802 Mouton Publishers Paris.

-Menéndez Sevillano M. C. 2002 Estudio y conservación del germoplasma silvestre y primitivo de Phaseolus vulgaris L. en el Noroeste argentino Memoria para optar al grado de Doctora Ingeniera Agrónoma, Departamento de producción vegetal, Universidad de Santiago de Compostela.

-Merculieff, L. 2002. Linking traditional knowledge and wisdom to ecosystem based approaches in research and management: supporting a marginalized way of knowing. En: Stepp JR, Wyndham FS y Zarger R. (Eds) Ethnobiology and Biocultural Diversity, Section VIII, pp. 523-531. The International Society of Ethnobiology, U.S.A.

-Merlino R. y M. Rabey 1978 El ciclo agrario-ritual en la puna argentina. Relaciones de la Soc. Arg. de Antropología XII: 47-70.

-Merrick L y Nabhan G. 1984 Natural Hybridization of Wild Cucurbita sororia Group and Domesticated C. mixta in Southern Sonora, Mexico Cucurbit Genetics Cooperative Report 7:73-75

-Metcalfe C y Chalk L. 1983 Anatomy of the dicotyledons Vol II Clarendon Press. Oxford

-Miante Alzogaray A. y Cámara Hernández J. 1996 Restos arqueológicos de maíz (Zea mays ssp. mays) de Pampa Grande, provincia de Salta, Argentina. Relaciones de la Soc. Arg. de Antropología XXI: 149-159

-Michelbacher A.E., Smith R. y Hurd P. 1964 Bees are essential...pollination of squashes, gourds and pumpkins California agriculture may 1964

-Millán R. 1943 Los zapallos Bugango y Angola Revista Argentina de Agronomia t. 10

-Millán R. 1945 Variaciones del zapallito amargo Cucurbita andreana y el origen de Cucurbita maxima Revista Argentina de Agronomía 12: 86-93.

-Millán R. 1946 Nuevo mate del Uruguay (Lagenaria siceraria var. laevisperma) Darwiniana 7 (2): 194-197 
-Millán R.1947. Los zapallitos de tronco de Sudamérica extratropical. Darwiniana VII-3

-Millán R. 1968 Observaciones sobre cinco Cucurbitáceas cultivadas o indígenas en la Argentina Darwiniana IV-4

-Minnis P. 1978 Paleoethnobotanical indicators of prehistoric environmental disturbance: a case study. Anthropological Papers 67: 347- 366

-Molina A. 2005 Malezas argentinas T. I Buenos Aires

-Monaghan G, Lovis W. y Egan Bruhy K 2006 Earliest Cucurbita from the Great Lakes, Northern USA Quaternary Research 65: 216-222

-Morello, J. 1958. La provincia fitogeográfica del Monte Opera Lilloana 2: 5-115

-Morello J. y Saravia Toledo C. 1959. El bosque chaqueño. Paisaje primitivo, paisaje natural y paisaje cultural en el oriente de Salta Revista agronómica del Noroeste argentino III (1-2): 6- 223

-Moure J.S., Urban D., Melo G. 2007 Catalogue of bees (Hymenoptera apoidea) in the Neotropical region. Ed. Sociedade brasileña de Entomología, Curitiba.

-Murra J 1972 El "control vertical" de un máximo de pisos ecológicos en la economía de las sociedades andinas, Iñigo Ortiz de Zúñiga, visitador, Visita de la Provincia de León de Huanuco en 1562. Universidad Nacional Hermilio Valdizan, Huanuco, Perú.

-Murray D. 1984 Seed physiology Vol.I Academic Press Sydney

-Muscio H. (1998/1999) Tendencias en la variabilidad ambiental de la Puna argentina: implicancias para la ecología humana prehistórica y para los paisajes arqueológicos. Cuadernos del INAPL 18:271-296

-Muscio H. 1999 Colonización humana del NOA y variación en el consumo de los recursos: la ecología de los cazadores recolectores de la Puna durante la transición Pleistoceno-Holoceno Publicación virtual en Revista Naya www.naya.com.ar

-Nabhan G. 1984 Evidence of Gene Flow Between Cultivated Cucurbita mixta and a Field Edge Population of Wild Cucurbita at Onavas, Sonora Cucurbit Genetics Cooperative Report 7:76-77

-Nazarea, V. D. 1998. Cultural memory and biodiversity. The University of Arizona Press, Tucson.

-Nee M. 1990 The domestication of Cucurbita (Cucurbitaceae) Economic Botany 44 (3) Supplement: Bretting (ed.) New perspectives on the origin and evolution of New World domesticated plants

-Newsom L.A., Webb S.D y Dunbar J.S. 1993 History and geographic distribution of Cucurbita pepo gourds in Florida Journal of Ethnobiology 13(1): 75-98

-Núñez L 1970 Algunos problemas de la arqueología del norte de Chile: el proceso de agriculturización. En: Primer Congreso de Arqueología Argentina :323-342 -Núñez L 1974 La agricultura prehispánica en los Andes Meridionales Ed. Orbe. Santiago 
-Núñez L. 1982 Temprana emergencia de sedentarismo en el desierto chileno: proyecto Caserones. Chungara 9:80-123

-Núñez L. 1989 Hacia la producción de alimentos y la vida sedentaria (5000 a.C a 900 d.C.). En: Culturas de Chile. Prehistoria. Desde sus orígenes hasta los albores de la conquista, pp:. 81-106 Ed. A. Bello. Chile

-Núñez L. 1994 Emergencia de complejidad y arquitectura jerarquizada en la Puna de Atacama: las evidencias del sitio Tulán-54. En: Taller de Costa a Selva pp. 85-115. Instituto interdisciplinario Tilcara. F.F.yL -U.B.A. Buenos Aires.

-Núñez L. y Santoro C. 1990 Primeros poblamientos en el cono sur de América (XII-IX milenio AP) Revista de arqueología americana 1: 91-139

-Núñez Regueiro, V. 1974 Conceptos instrumentales y marco teórico en relación al análisis del desarrollo cultural del noroeste argentino. Revista del Instituto de Antropología 5. Córdoba.

-Núñez Regueiro V. y Tartusi M 1987 Aproximación al estudio del Área Pedemontana de Sudamérica. Cuadernos Inst. Nac. de Antropología 12: 125-159

-O’Neale L. y Whitaker T. 1947 Embroideries of the Early Nazca Period and the crops plants depicted on them Southwestern Journal of Anthropology 3 (4): 294-321

-Ochoa C. y Ugent D. 2001 Maca (Lepidium meyenii Walp.; Brassicaceae): a nutritious root crop of the central andes. Economic Botany 55(3):363-364

-Olivera D., 2001. Sociedades agropastoriles tempranas: el formativo inferior del noroeste argentino. En: Historia Argentina Prehispánica, Editores: E. Berberián y A. Nielsen. Ed. Brujas

-Oliszewski N. 2004a Utilización de recursos vegetales en Campo del Pucará (Andalgalá, Catamarca) durante el periodo formativo (200-500 DC). Análisis de macrorrestos. Tesis de doctorado. F.C.N. e I.M.L. U.N.T.

-Oliszewski N. 2004b Estado actual de las investigaciones arqueobotánicas en sociedades agroalfareras del área valliserrana del Noroeste argentino (0-600 d.C.) Relaciones de la sociedad argentina de antropología XXIX:211-228

-Oliszeswski N 2008 Metodología para la identificación subespecífica de maíces arqueológicos. Un caso de aplicación en el noroeste de Argentina En: Archila S, Giovannetti M y Lema V. (comp.) Arqueobotánica y teoría arqueológica. Discusiones desde Sudamérica pp: 181-202. UNIANDES, Bogotá.

-Oliszewski N., Martínez J y Caria M Ocupaciones prehispánicas en una quebrada de altura: el caso de Cueva de Los Corrales I (El Infiernillo, Tafí del Valle, Tucumán) En prensa en: Relaciones de la sociedad argentina de antropología -Olivera D. 1988 La opción productiva: apuntes para el análisis de sistemas adaptativos de tipo Formativo del Noroeste argentino Precircular de las ponencias cientificas a los simposios del IX Congreso Nacional de Arqueología Argentina.

-Olivera D. 1992 Tecnología y estrategias de adaptación en el Formativo (Agro-alfarero temprano) de la puna meridional argentina. Un caso de estudio: Antofagasta de la Sierra 
(Catamarca, R.A.) Tesis Doctoral. F.C.N.yM. Universidad Nacional de La Plata, Argentina.

-Olivera D. 2001 Sociedades agropastoriles tempranas: el Formativo inferior del Noroeste argentino En: Historia argentina prehispánica. Directores: Berberian y Nielsen pp: 83-126. Ed. Brujas

-Olivera D. y Elkin D. 1994 De cazadores y pastores: el proceso de domesticación de camélidos en la Puna Meridional argentina Zooarqueología de camélidos 1: 95-124

-Oller M.R., D’Antoni H. L., Nieto M.A. 1984-1985 Contribuciones a la arqueoecología de Pampa Grande, provincia de Salta Relaciones XVI:153-163. -Orton C, Tyers P y Vince A 1997 La cerámica en arqueología Ed Crítica Barcelona -Ottonello M. y Ruthsatz B. 1986 Agricultura prehispánica y la comunidad hoy en la quebrada de Rachaite. Provincia de Jujuy, Argentina. Runa XVI: 1-27

-Palacios, R., Bravo, L., 1974. Estudio morfológico de las semillas de algunos Prosopis del noroeste Argentino. Darwiniana 18: 437-452

-Palacios, R., Bravo, L., 1981. Hibridación natural en Prosopis (Leguminosae) en la región chaqueña argentina. Evidencias morfológicas y cromatográficas. Darwiniana 23 (1): 3-35

-Parodi 1935 Relaciones de la agricultura prehispánica con la agricultura argentina actual. Observaciones generales sobre la domesticación de las plantas Anales de la Academia Nacional de Agronomía y Veterinaria de Buenos Aires 1:115-167

-Parodi L. 1938 El proceso biológico de la domesticación vegetal Revista argentina de agronomía 5(1):1-24

-Parodi L. 1966 La agricultura aborigen Argentina. Biblioteca de América Cuadernos 4: $1-48$

-Parodi L. 1978 Enciclopedia argentina de agricultura y jardinería Ed Acme Buenos Aires

-Passarelli L.M. 2002 Importancia de Apis mellifera L. en la producción de Cucurbita maxima Duch. (zapallito de tronco) Invest. Agr.: Prod. Prot. Veg. 17 (1): 513

-Paulsen E. 1936 Sobre el aislamiento de los principios amargos del fruto de "Cucurbita andreana" Revista argentina de agronomía 3: 250-252

-Pearsall D 1978 Paleoethnobotany in Western South America: progress and problems. Anthropological Papers 67: 389- 418

-Pearsall D. 1989a Palaeoethnobotany: a handbook of procedures. San Diego, Academic Press.

-Pearsall D. 1989b. Adaptation of prehistoric hunter-gatherers to the high Andes: the changing role of plan resources. En: D. Harris y G. Hillman (Ed.) Foraging and Farming. The evolution of plan exploitation.. Unwin Hyman, London.

-Pearsall D. 1989. Paleotnobotany, a handbook of procedures. Academic Press. 
-Pearsall D. 1992 The origins of plant cultivation in South America. En: C.W. Cowan y P.J. Watson (Eds.) The origins of Agriculture: an international perspective Smithsonian Institution Press Washingotn -Londres

-Pérez Gollán J y Heredia O. 1987 Hacia un replanteo de la cultura de La Aguada Cuadernos instituto nacional de antropología 12:161-177

-Perry L, Dickau R, Zarillo S, Holst I, Pearsall D, Piperno D, Berman M J, Cooke R, Rademaker K, Ranere A, Raymond S, Sandweiss D, Scaramelli F, Tarble K y Zeidler J. 2007 Starch fossils and the domestication and dispersal of Chili Peppers (Capsicum spp. L.) in the Americas. Science 315: 986-988

-Pickersgill B. 1969 The archaeological record of Chili Peppers (Capsicum ssp.) and the sequence of plant domestication in Peru American Antiquity 34(1): 54-61

-Pickersgill B., y Charles Heiser Jr. 1976. Origins and distribution of plants domesticated in the new world tropics. En: Ch. Reed (Ed) Origins of Agriculture.. Mouton Publishers, The Hague, Paris.

-Pinto R. 2002 Lobivia ferox britton et rose (cactaceae), nuevo registro para la flora chilena Gayana Bot. 59(2): 65-72

-Piperno D 1989 Non-affluent foragers: resource availability, seasonal shortages, and the emergence of agriculture in Panamanian tropical forest. En: D. Harris y G. Hillman (Ed.) Foraging and Farming. The evolution of plan exploitation. pp: 538-551. Unwin Hyman, London

-Piperno D. R. 2008 Identifying crop plants with phytolits (and starch grains) in Central and South America: a review and an update of the evidence. Quaternary International d.o.i: 10.1016/j. quaint. 2007.11.011

-Piperno D. y Pearsall D 1998 The origins of agriculture in lowland tropics Academic Press, San Diego.

-Piperno D. y Holst I 1998 The presence of starch grains on prehistoric stone tools from the humid neotropics: indications of early tuber use and agriculture in Panama Journal of Archaeological Science 25: 765-776

-Piperno D., Andres T. y Stothert K 2000 Phytolits in Cucurbita and others Neotropical Cucurbitaceae and their occurrence in early archaeological sites from the lowland American tropics Journal of archaeological science 193-208

-Piperno D., Holst I., Wessel Beaver L., Andres T. 2002 Evidence for the control of phytolith formation in Cucurbita fruits by the hard rind $(\mathrm{Hr})$ genetic locus: archaeological and ecological implications. PNAS 99: 10923-10928

-Piperno D. y Stothert K. 2008 Phytolith evidence for early Holocene Cucurbita domestication in Southwest Ecuador Science 299: 1054-1057

-Planchuelo A.M. 1975 Estudio de los frutos y semillas del género Chenopodium en la Argentina. Darwiniana 19: 528-565

-Planella M T y Tagle B 1998 El sitio agroalfarero temprano de La Granja: un aporte desde la perspectiva arqueobotánica Museo Nacional de Historia Natural Publicación ocasional 52: 5-64 
-Planella M T, Cornejo L y Tagle B 2005 Alero Las Morrenas 1: evidencias de cultívenos entre cazadores recolectores de finales del período Arcaico en Chile Central Chungara 37 (1): 59-74

-Plotnicov L. y Scaglion R. (Eds) 1999 Consequences of cultivar diffusion Ethnology monographs $\mathrm{N}^{\circ} 17$ Department of Anthropology University of Pittsburgh Pittsburgh.

-Pochettino M.L. 1985 Disemínulos utilizados por los aborígenes del noroeste de la República Argentina. Tesis para optar para el titulo de Doctor en Ciencias Naturales. F.C.N.yM. U.N.L.P.

-Pochettino M.L. y Scattolin MC 1991 Identificación y significado de frutos y semillas carbonizados de sitios arqueológicos formativos de la ladera occidental del Aconquija (Catamarca, Republica Argentina) Revista del Museo de La Plata IX (71): 169-181

-Pochettino M.L, Cortella A., Capparelli A. 1998 Identificación de macrorrestos vegetales: el microscopio, un aliado indispensable Revista del Museo de Historia Natural de San Rafael (Actas y memorias del XI C.N.A.A. Tomo: Paleoetnobotanica.) XXIX (1-4): 19-32

-Pochettino M.L y Capparelli A 1998 Paleoetnobotanica Revista del Museo de Historia Natural de San Rafael XXIX (1/4)

-Pochettino M.L, Cortella A 1999 Hallucinogenic snuff from Northwestern Argentina: Microscopical Identification of Anadenanthera colubrina var. cebil (Fabaceae) in Powered Archaeological material. Economic Botany 53(2):127-132.

-Pochettino, M.L. 2007 (difundida 2008). La dinámica en la horticultura en comunidades Mbya-Guaraní, Misiones, Argentina. Etnobiologia 5: 36-50

-Pochettino M.L., Lema V. y Capparelli A. 2008 “'Aprendices de shaman o piratas de la naturaleza?: apropiación del conocimiento botánico tradicional y ética etnobotánica. En: S. Archila, M. Giovannetti y V. Lema (Comp) Arqueobotánica y teoría arqueológica. Discusiones desde Suramérica. pp: 253-271 UNIANDES, Bogotá.

-Pochettino M.L. y Capparelli A (en prensa) Aportes para una paleoetnobotánica/arqueobotánica argentina del siglo XXI En prensa en: Xama -Politis G. 1996 Moving to Produce: Nukak Mobility and Settlement Patterns in Amazonia World Archaeology 27(3): 492-511

-Politis G. 2004 Tendencias de la etnoarqueología en América Latina. En: Politis G y Peretti D. (eds.) Teoría arqueológica en América del Sur. Serie Teórica No 3, pp 85-118 INCUAPA- UNICEN, Buenos Aires.

-Politis G., Martinez G. y Rodriguez J. 1997 Caza, recolección y pesca como estrategia de explotación de recursos en forestas tropicales lluviosas: los Nukak de la amazonia colombiana. Revista Española de Antropología Americana 27: 167-197. 
-Pozner R. 1999 Cucurbitaceae En: F. Zuloaga y O. Morrone (Eds.) Catalogo de las plantas vasculares de la República Argentina Vol. II Dycotiledoneae. Missouri Botanical Garden.

-Raffino, R. 1975 Potencial ecológico y modelos económicos en el NOA Relaciones de la Sociedad Argentina de Antropología n.s. t. IX

-Raffino, R. 1976 Las aldeas del Formativo inferior de la Quebrada del Toro. Obra del Centenario del Museo de La Plata, tomo II: 253-297

-Raffino, R. (Ed) 2004 El Shincal de Quimivil. Ed. Sarquis. Catamarca.

-Renfrew J. 1969. The archaeological evidence for the domestication of plants: methods and problems. En: P. Ucko y G. Dimbleby (Ed.) The domestication and exploitation of plants and animals. London.

-Renfrew, J. 1973. Palaethnobotany. The prehistoric food plants of the Near East and Europe. New York. Columbia University Press.

-Riehl, S. 2007 Archaeobotanical evidence for the interrelationship of agricultural decision-making and climate change in the ancient Near East. Quaternary International doi:10.1016/j.quaint.2007.08.005

-Reyes García V., Huanca T., Vadez V., Leonard W. y Wilkie D. 2006 Cultural, practical, and economic value of wild plants: a quantitative study in the Bolivian Amazon Economic Botany 60 (1): 1-13

-Rindos D. 1980. Simbiosis, instability, and the origins and spread of agriculture: a new model. Current Anthropology, 12(16): 751-773

-Rivera M. 1980 La agriculturizacion del maíz en el Norte de Chile: actualización de problemas y metodología de investigación. En: Actas del V Congreso Nacional de Arqueología Argentina T I: 47-54. San Juan

-Rivero M., Soto P., Ulloa L. y Kushner D. 1974 Aspectos sobre el desarrollo tecnológico en el proceso de agriculturización en el norte prehispánico, especialmente Arica (Chile) Chungara 3: 79-107

-Rivolta M. C. 1996 Quebrada de Sarahuaico: nuevas perspectivas (Depto. Tilcara, Pcia. jujuy) Revista del Museo de Historia Natural de San Rafael Actas y memorias del XI C.N.A.A. Tomo: Arqueología del noroeste argentino (13). XXV (1-2): 189-202

-Robinson R.W., H. Munger, T. Whitaker y G. Bohn 1976 Genes of the Cucurbitaceae HortScience 11(6) 554:568

-Rodríguez M.F. 1999 Arqueobotánica de Quebrada Seca 3 (Puna meridional argentina): especies vegetales utilizadas en la confección de artefactos durante el arcaico Relaciones de la Sociedad Argentina de Antropología XXIV:159-186

-Rodríguez M.F., Rúgolo de Agrasar Z y Aschero C. 2006 El uso de las plantas en unidades domésticas del sitio arqueológico Punta de la Peña 4, Puna Meridional argentina. Chungara 38(2):257-271 
-Rodriguez M.F. y Martínez J.G. 2001 Especies vegetales alóctonas como recursos arqueológicos en el ámbito puneño Asociación paleontológica argentina. Publicación especial XI Simposio Argentino de Paleobotánica y Palinología: 139-145

-Roig F. 1977 Frutos y semillas arqueológicas de Calingasta, San Juan. En: Gambier M. La cultura Ansilta Instituto de Investigaciones arqueológicas y Museo. F.F.H. y A. U.N.S.J. San Juan

-Roig F. 1992 Restos vegetales del yacimiento arqueológico de Punta del Barro, Angualasto, Provincia de San Juan, Argentina. I, basurero 2. Publicaciones 18 Instituto de Investigaciones arqueológicas y museo U.N.S.J.

-Roig F. y Bárcena J 1983 Tephrocactus andicola (Cactaceae) Recurso alimenticio de aborígenes pre y posthispánicos de Mendoza (Argentina) Parodiana 2(1): 59-66

-Rossen J., Dillehay T. y Ugent D. 1996 Ancient cultigens or modern intrusions?: evaluating plant remains in an Andean case study. Journal of archaeological science 23: 391-407

-Sanjur O., Piperno D., Andres T. Y Wessel-Beaver L 2002 Phylogenetic relationships among domesticated and wild species of Cucurbita (Cucurbitaceae) inferred from a mitochondrial gene: Implications for crop plant evolution and areas of origin. PNAS 99 (1): 535-540.

-Santoro C. 1980 Fase Azapa, transición del arcaico al desarrollo agrario inicial en los Valles Bajos de Arica Chungara 6: 46-56.

-Sarli A 1968 Notas sobre algunas plantas alimenticias americanas. Revista de la facultad de agronomía XLIX:113-123. La Plata

-Scattolin M C 2003 Representaciones sexuadas y jerarquías sociales en el noroeste argentino prehispánico Acta Americana 11(1): 30-48

-Scattolin M C 2007 Santa María antes del año mil. Fechas y materiales para una historia cultural En: Williams V, Ventura B., Callegari A., Yacobaccio H.(eds.) Sociedades precolombinas surandinas: temporalidad, interacción y dinámica cultural del NOA en el ámbito de los Andes centro-sur pp. 203-220. Buschi, Buenos Aires

-Scattolin M. C y Lazzari M. 1997 Tramando redes: obsidianas al oeste del Aconquija. Estudios atacameños 14:211-218

-Schiffer M. (ed.) 1979 Advances in archaeological method and theory. Academic Press. New York

-Schmidl U. 1993 [1567] Viaje al Río de La Plata Ed. Emecé, Buenos Aires.

-Schóbinger, J. 1988 Prehistoria de Sudamérica-Culturas precerámicas Ed. Alianza América. Madrid.

-Seeland, K 1997 Indigenous knowledge of trees and forests in non- European socities En: K. Seeland (Ed.) Nature is culture Intermediate technology publications

-Seelenfreund, A. 1995-1996 Análisis de restos botánicos de dos sitios alfareros tempranos en la Bahía de las Cañas (VII Región) Revista Chilena de Antropología 13 
-Sempé M C 1993 Principios normativos del estilo de decoración de la cerámica Cienaga Universidad Nacional de San Juan FFHyA Publicaciones 20: 1-17

-Sempé de Gomez Llanez, M.C. 1975 Algunas consideraciones sobre la arqueología del Valle de Abaucán En: Actas y trabajos del Primer Congreso de Arqueología Argentina pp: 205-219

-Sempé de Gomez Llanez, M.C. 1984 Estética o estéticas: imagen y representación en el arte americano Arte Sur 1 (1).

-Shiva, V. $2006 \mathrm{El}$ acuerdo de los TRIPs: de los bienes comunales a las patentes comerciales sobre la vida. En: Mander J. y Tauli Corpuz V (eds) Guerra de paradigmas. Resistencia de los pueblos indígenas a la globalización económica. Foro Internacional sobre la globalización. Comité sobre pueblos indígenas.

-Singh D. y Dathan A. 1972 Structure and development of seed coat in Cucurbitaceace IV. Seeds o Cucurbita. Phytomorphology 22(1):29-45.

-Singh D. y Dathan A 1990 Seed coat anatomy of the Cucurbitaceae En: Bates, Robinson y Jeffrey (Eds.) Biology and utilization of the Cucurbitaceae pp: 225-238. Cornel University Press, Ithaca

-Smith B 1985 The role of Chenopodium as a domesticate in pre-maize garden systems of the eastern United States Southeastern archaeology 41 (1): 51-72

-Smith B. 1992 Prehistoric plant husbandry in eastern North America En: C.W. Cowan y P.J. Watson (Eds.) The origins of agriculture. An international perspective pp: 101-120. Smithsonian Institution Press Washington

-Smith B. 1997 The initial domestication of Cucurbita pepo in the Americas 10.000 years ago Science 276: 865-996

-Smith B. 2000 Guila Naquitz Revisited. Agricultural origins in Oaxaca, México. En: Feinman G. y Manzanilla L. (Eds.) Cultural evolution: contemporary viewpoints Cap. 2 pp:15-60 Kluwer Academic/Plenum Publishers New York.

-Smith B 2006a Documenting domestication in plants in the archaeological record. En: Zeder M, Emshwiller E, Bradley D, Smith B (eds) Documenting domestication: new genetic and archaeological paradigms. University of California Press, Berkeley

-Smith B 2006b Seed size increase as a marker of plant domestication. En: Zeder M, Emshwiller E, Bradley D, Smith B (eds) Documenting domestication: new genetic and archaeological paradigms. University of California Press, Berkeley

-Sosa Verón H. 1948 Calabazas chaquenses. Revista geográfica americana Año XV, Vol. XXIX No 178 pp: 20-22.

-Solbrig, O.T., Cantino, P. D., 1975. Reproductive adaptations in Prosopis (Leguminosae, Mimosoideae). Journal of the Arnold Arboretum 56 (2): 185-210.

-Sthapit B., Shrestha P., Subedi M. y Castillo-González F. 2000 Mass selection: a low-cost, widely aplicable meted for local crop improvement in Nepal and México En: Esbern Friis-Hansen and Bhuwon Sthapit (Eds.) Participatory 
approaches to the conservation and use of plant genetic resources. IPGRI Centre for development research-denmark

-Storni, J.S. 1937 Vegetales que utilizaban nuestros indígenas para su alimentación Ed. Universidad del Tucumán.

-Storni J.S 1944 Hortus guranensis Flora Gabinete de etnología biológica U.N.T. Tucumán.

-Stothert K., Piperno D., Andres T. 2003 Terminal Pleistocene/Early Holocene human adaptation in coastal Ecuador: the Las Vegas evidence Quaternary International 109-110: 23-43

-Tarragó M. 1974 Aspectos ecológicos y poblamiento prehispánico en el Valle Calchaquí, provincia de Salta, Argentina Revista del Instituto de Antropología (Universidad Nacional de Córdoba) 5: 195-216

-Tarragó M. 1980. El proceso de agriculturización en el noroeste argentino, zona Valliserrana, y sus relaciones con zonas vecinas. Actas del $V$ Congreso Nacional de Arqueología Argentina

-Tarragó M. 1983 La historia de los pueblos circumpuneños en relación con el altiplano y los andes meridionales Ponencias del Simposio de Arqueología atacameña San Pedro de Atacama, Chile.

-Tarragó M. 1996 El formativo en el noroeste argentino y el alto Valle Calchaquí Revista del Museo de Historia Natural de San Rafael XXIII (1/4):103-164

-Tarragó M. 2003 La arqueología de los Valles Calchaquíes en perspectiva histórica Anales. Nueva Época 6: 13-42 Goteberg

-Tarragó M y De Lorenzi M. 1976 Arqueología del Valle Calchaquí Etnia 23-24: 1-35

-Tartusi M.R. y Núñez Regueiro V. 1993 El papel de los centros ceremoniales en la historia prehispánica del Noroeste argentino Terceras jornadas arqueológicas cuyanas Resumenes de conferencias y comunicaciones 11 Mendoza

-Tartusi M. y Núñez Regueiro V. 2005 La presencia de Condorhuasi y Aguada en Tucumán. En: Martin S., Gonaldi M.E., Ferraris S. y Giordano A. (eds.) La cultura de la Aguada y sus expresiones regionales Eudelar La Rioja

-Teppner H. 2004 Notes on Lagenaria and Cucurbita (Cucurbitaceae) Review and new contributions. Phyton 44 (2): 245-308

-Toledo 2002 Ethnoecology. A conceptual framework for the study of indigenous knowledge of nature. En: Stepp, Wyndham y Zarker (eds.)Ethnobiology and biocultural diversity International society of Ethnobiology

-Torres M y Baffi E. 1996 Evaluación de diferencias sociales en un grupo prehistórico: Las Pirguas (Salta, Argentina) Actas y memorias del XI Congreso Nacional de arqueología argentina (11 parte). Revista del Museo de Historia Natural de San Rafael XXIII (1/4):121-131

-Torres G, Santoni M y Romero L 2007 Los Wichi del Chaco Salteño ayer y hoy. Alimentación y Nutrición Ed. Cristol. 
-Towle M. 1961 The Ethnobotany of Pre-Columbian Peru Ed. Aldine Publishing Company. Chicago

-Trobok, S., 1985. Morfología de frutos y semillas de Prosopis (FabaceaeMimosoideae) chilenos. En: Estado actual del conocimiento sobre Prosopis tamarugo, FAO, pp, 239-253.

-Unger- Hamilton R. 1985 Microscopic striations on flint sickle-blades as an indication of plant cultivation: preliminary results World Archaeology 17(1): 121-126 -Urrutia M.E. y Bogazzi E. 1996 Determinación taxonómica de una semilla de cucurbitacea procedente de la cueva Epullan Grande (Provincia de Neuquen) Praelustana 2: 23-24

-Valderas J. 2000 Francisco Vélez de Arciniega en la polémica de la coloquíntida Asclepio LII- I: 7-35

-Valega Rosas R, T. Andres y M. Nee 2004 The Goldman Cucurbit Collecting Expedition in Peru (Informe). www.cucurbit.org

-Vargas E., Castro E., Macaya G. y Rocha O. 2003 Variación del tamaño de frutos $y$ semillas en 38 poblaciones silvestres de Phaseolus lunatus (Fabaceae) del Valle Central de Costa Rica Revista de biología tropical 51 (3-4)

-Vaughant D., Balazs E.y Heslop-Harrison J.S. 2007 From crop domestication to super-domestication Annals of botany 100:893-901

-Vavilov N 1951 Estudios sobre orígenes de las plantas cultivadas. Acme Agency, Buenos Aires.

-Vega-Centeno Sara-Lafosse R. 2005 Ritual and architecture in a context of emergent complexity: A perspective from Cerro Lampay, a late archaic site in the Central Andes. Disertación enviada al departamento de antropología para optar al grado de Doctor en Filosofía. Universidad de Arizona

-Villagrán C., Castro V., Sánchez G., Hinojosa F. y Latorre C. 1999 La tradición altiplánica: estudio etnobotánico en los andes de Iquique, primera región, Chile. Chungara 31 (1):81-186.

-Vogl C.R, B.N. Vogl-Lukasser y J. Caballero 2002 Homegardens of Maya Migrants in the District of Palenque, Chiapas, México. En: Stepp, Wyndham y Zargeer (Eds).Ethnobiology and biocultural diversity, pp:631-647. I.S.E.. EE.UU.

-Vogl-LukasserB.N., C.R. Vogl y H. Bolhar-Nordenkampf 2002 Homegarden composition on small peasant farms in the alpine regions of Osttirol (Austria) and their role in sustainable rural developement. En: Stepp, Wyndham y Zargeer (Eds).Ethnobiology and biocultural diversity. pp:648-658I.S.E.. EE.UU

-Wagner G. 2002 Why plants have meaning. En: A. Stepp, E. Wyndham y D. Zargeer (Eds). Ethnobiology and biocultural diversity. . pp: 659-667I.S.E.. EE.UU

-Warman A. 1988 La historia de un bastardo: maíy y capitalismo Ed. Fondo de Cultura Económica. 
-Watson P. 1985 The impact of early horticulture in the upland drainages of the Midwest and Midsouth Anthropological Papers 75: 99- 148

-West M. y Whitaker T. 1979. Prehistoric cultivated cucurbits from the Viru Valley, Peru. Economic Botany 33 (3): 275-279

-Western C. 2008 Wood reference collection notebook http://wmw.liv.ac.uk

-Wetterstrom W. 1978 Cognitive systems, food patterns and paleoethnobotany Anthropological papers 67:81-95

-Willey G y Phillips P. 1958 Método y teoría en la arqueología americana. The University of Chicago Press.

-Winterhalder B. y Goland C. 1997 An evolutionary ecology perspective on diet choice, risk and plant domestication En: Gremillion K. (Ed.) People, plantas and landscapes. Studies in paleoethnobotany. pp:108-123. Alabama Press. Tuscaloosa

-Whitaker T. 1968 Ecological aspects of the cultivated Cucurbita Hort Science 3 (1) -Whitaker T. 1974 Cucurbitales Enciclopedia británica 15² Ed. Helen Hemingway Benton Publisher U.S.A.

-Whitaker T. 1980 Cucurbitáceas americanas útiles al hombre Conferencia dada en La Plata. Comisión de Investigaciones Científicas de la provincia de Buenos Aires.

-Whitaker T. 1981 Archaeological cucurbits Economic Botany 35(4) 460:466

-Whitaker T. 1982 All about pumpinks, squashes and gourds California Garden January-February

-Whitaker T. 1983 Cucurbits in Andean prehistory American antiquity 48 (3): 576585

-Whitaker y I.C. Jagger 1937 Breeding and improvement of cucurbits Yearbook

-Whitaker T. y Bohn G.W. 1950 The taxonomy, genetics, production and uses of the cultivated species of Cucurbita. Economic Botany 4:52-81.

-Whitaker T.W. y Bemis W.P. 1964 Evolution in the genus Cucurbita Evolution 18 (4): 553-559

-Whitaker T. y Bemis W. 1976 Cucurbits. Cucumis, Citrullus, Cucurbita, Lagenaria (Cucurbitaceae). En: N.W. Simmons (ED.) Evolution of crop plant. pp: 64-69 Longman Group Lted. London, New York

-Whitaker T. y Cutler H. 1967 Pottery and Cucurbita species American Antiquity 32 (2): 225-226

-Whitaker T. y Cutler H. 1968 A new species of Cucurbita from Ecuador Annals of the Missouri Botanical Garden 55 (3):392-396

-Willey y Phillips 1958. Método y teoría en la arqueología americana. The University of Chicago Press.

-Winton A y Winton K 1935 The structure and composition of foods Vol II J. Wiley \& Sons Inc. New Cork

-Wright K. 1994 Ground-stone tools and hunter-gatherer subsistence in Southwest Asia: implications for the transition to Farming American Antiquity 59 (2): $238-263$ 
-Wright P. 2003 Preservation or destruction of plant remains by carbonization? Journal of Archaeological Science 30: 577-583

-Würschmidt A. 2003 Evidencias prehispánicas de Cucurbitáceas en un sitio arqueológico de la provincia de Jujuy (Argentina) Relaciones de la Sociedad Argentina de Antropología XXVIII:253-256

-Würschmidt A. y Korstanje A. 1998/1999 Maíz en la cocina: primeras evidencias de fitolitos en sitios arqueológicos del NO argentino Cuadernos del Instituto Nacional de Antropologia y Pensamiento latinoamericano 18: 457-468

-Yacobaccio H. 1994 Biomasa animal y consumo en el pleistoceno-holoceno surandindo Arqueología 4: 43-71

-Yacobaccio H. 2007 Complejidad social, especialización y domesticación de camélidos en cazadores recolectores Surandinos. En: Williams V, Ventura B., Callegari A., Yacobaccio H.(eds.) Sociedades precolombinas surandinas: temporalidad, interacción y dinámica cultural del NOA en el ámbito de los Andes centro-sur pp. 203-220. Buschi, Buenos Aires

-Yacobaccio H, Madero C, Malmierca M y Reigadas M. C 1997-1998 Caza, domesticación y pastoreo de camélidos en la Puna argentina Relaciones de la Sociedad Argentina de Antropología. XXII-XXIII: 389-429

-Yacovleff E y Herrera F. 1934 El mundo vegetal de los antiguos peruanos (parte I) Revista del Museo Nacional III (3): 243-323

-Yacovleff E y Herrera F. 1935 El mundo vegetal de los antiguos peruanos (parte II) Revista del Museo Nacional IV (1): 31-102

-Yetsir H., Sakar M. y Serce S. 2008 Collection and morphological characterization of Lagenaria siceraria germplasm from the Mediterranean region of Turkey Genetic resources and crop evolution 55: 1257-1266

-Zardini, E. 1991. Ethnobotanical notes on Yacon. Economic Botany 45:72-85.

- Zardini E. y Pochettino M.L. 1983 Resultados de un viaje etnobotánico al norte de Salta (Argentina) IDIA: 108-121

-Zohary D., 1969. The progenitors of wheat and barley in relation to domestication and agricultural dispersal in the Old World. En: P.Ucko y G. Dimbleby (Eds).. The domestication and exploitation of plants and animals. London.

-Zuloaga F. y Morrone O. (Eds.) 1999 Catalogo de las plantas vasculares de la República Argentina Vol. II Dycotiledoneae. Missouri Botanical Garden. 
ANEXOS.

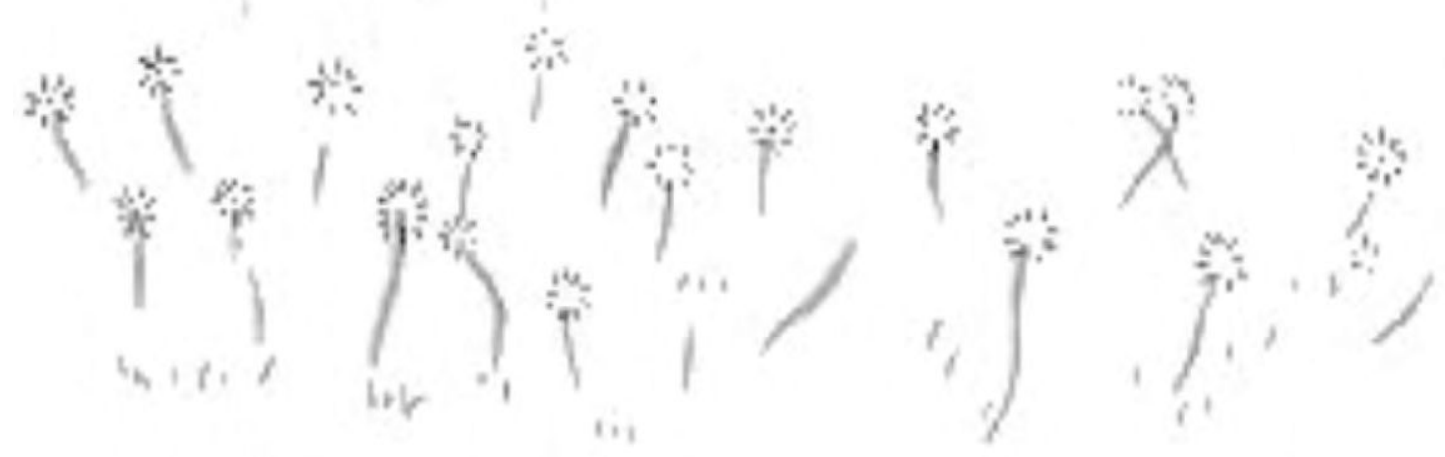




\section{ANEXO I \\ Reconstrucción de los contextos del sitio Puente del Diablo (SSalLap20) a partir de los datos registrados en libretas de campo originales.}

\section{Cuadrícula A2}

\section{Capa $1(0-10 \mathrm{~cm})$}

Restos de Lagidium sp. mordidos por carnívoros in situ.

Endocarpos de Prosopis flexuosa (24), P chilensis o alba (15), P. torquata (4), P. ferox (2), P. alba (5), Prosopis sp (9) varios con restos de mesocarpo y epicarpo, semillas de Tephrocactus sp. (93), ovarios de Lobivia sp. (2), un fragmento de posible epicarpo de Lagenaria sp. o Cucurbita sp., dos fragmentos de cubiertas seminales de Cucurbita sp., fragmentos pequeños de madera, algunos termoalterados, uno es madera de Cactácea, una posible semilla de quínoa, un ovario o receptáculo y una flor y seis espinas de cactácea, cinco pequeños carboncitos.

Además de flotación se recuperaron muchas heces de roedor, un posible zarcillo, cubiertas de insectos castaño claro y oscuro, fragmentos de cáscara de huevo blanco, posibles restos de hojas, dos fragmentos de valvas.

Un coprolito

Fragmentos pequeños de concreción calcárea blanca, uno de ellos con una porción de pluma gris-negra adherida

Dos trozos pequeños de sedimento de color rojizo (¿ocre?)

Agregado de lana color castaño claro amarillento con forma de ovillo pequeño. Al microscopio se ve todo lana y algunas ramitas, al apretarlo es duro, diámetro aprox.: $1 \mathrm{~cm}$ (¿origen animal?)

Anudado de varios cordones finos y gruesos. Todos color castaño claro.

Lasca secundaria de desecho de metacuarcita gris

\section{Capa 2 (10-20)}

Endocarpos de Prospis flexuosa (9), P. chilensis/alba (9), P. torquata (1), Prosopis sp. (1) varios con restos de epicarpo y mesocarpo; un ovario de Lobivia sp y un fruto de P. ferox.

Restos de Lagidium sp. con señales de exposición al fuego.

\section{Capa 3 (20-30)}


Restos de Cervidae y huesos con señales de corte y exposición al fuego. Restos de animales pequeños: roedores y aves.

Cordel de lana conformado por el trenzado de cuatro cordeles hilados, dos más delgados y dos más gruesos, castaño rojizo, $32 \mathrm{~cm}$. largo

\section{Cuadrícula A3}

\section{Capa $1(0-10)$}

Endocarpos de Prosopis. flexuosa (11), P. chilensis/alba (3), P. chilensis (2) y Prosopis sp. (1) con restos de epicarpo. Restos de Lagidium sp. y de ave.

Cáscara de huevo verde determinado como perteneciente a Eudromia elegans

\section{Capa 2 (10-20)}

Restos de Lagidium sp. y placas móviles de Chaetophractus sp. Huesos con huellas de mordida de carnívoro. Posible metapodio de mamífero grande y restos de pezuña. Posibles restos de aves.

Endocarpos de P. flexuosa (2), P. chilensis/alba (4), con restos de epicarpo. Resto de cubierta seminal de Cucurbita sp. (C)

\section{Capa 3 (20-30)}

Restos de Lama sp .y otros de mamífero mediano-grande con marcas de corte y de roído. Restos de Lagidium sp.

Endocarpos de Prosopis sp. (1), P. chilensis/alba (2), con escasos restos de mesocarpo.

\section{Capa 4 (30-40)}

Restos de Lagidium sp. Un endocarpo de P. flexuosa .

Cáscara de huevo verde determinado como perteneciente a Eudromia elegans

\section{CUADRÍCULA B3}

\section{Capa 1(0-10)}


Restos de molariformes de Lagidium sp. y Cricetidae. Fruto con semillas de Tephrocactus sp., endocarpos de P. chilensis/alba (23), de P. flexuosa (6), de P. torquata (2) y de P. ferox (2), fragmento de tronco de arbusto.

\section{Capa 2 (10-20)}

Restos de Xenartro juvenil y de metapodios de Lama sp. Restos con señales de meteorizacion intensa.

\section{Capa 3 (20-30)}

Resto vegetal indet..

\section{CUADRÍCULA C3}

\section{Capa $1(0-10)$}

Endocarpos de P. flexuosa (1), P. alba (1) y Prosopis sp. (8) algunos con restos de epicarpo.

\section{Capa 2 (10-20)}

Dos pequeños fragmentos de ocre rojo

\section{Capa 3 (20-30)}

Endocarpos secos de P. flexuosa (3). Restos de Lagidium sp. con marcas de mordidas, astillas de hueso largo de mamífero grande termoalterado, canino de Pseudalopex gymnocercus o P. griseus.

\section{Capa 5 (40-50)}

Aparente artefacto tallado en madera semejante a tarabita aunque la curvatura que describe no parece corresponder a la típica de estos artefactos. Un extremo es de tipo tarabita, el otro no está y no parecería haber fractura intencional, además este extremo es más ancho que la cabeza tallada. Esta última no se continúa en el reverso de la pieza, el cual es totalmente liso. Madera abierta en varias capas ( 5 aproximadamente), la capa más superficial del anverso se halla craquelada, lo cual no ocurre en la superficie del reverso. Cabeza tallada (solo del anverso) con abertura en forma de $\mathrm{V}$ de unos $5 \mathrm{~mm}$. de profundidad (Hay dibujo con datos) (¿tarabita? ¿tarabita "mal hecha" y descartada?). Fragmento de cardón. Conjunto de raicillas, probablemente 
correspondientes a un arbusto. Dos fragmentos de hojas de gramíneas aparentemente del tipo ya visto color naranja-ocre cubiertas con sustancia blanca. Restos indet.

Restos de vértebras y costilla de mamífero grande. Restos de insecto (Ortóptero)

Lasca secundaria de metacuarcita gris (mismo tipo que punta 2-204 y 2-205)

\section{Capa 6 (50-60)}

Semilla de Tephrocactus sp. roída. Restos de Lagidium sp y de Lama sp (vértebras, costillas, autopodio, hueso largo) con marcas de corte y de roído.

\section{Capa 7 (60-70). Asociado al E7}

Pequeños fragmentos deteriorados de madera y fragmentos de viruta de madera delgada y enrollada sobre sí misma color castaño muy claro y con una veta más oscura aparentemente de la misma madera, tiene marcas transversales y oblicuas a la dirección en que se sacó la viruta. Endocarpos secos de Prosopis sp, (2), semilla de Tephrocactus sp.

Rama mandibular y piezas dentales de Canidae indet. posiblemente P. culpaeus (zorro colorado). Restos de insectos, Lagidium sp, cricétidos y aves. Restos de Lama sp.y otros de mamíferos grandes con marcas de corte y carbonización. Fragmento de ocre rojo

\section{Capa 8 (70-80 cm.). Corresponde a entierro7}

Posibles restos de roedor

Punta triangular de base recta y lados convexos, talla bifacial, a presión. Materia prima: basalto (=TC6) Hallada entre las costillas del E7.

\section{Asociado al E7.}

Lasca de rebaje bifacial/ de desecho y otra lasca de rebaje bifacial de Basalto/Metacuarcita negra. Ninguna de las puntas recuperadas posee similar materia prima. Metacuarcita.

Lasca de rebaje bifacial de calcedonia/arenita verde.

Lasca de desecho secundario de metacuarcita verde (mat. prima similar a la de la punta 2-207) con marcas de lascado previo en cara dorsal Dos lascas de metacuarcita gris-marronaceo. Una partida por extracción, con filos potencialmente útiles.

\section{C3 y D3-a}


Cuatro pequeños fragmentos (menos de un $\mathrm{cm}$.) de carbón, con brillo muy intenso en todos los casos, fragmentos de corteza

Restos de Cricetidae y molares de artiodáctilo juvenil. Huesos de cráneo indet. termoalterados.

Un cordel de lana trenzada color amarillo-ocre de $3,5 \mathrm{~cm}$. de largo.

Lasca pequeña de basalto gris oscuro, obtenida por presión, con varios negativos de lascado. Dos lascas secundarias de igual materia prima que la lasca anterior, la cual es muy similar a la de las puntas 2-229 y 2-241.

Lasca primaria (con restos de talón) de desecho secundario y lámina con negativos de lascada, ambas de obsidiana traslúcida.

Siete lascas secundarias de calcedonia/arenita verde, algunas con negativos de lascado, algunas parecen ser el producto de lascado por presión (rebaje bifacial)

Catorce lascas secundarias de metacuarcita de grano fino verde (mismo tipo que punta 2-207), varias con marcas de lascado y aristas en su superficie, una de ellas obtenida aparentemente por presión. De la misma materia prima hay dos lascas primarias de descortezamiento, tres de desecho, tres esquirlas y una microlasca.

Cinco esquirlas de metacuarcita verde con malas características para el lascado. Nueve lascas secundarias, una lámina con negativos de lascado, una lasca primaria de desecho, dos lascas, tres microlascas de metacuarcita gris de grano fino (mismo tipo que punta 2-207 pero más oscura)

Seis lascas secundarias, una lámina, una lasca primaria de descortezamiento y una lasca de metacuarcita gris (mismo tipo que puntas 2-204 y 2-205)

Tres lascas secundarias, una lámina y una lasca de metacuarcita rosa.

Ocho lascas secundarias, algunas con marcas de lascado; dos láminas y una lasca primaria de descortezamiento de basalto gris y una lasca de basalto negro.

\section{Sector B2/B3/C2/C3}

\section{Capa $1(0-10)$}

Fragmento de hueso largo con parte de diáfisis y de epífisis proximal de mamífero grande. Resto de fruto indet.

\section{Capa 2 (10-20)}

Restos de Lagidium sp. y fragmentos de huesos de mamífero mediano-grande muy alterado. Resto de fruto indeterminado. Un endocarpo Prosopis sp. 


\section{Capa 3 (20-30)}

Fragmentos de huesos de mamífero mediano-grande y de mamífero mediano.

\section{Capa 4 (30-40)}

Astilla de hueso largo de mamífero grande.

\section{Capa 5 (40-50)}

Fragmentos de huesos de mamífero mediano-grande y de mamífero mediano. Posibles restos de ave

Una flor de Cactaceae.

\section{Capa 6 (50-60)}

Restos de Lagidium sp. Fragmentos de huesos de mamífero mediano-grande y de mamífero mediano. Escasas marcas de corte y de roído.

Punta triangular de base recta y de lados convexos, talla bifacial y retoques a presión muy similar y misma materia prima que la recuperada en C3, capa 8

\section{Capa 7 (60-70)}

Preforma de punta muy gruesa en varios sectores, sólo posee rasgos de rebaje bifacial. Posee restos escasos de corteza. Se insinúa una morfología similar a la de la cuadrícula D2 La materia prima es una cuarcita gris- violácea (del tipo $2 \mathrm{a}-2 \mathrm{~b})$

\section{$2-243$}

\section{Asociado al hallazgo $\mathrm{N}^{\circ} 1$}

Fragmentos de huesos de animal mediano-grande, posiblemente artiodáctilo, marcas de corte y de roído. Una semilla de Phaseolus sp., un ovario de Lobivia sp., una posible cuenta vegetal y un resto vegetal indet.

Coprolito de unos $2 \mathrm{~cm}$. de largo por $1,5 \mathrm{~cm}$. de ancho con varias cáscaras pequeñas incluidas 
Cuatro cordeles de lana dobles (cuatro cabos) color castaño, tres de $9 \mathrm{~cm}$ de largo y uno de $5 \mathrm{~cm}$ de largo. Cordel de cuatro cabos más gruesos que los anteriores y de color castaño más intenso., largo: 7,5 centímetros.

Dos cordones de lana color castaño oscuro y con nudos no muy definidos en sus extremos, producto del retorcido de dos cordeles, ambos de $9 \mathrm{~cm}$. de largo. Dos cordones de lana color castaño oscuro. Uno de ellos con un nudo en un extremo de $7 \mathrm{~cm}$ de largo; el otro posee 4,5 $\mathrm{cm}$ de largo. Podría ser parte de un único cordón con el anterior.

Inicio de un cordón de lana trenzado, castaño, muy deshecho, largo: $2,5 \mathrm{~cm}$ Vellón de lana con forma de ovillo que posee adherido paja, ramitas y sedimento, $4 \mathrm{~cm}$ de diámetro, color gris ceniciento.

\section{Cuadrícula D2}

Etiqueta: "Moño del entierro central, asociado a E3". Son 5 haces de gramíneas doblados sobre sí mismos en 3 o 4 partes o bien conformando un círculo. El más largo de ellos debe medir unos $10 \mathrm{~cm}$. y los otros unos $5 \mathrm{~cm}$ Pequeño cordón de lana color castaño claro, largo: 2 centímetros.

Preforma de posible punta triangular de base recta con dos aletas insinuadas, Punta (extremo) fracturada, posee adherido hacia el extremo y algo sobre los filos una sustancia castaño-oscura (¿sangre?). Salió dentro de la consolidación, debajo del E3 a $26 \mathrm{~cm}$ de profundidad, asociado a un posible cúbito partido en su extremo distal.

\section{Cuadrícula E1}

\section{Capa 2 (10-20)}

Restos de Lagidium sp. y de Cricetidae. Restos de autopodios de mamífero mediano-grande indet.

Endocarpos de Prosopis flexuosa (43), P. torquata (10), P. ferox (3) y P. alba (5), estos últimos con restos de mesocarpo y epicarpo. Restos de fruto de $P$. ferox, una semilla de Tephrocactus sp. y restos de raíces de cactáceas.

Cordón de lana conformado por dos cuerdas de dos cordones retorcidos cada una (cuatro cabos), color castaño claro. Largo: $15 \mathrm{~cm}$ Cordón de lana compuesto por el retorcido de dos cordones gruesos color castaño claro. Largo: 9,5 centímetros.

Punta triangular de base recta, bifacial, con retoque a presión. Sale a $30 \mathrm{~cm}$ de profundidad, dentro del fogón, próximo a E5 


\section{Capa 3 (20-30)}

Endocarpos de P. flexuosa (3), P. chilensis/alba (4) y P. torquata (2).

\section{Cuadrícula E2}

\section{Capa $1(0-20)$}

Endocarpos de P. flexuosa (1), P. chilensis/alba (9), P. torquata (2) y Prosopis sp. (10). Un receptáculo de Lobivia sp.

Tres fragmentos de cerámica que remontan entre sí. Reductora, superficie externa gris pulida, superficie interna alisada con restos de hollín, sin adherencias.

\section{Capa 2 (10-20)}

Endocarpos de P. flexuosa (20), P. chilensis/alba (8), P. torquata (1)

Tiesto color negro oscuro en ambas superficies. Superficie interna y externa con alisado, no presenta pulido. Es de factura algo mas tosca que los tiestos de capa 1 y 4 .

\section{Capa $3(20-30 \mathrm{~cm}$.}

Restos de cráneo y esqueleto poscraneal de Lagidium sp. Restos de insectos. Endocarpos de P. torquata (1) y P. alba/ chilensis (1) con marcas de roído.

\section{Capa 4 (30-40)}

Endocarpos de P. torquata (2 sueltos y 3 unidos), P. chilensis/alba (2). Fruto termoalterado de $P$. ferox, dos cubiertas seminales de Cucurbita sp. (A y B)

Tiesto con las mismas características que el hallado en la capa 1 de esta cuadrícula, no remontan.

Pluma prácticamente entera color gris-oscuro (muy similar al fragmento de Cuadrícula A2, capa 1)

Fragmento de cristal columnar color castaño rojizo oscuro

Cordón de lana retorcido color castaño oscuro, largo: $21 \mathrm{~cm}$.

Punta triangular de base recta y lados convexos, talla bifacial, retoque a presión, misma materia prima que la punta de la cuadrícula D2. 


\section{Cuadrícula E3}

Capa 1 (0-10)

Un endocarpo de $P$. alba/ P. chilensis, raíces de arbustivas. 


\section{Anexo II}

Restos vegetales que conforman la colección de la localidad arqueológica de Pampa Grande (Museo de Ciencias Naturales de La Plata).

Los datos correspondientes a "localidad", "cuadrícula", "hallazgo", "excavador", "fecha" y "otros datos" fueron transcriptos de las etiquetas originales que se encuentran depositadas junto a los restos arqueológicos de la colección. En la columna "otras etiquetas" se transcribe información presente en etiquetas depositadas junto a los restos arqueológicos de la colección, pero que no corresponden a la originales de la excavación llevada a cabo por A.Rex González, Domingo García y José Togo.

\begin{tabular}{|c|c|c|c|c|c|c|c|c|}
\hline Localidad & Cuadrícula & Hallazgo & Excavador & Fecha & Otros datos & Otras etiquetas & Contenido & Cantidad \\
\hline Sin datos & sin datos & & sin datos & sin datos & & Caverna IV / I & $\begin{array}{l}\text { Cáscara de } \\
\text { cucurbita }\end{array}$ & 2 \\
\hline $\begin{array}{c}\text { Los } \\
\text { Aparejos }\end{array}$ & sin datos & $\begin{array}{c}\text { Hallazgo } \mathrm{n}^{\circ} 5 \text { / } \\
\text { telas que } \\
\text { envolvían al niño }\end{array}$ & Togo & $\begin{array}{c}8-a b r- \\
1971\end{array}$ & & & Chañar & \\
\hline El Litro & C5/ capa1 $(00-0.20)$ & & Togo & $\begin{array}{c}\text { 18-abr- } \\
1971\end{array}$ & & & paja & \\
\hline El Litro & C5/ capa1 $(00-0.20)$ & & Togo & $\begin{array}{c}\text { 18-abr- } \\
1971\end{array}$ & & & Caña & \\
\hline El Litro & superficial & & Sin datos & Sin datos & & & Marlo & 2 \\
\hline Sin datos & Sin datos & & Sin datos & Sin datos & & $\begin{array}{c}\text { Caverna } 2 \text { / Urna } n^{\circ} \\
30 / \text { PG } 26 \text { /250?o } \\
150 ? \text { / tortero de } \\
\text { hueso en exhibición }\end{array}$ & Indeterminado & varios \\
\hline El Litro & C1/ capa1 $(00-0.70)$ & & Togo y Mingo & $\begin{array}{c}17-a b r- \\
1971\end{array}$ & & & Marlo & 1 \\
\hline $\begin{array}{l}\text { Los } \\
\text { Aparejos }\end{array}$ & Sector II/ D3 hasta 0,20 & $\begin{array}{c}\text { Hallazgo } N^{\circ} 4: \\
\text { Restos de olla } N^{\circ} \\
4\end{array}$ & García & $\begin{array}{c}5-a b r- \\
1971\end{array}$ & & & Marlo & 1 \\
\hline $\begin{array}{c}\text { Los } \\
\text { Aparejos }\end{array}$ & Sector II/ D1/ capa 2 (hasta 0.40) & & Sin datos & $\begin{array}{c}2-a b r- \\
1971\end{array}$ & & & Fibra vegetal & \\
\hline $\begin{array}{c}\text { Los } \\
\text { Aparejos }\end{array}$ & Sector II/ D1/ capa 2 (hasta 0.40) & & Sin datos & $\begin{array}{c}2-a b r- \\
1971\end{array}$ & & & Indeterminado & 1 \\
\hline Los & Sector II/ recolección superficie/ & & Sin datos & 2-abr- & & & Marlo & 3 \\
\hline
\end{tabular}




\begin{tabular}{|c|c|}
\hline Aparejos & frente a D1 \\
\hline Los & Sector II/ recolección superficie \\
\hline Aparejos & frente a D1 \\
\hline & Sector II/ recolección superficie \\
\hline Aparejos & frente a D1 \\
\hline Los & Sector II/ recolección superficie \\
\hline Aparejos & frente a D1 \\
\hline $\begin{array}{c}\text { Los } \\
\text { Aparejos }\end{array}$ & Sector II/ D1/ capa1 \\
\hline $\begin{array}{c}\text { Los } \\
\text { Aparejos }\end{array}$ & Sector II/ D1/ capa1 \\
\hline $\begin{array}{c}\text { Los } \\
\text { Aparejos }\end{array}$ & Sector II/ D1/ capa1 \\
\hline $\begin{array}{c}\text { Los } \\
\text { Aparejos }\end{array}$ & Sector II/ C3/ 0,10-0,40 cm \\
\hline $\begin{array}{c}\text { Los } \\
\text { Aparejos }\end{array}$ & Sector II/ C3/ 0,10-0,40 cm \\
\hline $\begin{array}{c}\text { Los } \\
\text { Aparejos }\end{array}$ & Sector II/ C3/ 0,10-0,40 cm \\
\hline $\begin{array}{c}\text { Los } \\
\text { Aparejos }\end{array}$ & Sector II/ C3/ 0,10-0,40 cm \\
\hline $\begin{array}{c}\text { Los } \\
\text { Aparejos }\end{array}$ & Sector II/ C3/ 0,10-0,40 cm \\
\hline $\begin{array}{c}\text { Los } \\
\text { Aparejos }\end{array}$ & Sector II/ C3/ 0,10-0,40 cm \\
\hline $\begin{array}{c}\text { Los } \\
\text { Aparejos }\end{array}$ & Sector II/ C3/ 0,10-0,40 cm \\
\hline $\begin{array}{c}\text { Los } \\
\text { Aparejos }\end{array}$ & Sector II/ C3/ 0,10-0,40 cm \\
\hline El Litro & C5/ capa1 $(00-0.20)$ \\
\hline El Litro & C5/ capa1 (00-0.20) \\
\hline
\end{tabular}

\begin{tabular}{|c|c|c|}
\hline & 1971 & \\
\hline Sin datos & $\begin{array}{l}2-a b r- \\
1971\end{array}$ & \\
\hline Sin datos & $\begin{array}{l}2-a b r- \\
1971\end{array}$ & \\
\hline Sin datos & $\begin{array}{l}2-a b r- \\
1971\end{array}$ & \\
\hline Sin datos & $\begin{array}{l}\text { 31-mar- } \\
1971\end{array}$ & $\begin{array}{l}\text { Esquema } \\
\text { representado en el } \\
\text { cuaderno (corte- } \\
\text { Sector II). } \\
\text { Esquema }\end{array}$ \\
\hline Sin datos & $\begin{array}{c}\text { 31-mar- } \\
1971\end{array}$ & $\begin{array}{l}\text { representado en el } \\
\text { cuaderno (corte- } \\
\text { Sector II). } \\
\text { Esquema }\end{array}$ \\
\hline Sin datos & $\begin{array}{l}\text { 31-mar- } \\
1971\end{array}$ & $\begin{array}{l}\text { representado en el } \\
\text { cuaderno (corte- } \\
\text { Sector II). }\end{array}$ \\
\hline García & $\begin{array}{l}\text { 31-mar- } \\
1971\end{array}$ & $\begin{array}{c}\text { Hay estructura circular } \\
\text { de barro }\end{array}$ \\
\hline García & $\begin{array}{c}\text { 31-mar- } \\
1971\end{array}$ & $\begin{array}{c}\text { Hay estructura circular } \\
\text { de barro }\end{array}$ \\
\hline García & $\begin{array}{c}\text { 31-mar- } \\
1971\end{array}$ & $\begin{array}{c}\text { Hay estructura circular } \\
\text { de barro }\end{array}$ \\
\hline García & $\begin{array}{c}\text { 31-mar- } \\
1971\end{array}$ & $\begin{array}{c}\text { Hay estructura circular } \\
\text { de barro }\end{array}$ \\
\hline García & $\begin{array}{l}\text { 31-mar- } \\
1971\end{array}$ & $\begin{array}{c}\text { Hay estructura circular } \\
\text { de barro }\end{array}$ \\
\hline García & $\begin{array}{c}\text { 31-mar- } \\
1971\end{array}$ & $\begin{array}{l}\text { Hay estructura circular } \\
\text { de barro }\end{array}$ \\
\hline García & $\begin{array}{c}\text { 31-mar- } \\
1971\end{array}$ & $\begin{array}{l}\text { Hay estructura circular } \\
\text { de barro }\end{array}$ \\
\hline García & $\begin{array}{c}\text { 31-mar- } \\
1971\end{array}$ & $\begin{array}{c}\text { Hay estructura circular } \\
\text { de barro }\end{array}$ \\
\hline Togo & $\begin{array}{c}18-a b r- \\
1971\end{array}$ & \\
\hline Togc & $\begin{array}{c}18-a b r- \\
1971\end{array}$ & \\
\hline
\end{tabular}

\begin{tabular}{|c|c|}
\hline $\begin{array}{l}\text { Semillas de } \\
\text { poroto }\end{array}$ & 3 \\
\hline Chañar & 2 \\
\hline $\begin{array}{l}\text { Cáscara de } \\
\text { cucurbita }\end{array}$ & 1 \\
\hline Marlo & 12 \\
\hline $\begin{array}{l}\text { Semillas de } \\
\text { poroto }\end{array}$ & 5 \\
\hline Algarrobo & 2 \\
\hline $\begin{array}{l}\text { Semillas de } \\
\text { poroto }\end{array}$ & 32 \\
\hline Algarrobo & 1 \\
\hline Marlo & 13 \\
\hline Chala & 1 \\
\hline $\begin{array}{l}\text { Cáscara de } \\
\text { cucurbita }\end{array}$ & 4 \\
\hline Chañar & 1 \\
\hline Caña & 2 \\
\hline Fibra vegetal & Varios \\
\hline Marlo & 5 \\
\hline $\begin{array}{l}\text { Cáscara de } \\
\text { cucurbita }\end{array}$ & 1 \\
\hline
\end{tabular}




\begin{tabular}{|c|c|c|c|c|c|c|c|c|}
\hline El Litro & C4/ capa1 (00-0.20) & & Togo & $\begin{array}{c}\text { 18-abr- } \\
1971\end{array}$ & & & Marlo & 6 \\
\hline El Litro & C4/ capa1 $(00-0.20)$ & & Togo & $\begin{array}{c}\text { 18-abr- } \\
1971\end{array}$ & & & Caña & \\
\hline El Litro & C5/ capa1 (00-0.20) & & Togo & $\begin{array}{c}\text { 18-abr- } \\
1971\end{array}$ & & & $\begin{array}{l}\text { Cáscara de } \\
\text { cucurbita }\end{array}$ & 1 \\
\hline El Litro & C5/ capa1 (00-0.20) & & Togo & $\begin{array}{c}\text { 18-abr- } \\
1971\end{array}$ & & & Marlo & 8 \\
\hline El Litro & C1/ capa1 (00-0.70) & & $\begin{array}{l}\text { Togo y } \\
\text { García }\end{array}$ & $\begin{array}{c}\text { 17-abr- } \\
1971\end{array}$ & & & Marlo & 50 \\
\hline El Litro & C1/ capa2 (0.70-0.90) & & $\begin{array}{l}\text { Togo y } \\
\text { García }\end{array}$ & $\begin{array}{c}17 \text {-abr- } \\
1971\end{array}$ & & & vaina de maní & varias \\
\hline EI Litro & D4 & hallazgo $n^{\circ} 17$ & Sin datos & Sin datos & Hay huesos humanos & & Marlo & 1 \\
\hline Sin datos & Sin datos & & Sin datos & Sin datos & & & Marlo & 1 \\
\hline Sin datos & Sin datos & & Sin datos & Sin datos & & & vaina de maní & 4 \\
\hline Sin datos & Sin datos & & Sin datos & Sin datos & & & $\begin{array}{l}\text { Semillas de } \\
\text { poroto }\end{array}$ & 2 \\
\hline Sin datos & Sin datos & & Sin datos & Sin datos & & & Marlo & 1 \\
\hline Sin datos & Sin datos & & Sin datos & Sin datos & & $\begin{array}{l}\text { en trozo papel: el } \\
\text { marlo se usó como } \\
\text { muestra sobre } \\
\text { plastilina }\end{array}$ & Marlo & 1 \\
\hline Sin datos & Sin datos & & Sin datos & Sin datos & Siglado: D1/C1-2 & & $\begin{array}{l}\text { Cáscara de } \\
\text { cucurbita }\end{array}$ & 1 \\
\hline $\begin{array}{l}\text { Caverna IV/ } \\
\text { Q. } \\
\text { Lampazar }\end{array}$ & Sin datos & & Sin datos & Sin datos & & & vaina de maní & 6 \\
\hline $\begin{array}{l}\text { Caverna IV/ } \\
\text { Q. } \\
\text { Lampazar }\end{array}$ & Sin datos & & Sin datos & $\begin{array}{l}\text { 10-may- } \\
1971\end{array}$ & & & Marlo & varios \\
\hline $\begin{array}{l}\text { Caverna IV/ } \\
\text { Q. } \\
\text { Lampazar }\end{array}$ & Sin datos & & Sin datos & $\begin{array}{l}\text { 10-may- } \\
1971\end{array}$ & (marlo dentro de olla) & & Marlo & 19 \\
\hline $\begin{array}{l}\text { Los } \\
\text { Aparejos }\end{array}$ & sector III/ F0 (0.40-0.60) & & Togo & $\begin{array}{c}\text { 7-abr- } \\
1971\end{array}$ & & $\begin{array}{l}\text { Por su mal estado } \\
\text { fueron secados en la } \\
\text { parrilla de la cocina a } \\
\text { gas. } 1986\end{array}$ & $\begin{array}{l}\text { Semillas de } \\
\text { poroto }\end{array}$ & 56 \\
\hline $\begin{array}{c}\text { Los } \\
\text { Aparejos }\end{array}$ & $\begin{array}{l}\text { sector II/ superficial, mayorca, } \\
\text { cerca aparecen } 2 \text { paquetes } \\
\text { policromos (negro y rojo sobre }\end{array}$ & & Sin datos & Sin datos & & & Marlo & 1 \\
\hline
\end{tabular}


ante)

\begin{tabular}{|c|c|}
\hline $\begin{array}{c}\text { Los } \\
\text { Aparejos }\end{array}$ & Sector II/ D4/ capa3 (0.40-0.60) \\
\hline $\begin{array}{c}\text { Los } \\
\text { Aparejos }\end{array}$ & Sector II/ D4/ capa3 (0.40-0.60) \\
\hline $\begin{array}{l}\text { Los } \\
\text { Aparejos }\end{array}$ & Sector II/ D1 (superficial) \\
\hline $\begin{array}{l}\text { Los } \\
\text { Aparejos }\end{array}$ & Sector II/ D1 (superficial) \\
\hline $\begin{array}{c}\text { Los } \\
\text { Aparejos }\end{array}$ & Sector II/ D1 (superficial) \\
\hline $\begin{array}{c}\text { Los } \\
\text { Aparejos }\end{array}$ & Sector II/ D1 (superficial) \\
\hline $\begin{array}{c}\text { Los } \\
\text { Aparejos }\end{array}$ & Sector II/ D1 (superficial) \\
\hline $\begin{array}{l}\text { Los } \\
\text { Aparejos }\end{array}$ & Sector II/ D1 (superficial) \\
\hline $\begin{array}{l}\text { Los } \\
\text { Aparejos }\end{array}$ & Sector II/ D1 (superficial) \\
\hline Sin datos & Sector II/ C3/ capa 2a (040-060) \\
\hline $\begin{array}{c}\text { Los } \\
\text { Aparejos }\end{array}$ & sector II/ D1/ capa2 (0.20-0.40) \\
\hline $\begin{array}{l}\text { Los } \\
\text { Aparejos }\end{array}$ & sector II/ D1/ capa2 (0.20-0.40) \\
\hline Sin datos & Sin datos \\
\hline Sin datos & Sin datos \\
\hline Sin datos & Sin datos \\
\hline Sin datos & Sin datos \\
\hline Sin datos & Sin datos \\
\hline Sin datos & Sin datos \\
\hline $\begin{array}{l}\text { Los } \\
\text { Aparejos } \\
\text { Los }\end{array}$ & Sector II/ B-C(3) \\
\hline Aparejos & / D4 (00- \\
\hline
\end{tabular}

\begin{tabular}{|c|c|c|}
\hline García & $\begin{array}{c}\text { 1-abr- } \\
1971\end{array}$ & \\
\hline García & $\begin{array}{c}1-a b r- \\
1971\end{array}$ & \\
\hline García & $\begin{array}{c}\text { 30-mar- } \\
1971\end{array}$ & \\
\hline García & $\begin{array}{c}\text { 30-mar- } \\
1971\end{array}$ & \\
\hline García & $\begin{array}{c}\text { 30-mar- } \\
1971\end{array}$ & \\
\hline García & $\begin{array}{c}\text { 30-mar- } \\
1971\end{array}$ & \\
\hline García & $\begin{array}{c}\text { 30-mar- } \\
1971\end{array}$ & \\
\hline García & $\begin{array}{c}\text { 30-mar- } \\
1971\end{array}$ & \\
\hline García & $\begin{array}{c}\text { 30-mar- } \\
1971\end{array}$ & \\
\hline García & $\begin{array}{l}\text { 31-mar- } \\
1971\end{array}$ & $\begin{array}{l}\text { Cerca de restos } \\
\text { momificados de } \\
\text { adultos }\end{array}$ \\
\hline García & $\begin{array}{c}\text { 30-mar- } \\
1971\end{array}$ & Solo (?) ver tarjeta \\
\hline García & $\begin{array}{c}\text { 30-mar- } \\
1971\end{array}$ & Solo (?) ver tarjeta \\
\hline Sin datos & Sin datos & \\
\hline Sin datos & Sin datos & \\
\hline Sin datos & Sin datos & \\
\hline Sin datos & Sin datos & \\
\hline Sin datos & Sin datos & \\
\hline Sin datos & Sin datos & \\
\hline García & $\begin{array}{c}\text { 6-abr- } \\
1971\end{array}$ & \\
\hline García & $\begin{array}{c}\text { 31-mar- } \\
1971\end{array}$ & \\
\hline
\end{tabular}

$\begin{array}{cc}\begin{array}{c}\text { Semillas de } \\ \text { poroto }\end{array} & 1 \\ \text { Marlo } & 1 \\ \text { Chala } & \text { Varios } \\ \text { Chañar } & 1 \\ \begin{array}{c}\text { Semillas de } \\ \text { poroto }\end{array} & 2 \\ \begin{array}{c}\text { Cáscara de } \\ \text { cucurbita }\end{array} & 3 \\ \text { Vaina de } \\ \text { poroto } & 3 \\ \text { Marlo } & 3 \\ \text { Caña } & 2 \\ \text { Semillas } & \\ \text { Cáscara de } \\ \text { cucurbita } \\ \text { Marlo }\end{array}$


Los Sector I/ Cuad A/ capa 3a / ver

Aparejos

El Litro

Los

Aparejos

Los

Sin datos

Los

Aparejos

Los

Aparejos

Los

Aparejos

Sector III/ E1/ capa4 (0.60-0.80)

Los

Aparejos

Los

Aparejos

Los

Aparejos

Sector III/ E1/ nivel 2 (0.20-0.40)

Los

Aparejos

Sector III/ E1/ nivel 2 (0.20-0.40)

\section{Sin datos}

Sector I/ capa 1

Sector I/ capa 1

\section{D4}

sector III/ F1

Sector II/ B / capa 1 junto a la urna $n^{\circ} 5$

Togo

Sin datos

16-oct-

1971

Superficial producto

de saqueo de

huaqueros

Togo y ARG 29-mar-

1971

Togo y ARG 29-mar-

Hallazgo No 18 :

Dentro de la urna

$n^{\circ} 18$

23-abr-

1971

2-abr-

1971

al realizar el perfil

junto a la urna $n^{\circ} 5$,

con remoción anterior.

2-abr-

1971

Acumulación de

porotos. Ver esquema

2-abr- cuaderno donde está

marcado con $\mathrm{x}$. A

parecer "in situ" /

puede hacerse

$$
\text { fechado. }
$$

9-abr- Contenido de la urna

con esqueleto, etc

Hallazgo $n^{0}$ 1: olla García 1971

1 -abr-

Hallazgo $n^{\circ} 6$ :

Togo

1971

Formaba un núcleo

compacto entre las

piedras, rodeado de

paja; parece "in situ"

puede usarse para $C$ 14.

Formaba un núcleo

compacto entre las

piedras, rodeado de

paja; parece "in situ"

puede usarse para $\mathrm{C}$
Semillas

Varias

Marlo

1

Indeterminado

Vaina de

poroto

Indeterminado

Semillas de

poroto

Semillas de

poroto

Semillas de

poroto

Marlo

Fibra vegetal

Semillas de poroto

Semilla de

Cucurbita 


\begin{tabular}{|c|c|}
\hline $\begin{array}{c}\text { Los } \\
\text { Aparejos }\end{array}$ & Sector III/ E1/ nivel $2(0.20-0.40)$ \\
\hline $\begin{array}{c}\text { Los } \\
\text { Aparejos }\end{array}$ & Sector III/ E1/ nivel 2 (0.20-0.40) \\
\hline $\begin{array}{c}\text { Los } \\
\text { Aparejos }\end{array}$ & Sector I/ superficial \\
\hline $\begin{array}{c}\text { Los } \\
\text { Aparejos }\end{array}$ & Sector I/ superficial \\
\hline $\begin{array}{c}\text { Los } \\
\text { Aparejos }\end{array}$ & Sector II/ D4/ capa $2(0.20-0.40)$ \\
\hline $\begin{array}{c}\text { Los } \\
\text { Aparejos }\end{array}$ & Sector II/ D4/ capa 2 (0.20 -0.40) \\
\hline $\begin{array}{c}\text { Los } \\
\text { Aparejos }\end{array}$ & Sector II/ D4/ capa $2(0.20-0.40)$ \\
\hline $\begin{array}{c}\text { Los } \\
\text { Aparejos }\end{array}$ & Sector III/ E1/ capa 1 (00-0.20) \\
\hline $\begin{array}{c}\text { Los } \\
\text { Aparejos }\end{array}$ & Sector III/ E1/ capa 1 (00-0.20) \\
\hline $\begin{array}{c}\text { Los } \\
\text { Aparejos }\end{array}$ & Sector III/ E1/ capa 1 (00-0.20) \\
\hline $\begin{array}{c}\text { Los } \\
\text { Aparejos }\end{array}$ & Sector III/ E1/ capa 1 (00-0.20) \\
\hline $\begin{array}{c}\text { Los } \\
\text { Aparejos }\end{array}$ & Sector III/ E1/ capa 1 (00-0.20) \\
\hline $\begin{array}{l}\text { Los } \\
\text { Aparejos }\end{array}$ & Sector III/ E1/ capa 1 (00-0.20) \\
\hline Aparejos & Sector III/ E1/ capa 1 (00-0.20) \\
\hline
\end{tabular}

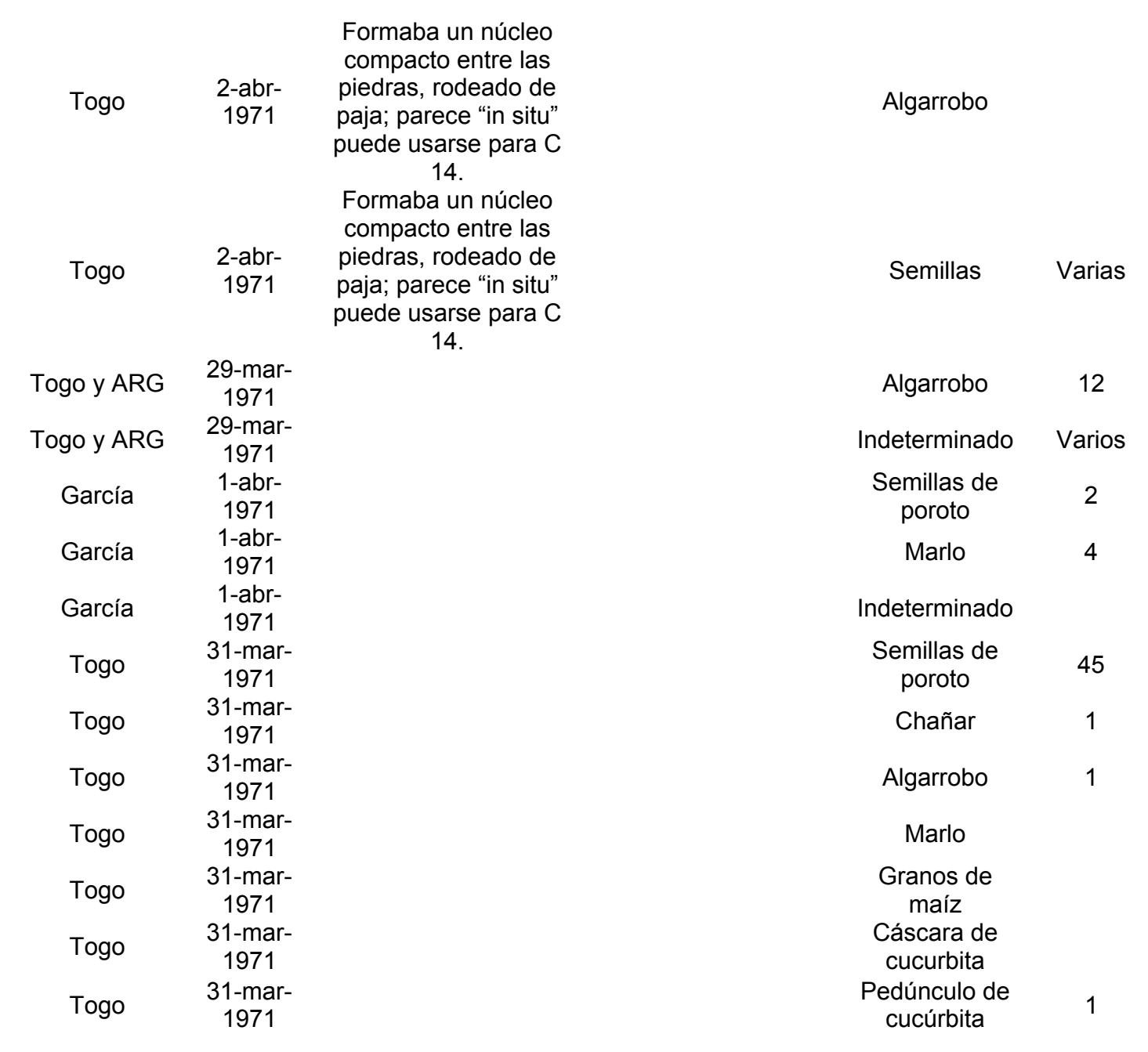


Sin datos

Sin datos

Sin datos

El Litro

Los

Aparejos

Los

Aparejos

Los

Aparejos

Los

Aparejos

Los

Aparejos

Los

Aparejos

Los

Aparejos

Aparejos

Los

Aparejos

Los

Aparejos

Los

Aparejos

Los

Aparejos

EI Litro

Los

Aparejos

Los

Aparejos

Los

Aparejos

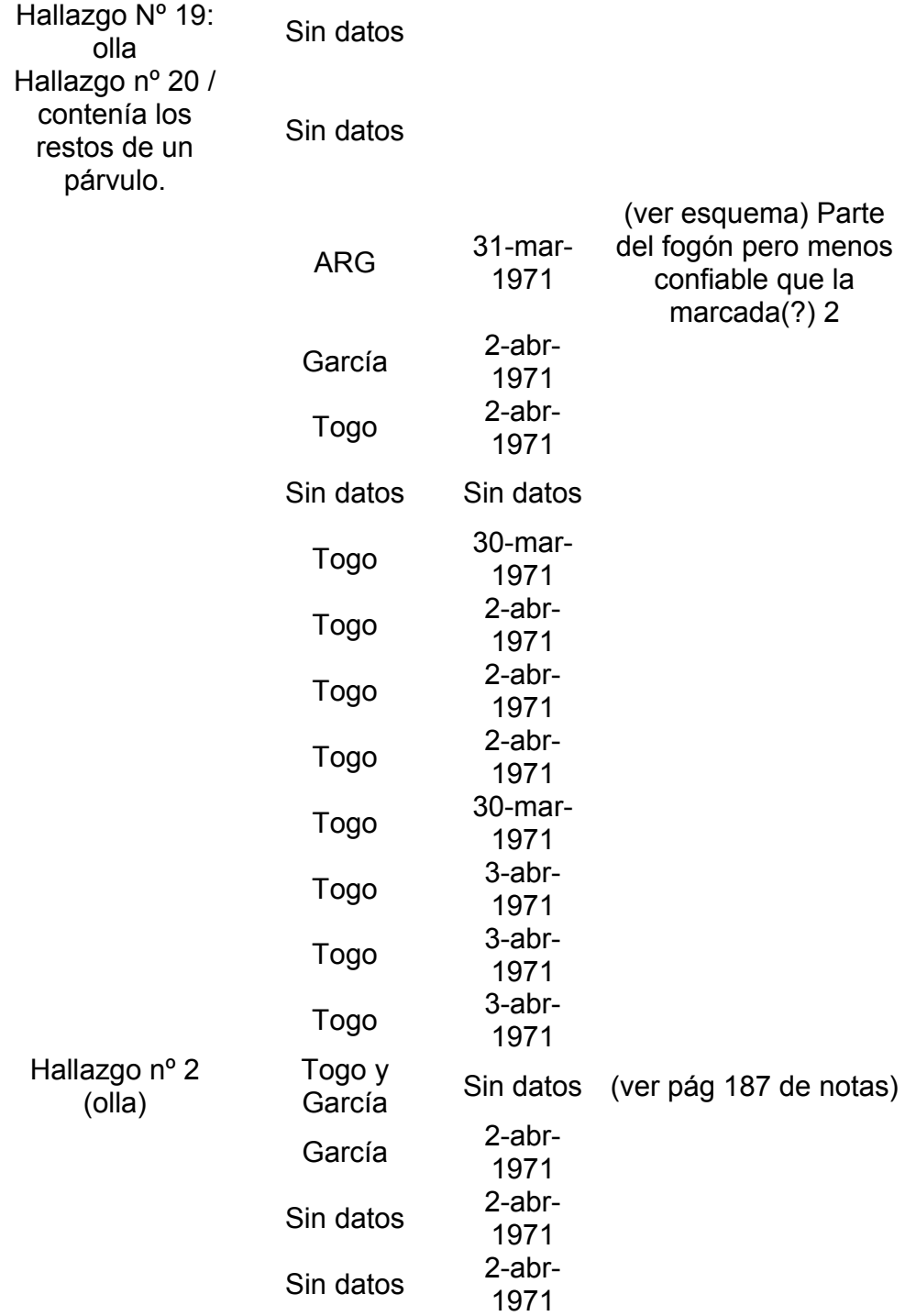

Marlo

Marlo

\begin{tabular}{|c|c|}
\hline Indeterminado & 3 \\
\hline $\begin{array}{l}\text { Semillas de } \\
\text { poroto }\end{array}$ & 80 \\
\hline Indeterminado & 2 \\
\hline Indeterminado & Varios \\
\hline Indeterminado & Varios \\
\hline $\begin{array}{l}\text { Semillas de } \\
\text { poroto }\end{array}$ & 35 \\
\hline Chañar & \\
\hline Marlo & \\
\hline Indeterminado & Varios \\
\hline Vaina & \\
\hline Hoja & \\
\hline Caña & \\
\hline Indeterminado & 6 \\
\hline $\begin{array}{l}\text { Semillas de } \\
\text { poroto }\end{array}$ & 4 \\
\hline $\begin{array}{l}\text { Semillas de } \\
\text { poroto }\end{array}$ & 7 \\
\hline $\begin{array}{l}\text { Vaina de } \\
\text { poroto }\end{array}$ & 3 \\
\hline
\end{tabular}




\begin{tabular}{|c|c|}
\hline $\begin{array}{l}\text { Los } \\
\text { Aparejos }\end{array}$ & Sector II/ D1/ capa 2 (hasta 0.40) \\
\hline $\begin{array}{c}\text { Los } \\
\text { Aparejos }\end{array}$ & Sector III/ E2/ superficial \\
\hline $\begin{array}{l}\text { Los } \\
\text { Aparejos }\end{array}$ & Sector III/ E2/ superficial \\
\hline $\begin{array}{l}\text { Los } \\
\text { Aparejos }\end{array}$ & Sector III/ E2/ superficial \\
\hline $\begin{array}{l}\text { Los } \\
\text { Aparejos }\end{array}$ & Sector III/ E2/ superficial \\
\hline Sin datos & Sin datos \\
\hline $\begin{array}{l}\text { Los } \\
\text { Aparejos }\end{array}$ & Sector III/ F0 (00-0.40) \\
\hline $\begin{array}{l}\text { Los } \\
\text { Aparejos }\end{array}$ & Sector III/ F0 (00-0.40) \\
\hline $\begin{array}{l}\text { Los } \\
\text { Aparejos }\end{array}$ & Sector III/ F0 (00-0.40) \\
\hline El Litro & C1/ capa2 (0.70-0.90) \\
\hline El Litro & C1/ capa2 (0.70-0.90) \\
\hline El Litro & C1/ capa2 (0.70-0.90) \\
\hline El Litro & C1/ capa2 (0.70-0.90) \\
\hline El Litro & $\begin{array}{l}\text { Superficial y capa fértil varias cuad } \\
\text { (?) }\end{array}$ \\
\hline El Litro & $\begin{array}{c}\text { Superficial y capa fértil varias cuad } \\
(?)\end{array}$ \\
\hline El Litro & B4 \\
\hline El Litro & B4 \\
\hline $\begin{array}{l}\text { Los } \\
\text { Aparejos }\end{array}$ & Sector II/ D3/ capa 0.10-0.40 \\
\hline $\begin{array}{l}\text { Los } \\
\text { Aparejos }\end{array}$ & Sector II/ D3/ capa 0.10-0.40 \\
\hline $\begin{array}{l}\text { Los } \\
\text { Aparejos }\end{array}$ & Sector II/ D3/ capa 0.10-0.40 \\
\hline $\begin{array}{c}\text { Los } \\
\text { Aparejos }\end{array}$ & Sector II/ D1/capa 2 \\
\hline
\end{tabular}

\begin{tabular}{|c|c|c|}
\hline Sin datos & $\begin{array}{l}2-a b r- \\
1971\end{array}$ & \\
\hline Togo & $\begin{array}{l}\text { 31-mar- } \\
1971\end{array}$ & \\
\hline Togo & $\begin{array}{c}\text { 31-mar- } \\
1971\end{array}$ & \\
\hline Togo & $\begin{array}{l}\text { 31-mar- } \\
1971\end{array}$ & \\
\hline Togo & $\begin{array}{c}\text { 31-mar- } \\
1971\end{array}$ & \\
\hline Sin datos & Sin datos & $\begin{array}{l}\text { En etiqueta dice: sin } \\
\text { indicación }\end{array}$ \\
\hline Togo & $\begin{array}{c}8 \text {-abr- } \\
1971\end{array}$ & \\
\hline Togo & $\begin{array}{c}8-a b r- \\
1971\end{array}$ & \\
\hline Togo & $\begin{array}{c}\text { 8-abr- } \\
1971\end{array}$ & \\
\hline Togo & $\begin{array}{l}\text { 7-abr- } \\
1971\end{array}$ & \\
\hline Togo & $\begin{array}{l}7-a b r- \\
1971\end{array}$ & \\
\hline Togo & $\begin{array}{l}\text { 7-abr- } \\
1971\end{array}$ & \\
\hline Togo & $\begin{array}{l}7-a b r- \\
1971\end{array}$ & \\
\hline Sin datos & $(04 / 71)$ & \\
\hline Sin datos & $(04 / 71)$ & \\
\hline Sin datos & (/1971) & \\
\hline Sin datos & $(/ 1971)$ & \\
\hline García & $\begin{array}{c}\text { 31-mar- } \\
1971\end{array}$ & \\
\hline García & $\begin{array}{c}\text { 31-mar- } \\
1971\end{array}$ & \\
\hline García & $\begin{array}{l}\text { 31-mar- } \\
1971\end{array}$ & \\
\hline ARG & $\begin{array}{l}\text { 31-mar- } \\
1971\end{array}$ & $\begin{array}{l}\text { Fogón extraído } \\
\text { cuidadosamente }\end{array}$ \\
\hline
\end{tabular}

\begin{tabular}{|c|c|}
\hline Indeterminado & 1 \\
\hline $\begin{array}{l}\text { Semillas de } \\
\text { poroto }\end{array}$ & 11 \\
\hline Vaina & 1 \\
\hline Algarrobo & 6 \\
\hline Chañar & 2 \\
\hline Marlo & 2 \\
\hline $\begin{array}{c}\text { Granos de } \\
\text { maíz }\end{array}$ & 4 \\
\hline $\begin{array}{l}\text { Vaina de } \\
\text { poroto }\end{array}$ & 1 \\
\hline \multicolumn{2}{|l|}{ Indeterminado } \\
\hline $\begin{array}{l}\text { Semillas de } \\
\text { poroto }\end{array}$ & 5 \\
\hline $\begin{array}{l}\text { Vaina de } \\
\text { poroto }\end{array}$ & 4 \\
\hline Chañar & 1 \\
\hline \multicolumn{2}{|l|}{ Indeterminado } \\
\hline $\begin{array}{c}\text { Vaina de } \\
\text { poroto }\end{array}$ & 14 \\
\hline \multicolumn{2}{|l|}{ Indeterminado } \\
\hline Marlo & 1 \\
\hline \multicolumn{2}{|l|}{ Fibra vegetal } \\
\hline Fibra vegetal & 3 grupos \\
\hline $\begin{array}{l}\text { Semillas de } \\
\text { poroto }\end{array}$ & 1 \\
\hline Indeterminado & \\
\hline Fibra vegetal & \\
\hline
\end{tabular}




\begin{tabular}{|c|c|}
\hline Sin datos & Sin datos \\
\hline $\begin{array}{c}\text { Los } \\
\text { Aparejos }\end{array}$ & Sector III/ E2/ capa 4 (0.60-0.80) \\
\hline $\begin{array}{c}\text { Los } \\
\text { Aparejos }\end{array}$ & Sector II/ D1/capa 1, mezcla con 2 \\
\hline $\begin{array}{c}\text { Los } \\
\text { Aparejos }\end{array}$ & Sector II/ D1/capa 1, mezcla con 2 \\
\hline $\begin{array}{c}\text { Los } \\
\text { Aparejos }\end{array}$ & Sector II/ D1/capa 1, mezcla con 2 \\
\hline $\begin{array}{c}\text { Los } \\
\text { Aparejos }\end{array}$ & Sector II/ D1/capa 1, mezcla con 2 \\
\hline $\begin{array}{c}\text { Los } \\
\text { Aparejos }\end{array}$ & Sector II/ D1/capa 1, mezcla con 2 \\
\hline $\begin{array}{c}\text { Los } \\
\text { Aparejos }\end{array}$ & Sector II/ D1/capa 1, mezcla con 2 \\
\hline El Litro & Superficial \\
\hline Sin datos & Sin datos \\
\hline Sin datos & 55 \\
\hline $\begin{array}{c}\text { Los } \\
\text { Aparejos }\end{array}$ & Sector III/ F2/ capa1 (0.20-0.40) \\
\hline $\begin{array}{c}\text { Los } \\
\text { Aparejos }\end{array}$ & Sector III/ F2/ capa1 (0.20-0.40) \\
\hline $\begin{array}{c}\text { Los } \\
\text { Aparejos }\end{array}$ & Sector III/ F2/ capa1 (0.20-0.40) \\
\hline $\begin{array}{c}\text { Los } \\
\text { Aparejos }\end{array}$ & Superficial y hasta $10 \mathrm{~cm}$ \\
\hline $\begin{array}{c}\text { Los } \\
\text { Aparejos }\end{array}$ & Superficial y hasta $10 \mathrm{~cm}$ \\
\hline
\end{tabular}

\begin{tabular}{|c|c|c|}
\hline Sin datos & Sin datos & \\
\hline Togo & $\begin{array}{c}5-a b r- \\
1971\end{array}$ & \\
\hline ARG & $\begin{array}{c}\text { 31-mar- } \\
1971\end{array}$ & $\begin{array}{c}\text { (ver esquema) Parte } \\
\text { del fogón pero menos } \\
\text { confiable que la } \\
\text { marcada } 2 \\
\text { (ver esquema) Parte }\end{array}$ \\
\hline ARG & $\begin{array}{c}\text { 31-mar- } \\
1971\end{array}$ & $\begin{array}{c}\text { del fogón pero menos } \\
\text { confiable que la } \\
\text { marcada } 2 \\
\text { (ver esquema) Parte }\end{array}$ \\
\hline ARG & $\begin{array}{c}\text { 31-mar- } \\
1971\end{array}$ & $\begin{array}{c}\text { del fogón pero menos } \\
\text { confiable que la } \\
\text { marcada } 2 \\
\text { (ver esquema) Parte }\end{array}$ \\
\hline ARG & $\begin{array}{c}\text { 31-mar- } \\
1971\end{array}$ & $\begin{array}{l}\text { del fogón pero menos } \\
\text { confiable que la } \\
\text { marcada } 2 \\
\text { (ver esquema) Parte }\end{array}$ \\
\hline ARG & $\begin{array}{c}\text { 31-mar- } \\
1971\end{array}$ & $\begin{array}{c}\text { del fogón pero menos } \\
\text { confiable que la } \\
\text { marcada } 2 \\
\text { (ver esquema) Parte }\end{array}$ \\
\hline ARG & $\begin{array}{c}\text { 31-mar- } \\
1971\end{array}$ & $\begin{array}{l}\text { del fogón pero menos } \\
\text { confiable que la } \\
\text { marcada } 2\end{array}$ \\
\hline Sin datos & Sin datos & \\
\hline Sin datos & Sin datos & \\
\hline Sin datos & Sin datos & \\
\hline Togo & $\begin{array}{c}2-a b r- \\
1971\end{array}$ & \\
\hline Togo & $\begin{array}{c}2-a b r- \\
1971\end{array}$ & \\
\hline Togo & $\begin{array}{c}2-a b r- \\
1971\end{array}$ & \\
\hline Sin datos & $\begin{array}{c}2-a b r- \\
1971\end{array}$ & Terreno removido \\
\hline Sin datos & $\begin{array}{c}2-a b r- \\
1971\end{array}$ & Terreno removido \\
\hline
\end{tabular}

\begin{tabular}{|c|}
\hline Indeterminado \\
\hline $\begin{array}{l}\text { Semillas de } \\
\text { poroto }\end{array}$ \\
\hline $\begin{array}{l}\text { Semillas de } \\
\text { poroto }\end{array}$ \\
\hline $\begin{array}{l}\text { Vaina de } \\
\text { poroto }\end{array}$ \\
\hline Algarrobo \\
\hline Chañar \\
\hline Hoja \\
\hline Indeterminado \\
\hline $\begin{array}{c}\text { Fibra vegetal } \\
\text { Chañar }\end{array}$ \\
\hline Flor seca \\
\hline $\begin{array}{l}\text { Vaina de } \\
\text { poroto }\end{array}$ \\
\hline Algarrobo \\
\hline Indeterminado \\
\hline $\begin{array}{l}\text { Semillas de } \\
\text { poroto }\end{array}$ \\
\hline Algarrobo \\
\hline
\end{tabular}




\begin{tabular}{|c|c|}
\hline $\begin{array}{l}\text { Los } \\
\text { Aparejos }\end{array}$ & Superficial y hasta $10 \mathrm{~cm}$ \\
\hline $\begin{array}{l}\text { Los } \\
\text { Aparejos }\end{array}$ & Sector III/ F1 \\
\hline $\begin{array}{l}\text { Los } \\
\text { Aparejos }\end{array}$ & Sector III/ F2 (00-0.40) \\
\hline $\begin{array}{l}\text { Los } \\
\text { Aparejos }\end{array}$ & Sector I/ capa 1 \\
\hline $\begin{array}{l}\text { Los } \\
\text { Aparejos }\end{array}$ & $\begin{array}{l}\text { Sector III/ F2/ capa } 1 \text { hasta 00-20- } \\
\qquad 40\end{array}$ \\
\hline $\begin{array}{l}\text { Los } \\
\text { Aparejos }\end{array}$ & $\begin{array}{l}\text { Sector III/ F2/ capa } 1 \text { hasta 00-20- } \\
\qquad 40\end{array}$ \\
\hline $\begin{array}{l}\text { Los } \\
\text { Aparejos }\end{array}$ & $\begin{array}{l}\text { Sector III/ F2/ capa } 1 \text { hasta 00-20- } \\
40\end{array}$ \\
\hline Sin datos & Sin datos \\
\hline Sin datos & Sin datos \\
\hline Sin datos & Sin datos \\
\hline Sin datos & Sin datos \\
\hline $\begin{array}{l}\text { Los } \\
\text { Aparejos }\end{array}$ & Sector III/ E2/ capa1(00-0.20-0.40) \\
\hline $\begin{array}{l}\text { Los } \\
\text { Aparejos }\end{array}$ & Sector III/ E2/ capa1(00-0.20-0.40) \\
\hline El Litro & B4/ capa1 (00-0.25) \\
\hline El Litro & B4/ capa1 (00-0.25) \\
\hline El Litro & B4/ capa1 (00-0.25) \\
\hline El Litro & B4/ capa1 (00-0.25) \\
\hline
\end{tabular}

\begin{tabular}{|c|c|c|c|}
\hline & Sin datos & $\begin{array}{c}2 \text {-abr- } \\
1971\end{array}$ & Terreno removido \\
\hline $\begin{array}{l}\text { Hallazgo } n^{\circ} 5 \text { : } \\
\text { junto a la urna } n^{\circ} 5\end{array}$ & Togo y ARG & $\begin{array}{c}2-a b r- \\
1971\end{array}$ & $\begin{array}{l}\text { Materiales recogidos } \\
\text { al realizar el perfil } \\
\text { junto a la urna } n^{\circ} 5 \text {, } \\
\text { con remoción anterior. }\end{array}$ \\
\hline
\end{tabular}

\section{Indeterminado 2 \\ Cáscara de cucurbita \\ Caña}

Indeterminado

Semillas de

poroto

Vaina de

poroto

Algarrobo

Semillas de poroto

Vaina de maní 3

Granos de 3

maíz

Indeterminado Marlo

Cáscara de cucurbita

Vaina de maní

Semillas de poroto

Chañar

Indeterminado

Hallada en la depresión (?) de la

conana grande del

bloque del sector III /

debe ser de remoción

$$
\text { anterior }
$$


Los

Aparejos

Superficial

Los

Aparejos

Sector III/ E / capa 4 (0.60-0.80)

Los

Aparejos

Sector III/ E / capa 4 (0.60-0.80)

Los

Aparejos

Sector III/ E / capa 4 (0.60-0.80)

Los

Aparejos

Sector III/ E / capa 4 (0.60-0.80)

Los

Aparejos

Sector III/ F1 depresión (?) de la

conana grande del

bloque del sector III /

debe ser de remoción

$$
\text { anterior }
$$

Acumulación de

porotos. Ver esquema

cuaderno donde está

marcado con $\mathrm{x}$. A

parecer "in situ" I

puede hacerse

$$
\text { fechado. }
$$

Acumulación de

porotos. Ver esquema

cuaderno donde está

marcado con $\mathrm{x}$. Al

parecer "in situ" /

puede hacerse

fechado.

Acumulación de

porotos. Ver esquema

cuaderno donde está

marcado con $\mathrm{x}$. A

parecer "in situ" /

puede hacerse

fechado.

Acumulación de

porotos. Ver esquema

cuaderno donde está

2-abr- marcado con x. A

parecer "in situ" /

puede hacerse

$$
\text { fechado. }
$$

Materiales recogidos

$2-a b r-$
$1971 \quad$ junto a la urna $n^{\circ} 5$,

junto a la urna $n^{\circ} 5$,
con remoción anterior.
Chañar

Semillas de poroto

Marlo

Algarrobo

1

Indeterminado

Marlo

2 


\begin{tabular}{|c|c|}
\hline $\begin{array}{l}\text { Los } \\
\text { Aparejos }\end{array}$ & Sector III/ F1 \\
\hline $\begin{array}{l}\text { Los } \\
\text { Aparejos }\end{array}$ & Sector III/ F1 \\
\hline $\begin{array}{l}\text { Los } \\
\text { Aparejos }\end{array}$ & Sector III/ superficial \\
\hline $\begin{array}{l}\text { Los } \\
\text { Aparejos }\end{array}$ & Sector III/ superficial \\
\hline Sin datos & Sin datos \\
\hline $\begin{array}{c}\text { Los } \\
\text { Aparejos }\end{array}$ & Sector II/ B3 \\
\hline $\begin{array}{c}\text { Los } \\
\text { Aparejos }\end{array}$ & Sector II/ B3 \\
\hline $\begin{array}{c}\text { Los } \\
\text { Aparejos }\end{array}$ & Sector II/ B3 \\
\hline $\begin{array}{c}\text { Los } \\
\text { Aparejos }\end{array}$ & Sector II/ B3 \\
\hline $\begin{array}{c}\text { Los } \\
\text { Aparejos }\end{array}$ & Sector II/ B3 \\
\hline $\begin{array}{l}\text { Los } \\
\text { Aparejos }\end{array}$ & $\begin{array}{c}\text { Sector II/ D1/capa } 2 \text { (ver esquema } \\
\text { del cuaderno) }\end{array}$ \\
\hline El Litro & C1/ capa1 (00-0.70) \\
\hline El Litro & C1/ capa1 (00-0.70) \\
\hline El Litro & C1/ capa1 (00-0.70) \\
\hline
\end{tabular}

\begin{tabular}{|c|c|c|}
\hline Togo & $\begin{array}{c}2-a b r- \\
1971\end{array}$ & \multirow{2}{*}{$\begin{array}{c}\text { Materiales recogidos } \\
\text { al realizar el perfil } \\
\text { junto a la urna } n^{\circ} 5 \text {, } \\
\text { con remoción anterior } \\
\text { Materiales recogidos } \\
\text { al realizar el perfil } \\
\text { junto a la urna } n^{\circ} 5 \text {, } \\
\text { con remoción anterior }\end{array}$} \\
\hline Togo & $\begin{array}{c}2 \text {-abr- } \\
1971\end{array}$ & \\
\hline Togo & $\begin{array}{c}\text { 31-mar- } \\
1971\end{array}$ & \\
\hline Togo & $\begin{array}{c}\text { 31-mar- } \\
1971\end{array}$ & \\
\hline García & $\begin{array}{c}\text { 6-abr- } \\
1971\end{array}$ & $\begin{array}{c}\text { Etiq del Inst Darwinion } \\
\text { con determinación de } \\
\text { Burkart que } \\
\text { transcribimos }\end{array}$ \\
\hline García & $\begin{array}{c}\text { 6-abr- } \\
1971\end{array}$ & $\begin{array}{c}\text { con determinación de } \\
\text { Burkart que } \\
\text { transcribimos }\end{array}$ \\
\hline García & $\begin{array}{c}\text { 6-abr- } \\
1971\end{array}$ & $\begin{array}{c}\text { Etiq del Inst Darwinion } \\
\text { con determinación de } \\
\text { Burkart que } \\
\text { transcribimos }\end{array}$ \\
\hline García & $\begin{array}{c}\text { 6-abr- } \\
1971\end{array}$ & $\begin{array}{c}\text { Etiq del Inst Darwinion } \\
\text { con determinación de } \\
\text { Burkart que } \\
\text { transcribimos }\end{array}$ \\
\hline García & $\begin{array}{c}\text { 6-abr- } \\
1971\end{array}$ & $\begin{array}{c}\text { Etiq del Inst Darwinion } \\
\text { con determinación de } \\
\text { Burkart que } \\
\text { transcribimos }\end{array}$ \\
\hline ARG & $\begin{array}{c}\text { 31-mar- } \\
1971\end{array}$ & \\
\hline $\begin{array}{l}\text { Togo y } \\
\text { García }\end{array}$ & $\begin{array}{c}\text { 17-abr- } \\
1971\end{array}$ & \\
\hline $\begin{array}{l}\text { Togo y } \\
\text { García }\end{array}$ & $\begin{array}{c}\text { 17-abr- } \\
1971\end{array}$ & \\
\hline Togo y & 17-abr- & \\
\hline
\end{tabular}

\begin{tabular}{|c|c|}
\hline Algarrobo & 4 \\
\hline Indeterminado & 1 \\
\hline Indeterminado & 9 \\
\hline Fibra vegetal & \\
\hline Fibra vegetal & \\
\hline $\begin{array}{l}\text { Semillas de } \\
\text { poroto }\end{array}$ & 11 \\
\hline Algarrobo & 20 \\
\hline Marlo & 2 \\
\hline Indeterminado & 5 \\
\hline Hoja & \\
\hline Flor seca & \\
\hline $\begin{array}{l}\text { Semillas de } \\
\text { poroto }\end{array}$ & 243 \\
\hline $\begin{array}{l}\text { Granos de } \\
\text { maíz }\end{array}$ & 3 \\
\hline Marlo & Varios \\
\hline
\end{tabular}


Los

Aparejos

Sector III/ F2/ capa4 (0.80-1 m)

Los

Aparejos

Sector III/ F2/ capa4 (0.80-1 m)

Los

Aparejos

Los

Aparejos

Los

Aparejos

Los

Aparejos

Los

Aparejos

Los

Aparejos

Los

Aparejos

Los

Aparejos

EI Litro

El Litro

Los

Aparejos

Los

Aparejos

Los

arejos

Sector III/ F2/ capa2 (040-060)

Sector III/ F2/ capa2 (040-060)

Sector III/ F2/ capa2 (040-060)

Sector III/ F2/ capa2 (040-060)

Sector III/ F2/ capa2 (040-060)

Sector II/ D1/ capa 2 (ver esquema del cuaderno;puede ser un gran fogón)

Sector II/ D1/ capa 2 (ver esquema del cuaderno;puede ser un gran fogón)

Sector II/ D1/ capa 2 (ver esquema del cuaderno;puede ser un gran fogón)

C1/ capa1 (00-0.70)

C1/ capa1 (00-0.70)

Sector III/ F0 (0.40-0.60)

Sector III/ F0 (0.40-0.60)

Sector III/ F0 (0.40-0.60)

C1/ capa1 (00-0.70)
Etiq del Inst Darwinion

con determinación de

$$
\text { Burkart que }
$$

Etiq del Inst Darwinion

Togo $\quad \begin{array}{cc}5-a b r- & \text { con determinación de } \\ 1971 & \text { Burkart que }\end{array}$

transcribimos

Togo 3-abr-

1971
$3-a b r-$

Togo 1971

Togo 3-abr-

3-abr-

1971

Togo 3-abr-

1971

ARG 31-mar-

1971

ARG 31-mar-

1971

ARG 31-mar-

1971

17-abr-

1971

Togo 7-abr-

1971

Togo $\quad \begin{array}{r}7-a b r- \\ 1971\end{array}$

Togo y 17-abr-

García 1971

\begin{tabular}{|c|c|}
\hline $\begin{array}{l}\text { Semillas de } \\
\text { poroto }\end{array}$ & 22 \\
\hline $\begin{array}{c}\text { Granos de } \\
\text { maíz }\end{array}$ & 6 \\
\hline $\begin{array}{c}\text { Semillas de } \\
\text { poroto }\end{array}$ & 8 \\
\hline $\begin{array}{l}\text { Vaina de } \\
\text { poroto }\end{array}$ & 3 \\
\hline Marlo & 1 \\
\hline Vaina de maní & 1 \\
\hline Chañar & 1 \\
\hline Algarrobo & 1 \\
\hline Marlo & 1 \\
\hline Indeterminado & Vari \\
\hline $\begin{array}{c}\text { Semillas de } \\
\text { poroto }\end{array}$ & 1 \\
\hline $\begin{array}{l}\text { Vaina de } \\
\text { poroto }\end{array}$ & 1 \\
\hline $\begin{array}{l}\text { Semillas de } \\
\text { poroto }\end{array}$ & 84 \\
\hline Indeterminado & 1 \\
\hline $\begin{array}{c}\text { Semillas de } \\
\text { poroto } \\
\text { Vaina de } \\
\text { poroto }\end{array}$ & 15 \\
\hline
\end{tabular}




\begin{tabular}{|c|c|c|c|c|c|c|}
\hline El Litro & C1/ capa1 (00-0.70) & & $\begin{array}{l}\text { Togo y } \\
\text { García }\end{array}$ & $\begin{array}{c}17-\mathrm{abr}- \\
1971\end{array}$ & & Indeterminado \\
\hline El Litro & C1/ capa1 (00-0.70) & & $\begin{array}{l}\text { Togo y } \\
\text { García }\end{array}$ & $\begin{array}{c}17-a b r- \\
1971\end{array}$ & & $\begin{array}{l}\text { Semillas de } \\
\text { poroto }\end{array}$ \\
\hline El Litro & C1/ capa1 (00-0.70) & & $\begin{array}{l}\text { Togo y } \\
\text { García }\end{array}$ & $\begin{array}{c}17-a b r- \\
1971\end{array}$ & & $\begin{array}{l}\text { Granos de } \\
\text { maíz }\end{array}$ \\
\hline $\begin{array}{l}\text { Los } \\
\text { Aparejos }\end{array}$ & sector III/ F1 & $\begin{array}{l}\text { Hallazgo } n^{\circ} 5 \text { : } \\
\text { junto a la urna } n^{\circ} 5\end{array}$ & Togo & $\begin{array}{c}2-a b r- \\
1971\end{array}$ & $\begin{array}{l}\text { Materiales recogidos } \\
\text { al realizar el perfil } \\
\text { junto a la urna } n^{\circ} 5 \\
\text { con remoción anterior. } \\
\text { Materiales recogidos }\end{array}$ & $\begin{array}{l}\text { Semillas de } \\
\text { poroto }\end{array}$ \\
\hline $\begin{array}{c}\text { Los } \\
\text { Aparejos }\end{array}$ & sector III/ F1 & $\begin{array}{c}\text { Hallazgo } n^{\circ} 5 \text { : } \\
\text { junto a la urna } n^{\circ} 5\end{array}$ & Togo & $\begin{array}{c}2-a b r- \\
1971\end{array}$ & $\begin{array}{l}\text { al realizar el perfil } \\
\text { junto a la urna } n^{\circ} 5 \text {, } \\
\text { con remoción anterior. } \\
\text { Materiales recogidos }\end{array}$ & $\begin{array}{l}\text { Vaina de } \\
\text { poroto }\end{array}$ \\
\hline $\begin{array}{c}\text { Los } \\
\text { Aparejos }\end{array}$ & sector III/ F1 & $\begin{array}{l}\text { Hallazgo } n^{\circ} 5 \text { : } \\
\text { junto a la urna } n^{\circ} 5\end{array}$ & Togo & $\begin{array}{c}2-a b r- \\
1971\end{array}$ & $\begin{array}{l}\text { al realizar el perfil } \\
\text { junto a la urna } n^{\circ} 5 \text {, } \\
\text { con remoción anterior. }\end{array}$ & $\begin{array}{l}\text { Semillas de } \\
\text { poroto }\end{array}$ \\
\hline $\begin{array}{c}\text { Los } \\
\text { Aparejos }\end{array}$ & sector III/ F1 & $\begin{array}{l}\text { Hallazgo } n^{\circ} 5 \text { : } \\
\text { junto a la urna } n^{\circ} 5\end{array}$ & Togo & $\begin{array}{c}2-a b r- \\
1971\end{array}$ & $\begin{array}{l}\text { Materiales recogidos } \\
\text { al realizar el perfil } \\
\text { junto a la urna } n^{\circ} 5 \text {, } \\
\text { con remoción anterior. } \\
\text { Materiales recogidos }\end{array}$ & Chañar \\
\hline $\begin{array}{c}\text { Los } \\
\text { Aparejos }\end{array}$ & sector III/ F1 & $\begin{array}{l}\text { Hallazgo } n^{\circ} 5 \text { : } \\
\text { junto a la urna } n^{\circ} 5\end{array}$ & Togo & $\begin{array}{c}\text { 2-abr- } \\
1971\end{array}$ & $\begin{array}{l}\text { al realizar el perfil } \\
\text { junto a la urna } n^{\circ} 5 \text {, } \\
\text { con remoción anterior. }\end{array}$ & Algarrobo \\
\hline $\begin{array}{c}\text { Los } \\
\text { Aparejos }\end{array}$ & sector III/ F1 & $\begin{array}{l}\text { Hallazgo } n^{\circ} 5 \text { : } \\
\text { junto a la urna } n^{\circ} 5\end{array}$ & Togo & $\begin{array}{c}2-a b r- \\
1971\end{array}$ & $\begin{array}{l}\text { Materiales recogidos } \\
\text { al realizar el perfil } \\
\text { junto a la urna } n^{\circ} 5 \text {, } \\
\text { con remoción anterior. } \\
\text { Materiales recogidos }\end{array}$ & Marlo \\
\hline $\begin{array}{c}\text { Los } \\
\text { Aparejos }\end{array}$ & sector III/ F1 & $\begin{array}{l}\text { Hallazgo } n^{\circ} 5 \text { : } \\
\text { junto a la urna } n^{\circ} 5\end{array}$ & Togo & $\begin{array}{c}\text { 2-abr- } \\
1971\end{array}$ & $\begin{array}{l}\text { al realizar el perfil } \\
\text { junto a la urna } n^{\circ} 5 \text {, } \\
\text { con remoción anterior. }\end{array}$ & $\begin{array}{l}\text { Vaina de } \\
\text { poroto }\end{array}$ \\
\hline $\begin{array}{c}\text { Los } \\
\text { Aparejos }\end{array}$ & sector III/ F1 & $\begin{array}{l}\text { Hallazgo } n^{\circ} 5 \text { : } \\
\text { junto a la urna } n^{\circ} 5\end{array}$ & Togo & $\begin{array}{c}2-a b r- \\
1971\end{array}$ & $\begin{array}{l}\text { Materiales recogidos } \\
\text { al realizar el perfil } \\
\text { junto a la urna } n^{\circ} 5 \text {, } \\
\text { con remoción anterior. }\end{array}$ & Vaina de maní \\
\hline
\end{tabular}




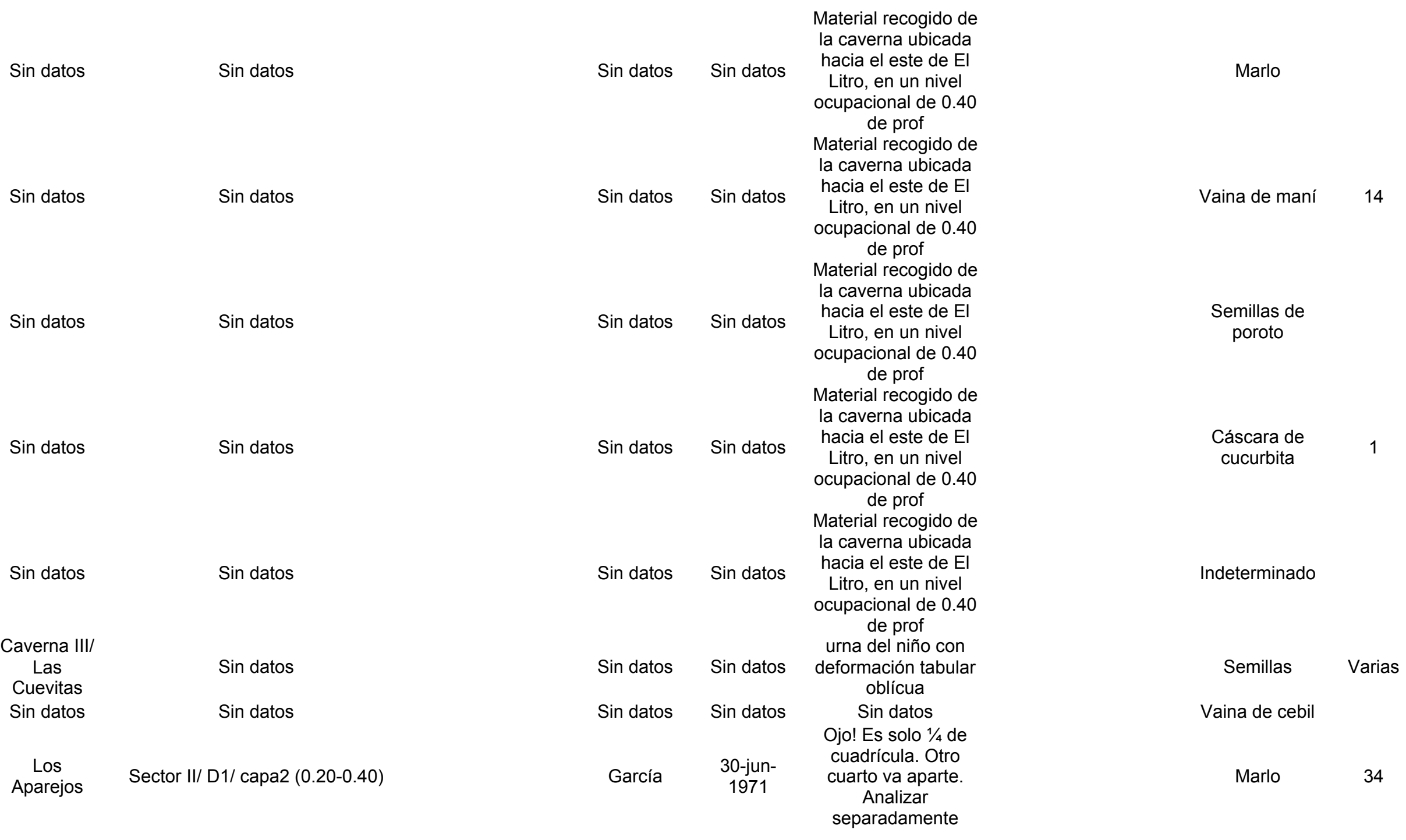


Los

Aparejos

Sector II/ D1/ capa2 (0.20-0.40)

Los

Aparejos

Sector II/ D1/ capa2 (0.20-0.40)

Los

Aparejos

Sector II/ D1/ capa2 (0.20-0.40)

Los

Aparejos

Los

Aparejos

Los

Aparejos

Los

Aparejos

El Litro

EI Litro

El Litro

El Litro

Los

Aparejos

EI Litro

El Litro

Caverna V

Los

Aparejos
Sector II/ D1/ capa2 (0.20-0.40)

Sector II/ D1/ capa2 (0.20-0.40)

Sector II/ D1/ capa2 (0.20-0.40)

Sector II/ D4/ capa1 (00-0.25)

C5/ capa1 (00-0.20)

$$
\text { Superficial }
$$

C4

C1/ capa2 (0.70-0.90)

Superficial y hasta $10 \mathrm{~cm} /$ terreno removido

B4/ capa1 (00-0.25)

Superficial

\section{Sin datos}

Sector II/ D3/ casi superficial a tierra/apoyado en 2 frag como la
Ojo! Es solo $1 / 4 \mathrm{de}$

cuadrícula. Otro

cuarto va aparte.

$$
\text { Analizar }
$$

separadamente

Ojo! Es solo $1 / 4$ de

cuadrícula. Otro

cuarto va aparte.

$$
\text { Analizar }
$$

Algarrobo

separadamente

Ojo! Es solo $1 / 4$ de

cuadrícula. Otro

cuarto va aparte.

Analizar

Indeterminado Varios

separadamente

$\begin{array}{lc}\begin{array}{c}\text { Semillas de } \\ \text { poroto } \\ \text { Cáscara de } \\ \text { cucurbita }\end{array} & 8 \\ \begin{array}{c}\text { Vaina de } \\ \text { poroto }\end{array} & 1 \\ \text { Marlo } & 2 \\ \begin{array}{c}\text { Cáscara de } \\ \text { cucurbita } \\ \text { Marlo }\end{array} & 1 \\ \text { Marlo } & 1 \\ \begin{array}{c}\text { Vaina de maní } \\ \text { Indeterminado }\end{array} & 2 \\ \text { Varios } \\ \begin{array}{c}\text { Indeterminado } \\ \text { Varios } \\ \text { Fibra vegetal }\end{array} \\ \begin{array}{c}\text { Semillas de } \\ \text { poroto }\end{array} \\ \text { Marlo }\end{array}$


muestra(?)

\begin{tabular}{|c|c|c|c|c|c|c|c|c|}
\hline $\begin{array}{l}\text { Los } \\
\text { Aparejos }\end{array}$ & Sector III/ E1/ capa 1 (00-0.20) & & Togo & $\begin{array}{l}\text { 31-mar- } \\
1971\end{array}$ & & & Fibra vegetal & \\
\hline $\begin{array}{l}\text { Los } \\
\text { Aparejos }\end{array}$ & $\begin{array}{c}\text { Superficial ...(?) (hacer traducir por } \\
\text { ARG) }\end{array}$ & & $\begin{array}{l}\text { Togo-García- } \\
\text { ARG }\end{array}$ & $\begin{array}{c}28- \\
29 / 03 / 71\end{array}$ & & & Indeterminado & Varios \\
\hline Sin datos & Sin datos & $\begin{array}{l}\text { Hallazgo No } 19 \text { y } \\
\text { 20: Hallazgos } \\
\text { entre la } 19 \text { y } 20\end{array}$ & Sin datos & Sin datos & & & Vaina de maní & 1 \\
\hline $\begin{array}{l}\text { Los } \\
\text { Aparejos }\end{array}$ & Sector III/ F0 (0.40-0.60) & & Togo & $\begin{array}{l}7 \text {-abr- } \\
1971\end{array}$ & & & $\begin{array}{l}\text { Semillas de } \\
\text { poroto }\end{array}$ & 1 \\
\hline El Litro & C4/ capa1 (00-0.20) & & Togo & $\begin{array}{l}18-a b r- \\
1971\end{array}$ & & & Indeterminado & \\
\hline El Litro & Superficial & & Sin datos & $\begin{array}{l}16 \text {-oct- } \\
1971\end{array}$ & $\begin{array}{l}\text { producto del saqueo } \\
\text { de huaqueros }\end{array}$ & & Marlo & 1 \\
\hline & & & & & & $\begin{array}{c}\text { Etiqueta del } \\
\text { Darwinion: } \\
\text { "Phaseolus vulgaris }\end{array}$ & & \\
\hline $\begin{array}{l}\text { Los } \\
\text { Aparejos }\end{array}$ & Sector I/ superficial & & Togo & $\begin{array}{c}\text { 29-mar- } \\
1971\end{array}$ & & $\begin{array}{l}\text { L., porotos, semillas } \\
\text { de -3 variedades y } 1 \\
\text { vaina dehiscene de } \\
\text { variedad primitiva. A. } \\
\text { Burkart 1972" } \\
\text { Etiqueta del } \\
\text { Darwinion: } \\
\text { "Phaseolus vulgaris }\end{array}$ & $\begin{array}{l}\text { Semillas de } \\
\text { poroto }\end{array}$ & 18 \\
\hline $\begin{array}{l}\text { Los } \\
\text { Aparejos }\end{array}$ & Sector I/ superficial & & Togo & $\begin{array}{l}\text { 29-mar- } \\
1971\end{array}$ & & $\begin{array}{c}\text { L., porotos, semillas } \\
\text { de }-3 \text { variedades y } 1 \\
\text { vaina dehiscene de } \\
\text { variedad primitiva. A. } \\
\text { Burkart 1972" }\end{array}$ & $\begin{array}{l}\text { Vaina de } \\
\text { poroto }\end{array}$ & 1 \\
\hline Sin datos & Sin datos & $\begin{array}{l}\text { Hallazgo No } 7: \\
\text { Urna }\end{array}$ & Sin datos & $\begin{array}{c}22-a b r- \\
1971\end{array}$ & & $\begin{array}{l}\text { Etiqueta amarilla: } \\
\text { "Cuentas de collar de } \\
\text { cascarudos } \\
\text { (Lumluros) hechos } \\
\text { dentro de la urna } n^{\circ} 7 "\end{array}$ & $\begin{array}{l}\text { Cáscara de } \\
\text { cucurbita }\end{array}$ & 10 \\
\hline Sin datos & Sin datos & $\begin{array}{l}\text { Hallazgo } N^{\circ} 7: \\
\text { Urna }\end{array}$ & Sin datos & $\begin{array}{c}22-a b r- \\
1971\end{array}$ & & $\begin{array}{c}\text { Etiqueta amarilla: } \\
\text { "Cuentas de collar de } \\
\text { cascarudos } \\
\text { (Lumluros) hechos }\end{array}$ & Indeterminado & 2 \\
\hline
\end{tabular}


dentro de la urna $n^{\circ} 7^{\prime \prime}$

\begin{tabular}{|c|c|c|c|c|c|c|}
\hline Sin datos & Sin datos & & Sin datos & Sin datos & $\begin{array}{l}\text { Semillas de } \\
\text { poroto }\end{array}$ & 1 \\
\hline Sin datos & Sin datos & & Sin datos & Sin datos & Marlo & 2 \\
\hline $\begin{array}{c}\text { Los } \\
\text { Aparejos }\end{array}$ & Sector III & $\begin{array}{c}\text { Hallazgo } N^{\circ} 5: \\
\text { urna }\end{array}$ & Togo & $\begin{array}{l}\text { 8-abr- } \\
1971\end{array}$ & $\begin{array}{l}\text { Semillas de } \\
\text { poroto }\end{array}$ & 6 \\
\hline $\begin{array}{c}\text { Los } \\
\text { Aparejos }\end{array}$ & Sector III & $\begin{array}{c}\text { Hallazgo No } 5: \\
\text { urna }\end{array}$ & Togo & $\begin{array}{c}\text { 8-abr- } \\
1971\end{array}$ & Algarrobo & 17 \\
\hline $\begin{array}{l}\text { Los } \\
\text { Aparejos }\end{array}$ & Sector III & $\begin{array}{c}\text { Hallazgo } N^{\circ} 5: \\
\text { urna }\end{array}$ & Togo & $\begin{array}{c}8-a b r- \\
1971\end{array}$ & $\begin{array}{l}\text { Granos de } \\
\text { maíz }\end{array}$ & 1 \\
\hline $\begin{array}{c}\text { Los } \\
\text { Aparejos }\end{array}$ & Sector III & $\begin{array}{c}\text { Hallazgo } N^{\circ} 5: \\
\text { urna }\end{array}$ & Togo & $\begin{array}{l}\text { 8-abr- } \\
1971\end{array}$ & $\begin{array}{l}\text { Cáscara de } \\
\text { cucurbita }\end{array}$ & 1 \\
\hline $\begin{array}{c}\text { Los } \\
\text { Aparejos }\end{array}$ & Sector III & $\begin{array}{l}\text { Hallazgo } N^{\circ} 5: \\
\text { urna }\end{array}$ & Togo & $\begin{array}{c}8-a b r- \\
1971\end{array}$ & Indeterminado & varios \\
\hline Sin datos & sin datos & & Sin datos & $\begin{array}{cc}\text { material que estaba } \\
\text { dentro del cesto de } \\
\text { tejido wiqueboy } \\
\text { común con doble } \\
\text { borde }\end{array}$ & marlo & 1 \\
\hline El Litro & C4 & hallazgo $n^{\circ} 5$ & Sin datos & $\begin{array}{c}26-a b r- \\
1971\end{array}$ & marlo & 1 \\
\hline El Litro & Sin datos & hallazgo $n^{\circ} 20$ & Sin datos & Sin datos & marlo & 2 \\
\hline El Litro & C1/ capa1 $(00-0.70)$ & & $\begin{array}{l}\text { Togo y } \\
\text { García }\end{array}$ & $\begin{array}{c}17-a b r- \\
1971\end{array}$ & vaina de maní & varias \\
\hline El Litro & B4/ capa1 $(00-0.40)$ & & Sin datos & $\begin{array}{c}\text { 18-abr- } \\
1971\end{array}$ & $\begin{array}{l}\text { Semillas de } \\
\text { poroto }\end{array}$ & 2 \\
\hline $\begin{array}{c}\text { Caverna III/ } \\
\text { Las } \\
\text { Cuevitas }\end{array}$ & Superficial y nivel ocupacional & & Togo & $\begin{array}{c}\text { 7-may- } \\
1971\end{array}$ & marlo & 28 \\
\hline $\begin{array}{c}\text { Caverna III/ } \\
\text { Las } \\
\text { Cuevitas }\end{array}$ & Superficial y nivel ocupacional & & Togo & $\begin{array}{c}\text { 7-may- } \\
1971\end{array}$ & vaina de maní & varias \\
\hline $\begin{array}{c}\text { Caverna III/ } \\
\text { Las } \\
\text { Cuevitas }\end{array}$ & Superficial y nivel ocupacional & & Togo & $\begin{array}{c}\text { 7-may- } \\
1971\end{array}$ & $\begin{array}{l}\text { Vaina de } \\
\text { poroto }\end{array}$ & varias \\
\hline
\end{tabular}




\begin{tabular}{|c|c|c|c|c|c|c|c|}
\hline $\begin{array}{c}\text { Caverna III/ } \\
\text { Las } \\
\text { Cuevitas }\end{array}$ & Superficial y nivel ocupacional & & Togo & $\begin{array}{c}\text { 7-may- } \\
1971\end{array}$ & & $\begin{array}{l}\text { semillas de } \\
\text { poroto }\end{array}$ & 2 \\
\hline $\begin{array}{l}\text { Caverna III/ } \\
\text { Las } \\
\text { Cuevitas }\end{array}$ & Superficial y nivel ocupacional & & Togo & $\begin{array}{c}\text { 7-may- } \\
1971\end{array}$ & & Algarrobo & varios \\
\hline $\begin{array}{l}\text { Caverna III/ } \\
\text { Las } \\
\text { Cuevitas }\end{array}$ & Superficial y nivel ocupacional & & Togo & $\begin{array}{c}\text { 7-may- } \\
1971\end{array}$ & & $\begin{array}{l}\text { Cáscara de } \\
\text { cucurbita }\end{array}$ & 2 \\
\hline $\begin{array}{l}\text { Caverna III/ } \\
\text { Las } \\
\text { Cuevitas }\end{array}$ & Superficial y nivel ocupacional & & Togo & $\begin{array}{l}\text { 7-may- } \\
1971\end{array}$ & & $\begin{array}{l}\text { semilla de } \\
\text { cucurbita }\end{array}$ & 1 \\
\hline $\begin{array}{l}\text { Caverna III/ } \\
\text { Las } \\
\text { Cuevitas }\end{array}$ & Superficial y nivel ocupacional & & Togo & $\begin{array}{c}\text { 7-may- } \\
1971\end{array}$ & & indeterminado & varios \\
\hline $\begin{array}{c}\text { Los } \\
\text { Aparejos }\end{array}$ & Sector III/ F2/ capa1 (0.20-0.40) & & Togo & $\begin{array}{l}\text { 2-abr- } \\
1971\end{array}$ & & marlo & 1 \\
\hline $\begin{array}{c}\text { Los } \\
\text { Aparejos }\end{array}$ & Sector III/ F2/ capa1 (0.20-0.40) & & Togo & $\begin{array}{c}\text { 2-abr- } \\
1971\end{array}$ & & caña & 1 \\
\hline $\begin{array}{l}\text { Los } \\
\text { Aparejos }\end{array}$ & Sector III/ F2/ capa1 (0.20-0.40) & & Togo & $\begin{array}{l}\text { 2-abr- } \\
1971\end{array}$ & & $\begin{array}{l}\text { Cáscara de } \\
\text { cucurbita }\end{array}$ & 1 \\
\hline $\begin{array}{c}\text { Los } \\
\text { Aparejos }\end{array}$ & Sector III/ F2/ capa1 (0.20-0.40) & & Togo & $\begin{array}{c}\text { 2-abr- } \\
1971\end{array}$ & & Vaina de cebil & 1 \\
\hline Sin datos & $\sin$ datos & & Sin datos & Sin datos & $\begin{array}{l}\text { pegado en la caja: El } \\
\text { Litro / material } \\
\text { superficial de } \\
\text { saqueos / inv } 1993\end{array}$ & marlo & 3 \\
\hline $\begin{array}{c}\text { Caverna IVI } \\
\text { Q. } \\
\text { Lampazar }\end{array}$ & $\sin$ datos & & Sin datos & Sin datos & & vaina de maní & 1 \\
\hline $\begin{array}{c}\text { Caverna IVI } \\
\text { Q. } \\
\text { Lampazar }\end{array}$ & $\sin$ datos & & Sin datos & Sin datos & & $\begin{array}{l}\text { Vaina de } \\
\text { poroto }\end{array}$ & 1 \\
\hline El Litro & E5 & hallazgo $n^{0} 21$ & Togo & $\begin{array}{c}26-a b r- \\
1971\end{array}$ & & marlo & 1 \\
\hline El Litro & E5 & hallazgo $n^{\circ} 21$ & Togo & $\begin{array}{c}26 \text {-abr- } \\
1971\end{array}$ & & $\begin{array}{l}\text { Cáscara de } \\
\text { cucurbita }\end{array}$ & 1 \\
\hline $\begin{array}{c}\text { Caverna IVI } \\
\text { Q. } \\
\text { Lampazar }\end{array}$ & Sin datos & & Sin datos & Sin datos & & marlo & 2 \\
\hline
\end{tabular}




\begin{tabular}{|c|c|c|c|c|c|c|}
\hline $\begin{array}{c}\text { Caverna IVI } \\
\text { Q. } \\
\text { Lampazar }\end{array}$ & Sin datos & Sin datos & Sin datos & & $\begin{array}{l}\text { pedúnculo de } \\
\text { cucúrbita }\end{array}$ & 1 \\
\hline $\begin{array}{l}\text { Los } \\
\text { Aparejos }\end{array}$ & Superficial & & $02-$ oct-69 & & Chañar & 3 \\
\hline $\begin{array}{l}\text { Los } \\
\text { Aparejos }\end{array}$ & Superficial & & 02-oct-69 & & Algarrobo & 5 \\
\hline $\begin{array}{l}\text { Los } \\
\text { Aparejos }\end{array}$ & Superficial & & 02-oct-69 & & $\begin{array}{l}\text { Cáscara de } \\
\text { cucurbita }\end{array}$ & 2 \\
\hline $\begin{array}{l}\text { Los } \\
\text { Aparejos }\end{array}$ & Superficial & & 02-oct-69 & & $\begin{array}{l}\text { Granos de } \\
\text { maíz }\end{array}$ & 1 \\
\hline El Litro & C1/ capa2 (0070-0090) & $\begin{array}{l}\text { Togo y } \\
\text { García }\end{array}$ & 17-abr-71 & $\begin{array}{l}\text { Referencia: } \text { p. } 169 \text { y } \\
170 \text { de las notas }\end{array}$ & $\begin{array}{l}\text { Cortezas de } \\
\text { cañas }\end{array}$ & Varios \\
\hline El Litro & C1/ capa2 (0070-0090) & $\begin{array}{l}\text { Togo y } \\
\text { García }\end{array}$ & 17-abr-71 & $\begin{array}{l}\text { Referencia: p. } 169 \text { y } \\
170 \text { de las notas }\end{array}$ & $\begin{array}{l}\text { Semillas de } \\
\text { poroto }\end{array}$ & 13 \\
\hline El Litro & C1/ capa2 (0070-0090) & $\begin{array}{l}\text { Togo y } \\
\text { García }\end{array}$ & 17-abr-71 & $\begin{array}{l}\text { Referencia: p. } 169 \text { y } \\
170 \text { de las notas }\end{array}$ & Chañar & 2 \\
\hline El Litro & C1/ capa2 (0070-0090) & $\begin{array}{l}\text { Togo y } \\
\text { García }\end{array}$ & 17-abr-71 & $\begin{array}{l}\text { Referencia: } \text { p. } 169 \text { y } \\
170 \text { de las notas }\end{array}$ & & 2 \\
\hline El Litro & C1/ capa2 (0070-0090) & $\begin{array}{l}\text { Togo y } \\
\text { García }\end{array}$ & 17-abr-71 & $\begin{array}{l}\text { Referencia: p. } 169 \text { y } \\
170 \text { de las notas }\end{array}$ & $\begin{array}{l}\text { Pedúnculo de } \\
\text { cucúrbita }\end{array}$ & 1 \\
\hline El Litro & C1/ capa2 (0070-0090) & $\begin{array}{l}\text { Togo y } \\
\text { García }\end{array}$ & 17-abr-71 & $\begin{array}{l}\text { Referencia: } \text { p. } 169 \text { y } \\
170 \text { de las notas }\end{array}$ & Indeterminado & 1 \\
\hline El Litro & C1/ capa2 (0070-0090) & $\begin{array}{l}\text { Togo y } \\
\text { García }\end{array}$ & 17-abr-71 & $\begin{array}{l}\text { Referencia: } \text { p. } 169 \text { y } \\
170 \text { de las notas }\end{array}$ & Indeterminado & Varios \\
\hline
\end{tabular}

